\title{
Michael Hagemeister
}

\section{Nikolaj Fedorov \\ Studien zu Leben, Werk \\ und Wirkung}

Verlag Otto Sagner München - Berlin - Washington D.C.

Digitalisiert im Rahmen der Kooperation mit dem DFG-Projekt „Digi20“

der Bayerischen Staatsbibliothek, München. OCR-Bearbeitung und Erstellung des eBooks durch den Verlag Otto Sagner:

http://verlag.kubon-sagner.de

() bei Verlag Otto Sagner. Eine Verwertung oder Weitergabe der Texte und Abbildungen, insbesondere durch Vervielfältigung, ist ohne vorherige schriftliche Genehmigung des Verlages unzulässig. 
Osteuropastudien der Hochschulen des Landes Hessen

\author{
Reihe II
}

\title{
Marburger Abhandlungen zur Geschichte und Kultur Osteuropas
}

Im Auftrag der Philipps-Universität Marburg

herausgegeben von

Háns-Bernd Harder und Hans Lemberg

Band 28

Verlag Otto Sagner

München 
Michael Hagemeister

\title{
NIKOLAJ FEDOROV
}

\section{STUDIEN ZU LEBEN, WERK UND WIRKUNG}

\author{
Verlag Otto Sagner $\cdot$ München
}


Eayerloche

Staat:

Muriatien

\section{ISBN 3-87690-461-7}

Copyright by Verlag Otto Sagner, München 1989

Abteilung der Firma Kubon und Sagner, München

Druck: Weihert-Druck GmbH, Darmstadt 


\section{VORWORT}

Vorliegende Arbeit wurde 1989 vom Fachbereich Neuere Fremdsprachen und Literaturen der Philipps-Universität Marburg als Dissertation angenommen. Das Thema der Arbeit geht auf eine Anregung von Herrn Prof. Dr. Peter Scheibert zurück. Betreut und gefördert wurde die Arbeit von Herrn Prof. Dr. Hans-Bernd Harder; ihm gilt mein besonderer Dank.

Für Informationen und Materialien sowie für ihre stete Anteilnahme danke ich Ol'ga Nikolaevna Setnickaja, die mir bei meinen Besuchen in Ljubimovka bei Moskau auch Einblicke in ihr Privatarchiv gewährte. Leider hat sie, die von der Bedeutung Fedorovs überzeugt war und das Werk seiner Anhänger bewahrt und fortgesetzt hat, die Fertigstellung dieser Arbeit nicht mehr erlebt.

Für Hinweise, Auskünfte und Materialien und nicht zuletzt für ihr ermutigendes Interesse danke ich Elisabeth Koutaissoff (Oxford) und Taras Zakydalsky (Toronto) sowie den Moskauer Freunden und Bekannten Pavel Florenskij, Arsenij Gulyga, Valentin Nikitin, Svetlana Semenova, Elena Setnickaja und Julij Berkovskij. Dankbar erinnere ich mich an Aleksej Losev, den ich im März 1984 besuchen und befragen durfte.

Da mir ein längerer Forschungsaufenthalt in Moskau nicht möglich war und somit auch auf Studien in staatlichen Archiven verzichtet werden mußte, wurde das Material in Moskauer Privatarchiven gesammelt. Dies geschah während zahlreicher Touristenreisen sowie zweier kurzfristiger Studienaufenthalte im Rahmen des Partnerschaftsabkommens zwischen der Philipps-Universität Marburg und der Moskauer Staatlichen Lomonosov-Universität.

Die Literatur wurde überwiegend durch den internationalen Leihverkehr beschafft. Dank gebührt den Mitarbeitern der Universitätsbibliothek Marburg, der Universitätsbibliothek Basel, der Universitätsbibliothek Helsinki und der LeninBibliothek Moskau. Zu danken habe ich auch den Mitarbeitern der Gedenkstätte für Nationales Schrifttum in Prag für die Möglichkeit, die Bestände des dortigen Fedorov-Archivs einzusehen und auszuwerten.

Für finanzielle Unterstützung, ohne die diese Arbeit nicht in der vorliegenden Form hätte veröffentlicht werden können, danke ich meiner Tante Maria Schroeder (Lübeck). Den Herausgebern der "Marburger Abhandlungen" danke ich für die Aufnahme der Arbeit in die Reihe.

M.H. 


\section{Inhaltsverzeichnis}

Vorwort

Inhaltsverzeichnis

Abkürzungsverzeichnis

EINLEITUNG

TEIL I: LEBEN UND WERK

1. N.F. FEDOROV: BIOGRAPHISCHER ABRISS 15

2. FEDOROVS SCHRIFTEN

3. GRUNDZŬGE der FILOSOFIJA OBSCEgo dela

3.0. Die 'Philosophie' des obšcee delo 59

3.1. Die Begründung des obščee delo 63

3.1.0. Die Diskrepanz zwischen der "Welt, wie sie ist" und der "Welt, wie sie sein soll" 63

3.1.1. Das Verhältnis zwischen Mensch und Natur 64

3.1.2. Das Verhältnis zwischen Mensch und Mensch(heit) 74

3.1.3. Das Verhältnis zwischen Denken und Handeln 88

3.2. Die Verwirklichung des obšcee delo 104

$\begin{array}{lll}\text { 3.2.0. Der utopische Entwurf } & 104\end{array}$

$\begin{array}{ll}\text { 3.2.1. Projektivismus } & 105\end{array}$

$\begin{array}{ll}\text { 3.2.2. Vereinigung } & 110\end{array}$

$\begin{array}{lll}\text { 3.2.3. Umgestaltung und Auferweckung } & 117\end{array}$

TEIL II: BEITRÄGE ZU EINER WIRKUNGSGESCHICHTE $\quad \mathbf{1 2 9 - 4 5 7}$

$\begin{array}{ll}\text { 1. FEDOROVS ZETTGENOSSEN } & 129\end{array}$

$\begin{array}{lll}\text { 1.1. L.N. Tolstoj } & 129\end{array}$

1.2. F.M. Dostoevskij 140

2. VON DER JAHRHUNDERTWENDE BIS ZUR OKTOBERREVOLUTION 155

2.1. Zwischen Fortschrittsglauben und Endzeiterwartung -

Das Problem des Todes im russischen Denken um die Jahrhundertwende

2.1.1. Das Problem des Todes im idealistischen und religiösen Denken

2.1.2. Das Problem des Todes im marxistischen (revisionistischen) Denken

2.1.3. Das Problem des Todes im naturwissenschaftlichen Denken 
2.2. Überblick über die Fedorov-Rezeption 1904-1917 188

2.2.1. Philosophen und Theologen 188

2.2.2. Symbolisten 203

2.3. Die Anfänge der Fedorov-Bewegung 217

2.3.1. I.P. Brichnicev und die Zeitschrift

'Novoe Vino' (1912-13) 217

2.3.2. A.K. Gorskij und der Sammelband

'Vselenskoe delo' (1914) 230

3. DIE FRŪHE SOWJETZETT 241

3.1. Der 'Prometheismus' der frühen Sowjetzeit 241

$\begin{array}{lll}\text { 3.1.0. 'Prometheismus' } & 241\end{array}$

3.1.1. Allorganisation, Universalwissenschaft, Monismus 246

3.1.2. Kosmismus 254

3.1.3. Überwindung des Todes 259

3.2. Die künstlerische Avantgarde $\quad 267$

$\begin{array}{lll}3.2 .0 . & \text { Fedorov und die Avantgarde } & 267\end{array}$

$\begin{array}{lll}\text { 3.2.1. } & \text { V.V. Majakovskij } & 269\end{array}$

3.2.2. V.V. Chiebnikov 276

3.2.3. K.S. Malevic 284

3.2.4. V.N. Čekrygin $286^{\sim}$

3.3. Die Biokosmisten 300

$\begin{array}{lll}\text { 3.4. V.N. Murav'ev } & 318\end{array}$

4. DIE ZWANZIGER UND DREIBIGER JAHRE 343

4.1. Die Fedorov-Anhänger in Moskau 343

4.2. N.A. Setnickij in Harbin 363

4.2.1. Der Weg nach Harbin: N.V. Ustrjalov und das

4.2.2. Setnickij und Maksim Gor'kij (I) 368

4.2.3. Setnickij und Gorskij 380

4.2.4. Setnickij und Maksim Gor'kij (II) 392

4.2.5. Setnickij 1928-1937 403

$\begin{array}{ll}\text { 4.3. Die europäische Emigration } & 417\end{array}$

4.3.0. Die "nachrevolutionären" Bewegungen 417

4.3.1. Die Eurasier in Paris 418

4.3.2. Die Eurasier in Prag: K.A. Coheidze 430

4.3.3. Der Sammelband 'Vselenskoe delo' (1934) 436

4.3.4. Kleinere "nachrevolutionäre" Bewegungen
in der Pariser Emigration

$\begin{array}{ll}\text { Bibliographie } & 459\end{array}$

$\begin{array}{ll}\text { Personenregister } & 541\end{array}$ 


\section{ABKÜRZUNGSVERZEICHNIS}
a) allgemeine Abkürzungen

kn.

Masch.

kniga

Ms.

PSS

sb.

maschinenschriftlich

SS

t., $t$ t.

Manuskript

Polnoe sobranie soxinenij

sbornik

Sobranie soxinenij

vyp.

tom(a)

vypusk

b) abgekürzt zitierte Archive und Bibliotheken

CGALI

FAP

IMLI

IRLI

VINITI

ed. chr.

f.

k.

op.

GPB
Central'nyj gosudarstvennyj archiv literatury i iskusstva, Moskva

Fedorov-Archiv Prag; Památník národního písemnictví, Literární pozůstalost č. 142:

Fedoroviana Pragensia, I, 318-342

GBL Gosudarstvennaja biblioteka SSSR

im. V.I. Lenina, Moskva

Gosudarstvennaja publižnaja biblioteka im. M.E. Saltykova-Ščedrina, Leningrad Institut mirovoj literatury im. A.M. Gor'kogo, AN SSSR, Moskva Institut russkoj literatury (Puskinskij dom) AN SSSR, Leningrad Vsesojuznyj institut naučnoj i technið̌eskoj informacii, Ljubercy [bei Moskau]

edinica chranenija

fond karton

opis' 
c) abgekürzt zitierte Zeitschriften, Reihen und Einzelwerke

\begin{tabular}{|c|c|}
\hline$B S \dot{E}$ & Bol'šaja sovetskaja énciklopedija \\
\hline FOD I; II & $\begin{array}{l}\text { N.F. FEDOROV, Filosofija obšcego dela, } \\
\text { t. 1, Vernyj 1906; t. 2, Moskva } 1913\end{array}$ \\
\hline$H Z$ & Historische Zeitschrift \\
\hline Izv.Jur.Fak. & $\begin{array}{l}\text { Izvestija Juridiceskogo Fakul'teta v gorode } \\
\text { Charbine }\end{array}$ \\
\hline JfGO & Jahrbücher für Geschichte Osteuropas \\
\hline$J P M$ & Journal of the Moscow Patriarchate \\
\hline MERSH & $\begin{array}{l}\text { The Modern Encyclopedia of Russian } \\
\text { and Soviet History }\end{array}$ \\
\hline$M E R S L$ & $\begin{array}{l}\text { The Modern Encyclopedia of Russian and Soviet } \\
\text { Literature [s] }\end{array}$ \\
\hline$S E E J$ & Slavic and East European Jourmal \\
\hline$S E E R$ & Slavonic and East European Review \\
\hline Vestnik R/S/ChD & $\begin{array}{l}\text { Vestnik Russkogo [Studenčeskogo] } \\
\text { Christianskogo Dviženija }\end{array}$ \\
\hline WdSl & Welt der Slaven \\
\hline $\begin{array}{l}Z f s l P h \\
Z M P\end{array}$ & $\begin{array}{l}\text { Zeitschrift für slavische Philologie } \\
\text { Žurnal Moskovskoj Patriarchii }\end{array}$ \\
\hline
\end{tabular}

d) abgekürzt zitierte Erscheinungsorte

L.

M.

$\mathrm{Pb}$.

$\mathrm{Pg}$.

$\mathrm{SPb}$.

Leningrad

Moskva

Peterburg

Petrograd

Sankt Peterburg 


\section{EINLEITUNG}

Als diese Arbeit begonnen wurde, waren Nikolaj Fedorovic Fedorov und seine Filosofija obšzego dela kaum bekannt. Fedorovs Name tauchte nur selten in der Literatur auf - zumeist in Anmerkungen und Fußnoten, verbunden mit der Erklärung, es handele sich um einen eigenartigen religiösen, mystischen oder utopischen Denker, einen geheimnisvollen, stillen Sonderling, der eine Zeitlang das Interesse von Tolstoj, Dostoevskij und Solov'ev auf sich gezogen habe. Über Fedorovs Person waren Legenden im Umlauf, sein Werk wurde mit ein paar Schlagworten 'charakterisiert', doch wurde ihm bisweilen eine geradezu phantastische Verbreitung und Wirkung zugeschrieben.

Inzwischen hat sich die Situation geändert: Heute gehört Fedorov in der Sowjetunion zu den am meisten zitierten und diskutierten russischen Denkern. Einige sehen in ihm sogar den russischen Philosophen schlechthin (samyj russkij filosof), den wahren Repräsentanten der welterlösenden "russischen Idee", den Begründer einer "Philosophie der Zukunft", die - gleichermaßen national und universal -, aus dem Geist des Russentums und der "Tiefe des russischen Herzens" (A.V. Gulyga) entstanden, für die gesamte Menschheit wegweisend sei.

Die Bewunderung für Fedorov und die Beschäftigung mit seinem Werk konzentrieren sich deutlich im rechten Spektrum der sowjetischen Intelligenz, in den Kreisen der sogenannten Neoslavophilen, Russophilen, Traditionalisten, Bodenverbundenen (počvenniki) oder wie immer sich die konservativen Anhänger der Idee einer "nationalen Wiedergeburt" nennen mögen. ${ }^{2}$ Sie waren es, die bereits in der zweiten Hälfte der siebziger Jahre Fedorov 'entdeckten' und bekannt zu machen suchten: 1977 erschienen die ersten Arbeiten über Fedorov

1 Als bezeichnende Beispiele für die Geringschätzung Fedorovs seien einige in jüngerer Zeit im Westen erschienene Standardwerke zur russischen Philosophie und Literatur angeführt: In dem 591 Seiten umfassenden Werk von H. DAHM, Grundzüge russischen Denkens. Persönlichkeiten und Zeugnisse des 19. und 20. Jahthunderts, München 1979, wird Fedorov nur einmal in einer Aufzăhlung genannt (S. 547). Bei W. GoERDr, Russische Philosophie. Zugänge und Durchblicke, Freiburg, München 1984, wird Fedorov auf 768 Seiten lediglich in einer Fußnote vorgestellt (S. 475). Das hochgelobte Werk von F.C. CopLESTON, Philosophy in Russia. From Herzen to Lenin and Berdyaev, Notre Dame, Ind. 1986, von dem eine Ubersetzung in der Sowjetunion vorbereitet wird, behandelt Fedorov nur beilăufig im Zusammenhang mit Solov'ev (S. 228f.) und Berdjaev (S. 385). Geradezu kümmerlich und zudem fehlerhaft ist auch der Fedorov-Artikel von R.L. BELKNAP in: V. TERRAS (Hg.), Handbook of Russian Literature, New Haven, London 1985, S. 164f. - Drei Monographien zu Fedorov, die in den spăten siebziger Jahren in den USA erschienen sind, haben nur geringe Beachtung gefunden; siehe II: 3. Anm. 1.

2 Die nach wie vor beste Darstellung der nationalen und konservativen Strömungen in der sowjetischen Intelligenz v.a. der sechziger und siebziger Jahre gibt J.B. DUNLOP, The Faces of Contemporary Russian Nationalism, Princeton, NJ. 1983 Vgl. ferner A. BEREl OWTTCH, "Des slavophiles aux russophiles." In: Revre des Etudes slaves, 53 (1981), 2, S. 233-244. E. MARKSTEIN, "Die Russischnationalen." In: Osteuropa, 1984, 3, S. 159-167. D. PosPIElowsKY, "The Neo-Slavophile Trend and Its Relation to the Contemporary Religious Revival in the USSR." In: P. RAmet (Hg.), Religion and Nationalism in Soviet and East European Politics, Durham, N.C. 1984, S. $41-58,245-250$. 
von Svetlana Semenova, einer Moskauer Literaturwissenschaftlerin, die sich seitdem als führende sowjetische Fedorov-Spezialistin profiliert hat. ${ }^{3}$ Veröffentlicht wurden sie mit Unterstützung der als russophil bekannten Literaturwissenschaftler Vadim Kožinov (eines der Ideologen des russofil'stvo) und Petr Palievskij sowie des Kosmonauten Vitalij Sevast'janov in den russophil-orientierten Almanachen Kontekst und Prometej. ${ }^{4}$ Seit 1978 lassen sich auch öffentliche Vorträge über Fedorov und sein Werk nachweisen, veranstaltet zumeist von der als Sammelbecken "patriotischer" Kräfte fungierenden "Allrussischen Gesellschaft zum Schutz der Geschichts- und Kulturdenkmäler" sowie der Volksbildungsgesellschaft "Wissen".5 1979 erschienen dann erstmals kurze Auszüge aus Fedorovs Schriften in einer Anthologie zur russischen Sozialutopie und wissenschaftlichen Phantastik, herausgegeben vom russophilen Verlag Molodaja gvardija. ${ }^{6}$

In den späten siebziger und frühen achtziger Jahren finden sich Hinweise auf Fedorov, abgesehen vom rechten Dissidentenmilieu - wo z.B. Igor' Ogurcov und Evgenij Vagin, die Führer des nationalreligiösen "Allrussischen Sozial-Christ-

3 Hinweise auf Fedorov und kürzere Arbeiten über ihn gab es freilich bereits in den sechziger und frühen siebziger Jahren, doch besitzen sie keinen oder nur geringen wissenschaftlichen Wert: Zumeist wurde Fedorov im Zusammenhang mit K.E. Ciolkovskij, dem "Vater der russischen Raumfahrt", erwăhnt und als dessen Lehrer und Inspirator gewürdigt, gelegentlich auch als "idealer Bibliothekar". Im Zusammenhang mit Ciolkovskij und V.I. Vernadskij finden sich früh schon Hinweise auf Fedorov in den philosophischen und wissenschaftsgeschichtlichen Arbeiten von Igor' Zabclin und in einigen der phantastischen Erzăhlungen von Gennadij Gor. (Siehe die Angaben in der Bibliographie).

Als besonders rührig erwies sich der 'Philosoph' und Wissenschaftsjournalist Vladimir L'vov, der in mehreren populärwissenschaftlichen Aufsătzen zu Fragen der Raumfahrt bereits in den sechziger Jahren auf Fedorov hingewiesen hatte, bevor er ihm 1974 in der Zeitschrift Neva eine reichlich phantasievolle biographische Erzăhlung widmete; darin versicherte er, die "Sowjetmenschen" würden Fedorov, "diesen originellen Denker und Patrioten"... "auf keinen Fall den Hysterikern und Heuchlern im Lager der Obskuranten überlassen." V.[E.] L'vov, "Zagadocnyj starik. Povest'-chronika." In: Neva, 1974, 5, S. 65, 119. (1977 auch im Rahmen einer Buchausgabe erschien). In den dreißiger Jahren hatte sich L'vov als fanatischer Gegner der Einsteinschen Kosmologie mit einer Serie primitivster Hetzartikel gegen prominente sowjetische Astronomen und Astrophysiker hervorgetan.

4 Siehe S.G. Semenova, "Nikolaj Fedorovið Fedorov. (Žizn' i uð̌enie)." In: Promerej, 11, M. 1977, S. 86-105. DiEs., "K publikacii stat'i N.F. Fedorova o Fauste." In: Kontekst 1975, M. 1977, S. 311-314. N.F. FEDOROV, "'Faust' Gete i narodnaja legenda o Fauste." Ebd., S. 315-336.

5 Mir liegen Programme von Veranstaltungen, die Fedorov gewidmet waren oder auf denen über Fedorov gesprochen wurde, aus folgenden Jahren vor: 1978, 1979, 1980, 1982, 1984, 1985. Hauptreferentin war zumeist S.G. Semenova. - Úber die 1966 gegründete und 1981 bereits 14 Millionen Mitglieder zählende "Allrussische Gesellschaft zum Schutz der Geschichts- und Kulturdenkmäler" und ihre Funktion als Sammelbecken "patriotischer" Kräfte vgl. A. BERELOWTTCH, "L'almanach 'Les Monuments de la Patrie' (Pamjatniki oterestva)." In: Revue des Etudes slaves, 54 (1982), 4, S. 767-771. DunLoP (wie Anm. 2), S. 63-92.

6 N.F. FEDORov, "Filosofija obšego dela." [Auszüge aus FOD I und II] In: VeXnoe solnce. Russkaja social'naja utopija i naucnaja fantastika vtoroj poloviny XIX - naCala XX veka. M. 1979, S. 390-398. (Anm. und Kommentar von S. KALMYKov [d.i. S.B. DżIMBINov], ebd., S. 3337, 426f.). Die Veroffentlichung stieB auf z.T. heftige Kritik. Siehe I: 2 Anm. 51. 
lichen Bundes der Befreiung des Volkes" (russ. Abkürzung VSChSON), wiederholt ihre Bewunderung für Fedorov äußerten -7 , vor allem bei russophilen und nationalistischen Autoren der offiziellen (rechten) Presse, ${ }^{8}$ wie z.B. den einschlägig bekannten Publizisten Viktor Čalmaev und Valerij Skurlatov, dem Schriftsteller Dmitrij Žukov, den Literaturwissenschaftlern Jurij Seleznev und Michail Lobanov sowie dem Filmregisseur Sergej Bondarcuk. ${ }^{9}$ Auch der Schriftsteller Vladimir Čivilichin wies in seinem monumentalen, die tausendjährige Geschichte Rußlands verherrlichenden "Roman-Essay" Pamjat' (1982) stolz auf Fedorov hin (wenn auch ein ganzes Kapitel, das Fedorov gewidmet war, erst postum 1987 veröffentlicht werden konnte). ${ }^{10}$ Von den Vertretern der "Dorfprosa", den derevenšciki, wurde Valentin Rasputin schon früh mit Fedorov in Verbindung gebracht. ${ }^{11}$ Und der stets trendbewußte Evgenij Evtušenko versah bereits seinen 1981 erschienenen Trivialroman Jagodnye mesta mit zahlreichen Anspielungen auf Fedorov. ${ }^{12}$

Fedorovs eigentlicher 'Durchbruch' fällt in die frühen achtziger Jahre und war von einem Skandal begleitet. Im Sommer 1982 erschien in der renommierten Reihe Filosofskoe nasledie des Moskauer Verlags Mysl' eine umfangreiche Auswahl aus Fedorovs Schriften. ${ }^{13}$ Die unter der Redaktion von A.V. Gulyga ${ }^{14}$

7 Siehe E.[A.] VAGIN, "Interv'ju 'Vestniku RChD'." In: Vesinik RChD, 122, 1977, S. 256. DERS., "N.F. Fedorov i naše vremja." In: Russkaja Mysl', 3242, 8.2.1979, S. 8. [Mit Zitat Ogurcov]. DERS., "Sovetskoe izdanie N.F. Fedorova." In: Vece, 11, 1983, S. 117-135. [Mit Zitat Ogurcov].

8 Als russophile Organe gelten die Zeitschriften Naš Sovremennik, Molodaja Gvandija, Oktjabr und Moskva sowie die Almanache Kontekst, Prometej (Verlag Molodaja gvardija) und Pamjatniki orecestra.

9 Siehe die Angaben in der Bibliographie.

10 V.A. ČIviuchin, Pamjat'. Roman-èsse. M. 1982. [Fedorov S. 766]. Nicht identisch mit der Buchausgabe: DERS., "Pamjat'." In: Naš Sovremennik, 1983, 10, S. 17-101. [Fedorov S. 92]. Das Kapitel mit dem Titel "N.F. Fedorov" wurde erst postum veroffentlicht in: V.A. ĆIVILICHIN, Zerkalo dust, M. 1987, S. 90-110.

11 Vgl. M. Niqueux, "La mémoire de la terre et du ciel: Valentin Raspoutine et la 'littérature paysanne' soviétique." In: Contacts, 115, 1981, S. 177. G.A. BELAJA, "Filosofsko-étizeskaja problematika sovremennoj prozy." In: Sovetskaja literatura i mirovoj literatumyj process, $\mathbf{M}$. 1982 , S. $48 f$.

12 Namentlich genannt wird Fedorov nur einmal: EA. EvTUŠENKo, Jagodnye mesta, M. 1982, S. 282; doch enthalten vor allem Epilog und Prolog (als besonderer Gag in dieser Reihenfolge) zahlreiche Anspielungen auf Fedorovs Gedanken. Darüber hinaus bietet die Rahmenhandlung ein wahres Panoptikum modischer Bilder und 'Reiz'-Themen, die mit ihrer ebenso aufdringlichen wie platten Symbolik den Kitschgemălden eines Il'ja Glazunov oder Konstantin Vasil'ev vergleichbar sind.

13 N.F. FEDOROV, Soxinenija, M. 1982. (= Filosofskoe nasledie; 85). Die Hơhe der Auflage war mit 50.000 angegeben.

14 Mit Hinweis darauf, daß in der Reihe Filosofskoe nasledie das "vaterländische Denken" weit unterrepräsentiert sei (von 80 Bănden seien nur 6 der russischen Philosophie gewidmet), hatte sich Gulyga schon 1979 vehement für eine Ausgabe der Werke Fedorovs eingesetzt. Dabei attestierte er Fedorovs Ansichten eine "durch und durch materialistische Grundlage". A.[V.] GULYGA, "Filosofskoe nasledie': 80 tomov." In: Literatumaja Gazeta, 39, 26.9.1979, S. 13. 
von S.G. Semenova zusammengestellte und kommentierte Ausgabe soll auf Initiative von Kožinov und Palievskij und dank der Protektion und dem Einfluß des Kosmonauten Sevast'janov zustande gekommen sein. Ein Teil der Auflage war bereits ausgeliefert, als höchste Stellen (genannt werden der Chefideologe M.A. Suslov und der Partei-Philosoph und Vizepräsident der Akademie der Wissenschaften P.N. Fedoseev) Alarm schlugen: Fedorov, so hieß es, sei ein "religiös-konservativer Utopist", die Veröffentlichung seiner Schriften "falsch" und "unpassend". ${ }^{15}$ Alle Exemplare, deren man habhaft werden konnte, wurden eingezogen und verschwanden in den specchrany der Bibliotheken. Die verantwortlichen Redakteure und Mitarbeiter des Verlags wurden gemaßregelt. ${ }^{16}$ In der Presse erschienen scharf-ablehnende Artikel, ${ }^{19}$ sogar eine gegen Fedorovs Lehre gerichtete Monographie wurde in Auftrag gegeben. ${ }^{18}$ Positive Erwähnungen in der Literatur wurden nachträglich getilgt. ${ }^{19}$ Die Anti-Fedorov-Kam-

15 Anstoß erregte auch die an alte Tradition anknüpfende Großschreibung der heiligen Namen Bog, Otec, Syn, Sv. Duch, Troica usw. -, die in der rechten Emigrantenpresse sogleich beifällig bemerkt wurde: N.[A.] STRUVE, "Bessmertnaja nadežda." In: Vesinik RChD, 137, 1982, S. 4. VAGIN (wie Anm. 7), S. 119, 123.

16 Eine angekündigte und z.T. bereits fertiggestellte dreibăndige Ausgabe der Werke Vladimir Solov'evs, die in derselben Reihe erscheinen sollte, wurde sofort vom Programm abgesetzt (sie ist 1988 in zwei Bănden und kleiner Auflage erschienen). - Einzelheiten über die Kampagne waren mir seinerzeit von den Betroffenen in Moskau berichtet worden (mit der Bitte allerdings, sie nicht weiterzugeben). Inzwischen wird in der sowjetischen Presse offen darüber geschrieben. Vgl. A.V. GulyGA, "Priblizit' filosofiju k żizni." In: Voprosy Filosofii, 1987, 8, S. 60. DERS., "Vladimir Sergeevic Solov'ev." In: Literatumaja Gazeta, 3, 18.1.1989, S. 5. V.[F.] PRuACHIN, V.[I.] SEvasT'JANOV, "Istoriju tvorit Celovek." In: Moskva, 1988, 8, S. 167. B.F. EGorov, "Čto skažet Mar'ja Alekseevna." In: Sovetskaja Kul'rura, 15.3.1988. DERs., [Diskussionsbeitrag zu] "Geografija intelligentnosti: eskiz problemy." In: Literatumaja Ǔ̌eba, 1989, 2, S. 12. - Siehe auch I: 2. Anm. 52.

17 S.R. Mikulunsku, "Tak li nado ot nosit'sja k nasledstvu?" In: Voprosy Filosofii, 1982, 12, S. 151157. (Eine Replik mit dem Titel "K nasledstvu nado ne otnosit'sja ne tak...", verfaßt von dem Historiker V.L. Janin, dem Philosophen V.V. Sokolov und dem Philologen S.I. Suchich, ist von den Voprosy Filosofii bis heute nicht veroffentlicht worden). A.N. IEZUTrov, "Partija i aktual'nye zadaci nauki o literature." In: Russkaja Literatura, 1983, 4, S. 7. JU. SUROVCEV, "Ob urokach našej klassovoj pamjati." In: Znamja, 1983, 6, S. 221. JU.A. LUXIN, "Otvetstvennost" chudožnika. Iskusstvo i literatura v formirovanii politiðeskoj kul'tury liznosti." In: Znamja, 1983, 9, S. 213-220. DERS., "V bor'be za budušcee Keloverestva." In: Literatumaja Gazeta, 44, 2.11.1983, S. 2. DERS., Kul'tura v bor'be idej, M. 1985, S. 78, 205, 207f., 236. M.T. IovCUK, A.L. ANDREEV, MA. MASLIN, "Aktual'nye voprosy issledovanija istorii marksizma-leninizma, ego filosofii i filosofskoj mysli narodov SSSR." In: Voprosy Filosofii, 1986, 1, S. 70 f.

18 V.P. Pazılova, Kriticeskij analiz religiozno-filosofskogo učenija N.F. Fedorova, M. 1985.

19 In seiner Geschichte der Raumfahr, die 1982 im Moskauer Kinderbuchverlag erschien, ging Ja.K. Golovanov ausführlich auf Fedorov und dessen "riesigen EinfluB" auf Ciolkovskij ein. Ja.K. Golovanov, Doroga na kosmodrom, M. 1982, S. 135-139. Das Buch wurde aus dem Handel gezogen und im folgenden Jahr durch eine 'gereinigte' Fassung ersetzt, in der jeder Hinweis auf Fedorov getilgt war. Auch aus Arbeiten, die philosophischen Fragen der Raumfahrt ("Kosmismus") gewidmet waren, wurde Fedorovs Name offensichtlich entfernt; siehe z.B. das im Verlag Mysl' erschienene Werk von JUA. SKOLENKo, Filosofija, ekologija, kosmonavrika, M. 1983. 
pagne, an der sich auch Kreise der orthodoxen Kirche beteiligten, ${ }^{20}$ erwies sich freilich als Werbefeldzug: Die (angeblich) wenigen in den Handel gelangten Exemplare der Werkausgabe waren sofort vergriffen und erzielten schon bald hohe Schwarzmarktpreise. ${ }^{21}$

Seitdem ist die Auseinandersetzung um Fedorov nicht mehr verstummt, wohl aber hat inzwischen eine offizielle Neubewertung weiter Teile jener Bereiche von Kultur und Tradition stattgefunden, die bislang als nicht-fortschrittlich abgelehnt oder gar als reaktionär bekämpft wurden. Aufgewertet und rehabilitiert werden derzeit jene Kräfte, die geeignet erscheinen, in der schwierigen Phase des "Umbaus" der Gesellschaft, in der der Appell an die herrschende Ideologie ohne Resonanz bleibt, als kompensierende, integrierende und stabilisierende Faktoren zu dienen.

Unter Parolen wie "russische kulturelle Renaissance", "nationales Wiedererwachen", "geistige Wiedergeburt", "moralische Erneuerung des Volkes", "Ökologie des Geistes" vollzieht sich gegenwärtig in der Sowjetunion eine bemerkenswerte, in ihren aktuellen Äußerungen im Westen bislang jedoch kaum beschriebene und gedeutete Rückbesinnung auf die russische Nationalkultur, z.T. unter Wiederbelebung slavophiler, aber auch nationalistischer und antiaufklärerischer Traditionen. ${ }^{22}$ Dabei handelt es sich um eine auf manchen Gebieten seit langem vorbereitete, außerordentlich vielschichtige und ambivalente Bewegung: Sie reicht vom Einsatz für Umweltschutz und für die Rettung und Bewahrung bedrohter Kulturdenkmäler (seit Mitte der sechziger Jahre organisiert in der mächtigen "allrussischen" Denkmalschutzgesellschaft) oder dem Programm des Sowjetischen Kulturfonds "Wiederkehr vergessener Namen" (vozvrašcenie zabytych imen), das im Januar 1989 mit einer Ausstellung über P.A. Florenskij begann, über die Verklärung der untergehenden dörflichen Welt und der "Bodenverbundenheit" (počennicestvo) im Zuge einer "Rückkehr zu

201983 erschien in den vom Moskauer Patriarchat herausgegebenen Bogoslovskie trudy ein diffamierender Artikel über Fedorov und dessen Lehre: "Voskresenie taemoe ili voschišaemoe? (O religioznych vozzrenijach N.F. Fedorova)." In: Bogoslouskie trudy, 24, 1983, S. 242-259. Gezeichnet mit A.M., den Initialen von Anatolij Sergeevið Mel'nikov (d.i. archiepiskop Antonij), stammte der Artikel in Wirklichkeit von N.K. GavrjuSin, einem Mitarbeiter von Mikulinskij am Institut für Geschichte der Naturwissenschaften. - DaB Fedorov in orthodoxen Kirchenkreisen auch positiv eingeschătzt wird, beweisen zahlreiche Reden und Aufsătze von Metropolit Pitirim sowie Beitrăge von Valentin Nikitin, Vitalij Borovoj u.a. (siehe Bibliographie).

21 Mitte der achtziger Jahre wurde die Moskauer Ausgabe in den USA nachgedruckt, wobei Einband, Druck und Papier so gut imitiert wurden, daB sich Original und Reprint nur bei sorgfaltigem Vergleich voneinander unterscheiden lassen.

22 Vgl. B. GroYs, "Ein neues Heidentum. Die 'russische nationale Wiedergeburt'. - Ein Blick auf jüngste Diskussionen." In: Frankfurter Allgemeine Zeitung, 118, 22.5.1987, S. 27. K. HoLM, "Rückwărts-Avantgarden. Das neue Aufleben des russischen Nationalismus." Ebd., 211, 10.9.1988, S. 27. 
den Ursprüngen" (vozvrašcenie $k$ istokam) in der Literatur der derevenšciki, der Absage an westlichen Rationalismus, Individualismus und Liberalismus, sowie dem Kampf gegen "moralische Verwilderung" bis zu den chauvinistischen Exzessen und paranoiden Verschwörungsideen der Pamjat'-Vereinigung.

Auf dem Gebiet der Philosophie hat die "nationale kulturelle Wiedergeburt" in Verbindung mit einer traditionalistischen, konservativen Wertediskussion, bei der die "Liquidierung der Amoralität" und die "Anerkennung des sittlichen Absoluten" gefordert werden, ${ }^{23}$ zur Rehabilitierung des russischen nichtmarxistischen Denkens geführt und damit weite, bislang tabuisierte Bereiche der Geschichte der "vaterländischen Philosophie" - darunter vor allem die russischen religiösen Denker des späten 19. und frühen 20. Jahrhunderts - einer freieren Erforschung und öffentlichen Diskussion zugänglich gemacht. ${ }^{24}$

Auch Fedorov zählt heute zu jenen nichtmarxistischen russischen Denkern, deren "geistige Wiedererweckung" im Zuge der sogenannten "russischen kulturellen Renaissance" mit Nachdruck betrieben wird. Für die nächste Zeit sind weitere Werkausgaben, ja sogar die Veröffentlichung des gesamten Nachlasses geplant. ${ }^{25}$ Hinzu kommen zahlreiche Aufsätze und, dem Vernehmen nach, in

23 Die Zitate stammen aus jüngsten Veroffentlichungen von A.V. Gulyga, einem renommierten Philosophiehistoriker, Fedorov-Forscher und Protagonisten der "nationalen Wiedergeburt" Siehe A.[V.] Gulyga, "Poiski absoljuta." In: Novyj Mir, 1987, 10, S. 245-253. DERs., "Stat' zerkalom duşi naroda." In: Voprosy Filosofii, 1988, 9, S. 113-115. DERS., "Revoljucija ducha." In: Zvezda, 1989, 2, S. 173-182. Vgl. ferner die scharfe Ablehnung der nihilistischen Moral des "Eigenwillens" und die Forderung nach Anerkennung absoluter sittlicher Ideale bei JU.N. DA. VYDOV, Etika ljubvi i metafizika svoevolija (problemy nravstvennoj filosofii), M. ${ }^{2} 1989$.

24 Zur jüngsten Entwicklung vgl. H. FleisCHER, "Die Perestrojka erreicht die Philosophie." In: Das Argument, 167, 1988, S. 9-31. D. GEYER, "Den toten Gott im Herzen tragen. Das Wiederaufleben der idealistischen russischen Philosophie." In: Frankfurter Allgemeine Zeitung, 118, 24.5.1989, S. N 3. I. VInOGRadov, "Bezumnaja russkaja ideja." In: Moskovskie Novosti, 24, 11.6.1989, S. 11. Sowie - besonders instruktiv am Beispiel der Wiederentdeckung von P.A. Florenskij - R. Gol.DT, "Aspekte der sowjetischen Idealismusdebatte." In: E. REISSNER (Hg.), Perestrojka und Literatur, Berlin [im Druck]. - Zur Renaissance religioser Themen in der Sowjetliteratur siehe A. BERELOWITCH, "La place vide de Dieu." In: Cahiers du Monde russe et soviétique, 29 (1988), 3-4, S. 575-580. - Zu den bis ins Jahr 2000 geplanten Werkausgaben russischer idealistischer und religiosser Denker siehe ANON., "Perspektivnyj plan izdanija trudov po ote飞estvennoj istorii, vidnych russkich i sovetskich filosofov, ékonomistov $i$ juristov, dlitel'noe vremja ne izdavavకichsja v našj strane." In: KniZnoe Obozrenie, 38, 23.9.1988, S. 9.

25 Dem Vernehmen nach bereitet das Moskauer Institut für Weltliteratur eine Gesamtausgabe der Werke Fedorovs vor. Für die Mitte der neunziger Jahre plant der Verlag Mysl', aus Fedorovs NachlaB den 3. Band der Filosofija obšcego dela zu veroffentlichen. Briefl. Mitteilung von V.A. Nikitin, Moskau, 13.4.1989. Die Veröffentlichung ausgewăhlter Werke Fedorovs ist in der Reihe Iz istonii otecestvennoj filosofskoj mysli vorgesehen, die auf Beschluß des ZK des Politbüros der KPdSU vom 12.5.1988 gegründet wurde und deren Programm die bislang unterdrückte russische nichtmarxistische Philosophie des 19. und 20. Jahrhunderts umfaBt. Vgl. die Ankündigung in: Voprosy Filosofii, 1988, 6. A. JAKOVLEV, "Vozvrašenie iz nebytija." In: Moskouskie Novosti, 9, 26.2.1989, S. 10. M. Michanlov, "Politbjuro i filosofija." In: Russkaja Mysl', 3751, 18.11.1988, S. 12. Veröfentlichungen aus dem Werk Fedorovs hat die Zeitschrift Noyyj Mir für 1989 angekündigt; siehe Novyj Mir, 1988, 8. - Eine umfangreiche Auswahl aus Fedorovs Schriften in deutscher Obersetzung wird derzeit vom Gustav Kiepenheuer Verlag, Leipzig und Weimar, vorbereitet. Eine Auswahl in englischer Obersetzung soll in den Verlagen L'Age d'Homme, Lausanne, und Honeyglen, London, erscheinen. 
naher Zukunft die Veröffentlichung populärwissenschaftlicher Monographien zu Leben und Werk. ${ }^{26}$ Neben den Fachleuten (zu nennen sind vor allem S.G. Semenova und A.V. Gulyga) widmen sich in verschiedenen Arbeitsgruppen und Vereinigungen auch Laien mit großem Enthusiasmus (der bisweilen freilich sektiererische Züge annimmt) dem Studium und der Verbreitung der Fedorovschen Ideen. ${ }^{27}$ Vom Interesse und der Verehrung, die Fedorov entgegengebracht werden, zeugen Filme, ${ }^{28}$ Bilder $^{29}$ und Gedichte ${ }^{30}$ sowie das Vorhaben,

26 So ist, um nur einige Beispiele zu nennen, in der im Oktober 1988 begonnenen Serie $I z$ istorii nusskoj filosofskoj mysli der Literaturnaja Gazeta, in der bereits ganzseitige Beiträge über A.F. Losev, P A. Florenskij, V.S. Solov'ev, L.P. Karsavin, K.N. Leont'ev, E.N. Trubeckoj, V.V. Rozanov und N.A. Berdjaev erschienen sind, auch ein Beitrag über Fedorov vorgesehen. Eine Arbeit über Fedorov wird in der populärwissenschaftlichen Reihe Stranicy istorii otečestvennoj filosofskoj mysli erscheinen, die 1988/89 mit Arbeiten über V.S. Solov'ev und P.A. Florenskij eroffnet worden ist. Für 1990 plant der Moskauer Verlag Sovetskij pisatel' die Veroffentlichung einer größeren, ebenfalls populärwissenschaftlichen Darstellung von Fedorovs Leben und Werk von S.G. Semenova mit dem Titel Nikolaj Fedorov. Tvortestvo zizni; ein auszugsweiser Vorabdruck soll in der Zeitschrift Volga, 1989, 9-12, erscheinen. Briefl. Mitteilung von VA. Nikitin, Moskau, 13.4.1989. Siche auch Novye knigi SSSR, 1989, 27, S. 21.

27 Zu nennen ist hier v.a. der Anfang 1987 gegründete, offenbar russophile Moskauer "Arbeitskreis Prometej", der bereits eine Reihe von Vortrăgen über Fedorov veranstaltet hat und in seinem selbst verlegten Vestnik Prometeja (inzwischen 3 Bănde) Fedorov zum Vorbild erhebt; (siehe P. [V.] TULAEv, "Prometej': opyt i problemy razvitija." In: Vestnik Prometeja, vyp. 3, M. 1988, S. 221-228); ferner das im Rahmen des "Allrussischen Kulturfonds" arbeitende "Philosophische Seminar" (Filosofskij seminar) sowie die Anfang Mărz 1989 in Moskau gegründete "Gesellschaft für Geisteskultur" (Obšcestvo duchovnoj kul'tury), der mehrere prominente Russophile angchören. In Moskau leiten S.G. Semenova und Ju A. Pogrebinskij Seminare über Fedorov. Der in Petrozavodsk lebende russophile Dichter und 'Kosmist' Ju.V. Linnik (Direktor des "N.-K.-Rerich-Museums für kosmische Kunst" und Leiter des "Zentrums zur Erforschung der Geisteskultur des Auslandsrussentums") erforscht Fedorovs Werk im Rahmen des russischen 'kosmischen Denkens' und untersucht seine Wirkung auf die Kultur der russischen Emigration. Unter Berufung auf Fedorov widmet sich in Leningrad die Kommission des Sowjetischen Kulturfonds Leningradskij nekropol' unter der Leitung von A.V. Kobak der Erforschung der "russischen Friedhofskultur" und der Restaurierung historischer Friedhofe. Briefl. Mitteilung von A.V. Kobak, Leningrad, 15.10.1988.

Vielfältig sind auch die Verbindungen zwischen sektiererischen Anhängem Fedorovs (fedorovcy) und anderen Gruppen und Strömungen der florierenden religioss-weltanschaulichen Subkultur in der Sowjetunion, wie z.B. den Anhăngern der Lehren von Georgij Gjurdžiev, Nikolaj Rerich, Daniil Andreev, Lev Gumilev sowie insbesondere von Porfirij Ivanov, den sog. ivanovcy, aber auch Ökogruppen, Lebensreformern, Gesundheitsaposteln und Vegetariern. Ein von Moskauer Fedorov-Anhängern 1985 verbreiteter Aufruf "an alle Bewohner des Planeten" zur Gründung einer "Weltweiten Organisation des obscee delo - Mission N. Fedorov" trăgt wahnhafte Züge.

28 Bekannt wurde ein Amateurfilm über Fedorov von $M$. und S. Baranov mit dem Titel Moskovskij Sokrat (1978). - Am 16. Juni 1989 zeigte das Moskauer Fernsehen unter dem Titel Pritca o voskrešenii einen zweiteiligen "Dokumentarfilm" über Fedorov, der unter der Regie von L. Nirenburg und der wissenschaftlichen Beratung von S.G. Semenova entstanden war: Aufnahmen von Orten, die mit Fedorovs Biographie verbunden waren sowie nachgestellte Szenen aus Fedorovs Leben wechselten mit Interviews, die die Überlieferung, Wirkung und heutige Bedeutung seines Denkens dokumentieren sollten. Der Informationsgehalt blieb freilich gering, statt dessen wurden alte Legenden wiederbelebt und durch kitschige Effekte, vordergründige Symbolik und theatralisches Pathos Fedorovs Person und seine geistige Entwicklung im Sinne des "russkoe duchovnoe voznozdenie" stilisien und mystifiziert. Kritisch dazu 
eine eigene Gedenkstätte einzurichten. Unter der Bezeichnung Fedorovskie ctenija fand erstmals im Mai 1988 in Borovsk bei Moskau eine zweitägige öffentliche Vortragsreihe statt, die Fedorov und seinem Werk sowie dessen engem Zusammenhang mit dem "russischen Kosmismus" gewidmet war; die zweiten Fedorovskie ttenija wurden im Juni 1989 in Moskau im Zentralen Haus der Sowjetarmee abgehalten. ${ }^{31}$

In jüngster Zeit wird Fedorovs Werk zunehmend im Rahmen eines philosophisch-weltanschaulichen Konzeptes rezipiert, das unter der Bezeichnung "russisches kosmisches Denken" oder "russischer Kosmismus" in der sowjetischen Presse wachsende Aufmerksamkeit und Anklang findet, im Westen bislang jedoch so gut wie unbeachtet geblieben ist. Ausgehend von einer ganzheitlichen Weltauffassung und der Annahme einer zielvollen und darum sinnvollen Evolution, sucht "kosmisches Denken" (nach dem Verlust des göttlichen Heilsplanes und im Bewußtsein drohender Selbstvernichtung) die Stellung und Aufgabe des Menschen und der menschlichen Vernunft im universalen Zusammenhang zu bestimmen. Der vernunftbegabte Mensch, in einem zielgerichteten Prozeß aus der belebten Materie der Erde hervorgegangen, wird als

die redaktionelle Vorbemerkung zum Artikel von I.[T.] Frolov, "Prizraki i illjuzii 'vežnoj žizni' i 'vseobక̌zego voskrešenija'." In: Sovetskaja Kul'tura, 73, 20.6.1989, S. 6. Vgl. ferner V. Novikova, "Pritとa o voskrešenii'. Prem'era televizionnogo dokumental'nogo fil'ma." In: Govorit i pokazyvaet Moskva. Programmy central'nogo televidenija i radiovešanija. 1989, 20 (maj), S. 4. - Für die Überlassung einer Videoaufzeichnung dieses Films danke ich Rainer Goldt, Wiesbaden.

29 Bekannt und veroffentlicht wurde ein Portrăt von Otari Kandaurov, der sich einen Verehrer von Fedorov und Nikolaj Rerich nennt, sowie eine Lithographie des Moskauer Graphikers Jurij Seliverstov. Siehe J. G[LEISNER], "Pictures at an Exhibition." In: Detente, [Leeds], 9/10, 1987, S. 40f. (m. Abb.). DeRs., "Memoirs of Moscow's 'Pictures at an Exhibition'." In: The Soviel Observer, 10.5.1988, S. 5. V. KuRBATOV, "Živaja duડ̌a Rossii. ('... iz russkoj dumy' chudožnika Jurija Seliverstova)." In: Literatumaja UCeba, 1989, 1, S. 103 (Abb.). In beiden Făllen handelt es sich um kitschige Darstellungen, die einem modischen Bedürfnis nach Stilisierung und Mystifizierung zu entsprechen suchen. - Eine Büste Fedorovs soll in den siebziger Jahren von der Bildhauerin Valerija Semenova geschaffen worden sein.

30 V Ja. LAZAREv, "Bibliotekar' Rumjancevskogo muzeja." [Gedicht] In: DeRs., Brat miloserdija. Stichomorenija. M. 1982, S. 77f. S.[G.] STRATANOvSKU, "Fedorov." [Gedicht] In: Russkaja Mysl', 3485, 6.10.1983, S. 12. V.[A.] Nikmn, Triptich pamjati N.F. Fedorova (1903)." [Gedichte] In: Vestnik RChD, 146, 1986, S. 145-148.

31 Organisiert wurden die Fedorouskie ctenija u.a. vom Komitee für Kosmonautik der DOSAAF, dem "Ökofonds der UdSSR" sowie der "Allrussischen Gesellschaft zum Schutz der Geschichtsund Kulturdenkmăler". Zu den prominentesten Rednem zăhlten der Kosmonaut V.I. Sevast'janov, der Physiker und Mathematiker N.N. Moiseev (Akademiemitglied und Vertreter der vielbeachteten "Gaia-Hypothese", wonach die Erde ein sich selbst regulierendes und optimierendes kybernetisches System sei) sowie die Fedorov-Forscher S.G. Semenova, A.V. Gulyga und Ju.V. Linnik. Siehe Fedorovskie cienija. [Programm] Borousk 1988. S. [A.] GeRasuUtin, "Pervye ctenija N.F. Fedorova." In: Vestnik Prometeja (wie Anm. 27), S. 289-291. PRJACHIN, Sevast'janov (wie Anm. 16), S. 166. Vionye usesojuznye Fedorovskie Etenija. [Programm] M. 1989. 


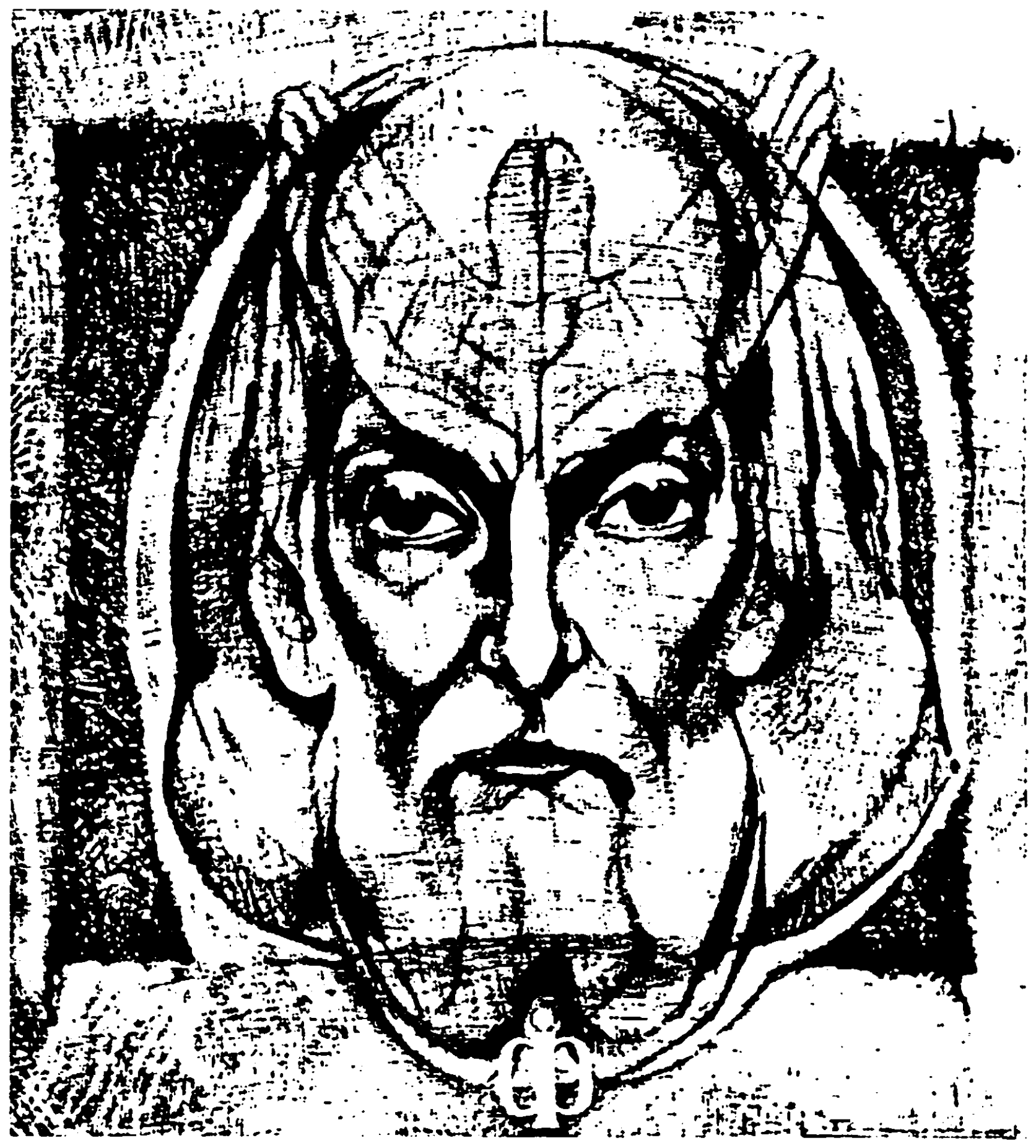

O. Kandaurov: N.F. Fedorov 
entscheidender Faktor der kosmischen Evolution verstanden, als ihr (Selbst-) Bewußtsein, ihr aktiver Lenker und (möglicher) Vollender. Von seinem Handeln hänge ab, ob die Evolution ihr Ziel, ein Höchstmaß an Vollkommenheit, erreichen oder verfehlen, d.h. katastrophal scheitern werde. In ihrer Entwicklung stehe die Welt am Übergang von der "Biosphäre" zur "Noosphäre": Durch die tätige Vereinigung aller Menschen zu einem einzigen Organismus werde ein höheres "planetarisches Bewußtsein" entstehen, das fähig sei, die weitere Entwicklung vernünftig und sittlich (im Sinne einer "kosmischen Ethik") zu lenken, das Universum zu verwandeln und zu vervollkommnen, Krankheit und Tod zu besiegen und unsterbliche Übermenschen hervorzubringen.

Dieses höchst spekulative, begrifflich oft unscharfe und in seinem anthropozentrischen Fortschrittsglauben anachronistisch anmutende Konzept, das seine wachsende Popularität offenbar einem zunehmenden Krisenbewußtsein und dem weltanschaulichen Bedürfnis nach Synthese und Sinngebung verdankt, wird von seinen Anhängern als eine spezifisch russische Denkrichtung ausgegeben, als originelle Hervorbringung des "russischen Geistes", die einmalig und mit nichts auf der Welt zu vergleichen sei: Das "vaterländische kosmische Denken" sei, so heißt es, in diesem Jahrhundert durch Gelehrte wie K.Ë. Ciolkovskij, V.I. Vernadskij und A.L. Čiževskij repräsentiert worden; am Beginn dieser Tradition stehe Fedorov. ${ }^{32}$ Der "russische Kosmismus" als "aktiv-

32 Zum "russischen kosmischen Denken" vgl. aus der Vielzahl jüngster Veroffentlichungen insbesondere F.I. GIRENOK, "Russkij kosmizm: Vzaimosvjaz' filosofskich i estestvennonaurnych problem." In: Filosofskie metodologiCeskie seminary. Problemy razvitija. M. 1983, S. 262-280. DERS., Ekologija, civilizacija, noosfera. M. 1987. A.[V.] GULYGA, "'Byt' ne prazdnym passažirom.' Russkij kosmizm: nasledie i nasledniki." In: Literatumoe Obozrenie, 1987, 7, S. 9195. Ders., "Priblizit'..." (wie Anm. 16). V.I. Sevast'janov, V.F. Pruachin, "Kosmonavtika i novoe polititeskoe myšlenie v jaderno-kosmiteskuju èru." In: Voprosy Filosofri, 1987, 9, bes. S. 38-42. Pruachin, Sevast'janov (wie Anm. 16), S. 162-168. S.[G.] Semenova, "Sem'ja idej. K 125-letiju so dnja roždenija V.I. Vernadskogo." In: Znamja, 1988, 3, S. 185-201. DiEs., "Aktivnoevoljucionnaja mysl' Vernadskogo." In: Prometej, 15, M. 1988, S. 221-248. N.[N.] MoISEEV, "V.I. Vernadskij i estestvennonaučnaja tradicija." In: Kommunist, 1988, 2, bes. S. 78-80. DeRs., "Opravdanie edinstva. (Kommentarii k ǔ̌eniju o noosfere). In: Voprosy Filosofii, 1988, 4, bes. S. 29f. UCenie V.I. Vemadskogo o noosfere i global'nye problemy sovremennosti. (Tezisy dokladov...). C. 1, M. 1988. V.P. KAZNACEEV, UZenie V.I. Vemadskogo o biosfere i noosfere, Novosibirsk 1989.

Bereits Ende der sechziger Jahre hatte Igor' Zabelin, einer der führenden Propagandisten des "kosmischen Denkens", die Frage nach der Bestimmung der Menschheit im kosmischen Maßstab mit Bezug auf Fedorov, Vernadskij, Ciolkovskij und Teilhard de Chardin positiv zu beantworten versucht. In einer daraufhin entstandenen Kontroverse wiesen die Parteiphilosophen Kol'man und Rabinovic eine solche Frage als sinnlos zurück. Siehe I.[M.] ZABELIN, "Celoverestvo - dlja rego ono?" In: Moskva, 1968, 5, S. 147-161. Zur Kontroverse siehe M.A. LATHOUWERS, "Pour un sens approfondi de l'existence humaine." In: Irenikon, 43 (1970), S. 222-226.

Zu erwăhnen ist schließlich das von dem ukrainischen Biologen N.G. Cholodnyj (1882-1953) in den vierziger Jahren entwickelte Konzept des "Anthropokosmismus", das jedoch - vielleicht wegen der geringen Verbreitung von Cholodnyjs naturphilosophischen Schriften - bislang nur schwache Resonanz gefunden hat. Siehe I.I. MoKalOV, K.CH. CHAnRULLIN, "Koncepcija antropokosmizma N.G. Cholodnogo." In: Voprosy Filosofii, 1982, 11, S. 131-139. N.G. CHOLOD. NYJ, Izbrannye trudy, Kiev 1982. 
evolutionäres, noosphärisches, kosmisches Denken ${ }^{\text {n33 }}$ sei jedoch nicht nur der "Stolz der vaterländischen Wissenschaft", ${ }^{34}$ sondern erweise sich auch dank seiner "allgemeinmenschlichen Bedeutung" als "Philosophie der Zukunft ${ }^{\text {"35 }}$, die geeignet sei, die drängenden Probleme der Menschheit - Naturzerstörung, kriegerisches Gegeneinander und Werteverfall - global zu lösen. "Kosmismus" wird damit zur Formel einer neuen russischen Heilslehre für die Welt.

Durch das (hier nur skizzierte) Konzept des "russischen Kosmismus" wird freilich der Blick auf das Werk seiner "Repräsentanten" eher verstellt, wird eine Tradition konstruiert, deren Begründung zumindest fragwürdig erscheint, ${ }^{36}$ wird schließlich eine Ideologie kreiert, die sich bei genauerer Betrachtung weithin als russische Variante des New Age-Denkens erweist, wie es seit Beginn der siebziger Jahre vor allem im angelsächsischen Sprachraum grassiert. ${ }^{37}$ Die Fülle publizistischer und populärwissenschaftlicher Veröffentlichungen zum "russischen Kosmismus" steht in einem auffallenden Mißverhältnis zur Zahl seriöser

33 Semenova, "Sem'ja idej" (wie Anm. 32), S. 221.

34 Sevastijanov, Pruachin (wie Anm. 32), S. 39. - Gulyga nennt den Kosmismus "unseren nationalen Stolz". GUL YGA, "Priblizit'..." (wie Anm. 16).

35 Gulyga, "Stat' zerkalom..." (wie Anm. 23), S. 113.

36 So wăre zu fragen, ob das Konzept des "russischen Kosmismus" wirklich geeignet ist, Ciolkovskij, Cižcuskij und Vernadskij in eine gemeinsame Denktradition zu stellen, obwohl diese sich in ihren Forschungszielen und Methoden so sehr voneinander unterscheiden, da $B$ sie sich (mit gelegentlichen Ausnahmen bei Ciolkovskij und Ciževskij) in ihren wissenschaftlichen Arbeiten nirgends aufeinander beziehen. Was das Verhăltnis zu Fedorov betrifft, der diese Tradition begründet haben soll, so finden sich in den veroffentlichten Werken Vernadskijs und Ciževskijs keinerlei Hinweise auf eine Rezeption; Ciolkovskij hat sich zwar gegen Ende seines Lebens anerkennend über Fedorov geăußert, einen Einfluß auf seine eigenen Raumfahrtplăne jedoch stets vemeint.

Das Originelle und spezifisch Russische in der Konzeption des "Kosmismus" ließe sich erst durch sorgfältige Vergleiche mit "westlichen" Entwicklungslehren feststellen, vor allem mit der auch in Rußland einst populăren philosophisch-biologischen Lehre Bergsons von der Evolution crétrice, aber auch mit Comte, Renan, Spencer oder mit John Fiske, dem Verfasser der Outlines of Cosmic Philosophy; zu untersuchen wäre ferner der (in der Sowjetunion bis heute verschwiegene) Einfluß theosophischer und okkultist ischer Literatur auf den "Vater der russischen Raumfahrt" K.E. Ciolkovskij, dessen naturphilosophische und gesellschaftsutopische Arbeiten, soweit sie überhaupt veröfentlicht wurden, nur schwer zugănglich sind. Immerhin wird auf die Evolutionslehre Teilhard de Chardins verwiesen, die auffallende Ubereinstimmungen mit Ideen Vernadskijs aufweist, aber auch mit Solov'evs Lehre von der "Gottmenschheit" und deren Bestimmung, der Einigung, Verwandlung und Rettung des Universums; siehe zuletzt die Besprechung der russischen Ausgabe von Teilhard de Chardins Hauptwerk Le phénomène humain, das 1987 stark gekürzt in einer Auflage von 130.000 Exemplaren in Moskau erschienen ist (und sofort vergriffen war). S.G. SEMENOVA, "'Da' soznatel'noj évoljucii. P'er Tejjar de Sarden, Fenomen Celoveka... M. 1987" [Rezension] In: Novyj Mir, 1988, 12, S. 253-255. Zu Solov'ev vgl. N.F. UtKINA, Tema vseedinstva v filosofii Vl. Solov'eva." In: Voprosy Filosofii, 1989, 6, bes. S. 66-68.

37 Erinnert sei hier nur an die ganzheitlich-organischen und kybernetisch-systemtheoretischen Welt-Auffassungen eines Fritjof Capra, Gregory Bateson, Jim Lovelock oder Ilya Prigogine (Prigožin). Begriffe wie "planetarisches Bewußtsein", "Noosphăre", "Ökologie des Geistes" u.v.a. sind lăngst Gemeingut westlicher New Age-Ideologen und russischer "Kosmisten". Eine genauere Untersuchung wăre lohnend. 
wissenschaftlicher Untersuchungen, vor allem aber zum Umfang und zur Qualität der Editionen: Noch immer sind wichtige philosophische Arbeiten Vernadskijs unveröffentlicht oder werden durch zensierende Eingriffe verstümmelt. ${ }^{38}$ Einige von Ciolkovskijs naturphilosophischen und gesellschaftsutopischen Traktaten (die Originale sind längst bibliographische Raritäten) wurden erstmals 1986 wieder herausgegeben - in einem editorisch ganz unzulänglichen Band, der in der Provinz erschienen ist und praktisch nicht erhältlich war. ${ }^{39}$ Ähnliches gilt für das Werk von Pavel Florenskij, dessen Auffassungen von der "Pneumatosphäre" und dem "antientropischen Wirken" des menschlichen Geistes gelegentlich dem "russischen Kosmismus" zugerechnet werden: ${ }^{40}$ die Vielzahl der in den letzten Jahren an den verschiedensten Orten (von der Tagespresse bis zu hochspezialisierten Fachzeitschriften) veröffentlichten Schriften Florenskijs ist kaum noch zu überblicken, doch handelt es sich in den meisten Fällen um Fragmente und Auszüge, bei denen sich der Verdacht auf zensierende Eingriffe (bei früheren sowjetischen Publikationen eine Selbstverständlichkeit) bis in die jüngste Zeit bestätigt. ${ }^{41}$ Eine Werkausgabe, die wissenschaftlichen Ansprüchen auch nur annähernd zu genügen vermag, liegt weder in der Sowjetunion noch im Westen vor. ${ }^{42}$ Auch die 1982 erstellte Werkausgabe Fedorovs weist Aus-

38 Zur gleichen Zeit, da man in der Sowjetunion den 125. Geburtstag Vernadskijs - zweifellos eine der imponierendsten russischen Gelehrtengestalten dieses Jahrhunderts - mit großem propagandistischem Aufwand feierte (ich selbst hatte Gelegenheit, im Mărz 1988 an der pompösen Festsitzung im Moskauer Bolschoi-Theater teilzunehmen), beklagten mehrere Wissenschaftler in einem Leserbrief an eine Fachzeitschrift, daß "seit dem Tod Vernadskijs kaum eine cinzige Ausgabe seiner Werke ohne redaktionelle Kürzungen erschienen" sei. Am Beispiel einer Edition aus dem Jahre 1977 wurde sodann demonstriert, wie durch Auslassung einzelner Sătze, aber auch ganzer Passagen, v.a. aber durch "chirurgische Operationen' am Text" Aussagen geradezu in ihr Gegenteil verkehrt worden waren. 1988 wurde das betreffende Werk erneut herausgegeben - vollständiger zwar, jedoch nach wie vor mit erheblichen Kürzungen! I.I. Mócalov, N.F. OvČnNIKov, A.P. OGURCov, "Pis'mo v redakciju." In: Voprosy Istorii Estestvoznanija i Techniki, 1988, 1, S. 66-71. Vgl. V.I. VERNADSkU, Filosofskie mysli naturalista, M. 1988.

39 Siehe T.N. ŻelnINA, "K.E. Ciolkovskij, Grezy o zemle i nebe, Tula 1986." [Rezension] In: Voprosy Istonii Estestuoznanija i Techniki, 1987, 3, S. 151-154.

40 So z.B. GIRENOK, "Russkij kosmizm" (wie Anm. 32), S. 265. B. LuUbimov, "Zagadka dlja issledovatelej i Citatelej." In: Teatral'naja Žizn', 1988, 20, S. 17. V.A. Frolov, "O pnevmatosfere P.A. Forenskogo." In: P.A. Florenskij: filosofija, nauka, lechnika. L. 1989, S. 31 f.

41 So bemerkte Goldt an den 1985 in der Zeitschrift Literatumaja Gruzija veröffentlichten Kindheits- und Jugenderinnerungen Florenskijs: "'Bereinigt' waren die ... Memoiren um eine gegen Dostojewskij gerichtete Polemik von mehr als einer Druckseite, deren Fehlen von der Redaktion noch nicht einmal durch einen Absatz, geschweige denn Auslassungszeichen, Rechnung getragen worden war." GolDT (wie Anm. 24). - Eine weitere Schwierigkeit bereitet die gerade im Falle Florenskijs verbreitete Praxis westlicher Emigrantenzeitschriften und Verlage, offenbar jeden auch noch so zweifelhaften oder korrumpierten Text, der in ihren Besitz gelangt, ungeprüft als authentisch zu veröffentlichen. Ausführlich dazu M. HAGEMEISTER, "P.A. Florenskijs 'Wiederkehr': Materialien zu einer Bibliographie (1985 - 1989)." In: Ostkirchliche Studien [im Druck].

42 Siehe M. HAgemeister, "Pavel Florenskij: Zu neuen Ausgaben." In: Ostkirchliche Studien, 36 (1987), S. 45-50. Dass. [russ.] "Novye izdanija svjasz. P.A. Florenskogo." In: Vestnik RChD, 150, 
lassungen im Text auf und enthält im Kommentar Zugeständnisse an die herrschende Ideologie, doch war sie damals ihrer Zeit - der Hochphase der "Stagnation" - weit voraus, wie ihr Schicksal beweist.

Es bleibt zu hoffen, daß auf dem "Weg zu einer normalen Kultur" die genannten Denker jene mythische Faszination verlieren werden, die lediglich auf ihrem Gegensatz zur offiziellen Ideologie beruht, ${ }^{43}$ und daß sie nicht zu Trägern einer neuen welterlösenden Ideologie funktionalisiert werden, sondern da $B$ - nachdem ihre Werke zugänglich gemacht und ihre 'wahren' Biographien geschrieben worden sind - sie in ihrer Eigenständigkeit ebenso wie im Kontext ihrer Zeit erkennbar werden.

Einen Beitrag dazu möchte die vorliegende Arbeit über Leben, Werk und Wirkung von Nikolaj Fedorov leisten. Fedorov, seit jeher heftig umstritten und wenig gelesen, war schon zu Lebzeiten zu einer Legende geworden. Das Hauptziel dieser Arbeit bestand darin, an die Stelle von Legenden Fakten zu setzen, Mutmaßungen von gesichertem Wissen zu unterscheiden. Dies geschah auf der Basis aller nur erreichbaren Informationen (was sich auch im umfangreich geratenen Anmerkungsteil niederschlug) sowie durch den Versuch, die geistigen Umfelder zu rekonstruieren, in denen Fedorovs Ideen Anklang fanden und rezipiert wurden. Die dabei gewonnenen Einblicke in bislang kaum oder gar nicht erforschte Bereiche der russischen Geistesgeschichte können als Ausgangspunkte für weitere Forschungen dienen.

Die Arbeit gliedert sich in zwei Teile (I: Leben und Werk, II: Beiträge zu einer Wirkungsgeschichte), wobei das Schwergewicht auf der Wirkungsgeschichte liegt. Da jeder dieser Teile in sich abgeschlossen ist, wurde auf eine Zusammenfassung am Schluß der Arbeit verzichtet.

Um den Umfang der Arbeit nicht weiter auszudehnen, erwies es sich im Verlauf der Untersuchung angesichts der Fülle des Materials und der Kompliziertheit der Themen als notwendig, einzelne Bereiche der Wirkungsgeschichte auszuklammern. Dies betrifft insbesondere:

- Das Verhältnis zwischen Fedorov und Vladimir Solov'ev und die Frage nach ihren wechselseitigen Einflüssen. (Das entsprechende Kapitel wurde ausgearbeitet, jedoch nicht in die vorliegende Arbeit aufgenommen; es soll an anderer Stelle veröffentlicht werden).

- Den "russischen Kosmismus", insbesondere die Frage nach Fedorovs Einfluß auf K.É. Ciolkovskij sowie auf das Werk des Dichters Nikolaj Zabolockij. Bereits vorliegende einschlägige Arbeiten sind in die Bibliographie auf-

1987, S. 34-41. - Für 1991-1992 hat der Verlag Mysl' eine dreibăndige Ausgabe der philosophischen Schriften Florenskijs angekündigt; zwei Bände mit kunsttheoretischen Schriften sollen im Verlag Iskusstvo erscheinen; eine einbändige Auswahl von Schriften zur Literatur wird vom Verlag Chudožestvennaja Literatura vorbereitet. Siehe HAGEMEISTER (wie Anm. 41).

43 Siehe dazu D.[E.] FURMAN, "Naš put' k normal'noj kul'ture." In: JU.N. AFANAS'Ev, Inogo ne dano, M. 1988, S. 569-580. 
genommen worden. Das Thema wird von mir in einem Vortrag "Russian cosmism in the 1920s: Its connections with occult and esoteric tendencies" im Rahmen einer Konferenz über The Occult in Russian and Soviet History and Culture (Fordham University, New York, Juni 1991) behandelt werden.

- Fedorovs Einfluß auf Andrej Platonov. Zu dieser noch immer umstrittenen und weitgehend ungeklärten Frage liegen inzwischen mehrere, darunter umfangreiche und gründliche Untersuchungen vor (auch sie wurden in die Bibliographie aufgenommen). Die vorliegende Arbeit beschränkt sich auf einige (z.T. neue) Hinweise in den Abschnitten II: 3.1., 3.3. und 4.1.

- Fedorovs Einfluß auf Boris Pasternak. Pasternaks Kenntnisse der Ideen Fedorovs (und ihr Niederschlag in Doktor Živago) lassen sich auf enge Kontakte des Dichters zu den Fedorov-Anhängerinnen E.A. Krašeninnikova und O.N. Setnickaja in den frühen vierziger Jahren zurückführen. O.N. Setnickaja ("Al'-Alisa") verkehrte damals wie Pasternak im Kreis um den Dichter A.E. Kručenych. Archivmaterialien, die darüber näheren Aufschluß geben könnten, waren mir nicht zugänglich.

Abschließend noch einige Hinweise zur Benutzung: Russische Namen, Titel und Zitate werden nach der modernen Orthographie transliteriert. Übersetzungen aus fremden Sprachen stammen, soweit nicht anderes vermerkt, von mir. Datumsangaben vor der Kalenderreform im Februar 1918 richten sich nach dem julianischen Kalender, dem sog. alten Stil (a.St.). Die beiden Teile der Arbeit sind in sich abgeschlossen gegliedert; bei Verweisen wird eine römische Ziffer vorangestellt (also z.B. II: 4.3.1.). 
TEIL I: LEBEN UND WERK

\section{N. F. FEDOROV: BIOGRAPHISCHER ABRISS}

Fedorovs Denken kreiste um eine einzige Idee, die Idee des obščee delo, der von allen Menschen gemeinsam ins Werk zu setzenden Verwandlung der Welt und der Auferweckung aller Verstorbenen. Diese Idee prägte Fedorovs Leben. Unklar bleibt hingegen, ob und in welcher Weise die Umstände, unter denen Fedorov lebte, zur Entstehung und Entwicklung dieser Idee beigetragen haben.

Über Fedorovs Herkunft und über die ersten Jahrzehnte seines Lebens, in denen seine Persönlichkeit und sein Denken geformt wurden, ist nur sehr wenig bekannt; ${ }^{1}$ die spärlichen biographischen Daten sind größtenteils ungesichert und nicht selten widersprüchlich. ${ }^{2}$ Das ist kein Zufall: Fedorov legte, was die eigene Person betraf, eine fast krankhafte Zurückhaltung an den Tag. Je höher er die Bedeutung seines Werkes einschätzte, desto mehr war er bestrebt, selbst dahinter zurückzutreten und seine Gefühle und leitenden Motive zu verbergen. $\mathrm{Da}$ er der eigenen Person keine Bedeutung beimaß, vielleicht auch aus Scham

1 Allein schon deshalb ist es fragwürdig, Fedorovs Leben und seine Persönlichkeit zur Erklärung (Bewertung, Rechtfertigung) seines Denkens heranzuziehen, wie dies immer wieder gefordert wird und geschieht. Fedorovs Biographie, heißt es bereits in der ersten großeren Arbeit über ihn, müsse "die notwendige Einfuhrung in die Darstellung seiner Lehre bilden; erst wenn man ihn als Menschen kennengelernt [habe, könne] man ihn auch als Denker gebührend würdigen." V.A. KoŽEvNIKov, Nikolaj Fedonoviz Fedorov. Opyt izloženija ego utenija po izdannym i neizdannym proizvedenijam, perepiske i litnym besedam. C. 1, M. 1908, S. 2. Mit Recht kritisierte noch unlängst die Verfasserin einer sowjetischen Monographie, da $B$ die "Würdigung von $\mathrm{Fe}$ dorovs geistigem Erbe oft mit einer Würdigung seiner persönlichen, menschlichen Qualitäten vermischt" werde, um dann freilich an anderer Stelle zu behaupten: "Um die ungewöhnliche Lehre Fedorovs zu verstehen", sei es "nötig, auf die persönliche Biographie des Denkers einzugehen, die teilweise die Bildung einiger Grundsătze seiner Konzeption bedingt" habe. "Zufăllige Momente seines Lebenswegs" hătten sich "ganz wesentlich in seinem Werk niedergeschlagen". Man fmde "kaum einen zweiten Denker, dessen Ideen so unlösbar mit seiner Persönlichkeit und seiner Lebensweise verbunden" seien; worauf der (bei Anhängern wie bei Gegnem beliebte) 'Schluß' von Fedorovs christlicher Lebensweise auf den christlichen Charakter seiner Lehre erfolgt: Fedorovs Werk lese sich bisweilen wie das "Tagebuch eines tiefreligiosen Menschen". V.P. PAZILova, Kriticeskij analiz religiozno-filosofskogo učenija N.F. Fedorova, M. 1985, S. 9, 23f., 128. Ebenso fragwürdig, weil im 'Ergebnis' nicht nachprüfbar, ist der von Lukashevich unternommene Versuch, Fedorovs "Ideologie" als "Rationalisierung seiner psychologischen [sic] Probleme" zu deuten. ST. LuKasheVich, N.F. Fedorov (1828-1903). A Siudy in Russian Eupsychian and Utopian Thought. Newark, London 1977, bes. S. 43, 57, 291-303.

2 In der Lit eratur st $8 ß t$ man deshalb auf divergierende Angaben, was freilich nicht in jedem Fall der Quellenlage, sondern mitunter auch der Nachlässigkeit der Autoren zuzuschreiben ist. So sind, um ein besonders krasses Beispiel zu nennen, in der 1970 erschienenen Arbeit von R. Lord ("Fyodorov ... is clearly no bingrapher's meat") nicht nur sämtliche Daten zu Fedorovs Biographie falsch, sondern stehen auch noch untereinander in Widerspruch. $R$. LORD, Dostoevsky. Essays and Perspectives. London 1970, S. 175-179. Auch die biographischen Angaben in der weitgehend brauchbaren Arbeit von G. YouNG, N.F. Fedorov: An Introduction. Belmont, Mass. 1979, S. 17-20, enthalten eine Reihe von Fehlern, die bei großerer Sorgfalt hätten vermieden werden können; siehe meine Rezension in $Z f s l P h, 44,2,1984$, S. 440-449. 
über seine Herkunft, vermied er oder lehnte es ab, über sich selbst zu sprechen. Fragen nach seinem Elternhaus oder nach seinem Alter wies er stets zurück, und nur selten sprach er über die Jahre vor seinem Eintritt in den Moskauer Bibliotheksdienst. Selbst Fedorovs Freunde wußten von ihm kaum mehr als seinen Familiennamen; den meisten war er nur als "Nikolaj Fedorovic" bekannt.

Über Fedorovs zweite Lebenshälfte, die Zeit, in der er an Moskauer Bibliotheken tätig war und zu einer bekannten Figur in Kreisen der Intelligenz wurde, liegen zahlreiche Berichte und Erinnerungen vor. Sie stammen zumeist aus der Feder von Freunden und Verehrern und erweisen sich gerade deshalb nicht selten als fragwürdig: unübersehbar ist ein Hang zu legendärer Stilisierung und Verklärung, und bisweilen wird Fedorovs Biographie zur Hagiographie. ${ }^{3}$

Vor diesem Hintergrund soll im folgenden versucht werden, die wichtigsten Stationen von Fedorovs Lebensweg nachzuzeichnen und ein Porträt seiner Persönlichkeit wenigstens zu skizzieren. ${ }^{4}$

"Fedorov ist anscheinend der einzige Philosoph (wenn man einmal von Sokrates absieht), dessen Leben keine Biographie, sondern eine 'Vita' war." V.N. IL'IN, "O religioznom i filosofskom mirovozzrenii N.F. Fedorova." In: Evrazijskij sbomik, 6, Prag 1929, S. 18. Ähnlich ăußerte sich die sowjetische Fedorov-Forscherin S.G. Semenova als sie Fedorov einen "filosof ne $s$ Žizn'ju, a s žitiem" nannte. S.G. SEMENova, "Nikolaj Fedoroviそ Fedorov. (Žizn' i uženie)." In: Prometej, t. 11, M. 1977, S. 87.

4 Eine detaillierte Biographie Fedorovs, die sich nicht in Spekulationen ergeht, läßt sich bei der gegenwărtigen Quellenlage nicht verwirklichen. Die folgende Skizze beschrănkt sich deshalb auf Daten, die als gesichert angesehen werden können und konzentriert sich auf jene Züge Fe. dorovs, in denen seine Gedankenwelt zum Ausdruck kommt; darüber hinaus bietet sie eine Anzahl bislang unbekannter Materialien.

Angaben zur Biographie Fedorovs und Schilderungen seiner Persönlichkeit wurden erstmals veröffentlicht in Nachrufen und Erinnerungen, die nach Fedorovs Tod in der Moskauer Presse erschienen; siehe auch II: 2.2.1. Besonders informativ sind folgende Artikel: P.JA. PoKrovskJ [d.i. G.P. GeORGIEvSKU], "Iz vospominanij o Nikolae Fedorovize. (K 40 dnju konciny)." In: Moskorskie Vedomosti, $23-26$ (23.-26.1.1904), S. 4f., 4f., 5, 4. E.S. NeKrasova, "Pamjati N.F. Fedorova." In: Russkie Vedomosti, 353 (24.12.1903), S. 4. V.I. SENROK, "Pamjati N.F. Fedorova i A.E. Viktorova." In: Istoriceskij Vesinik, 25 (1904), 95,2, S. 663-670. - Der Bibliothekar Grigorij Petrovið Georgievskij (1866-1948) war seit 1890 Mitarbeiter Fedorovs im Lesesaal der Rumjancev-Bibliothek, spăter wurde er Kustos der Handschriftenabteilung und ein bedeutender Palăograph. Siehe G.I. Dovgallo, "Iz istorii otdela rukopisej po materialam archiva G.P. Georgievskogo." In: Zapiski oldela rukopisej, vyp. 45, M. 1986, S. 61-63, 66, 76. Die Literaturwissenschaftlerin und Schriftstellerin Ekaterina Stepanovna Nekrasova (1847-1905) und der Literaturwissenschaftler und Gogol'-Spezialist Vladimir Ivanovið Senrok (1853-1910) waren als regelmåßige Benutzer der Rumjancev-Bibliothek mit Fedorov gut bekannt.

Biographische Angaben finden sich außerdem in den Veröffentlichungen der Fedorov-Anhänger N.P. Peterson (zu ihm unten Anm. 42 und 46) und V.A. Koževnikov (zu ihm unten Anm. 59): N.P. PETERSON, N.F. Fedorov i ego kniga 'Filosofija obšcego dela'v protivopolożnost' uČeniju L.N. Tolstogo 'o neprotivlenii' $i$ drugim idejam naśego vremeni, Vernyj 1912. KoZEVNI. Kov (wie Anm. 1); Koževnikovs Arbeit erschien großtenteils als Vorabdruck im Russkij Archiv, 42 (1904) - 44 (1906). Im folgenden wird stets nach der Buchausgabe von 1908 zitiert.

Zahlreiche Angaben zur Biographie Fedorovs enthalten ferner der Artikel des Journalisten und Schriftstellers A.S. PANKRaTOV, "Filosof-pravednik." In: Novoe Slovo, 5 (1913), 8, S. 17-25 (zu Pankratov, der auch eine verschollene Biographie Fedorovs verfaßt haben soll, siehe II: 2.2.1.), sowie insbesondere die wahrscheinlich 1911 verfaßten, jedoch erst unlăngst vollstăndig veröf- 
Nikolaj Fedorovix Fedorov wurde wahrscheinlich im Mai 1829 (anderen Angaben zufolge zwischen Januar und April 1828) als unehelicher Sohn des Fürsten Pavel Ivanovix Gagarin (geb. 1798, gest. zwischen 1858 und 1865) und des Adelsfräuleins Elizaveta Ivánova im Kreis Elat'ma im nördlichen Teil des Gouvernements Tambov geboren. ${ }^{5}$ Am 26. Mai 1829 wurde das Kind im Dorf Vjalsy

fentlichten ausführlichen Erinnerungen von G.P. GEORGIEVSKJJ, "L.N. Tolstoj i N.F. Fedorov. Iz lǐ̌nych vospominanij." In: Četvertye Tynjanovskie ctenija, Riga 1988, S. 46-66. Siehe dazu G.I. DOVGAllo und A.P. CudAKOV ["Vstupitel'nye stat'i"], ebd., S. 27-45. S.V. ŽrTOMIRSKAJA, Vospominanija i dnevniki XVIII-XX wv. Ukazatel' nukopisej. M. 1976, S. 124f. Eine gekürzte und stellenweise abweichende Fassung von Georgievskijs Erinnerungen in: Novyj Žumal, 142, 1981, S. 91-109. Im folgenden wird nach der 1988 veroffentlichten Fassung zitiert.

Angaben über Fedorovs Ausbildung, seinen beruflichen Werdegang und seine regelmăßigen Beförderungen - er brachte es bis zum Kollegienassessor - enthălt ein anläBlich seiner Entlassung aus dem Bibliotheksdienst am 15.9.1898 ausgestelltes Attestat N.F. Fedorova (PetersonArchiv, GBL f. 657; im folgenden zitiert Attestat, nach einer Abschrift in Moskauer Privatbesitz). Den Angaben des Attestats liegt offenbar Fedorovs Dienstliste (poslužnoj spisok) zugrunde; diese befindet sich zusammen mit einer Kopie des Attestats in Fedorovs Personalakte, die im Archiv der Lenin-Bibliothek aufbewahrt wird. Delo Moskovskogo Publiznogo i Rumjancevskogo Muzeev o sluzbe detumogo cinovnika pri cital'ne Muzeev Kollez. Sekretaja N.F. Fedorova (27.11.1874-15.9.1898); Archiv GBL, op. 126, ed. chr. 53. Ein Verzeichnis der darin enthaltenen 82 Schriftstücke wird nach einer Abschrift in Moskauer Privatbesitz zitiert Opis'. Einige der Angaben des Attestats (wie offenbar auch der Dienstliste) müssen als höchst zweifelhaft angeschen werden; anscheinend dienten sie dazu, Fedorovs Herkunft und Alter zu verschleiern (siehe unten Anm. 5 und 6).

Um die Mitte der zwanziger Jahre verfaßte der Moskauer Fedorov-Anhănger A.K. Gorskij (zu seiner Person II: 2.3.2. und 4.1.) auf der Grundlage der genannten Literatur sowie eigener Forschungen (als erster benutzte er die erwăhnte Dienstliste und das Attestat) eine biographische Skizze, die 1928 unter dem Pseudonym "A. Ostromirov" in zwei textgleichen Ausgaben in Harbin (Mandschurei) erschien; im folgenden zitiert nach der Ausgabe A. OsTROMIRov [A.K. Gorsku], Nikolaj Fedorovic Fedorov. 1828-1903-1928. Biografija. O.O. [Harbin] 1928.

Biographische Materialien und Erinnerungen an Fedorov sollten im dritten Band der FOD veroffentlicht werden. Vgl. V. KoŽEvnikov, N. PETERson, "Predislovie." In: FOD II, S. IV. N.[P.] Peterson, O religioznom chanaktere učenija N.F. Fedorova, M. 1915, S. 30. Dieser Band ist jedoch nie erschienen (dazu I: 2.). Die Materialien befinden sich heute im Archiv von N.P. Peterson (GBL f. 657); nur ein geringer Teil davon war mir in Abschriften zugänglich.

5 Fedorov hat es meisterhaft verstanden, seine Herkunft zu verschleiern und durch falsche Informationen die Biographen in die Irre zu führen. Das daraus enwachsene, sich nur langsam lichtende Dickicht aus widersprüchlichen Behauptungen, Mutmaßungen und Legenden soll im folgenden kurz skizziert werden.

Fedorovs genaues Geburtsdatum laßt sich bis heute nicht feststellen. Es liegen zahlreiche widersprüchliche Angaben vor. - Am hăufigsten wird das Jahr 1828 genannt. So lautet Fedorovs eigene Angabe in seiner Dienstliste auf den Zeitraum zwischen Januar und April 1828. SEMENOVA (wie Anm. 3). Damit übereinstimmend vermerkt das Attestat vom 15.9.1898 (wie Anm. 4): "Ot rodu on, Fedorov, imeet nyne 70 let." - Erstmals wurde dieses Datum im Jahre 1928 von OSTROMIROV (wie Anm. 4), S. 8, genannt, der sich dabei offenbar auf die genannten Dokumente stützte. Bereits zwei Jahre zuvor hatte M.M. Klevenskij mitgeteilt, Fedorov sei "um 1828 " geboren. Anmerkung zu "PokuŠenie Karakozuva 4 aprelja 1866 g." In: Krasnyj Anchiv, 17, 1926, S. 137; von dort übernommen auch in: Dejateli revoljucionnogo dviženija, t. 1, Ł. 2, M. 1928, Sp. 427.

Es gibt indessen gewichtige Gründe, die daran zweifeln lassen, daß Fedorov im Jahre 1828 geboren wurde. Fedorov selbst widerspricht diesem Datum, wenn er in einem Brief an 
Koževnikov vom 10.12 .1898 schreibt, er stehe im 74 . Jahr ("v 74 goda"). KožEvNIKov (wie Anm. 1), S. 214. Fedorovs enger Vertrauter Peterson weiB zu berichten, Fedorov sei "etwa vier Jahre älter gewesen als Tolstoj". PETERson, Fedorov (wie Anm. 4), S. 77, 88. Tolstoj selbst hielt Fedorov 1881 für einen Sechzigjăhrigen. Brief Tolstojs an V. Alekseev, November 1881. In: L.N. TolsToJ, PSS, t. 63, M.-L. 1934, S. 83. Bis zum Erscheinen von Ostromirovs (Gorskijs) biographischer Skizze - und in einigen Fällen auch noch danach - wurde Fedorovs Geburtsjahr entweder mit 1821 (Pokrovskis, wie Anm. 4, Nr. 25, S. 5. PANKRATOV, wie Anm. 4, S. 18) oder mit 1824 (A.A. GINKEN, "Ideal'nyj bibliotekar' - Nikolaj Fedorovic Fedorov." In: Bibliotekar', 1911, 1, S. 12) angegeben. Auch die Inschrift auf Fedorovs Grabkreuz nennt 1824 als Geburtsjahr. Ostromirov (wie Anm. 4), S. 20. Für dieses Datum plădierten erst unlăngst wieder sowjetische Forscher, die sich dabei auf - nicht năher bezeichnete - "biographische Materialien zu Fedorov" im Peterson-Archiv (GBL f. 657) beriefen. [Igumen] TichoN, V.[A.] Nikrris, "Ekumeniðeskoe dviženie i Russkaja Pravoslavnaja Cerkov' do ee vstuplenija v VSC." In: ŽMP, 1983, 11, S. 63. - Ganz abwegig ist hingegen die Angabe, Fedorov sei in den 1840er Jahren geboren. Enciklopediceskij slovar' Granat, 7-oe izd., t. 43, M. o.J., S. 102.

Die jüngste, von der sowjetischen Forschung gemachte Angabe, wonach Fedorov im Mai 1829 geboren worden sei, stützt sich auf "Dokumente", die der Moskauer Fedorov-Forscher V.S. Borisov im Jahre 1985 im Gebietsarchiv von Tambov gefunden hat. Mitgeteilt wurde bislang nur der Text einer Bescheinigung über die Taufe (!) am 26. Mai 1829. V.S. BoRISOV, Kto ze byla mat' vydajus'zegosja russkogo myslitelja N.F. Fedorova? Ms. [Masch.] M. 1986, Bl. 2f.; siehe auch unten Anm. 6. - Im Einklang mit diesem Datum befindet sich Koževnikovs Bemerkung, Fedorov sei (im September 1898) im Alter von fast 70 Jahren pensioniert worden. KožeVnikov (wie Anm. 1), S. 3. In einem Brief vom 11.12.1903 gibt Koževnikov Fedorovs Alter mit 74 Jahren an (siehe unten Anm. 121).

Auch zu Fedorovs Eltem gibt es eine Fülle widersprüchlicher Angaben. - Erst zwei Jahrzehnte nach Fedorovs Tod gelang es seinem Biographen A.K. Gorskij, Fedorovs Vater zu ermitteln. Bis dahin war lediglich bekannt geworden, daß Fedorov der "uneheliche Sohn eines Fürsten Gagarin" war. So z.B. Pankratov (wie Anm. 4), S. 18; vgl. auch K.N. AltajSKu [K.N. Ko. ROLEV], "Moskovskaja junost' Ciolkovskogo." In: Moskva, 1966, 9, S. 180. Von Koževnikov hatte Gorskij erfahren, daß Fedorovs Vatersname eigentlich "Pavloviz" hătte lauten müssen. Zwar gab es in der ersten Hălfte des 19. Jahrhunderts mehrere Fürsten Gagarin, die den Vornamen Pavel trugen und ihrem Alter nach als Väter Fedorovs in Frage kommen konnten (siehe N. IkonNIKov, La noblesse de Russie, t. D.1 [pr. Gagarine], Paris 1958), doch hatte bereits 1911 P.I. Bartenev einen knappen Hinweis auf Fedorovs Großvater gegeben, der offenbar unbeachtet geblieben war (P.I. BARTENEv, Anm. in: Russkij Archiv, 1911, 2, S. 308), so daß aus der Kombination beider Angaben Pavel Ivanovič Gagarin hătte ermittelt werden können. Die Identifizierung von Fedorovs Vater gelang Gorskij schließlich aufgrund - nicht näher mitgeteilter - Angaben eines gewissen N.P. Culkov, eines ehemaligen Mitarbeiters von Fedorov im Archiv des Außenministeriums. Vgl. Ostromarov (wie Anm. 4), S. 8. Brief von A.K. Gorskij an N.A. Setnickij, 20.4.1927; FAP I, 328. IKONNIKOV, a.a.O.

Die Nachforschungen nach Fedorovs Mutter erwiesen sich als noch schwieriger. Ihre Identităt wurde erst unlängst durch die erwăhnten Archivfunde Borisovs festgestellt. Bis dahin hatte man von einer leibeigenen Băuerin, einer gefangenen Cerkessin oder einer Georgierin gesprochen. Ostromirov (wie Anm. 4), S. 8. GeOrgIEvsKu (wie Anm. 4), S. 48. Immerhin gehen diese bis heute vielfach verbreiteten - Angaben auf Gewăhrsleute zurück, die mit Fedorov bestens bekannt waren, nämlich P.I. Bartenev und Ju.P. Bartenev: Petr Ivanovið Bartenev (1829-1912), slavophiler Historiker, Bibliograph und Publizist, Gründer und Herausgeber des Russkij Archiv und von 1859 bis 1873 Direktor der Moskauer Certkov-Bibliothek, kannte Fedorov seit 1869, als dieser in der Certkov-Bibliothek zu arbeiten begann. Bartenevs Erinnerungen an Fedorov (angekündigt in Russkij Archiv, 1911, 4, S. 634) wurden nicht veroffentlicht und sind verschollen. Siehe A.D. ZaJCEv, Petr Ivanoviz Bantenev, M. 1989. Auch sein Sohn Jurij Petroviz Bartenev (1866-1908), Historiker, Beamter der Moskauer Zensurbehorde und Erzmonarchist, war mit Fedorov gut bekannt (siehe seinen Nachruf "Pamjati Nikolaja Fedorova." In: Russkij Archiv, 1904, 1, S. 191f.). Seinen Angaben zufolge soll Fedorovs Vater, ein "Fürst G." aus dem Gouvernement Penza, wăhrend seiner Dienstzeit im Kaukasus die spätere Mutter Fedorovs 
(Kreis Elat'ma) auf den Namen Nikolaj getauft; den Familien- und Vatersnamen erhielt es von seinem Paten, dem Kollegienregistrator Fedor Karlovic Belevskij. ${ }^{6}$

Durch seinen Vater, der einem der vornehmsten Geschlechter Rußlands entstammte, ${ }^{7}$ war Fedorov mit illustren und bisweilen eigenwilligen Vertretern des russischen Geisteslebens verwandt, darunter dem Slavophilen Ivan Sergeevic Gagarin (1814-1882), der zum Katholizismus konvertierte, in den Jesuitenorden eintrat und 1862 in Paris Čaadaevs Lettres philosophiques herausgab, ${ }^{8}$ sowie dem berühmten Naturforscher und Anarchisten Petr Alekseevic Kropotkin $(1842-1921)^{9}$

kennengelernt und ihretwegen den Dienst quittiert haben. Nach GEORGIEVSKU, a.a.O.; übernommen von S.G. SEMENOVA, "V usilii $k$ budušemu vremeni...' (Filosofija Andreja Platonova)." In: Literatumaja Gruzija, 1979, 11, S. 107. Diese Version beruht wahrscheinlich auf einer Verwechslung mit dem jüngsten Bruder von P.I. Gagarin, Aleksandr Ivanovix (1801-1857), der lange in Georgien diente. Russkij biograficeskij slovar', t. 4, M. 1914, S. 55f.

Schließlich gibt es auch zu Fedorovs Geburtson unterschiedliche Angaben. - Genannt werden Neurußland (Novorossijskij kraj), wo die Fürsten Gagarin große Güter besaßen (OsTROMarov, wie Anm. 4, S. 10), "der Süden" (Pankratov, wie Anm. 4, S. 18) oder Moskau (Pokrovsku, wie Anm. 4, Nr. 26, S. 4: "Erst jetzt nach seinem Tod wurde bekannt, daß er [Fedorov] der Herkunft nach ein Moskauer war"). - Borisovs Forschungen lassen indessen vermuten, da B Fedorov auf dem Gagarinschen Gut Sasovo (Kreis Elat'ma, Gvt. Tambov) oder in dessen Umgebung, z.B. dem nahegelegenen Dorf Kljuci, in dem seine Mutter lebte, geboren wurde. (Siehe auch unten Anm. 6).

6 Die Angaben beruhen auf einer am 2. April 1834 ausgestellten Taufbescheinigung, die im Jahre 1985 von V.S. Borisov im Gebietsarchiv von Tambov gefunden wurde (siehe Borisov, wie Anm. 5). Darin bestătigt ein Nikolaj Fedorov (sic), Priester des Dorfes Vjalsy im Kreis Elat'ma (Gvt. Tambov), daß er am 26. Mai 1829 in Vjalsy den unehelichen Sohn des Adelsfräuleins Elizaveta Ivánova aus dem Dorfe Kljuti im Kreis Elat'ma auf den Namen Nikolaj getauft habe. Taufpaten seien der Kollegienregistrator Fedor Karlovið Belevskij und die Kleinbürgerin Aleksandra Jakovleva gewesen. Gosudarstvennyj archiv Tambovskoj oblasti f. 105, ok. 7, d. 4, str. 107. In dem Dokument werden weder der Name des Vaters, noch Familien- und Vatersname des Kindes genannt!

Uber Fedorovs Taufpaten ist nichts weiter bekannt. Von Fedorovs Mutter wird berichtet, sie habe den Direktor des 1. Moskauer Gymnasiums geheiratet. GEORGIEvskI (wie Anm. 4), S. 48. Dies ist unwahrscheinlich: Von 1830 bis 1853 war Matvej Alekseeviz Okulov (1792-1853) Direktor des Gymnasiums. Siehe I.O. GobZA, Stoletie Moskovskoj 1-j gimnazii. 1804-1904 gg. Kratkij acerk. M. 1903, S. 86, 324. Seine Frau war die mit Puskin gut bekannte Nastasja Vojnovna Našcokina.

Fedorov selbst hatte spăter in sciner Dienstliste angegeben, er stamme aus dem Kaufmannsstand, aus dem er durch Erlaß des Dirigierenden Senats vom 29.9.1849 ausgeschlossen worden sei.

7 Die Fürsten Gagarin führten, ebenso wie das Herrscherhaus, ihre Abstammung auf Rjurik zurück. Siehe P. de GMELINE, Dictionnaire de la noblesse nusse, Paris o.J. [1978], S. 269.

8 Ostromirov (wie Anm. 4), S. 9. - Zu I.S. Gagarin vgl. Russkij biograficeskij slovar (wie Anm. 5), S. 69-74. W. ŚlwWOWSKA, $W$ kregu poprzednikow Hercena, Wroctaw u.a. 1971, bes. S. 301337.

9 Sein Großvater, Petr Nikolaevið Kropotkin (1771-1826), hatte Praskov'ja Alekseevna Gagarina geheiratet, die Schwester von Fedorovs GroBvater Ivan Alekseeviz Gagarin. Ostromarov (wie Anm. 4), S. 9. MA. MilLeR, Kropotkin, Chicago, London 1976, S. 3f. Fedorov und Petr Alek- 
Fedorovs Vater war der älteste von sechs Söhnen aus der ersten Ehe des Fürsten und Senators Ivan Alekseevic Gagarin (1771-1832), eines reichen Grundbesitzers und führenden Freimaurers zur Zeit Alexanders I. ${ }^{10}$ Bekannt als Liebhaber und Förderer der Künste, ${ }^{11}$ insbesondere des Theaters, hatte sich Ivan Alekseevix Gagarin 1828 in zweiter Ehe mit der gefeierten Schauspielerin Ekaterina Semenovna Semenova (1786-1849) verbunden, der Tochter eines Gutsherrn und einer Leibeigenen. ${ }^{12}$

Sein Sohn Pavel Ivanovix war weniger bedeutend. ${ }^{13}$ Er erhielt eine Erziehung durch Hauslehrer und im vornehmen Pagenkorps, besuchte die Moskauer Universität und trat nach kurzem Militärdienst in das Kollegium der auswärtigen Angelegenheiten ein. 1822 wurde er auf eigenen Wunsch der ständigen diplomatischen Vertretung in Philadelphia zugewiesen. ${ }^{14}$ Nach seiner Rückkehr aus den Vereinigten Staaten verließ er 1826 den Staatsdienst und zog sich auf seine Besitzungen zurück. ${ }^{15}$

seevið Kropotkin waren also Vettern zweiten Grades. In seinen Erinnerungen hebt PA. Kropotkin besonders die künstlerischen und literarischen Neigungen der Familie Gagarin hervor. P.[A.] KRAPOTKIN [KROPOTKIN], Memoiren eines Revolutionärs, Bd. 1, Stuttgart 21901, S. 10.

10 Russkij biografixeskij slovar (wie Anm. 5), S. 67f. - Zum Todesdatum (1832) vgl. Moskovskij nekropol', t. 1, SPb. 1907, S. 250. A.N. SIROTININ, "Ekaterina Semenowna Semenova." In: Istoriceskij Vestnik, 25 (1886), 7,9, S. 506. T. BAKOUNINE, Répertoire biographique des francs-maçons russes (XVII ${ }^{\prime}$ et XIX ${ }^{e}$ sieccles), Paris 1967, S. 164. Dagegen nennt IKONNIKOV (wie Anm. 5) als Todesdaten 1838 oder 1846; GMELINE (wie Anm. 7) nennt nur 1846. - Ostromirov (Gorskij), der IA. Gagarin als "einen der hervorragendsten Freimaurer aus der Zeit Katharinas" bezeichnet, verwechselt ihn offenbar mit Gavriil Petrovit Gagarin (1745-1808).

11 Unter anderem hatte er die "Gesellschaft zur Förderung von Künstlern" (Obšcestvo poošrrenija chudożnikov) gegründet mit dem Ziel, "zur Verbreitung der schönen Künste in RuBland beizutragen". N.G. ZoGRAF, Aleksandr Pavlovic Lenskij, M. 1955, S. 7.

12 Russkij biograficeskij slovar, t. 18, SPb. 1904, S. 299-304. Vgl. auch SIROTININ (wie Anm. 10), S. 474-508, bes. S. 474, 497 (Portrăt von I.A. Gagarin), 505f. I.N. MEdVEdEVA, Ekaterina Semenova. Zizn' i mortestuo tragiteskoj aktrisy. M. 1964, bes. S. 76-78, 161f., 255, 269. Ostromirov (Gorskij) und, ihm folgend, alle übrigen Autoren hielten die Opernsăngerin Nimfodora Semenova (1788-1876), die jüngere Schwester von Ekaterina, für I.A. Gagarins zweite Frau. Dieser Irrtum wurde zuerst berichtigt von E. KouTAISsOFF, "Some Futurological Aspects of Fedorov's 'Philosophy of the Common Cause'." In: Russian Literature Triquarterty, 12 (1975), S. 406 Anm. 1.

13 Das folgende nach Ostromarov (wie Anm. 4), S. 8f. - Vgl. auch Ikonnikov (wie Anm. 5), No. 320. Ikonnikov stützt sich auf Mitteilungen eines gewissen V.S. Arsen'ev, die moglicherweise auf den Angaben von Ostromirov (Gorskij) beruhen.

14 In jenen Jahren kam auch die Verbindung eines anderen Mitglieds der Familie Gagarin in die Vereinigten Staaten zustande: Im Mai 1828 heiratete die Fürstin Elena Pavlovna Gagarina den Schriftsteller Aleksandr Gavrilovið Rotそev, den spăteren (und letzten) Kommandanten von Fort Ross, einer russischen Niederlassung in Kalifornien. Der Vater von Elena Pavlowna konnte nicht mit Sicherheit ermittelt werden; möglicherweise handelt es sich um den hohen Staatsbeamten Pavel Pavlovið Gagarin (1789-1872). Eine năhere Verwandtschaft mit Pavel Ivanoviz Gagarin lieB sich nicht nachweisen. (Briefl. Mitteilung von Victor P. Petrov, Arlington, VA, 18.4.1983).

15 Ostromarov (wie Anm. 4), S. 8f.; ohne genaue Angaben. - Die Gagarins besaßen Güter in verschiedenen Teilen Rußlands. P.I. Gagarin war u.a. Herr auf Sasovo im Kreis Elat'ma im nörd- 
In diese Zeit fällt wahrscheinlich die Liaison mit Fedorovs Mutter - offenbar mehr als eine flüchtige Affaire, da aus ihr, soweit bekannt, zwei Söhne und zwei Töchter hervorgingen. ${ }^{16}$ Verheiratet war Pavel Ivanovix mit Ludmila Ivanovna Vyrubova. Aus dieser Ehe gingen fünf Kinder hervor, ${ }^{17}$ darunter eine Tochter Zinaida Pavlovna, die einen Obersten Šatov heiratete und in Vladimir lebte; ${ }^{18}$ Nikolaj Fedorovic soll zu dieser seiner Halbschwester "gute Beziehungen" unterhalten haben. ${ }^{19}$

In den dreißiger Jahren zog Pavel Ivanovix nach Odessa, wo sein Bruder Aleksandr dem Generalgouverneur von NeuruBland, dem Grafen M.S. Voroncov, als Adjutant diente. ${ }^{20}$ Wie sein Vater war auch Pavel Ivanovic ein leidenschaftlicher Liebhaber der Musik und des Theaters. Er besa B ein eigenes Orchester, das aus Leibeigenen bestand, und gründete in den frühen vierziger Jahren in Odessa eine Schauspielschule sowie eine Privatbühne, die unter den Ausländern als "il teatrino Gagarini" bekannt war. ${ }^{21}$ Im November 1845 begann er, mit einer eigenen Truppe Stücke aufzuführen, vor allem Vaudevilles, aber auch Dramen, Tragödien, Opern und Ballette, zunächst in Odessa, ab April 1846 in KiSinev. ${ }^{22}$ Dort wurde am 1.(13.) Oktober 1847 sein unehelicher Sohn Aleksandr Pavlovið̌ geboren, der unter dem Künstlernamen Lenskij einer der berühmtesten Schauspieler seiner Zeit wurde; die Mutter, Ol'ga Verviciotti, war die Primadonna der italienischen Oper von Odessa. ${ }^{23}$ P.I. Gagarins künst-

liehen Teil des Gouvernements Tambov. - Wie Ostromirov weiter berichtet, sei P.I. Gagarin 1832 gestorben und auf dem Dorogomilov-Friedhof (Dorogomilovskoe kladbisce) im Westen Moskaus beigesetzt worden. Diese Angaben stammen offensichtlich aus Moskovskij nekropol' (wie Anm. 10), S. 251; als Todesdatum von P.I. Gagarin ist dort der 22.5.1832 genannt (übernommen von IKONNIKOV, wie Anm. 5); dieses Datum ist jedoch falsch.

16 Über Fedorovs Geschwister siehe unten Anm. 34.

17 Siehe IKonnikov (wie Anm. 5), No. 320.

18 Vgl. Ixonnkov (wie Anm. 5). A.P. Lensku, Stat'i. Pis'ma. Zapiski. M. ${ }^{2} 1950$, S. 288 Anm. 5, 7; S. 349.

19 "Chorosie otnošenija Fedorov podderžival i so svoej svodnoj sestroj knjažnoj Zinaidoj Pavlovnoj Gagarinoj." Aufzeichnung im Peterson-Archiv, GBL f. 657, kart. 1; nach einer Abschrift in Moskauer Privatbesitz.

20 Vgl. E.S. ANDREEvSKU, "Zapiski." In: Iz archiva KE. Andreevskogo, t. 1, Odessa 1913, S. 276, 363. N.N. RožkovskAjA, Teatral'naja żizn' Kisineva XIX - naZala XX v., Kisinev 1979, S. $38 f$. Russkij biograficeskij slovar' (wie Anm. 5).

21 ANDREEvSKIJ (wie Anm. 20), S. 276f. Über die von den Biographen Fedorovs bisher übersehene Theatertătigkeit P.I. Gagarins ausführlich RožkovskAsA (wie Anm. 20), S. 37-63. Siehe auch A.P. KuINCIN, "Provincial'nyj teatr." In: Istonija nusskogo dramatizeskogo teatra, t. 4, M. 1979 , S. $231 f$.

22 Ausführlich Rožkovskasa (wie Anm. 20), S. 37-63. Vgl. auch die Erinnerungen des Schauspielers A A. ALFKSEEv, "Vospominanija artista imperatorskich teatroy." In: Istoriceskij Vestnik, 49, 1892, S. $97 f$.

23 Von Fedorovs Biographen ist die Verwandtschaft mit A.P. Lenskij (Verviciotti) bislang nicht bemerkt worden, wahrscheinlich weil man, Ostromirov (Gorskij) folgend, davon ausgegangen war, daß P.I. Gagarin bereits 1832 gestorben sei. In seinen Memoiren schildert Lenskij die 
lerische Unternehmungen blieben jedoch erfolglos und führten gegen Ende der vierziger Jahre zum finanziellen Ruin. ${ }^{24}$ Von seiner Verwandtschaft geächtet und unter Kuratel gestellt, verbrachte er die letzten zehn Jahre seines Lebens enttäuscht und vereinsamt auf seinem Gut Sasovo im Gouvernement Tambov. ${ }^{25}$ 1858 starb Ol'ga Verviciotti. ${ }^{26}$ P.I. Gagarin überlebte sie, doch anscheinend nicht lange; sein genaues Todesdatum ist nicht bekannt. ${ }^{27}$

Ungeklärt ist die Frage, wo Fedorov seine Kindheit verbracht hat; vielleicht auf Okna, ${ }^{28}$ dem Familienbesitz der Gagarins nördlich von Odessa an der Grenze zu Podolien (das Gut besa $B$ eine umfangreiche Bibliothek, die von den wissenschaftlichen und künstlerischen Interessen der Familie zeugte), ${ }^{29}$ wahrscheinlicher aber auf dem väterlichen Gut Sasovo oder einem anderen Ort im nördlichen Teil des Gouvernements Tambov. ${ }^{30}$ Über die Jahre seiner Kindheit scheint Fedorov später kaum gesprochen zu haben. Unter seinen nachgelassenen Papieren fand man jedoch einen Zettel, der den Vermerk "Notwendige Ergänzung" trug und folgende offenbar autobiographische Notiz enthielt:

Aus den Jahren der Kindheit sind mir drei Erinnerungen verblieben: ich sah das schwarze, sehr schwarze Brot, von dem sich (man sprach davon in meinem Beisein) die Bauern in irgendeinem

bedrückende Atmosphăre im elterlichen Haus, dem Gut Sasovo (Gvt. Tambov), und die schweren Jugendjahre, die er nach dem Tod der Mutter (1858) in Moskau in der Familie des Schauspielers K.N. Poltavcev verbrachte, der mit einer Schwester Fedorovs verheiratet war (dazu unten Anm. 34). A.P. Lenskijs Memoiren mit dem Titel "Perežitoe" wurden zuerst veroffentlicht in Russkaja Mysl', 30 (1909), 3, S. 33-55; 4, S. 1-18; 5, S. 31-44. Wieder abgedruckt und kommentiert in: A.P. LeNSKu, Stat'i, pis'ma, zapiski, M.-L. 1935, S. 1-99. DeRS., dass. (wie Anm. 18), S. $19-76$ (mit abweichender Kommentierung!). Siehe ferner die Biographie A.P. Lenskijs von ZoGRAF (wie Anm. 11), S. 7-10.

Zu Ol'ga Verviciotti siehe auch RožKovskaja (wie Anm. 20), S. 44. O. Verviciotti soll die britische Staatsbürgerschaft besessen haben. LENSKU, Stat'i, Ausg. 1935, a.a.O., S. 630. Aus ihrer Verbindung mit P.I. Gagarin ging noch mindestens ein Sohn hervor - Anatolij Pavloviz Verviciotti, der ebenfalls unter dem Künstlernamen Lenskij von 1888 bis 1903 als Schauspieler am Malyj leatr in Moskau auftrat. LENSKIJ (wie Anm. 18), S. 288 Anm. 13.

24 Vgl. Zograf (wie Anm. 11), S. 8f. Rožxovskaja (wie Anm. 20), S. 44.

25 Vgl. Zograf (wie Anm. 11), S. 9. LeNSKu (wie Anm. 18), S. 27-31.

26 LENSKU (wie Anm. 18), S. 349.

27 Lensku, Stat'i, Ausg. 1935 (wie Anm. 23), S. 25, 532 Anm. 20, 533 Anm. 29. Aus Lenskijs Angaben geht lediglich hervor, daß P.I. Gagarin zwischen 1858 und 1865 gestorben ist.

28 So die Vermutung von Koutaissoff (wie Anm. 12), S. 394.

29 Wăhrend des Bürgerkriegs wurde Okna zerstört, wie Gorskij, der sich zu jener Zeit in Odessa aufhielt, berichtet. Ostromirov (wie Anm. 4), S. 14.

30 Einige Angaben zu Sasovo und seiner Umgebung bei V.P. SEMENov (Hg.), Rossija. Polnoe geografižeskoe opisanie našego otě̌estva. T. 2, SPb. 1902, S. 335. - Die Rückstăndigkeit des Provinzlebens im Gouvernement Tambov zu jener Zeit schildert der (spăter als Anhănger Petraševskijs verurteilte) PA. Kuz'min (1819-1885), der im Auftrag des Generalstabs im Sommer 1848 das Gouvernement bereiste. Ausführlich berichtet Kuz'min von dem selbst für russische Verhăltnisse niedrigen Stand der Bildungseinrichtungen und der Unkultiviertheit und Ignoranz des ortlichen Adels; der Adelsmarschall, ein Fürst Gagarin, sei die "Dummheit in Person" gewesen. "Bumagi P.A. Kuz'mina." In: Delo petraševcev, t. 2, M.-L. 1941, S. 241-253. 
Jahr, wahrscheinlich in einem Hungerjahr, ernährten. ${ }^{31}$ ) Von Kindheit an bekam ich (auf meine Frage danach) eine Erlăuterung des Krieges zu hören, die bei mir schreckliche Bedenken erregte: 'Im Krieg schieBen die Menschen aufeinander'; schlieBlich erfuhr ich noch, daB es auch Nichtverwandte (nerodnye), Fremde (Cutie) gebe und daB selbst die Angehörigen (rodnye) nicht Verwandte (ne rodnye), sondern Fremde seien. ${ }^{32}$

Die letztgenannte Erinnerung bezieht sich wahrscheinlich auf Fedorovs uneheliche Herkunft und auf die Eindrücke, die er im väterlichen Haus empfing. ${ }^{33}$

Fedorovs Unterhalt und seine Ausbildung scheinen indessen gesichert gewesen zu sein. ${ }^{34}$ Auf Betreiben und mit finanzieller Unterstützung seines Onkels, des Fürsten Konstantin Ivanovix Gagarin (1800-1851), besuchte Fedorov von 1836 bis 1842 die Schule in der Sasovo nächstgelegenen Kreisstadt Šack und

31 Dieses schwarze "Hungerbrot" (golodnyj chleb) wurde aus grober Spreu und anderen Ersatzstoffen hergestellt und sah aus "als sei es aus Schlamm geformt", wie ein Korrespondent aus einem russischen Hungergebiet berichtete. A.S. PANKRATov, Bez chleba. Ocerki russkogo bedstvija. M. 1913, S. 121; vgl. ebd., S. 166 und pass.

32 KoŽeVnikov (wie Anm. 1), S. 55f. - Vgl. Ostromirov (wie Anm. 4), S. 9 (etwas abweichend). - Diese Notiz, die nicht in die Ausgabe der Werke Fedorovs aufgenommen wurde, wird in der Literatur häufig zitiert und dient nicht selten als Grundlage weitreichender Spekulationen. Siehe z.B. Young (wie Anm. 2), S. 18f. Pazilova (wie Anm. 1), S. 24 f.

33 Uber die wir aber nichts Naheres wissen. Bekannt ist lediglich, daB Fedorovs Vater P.I. Gagarin als das "schwarze Schaf" der Familie galt und selbst von seinen nächsten Verwandten geschnitten wurde.

Ungeklărt ist auch ein Vorfall, der von Fedorovs Biographen immer wieder hervorgehoben wird. Danach habe nach dem Tode seines Vaters (im Jahre 1832!) und, kurz darauf, auch seines Großvaters der damals erst vierjăhrige Nikolaj Fedoroviž zusammen mit seiner Mutter und seinen Geschwistern das văterliche Haus verlassen müssen. Ostromirov (Gorskij), auf den diese Version zurückgeht, vermutet dahinter Intrigen der Witwe I.A. Gagarins. OstromRov (wie Anm. 4), S. 8f. Eine etwas andere Darstellung dieses Vorfalls gibt KoZZEVNIKov (wie Anm. 1), S. 56: Danach habe IA. Gagarin, um eine Mésalliance seines Sohnes zu verhindern, Fedorov und dessen Geschwister aus dem Haus gewiesen. So auch PaNkRatov (wie Anm. 4), S. 18. Wie sich dieser Vorfall abgespielt hat, bleibt unklar; und auch die Frage, ob derlei Demütigungen bei Fedorov einen psychischen Schock ausgelठst und ein soziales Trauma hinterlassen haben, wodurch - wie einige Autoren versichern - seine Persönlichkeit und sein spăteres Denken entscheidend geprägt worden seien (Sehnsucht nach dem Vater und dem verlorenen Paradies der Kindheit), bleibt angesichts der Spärlichkeit und Unsicherheit der biographischen Daten Gegenstand bloßer Spekulation. Siehe z.B. PAzıLova (wie Anm. 1), S. 24-26.

34 Dies gilt, den wenigen Informationen zufolge, auch für seine Geschwister. Fedorovs ein Jahr allterer Bruder Aleksandr Fedorovið soll es zum vereidigten Rechtsanwalt gebracht haben und in den neunziger Jahren in Petersburg gestorben sein. $\mathrm{Zu}$ Fedorovs Begrăbnis sei, so wird berichtet, eine alte, mit Orden und Auszeichnungen dekorierte Frau erschienen, die sich zur Oberraschung aller als seine Schwester zu erkennen gegeben habe; sie sei eine pensionierte Klassendame gewesen. Angaben nach GeORGIEvSKy (wie Anm. 4), S. 48, sowie private Mitteilungen. Vielleicht handelte es sich um Fedorovs Schwester Elizaveta Pavlovna Makarova, die um das Jahr 1847 den Schauspieler Kornelij Nikolaevix Poltavcev (1823-1865) geheiratet hatte; beide gehörten damals zur Truppe von P.I. Gagarin. Spăter nahmen sie dessen unehelichen Sohn A.P. Verviciotti (Lenskij) in ihre Familie auf. Vgl. LENSKU (wie Anm. 18), S. 287 Anm. 3. Zograf (wie Anm. 11), S. 8. Notiz im Peterson-Archiv, GBL f. 657, kart. 1; nach einer Abschrift in Moskauer Privatbesitz. - Von einer anderen Schwester Fedorovs, Julija Pavlowna, wird lediglich mitgeteilt, sie sei die Frau des Gouverneurs von Tambov gewesen (Notiz im Peterson-Archiv, ebd.). 
anschließend, bis Juli 1849, das Gymnasium in Tambov. ${ }^{35}$ Im August 1849 bezog er die kameralwissenschaftliche Abteilung des vornehmen Richelieu-Lyzeums in Odessa; ${ }^{36}$ sein Studium dort soll er im März 1852 abgebrochen haben. ${ }^{37}$

35 Angaben nach BoRisov (wie Anm. 5), Bl. 2. - Auch Fedorovs ălterer Bruder Aleksandr besuchte die Schule in Sack und das Gymnasium in Tambov. Konstantin Ivanovic Gagarin war Adelsmarschall des Kreises Sack.

36 Offenbar verdankte Fedorov die Aufnahme in das Lyceum, wo, wie ein sowjetischer Wissenschaftler bewundernd bemerkte, "man einen Belinskij, geschweige denn einen Pogodin nicht einmal über die Schwelle gelassen hătte", seiner Abkunft aus einer der altesten Familien des Landes. V.V. KoŽınov, "My menjaemsja'? Polemizeskie zametki o kul'ture, žizni i 'litdejateljach'." In: Naš Sovremennik, 1987, 10, S. 163.

Das 1817 gegründete Richelieu-Lyceum war, ăhnlich dem berühmten Alexander-Lyceum in Carskoe Selo (spăter St. Petersburg), eine vorwiegend für Adlige bestimmte Eliteschule. Die Absolventen nahmen oftmals hohe Posten im Staatsdienst ein. Das Ausbildungsniveau unterschied sich kaum von dem einer Universităt. Siehe I.G. MICHNEVIC, Istoriceskij obzor sorokaletija Risel'evskogo liceja, s 1817 po 1857 god, Odessa 1857, S. 39, 47, 105f. Zu der Zeit, als Fedorov das Lyceum besuchte, bestand dieses aus drei Abteilungen, einer physikalisch-mathematischen, einer juristischen und einer kameralwissenschaftlichen. Das Făcherangebot war breit; die obligatorischen Fächer umfaßten u.a. Dogmatik, Ethik, Kirchengeschichte, Philosophie und Philosophiegeschichte, Russische Literatur, Russische und Allgemeine Geschichte, Statistik, Geographie sowie Französisch und Deutsch. Hinzu kamen in der kameralwissenschaftlichen Abteilung: Polit $\delta$ konomie, Finanzwissenschaft, Handelswissenschaft, Physik und physikalische Geographie, Chemie, Naturgeschichte, Agronomie, Technologie und Russische Gesetzeskunde. MiCHNEviC, ebd., S. 51f. Nach erfolgreichem AbschluB der dreijăhrigen Ausbildung avancierte der Absolvent, sofern er in den Staatsdienst eintrat, sofort zum Rang eines GouvernementSekretărs (12. Klasse der 14 Klassen umfassenden zivilen Rangtabelle). MichNEviC, ebd., S. 105.

37 Ostromirov (wie Anm. 4), S. 9. - Im Verlauf eines der Abschlußexamina soll es zu einem heftigen Streit zwischen Fedorov und einem seiner Professoren gekommen sein; daraufhin sei Fedorov zu den weiteren Prüfungen nicht mehr erschienen. (N.P. Peterson, nach Ostromarov, ebd.). Fedorov selbst soll einmal geăußert haben, er sei "wegen Auflehnung" (za buntarstvo) relegiert worden. (N.N. Cernogubov, nach OsTromirov, ebd.).

Die genauesten Angaben zur Datierung im Altestat (wie Arm. 4; von dort übernommen bei OSTROMIROV). Danach habe Fedorov 1849 das Gymnasium in Tambov absolviert und anschließend die kameralwissenschaftliche Abteilung des Richelieu-Lyceums besucht; von dort sei er am 19. Mărz 1852 ohne AbschluB abgegangen. - Der Hinweis auf das Gymnasium in Tambov und auf das Abgangsjahr 1852 findet sich nur noch bei PoKRovsKu (wie Anm. 4), Nr. 26, S. 4. In der übrigen Literatur wird lediglich der Besuch des Richelieu-Lyceums ohne Angabe eines Datums erwahnt. KoŽevnikov (wie Anm. 1), S. 56. Nekrasova (wie Anm. 4). Pankratov (wie Anm. 4), S. 18.

In diesem Zusammenhang sei noch auf einen merkwürdigen Umstand hingewiesen: In dem bereits genannten Jubilăumsband des Richelieu-Lyceums (MICHNEVIC, wie Anm. 36) wird unter den erfolgreichen Absotventen (nur diese finden sich namentlich verzeichnet) der kameralwissenschaftlichen Abreilung im Jahre 1846 (!) ein Nikolaj Fedorov genannt (ebd., S. 110, 165). Dieser habe spăter das Amt eines Wagstempelmeisters (vagstempel'mejster) beim Hafenzoll in Odessa versehen und dabei den Rang eines Gouvernement-Sekretărs bekleidet (ebd., S. 165). Wăhrend es in der einschlăgigen Literatur keinerlei Hinweise auf eine solche Tătigkeit Fedorovs gibt, findet sich eine kaum anders denn als diesbezüglich zu verstehende Anspielung in einem Fedorov gewidmeten Gedicht von I.P. Brichnirev aus dem Jahre 1914: "... Tvoi stanki Tamožnja [!] i Archiv ..." I.P. BriChINICEv, "N. Fedorovu." In: Ders., Osanna, Odessa 1914, S. 111; über Brichnitev ausführlich unten 2.3.1. und 2.3.2. 
In den zuletzt genannten Zeitraum fällt jenes Ereignis, das die entscheidende Wende in Fedorovs Leben herbeigeführt hat - die Entstehung des Grundgedankens seiner erst viel später ausgearbeiteten Lehre des obšcee delo. Fedorov selbst gibt hierfür den Herbst 1851 an, ${ }^{38}$ ohne jedoch Näheres über Umstände und Einflüsse mitzuteilen. ${ }^{39}$ Kurz vor seinem Tod kam Fedorov in einer seiner letzten Aufzeichnungen noch einmal auf jenes Datum zurück:

Zweiundfünfzig Jahre sind seit der Entstehung dieses Gedankens vergangen, dieses Planes, der mir als der gröBte und zugleich einfachste, natürlichste erschienen ist und erscheint, nicht als ein ausgedachter, sondern von der Natur selbst hervorgebrachter! Der Gedanke, daß durch uns, die Vernunftwesen, die Natur zu vollem SelbstbewuBtsein und Selbstbeherrschung gelangt und alles wiederherstellt, was zerstort wurde und wird durch ihre andauernde Blindheit...

Fedorov wurde Lehrer. Von 1854 bis 1868 unterrichtete er Geschichte und Geographie an den Kreisschulen (uezdnye ucilišca) mittelrussischer Provinzstädte; dabei wechselte er sechsmal die Stelle. ${ }^{41}$ In jene Zeit fällt seine Bekanntschaft mit Nikolaj Peterson, einem jungen, revolutionär gesinnten Lehrer, der zu seinem engsten Anhänger und Propagandisten werden sollte. ${ }^{42}$ Als Mitglied

38 V.[A.] Nikrtin, "'Bogoiskatel'stvo' i bogobortestvo Tolstogo." In: Prometej, t. 12, M. 1980, S. 137 Anm. 18. Nikitin beruft sich dabei auf Angaben Fedorovs, die sich in den unveroffentlichten Materialien zum dritten Band der FOD befinden (Peterson-Archiv, GBL f. 657). Vgl. auch die Einleitung von S.G. SEMENOVA, "N.F. Fedorov i ego filosofskoe nasledie." In: N.F. Fedorov, Soxinenija, M. 1982, S. 10. Auch Peterson weist darauf hin, daß die Grundgedanken der FOD bereits zu Beginn der 1850er Jahre ausgebildet gewesen seien. PETERSON, Fedorov (wie Anm. 4), S. 74, 82.

39 Unmittelbarer Anlaß könnte der Tod des Onkels Konstantin Ivanovið gewesen sein. Hinsichtlich der Einflüsse ăuBerte Tschižewskij, "daß die Lehre Fedorovs uber die 'Wiederauferwekkung der Toten' einer ăhnlichen Lehre Baaders venwandt sei und daB Fedorov auf Baader eventuell durch Michnevy̌̌ aufmerksam gemacht worden sei". D. CYYŽEvśKYYJ [TSCHIŽEWSKU], "Literarische Lesefrüchte. Teil 2." In: ZfslPh, 10, 1933, S. 400. Pletnev vermutete einen - ebenfalls durch Michneviz vermittelten - EinfluB Schellings. R.[V.] PLETNIOw [PLETNEv], "Grundlinien der philosophischen Lehre N.O. [sic] Fiodorows." In: Festschrifi N.O. Losskij, Bonn 1934, S. 140. - I.G. Michnevið (1809-1885) war seit 1839 Professor für Philosophie am Richelieu-Lyceum in Odessa.

40 Notiz im Peterson-Archiv, GBL f. 657. Erstmals veroffentlicht und von der Herausgeberin ins Jahr 1903 datiert in: FEDOROV (wie Anm. 38), S. 633.

41 Vielleicht wegen seiner eigenwilligen Auffassungen von Ziel und Methode des Schulunterrichts, wie KožEVNIKOV (wie Anm. 1), S. 23, vermutet. Stationen seiner Wanderung waren die Stădte Lipeck (1854-1857), Bogorodsk, Gvt. Moskau (1858-1864), Uglix (1864-1865), Odoev, Gvt. Tula (1865), Bogorodick, Gvt. Tula (1865-1866), Borovsk, Gvt. Kaluga (1866-1867), Podol'sk, Grt. Moskau (1867-1868). In dieser Zeit wurde Fedorov bis zum Rang eines Titularrats befordert. Siehe Attestal (wie Anm. 4). Vgl. auch KozEVnNov (wie Anm. 1), S. 22. GEORGIEVSKJ (wie Anm. 4), S. 53.

42 Nikolaj Pavlovic Peterson wurde am 16. Juni 1844 in Baranovka, Gvt. Penza, als Sohn eines Beamten geboren. Den Familiennamen erhielt er vor seine: Adoptivmutter, die schwedischer Abstammung war. Er besuchte das Adelsinstitut in Penza und wurde dort Schüler und Freund von Il'ja Nikolaevic Ul'janov (dem Vater Lenins), der zu jener Zeit in Penza Mathematik und Physik unterrichtete. Peterson schrieb sich an der mathematischen Fakultăt der Universităt Moskau ein, muBte sie jedoch wegen seiner Teilnahme an den Studentenunruhen des Jahres 1861 vorzeitig verlassen. Anfang 1862 folgte er einer Einladung Tolstojs und unterrichtete an 
des revolutionären Išutin-Kreises (aus dem 1866 der Zaren-Attentäter Karakozov hervorging) hatte sich Peterson mit der Absicht, in der Provinz politische Agitation zu betreiben und neue Anhänger zu gewinnen, im Frühjahr 1864 als Lehrer für Mathematik und Geographie nach Bogorodsk (heute Noginsk) im Gouvernement Moskau gemeldet, wo zu jener Zeit auch Fedorov unterrichtete. ${ }^{43}$ Bereits in Moskau hatte Peterson von Fedorov gehört:

Ein Mitglied des Zirkels hatte mir mitgeteilt, in Bogorodsk sei ein Lehrer an der Kreisschule, ein gewisser Nikolaj Fedorovit Fedorov, ein selbstloser Mensch, dessen Lebensweise einen an Rachmetov erinnere, ein Mensch von ungewøhnlicher Klugheit und Aufrichtigkeit; wir aber dachten damals, ein kluger und aufrichtiger Mensch müsse auf unserer Seite sein. ${ }^{4}$

\section{Über seine erste Begegnung mit Fedorov berichtet Peterson:}

Als ich am 15. Mărz 1864 nach Bogorodsk kam, begab ich mich sogleich zu Nikolaj Fedoroviz, der sich als ein Mann von etwa vierzig Jahren herausstellte, d.h. etwa vier Jahre alter war als Lev Nikolaevit [Tolstoj; M.H.]; er war ledig und lebte wie ein Asket, er besaB nicht nur kein Bett, sondern hatte nicht einmal ein Kissen; er ernahrte sich von dem, was ihm seine Wirtsleute gaben, einfache Kleinbürger, deren Kost gesund, aber einfach war. (...) Nie ăußerte Nikolaj Fedorovił irgendwelche Sonderwünsche, stets war er zufrieden mit dem, was man ihm gab.

Bereits bei der ersten Begegnung mit Nikolaj Fedorovið offenbarte ich mich ihm ganz, erklărte ihm auch die Absicht, mit der ich Lehrer an der Kreisschule geworden war. Darauf bekam ich zu horen: "Ich verstehe nicht," so Nikolaj Fedorovic, "wofür ihr euch abplagt?! Außer materiellem Wohlstand könnt ihr denen, für die ihr euch abmüht, doch nichts geben, da ihr keinerlei anderen Wohistand für moglich haltet; inzwischen aber, wăhrend ihr materiellen Wohlstand für andere zu erlangen sucht, verzichtet ihr selbst darauf und seid bereit, dafür sogar euer Leben zu opfern. Was aber, wenn ma-

mehreren der neugegründeten Bauernschulen in der Năhe von Jasnaja Poljana. Seine dabei gewonnenen Erfahrungen legte er in zwei Aufsătzen nieder, die in der Zeitschrift Jasnaja Poljana erschienen. Bereits im Herbst 1862, kurz nach Tolstojs Heirat, wurde das mit viel Enthusiasmus begonnene Volksbildungsprojekt abgebrochen und die Schulen geschlossen. Peterson diente noch einige Monate als Hauslehrer bei Lev Tolstojs Bruder Sergej in Tula und kehrte dann 1863 enttăuscht an die Moskauer Universităt zurück, wo er sich dem konspirativ-revolutionăren Zirkel um N.A. Išutin anschloB. Die meisten Mitglieder dieser Vereinigung stammten wie Peterson aus dem Gouvernement Penza. Ihr Vorbild war Rachmetov, der fanatische und asketische 'Berufsrevolutionăr' aus dem damals gerade erschienenen Roman C'to delat'? von Cemyß̌evskij.

Zur Biographie von N.P. Peterson vgl. M. P-s. [M.N. PETERSON ?], "Nikolaj Pavlovið Peterson." In: Vselenskoe delo, sb. 2, Riga 1934, S. 179-181. PETERson, Fedorov (wie Anm. 4), bes. S. 8393. TOLSTOJ (wie Anm. 5), t. 8 (1936), S. 511-513; t. 7 (1956), S. 49; t. 83 (1938), S. 125. - Zu Peterson und I.N. Ul'janov siehe O.S. SIROKov, "Michail Nikolaevi飞 Peterson (k 20-letiju so dnja smerti)." In: Vestnik Moskovskogo universiteta. Ser. 9. Filologija. 1983, 3, S. 57. VA. KoCER. GINA, "Michail Nikolaevil Peterson (k 100-letiju so dnja rożdenija)." In: Ebd., 1985, 6, S. 48. • Ausführlich über den İutin-Kreis und Petersons Verbindungen zu ihm: E.S. VILENSKAJA, Revoljucionnoe podpole v Rossii v seredine 6a-ch godov XIX veka, M. 1965, S. 187, 201-205, 212 und pass. - Peterson soll Tolstoj als Vorbild für den verbannten Revolutionär Simonson in Voskresenie gedient haben. Vgl. S.L. ToLsToJ, Oxerki bylogo, Tula ${ }^{3} 1966$, S. 135. Tolstos (wie Anm. 5), t. 33 (1935), S. 389. V.A. ŻDANOV, Trorteskaja istorija momana L.N. Tolstogo 'Voskresenie', M. 1960, S. 217-222.

43 Siehe VilensKaja (wie Anm. 45), S. 212. 
terieller Wohlstand auch für jene, für die ihr ihn zu erlangen sucht, ebenso unwichtig ist wie für euch selbst?! Wozu dann all eure Mühe?!.."

Im weiteren Verlauf unseres Gesprăchs hörte ich von Nikolaj Fedorovið an jenem Abend, daB die sogenannten großen Prinzipien der großen Französischen Revolution - Freiheit, Gleichheit und Brüderlichkeit - das Produkt ăuBerster Leichtsinnigkeit oder Unüberlegtheit seien, da aus der Freiheit, die eigenen Launen zu erfüllen, und aus neidvoller Gleichtheit niemals Brüderlichkeit enwachsen könne; erst Brüderlichkeit führe zu Freiheit, da Brüder, die einander lieben, sich nicht gegenseitig versklaven kőnnten; Brüder, die einander lieben, würden auch den Bruder nicht beneiden, der sich über die anderen erhoben hat, und würden nicht versuchen, ihn zu sich herabzuziehen; der Bruder aber, der sich über die anderen erhoben hat, würde versuchen, alle Brüder zu sich emporzuheben. Deshalb müBten wir zuallererst Brüderlichkeit suchen, anstatt sie hintanzusetzen, nach Freiheit und Gleichheit, wie dies die Verkünder von Freiheit, Gleichheit und Brüderlichkeit getan hătten - wir müBten Brüderlichkeit suchen, alles übrige würde sich fügen. Brüderlichkeit aber sei nicht moglich ohne Vaterschaft (otě̌estvo) - denn nur dank der Văter seien wir Brüder; deshalb müsse die Sohnes- und die Vaterliebe an den Anfang gestellt werden, daraus gehe dann auch die Bruderliebe hervor.

Indem er so sprach, entwickelte Nikolaj Fedorovix nach und nach eine komplette und für mich völlig neue Weltanschauung, derzufolge die Vereinigung aller Menschen nötig sei im Bemühen um eine allumfassende Wiederauferweckung. Ich war sofort und für immer bezwungen. Nikolaj Fedorovix blieb nicht lange mit mir in Bogorodsk, nur etwa drei Monate, doch diese drei Monate bereicherten mich mehr als das ganze vorangegangene Leben und gaben mir eine solide Grundlage für den Rest meines Lebens. ${ }^{45}$

Aus Petersons Bericht über seine Gespräche mit Fedorov im Frühjahr 1864 geht hervor, daß die Grundgedanken der späteren Filosofija obšcego dela zu diesem Zeitpunkt bereits klar ausgeprägt gewesen sein müssen. Sie reichten hin, den neunzehnjährigen Peterson, der nach einer festen Orientierung und Aufgabe suchte, für immer zu gewinnen:

Diese drei Monate des gemeinsamen Lebens mit Nikolaj Fedorovið führten dazu, daB ich nie mehr die Verbindung mit ihm verlor; wo immer er auch war, ich schrieb ihm nicht nur, sondern suchte ihn auch auf, und er fuhr zu mir, und beinahe jedes Jahr bis fast zu seinem Tode verbrachten wir gemeinsam unsere Freizeit. Wenn wir zusammen waren, so diskutierten wir nicht nur, sondern schrieben auch, d.h. ich schrieb nach Nikolaj Fedoroviðs Diktat. Ich wollte seine Lehre, die mich fasziniert hatte, bekanntmachen und dachte daran, eine Darstellung dieser Lehre drucken zu lassen, doch Nikolaj Fedoroviz widersetzte sich dem stets, da er fand, dies sei nicht an der Zeit und die Lehre selbst sei noch unzureichend entwickelt und nicht vollkommen klar ausgedrückt. ${ }^{46}$

45 Ebd., S. 88f. - 1865 wurde Peterson an die Kreisschule in Bronnicy (Gvt. Moskau) versetzt.

46 Ebd., S. 89. - In einem Brief an P.I. Bartenev, den Herausgeber des Russkij Archiv, schreibt Peterson: "Anfangs legte Nikolaj Fedorovit seine Lehre bloB mündlich dar, spăter aber begannen wir zu schreiben, d.h. er sprach, und ich machte Notizen und dies mehrere Jahre lang, freilich mit großen Unterbrechungen, da wir die meiste Zeit an verschiedenen Orten lebten und nur zusammenkamen, wenn wir arbeitsfreie Zeit hatten..." N.P. PETERSON, "Pis'mo k izdatelju Russkogo Archiva. Po povodu otzyva F.M. Dostoevskogo o N.F. Fedorove." In: Russkij Archiv, 1904,2, S. 300.

Peterson war bis kurz vor seinem Tode im Gerichtswesen tătig; zunăchst als Sekretăr am Friedensgericht in Spassk, Gvt. Tambov (1869), und in Kerensk (ab 1870), dann als Richter am Stadtgericht von Mokłansk nahe Penza (ab 1891) und in Voronež (ab 1894), schließlich als Mitglied des Bezirksgerichts in den Kreisstădten Aschabad (ab 1899), Vernyj (ab 1904) und Zarajsk, Gvt. Rjazan' (von 1912 bis zur Revolution). Im Sommer 1918 begab sich Peterson 
Gleichwohl schickte Peterson ohne Wissen Fedorovs im Dezember 1877 eine kurze Zusammenfassung Fedorovscher Gedanken an Dostoevskij. In seinem Antwortschreiben äußerte Dostoevskij lebhaftes Interesse. Peterson gab den Brief an Fedorov weiter, und im Sommer 1878 ging dieser daran, eine ausführliche Darlegung seiner Gedanken als Antwort an Dostoevskij zu verfassen. ${ }^{47}$

Unter dem Einfluß Fedorovs gab Peterson seine revolutionären Ziele auf und versuchte sogar, von Fedorov unterstützt, seine ehemaligen Gesinnungsgenossen zur Umkehr zu bewegen. Dennoch wurde Peterson im Mai $1866 \mathrm{im}$ Zusammenhang mit dem fehlgeschlagenen Attentat Karakozovs (eines Vetters von N.A. Išutin) verhaftet und zu sechs Monaten Festungshaft verurteilt, da er einen flüchtigen Verschwörer nicht angezeigt hatte. Auch Fedorov wurde in dieser Sache vernommen - durch Peterson war er mit Karakozov und anderen angeklagten ǐutincy zusammengebracht worden -, doch wurde er von jeglichem Verdacht freigesprochen. ${ }^{48}$

Im Jahre 1868 gab Fedorov seinen Beruf als Lehrer in Podol'sk auf ${ }^{49}$ und ging nach Moskau ${ }^{50}$, wo er sich zunächst mit Gelegenheitsarbeiten durchschlug, ${ }^{51}$ bis er 1869 eine Anstellung als Gehilfe des Bibliothekars P.I. Bartenev

nach Zvenigorodka, Gut. Kiev, wo er am 4. Mărz 1919 (n.St.) starb (M. P-s., wie Anm. 42, S. 179f.). Fedorov besuchte Peterson fast jedes Jahr. Georgievsku (wie Anm. 4), S. 49; vom Sommer 1899 an verbrachte er ein Jahr bei Peterson in Aschabad; vgl. KoźEVNIKov (wie Anm. 1), S. 19. "Iz perepiski N.F. Fedorova s V A. Koževnikovym o Turkestane." In: Versty, 3, 1928, S. 278-288.

47 Peterson, Fedorov (wie Anm. 4), S. 89f. Ausführlich dazu II: 1.2.

48 Fedorov soll drei Wochen in Untersuchungshaft verbracht haben. SEMENOVA (wie Anm. 38), S. 10. Vgl. "Pokusenie Karakozova..." (wie Anm. 5), S. 91-137; bes. 115-117, 136f. VILENSKAJA (wie Anm. 42), bes. S. 201f. Anm. 59, 212. Dejareli (wie Anm. 5), Sp. 311 (Peterson), Sp. 427 (Fedorov).

Fedorovs EinfluB auf Peterson geht auch aus dem Bericht hervor, mit dem der Schulinspektor von Bronnicy im April 1866 Peterson bei seinem Vorgesetzten denunzierte: "Er [Peterson] glaubt in der Art wie Renan (veruet on po Renanu) und verbirgt seine Ideen vor niemandem (außer vor den Schülern), wenngleich er bisweilen auch in die Kirche geht. Diese Ideen vertrat er bereits vor dem 4. April [dem Tag von Karakozovs Attentatsversuch; M.H.] sogar gegenüber dem Religionslehrer. (...) Er besitzt fast kein Eigentum, und auch die anderen sollen, nach seinen Worten, keines besitzen. Gesellschaft meidet er nicht, doch sucht er merklich den Umgang mit Gleichgesinnten." Nach VILENSKAJA (wie Anm. 42), S. 212. - Renans sensationelles und skandaloses Buch $L a$ vie de Jésus, in dem der Nazarener nicht als Sohn Gottes, sondern als gew rhnlicher, wenn auch sittlich vorbildlicher Mensch sowie als idealistischer Revolutionăr und Utopist geschildert wird, war 1863 erschienen und bereits ein Jahr spăter ins Russische übersetzt worden. Trotz kirchlichen Verbots fand das Buch weite Verbreitung und wirkte beispielsweise auf Dostoevskij (Gestalt des Füsten Myskin), Tolstoj und Solov'ev; auch Fedorov hat sich mit Renan auseinandergesetzt.

49 Auf sein Gesuch wurde Fedorov am 23. April 1868 wegen Krankheit aus dem Schuldienst entlassen. PoKrovsku (wie Anm. 4), Nr. 26, S. 4.

50 Wobei er, wie Peterson berichtet, den ganzen Weg zu FuB zurücklegte und an keinem "Bach oder Flu $B$ vorüberging, ohne darin zu baden, denn Baden liebte er bis an sein Lebensende"; Peterson-Archiv, GBL f. 657; nach einer Abschrift in Moskauer Privatbesitz.

51 So soll er, wie Peterson berichtet, Privatstunden (Castmye umki) gegeben haben; PetersonArchiv, GBL f. 657; nach einer Abschrift in Moskauer Privatbesitz. 
an der Certkov-Bibliothek fand. ${ }^{52}$ Doch war auch diese Stelle nicht von Dauer. Am 16. August 1874 wandte sich Peterson an den Schriftsteller N.A. Caev (1824-1914) mit der Bitte, Fedorov eine Arbeit zu vermitteln, "Korrigieren, Abschreiben oder irgend etwas anderes in dieser Art", wovon er seinen Unterhalt bestreiten könne; "seine Bedürfnisse in dieser Hinsicht" seien ja "nicht gro $B^{\text {" }} .{ }^{53}$

Am 27. November 1874 erhielt Fedorov eine Anstellung an der Bibliothek des Moskauer Öffentlichen und Rumjancev-Museums (Moskovskij publicnyj $i$ Rumjancevskij muzej)..$^{54}$ Fast vierundzwanzig Jahre - bis zum 15. September 1898 - versah er das Amt eines diensthabenden Beamten (dežurnyj cinovnik) im Lesesaal und Katalog der Bibliothek. ${ }^{55}$ Nach seiner Pensionierung im Jahre 1898 arbeitete er bis zu seinem Tode (1903) in der Bibliothek des Moskauer Archivs des Außenministeriums. ${ }^{56}$

Fedorov verbrachte 35 Jahre in Moskau. In dieser Zeit wurde er Bibliotheksund Archivbenutzern zur vertrauten Erscheinung. Zahlreiche Erinnerungen und Anekdoten, von denen manche in Legenden übergehen, vermitteln ein anschauliches, wenn auch bisweilen fragwürdiges Bild seiner Persönlichkeit und seiner Lebensumstände. ${ }^{57}$

52 Georgievskw (wie Anm. 4), S. 53. - Vgl. auch N.P. Barsukov, Zizn' $i$ inudy M.P. Pogodina, t. 16, SPb. 1902, S. 482f. - Fedorov wurde offenbar Nachfolger von N.P. Peterson, der 1867 auf Empfehlung Tolstojs als Gehilfe von P.I. Bartenev in der von diesem geleiteten Certkov-Bibliothek eingestellt worden war, wo er bis 1869 arbeitete. Tolstos (wie Anm. 5), t. 61, S. 177f. In dieser Zeit las er die Korrekturen des ersten Teils von Tolstojs soeben abgeschlossenem Roman Vojna i mir. Vgl. Peterson, Fedorov (wie Anm. 4), S. 86. DeRs., "Iz zapisok byvక̌ego ucitelja." In: Mezdunarodnyj tolstovskij al'manach, M. 1909, S. 261.

P.I. Bartenev (über ihn oben Anm. 5) war bis 1873 Direktor der Certkov-Bibliothek und traf dort oft mit Tolstoj zusammen. Vgl. N. JaŠVIL, "Moj deduska, Petr Ivanovił Bartenev." In: Prometej, t. 7, M. 1969, S. 292-301. ZANCEv (wie Anm. 5). - Die nach dem Vorbild des British Museum aufgebaute Bibliothek des Moskauer Historikers und leidenschaftlichen Büchersammlers A.D. Certkov (1789-1858) galt mit ihren über 17.000 Bănden als die umfangreichste Privatsammlung von Rossica. Sie befand sich im Hause Certkovs in der Mjasnickaja ulica (heute ulica Kirova); das Gebăude dient gegenwărtig als Dom naǔ̌no-rechnixeskoj propagandy.

53 N.[P.] Peterson, "Pis'mo N. Petersona k N.A. Caevu o N.F. Fedorove." In: Russkij Archiv, 1915, 11-12, S. 280f. Wieder abgedruckt in: Vselenskoe delo (wie Anm. 42), S. 160 f.

54 Zur Geschichte und Organisation der Bibliothek des Rumjancev-Museums vgl. Pjatidesjatiletie Rumjancevskogo muzeja v Moskve. 1862-1912. Istoriceskij očerk. M. 1913. I. RoMANOvSKU, Kniga i zizn'. Oxenki o Gosudarstvennoj biblioteke SSSR imeni Lenina. M. 1950. M.M. KLEVENSKIJ, Geschichte der staatlichen Lenin-Bibliothek der UdSSR, Bd. 1, Leipzig 1955. Istorija gosudarstvennoj ondena Lenina biblioreki SSSR imeni V.I. Lenina za 100 let. 1862-1962. C. 1, M. 1962, S. 9-51.

55 Laut Atrestat und Opis' (wie Anm. 4). - Siehe auch V.S. Borisov, "'Ideal'nyj' bibliotekar'." In: Al'manach bibliofila, vyp. 6, M. 1979, S. 201.

56 Siehe Koževnixov (wie Anm. 1), S. 3.

57 Die zahlreichen Anekdoten und Legenden über Fedorov (von denen nicht selten mehrere Versionen überliefert sind!) nehmen in der Literatur bisweilen so breiten Raum ein, daß der Eindruck entsteht, Fedorovs Gedankengebăude sei lediglich Auswuchs einer exzentrischen Biographie. Um diesen Eindruck zu vermeiden, vor allem aber weil anekdotische Schilderungen Fedorovs vielerorts nachzulesen sind, sollen sie hier weitgehend auBer acht bleiben. 


\section{Immer wieder wird Fedorov als ein Original geschildert:}

Alles an ihm war eigenartig, und in nichts glich er einem Durchschnittsmenschen, angefangen von seinem ÄuBeren über seine Gewohnheiten und seine Lebensweise bis hin zu seiner Weltanschauung. 58

\section{Fedorovs äußere Erscheinung gibt V.A. Koževnikov ${ }^{59}$ mit folgenden Worten wieder:}

Wer von denen, die sich in den siebziger und achtziger Jahren im Lesesaal und später im sogenannten 'Katalog' aufhielten, erinnert sich nicht jener großen, mageren, leicht gebeugten, doch energiegeladenen Gestalt dieses in alte, zerlumpte Kleider gehüllten Greises, in dessen Augen das leidenschaftliche Feuer unschuldiger Jugend leuchtete, dieser auf den ersten Blick strengen Erscheinung

58 PoKrovsku (wie Anm. 4), Nr. 23, S. 4.

59 Vladimir Aleksandrovic Koževnikov war neben Peterson der engste Vertraute Fedorovs. Gemeinsam mit Peterson edierte er postum Fedorovs Schriften und verfaßte eine eingehende Darstellung seines Denkens (siehe oben Anm. 1). Im Gegensatz zu Peterson machte sich Koževnikov jedoch Fedorovs Ansichten nicht zu eigen.

V.A. Koževnikov wurde am 15. Mai (a.St.) 1852 als Sohn eines wohlhabenden Kaufmanns in Kozlov, Gvt. Tambov, geboren. Er besuchte die Moskauer Universităt und lernte, noch als Student, um das Jahr 1875 Fedorov in der Bibliothek des Rumjancev-Museums kennen. KozEVNIKov (wie Anm. 1), S. 2. "Ein Mensch von unermeBlicher Gelehrsamkeit" (N.A. BERDJAEv, Samopoznanie, Paris ${ }^{2} 1983$, S. 212), verfaßte Koževnikov, der sich nie um einen akademischen Titel bemühte, mehrere umfangreiche religionsphilosophische und kulturhistorische Werke, deren Themen nicht selten in Fedorovs Schriften wiederkehren. Die meisten Arbeiten des Privatgelehrten, darunter eine mehrbăndige Geschichte der Săkularisierung der europäischen Kultur von der Renaissance und der Reformation bis ins 20. Jahrhundert sowie umfangreiche Studien zu Locke, Hume, Wolf, Lessing, Jacobi, blieben unveroffentlicht. Zu seinen wichtigsten Veroffentlichungen zăhlen Filosofija cuustva $i$ very v ee otnošenii $k$ racionalizmu XVIII v. i k kriticeskoj filosofit, M. 1897 (eine breit angelegte Arbeit über Hemsterhuis, Herder, Hamann, Jacobi), und die zweibändige, mehr als tausend Seiten umfassende Arbeit Buddizm v sravnenii s christianstvom, Pg. 1916. In den Jahren vor dem Ersten Weltkrieg gehörte Koževnikov zusammen mit S.N. Bulgakov, P.A. Florenskij, E.N. Trubeckoj und P.B. Mansurov einem konservativ-slavophilen Kreis um F.D. Samarin und M.A. Novoselov an (siehe dazu II: 2.2.1.). Im Gegensatz zu dem bisweilen verkniffen wirkenden, kleinlichsektiererischen Peterson wird Koževnikov als großzügig, souverăn und lebensfroh geschilder. Koževnikov starb am 3. Juli 1917 in Chlebnikovo, einem Dorf nördlich von Moskau an der Kljazma, und wurde auf dem Friedhof des Moskauer Novodevizij-Klosters beigesetzt.

Angaben zur Biographie Koževnikovs und eine Liste seiner wissenschaftlichen Arbeiten bei N.A. SETNICKU, "Vladimir Aleksandrovið Koževnikov. 1852-1917-1927." In: Izv.Jur.Fak., 4 (1927), S. 323-328. Vgl. auch A. G-v. [d.i. A.K. GoRsKu], "Vladimir Aleksandroviz Koževnikov." In: Vselenskoe delo (wie Anm. 42), S. 178f. S.[N.] BuLgakov, "Pamjati Vladimira Aleksandroviza Koževnikova." In: Christianskaja Mysl', 1917, 11-12, S. 75-83. - Uber Koževnikov, der eine bedeutende Rolle im Kulturleben Moskaus spielte, ausführlich (aber nicht immer genau!) die Arbeiten von N.S. ARSEN'Ev, La Sainte Moscou. Tableau de la vie religieuse et intellectuelle russe au XIX" siecle. Paris 1948, S. 112-115. DERS., "Iz junosti. (Kartiny moskouskoj zizni)." In: Vozrotdenie, 18, 1951, S. 79f. DERS., Iz nusskoj kul'tumoj i ruorteskoj radicii, Frankfurt/M. 1959, S. 105f. DERS., "A.S. Chomjakov i V.A. Koževnikov." In: Vozrozdenie, 216, 1970, S. 35-55 (wieder abgedruckt in: DERS., Dary $i$ vstredi ziznennogo puti, Frankfurt/M. 1974, S. 229-236). DERS., "Der gottliche Logos in der russischen Religionsphilosophie." In: Kyrios, 17 (1974), bes. S. 129-133. DERS., "O nekotorych osnovnych temach v russkoj religioznoj mysli 19-go veka." In: Russkaja religiozno-filosofskaja mysl' XX veka, Pittsburgh 1975, S. 18-36. 
mit dem kurzen ergrauten Bart, den langen dünnen Silberlocken und der hohen, măchtigen und freien Stim...? ${ }^{60}$

Und G.P. Georgievskij schreibt:

Am anziehendsten an Nikolaj Fedorovic war zweifellos sein Gesicht. Ein offenes, längliches, mit vollkommen regelmåßigen Zügen, eingerahmt von einem ergrauten Bart und gekront von einer hohen Stirn, wurde es stets belebt und erleuchtet von schwarzen, glänzenden Augen, die kindlich rein und ungewrhnlich durchdringend waren. ${ }^{61}$

Offenbar gibt es keine Photographie, die Fedorov zu Lebzeiten zeigt. Die Darstellung einer Person hielt Fedorov nur in der Ikonenmalerei für zulässig, weshalb er alle Bitten, ihn photographieren oder porträtieren zu dürfen, entschieden ablehnte. ${ }^{62}$ Dem Maler Leonid Pasternak gelang es jedoch, Fedorov unbemerkt an seinem Arbeitsplatz zu skizzieren. ${ }^{63}$ In seinen Erinnerungen schildert Pasternak ihn als einen

... kleinen gebückten Greis mit grauem Vollbart und Schnurrbart, mit spărlichem Haar auf dem fast kahlen Schădel, sehr arm und seltsam gekleidet in eine Art alter dünner Frauenjacke. Seine Hănde waren stets in die Ärmel gesteckt, als ob ihn vor Kälte fröstele. Aus dem grünlich-gelben, blaß-braunen hageren Greisengesicht durchdrang einen lebhaft und scharf der brennende Blick seiner schwarzen, tiefliegenden Augen. Er hatte etwas ganz Seltsames, Originelles an sich ... ${ }^{64}$

60 KoŽevinikov (wie Anm. 1), S. 3.

61 Georgievsku (wie Anm. 4), S. 50. - Vgl. Pokrovsku (wie Anm. 4), Nr. 24, S. 4.

62 GeorgievsKu (wie Anm. 4), S. 50.

63 Pasternaks Skizzen entstanden wahrscheinlich in Fedorovs letzten Lebensjahren, als dieser bereits im Archiv des AuBenministeriums arbeitete. Hinweise darauf enthălt der Briefwechsel zwischen L.O. Pasternak und N.N. Cernogubov, 1901-1905, GBL f. 328, k. 5, ed. chr. 37; Abschriften in Moskauer Privatbesitz. Nach diesen Skizzen, von denen bislang nur ein Teil publiziert worden ist, schuf Pasternak 1919 ein großes Olportrăt von Fedorov, das eine Zeitlang im Katalograum des Rumjancev-Museums hing. Vgl. Ostromarov (wie Anm. 4), S. 18. M. Woloschin [M.V. Volosina-Sabasnikova], Die grüne Schlange [1954], Frankfurt/M. 1982, S. 67. 1903 komponierte er aus mehreren Skizzen eine Zeichnung, die Fedorov im Gespräch mit Solov'ev und Tolstoj zeigt. L.O. PASTERNAK, Zapisi raznych let, M. 1975, S. 145, 285. Auch dieses Bild wurde spăter in Ol ausgeführt. Siehe die eindrückliche Beschreibung dieser "Ikone der Philosophen" bei M. DEPPERMANN, "RuBland um 1900: Reichtum und Krise einer Epoche im Umbruch." In: Musik-Konzepte, 37/38, München 1984, S. 78f. Heute befindet sich das Bild im Haus von Josephine Pasternak in Oxford; siehe L. ZAMUATIN, "Otec vsegda byl russkim chudožnikom.' Beseda s Žosefinoj Pasternak." In: Literarumaja Gazeta, 39, 28.9.1988, S. 15.

AuBer den Darstellungen Pasternaks existiert nur noch eine Zeichnung von M.I. Sesterkin, die Fedorov auf dem Balkon des Rumjancev-Museums zeigt. Die einzigen Photographien von Fedorov entstanden nach seinem Tod: sie zeigen ihn auf der Bahre; aufgenommen von I.P. Borisov, erstmals veroffentlicht von M. HAGEMEISTER, "Neue Materialien zur Wirkungsgeschichte N.F. Fedorovs: M. Gor'kij und die Anhănger Fedorovs in Moskau und Harbin." In: Studia Slavica. Beiträge zum VII. Intemationalen Slawistenkongre $\beta$ in Zagreb 1978. Gießen 1981, S. 241. Ob Fedorov auch auf dem bei KLEVENSKU (wie Anm. 54) nach S. 136 wiedergegebenen Photo der "etatmäBigen Mitarbeiter" des Rumjancev-Museums "um 1890" zu sehen ist, vermag ich nicht zu entscheiden.

64 Pasternak (wie Anm. 65), S. 143. - Etwas abweichend Ders., "Iz zapisok Leonida Pasternaka." In: Noyj Zumal, 77, 1964, S. 207f. Vgl. auch PANKRATov (wie Anm. 4), S. 18. 
Mehr noch als durch seine äußere Erscheinung beeindruckte Fedorov durch sein immenses Wissen. Er verfügte über ein erstaunliches Gedächtnis, kannte nicht nur Titel und Standort der meisten Bücher des Rumjancev-Museums auswendig, sondern, so wird immer wieder berichtet, habe selbst über deren Inhalt jederzeit genaue Auskunft geben können: ${ }^{.6}$

Wenn man ihn nach einigen Büchern fragte, so bestimmte er genau den Gegenstand der Untersuchung, wobei er im voraus den gesamten Inhalt eines jeden bestellten Buches in allen Einzelheiten kannte. Erstaunlich war auch, daß es für ihn nicht eine Frage gab, die ihm neu oder unbekannt gewesen wăre oder die ihm selbst nicht am Herzen gelegen hătte.

Koževnikov berichtet, daß Fedorov fast alles, was er je gelesen hatte, in seinem Gedächtnis bewahrte. In fremden Literaturen war er ebenso bewandert wie in der russischen. Obwohl er sich nur der russischen Sprache bediente, las er fremdsprachige Literatur zumeist mühelos im Original. ${ }^{67}$ Sogar Chinesisch soll er ausgezeichnet beherrscht haben. ${ }^{68}$

Fedorovs Interesse umfaßte alle Literatur mit Ausnahme der künstlerischen: Er beschäftigte sich nie mit Belletristik, nie las er Gedichte; er mochte sie nicht. Dagegen war er stets auf der Suche nach entlegenen, kuriosen Informationen, um sie in sein Gedankengebäude einzufügen oder zum Anlaß neuer Spekulationen zu nehmen. Artikel aus der Tagespresse konnten diesem Zweck ebenso dienen wie die klassischen Werke der Philosophie, Berichte über jüngste naturwissenschaftliche Forschungsergebnisse oder folkloristisches Material (Märchen, Sagen, Legenden).

Fedorov war nicht nur ein leidenschaftlicher Bibliograph, sondern erschien manchen geradezu als ein Bibliomane. ${ }^{69}$ In der Tat betrachtete er seinen Dienst in der Bibliothek und den Umgang mit Büchern als eine "heilige Sache" (svjašcennoe delo), ${ }^{70}$ doch wird diese Haltung erst verständlich vor dem Hintergrund seiner Lehre ${ }^{71}$ - in Fedorovs Projekt der Wiederherstellung aller Verstorbenen nehmen Bücher eine zentrale Stellung ein.

65 Vgl. Pokrovsku (wie Anm. 4), Nr. 23, S. 4. Georgievsku (wie Anm. 4), S. 54. IA. LINNICENKo, "Moi vstreði s L.N. Tolstym." In: DeRs., Reði i pominki. Sbomik statej po istorii russkoj literatury i biograficeskich vospominanij. Odessa 1914, S. 315f. - Der Bücherbestand des Rumjancev-Museums wuchs von ca. 100.000 Bănden im Jahre 1864 auf ca. 500.000 gegen Ende der neunziger Jahre. KLEVENSKU (wie Anm. 54), S. 40, 51.

66 Pokrovsku (wie Anm. 4), Nr. 23, S. 5.

67 LINNICENKO (wie Anm. 65), S. 315.

68 Ostromirov (wie Anm. 4), S. 13. - Uber Fedorovs besonderes Interesse für China siehe N.A. SETNICKIJ, "Russkie mysliteli o Kitae. (V.S. Solov'ev i N.F. Fedorov)." In: Izv.Jur.Fak., 3 (1926), S. 4.

69 Pokrovsku (wie Anm. 4), Nr. 23, S. 4. Georgievsku (wie Anm. 4), S. 54.

70 FOD II, S. 44.

71 Läßt man diesen Zusammenhang außer acht, so entsteht der Eindruck eines lediglich übereifrigen Bibliothekars oder, schlimmer noch, eines exzentrischen Bibliomanen. Siehe z.B. L. KOEHIER, N.F. Fedorov: The Philosophy of Action. Pittsburgh 1979, S. 33 f. 


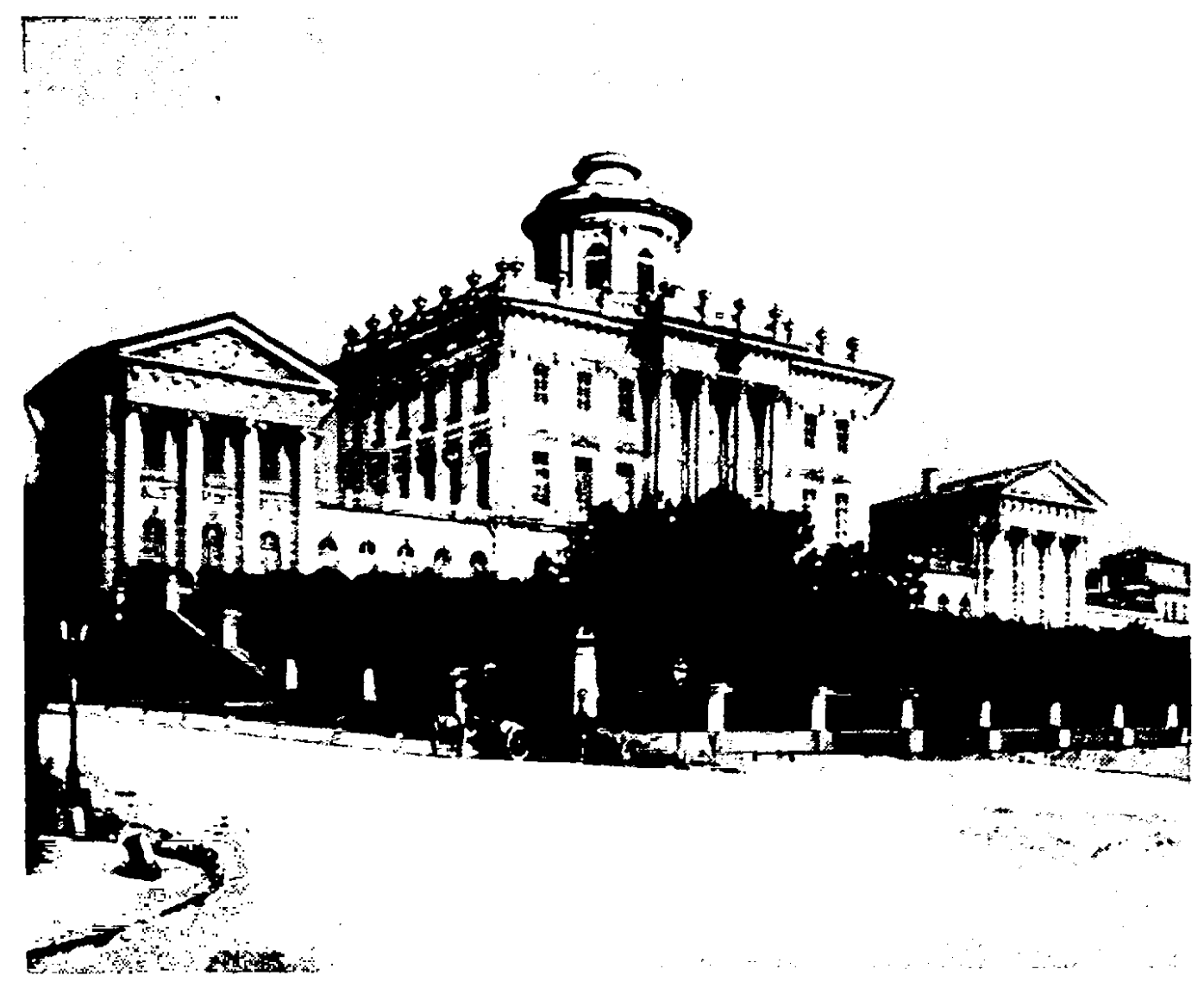

Rumjancev-Museum, Moskau, Aufnahme vom Beginn des 20. Jh.

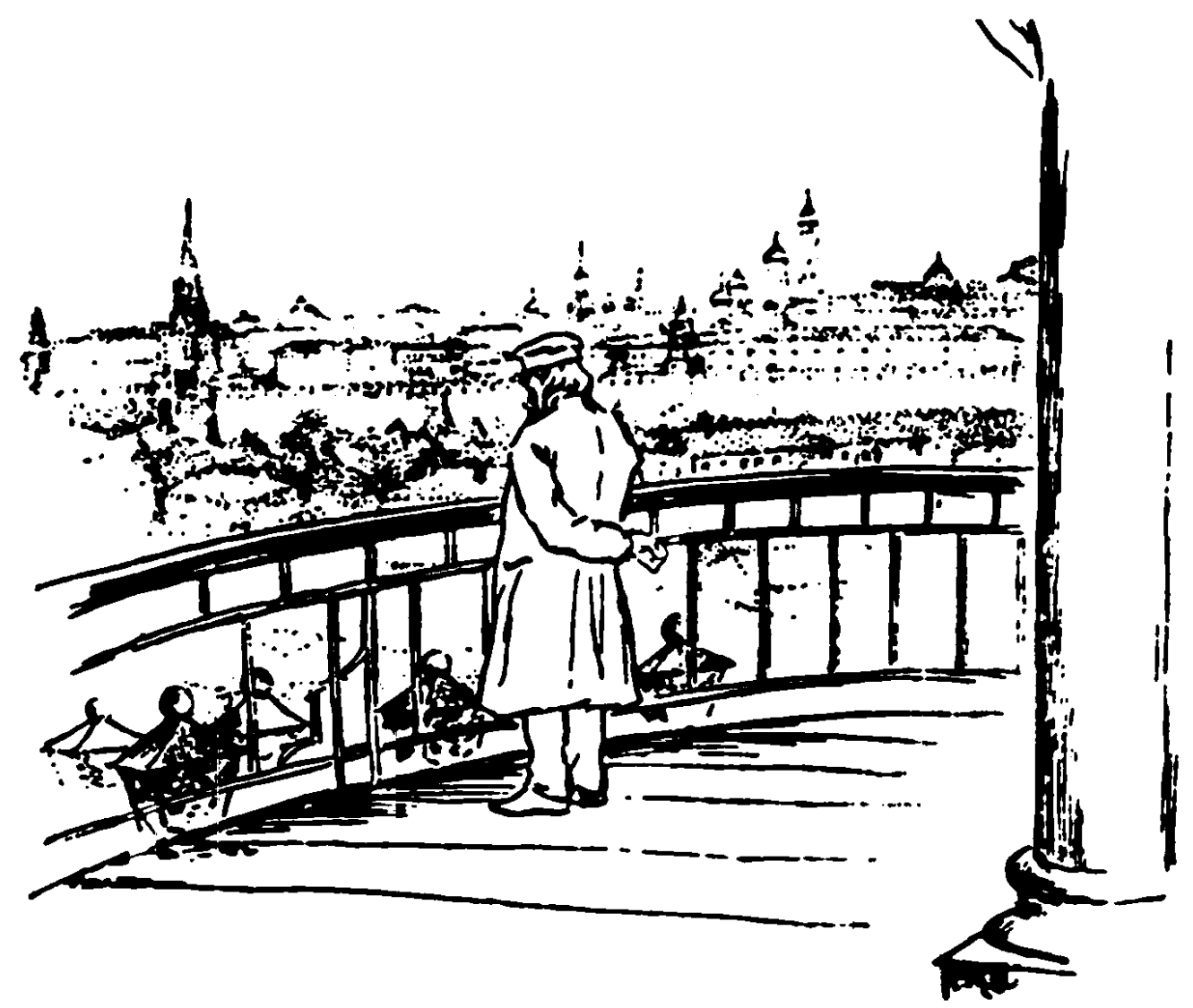

M.I. Šesterkin: N.F.Fedorov auf dem Balkon des Rumjancev-Museums 


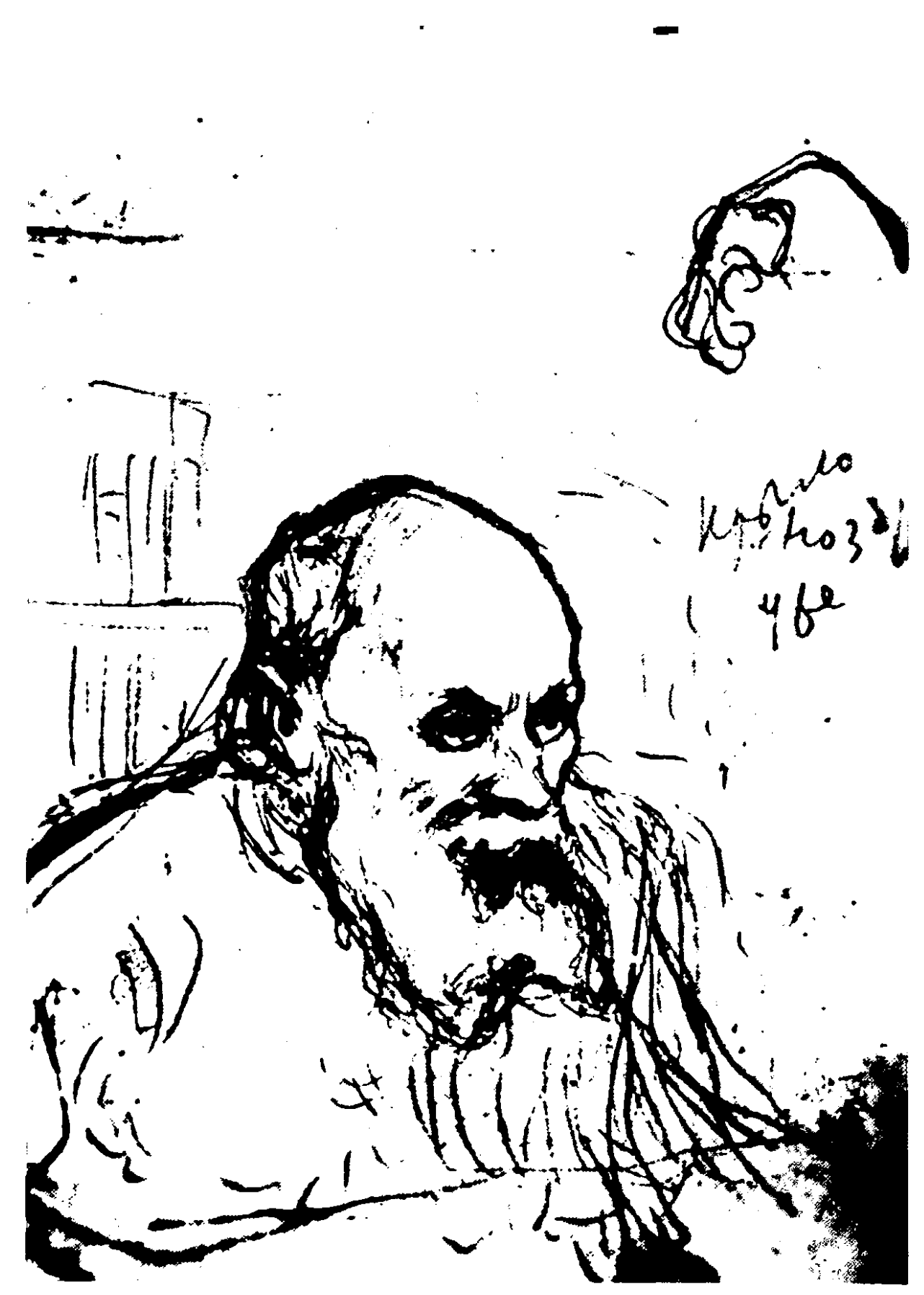

L.O. Pasternak: N.F. Fedorov 


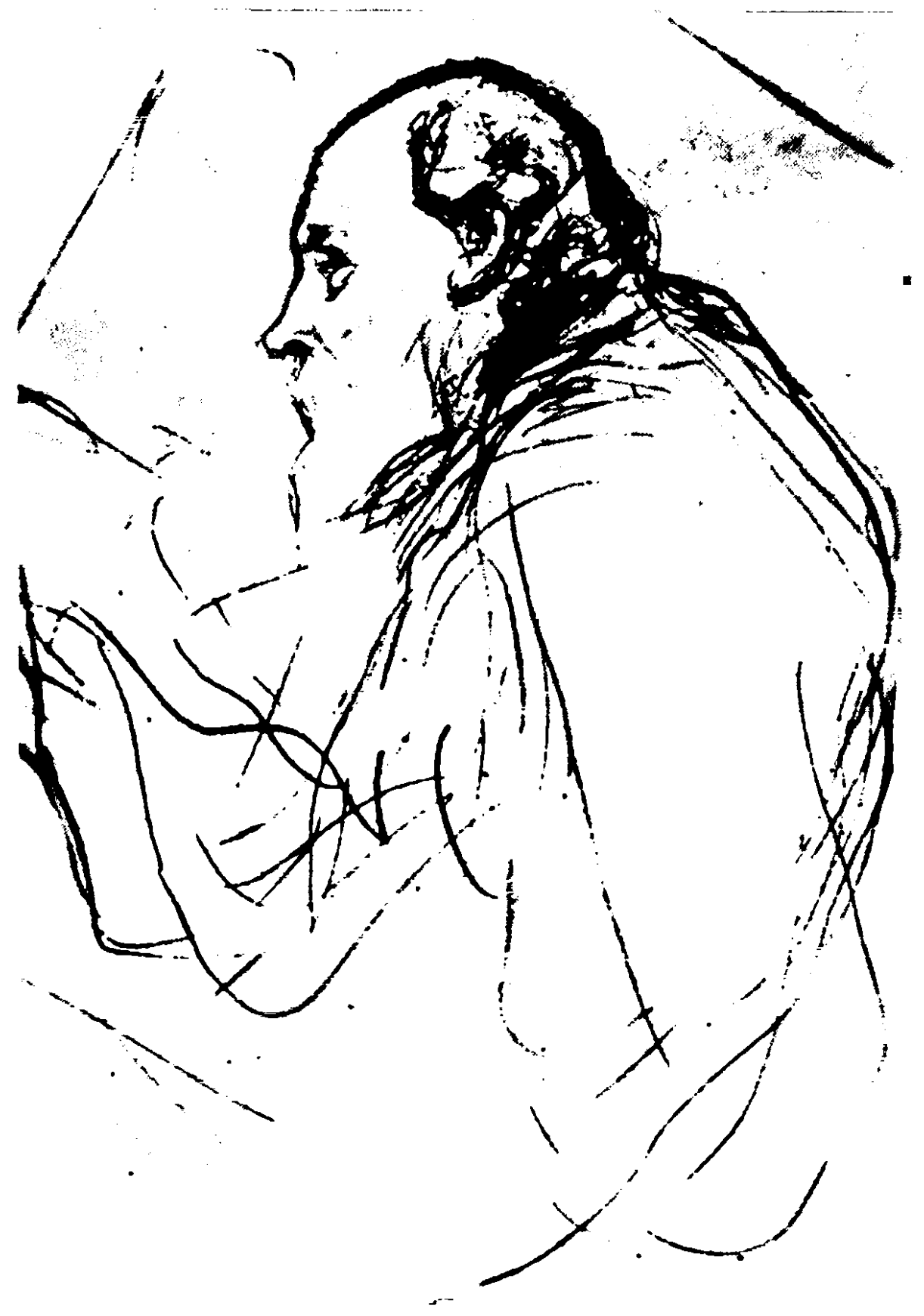

L.O. Pasterrak: N.F. Fedorov 


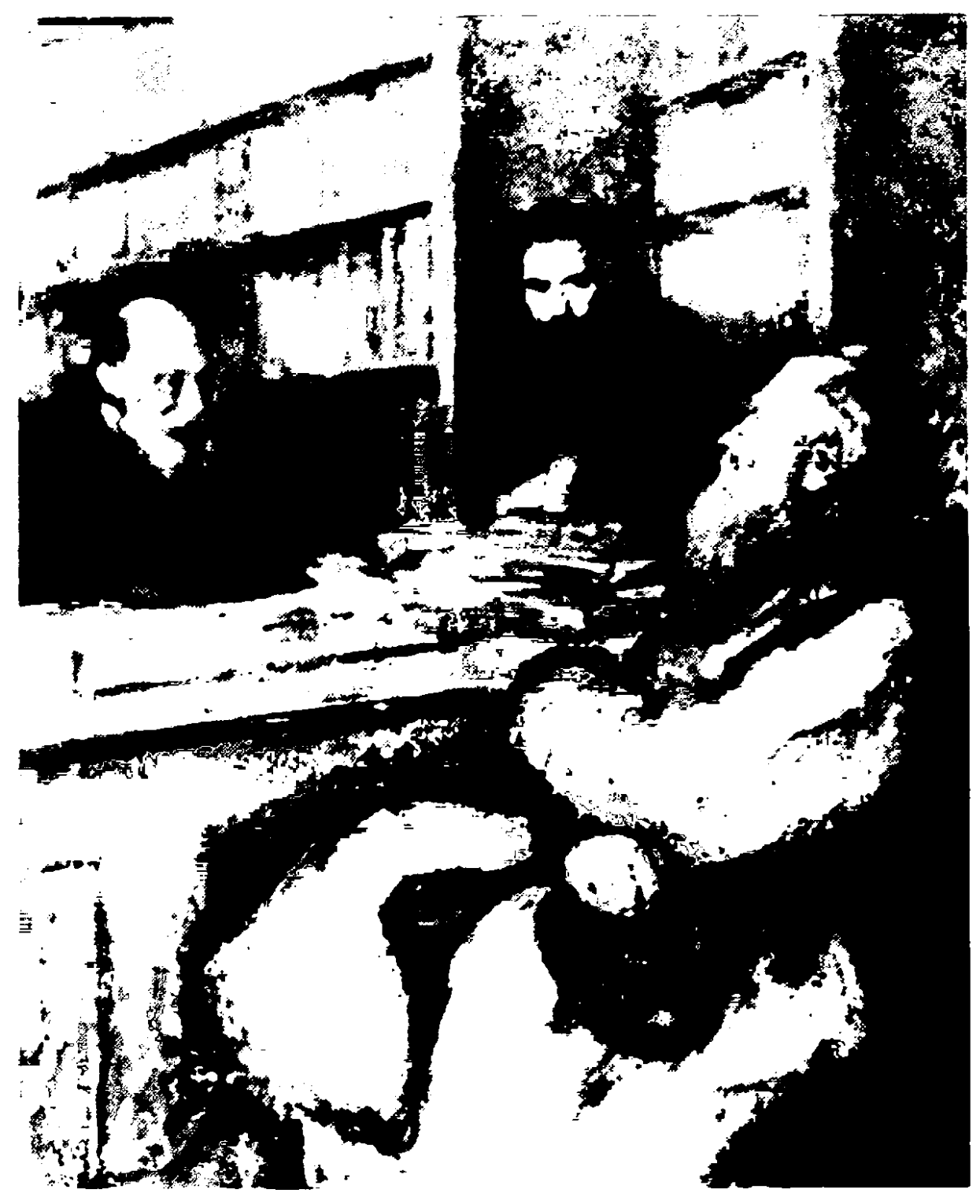

L.O.Pasternak: N.F. Fedorov, V.S. Solov'ev, L.N. Tolstoj 
Bücher waren für Fedorov keine bloßen Informationsmittel, keine toten Gegenstände. Vielmehr sah er in ihnen die Hinterlassenschaft von Menschen, deren Gedanken, Gefühle und Bestrebungen sie vor dem Vergessenwerden zu retten suchten. ${ }^{72}$ "Man darf nie vergessen," pflegte Fedorov zu sagen, "daß hinter jedem Buch ein Mensch sich verbirgt. ${ }^{m 33}$ Intensives Studium der schriftlichen Hinterlassenschaft eines Menschen bewirke, so Fedorov, daß vor dem geistigen Auge des Lesers das "lebendige Abbild" (zivoj obraz) des Urhebers entstehe; dies sei der erste Schritt auf dem Weg zu dessen vollständiger, realer Wiederherstellung. Für Fedorov war deshalb jedes Buch und jedes Schriftstück gleichermaßen wertvoll, und er forderte, auch der unscheinbarsten Veröffentlichung gleiche Ehrfurcht und gleiches Interesse entgegenzubringen. Kein Buch dürfe aus einer Bibliothek entfernt oder gar vernichtet werden. ${ }^{74}$ Die Bibliothek, so Fedorov, sei kein bürgerlicher Verein, der die Verstorbenen einfach aus seinen Listen streiche; 75 vielmehr sei sie der Ort, an dem alle schriftlichen Andenken an vergangene Generationen gesammelt und sicher bewahrt werden müßten bis zu dem Tag, da die Verstorbenen selbst ins Leben zurückgeholt werden würden. ${ }^{76}$

Da jedoch nur intensives Studium einen Autor (wenn auch zunächst nur metaphorisch) wieder zum Leben erwecke, dürfe die Bibliothek kein bloßer "Bücherfriedhof" (knižnoe kladbišče) bleiben, sondern müsse in eine Stätte allumfassender wissenschaftlicher Arbeit verwandelt werden, die dem Ziel diene, untergegangenes Leben wiederherzustellen. ${ }^{77}$ Diesem Ziel suchte auch Fedorov zu dienen. An sich war seine Aufgabe bescheiden; sie bestand darin, die von den Benutzern gewünschten Bücher zu ermitteln und die Bestellscheine zu signie-

72 Vgl. FOD I, S. 679.

73 Zitiert nach Kozennikov (wie Anm. 1), S. 3, 6. - Vgl. Georgievsku (wie Anm. 4), S. 55. PankRatov (wie Anm. 4), S. 20. FOD I, S. 605. - Die Vernichtung von Büchern zum Zweck der Austilgung aller Erinnerung schildert Ray Bradburys Roman "Fahrenheit 451"; der Protagonist Montag lehnt sich dagegen auf, als er erkennt, daB "hinter jedem Buch ein Mensch" steht. R. BRADBURY, Fahrenheit 45I, Zürich 1981, S. 60.

74 Georgievskis (wie Anm. 4), S. 55. Kozevnikov (wie Anm. 1), S. 7. - Als Tolstoj einmal angesichts der Bücherbestănde des Rumjancev-Museums meinte, man tăte besser daran, all den geschriebenen Unsinn zu verbrennen, soll er damit Fedorovs heftigen Zorn erregt haben. A.S. PrugaviN, "O paradoksach L.N. Tolstogo." In: Sbomik vospominanij o L.N. Tolstom, M. 1911, S. 7. Von dieser Anekdote gibt es mehrere Versionen. Vgl. Ostromrov (wie Anm. 4), S. 16. N.N. GuSEV, Lev Nikolaevic Tolstoj. Materialy k biografii s 1881 po $1885 \mathrm{god}$. M. 1970, S. 76. ALTASSKIJ (wie Anm. 5), S. 181.

75 Kozennikov (wie Anm. 1), S. 6. Georgievsku (wie Anm. 4), S. 55.

76 KoZEVVNKoV (wie Anm. 1), S. 7f. - In krassem Widerspruch zu dieser - im Rahmen seiner Lehre wesentlichen - Forderung steht Fedorovs Bestreben, über die eigene Person möglichst wenig Informationen preiszugeben und lediglich anonyme Werke zu hinterlassen; letzteres geschah vielleicht aus Furcht vor Zensur und möglicher Exkommunikation (wie PANKRATOV, wie Anm. 4, S. 25, vermutet) oder in der Annahme, "daB diese Schriften niemandem von Nutzen" sein würden, wie Fedorov gegen Ende seines Lebens an Koževnikov schrieb (Brief vom 15.7.1902; KoŽEVNikov, wie Anm. 1, S. 214).

Vgl. FOD I, S. 495, 683. 
ren. ${ }^{78}$ Doch gab sich Fedorov damit nicht zufrieden. Sobald er einen Benutzer als seriösen Wissenschaftler erkannt hatte, bemühte er sich nach Kräften, ihm nicht nur die gewünschte Literatur zu beschaffen, sondern darüber hinaus alle für seine Arbeit nötigen Materialien. ${ }^{79}$ War ein benötigtes Buch in der Bibliothek nicht vorhanden, so wandte sich Fedorov an andere Bibliotheken oder an private Sammler oder kaufte es gar von seinem eigenen bescheidenen Gehalt. ${ }^{80} \mathrm{Um}$ die Bestände der Bibliothek zu vermehren und sie den Benutzern besser zu erschließen, schlug Fedorov eine Reihe von Maßnahmen vor. So regte er einen internationalen Austausch wissenschaftlicher Literatur an, ${ }^{81}$ empfahl die Einführung standardisierter und unzerstörbarer Katalogkarten, auf denen nicht nur die bibliographischen Angaben, sondern auch eine Zusammenfassung des Inhalts eines Buches zu verzeichnen seien, ${ }^{82}$ und entwarf einen Plan, nach dem alle privaten Büchersammlungen in ganz Rußland der Öffentlichkeit zugänglich gemacht werden sollten. ${ }^{83}$ Um zu erreichen, da $B$ alle Bücher auch gelesen würden, schlug Fedorov vor, die Bestände der Bibliotheken kalendarisch zu ordnen, und zwar nach dem Todestag der Autoren: ${ }^{84}$ Dem Vorbild des kirchlichen Heiligenkalenders folgend, würde man sich an jedem Tag eines anderen Autors erinnern und ihn durch das Studium seiner Werke der Vergessenheit entreißen. Auf diese Weise würde kein Buch und kein Autor unbeachtet bleiben. ${ }^{85}$

Große Bedeutung maß Fedorov der Arbeit des Bibliographen bei: Seine Aufgabe sei es, vergessene Autoren wiederzuentdecken und ihre Werke zugänglich zu machen; auch solle er Bücherverzeichnisse für die unterschiedlichsten Benutzerkreise erstellen, um auf diese Weise schließlich einem jeden die Teilhabe am angesammelten Wissen der Menschheit zu ermöglichen. ${ }^{86}$

78 Siehe GeorgievsKu (wie Anm. 4), S. 54.

79 Ebd., S. 98f. - Vgl. Senrok (wie Anm. 4), S. 666f. Nekrasova (wie Anm. 4). Pokrovsku (wie Anm. 4), Nr. 23, S. 4. A. NeCvolodov, Skazanija o Russkoj Zemle, c. 1, SPb. 1913, S. III. - Zu jenen, die sich immer wieder an Fedorov um Rat und Auskunft wandten, gehorten Kapazităten wie der Philologe F.I. Buslaev und der Kunsthistoriker D.A. Rovinskij.

80 Koževinkov (wie Anm. 1), S. 4f., 9. - Nekrasova (wie Anm. 4). Pankratov (wie Anm. 4), S. 20.

81 KozeVnikov (wie Anm. 1), S. 10f.

82 Ebd., S. 8f. - Vgl. FOD I, S. 677-680. GINKEN (wie Anm. 5), S. 22 f.

83 KožzVnikov (wie Anm. 1), S. 9 .

84 Den Vorschlag, die Bücher nach dem Geburtstag ihrer Autoren aufzustellen, lehnte Fedorov mit dem Einwand ab, es gebe zu viele, deren Herkunft unbekannt sei und deren Geburtstag niemand wisse, wahrend man sich an ihr Todesdatum erinnere (FOD I, S. 684). - Fedorov mag dabei auch an sich gedacht haben.

Vgl. FOD I, S. 605, $683 f$.

86 Die so erstelite Bibliographie war für Fedorov der "Schlüssel zum Wissen" (kljuC znanija), der allen den Zugang zur Wissenschaft eroffne (FOD I, S. 681-684). 
Um die Bibliothek in eine Stätte universeller wissenschaftlicher Arbeit zu verwandeln und um den Gedankenaustausch zu fördern, lud Fedorov Freunde und Bekannte ein, sich regelmäßig außerhalb der Dienstzeit an seinem Arbeitsplatz im Katalograum des Rumjancev-Museums zu treffen, um miteinander zu diskutieren und um die bibliographischen Hilfsmittel zu benutzen, die sonst unzugänglich waren. Im Laufe der Zeit wurde daraus eine feste Einrichtung in der Art gelehrter Zusammenkünfte. Zu den Teilnehmern zählten bedeutende Vertreter des geistigen Lebens Moskaus, unter ihnen Lev Tolstoj, Vladimir Solov'ev, Vladimir Koževnikov, Petr Ivanoviæ̌ Bartenev und seine Söhne Jurij und Sergej, die Philologen und Bibliothekare Ivan Ivakin und Grigorij Georgievskij, der Literaturwissenschaftler Vladimir Šenrok, der Dichter Afanasij Fet und sein Freund, der Kunstsammler und Kustos der Tret'jakov-Galerie, Nikolaj Černogubov. ${ }^{87}$ In späteren Jahren kam noch Valerij Brjusov hinzu. ${ }^{88}$ Durch Fedorovs Initiative wurde der bescheidene Katalograum des Rumjancev-Museums zu einem "geistigen Mittelpunkt Moskaus". 89

Eine ähnliche Bedeutung wie der Bibliothek maß Fedorov auch dem Museum bei. Er schlug vor, in jeder Provinzstadt eine Art Heimatmuseum einzurichten, in dem die Andenken an die vergangenen Generationen aus der jeweiligen Gegend gesammelt, bewahrt und erforscht werden sollten. ${ }^{90}$ Fedorov selbst legte ein Archiv für historische Dokumente in Kerensk (heute Vadinsk) an und sam-

Einige der von Fedorov in diesem Zusammenhang erhobenen Forderungen verwirklichte - offenbar unabhăngig von ihm - der russische Bibliograph, 'Bibliopsychologe', Büchersammler und Volksaufklărer Nikolaj Aleksandrovið Rubakin (1862-1946), den man einen "Lotsen im Meer der Bücher" (locman knižnogo morja) nannte, wăhrend er sich selbst als einen "einfachen Bücheruurm" (skromnyj kniznyj cenvjak) sah. Mit Hilfe sorgfaltig zusammengestellter Auswahlbibliographien versuchte Rubakin, allen Schichten der Bevolkenung den Zugang zur Wissenschaft zu erschließen. Seine eigene umfangreiche Privatbibliothek, die er seit seiner Emigration aus Rußland (1907) in Lausanne aufgebaut hatte und die bei seinem Tod mehr als 100.000 Bănde zur russischen Kultur- und Geistesgeschichte und den Naturwissenschaften umfaBte, machte Rubakin allen Interessierten zugănglich. Mit Fedorov teilte er auch die Ehrfurcht vor dem geschriebenen Wort: kein Buch, keine Zeitung durfte vernichtet werden. Siehe die Biographie aus der Feder seines Sohnes A.N. RuBAKIN, Rubakin (Locman kniznogo morja), M. ${ }^{2} 1979$, bes. S. 137. Ferner A.E. SENN, Nicholas Rubakin. A Life for Books. Newtonville, Mass. 1977.

87 Im Archiv von Nikolaj Nikolaevił Cernogubov (1874-1941) befinden sich bislang unveröffentlichte Aufsătze über Fedorov (GBL f. 328). Vgl. Kratkij ukazatel' archimych fondov otdela rukopisej, M. 1948, S. 204. Litnye archivnye fondy v gosudarstvennych chranilistach SSSR. Ukazatel'. T. 2, M. 1963, S. 293. - A. Belyj nennt in seinen Erinnerungen N.N. Cernogubov einen "fedorovec". A. BELYJ, Mezdu dvuch revoljucij, L. 1934, S. 219. Vgl. Ders., Nacalo veka, M.-L. 1933, S. 168: "Cemogubov N.N., znatok Feta i Fedorova". Von Cemogubov stammt eine ausgesprochen negative Charakterisierung Fedorovs; siehe unten Anm. 111 und 121.

88 Brjusov war von 1899 bis 1902 Sekretăr in der Redaktion von P.I. Bartenevs Russkij Archiv. Siehe V.JA. Bruusov, Iz moej tizni, M. 1927, S. 93ff. Zu Brjusovs Bekanntschaft mit Fedorov siehe II: 2.1.2.

89 Ju.[P.] Bartenev (wie Anm. 5), S. 191. - Vgl. Ostromarov (wie Anm. 4), S. 14. Pankratov (wie Anm. 4), S. 21. KožeVnikov (wie Anm. 1), S. Sf. SENROK (wie Anm. 4), S. 665f.

90 Vgl. N.F. FEdorov, "Muzej, ego smysl i naznarenie." In: FOD II, S. 398-473. KožEVNIKov (wie Anm. 1), S. 11-22. 
melte Materialien zur Geschichte jener Gegend. ${ }^{91}$ Im Bestreben, alle Zeugnisse der Vergangenheit zu sammeln, unterstützte Fedorov archäologische und regionalgeschichtliche Forschungen in Rjazan' und Tambov, ${ }^{92}$ förderte die Gründung eines Museums in Voronež, ${ }^{93}$ sammelte Volkslegenden ${ }^{94}$ und erforschte altes Brauchtum. ${ }^{95}$

Fedorov führte ein äußerst bescheidenes Dasein, das dem eines Asketen oder Kynikers glich. ${ }^{96}$ Obwohl er (seit 1876) den Rang eines Kollegienassessors bekleidete, ${ }^{97}$ bezog er nur ein geringes Gehalt, wovon er den größten Teil an Bedürftige weitergab, die er seine "Stipendiaten" oder "Pensionäre" nannte. ${ }^{98}$ Mehrmals wurde ihm eine Beförderung oder Erhöhung seiner Bezüge angeboten, doch lehnte er stets $a b .{ }^{99}$ Fedorov wechselte häufig seine Unterkunft und

91 Siehe PETERson (wie Anm. 53).

92 KožeVnikov (wie Anm. 1), S. 18.

93 Ebd., S. 19.

94 Siehe [N.F. FEDOROv], "Skazanie o postroenii obydennogo chrama v Vologde 'vo izbavlenie ot smertonosnyja jazvy'." In: C'tenija v imperatorskom obscestve istorii $i$ drevnostej rossijskich pri Moskovskom universitete 1893 god, kn. 3 (166), M. 1893, S. 11-21. [DERS.], "Bytie krestnogo syna." In: Russkij Anchiv, 1915, 11-12, S. 296-303.

95 Insbesondere den altrussischen Brauch, Kirchen in einmütiger kollektiver Arbeit an einem Tag zu erbauen (sog. obydennye cerkvi). Vgl. Fedorovs Vorwort zu "Skazanie o postroenii..." (wic Anm. 94), S. III-X (auch in: FOD I, S. 650-655). [DERS.] "Obydennye cerkvi na Rusi." In: Russkij Archiv, 1894, 11, S. 448-453. [DERS.], "O znatenii obydennych chramov..." In: FOD I, S. 685-731. - In Moskau gibt es heute noch drei solcher "an einem Tage erbauter Kirchen".

96 Fedorov selbst wandte sich allerdings heftig gegen solche Vergleiche. Vgl. Ju.[P.] BARTENEV (wie Anm. 5), S. 192. FOD II, S. 129 Anm. 1. Bedürfnislosigkeit war für ihn weder ein Wert an sich, noch ein Mittel zur Selbstvervollkommnung oder zu individueller Selbsterlösung (licnoe samospasanie), sondern Ausdruck der Solidarităt mit all jenen, die gezwungenermaßen in Armut lebten. Im Gebrauch dessen, was andere entbehren müssen, sah Fedorov bereits eine Verletzung der Christenliebe und der menschlichen Einheit (FOD I, S. 174). Fedorovs Lebensweise, seine Bedürfnislosigkeit und Selbstverleugnung, seine Verachtung des "Kults der Dinge" (kul't vešcej) und seine Geringschätzung von Rang und Namen entsprachen dem Ideal der radikalen Jugend der sechziger Jahre. Dazu A.I. Novikov, Nigilizm i nigilisty. Opyt kriticeskoj charakteristiki. L. 1972, S. 60f. Nicht zufallig wurde Fedorov mit Rachmetov verglichen.

97 Attestat (wie Anm. 4). - Der kolležskij assessor stand in der 8. Klasse der 14 Klassen umfassenden zivilen Rangtabelle.

98 Peterson, Fedorov (wie Anm. 4), S. 78, gibt das jăhrliche Einkommen Fedorovs mit 498 Rubeln an. GEORGIEvSKU (wie Anm. 4), S. 52, berichtet, Fedorov habe 33 Rubel im Monat erhalten, wovon er 8 Rubel für sich, d.h. für Kost und Logis, verbrauchte, den Rest aber fortgab. Vgl. auch Poxrovsku (wie Anm. 4), Nr. 24, S. 4. Pankratov (wie Anm. 4), S. 19f. LiNNICENKo (wie Anm. 65), S. 316. - Einer dieser "Stipendiaten" war der junge Konstantin Eduardovi Ciolkovskij (1857-1936), der - mogglicherweise nicht ohne Fedorovs EinfluB - spăter zum Pionier der russischen Raumfahrt wurde. Siehe Altassku (wie Anm. 5), S. $180 f$.

99 Pankratov (wie Anm. 4), S. 20. Nekrasova (wie Anm. 4). - Peterson zufolge war Fedorov froh, daß sein Jahresgehalt weniger als 500 Rubel betrug, da er infolgedessen von der Geschworenenpflicht befreit war; er wollte nicht über andere zu Gericht sitzen (PETERson, Fedorov, wie Anm. 4, S. 78). Vgl. auch Georgievsky (wie Anm. 4), S. 60f. PoKrovsKu (wie Anm. 4), Nr. 25, S. 5. 
bewohnte zumeist winzige Zimmer, die er für wenige Rubel im Monat gemietet hatte. ${ }^{100}$ Er schlief auf einem Stapel Zeitungen, einer leeren Truhe oder einer Holzpritsche; statt eines Kissens schob er einen Mantel, ein Buch oder einen anderen harten Gegenstand unter den Kopf. ${ }^{101}$

Sergej L'vovic Tolstoj, der einmal im Auftrag seines Vaters in Fedorovs Wohnung war, berichtet:

Sein Kämmerchen war so eng, daß das Bett, falls man ein paar Bretter als Bett bezeichnen kann, mit beiden Enden an die Wand stieB. Er deckte sich mit seinem einzigen, abgetragenen Mantel zu, der inm im Sommer wie im Winter diente. ${ }^{102}$

Fedorov mied den Schlaf, da er ihn an den Tod erinnerte (weshalb er auch den Anblick Schlafender nicht ertragen konnte und stets das Bedürfnis verspürte, sie zu wecken). ${ }^{103}$ Seine dienstfreie Zeit verbrachte er mit Lesen und Schreiben; ${ }^{104}$ bisweilen lud er auch Gäste in seine ärmliche Behausung, Gelehrte, Philosophen, Schriftsteller - unter ihnen Tolstoj und Solov'ev -, um ihnen seine Ideen vorzutragen und zu diskutieren. ${ }^{105}$ Mit Frauen pflegte er keinen Umgang;

100 GeORgIEvSKU (wie Anm. 4), S. 51, gibt eine genaue Schilderung von Fedorovs ärmlicher Behausung im Molocnyj pereulok; das Haus Nr. 9, in dem Fedorov in den achtziger und neunziger Jahren wohnte, ist noch heute zu sehen. 1886 wohnte Fedorov im Moloznyj pereulok Nr. 12; 1903 ebd. Nr. 4. Angaben nach S.K. RomanjUK, Iz istonii moskovskich pereulkov, M. 1988, S. 132. Ähnlich beschreibt NekRAsOva (wie Anm. 4) Fedorovs Unterkunft gegen Ende der siebziger Jahre im Nabilkovskij pereulok. Zu Beginn der achtziger Jahre wohnte Fedorov in der Ostoženka unweit der inzwischen abgerissenen großen Erloser-Kirche. Vgl. BORISOV (wie Anm. 55), S. 202. Nikmin (wie Anm. 38), S. 124. Peterson, Fedorov (wie Anm. 4), S. 106, nennt für die neunziger Jahre eine Adresse in der Mochovaja; O.N. Setnickaja (in einem Brief an mich, 20.5.1982) eine Adresse im Statnyj pereulok Nr. 3. - Gegenwărtig versucht V.S. Borisov, Moskau, ein Verzeichnis sămtlicher Moskauer Wohnadressen Fedorovs zu erstellen.

101 Vgl. Georgievsku (wie Anm. 4), S. 51. Pokrovsku (wie Anm. 4), Nr. 24, S. 4. Nekrasova (wie Anm. 4). Pankratov (wie Anm. 4), S. 19. Peterson, Fedorov (wie Anm. 4), S. 78.

102 S.L. Tolstoj (wie Anm. 42), S. 138.

103 Peterson, Fedorov (wie Anm. 4), S. 78. - Bemerkenswert ist in diesem Zusammenhang, da B bereits der englische Aufklărer William Goowvin (1756-1836), der - wie Fedorov - an die Fähigkeit des Menschen glaubte, den Tod zu überwinden, zunăchst den Schlaf zu bekämpfen suchte: "... before death can be banished, we must banish sleep, death's image. Sleep is one of the most conspicuous infirmities of the human frame." W. GoDWIN, Enquiry Conceming Political Justice, and its Influence on Morals and Happiness [1793], Bd. 3, Toronto 31946, S. 226. Für Schopenhauer war Schlaf "ein Stück Tod, welches wir antizipierend borgen..." 'Aphorismen zur Lebensweisheit'. In: A. SCHOPENHAUER, Sämtliche Werke, Bd. 4, Frankfurt/M. 1987, S. 289. Auch in der Wissenschaft wurde zu Fedorovs Zeit eine Analogie zwischen Schlaf und Tod angenommen: beide seien Folgen einer Selbstvergiftung des Organismus. Siehe E. METSCHNIKOFF [I.I. MECNIKOV], Beiträge zu einer optimistischen Weltanschauung, München 1908, S. 119ff. Berichte, die im Falle Fedorovs von nur zwei bis drei Stunden Schlaf sprechen (S.P. BAR. TENEV, "Nikolaj Fedoroviz Fedorov. Dva razgovora o voskreŠenii mertvych." In: Russkij Archiv, 1909, 1, S. 122), gehoren wohl ins Reich der Legenden.

104 Ju.[P.] Bartenev (wie Anm. 5), S. 192. Pankratov (wie Anm. 4), S. 20.

105 Pasternak, Zapisi (wie Anm. 63), S. 144. Georgievsku (wie Anm. 4), S. 58. Fedorov führe das Leben eines Asketen, jedoch nicht das eines Einsiedlers, bemerkte I.A. Linnitenko; 
alle Äußerungen menschlicher Sexualität lehnte er ab. ${ }^{106}$ Seine Nahrung bestand aus Tee und Kringeln, gelegentlich aus altem Käse und gesalzenem Fisch; monatelang lebte er ohne warmes Essen. ${ }^{107}$ Seine Kleidung war so schäbig, daß er von Fremden, denen er auf der Straße begegnete, für einen Bettler gehalten wurde. ${ }^{108}$ Möbel besa $B$ er keine, und bei jedem Umzug verschenkte er alles, was sich in seiner Behausung angesammelt hatte. ${ }^{109}$ Geld verursachte ihm Ekel; fand er Kleingeld in seinen Taschen, so ärgerte er sich, daB es ihm nicht gelungen war, es wegzugeben. Er fürchtete, man könne ihn eines Tages tot finden mit ein paar Kopeken in der Tasche. ${ }^{110}$ Fedorov galt als praktizierender Christ; regelmäßig besuchte er den Gottesdienst, beichtete und kommunizierte. Oft sah man ihn in der Uspenskij-Kathedrale oder in der großen Erlöser-Kirche unweit des Kremls. ${ }^{111}$

In seinen Erinnerungen berichtet Il'ja L'vovix Tolstoj über den alten Fedorov:

Er war ein ziemlich magerer Greis von mittlerer Statur, stets schlecht gekleidet, ungew $8 \mathrm{hnlich}$ still und bescheiden. Um den Hals trug er an Stelle eines Kragens einen grauen karierten Schal und ging in Winter wie im Sommer in ein und demselben alten, ziemlich kurzen Uberzieher. Er hatte einen Gesichtsausdruck, den man nicht vergißt. Seine klugen und durchdringenden Augen waren in stăndiger Bewegung; dabei strahlte er von einer inneren Güte, die bis zu kindlicher Naivităt reichte. Wenn es Heilige gibt, dann müssen sie genau so sein. Nikolaj Fedorovix war nicht nur physisch un-

Menschen und Gesellschaft liebe er sehr. LinNiCENKo (wie Anm. 65), S. 316. Vgl. auch SENROK (wie Anm. 4), S. 665.

106 Wiederholt ist vermutet worden, daB Fedorovs Misogynie (wie sie auch und vor allem in seinem Werk begegnet) ihren Grund in einer (latenten) Homosexualitat gehabt habe. Dafür gibt es jedoch keinen Anhaltspunkt. Offensichtlich ist hingegen eine ausgeprăgte Lustfeindlichkeit verbunden mit einem übersteigerten Schamgefühl, was in einem Gesprach (1895) zwischen dem 32-jăhrigen S.P. Bartenev und dem mehr als doppelt so alten Fedorov zum Ausdruck kommt: "Ich [d.i. S.P. Bartenev]: Haben Sie, der Sie ein solches Leben führen, nicht unter Entbehrungen und Qualen gelitten? - Fedorov: Ich habe mir nie Gewalt angetan. Mir fiel das überhaupt nicht schwer. - Ich: Ich halte mich zurück, aber ich leide, wenn ich keine Frauen habe. Haben Sie denn nicht gelitten? - Er: Lassen Sie das! - Ich: Ich denke, das heftige Verlangen hört gegen vierzig auf. - Er (geht in eine Ecke, errötet, energisch): Es hort niemals auf." S.P. BARTENEV, "Iz dnevnika S.P. Barteneva." in: Novyj Zumal, 129, 1977, S. 178f. - S.P. Bartenev (1863-1930), Sohn von P.I. Bartenev (vgl. Anm. 5), war ein bedeutender Pianist und Musiklehrer in Moskau. Er soll sich als "Schüler Fedorovs" bezeichnet haben.

107 Vgl. Nekrasova (wie Anm. 4). Georgievsku (wie Anm. 4), S. 52. Pankratov (wie Anm. 4), S. 19. Peterson, Fedorov (wie Anm. 4), S. 78.

108 Ausführlich Georgievskiu (wie Anm. 4), S. 48f. - Vgl. Pokrovsku (wie Anm. 4), Nr. 24, S. 4. Nekrasova (wie Anm. 4). Pankratov (wie Anm. 4), S. 20.

109 Ostromirov (wie Anm. 4), S. 15. Pankratov (wie Anm. 4), S. 19.

110 Ostromirov (wie Anm. 4), S. 15. Georgievsku (wie Anm. 4), S. 52. PokrovskU (wie Anm. 4), Nr. 24, S. 4 f.

111 Pokrovsku (wie Anm. 4), Nr. 25, S. 4. Pankratov (wie Anm. 4), S. 25. - Dagegen schildert N.N. Cernogubov Fedorov als einen Atheisten, der sich nur eines religiosen Vokabulars bedient habe. Angaben von N.N. Cernogubov, mitgeteilt in einem Brief von N.I. Dorofeeva an I.P. Brichnirev, 1913; Archiv von I.P. Brichnirev, GBL f. 516; nach einer Abschrift in Moskauer Privatbesitz. Siehe auch 1: 3. Anm. 7. 
fahig, etwas Boses zu tun, sondern ich denke, daB er auch selbst unverwundbar war durch jegliches Bose. Er begriff es einfach nicht. ${ }^{112}$

Fedorovs letzte Lebensjahre waren schriftstellerisch besonders produktiv, zugleich aber überschattet von Enttäuschungen, Selbstzweifeln und dem Gefühl zunehmender Isolierung. Am 15. September 1898 hatte Fedorov wegen persönlicher Differenzen mit M.A. Venevitinov, dem neuen Direktor des RumjancevMuseums, auf eigenen Wunsch den Bibliotheksdienst verlassen ${ }^{113}$ und - da die bescheidene Pension von 17 Rubeln und 51 Kopeken im Monat zum Leben nicht reichte - eine Stelle als Aufseher im Lesesaal des Moskauer Archivs des Außenministeriums angenommen. Im Sommer des darauffolgenden Jahres reiste Fedorov zu Peterson nach Aschabad, wo er fast ein Jahr blieb. In dieser Zeit wurde der größte Teil seines philosophischen Werkes ausformuliert und schriftlich niedergelegt, offenbar in der Absicht, eine Publikation vorzubereiten. ${ }^{114}$ Gleichzeitig verstärkte sich jedoch bei Fedorov die Überzeugung, da $B$ seine Gedanken niemandem von Nutzen seien und zumindest bei seinen Zeitgenossen auf Unverständnis und Ablehnung stoßen würden. "Ich hege keine Hoffnung," schrieb er am 17. Juni 1901 an Koževnikov, "daB in unserer Zeit der Gedanken- und Tatenlosigkeit das Projekt des obšcee delo, der Regulierung der Natur durch den Verstand und den Willen der Menschheit, Aufmerksamkeit auf sich zu ziehen vermag." ${ }^{.115}$ Er schreibe deshalb, so Fedorov, "unter dem Eindruck völliger Hoffnungslosigkeit" und in "geistiger Einsamkeit". ${ }^{116}$ Dieses Gefühl verstärkte sich so sehr, daß Fedorov schließlich einen Teil seiner Manuskripte verbrannte. ${ }^{117}$ Als Peterson daraufhin die restlichen Papiere an sich nahm und sie heimlich nach Aschabad schaffte, um sie dort abzuschreiben, erregte er Fedorovs heftigen Zorn; es kam zum Bruch zwischen beiden, der bis zu

\section{I.L. Tolstos, Moi vospominanija, M. 1969, S. 1896.}

113 Siehe Attestat und Opis' (wie Anm. 4). - Der Entlassung waren mehrere Schreiben Fedorovs an den Direktor vorausgegangen, in denen er sein Abschiedsgesuch mit seinem Gesundheitszustand und dem Nachlassen seiner Kräfte begründete, gleichzeitig aber anbot, weiterhin freiwillig im Museum zu arbeiten. Siehe Opis' (wie Anm. 4), sowie Abschriften der Schreiben Fedorovs an Venevitinov vom 16.(28.)4. und 12.(24.)8.1898 in Moskauer Privatbesitz. Von 1867 bis 1896 war V.A. Daskov Direktor des Rumjancev-Museums; er sei, so heißt es, Fedorov stets wohlgesonnen gewesen. Ihm folgten MA. Venevitinov (1896-1901) und I.V. Cvetaev (19011910), der Vater Marina Cvetaevas. Ober letzteren, seine Tătigkeit am Rumjancev-Museum und seine anerkennende Äußerung über Fedorov siehe JU.M. KAGAN, I.V. Cvetaev, M. 1987, bes. S. 55-63.

114 In dieser Zeit entstanden fast alle Aufsăaze, die spăter im zweiten Band der FOD verơffentlicht wurden, sowie ein großer Teil der unveroffentlicht gebliebenen Manuskripte. Vgl. die Einleitung von " $S$ " [d.i. N.A. SETNICKU] zu "Iz perepiski..." (wie Anm. 46), S. 278, und SEMENOVA (wie Anm. 38), S. 15.

115 KožeVnikov (wie Anm. 1), S. 214.

116 Briefe an Koževnikov vom 28.6.1901 und 10.12.1898 (ebd., S. 213f.).

117 Dies geschah im Jahre 1901 oder 1902. AnlaB soll das Verbot der Veroffentlichung einer Arbeit Fedorovs mit dem Titel $V$ zašitu znanija I dela und die Beschlagnahmung des Manuskripts durch die Moskauer Zensurbehorde gewesen sein. (Mitteilung V A. Nikitin, Moskau). 
Fedorovs Tod nicht mehr überwunden werden konnte. ${ }^{118}$ Auch von Koževnikov und Černogubov ${ }^{119}$ fühlte Fedorov sich mißverstanden und verlassen; ein Jahr vor seinem Tod stellte er resignierend fest:

$\mathrm{N}$ [ikolaj] P[eterson], der fast vierzig Jahre lang an die Mogglichkeit einer Verwirklichung dieses Gedankens [des obšcee delo; M.H.] geglaubt hat, verfiel in Zweifel, als er erkannte, daB die Zeit noch nicht reif ist. V[ladimir] K[oževnikov] hat nie [daran] geglaubt und wird es jetzt um so weniger tun. $\mathrm{N}$ [ikolaj] Č [erno]g[ubo]v aber, der sich von der Gegenwart nicht lösen kann, erklärte ihn, den Gedanken, für schieren Wahnsinn. ${ }^{120}$

Cernogubov zeichnete denn auch ein ausgesprochen negatives Bild von Fedorov; geschildert wird ein verschrobener, engstirniger, auf eine einzige Idee fixierter, zorniger Greis, "lebensuntüchtig wie ein neunjähriger Knaben", argwöhnisch und ungerecht gegenüber seinen Mitmenschen, ohne Freunde oder gar Schüler:

Einen jeden, der nicht mit ihm übereinstimmte, betrachtete er als seinen Feind und war nicht bereit, mit diesem auch nur ein Wort über irgend etwas zu sprechen. Je begabter sein Gegner war, desto schädlicher, glaubte Fedorov, sei er für inn. Er war ăußerst unduldsam und schrecklich mißtrauisch. Es war schwierig, ja fast unmoglich, mehr als zwei Tage mit ihm auszukommen. Das war kein stiller Philosoph, das war ein zorniger Prophet... ${ }^{121}$

Am 15.(28.) Dezember 1903 starb Nikolaj Fedorov an den Folgen einer schweren Lungenentzündung im Moskauer Mariinskij-Armenhospital. ${ }^{122}$ Zwei Tage später wurde er auf dem Friedhof des nahe gelegenen Skorbjašcenskij-Frauen-

118 Siehe Semenova (wie Anm. 38), S. 15f. - Dieser Darstellung wurde inzwischen von einer Enkelin Petersons, der in Frunze lebenden Julija Andreevna Rodzeviz, widersprochen: In einem Brief an S.G. Semenova versicherte sie, das Verhăltnis zwischen Peterson und Fedorov sei bis zuletzt gut gewesen; Petersons Sohn Grigorij Nikolaeviz habe Fedorov noch kurz vor dessen Tod im Krankenhaus besucht. (Brief aus dem Jahre 1983 in Moskauer Privatbesitz).

119 N.N. Cernogubov sammelte zu jener Zeit Fedorovs Schriften und wirkte als Kontaktmann zum Moskauer Symbolisten-Verlag Skorpion, der ihre Veroffentlichung plante. Fedorov verfolgte dieses Vorhaben mit Mißtrauen. S.G. SEmenova, "Primełanija." In: Fedorov (wie Anm. 38), S. 695.

120 Undatierte Aufzeichnung Fedorovs (aus dem Jahre 1902) in: FEDOROv (wie Anm. 38), S. 634.

121 Angaben von N.N. Cernogubov; siehe Anm. 111.

122 Opis' (wie Anm. 4). ANON., [Nachricht vom Tode N.F. Fedorovs]. In: Moskovskie Vedomosti, 16.(29.)12.1903, S. 3.

Koževnikov hatte sich vergebens um eine Aufnahme des Schwerkranken in eine Privatklinik bemüht. Am 11. Dezember schreibt er an N.N. Cernogubov, daB Fedorovs Krankheit "wegen der Schwăche seines Herzens und seines Alters von 74 [!] Jahren" einen tðdlichen Ausgang befürchten lasse. Die Ärzte, so Koževnikov, hătten nur geringe Hoffnung auf eine Genesung. Brief vom 11.12.1903, GBL f. 328; nach einer Abschrift in Moskauer Privatbesitz. In einem Brief an Gorskij schildert Koževnikov die letzten Stunden Fedorovs, sein langsames, schweres Sterben. OStromirov (wie Anm. 4), S. 19.

Im Mariinskij-Armenhospital war 1821 F.M. Dostoevskij als Sohn eines Arztes geboren worden und hatte dort seine Kindheit verbracht. In einem Seitenflügel des Gebăudes befindet sich heute ein Dostoevskij-Museum. 
klosters im Norden Moskaus begraben. ${ }^{123}$ Er hat nichts hinterlassen, außer seinen Schriften.

123 ANon., "Pochorony N.F. Fedorova." in: Moskovskie Vedomosti, 364, 18.(31.)12.1903, S. 3. OsTROMIROV (wie Anm. 4), S. 20.

Fedorovs Grab, das um die Mitte der zwanziger Jahre noch erhalten war, besteht nicht mehr. Wie Nachforschungen im Dezember 1982 am Ort ergaben, wurde es Ende der zwanziger Jahre zerstört, als man auf dem Gelănde des Friedhofs Wohnhăuser errichtete und einen Kinderspielplatz anlegte (heute: Detskij park No. 1). Auch mit Hilfe ortskundiger Anwohner konnte die Lage des Grabes nicht mehr festgestellt werden. Die Kirche des ehemaligen Skorbjašenskij-Klosters, ein häßlicher Backsteinbau vom Ende des 19. Jahrhunderts, ist noch erhalten, wenn auch zweckentfremdet (heute: Novoslobodskaja ul., 58). 


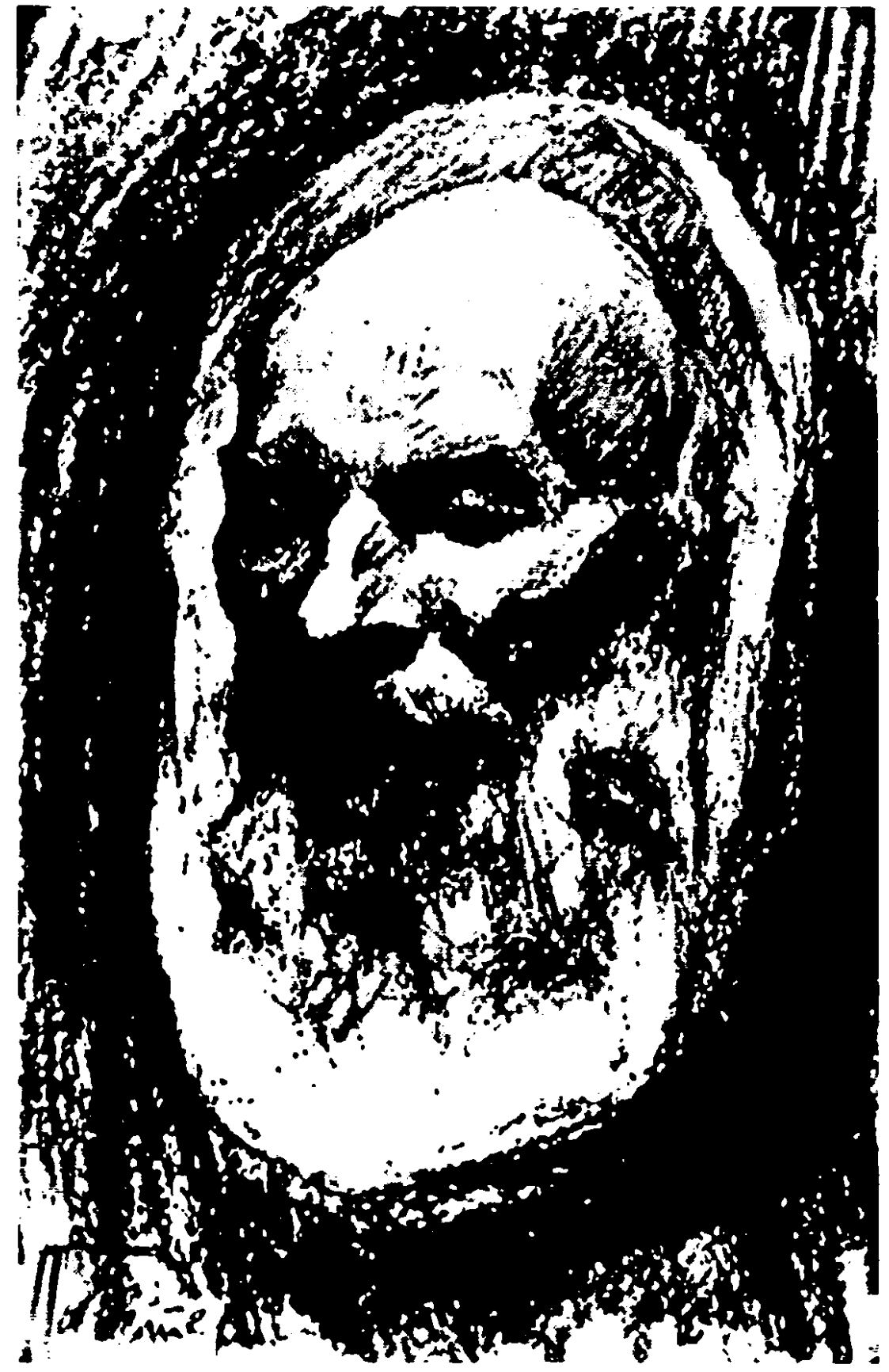

\section{L.O. Pasternak: Fedorovs Totenmaske}




\section{FEDOROVS SCHRIFTEN}

Nur wenige wußten, daß Fedorov schrieb. ${ }^{1}$ Gewöhnlich brachte er seine Gedanken nachts in seiner Kammer beim trüben Schein einer Kerosinlampe zu Papier. ${ }^{2}$ Er schrieb spontan und unsystematisch, fast immer mit Bleistift in einer oft nur schwer lesbaren Schrift auf den unbedruckten Rand von Zeitungen oder auf Papierfetzen. ${ }^{3}$ Die so entstandenen Aufzeichnungen bewahrte er in einem Sack, der ihm bisweilen auch als Kopfkissen diente; einige Bündel Manuskripte trug er stets bei sich, "entweder in der Seitentasche seines Mantels oder einfach zwischen dem Mantelfutter, wodurch seine Rockschöße weit abstanden". ${ }^{4}$ Hatte er zu jemandem Vertrauen gefaßt, so las er ihm aus seinen Aufzeichnungen vor, und zeigte der Zuhörer Interesse und schien er überdies schriftstellerisch begabt, so gab ihm Fedorov das Manuskript "in der Hoffnung, die Saat möge aufgehen und Frucht bringen". 5

Außer in den genannten Aufzeichnungen legte Fedorov seine Gedanken in Briefen dar; ${ }^{6}$ zumeist jedoch entwickelte er sie mündlich in langen, leidenschaftlichen Gesprächen, was ihm den Ruf eines "Moskauer Sokrates" (Moskovskij Sokrat) ${ }^{7}$ eintrug. Einige Teilnehmer an solchen Gesprächen machten sich Notizen, die - mehr oder weniger genau - Fedorovs Gedankengang und den

1 A.S. PankRatov, "Filosof-pravednik." In: Novoe Slowo, 5 (1913), 8, S. 20.

2 L.O. Pasternak, "Iz zapisok Leonida Pastemaka." In: Novyj Zumal, 77, 1964, S. 2086.

3 "Fedorov schrieb bisweilen auf Papierfetzen kurze, nichtssagende Thesen, die nur ihm - Fedorov - verstăndlich waren." Angaben von N.N. Cernogubov, mitgeteilt in einem Brief von N.I. Dorofeeva an I.P. Brichnitev, 1913; Archiv von I.P. Brichnirev, GBL f. 516; nach einer Abschrift in Moskauer Privatbesitz. Vgl. auch V.A. KozEnNIKov, Nikolaj Fedorovic Fedorov. Opyt izlotenija ego uČenija po izdannym i neizdannym proizvedenijam, perepiske i ližnym besedam. C. 1, M. 1908, S. 3. Pankratov (wie Anm. 1). A.K. Gornostaev [Gorsku], Pered licom smerti. L.N. Tolstoj i N.F. Fedorov. O.O. [Harbin] 1928, S. 18. S.G. SEmenova, Nikolaj Fedoroviz Fedorov. (Žizn' i uð̌enie)." In: Prometej, t. 11, M. 1977, S. 103. - Fedorov glich darin seinem Zeitgenossen V.V. Rozanov, der nach Auskunft seines Biographen auf winzige Papierfetzen, Buchumschläge und sogar auf Zigarettenschachteln schrieb. E. GolLERBACH, V.V. Rozanov. ZZizn' $i$ twortestuo. Pb. 1922, S. 81. Gleiches wird auch von Chlebnikov berichtet (siehe II: 3.2.2.).

4 G.P. Georgievsku, "L.N. Tolstoj i N.F. Fedorov. Iz liðnych vospominanij." In: Cervertye Tynjanouskie ctenija, Riga 1988, S. 51.

5 Ebd. - Auf diese Weise scheinen zahlreiche Manuskripte in Umlauf gelangt zu sein; wieviele es waren, ist unbekannt. Als nach Fedorovs Tod Koževnikov und Peterson den schriftlichen Nachlab zusammentrugen, erwies sich dieser als weit umfangreicher, als sie zunăchst vermutet hatten.

6 Regelmăßig korrespondierte Fedorov mit Peterson und Koževnikov; die meisten der zahlreichen erhaltenen Briefe datieren aus den 1890er Jahren. Bekannt sind ferner zwei Schreiben an Vladimir Solov'ev, an den Schlachtenmaler V.V. Verestagin (1842-1904) scwie an einige wenige andere Adressaten. Siehe S.G. SEmenova, "Primetanija." In: N.F. Fedorov, Socinenija, M. 1982, S. $695 f$.

7 Siehe S.N. Bulgakov, "ZagadoŁnyj myslitel'. (N.F. Fedorov)." In: DERS., Dva grada. Issledovanija o prirode obšestestvennych idealov. T. 2, M. 1911, S. 261. 
Stil seiner Argumentation wiedergeben. ${ }^{8}$ Peterson berichtet, Fedorov habe ihm diktiert; ${ }^{9}$ auch Koževnikov soll Aufzeichnungen nach Diktat angefertigt haben. ${ }^{10}$

Aus den letzten zehn Jahren seines Lebens sind etwa dreißig veröffentlichte Aufsätze Fedorovs bekannt. Keiner davon trägt seinen Namen. Die meisten erschienen anonym, einige unter Pseudonymen oder mit Initialen gezeichnet in der Moskauer Presse und, häufiger noch, in verschiedenen Provinzblättern. ${ }^{11}$ Die Thematik ist breit: sie reicht von praktischen Vorschlägen zur Verbesserung des Bibliothekswesens und des internationalen Bücheraustausches über die Behandlung historischer Fragen bis zu Stellungnahmen zu aktuellen politischen Ereignissen. Nur selten enthalten diese Aufsätze Anspielungen auf den zentralen Gedanken der Fedorovschen Lehre, das Projekt des obšcee delo; wo sich solche Hinweise finden, bleiben sie knapp und vage, so da $B$ Fedorovs eigentliches Anliegen kaum erkennbar wird. ${ }^{12}$ Die Resonanz auf die zu Leb-

8 Insbesondere S.P. Bartenev, der, wie er versichert, seine Gespräche mit Fedorov "fast wörtlich" wiedergibt (S.P. BARTENEV, "Nikolaj Fedorovi Fedorov. Dva razgovora o voskresenii mertyych." In: Russkij Archiv, 1909, 1, S. 119-122. DERS., "Iz dnevnika S.P. Barteneva." In: Novyj Zumal, 129, 1977, S. 173-182). - Auf mündlichen (und somit nicht nachprüfbaren) Äußerungen Fedorovs basiert ein großer Teil der Studie Koževnikovs (wie Anm. 3).

9 N.P. PETERSON, N.F. Fedorov i ego kniga 'Filosofija obšego dela' v protivopoložnost' uCeniju L.N. Tolstogo 'o neprotivlenii' i drugim idejam naśego vremeni, Vernyj 1912, S. 89.

10 Siehe S.[N.] Bulgakov, "Pamjati Vladimira Aleksandrovið̌a Koževnikova." In: Christianskaja Mysl', 1917, 11-12, S. 77.

11 Siehe die Zusammenstellung bei G. Young, N.F. Fedorov: An Introduction. Belmont, Mass. 1979 , S. 248-250.

Jeweils mehrere Aufsătze Fedorovs erschienen in den Moskauer Tageszeitungen Moskovskie Vedomosti und Russkie Vedomosti, ferner im Russkij Archiv sowie in den Zeitschriften Nauka $i$ Zizn' und Novoe Vremja. In der Provinz erschienen Fedorovs Aufsătze jeweils in der Presse jener Orte, in denen Peterson tătig war und Fedorov als Feriengast weilte: Als Peterson in Mokకansk nahe Penza lebte, publizierte Fedorov in verschiedenen Penzaer Blăttern (1892-93); nachdem Peterson nach Voronež versetzt worden war, erschienen zahlreiche Artikel in der dortigen Zeitung Don (1896-99) und nach Petersons Versetzung nach Aschabad in der dortigen Tageszeitung gleichen Namens (1899-1903) (zu den Veroffentlichungen in Aschabad ausführlich YouNG, a.a.O., S. 237-245). - Fedorovs Veroffentlichungen in der Provinzpresse konnten nur bibliographisch ermittelt werden; sie blieben mir ausnahmslos unzugänglich. $\mathrm{Ob}$ und wieviele Beiträge Fedorovs darüber hinaus noch in der Provinzpresse verofffentlicht worden sind, ist unbekannt, doch sollen es, Peterson zufolge, insgesamt nur wenige gewesen sein. PeTERson (wie Anm. 9), S. 1. Weder Fedorov selbst noch die Herausgeber seiner Schriften haben eine Bibliographie hinterlassen.

12 Man darf vermuten, daß Fedorovs Aufsătze vor dem Abdruck von ängstlichen Redakteuren erheblich überarbeitet wurden, wobei die 'ungewöhnlichen' Gedanken der Zensur zum Opfer fielen. Einen solchen Fall, in dem die Veroffentlichung dann allerdings nicht zustande kam, schildert VA. Koževnikov in einem Brief an A.K. Gorskij. Danach habe Fedorov kurz vor seinem Tod einen Artikel zur Publikation in der religios-philosophischen und symbolistischen Zeitschrift Novyj Put' bestimmt, die von Januar 1903 bis Dezember 1904 erschien und dem Kreis um D.S. Merežkovskij und den Initiatoren der Petersburger Religiös-Philosophischen Versammlungen nahestand. "Dort versprach man, [ihn] zu drucken, jedoch mit Kürzungen, nur auszugsweise das, was 'geeignet' sei und der Lehre einiger anderer Mitarbeiter 'ăhnlich' zu sein schien. Er (N.F.) aber wandte sich zornig gegen eine Kürzung oder Verstümmelung seines Ar- 
zeiten veröffentlichten Schriften war gering. Erst nach Fedorovs Tod wurde sein philosophisches Werk dem lesenden Publikum bekannt.

Im Februar und Juni 1904 erschienen in der von Valerij Brjusov herausgegebenen literarischen Zeitschrift Vesy zwei kurze Artikel - die ersten Veröffentlichungen, die mit Fedorovs Namen gezeichnet waren. Vorangestellt war ihnen jeweils eine Porträtskizze des Philosophen. Der erste Artikel, "Astronomie und Architektur", gibt eine zusammenfassende Übersicht über Fedorovs Projekte zur Beherrschung der Natur (Regulierung des Klimas, Umwandlung der Erde in ein Raumschiff, Wiederherstellung der Verstorbenen, Besiedlung des Weltalls). ${ }^{13}$ Der zweite Artikel, "Über die Schriftzeichen", enthält Betrachtungen über den Niedergang der Kultur am Beispiel des Verfalls der Schrift. ${ }^{14}$

Ebenfalls im Jahre 1904 begann in der Zeitschrift Russkij Archiv eine breit angelegte Studie von V.A. Koževnikov über Fedorov und sein Werk in Fortsetzungen zu erscheinen. ${ }^{15}$ Diese unvollendet gebliebene Arbeit, die 1908 auch in einer Buchausgabe vorlag, ${ }^{16}$ enthält eine Fülle von Zitaten und Fragmenten aus Fedorovs Schriften, die seitdem nicht wieder publiziert worden sind und als verschollen angesehen werden müssen.

Ein Teil von Fedorovs verstreuten Manuskripten war noch zu seinen Lebzeiten von N.N. Černogubov gesammelt und zum Druck vorbereitet worden. Als die Finanzierung durch den Großfürsten Konstantin Konstantinovið gesichert zu sein schien, wandte sich Černogubov im Jahre 1902 an Fedorov mit dem Vorschlag, die Schriften im Moskauer Symbolistenverlag Skorpion, der damals

tikels." Dem Herausgeber des Novyj Put', P.P. Percov, warf Fedorov Intoleranz vor und schlo $B$ zugleich jede Gemeinsamkeit mit den Vertretern des 'neuen religiosen BewuBtseins' aus. Sein Denken folge dem 'alten Weg'; einen "Neuen Weg" zur Wahrheit und zum Sinn des Lebens aber könne es nicht geben. A. Ostromarov [A.K. GoRsku], Nikolaj Fedorovic Fedorov $i$ sovremennost'. Oxerki. Vyp. 2, Charbin 1928, S. 16f. Zum 'neuen religiosen BewuBtsein' und zu Merežkouskij siehe auch II: 2.1.1. - Fedorovs für den Novyj Put' bestimmter Beitrag sowie ein weiterer Artikel über den hl. Serafm von Sarov, den Gorskij in diesem Zusammenhang erwathnt (ebd., S. 17), sind offenbar verschollen.

13 N.F. FEDOROV, "Astronomija i architektura." In: Vesy, 1 (1904), 2, S. 20-24. - Die knappe, gedrăngte Darstellungsweise der Fedorouschen Ideen läßt vermuten, daß der Artikel in der vorliegenden Form nicht von Fedorov selbst verfaBt worden ist. In die Werkausgabe wurde er nicht aufgenommen. Zweifelhaft ist eine Angabe, wonach der Text aus Fedorovs Nachlaß stamme und von Peterson an Brjusov übergeben worden sei. V.E. L'vov, Zagadatnyj starik, L. 1977, S. 175.

14 N.F. Fedorov, "O pis'menach. Posmentnaja stat'ja." In: Vesy, 1 (1904), 6, S. 1-5. - Hierbei handelt es sich um die offenbar vom Herausgeber bearbeitete Fassung eines Auszuges aus einer lăngeren Schrift, die spăter in FOD I, S. 23-25, veroffentlicht wurde.

15 VA. Kozevnikov, "Nikolaj Fedoroviz Fedorov." In: Russkaj Archiv. 42 (1904), kn. 1, vyp. 2, S. 315-325; vyp. 3, S. 390-401; vyp. 4, S. 545-554; kn. 2, vyp. 5, S. 5-26; kn. 3, vyp. 9, S. 106-124; vyp. 10 , S. 225-261. 43 (1905), kn. 1, vyp. 1, S. 180-200; vyp. 2, S. 333-365; kn. 2, vyp. 7, S. 417-470. 44 (1906), kn. 1, vyp. 1, S. 63-102; vyp. 2, S. 260-301. - Eine anonyme Besprechung der ersten Folgen erschien in Vesy, 1 (1904), 6, S. $65 f$. 
von Brjusov geleitet wurde, herauszubringen. ${ }^{17}$ Die Sache zog sich jedoch hin und scheiterte schließlich. Offenbar war auch kein anderer Verleger bereit, das Risiko zu übernehmen. ${ }^{18}$ In einem Brief an Cernogubov vom 22. August 1903 äußerte Fedorov Sorge über den Verbleib der Manuskripte und veranlaßte, daß der größte Teil seines Nachlasses (darunter zahlreiche Briefe) Koževnikov übergeben wurde. ${ }^{19}$ Nach Fedorovs Tod verwahrte Koževnikov die Materialien in seinem Sommerhaus in Jalta auf der Krim. ${ }^{20}$ Dort besuchte ihn während mehrerer Jahre Peterson (auch er besaB einen Teil des Nachlasses), um in gemeinsamer Arbeit Fedorovs Schriften zu entziffern und zum Druck vorzubereiten. Geplant war eine Ausgabe in drei Bänden.

Der erste Band erschien im April $1907^{21}$ in Vernyj ${ }^{22}$ unter dem Titel "Die Philosophie des obščee delo. Aufsätze, Gedanken und Briefe von Nikolaj Fedorovic Fedorov". ${ }^{23}$ Der mehr als siebenhundert Seiten starke Großoktavband hatte eine Auflage von nur 480 Exemplaren. ${ }^{24}$ Auf dem Titelblatt trug er den Vermerk "Nicht zum Verkauf". Er war, wie Peterson in seinem Vorwort schreibt, "... bestimmt zum Versand an öffentliche Bibliotheken, gelehrte Gesellschaften und ähnliche Einrichtungen. Einige verbleibende Exemplare

17 Siehe Semenova (wie Anm. 6), S. 695. Private Mitteilung, Moskau.

18 L.N. Tolstoj ăußerte im Sommer 1903: "Er [Fedorov] hat sehr viel geschrieben, doch sind seine Arbeiten unveroffentlicht; seine Gesinnungsgenossen haben nicht die Mittel, sie zu drucken, und von den Verlegern will es keiner übernehmen." A.B. Gol'DENVEJZER, Vblizi Tolstogo, M. 1959, S. 128; Aufzeichnung eines Gesprăchs in Jasnaja Poljana am 14.7.1903.

19 Koževnikov an Peterson, 20.9.1909, GBL f. 657; Abschrift in Moskauer Privatbesitz. Vgl. A. Ostromarov [A.K. GorSKU], Nikolaj Fedorovic Fedonov. 1828-1903-1928. Biografija. O.O. [Harbin] 1928, S. 19. N.P. PETERSON, "Pis'mo k izdatelju Russkogo Archiva. Po povodu otzyva F.M. Dostoevskogo o N.F. Fedorove." In: Russkij Archiv, 1904, 2, S. 301.

20 Diese und die folgenden Angaben nach einer brieflichen Mitteilung von Ju A. Rodzeviz, einer Enkelin von N.P. Peterson, Frunze 1983; Brief in Moskauer Privatbesitz.

21 Dieses Datum nennt PETERson (wie Anm. 9), S. 74. - 1907 als Erscheinungsjahr ferner ebd., S. 1, 20, 40, 139, 167, sowie KoŽEVNikov (wie Anm. 3), S. V, 300. - Auf dem Titelblatt ist als Erscheinungsjahr 1906 angegeben. So auch die Angabe in Kniznaja letopis', Nr. 9, 8.9.1907, S. 18, Pos. 2718 (alle übrigen dort verzeichneten Titel stammen von 1907!). Die Moskauer Zensurbehorde hatte die Druckerlaubnis bereits am 27.10.1905 erteilt.

22 Heute Alma-Ata. Von 1904 bis 1912 war Peterson Mitglied des dortigen Kreisgerichts.

23 Filosofija obscego dela. Stat'i, mysli i pis'ma Nikolaja Fedorovica Fedorova, izdannye pod redakciej VA. Koteunikova i N.P. Petersona. T. 1, Vernyj: Tipografija Semireそenskogo Oblastnogo Pravlenija. 1906. XII, 731, III, 5 S.

Der Titel geht nicht auf Fedorov zurück - dieser hatte in bezug auf sein Werk zumeist von "Supramoralismus" (supramoralizm), vom "Projekt des obstee delo" oder von der "Lehre der Auferweckung" gesprochen -, sondern stammt von Koževnikov. Peterson war damit nicht einverstanden; Fedorovs Werk sei keine 'Philosophie', kein Lehrgebăude, sondern ein delo. Peterson schlug deshalb als Titel vor: "Prizyv $k$ delu, $k$ obsčemu $i$ edinomu delu vsech ljudej, vsego roda Celovełeskogo v ego sovokupnosti". Aufzeichnung im Peterson-Archiv, GBL f. 657; nach einer Abschrift in Moskauer Privatbesitz. Einig waren sich beide Herausgeber freilich darin, den Begriff 'Auferweckung' im Titel zu vermeiden.

N.P. PETERSON, "Predislovie." In: FOD I, S. XII. 


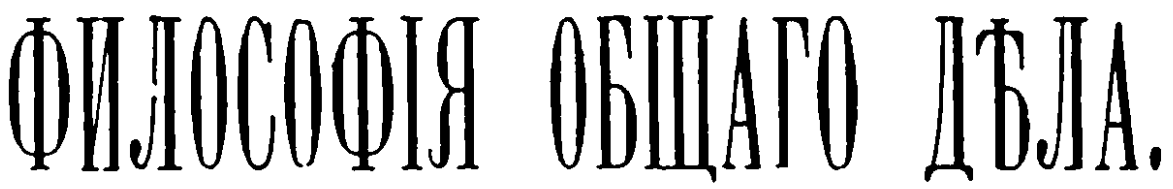

Cmambl, mbcru u nucbma

\section{Николая Өедоровича Өедорова,} иаданныя подъ редакціен

B. А. Кожеввикова В. П. Петерсова.

TOM $\mathrm{B} Y$ I.

$\underline{\text { He }}$ для продамеи.

$\triangle B P \mathscr{H}$

Tunorpaфla Cemptyencxaro O6nacruoro Праanewla

1906. 
werden (unentgeltlich) Interessenten auf Anfrage zugesandt..." ${ }^{25}$ Ausdrücklich wurde - im Sinne Fedorovs - auf jegliche Urheberrechte verzichtet und der Leser aufgefordert, den Inhalt des Buches auf jede nur mögliche Weise zu verbreiten. ${ }^{26}$

Der Band enthält mehrere umfangreiche und in sich abgeschlossene Aufsätze (darunter Fedorovs längste und bedeutendste Schrift "Die Frage nach der Bruderschaft oder der Verwandtschaft...", S. 1-352), in denen Fedorov die Grundgedanken seiner Lehre entwickelt. Die meisten dieser Schriften waren mit Petersons Hilfe in den achtziger und neunziger Jahren entstanden und wurden hier zum ersten Mal veröffentlicht.

Im Jahre 1913 erschien in Moskau der zweite Band der Werke Fedorovs. Er trägt denselben Titel wie Band I, allerdings ohne den Vermerk "Nicht zum Verkauf", ${ }^{27}$ und umfaßt knapp fünfhundert Seiten. ${ }^{28}$ Die Höhe der Auflage ist nicht bekannt. ${ }^{29}$ Im Unterschied zum ersten Band besteht er aus einer Vielzahl zumeist kurzer und oftmals fragmentarischer Abhandlungen und Skizzen, die unter vier Themen geordnet sind: Religion, Philosophie, Regulierung der Natur und Friedensstiftung, Verschiedenes. Sämtliche Schriften wurden erstmals veröffentlicht.

In ihrem Vorwort zum zweiten Band gehen die Herausgeber, Koževnikov und Peterson, auch auf den Zustand des von Fedorov hinterlassenen Materials ein und erläutern die ihrer Edition zugrundeliegenden Prinzipien. Danach handelt es sich bei den im zweiten Band veröffentlichten Schriften zumeist um Skizzen und Entwürfe zu geplanten umfangreicheren Arbeiten. In ihrer fragmentarischen, unbearbeiteten Form seien diese Aufzeichnungen nicht für eine Publikation vorgesehen gewesen. Manche Manuskripte seien, so die Herausgeber, infolge des "nachlässigen Verhältnisses ihres Verfassers zu ihnen" beschädigt, auseinandergerissen und stellenweise schwer zu entziffern gewesen. Eine nachträgliche Bearbeitung habe sich allein schon aus diesen Gründen als unumgänglich erwiesen. ${ }^{30}$

25 Ebd.

26 Ebd., S. XIf.

27 Anzeigen in der Presse (z.B. Voprosy Filosofii i Psichologii, 118, 1913, 3, S. 400) ist zu entnehmen, daB der Band zum - keineswegs hohen - Preis von 2.50 Rubeln angeboten wurde.

28 Filosofija obstego dela. Stat'i, mysli i pis'ma Nikolaja Fedorovica Fedorova, izdannye pod redakciej V A. Kolevnikova i N.P. Petersona. T. 2, Moskva: Pełatnja A. Snegirevoj. 1913. IX, 473 S.

Die Druckerei von A.I. Snegireva druckte die zahlreichen Schriften der von M.A. Novoselov gegründeten und betreuten "Religios-philosophischen Bibliothek", zu der auch Kozevnikov mit mehreren Arbeiten beitrug. Siehe II: 2.2.1. Das Gebăude der Druckerei im Savelovskij pereulok, in dessen Năhe Fedorov lange Zeit gelebt hatte, ist noch erhalten.

29 Sie soll etwas über der des ersten Bandes gelegen haben. SemENOVA (wie Anm. 6), S. 658. Mikulinskij gibt sie mit "etwa 600 Exemplaren" an. S.R. MIKULINSKW, Tak li nado otnosit'sja k nasledstvu?" In: Voprosy Filosofii, 1982, 12, S. 153.

V. KoZzennikov, N. PETERson, "Predislovie." In: FOD II, S. IIIf. 
Die dann im einzelnen erläuterten Editionsprinzipien lassen vermuten, da $B$ die von Koževnikov und Peterson vorgenommenen Eingriffe recht erheblich gewesen sind: So seien wörtliche oder fast wörtliche Wiederholungen weggelassen, ursprünglich separate Ergänzungen und Erläuterungen in den Text aufgenommen und Unterbrechungen durch verbindende Einschübe der Herausgeber ergänzt worden (die, so versichern sie, freilich in jedem Falle als solche gekennzeichnet worden seien). Nicht vermerkt wurde hingegen, welche der Überschriften von Fedorov stammen und welche das Werk seiner Herausgeber sind. Allein schon das von den Herausgebern in ihrem Vorwort Gesagte läßt erkennen, da $B$ die von ihnen besorgte Edition wissenschaftlichen Ansprüchen nicht zu genügen vermag, doch ist eine Überprüfung oder gar die Erstellung einer textkritischen Ausgabe nicht mehr möglich, da keinerlei Manuskripte des ersten und zweiten Bandes der Filosofija obšcego dela erhalten sind. ${ }^{31}$ Wie weitreichend die redaktionelle Bearbeitung der Vorlagen gewesen sein muß, zeigt ein Vergleich jener Passagen, die bereits zuvor von Koževnikov in seiner Studie über Fedorov im Russkij Archiv zitiert worden waren, mit dem entsprechenden Text der Werkausgabe: Sowohl im Satzbau wie auch inhaltlich weichen die Fassungen erheblich voneinander ab, wobei die Textvariante der Werkausgabe gegenüber der von Koževnikov veröffentlichten Fassung 'glatter' wirkt und mithin stärker bearbeitet sein dürfte. ${ }^{32}$

Über Art und Umfang der Materialien, die Koževnikov und Peterson für ihre Werkausgabe zur Verfügung standen, ist kaum etwas bekannt. Ungeklärt ist beispielsweise, welche Schriften ihnen im Original vorlagen und welche nur in Abschriften (von denen es möglicherweise mehrere Varianten gab). Was den Umfang der Materialien betrifft, so hatte Peterson nach dem Erscheinen des ersten Bandes erklärt, der noch unveröffentlichte Nachlaß sei mindestens zweimal so umfangreich wie der bereits gedruckte. ${ }^{33}$ Der zweite Band fiel dann allerdings erheblich schmaler aus. Im Vorwort teilen die Herausgeber mit, mehrere Arbeiten - u.a. über Wagner, Puskkin, Lermontov, Ibsen, Hauptmann, Zola, Bourget, über die Fastenzeit und Ostern - seien verlorengegangen. Was noch aufgefunden werde, solle zusammen mit Fedorovs zahlreichen Briefen sowie eventuell einigen biographischen Daten und Erinnerungen in einem dritten Band veröffentlicht werden. ${ }^{34}$

31 Semenova (wie Anm. 6), S. 658.

32 Tschižewskij, der als erster (und bislang einziger) Zweifel an der Zuverlässigkeit der Werkausgabe Fedorous geăußert hat (D. CYZEvŚKYJ [TSCHZZEWSKU], "Lit erarische Lesefrüchte. Teil 2." In: ZfSIPh, 10, 1933, S. 396-398), gibt Proben eines Vergleichs beider Textvarianten. - Vgl. auch die Textfassung von "O pis'menach" (Anm. 14) mit der entsprechenden Passage in FOD I, S. 23-25.

33 Peterson (wic Anm. 9), S. 20.

34 Kozevnikov, Peterson (wie Anm. 30), S. IV. - Die meisten der in den 1890er Jahren veroffentlichten Zeitungs- und Zeitschriftenartikel Fedorovs sind weder in die beiden Bănde der FOD aufgenommen worden, noch war ihre Publikation im dritten Band vorgesehen, vielleicht, weil die Idee des obšcee delo in ihnen kaum zum Ausdruck kommt. 
Dieser Band ist nie erschienen. ${ }^{35}$ Zwar hatten Koževnikov und Peterson während des Krieges aus Fedorovs NachlaB einen dritten Band der Filosofija obš̌ego dela zusammengestellt, und Koževnikov hatte diesen Band 1916 zum Druck vorbereitet, doch konnte er wegen finanzieller Schwierigkeiten infolge der herrschenden Inflation nicht veröffentlicht werden. ${ }^{36}$ Nach Koževnikovs Tod im Juli $1917^{37}$ befanden sich die Materialien im Besitz von Peterson, doch verhinderten nun die politischen Wirren eine Publikation. Im Zuge der Revolution verlor Peterson sein Amt als Richter am Kreisgericht in Zarajsk und ging nach Zvenigorodka (Gvt. Kiev), wo er am 4. März 1919 starb. $^{38}$

$\mathrm{Zu}$ Beginn der zwanziger Jahre gelangte ein Teil der unveröffentlichten Materialien in Abschrift an eine Gruppe Moskauer Fedorov-Anhänger, die sich zunächst um eine Veröffentlichung in der Sowjetunion bemühten. Nachdem ihre Versuche dort gescheitert waren, gelang es einem Mitglied dieser Gruppe, dem Wirtschaftswissenschaftler N.A. Setnickij, gegen Ende der zwanziger und zu Beginn der dreißiger Jahre von Harbin aus einige kürzere Artikel Fedorovs sowie Auszüge aus seiner Korrespondenz in der westeuropäischen Emigrantenpresse unterzubringen. ${ }^{39}$ Die so veröffentlichten Schriften stellen jedoch nur einen Bruchteil der Materialien dar, die Setnickij zur Verfügung standen. Diese umfaßten, seinen Angaben zufolge, etwa dreihundert Seiten Typoskripte. ${ }^{40}$ Vor seiner Rückkehr in die Sowjetunion übergab Setnickij diese Materialien 1933 dem neueingerichteten Fedorov-Archiv in Prag. ${ }^{41}$

35 Aus den Materialien zu diesem Band wurde wahrscheinlich zunăchst nur das kurze Fragment "Über das Krankenhaus" veroffentlicht. "Iz perepiski N.F. Fedorova. O bol'nice." In: Vselenskoe delo, sb. 1, Odessa 1914, S. 97f. Eine Veroffentlichung Fedorovs in der Zeitschrift Propilei (siehe den Hinweis in Vselenskoe delo, sb. 2, Riga 1934, S. 189) konnte nicht ermittelt werden.

36 Vgl. N.A. SETNICKU, "Vladimir Aleksandrovic Koževnikov. 1852-1917-1927." In: Izv.Jur.Fak., 4 (1927), S. 328. "S" [d.i. N.A. SETNICKU], "Iz perepiski N.F. Fedorova o Turkestane." In: Versty, 3 (1928), S. 278. Burgakov (wie Anm. 10).

37 Vgl. SETNICKU (wie Anm. 36). A. G-v [d.i. A.K. GoRSKU], "Vladimir Aleksandroviz Koževnikov." In: Vselenskoe delo, 2 (wie Anm. 35), S. 179. - Koževnikovs Archiv, das zunăchst von seiner Witwe A.V. Koževnikova verwaltet wurde, befindet sich heute im CGALI (f. 260); über seinen Inhalt ist nichts bekannt. Siehe Lienye archivnye fondy v gosudarstvennych chnaniliszach SSSR. Ukazatel'. T. 1, M. 1962, S. 336.

38 M. P-s. [M.N. PETERson ?], "Nikolaj Pavloviz Peterson." In: Vselenskoe delo, 2 (wie Anm. 35), S. 180.

39 Es handelt sich um folgende Publikationen: "Iz perepiski N.F. Fedorova s V A. Koževnikovym o Turkestane." In: Versty, 3, 1928, S. 278-288. "Iz tret'ego toma 'Filosofii obšego dela'." In: Put', 10, 1928, S. 3-42. "Pis'ma N.F. Fedorova k V.A. Koževnikovu." In: Evrazija, 24 (4.5.1929), S. $7 f$. "Iz posmertnych rukopisej N.F. Fedorova." In: Put', 18, 1929, S. 3-24. "Cto takoe dobro?" In: Put', 40, 1933, S. 3-15. "Iz perepiski s N.P. Petersonom i V.A. Koževnikovym." In: Vselenskoe delo, 2 (wie Anm. 35), S. 149-155.

40 Brief von N.A. Setnickij an V.A. Rjazanovskij vom Mărz 1926 sowie Aufzeichnungen Setnickijs im FAP I, 338. Siehe auch II: 4.2.2.

41 Materiály ke sbomíku Filosofia obšego dela (FAP I, 320). 
Jene (vollständigen) Materialien zum dritten Band der Filosofija obšcego dela, die sich zuletzt im Besitz von N.P. Peterson befunden hatten, galten lange Zeit als verschollen. ${ }^{42}$ Erst als im Laufe der siebziger Jahre die Witwe des Moskauer Sprachwissenschaftlers und Indogermanisten Michail Nikolaevix Peterson (1885-1962), eines Sohnes von N.P. Peterson, auf Betreiben des Moskauer Fedorov-Anhängers A.A. Dorogov das Privatarchiv ihres Schwiegervaters der Handschriftenabteilung der Lenin-Bibliothek übergab, erwies es sich, da $B$ darin neben zahlreichen Zeugnissen zur Wirkungsgeschichte Fedorovs auch die Materialien zum dritten Band der Filosofija obscego dela enthalten waren. ${ }^{43}$ Dabei handelt es sich - bisherigen knappen Angaben zufolge - ${ }^{44}$ um Aufsätze und Fragmente über historische, literarische, philosophische und theologische Themen, die zum Teil in den Originalmanuskripten vorliegen, zum Teil in Abschriften (zumeist von Peterson), und insgesamt mehr als achthundert Blätter umfassen. Hinzu kommen mehr als zweihundert Seiten Briefe, die jedoch nur als maschinenschriftliche Kopien erhalten sind. Von diesen Materialien, unter denen sich die einzigen bislang bekannten authentischen Texte Fedorovs befinden (abgesehen von einigen kleineren Schriften im Archiv Petersons), ${ }^{45}$ ist bislang nur ein geringer Teil veröffentlicht worden. ${ }^{46}$

42 Siehe z.B. N.[M.] ZERNov, "Introduction." In: FOD I, (Reprint 1970): "The third volume was prepared for printing in 1917 but the manuscript was lost after the revolution." Derselbe Autor hatte einige Jahre zuvor erklär: "A second [!] volume was printed on the eve of the revolution and destroyed by the Communists." N. ZERNOV, The Russian Religious Renaissance of the Twentieth Century, London 1963, S. 293.

43 Siehe Zapiski otdela rukopisej, M. vyp. 36 (1975), S. 104; vyp. 37 (1976), S. 170, 178; vyp. 38 (1977), S. 181f.; vyp. 39 (1978), S. 143, 234f. Handschriftenabteilung der Lenin-Bibliothek Moskau: Archiv N.P. Petersona (f. 657). - Das Archiv war mir nicht zugănglich.

M.N. Peterson hatte das von seinem Vater übernommene Archiv mehr als vierzig Jahre lang bewahrt, jedoch über seine Existenz geschwiegen ("... welchen Mutes bedurfte es, die Archive ... offenkundig Verfemter [wie des Philosophen Fedorov] Tausende von Nächten hindurch nicht zu verbrennen, sondern aufzubewahren!" A.S. SOLZENICYN, Archipelag GULag 1918-1956, t. 34, Paris 1974, S. 627). Im Kreise seiner Kollegen - darunter R.O. Jakobson, N.S. Trubeckoj und D.N. Uకakov - war freilich bekannt, daB Peterson den Ideen Fedorovs anhing: Es hieB, er betreibe seine indogermanistischen Studien, um auf diese Weise die Sprache der Vorvăter zu rekonstruieren. A.A. Dorogov an mich, 5.4.1984; Dorogov bezieht sich auf eine Mitteilung von Jakobson. - Zu M.N. Peterson siehe O.S. SIRokov, "Michail Nikolaevi Peterson (k 20-letiju so dnja smerti)." In: Vestmik Moskouskogo universiteta. Ser. 9. Filologija. 1983, 3, S. 57. VA. KóERgINA, "Michail Nikolaevið Peterson (k 100-letiju so dnja roždenija)." In: Ebd., 1985, 6, S. 48.

44 Semenova (wie Anm. 6), S. 658, 689-696. Zapiski (wie Anm. 43), vyp. 39 (1978), S. 143.

45 Die wohl bedeutendste davon wurde bereits veroffentlicht: N.F. FEDOROV, "Faust' Gete i narodnaja legenda o Fauste." In: Kontekst 1975, M. 1977, S. 315-336. Siehe auch S.G. SEMENOVA, "K publikacii stat'i N.F. Fedorova o Fauste." Ebd., S. 311-314, und DIES., "Primetanija." Ebd., S. 336-343.

46 N. FEDOROV, "Proektivnoe opredelenie literatury o 'Mertvych dušach'." In: Literatumaja Ureba, 1982, 3, S. 163-167. S.G. SEMENova, "Primetanija." Ebd., S. 167f. "Iz neopublikovannogo." In: Fedorov (wie Anm. 6), S. 607-654. Semenova (wie Anm. 6), S. 689-696. Ferner die in Anm. 35 und 39 genannten Auszüge aus den Materialien zum dritten Band der FOD. 
Bereits zu Beginn der zwanziger Jahre hatten die Moskauer Fedorov-Anhänger versucht, den ersten und zweiten Band der Filosofija obščego dela in einer Neuausgabe herauszubringen, doch waren sie damit ebenso gescheitert, wie mit ihrem Versuch, einen dritten Band zu veröffentlichen. Auch in diesem Falle gelang es schließlich Setnickij, das Vorhaben wenigstens teilweise zu realisieren. 1928 begann er aus AnlaB des 100. Geburtstags Fedorovs in Harbin eine unveränderte Neuausgabe des ersten Bandes der Filosofija obš̌ego dela in einzelnen Lieferungen zu veröffentlichen. Bis 1930 lagen drei Lieferungen vor, die zusammen etwa ein Drittel des ersten Bandes umfassen; dann mußte Setnickij das Unternehmen aus finanziellen Gründen abbrechen. ${ }^{47}$

Die zweibändige Erstausgabe der Filosofija obšcego dela blieb selten und schwer zugänglich, ${ }^{48}$ bis 1970 in England ein photomechanischer Nachdruck veranstaltet wurde, ${ }^{49}$ dem 1985 eine zweite vollständige Reprintausgabe in der

47 Filosofija obszego dela. Stat'i, mysli i pis'ma Nikolaja Fedorovica Fedorova, izdannye pod redakciej VA. Koževnikova i N.P. Petersona. Izdanie vtoroe. T. I, vyp. 1, s portretom N.F. Fedorova i priloženiem biografizeskogo orerka, sostavlennogo A. Ostromirovym, Charbin 1928, XXX, 38 S. T. I, vyp. 2, Charbin 1929, 75 S. T. I, vyp. 3, Charbin 1930, 102 S.

Die erste Lieferung, die mit einer Auflage von 750 Exemplaren veroffentlicht wurde, enthält ein Bildnis Fedorovs (S. I), ein kurzes Vorwort (S. IIIf.) sowie einen biographischen AbriB (S. V-XX) von A. Ostromirov (Gorskij), der auch als Separatdruck erschienen ist (OsTROMIRov, wie Anm. 19); ferner die Vorworte von Koževnikov und Peterson zur ersten Ausgabe (S. XXIII-XXX). Es folgt der Abdruck des ersten Teils von Fedorovs "Vopros o bratstve..." (auch als Separatdruck erschienen); die Teile 2 und 3 sind in der zweiten und dritten Lieferung enthalten. Die Neuausgabe weicht von der Erstausgabe in der (modernisierten) Orthographie und in der Anordnung des Textes, nicht aber in diesem selbst ab. - Besprechungen dieser Ausgabe: 1. K[OZODOE]V in: Vselenskoe delo, 2 (wie Anm. 35), S. 188. D. CYY̌́Ev'́KYJ [TSCHIZEWSKU] in: Slavische Rundschau, 2, 1930, S. 515f. L. SESTOV, "N.F. Fedorov." In: DERS., Umozrenie i otkrovenie, Paris 1964, S. 125-130.

Uber die Neuausgabe der Filosofija obšcego dela werden bis in die jüngste Zeit immer wieder falsche Angaben gemacht, 2.B.: Bde. I und II seien 1928 und 1930 in Harbin erschienen. V.V. ZENKovsky [ZeN'Kovsku], A History of Russian Philosophy, Bd. 2, New York, London 1953, S. 591f. E. KouTAIssofF, "Some Futurological Aspects of Fedorov's 'Philosophy of the Common Cause'." In: Russian Literature Triquarterty, 12, 1975, S. 407. - Bd. II, vyp. 2, sei 1929 in Harbin erschienen. Literatumoe nasledstwo, t. 70 [Gor'kij i sovetskie pisateli. Neizdannaja perepiska.], M. 1963, S. 587. - Etwa ein Drittel des ersten Bandes sei in der Sowjetunion nachgedruckt worden. Koutalssoff, a.a.O., S. 406. - Eine dritte Ausgabe in drei Bänden sei 1928 in Harbin erschienen; eine weitere in einem Band 1932 von Ostromirov herausgegeben worden. N. Bosco, "Introduzione." In: Occidente, cristianesimo e progresso. Antologia dagli scritti di C. Leont'ev e N. Fedorov. Torino 1981, S. 91. - Fedorovs Werk sei in zwei Bănden in Harbin erschienen. A. TEsKeY, Platonov and Fyodorov, Amersham 1982, S. 154. - Nach der Revolution sei in Harbin eine gekürzte Version der FOD veroffentlicht worden. L. KOEHLER, in einer Rez. des vorgenannten Werkes in: SEEJ, 27, 1983, 2, S. 265.

48 Mitunter gelangen Exemplare der FOD in den Moskauer Antiquariatshandel: Im Mărz 1984 wurde der 2. Band der FOD im "Dom knigi" am Kalinin-Prospekt für 225 Rubel angeboten, im Mărz 1985 konnte man dort beide Bănde für 425 Rubel kaufen. - Die năchst erreichbaren Exemplare (die auch für diese Arbeit benutzt wurden) befinden sich in der "Sammlung Lieb" der Universitătsbibliothek Basel (Signatur: Lieb Eb 214).

49 Nachdruck von Gregg International Publishers Ldd., Westmead, Farnborough, Hants. Der erste Band enthălt ein kurzes Vorwort in Englisch von N.[M.] Zernov. 
Schweiz folgte..$^{50}$ In der Sowjetunion erschienen erstmals im Jahre 1979 kurze Auszüge aus Fedorovs Schriften in einer vom Verlag Molodaja gvardija herausgebrachten Anthologie zum russischen utopischen Denken. ${ }^{51}$ Im Sommer 1982 veröffentlichte dann der Moskauer Verlag Mysl' in seiner Reihe Filosofskoe nasledie eine umfangreiche - wenn auch mehrfach zensierend gekürzte - Auswahl aus Fedorovs Werk, insbesondere aus dem ersten und zweiten Band der Filosofija obšcego dela sowie aus bislang unveröffentlichten Materialien. ${ }^{52}$

Die nachfolgende Darstellung der Grundzüge der Filosofija obšego dela stützt sich im wesentlichen auf die Gesamtheit der postum veröffentlichten Schriften Fedorovs. ${ }^{53}$ Die Frage der Authentizität kann dabei nur angesprochen, nicht aber geklärt werden. Für die Geschichte der Rezeption ist sie ohne Bedeutung: Fedorovs Werk hat in der Fassung gewirkt, wie sie von seinen Anhängern erstellt wurde, fragmentarisch, bearbeitet und offenbar nicht autorisiert.

50 Editions L'Age d'Homme, Lausanne.

51 N.F. FEDOROV, "Filosofija obšego dela." [Auszüge aus FOD I und II] In: Velnoe solnce. Russkaja social'naja utopija i nauZnaja fantastika vtoroj poloviny XIX - nacala XX veka. $\mathrm{M}$. 1979, S. 390-398. (Anm. und Kommentar von S. Kalmykov [d.i. S.B. DžimBinov], ebd., S. 3337, 426f.). - Diese Veroffentlichung stieB auf heftige Kritik. So wies V.P. Pazilova darauf hin, da $B$ der Herausgeber in einem Auszug von 57 Zeilen aus der Filosofija obšcego dela, den er unter dem Titel "Die Notwendigkeit des Vordringens in den Weltraum" präsentierte, 44 Zeilen gestrichen habe, in denen von der religiosen Begründung dieses Vordringens die Rede sei. Die auf 8 Seiten veroffentlichten Textauszüge wiesen insgesamt 18 Auslassungen auf. Geschehen sei dies mit der Absicht, Fedorov als kühnen utopischen Denker erscheinen zu lassen und dabei die religiose Tendenz seines 'Projekts' zu verschleiern. V.[P.] PAZıLovA, "Proekt 'ob\$̌kego dela' N.F. Fedorova." In: Nauka i Religija, 1984, 4, S. 39. Der Science-fiction Autor und OkkultismusSpezialist E.I. Parnov nahm selbst an den 'gereinigten' Passagen aus Fedorovs Werk Anstoß und hielt dem Herausgeber vor, die "idealistischen, offen religiðs-utopischen Anschauungen Fedorovs" würden "praktisch ohne Kommentar dem jungen Leser an den Kopf geworfen." E. [I.] PARnov [in dem Artikel] "Fantastika: krizis žanra?" In: Literatumaja Gazela, 9, 27.2.1980, S. 4. Vgl. auch die scharfe Kritik von JU.A. LUKIN, "Bescennoe oružie." In: Voprosy Literatury, 1980,4, S. $125 f$.

52 FEDOROV (wie Anm. 6). - Zusammengestellt, eingeleitet und kommentiert wurde die Ausgabe, die dank der Protektion des Kosmonauten V.I. Sevast'janov zustande gekommen sein soll, von der Moskauer Fedorov-Spezialistin S.G. Semenova unter der Redaktion von A.V. Gulyga. Die Auflage wurde mit 50.000 angegeben, doch gelangte nur ein Teil davon in den Handel; ein großer Teil der Auflage soll nach einer Intervention von M.A. Suslow und P.N. Fedoseev zurückgezogen worden sein. Vgl. V.[F.] PRJACHIN, V.[I.] SEVAst'janov, "Istoriju tvorit relovek." In: Moskva, 1988, 8, S. 167. A.[V.] GulYGA, "Vladimir Sergeevit Solov'ev." In: Literatumaja Gazeta, 3, 18.1.1989, S. 5. Siehe auch Einleitung, Anm. 16 und 17. - Scharf kritisiert wurde die Veroffentlichung u.a. von Mikulinsku (wie Anm. 29), S. 151-157. Vgl. auch die Rezensionen von V.[V.] LEPACHIN in: Acta Universitatis Szegediensis. Dissertationes Slavicae. 15, Szeged 1982, S. 195-207. B.[B.] VAl' in: Russkaja Mysl', 3484, 29.9.1983, S. 12; 3485, 6.10.1983, S. 12. E.[A.] VAGIN in: Veze, 11, 1983, S. 117-135 (übt scharfe Kritik an den Kürzungen und Auslassungen, wodurch "der wissenschaftliche Wert dieser Ausgabe gleich Null" sei; S. 133). E. Koutalssoff in: SEER, 62 (1984), 1, S. 98-101. - Mitte der achtziger Jahre wurde in den USA eine Imitation der Moskauer Ausgabe hergestellt. - Zu geplanten neuen Ausgaben der Werke Fedorovs siehe Einleitung Anm. 25.

53 Nur vereinzelt wurden zu Lebzeiten veröffentlichte Aufsătze sowie unveroffentlichte Materialien aus Moskauer Privatbesitz herangezogen. 


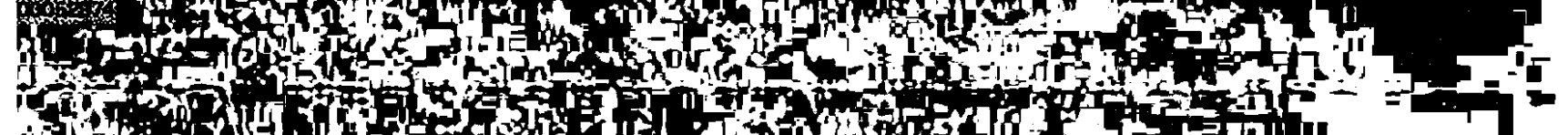

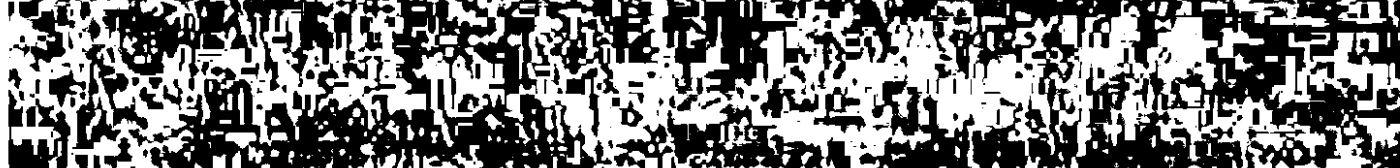

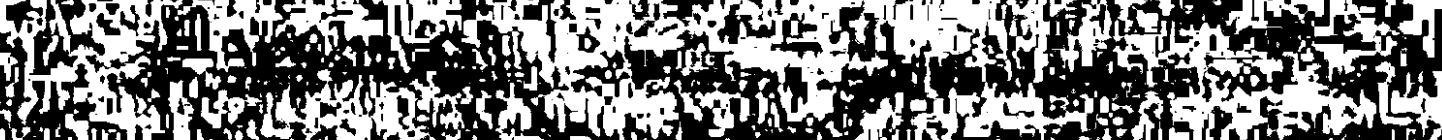

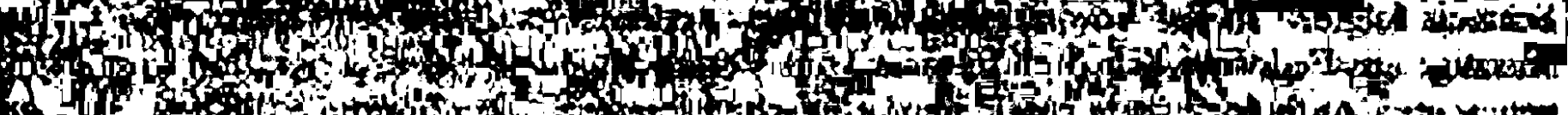

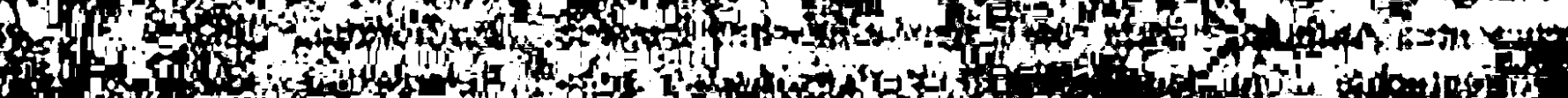
if

If $x$ (n)

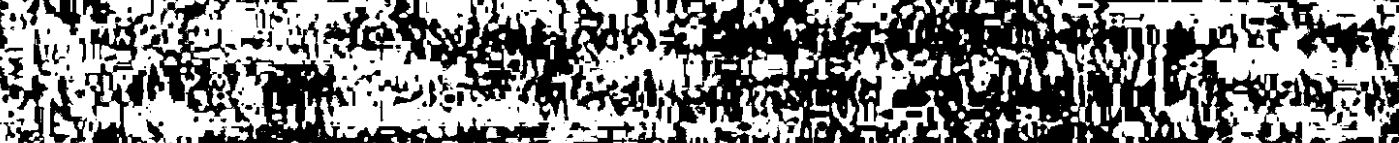

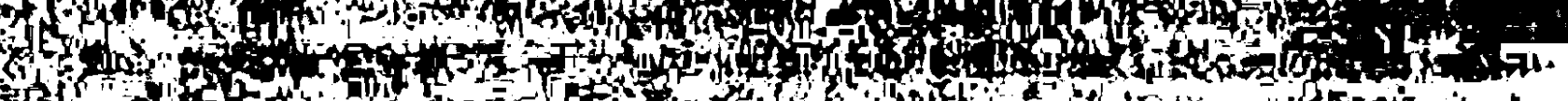

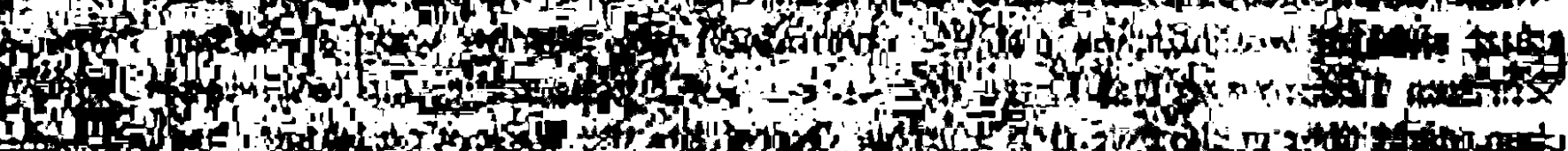

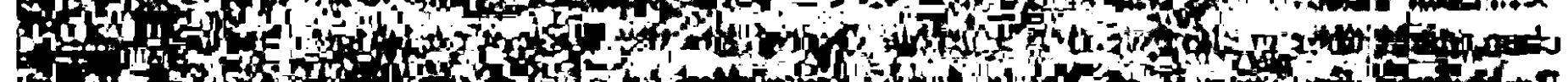
(5)

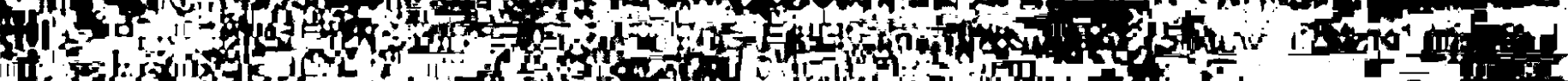
IIf

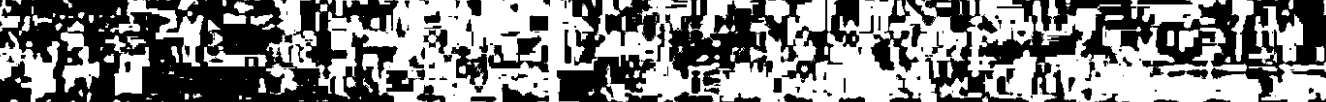

gi

its

fow

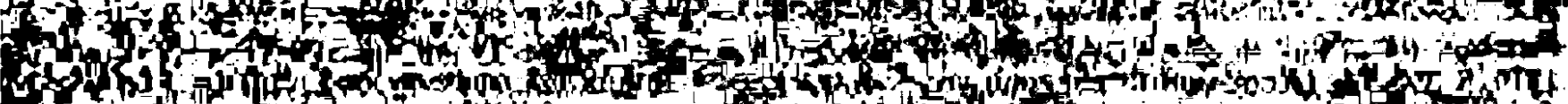

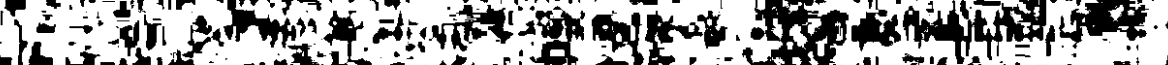
in

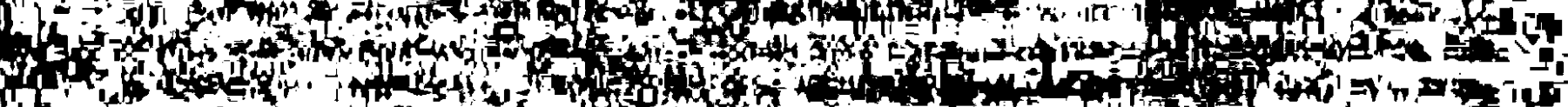

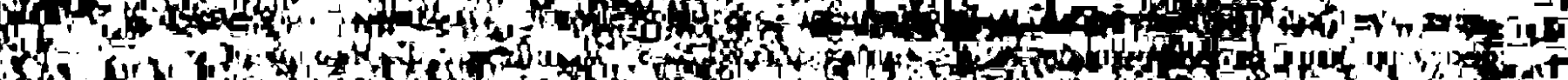

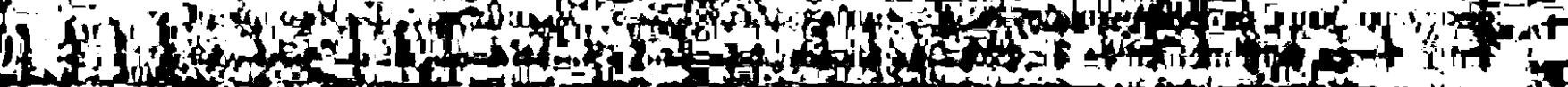

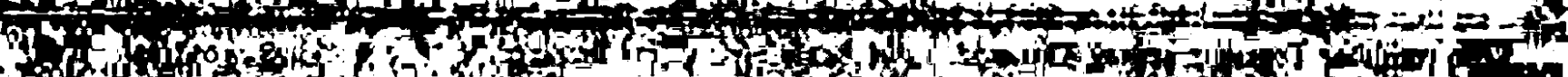
Shi

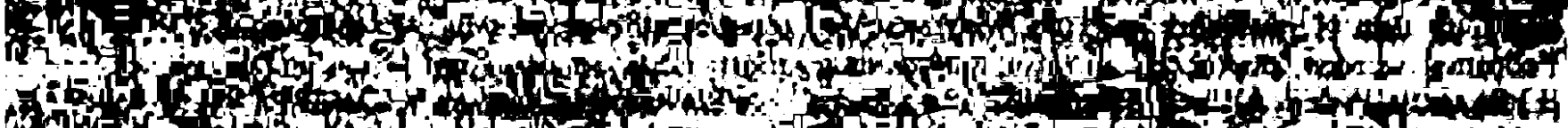

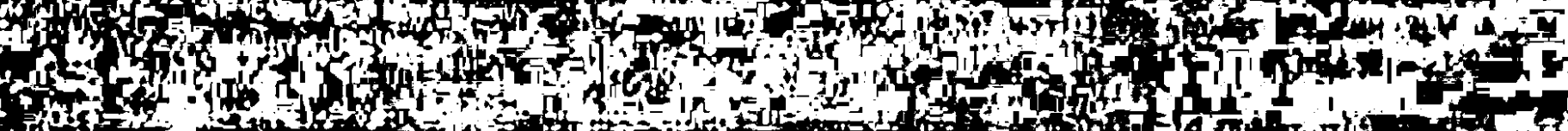

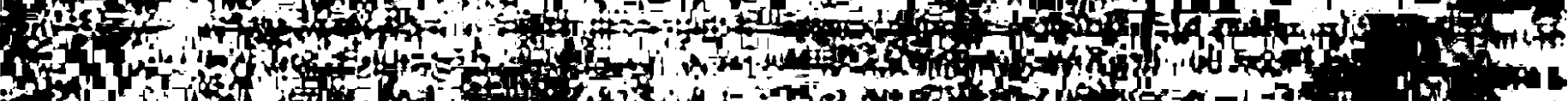

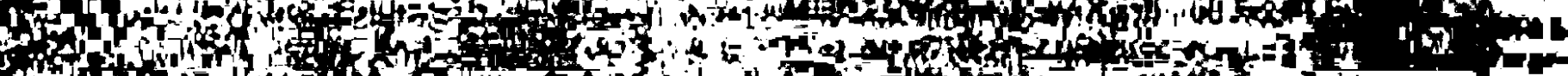

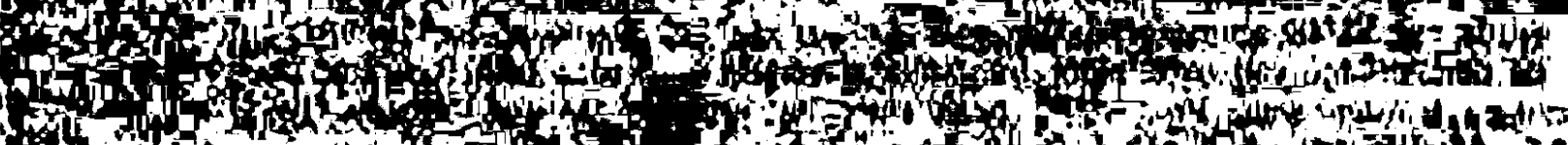

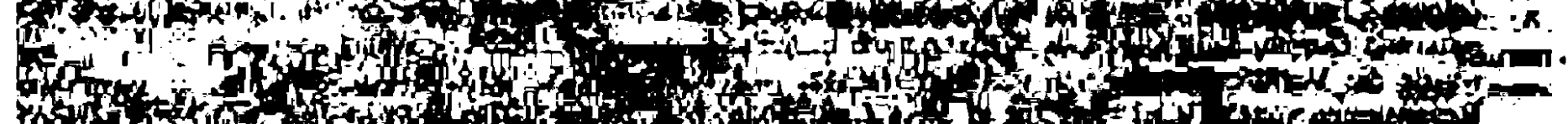

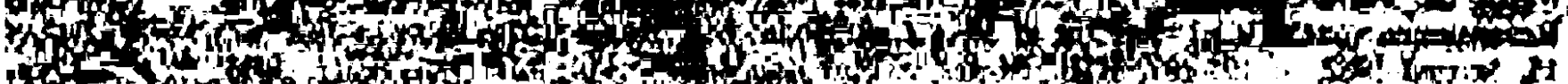

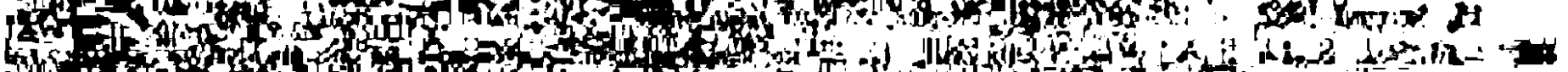

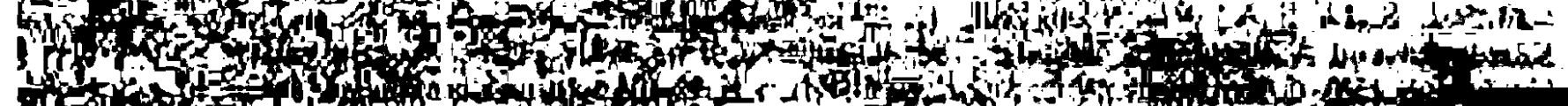
1.5

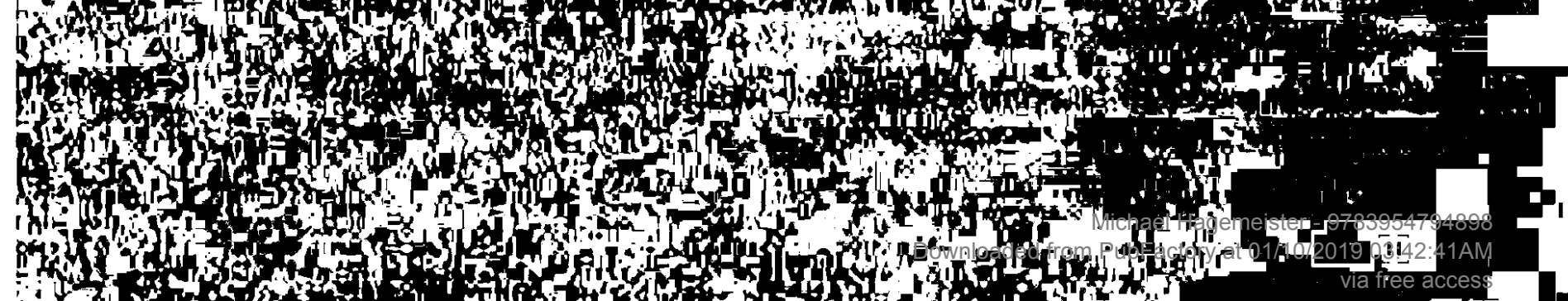




\section{GRUNDZÜGe der FILOSOFuA OBSCEGo deLA}

\subsection{Die 'Philosophie' des obšce delo}

Fedorovs Werk, wie es unter dem Titel Filosofija obšcego dela als Sammlung nachgelassener Schriften vorliegt, ist kein philosophisches System im herkömmlichen Sinne, keine einheitliche und kohärente Lehre. ${ }^{1}$ Es ist aber auch

1 Fedorov selbst hat sein Werk nie als 'Philosophie' bezeichnet (worunter er isoliertes, selbstgenügsames und folgenloses Denken verstand), sondern abwechselnd als "Lehre" (uCenie), "Projekt" (proekt) oder "Aufruf" (prizyv). - Der Titel Filosofija obšzego dela stammt von Koževnikov; siehe I: 2. Anm. 23. Im Rahmen dieser Arbeit wird damit Fedorovs Werk bezeichnet, wie es in der von seinen Anhăngern herausgegebenen Gestalt vorliegt und rezipiert wurde.

Zu Fedorovs Werk liegen zahlreiche Arbeiten von unterschiedlichem Umfang und Gehalt vor; nachfolgend seien die wichtigsten neueren Veroffentlichungen genannt (altere Arbeiten werden im 2. Teil behandelt).

A) Im Westen erschienene Arbeiten: E. KouTAussoff, "Some Futurological Aspects of Fedorov's 'Philosophy of the Common Cause'." In: Russian Literature Triquarterty, 12, 1975, S. 393 407. T.D. ZaKYDALSKY, N.F. Fyodonov's Philosophy of Physical Resurrection, Ph.D. diss. Bryn Mawr 1976 [Masch.]. Beschrănkt sich auf eine - allerdings umfassende und akribische - Untersuchung des zentralen Gedankens der Auferweckung; fuhrt den Nachweis, daB Fedorovs Auffassung von Mensch und Natur sich als materialistisch interpretieren läBt. ST. LUKASHEVICH, N.F. Fedonov (1828-1903). A Study in Russian Eupsychian and Utopian Thought. Newark, London 1977. Gescheiterter Versuch, Fedorovs Lehre zu systematisieren. (Siehe auch unten Anm. 3). L. Koeriler, N.F. Fedorov: The Philosophy of Action, Pittsburgh, Pa. 1979. Behandelt Leben, Werk und Wirkung; oberflăchlich und fehlerhaft, über weite Strecken lediglich unkritisch zusammengestellte Zitatensammlung. Siehe meine Rezension in: ZfSIPh, 43 (1983), S. 203-210. G.M. YoUNG, Nikolai F. Fedorov: An Introduction, Belmont, Mass. 1979. Hervorgegangen aus einer 1973 vorgelegten Dissertation des Verfassers; bislang beste Einfuhrung in Leben, Werk und Wirkungsgeschichte. Siehe meine Rezension in ZfSIPh, 44 (1984), S. 440-449.

B) Arbeiten sowjetischer Autoren: Von den zahlreichen Veroffentlichungen der Moskauer Fedorov-Spezialistin S.G. SEMENOVA sind vor allem zu nennen: "Nikolaj Fedoroviz Fedorov. (Žizn' i utenie)." In: Prometej, 11, M. 1977, S. 86-105. "Tvortestvoto na Żivota. (Filosofskoestetizeskite idei na N.F. Fodorov)." In: Literatuma Misăl, 22 (1978), 3, S. 88-107. "N.F. Fedorov i ego filosofskoe nasledie." In: N.F. FEDOROV, Sodinenija, M. 1982, S. 5-50. - P.K. GRECKO, G.L. EPISKOPOSOV, "N.F. Fedorov: Filosofija dela kak delo filosofii." In: Vestnik MGU, ser. 7 (filosofija), 1981, 6, S. 66-74. Untersuchung der Filosofija obscego dela unter theoretisch-methodologischem Aspekt; hervorgehoben wird die Originalităt ihrer "kreativ-okologischen, negentropisch kosmischen Orientierung" (S. 74). V.P. PAzILOVA, Kriticeskij analiz religiozna-filosofskogo učenija N.F. Fedorova, M. 1985. Hervorgegangen aus einer 1981 vorgelegten Dissertation der Verfasserin; bemüht sich um den Nachweis, daß Fedorovs Lehre eine reaktionăre, religiose Utopie darstelle. Bislang einzige in der Sowjetunion erschienene Monographie zu Fedorov. A.M. [steht für Anatolij Sergeevi飞 Mel'nikov, d.i. archiepiskop Antonij; wirkl. Verfasser N.K. GAVRJUSIN], "Voskresenie taemoe ili voschišaemoe? (O religioznych vozzrenijach N.F. Fedorova)." In: Bogoslouskie trudy, 24, 1983, S. 242-259. Eine mit großem Aufwand an Gelehrsamkeit betriebene Diffamierung Fedorovs; gibt die ablehnende Haltung orthodoxer Kirchenkreise wieder.

Bei der folgenden Darstellung der Grundzüge der Filosofija obsčego dela muB auf eine (kritische) Wiedergabe der vorliegenden, zum Teil erheblich divergierenden Interpretationen weitgehend verzichtet werden. Umstritten ist vor allem die Frage, ob Fedorovs Werk als christliche oder religiose Philosophie zu verstehen sei (so z.B. Koehler, Pazilova) oder ob es sich um eine 
nicht, wie es zunächst scheinen mag, eine Sammlung gelegentlicher disparater Äußerungen zu unterschiedlichsten Themen. Fedorov war kein Systemdenker, sondern ein Problemdenker. Bei allem, was er schrieb, kreiste sein Denken um immer dieselbe Idee: die Abschaffung des Todes, die Auferweckung der Verstorbenen und die totale Verwandlung der Welt als obšcee delo, d.h. als Aufgabe und Werk der gesamten vereinigten Menschheit. ${ }^{2}$ Diese Idee bildet das Zentrum von Fedorovs Denken und stiftet die innere, gleichsam organische Einheit seines gesamten Werks. ${ }^{3}$

im Grunde positivistische oder materialistische Lehre handele (so z.B. Zakydalsky) oder gar um eine "reaktionäre Hăresie" mit gnostischen, okkultistischen und magischen Elementen (so A.M. [Gavrjuక̌in]).

2 Fedorovs zentraler Begriff obšcee delo lăßt sich im Deutschen nicht eindeutig wiedergeben: obšcij bedeutet sowohl 'gemeinsam', 'gemeinschaftlich' wie auch 'allgemein', 'allumfassend'; delo bedeutet 'Tat', 'Werk', 'Sache', aber auch 'Angelegenheit', 'Aufgabe'. (Im Englischen beispielsweise wurde obszee delo mit Common Task, Common Cause, Universal Task oder General Deed wiedergegeben). Wegen dieser - von Fedorov absichtlich benutzten - Bedeutungsbreite bleibt der Begriff obšcee delo hier und im folgenden unübersetzt. - Als einziger hat bislang Young Sprache und Stil Fedorovs nahher untersucht und dabei der weit verbreiteten Auffassung widersprochen, der Verfasser der Filosofija obšego dela sei schriftstellerisch ausgesprochen unbegabt gewesen. Young (wie Anm. 1), S. 78-85.

3 Seit S.N. Bulgakovs Rezension aus dem Jahre 1908 gehören Klagen über den unsystematischen Charakter der Filosofija obšzego dela und die damit verbundenen Schwierigkeiten der Darstellung und Interpretation zum festen Bestandteil der einschlăgigen Literatur.

Einige Autoren gehen dabei so weit, Fedorovs Werk jeden wissenschaftlichen Wert abzusprechen und seinen Verfasser für geistesgestort zu erklären: "Schon allein der Stil seiner Schriften, der schulmeisterliche Ton und die langweilige Ausfuhrlichkeit, mit der er vollkommen absurde Dinge darstellt, lassen an eine Geistesstörung (pomesatel'stwo) denken. Irgendwo zwischen wunderlichem Sehertum und vulgărstem Positivismus, neben dem sich Cernyševskijs Positivismus geradezu als geistiger Höhepunkt ausnimmt, ist diese um vier Jahrhunderte verspătete Naturphilosophie entstanden." B. Chazanov [d.i. G.M. Fasbusovic], "Ne pojmet i ne ocenit." [1984] In: DERS., Idušij po vode, München 1985, S. 12. - Siehe auch die scharfe Ablehnung Fedorovs durch den Philosophen A.F. Losev (II: 2.2. Anm. 52) und den Publizisten P.B. Struve (II: 4.3. Anm. 119).

Andere zeigen sich irritiert: "Je mehr wir uns in die Welt Fedorovs vertiefen, desto großere Gefahren, ihn mißzuverstehen, liegen vor uns. Er war ein Denker von einer eisernen Konsequenz, und dies fuhrte ihn zu solchen Folgenungen, die wegen ihrer Kühnheit und Ungewohnlichkeit die ganze Aufmerksamkeit des Lesers fesseln, zu einem wahren Skandalon werden und alles andere zu vergessen zwingen. Infolgedessen entsteht bei seiner Lektüre ein Zerrbild seiner Weltanschauung, indem das Geniale durch das Paradoxale ersetzt wird." LA. ZANDER, "Technik und Glaube. Eine Skizze aus russischer Religionsphilosophie." In: Studium Generale, 15 (1962), 5, S. 327.

Jeder Versuch einer systematischen Darstellung begegnet schier unüberwindbaren Schwierigkeiten: "Gegen die Auffassung, Fedorovs Lehre sei ein System von Ideen, das sich logisch analysieren und darstellen lasse, stehen die Unbestandigkeit und Inkonsequenz in der Terminologie, ihre Unklarheit und Subjektivităt, sowie eine gewisse Verworrenheit und Unentschiedenheit selbst in den Grundthesen. Dies liegt daran, daB der Denker sich auf die Kraft intuitiver Einsicht und nicht auf die Schärfe rationalen Denkens verlassen hat. Am allerwenigsten hat $\mathrm{Fe}$ dorov an die Stimmigkeit, Folgerichtigkeit und Kohärenz seiner Lehre gedacht. Zwar unternahm er Versuche, seine Ideen systematisch darzulegen, doch kann man diese kaum als gelungen ansehen. Mal bewegt sich das Denken des Philosophen in konzentrischen Kreisen, dann wieder in spiralformigen, es verweilt, bildet Abschweifungen, die einen eigenen Wert darstel- 
So vielfältig und oftmals verwirrend sich die Filosofija obš̌ego dela im einzelnen präsentiert, als Ganzes und ihrer Intention nach ist sie praktische Philosophie, Anleitung zum richtigen (sittlichen) Handeln, mithin eine Art Ethik (Fedorov selbst sprach von "Supramoralismus" [supramoralizm]). Sie erhebt den Anspruch, eine eindeutige, allgemein-verbindliche und begründete Antwort auf die Fragen zu geben, worin das 'höchste Gut' und damit das letzte Ziel menschlichen Handelns besteht, wie dieses Ziel verwirklicht werden kann und warum es verwirklicht werden muß. Die Klärung dieser Perspektive gibt die Antwort auf die Frage nach dem letzten Sinn des menschlichen Daseins.

Heute geht es darum, endlich den verlorenen Sinn des Lebens wiederzufinden, das Ziel zu erkennen, um dessentwillen der Mensch existiert, und das Leben dementsprechend zu gestalten. Dann wird sich alle Verwirrung von selbst aufosen, alle Sinnlosigkeit des heutigen Lebens, die imstande ist, einen in Schrecken zu versetzen und in Verzweiflung zu stürzen. (...) Wenn wir nicht begreifen, worin unsere Pflicht und unser Ziel besteht, dann müssen wir offensichtlich zugrunde gehen, und man muß annehmen, daß unser Untergang nahe ist. (...) Worin besteht nun aber die Pflicht eines Wesens, das nichts Eigenes besitzt, dem weder sein Leben gehorn, noch die Bedingungen dafür, dem all dies gegeben wurde, gegeben ohne eigene Anstrengung, das nicht einmal ein Recht auf sein, wie wir zu sagen pflegen, eigenes Leben hat? Worin kann das Ziel eines sterblichen Wesens bestehen? (II, 237)

Diese Sätze markieren den Ausgangspunkt des Fedorovschen Denkens: die Beschreibung der Grundbefindlichkeit des Menschen und die Frage nach dem Sinn seines Daseins und dem Ziel seines Handelns. Fedorovs Antwort - zugleich der zentrale Gedankengang seines Werks - läßt sich kurz nachzeichnen.

Der Mensch ist sterblich. Angesichts der Realität des Todes besitzt er nichts, nicht einmal 'sein' Leben. Alles ist ihm gegeben und kann ihm jederzeit wieder genommen werden. Ein solches Dasein ist unfrei, entwürdigend und sinnlos. Ziel eines sterblichen Wesens muß deshalb sein, den Tod zu überwinden und unsterblich zu werden.

Ursache der Sterblichkeit ist die Abhängigkeit von der Natur, genauer, dem vernunftlosen, chaotischen Zustand, in dem diese sich befindet. Ihn gilt es zu

len, es wiederholt sich und kehrt schließlich wieder 'in seine Kreise' zurück. Den Typ oder den Stil des Fedorovschen Denkens könnte man vielleicht mit einem Ausdruck P. Florenskijs als 'kontrapunktisch' bezeichnen." V.[V.] LEPACHIN, [Rez.] "N.F. Fedorov. Sołinenija. M. 1982." In: Acta Universitatis Szegediensis. Disserationes Slavicae. 15, Szeged 1982, S. 205.

Scheitern mußte der mit großem Aufwand unternommene Versuch von St. Lukashevich, Fedorovs Gedankenwelt durch Unterscheidung von "Stromungen", "Rubriken" und "Felder" und deren anschließende Verknüpfung zu strukturieren. Das Ergebnis ist ein hochkompliziertes Schema, das sich freilich in den Schriften Fedorovs nicht belegen läßt und zudem jeder inneren Logik entbehrt. LUKASHEVICH (wie Anm. 1). Siehe dazu die Rezension von T.D. ZaKYDALSKY in: SEEJ, 23 (1979), 2, S. 273f. Hingegen ist es - wie Zakydalskys Arbeit beweist (ZAKYDALSKY, wie Anm. 1) - durchaus sinnvoll, anhand bestimmter Ansătze Fedorovs eine kohărente Lehre in dicsem Falle die einer materialistischen Auferweckung - auszuarbeiten. Dabei ist freilich stets anzugeben, welche Gedanken Fedorovs aufgenommen und 'konsequent' weiterentwickelt und welche als nicht integrationsfahig beiseite gelassen werden.

4 Im Tex dieses Kapitels werden Zitate aus der Filosofija obscego dela nur durch Angabe des Bandes (mit romischen Ziffern) und der Seitenzahl (mit arabischen Ziffern) nachgewiesen. 
überwinden, und zwar durch Erkennen und Lenken, d.h. durch "Regulieren" (reguljacija), durch das "Hineintragen von Wille und Vernunft in die Natur" (vnesenie v prirodu voli i razuma). Allein der Mensch als wollendes und vernunftbegabtes Wesen ist dazu imstande. Er allein vermag durch bewußte, zielgerichtete ("projektive") Arbeit alles bislang Natur-Gegebene und darum Hinfällige einschließlich seiner selbst - in Vernunft-Geschaffenes, "Künstliches", und damit Unvergängliches zu verwandeln. Indem der Mensch sich selbst und die äußere Natur vollständig reguliert und in ein Kunst-Werk verwandelt, beseitigt er jegliche Trennung, Zerstörung und Vergänglichkeit und damit jede Begrenzung in Raum und Zeit.

$\mathrm{Da} B$ er dazu auch verpflichtet ist, das nachzuweisen ist das Hauptanliegen der Fedorovschen Lehre. Angesichts der Realität des Todes ist die menschliche Existenz nämlich nicht nur sinnlos, sondern auch unsittlich: solange der Mensch sein Leben empfängt, anstatt es selbst zu schaffen, nimmt er es anderen und wird dadurch schuldig an ihnen. Leben "auf den Gräbern vergangener Generationen" aber ist verwerflich, die Behauptung eines 'Fortschritts' angesichts der erbrachten Opfer zynisch und absurd. Der Mensch hat deshalb die moralische Pflicht, Leben zu schaffen und es denen zurückzugeben, von denen er es empfangen hat, d.h. er hat die "Pflicht zur Auferweckung" (dolg $k$ voskreseniju). ${ }^{5} \mathrm{Da}$ alle Menschen Söhne (und Töchter) sind, d.h. ihr Leben empfangen haben, erstreckt sich diese Pflicht ausnahmslos auf die gesamte Menschheit.

Daraus erwächst die Forderung an alle Lebenden (die "Söhne"), sich "brüderlich" zu vereinigen, um mit rationalen, d.h. wissenschaftlich-technischen Mitteln alle Verstorbenen (die "Väter") physisch wiederherzustellen. Auferweckung, die vom Menschen bewußt und mit Kunst bewerkstelligte, allmählich fortschreitende, immanente Wiederherstellung aller untergegangenen $\mathrm{Ge}$ schlechter, tritt an die Stelle der unbewußten, ziellosen, 'natürlichen' Fortpflanzung (sowie der passiven Erwartung einer transzendenten Auferstehung), die den Zustand blinder Naturverfallenheit perpetuiert und schließlich in den Untergang (oder zur "Auferstehung des Zorns" und zum Gottesgericht) führt. Auferweckung aller und vollständige Regulierung und Verwandlung der Natur, die den Tod endgültig ausschließt, bedingen sich gegenseitig; das eine kann nicht ohne das andere vollbracht werden, und keines von beiden darf isoliert angestrebt werden. Nur die allumfassende Gemeinschaft der Menschheit (einschlieBlich aller Verstorbenen) ist imstande, das Universum zu vollenden, d.h. in ein vollkommenes Kunstwerk zu verwandeln, wie Vollkommenheit und Unsterblichkeit nur dann sittlich gerechtfertigt sind, wenn alle ohne Ausnahme daran teilhaben und so das geschichtlich akkumulierte Unrecht und Leiden aufgehoben wird. Fedorovs innerweltliches Paradies, beruhend auf der ver-

5 Mit voskresenie bezeichnet Fedorov die aktive immanente Aufenweckung aller Menschen im Unterschied zur passiven transzendenten Auferstehung (woskresenie) und Errettung der Auserwahlten durch Gott. - In der Literatur zu Fedorov wird diese terminologische Unterscheidung nicht immer beachtet. 
wirklichten Einheit aller Menschen (vsěedinstvo), ${ }^{6}$ ist mithin vollkommen: von allen für alle geschaffen, kennt es keine 'Verdammten', keine 'Opfer der Geschichte'.

Mag das Ziel, so Fedorov, auch unerreichbar sein, "wissend, daß dies die einzige Aufgabe ist, die dem menschlichen Leben Sinn verleiht (edinstvennoe delo, osmyslivajušče Žizn' Celoveka), müssen wir sie angehen".7

\subsection{Die Begründung des obšcee delo}

\subsubsection{Die Diskrepanz zwischen der "Welt, wie sie ist" und der "Welt, wie sie sein soll"}

Wiederholt ist bemerkt (und kritisiert) worden, daß die theoretische Basis für Fedorovs praktische Philosophie, sein kühnes Projekt zur Erlösung der gesamten Menschheit, nur sehr unvollkommen ausgearbeitet ist und zahlreiche Unstimmigkeiten, ja Widersprüche aufweist. Dies dürfte nur zu einem geringen Teil auf die Umstände der Überlieferung zurückzuführen sein, in der Hauptsache aber darauf, da $B$ Fedorov gar nicht die Absicht gehabt hatte, seinen Aufruf zum gemeinsamen Handeln durch eine ausgeklügelte Theorie abzusichern. Fedorov wandte sich an alle Menschen; was er sagte, mußte deshalb für alle verständlich und akzeptabel sein. Die Chancen dafür aber waren um so größer, je offener, skizzenhafter seine theoretischen Ausführungen waren. Wahrscheinlich sollte die Aufgabe, eine 'endgültige' Fassung der Philosophie des obšcee delo zu formulieren, der gemeinsamen Arbeit künftiger Generationen überlassen bleiben. Fedorov, so scheint es jedenfalls, hat dazu nur einen ersten Entwurf liefern wollen. Dennoch beruht seine Lehre - bei aller 'utopischen' Offenheit ihrer

6 Fedorovs Begriff des ustedinstvo meint die zu venwirklichende Einheit aller Menschen, die Einheit des Menschengeschlechts, und unterscheidet sich - sichtbar nur in der alten Orthographie von Solov'evs useedinstuo (hen kai pan, Einheit von allem), der ursprünglichen, dann verlorenen und in einem kosmogonischen und theurgischen ProzeB wiederherzustellenden Einheit der Schopfung. Siehe FOD I, S. 71. Solov'ev hatte den Begriff useedinstvo in die russische philosophische Terminologie eingeführt und in den Cienija o Bogocelovecestve (1877-1881) ausführlich entwickelt. Siehe zuletzt N.F. UTKINA, "Tema vseedinstva v filosofii Vl. Solov'eva." In: Voprosy Filosofii, 1989, 6, S. 59-75.

7 Fedorov zitiert nach S.[P.] BARTENEv, Nikolaj Fedorovic Fedorov. Dva razgovora o voskreß̌nii mertvych." In: Russkij Archiv, 47 (1909), 1, S. 121. Vgl. auch DERs., "Iz dnevnika S.P. Barteneva." In: Novyj Zumal, 129, 1977, S. 175. - N.N. Cernogubov faBte Fedorovs Anliegen so zusammen: "Fedorov war Atheist; nahe waren ihm Schopenhauer und ahnliche Denker, doch gefiel ihm nicht das Ende ihrer Theorien, das Eintauchen ins Nichtsein. So darf man es nicht machen, sagte er, man muB alles versuchen, und wenn es dann nicht gelingt, so ist das etwas anderes. Dabei riskieren die Menschen überhaupt nichts, denn im außersten Fall werden sie sterben... Seine einzige Hoffnung setze er nicht auf Gott und auch nicht auf die Krafte der Natur, sondern auf die Menschen, auf ihre Auferstehung." Angaben von N.N. Cernogubov, mitgeteilt in einem Brief von N.I. Dorofeeva an I.P. Brichnirev, 1913; Archiv von I.P. Brichnitev, GBL f. 516; nach einer Abschrift in Moskauer Privatbesitz. 
Begriffe - auf klar formulierten Grundsätzen, die als nicht weiter begründete Prämissen seines Denkens hervorgehoben werden müssen.

Die "Welt, wie sie ist", liegt im argen. In ihr walten die zerstörerischen Kräfte einer blinden Natur und treiben sie in den Untergang. Das Prinzip der Natur ist Trennung, Zerklüftung in Raum und Zeit, sein Ausdruck der Tod. Rettung erwächst der Welt durch den Menschen, der sich erhebt und dabei seine Schranken wahrnimmt, zugleich aber sich seiner selbst als Selbst- und Weltschöpfer bewußt wird. Der Mensch besitzt eine Vorstellung von der vollkommenen Ganzheit der Welt, der "Welt, wie sie sein soll"; er besitzt den Willen zum Leben und kennt die Furcht vor dem Tod, er empfindet Trauer über die Trennung und den Verlust und hat das Gefühl der Schuld gegenüber den Verstorbenen. Aus alldem entsteht in ihm der Wunsch nach unbegrenztem Leben mit allen Menschen: "Das Leben ist das Gute, der Tod das Böse. Die Rückerstattung des Lebens durch alle Lebenden an alle Verstorbenen um des ewigen Lebens willen ist Gutes ohne Böses ... ist das höchste Gut." (II, 122) Auf dem Weg der Verwirklichung des höchsten Gutes vereint der Mensch alles, was getrennt und zerstreut ist, und verleiht allem einen Sinn, den es von sich aus nicht hätte. Dem Menschen ist aufgegeben, durch sein Tun die Welt vor dem Untergang zu bewahren und zur Vollendung zu führen.

Am Anfang des Fedorovschen Philosophierens steht der Mensch, steht die Bestimmung seines Wesens, seiner Stellung und Beziehung zur Welt. Fedorovs dynamische Anthropologie bildet die Grundlage seiner praktischen Philosophie: Als Naturwesen ist der Mensch sterblich, als Vernunftwesen selbsterschaffen und damit potentiell unsterblich. Als verwandtes Wesen ist der Mensch schuldig, als fühlendes, denkendes und wollendes Wesen jedoch fähig, diese Schuld zu begleichen und ein freies, vollkommenes Wesen zu werden; nicht durch eine von seinem Willen unabhängige Evolution, sondern als Ergebnis willentlicher, kollektiver Regulation. Voraussetzung dafür ist die Überwindung der herrschenden Trennungen, insbesondere der Trennung von Denken und Handeln. Dies geschieht im obšcee delo.

\subsubsection{Das Verhältnis zwischen Mensch und Natur}

Der Mensch ist Teil einer Natur, in der Blindheit, Unvernunft und Chaos herrschen; einer Natur, die infolgedessen sinn- und ziellos schafft und wieder zerstört, gebiert und tötet. Alles, was von dieser Natur hervorgebracht wird, trägt in sich bereits den Keim des Todes und der Vernichtung.

Von dieser Natur empfängt der Mensch, worauf er nicht verzichten kann: Nahrung, Gesundheit, Leben. Von ihr ist er mithin gänzlich abhängig, ihrer blinden Willkür nahezu schutzlos ausgeliefert. Mögen sich einzelne auch gegen die Naturgewalten, gegen Mißernten und Seuchen, Hunger und Krankheit er- 
folgreich wehren, so erfährt doch ein jeder sein ohnmächtiges Ausgeliefertsein spätestens in der Stunde des Todes. ${ }^{8}$

Unter den herrschenden Verhältnissen ist das menschliche Leben ein ständiger Kampf um Selbsterhaltung, um ein befristetes, widerrufliches Dasein. Zuletzt aber unterliegt der Mensch den zerstörerischen Kräften der Natur:Der Tod bleibt Sieger und beweist damit die Abhängigkeit des Menschen von einer ihm feindlichen Macht.

Die drei großen Probleme der Menschheit, nämlich Hunger (Ernährungsproblem), Krankheiten (Gesundheitsproblem) und die ungleiche Verteilung der Güter (die "soziale Frage"), sind letztlich Folgen dieser Abhängigkeit; sie alle lassen sich auf ein Grundproblem reduzieren, das Problem von (gegebenem) Leben und Tod.

Tod ist die Folge von Hunger, entweder im Sinne eines Mangels an Nahrung oder ihres volligen Fehlens. Mangel [an Nahrung] aber fuhrt zum Kampf, der das Leben der Menschen begrenzt... Tod entsteht auch aus Krankheit im Sinne eines mehr oder weniger schådlichen Einflusses der Natur (Tod als Zersetzung, Infektion). Ganz allgemein ist der Tod die Folge der Abhängigkeit von der blinden Gewalt der Natur, die innerhalb und außerhalb von uns wirkt... Wir aber akzeptieren diese Abhăngigkeit und unterwerfen uns ihr. $(I, 276)$

Solange der Tod nicht als das Grundübel erkannt und angegangen wird, kann es keinen wahren Fortschritt geben, bleiben alle sozialreformerischen Bemühungen, alle Verheißungen eines freien und glücklichen Daseins letztlich eitel und sinnlos.

Es ist unmoglich, die [materielle] Not als Ursache [für menschliches Leid] vom Tode zu trennen; doch eine solche unmogliche Aufgabe steltten sich alle Reformer einschließlich der Sozialisten. Jene, die den Sierblichen zu einem Glücklichen machen wollten, venwechselten Glück und Reichtum und kannten gerade nicht die tatsăchliche allgemeine Ursache der menschlichen Note. (II, 204; Hervorhebung im Orig.)

Man muB vor allem anerkennen, daB man durch keinerlei gesellschaftliche Umstrukturierungen das Los des Menschen verbessern kann; das Obel liegt viel tiefer, das Ubel liegt in der Natur selbst, ihrer Unbewußtheit (bessoznatel'nost'), das Obel liegt in der Geburt und, untrennbar damit verbunden, im Tod. (I, 320)

[Die tiefsten Ursachen] der Unordnung (neustrojstro) in der Welt und unter den Menschen ... liegen nicht in den Beziehungen der Menschen zueinander, sondern in den Beziehungen der Natur zu den Menschen und der Menschen zur Natur. (II, I88)

Die Natur ist dem Menschen feind, doch auch der Mensch, der um sein Leben kämpfen muß, steht der Natur in blinder Feindschaft gegenüber, was sich darin äußert, daß er sie rücksichtslos ausplündert und zerstört. Dadurch vermehrt er nicht nur seine Abhängigkeit und somit sein Elend, er fördert auch die chaotischen Kräfte innerhalb der Natur, die auf einen Untergang der Welt zutreiben. lypse - Fedorows formelhafte Bezeichnung der Grundübel, denen die Menschheit ausgesetzt ist. 
... die Welt geht dem Ende entgegen, und der Mensch befordert durch sein Tun noch das Herannahen dieses Endes, denn die Zivilisation, die ausbeutet, nicht aber wiederherstellt, kann kein anderes Ergebnis zeitigen als die Beschleunigung des Endes. (I, 209)

Schon mehren sich die Anzeichen für ein Wachsen des Chaos und ein Nahen des Endes: die Wälder werden zerstört, der Boden verliert seine Kraft, Wüsten dringen vor, das Klima gerät durcheinander, es kommt zu Überschwemmungen und Dürrekatastrophen, zu "meteorischen Pogromen", und, in der Folge davon, zu verheerenden Hungersnöten. ${ }^{9}$ - Doch liegt in alldem auch eine Mahnung an den Menschen, eine Aufforderung, sich auf seine universale Aufgabe zu besinnen.

Der Mensch ist ein Naturwesen, d.h. in seinem hinfälligen Organismus selbst ein Teil der zerstörerischen Natur. Jedoch unterscheidet er sich von der äußeren Natur wesentlich dadurch, daß er Vernunft (razum) und Bewußtsein (soznanie), Willen (volja) und Gefühl (Cuvstvo) besitzt. Diese Eigenschaften hat der Mensch nicht von der äußeren Natur empfangen - in ihr waren und sind sie nicht vorhanden -, sondern er hat sie im ProzeB der Menschwerdung selbst geschaffen als Mittel, um sich im Daseinskampf gegen die blinden, vernunftlosen Naturkräfte zu behaupten.

Von Natur aus benachteiligt (sušcestvo obdelennoe), schutzlos und hinfällig und in einer ihm feindlichen Umwelt ständig vom Tode bedroht, war der Mensch gezwungen, selbsttätig Fähigkeiten und Verhaltensweisen zu entwickeln, die sein Überleben ermöglichten und absicherten.

Schutzlos Kalte, Hunger und Krankheiten ausgesetzt, verspürte der Mensch bei jedem Schritt die Nahe des Todes, und so wurde er von einem geborenen (iz rozdennogo) zwangslaufig (ponevole) zu einem schaffenden (sozidajuscim) [Wesen] - zu einem Erbauer seines eigenen Korpers -, und er wurde genotigt, seinen EinfluB immer weiter auf die auBere Welt auszudehnen, die ihn mit Hunger, Seuchen und Tod schlägt. Der Mensch, ohnmăchtig von Natur aus, ist măchtig durch Arbeit und Anstrengung. $(I, 456) .^{10^{8}}$

9 Als Beispiel für einen "schrecklichen meteorischen Pogrom" (strašnyj meteoriceskij pogrom) nennt Fedorov immer wieder die durch anhaltende Dürre hervorgerufene Mißernte des Jahres 1891, die an der Wolga und in ZentralruBland zur schlimmsten Hungersnot des Jahrhunderts geführt hatte. Siehe z.B. FOD I, S. S1f. - Zur "Plündenung" der Wălder und den dadurch hervorgerufenen Klimaverănderungen siehe FOD I, S. 54. Fedorov folgt hier (wie auch in anderen Zusammenhăngen, oft jedoch ohne dies anzugeben) den Ausfuhrungen von V.N. Karazin (17731842), einem vom Geist der Aufklarung geprägten Gelehrten, Erfinder und Staatsmann, der bereits in den ersten Jahrzehnten des 19. Jahrhunderts vor der Vernichtung des Waldes und den Folgen fur Klima und Bodenbeschaffenheit gewamt hatte. Um die Waldbestănde RuBlands zu schonen, hatte Karazin einen Apparat zur Branntweinherstellung entwickelt, der mehr Alkohol abgab, dabei aber erheblich weniger Brennmaterial verbrauchte. Siehe A.G. SUUSARSKU, V.N. Karazin, ego naulnaja i obstestvennaja dejasel'nost', Char'kov 1955, S. 52-54, 61.

10 Ausfuhrlich zum ProzeB der Menschwerdung als "Selbsterschaffung" FOD II, S. 260-270, 396f. Fedorovs Theorie über den Zusammenhang von Menschwerdung und der Selbst- und Welter- 
Das, wodurch der Mensch zum Menschen wurde, ist also nichts Gegebenes, Angeborenes (darovoe-roždennoe), sondern etwas Erarbeitetes, Selbstgeschaffenes (nečto trudovoe, samim sozdannoe) und damit etwas Künstliches (iskusstvennoe).

Der Mensch ist nicht nur eine Hervorbringung der Natur, sondern auch ein Werk oder eine Schopfung der Kunst. (II, 239)

Der Prozeß der Menschwerdung wird demzufolge beschrieben als Prozeß der bewußten Selbsterschaffung (samosozdanie) des Menschen. Der erste und für den weiteren Verlauf dieses Prozesses entscheidende selbsterschaffende Akt war der "Aufstand" (vosstanie) des Menschen gegen die Schwerkraft, die Selbsterschaffung seiner aufrechten Haltung (vertikal'noe položenie), der erste Sieg über die im wörtlichen Sinne eigene Hinfälligkeit. ${ }^{11}$

Die aufrechte Haltung ist bereits nicht mehr eine Gabe der Geburt (dar rozdenija) ... sie ist bereits das Ergebnis einer ursprünglichen Selbsttătigkeit (pervonačal'noj samodejatel'nosti) und die notwendige Bedingung weiterer Selbsttătigkeit. (II, 266)

Ursprünglich zum Schutz vor Gefahren (als "Wächterhaltung", storoževoe položenie) und im Protest gegen den Tod (als "Gebetshaltung", molitvennoe položenie) angenommen, setzte die aufrechte Haltung die Hände frei, verwandelte sie in Arbeitsorgane und ermöglichte im weiteren Verlauf der Selbsterschaffung des Menschen die Ausbildung des Denkens, des bewußten "Begreifens" und zielgerichteten "Handelns".

In dieser Haltung [der aufrechten] erarbeitete (yyrabotal) sich der Mensch Organe der Selbsttatigkeit ... und wurde ein handelndes, arbeitendes Wesen. Eine kleine Verănderung des Organs, das den Tieren zum Greifen dient, hatte groBte moralische Folgen. Mit Hilfe dieses Organs brauchte der Mensch sich nicht länger mit Fertigem, Gegebenem zu begnügen, mit dem, was ist, sondern begann, den Gedanken zu fassen von dem, was sein soll, was die Welt sein soll und was er selbst. Mit den Organen des Handelns und der Fortbewegung erschien das BewuBtsein des Ziels. (II, 204; Hervorhebungen im Orig.) 12

zeugung durch Arbeit gleicht der marxistischen Theorie der Anthropogenese, wie sie bereits in den Frühschriften von Marx und dann besonders in der Deutschen Ideologie und in Engels' Studie Anteil der Arbeit an der Menschwerdung des Affen dargelegt ist. Siehe auch unten Anm. 16 und 19.

11 In der Schwerkraft außert sich für Fedorov das universelle Prinzip des Todes: Fallen deutet auf Hinfalligkeit, Naturverfallenheit; das Tier bewegt sich in der Horizontalen, der Tote liegt, wăhrend sich der Lebende im Protest und im Kampf gegen den Tod erhebt. Die Grabmaler der Menschen - vom einfachen Stein bis zur Pyramide - bedeuten ursprünglich die Wiederaufrichtung eines Gefallenen, d.h. eines Toten, und zeugen damit vom "Aufstand" und vom scheinbaren Sieg über den Tod. An diese Tradition erinnert auch die Orthodoxie, indem sie - im Unterschied zum Katholizismus und besonders zum Protestantismus - im Gottesdienst das Stehen verlangt. Vgl. FOD I, S. 413; II, S. 242.

12 Siehe auch FOD I, S. 102. - Die entscheidende Bedeutung des aufrechten Ganges und der Freisetzung der Hănde für die Entwicklung des menschlichen Gehirns und der Denkfahigkeit - und damit für die Menschwerdung - ist oft beschrieben worden; so z.B. von Herder im 3. und 4. Buch seiner Ideen zur Philosophie der Geschichte der Menschheit (1784-1791): "Mit dem aufgerichteten Gange", dem Merkmal des Lebendigen ("kein todter Korper kann aufrecht stehen..."), "wurde der Mensch ein Kunstgeschopf; denn durch ihn, die erste und schwerste 
Infolge dieser "Erhebung über die Natur" trennten sich Ich- und Weltbewußtsein, wurde die gegenständliche Außenwelt zum Objekt. ${ }^{13}$ Der Mensch nahm geistig vorweg, was er dann in die Wirklichkeit übersetzte. Er wurde fähig, sich das Ziel seines Begehrens und Sehnens auszumalen als ein besseres Etwas, ein Ganzes, das schließlich die Gestalt eines schlechthin Vollkommenen annahm. Der Mensch gewann die Vorstellung von der "Welt, wie sie sein soll". Mit der Erweiterung seines Gesichtskreises aber wurden ihm die Zerrissenheit der gegenwärtigen Welt sowie seine eigene Unvollkommenheit und Abhängigkeit schmerzlich bewußt.

Die aufrechte Haltung ist der erste Ausdruck des Bestrebens, die Welt als ein Ganzes (kak celoe) zu betrachten. Sie machte es moglich, die Einheit zu empfinden und zu begreifen und zugleich mit dem ganzen eigenen Wesen die Trennung, den RiB und den Tod wahrzunehmen. (II, 263)

Alle Entdeckungen, alles, was der Mensch in seiner neuen Haltung (der aufrechten) erfuhr, brachte ihn zum BewuBtsein seiner Sterblichkeit, denn Sterblichkeit ist der gemeinsame Ausdruck für alle Leiden, die den Menschen bedrïcken... (II, 262)

Wie Hunger und Krankheit, so ist auch die Sterblichkeit des Menschen, seine Begrenztheit in Raum und Zeit (ograniCennost' $i$ vremennost'), Ausdruck seiner Abhängigkeit von der blinden, vernunftlosen Natur. Während sich der Mensch aber die Beherrschung und Überwindung der natürlichen Notwendigkeit zum Ziel setzte, war er nur allzu schnell bereit, seine Endlichkeit - und damit das Grundübel in der Welt, den Tod - als wesentliche, unüberwindbare Notwendigkeit anzusehen und hinzunehmen. ${ }^{14}$ Die Feststellung, da $B$ alle Menschen sterblich seien, ist jedoch lediglich eine induktive - und deshalb nicht absolut zu setzende - Folgerung aus der Beobachtung, daß die Lebenden Söhne verstorbener Väter sind. Aus dem empirischen Faktum des Todes folgt keineswegs, da $B$ der Tod zum Wesen des Menschen gehört. In Wahrheit ist der Tod das Produkt von Faktoren, die es zu beherrschen gilt; als solcher aber markiert er lediglich eine wissenschaftlich-technische Grenze, nicht jedoch eine ontologische:

Kunst, die ein Mensch lernet, wird er eingeweihet, alle zu lernen und gleichsam eine lebendige Kunst zu werden." J.G. HeRDER, Sämtliche Werke, hg. von B. Suphan, Bd. 13, Berlin 1887, S. 111, 137. Ober den Vorgang selbst schreibt Teilhard de Chardin in seinem Hauptwerk Le Phénomene Humain (1947): "Dank der Zweibeinigkeit, welche die Hănde frei machte, konnte das Gehirn großer werden; ihr ist auch zu verdanken, daB sich zugleich auch die Augen auf der verkleinerten Gesichtsflache einander nahern und nun beginnen konnten zu konvergieren und zu fixieren, was die Hănde ergriffen, annăherten und von allen Seiten vorzeigten: das Nachdenken selbst in eine äußere Geste übersetzt!" P. TEILHARD DE CHARDIN, Der Mensch im Kosmos, München 1969, S. 171. Siehe auch O. SPENGLER, Der Mensch und die Technik, München 1931, S. 26-36.

13 Siehe FOD II, S. 269 .

14 Siehe FOD I, S. 276. - Dabei ist es unerheblich, ob der Tod resigniert hingenommen, als notwendig anerkannt oder gar freudig begrüBt wird (als "Sănger des Todes" nennt Fedorov u.a. Leopardi; FOD I, S. 91). Jede Haltung gegenüber dem Tod, die nicht aktiver Kampf ist mit dem Ziel, ihn vollstăndig zu überwinden, bedeutet Todesvergottung" (ein Begriff, den Anhănger Fedorovs in den 1920er Jahren geprägt haben; siehe II: 4.1.). 
Der Tod ist eine Eigenschaft, ein Zustand, hervorgerufen durch Ursachen, nicht jedoch eine Qualităt, ohne die der Mensch nicht mehr wăre, was er ist und was er sein soll. (I, 287; Hervorhebung im Orig.)

Als Naturwesen (geboren) ist der Mensch abhängig, unfrei, unvollkommen und sterblich; als Vernunftwesen (selbstgeschaffen) wird ihm dieser Mangel bewußt, wie auch dessen Ursache - die Abhängigkeit von der vernunftlosen Natur.

Diese Abhängigkeit kann indessen - wie der bisherige Proze $B$ der Menschwerdung zeigt - gemindert und schließlich sogar überwunden werden durch "Selbsterschaffung", d.h. durch die Ersetzung alles Natur-Gegebenen durch Vernunft-Geschaffenes oder, mit den Worten Fedorovs,

... die Umwandlung alles Geborenen, alles von selbst Entstandenen, Erzeugten und deshalb Sterblichen in Erarbeitetes (trudovoe) und deshalb Unsterbliches. $(1,500)^{\mathfrak{B}^{3}}$

Nur durch vernunftgelenkte Arbeit an sich selbst und an der äußeren Natur kann sich der Mensch Freiheit verschaffen gegenüber den blinden, zerstörerischen Naturkräften und damit seine "Bestimmung" (naznacenie) verwirklichen,

... ein freies und folglich selbstgeschaffenes Wesen zu sein, da nur ein selbstgeschaffenes Wesen frei scin kann. (II, 239)

Für den Menschen bedeutet das, seinen hinfälligen, weil naturgegebenen Organismus so umzugestalten, daß er von einem "Produkt blinder, unbewußter Evolution" (II, 124) zu einer "Schöpfung der Kunst" (II, 239) wird, zu einem neu geschaffenen, vollständig von Vernunft geleiteten Organismus (organizm upravljaemyj razumom, vossozdanny; II, 124).

Selbsterschaffung mit dem Ziel, Vollkommenheit und Freiheit zu verwirklichen, kann sich jedoch nicht auf den Menschen beschränken; da dieser selbst ein Teil der Natur ist, bleibt seine Umgestaltung und Vervollkommnung untrennbar mit der Umgestaltung und Vervollkommnung der Natur verbunden:

15 Vgl. auch FOD II, S. 396 .

16 Hier wie auch an anderen Stellen gibt es erstaunliche Berührungspunkte zwischen Fedorov und dem jungen Marx. In den (1844 entstandenen und 1932 erstmals veroffentlichten) Pariser Manuskripten schreibt Marx im Hinblick auf die "Selbsterzeugung" des Menschen durch Arbeit: "Ein Wesen gilt sich erst als selbstaxndiges, sobald es auf eignen Füßen steht, und es steht erst auf eignen Füßen, sobald es sein Dasein sich selbst verdankt. Ein Mensch, der von der Gnade eines andern lebt, betrachtet sich als ein abhängiges Wesen. Ich lebe aber vollstăndig von der Gnade eines andern, wenn ich ihm nicht nur die Unterhaltung meines Lebens verdanke, sondern wenn er noch außerdem mein Leben geschaffen hat, wenn er der Quell meines Lebens ist, und mein Leben hat notwendig einen solchen Grund auBer sich, wenn es nicht meine eigne Schöpfung ist." K. MARX, F. ENGELS, Werke, Erganzungsband, 1. Teil, Berlin 1968, S. 544f.; Hervorhebungen im Orig. - In der Konsequenz geht Fedorov dann freilich weit über Marx hinaus. 
Der Mensch ist nicht allein eine Hervorbringung der Natur, noch erschafft er die Natur oder sich selbst unabhăngig von der Natur. Er ist von Natur aus unvollendet (nedosozdannyj) und aufgerufen, sich zu vollenden (dosozdat'), indem er die Natur und sich selbst in der Natur neu schafft. ${ }^{17}$

Der Mensch ist der Teil der Natur, der sich - im Unterschied zur sogenannten äußeren Natur - durch Bewußtsein und Vernunft auszeichnet. Anders gesagt: Im Menschen ist die Natur zu Bewußtsein gelangt, zum Bewußtsein ihrer selbst, das aber heißt angesichts von Tod und Zerstörung - zum Bewußtsein ihrer Unvollkommenheit, ihrer Destruktivität und des damit verbundenen drohenden Untergangs.

Im Menschen wurde sich die Natur des Ubels des Todes bewuBt, erkannte sie ihre eigene Unvollkommenheit. (II, 239) ${ }^{18}$

Im Menschen hat die Natur jedoch nicht nur begonnen, sich selbst zu erkennen, sondern auch - durch vernunftgeleitetes Handeln - sich selbst zu regulieren und zu vervollkommnen, d.h. Blindheit und Unvernunft als Ursachen von Tod und Zerstörung zu beseitigen.

[Die Natur] ... hat in uns bereits begonnen, sich selbst zu erkennen und teilweise schon sich zu regulieren, und wenn man [wie Nietzsche] von ihr Katastrophen erwartet und die Vernichtung der Welt, so wird dies nur durch unsere Schuld geschehen, weil wir uns noch nicht zu der Tat der Erkenntnis dieser Macht und zu ihrer Regulierung vereinigt haben. Wie aber konnte eine so seltsame, um nicht zu sagen dumme Lehre aufkommen, von einem passiven Verhăltnis vernunftbegabter Wesen zu einer blinden, irrationalen Macht, die uns in Wirklichkeit gar nicht feindlich ist, sondern nur so erscheint, die uns gar nicht feindlich sein kann, weil sich in uns ja ihrer selbst bewruBt wird (...), und wenn sie uns schadet, so [tut sie dies] nicht bewnBt, sondern nur infolge ihrer Blindheit und unserer eigenen Schuld, unserer Untătigkeit und Uneinigkeit, weil wir, die wir das BewuBtsein dieser Macht sind, uns bis heute nicht vereint haben, um sie zu erkennen, d.h. in volles BewuBtsein zu versetzen und sie zu regulieren, um sie von einem scheinbaren Feind, einem temporăren Feind, in einen ewigen Freund zu verwandeln. (I, 430; Hervorhebungen im Orig. $)^{19}$

17 Fedorov nach V.[A.] KožnvnIkov, "Nikolaj Fedorovix Fedorov." In: Russkij Archiv, 44 (1906), 1, vyp. 2, S. 278; ohne Nachweis.

18 Vgl. auch FOD I, S. 98, 294, 311. - Den Gedanken, wonach die unvollkommene Natur im Menschen zum BewriBtsein (ihrer selbst) gelangt sei, konnte Fedorov von Aleksandr Herzen übernommen haben. Herzens EinfluB auf Fedorov erwăhnt VA. KozEvNIKov Nikolaj Fedorovic Fedonov. Opyt izlotenija... C. 1, M. 1908, S. 56. - In dem 1846 veroffentlichten achten Brief seiner berühmten Pis'ma ob izutenii prirady schreibt Herzen: "... das Gehirn des Menschen ist das BewruBtseinswerkzeug (onudie soznanija) der Natur. [...] Ohne den Menschen betrachtet, besitzt die Natur nicht die Moglichkeit, sich zu konzentrieren, sich in sich selbst zu vertiefen, nicht die Moglichkeit, sich ihrer bewuBt zu werden und sich in logischer Form zu verallgemeinern... [...] Als ewige Unmündigkeit ist die Natur einem notwendigen, schicksalhaften, fur sie selbst unklaren Gesetz unterworfen, eben weil ihr dieses entwickelte Selbst, nămlich der Mensch, fehlt; im Menschen gelangt das Gesetz zur Klărung, wird zur Vernünftigkeit, die der BewuBtwerdung făhig ist; die sittliche Welt ist in dem MaBe frei von auBerer Notwendigkeit, wie sie mündig, d.h. bewuBt, ist. [...] Die Natur, aufgefaBt ohne Bewr Btsein, ist nur ein Torso, ein unentwickeltes Wesen, ein Kind, das noch nicht zur Beherrschung all seiner Organe gelangt ist, weil sie noch nicht alle fertig sind." A.I. GERCEN, SS v 30 it., t. 3, M. 1954, S. $301 f$.

19 Vgl. auch FOD I, S. 400f;; II, S. 47, 247. N.F. FEDOROv, Soxinenija, M. 1982, S. 633. Wieder finden sich erstaunlich ahnliche Gedanken in den Pariser Manuskripten des jungen 
Allein der Mensch als bewußter Teil der Natur und einziges vernunftbegabtes Wesen ist imstande, Vernunft und Bewußtsein in die äußere Natur hineinzutragen, indem er sie bewußtermaßen lenkt und neu schafft, anstatt sie, wie bisher, heillos auszuplündern und zu zerstören und damit der völligen Selbstvernichtung entgegenzutreiben.

Für sich belassen geht das Universum zugrunde; dies wird auch von der Wissenschaft bestätigt, die mit Hilfe der Spektralanalyse das Alter von Gestirnen und Welten zu bestimmen vermag, damit aber auch ihre Vergänglichkeit. ${ }^{20}$

Die Natur ist die Gesamtheit fallender Steme (oder Welten)... Fallen aber ist mit Tod und Sterben verbunden; Fallen ist Ausdruck eines Unterschiedes zwischen Zuwachs und Verlust an Kraft, ein Defizit. (...) Das Fallen der Sterne und das Ende der Welt haben eine gemeinsame Ursache; der Untergang der Welt wird sich vollziehen, wenn die vernunftbegabte Macht untătig bleibt. (II, 253; vgl. auch II, 350)

Der Kosmos (wie er ist, nicht wie er sein soll) ist Macht ohne Vernunft, der Mensch aber (noch) Vernunft ohne Macht. Wie aber kann Vernunft Macht werden und Macht Vernunft? Macht wird Vernunft, wenn Wissen, wenn Vernunft sie regieren werden. Folglich hăngt alles vom Menschen ab. (II, 5S)

Die Apokalypse ist also bedingt, nicht unvermeidlich; allein vom Menschen hängt $a b$, ob die Welt untergehen oder zur Vollendung gelangen wird.

Auf einen vorgegebenen "Schöpfungsplan" scheinen die folgenden Äußerungen Fedorovs zu deuten:

Die Erschaffung des Menschen oder sein Erscheinen war nicht zufallig, sondern notwendig für die Erde, für das ganze Universum... (11, 204)

... die Erde selbst gelangte in uns zum BewuBtsein ihres Schicksals, und dieses BewuBtsein, natürlich ein aktives, ist das Mittel zu ihrer Rettung. Es erschien ein Mechaniker, als der Mechanismus zu verderben begann. $(1,284)$

Marx: Im Menschen (als einem Teil der Natur) ist die Natur zum SelbstbewuBtsein gelangt und tritt sich - entzweit in Mensch und zu bearbeitendes Material - gleichsam selbst gegenüber. Die auf die "Aneignung" der Natur gerichtete theoretisch-praktische Tătigkeit des Menschen vermag indessen den "Widerstreit" zwischen Mensch und Natur aufzulosen und die "vollendete Wesenseinheit des Menschen mit der Natur, die wahre Resurrektion der Natur" herbeizufuhren. MARX, ENGEIs (wie Anm. 16), S. 536, 538. Siehe auch A. SCHMIDT, Der Begriff der Natur in der Lehre von Marx, Frankfurt/M. ${ }^{2}$ 1974, S. 77f. - In spăteren Prognosen über das Verhăltnis von Mensch und Natur geht Marx dann freilich von dem Gedanken einer vollstăndigen Versohnung und einer "vollendeten Wesenseinheit" zugunsten einseitiger Naturbeherrschung ab, wathrend er zugleich die unaufhebbaren Grenzen, die "ewige Naturbedingung des menschlichen Lebens", deutlich macht: immer wird der Mensch, um sein Leben zu erhalten, arbeiten müssen, und immer wird er als Kreatur sterblich bleiben. Siehe SCrMIDT, a.a.O., S. 129-142, 159. - Eben diese Grenze hat Fedorov nicht akzeptiert.

20 Vgl. FOD I, S. 92, 209, 343; II, S. 204, 350. - Die um die Mitte des 19. Jahrhunderts aufgestellten Theorien vom Erloschen der Sonne, von der Zunahme der Entropie und vom unabwendbaren Warmetod des Universums wirkten als schwere Schlăge gegen das herrschende Fortschrittsdenken. Berdjaev sprach in diesem Zusammenhang von der "physikalischen Apokalypse". N.[A.] BERDJAEV, "Predsmertnye mysli Fausta." In: Osval'd Spengler i zakat Evropy, M. 1922, S. 70. Zu den philosophischen Konsequenzen siehe zuletzt M. SGALAMBRO, Vom Tod der Sonne, München 1988, bes. S. 83-95. Siehe auch II: 3.1. Anm. 82. 


\section{Allerdings fährt Fedorov fort:}

Es ist [aber] unsinnig zu sagen, die Natur habe nicht nur den Mechanismus, sondern auch den Mechaniker geschaffen. (Ebd.)

Auch wenn Fedorov versichert, das Auftreten des Menschen sei nicht zufällig gewesen, sondern notwendig für die Fortdauer und die Vervollkommnung des Universums, so verbindet er damit nicht die Vorstellung, der Mensch und das menschliche Denken seien notwendige Produkte (und künftige Faktoren) einer zielgerichteten und darum sinnvollen universellen Evolution: Weder kennt die (außermenschliche) Natur Sinn und Ziel - die Evolution ist "blind und unbewuBt" (IJ, 124) -, noch hat sie den Menschen als solchen hervorgebracht. Dieser hat sich vielmehr im Aufstand gegen die blinde Natur selbst geschaffen, und es ist an ihm, Ziele und Zwecke zu setzen ("deshalb ist in der Natur auch keine ZweckmäBigkeit [celesoobraznost ], weil der Mensch selbst sie hineintragen muß..." I, 286). ${ }^{21}$ Dabei kann er sich nicht an objektiven natürlichen Gegebenheiten orientieren - etwa an vermeintlichen Gesetzen der Evolution oder des gesellschaftlichen Fortschritts; die Richtlinie seines Handelns bildet vielmehr eine moralische Fordenung, die aus der Bestimmung des menschlichen Wesens erwächst. ${ }^{22}$

Bisweilen spricht Fedorov von der Welt (Natur) als der unvollendeten Schöpfung Gottes. Die Menschheit ist aufgerufen, sie zur Vollendung zu führen. Folgt sie diesem Aufruf, wird sie zum "Werkzeug" (orudie) des "göttlichen Willens". ${ }^{23}$

21 Vgl. auch FOD II, S. 49-51.

22 Darin unterscheidet sich Fedorovs Auffassung von den "wissenschaftlichen" Fortschrittskonzeptionen des 19. und 20. Jahrhunderts, die der Natur, bzw. der als ihre Verlăngerung aufgefaBten Menschheitsgeschichte, ein Projekt unterstellen: Menschliches Handeln orientiert sich dann am einmal erkannten Ziel des Fortschritts und an der Einsicht in dessen objektive Notwendigkeit; moralische Maßstabe aber werden überflüssig. Der Grundirrtum solcher sinnhaft-teleologischer Konzeptionen - genannt seien nur die biologischen Utopien von Teilhard de Chardin und Julian Huxlcy sowie die ihnen eng verwandte Evolutionslehre V.I. Vernadskijs oder Ernst Blochs kosmische Erlठsungsspekulationen über eine schøpferische Materie als dynamisches Subjekt der Natur - besteht nach Jacques Monod in der Annahme einer die Evolution zielgerichtet vorantreibenden Kraft, bei der es sich in Wirklichkeit um eine "animistische Projektion" handelt, d.h. um die - wissenschaftlich unzulässige - Ubertragung der spezifisch menschlichen Făhigkeit zu bewuBtem, planendem Handeln auf die auBermenschliche Natur. J. MONOD, Zufall und Notwendigkeil [1970], München 1971.

23 Siehe z.B. FOD II, S. 387. - Die Vorstellung vom Menschen als dem Mitarbeiter Gottes und dem Vollender der Schopfung ist alt (siehe bereits 1. Kor. 3,9: "Denn wir sind Gottes Mitarbeiter"). Vielfaltige Ausprägung fand sie im Denken der Renaissance und des Humanismus (namentlich in der Vorstellung des "homo secundus Deus"). Bereits Cusanus hatte gelehrt, daB Gott die "wirklichen Dinge" und die "natürlichen Formen" geschaffen habe, der Mensch aber berufen sei, die "Verstandesdinge" und die "Künstlichen Formen" zu schaffen. Indem der Mensch verwirkliche, was in der Welt und in ihm selbst - dem Ebenbild Gottes - als moglich angelegt sei, gleiche er sich dem Schøpfer an, năhere er sich der Gottgestaltigkeit. In diesem Jahrhundert haben den Gedanken einer Teilnahme des Menschen am gottlichen Schopfungswerk etwa Nikolaj Berdjaev in seiner "Philosophie des Schaffens" oder Friedrich Dessauer in seiner "Philosophie der Technik" (1927) vertreten: Der Schöfer bedient sich des menschlichen Geistes, um sein Werk weiter zu bauen. Der Mensch aber (er)findet und verwirklicht nur, was 
... notwendig ist die Regulierung der Natur oder, anders gesagt, ihre Vervollkommnung, denn man kann sie in ihrem unvollkommenen Zustand, in dem sie sich wegen der menschlichen Ignoranz und Unsittlichkeit bis jetzt befindet, streng genommen nicht einmal als Schøpfung Gottes betrachten, denn die Entwürfe des Schopfers sind in ihr zum Teil noch nicht verwirklicht, zum Teil sogar entstellt. (II, 191)

Unsere Bestimmung kann nur darin bestehen, daB wir Werkzeuge zur Ausführung des grttlichen Willens in der Welt sind, Werkzeuge zur Regulierung jener Kraft, die, in ihrer Blindheit belassen, Hunger, Krankheit und Tod bringt... Somit sind wir schuld nicht nur an dem, was durch unser Tun geschieht (Raubbau), sondern auch an dem Ubel, das aus unserer Untătigkeit erwăchst. Man darf nicht einmal sagen, Gott habe die blinde Gewalt geschaffen, denn er schuf doch auch eine vernünftige, und nur infolge der Untătigkeit dieser bewirkt jene Ubel. $(I, 76)$

Die Rede vom Menschen als dem Vollender der Schöpfung hat immer wieder dazu geführt, daß Fedorovs obšcee delo als gemeinsames göttlich-menschliches Werk verstanden wurde, als Verbindung von göttlicher Gnade und menschlichem Tun. Das ist nicht der Fall. Wo immer Fedorov auf eine religiöse Deutung des Weltgeschehens zu sprechen kommt, gleicht seine Position der des (von ihm freilich scharf abgelehnten) Deismus: Gott hat die Welt geschaffen, doch ist er nicht in ihr, greift (vorerst) nicht in ihren Lauf ein, tut keine Wunder. Zwar spricht Fedorov von der Möglichkeit eines göttlichen Eingreifens, doch nur für den Fall, da $B$ die Menschheit es versäumt, ihre Aufgabe zu erfüllen. ${ }^{24}$ Mit anderen Worten: durch das obšcee delo wird die Möglichkeit ausgeschlossen, daß Gott die Welt zerstört und die Menschheit auf immer zweiteilt, indem er die Auserwählten mit Vollkommenheit und ewiger Glückseligkeit belohnt, die übrigen aber zu ewigen Qualen verdammt. ${ }^{25}$ Die Menschheit, die - in freier Entscheidung - die Schöpfung vollendet ${ }^{26}$ und ein diesseitiges Paradies schafft.

in der Potenz immer schon vorhanden ist. F. Dessauer, Philosophie der Technik, Bonn ${ }^{2} 1928$, bes. S. 19-21, 63 .

24 Die Lehre von der Bedingtheit der apokalyptischen Prophezeihungen wurde spăter vor allem von Berdjaev als einer der originellsten Gedanken Fedorovs hervorgehoben.

25 "Das Menschengeschlecht, wenn es in Unmündigkeit und Zwietracht verharrt und sich nicht in der Arbeit der Erkenntnis der blinden Macht vereint, sondern sich ihr unterwirf, wird auf narürtichem Wege verfallen und aussterben, auf über-natürlichem Wege aber kann es nur eine transzendente Auferstehung erwarten, die nicht durch uns vollzogen wird, sondern die von außen (izune), unabhăngig von uns, ja sogar gegen unseren Willen geschieht, eine Auferstehung des Zorns (voskresenie gneva), des schrecklichen [Jüngsten] Gerichts und der Verurteilung der einen (der Sünder) zu ewigen Qualen und der anderen (der Gerechten) zur Betrachtung dieser Qualen." FOD I, S. 417f.; Hervorhebungen im Orig.; vgl. auch ebd., S. 471f.; II, S. 294.

Gegen die kirchliche Lehre von der endgültigen und ewigen Zweiteilung der Menschheit und der unwiederbringlichen Verdammnis ihres gr ðBeren Teils (wie sie beispielsweise mit gnadenloser Akribie von Augustin im "Gottesstaat" beschrieben wird) stand die auf Origenes zurückgehende nonkonformistische Vorstellung von der "Wiederbringung aller" (apokatastasis pan(on), der Wiederherstellung allgemeiner Vollkommenheit und Glückseligkeit, die, auf apokryphe Schriften gestützt, im religiosen BewuBtsein des russischen Volkes fortdauerte. Mit seiner Forderung nach allumfassender Rettung steht Fedorov dieser Tradition nahe.

26 Wenn Fedorov in diesem Zusammenhang von den "Entwürfe[n]" des Schøpfers spricht, so heiBt das nicht, daB das Ziel in den Dingen, in der Welt liegt. Die Welt ist für Fedorov nur Material, nicht Potential: "Die Welt, wie sie uns gegenwărtig in der Erfahrung gegeben ist, frei- 
handelt zwar gemäß dem Willen des Schöpfers, doch ohne dessen Mitwirkung. In seiner immanenten Begründung und Durchführung bleibt das obš̌̌ee delo eine rein menschliche Angelegenheit:

Der Supramoralismus fordert das Paradies, das Reich Gottes, nicht ein jenseitiges, sondern ein diesseitiges, fordert die Umgestaltung der diesseitigen, irdischen Wirklichkeit, eine Umgestaltung, die sich auf alle Himmelswelten erstrecken wird... Also ist das Reich Gottes oder das Paradies das Werk aller Kraffte, aller Făhigkeiten aller Menschen in ihrer Gesamtheit, das Werk nicht negativer, sondern positiver Tugenden; es ist, so kann man sagen, das Paradies für die Mündigen, und es kann nur das Werk der Menschen selbst sein, das Werk der Fülle des Wissens, der Tiefe des Gefühls und der Stărke des Willens; das Paradies kann nur von den Menschen selbst geschaffen werden... $(I, 419 f .)^{27}$

\subsubsection{Das Verhältnis zwischen Mensch und Mensch(heit)}

Der Mensch empfängt nicht nur sein Leben, sondern auch die zu seinem Unterhalt nötigen Mittel. Unter den herrschenden Verhältnissen einer ungebändigten Natur und der Beschränkung der Menschheit auf die Erde mit ihren knappen, endlichen Ressourcen sind diese Mittel jedoch so begrenzt, daß sie Leben weder für alle noch für immer ermöglichen. ${ }^{28}$

Um sein Dasein wenigstens als ein befristetes zu sichern, sieht sich der Mensch gezwungen, sich feindlich nicht nur gegen die Natur, sondern auch gegen seine Mitmenschen zu verhalten. Anstatt sich ihnen - im Bewußtsein gemeinsamen Ursprungs und gleichen Schicksals - verwandt zu fühlen und sie als seine Brüder und Leidensgenossen zu erkennen, betrachtet der isoliert um sein Dasein kämpfende Mensch die anderen als Fremde, Konkurrenten und Feinde. Der Kampf um Selbsterhaltung spaltet die Menschheit in Individuen und Gruppen, die einander feindlich entgegenstehen. Ökonomische, soziale, religiöse und nationale Trennungen und Rivalitäten, die Spaltung der Menschheit in Arme und Reiche, Stadt- und Landbewohner, Gelehrte und Nichtgelehrte, Bürger verschiedener Staaten, Anhänger verschiedener Religionsgemeinschaften und Sekten, sowie die Feindschaft, die zwischen all diesen Fraktionen herrscht, sind letztlich Folgen (und zugleich auch Ursache) der Naturverfallenheit. Sie kenn-

lich in einer sozusagen passiven Erfahrung, ist nur die Gesamtheit der Mittel zur Verwirklichung jener Welt, welche uns in Gedanken, in der Vorstellung gegeben ist... Doch muß diese Verwirklichung oder Neuschaffung immanent sein." FOD I, S. 207.

27 Früh schon hatten N.A. Berdjaev und S.N. Bulgakov, offenbar in enger Anlehnung an Solov'evs Lehre von der "freien Theurgie", das obšce delo als "Mitwirkung" und "aktive Teilnahme" der Menschheit am "gottlich-menschlichen Akt" der Auferweckung der Verstorbenen und der Erlosung der Welt dargestellt. Siehe II: 2.2.1. In der Folge hat dann vor allem Berdjaev in zahlreichen AuBerungen über Fedorov zur Verbreitung dieses Irrtums beigetragen. Siehe auch II: 43.4. Oberzeugend widerlegt wurde er durch Zakydalsky, der nachwies, daB Fedorovs "project of immanent resurrection is a strictly scientific one and has no use for God, grace, or supernatural powers." ZAKYDALSKY (wie Anm. 1), S. 257. Allerdings wies Zakydalsky auch auf Inkonsequenzen in Fedorovs Denken hin: So ist die "Drohung" einer (jederzeit moglichen) transzendenten "Auferstehung des Zorns" unvereinbar mit Fedorovs immanenter Begründung des obszee delo. Ebd., S. 309-311.

Vgl. FOD I, S. 276, 280. 
zeichnen einen weltweit herrschenden Zustand, in dem die auf allumfassender "Verwandtschaft" (rodstvo) beruhende Einheit aller gleichzeitig lebenden Menschen, die "Bruderschaft" (bratstvo), aus BewuBtsein und Gefühl weitgehend verdrängt oder gänzlich geschwunden ist. - Der detaillierten Beschreibung und vehementen Kritik dieses "unbrüderlichen Zustandes" (nebratskoe sostojanie) ist ein großer Teil der Schriften Fedorovs gewidmet. ${ }^{29}$

Der unbrüderliche Zustand wird von den meisten Menschen nicht nur als natürlich ${ }^{30}$ und unabänderlich betrachtet, sondern auch noch gutgeheißen:

Man erblickt kein Ubel in der Entfremdung des einen vom anderen, und man sieht sogar etwas Gutes in der Unterwerfung unter die blinde Gewalt [der Natur], indem man das alles für natürlich (estestvennyj) und notwendig hălt. $(1,336)$

Die Zivilisation hat mittlerweile ein Stadium moralischen Verfalls erreicht, in dem Streit und Konkurrenz, Opposition und Revolution, also Entzweiung und Kampf jeglicher Art, nicht als die apokalyptischen Vorzeichen des nahenden Weltuntergangs erkannt, sondern im Gegenteil als Voraussetzung eines - in Wahrheit freilich perversen - "Fortschritts" begrüßt werden. ${ }^{31}$

Die treibenden Kräfte solchen "Fortschritts" sind der Kampf ums Dasein, der seinen Ausdruck im modernen Militarismus findet, und die geschlechtliche Zuchtwahl (polovoj podbor), auf der die gesamte moderne Industriegesellschaft beruht (Industrialismus). Erwerb und Genuß von Dingen und die Sucht, dem anderen Geschlecht zu gefallen, stellen gegenwärtig die alleinigen Ziele einer Menschheit dar, die ihre Naturverfallenheit dadurch demonstriert, da $B$ sie den von Darwin formulierten Gesetzen der vernunftlosen Natur gehorcht.

Darwin ist der aktuellste Philosoph: er sah in der gesamten Natur nur Militarismus (Kampf) und Industrialismus (geschlechtliche Zuchtwahl); Darwin zufolge herrschen in der Natur entweder Stărke (genauer gesagt Gewalt) oder Schðnheit. (II, 332)

29 Fedorovs scharfe Kritik der Zivilisation des Westens und ihres verderblichen Einflusses auf Rußland steht ganz offensichtlich in der Tradition der Slavophilen, deckt sich aber auch mit zeitgenossischer westlicher Zivilisationskritik etwa Schopenhauers und Nietzsches (worauf im folgenden jedoch nur gelegentlich hingewiesen werden kann).

30 Was er im eigentlichen Wortsinne ja auch ist: "estestvennyj, chotja i ne normal'nyj, ne podobajušij zeloveku i miru..." Fedorov zitiert nach KožEvnKov (wie Anm. 18), S. 60; ohne Nachweis.

31 Vgl. FOD I, S. 210; II, S. 237.

32 Vgl. auch FOD I, S. 32 . - 1874 hatte Nietzsche in den Unzeitgemäßen Betrachtungen die 'tชdlichen' Konsequenzen eines auf Darwins Lehre gegründeten Menschenbildes noch in der $\mathrm{Zu}$ kunft gesehen: "Wenn ... die Lehren vom souveranen Werden, von der Flüssigkeit aller ... Arten, von dem Mangel aller kardinalen Verschiedenheit zwischen Mensch und Tier - Lehren, die ich für wahr, aber für tơdlich halte - ... noch ein Menschenalter hindurch in das Volk geschleudert werden, so soll es niemanden wundernehmen, wenn ... Systeme von Einzelegoismen, Verbrüderungen zum Zweck raubsüchtiger Ausbeutung der Nicht-Brüder und ahnliche Schopfungen utilitaristischer Gemeinheit auf dem Schauplatz der Zukunft auftreten werden." F. NIETZSCHE, Werke in drei Bänden, hg. von K. Schlechta, Bd. 1, München ${ }^{5} 1966$, S. 272 . Von der Gegenwart stellte Nietzsche fest: "Wir leben die Periode der Atome, des atomistischen Chaos. (...) 
Forciert werden Besitzstreben und damit Kampf und Rivalität durch die Industrieproduktion, die fabrikmäßige Herstellung überflüssiger Dinge (Fedorov nennt sie abschätzig igruski, bezdeluski, trjapki), die bloß der Eitelkeit und Wollust, der Befriedigung weibischer Launen und künstlich geweckter Bedürfnisse dienen, die Wünsche wecken, Neid, Streit, Ungleichheit und Spaltung unter den Menschen erzeugen, nicht aber zur wirklichen Sicherung ihrer Existenz beitragen. ${ }^{33}$

Ursprung und Antrieb der Industrieproduktion (und der auf ihr beruhenden modernen (europäisch-amerikanischen) Kultur und Zivilisation liegen in der Vergötzung des Weibes und der dadurch angestachelten sexuellen Konkurrenz. ${ }^{34}$

Der Industrialismus ist das Produkt der geschlechtlichen Leidenschaft, der Sucht, sich zu schmücken, auf jung zu machen, sich zu rasieren und zu schminken. (II, 119)

Die "Herrschaft der Frauen, eine [zwar] nicht drückende, jedoch verderbliche Herrschaft", (I, 495) führte zur Hypertrophie der Sexualität und damit zum Triumph des blinden, tierischen Elements im Menschen. Das Streben nach purem Lustgewinn (wie es sich in der "kinderlosen Ehe" äußert) konzentriert sich ganz auf das Hier und Jetzt: Es verachtet das Alte, erhebt sich über die Vergangenheit und vergißt die "Väter", es ignoriert die Zukunft und kümmert sich nicht um die Kinder. In seiner absoluten Selbstbezogenheit erweist es sich als schlechthin destruktiv:

Was wird es mit Tieren und Pflanzen machen, die ihm nutzlos sind, dieses Tier, das seine Vorfahren verdrăngt hat und selbst seinen eigenen Nachkommen gegenüber kein Erbarmen zeigt?! Schonungslos gegen jeden wird dieser vertierte Mensch ... sein eigenes Dasein überaus hoch schătzen; er wird es sich zum Ziel machen, dieses Dasein so weit wie möglich zu verlăngern, indem er alles vernichtet, was ihm auch nur im geringsten gefahrlich werden könnte... $(I, 429)$

Beispielhaft verkörpert findet sich die vollständige Demoralisierung der modernen Zivilisation in den großen Weltausstellungen - wie der in Paris im

Jetzt wird fast alles auf Erden nur noch durch die gröbsten und bösesten Kräfte bestimmt, durch den Egoismus der Erwerbenden und die militărischen Gewaltherrscher." Ebd., S. 313.

33 FOD II, S. 331ff. - Mit seiner Kritik am Industrialismus und den gesellschaftlichen Folgen Isolierung des Individuums, Ersetzung organischer Gemeinschaft durch mechanisch-zweckhafte Gesellschaft, Spaltung und Rivalităt - steht Fedorov in der Tradition der Slavophilen. So hatte um nur ein Beispiel zu zitieren - Ivan Kireevskij in einem Essay "Úber die Notwendigkeit und Mðglichkeit neuer Prinzipien für die Philosophie" 1856 geschrieben: "Die Industrie regiert die Welt ohne Glauben und Poesie. In unserer Zeit verbindet und trennt sie Menschen, sie entscheidet über das Vaterland, sie bezeichnet Klassen, sie liegt Staatsordnungen zugrunde, sie bewegt Volker, sie erklärt Krieg, schließt Frieden, verä̈ndert die Sitten, bestimmt die Richtung der Wissenschaften und den Charakter der Bildung. Vor ihr verbeugt man sich, ihr baut man Tempel; sie ist eine wirkliche Gottheit, an die die Menschen aufrichtig glauben und der sie sich unterwerfen. Selbstloses Handeln aber ist unwahrscheinlich geworden... I.V. KIREEVSKI, PSS v druch tomach, t. 1, M. 1911, S. 246.

Vgl. FOD I, S. 313f.; II, S. 331. 
Jahre 1889 aus Anlaß der "hundertjährigen Herrschaft der Bourgeoisie": ${ }^{35}$ Als prahlerische Selbstdarstellung des dritten Standes und als Exposition der Fetische seiner Genußsucht und Aggressivität - "von außen eine Rüstkammer, im Innern aber ein Magazin der Begierden" (II, 239) -, sollte, so Fedorov, die Weltausstellung in ein Museum verwandelt werden, ein ständiges Denkmal einer zum Untergang verurteilten Epoche.

Durch die Industrie wurde das Tempo der Produktion rapide beschleunigt. Die Folgen sind Überproduktion und Unbeständigkeit der Erzeugnisse, ${ }^{36}$ vor allem aber eine veränderte Einstellung der Menschen zur Arbeit, zur mechanischen wie zur intellektuellen. Einst mit Liebe und Hingabe betrieben, war Arbeit eine Form künstlerischer oder religiöser Äußerung, ein Weg zur Befreiung aus den Zwängen der Natur und damit zur Selbsterzeugung und Selbstvervollkommnung. Heute hingegen gilt Arbeit als Fluch, wird als Zwang empfunden, und die Eile, mit der sie betrieben wird, beraubt sie nicht nur jeglichen künstlerischen Reizes, sondern pervertiert sie in ein bloßes Mittel des Profits. ${ }^{37}$

Voraussetzung für Industrie und Handel (und gleichzeitig deren Produkt) ist die Stadt, ein Hort künstlichen und entfremdeten Lebens. Während die Bewohner des Landes, die Bauern, in zähem Kampf gegen die Natur zusammenstehen, um ihr die Mittel zur Sicherung des menschlichen Lebens abzuringen, befassen sich die Städter mit der Herstellung und Verteilung künstlicher Luxusgüter und tragen auf diese Weise nichts zur Existenzsicherung bei, im Gegenteil: Je größer die Zahl derer wird, die nicht - wie die Bauern - auf Kosten der Natur (na sčet prirody), sondern - wie die Städter - auf Kosten anderer leben, ${ }^{38}$ desto mehr wird sich das Ernährungsproblem (vopros prodovol'stvennyj) verschärfen, und da dieses Problem für die Städter keine Frage des gemeinsamen Kamp-

35 Ausführlich dazu Fedorovs Artikel "Vystavka 1889 goda..." In: FOD I, S. 492-519. Die vollstăndige, barock-umstăndliche Oberschrift des Artikels lautet: "Die Ausstellung des Jahres 1889 oder eine anschauliche Darstellung der Kultur, Zivilisation und Exploitation, das Jubilăum der hundertjăhrigen Herrschaft des Mittelstandes, der Bourgeoisie oder des Stadtbürgertums; und was eine Ausstellung im letzten Jahr des 19. Jahrhunderts oder im ersten Jahr des 20. Jahrhunderts sein soll oder, genauer, eine Ausstellung an der Wende dieser beiden Jahrhunderte; was vermacht das 19. Jahrhundert dem 20.?" Ebd., S. 492. - Die groBen Ausstellungen der zweiten Hăfte des 19. Jahrhunderts (allein zehn Weltausstellungen zwischen 1851 und 1900), auf denen die zivilisatorischen Errungenschaften der bürgerlichen Epoche in fortschrittlicher Hochstimmung glanzvoll präsentiert wurden, riefen bei manchen Beobachtern auch Unbehagen und Kritik hervor; erinnert sei nur an Dostoevskijs apokalyptische Vorstellung von einer HerdenMenschheit, die ihn beim Besuch der zweiten Londoner Ausstellung (1862) überkam (Zimnie zametki o letnich vpetCatlenijach, 1863).

36 FOD I, S. 25.

37 Ebd. - Fedorov verdeutlicht diese Entwicklung am Beispiel der Schrift: ursprünglich Malerei, d.h. "lebendige Schrift" (Zivopis'), die "vom Schreibenden künstlerische Făhigkeiten und die volle Hingabe seiner Seele verlangte", verfiel die Schrift über die noch immer erhabenen Buchstaben mittelalterlicher Kalligraphie zur modernen schnellen Kursivschrift und schlieBlich zur vollig seelenlosen Stenographie, die den Menschen zum Phonographen erniedrigt. FOD I, S. 23-25; etwas verăndert auch unter dem Titel "O pis'menach" in: Vesy, 1 (1904), 6, S. 1-5. 
fes gegen die Natur, sondern eine Frage der individuellen Verteilung ist (eine Frage also des Kampfes der Menschen gegeneinander), werden mit dem Anwachsen der Städte auch Konkurrenz, Klassenhaß und Feindschaft zunehmen.

Die stădtische [Klasse] erzeugt nichts; sie gibt nur allem eine verfeinerte [raffinierte] Form, was außerhalb der Stadt erworben wurde. Das Ernahhrungsproblem stellt sich für die Stadt nur von der okonomischen Seite, d.h. von der Seite der Verteilung [Distribution]. Die Stadt ignoriert die Abhängigkeit des Menschen von der Natur, sie ist gleichgültig gegenüber Ernte und Mißernte... (...) Die Abspaltung der Stadt vom Dorf, das unabhängige Bestehen der Manufakturproduktion von der Landwirtschaft und sogar ihre Herrschaft über die letztere, bildet die Hauptursache des Proletariats. Außer wechselseitiger Assekuranz hat sich die Stadt nichts zur Existenzsicherung ausgedacht... (I, $278)^{39}$

Die Stadt ist lebensfeindlich auch noch in anderer Hinsicht: Im Gegensatz zur Landwirtschaft, die es mit der Erzeugung und Aufzucht von Lebendem zu tun hat, indem sie aus den Produkten von Fäulnis und Verwesung, aus Totem also, pflanzliche und tierische Materie (rastitel'noe i životnoe vešcestvo) hervorbringt, um damit bestehendes Leben zu erhalten, verwandelt städtische Industrie Materie in tote Fabrikate; ${ }^{40}$ dagegen werden Fäulnis und Verwesung in der Stadt zu Brutstätten todbringender Krankheits- und Seuchenerreger und damit zu einem Gesundheitsproblem (vopros sanitamyj).

In sanitărer Hinsicht erzeugen die Stădte nur Făulnis, und sie verwandeln diese nicht in pflanzliche Produkte; folglich muB die Isolierung der Stădte den Prozessen der Venwesung ein Ubergewicht über die Prozesse des Lebens geben. Die Stadde bringen eine Fauna von Vibrionen und Bakterien hervor, die zu bekămpfen unvergleichlich viel schwieriger sein wird als der Kampf mit Mammuten und Mastodonten... $(I, 279)$

Bislang aber unternimmt die Stadt nicht nur nichts, um die Hauptursachen des Todes, nämlich Hunger und Seuchen, zu beseitigen, sie fördert sie geradezu: "Mit fortschreitender Vergrößerung der Städte werden die Gesundheits- und Ernährungsprobleme eine immer schärfere Form annehmen..." (I, 279).

Schließlich werden die Menschen durch die städtische Lebensweise auch moralisch korrumpiert:

39 Das parasităre, künstliche Luxusleben der Stadt war ein nicht nur bei den Slavophilen beliebter Topos der Zivilisationskritik. So geißelte beispielsweise Schopenhauer den stădtischen "Luxus" zu Lasten vor allem der Landbevolkerung: "Damit nămlich einige Wenige das Entbehrliche, Oberflüssige und Raffinirte haben, ja, erkünstelte Bedürfnisse befriedigen können, muß auf Dergleichen ein großes Maaß der vorhandenen Menschenkräfte verwendet und daher dem Nothwendigen, der Hervorbringung des Unentbehrlichen, entzogen werden. (...) Aus ... Luxusarbeitern besteht ein großer Theil der Bevolkerung der Stădte: für diese also und ihre Besteller muB nun der Bauer mit pflügen, săen und weiden, hat also mehr Arbeit, als die Natur ihm ursprünglich auferlegt hatte." A. SCHOPENHAUER, Parerga und Paralipomena, Bd. 2, 8125 , Leipzig 1939, S. 261. (= Sămtliche Werke, hg. von A. Hübscher, Bd. 6). Achtzig Jahre spăter sprach Spengler von der "steinerne[n] Stadt" als dem "Gehăuse des ganz künstlichen, von der mütterlichen Erde getrennten, vollkommen gegennatürlich gewordenen Lebens," der "Stadt des wurzellosen Denkens, welche die Strome des Lebens vom Lande an sich zieht und verbraucht." SPENGLER (wie Anm. 12), S. 61. 
Das hygienische Problem entstand in den Stădten, weil die Stadt gesundheitsfeindlich ihrem Wesen nach ist: Krankheiten werden durch die Fabrikproduktion hervorgerufen, aber auch der Konsum führt zu Krankheiten, d.h. das ganze künstliche Leben in der Stadt ist krankheitserregend. Die Konkurrenz ruft seelische Leiden hervor. Mit einem Wort, die ganze juridisch-okonomische Lebensform [der Stådter] ist ebensosehr eine sittliche Verzerrung der verwandtschaftlichen, wie die pathologische stădtische eine Perversion der gesunden dơrflichen darstellt. Die gesamte Geschichte als Geschichte der Zivilisation, der künstlichen Kultur (d.h. der Verwandlung des Dorfes in die Stadt), ist die Abwendung vom Problem der Ernăhrung und die Entwicklung einer gesundheitsfeindlichen Lebensform. (I, 299)

Die moderne städtische Industriegesellschaft, die wesentlich auf dem Unrecht der Zwangsarbeit in den Fabriken und Bergwerken beruht, auf der Ausbeutung von Mensch und Natur also, ${ }^{41}$ hat die verwandtschaftliche Eintracht, wie sie sich unter den Bedingungen des patriarchalischen Landlebens und der Heimarbeit (kustamiCestvo) erhalten hat, zerstört und an ihre Stelle künstlich geschaffene juristische, ökonomische und politische Beziehungen gesetzt; gleichzeitig hetzt sie die Individuen und Gruppen gegeneinander in Konkurrenz und Profitgier, erweckt Klassenhaß und schürt Feindschaft zwischen den Staaten. Der Kampf ums Dasein ist zum "Kampf zwischen den Menschen um den Besitz von Dingen" $(I, 17)$ geworden. Im modernen Militarismus hat dieser Kampf seinen aggressivsten Ausdruck gefunden.

"Der neue Militarismus ist die Schöpfung des neuen Industrialismus" (II, 331). Er dient "... dem Schutz der Städte vor inneren Feinden, die in den Fabriken, Bergwerken und Gruben arbeiten, wie auch vor äußeren, fremdländischen Feinden" (II, 333), der Ausschaltung unliebsamer Konkurrenz wie der Eroberung neuer Rohstoffquellen und Absatzmärkte. Zur Durchsetzung industriellkommerzieller Interessen wird das ganze Volk im Töten und Zerstören ausgebildet und ein beträchtlicher Teil unter hohen Aufwendungen ständig unter Waffen gehalten. ${ }^{42}$

Auch die Wissenschaft wird in den Dienst von Industrie und Militär genommen.

Die enorme Entwicklung der Großindustrie erfordert allgemeine Aufrüstung, allgemeine Wehrpflicht, und ruft auf zur Erfindung immer perfekterer Waffen und Vernichtungsmittel und verwandelt in dieser Hinsicht die Wissenschaft in eine Dienerin von Industrie und Handel. (II, 331)

Während die reine Wissenschaft (cistaja nauka) Kampf und Vernichtung gleichgültig gegenübersteht und in Untätigkeit und distanzierte Betrachtung versinkt, hat sich die angewandte Wissenschaft (prikladnaja nauka) bereitwillig in den Dienst oder, wie Fedorov sagt, "unter das Joch" von Industrie, Handel und Rü-

41 Vgl. FOD I, S. 5, 31; II, S. 332.

42 Hinter all dem steht das Streben nach "Luxus", d.h. nach nicht lebensnotwendigen Gütern. Wiederum erinnert Fedorous Kritik an die Schopenhauers, wenn dieser schreibt: "Der ganze unnatürliche Zustand der Gesellschaft, der allgemeine Kampf, um dem Elend zu entgehn, die so viel Leben kostende Seefahrt, das verwickelte Handelsinteresse und endlich die Kriege, zu welchen das Alles AnlaB giebt, - alles Dieses hat zur alleinigen Wurzel den Luxus..." SCHOPENHAUER (wie Anm. 39), S. 262. 
stung begeben. ${ }^{43}$ So dienen beispielsweise die von der Wissenschaft bereitgestellten Kommunikationsmittel, "auf die der moderne Mensch besonders stolz ist, nur der Strategie oder dem Handel, dem Krieg oder der Profitgier" (I, 3).

Alles dient gegenwărtig dem Krieg; es gibt keine einzige Entdeckung, deren kriegerische Nutzanwendung von den Militărs nicht ins Auge gefaßt würde, und es gibt keine einzige Erfindung, die sie nicht für militărische Zwecke einzusetzen bemüht wăren. $(\mathrm{I}, 4)$

Der künftige Krieg wird folglich ein "wissenschaftlicher" sein, d.h. "unter voller Anwendung allen Wissens" geführt werden, "zu Lande und zu Wasser, unter der Erde und unter Wasser, in luftiger Höhe, Tag und Nacht beim Schein elektrischer Sonnen. Vor dieser Wirklichkeit wird selbst die phantastischste apokalyptische Vision erblassen." (I, 145)

Eine weitere Folge der Industrialisierung, welche die Menschen entzweit, sie gegeneinander aufbringt und ihre Selbstvervollkommnung verhindert, ist die zunehmende Arbeitsteilung und Spezialisierung, die darauf abzielt,

... einem jeden Menschen nur noch eine einzige Făhigkeit zu belassen und ihn aller übrigen zu berauben, so daß die Menschen nur noch in ihrer Gesamtheit einen ganzen Menschen bilden. Eine solche Gesellschaft besteht nicht aus Persönlichkeiten, nicht aus Menschen, sondern aus Produktionsinstrumenten (organy proizvodstva). $(\mathrm{I}, 273)^{44}$

Am verhängnisvollsten erweist sich dabei die immer tiefer werdende Kluft zwischen Denken und Handeln, zwischen reinem Intellekt und stumpfer Arbeit. ${ }^{45}$ Die Isolierung und Verabsolutierung des menschlichen Intellekts ist die gravierendste Folge der gesellschaftlichen Arbeitsteilung mit dem Ziel, diese auf der Basis der natürlichen Konstitution des Menschen zu rechtfertigen, das heißt, den Gelehrten eine parasitäre Lebensweise auf Kosten des arbeitenden Volkes zu sichern.

Sowohl die Franzosische Revolution wie die deutsche Philosophie hielten das Volk für unfahig zum Wissen, d.h. sie bestritten ihm den dazu notigen Verstand. Deshalb wurde alles Wissen, reines und angewandtes, unwirksam (bezdel'nyj); das Volk aber, verurteilt zur Herstellung von (industriell fabriziertem) Luxuskram ... verurteilte sich selbst zur Atrophie des Verstandes (im ProzeB gedankenloser Arbeit)... (II, 78)

Arbeitsteilung, Rivalität und Besitzstreben haben den einzelnen auf sich selbst zurückgeworfen und in "völlige innere Isoliertheit" ( $k$ soveršennoj vnutrennej

43 Vgl. FOD I, S. 6f., 395; II, 238.

44 Derselbe Gedanke findet sich, ganz ăhnlich formuliert, in Engels' Anti-Dühring (1877-78): "Indem die Arbeit geteilt wird, wird auch der Mensch geteilt. Der Ausbildung einer einzigen Tătigkeit werden alle übrigen körperlichen und geistigen Fähigkeiten zum Opfer gebracht." MARX, ENGels, Werke, Bd. 20, Berlin 1962, S. 272. Zur Kritik der Arbeitsteilung ebd., pass.

45 Dazu unten 3.1.3. - Im Unterschied zu Marx und Engels sah Fedorov den Ursprung der Klassenspaltung schon in der Teilung von körperlicher und geistiger Arbeit, nicht im Besitz oder Nichtbesitz von Produktionsmitteln. Ähnliche Gedanken - verbunden mit dem Aufruf, das Wissensmonopol der "Geistesschaffenden" zu brechen - vertraten spăter in RuBland A. VoYskij (d.i. Ja.V. Machajskij) und A. Bogdanov (d.i. A.A. Malinovskij). 
razobš̌ennosti) getrieben. (I, 216) Die Menschen sind zu bloßen "Organen ihrer verschiedenen Unternehmungen, zu Rädchen und Schräubchen geworden, obgleich sie glauben, sie lebten sich selbst." $(I, 11)$ Die Vereinzelung ist bereits so weit fortgeschritten, da $B$ die Menschen aufhören, einander zu verstehen. ${ }^{46}$ Individuelle Freiheit wird zum Maßstab des Fortschritts, der Gewinn eines Höchstmaßes an persönlicher Freiheit, d.h. "die geringstmögliche Einschränkung im Genuß von Tand" (I, 210), wird zum Ziel der gesellschaftlichen Entwicklung erhoben.

'Ziel des Fortschritts ist die entfaltete und sich weiter entfaltende Persönlichkeit oder das höchste $\mathrm{MaB}$ an Freiheit, das für den Menschen erreichbar ist' - d.h. nicht Vereinigung..., sondern Entzweiung ist das Ziel des Fortschritts. Folglich ist das geringste $\mathrm{MaB}$ an Brüderlichkeit Zeichen hochsten Fortschritts. (I, 21)

Die Menschheit ist gegenwärtig zerspalten in eine Menge (tolpa) einander bedrängender und bekämpfender Individuen, die lediglich zur Erreichung ihrer materiellen Ziele Zweckbündnisse miteinander eingehen, sich in Ständen, Klassen, Staaten vertraglich zusammenschließen, damit aber zugleich gegen andere feindlich abgrenzen. Solche Zusammenschlüsse "um des Komforts willen und zum Zwecke des eigenen Vergnügens" (I, 30), durch die die Kluft zwischen den Menschen nur noch vertieft wird, bilden die schlimmste Perversion des menschlichen Gemeinschaftsgefühls.

Im Streben nach materiellem Besitz und Genuß, in diesem Kampf aller gegen alle, wird der Mitmensch entweder als Konkurrent betrachtet, als etwas Fremdes, Feindliches also, oder als Mittel. In diesem Fall wird ihm überhaupt alles Menschliche abgesprochen; er wird zur Sache, deren Wert sich lediglich nach ihrer Verwendbarkeit bemißt. Infolge dieser Entfremdung und Verdinglichung ist sich jeder nur noch des eigenen Ich bewußt und damit des eigenen Seins sicher, empfindet nur noch sich selbst als Menschen. Das Menschsein des anderen kann allenfalls durch Analogie erschlossen werden, ${ }^{47}$ d.h. bloß gedanklich durch die Vermittlung des eigenen individuellen Bewußtseins, nicht aber unmittelbar empfunden im Gefühl gemeinsamen Ursprungs und allumfassender Verwandtschaft.

"Bruderschaft" (bratstvo) bezeichnet gleichsam die räumliche Dimension der Verwandtschaft (und damit der Einheit des Menschengeschlechts), ihre - oftmals übersehene - zeitliche Dimension erfassen die Begriffe "Sohnschaft" (synovstvo) bzw. "Vaterschaft" (otečestvo).

FOD I, S. 19. 
Bruderschaft gründet sich auf Vaterschaft, nur durch die Văter sind wir Brüder, ohne Vaterschaft ist Bruderschaft unbegreiflich, und die brüderliche Vereinigung der Söhne kann vollkommen nur sein im Bemühen um die Văter (delo oreceskoe). ${ }^{48}$

Infolge der Zersplitterung der Gesellschaft in ihre individuellen Bestandteile, deren Bewußtsein sich auf immer kürzere Zeiträume reduziert, ist nicht nur das Gefühl der Bruderschaft (die Einheit aller Lebenden), sondern auch dessen Grundlage, das Gefühl der Sohnschaft (die Verbindung zu allen vorangegangenen Generationen und das Wissen um die Abstammung von einem allen gemeinsamen Urvater [praotec]) zerstört. Sohnschaft, die Tatsache, daß jeder Mensch geboren wurde, bedeutet aber auch eine ungetilgte und mit jeder Generation wachsende Schuld, denn

[w]ir besitzen nichts Eigenes, von uns Hervorgebrachtes, sondern alles ist gegeben, genauer, geschuldet (dolgovoe). Unser Leben ist überhaupt nicht das unsere, es ist widerruflich, konfiszierbar, sterblich; wir haben das Leben von unseren Vătern empfangen, die in der gleichen Schuld bei ihren Eltern stehen usw. Geburt ist Weitergabe der Schuld, nicht ihre Tilgung. Von unseren Eltern, wie überhaupt von unseren Vorfahren, haben wir nicht nur das Leben empfangen, sondern auch die Mittel zum Leben, die Arbeitsmethoden. Davon gehơrt [fast] alles unseren Vătern und Vorvătern, und nur ganz wenig gehort ausnahmsweise uns selbst. $(I, 93)$

Jeder Mensch, der geboren wird, lebt auf Kosten seiner Eltern, seiner Vorfahren: aus organischer Materie, den Überresten der Verstorbenen, zieht er seine Nahrung ("verdeckter Kannibalismus"; I, 95f.), während er die Kräfte seiner Eltern absorbiert und sie aus dem Leben drängt.

... der Mensch wird unmündig geboren. In der gesamten Zeit, da er ernăhrt und aufgezogen wird, saugt er die Krăfte der Eltern auf, er ernăhrt sich sozusagen von ihrem Fleisch und Blut (natürlich nicht wortlich, nicht in direktem Sinne), so daß, wenn seine Aufzucht beendet ist, die Krafte der Eltern vollig erschøpft sind und sie sterben oder hinfallig werden, d.h. sich dem Tode năhern. Der Umstand, daB der ProzeB der Abtotung sich nicht innerhalb des Organismus abspielt - wie beispielsweise in der Zelle -, sondern innerhalb der Familie, mindert nicht das Verbrecherische dieses Tuns. $(\mathrm{I}, 313)$

"Jede Generation bringt bereits durch ihre Geburt den Eltern den Tod" (I, 94), denn "Geburt bedeutet, den Vätern das Leben zu nehmen, es ihnen wegzunehmen, d.h. sie des Lebens zu berauben" (I, 401). Jede Generation vermehrt also die Schuld, und mit jeder Generation vergrößert sich die Sohnespflicht.

Das BewuBtsein, daß unsere Geburt den Vătem das Leben kostet, daß wir sie verdrăngen, ist das BewuBtsein unserer Schuld. (I, 78)

Für unser abgestumpftes Gefühl ist es unbegreiflich, welche Anomalie, welche Unsittlichkeit in dem Ausdruck 'Söhne verstorbener Väter' liegt, d.h. Sorhne, die infolge des Todes der Văter leben, als wăre nichts Besonderes, nichts Schreckliches geschehen! Der sittliche Widerspruch von 'lebenden Söhnen' und 'verstorbenen Värem' kann nur aufgehoben werden durch die Pflicht zur allumfassenden Auferweckung. (I, 287; Hervorhebungen im Orig.) 
Würden die Menschen diese Pflicht erkennen, so würden sie nicht länger in Sinnenlust neue Menschen zeugen und gebären, sondern beginnen, die den Tod perpetuierende natürliche Fortpflanzung durch die "bewuBte Wiedererschaffung" und "Rückerstattung" des von den Vätern empfangenen Lebens zu ersetzen ("positive Keuschheit"; polozitel'noe celomudrie). ${ }^{49}$ Damit aber würden sie zu "wahren Menschensöhnen" (istinnye syny celoveceskie) werden. Denn "der ist nicht würdig des Lebens und der Freiheit, der nicht denen das Leben zurückgibt, von denen er es empfangen hat." $(I, 338)^{50}$ Bislang aber lassen die Söhne verblendet durch die Schönheit der Frau - ihre Eltern im Stich, widmen sich der Selbsterhaltung und geben sich dem Genuß des Augenblicks hin; sie sind "verlorene Söhne" (bludnye syny), d.h. Söhne, die "ihre Väter verraten" haben. ${ }^{51}$ Ausdruck findet solcher Verrat im positivistischen Fortschrittsdenken, der modernen intellektuellen Form der Verachtung und Verdrängung der Vorfahren durch die Nachkommen.

Fortschritt wird bewußt im Vergleich mit früheren Zuständen. Unter den herrschenden Verhältnissen führt solches Vergleichen zu einem Gefühl der Überlegenheit der Jungen gegenüber den Alten, der Lebenden gegenüber den Toten. ${ }^{22}$ Der Blick in die Vergangenheit dient den Söhnen einzig dazu, sich als Herren und Richter über ihre Väter und Vorväter zu erheben, sie anzuklagen, zu verurteilen und zu verachten; damit aber werden diese endgültig zu Opfern der Geschichte. ${ }^{53}$

Der Triumph der jüngeren Generation über die ăltere - das ist der wesentliche Zug des Fortschritts. Biologisch besteht Fortschritt im Aussaugen (poglosenie) der Älteren durch die Jüngeren, im Verdrăngen (yresnenie) der Văter durch die Söhne; psychologisch im Ersetzen der Liebe zu den Vătern durch seelenlose Erhebung über sie, durch Verachtung, die moralische oder, richtiger, außerst amoralische Verdrăngung der Văter durch die Söhne. (...) Fortschritt ist genau jene Form des Lebens, in der das Menschengeschlecht die grøBte Summe Leids erfahrt, wahrend es nach der groBten Summe von Vergnugungen strebt. (...) Zwar ist Stagnation Tod und Rückschritt kein Paradies, doch Fortschritt ist die wahre Holle, und die wahre gottliche, die wahre menschliche Aufgabe besteht darin, die Opfer des Fortschritts zu erlosen, sie aus der Holle herauszufuhren. Fortschritt als Negation der Vaterschaft und Bruderschaft ist sittlicher Tiefststand, ist totale Negation der Sittlichkeit. (I, 19.)

Früher wurden die Alten umgebracht; heute begnügt man sich damit, sie zu verachten und zu vergessen. Doch "was subjektiv Vergessen ist, ist objektiv Tren-

49 Fedorow unterscheidet davon die bloße geschlechtliche Enthaltsamkeit, die er als lebensfeindliche "negative Keuschheit" (otricatel'noe celomudrie) bezeichnet. Vgl. z.B. FEDOROV (wie Anm. 19), S. 693f. FOD I, S. 315-317.

50 Fedorov spielt hier offensichtlich auf Goethes Faust an: "Das ist der Weisheit letzter SchluB: Nur der verdient sich Freiheit wie das Leben, der tăglich sie erobern muB." (Faust II, 5. Akt)

51 FOD I, S. 72, 507.

52 FOD I, S. 18-21, 40.

53 "Die Historiker sind die Richter über die Verstorbenen, d.h. über diejenigen, die bereits das hochste StrafmaB erduldet haben, die Todesstrafe..." FOD I, S. 21. Selbsterhebung (samovozuysenie) war auch die Sünde des babylonischen Turmbaus - sie wurde mit Sprachverwirrung, d.h. Isolienung, bestraft. Vgl. FOD I, S. 10, 19. 
nung, Tod" (II, 263). Physischer Mord wurde durch geistigen ersetzt - ein "Fortschritt des Fortschritts", wie Fedorov ironisch bemerkt (I, 21).

Fortschritt, der einhergeht mit dem Vergessen der Väter (zabvenie otcov) und dem Abfall der Söhne (raspadenie synov), der das Aussaugen, Verschlingen und Verdrängen der vorangegangenen Generation durch die nachfolgende, den Tod also, zum Gesetz erhebt, solcherart Fortschritt errichtet das 'Paradies' auf einem Friedhof, auf den vermodernden Gebeinen der Vorfahren. ${ }^{54}$ Erst wenn alle Menschen sich als Söhne aller verstorbenen Väter - und folglich untereinander als Brüder - fühlen und erkennen und somit auch die Fernsten zu Nächsten werden, wird Geschichte Erinnerung sein an alle Menschen, und es wird niemanden mehr geben, der des Gedenkens unwürdig wäre. "Was aber subjektiv Gedenken ist, ist objektiv Bewahren der Verbindung ... was subjektiv Erinnern ist, ist objektiv Auferweckung." (II, 263)

Nicht nur zum Schutz vor Gefahren (Selbsterhaltung), sondern auch im Protest gegen den Tod (wahrgenommen im Tod des Mitmenschen) hatte der Mensch die aufrechte Haltung angenommen. Die Trauer des Sohnes über den Verlust des Vaters und die dadurch ausgelöste Furcht vor dem (eigenen) Tod waren die ersten Gefühle, die den Menschen überkamen. Mit dem Denken, welches zuerst Andenken an den Vater war, entstand das Bewußtsein der Unvollkommenheit und Zerrissenheit der Welt, der Vergänglichkeit alles Natur-Gegebenen. ${ }^{55}$ Als der Mensch die Ursache der Sterblichkeit erkannte, begann er, sich seiner Geburt zu schämen.

Man darf vermuten, daB dem Menschen alles Blut ins Gesicht schoB, als er von seinem Ursprung erfuhr, und daB er vor Entsetzen erbleichte, als er im Antlitz eines ihm gleichenden, blutsverwandten Menschen das Ende erblickte. Wenn diese beiden Gefühle den Menschen nicht augenblicklich tơteten, so nur deshalb, weil er sie wahrscheinlich erst allmăhlich erfuhr und somit nicht auf einmal die ganze Schrecklichkeit und Niedrigkeit seiner Lage abschăızen konnte. $(I, 312)$

Dann aber verbanden sich die "Schande der Geburt" (styd roždenija) und die "Furcht vor dem Tod" (strach smerti) zu einem "Gefühl des Verbrecherischen" (cuvstvo prestupnosti), daraus die Pflicht zur Auferweckung erwuchs. ${ }^{56}$

Die ersten Menschensöhne, die zu Waisen geworden waren, versuchten dieser Pflicht zu entsprechen, indem sie ihre Toten bestatteten; denn das Begräbnis und die damit verbundenen Vorkehrungen und Rituale (Grabbeigaben, Konservierung des Körpers, Leichenmahl u.a.) sind ebenso wie die Errichtung himmelstrebender, schwerkraftüberwindender Grabmäler nichts anderes als

54 In diesem Sinne kritisiert Fedorov auch Edward Bellamys Looking Backward 2000 1887; der Roman zeige, wie sich die bürgerliche Gesellschaft das Paradies auf Erden vorstelle: als Gelage auf den Grăbern der Vorfahren. Siehe FOD I, S. 140. FEDOROV (wie Anm. 19), S. 616.

55 FOD I, S. 761.; II, S. 267.

56 FOD I, S. 313. 
Zeugnisse des "Aufstands" gegen den Tod und "Maßnahmen zur Sicherung des Lebens, mochte es auch ein jenseitiges sein" (II, 237) ${ }^{57}$ Der Waisenzustand ließ die Menschen in ein verwandtschaftliches Verhältnis zur Erde treten, die den "Staub der Ahnen" (prach predkov) in sich aufgenommen hatte, und die Erde wurde ihnen teuer; sie band den Nomaden an sich und verwandelte ihn in einen arbeitsliebenden, friedlichen Ackerbauern, bei dem die Sorge um die Saat sich mit der Sorge um die Toten verband:

Lebendig ist die Religion im lăndlichen Heidentum, das nicht nur das Korn und seine Toten in der Erde birgt, begrăbt, săt, sondern auch glaubt, daß es durch seine Reigentănze..., die den Lauf der Sonne nachahmen, die Sonne vom Winter in den Sommer holt und durch die lebenspendende Kraft dieses Gestirns das Korn wiederbringt und die Toten auferweckt, auferweckt freilich nur in der lebendigen Phantasie des Volkes. $(I, 404)$

Zum Schutz der Begräbnisstätten, zur Bewahrung des kostbaren Staubs der Väter, entstanden Grabbauten, Friedhöfe, Burgen (kremli) und Ansiedlungen; rings um diese bildeten sich Städte, die durch das Andenken der Väter die Bedeutung von "Heimat" und "Vaterland" erhielten. Man versuchte, die Väter durch Lieder und Sagen, durch Überlieferung und Geschichte im Gedächtnis zu beleben, ebenso wie die Kunst sich bemühte, sie in Nachbildungen (Denkmälern) wiederherzustellen. ${ }^{58}$ Die verwaisten Söhne entwarfen eine "mythische Geographie", in der das "Reich der Toten", Paradies und Hölle, seinen Ort hatte; sie begannen, ihre Väter in fremden Ländern zu suchen (Odyssee, Alexandreis, Entdeckerfahrten) ${ }^{59}$ und sogar auf dem Firmament (Astronomie) ${ }^{60}$. Damals war die "Liebe zu den Verstorbenen" nicht auf einen engen Kreis be-

57 Im Totenkult der Alten werden wir, so Fedorov, "die Dankbarkeit der Kinder gegenüber ihren Eltern finden, die durch die Dankesplicht der Lebenden gegenüber jener langen Reihe der Vorfahren gefordert ist, durch deren schwere Anstrengungen all die Güter geschaffen wurden, deren sich die gegenwărtige Generation bedient. (...) Das Bemühen der Ägypter und Griechen, den Seelen ihrer Vorfahren Blut, Milch und Met zu trinken zu geben, kann bei uns natürlich nur ein Lächeln hervorrufen; doch dürfen wir nicht vergessen, da $B$ alle diese Volker ungeachtet ihrer Primitivităt - eine Wahrheit vorausgesehen haben, die zu erfassen man in unseren Tagen infolge des revolutionăren Geistes und seiner kindischen und rohen Verachtung alles Vergangenen oft nicht imstande ist. Auf ihre Weise spürten die Alten tief das Band, das alle Generationen des Menschengeschlechts vereint. (...) ... diese Idee von der Einheit aller Geschlechter und das Gefühl der Liebe und der Achtung, zu dem sie hinführt, waren für die primitiven Volker ein măchtiges Mittel zur sittlichen Vervollkommnung, ein festes Band für Familie und Gesellschaft." FOD II, S. 236.

Vgl. auch FOD I, S. 103, 138; II, S. 228-237. FEDOROV (wie Anm. 48), S. 12. - Fedorov definier den Menschen als "das Wesen, das [seine Toten] bestattet" (sušcestwo pogrebajušcee), um sie fortdauern zu lassen. FOD II, S. 33. Fedorovs Gedanken über den Ursprung und das Wesen der Religion, die oft als originell hervorgehoben werden, dürften auf Herbert Spencer zurückgehen, der in seinen Principles of Sociology (1855; verändert 1876-1896) die Religion auf den Ahnen- oder Totenkult zurückführt, diesen allerdings mit der Furcht vor den Toten begründet.

FOD I, S. 413.

FOD I, S. 102, 184.

FOD II, S. 267. 
schränkt, sondern "umfaßte das ganze Geschlecht, zu dem der Mensch gehörte" (II, 236).

Die Religion, die in ihrer ursprünglichen und einzig wahren Form Totenund Ahnenkult ist,

... das vereinte Gebet aller Lebenden, hervorgerufen durch Leiden und Tod, das Gebet um Rückgabe des Lebens an alle Verstorbenen, dessen Erfüllung die Pflicht und Tat der Betenden selbst ist, $(I, 414)$

sie schuf in der sakralen Kunst den Tempel, das Gotteshaus (chram) als Ebenbild des aufgerichteten menschlichen Körpers und als Projekt des vollkommenen Weltenbaus, der "neuen Erde und des neuen Himmels" (II, 152):

Die sakrale Kunst ist die Nachbildung der Welt in Gestalt des Gotteshauses, das alle Künste in sich vereinigt, wobei es als Werk der Architektur, Malerei und Bildhauerkunst zum Abbild der Erde wird, die ihre Toten herausgibt, und des Himmels (Kirchengewölbe und Ikonostase), der von den zum Leben erweckten Geschlechtern besiedelt wird; als Stătte des Gesangs, genauer des Totengesangs, ist das Gotteshaus die Stimme, unter deren Klang der Staub auf der Erde, der Erde als einem Friedhof, Leben erhalt und der Himmel zur Wohnstatt der Wiederbelebten wird. (II, 241)

Im Gottesdienst vereinigen sich alle diese Himmelsbewohner zu einem Ganzen mit denen, die den Gottesdienst im Gotteshaus vollziehen ... (den noch Lebenden); im Gottesdienst bilden sie alle, die Toten und die Lebenden, eine Kirche. $(1,413)^{61}$

Doch wurde dieses Projekt nicht verwirklicht: Das Gotteshaus blieb ein Gebäude, es wurde nicht zum Weltgebäude, und der Gottesdienst, die Liturgie als gemeinsames Werk der Auferweckung, blieb auf das Gotteshaus beschränkt (chramovaja liturgija); er wurde zur Sache der Priester und der Gemeinde, und der Vorgang der Wandlung, d.h. der Wiederbelebung, sank zum leeren Ritual herab. ${ }^{62}$ Wahre Liturgie aber muß die Grenzen des Gotteshauses überschreiten und als vnechramovaja liturgija (vnechramovoe dejstvie) zum wirklichen Handeln aller Menschen werden:

Die Liturgie besteht darin, daB man Staub der Ahnen in Gestalt von Brot nimmt, daB vom Brot Teile abgetrennt, mit Namen genannt, in Wein getaucht und dann in Leib und Blut verwandelt werden; das aber wăre wirklich Leib und Blut, wenn unser Glaube lebendig wăre, wenn er sich in der Tat außern und ausdrücken wiurde, wenn sich die Liturgie nicht auf das Gotteshaus beschränken würde, wenn die innere Gemeinschaft übergehen wïrde in die gemeinsame allmenschliche Tat. $(I, 260)$

Vorbild der vollkommenen Gemeinschaft aller Menschen, der Alleinheit (vseedinstvo), und zugleich Gebot und Wegweiser zu ihrer Verwirklichung im obšcee delo ist die unsterbliche göttliche Dreieinigkeit (Troica). ${ }^{63}$ Die Lehre von den drei Hypostasen - Vater, Sohn und Heiliger Geist (wobei der Geist als Vorbild

61 Vgl. FOD I, S. $220 f$., 512f.; II, S. 155, 267-269.

62 FOD I, S. 104f., 112, 176.

63 Ausführlich dazu FOD I, S. 68-87, 116; II, S. 182. 
für die Töchter dient) ${ }^{64}$ - beschreibt in idealer Weise alle zwischen Menschen möglichen Verwandtschaftsverhältnisse.

Die Lehre von der Dreieinigkeit bezieht sich auf das ganze Menschengeschlecht, denn sie umfaßt alle Lebenden (Söhne und Tơchter) und alle Toten (Văter und Mütter), und sie macht die letzteren (die Toten) zu einer Aufgabe für die ersteren (die Lebenden). $(I, 84)$

Die Wesenseinheit der trinitarischen Personen - "Einheit ohne Vermischung, Unterscheidung ohne Trennung" (I, 79) - fordert die Verwirklichung der allumfassenden "Einheit selbständiger unsterblicher Personen", d.h. die Auferwekkung aller Väter durch die "Menschensöhne" und die jungfräulichen, keuschen "Menschentöchter".

Die Dreieinigkeit ist die Kirche der Unsterblichen, und ihr Ebenbild von seiten des Menschen kann nur die Kirche der Auferweckten sein. (I, 70; Hervorhebungen im Orig.) ${ }^{65}$

Die Dreieinigkeit ist der hðchste Ausdruck der Verwandtschaft. $(I, 116)$

Egoismus kennt nur sich selbst (das "Ich"), Altruismus nur die anderen (das "Nicht-Ich"), Verwandtschaft aber überwindet diese Trennung: das "verwandte Ich" (rodnoe Ja) erkennt sich selbst in allen anderen und alle anderen in sich selbst, kennt mithin nur ein allumfassendes "Wir". Für das "verwandte Ich" gibt es keine "anderen" im Sinne von "Fremden" und keine künstlich-mechanischen Verbindungen. ${ }^{66}$ Allein die Kinder haben das Gefühl allumfassender Verwandtheit bewahrt, indem sie auch für "Fremde" verwandtschaftliche Bezeichnungen ("Onkel", "Tante") gebrauchen. ${ }^{67}$ Für das "verwandte Ich" wird Glück nur möglich in der Verwirklichung des Glückes aller.

64 FOD I, S. 77, 120-122. - Fedorov spricht nur selten von den "Töchtern", worrit (analog zu den "Söhnen") alle lebenden Frauen gemeint sind, wăhrend er mit dem Begriff "wahre Menschentochter" (istinnye doceri celoveceskie) jene Frauen bezeichnet, die, im Unterschied zur "Gattin" und "Mutter", aus Liebe zu den Eltern der Sinnlichkeit entsagen und in "positiver Keuschheit" Kindergebăren durch Auferwecken ersetzen. - Die Zuordnung der jungfraulichen Tochter und des Heiligen Geistes durch Fedorov hat wiederholt Verwunderung hervorgerufen ("... eine seiner undogmatischsten Thesen..." LEPACHIN, wie Anm. 3, S. 198), doch finden sich entsprechende Gedanken auch in der Trinitătslehre von Pavel Florenskij. Siehe unten Anm. 65.

65 Hingewiesen sei an dieser Stelle auf Entsprechungen in der Trinitătslehre von Pavel Florenskij, wie dieser sie v.a. in seinem theologischen Hauptwerk Stolp $i$ utverzdenie istiny dargelegt hat. Wie Fedorov, so übertrăgt auch Florenskij den Begriff der Wesenseinheit (edinosuscie, Homousie), der das Verhăltnis der drei gottlichen Hypostasen kennzeichnet, auf die Beziehungen zwischen den Menschen: Nach dem Urbild der trinitarischen Wesenseinheit vermag der Mensch auf dem Weg der Liebe, der Keuschheit und Askese die Einheit aller Geschopfe in der Kirche zu verwirklichen. Wie Fedorov schreibt Florenskij der dritten Hypostase das weibliche Element zu. "Der Heilige Geist manifestiert sich im Geschopf als Jungfrauschaft (deustuo)." P.[A.] FLORENSKIJ, Stolp i utverldenie istiny, M. 1914, S. 350. Ausführlich dazu M. SILBERER, Die Trinitätsidee im Werk von Pavel A. Florenskij, Würzburg 1984. Zu Florenskij und Fedorov auch II: 2.2.1.

66 Vgl. FOD II, S. 97f., 201f.

67 Vgl. FOD I, S. 58, 198. - Daher die Aufforderung des Evangeliums, umzukehren und zu werden wie die Kinder (Matth. 18,3). 
Indem der Mensch aus seinen Handlungen die persőlichen Antriebe, das Streben nach persönlichem Glück beseitigt, erlangt er dieses dennoch mit Notwendigkeit, weil die gemeinsame Tugend, d.h. die Sache aller, auch der Grund der Auferweckung aller und folglich auch der persönlichen Unsterblichkeit ist. $(I, 96)$

Die Maxime der Fedorovschen Ethik, des "Supramoralismus", lautet also:

Man darf nicht [nur] für sich selbst leben (Egoismus) und nicht [nur] für andere (Altruismus), sondern mil allen für alle; das ist die Vereinigung der Lebenden (der Söhne) zur Auferweckung der Verstorbenen (der Văter). (Ebd.; Hervorhebung im Orig.) ${ }^{68}$

\subsubsection{Das Verhältnis zwischen Denken und Handeln}

Die am tiefsten reichende und verhängnisvollste Entzweiung ist die Kluft zwischen Denken und Handeln.

Von allen Trennungen ist das Auseinanderfallen von Gedanke und Tat (raspadenie mysli $i$ dela) ... das allergroßte Ubel... $(I, 70)^{69}$

Denken und Handeln sind zu Angelegenheiten spezialisierter und dadurch einander entfremdeter Stände geworden; die Menschheit ist gespalten in Gelehrte (uð̌enye) und Nichtgelehrte (neuðenye). Der Grund dafür liegt "im ursprünglichen Zerbrechen der Ganzheit des Menschengeschlechts, d.h. im Vergessen seiner Pflicht gegenüber den Vätern" (I, 253). Tiefer noch als die dadurch hervorgerufene Zersplitterung der Menschheit in einzelne Völker mit ihren einander fremden Sprachen geht der Riß zwischen Gelehrten und Nichtgelehrten. Unfähig, einander zu verstehen, weil die einen sich einer "künstlichen Büchersprache $^{n}$ bedienen, die anderen aber sich in "lebendiger Volkssprache" ausdrücken, haben sich die Stände immer weiter voneinander entfernt.

Je tiefer der Unterschied zwischen den Ständen wurde, desto toter wurde der eine und desto grober der andere. (...) Wissen, vom Handeln getrennt, wurde zu Kontemplation, Handeln ohne Wissen zu mechanischer Arbeit. (I, 253)

Erkenntnis, bzw. im engeren Sinne Wissenschaft, wurde zum Monopol des Gelehrtenstandes, der, aus der städtischen Bevölkerung hervorgegangen, jeden Kontakt zum Landvolk, damit aber auch jede unmittelbare Beziehung zur Natur verloren hat. ${ }^{70}$ Nur der Bauer steht noch in einer ursprünglichen, unmittelbaren

68 Vgl. auch FOD I, 118, 314.

69 Vgl. auch FOD I, S. 45, 400. - Daß Fedorov die Trennung von Denken und Handeln, von Gelehrten und Nichtgelehrten für fundamental, die Trennung in Arme und Reiche hingegen für sekundär ("außerlich") gehalten hat, wurde von der sowjetmaxxistischen Kritik wiederholt als besonderer Mangel seiner Lehre hervorgehoben. Siehe auch oben Anm. 45.

70 Vgl. FOD I, S. 6, 208, 250; II, S. 65. - Fedorov spricht deshalb vom "künstlichen Leben der Stadt" (FOD I, S. 15, 293; II, S. 74). Siehe auch oben 3.1.2. 
Beziehung zur Natur, ist ihrem blinden Wirken direkt ausgesetzt; der Städter kann sich eine solche unmittelbare Beziehung nur mehr vorstellen:

... in den Stădten aber, die von der Natur weit entfernt sind, kann man sich eben deshalb nur mehr vorstellen, daß jemand ein Leben lebt, das eins ist mit dem der Natur. $(I, 7)^{71}$

Der Städter wähnt sich frei, sobald er Bürgerrechte besitzt, und hält sich für autonom und aufgeklärt, da er die Bedrückung durch die Natur kaum mehr verspürt. Dem Bauern hingegen wird sie täglich bewußt; er ahnt, daß erst die Beherrschung der blinden Naturgewalten wirkliche Freiheit bedeutet. ${ }^{72}$

Der Beginn der richtigen, modernen Wissenschaft fallt zusammen mit der Herausbildung eines gesonderten städtischen Standes, mit der Trennung der Stadt vom Dorf, ... mit der Trennung des Manufakturgewerbes vom Ackerbau... (I, 250)

Der Bauer hat es mit der lebendigen Natur zu tun, der städtische Handwerker hingegen mit Objekten, die er aus ihrer natürlichen Umgebung herausnimmt, isoliert und tötet, um an ihnen seine Operationen durchführen zu können. Die aus dem Handwerk hervorgegangenen empirisch-analytischen Wissenschaften tragen den Stempel ihrer Herkunft: Ihr Verfahren besteht im Trennen, Isolieren und Abstrahieren - im Abtöten also. ${ }^{73} \mathrm{Je}$ gründlicher nämlich die Analyse ist, und je weiter die Spezialisierung der Wissenschaften und ihre Abkapselung vom Leben in Gelehrtenstuben und Museen fortschreitet, "desto lebloser sind ihre Ergebnisse" (I, 250). Dies gilt vor allem für die Philosophie und ihre extremste Aberration, die Metaphysik, "diese am meisten leblose der leblosen, abstrakteste der abstrakten [Wissenschaften]" (ebd.).

Abgeschnitten von der Natur und den Nichtgelehrten, dem arbeitenden Volk und seinen Sorgen entfremdet (wenngleich auf seine Kosten lebend), verfällt die städtische Intelligenz, indem sie Denken über Handeln stellt, in eine inaktive, rein kontemplative Haltung. ${ }^{74}$ Die wissenschaftlich Gebildeten, soweit sie nicht im Dienst von Industrie und Militär, also von Ausbeutung und Zerstörung stehen, ziehen sich auf die reine Theorie zurück, die sich im interesselosen Begreifen der Welt, im passiven Nachbilden des Gegebenen erschöpft und somit

71 Vgl. FOD I, S. 278. - Wieweit der Stådter (und damit auch und insbesondere der Gelehrte) bereits den Kontakt zur Natur verloren hat, wird an einem einfachen Beispiel deutlich: derselbe Witterungswechsel, der vom Stadtbewohner als durchaus angenehme Abwechslung empfunden wird, bereitet dem Bauern møglicherweise eine Mißernte. FOD I, S. 7.

72 FOD II, S. 47f. - Freiheit ohne Macht über die Natur und ohne ihre Lenkung ist das gleiche wie eine Befreiung leibeigener Bauern, ohne ihnen Land zu geben. FOD II, 48.

73 Eine ihrer wesentlichen Aufgaben sieht die moderne Wissenschaft im Sammeln von getöteten Tieren, getrockneten Pflanzen, Mineralien und Metallen, die als ausgestopfte Bălge und Skelette, in Herbarien und Sammlungen von Proben und Bruchstücken auf speziellen Friedhofen Museen genannt - zusammengetragen werden, um don, fern ihrer natürlichen Umgebung, lediglich als Objekte gelehrter, d.h. passiver Betrachtung zu dienen. Fedorov spricht in diesem Zusammenhang von "Museolatrie" (muzeolatrija). FOD I, S. 251. 
folgenlos bleibt. Ihr erhabenstes Ziel ist Wissen um seiner selbst willen, Wissen, das ohne Anwendung bleibt oder gar unanwendbar ist:

Der gelehrte Professor ... mißt die grøßte Bedeutung dem Wissen um seiner selbst willen bei, dem reinen Wissen als geistigem Interesse, und seine Unanwendbarkeit (neprilotimost') rechnet er ihm noch als Verdienst an... $(1,22)^{75}$

Solches vom Handeln getrennte Wissen ist bloßes Standeswissen (soslovnoe znanie); das Volk, die Nichtgelehrten, haben weder Anteil daran noch Nutzen davon. ${ }^{76}$ Wissen um seiner selbst willen, die Ersetzung jeglicher Aktivität durch Welt-Anschauung, führt die Gelehrten schließlich zur Ideolatrie, zur Fetischisierung und Vergötzung des reinen Wissens:

Ideolatrie ist die Ehrfurcht vor dem Gedanken, der nicht in Tat übergeht, vor zweckfreiem, seelenlosem Wissen, vor dem Wissen der Gelehrten. (II, 241) ${ }^{\pi}$

Infolge ihrer kontemplativen, untätigen Lebensweise (kabinetnaja zizn') wird den Gelehrten die äußere, reale Welt zu einer Idee oder Vorstellung, zu einem bloß psychischen Faktum, schließlich zum Phantom. ${ }^{78}$

Wenn man die Welt ausschließlich unter theoretischem Aspekt betrachtet, wie dies jene Menschen tun, die sich nur dem Wissen verschrieben haben, so werden die von ihnen beobachteten Phănomene ... ihnen als ihre eigenen Vorstellungen erscheinen, und für solche Menschen wird es zweifelhaft sein, ob es irgendein Ding oder eine Kraft außerhalb des subjektiven Denkens gibt oder ob alle Erscheinungen nur im Innern derer zustande kommen, die sie denken. (II, 70)

\section{Auf diesem Weg gelangten die Philosophen}

... schließlich zu der Oberzeugung, daß das Leben eigentlich nichts Reales enthălt..., daß es sogar unmoglich ist, sich zu vergewissern, ob die Welt einem anderen genauso erscheint, wie sie mir erscheint. Von diesem Standpunkt aus hatte Fichte recht, als er sagte, da $B$ mit jedem abgeschlagenen Kopf eine ganze Welt zugrunde geht. (II, 238)

Die Verkehrung der Welt in eine subjektive Erscheinung, eine bloße Vorstellung, eine "Täuschung" (obman), "die letzte Ausgeburt (isčadie) der Untätigkeit" $(I, 13),{ }^{79}$ mindert den Wert des Lebens - "weshalb auch Projekte zu einer allgemeinen Selbstvernichtung auftauchen" (II, 238) - und verstellt den Blick für die Schrecken des Todes. Nur in sich selbst versenkt und dadurch den übrigen

75 Vgl. FOD I, S. 11.

76 Vgl. FOD I, S. 249f. - Es wăre nutzlos, sogar schădlich, stådtisches Gelehrtenwissen (gorodskoe soslovnoe znanic) unter der Landbevolkerung zu verbreiten, da es zur Behebung ihrer Note untauglich ist, hingegen den verderblichen Einfluß der Stadt auf das Land fördern würde. FOD I, S. $252 \mathrm{f}$.

77 Vgl. FOD I, S. 22, 391, 403.

$78 \mathrm{Vgl}$. FOD I, S. 251, 334.

79 Die Welt als bloße Vorstellung ist "unvermeidlich für Stubengelehrte (kabinetnye uxenye), die ohne jede Tătigkeit sind, verurteilt einzig zur Kontemplation..." (FOD I, S. 13). 
Menschen entfremdet, empfindet der Gelehrte den Tod anderer nicht als Verlust und kennt folglich nicht den Wunsch, verlorenes Leben wiederherzustellen. Die Macht des Todes wird von ihm als ewig und unüberwindbar akzeptiert.

Alle Philosophen, wenn sie auch in allem uneins sind, stimmen doch in einem überein: sie alle anerkennen die Realităt des Todes, seine Unbezweifelbarkeit, selbst wenn sie, wie einige von ihnen, nichts Wirkliches in der Welt anerkennen. Sogar die allerskeptischsten Systeme, die sogar den Zweifel selbst bezweifeln, beugen sich vor dem Faktum der Wirklichkeit des Todes. (I, 287)

Seine eigene Abhängigkeit von Natur und Tod nimmt der Gelehrte entweder passiv hin, oder er sucht - was auf das gleiche hinausläuft - sich ihr zu entziehen, jedoch nicht durch wirkliche Befreiung von den elementaren Naturgewalten, sondern "im Bereich spekulativer Abstraktion (umozritel'noe otvlecenie) von der Wirklichkeit" (II, 70).

Verlust und Tod werden in diesem Falle nicht einmal mehr wahrgenommen. $\mathrm{Da}$ ihm alles zur Vorstellung wird, begnügt sich der Philosoph mit dem Bild, das in seinem Geist zurückbleibt, wenn der Gegenstand selbst verschwunden ist, ohne da $B$ dieses nur gedachte Bild in ihm ein Gefühl des Verlustes hervorrufen würde oder gar das Bestreben, das Verlorene wiederherzustellen. ${ }^{80}$

Einer nur gedanklichen Rekonstruktion von Vergangenem dient auch das Sammeln und Aufbewahren historischer Zeugnisse in Form isolierter Überbleibsel und Bruchstücke in Kabinetten und Museen. Aus ihnen entsteht nur ein Bild der Welt, das begrenzt bleibt auf die Vorstellung des jeweiligen Betrachters. Der Gelehrte, der kein Gefühl, sondern nur Verstand besitzt, empfindet beim Anblick solcher Zeugnisse keinen Schmerz über die Dahingegangenen, wird sich keiner Schuld bewußt - eben dies aber wäre die Voraussetzung, um von der scheinbaren Restitution der Vergangenheit überzugehen zu ihrer realen Auferweckung. ${ }^{81}$

Nirgends wird der allmähliche Zerfall ursprünglicher Ganzheit (celost nost) so deutlich, wie in der Entwicklung des abendländischen Denkens. ${ }^{82}$ Der delphische Imperativ 'Erkenne dich selbst', der zum Prinzip der Philosophie

80 Vgl. FOD I, S. 334f. - Der Philosoph, der nur sich selbst kennt, gelangt darüber sogar zur Leugnung des Todes, denn, so Epikur, "solange ich bin, ist der Tod nicht, wenn aber der Tod ist, so bin ich nicht." FOD I, S. 697. - In Wirklichkeit suchte mit dieser Öberlegung der Epikurăer Lukrez die Todesangst zu überwinden.

81 Vgl. FOD I, S. 28, 249f; II, S. 211.

82 Die Auseinandersetzung mit den großen Vertretern der abendlăndischen Philosophie nimmt deshalb in Fedorovs Schriften breiten Raum ein. Zumeist polemisch in Ton, handelt es sich dabei stets um grundsatzliche Kritik aus der Position des obšce delo, die ihrem Gegenstand kaum je gerecht wird, dafür aber um so mehr über Stil und Inhalt von Fedorovs Denken aussagt. Auf die Vielzahl von MiBverstăndnissen und Fehlinterpretationen - besonders kraB und offensichtlich im Falle von Kant und Nietzsche - soll im folgenden nicht eigens hingewiesen werden. 
Sokrates' und Platons wurde, markiert den Beginn jener verhängnisvollen Tradition, die gekennzeichnet ist durch das Auseinanderfallen von Theorie und Praxis und die fortschreitende Isolierung des denkenden und erkennenden Subjekts. ${ }^{83}$

Die Aufforderung zur Selbsterkenntnis beruht auf der Überzeugung, "das wahre Wesen der Welt und der Sinn des Lebens [gäben sich] dem Menschen innerlich, in sich selbst [zu] erkennen" (II, 89; Hervorhebungen im Orig.), weshalb es genüge, nur sich selbst und in sich selbst zu erkennen. ${ }^{84}$ Erkenntnis geschieht demnach unmittelbar und individuell, d.h. ohne Zutun anderer, durch Introspektion, durch Versenkung ins eigene Innere. Voraussetzung und Folge davon sind Absonderung, Vereinzelung und Entfremdung der Individuen. ${ }^{85}$

'Erkenne dich selbst' bedeutet, glaube nicht den Vătern (das heißt der Uberlieferung), traue auch nicht den Brüdern (dem Zeugnis der anderen), sondern traue nur dir selbst, kenne nur dich selbst... $(I, 46)^{86}$

Solcherart Erkenntnis zielt nur auf ein Wissen, das nichts anderes als Gegebenes konstatiert und beschreibt, und das sich dadurch vom Handeln trennt. Bloße Theorie drängt nicht auf praktische Verwirklichung, ist Selbstzweck. Die Konzentration auf das eigene Ich ohne Anerkennung aller anderen, der Lebenden und der Toten, führt zu Selbstsucht und Eigenliebe und macht Brüder und Väter vergessen. ${ }^{87}$

In Platons Philosophie hat die sokratische Macht der unmittelbaren Erkenntnis oder die innere Stimme des daimonion, der neue Gott im individuellen Subjekt, die Götter der griechischen Mythologie entthront oder zumindest umgeformt; sie sind zu Ideen geworden:

... der Bildhauer Sokrates gab sein Handwerk auf und wurde Philosoph, das heiBt, er ging von der Anbetung der Idole über zur Anbetung der Ideen, und diese Anbetung ging bei seinem Schüler Platon über in Ideolatrie, in die unsinnige Trennung des Gedankens von der Tat. $(I, 225)$

Die Trennung des Denkens vom Handeln markiert das Ende des mythischen (oder mythologischen) Zeitalters und den Beginn des metaphorischen. ${ }^{88}$ Das

83 Vgl. FOD I, S. 319, 390f., 429f., 453; II, S. 89.

84 Gnöthi seauton war bei Platon Aufforderung zur Selbsterkenntnis als Voraussetzung richtigen Handelns. Wenn Fedorov in diesem Zusammenhang von 'Selbsterkenntnis' (samopoznanie) spricht, so ist damit nicht nur gemeint, daB das eigene Ich Gegenstand von Erkenntnis wird, sondern auch, daß es die einzige Quelle wahren Wissens darstellt.

85 FOD II, S. 90.

86 Vgl. FOD I, S. 407; II, S. 107, 113, 199 f.

87 Vgl. FOD I, S. 46, 390f., 453.

88 Die (auf A. Comte zurückgehende) Dreiteilung der Zivilisation in ein mythologisches (theologisches), metaphysisches und positivistisches Stadium wird von Fedorov verworfen (FOD I, S. 335). Er unterscheidet nur zwei Perioden, nămlich eine mythologische und eine metaphorische (ebd., S. 336). Die mythologische Periode müsse, so Fedorov, eigentlich 
mythische Entwicklungsstadium der Menschheit war gekennzeichnet durch die Einheit von (mythischem) Wissen und (mythischem) Handeln zum Zweck der Beeinflussung der Natur. Die Naturvorgänge dachte man sich abhängig von menschenähnlichen, bewußtseinsbegabten Wesen; diese könne der Mensch durch Beschwörungen und Gebete zwingen, ihm zu Willen zu sein, "das heißt, der Mensch schrieb in diesem Entwicklungsstadium seinem Wort die Macht unmittelbaren Wirkens in der Welt zu" $(I, 335)$.

Mythische Vorstellungen und Bilder sind Projekte des Handelns; auch die Vorstellung der Unsterblichkeit, die die Lebenden veranlaßt, die Toten zu versorgen und ihr Andenken zu bewahren. ${ }^{89} \mathrm{Da}$ der mythische Unsterblichkeitsglaube jedoch ein jenseitiges Totenreich imaginierte, in welchem er sich die Verstorbenen als Lebende vorstellte, war er nicht imstande, die wesentliche Pflicht gegenüber den Verstorbenen zu erfüllen, nämlich sie in diese Welt zurückzuholen. ${ }^{90}$ Wenn auch zur Wirkungslosigkeit verurteilt, so waren der mythische Unsterblichkeitsglaube und die ihm entspringenden Aktivitäten doch Ausdruck von Schuldbewußtsein und Pflichtgefühl der Lebenden gegenüber den Toten. ${ }^{91}$

Der Übergang zur Ideolatrie der Philosophen bedeutet hingegen die völlige Verneinung dieser Pflicht ${ }^{92}$ und führt zur Anerkennung des Todes. "Der lebendigen Wirklichkeit und Tätigkeit entfremdet, im Gefilde toter Abstraktionen weilend", (I, 155) erklärten die Philosophen den Tod für unausweichlich und endgültig ${ }^{93}$ und verwarfen alle Versuche, ihn zu überwinden, als unwirksam:

Es war der Philosophie ein leichtes zu beweisen, daß die Toten keine Speise brauchen und daß keinerlei Beschworrungen und Gebete das Schicksal der Verstorbenen zu ăndern vermögen. $(I, 115)$

Verhängnisvoller noch als die berechtigte Kritik der Philosophen an der Unzulänglichkeit des traditionellen Ahnenkults war ihr Angriff auf andere Institutionen, die ebenfalls aus dem Gefühl der Verwandtschaft und der Pflicht gegenüber den Verstorbenen erwachsen waren: die Familie, die Sippe, das Gemeinwesen. ${ }^{94}$

mythourgische oder theurgische heißen, da die mythische Tat (ergon) im Vordergrund gestanden habe, Denken (logos) hingegen nur als Projekt, d.h. im Hinblick auf eine Handlung geübt wurde (ebd., S. 352). Der metaphorischen Periode, die mit der Trennung von Denken und Handeln anbricht, sind auch die metaphysischen und positivistischen Epochen zuzurechnen, "weil sowohl von der Metaphysik wie vom Positivismus gleichermaßen zum Grundsatz erhoben wird, sich nicht das Handeln, sondern das nur gedachte Wissen zum Ziel zu setzen." (FOD I, S. 336)

89 Vgl. FOD I, S. 46f., 169, 221, 335; II, S. 5f. - Ausführlich und mit besonderer Bewunderung spricht Fedorov in diesem Zusammenhang vom altägyptischen Totenkult. Siehe FOD II, S. 228-235.

90 Vgl. FOD I, S. 26, 114; II, S. 237.

91 FOD II, S. 236f.

92 Vgl. FOD I, S. 47, 221.

93 Vgl. FOD I, S. 79, 287.

94 FOD I, S. 114. 
Der Mensch trat als Individuum in Erscheinung, als die Gemeinschaft (obšcina) ihre Bindekraft zu verlieren begann und er den Unterschied gewahrte zwischen seinem Leben und der scheinbar ewigen Einheit der Väter und Söhne. Indem das Individuum an Selbstbewußtsein gewann, schwand das Gefühl der Verwandtschaft und damit der Pflicht gegenüber den Toten; die Liebe zu den Vätern erstarb, ${ }^{95}$ der Tod nahm einen totalen Aspekt an.

Das gemeinschaftliche Leben (obšCestvennaja Žizn') wurde seines sakralen Charakters beraubt; sein Ziel war nicht länger die Sorge um die Toten, sondern nur noch Nutzen und Annehmlichkeit für die Lebenden. ${ }^{96} \mathrm{Zu}$ diesem Zweck gingen die Menschen künstliche Verbindungen ein oder zogen sich aus dem als leidvoll erfahrenen gesellschaftlichen Leben auf sich selbst zurück. ${ }^{97}$

Unter den Einfluß des von Sokrates und Platon philosophisch begründeten Individualismus geriet auch das Christentum. Als passiv und egoistisch erweist sich die asketische Haltung jener Christen, die, in Erwartung des Untergangs, sich aus der Welt zurückziehen und dabei, nur auf die eigene, jenseitige Erlösung bedacht, ihre Mitmenschen dem Unheil überlassen. ${ }^{98}$

Gott zu verehren, ohne den Vorfahren das ihnen Schuldige zu erweisen, ... ist das gleiche, wie Gott, den wir nicht sehen, zu lieben, den Năchsten aber, den wir sehen, nicht zu lieben. $(I, 46)$

Zwar verkündet das Evangelium den Triumph über den Tod, doch ist der Glaube daran erstorben:

... selbst Christus ... ist nicht wiederauferstanden, sondern starb in den Kopfen der deutschen und anderer Professoren und der "Intelligenz" Gberhaupt. Doch wenn Christus nicht auferstanden ist, dann werden auch die Vater nicht in ihren Herzen auferstehen, sondern nur in Gedanken und Vorstellungen weiterleben. (II, 211)

"Platonisch" ist ein Christentum, dem das Vorbild der Auferstehung Christi bloßes Bild bleibt, das sich mit "scheinbarer Auferweckung" (mnimoe voskre-

95 FOD I, S. 115.

96 Vgl. FOD I, S. 30, 115.

97 "Die Lehre der Stoiker von der Verachtung alles Äußerlichen, von der Unabhăngigkeit des Weisen gegenüber der Welt und den Menschen, von der doppelten Wahrheit, für die Weisen und für die geworhnlichen Menschen, schließlich von der inneren Freiheit durch den Selbstmord als ultimum refugium: all das sind hochtrabende Varianten des entarteten 'Erkenne dich selbst!" Fedorov zitiert nach KožEVNIKOv (wie Anm. 18), S. 66; ohne Nachweis.

98 Fedorov, der selbst ein in jeder Hinsicht streng asketisches Leben führte, wollte Askese nicht als Tugend an sich oder gar als Mittel zur Selbsterlosung ("negative Askese") verstanden wissen. "Positive Askese" sollte der "sittlichen Selbsterziehung" dienen, der Sammlung und "Ausrichtung aller Kräfte des menschlichen Organismus auf das höchste Ziel des Lebens". K[OŽEVNIKOV] in: FOD II, S. 129 Anm. 1. Askese dürfe also nicht zur Vereinzelung und Weltflucht führen, sondern müsse im Gegenteil in die gemeinsame Tat übergehen. - Wieweit Fedorov selbst dieser Forderung nachgekommen ist, soll hier nicht erortert werden. 
Senie) im Gedenken an die Verstorbenen begnügt und sich mit der Vorstellung eines jenseitigen Lebens tröstet. ${ }^{99}$

Was ist phantastischer: die Errichtung einer sittlichen Gesellschaft auf der Anerkennung der Existenz anderer Wesen in anderen Welten und der Anerkennung einer Emigration der Seelen dorthin, von deren wirklicher Existenz wir uns freilich nicht überzeugen kơnnen - oder aber die Verwandlung dieser transzendenten Migration in eine immanente, in ein Ziel menschlichen Handelns? (I, 284f.)

Einen entscheidenden Schritt auf dem Weg zur Isolierung des Individuums und zur Hypostasierung des bloß Gedachten tat Descartes. ${ }^{100}$ Schloß das delphische 'Erkenne dich selbst' die Möglichkeit anderer als eigener Erkenntnis noch nicht gänzlich aus, sondern lenkte bloß davon ab, indem es die Aufmerksamkeit und Liebe des Menschen auf sich selbst konzentierte, so folgt aus dem cartesischen Cogito ergo sum die völlige Abschließung des denkenden Subjekts in sich und als Ergebnis seines Denkens nur "seelenloses Wissen" (bezdứnoe znanie). (I, 137)

Nach dieser Formel ist das erste, unmittelbar Gegebene nicht das Sein, sondern das Bewußtsein. Die Gewißheit des eigenen Seins wird vom Ich-Denke her deduziert. Denken, nicht Handeln, wird zur einzigen Versicherung des eigenen und nur des eigenen Seins: Ich denke, folglich existiere ich. "Im Bewußtsein nur seiner selbst findet der Philosoph den Beweis für seine Existenz" (ebd.), und nur der eigenen Existenz wird volle Glaubwürdigkeit (dostovernost') zugeschrieben. ${ }^{10}$

Auch das übrige Sein ist nicht unmittelbar evident, sondern nur durch die Vermittlung des Wissens, also des Bewußtseins, zugänglich. Descartes verwirft jedoch alles, was nicht vom individuellen denkenden Subjekt selbst gedacht worden ist. Alles Wissen anderer ist fremdes Wissen und somit ohne Bedeutung für das Subjekt, das damit zu einem eigenmächtigen und selbstgenügsamen, von allem Übrigen abgeschlossenen Wesen wird. ${ }^{102}$

Die Philosophie Kants ist die "Legitimierung, die Heiligung des Bösen, nämlich der Trennung, die in der Welt herrscht" (I, 442; Hervorhebungen im Orig.). ${ }^{103}$

99 Vgl. FOD I, S. 32, 46, 69f., 74, 104f., 112, 139, 141f., 260. - Christi Auferstehung wurde, so Fedorow, in zweifacher Weise mißdeutet: als immanentes, jedoch einmaliges, abgeschlossenes Ereignis oder als transzendente Erscheinung und Vorbild für den einzelnen, nicht aber für die Gesamtheit der Menschen. FOD I, S. 150f. In Wahrheit, so Fedorov, sei Christi Auferstehung Vorbild und Beginn der durch die vereinte Menschheit zu verwirklichenden immanenten und allumfassenden Auferweckung. Vgl. FOD I, S. 22, 139, 144, 249.

100 Vgl. FOD I, S. 137, 148; II, S. 49, 90. - Die folgenden Ausführungen zu Descartes stützen sich auch auf KožEVNIKOV (wie Anm. 18), S. 68f., $72 f$.

101 Vgl. FOD II, S. 90, 340.

102 Vgl. FOD II, S. 49. KoŽeVnNKov (wie Anm. 18), S. 68.

103 Fedorov beschăftigt sich ausfuhrlich mit Kant und widmet ihm zahlreiche Artikel. Siehe FOD II, S. 52-82. Kants EinfluB auf das abendlăndische Denken hălt Fedorov für so groB, daB er bezweifelt, ob "der Westen sich je vom Joch und vom Druck der Kantschen Kritik [werde] befreien können" (FOD II, 54). - Fedorovs 'slavophile' Kantkritik ist als Kritik des Agnostizismus in der neueren sowjetischen Literatur wiederholt positiv bewertet worden. Vgl. GRECKO, EPI. sKoposov (wie Anm. 1), S. 67. M.G. FEDOROV, "Materializm velikich russkich revoljucionnych 
Durch die Unterscheidung von reiner (theoretischer) und praktischer Vernunft hat Kant die Trennung von Theorie und Praxis bestätigt und für "ewig und unaufhebbar" (II, 56) erklärt. ${ }^{104}$ Damit hat er - ein typischer Vertreter des Stadtbürgertums - auch die unnatürliche und unmoralische Trennung des Gelehrtenstandes vom Volk sanktioniert. ${ }^{105}$

Die Kritik der reinen Vernunft gestattet nur subjektive, eng begrenzte Erkenntnis, da sie den Bereich der Erfahrung (opyt) einschränkt auf Erfahrungen, "die an einem bestimmten Ort, zu einer bestimmten Zeit von einer bestimmten Person gemacht werden. Sie kennt nicht die Erfahrung, die von allen Menschen immer und überall gewonnen wird..." (I, 15; Hervorhebungen im Orig.). Zudem beschränkt sie Erkenntnis auf die Erscheinungen und macht sie damit "unfähig, Wahn (bred) und Wirklichkeit zu unterscheiden" (I, 443).

Eng begrenzt ist auch der Bereich der praktischen Vernunft. Die Ziele menschlichen Handelns vermag sie nur als gedachte, geglaubte zu entwerfen, ohne den Weg zu ihrer Verwirklichung zu weisen. ${ }^{106}$ Voneinander isoliert, erlangt die reine Vernunft keine Wahrheit (istina), die praktische verwirklicht kein Gut (blago). ${ }^{107}$ Zwar fordert letztere "imperativ", das Gute zu tun, ${ }^{108}$ doch ist sie außerstande, das Böse zu beseitigen:

Kants Vorurteil besteht darin, daB er die Forderung der praktischen Vernunft, die sinnliche Welt (die Welt, wie sie ist) der sittlichen Welt (der Welt, wie sie sein soll) unterzuordnen, für unerfüllbar erklärt. (II, 68)

Damit aber bleiben die drei "praktischen Postulate", nämlich Freiheit, Unsterblichkeit und Gott (Vollkommenheit), nur leere Begriffe eines passiven, toten Glaubens. Um sie wirksam werden zu lassen, müßten sie zum Ziel menschlichen Handelns gemacht und in gemeinsamer Tat verwirklicht werden. ${ }^{109}$

Die praktische Vernunft, die die Anerkennung wahrer Freiheit, wirklicher Unsterblichkeit, realer Existenz Gottes forden, wird vemünftiger, nicht aber toter Glaube nur dann sein, wenn sie zu ihrem Beweis die Tat selbst hat, noch dazu die gemeinsame Tat. (II, 62; Hervorhebungen im Orig.)

Kant aber ist ein "Feind der Tat im allgemeinen und der gemeinsamen Tat im besonderen" (II, 55). Deshalb hat die "praktische Vernunft das Böse in der Welt

demokratov i russkij filosofskij idealizm $\mathbf{v}$ ich otnošenii $k$ klassizeskoj nemeckoj filosofii. ${ }^{\text {" In: }}$ Istonja filosofii i sovremennaja ideologiceskaja borba. Sb. nautnych trudov. Novosibirsk 1981, S. 31-33.

104 Vgl. FOD I, S. 16, $442 f$.

105 Vgl. FOD II, S. 60, 65f.

106 Dies wird besonders deutlich an Kants Projekt des "ewigen Friedens", das auf den Bereich der Spekulation beschrănkt bleibt. Vgl. FOD I, S. 245f.; II, S. 340f.

107 FOD II, S. 56.

108 FOD II, S. 53.

109 Vgl. FOD I, S. 206f., 245; II, S. 341. 
nicht beseitigt, weil sie die gemeinsame Tat nicht zuließ, sondern nur Einzelaktionen (dejstvija v odinocka)" (II, 53).

Abgrenzung und Passivität kennzeichnen auch die dritte Kantsche Kritik:

Die 'Philosophie der Kunst', von Kant 'Kritik der Urteilskraft' genannt, spricht nicht davon, wie zu schaffen sei, sondern nur davon, wie Kunstobjekte und Hervorbringungen der Natur vom Standpunkt der Ästhetik zu beurteilen seien. Das ist eine Philosophie für Rezensenten, nicht aber für Maler und Dichter... (II, 75; Hervorhebungen im Orig.)

Für Kant wird die Natur zum "Gegenstand bloßer Beurteilung und Betrachtung, noch dazu von einem ästhetischen Standpunkt, nicht von einem sittlichen, von dem aus sie sich als eine zerstörende, todbringende Macht zeigt." (II, 75) Dabei vergißt er, da $B$ "Schönheit und ZweckmäBigkeit" keine Schöpfungen der Natur, sondern der vernunftbegabten Menschheit sind. ${ }^{110}$ Als typischer Stadtbürger, der zum bloßen Denken verurteilt ist ohne Willen und Möglichkeit zu handeln, der mit Verachtung aufs Dorf herabsieht, der nie den Druck der Natur verspürt hat und alles von sich fernhält, was an den Tod gemahnt, ${ }^{111}$ akzeptiert Kant die "Natur in all ihrer seelenlosen Macht" (II, 58). Ihr gegenüber stellt er die "Vernunftwesen, einzeln und passiv, und verurteilt sie zu ewiger Begrenztheit nicht nur im Raum, sondern auch in der Zeit..." (II, 55).

Ihm, dem Philosophen der Hoffnungslosigkeit und der Verzweiflung, scheinen überall Grenzen und Schranken zu sein, die er auch selbst in allen Bereichen des Lebens, des Denkens und Handelns errichtet. (1I, 55)

Dieses Sichabfinden mit dem Gegebenen, die Unterwerfung unter die blinde Gewalt der Natur

...ist die Ursache der Ohnmacht der Menschen, ihrer Begrenztheit im Raum durch die Bindung an die Erde, davon sich zu befreien und den Weg zu himmlischen Welten zu offnen der Stadtmensch nicht einmal zu trăumen wagt. Dieselbe Ursache, dieselbe Sklaverei bewirkt auch die Begrenztheit in der Zeit durch unsere Sterblichkeit. Den Ubergang von ihr zum (unsterblichen) Leben kann sich der Stădter ebensowenig vorstellen, wie den Obergang von der Erde zum Himmel. Die Begrenztheit im Raum verhindert ein allseitiges Einwirken der Vernunftwesen auf alle Welten des Universums, die Begrenztheit in der Zeit, die Sterblichkeit, verhindert ein gleichzeitiges Einwirken aller Generationen der Vernunftwesen auf das gesamte Universum. Kant erklărt kategorisch, wie es sich für einen echten stădtischen Denker gehör, ohne in die Ursachen einzudringen, die die Menschen gegen die blinde Gewalt ohnmăchtig machen, die Menschen für unfahig nicht nur zur Regulierung, sondern sogar zur Wahrnehmung der Welt in ihrer Ganzheit, was natürlich ohne Regulierung auch unmoglich ist. (1I, 58)

[Kant], wie überhaupt der westliche Mensch, sieht das höchste Gut in der Getrenntheit (rozn), (in der Individualităt, in der Persónlichkeit), da er Getrenntheit für die notwendige Bedingung der unabhăngigen Persơnlichkeit und der Freiheit hălt. (II, 68)

110 FOD II, S. 54.

111 FOD II, S. $57 f$.

Bayerische

Staatsbibliothek München 
Kants Insistieren auf dem Wert (dostoinstvo) ${ }^{112}$ und der Autonomie des Individuums beweist gerade, da $B$ die Menschen einander fremd geworden sind, da $B$ sie "die Väter vergessen und aufgehört haben, Brüder zu sein," (II, 66) daß ihre Beziehungen untereinander nicht mehr durch das Bewußtsein allumfassender Verwandtschaft geprägt, sondern juristisch, d.h. durch künstlich geschaffene Gesetze geregelt sind. Die Frage nach der gesetzgebenden Instanz ist dabei unerheblich, da sowohl Autonomie wie Heteronomie Ausdruck fehlender Verwandtschaft und somit gleich verwerflich sind. ${ }^{113}$

Geradezu höhnisch ist es, den Menschen angesichts seiner Abhängigkeit von der blinden Natur als autonom zu bezeichnen:

Der Mensch ist sich selbst Gesetz in der Sphăre des Denkens, in Wirklichkeit aber ist er Sklave einer jeden Mikrobe! Nach Auffassung des Verstandes ist der Mensch unbedingt frei und unfehlbar 'ex cathedra'; faktisch, in Wirklichkeit aber ist er überall Sklave der blinden Gewalt [der Natur]! Oder hat der Professor Kant (als er von der Autonomie des Menschen sprach) vergessen, was er selbst gesagt hatte, daß nămlich 'ein Taler in Gedanken nicht dasselbe sei wie ein Taler in der Tasche?' Ein vom Verstand bloB vorgestellter Taler ist kein wirklicher, ist weniger noch als ein gefalschter. Kurz: Autonomie ist eine Falschung! (...) Autonomie (wie sie bis heute verstanden wird) ist etwas in Gedanken Gemachtes, Fiktives und gröBtenteils nur Projektives. In Wirklichkeit ist solche Autonomie Heteronomie, die unweigerlich in Antinomie übergeht. (II, 63; Hervorhebungen im Orig.)

Der Mensch bleibt unfrei, solange er dem blinden Wirken der Natur ausgesetzt und dem Tod verfallen ist. ${ }^{114}$ Die Sterblichkeit als letzte Ursache menschlicher Unfreiheit nicht erkannt, oder richtiger, sie ignoriert zu haben, ist der größte Fehler der Kantschen Philosophie. ${ }^{115}$

Dieser Vorwurf trifft auch andere Vertreter des klassischen deutschen Idealismus - Hamann, Jacobi, Fichte, Hegel und Schopenhauer. ${ }^{116}$ In Hegels Philosophie, in der sich alles Seiende in Gedachtes verwandelt, ist die Entwicklung des spekulativ-theoretischen Denkens auf die Spitze getrieben und zum Abschluß gelangt: "Weiter kann man auf dem Gebiet des abstrakten, allesverschlingenden Denkens, der Idealisierung des Realen, nicht mehr gehen." (II, 88) ${ }^{117}$ Schopenhauers Satz von der "Welt als Wille zum Sein" (mir kak volja $k$ bytiju)

112 Vgl. FOD II, S. 66, 82.

113 "Autonomie und Heteronomie kőnnen nur bestehen, wenn keine Verwandtschaft herrscht." FOD II, S. 66.

114 Für Fedorov ist 'volle Freiheit, selbstbestimmtes und selbsttătiges Handeln (samodejatel'nost'), identisch mit Unsterblichkeit". FOD I, S. 338.

115 Vgl. FOD I, S. 16; II, S. 68.

116 Siehe FOD II, S. 82-97. - Die Anregung, sich mit Hamann und Jacobi zu beschätigen, dürfte Fedorov von seinem Freund Koževnikov empfangen haben; letzterer war ein Kenner des deutschen und englischen Idealismus und hatte umfangreiche Studien zu Locke, Hume, Wolff, Lessing, Hamann, Jacobi und Herder betrieben. Siehe auch I: 1. Anm. 59.

117 Hegel wird deshalb (neben Kant und Nietzsche) von Fedorov als der "letzte Philosoph" bezeichnet. Zu Hegel FOD II, S. 82-89. Siehe auch D. TschnZEwSKU, Hegel bei den Slaven, Darmstadt ${ }^{2} 1961$, S. $354 f$. 
meint in Wahrheit die "Welt als Wollust" (mir kak pochot) und infolgedessen als "Unfreiheit zum [vor dem] Tode" (mir kak nevolja k smerti [pered smert'ju]) und dies so lange, wie die Welt eine "Vorstellung" (predstavlenie) in den Köpfen der Gelehrten bleibt, anstatt zum Projekt der Wiederherstellung des Lebens zu werden. ${ }^{118}$

Nietzsche schließlich hat mit seinem Ästhetizismus und Amoralismus die letzten Konsequenzen aus dem 'Erkenne dich selbst' gezogen und damit den Irrweg des abendländischen Denkens zu seinem Ende gebracht. ${ }^{119}$

118 FOD I, S. 405. Vgl. ferner FOD II, S. 89f., 110, 113f., 118, 151. KoŽEVNKov (wie Anm. 18), S. 90-93. - Zwischen Fedorov und Schopenhauer gibt es eine Reihe von Berührungspunkten und Gemeinsamkeiten, die eine genauere Untersuchung rechtfertigen würden: Für Fedorow wie für Schopenhauer bilden das Wissen um den Tod, die Betrachtung des Lebens als eines Kampfes aller gegen alle sowie die Empörung über das geschichtliche Leiden die zentralen Motive ihres Philosophierens. Beide sehen im Menschen die Natur zum SelbstbewuBtsein gelangt, beide verwerfen die Geschlechtsliebe als blinden, immer neues Leid verursachenden Trieb. Für Schopenhauer bildet das Gefühl des Mitleids die Grundlage der Moral, für Fedorov das Gefühl der Schuld gegenüber den Vorfahren. Voraussetzung ist in beiden Fällen das Sichwiedererkennen in den anderen: das Durchschauen des principium individuationis (Schopenhauer), das Sichbewußtwerden als Bruder und Sohn (Fedorov). - Ganz gegensătzlich ist jedoch die Bewertung von Leben und Tod: Wăhrend für Fedorov Leben das absolut Gute ist und seine Bewahrung und Wiederherstellung høchstes Ziel menschlichen Handelns, ist es - so Schopenhauers pessimistische Kardinalthese - um den "objektiven Wert des Lebens" schlecht bestellt. Als unvernünftig kritisiert Schopenhauer die "mächtige Anhănglichkeit an das Leben" und preist das Loskommen von der schlechten Welt in der Verneinung des Lebenswillens; Sterben ist für ihn Befreiung, Nichtsein dem Leben vorzuziehen: "Klopfte man die Grăber an und fragte die Toten, ob sie wieder auferstehen wollten; sie würden mit den Kopfen schütteln."

In Anbetracht der genannten Gemeinsamkeiten und Gegensătze sowie der Popularităt, die Schopenhauers Werk in RuBland in den achtziger und neunziger Jahren genoB, bleiben Fedorovs Äußerungen erstaunlich oberflăchlich und beschränken sich weitgehend auf polemische Wortspiele mit dem russischen Titel von Die Welt als Wille und Vorstellung - Mir kak volja i predstavlenie -, wobei Fedorov sich der Doppelbedeutung von russ. volja, 'Wille' und 'Freiheit', bedient. Der erste Band von Schopenhauers Hauptwerk war 1881 in der Ubersetzung des Dichters A.A. Fet erschienen. Fet, selbst ein Anhănger Schopenhauers, war mit Fedorov bekannt. N.N. Cemogubov enwăhnt Fedorovs Affinităt zu Schopenhauer (siehe oben Anm. 7). In der materialreichen Arbeit von S. MCLAUGHIN, Schopenhauer in Rußland, Wiesbaden 1984, fehlt jeder Hinweis auf Fedorov.

119 Vgl. FOD I, S. 453; II, S. 134. - Mit keinem anderen Philosophen hat Fedorov sich gegen Ende seines Lebens so intensiv beschaftigt wie mit Nietzsche, und zu keinem anderen hat er sich so ausführlich geauuBert. Siehe FOD I, S. 429-433, 449, 453; II, S. 100-163. Keinen anderen Denker hat Fedorov aber auch so heftig bekămpft: Nietzsche ist für ihn der "verlorene Sohn der Philosophie" (II, 159), der "schwarze Prophet" (II, 104), der "Philosoph des Schwarzen Reiches" (II, 100), der "Prophet der Finstemis" (II, 104), der "Verehrer des Antichrist" (II, 109) usw. Dennoch bleibt anzunehmen, daB Fedorov in Nietzsche auch Gemeinsamkeiten wahrnahm und Anregungen von ihm empfing. So deckt sich - um nur einige Beispiele zu nennen - Fedorovs Zivilisationskritik in vielem mit derjenigen Nietzsches, wie sie v.a. in den Unzeitgemäßen Betrachtungen (1873-1876; russ. Neswoevremennye razmyslenija, M. 1901) vorgebracht wird (siehe auch oben Anm. 32). Beide Denker besaßen ein naturalistisches Menschenbild, verwarfen überirdische Hoffnungen und bekannten sich zu einer vorbehaltlosen Bejahung des Lebens. Beide gaben vor, ihr ganzes Denken auf die Wirklichkeit und ihre sinngebende Umgestaltung zu richten und beklagten die Trennung von Erkennen und Handeln (deren Aufhebung ihnen freilich nur 'schreibend' gelang). Bcide suchten schließlich den gegenwärtigen Menschen zu überwinden: Nietzsche im "Obermenschen", Fedorov in der "Obermenschheit". - Eine gute Darstellung von Fedorovs Nietzsche-Kritik gibt T.D. ZAKYDALSKY, "Fedorov's Critique of Nietzsche, the 'Eter- 
Derselbe Dämon, der an der Schwelle des Eingangs zum Tempel der antiken Philosophie erscheint und ihren Vater (Sokrates) lehrt, 'sich selbst zu erkennen', d.h. nur sich selbst zu kennen, begeistert auch den letzten Philosophen, Nietzsche... (II, 134; Hervorhebung im Orig.)

'Ich bin der Einzige und erkenne nichts anderes an', sagt Max Stimer, und Nietzsche stimmt dem zu; das aber ist die letzte Antwort auf das 'Erkenne dich selbst', den Beginn der philosophischen Verirrungen. (1, 429f.) ${ }^{120}$

Theoretische Haltung und Selbstbezogenheit machen Nietzsche zum Ästheten, zum passiven Betrachter des Daseins. Die ganze Welt wird ihm zur Vorstellung, zum Schauspiel, dessen Akteure ihm fremd bleiben und an dessen endloser Wiederholung er sich mitleidlos ergötzt.

In diesem unstillbaren Verlangen nach Theaterstucken, nach Vorstellungen, haben wir den Schlüssel zu Nietzsches Leben und zu seiner Lehre. Seit seiner Kindheit war er ein leidenschaftlicher Liebhaber der Musik, spăter ein Wagnerianer, schlieBlich ein Anti-Wagnerianer, doch blieb er immer ein Ästhet, nie war er ein Agierender, nie wünschte er Tătigkeit. Unzufrieden mit dem deutschen Bayreuth, verwandelte er in seiner Vorstellung die ganze Welt in ein Theater, in ein Spiel, und winschte sich nichts als ein Spiel. $(I, 433)^{121}$

Selbst gegenüber der drohenden Katastrophe, die er für unabwendbar hält, nimmt Nietzsche eine rein ästhetische Haltung ein und konzentriert - darin ein Nachfolger Schopenhauers und Wagners - "alle Mittel und Kräfte auf die reizvolle Darstellung des Untergangs des Menschengeschlechts" (II, 151). ${ }^{122}$ Mit rhetorischem Pathos beschworen, wird so noch das Schrecklichste dem allen

nal Tragedian'." In: B.G. Rosenthal (Hg.), Nietzsche in Russia, Princet on, New Jersey 1986, S. 113-125.

Das erste ins Russische übersetzte großße Werk Nietzsches, und zweifellos sein populärstes, war Also sprach Zarathustra (Tak govoril Zaratustra. Kniga dlja usech i ni dlja kogo. SPb. 1898), das in den folgenden Jahren in verschiedenen Ubersetzungen zahlreiche Auflagen erlebte. Es folgten Proizchozdenie tragedii (SPb. 1899), Pomracenie kumirov (M. 1900) und Po tu storonu dobra i zla (M. 1900); eine Ausgabe der gesammelten Werke (Sobranie soxinenij, M.) in zehn Bănden erschien 1900-1903 in zwei parallelen Ausgaben, eine (sehr lückenhafte) Gesamtausgabe (Polnoe sobranie soxinenij, M.) 1909-1912. Die ersten Arbeiten über Nietzsche stammen aus den 1890er Jahren und wurden meist von akademischen Philosophen verfaBt. Siehe R.D. DAvies, "Nietzsche in Russia, 1892-1919: A Chronological Checklist." In: RosentHAl (Hg.), a.a.O., S. 355-392.

Obwohl Fedorov vergleichsweise früh und mit besonderer Vehemenz auf Nietzsche reagier hatte, fehlt in der inzwischen recht umfangreichen Literatur zur Nietzsche-Rezeption in RuBland (von Zakydalskys Beitrag abgesehen) jeder Hinweis auf ihn. Dies gilt, neben der o.g. Bibliographie von Davies, auch fur die bislang ausführlichsten Arbeiten von A.M. LANE, Nietzsche in Russian Thought 1890-1917, Ph.D. diss. Univ. of Wisconsin, Madison 1976; Ann Arbor 1981, und E.W. CLowEs, A Philosophy 'For All and None': The Earty Reception of Friedrich Nietzsche's Thought in Russian Literature, 1892-1912. Ph.D. diss. Yale Univ., 1981; Ann Arbor 1983.

Vgl. FOD I, S. 407, 453. 
Nöten der Lebenswelt enthobenen Professor zum Gegenstand ästhetischen Genusses:

Nietzsche, der Philosoph, ... unternimmt alle Anstrengungen, um die Apokalypse, d.h. die schreckliche Botschaft vom Untergang der Welt, reizvoll und interessant zu gestalten, um das Schreckliche in etwas Erhabenes zu verwandeln und selbst dem Untergang in seiner künstlerischen Vorstellung etwas Verlockendes zu geben. (II, 133)

Mehr noch: Das Verlangen, das einmal genossene Spektakel wiederzusehen, führt Nietzsche zu der absurden und menschenverachtenden Idee der "ewigen Wiederkunft des Gleichen".

Wenn man das Leben als ein Spiel betrachtet und die Welt als eine Theateraufführung, so kann man auch jenen absurden Unsinn verstehen, den Wunsch, 'daB sich alles wiederholen möge, und zwar genau so, wie es ist, auf immer und ewig' (wie schlecht auch immer es sein mag!), d.h. hochst unvollkommen. Nietzsche gibt sich nicht nur mit dem zufrieden, was war, sondern schreit auch noch unersăttlich: 'da capo!' und 'bis!', und fordert endlose Wiederholungen, wobei er nicht nur sich selbst, sondern die ganze Weltkomodie im Sinn hat... (II, 136; Hervorhebung im Orig.)

123 Im Gegensatz zu Fedorovs Projekt der Auferweckung beschreibt Nietzsches Lehre von der "ewigen Wiederkunft" ein blindes, sinn- und zielloses Geschehen, dem der Mensch ohnmăchtig ausgeliefert ist. Doch laBt sich, so Fedorov, die Richtigkeit von Nietzsches Lehre nicht beweisen, da es keine Erinnerung an ein früheres Dasein und mithin an eine Wiederkunft gibt. Vgl. FOD II, S. 119f., 138f.

Hohnisch ăußert sich Fedorov zum Zarathustra: "Der Grundgedanke dieses Werks ist die Idee von der ewigen Wiederkunft aller Dinge. Die Aneignung dieser 'hochsten aller erreichbaren Formeln' gehort in den August des Jahres 1881. Empfangen wurde sie ' 6000 FuB jenseits von Mensch und Zeit'. Ist es nicht seltsam, daB eine so geringe Hohe sich als ausreichend erwies, Herrschaft uber die Zeit zu erlangen und ein Ubermensch zu werden? Nur einem Sohne Deutschlands, wo man, einem Ausspruch Heines zufolge, bei Regenwetter ein halbes Fürstentum an den Stiefeln davontragen kann, konnte eine Hohe von 6000 FuB so imposant erscheinen..." FOD II, S. 106. Vgl. ebd., S. 138. - Die von Fedorov angeführten Zitate finden sich in Nietzsches philosophisch-autobiographischem Werk Ecce homo (erstmals dt. 1908, russ. 1911); dort heiBt es: "Die Grundkonzeption des Werks, der Ewige-Wiederkunfts-Gedanke, die hðchste Formel der Bejahung, die überhaupt erreicht werden kann -, gehört in den August des Jahres 1881: er ist auf ein Blatt hingeworfen, mit der Unterschrift: ' 6000 FuB jenseits von Mensch und Zeit'." NieTzSCHE (wie Anm. 32), Bd. 2, S. 1128. Fedorov kőnnte dieses Zitat einem der Kommentare von E. Forrster-Nietzsche entnommen haben.

Und an anderer Stelle: "Wenn man in den Erinnerungen ... von der Begeisterung und Ekstase bei der Abfassung des 'Zarathustra' liest, kőnte man meinen, daB nicht nur die 'Geburt der Tragödie', sondern auch dieses Buch aus dem Geiste der Trunkenheit entstanden ist, hervorgerufen freilich nicht durch das primitive Mittel Noahs oder Bacchus', sondern durch die Erzeugnisse modernster Chemie. Andernfalls bliebe es unbegreiflich, wie im Verfasser solche Freude aufkommen konnte, solcher Jubel über die endlose Wiederkunft der Leben und folglich ebensovieler Tode! Oder ist es wirklich so angenehm, millionenmal Professor zu werden oder ebensooft am Krieg teilzunehmen oder ebensooft sich in der Einsamkeit zu qualen, in Kurorten, indem man von unendlicher Wiederkunft trăumt, freilich ohne die geringste Gewißheit, da es keinerlei Beweise dafür gibt...' FOD II, S. 106.

Bereits in den 1860er Jahren (also lange vor Nietzsche) hatten Nikolaj Strachov und, von diesem beeinflußt, Dostoevskij die Idee einer "ewigen Wiederkunft" diskutiert und als unzulănglichen Ersatz für den christlichen Glauben an Auferstehung und Unsterblichkeit verworfen. Vgl. D. CYZEVŚKYJ [TSCHIZEWSKU], "Literarische Lesefrüchte, Teil 2." In: ZfSIPh, 10 (1933), 3-4, S. 
Schopenhauers "Wille zum Sein" wurde bei Nietzsche zum "Willen zur Macht", der den nur seiner selbst bewußten einzelnen treibt, Herrschaft über diejenigen zu erringen, die nichts mehr mit ihm gemein zu haben scheinen. Die am tiefsten reichende Gemeinsamkeit, die darin besteht, daß alle Menschen Söhne und Töchter verstorbener Väter sind, bleibt Nietzsche und seinem gefühl- und erinnerungslosen "Übermenschen" (sverchと̌lovek) verborgen. ${ }^{124}$ Geleitet allein vom Willen, über die als "Herde" verachteten Menschen zu herrschen, verkörpert Nietzsches Übermensch die völlige Verneinung aller Verwandtschaft. ${ }^{125}$

Dieser arrogante Ubermensch braucht sich nicht um eine Gemeinsamkeit im Denken und Handeln muit Menschen zu kümmern, die er für eine 'verächtliche Herde' hălt. Verkehren kann er nur mit seinesgleichen Ehrgeizigen und Machthungrigen. Doch was für eine Gesellschaft, so fragt man sich, kann daraus entstehen, auBer vielleicht einer Bande von Dieben und Raubern, die auf Kosten derer leben, die sie unterdrücken und verachten? $(\mathrm{II}, 161)^{126}$

Nietzsches Begriff des Übermenschen ist nicht nur zutiefst amoralisch, er ist auch ein "krasser Widerspruch" und eine "völlige Absurdität" (II, 111) angesichts der fortbestehenden Naturverfallenheit und Sterblichkeit, die es, so Nietzsche, schicksalsergeben hinzunehmen gilt (amor fati). ${ }^{127}$ Für Fedorov hingegen bleibt das Ziel die wahre "Übermenschheit" (sverchとeloveðestvo) als Sache aller: angetrieben vom odium fati und verwirklicht im vollständigen Sieg über Natur und Tod. ${ }^{128}$

Mit der Lehre vom unmenschlichen Übermenschen und dem passiv-freudigen Erwarten des allgemeinen Untergangs ist die abendländische Philosophie ans Ende jenes Irrwegs gelangt, an dessen Anfang der delphische Imperativ stand:

388-390. DERs., Dostojewskaj und Nietzsche. Die Lehre won der ewigen Wiederkunft. Bonn oJ. [1948]

124 Hăufiger als zu allen anderen Lehren Nietzsches äußert sich Fedorov zur Idee des "Ubermenschen": vgl. FOD I, S. 429-431, 453; II, S. 101f., 107, 110, 113f., 118, 123, 131, 137, 143, $243 f$.

125 Vgl. FOD II, S. 122f., 137, 159f. - Nietzsches pervertierten Begriff der Macht (Macht über Menschen statt Macht über die Natur) sowie die Unterscheidung von Obermenschen und Pobel bringt Fedorov mit der (inzwischen als Legende erwiesenen) Abstammung Nietzsches aus der Schlachta, dem polnischen Adel, in Verbindung. FOD II, S. 117-120, 137.

126 Nietzsches Lehre vom "Willen zur Macht" und vom "Obermenschen" deutet Fedorov als Versuch, das Hegemoniestreben des preuBischen Militarismus und das Oberlegenheitsgefühl der teutonischen Rasse philosophisch zu begründen. FOD II, S. 100-102, 104f. Nietzsche, der "Philosoph des Militarismus und Feind des Friedens" (ebd., S. 104), wird zum "schwarzen Propheten" des "schwarzen Kaisers", d.i. Wilhelm II., denn "wovon Nietzsche nur trăumte, das hat Wilhelm bereits verwirklicht" (ebd., S. 105).

127 FOD II, S. 138, 162 f.

128 "Obermenschheit wird nicht im mystischen, sondern im materiellen Sinne Auferweckung und Unsterblichkeit sein." FOD II, S. 110. Vgl. ebd., S. 121f. 
Der letzte Philosoph zeigt uns die letzten Menschen, die vollig ersch Øpft sind von der Untătigkeit, und den allerletzten Menschen, der (trotz seines tiefen Falls) nicht imstande ist, sich selbst zu verachten. (II, 107)

Führt Nietzsches Philosophie zur Menschenverachtung und in den Untergang, so zeigt sie gerade dadurch mit aller Deutlichkeit, wenn auch gegen ihre $\mathrm{Ab}$ sicht, den Weg zur Rettung:

Die Philosophie Nietzsches fordert bereits dringend als Reaktion auf sich selbst ... die Vereinigung zur Auferweckung... (II, 133)

Sie ... fuhrt, wenn auch gegen ihren Willen, vom fruchtlosen Denken zum rettenden Handeln, zur Tat der Liebe und des Wissens. (II, 134)

$+*$

Die Menschheit steht vor der Entscheidung, ob sie "in Unmündigkeit verharren" und damit der sicheren Katastrophe des Untergangs oder der ewigen Spaltung anheimfallen oder aber ob sie die "Fülle der Mündigkeit erlangen" soll. Soll sie "auf jener ersten Stufe des Übergangs der Natur von der Blindheit zum Bewußtsein", auf die sich die Natur durch den Menschen emporgehoben hat, stehenbleiben, oder "soll die Natur die Fülle des Bewußtseins und der Lenkung aller Welten durch alle auferweckten Generationen erlangen"? (I, 419) Verweigert sich die Menschheit dem obšcee delo der Auferweckung, so bleibt ihr nur die Wahl:

... bei Ostern als einem bloßen Feientag stehenzubleiben und bei der Liturgie als einer bloB innerkirchlichen Angelegenheit, als Ausdruck einer noch unvollstăndigen Liebe zu den Vătern, ein Ausdruck, der nicht zur wirklichen Auferweckung überleitet - oder aber unter volliger Absage an Vaterschaft und Bruderschaft sich an den Gräbern der Văter viehischen Orgien und dann der grausamen gegenseitigen Ausrottung hinzugeben; bei der Kunst bloB toter Ebenbilder stehenzubleiben - oder aber alle Ebenbilder zu vernichten; nicht nur die Văter dafur zu verurteilen, daß sie Leben gaben ohne Einwilligung der Geborenen - sondern auch die zur Welt Gekommenen zu verfluchen; bei einer stăndischen Stubenwissenschaft stehenzubleiben - oder aber, jegliches Wissen ablehnend, sich in die undurchdringliche Finsternis des Obskurantismus zu versenken; bei der ewigen Stadt der Freier und Brăute, umgeben von Spielsachen und Nippes, bei GenuB und Vergnügungen zu verharren oder aber, nachdem man sich nicht nur von den Vorfahren und Vătern losgesagt hat, sondern auch von den Nachkommen und Söhnen (die künstlich kinderlose Ehe), sich grenzenloser Sinnlichkeit hinzugeben; beim Willen als Wollust stehenzubleiben - oder bei der Abtotung des Fleisches; bei Empfindsamkeit und bloBer Trauer über die Verstorbenen zu verharren - oder aber, als letztes und grobtes Obel, sich ins Nirwana zu versenken... $(I, 419)$

129 Bezieht sich auf "Zarathustra's Vorrede", 5. Abschnitt (Also sprach Zarathustra). 


\subsection{Die Verwirklichung des obscee delo}

\subsubsection{Der utopische Entwurf}

Den Weg zur Verwirklichung des obšcee delo beschreibt Fedorov mit einer Vielzahl utopischer Projekte. Sie lassen sich im wesentlichen drei Bereichen zuordnen: dem Bereich der Philosophie - hier geht es um die Überwindung der Trennung von Denken und Handeln im sogenannten "Projektivismus"; dem sozialen Bereich - er umfaßt Maßnahmen zur Vereinigung aller Menschen und zur Ausrichtung ihres Handelns auf das gemeinsame Ziel; und dem Bereich der Auseinandersetzung mit der Natur - hier geht es um Projekte, die auf die Beherrschung und völlige Umgestaltung alles Natürlichen zielen und die künstliche Wiederherstellung der Verstorbenen ins Werk setzen.

Betrachtet man die Art und Weise der Rezeption Fedorovs, so fällt auf, da $B$ häufig nur einzelne seiner Projekte aufgegriffen und übernommen wurden, der Gesamtzusammenhang aber, und das heißt vor allem ihre ethische Begründung, unbeachtet blieb. Fedorovs Werk wurde gleichsam zum Ideensteinbruch, aus dem man willkürlich das herausschlug (und dabei oft genug beschädigte), was einem brauchbar erschien; das aber waren - neben einigen politischen und sozialen Ideen - vor allem Fedorovs naturwissenschaftlich-technischen Projekte.

Diese Projekte, die, in besonderem Maße zeitbedingt, mitunter bis in Einzelheiten an die Science-fiction eines Jules Verne (1828-1905) oder Albert Robida (1848-1926) ${ }^{130}$ oder an die naturphilosophischen Spekulationen von Herbert Spencer (1820-1903), Ernest Renan (1823-1892) ${ }^{131}$ oder Jean Marie Guyau (1854-1888) ${ }^{132}$ erinnern, sind für die Filosofija obšx cego dela als Ethik unerheblich; im Hinblick auf die Wirkungsgeschichte Fedorovs kommt ihnen hingegen größte Bedeutung zu.

Im folgenden sollen Fedorovs Projekte unter wirkungsgeschichtlichem Aspekt dargestellt werden, d.h. der Schwerpunkt wird auf jenen Entwürfen und Ideen liegen, die später rezipiert wurden und nachweislich gewirkt haben; dagegen sollen jene Bereiche, von denen offenbar keine oder nur geringe Wirkung ausging (wie etwa Fedorovs Geschichtsphilosophie), lediglich am Rande erwähnt werden.

130 In Robidas Le Vingtieme siecle (1883) finden sich mehrere von Fedorovs Projekten beschrieben und illustrient: Beeinflussung des Wetters, Raumfahrt und Planetenbesiedlung, der Einsatz elektrischer Kraftmaschinen und lenkbarer Aerostate.

131 Siehe unten Anm. 186.

132 Vor allem in L'imeligion de l'avenir (1887). Die am SchluB dieses Werkes skizzierte Vision einer Uberwindung des Todes durch die Liebe und einer Art geistiger Wiedergeburt erinnert sehr an Solov'ev. 


\subsubsection{Projektivismus}

Dem antiken "Erkenne dich selbst", das zum abstrakten Denken, zur "Ideolatrie" und zur Isolierung des einzelnen führt, stellt Fedorov das Prinzip der rodstvennost' im Erkennen entgegen: "Erkennt einander", d.h. "Erkennt in Euch die Väter und in den Vätern Euch und in allen Gott. ${ }^{133}$ Wahre Erkenntnis erlangt demnach nicht das Individuum auf dem Weg der Introspektion und des reinen Denkens, sondern die Gesamtheit der "Menschensöhne", also jener, die sich als Söhne und Brüder fühlen, die ihre Väter nicht vergessen und sich ihren Mitmenschen nicht entfremdet haben. ${ }^{134}$

In einem Menschen, der sich als Teil der überindividuellen Ganzheit des Menschengeschlechts weiß, ruft der Tod ein "Gefühl des Verlustes" (zuvstvo utraty) hervor, ein "Gefühl der Verwaisung" (Cuvstvo sirotstva), ${ }^{135}$ verbunden mit dem Wunsch, das Verlorene wiederherzustellen, den Verstorbenen das Leben zurückzugeben.

Die Fragen der Verwandtschaft und des Todes hăngen aufs engste miteinander zusammen: solange der Tod nicht Wesen trifft, mit denen wir uns verwandt, mit denen wir uns eins wissen, solange zieht er nicht unsere Aufmerksamkeit auf sich, bleibt er für uns gleichgültig. Andererseits zwingt uns nur der Tod, indem er uns derer beraubt, die uns nahestehen, den groBten Wert der Verwandtschaft beizumessen, und je tiefer das BewruBtsein des Verlustes ist, desto stärker ist das Bestreben zur Wiederbelebung. $(I, 136)$

Aus dem Gefühl der Trennung und des Verlustes verbunden mit dem "Willen zur Wiederbelebung" (volja $k$ oživleniju), d.h. zur Wiederherstellung der Ganzheit, erwächst die einzig wahre und wesentliche Erkenntnis, die Erkenntnis nämlich der Ursachen der Trennung, der Vergänglichkeit und des Todes, verbunden (darin äußert sich der Anteil des Willens) mit dem Bestreben, sie zu überwinden und das Vergangene wiederherzustellen. ${ }^{136}$ Für die Organisation der Erkenntnis, die Wissenschaft, bedeutet dies:

... Wissenschaft darf nicht Wissen der Ursachen sein ohne Wissen des Ziels ... darf nicht Wissen dessen sein, was ist, ohne Wissen dessen, was sein soll; das bedeutet, daß Wissenschaft nicht Wissen der Ursachen im allgemeinen sein darf, sondern gerade Wissen der Ursachen der Unbrüderlichkeit sein soll, Wissen der Ursachen der Trennung, die uns zu Werkzeugen der blinden Kraft der Natur macht... (I, 11; Hervorhebungen im Orig.)

133 FOD I, S. 391; vgl. FOD I, S. 135, 407.

134 Vgl. FOD I, S. 137, 390 .

$135 \mathrm{Vgl}$. FOD I, S. 1361., 335.

136 Erkenntnis, die frei ist von Gefühl, führt zu abstraktem, seelenlosem Wissen. Erkenntnis ohne Willen ist passive Betrachtung des Bosen, der Trennung und Zerstorung. Gefühl ohne Vernunft und Wissen bleibt fruchtloses Mitleid. Wille ohne Gefühl ist boser Wille (wie Nietzsches "Wille zur Macht"). Wille ohne Vernunft schlieBlich ist blinder, ohnmächtiger Wille. Siehe FOD II, S. 47. 
Während die - für das städtische Denken bezeichnende - allgemeine Frage, "weshalb das Seiende existiert", künstlich ist und folgenlos bleibt, bildet die aus dem Gefühl der Trennung und des Verlustes entstehende Frage des Landbewohners, "weshalb Lebendes leidet und stirbt", den Anfang eines Denkens und Forschens, das über das Konstatieren und Beschreiben des Gegebenen hinausgeht, indem es aufzeigt, "was sein soll" (Ziel), und den Weg weist zu dessen tätiger Verwirklichung (Mittel). ${ }^{137}$ Fedorov bezeichnet solches Denken als "projektiv":

... beflügelt vom Wunsch, vom Gefüh, versucht das Denken das Seiende durch das Gewünschte zu ergănzen oder zu ersetzen, vereinigt es das leblose Objektive und das unbewiesene Subjektive durch das Projektive, das, was sein kann. In den Bereich des reinen Denkens gelangt so das aktive Prinzip aus dem Bereich des Gefühis, welches seinerseits, indem es in die Sphăre exakten Wissens eintritt, sich von seiner früheren Willkür befreit und in die Welt des Wissens, der Wahrheit, ein sittliches Element einfuhrt, das Verlangen und Bemühen, das Seiende durch das Seinsollende zu ersetzen entsprechend den höchsten ethischen Forderungen, mit denen eine gefühllose Wissenschaft nichts anzufangen weiß. In der großen Synthese des Objektiven und des Subjektiven, die sich in der Projektivität des Wissens und Fühlens ausdrückt, werden beide aktiv, um in ihren Resultaten produktiv zu werden. ${ }^{138}$

Im "projektiven Vermögen" (proektivnaja sposobnost') des menschlichen Denkens verbindet sich die - von Kant getrennte - theoretische mit der praktischen Vernunft. Auf die transzendentale Analytik Kants muB nach Fedorov die "immanente Synthese oder die Projektivität (proektika)" folgen, die "von der theoretischen Vernunft nicht getrennte, mit ihr in aller Fülle in eins zusammenfließende praktische Vernunft. Das ist gleichbedeutend mit einem Zusammenfließen des Willens und der Vernunft." (II, 69)

... der Vorrang, den man der theoretischen Vernunft gibt, ist eine Usurpation, ein Verrat an ihrer Erzeugerin - der praktischen Vernunft, aus der sie, die theoretische Vernunft, hervorgeht, so wie die Stadt aus dem Dorf, wie der Stădter aus dem Bauern hervorgeht; die Rückkehr aber der theoretischen Vernunft zur praktischen, d.h. die Rückkehr ins Dorf, wird Ausdruck der Reue über ihren Verrat oder ihre Usurpation sein. $(I, 408)$

Für die Philosophie bedeutet dies:

Als Produkt der theoretischen Vernunft kann Philosophie nur abstrakt sein. Um konkretes und lebendiges Wissen zu werden, muß sie Wissen werden nicht nur um das, was ist, sondern auch um das, was sein soll, d.h. sie muß von einer passiven, spekulativen Erklărung des Seienden zum aktiven Projekt des Seinsollenden werden, zum Projekt des obsčee delo. Dann werden die beiden Arten der Vernunft, die theoretische und die praktische, sich vereinen, und es wird keine Trennung von Gelehrten und Nichtgelehrten in zwei isolierte Stănde geben; alle Lebenden werden Erkennende

137 Siehe FOD I, S. 12, 137, 402, 412, 447-449; II, 190.

138 Fedorov nach KoźeVnikov (wie Anm. 17), 43 (1905), 1, S. 188; ohne Nachweis. Hervorhebungen im Orig. 
sein, und diese Erkenntnis wird nicht abstrakt, sondern lebendig sein; Wissen wird mit Handeln verschmelzen. (II, 179; Hervorhebungen im Orig.) ${ }^{139}$

Die Befreiung des Wissens aus der Isolierung reiner Theorie und seine Verwandlung "in eine Vorstellung dessen, was sein soll, d.h. in ein Projekt" (I, 135), wird möglich nur in der wechselseitigen Verknüpfung von Denken und Handeln, von theoretischer und praktischer Vernunft, die Fedorov in der Weise vornimmt, daß er zum einen die Bedeutung der Praxis beim Erwerb und beim Überprüfen von Wissen betont und zum anderen fordert, daB Wissen sich auf sittliches Handeln beziehe, Ontologie durch Deontologie ergänzt werde (I, 92). Erkennen bedeutet für Fedorov 'realisieren' in der zweifachen Bedeutung des Wortes, nämlich 'begreifen' und 'verwirklichen': "Nur handelnd, in der Tat verwirklichend kann man begreifen." (I, 71) "... der Gedanke wird nur durch die Handlung bewiesen, durch die [praktische] Erfahrung aller..." (I, 208) Wissen, das nicht in die Tat übergeht, bleibt abstraktes, unbewiesenes, totes Wissen.

Durch die "projektive" Verknüpfung von Denken und Handeln sucht Fedorov auch die zwischen Subjekt und Objekt, zwischen "Gedachtem und Seiendem" (II, 88) bestehende Kluft zu überwinden, die daher rührt, daß der (abendländische) Philosoph sich als ein individuelles denkendes BewuBtsein empfindet und alles übrige als nur für dieses Bewußtsein und durch seine Vermittlung Gegebenes. Er bleibt vom Sein geschieden, solange er zu ihm nur auf dem Um-

139 Fedorovs Projektivismus mit seiner Forderung an die Philosophie (wie auch an alle übrigen Wissenschaften und Künste), von der Darstellung der Welt zu ihrer Umgestaltung fortzuschreiten ("Die Welt ist nicht zur [bloBen] Betrachtung da, nicht Weltanschauung ist das Ziel des Menschen. Der Mensch hat es stets für moglich gehalten, handelnd auf die Welt einzuwirken und sie entsprechend seinen Wünschen zu verăndern." FOD I, S. 335), wurde gelegentlich mit dem amerikanischen Pragmatismus (James, Dewey), aber auch mit Marx' berühmter 11. These über Feuerbach (1845) verglichen: "Die Philosophen haben die Welt nur verschieden interpretien; es kðmmt darauf an, sie zu verändem."

Tatsăchlich steht Fedorovs Wissenschaftsbegriff in einer genuin russischen Tradition. Bereits zu Beginn des 19. Jahrhunderts hatte sich der von Fedorov geschătzte Gelehrte und Erfinder V.N. Karazin gegen eine selbstgenügsame "Wissenschaft um der Wissenschaft willen" gewandt. Siehe SLUUSARSKu (wie Anm. 9), S. 60. Spăter kritisierten Slavophile und Narodniki die 'westliche' theoretisierende Stubengelehrsamkeit (kabinetnaja nauka) und forderten eine praxisbezogene, lebensnahe Wissenschaft, mit der die Intelligencija die Distanz zum Volk überwinden und ihre Schuld ihm gegenüber abtragen sollte. Durch engen Praxisbezug und Volksverbundenheit (narodnost') zeichnete sich zu Zeiten Stalins beispielsweise die Lehre des Pflanzenzüchters I.V. Miðurin aus, den man als "grandiosen Umgestalter der Natur" feierte (berühmt wurde sein Ausspruch: "Wir dürfen von der Natur keine Gnadengeschenke enwarten; unsere Aufgabe ist es vielmehr, ihr diese zu entreißen"), wăhrend die von dem berüchtigten T.D. Lysenko propagierte Bewegung der "Hütten-Laboratorien" (chaty-laboratorii) darauf abzielte, Wissenschaft zu einer Sache der Volksmassen zu machen und den Unterschied zwischen Gelehrten und Nichtgelehrten aufzuheben. Siehe V.P. Filatov, "Ob istokach tysenkovskoj 'agrobiologii'. (Opyt social'no-filosofskogo analiza)." In: Voprosy Filosofii, 1988, 8, bes. S. 18-20. - Als Grundzug russischen Denkens ist die enge Verbindung von Theorie und weltverwandelnder Praxis oft beschrieben worden; siehe z.B. S.[L.] FruNK, Die nussische Welianschauung [1926], Darmstadt 21967. 
weg subjektiver oder objektiver Erkenntnis gelangt, nicht aber projektiverkennend und -handelnd: ${ }^{140}$

Denken und Sein sind nicht identisch, das bedeutet, der Gedanke ist nicht verwirklicht; er muB aber verwirklicht werden. $(1,334)$

Indem sie den Gedanken verwirklicht, wird die Menschheit in ihrer Gesamtheit zu einem einzigen Künstler, dem die ganze Welt als Material dient zur Schaffung des irdischen Paradieses.

Die Welt, wie sie uns gegenwartig in der Erfahrung gegeben ist, freilich in einer sozusagen passiven Erfahrung, ist nur die Gesamtheit der Mittel zur Verwirklichung jener Welt, die uns in Gedanken, in der Vorstellung gegeben ist und die wir uns als auBerhalb der sinnlich wahrgenommenen Welt existierend vorstellen. Doch muB diese Verwirklichung oder Neuschaffung immanent sein; sie überschreitet nicht die Grenzen dessen, was dem Menschen zugănglich ist, den Bereich der aktiven Erfahrung... (I, 207)

Alle müssen Erkennende werden und alles muß zum Gegenstand des Wissens werden, jedoch so, da $\beta$ Wissen nicht vom Handeln getrennt wird, denn ohne letzteres ist ersteres nicht möglich. (I, 47; Hervorhebung im Orig. $)^{141}$

Damit die ganze Natur zum Gegenstand des Handelns wird, ist es nơtig, daß das ganze Menschengeschlecht zu einem einzigen Handelnden wird. $(1,395)$

Dann wird die Gesamtheit (Ganzheit) der erkennenden Vernunftwesen, indem sie sich der Fülle alles Erkennbaren, Vernunftlosen zuwendet, dieses neu schaffen und lenken. Auf diese Weise wird die Welt oder die Natur zur Selbsterkenntnis und zur Selbstregulierung gelangen durch die im gemeinsamen Ziel und im gemeinsamen Handeln vereinten Wesen... $(I, 47)$

\section{Die Wissenschaft der Zukunft wird eine Wissenschaft sein,}

... die auf gemeinsamer Beobachtung und Erfahrung basiert, auf SchluBfolgerungen aus Beobachtungen, die überall (an allen Orten), zu allen Zeiten und von allen Menschen vorgenommen werden und auf einem Versuch (opyt), der in der Natur selbst durchgefüht wird, auf einem Versuch der Regulierung meteorischer, vulkanischer oder plutonischer und kosmischer Phănomene - und nicht auf Versuchen, die nur in Gelehrtenstuben und Laboratorien durchgefüht werden und ihre Anwendung in Fabriken und Werkstătten finden, sondern auf einem einzigen Versuch, der von der Gesamtheit der Lebenden durchgeführt wird an der ganzen Erde als dem einzigen Objekt, als dem Friedhof einer Vielzahl von Generationen. Diese Generationen werden allmăhlich ins Leben zurückgeholt und verbinden sich mit den Erkennenden und Regulierenden, um die Regulierung von einem Planeten, unserer Erde, auszudehnen auf andere Planeten, auf das ganze Sonnensystem, dann auf andere Sonnensysteme und schlieblich auf das ganze Universum. (1, 411)

Der Beweis für die Richtigkeit des Wissens liegt in seiner Anwendung. So beweist sich das Wissen der Chemie durch die Fähigkeit, Stoffe zu analysieren

140 Wahre Erkenntnis ist nach Fedorov weder subjektiv noch objektiv, sondern projektiv. Dem Subjektivismus erscheint die Welt als bloB in der Vorstellung des denkenden Subjekts gegeben, das sich damit jeder Möglichkeit, handelnd in die wirkliche Welt einzugreifen, begibt. Dem Objektivismus (Fedorov meint damit vor allem den Positivismus) erscheint der Mensch als bloBes Objekt in einer Welt der Objekte, denselben Gesetzen wie diese unterworfen und deshalb ohnmăchtig. Siehe FOD I, S. $17 f$.

141 Vgl. auch FOD I, S. 403; II, S. 179 f. 
und zu synthetisieren. Die Chemie wird dann ihre Aufgabe (das, "was sein soll") erfüllen, wenn es ihr gelingt, als "Himmelschemie" (nebesnaja chimija) aus elementarer Materie, die sie im gesamten Weltall aufspürt und sammelt, menschliche Organismen künstlich zu synthetisieren. Gleiches gilt für die Biologie, die, nachdem sie die Ursache des Todes in der natürlichen Geburt erkannt hat, zur "Kunst der (Wieder)belebung" (iskusstvo ozivlenija) werden und das Universum mit künstlichem Leben erfüllen muß. ${ }^{142}$

Um ihre universale Aufgabe erfüllen zu können, müssen alle Einzelwissenschaften vereinigt werden, und zwar in der "kopernikanischen Astronomie", der Kunde von allen Körpern im Weltall, ihren Größen, Bewegungen und den zwischen ihnen wirkenden "fühllosen und blindwaltenden Kräften" (v.a. der Schwerkraft als Ausdruck des Todes und des Zerfalls im kosmischen Maßstab). Bewiesen wird die "Welterkenntnis" (mirosoznanie) der Astronomie durch ihre Anwendung in der "Weltenregulierung" (miroupravlenie) und im "Weltenbau" (miroustrojstvo, mirozdanie), der Aufgabe der "kopernikanischen Himmelsarchitektur" als der Vereinigung aller Künste. ${ }^{143}$

Die Wissenschaft wird durch die Kunst bewiesen: Die kopernikanische Astronomie, die alle Wissenschaften beinhaltet, wird bewiesen durch die Himmelsarchitektur, die alle Künste umfaßt... (II, 348)

Das kopernikanische Weltbild bleibt eine bloße Hypothese und nahe dem Aberglauben, solange es ein nur gedachtes, nicht aber ein "spürbar" (osjazatel'no) bewiesenes ist, d.h. solange nicht "alle Welten des Universums" durch die "wiederhergestellten vergangenen Geschlechter" besiedelt sind und der Lauf der Gestirne nicht beherrscht wird $(I, 416,422)$.

Wie aber kann das kopernikanische Weltbild spürbar bewiesen werden, wenn wir nicht die Fähigkeit erwerben, auch außerhalb der Erde, in gesamten Weltall, zu leben; ohne diese Făhigkeit, die uns die Moglichkeit gibt, alle Welten des Alls nicht nur zu besuchen, sondern auch zu besiedeln, konnen wir uns nicht vergewissern, daß diese Welten genau so sind, wie dies aus dem Weltbild des Kopernikus folgt, und nicht so, wie sie uns erscheinen. Die Fähigkeit aber, im ganzen All zu leben, die dem Menschengeschlecht die Möglichkeit gibt, alle Welten zu besiedeln, wird uns auch die Macht geben, die Welten des Alls zu einem künstlerischen Ganzen zu vereinen, zu einem Kunstwerk, dessen vieleiner Künstler, nach dem Vorbild des Dreieinigen Schøpfers, die ganze Menschheit sein wird mitsamt allen auferweckten und wiederhergestellten Generationen. $(I, 416)$

142 Ausführlich dazu N.F. FEDORov, "Astronomija i architektura." In: Vesy, 1904, 2, S. 22-24.

143 Ebd., S. 20-22. Vgl. FOD II, S. 248-250, 297f. - Der Obergang von der passiven Betrachtung einer Welt der Erscheinungen zur aktiven Gestaltung der Wirklichkeit ist der Úbergang vom ptolemåischen zum kopernikanischen System. Für Fedorov zeichnet sich das kopernikanische Weltbild durch seinen aktiv-projektiven Charakter aus, wăhrend das ptolemaische den Menschen zwar in den Mittelpunkt stelit, ihn jedoch zum bloBen "Betrachter seiner eigenen Nichtigkeit" macht (II, 347). Vgl. FOD I, S. 179, 293; II, S. 200, 347-351. Entsprechend ist "ptolemaische Kunst" illusionistische Nachahmung, Kunst der Ähnlichkeit (iskusstvo podobij), "Wiedergabe der Welt, wie sie den außeren Sinnen erscheint" (II, 241), Schaffung toter Abbilder; "kopernikanische Kunst" hingegen ist reale Wiederherstellung und Neuschopfung; siehe FOD I, S. 412f.; II, S. 190, 241-244, 251. 
Der Beweis allen Wissens besteht in seiner Anwendung, seiner realen Macht, die in diesem Fall ihren Ausdruck findet in der zunehmenden und ausgreifenden Regulierung und Verwandlung aller Welten durch die "Vernunft der wiedererweckten Geschlechter" (II, 240). Das Ziel ist die totale Verwandlung des Universums in ein "künstlerisches Ganzes" (chudožestvennoe celoe), ein "Kunstwerk" (chudožestvennoe proizvedenie), durch die allwissende und allmächtige vereinte Gesamtmenschheit. ${ }^{144}$

\subsubsection{Vereinigung}

Allein das obšcee delo, der Kampf aller Lebenden (der Söhne) gegen den gemeinsamen Feind, die blindwaltende, todbringende Natur, mit dem Ziel, die gemeinsame Schuld gegenüber allen Verstorbenen (den Vätern) zu begleichen, vermag alle zwischen den Menschen herrschenden Trennungen und Gegensätze zu überwinden und echte - da nicht auf theoretischen, künstlichen Prinzipien, sondern auf gemeinsamem sittlichem Handeln beruhende - Einheit zu stiften:

Die Auferweckung als eine sich vollziehende Handlung vereinigt nicht nur alle Religionen, alle Bekenntnisse, sie vereinigt im gemeinsamen Handeln, in der allumfassenden verwandtschaftlichen, urvăterlichen Liebe, die Glăubigen wie die Zweifler, die Gelehrten und die Nichtgelehrten, die Stănde, die Stadt und das Dorf. Die Zeit der Streitigkeiten geht zu Ende, denn Worte oder Gedanken haben keine Beweiskraft; indem wir das Dogma in ein Gebot verwandeln, in eine Sohnes-, eine Ursohnespflicht, begeben wir uns vom Gebiet der Theorie, dem am meisten strittigen, vom Gebiet des Wissens im allgemeinen, auf das Gebiet des Sittlichen, das am wenigsten strittige, auf das Gebiet des Handelns. $(1,248)$

Die Vereinigung zu solchem Handeln ist keine juristische und keine okonomische Aufgabe, sondern eine psychologische, sitnliche; es geht um die Schaffung einer Gesellschaft, die keiner Kontrolle, keiner Strafen und keiner Zwangsmaßnahmen bedarf, oder, genauer gesagt, um den Ubergang der Gesellschaft von erzwungener zu freiwilliger, vereinter und zudem weltweiter Tătigkeit. (II, 272; Hervorhebung im Orig.)

Die Wiederherstellung der brüderlichen Einheit unter den Menschen und die Ausrichtung ihres Handelns auf das obšcee delo ist Aufgabe des Selbstherrschers (samoderžec) in der Person eines künftigen rechtgläubigen russischen Zaren. ${ }^{145}$ "Stehend an der Väter Statt" (stojašcij v otcov-mesto), vertritt dieser als "Statthalter" (namestnik) und "Willensvollstrecker" (dušeprikaz ${ }^{i k}$ ) die verstorbenen Väter, indem er die Erde, den "Staub der Väter", schützt und vertei-

144 Siehe z.B. FOD I, S. 407, 416; II, S. 348. - Siehe auch unten Abschn. 3.2.3.

145 Das von Fedorov im Rahmen seiner patriarchalischen Gesellschaftsutopie gezeichnete Idealbild des Selbstherrschers hat - was oft übersehen wird - nichts mit den historischen Vertretern der in RuBland herrschenden Dynastie zu tun. Nur in einer idealen, zukunftsweisenden Form wird die Autokratie gegenüber anderen Herrschaftsformen (v.a. Konstitutionalismus und Despotie) verteidigt. - Zur Rolle des Selbstherrschers beim obšcee delo ausführlich FOD I, S. 353-398. 
digt und indem er die verwaisten Kinder ${ }^{146}$ eint und leitet im "Väter-Werk" (delo oteceskoe) der allgemeinen Auferweckung $(I, 367){ }^{147}$

Die lange Aufzählung von Völkernamen im Titel des russischen Zaren kündet von seiner Aufgabe - der Sammlung und Befriedung der Länder und Völker der Welt. Wichtige Schritte auf diesem Weg sind die auf Vorschlag des Zaren einberufene Haager Friedenskonferenz (1899), ${ }^{148}$ vor allem aber das Ausgreifen Rußlands nach Mittelasien (im letzten Viertel des 19. Jahrhunderts): Durch die Herrschaft über den Pamir - die 'Wiege der Menschheit', das biblische Eden, den Ort, an dem (der Überlieferung nach) die Gebeine Adams ruhen 149 wird der russische Zar mit dem Titel "pamirskij" an die "Statt des Urvaters" ( $v$ praotca-mesto), des Vaters aller Menschen, treten; er wird den Schutz des Grabes Adams übernehmen und das verlorene Paradies wiederherstellen. ${ }^{150}$

Auf den Pamir als 'Wiege der Menschheit' verweist auch die Suche nach den ältesten Formen der Sprache. Während jedoch die historische vergleichende Sprachwissenschaft in der richtigen Annahme der Verwandtschaft aller Sprachen sich darauf beschränkt, die ursprüngliche Einheit der Sprachen zu erkennen und darzustellen, erfordert das obšcee delo die Verwirklichung der sprachlichen Einheit, denn: "Solange es keine Einheit im Wort gibt, solange werden die Menschen Brüder sein, die nicht miteinander sprechen..." (I, 256) Da der Zerfall der ursprünglichen Einheit der Sprache eine Folge des Vergessens der Pflicht gegenüber den Vätern ist, vermag die Vereinigung in der Sprache nur aus der Anerkennung der Verwandtschaft und der Sohnespflicht zu erwachsen. Praktische Aufgabe der Linguistik im Rahmen des obšcee delo muß deshalb die "Ausarbeitung einer allgemeinen Sprache für alle Völker" (I, 367), einer menschenvereinigenden Universalsprache sein, nicht durch die Schaffung einer künstlichen Sprache, sondern durch die - auf dem Wege der Erforschung der

146 Als "Waisen" (siroty) bezeichneten sich Bauern und niedere Leute, wenn sie sich (2.B. in Bittschriften) an den Zaren wandten.

147 Vgl. FOD I, S. 367, 424.

148 Fedorov setzte große Hoffnungen in die erste internationale Friedenskonferenz, die im Mai 1899 im Haag zusammentrat, und forderte, sie müsse in das Projekt einer Vereinigung zur Rückerstattung des Lebens münden. Vgl. FOD II, S. 308-310, 321-343.

149 Vgl. FOD I, S. 218, 233, 246f., 268f., $350 f$.

150 FOD I, S. 292. - Fedorov schlug vor, eine Expedition zum Pamir zu senden, um die Gebeine und Werkzeuge der frühesten Menschen zu bergen und nach Moskau zu bringen, wo sie im Kreml (der Festung zum Schutz des "Staubs der Văter" und zur Vereinigung der Sorhne) aufbewahr werden sollten. Moskau, das "dritte Rom", (nicht jedoch das 'künstliche" Petersburg) würde so zum Zentrum der Menschheitsvereinigung und Wiedererweckung werden. (FOD I, S. 268f.) Der Pamir aber sollte von einem On der Konfrontation des băuerlichen RuBland mit dem kapitalistischen und imperialistischen England (Afghanistan) zu einem On der Versohnung werden. Zu Fedorovs Deutung der Mission RuBlands in Asien (und ihren Entsprechungen in der politischen Publizistik jener Zeit) siehe E. SARKISYANZ, Rußland und der Messianismus des Orients, Tübingen 1955, bes. S. 208-211. 
Wortwurzeln betriebene - allmähliche Wiederherstellung der Urvätersprache (praoteceskij jazyk). ${ }^{151}$

Die Erforschung der Wortwurzeln ... wird sich überallhin erstrecken; und das Studium der eigenen und fremder Sprachen wird zu der Erkenntnis dessen führen, was in ihnen gemeinsam, verwandt und urvăterlich ist. $(I, 367)$

Man muß die Urvătersprache studieren, um in einer einzigen Brudersprache zu sprechen; von den sogenannten lebenden Sprachen muB man sich den toten Sprachen zuwenden, den altesten unter ihnen, wie Sanskrit, Zend[awestisch] usw., damit die Worte, mit denen wir sprechen, sich beleben und verständlich werden. Die Entdeckung der gemeinsamen Wurzeln aller Sprachen der arischen Familie konnen wir mit vollem Recht als philologische Auferstehung bezeichnen. (I, 348; Hervorhebung im Orig.)

Die Vereinigung der Menschheit und der Anstoß zum obšcee delo werden vom russischen Volk und seinem Herrscher ("stehend an der Väter und des Urvaters Statt") ausgehen. Von allen Eigenschaften, die den russischen Menschen auszeichnen, ist es besonders das tief verwurzelte Verwandtschafts- und Gemeinschaftsgefühl, das ihn zu dieser Aufgabe befähigt:

Unser ganzer Vorzug besteht darin, daß wir die ursprünglichste Lebensform bewahrt haben, mit der das wahrhaft menschliche Dasein begann, nămlich die verwandtschaftliche (rodovoj byt). $(1,274)$

Bei uns bildet das Gefühl der Verwandtschaft mit allen einen kennzeichnenden Zug des Volkscharakters, der sich durch die Form der Lebensweise (der verwandtschaftlichen), wie sie bei uns bis heute herrscht, herausgebildet hat. $(1,254)$

Im Gegensatz zur Gesellschaft des Westens, in der die Beziehungen zwischen den isolierten Individuen juristisch, d.h. künstlich geregelt sind, ist das Leben in der Gemeinschaft, wie sie sich vor allem auf dem russischen Dorf erhalten hat, patriarchalisch organisiert und beruht auf dem Gefühl allumfassender Verwandtschaft. Davon zeugt die althergebrachte Einrichtung der Bauerngemeinde (obšina) mit ihrer wechselseitigen Verantwortung zum Wohle aller ebenso wie die Selbstbezeichnung als "Waisen", der Gebrauch des Vatersnamens (otČestvo) oder die Anrede Fremder als Verwandte (batjuska, matjuska, brat). ${ }^{152}$

Ganz in der Tradition der Slavophilen werden Rußlands "Rückständigkeit" und Ursprünglichkeit als Vorzüge gewertet: Die auf dem ungebrochenen Gefühl der Verwandtschaft beruhenden "organischen" Lebens- und Glaubensformen, der Mangel an selbstgenügsamer Rationalität, der niedrige Grad der Verstädterung und Industrialisierung und damit der sozialen Differenzierung, alle diese Eigenheiten, "die andere nur für niedere Formen des Lebens halten können" (I, 211), prädestinieren Rußland gegenüber der verderbten, seelenlosen,

151 Vgl. FOD I, S. 253-256, 348f., 367, 608f.

152 Vgl. FOD I, S. 211f., 254, 319. 
künstlichen Zivilisation des "fortgeschrittenen" Westens zur Führung bei der Wiederherstellung allumfassender Einheit im obšcee delo. ${ }^{153}$

Schließlich ist Rußland auch durch seine geographische Lage und seine physikalische Beschaffenheit besonders geeignet, um zum Ausgangspunkt für das obšcee delo zu werden: Als Brücke zwischen Europa und Asien besitzt es eine natürliche Vermittlerfunktion, während seine kontinentale Lage das Entstehen eines aggressiven Volkscharakters verhindert, wie er für die Bewohner "ozeanischer Länder" (Engländer, Waräger) kennzeichnend ist. ${ }^{154}$ Das rauhe Klima, das eintönig-flache Land und der graue Himmel erlauben keine schwärmerische Naturverehrung; sie fesseln den Blick nicht in der Horizontalen, sondern geben ihn frei, damit er sich gen Himmel richte und weiter in den Weltraum:

Unser weiter Raum dient als Ubergang in die Weite des himmlischen Raums, dieses neuen Feldes für eine große Heldentat. (I, 282)

Die Vereinigung zum obšcee delo wird nicht von jenen ausgehen, die als Nomaden die Gräber der Väter verlassen, noch von jenen, die "den Staub der Verstorbenen von ihren Füßen schütteln" und ihn "aus den Grenzen der Siedlung" entfernen (I, 414), den Städtern also, die die Väter vergessen haben. Die Rettung kommt vom Dorf, wo "dieser Staub stets einen zentralen Platz einnimmt" (ebd.) und wo die "Söhne verstorbener Väter" im Bewußtsein des Verlustes und ihres Waisentums die Erde verehren, die diesen Staub aufgenommen hat, auch wenn sie als Ackerbauern noch immer gezwungen sind, ihn in Nahrung zu verwandeln.

Worauf soll man sich ausrichten - auf den städtischen Kult des Dinges und der Frau, auf die "Pracht der Fäulnis", oder aber auf das Dorf, den Staub der Văter, auf das Dorf in der Hoffnung, daß es einen solchen Zustand erreichen wird, in dem der Staub der Văter nicht mehr in Nahrung für die Nachkommen verwandelt wird, sondern in Fleisch und Blut der Văter selbst...? (I, 410; Hervorhebung im Orig.)

Das Landleben in seiner jetzigen Form ist, obgleich es höher steht als die beiden anderen Lebensweisen (die städtische und die nomadenhafte), noch kein vollkommenes Leben; das Landleben gewinnt erst dann die Voraussetzung zur Erlangung der Vollkommenheit, wird erst dann făhig, die Vollkommenheit zu erreichen, wenn die Stădter zum Staub der Văter zurückkehren und die Nomaden seßhaft werden, d.h. niemand mehr die Grăber der Văter verlăßt, wenn die Friedhöfe zu Zen-

153 Fedorovs enge Anlehnung an die Slavophilen hinderte ihn nicht, sie einer scharfen Kritik zu unterziehen, wobei er ihnen insbesondere Passivităt und gedankliche Unklarheit vorwarf: Zwar wïrden sie sich zu den Werten der Einheit und sobomost' bekennen, doch hătten sie nie darüber nachgedacht, zu welchem Zweck, mit welchen Mitteln und in welcher Form eine Vereinigung herbeizuführen sei. FOD I, 193.

Zur Ideologie der Slavophilen vgl. insbesondere A. WALICKI, The Slavophile Controversy. History of a Conservative Utopia in Nineteenth-Century Russian Thought. Oxford 1975. DERS., A History of Russian Thought. Stanford, Calif. 1979, S. 92-114. Zur Idee des "Privilegs der Rückstăndigkeit" und ihrem Fortwirken bis ins 20. Jahrhundert siehe M. HILDERMEIER, "Das Privileg der Rückstăndigkeit. Anmerkungen zum Wandel einer Interpretationsfigur der neueren russischen Geschichte." In: HZ, 244, 1987, 3, S. 557-603. 
tren der Sammlung der Söhne werden, wenn sich die Vereinigung im Văter-Werk, welches zugleich ein brüderliches ist, vollzieht. $(I, 411)$

Um die Erinnerung an die Väter und schließlich diese selbst zu beleben, müssen die Stätten, an denen sie ruhen, und die heute dem Verfall und der Zerstörung preisgegeben sind, wiederhergestellt und gepflegt werden; das aber bedeutet: "der Schwerpunkt der Gesellschaft muß auf den Friedhof verlegt werden." (I, 49) ${ }^{155}$ Der Friedhof muß zu einer "Stätte der Versammlung und Beratung" (I, 48) werden, aber auch zu einer Stätte, an der alle Spuren der Verstorbenen bewahrt und erforscht werden; das bedeutet: auf den Friedhöfen müssen Museen mit Schulen errichtet werden, "darin der Unterricht verpflichtend wäre für alle Söhne und Brüder, deren Väter, Mütter und Brüder auf dem [jeweiligen] Friedhof begraben liegen." $(I, 48)$

Das Museum ist kein Magazin toter Dinge, sondern der Ort, an dem durch Artefakte aller Art (nicht zuletzt durch Bücher) die Verstorbenen erinnert und wenn auch vorerst nur im Gedenken, in der Vorstellung - ins Leben zurückgeholt werden; das Museum dient somit dem Ziel, den Tod zu überwinden und die Sterblichen unsterblich zu machen: ${ }^{156}$

Der erste Gegenstand, der aufbewahrt wurde zur Erinnerung an die Văter, war der Beginn des Museums... $(\mathrm{I}, 258)$

Heute ist das Museum "das letzte Überbleibsel des Ahnenkults" (II, 399), denn die Tatsache, da $B$ in einer dem Fortschritts- und Nützlichkeitsdenken verfallenen Zeit die veralteten, unbrauchbaren und oftmals wertlosen Gegenstände der Väter gesammelt und (in Museen) aufbewahrt werden, zeugt davon, da $B$ das Gewissen der Söhne noch nicht ganz abgestorben ist. Nun gilt es, den Blick dafür zu schärfen, daß hinter jedem Gegenstand, jedem Schriftstück, jedem Buch ein Mensch sich verbirgt, daß das Museum mithin "die Menschheit selbst in ihrem literarischen und überhaupt materiellen Ausdruck" ist (II, 410); dann wird das Museum - errichtet auf dem Friedhof und in Verbindung mit der Schule - zu einer Stätte werden, an der sich Denken und Handeln vereinen, an der

$155 \mathrm{Vgl}$. FOD I, S. 48-51. - Bitter beklagt Fedorov die Zerstorung der Friedhofe oder ihre Entfernung aus dem Stadtgebiet (wofür medizinische und hygienische Gründe angegeben werden) als "Folge des Verfalls der Verwandtschaft (rodstwo) und ihrer Verwandlung in Bürgerschaft (grazdanstwo)". FOD I, S. 48f. Mangelnde Sorge um die Toten bei gleichzeitigem Drang der Lebenden zur Selbstdarstellung beweist, so Fedorov, die moderne Grabarchitektur, die von dem Gedanken ausgeht, "daB das Grab leer sei, daB das, was in das Grab hineingelegt wurde, dieses bald wieder verlaßb, fortgetragen oder gleichsam mitgerissen vom Strom des weltlichen Lebens. Unter diesen Umstănden wird das Grabmal zum bloßen Monument, zum Denkmal, zum Zeugnis mehr oder weniger aufrichtiger Gefühle der Familie oder der Gesellschaft beim Verlust eines ihrer Mitglieder." FOD II, S. 235. Die "heutigen Anforderungen" beim Bau eines Grabmals haben denn auch nicht "den Verstorbenen im Auge, sondern die Lebenden, zu deren Bewunderung und Andenken allein das Denkmal errichtet wird". Ebd.

156 Ausführlich über "das Museum, seinen Sinn und seine Bestimmung" FOD II, S. 398-473. 
das Andenken an die Verstorbenen übergeht in die Suche nach Mitteln und Wegen zu ihrer physischen Wiederherstellung. ${ }^{157}$

Jeder Ort, jedes Dorf wird in seiner Mitte, d.h. auf dem Friedhof, eine Museums-Schule einrichten, in der die Überreste der Bewohner einer Gegend und alle erreichbaren Informationen über sie gesammelt werden im Hinblick auf ihre einstige Wiederherstellung. Um an diesem Werk teilzunehmen, werden die Söhne die Städte mit ihrem künstlichen Leben verlassen und aufs Dorf, zum Staub ihrer Väter zurückkehren.

Das Museum ist keine Sammlung von Dingen, sondem eine Versammlung von Personen; seine Tătigkeit besteht nicht im Anhăufen toter Dinge, sondern in der Rückerstattung des Lebens an die Uberreste des Abgelebten, in der Wiederherstellung der Verstorbenen - aufgrund ihrer Erzeugnisse durch die tătigen Lebenden. (II, 407; Hervorhebung im Orig.)

Zu diesem Zweck wird die Museums-Schule mit einem Gotteshaus (Versammlungsort und Projekt des Weltgebäudes) und einem Laboratorium versehen sein sowie mit einem Turm (Observatorium) zur Beobachtung und Erforschung von Himmelserscheinungen (insbesondere der Schwerkraft) sowie zur Regulierung meteorischer Vorgänge (vor allem der Erzeugung von Regen). ${ }^{158}$ Vorbild und Vollendung finden diese Anlagen im Kreml, jener ursprünglichen "FriedhofsFestung" (kladbišce-krepost') zum Schutz des Staubs der Vorfahren, die zu einer Stätte der Sammlung und Auferweckung wird, wobei die "Waffen zur Verteidigung sich in Waffen zur Rückerstattung des Lebens verwandeln" (I, 427). ${ }^{159}$

All dies wird unter der Führung des russischen Zaren geschehen. Er wird die "Hindernisse" beseitigen, die einer räumlichen Vereinigung der Menschheit (also der Brüder) entgegenstehen und damit den ersten Schritt tun im Kampf gegen die "allesverschlingende Zeit" (I, 393). Er wird die Nationen der Welt vereinen - und sei es unter Einsatz des "christusliebenden Heeres" (christoljubivoe vojsko) und des "Kreuzerwesens" (krejserstvo) $-^{160}$, und er wird die Verbrüderung fördern durch die Wiederherstellung und Verbreitung der Urvätersprache. Neben die allgemeine Pflicht zur Ausbildung wird - auf Beschluß einer Weltfriedenskonferenz - die allgemeine Wehrpflicht treten, doch werden die Waffen, die bislang der gegenseitigen Vernichtung dienen, dann gegen die Na-

157 Fedorov hatte seinen Dienst an der Schule (als Geschichtslehrer) und dann am RumjancevMuseum stets als Einheit betrachtet, als eine "geheiligte Sache" (svjašennoe delo). FOD II, S. 43f.

158 Ein Gedanke, der wahrscheinlich von V.N. Karazin angeregt wurde; dieser hatte bereits zu Beginn des 19. Jahrhunderts vorgeschlagen, in allen Kreisschulen meteorologische Observatorien einzurichten, um über die Beobachtung des Wetters zu dessen Regulienung zu gelangen. Siehe SLJUSARSKU (wie Anm. 9), bes. S. 76-78.

159 Vgl. FOD I, S. 111, 427, 513; II, S. 242, 399-404, 463f. - Fedorov dachte an eine Vereinigung des Moskauer Kreml (der Grabstătte der vom Pamir dorthin überführten ersten Menschen) mit dem nahegelegenen Rumjancev-Museum (in dessen Turm das Observatorium einzurichten sei). FOD I, S. 645-647.

160 Die "Befriedung" (umirotworenie) durch Heer und Flotte soll nach Moglichkeit "ohne BlutvergieBen" erfolgen. Vgl. FOD I, S. 264f., 663. 
tur, den gemeinsamen Feind, sich richten; die Heere der Nationen aber werden zu einer weltweiten Forschungs- und Arbeitsarmee vereint. ${ }^{161}$

Die Gelehrten werden die Grenzen ihrer Wissenschaften überwinden und eine "Kommission" bilden "zur Erarbeitung eines gemeinsamen Aktionsplanes" $(I, 28)$. Unter der Führung des Zaren wird eine "neue Epoche in der Wissenschaft" anbrechen:

... die Archăologen werden sich dann nicht mehr auf die bloße Erforschung der Überreste des Abgelebten und Zerstorten beschrănken und die Naturwissenschaftler nicht auf die bloBe Erforschung der tötenden und zerstörenden Kraft, vielmehr werden alle diese Gelehrten mit dem Zaren an der Spitze und gemeinsam mit dem Volk oder gar allen Volkern ihre Aufgabe in der Regulienung (Lenkung) des Gegenwartigen zur Wiederherstellung des Vergangenen (der Văter) finden, in der Verwandlung der todbringenden Kraft in eine lebenspendende; die Wissenschaft wird in den Hănden der Autokratie ein Mittel sein zur Verbrüdenung (bratorvorenie) durch die Erfüllung der Pflicht gegenüber den Vătern durch die Sorhne. $(I, 393)$

Nach dem Übergang der Wissenschaft von der passiven "ptolemäischen Weltsicht" (die den Schein für die Wirklichkeit nimmt) zur "kopernikanischen", wird ihre Ausrichtung auf das obšcee delo zur Vereinigung aller Einzelwissenschaften in der "kopernikanischen Astronomie" führen. ${ }^{162}$ Auch die Kunst, deren Bestimmung die schöpferische Anwendung des Wissens ist, muß sich von der ptolemäischen Weltsicht befreien, um aktiv zu werden und zur Einheit zu gelangen:

Alle Künste können miteinander vereinigt werden, entweder auf deutsche Art - im Musikdrama, im Theater, oder aber, wie wir meinen, auf slawische, auf russische Art - in der Architektur, in ihrer hðchsten Schðpfung, dem Gotteshaus, und im Gottesdienst, der darin vollzogen wird, im Gotteshaus als dem Abbild des Weltgebăudes, ... dem Projekt der Welt, wie sie sein soll. (...) Doch ist das Gotteshaus ein Abbild der Welt nach ptolemăischer Weltsicht, und solange die ptolemăische Weltsicht herrschte, gab es zwischen Wissen und Kunst keinen Widerspruch. Als aber die ptolemäische Weltsicht durch die kopernikanische abgelost wurde, entstand ein Widerspruch zwischen Wissen und Kunst, denn die Kunst blieb ptolemăisch, das Wissen aber wurde kopernikanisch. Die ptolemăische Weltsicht, wie sie in der Kunst zum Ausdruck kommt, mu Gotteshaus mit seinen Gottesdiensten, ist imaginăre Patrofikation (mnimaja patrofikacija), $\left({ }^{163}\right)$ die kopernikanische Weltanschauung aber muB wirkliche Văterschøpfung (dejstvitel'noe otcetvorenie), muB Auferweckung sein, worin auch der Widerspruch zwischen Wissen und Kunst seine Auflosung finden wird. $(I, 413)$

Um ihre Bestimmung zu erfüllen, muß die Kunst übergehen von der Schaffung bloß toter Ebenbilder alles Vergangenen zu dessen tatsächlicher Wiederherstellung und von der Darstellung des Weltgebäudes (als Tempel, Gotteshaus) zu dessen tatsächlichem Bau; d.h. alle Künste müssen sich vereinigen in der "kopernikanischen Himmelsarchitektur". Wissenschaft und Kunst werden nicht län-

161 Vgl. FOD I, S. 4, 371, 393, 423f., 432, 459, 644, 661-663, 669-676; II, S. 238, 295. Fedorov spricht sich stets gegen Abrüstung und Demobilisierung aus, da Kriegsmittel und militărische Organisationsformen hervorragend für den Kampf gegen die Natur geeignet seien (als Beispiel nennt er zumeist den BeschuB von Wolken, um Regen auszulosen).

162 Zur Bedeutung von "ptolemäischer" und "kopernikanischer Weltsicht" siehe oben Anm. 143.

163 Patrofikation, d.i. "Umwandlung des Himmels in eine Wohnstatt der Văter". FOD II, S. 240. Siehe auch oben Anm. 61. 
ger getrennt sein, wenn im Zeichen des obšzee delo das Wissen über die Welt seine Anwendung und Bestätigung finden wird in der schöpferischen Verwandlung der Welt. ${ }^{164}$

\subsubsection{Umgestaltung und Auferweckung}

Der gemeinsame Kampf aller Menschen gegen die blindwaltende Natur beginnt mit der Regulierung des Klimas, dem "ersten Schritt" auf dem Weg der Auferweckung. ${ }^{165}$ Die Heere aller Nationen, die sich zu einer großen, die Natur erforschenden und verwandelnden Armee zusammengeschlossen haben, werden ihre Geschütze gen Himmel richten und durch planmäßigen Beschuß von Wolken Regen hervorrufen. ${ }^{166}$ Auf diese Weise werden "meteorische Pogrome", wie die verheerende Dürrekatastrophe, die Rußland zu Beginn der 1890er Jahre heimgesucht hatte, künftig verhindert werden, die Ernte wird nicht länger abhängig sein von den Zufällen der Witterung, und es wird sichergestellt werden, $\mathrm{da} \beta$ jeder Mensch auf friedlichem Wege sein "tägliches Brot" erhält. Die bisherigen Vernichtungswaffen aber werden sich in Instrumente zum Wohle der Menschheit verwandeln.

Weitaus größere Erfolge versprechen freilich die Beherrschung und der planmäßige Einsatz der atmosphärischen Elektrizität. ${ }^{167}$ Lenkbare Luftschiffe (Aerostate), die mit Blitzableitern versehen sind, werden die meteorischen Vorgänge regulieren und die atmosphärische Elektrizität nutzbar machen.

... dann wird das Wesen, dem drei Arschin Land genügen, mit diesem von ihm neu geschaffenen Arm die Wolken berühren und, indem es die Gewitterkraft aus der Atmosphăre holt, die Stürme be-

164 Siehe FOD II, S. $347 f$.

165 Vgl. FOD I, S. 2-5, 51-54, 281f., 656-668; II, S. 79, 177, 252, 275-279, 281.

166 Fedorov verwies in diesem Zusammenhang immer wieder auf Berichte, wonach es zu Beginn der 1890er Jahre in Amerika gelungen sei, durch ArtilleriebeschuB von Wolken Regen hervorzurufen. Ein weiteres Beispiel sei die auf Befehl Napoleons im Oktober 1812 versuchte Sprengung des Moskauer Kreml: Die Detonationen hătten Regenfalle und ungewðhnlich starken Fost hervorgerufen, wodurch der Brand gelరscht und der Schaden begrenzt worden sei. FOD I, S. 662. Siehe auch N.F. Fedorov an N.P. Peterson, 16.10.1891. In: Vselenskoe delo, sb. 2, Riga 1934, S. 149f. I.M. Ivakin an L.N. Tolstoj, 17.10.1891. Ebd., S. 156-159.

167 Elektrizităt ist die "allgemeine Kraft", die "in allem, überall und immer wirkt", der "allgemeine Ursprung aller Krafte" (FOD II, S. 255). Nicht reguliert, áuBent sie sich als "zerstorerische Kraft" in Gewitter und Sturm, doch kann sie in eine "schaffende oder wiederherstellende Kraft" verwandelt werden. Die Aufforderung, das "himmlische Feuer" zu zăhmen, anstatt es als gottlich zu verehren, findet ihren mythisch-symbolischen Ausdruck in der Ersetzung des heidnischen Donnergottes Perun durch den christlichen Propheten Il'ja (Elias). Vgl. FOD I, S. 347, 699f.; II, S. 257f. Siehe auch N. ALEKSEEv, "Priroda i Kelovek v filosofskich vozarenijach russkoj literatury." In: Grani, 42, 1959, S. 200, 204. V.[V.] IVANOV, "Motivy vostő̌no-slavjanskogo jazyzestva i ich transformacii v russkich ikonach." In: Nanodnaja gravjura i fol'klor v Rossii XVII$X I X$ w., M. 1976, S. 269. 
sănftigen, die Orkane beruhigen, die Winde lenken und die Niederschlăge unter allen Feldern nach Bedarf verteilen. ${ }^{168}$

Das Luftschiff muß von einem "Spielzeug" in ein "großes Werkzeug" verwandelt werden. ${ }^{169}$ Jeder Landkreis wird dann einen "Luftkreuzer" (vozdušnyj krejser) besitzen, der die für die Landwirtschaft günstigsten Witterungsbedingungen schaffen und die Heimindustrie mit der nötigen Energie versorgen wird. Außerdem werden Luftschiffe zu Forschungszwecken und Experimenten eingesetzt, eröffnen sich doch für die mit ihrer Hilfe beherrschte "elektrische Kraft" schier unbegrenzte Anwendungsbereiche: So vermag elektrischer Strom nicht nur Stimmen und Bewegungen zu übertragen, sondern auch "physiologische und psychische Phänomene" (etwa zum Zweck der Heilung von einem gesunden auf einen kranken Organismus). (I, 328) Karazins Luftschiff, bestimmt zur Regulierung atmosphärischer Erscheinungen, könnte den Sauerstoff ozonisieren und durch Aktivierung "telluro-solarer Kräfte" zur Ausrottung der Krankheiten beitragen, ja vielleicht sogar Tote erwecken:

Kann nicht das von Karazin genannte Gerăt auch angewandt werden zur direkten Einwirkung auf Leichname, zu Zwecken der Forschung und vielleicht sogar der Wiederbelebung, und wird dies nicht der erste Schritt auf dem Weg zur Auferweckung sein? $(1,289)$

Bei alldem wird das Luftschiff, das über der Erde schwebt, auch eine pädagogische Funktion erfüllen: Ausdruck des Aufstandes gegen die Schwerkraft,

168 FEDOROV (wie Anm. 142), S. 20f. Vgl. FOD I, S. 53f., 280, 401. - Diese Idee hat Fedorov (was in der Literatur zumeist übersehen wird) bis in Einzelheiten von V.N. Karazin übernommen, der sie 1818 in einem Vortrag "Ober die Moglichkeit, die elektrische Kraft der oberen Schichten der Atmosphăre für die Bedürfnisse des Menschen anzuwenden" dargelegt hatte. Siehe V.N. Karazin, Soxinenija, pis'ma i bumagi, Char'kov 1910, S. 430-436. - Nachdem Benjamin Franklin den Blitz als elektrische Erscheinung erkannt und 1752 den Blitzableiter erfunden hatte (russischerseits wird diese Erfindung gelegentlich Lomonosov zugeschrieben), ging von dem Gedanken einer Beherrschung und Nutzung der atmosphărischen Elektrizităt eine starke und langanhaltende Faszination aus (siehe 2.B. die Arbeiten des FedorovAnhăngers P.I. Ivanickij aus den 1920er Jahren; II: 3.3.). Karazins Arbeiten zur "Beherrschung und Nutzung der in der Atmosphäre verstreuten elektrischen Kraft" durch den Menschen reichen bis ins Jahr 1808 zurück. Bereits 1814 hatte Karazin in einem Brief an Arakteev von der Möglichkeit gesprochen, durch die Beherrschung der atmosphărischen Elektrizităt das Wetter "nach eigenem Gutdunken" zu regulieren. Siehe KARAZIN, a.a.O., S. 712f. Ausführlich dazu SLUUSARSKU (wie Anm. 9), S. 69-79. - Fedorov zitiert Karazin: "Der Mensch, der mit der elektrischen Kraft ausgerüstet ist, wird, wenn nicht alle, so immerhin doch einen großen Teil der Wunder vollbringen, die die Natur bislang sich selbst vorbehalten hat." FOD I, S. 281. Zu Karazin auch ebd., S. 4, 280f., sowie ausführlich Fedorovs Artikel "Karazin als Meteorourg und nicht als Meteorologe" in: FOD II, S. 275-279.

169 "Auf den Gedanken, den Aerostat mit dem durch ihn emporgehobenen Blitzableiter in ein Werkzeug zur Rettung vor der Hungersnot zu verwandeln, ist einer von den wahren Slavophilen gekommen, doch hat Deutschland in der Person des Akademiemitglieds Fuss die slavische Erfindung für nutzlos erklărt." FEDOROV (wie Anm. 142), S. 21. Tatsăchlich war Karazins Vorschlag bei Mitgliedern der Petersburger Akademie auf Ablehnung gestoßen, darunter auch bei Nikolaj Fuss (der allerdings Schweizer Herkunft war). 
wird es Kühnheit und Erfindergeist wecken und den Weg weisen in die Weite des Himmels. ${ }^{170}$

Die kühnste Perspektive eröffnet jedoch erst weltweit gemeinsames Handeln: Ein riesiger (dem transozeanischen Telegraphenkabel vergleichbarer) Drahtring, der an beweglichen, mit Blitzableitern versehenen Luftschiffen befestigt, die Erde umspannt, wird die Grundlage für einen "meteorischen Apparat" bilden, der auf den Gewitter- und Wolkengürtel einwirkt, ihn nach Bedarf verschiebt und verändert und so weltweit das Wetter reguliert. ${ }^{171}$ Die gemeinsame Verantwortung für das Wetter auf der ganzen Erde wird alle Nationen verbinden, denn: "Wird Krieg möglich sein, wenn die Ernte in jedem Land abhängen wird vom Funktionieren dieses Apparates, der die ganze Welt umspannt und der von allen gelenkt wird?" (I, 54) "Solange aber auf Erden Krieg sein wird, werden auch am Himmel Gewitter sein" (II, S. 257).

Mehrere Drahtringe, in Form einer Spirale um die Erde gelegt, werden diese in einen Elektromagneten verwandeln, mächtig genug, um aus den Tiefen des Weltalls "kosmisches Material" heranzuholen zum Umbau und zur Neugestaltung der Erde und des Himmelsgewölbes:

Nehmen wir, indem wir Karazins Gedanken weiterfuhren, an, daB die elektrischen Strome auf der Erde bestimmte Ausrichtungen erfahren - sei es durch Telegraphendrăhte, die die Erde in Form einer Spirale umspannen, oder auf sonst eine Weise - und daB die Erde, dieser riesige Siderolith und natürliche Magnet, sich dadurch in einen Elektromagneten verwandeln würde, so würde dies den Wirkungsbereich der Erde steigern und erweitern: Kleine Siderite und Siderolithe, die, wie man annimmt, sich der Erdenbahn anschließen und sich uns als Zodiakalschein zeigen, konnten unter dem EinfluB der regulienten Kraft des Erdmagnetismus ăhnlich wie Dämpfe verdichtet und verdünnt werden und somit ihrerseits zur Regulierung der Sonneneinstrahlung und zur Vergroßenung der Erdmasse dienen wie auch zur Bildung von Ringen und Spiralen auf der Bahn der Erdbewegung oder um die Sonne herum; sie kðnnten zum Bau eines neuen Himmelsgewolbes, neuer Himmelsb\&gen dienen, und auf diese Weise kőnten wir sogar die Magnetkraft der Sonne lenken. $\left(\right.$ I, 281f.) ${ }^{17}$

Bislang wird der Lauf der Erde (wie auch aller anderen Himmelskörper) von der blinden, zerstörerischen Schwerkraft bestimmt, und der Mensch als "Sklave der Erden, als "müßiger Passagier, Parasit und Schmarotzer" vollführt mit ihr "unfreiwillige Fahrten um die Sonne" (I, 336).

... die Menschheit aber darf kein müBiger Passagier sein, sondern muß die Mannschaft werden, die Besatzung unseres irdischen - unbekannt noch, durch welche Kraft in Bewegung gehaltenen - Schiffes, sei es ein Photo-, Thermo- oder Elektrogefahrt. Solange werden wir nicht sicher wissen, wodurch sich unsere Erde bewegt, wie wir ihren Lauf nicht lenken. $(1,284)$

Wenn aber diese Frage gelost sein wird, so wird im Weltraum erstmals ein Stern oder ein Planet erscheinen, der gelenkt sein wird vom BewruBtsein und vom Willen. $(1,293)$

170 Vgl. FOD I, S. 283; II, S. 254.

171 FOD, I, S. 53f.

$172 \mathrm{Vgl}$. FOD II, S. 255. - Die Nutzung der Sonnenenergie wird die Kohle ersetzen und die "qualvolle unterirdische Arbeit" in den Bergwerken überflüssig machen. Vgl. FOD I, S. 5, 31, 282; II, S. 273. 
Die vereinte Menschheit wird die Erde aus den "Fesseln der Schwerkraft" befreien und sie in ein lenkbares Raumschiff verwandeln zum "Übergang von einer Welt in die andere $(I, 284) .{ }^{173}$ Sie wird die irdische Begrenztheit überwinden und die Weiten des Alls erforschen und erobern, sie wird die verstreuten Überreste der Verstorbenen sammeln und mit den auferweckten Geschlechtern die Gestirne besiedeln und lenken, und sie wird schließlich das gesamte Universum von der blinden Schwerkraft befreien, es neu gestalten und vernünftig ordnen.

Solange freilich die Erde im All isoliert ist, bleiben auch die Mittel zum Leben begrenzt, ist beständiges, unsterbliches Dasein auf ihr unmöglich. Schon die gleichzeitige Existenz mehrerer Generationen von Menschen erfordert ein Ausgreifen in den Weltraum. Nur so kann dem (von Malthus behaupteten) wachsenden Mißverhältnis zwischen der Anzahl der Menschen und der Menge der Existenzmittel begegnet werden. ${ }^{174}$

Für die Menschensठ̋hne sind die himmlischen Welten die künftigen Wohnsitze der Văter, denn die Himmelsrăume kőnnen nur für Wiedererweckte und Wiedererweckende zugănglich sein; die Erforschung der Himmelsrăume ist die Vorbereitung dieser Wohnsitze. (...) Die Pflicht zur Auferweckung fordent die Eröffnung [des Weges ins Weltall], denn ohne die Beherrschung des Himmelsraumes ist gleichzeitiges Existieren der Generationen nicht moglich, wăhrend andererseits eine vollige Beherrschung des Himmelsraumes ohne die Auferweckung auch nicht moglich ist. $(\mathrm{I}, 283)^{175}$

Dazu müssen Mittel und Wege der Beobachtung und direkten Einwirkung auf außerirdische Bereiche gefunden werden. Nach dem Vorbild des menschlichen Organismus mit seinen Sinnes- und Bewegungsnerven, die im Gehirn verbunden sind und als elektrische Leiter wirken, könnte ein das Sonnensystem "regulierender Apparat" geschaffen werden, eine Art kosmisches Nervensystem, durch das "alles, was sich unter der Sonne abspielt, zum menschlichen Bewußtsein gelangen" und "alles, was im Bewußtsein entsteht, in wiederherstellendes Handeln umgesetzt werden würde" $(I, 331) .{ }^{176}$

$173 \mathrm{Vgl}$. FOD I, S. 328f., 338; II, S. 205f. - Die Beherrschung der Erdbewegung durch den Menschen wird auch als Beweis für das kopernikanische Weltbild dienen: "Dann wird es keinerlei Zweifel mehr darüber geben, daB nicht die Sonne, sondern die Erde sich bewegt, so wie es für einen Kahnfahrer keinen Zweifel gibt, daB der Kahn sich bewegt und nicht die Ufer." FEDOROV (wie Anm. 142), S. 21.

174 Vgl. FOD I, S. 276f., 284.

175 Siehe auch Fedorovs Antwort auf den Einwand von S.P. Bartenev, daB für die Wiedererweckten kein Platz auf Erden sei: "Also Sie sind irritiert wegen der riesigen Menge [der Wiedererweckten]. Denken Sie doch an all die Sterne, die ganze Nebelflecken am Himmel bilden. Wenn der Mensch die Erde beherrscht, so wird dies der erste Planet sein, der von Vernunft, oder sagen wir BewuBtsein, bewohnt und regiert wird... Besiedelt alle Welten, damit das Weltall von Vernunft regiert wird. Was sorgen Sie sich, daß der Platz nicht reichen wird? Ich hatte gedacht, daB es im Vergleich zur Aufgabe der Wiederenweckung der Toten eine ganz einfache Sache sein würde, zum Sirius überzusetzen, und daß man darüber gar nicht zu reden bräuchte." Fedorov nach BARTENEv, "Nikolaj Fedorovił Fedorov..." (wie Anm. 7), S. 122.

$176 \mathrm{Vgl}$. FOD I, 401: "Der [menschliche] Organismus mit seinen Empfindungs- und Bewegungsnerven, die im Gehirnknoten verbunden sind, liefert ein Vorbild für die Steuerung des ganzen 
Um ins Weltall vordringen und in allen Welten des Universums existieren zu können, muß sich der Mensch von organischer Ernährung unabhängig machen. Er muß fähig werden, seinen Körper aus "elementaren, kosmischen Stoffen" (I, 317) zu regenerieren.

Dem Menschen werden alle Himmelsrăume und alle Himmelswelten erst dann zugănglich sein, wenn er sich selbst aus den allerursprünglichsten Stoffen, Atomen und Molekülen wiederherstellt, denn erst dann wird er fahig sein, in allen Milieus zu leben, jectwede Form anzunehmen und bei allen Generationen zu Gast zu sein... $(I, 421)^{1 \pi}$

Indem er sich selbst aus elementarer Materie regeneriert und konstruiert, verwandelt sich der Mensch aus einem geborenen und deshalb unvollkommenen und hinfälligen Naturwesen in ein selbstgeschaffenes und schließlich vollkommenes Kunstwerk:

Dieser Organismus ist die Einheit von Wissen und Handeln; die Emähnung dieses Organismus ist der bewußt-schaffende Proze $\beta$ - die vom Menschen vollzogene Verwandlung elementarer, kosmischer Stoffe in mineralische, dann in pflanzliche und schließlich in lebende Gewebe. (I, 317f.; Hervorhebungen im Orig.)

Im Verlauf der Selbsterschaffung und Selbstvervollkommnung wird der Mensch seinen Horizont erweitern, seine Sensibilität steigern und mit dem Zuwachs an Wissen auch seine Macht vermehren. Durch "psychophysiologische Regulierung (d.h. die Lenkung geistig-körperlicher Erscheinungen)" werden Organe geschaffen,

... die nicht nur das Wachsen der Grăser spüren werden, sondern auch die Bewegung der Moleküle und Atome des ganzen Alls, was auch die Aufenweckung und Umgestaltung des ganzen Alls ermoglichen wird. $(I, 420)$

Die Fähigkeiten und Werkzeuge des Menschen werden zu Organen seines künstlichen Körpers werden:

$\mathrm{Zu}$ seinen Organen werden auch jene aero- und ăthero-nautischen Mittel, mit deren Hilfe er sich fortbewegen und im Weltraum Materialien zum Bau seines Organismus verschaffen wird. Der Mensch wird dann die ganze Geschichte der Entdeckungen, den ganzen Verlauf dieses Fortschritts in sich tragen; in ihm werden auch Physik und Chemie enthalten sem, mit einem Wort, die ganze Kosmologie, freilich nicht als ein gedankliches Bild, sondern in Form eines kosmischen Apparates, der es ihm ermoglichen wird, ein wirklicher Kosmopolit zu sein, d.h. überall zu sein; dann wird der Mensch ein wirklich aufgeklartes Wesen sein. $(1,318)$

Weltalls; alle Welten des Alls sollten durch zwei Reihen von Leitern miteinander verbunden werden, durch Leiter der Empfimdungs- und der Bewegungskrafte."

177 Vgl. FEDOROV (wie Arm. 142), S. 22-24. - Die von Fedorov beschriebene Art der 'Emăhrung' und Regeneration gleicht der Autotrophie, d.h. der Făhigkeit der grünen Pflanzen, sich (durch Photo- oder Chemosynthese) von anorganischen Stoffen zu ernăhren. - Der Gedanke einer Autotrophie des Menschen, der in den zwanziger Jahren von V.I. Vernadskij entwickelt wurde (siehe V.I. VERNADSKU, "Avtotrofnost' reloverestva." In: DERS., Biogeochimizeskie orerki 1922. 1932 88., M.-L. 1940, S. 47-58), findet derzeit in der sowjetischen "Kosmismus"-Diskussion, auch mit Hinweis auf Fedorov, besondere Beachtung. Siehe 2.B. S.G. SEMENova, "Aktivnoevoljucionnaja mysl' Vernadskogo." In: Prometej, 15, M. 1988, S. $240-242$. 
Trotz dieser Veränderungen aber wird der Mensch dann kein anderes Wesen, sondern im Gegenteil noch "mehr er selbst sein", denn das, was in ihm bislang nur in Gedanken oder als Wunsch angelegt ist, wird dann verwirklicht sein: "Die Schwingen der Seele werden zu körperlichen Flügeln werden." $(I, 318)^{178}$

Der Mensch wird nicht länger gezwungen sein, den "Staub der Vorfahren" in Nahrung für sich und seine Nachkommen zu verwandeln, sondern wird aus ihm - mit Hilfe des Wissens und Könnens, das er bei der Konstruktion seiner eigenen Organe (organostroenie) und seines eigenen Körpers (telostroenie) erworben hat - die Vorfahren wiederherstellen. An die Stelle des "Verdrängens und Verschlingens ${ }^{n}$ der vergangenen Generationen wie auch der blinden natürlichen Fortpflanzung wird die Sorge um die Verstorbenen und deren bewußte Wiederherstellung treten.

Unser Körper muß unser Werk sein (naše telo dolzno byt' nasim delom), jedoch nicht durch egoistische Selbstkonstruktion, sondern durch die Tat, durch die Rückerstattung des Lebens an die wiederhergestellten Văter. (1, 61; Hervorhebung im Orig.)

... die innere, psychophysiologische Regulierung wird der Liebe zu den Eltern ein Obergewicht geben über den Geschlechtssinn und die sinnliche Begierde und sie sogar ganz ersetzen, wobei sie die gebărende Kraft in eine wiederherstellende, die tötende in eine belebende verwandelt, d.h. Kinderzeugen (detorożdenie) durch Vaterschaffen (otcetvorenie) ersetzt... $(1,424)$

Bloße geschlechtliche Abstinenz (otricatel'noe celomudrie) ist lebensfeindlich und führt im Extrem zum Selbstmord der Gattung. "Positive Keuschheit" (polozitel'noe celomudrie) hingegen richtet die freigesetzten Energien auf die Schaffung unsterblichen Lebens und seine Rückerstattung an die Verstorbenen: "Die ungeheure Kraft, die sich in der Wollust zeigt, findet ihren adäquaten Ausdruck in der Wiedererschaffung." (II, 13)

178 Fedorovs Vision der Selbstkonstruktion und bewuBt-schaffenden Organbildung ist möglicherweise angeregt durch die Entwicklungs- und Vererbungslehre von Lamarck, die dem Mechanismus der Mutations-Selektion ein aktives Umkonstruktionsvermögen entgegensetzte. Gelegentlich erwahnt Fedorov in diesem Zusammenhang auch histologische Forschungen seiner Zeit. Vielleicht geht dieser Gedanke aber auch auf Fourier zurück, der annahm, daB sich dem künftigen Menschen ein neues Organ bllden werde, mittels dessen er die "ătherischen Fluida" aufnehmen und mit den Bewohnern anderer Sterne in Verbindung treten werde. Siehe E. BLoch, Das Prinzip Hoffnung, Bd. 2, Frankfurt/M. 1959, S. 549.

179 Siehe auch oben Anm. 49. - Fedorovs Theorie über den engen Zusammenhang von Geschlechtlichkeit und Tod bzw. Keuschheit und Unsterblichkeit besitzt nach einer Beobachtung von Florouskij eine "sehr interessante Ähnlichkeit" mit den Trăumen jenes Kreises "denkender Menschen", zu dem gegen Ende der 1850er Jahre der junge Dmitrij Pisarev gehorte: Die Mitglieder dieses Kreises, die sich "zu frommen Gesprăchen und gegenseitiger sittlicher Unterstützung" zusammenfanden, stellten sich u.a. die Aufgabe, die geschlechtliche Leidenschaft in der gesamten Menschheit auszulosschen und Zeugen und Gebăren abzuschaffen. Als Belohnung für eine solche Tat würden, so hofften sie, die Menschen unsterblich werden. Siehe G.[V.] FLo. ROVSKI, "Proekt mnimogo dela." In: Sorremennye Zapiski, 59, 1935, S. 408. Als mogliche Quelle verweist Florovskij auf Comte. Dieser hatte im vienten Band seiner Politique positive (1854) ein Ende der Geschlechtllchkeit prophezeit und von einer Umwandlung sinnlicher Energien in geistige gesprochen. Deutlich in dieser Tradition steht Solov'ev (bes. Smysl ljubvi, 18921894; Opravdanie dobra, 1894-1897). 
Die Wiederherstellung der Verstorbenen vollzieht sich in drei Schritten: zuerst werden die Teilchen, aus denen der Körper eines Verstorbenen bestand, identifiziert; sodann werden sie gesammelt und schließlich wird aus ihnen der Körper des Verstorbenen rekonstruiert. ${ }^{180}$

Jeder (menschliche) Organismus ist eine mechanische Verbindung kleinster "Teilchen" (casticy). Während die Verbindung nach dem Tod des Organismus zerfällt, sind die Teilchen selbst unvergänglich. Sie erfüllen das (endliche) Universum und gehen immer neue Verbindungen ein. Dabei werden sie "geprägt", d.h. jeder äußere Einfluß und jede Verbindung hinterläßt charakteristische Spuren.

Aller Stoff ist Staub der Vorfahren, und in diesen winzig kleinen Teilchen ... können wir die Spuren unserer Vorfahren finden. (...) Jedes Milieu (sreda), durch das ein solches Teilchen gegangen ist, hat auf ihm seinen Einfluß, seine Spur hinterlassen. Aus archăologischer oder paläontologischer Sicht stellt dieses Teilchen vielleicht so etwas wie Schichten dar, die die Eindrücke aller Einflüsse bewahren, denen das Teilchen ausgesetzt war, wh̆hrend es durch die verschiedenen Milieus, die verschiedenen Organismen gewanden ist. Auch wenn das Teilchen sich zerspalten hat, so werden die neuen, aus dieser Spaltung entstandenen Teilchen wahrscheinlich doch die Bruchspuren bewahren. $(1,329)$

Jedes Teilchen trägt und bewahrt die Spuren seiner Geschichte, ist somit individuell und unterscheidbar. ${ }^{181}$ Gelingt es, diese Spuren zu 'lesen', so werden alle früheren Verbindungen und Trennungen eines Teilchens erkennbar. Das aber bedeutet, da $B$ die in den Teilchen enthaltene 'Information' es auch ermöglicht, ihre Kombination in einem bestimmten Körper zu einem bestimmten Zeitpunkt

180 Fedorov selbst betont, daß es sich bei seinen Ausführungen über den "Gang der Auferweckung" um bloBe Vermutungen handelt, die "andere Hypothesen" nicht ausschließen. FOD II, S. 273. Wesentlich ist jedoch die konsequent materialistische Darstellung des Menschen und seiner Wiederherstellung, wie sie in Fedorovs vielzitiertem Satz zum Ausdruck kommt: "... der Organismus ist eine Maschine, und ... das BewuBtsein verhălt sich zu ihm wie die Galle zur Leber; setzt die Maschine zusammen, und das BewruBtsein kehrt in sie zuruck!" FOD I, S. 288. Dabei handelt es sich (was bislang nicht bemerkt worden ist) um die Paraphrase einer Äußerung des Materialisten Karl Vogt (Köhlerglaube und Wissenschaft, 1855), die durch Ludwig Büchners Kraft und Stoff, die "Bibel des Materialismus", weithin bekannt wurde: "Die Gedanken stehen in demselben Verhaltnis zu dem Gehirn, wie die Galle zur Leber oder der Urin zu den Nieren." "Sobald die Substanzen, welche das Gehirn bilden, wieder in derselben Form zusammengewürfelt werden, so werden auch dieselben Funktionen wieder eintreten..." L. BOCHNER, Krafi und Stoff, Leipzig oJ., S. 120, 155.

181 Dabei kann es sich außer um mechanische Eindrücke oder Verformungen auch um charakteristische Schwingungen handeln, die eine Identifizierung der Teilchen ermoglichen. Siehe z.B. FOD II, S. 273. - Fedorows Vorstellung von einer "Pragung" der Teilchen findet, wie schon früh bemerkt wurde, eine wenn auch entfernte Entsprechung in der Auferweckungslehre des Gregor von Nyssa: Dort ist es die gegenseitige Prägung von Leib und Seele, die nach dem Tod, verstanden als Auflosung und Zerstreuung der leiblichen Elemente, fortdauert und die Wiederherstellung der individuellen Einheit bei der Auferstehung des nunmehr freilich verklărten Leibes ermöglicht. Ausführlich dazu P.[S.] STRACHOV, "Atomy žizni." In: DERs., Nauka i religija, M. 1915, S. 141-170; Hinweis auf Fedorov, "einen der interessantesten Denker der jüngsten Vergangenheit", ebd., S. 167. 
zu erkennen und - dank der Macht des Menschen über die Materie - diesen Körper dann zu rekonstruieren. ${ }^{182}$ Es ist "möglich und notwendig",

... alle Moleküle und Atome der AuBenwelt so zu erkennen und zu lenken, daB das, was zerstreut ist, gesammelt wird und das, was zerfallen ist, wieder vereint wird, d.h. zusammengesetzt wird zu jenen Korpern, wie die Văter sie bei ihrem Tode hatten. $(1,442)$

Dazu müssen die im Innern der Erde und in den Weiten des Alls verstreuten Teilchen geortet und gesammelt werden. Dies geschieht mit Hilfe technischer Mittel - dem Einsatz der Elektrizität, der Verwendung aero- und ätheronautischer Apparate - aber auch durch die Ausbildung hochsensibler Organe beim Menschen, mit denen sich noch die feinsten Schwingungen der Moleküle und Atome wahrnehmen lassen. ${ }^{183}$ Künstlich ausgelöste Erdbeben fördern die im Erdinnern verborgenen Teilchen zutage, während ein Netzwerk elektrischer Leiter die (auch gasförmigen!) Reste der Verstorbenen im Weltall gewinnt. ${ }^{184}$

Das Sammeln der verstreuten Teilchen ist Sache der kosmotellurischen Wissenschaft und Kunst, folglich eine mănnliche Aufgabe; das Zusammensetzen der gesammelten Teilchen ist eine physiologische, histologische Angelegenheit, und, da es sich sozusagen um das Zusammennăhen der Gewebe des menschlichen Kðrpers, des Kðrpers unserer Văter und Mütter, handelt, eine weibliche Aufgabe. $(\mathrm{I}, 329)$

Bei der Wiederherstellung der Verstorbenen handelt es sich (im Gegensatz zur christlichen Vorstellung der Auferstehung) um einen allmählich fortschreitenden Prozeß, der gekennzeichnet ist durch ständigen Zuwachs an Wissen und Erfahrung - und damit an Macht:

Obwohl der erste Wiedererweckte höchstwahrscheinlich unmittelbar nach seinem Tod, also kaum daß er gestorben ist, wiedererweckt werden wird und ihm dann jene folgen werden, die erst ein wenig in Făulnis übergegangen sind, so wird doch jeder neue Versuch in dieser Angelegenheit weitere Schritte erleichtern. Denn mit jedem neuen Wiedererweckten wird das Wissen wachsen, und es wird dann auf der Hohe der Aufgabe sein, wenn das Menschengeschlecht zum ersten Verstorbenen gelangt. (I, 330)

Da jede Generation bei der Auferweckung ihrer Väter sich der Erfahrungen aller inzwischen Auferweckten bedienen kann, wird es für ältere Generationen immer leichter werden, ihre Vorfahren wiederherzustellen. Am leichtesten wird es für den ersten Menschensohn sein, der sich bei der Auferweckung seines Va-

182 FOD I, S. 329f. - Selbst für den Fall, daB sich die Spuren auf den Teilchen mit der Zeit verwischen oder daß sie ganz verloschen, genügt es, so Fedorov, das "Gesetz der Erhaltung und des Schwindens der Spuren" zu kennen, um die notige Information wiederzugewinnen. FOD I, S. 330 .

183 Vgl. FOD I, S. 420; II, S. 273.

184 Vgl. FOD I, S. 330; II, S. 255, 273. 
ters - des Vaters aller Menschen - der Hilfe der gesamten wiedererweckten Menschheit gewiß sein kann. ${ }^{185}$

Die vereinte, alle Generationen umfassende Menschheit, die sich im gesamten Universum bewegt, wird alle Grenzen in Raum und Zeit überwunden haben; sie wird allwissend, allmächtig und unsterblich sein:

Die allumfassende Auferweckung ist der vollstăndige Sieg über Raum und Zeit. Der Übergang 'von der Erde zum Himmel' ist der Sieg, der Triumph über den Raum (oder fortlaufende Allgegenwart). Der Ubergang vom Tod zum Leben oder das gleichzeitige Nebeneinandersein des gesamten Zeitablaufs (der Generationen), das Nebeneinandersein der Aufeinanderfolge, ist der Triumph über die Zeit. (II, 351; Hervorhebung im Orig.)

Die Menschheit wird "göttliche Vollkommenheit" erlangen (I, 416), und sie wird Gott, indem sie ihm gleich sein wird, "von Angesicht zu Angesicht sehen" und darin den "endgültigen Beweis für seine Existenz" finden. 186

185 FOD I, S. 330. - Fedorovs Forderung, die Verstorbenen nicht nur in derselben Form, sondern aus genau denselben Teilchen wiederherzustellen, aus denen sie zum Zeitpunkt ihres Todes bestanden haben, hat v.a. den Einwand hervorgerufen, daB ein und dasselbe Teilchen, das zu verschiedenen Zeiten Bestandteil verschiedener Korper gewesen sei, bei der Auferweckung dann gleichzeitig mehreren Kסrpern zugeteilt werden müBte. Somit kס̋ne zumindest nicht jeder wiederenweckte Kठrper mit einem Korper vor dessen Zerst $\measuredangle r u n g$ materiell identisch sein. T.D. Zakydalsky, der sich eingehend mit der Frage der Identităt von Verstorbenen und Wiederhergestellten befaBt hat, verweist zur Losung dieses Problems auf den Prozeßcharakter der Fedorouschen Auferweckung: Bei einer nicht gleichzeitig, sondern schrittweise erfolgenden Wiederherstellung könne ein und dasselbe Teilchen nacheinander zur identischen Wiederherstellung mehrerer verschiedener Korper dienen. ZAKYDALSKY (wie Anm. 1), S. 445f. - Zu den verschiedenen Konzeptionen von Unsterblichkeit und körperlicher Auferweckung und den damit verbundenen Problemen der Entwicklung eindeutiger Kriterien zum Nachweis personaler Identităt siehe die überaus anregende Arbeit von R.W. PERRETT, Death and Immonaliny, Dordrecht 1987 (mit weiterführender Literatur).

186 Vgl. FOD I, S. 116; II, S. 182, 262. - Fedorovs Spekulationen über eine Gottwerdung der Menschheit gleichen in erstaunlicher Weise dem Wissenschaftsglauben Renans, wie dieser ihn 1863 in einem Brief an Berthelot (und spatter in L'Avenir de la Science) dargelegt hatte, der noch im selben Jahr in der Revue des Deux Mondes erschienen war. Fedorov war diese Veroffentlichung offenbar bekannt (siehe den wahrscheinlich diesbezüglichen Hinweis in FOD II, S. 32).

Wie Fedorov glaubte Renan an die Allmacht der Wissenschaft als Ergebnis allumfassenden Wissens, und er nannte, wie Fedorov, als Beispiele Chemie und Biologie: "Qui sait si l'homme ou tout autre être intelligent n'arrivera pas à connaître le dernier mot de la matière, la loi de la vie, la loi de l'atome? Qui sait si, étant maître du secret de la matière, un chimiste prédestiné ne transformera pas toute chose? Qui sait si, maitre du secret de la vie, un biologiste omniscient n'en modifiera pas les conditions, si un jour les especes naturelles ne passeront pas pour des restes d'un monde vieilli, incommode, dont on gardera curieusement les restes dans des musées? Qui sait, en un mot, si la science infinie n'amènera pas le pouvoir infini, selon le beau mot baconien: 'savoir, c'est pouvoir?'." E. RENAN, "Les sciences de la nature et les sciences historiques." In: Revrue des Deux Mondes, 33 (1863), 47, S. 772.

Auch der Gedanke einer Ausdehnung von Wissen und Macht über das Weltall und der damit einhergehenden Gottwerdung findet sich bei Renan: "L'être en possession d'une telle science et d'un tel pouvoir sera vraiment maitre de l'univers. L'espace n'existant plus pour lui, il franchira les limites de sa planète. Un seul pouvoir gouvernera réellement le monde, ce sera la science, ce sera l'esprit. Dieu alors sera complet, si l'on fait du mot Dieu le synonyme de la totale existence. En ce sens, Dieu sera plutốt qu'il n'est: il est in fieri, il est en voie de se faire. (Ebd.) 
Die von der Erde ausgehende Besiedlung, Lenkung und Umgestaltung des Universums durch die wiedererweckten Generationen und seine Verwandlung in ein vollkommenes "Kunstwerk", aus dem alle Unordnung beseitigt und alle Zerstörung ausgeschlossen sein wird, erweist sich als universelle "Moralisierung" (moralizacija) und "Rationalisierung" (racionalizacija), da alle Welten, "die jetzt von fühllosen und blinden Kräften bewegt werden", dann vom "brüderlichen Gefühl" und von der "Vernunft aller auferweckten Generationen gelenkt werden" $(I, 410)$. Nur das gemeinsame Handeln aller wiedererweckten Generationen vermag das Universum vor dem drohenden Untergang zu retten. Dennoch findet die Auferweckung ihre letzte Begründung weder in der Annahme einer noch zu vollendenden Schöpfung noch in der Erkenntnis Gottes, sondern allein in der sittlichen Pflicht, die Schuld gegenüber all jenen zu begleichen, "die ihr Leben verloren haben":

Die Erde ist ein Friedhof und, da sie eine Geschichte besitzt, ist sie inhaltsreicher als alle Welten, die keine solche Geschichte besitzen. Bis jetzt waren BewuBtsein, Vernunft und Sittlichkeit auf den Planeten Erde beschränkt; durch die Auferweckung aller Geschlechter, die auf Erden gelebt haben, wird sich das BewuBtsein auf alle Welten ausbreiten. Die Auferweckung ist die Verwandlung des Universums aus dem Chaos, dem es entgegengeht, in den Kosmos, d.h. in die Schönheit der Unvergănglichkeit und Unzerstörbarkeit.

Nirgends zeigen sich Tiefe und Reichtum der Allweisheit so sehr, wie in der Rettung des grenzenlosen [!] Alls, einer Rettung, die von einem so winzigen Staubkorn wie der Erde ausgeht. Die Tatsache, daß von allen Planeten allein die Erde bewohnt ist, stellt eine Forderung durch das höchste Sittengesetz dar. Wenn die Welt nicht das Produkt eines blinden Zufalls ist, so ist zwischen der Menge der verstorbenen Geschlechter und der Vielzahl der Welten ein mögliches zweckmäBiges Verhăltnis gegeben, damit allein aus dem irdischen Staub, dem einen Blut, alle Bewohner aller Welten geschaffen werden. Doch selbst wenn die Welt das Produkt eines Zufalls wăre, müBte ein vernunft- und gefühlsbegabtes Wesen von der Vielzahl der Krafte Gebrauch machen, um die vielen Generationen, die ihr Leben verloren haben, wiederzubeleben. (II, 242f.)

Der Tod ist der Triumph der blinden, unsittlichen Kraft, die allumfassende Aufenweckung aber wird der Sieg der Sittlichkeit sein, die letzte, höchste Stufe der Sittlichkeit. (I, 339)

Nur an wenigen Stellen seines umfangreichen Werks zeichnet Fedorov ein zusammenfassendes Bild des verwirklichten obšcee delo; die wohl ausführlichste, im Ton geradezu hymnische Schilderung findet sich unter dem Titel "Das Ende des Waisentums; unbegrenzte Verwandtschaft":

Im Menschen gelangt die Natur zur Selbsterkenntnis und durch die Menschheit zur Einheit und Selbstvervollkommnung: "Ce triomphe de l'esprit, ce vrai royaume de Dieu, ce retour au modèle idéal, me semblent la fin suprème du monde. C'est l'humanité qui, à notre connaissance, est le principal instrument de cette oeuvre sacrée [!]. L'animal le plus humble, le dernier zoophyte, est à sa manière déjà un commencement de connaissance de la nature par elle-même, un retour obscur vers l'unite... Le règne de l'esprit est l'oeuvre propre de l'humanité." Ebd.

Sogar von einer "letzten Auferstehung durch die Wissenschaft" ist bei Renan die Rede, wenn auch nur sehr vage: "... la résurrection finale se fera par la science, par la science, dis-je, soit de l'homme, soit de tout autre être intelligent." Ebd., S. 774. 
Der ersehnte, seit jeher erwartete Tag, der Jubel des unermeBlichen Himmels, wird erst dann anbrechen, wenn die Erde, die Generationen in Finsternis verschlungen hat, bewegt und gelenkt durch himmlische Sohnesliebe und Wissen, die von ihr Verschlungenen zurückgeben und mit ihnen die himmlischen Sternenwelten besiedeln wird, die jetzt unbeseelt sind und kalt und wie voll Trauer auf uns herabblicken; - wenn wir den Staub derer, die uns ihr Leben gegeben oder genauer: weggegeben haben, wenn wir diesen Staub sammeln und beleben, anstatt ihn in Nahrung für uns und unsere Nachkommen zu verwandeln, wozu wir genotigt waren durch die Getrenntheit der Welten und die Notwendigkeit, von den Mitteln unseres kleinen Planeten zu leben. Mit ihrer Kenntnis der Materie und deren Kraften werden die wiederhergestellten vergangenen Generationen bereits fahig sein, ihren Korper aus Grundelementen zu regenerieren, sie werden die Welten besiedeln und die Trennung zwischen ihnen überwinden... (...) Die Erde wird der erste Stern am Himmel sein, der nicht durch die blinde Kraft des Falls bewegt wird, sondern durch die Vernunft, die wiederherstellt und [dadurch] Fall und Tod verhindert. Es wird nichts Fernes geben, wenn wir in der Gesamtheit der Welten die Gesamtheit aller vergangenen Generationen erblicken. [Anm.: Das allumfassende Wiedersehen. Das ist die große Zukunft, die die Vergangenheit enwartet, wenn die Gegenwart ihre Berufung annimmt, ihre Aufgabe, ihr Ziel.) Alles wird verwandt, nicht aber fremd sein. Dabei wird sich allen eine unermeßliche Breite, Hơhe und Tiefe erðffnen, die jedoch nicht überwăltigt und beăngstigt, sondern vielmehr grenzenloses Verlangen zu befriedigen vermag, unbeschrănktes Leben. Dieses Leben wird ewig neu sein, ungeachtet seines Alters, ein Frühling ohne Herbst, ein Morgen ohne Abend, Jugend ohne Alter, Auferstehung ohne Tod. Freilich wird es dann auch Herbst und Abend, sogar finstere Nacht geben, wie auch die Holle der Leiden bleiben wird, die es im jetzigen und im vergangenen Leben des Menschengeschlechts gab, doch wird sie nur in der Vorstellung fortdauern als durchlebtes Leid, das den Wert des strahlenden Tages der Auferstehung erhoht. Dieser Tag wird ein herrlicher scin, ein wunderbarer, aber kein Tag der Wunder (Cudnyj, no ne cudesnyj), denn die Auferweckung wird kein Wunderwerk sein, sondem ein Werk des Wissens und der gemeinsamen Aibeit. (II, 205f.; Hervorhebungen im Orig.) 



\section{TEIL II: BEITRÄGE ZU EINER WIRKUNGSGESCHICHTE}

\section{FEDOROVS ZETrGenOSSEN}

\subsection{L.N. Tolstoj}

Fedorov und Tolstoj wurden wahrscheinlich im Herbst 1881 miteinander bekannt; Fedorov berichtet:

Ende September 1881 lemte ich Tolstoj kennen; ich horte eine Lesung seines "Evangeliums". Bei ihm traf ich auch mit Solov'ev zusammen. Im Herbst jenes Jahres fand eine Volkszăhlung in Moskau statt, an der Tolstoj teilnahm. Im selben Jahr begann die Verwandlung des großen Künstlers in einen schlechten Philosophen. Damals wurde das Vorwort zum Projekt [gemeint ist Fedorovs Lehre; M.H.] Solov'ev, Tolstoj und Strachov mitget eilt. ${ }^{\text {' }}$

\section{Am 5. Oktober 1881 notierte Tolstoj seine ersten Eindrücke in sein Tagebuch:}

Nikolaj Fedoryc ist ein Heiliger. Ein Kämmerchen. Seine Pflicht erfüllen! - Das versteht sich von selbst. Er will keinen Lohn. Keine Wassche, kein Bett. ${ }^{2}$

\section{Einen Monat später schrieb Tolstoj an V.I. Alekseev:}

Der Aufenthalt in Moskau ist sehr schwer fur mich. Schon mehr als zwei Monate lebe ich hier, und noch immer ist es mir schwer. (...) Doch gibt es auch hier Menschen. Gott hat mich mit zweien zusammengeruhrt. Der eine ist [V.F.] Orlov, der andere, vor allem wichtige, Nikolaj Fedorov[ið] Fedorov. Er ist Bibliothekar der Rumjancev-Bibliothek. Erinnern Sie sich, ich habe Ihnen von ihm erzăhit. Er hat den Plan einer gemeinsamen Tat (obscee delo) fur die ganze Menschheit erstellt, deren Ziel die leibhaftige Auferweckung aller Menschen ist. Erstens ist das gar nicht so verrückt, wie es scheint (keine Angst, ich teile seine Ansichten nicht, doch verstehe ich sie so gut, daB ich mich

1 Unveroffentlichte Aufzeichnung Fedorovs im Peterson-Archiv, GBL f. 657; zitiert nach S.G. SEMENOVA, "Ob odnom idejno-filosofskom dialoge. (L.N. Tolstoj i N.F. Fedorov)." In: Sever, 1980, 2, S. 116. Siehe auch N.N. Strachovs Brief aus Petersburg an Tolstoj vom 19.10.1881, in dem Strachov an die kurz zuvor erfolgte Begegnung erinnert: Tolstoj habe auf ihn einen selbstquălerischen Eindruck gemacht, Fedorov dagegen gleiche den heiteren Mönchen vom Athos, von denen es heiße, sie seien der Heiligkeit năher als alle anderen. Tolstovskaj muzej, t. 2 [Perepiska L.N. Tolstogo s N.N. Strachovym 1870-1894], SPb. 1914, S. 284.

Moglicherweise war es bereits im Herbst 1878 zu einer kurzen Begegnung zwischen Fedorov und Tolstoj in der Bibliothek des Rumjancev-Museums gekommen. Davon berichtet N.[P.] PETERSON, "Pis'mo k izdatelju Russkogo Archiva. Po povodu otzyva F.M. Dostoevskogo o N.F. Fedorove." In: Russkij Archiv, 42 (1904), 6, S. 301. DERS., N.F. Fedorov i ego kniga 'Filosofija obscego dela' v protivopolotnost' učeniju L.N. Tolstogo 'o neprotivlenii' $i$ drugim idejam naśego vremeni, Vernyj 1912, S. 90 . Siehe auch N.N. GUSEV, Lev Nikolaeviz Tolstoj. Materialy k biografii s 1881 po 1885 god. M. 1970, S. 75. - Im Sommer des Jahres 1878 hatte Peterson Tolstoj wăhrend einer Bahnfahrt getroffen und ihm von Fedorov erzăhlt. Peterson las Tolstoj einen Brief Dostoevskijs sowrie den Anfang von Fedorovs Antwortschreiben vor (siehe unten 1.2.). Letzteres, so Peterson, habe Tolstoj "nicht sympathisch" gefunden. PETERSON, "Pis'mo...", a.a.O.

2 L.N. TolstoJ, PSS, t. 49, M. 1952, S. 58. - Weitere Tagebucheintragungen ebd., S. 73, 89f.; t. 50 (1952), S. 23, 33, 65, 72. 
imstande fühle, sie gegenüber jedem anderen Glauben zu verteidigen, der [nur] ein ăußerliches Ziel verfolgt). Zweitens aber und vor allem ist er dank dieses Glaubens in seinem Leben der reinste Christ. Wenn ich zu ihm von der Erfüllung der Lehre Christi spreche, sagt er: Ja, das ist selbstverstăndlich; und ich weiB, daß er sie erfüllt. Er ist sechzig Jahre alt, arm und gibt alles weg, immer heiter und sanft. ${ }^{3}$

Tolstoj hatte zu jener Zeit eine tiefe seelische Krise durchlebt, in deren Mittelpunkt die Frage nach dem Sinn des vergänglichen Lebens und der Existenz der Menschheit gestanden hatte. Infolge dieser Krise hatte Tolstoj sich von der 'reinen, zweckfreien Kunst' abgewandt und begonnen, sich mit 'praktischen Fragen' zu beschäftigen, denen er im Rahmen seiner Lehre eines rationalen, ethischen, von Dogmen und Mystik gereinigten Christentums eine Reihe religiös-philosophischer Schriften widmete. Das erste Werk, in dem er seine neue Lehre verkündete, war die 1882 vollendete "Beichte" (Ispoved').

Im September 1881 hatte Tolstoj sich mit seiner Familie in Moskau niedergelassen. Häufig besuchte er die Bibliothek des Rumjancev-Museums, um dort zu lesen oder - ein seltenes Privileg - Bücher auszuleihen. ${ }^{4}$ Mit Fedorov traf er sich zumeist in der Bibliothek, bisweilen aber auch in seinem Moskauer Wohnhaus in Chamovniki oder in einer von Fedorovs armseligen Behausungen in der nahegelegenen Ostoženka oder im Moločnyj pereulok. ${ }^{5}$ Über ihre Begegnungen - in den achtziger und frühen neunziger Jahren - gibt es zahlreiche Berichte. ${ }^{6}$

3 Tolstoj an V.I. Alekseev, November 1881, ebd., t. 63, M.-L. 1934, S. 80f. Siehe auch P.I. BiRJUKov, L.N. Tolstoj. Biografija. T. 2, Berlin 1921, S. 425-428. - Weitere Hinweise auf Fedorov in Tolstojs Briefen: Tolstos (wie Anm. 2), t. 66 (1953), S. 85; t. 68 (1954), S. 247; t. 78 (1956), S. 48; t. 82 (1956), S. 179r; t. 83 (1938), S. 314.

4 S.A. Tolstaja, "Moja žzn'." In: Noyyj Mir, 1978, 8, S. 73.

5 Vgl. I.L. TolstoJ, Moi vospominanija, M. 1969, S. 189. S.L. TolstoJ, Oxenki bylogo, Tula ${ }^{3} 1966$, S. $137 f$.

6 Besonders ausfuhrlich die wahrscheinlich 1911 verfaBten, jedoch - wegen des sehr negativen Tolstoj-Bildes - erst unlăngst vollstăndig veroffentlichten Erinnerungen von G.P. GEORGIEVSKU, "L.N. Tolstoj i N.F. Fedorov. Iz litnych vospominanij." In: Cetvertye Tynjanovskie ¿tenija, Riga 1988, S. 46-66; bes. S. 57-66. (Eine gekürzte und stellenweise abweichende 'entschärfte' Fassung in: Novyj Zumal, 142, 1981, S. 91-109). Vgl. ferner A.S. PRugavin, "O paradoksach L.N. Tolstogo." In: Sbomik vospominanij o L.N. Tolstom, M. 1911, S. 1-16. PETERSON, Fedorov (wie Anm. 1). IA. LINNICENKo, "Moi vstredi s L.N. Tolstym." In: DerS., Rexi i pominki, Odessa 1914, S. 311-319; hier S. 315-317. L.P. NIKIFOROV, "Vospominanija o L.N. Tolstom." In: Lev Nikolaevit Tolstoj. Jubilejnyj sbomik. M.-L. 1928, S. 218-237; hier S. 225227. V.F. LAZURSKU, "Dnevnik V.F. Lazurskogo." In: Literatumoe nosledstvo, t. $37 / 38$ [L.N. Tolstoj], kn. 2, M. 1939, S. 443-509; hier S. 465f. I.M. IVAKIN, Tolstoj v 1880-e gody. Zapiski I.M. Ivakina." In: Literatumoe nasledstvo, t. 69 [Lev Tolstoj], kn. 2, M. 1961, S. 21-124. D.P. MAKoviCKU [MAKoviCKÝ], "Dnevnik." In: Literatumoe nasledstuo, t. 90 [U Tolstogo 1904 1910. "Jasnopoljanskie zapiski" D.P. Makovickogo], M. 1979, kn. 1, S. 380f.; kn. 2, S. 474, 560; kn. 3, S. 296. - Scheinbar authentische Berichte Ciolkovskijs über Begegnungen zwischen Tolstoj und Fedorov (siehe K.N. ALTNSKU [K.N. KOROLEV], 'Moskovskaja junost' Ciolkovskogo." In: Moskva, 1966, 9, S. 176-192; hier S. 181) stammen offenbar aus zweiter Hand. Ciolkovskij kam in den Jahren 1873 bis 1876 mit Fedorov zusammen, also bevor dieser mit Tolstoj personlich bekannt wurde. 
Aus ihnen wird deutlich, daB das Verhältnis zwischen Tolstoj und Fedorov von wachsenden Spannungen geprägt war, obwohl Tolstoj - entgegen seiner sonstigen Eitelkeit und seinem Geltungsdrang - den alten Bibliothekar geradezu verehrte und ihm gegenüber eine ungewohnte Geduld und Zurückhaltung an den Tag legte. Darüber berichtet Tolstojs Sohn Il'ja:

[Mein] Vater, der in Gesprăchen immer aufbrausend und ungehalten war, horte Nikolaj Fedorovix mit besonderer Aufmerksamkeit zu und wurde nie zornig mit ihm.

Tolstoj zeigte sich tief beeindruckt von Fedorovs Persönlichkeit und seiner konsequent bedürfnislosen, asketischen Lebensweise, "... ja er verneigte sich geradezu vor ihm, da er in ihm eine der besten Verkörperungen seiner eigenen Theorien der Nächstenliebe und des einfachen Lebens sah. ${ }^{{ }^{8}}$

Tolstoj selbst berichtet:

Er [Fedorov] lebt wie ein echter Asket ..., verzichtet auf alles und beschrănkt alle seine Bedürfnisse auf ein ăuBerstes Minimum. Ich war richtig betroffen von der Umgebung, in der er lebt - arm und dürftig bis zum Extrem.'

Kein monchischer Asket führt ein so hartes Leben wie Fedorov. Ich war bei ihm. Er lebt in einem winzigen Zimmer. Darin steht eine hrlzerne Truhe mit einer Zeitung bedeckt - das ist sein Bett. An Kleidung besitzt er nur, was er auf dem Leib trăgt. Er ernăhrt sich von Milch, die er gleich in der Molkerei trinkt. Allerdings, ... er raucht; sagt, daB er von dieser Gewohnheit nicht lassen konne. ${ }^{10}$

Das Verhăltnis zwischen Tolstoj und Fedorow wurde vielfach untersucht und kann als ausreichend erforscht gelten. Im Rahmen dieser Arbeit soll deshalb nur ein skizzenhafter Oberblick gegeben werden. - Eine einseitige, Fedorovs Bedeutung weit überbewertende Darstellung gibt der Fedorov-Anhănger A.K. Gornostaev [d.i. A.K. GoRsKu], Pered licem [sic] smerti. L.N. Tolstoj $i$ N.F. Fedorov 1828-1903-1910-1928. O.O. [Harbin] 1928; diese 18 Seiten umfassende Studie erschien 1933 auch in Tschechisch und Japanisch. - Sachlich, materialreich und bislang am gründlichsten SEMENOVA (wie Anm. 1), S. 115-128. Vgl. ferner GuSEv (wie Anm. 1), S. 7579. N.[N.] SkATOV, "Spor dvuch utopistov." In: Zvezda, 1978, 8, S. 172-180; wieder abgedruckt in: DERS., Dalekoe i blizkoe. Literatuma-kritixeskie oxerki. M. 1981, S. 196-221. DERS., "Lev Tolstoj i Nikolaj Fedorov." In: Ogonek, 1978, 37, S. 14f. V.[A.] NikrrIN, "Bogoiskatel'stvo' i bogobortestvo Tolstogo." In: Prometej, 12, M. 1980, S. 113-138; hier S. 123-130. A.P. Cudakov, [Vstupitel'naja stat'ja] "G.P. Georgievskij. L.N. Tolstoj i N.F. Fedorov." In: Cervertye Tynjanovskie čtenija, a.a.O., S. 32-45. - Eine gute Darstellung des Verhăltnisses zwischen Tolstoj und Fedorov auch bei G.M. Young, Nikolai F. Fedorov: An Introduction, Belmont, Mass. 1979, S. 60-71. Oberffachlich und bisweilen fehlerhaft hingegen L. KoEHnER, N.F. Fedorov: The Philosophy of Action, Pittsburgh 1979, S. 52-58. N. STRUVE, "Nicolas Fedorov et LEon Tolstoi." In: Cahiers Leon Tolstoi, 2, Paris 1985, S. 41-46. E. Dieckmann, Polemik um einen Klassiker. Lew Tolstoi im Uneil seiner russischen Zeitgenossen 1855-1910. Berlin, Weimar 1987, S. 169-171. Nicht zugănglich war A. SMaRNov, "Dva filosofa: o znakomstve i otnosenii Tolstogo i N.F. Fedorova." In: Golos Rabozego [Noginsk], 21.11.1940. Angabe nach ST. LUKASHEVICH, N.F. Fedorov (1828-1903). A Study in Russian Eupsychian and Utopian Thought. Newark, London 1977, S. 309.

7 I.L. Tolstos (wie Anm. 5), S. 190.

8 LINNICENKo (wie Anm. 6), S. 317.

9 Prugavin (wie Anm. 6), S. 11.

10 E.I. Raevskaja, "Lev Nikolaevit Tolstoj sredi golodajustich." In: Letopisi Gosudarstrennogo Literatumogo muzeja, kn. 2 [L.N. Tolstoj], M. 1938, S. 382; ÄuBerung Tolstojs vom 28.10.1891. 
Der Dichter Afanasij Fet überlieferte Tolstojs Ausspruch: "Ich bin stolz, da B ich zur selben Zeit mit einem solchen Menschen lebe. ${ }^{11}$

Fedorov freilich bemerkte rasch das Widersprüchliche in Tolstoj, die schroffe Diskrepanz zwischen Anspruch und Wirklichkeit, Lehre und Leben, und er ließ keine Gelegenheit aus, sie ihm schonungslos vorzuhalten. Als Tolstoj bei einem Besuch in Fedorovs ärmlicher Behausung einmal bewundernd bemerkte: "Wie gut, daß Sie sich Ihr Leben so eingerichtet haben", entgegnete Fedorov scharf: "Auch Sie können es sich so einrichten, wenn Sie wollen. Mir ist es nicht möglich, mich auf Ihr Niveau zu erheben, Sie hingegen können sich leicht auf meines begeben..." ${ }^{n 12}$

Immer wieder wies Fedorov auf den Gegensatz zwischen Tolstojs aufdringlich moralisierender Predigt von Armut und tätiger Nächstenliebe und dem Wohlleben des reichen und eitlen Grafen hin, der sich, nach einem Bericht von Georgievskij, nicht gescheut haben soll, einen hilfesuchenden Armen mit einem Empfehlungsschreiben versehen an Fedorov weiterzuverweisen. ${ }^{13}$

Fedorov, der sich selbst nie porträtieren ließ, warf Tolstoj vor, er lehne die bildliche Darstellung von Heiligen ab, ja wende sich mit $\mathrm{HaB}$ und Verachtung gegen verehrungswürdige Ikonen, zugleich aber sei er bestrebt, Darstellungen seiner eigenen Person zu fördern, indem er sich zeichnen, malen und photographieren lasse und auch noch für die Verbreitung dieser Bildnisse sorge. ${ }^{14}$ Ein Photo Tolstojs versah Fedorov mit der Aufschrift:

Portrăt eines berühmten Verehrers seiner eigenen Ikone und eines Bekămpfers aller übrigen Ikonen - von der Ikone des Heilands und der Gottesmutter (besonders der Iverskaja) bis zur Ikone von Feodosij und Serafm. ${ }^{15}$

Einen Widerspruch sah Fedorov auch in der Tatsache, da B Tolstoj jegliches Privateigentum ablehnte, seine Manuskripte jedoch nicht, wie Fedorov es gefordert hatte, der Bibliothek des Rumjancev-Museums und damit der Allgemein-

11 Brief von A.A. Šenšin (Fet) an N.F. Fedorov, 1887; zitiert nach VA. KožEvNixov, Nikolaj Fedorovic Fedorov. Opyt izlotenija ego ucenija po izdannym i neizdannym proizvedenijam, perepiske $i$ licnym besedam. C. 1, M. 1908, S. 320 . - Dieser in der Fedorov-Literatur nach Koževnikov viel zitierte Brief soll sich unter den Papieren befunden haben, die Fedorov vor seinem Tod an Koževnikov gegeben hatte; über seinen Verbleib ist nichts bekannt.

12 A.S. Pankratov, "Filosof-pravednik." In: Nowoe Slovo, 5 (1913), 8, S. 19f. - Tolstoj, der es liebte, sich als einfacher Bauer zu verkleiden, soll, so wird berichtet, Fedorov sogar um dessen auffallend alte und abgetragene, dabei aber würdig wirkende Kleidung beneidet haben. GEORGIEVSKU (wie Anm. 6), S. 49f.

13 Georgievsku (wie Anm. 6), S. 52. - Wie Fedorov sah auch Tolstoj das Geld als etwas Widerwartiges und Unsittliches an (zumindest 'theoretisch', in seinem 1882-1886 entstandenen sozialkritischen Traktat Tak dıo te nam delat'?) und hielt deshalb auch Almosen, d.h. finanzielle Hilfe für andere, für verwerflich. Fedorov war weniger 'konsequent': er hatte meist kein Geld, da er mit Almosen sehr großzügig war.

14 Ebd., S. 60.

15 Photo in Moskauer Privatbesitz. Siehe die nebenstehende Abb. 
00052974

L.N. Tolstoj

133

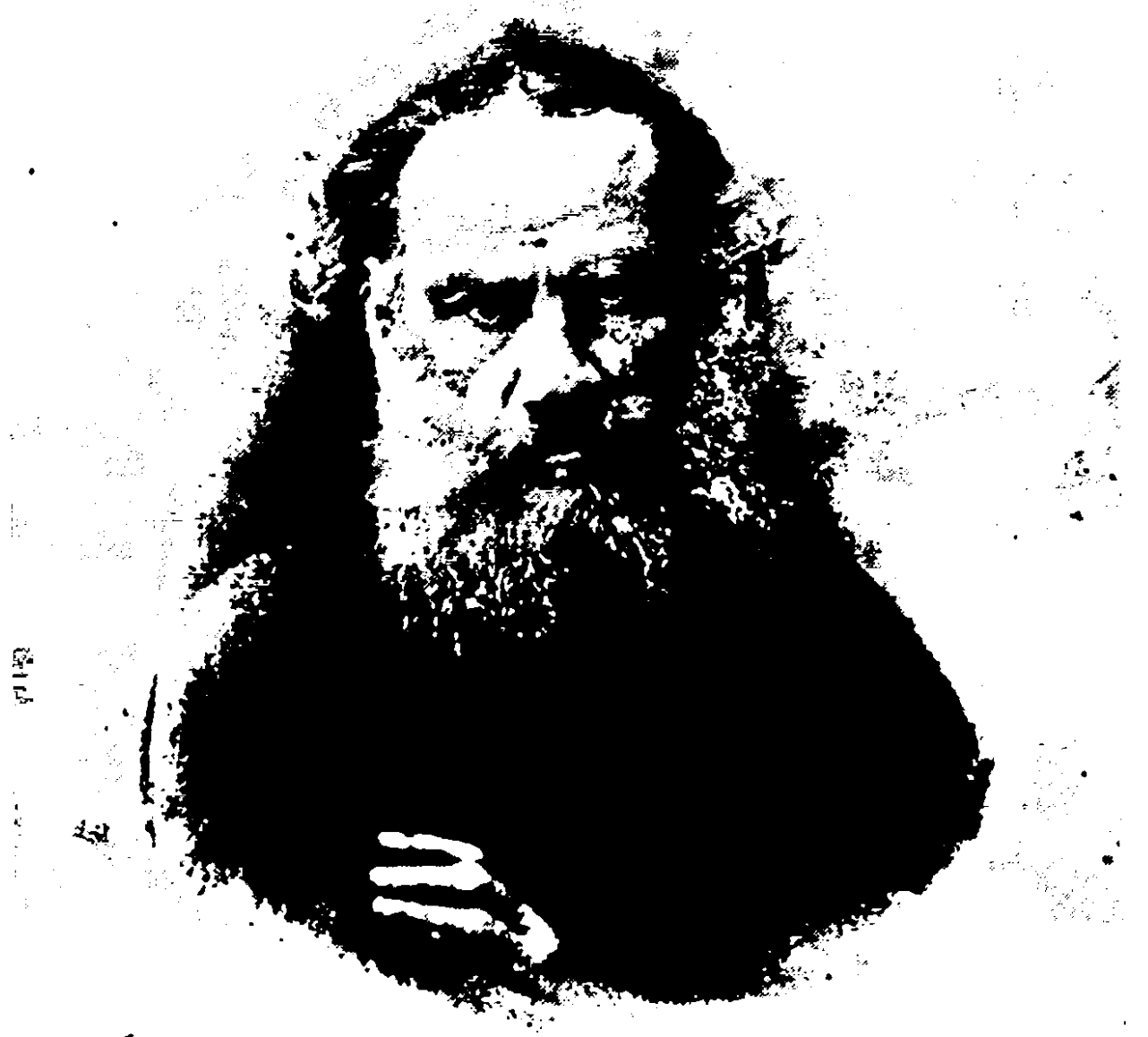

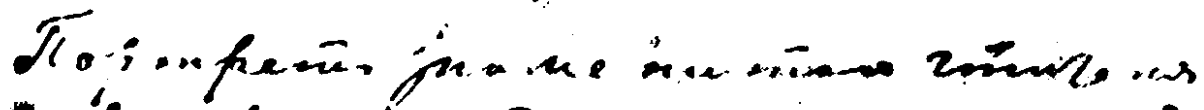

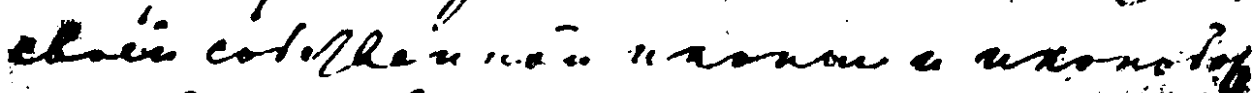

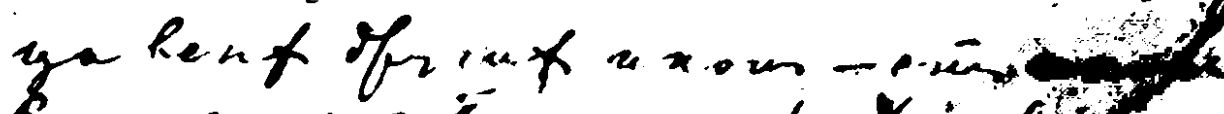

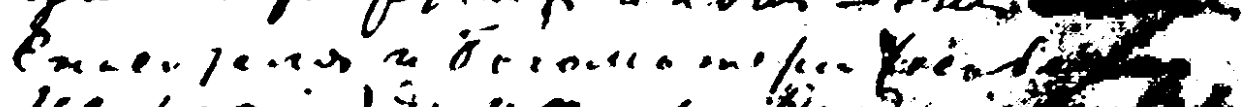

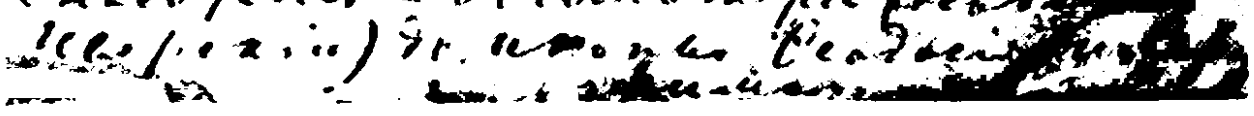

Michael Hagemeister - 9783954794898

Downloaded from PubFactory at 01/10/2019 03:42:41AM

via free access 
heit überlassen, sondern seiner Frau geschenkt hatte. Von Fedorov darauf angesprochen, hatte Tolstoj sich herauszureden versucht: "Da kann ich nichts machen, ich kann mein Wort nicht zurücknehmen: alle meine Autographen habe ich Sof'ja Andreevna geschenkt, also sind sie ihr Eigentum. ${ }^{\text {16 }}$

Tolstojs Selbstbezichtigungen und Selbstrechtfertigungen waren für Fedorov nichts als Heuchelei (licemerie), und in der Versöhnungsbereitschaft des Pazifisten sah er lediglich das Bestreben, Konflikte zu vertuschen, anstatt sie durch offenes Austragen wirklich zu überwinden. ${ }^{17}$

Mit aller Schärfe wandte sich Fedorov gegen Tolstojs - die Bergpredigt wörtlich nehmende - Lehre vom "Nicht-Handeln" (nedelanie) und "dem Bösen NichtWiderstreben" (neprotivlenie zlu): Nur durch vernünftiges Handeln und aktiven Kampf sei das Böse, das schlechthin Unvernüftige, aus der Welt zu schaffen. Doch selbst wenn durch Nichtwiderstreben ein paradiesischer Zustand herbeigeführt werden würde, so bliebe alles geschehene Unrecht und Leiden davon unberührt; das Böse würde fortdauern als die ungetilgte Schuld gegenüber den Vorfahren:

Nehmen wir einmal das ganz Unwahrscheinliche an: alle Gefangnisse zu offnen, alle Schilderhăuser zu beseitigen, alle Armeen zu entwaffnen, koste kein einziges Menschenleben; nehmen wir an, da $B$ das Nichtwiderstreben des Menschen auch den Tieren gegenüber selbst die Wolfe in Vegetarier verwandelt, die Heuschrecken hingegen und die 8sterreichische Fliege veranlaBt, auf ihre vegetarische Ernăhrung zu verzichten; nehmen wir an, daB diese Haltung die Bakterien und Bazillen unschădlich macht und daß am Ende selbst die blinde Kraft der Natur, gerührt durch unsere Untătigkeit, keine Oberschwemmungen und keine Dürre mehr anrichten wird, - so lost dies dennoch nicht das Problem, weil dadurch nicht die Schuld am Bosen genommen wird, welches bereits geschehen ist durch unsere Untătigkeit wie durch unser direktes Tun. Was aber kann man durch Nichtwiderstreben gegen das ausrichten, was bereits geschehen ist und wofur die Schuld bei dem vernunftbegabten Wesen liegt, das in der Vernichtung ein Obel erkennt und doch nichts unternommen hat, um Frieden in die Welt zu bringen? Ein solches Wesen muB gerade seiner Untătigkeit, seiner Tatenlosigkeit alles Bose zuschreiben, was bereits geschehen ist. Und wie wird der Mensch sich wohl betăuben, um das Bose zu vergessen, das er vollbracht hat und dessen er sich bewr Bt ist? ${ }^{13}$

Das Böse kann, so Fedorov, nur überwunden werden durch die erlösende Tat des obšcee delo, d.h. durch die brüderliche Sorge um die vergangenen Generationen im Bewußtsein der Schuld ihnen gegenüber. Tolstojs Vorstellung von brüderlicher Liebe und Vereinigung muß dagegen oberflächlich bleiben, da er die Beziehung zu den verstorbenen Vätern nicht erkennt. Nur durch sie aber sind alle Menschen Brüder und nur in Erfüllung der Pflicht der Auferweckung kann wahre Brüderlichkeit verwirklicht werden. ${ }^{19}$

16 Brief von G.P. Georgievskij an S.A. Tolstaja, 24.4.1911; zitiert nach G.I. DovGALLo, "Iz istorii otdela rukopisej po materialam archiva G.P. Georgievskogo." In: Zapiski otdela nukopisej, vyp. 45, M. 1986, S. 66. Dasselbe auch bei Pankratov (wie Anm. 12), S. 21.

17 FOD I, S. 9. - Siehe auch GeORGIEVSKu (wie Anm. 6), S. 59.

18 FOD II, S. 384; Hervorhebung von mir; M.H.

19 N.F. Fedorov, "Čto takoe dobro." In: Put', 40, 1933, S. 5f. - Siehe auch S.[A.] Golovanenko, Tajna synovstva. (O christianstve N.F. Fedorova)." In: Bogoslovskij Vestnik, 24 (1915), 3, S. 
Tolstojs Ethik, die das Gute nur negativ zu definieren erlaubt - indem sie vorschreibt, was zu unterlassen, nicht aber, was zu tun sei - fordert in bezug auf das Leben, dieses nicht zu schädigen oder wegzunehmen:

Was also bleibt, wenn diese Gebote erfüllt sind, ... die nicht einmal vorschreiben, das Leben zu bewahren, sondern nur, es nicht wegzunehmen? Es bleibt immerhin das Leben. Also, sogar auf dem Wege der Negation gelangen wir zur Definition des Guten: das Gute ist das Leben. Negativ ist das Gute nur das Nichtwegnehmen des Lebens, positiv aber die Bewahrung und Rückerstattung des Lebens. Das Gute ist die Bewahnung des Lebens für die Lebenden und seine Rückerstattung an die, die das Leben vertoren haben oder es vertieren werden. - Also folgt schon aus dem, was Tolstoj predigt, nach strenger Logik, daB das Gute in der Auferweckung der Verstorbenen und der Unsterblichkeit der Lebenden besteht. 20

Tolstoj konnte und wollte Fedorov darin nicht folgen. Zwar bewunderte er dessen moralischen Rigorismus, doch lehnte er die Vorstellung ab, mit wissenschaftlich-technischen Mitteln den Tod zu überwinden und die Verstorbenen wiederherzustellen:

Nikolaj Fedorovið sagt, zwischen den Menschen herrsche deshalb keine Brüderlichkeit, weil es keine gemeinsame Tat (obšee delo) gebe; würde es sie geben, so würde auch Brüderlichkeit herrschen. Diese Tat aber sei die Auferweckung. Ich hingegen sage, Brulderlichkeit kann auch ohne die gemeinsame Tat herrschen, vielleicht als Folge jenes Schrecklichen an unserer Lage, das unmittelbar aus dem Fehlen von Brüderlichkeit resultiert. Er aber will das nicht verstehen. Bei ihm gibt es einen Punkt geistiger Verwirnung, den es bei mir anscheinend nicht gibt. Ich habe ihm gesagt: Stellen Sie eine gemeinsame Tat als Ziel auf, aber bestimmen Sie sie nicht genau... Doch vom philosophischen Standpunkt ist seine Konstruktion richtig, er hat recht, der Menschheit eine solche Aufgabe zu stellen, wenn er nur ihre Erfüllung ins zeitlich Unendliche verschiebt. ${ }^{21}$

V.F. Lazurskij berichtet von einem Gespräch im Sommer 1894, in dem Tolstoj sich über Fedorov und dessen Lehre äußerte:

"Das ist ein heiliger Mensch," sagte Lev Nikolaevix, "er besitzt nichts; jedes Buch, das er kauft oder das man ihm schenkt, gibt er sofort dem Museum. Zuhause schlaft er auf einer Truhe und auf Zeitungen in einem winzigen Zimmer; er wohnt bei irgendeiner alten Frau. Natürlich ist er Vegetarier, doch geniert er sich, darüber zu sprechen. Und wiBt Ihr, er hat seine eigene Theorie!"

Und Lev Nikolaevit erzahlte etwas Seltsames: Fedorov konnte sich nicht mit dem Gedanken versöhnen, daB der Mensch stirbt und daB die uns liebsten Menschen spurlos verschwinden, und er schuf eine Theorie, wonach die Wissenschaft in ihrer gigantischen Vorwartsentwicklung Methoden entdecken werde, um die Oberreste und Teilchen unserer Vorfahren aus der Erde zu gewrinnen und sie dann von neuem lebendig wiederherzustellen.

498-501. - Mit Tolstojs Lehre vom "Nicht-Handeln", hatte sich auch Fedorovs Vertrauter Koževnikov kritisch auseinandergesetzt, allerdings ohne Fedorov zu erwahnen; siehe VA. KožzeVNIKov, Bezcel'nyj anud, 'ne-delanie' ili delo? Razbor valjadov Emilja Zolja, Aleksandra Djuma i grafa L.N. Tolstogo na trud. M. 1893 [21894].

20 FEDOROV (wie Anm. 19), S. 4f.; Hervorhebungen im Orig.

21 Tolstoj nach IVAKIN (wie Anm. 6), S. 51f.; Aufzeichnung eines Gesprächs in Jasnaja Poljana am 5.7.1885. Vgl. auch A.B. Gol'DENVEJZER, Vblizi Tolstogo, M. 1959; Aufzeichnung eines Gesprăchs in Jasnaja Poljana am 14.7.1903. 
Ich konnte mich eines Lächelns nicht erwehren, obwohl ich mich bemühte, ernsthaft zuzuhören, zumal Lev Nikolaevit vorausgeschickt hatte, diese Theorie werde dem, der sie zum erstenmal horre, als Ausgeburt eines verwirtten Geistes erscheinen, wăhrend sie doch in Wirklichkeit nicht ohne Sinn sei.

"Ja, falls Sie versucht hătten, in seiner Gegenwart zu lăcheln, so würde er es Ihnen schon gegeben haben. Einmal sah ich in der Rumjancev-Bibliothek ein kleines Buch - Listen von Regimentskommandeuren für eine bestimmte Anzahl von Jahren -, und ich lăchelte. Da fuhr er mich an: 'All das wird gebraucht; noch wissen wir nicht wofür, doch es wird gebraucht; all das sind Erinnerungen an unsere Vorfahren'. Jetzt kann er mich nicht mehr leiden, erstens, weil ich seine Theorie nicht teile, und zweitens, weil ich den Tod liebe. Nach seiner Theorie müssen die Menschen Ackerbau betreiben, um mit Hilfe der Pflanzen die Teilchen der Vorfahren aus der Erde wiederzugewinnen, wăhrend an einigen Orten Museen sein sollen, in denen jede Zeile der Ahnen heiliggehalten und aufbewahrt wird. Für ihn ist der Museumsdienst eine Religion. Erstaunlicherweise aber glaubt er an die Wissenschaft und die Grenzenlosigkeit des menschlichen Verstandes. ${ }^{22}$

Im Gegensatz zu Fedorov lehnte Tolstoj alle Technik und Naturbeherrschung sowie die darauf gegründeten Erwartungen eines irdischen Paradieses ab. ${ }^{23}$ Den Tod fürchtete er, doch weigerte er sich, ihn zu bekämpfen; statt dessen deutete er ihn - tröstlich und versöhnend - als Auflösung des einzelnen im Unendlichen ("Tropfen im Ozean", Aufgehen in der abstrakten Menschheit, im Nirwana, im Universum). ${ }^{24}$ Die traditionellen Vorstellungen von Auferstehung und persönlicher Unsterblichkeit (der Seele) nannte er dagegen "irrational" und "absurd", "offenkundigen und augenscheinlichen Unsinn" und zudem moralisch schädlich, da sie auf egoistischen Gelüsten beruhten. ${ }^{25}$

Fedorov sah darin freilich eine Verherrlichung des Todes, denn, so warf er Tolstoj vor, die "Lehre, daß der Tod eine gute Sache oder gar nicht sei," bedeute, $\mathrm{da} ß$ "weder Auferstehung oder Auferweckung noch Unsterblichkeit" nötig seien;

22 LAZURSKI (wie Anm. 6), S. 465f.; Aufzeichnung eines Gesprăchs in Jasnaja Poljana am 13.7.1894.

23 Siehe z.B. W. SmYrniw, Tolstoi's Response to Modern Utopian Theories." In: Studies in Honour of Louis Shein, Hamilton, Ont. 1983, S. 135-143.

$24 \mathrm{Zu}$ Tolstojs Auffassung von Tod und Unsterblichkeit vgl. V.V. ZEN'KovsKu, "Problema bessmertija u L.N. Tolstogo." In: O religii L'va Tolstogo. Sb. statej. M. 1912, S. 27-58; kurzer Hinweis auf Fedorov S. 56 Anm. 1. M.K. MAKRAKĒS, Hé aisthèsis tu thanatu kai ho pothos tès lytrōseōs eis ton L. Tolston, Athen 1978 (mit ausführl. Bibliographie). L.J. SHEIN, "L.N. Tolstoy's Concept of Immortality." In: Ekklésia kai Theologia, [London] 1 (1980), S. 131-140. A. Kodjak, "Tolstoy's Personal Myth of Immortality." In: Myth in Literature, Columbus, Ohio 1985, S. 188-207.

25 In einem Gesprăch mit V.I. Vernadskij, der an eine persönliche Unsterblichkeit glaubte, erlăuterte Tolstoj 1893 seine Ansichten. Siehe I.I. MoCALOV, "L.N. Tolstoj i V.I. Vernadskij." In: Russkaja Literarura, 1979, 3, bes. S. 200f., 203f. - Vgl. ferner I.[1.] LAPSCHIN [LAPSIN], "Die Metaphysik Leo Tolstojs." In: Festschrift Th.G. Masaryk zum 80. Geburtstage, 1. Teil, Bonn 1930, S. 187f. G.L. KLINE, "Russian Religious Thought." In: Nineteenth Century Religious Thought in the West, 2, Cambridge 1985, bes. S. 200-202. 
und er nannte Tolstoj nicht nur einen "Heuchler" und "Pharisäer", sondern auch den "größten Feind der Auferstehung" und einen "Panegyriker des Todes" ${ }^{26}$

Dennoch hatte Fedorov lange Zeit gehofft, Tolstoj werde die Idee des obšcee delo annehmen und in seinen Werken propagieren. Von Fedorovs hartnäckigen Bekehrungsversuchen berichtet Tolstojs Sohn Sergej:

Bei jeder Begegnung mit meinem Vater forderte er [Fedorov], daß Vater diese Ideen verbreite. Er bat nicht, sondern forderte beharrlich, und wenn Vater in außerst milder Form ablehnte, so wurde er verdrieBlich, fühlte sich beleidigt und konnte ihm das nicht verzeihen. ${ }^{27}$

Tolstoj erklärte das so:

Nikolaj Fedoroviz ... ist ein Mensch von hoher Herzensbildung, aber ein Sektierer. Was nicht mit seiner Auferweckungstheorie zusammenpaBt, das will er nicht wissen. $\mathrm{Er}$ ist ein Sektierer, aber [auch] ein Mensch, wie es nur schrecklich wenige gibt. ${ }^{28}$

Das Verhältnis zwischen Tolstoj und Fedorov erscheint als eine Art Haßliebe: Für Tolstoj war Fedorov die Verkörperung seines von ihm selbst unerreichten Lebensideals; Fedorov hingegen mußte bitter zusehen, wie der eitle und eigensüchtige Graf als Prophet einer neuen Religion der Liebe und Brüderlichkeit weltweit Gehör fand, während er mit seinem Aufruf zum obšcee delo unbeachtet blieb.

Im Laufe der achtziger Jahre verschlechterten sich die Beziehungen zwischen Fedorov und Tolstoj. Am 14. Januar 1889 notierte Tolstoj in sein Tagebuch:

... traf Nik[olaj] Fed[orovit] und unterhielt mich mit inm. Bei ihm ist es etwa so wie bei Unusov, im Leben und in den Büchern findet er nicht das, was ist, sondern das, was er morchte. Der Ton, in dem er seine Oberzeugung zum Ausdruck bringt, ist erstaunlich. Dieser Ton steht immer im umgekehrten Verhaltnis zur Wahrheit. ${ }^{29}$

1892 kam es dann zum offenen und endgültigen Bruch. Anläßlich der großen Hungersnot im Jahre 1891 hatte Tolstoj einen schonungslos offenen Artikel $O$ golode verfaßt, in dem er die Hauptschuld an der Katastrophe den herrschenden sozialen Mißständen zuschrieb. ${ }^{30}$ Der Artikel wurde von der Zensur unterdrückt und erschien am 14. Januar 1892 in der Londoner Zeitung Daily Telegraph. Heftige Angriffe konservativer Regierungskreise, vor allem des Oberprokurors K.P. Pobedonoscev, sowie der ihnen nahestehenden Presse waren die

26 N.F. FEDOROV, Sotinenija, M. 1982, S. 637, 641. FOD I, S. 415. - Angriffe gegen Tolstoj finden sich im gesamten Werk Fedorovs. Siehe insbesondere FOD I, S. 434-438; II, S. 355-398. FEDOROV (wie Anm. 19), S. 3-15.

27 S.L. Tolstoj (wie Anm. 5), S. 138.

28 Tolstoj nach IVAKIN (wie Anm. 6), S. 83; Aufzeichnung aus dem Jahre 1886.

29 Tolstos (wie Anm. 2), t. 50 (1952), S. 23.

30 Für Fedorov dagegen war die Hungerkatastrophe ein "meteorischer Pogrom". - Hierzu und zum folgenden NIKInN (wie Anm. 6), S. 128f. 
Folge. Man warf Tolstoj vor, er habe zum Umsturz der bestehenden Gesellschaftsordnung aufgerufen und darin sogar noch die revolutionäre Untergrundpropaganda übertroffen. ${ }^{31}$ Auch Fedorov scheint diese Sicht geteilt zu haben. Jedenfalls nahm er den Artikel zum Anlaß, die Beziehungen zu Tolstoj abzubrechen. Über die letzte Begegnung beider - Ende November 1892 im RumjancevMuseum - berichtet Georgievskij:

Als Fedorov sah, wie Tolstoj auf ihn zueilte, fragte er ihn schroff: "Was wünschen Sie?"

"Gleich", antwortete Tolstoj, "erst wollen wir uns begrüßen... Ich habe Sie so lange nicht gesehen."

"Ich kann Ihnen nicht die Hand geben," entgegnete Fedorov, "zwischen uns ist alles zu Ende." Nikolaj Fedorovið hielt nervős die Hănde hinter dem Rücken und wechselte von der einen Seite des Korridors auf die andere, um zu seinem Gesprăchspartner auf Distanz zu gehen.

"Sagen Sie, Nikolaj Fedorovix, was bedeutet das alles?" fragte Tolstoj, und auch in seiner Stimme waren Anzeichen von Nervosităt zu vernehmen.

"Ist das Ihr Brief, der im Daily Telegraph veroffentlicht wurde?"

"Ja, das ist meiner."

"Ist Ihnen denn nicht bewußt, von welchen Gefühlen dieser Brief diktiert ist und wozu er aufruft? Nein, mit Ihnen habe ich nichts gemein, Sie kőnnen gehen."

"Nikolaj Fedorovił, wir beide sind alte Leute, so wollen wir uns doch wenigstens verabschieden..."

Doch Nikolaj Fedorovit blieb ungerührt, und Tolst oj, sichtlich erregt, wandte sich um und ging. ${ }^{32}$

Ungeachtet der schroffen und unversöhnlichen Haltung Fedorovs bewahrte Tolstoj bis zu seinem Lebensende tiefe Sympathie für die Person des alten Bibliothekars. Von seiner Lehre wollte er hingegen nichts wissen. ${ }^{33}$ Als Peterson, vermutlich im März 1908, den ersten Band der Filosofija obščego dela an Tolstoj schickte, erhielt er von dessen Sekretär einen kühlen Brief, aus dem hervorging, $\mathrm{da} B$ Tolstoj die Ansichten Fedorovs nicht teile und sein Werk wohl kaum lesen

31 Siehe N.P. SoKolov, "Kramol'naja' stat'ja L'va Tolstogo." In: Naše nasledie, 3, 1988, S. 110112.

32 GeorglevsKu (wie Anm. 6), S. $63 \mathrm{f}$.

33 Abwegig ist die Annahme, Tolstoj habe in seiner Erzahlung Krejcerova sonata (1887-1889; ersch. 1891) Fedorovsche Ideen gestaltet. So H. MONDRY, "One or Two 'Resurrections' in Tolstoy's Writing? (Fedorov and the Kreutzer Sonata)." In: WdSl, 33 (1988), 1, S. 169-182. Fedorov selbst kritisierte Tolstojs Aufruf zur geschlechtlichen Enthaltsamkeit und Askese als lebensfeindlich ("negative Keuschheit"); die dumpfe Lust am Zeugen und Gebăren als zerstörende Macht und Ursache des Todes müsse durch die bewuBt schaffende Liebe zu den Vătern, d.h. durch ihre Auferweckung, ersetzt werden ("positive Keuschheit"). Siehe FEDOROV (wie Anm. 26), S. 640. Zum ideologischen Hintergrund von Tolstojs Erzăhlung (ohne Hinweis auf Fedorov) jetzt ausführlich P.V. MøLLER, Postlude to the Kreutzer Sonata, Leiden 1988.

Als sicher gilt hingegen, daB Fedorovs Anhănger N.P. Peterson als Vorbild für den verbannten Revolutionär Simonson in Tolstojs Roman Voskresenie (1889-1899; ersch. 1899) gedient hat. Vgl. S.L. Tolstos (wie Anm. 5), S. 135. N.K. GuDzy, Kak rabotal L. Tolstoj, M. 1936, S. $202 f$. Fedorov polemisierte heftig gegen den Titel des Romans: "Um die wahre Auferstehung zu leugnen", habe Tolstoj "eine unbedeutende und vollig nutzlose sittliche Wandlung" Auferstehung genannt. FOD I, S. 415 . 
werde. ${ }^{34}$ Am 25. Oktober 1910, fünf Wochen vor seinem Tod, schrieb Tolstoj an Peterson:

Ihre Aufsătze habe ich durchgelesen und stimme mit vielem überein, mit Ihren Grundgedanken jedoch (über die Errettung in dem Sinne, wie Sie sie auffassen) kann ich, wie immer, leider nicht einverstanden sein - weder mit Ihnen noch mit Nikolaj Fedorovic, dessen Andenken mir sonst teuer ist. $^{35}$

$34 \mathrm{Zu}$ Petersons Korrespondenz mit Tolstoj bzw. dessen Sekretăr in den Jahren 1908 bis 1910 siehe N.P. PETERson, "Moja perepiska s gr. L.N. Tolstym." In: PETERson, Fedorov (wie Anm. 1), S. 94-120. - Tolstoj hat im ersten Band der Filosofija obšego dela gelesen, wie seine Anstreichungen auf 20 Seiten des in der Bibliothek von Jasnaja Poljana erhaltenen Exemplars be. weisen. Siehe Biblioteka L'va Nikolaevita Tolstogo v Jasnoj Poljane. Bibliograficeskoe opisanie. T. 1, ¿. 2, M. 1975, S. 392f.

35 Tolstoj (wie Anm. 2), t. 82 (1956), S. 179. Vgl. auch PETERson, Fedorov (wie Anm. 1), S. VIf. 


\subsection{F.M. Dostoevskij}

In den letzten Jahren seines Lebens soll Dostoevskij (er starb 1881) unter den Einfluß Fedorovscher Gedanken geraten sein. ${ }^{1}$ Dostoevskij und Fedorov waren weder persönlich miteinander bekannt, noch standen sie im Briefwechsel, ja Dostoevskij kannte nicht einmal Fedorovs Namen. Von Fedorovs Ideen erfuhr er nur durch die briefliche Vermittlung N.P. Petersons. Diese Korrespondenz aus den Jahren 1876 bis 1878 (und vielleicht auch dem Jahre 1880) -, die alles enthält, was Dostoevskij von Fedorov wußte, bildet somit die Grundlage, von der ein jeder Versuch zur Klärung der möglichen Wirkung Fedorovs auf Dostoevskij auszugehen hat. ${ }^{2}$

1 Fedorovs Einfluß auf Dostoevskij ist in der Forschung stark umstritten. Die Äußerungen hierzu reichen von der Behauptung, das Spătwerk Dostoevskijs, insbesondere der Roman Brat'ja Kanamazovy, sei eine künstlerische Gestaltung Fedorovscher Ideen, bis zur vollstăndigen Leugnung jeglicher Einwirkung. Im folgenden seien die wichtigsten Arbeiten und ihre Positionen genannt (auf weitere Literatur wird an gegebener Stelle verwiesen).

Die bereits 1918 verfaBte Studie des Fedorov-Anhăngers A.K. GornostaEv [d.i. A.K. Gorsku], Raj na zemle. K ideologii tvortestva F.M. Dostoevskogo. F.M. Dosioevskij i N.F. Fedorov. O.O. [Harbin] 1929, eine Sammlung haltloser Spekulationen mit dem Ziel, Fedorovs Einflu B auf Dostoevskij als gravierend darzustellen, ist wissenschaftlich ganz wertlos, doch wird sie bis heute in der Literatur zitiert (zuletzt bei Semenova, siehe unten). Zu einer hohen Bewertung von Fedorovs EinfluB gelangt auch der Leningrader Dostoevskij-Forscher W. Komarowrtsch [V.L. Komarovie], "Der Vatermord und Fjodoroffs Lehre von der 'Fleischlichen Auferstehung'." In: F.M. Dostojewski. Die Urgestalt der Brüder Kanamasoff. München 1928, S. 3-58. Wichtig ist dieser inzwischen selten gewordene und hăufig übersehene Aufsatz v.a. wegen der darin ausführlich zitierten Materialien, die nie im russischen Original veröffentlicht worden sind! $\mathrm{Zu}$ Komaroviz siehe auch II: 4.2. Anm. 88. Eine ahnliche Position wie Komarovix vertritt R. LORD, "Dostoyevsky and N.F. Fyodorov." In: SEER, 40 (1962), 95, S. 409-430. Ders., Dosioevsky. Essays and Perspectives. London 1970, S. 175-200. (Beide Arbeiten enthalten zahlreiche faktische Fehler!). Auch L. KOEHLER, N.F. Fedorov: The Philosophy of Action, Pittsburgh 1979, S. 43-52, hălt Fedorovs EinfluB für sehr bedeutend; Dostoevskijs Braf'ja Karamazovy beweise "the writer's interest and intimacy with Fedorov's concepts" (S. 47) und enthalte "a strong undercurrent of Fedorovian motifs and themes" (S. 48). Siehe auch DiEs., "Renan, Dostoevskii, and Fedorov." In: Canadian-American Slavic Studies, 17 (1983), 3, S. 362-371. Von Beeinflussung und enger Geistesverwandtschaft zwischen Dostoevskij und Fedorov sprechen die sowjetischen Forscher B.[I.] BURsov, Licnost' Dostoevskogo, L. 1974, S. 73-79 (zuerst in: Zvezda, 1969-70), und - differenzierter - S.G. SEMENOVA, "Vysłaja ideja suß̌lestvovanija' u Dostoevskogo." In: Voprosy Literatury, 1988, 11, S. 166-195; hier 185-195.

Eine vorsichtigere Bewertung enthălt G.M. Young, Nikolai F. Fedorov: An Introduction, Belmont, Mass. 1979, S. 37-52; der Verf. schlägt vor, statt von direktem "EinfluB" (influence) von "Eindruck" (impact) zu sprechen: Fedorov und Dostoevskij hătten sich gegenseitig inspiriert und zu neuen eigenen Gedanken angeregt. Ähnlich bereits J. GRUNWALD, "Fédorov: l'homme et l'oeuvre. IIl. Fédorov et Dostoievski." In: Contacts, 62-63, 1968, S. 198-223.

Bestritten wird die Annahme, Fedorovs Ideen hătten einen nennenswerten EinfluB auf Dostoevskij ausgeübt, von R.V. PLETNEv, "N.F. Fedorov i F.M. Dostoevskij." In: Novyj Zumal, 50, 1957, S. 220-245. S. LiNNÉR, Starets Zosima in The Brothers Karamazov, Stockholm 1975, bes. S. 198-204. - Unzugănglich blieb der Vortrag von A A. DOROGov, Dostoevskij i Fedorov. (Doklad na VI-ch Dostoevskich Ctenijach: Dostoevskij i mirovaja kul'tura, Leningrad 11.-13. Nov. 1981).

2 In der Literatur wird der Korrespondenz zwischen Peterson und Dostoevskij oft nur geringe Aufmerksamkeit geschenkt; eine gründliche Untersuchung, die auch alle bislang unveroffent- 
Damals, d.h. in der zweiten Hälfte der siebziger Jahre, hatte Fedorov noch nicht jene Bekanntheit in Moskauer Intellektuellenkreisen erlangt, die dann später auch zu einer gewissen Verbreitung seiner Ideen beitrug. Erst vor kurzem, nämlich Ende 1874, hatte er seine Stelle an der Bibliothek des RumjancevMuseums angetreten. Die Kontakte zu Tolstoj und Solov'ev bestanden noch nicht, und auch der Gesprächskreis im Katalograum des Museums, zu dem sich bedeutende Vertreter des geistigen Lebens Moskaus versammelten, entstand erst in späteren Jahren. Somit kann nahezu ausgeschlossen werden, daß Dostoevskij auch noch auf anderem Wege von Fedorovs Ideen erfuhr. Hinzu kommt, $\mathrm{da} ß$ Fedorov seine Ideen zu jener Zeit allenfalls in Ansätzen schriftlich niedergelegt hatte (in der Form, wie sie dann später als Filosofija obšcego dela veröffentlicht wurden, stammen sie aus den achtziger und neunziger Jahren).

Dostoevskijs erster, noch sehr oberflächlicher Kontakt mit Fedorovschen Ideen fällt in das Jahr 1876. Am 6. März 1876 wandte sich N.P. Peterson, der damals als Sekretär am Friedensgericht in Kerensk (Gvt. Penza) arbeitete, mit einem Brief an Dostoevskij. ${ }^{3}$ Dem Brief beigefügt waren das Manuskript eines Artikels sowie eine Nummer eines regionalen Anzeigenblattes. Darin, so Peterson, finde sich "eine Notiz aus Kerensk und eine ziemlich lange Erwiderung der Redaktion auf diese Notiz". ${ }^{4}$ Der Verfasser der Notiz habe auf die Einwände der Redaktion mit dem beigefügten Artikel antworten wollen, doch sei dessen Abdruck mit der Begründung abgelehnt worden, er trage "den Charakter einer Predigt, die nur in einer geistlichen Zeitschrift oder Zeitung veröffentlicht werden könne. ${ }^{5}$ Peterson bat Dostoevskij, den Artikel zu lesen und über seinen "Eindruck" im Dnevnik pisatelja zu berichten.

Bei dem beigefügten Anzeigenblatt handelt es sich um den in Penza erscheinenden Spravocnyj listok rajona Mořansko-syzranskoj Železnoj dorogi, Nr. 20, vom 25. Januar $1876 .{ }^{6}$ In der Nr. 2 dieser Zeitung vom Jahre 1875 war ein Arti-

lichten oder nur in deutscher Ubersetzung vorliegenden Materialien heranziehen müBte, fehlt. Statt dessen mangelt es nicht an ebenso weitreichenden wie unbegründeten Spekulationen über die Geistesverwandtschaft zwischen Dostoevskij und Fedorov und über gedankliche und motivische Entsprechungen in den Werken beider.

3 Original IRLI, f. 100, No. 29806, CCXIb. 9; unveroffentlicht; siehe die Beschreibung bei T.V. GaRmaSEVA, V.N. KAPELJUS, "Rukopisi i perepiska F.M. Dostoevskogo." In: Bjulleteni nukopisnogo otdela Puskinskogo doma, vyp. 7, M.-L. 1957, S. 105. - Deutsche Úbersetzung (anscheinend vollstăndig) bei KoMAROWTrSCH (wie Anm. 1), S. 50 .

4 KomarowtTsch (wie Anm. 1), S. 50.

5 F.M. DostoevSKU, PSS v 30-i tomach, t. 22 [Dnevnik pisatelja za 1876 god, janvar' - aprel'], L. 1981, S. 356. Vgl. KOMAROWTrSCH (wie Anm. 1), S. 50f. - Die Kommentierung der zitierten Dostoevskij-Gesamtausgabe (PSS) ist in bezug auf Peterson und Fedorov nicht immer zuverlăssig: So ist nicht der Anfang von Petersons Brief verlorengegangen, sondern der des beigefügten Manuskripts, und nur aus diesem hat Dostoevskij im Dneunik pisatelja zitiert (t. 22, S. 356). Fedorovs Geburtsjahr ist nicht 1824 (ebd.). Die in diesem Zusammenhang grundlegende Arbeit von Komaroviz wird nicht erwăhnt (ebd.). Peterson und Fedorov haben sich nicht erst 1868-69 in der Certkov-Bibliothek, sondem bereits 1864 in Bogorodsk kennengelernt (t. 30, 1, S. 435). Es ist vom "mystisch-religiosen Charakter der Lehre Fedorovs" die Rede (ebd., S. 444).

Genaue Beschreibung bei GARMASEVVA, KAPELUUS (wie Anm. 3). 
kel über die Verbreitung der Trunksucht und ihre Bekämpfung erschienen, in dem vorgeschlagen worden war, das Bildungsniveau des Volkes zu heben und Versammlungsstätten für Bauern und Handwerker zu schaffen, um sie von den Kneipen fernzuhalten. ${ }^{7}$ Dagegen wandte sich der Verfasser der erwähnten, nur mit "K-v" gezeichneten Notiz vom 25. Januar 1876. Den Grund für die verbreitete Trinkerei sah er im allmählichen Schwinden der gemeinschaftlichen Bindungen im Volk, wodurch die natürliche "Sehnsucht nach der Gemeinschaft mit dem Nächsten", die "zu entwickeln die höchste, wenn nicht gar die einzige Aufgabe der Kirche sem sollten, zunehmend unbefriedigt bleibe. ${ }^{8}$

Die Redaktion mochte diese Sicht jedoch nicht teilen: Die Rettung vor der Trunksucht liege in der Befriedigung des "rein menschlichen Bedürfnisses nach Gemeinschaft mit seinesgleichen". Auf dieser Grundlage seien "die russischen Arbeiterartels, die deutschen Korporationen, die französischen Assoziationen und die englischen und amerikanischen Genossenschaften" entstanden, deren Bedeutung mit jedem Jahr zunehme. In ihnen sei "wohl die einzige Quelle für die Erlösung zu suchen..." 9

Die Erwiderung auf diese redaktionelle Notiz war der Artikel, den die Redaktion wegen seines angeblichen Predigtcharakters nicht hatte veröffentlichen wollen und den Peterson daraufhin an Dostoevskij schickte. Das Manuskript von 7 Seiten in derselben Schrift wie Petersons Brief war wiederum mit "K-v" gezeichnet und datiert "Kerensk, 20. Februar 1876".10

Dostoevskij hatte Petersons Sendung am 16. März 1876 erhalten und reagierte prompt. In der März-Ausgabe des Dnevnik pisatelja behandelte er unter der Überschrift Obosoblenie das Phänomen fortschreitender Zersplitterung, Absonderung und Isolierung der Menschen, nicht nur im Verhältnis zueinander, sondern auch in ihrem Denken und Fühlen. "Bei dieser Gelegenheit," so schreibt er, "will ich einige Gedanken über unsere Korporationen und Assoziationen aus einem Manuskript anführen, das nicht von mir stammt, sondern mir zugeschickt wurde und nirgends gedruckt ist." ${ }^{11}$ Es folgt der Anfang des Artikels, den Peterson ihm geschickt hatte.

Der Artikel wendet sich gegen die Annahme, Korporationen, Assoziationen und Genossenschaften seien aus einem angeborenen Bedürfnis nach Geselligkeit entstanden; vielmehr handele es sich um Zweckbündnisse der einen gegen die anderen im Kampf ums Dasein oder um den größeren Nutzen auf Kosten

7 Siehe Dostoevsku (wie Anm. 5).

8 Dostoevsku (wie Anm. 5). Komarowtrsch (wie Anm. 1), S. 51 .

9 Dostoevsku (wie Anm. 5). Komarowtrsch (wie Anm. 1), S. 52.

10 Angaben nach Garmaseva, Kapeuus (wie Anm. 3). Komarowtrsch (wie Anm. 1), S. 52f., 57f. - Original IRLI, f. 100, No. 29806, CCXIb. 9. Die ersten zwei Blătter des Manuskripts sind nicht erhalten, doch dürfte ihr Text dem entsprechen, den Dostoevskij im Dneunik pisatelja zitiert hat (siehe unten). Der Text der restlichen fünf Blătter liegt veroffentlicht (wahrscheinlich vollstăndig) nur in deutscher Úbersetzung vor bei KoMAROWTrSCH (wie Anm. 1), S. 53-57.

11 Dostoevsku (wie Anm. 5), S. 81. 
des Mitmenschen. Bruderfeindschaft und Abgrenzung, nicht aber das Streben nach Zusammenschluß lägen diesen Institutionen zugrunde. Im russischen Volk jedoch wirke - im Unterschied zu seinen westlichen Nachbarn - noch das Gefühl der Zusammengehörigkeit ( $($ uvstvo edinenija) und der gegenseitigen Liebe:

Für denjenigen aber, in dem dieses Gefühl noch nicht abgetరtet ist, ist alles møglich, wenn nur dieses Gefühl von einem unbewuBten, einem Instinkt, zu einer bewuBten Kraft wird, die einen nicht nach der blinden Laune des Zufalls mal hierher und mal dorthin wirft, sondern die von uns auf die Erreichung vernünftiger Ziele gelenkt wird. ${ }^{12}$

Wie dies geschehen könne und worin die Ziele liegen, wird in jenen Teilen des Manuskripts angedeutet, die Dostoevskij, wie er sagt, "nicht zu zitieren wag[t]e"..$^{13}$ - In einer Gemeinschaft, heißt es dort, die vom "Gefühl der allgemeinen Zusammengehörigkeit" durchdrungen sei, würden "alle in eins" verschmelzen. In einer solchen Gemeinschaft

... wird das, was jedes einzeine Mitglied dieser Gemeinschaft tut, ihm den gleichen Nutzen bringen wie dem Ganzen. Dann wird das Wirken eines jeden einzelnen Menschen von selbst den hochsten Begriffen von Pflicht und Sittlichkeit entsprechen. ${ }^{14}$

Es sei die eigentliche Aufgabe der Kirche, dieses Gemeinschaftsgefühl in den Menschen zu fördern und sie zu einen, doch habe die Kirche sich aufs Beten beschränkt, anstatt durch tätiges Bemühen das Erbetene auch zu verwirklichen.

Das Gebet allein, ohne Anwendung der eigenen Kräfte zur Erreichung dessen, worum wir beten, kommt einer BuBfertigkeit gleich, bei der die Absicht, sich zu bessem, fehlt. ${ }^{15}$

Indem die Kirche für das Wohlergehen der Menschen bete, für "Reinheit der Luft, Fruchtbarkeit des Bodens, Frieden für die ganze Welt und Einigkeit aller", habe sie auch die Pflicht, die Bedingungen zu erforschen und zu verändern, an die das Menschendasein gebunden ist.

Dann konnte die Kirche auch der Mittelpunkt für die Vereinigung der Menschen werden, nicht nur in allem, was die Wohltatigkeit betriff, sondern auch im Hinblick auf die Erforschung der Welt, sowohl in sittlicher Hinsicht, diese im weitesten, historischen Sinne genommen, wie auch in physischer. Denn nur eine mit dem Gebet verbundene, hochst sorgfaltige und nach allen Richtungen reichende Erkenntnis der Welt vermag jenes, alle in gleicher Weise erleuchtende und die Welt von allen Ubeln erlosende Licht zu spenden. ${ }^{16}$

12 Ebd., S. 82.

13 Ebd., S. 83.

14 KOMAROWTTSCH (wie Anm. 1), S. 54.

15 Ebd., S. 56.

16 Ebd., S. 55. 
Die Vereinigung des Glaubens und des Gebetes mit der Tat wird die Hoffnung beleben und die Menschen zur Liebe führen, ... zu der neuen Geburt, ohne die es, nach den Worten des Erlosers, kein Heil geben kann...

In seinem anschließenden Kommentar, in dem er auch auf die "Geschichte des Manuskripts" eingeht, nennt Dostoevskij den zitierten Artikel "jugendlich, frisch, theoretisch und unpraktisch, im Prinzip jedoch vollkommen richtig und nicht nur aufrichtig, sondern auch unter Schmerzen und Qualen geschrieben", und er dankt dem Verfasser, von dem er nicht wisse, ob er "ein junger Mann" sei oder einer "von den jungen Alten", denn die Lektüre habe ihm "außerordentliches Vergnügen" bereitet: "Selten habe ich etwas so Logisches (Cto-nibud" logiznee) gelesen....18 Doch noch aus einem anderen Grund habe er, so Dostoevskij, den Artikel angeführt:

Die Sache ist nămlich die, daß ich bei seinem Verfasser, der sich so sehr um die wahre Einigung der Menschen bemüht, auch einen in seiner Art außerst "abgesonderten" Impetus (Erezuyzajno tože "obosoblennyj" v swoem rode razmach) feststellte, und zwar in den Teilen des Manuskripts, die ich nicht zu zitieren wage, einen so abgesonderten, wie man ihn nur selten antrifft; so bestătigt nicht nur der Arikel selbst, sondern auch sein Verfasser meine Ansicht von der "Absonderung" der Individuen und von der außerordentlichen, sozusagen chemischen Zersetzung unserer Gesellschaft in ihre Grundbestandteile, die in unserer Zeit plotzlich eingesetzt hat. ${ }^{19}$

Dostoevskijs lebhafte Zustimmung beruhte auf der engen Verwandtschaft der in dem Artikel geäußerten Ansichten mit seinen eigenen. Beide, Dostoevskij und der Verfasser der Artikels, beklagten den Zerfall der modernen Gesellschaft in Interessengruppen und Individuen und hielten der Absonderung und Vereinzelung das Ideal einer auf Bruderliebe und Einigung beruhenden allumfassenden organischen Gemeinschaft entgegen, das sie im religiösen Russentum bewahrt sahen. ${ }^{20}$ Dostoevskij fand somit, wie er selbst schrieb, seine eigenen Ansichten bestätigt, und er dürfte kaum etwas Neues erfahren haben. Dazu waren Fedorovs originelle Gedanken viel zu sehr verschleiert. Am deutlichsten noch werden sie in der Idee einer kirchlichen Vereinigung der Menschen zur tätigen Erforschung und Abwendung der natürlichen Schadensbedingungen. Vom eigentlichen obšce delo und seinem Ziel ist jedoch nirgends die Rede. ${ }^{21}$

17 Ebd., S. 57.

18 Dostoevsku (wie Anm. 5), S. 82f.; Hervorhebung im Orig.

19 Ebd., S. 83.

20 Erinnert sei an die Lehren des Starec Zosima in Brat'ja Kanamazovy, der von der Idee seines früh verstorbenen Bruders beflügelt ist, daB "ein jeder vor allen für alle und für alles schuldig" ist (DOSTOEVSKU, wie Anm. 5, t. 14, L. 1976, S. 262), und daB alles menschliche Unglück in der "Absonderung und Einsamkeit" (ot-edinenie / uedinenie) besteht, die an die Stelle der "Bruderliebe und Menscheneinigung", der organischen "Ganzheit der Menschen" (celostnost' ljudej) getreten ist (ebd., S. 285).

21 In der Fedorov-Literatur werden mit Vorliebe Dostoevskijs zustimmende Äußerungen ("Selten habe ich etwas so Logisches gelesen...") zitiert, ohne daB auf den Inhalt des Artikels, auf den sie sich beziehen (und dessen großerer Teil nur in deutscher Obersetzung bei Komaroviz zu- 
Verfasser des mit "K-v" gezeichneten Artikels (wie auch der Notiz in dem Penzaer Anzeigenblatt) dürfte Peterson gewesen sein. In seinen unveröffentlichten Erinnerungen heißt es: "In dem Wunsch, Nikolaj Fedorovižs Ideen bekannt zu machen, schrieb ich bisweilen [inogda] an F.M. Dostoevskij, und etwas aus meinen Briefen veröffentlichte er in seinem Dnevnik pisatelja." 22

Zum zweiten Mal wandte sich Peterson im Dezember 1877 an Dostoevskij. In einem anonymen Schreiben schickte er ihm ein Manuskript, offenbar wieder mit der Bitte um Besprechung im Dnevnik pisatelja. ${ }^{23}$ Wie Peterson später angab, enthielt das Manuskript eine kurze Darlegung (Zusammenfassung) der Lehre Fedorovs; diese sei ohne Wissen Fedorovs abgefaßt und an Dostoevskij geschickt worden. ${ }^{24}$

Am 3. März 1878 schickte Peterson einen weiteren Brief an Dostoevskij, in dem er um die Übersendung von (nicht näher bekannten) Büchern an die Bibliothek von Kerensk bat und sich offenbar als Absender des Manuskripts vom Dezember zu erkennen gab. ${ }^{25}$

Dostoevskij antwortete darauf am 24. März 1878:

gănglich ist) năher eingegangen wird. Damit entsteht der (beabsichtigte) Eindruck einer begeisterten Zustimmung Dostoevskijs zu Fedorovs Ideen oder gar zu dessen gesamtem Projekt! Siehe zuletzt SEMENOVA (wie Anm. 1), S. 185f. Zutreffend ist dagegen die Feststellung von LiNNER (wie Anm. 1), S. 198: "His [Dostoevskijs] enthusiasm is easily explained as springing from recognition. There is no reason to presume that he learned anything from Fedorov." Linnér bezieht sich freilich nur auf den im Dnewnik pisatelja zitierten Teil des Artikels.

22 Zitiert nach SEMENova (wie Anm. 1), S. 185. - Für die Behauptung, der genannte Artikel sei unmittelbar von Fedorov verfaBt worden (so z.B. PLETNEV, wie Anm. 1, S. 230f. LINNÉR, wie Anm. 1, S. 198), gibt es keinerlei Anhaltspunkte. Unwahrscheinlich ist auch die Verfasserschaft Koževnikovs (auf den das Namenszeichen "K-v" deuten kőnnte); dieser war damals gerade erst mit Fedorov bekannt geworden. Zur Verfasserfrage auch KoMAROWTTSCH (wie Anm. 1), S. 58.

23 Schreiben und Manuskript sind nicht erhalten. - Angaben nach Dostoevskijs Brief an Peterson vom 24.3.1878 (siehe unten); Dostoevskij spricht dort von einem "Manuskript in dem nicht unterzeichneten Brief vom Dezember'; der Umschlag habe den Stempel Kerensk getragen; in seinem "Tagebuch" sei er nicht darauf eingegangen.

24 "... im Jahre 1877 schickte ich Fedor Michajlovit [Dostoevskij] ein kleines Manuskript [nebol'suju rukopis']..." N.P. Peterson an K.P. Pobedonoscev, 14.3.1881; in: K.P. POBEDONOSCEV, KP. Pobedonoscev i ego korrespondenty. Pis'ma i zapiski. T. 1, 1, M. 1923, S. 285. "Im Jahre 1877 hielt ich mich nicht [mehr] zurück und verfaBte, ohne Nikolaj Fedorovit etwas davon zu sagen, eine kurze Darlegung [Zusammenfassung; kratkoe izlozenie] dessen, was ich von ihm gehort hatte, und schickte diese Darlegung an Dostoevskij." N.[P.] PETERSON, "Pis'mo $k$ izdatelju Russkogo Archiva. Po povodu otzyva F.M. Dostoevskogo o N.F. Fedorove." In: Russkij Anchiv, 42 (1904), 6, S. 301.

"... ohne Nikolaj Fedorovił etwas zu sagen, da er niemals damit einverstanden gewesen wăre, legte ich seine Lehre kurz dar [vknatce izlozil ego ucenie] und schickte diese Darlegung an F.M. Dostoevskij..." DERS., N.F. Fedorov i ego kniga 'Filosofija obscego dela' v protivopolotnost' uČeniju L.N. Tolstogo 'o neprotivlenii' i drugim idejam naśego vremeni, Vernyj 1912, S. 89.

25 Auch dieses Schreiben ist nicht erhalten. Der einzige Hinweis darauf in Dostoevskijs Brief an Peterson vom 24.3.1878 (siehe unten). 
Petersburg, 24. Mărz [18]78.

Gnådiger Herr, Nikolaj Pavlovið,

Was die Bücher für die Kerensker Bibliothek betrift, so habe ich ihren Versand schon lăngst veranlaßt, und inzwischen haben Sie gewiB alles erhalten.

Nun aber zu dem Manuskript in dem nicht unterzeichneten Brief vom Dezember [1877]. Im "Tagebuch" bin ich nicht darauf eingegangen, weil ich hoffte, Ihre Anschrift über das Subskribentenbuch herauszufinden (der Umschlag trug den Stempel Kerensk) und mit Ihnen personlich zu korrespondieren, doch infolge haufigen Zeitmangels und verschiedener Krankheiten schob ich es von einem Tag auf den anderen. SchlieBlich kam Ihr Brief vom 3. Mărz [1878] und klărte alles auf. ${ }^{26}$ ] Ich antwortete nicht sofort, weil ich wieder krank wurde. Ich bitte Sie deshalb demütigst, die Verzgerung zu entschuldigen.

Zu allererst eine Frage: Wer ist dieser Denker, dessen Gedanken Sie übermittelt haben? Teilen Sie, wenn moglich, seinen richtigen Namen mit. Zu sehr hat er mein Interesse erweckt. Berichten Sie zumindest etwas ausführlicher über seine Person; all das, falls möglich.

Dann möchte ich Ihnen sagen, daß ich im wesentlichen mit diesen Gedanken völlig einverstanden bin. Ich habe sie gelesen als wären sie meine eigenen. Heute habe ich sie (anonym) Vladimir Sergecvix Solov'ev vorgelesen, unserem jungen Philosophen, der gegenwărtig Vorlesungen über Religion hălt - Vorlesungen, die von einer fast tausendkopfigen Menge besucht werden. ["] Ich hatte eigens auf ihn gewartet, um ihm Ihre Darlegung der Ideen des Denkers vorzulesen, da ich in seiner Anschauung viel Ähnliches fand. Dies bereitete uns herrliche 2 Stunden. Er hat tiefes Verstăndnis für diesen Denker und wollte fast das gleiche in seiner năchsten Vorlesung sagen (er hat noch 4 von 12 Vorlesungen zu halten). $\left[{ }^{28}\right]$

Hier aber habe ich eine bestimmte und klare Frage, die ich Ihnen schon im Dezember vorlegen wollte:

In der Darlegung der Ideen dieses Denkers ist das Wesentlichste zweifellos die Pflicht der Auferste hung [dolg voskresen'ja] der Vorfahren, die früher gelebt haben, eine Pnicht, die, wenn sie erfüllt wăre, das Zeugen von Nachkommen beenden würde; dann würde eintreten, was in den Evangelien und in der Apokalypse die erste Auferstehung genannt wird. $\left.{ }^{29}\right]$ Was freilich bei Ihnen, in Ihrer Darlegung, ganz und gar nicht kenntlich gemacht ist: Wie verstehen Sie diese Auferstehung der Vor-

26 Es bleibt unklar, weshalb Petersons Anschrift für Dostoevskij nicht leichter zugănglich war. Peterson hatte seinen Brief an Dostoevskij vom 6.3.1876 mit Namen und voller Anschrift versehen. Zudem findet sich der Name Peterson im Jahre 1876 dreimal in Dostoevskijs Notizbuch (wahrscheinlich stammen alle drei Eintragungen aus der zweiten Mărzhalffte), davon einmal mit dem Vermerk "An Peterson schreiben" ("Napisat': ... Petersonu"). Literatumoe nasledstvo, t. 83 [Neizdannyj Dostoevskij. Zapisnye knižki i tetradi 1860-1881 g8.], M. 1971, S. 450, 452, 459; Anm. S. So8f.

27 Es handelt sich um die offentlichen "Vorlesungen über die Philosophie der Religion", die der fünfundzwanzigjăhrige Solov'ev vom 29. Januar bis 2. April mit großem Erfolg in Petersburg hielt und die spăter (in z.T. verănderter Form) als "Vorlesungen über das Gottmenschentum" (Cienija o bogocelovecestve) veröffentlicht wurden. Dostoevskij gehorte zu den regelmäBigen Horem.

28 Gemeint ist wahrscheinlich die 9. Vorlesung, in der Solov'ev über die (feindliche) Absonderung der Einzelelemente (der physischen Wesen) vom universalen organischen Ganzen als dem Grund-Bosen und der Ursache des Leidens sprach.

29 Die erste Auferstehung steht am Beginn der tausendjahrigen Herrschaft Christi und betrifft nur die Mărtyrer; an ihrem Ende erfolgt die (zweite) Auferstehung aller zum Weltgericht (Off. 20, 4-6). 
fahren, in welcher Form stellen Sie sie sich vor und glauben Sie daran? Das heißt, verstehen Sie sie irgendwie gedanklich, allegorisch, so wie etwa Renan, der sie als ein Sichaufklăren des menschlichen BewuBtseins am Ende des Lebens der Menschheit auffaßt, ein Sichaufklăren bis zu einem solchen Grade, daß für den Verstand der künftigen Menschen ganz klar sein wird, wie groB zum Beispiel der EinfluB eines ihrer Vorfahren auf die Menschheit gewesen ist, worin er bestand, wie er ausgeübt wurde und so weiter; und dies so weit, daB die Rolle eines jeden Menschen, der früher gelebt hat, vollkommen klar wird und seine Taten richtig entrătselt werden (durch die Wissenschaft, die Kraft der Analogie) - und dies alles so weit, daB wir sogar erkennen, wie sehr all diejenigen, die früher gelebt haben, uns beeinfluBt und sich eben dadurch in uns wiederverkörpen haben und folglich auch in jenen letzten Menschen, den altwissenden und harmonischen, in denen die Menschheit ihren AbschluB findet.

Oder:

Ihr Denker stellt sich direkt und buchstăblich vor, daß, wie die Religion es andeutet, die Auferstehung eine reale, persönliche sein wird, daB der Abgrund, der uns von den Seelen unserer Vorfahren trennt, zugeschüttet, durch den besiegten Tod überwunden wird und die Vorfahren nicht nur in unserem BewuBtsein, nicht allegorisch, sondern wirklich, persőlich, real körperlich auferstehen werden. (NB. Natürlich nicht in ihren jetzigen Korpern, denn allein schon, daB mit dem Eintreten der Unsterblichkeit Ehe und Kindergebăren aufhören werden, beweist, daß die Korper in der ersten Auferstehung, die auf Erden erfolgen soll, andere sein werden als die jetzigen, ăhnlich vielleicht dem Leib Christi von seiner Auferstehung bis zu seiner Himmelfahrt an Pfingsten [sic!]?)

Eine Antwort auf diese Frage ist unbedingt notig - andernfalls bleibt alles unverstăndlich. Ich sage Ihnen im voraus, daB wir hier, das heiBt zumindest ich und Solov'ev, an eine reale, buchstabliche und personliche Auferstehung glauben und auch daran, daB sie auf Erden stattfinden wird.

Teilen Sie mir, so Sie konnen und wollen, hochverehrter Nikolaj Pavlovix, mit, was Ihr Denker darüber denkt und dies, wenn möglich, ausführlicher.

Hinsichtlich der Bestimmung: was die Volksschule sein soll, bin ich mit Ihnen vollig einverstanden. [ [0] (...)

Mit vorzüglicher Hochachtung

$$
\text { F. Dostoevskij. }{ }^{31}
$$

30 "Was die Volksschule sein soll" (Cem dolžna byt' narodnaja skola) war moglicherweise der Titel des Manuskripts, das Peterson im Dezember 1877 an Dostoevskij geschickt hatte. In seinem 'Kommentar' zur Erstveröffentlichung von Dostoevskijs Brief an Peterson in der Voronežer Zeitung Don, No. 80, 1897, schreibt Fedorov: "Zusammen mit Dostoevskijs Brief [vom 24.3.1878] fiel uns auch ein kleines Heft zu, leider unvollstăndig, mit dem Titel 'Was die Volksschule sein soll', - wahrscheinlich die Kopie oder der Entwurf des Artikels, über den Dostoevskij [in seinem Brief] spricht und mit dem er seine volle Obereinstimmung bekundet." N.F. FEDOROV, "Pi'smo N.F. Fedorova $k$ redaktoru gazety 'Don' po povodu pis'ma F.M. Dostoevskogo k N.P. Petersonu ob u飞enii N.F. Fedorova." In: Vselenskoe delo, 1, Odessa 1914, S. 26. Ein Manuskript mit dem Titel Cem dolzna byt' narodnaja skola befindet sich im Archiv von N.P. Peterson; GBL f. 657.

31 Hier zitiert nach Dostoevsku (wie Anm. 5), t. 30, kn. 1 [Pis'ma 1878-1881], L. 1988, S. 13-15. Anm. S. 266f., 435, 443f. Vgl. auch die Ausgabe F.M. DosToEvsku, Pis'ma v 4ch tomach, t. 4, M. 1959, S. 9f. Anm. S. 347-349. - Dostoevskijs Brief an Peterson erschien zuerst (erheblich gekürzt und mit einem 'Kommentar' von Fedorov) in der Voronežer Zeitung Don, No. 20, 1897; sodann (leicht gekürzt) in: Russkaj Archiv, 42 (1904), 3, S. 402f. Weitere Veroffentlichungen: VA. KoZzEVNIKOV, Nikolaj Fedorovic Fedorov. Opyt izloťenija ego utenija po izdannym i neizdannym proizvedenijam, perepiske i liznym besedam. C. 1, M. 1908, S. 316f. Vselenskoe delo (wie Anm. 30), S. 30r. 
Soweit Dostoevskijs Reaktion auf die kurze Darlegung der Lehre Fedorovs durch Peterson. ${ }^{32}$ Der Brief macht deutlich, daB Dostoevskij sich über den zentralen Gedanken Fedorovs - nämlich die von der vereinten Menschheit mit wissenschaftlich-technischen Mitteln zu bewerkstelligende materielle Auferwekkung (voskrešenie) aller Verstorbenen - völlig im Unklaren befand und deshalb auch annehmen konnte, die Auferstehung sei vielleicht nur "gedanklich, allegorisch" gemeint, als Wiedererstehen der Vorfahren im sich erweiternden und aufklärenden Bewußtsein einer fortschreitenden Menschheit. ${ }^{33}$

Doch auch die von Dostoevskij formulierte Alternative, zu der er und Solov'ev sich bekannten, hat mit Fedorovs Denken nichts gemein, sondern bleibt ganz im Rahmen der traditionell christlichen Auffassung einer Auferstehung (voskresenie) in einem verwandelten, verklärten Leib, die als göttliches Wunder ohne menschliches Zutun stattfinden werde. Fedorov nannte diese Auffassung "Mystizismus" und hob ihren Gegensatz zu seiner eigenen Lehre hervor:

Weder in seinem Brief vom 23. [sic] Mărz 1878..., in dem er [Dostoevskij] von der Pflicht der Auferstehung als dem Wesentlichsten spricht, noch in all seinen übrigen Werken gibt er den leisesten Hinweis auf den Weg, den Gang der Arbeit, durch den diese Pflicht erfullt werden soll, nămlich die Pflicht zur Auferweckung. In dem Brief heiBt es, daB sie, die Auferstehung, "auf Erden staltfinden wind"; - allein schon dieses "stattfinden wind" zeigt, daB nach Dostoevskijs Ansicht die Auferstehung gleichsam von selbst geschieht, daß sie nicht das Werk des Menschengeschlechts ist. (...) Dostoevskij ... war ein Mystiker und als solcher überzeugt, daß die Menschheit sich "im Kontakt mit anderen Welien" befinde... ... der Tod aber [sei] der Öbergang in diese anderen Welten. (...) Unter diesem Gesichtspunkt ist die Pnicht zur Auferweckung eine leere Phrase, weil sie zu nichts verpflichtet, auf keine Aufgabe hinweist; alles geschieht von selbst, ohne Beteiligung des Menschen, ohne Beteiligung seines Verstandes, seines Gefühls, seines Willens; alle seine Fähigkeiten wie auch er selbst erweisen sich als nutzlos, alles wird ihm umsonst zuteil. DaB Dostoevskij sich die Pflicht zur Auferweckung genau so vorgestellt hat, ... wird deutlich auch aus folgendem Satz in seinem Brief...: "der Abgrund, der uns von den Seelen unserer Vorfahren trennt, wird zugeschüttet, wird durch den besiegten Tod überwunden, und sie (d.h. unsere Vorfahren) werden auferstehen..." Wir dagegen wissen nichts

32 Dostoevskijs Bemerkung, die Lektüre habe ihm und Solov'ev "herrliche 2 Stunden" bereitet, ist der einzige Hinweis auf den Umfang dieser Schrift. Ober ihren Inhalt fmden sich in der Dostoevskij-Literatur bisweilen erstaunliche Angaben. So zitiert N. Zernov angeblich lăngere Passagen aus dem Manuskript ("The manuscript which so profoundly stirred both Dostoevsky and Soloviev contained, among others, the following statements: [...] Such were some of the paradoxical ideas contained in the manuscript."); in Wirklichkeit handelt es sich dabei um Zitate aus Fedorovs postum veroffentlichten Schriften! N.[M.] Zernov, Three Russian Prophets. Khomiakov, Dostoevsky, Soloviev. London 1944, S. 110f. 'Konsequent' heißt es dann an anderer Stelle von Dostoevskij und Solov'ev: 'Together, they read in manuscript a book [!] with the title [!] The Philosophy of the Common Cause..." E. KRAG, Dostoevsky. The Literary Artist. Oslo, New York 1976, S. 249. Weitere Beispiele ließen sich anführen.

33 Es stimmt also gerade nicht, wenn Koehler schreibt, "... Dostoevskii correctly contrasted Fedorov's and Renan's views." KOEHLER, "Renan..." (wie Anm. 1), S. 368. Fedorovs Standpunkt wird von Dostoevskij überhaupt nicht erwăhnt, weil er ihn offenbar gar nicht kannte. - Renan hatte in La vie de Jésus (1863) geschrieben: "Wer weiB, vielleicht wird dereinst das Menschengeschlecht auf der hochsten Stufe seines Fortschritts in Millionen von Jahren zur absoluten Erkenntnis des Universums gelangen und in dieser Erkenntnis den Weg finden, das, was schon einmal gelebt hat, wieder ins Leben zurückzuholen." Zitiert nach Dostoevsku (wie Anm. 5), t. 30, kn. 1, L. 1988, Anm. S. 267. Vgl. auch die etwas abweichende Obersetzung bei E.I. KuKo, "Dostoevskij i Renan." In: Dostoevskij. Materialy i issledovanija. T. 4, L. 1980, S. 121. 
von einem Abgrund oder von etwas, das durch den besiegten Tod überwunden wird, vielmehr sind wir der Meinung, daß es für uns möglich ist und nötig, ... mit Hilfe schließlich aller Menschen Wissen und Herrschaft über alle Moleküle und Atome der ăuBeren Welt zu erlangen, um das Zerstreute zu sammeln, das Zerfallene zu verbinden und es zusammenzusetzen zu den Korpern der Văter, wie diese sie bei ihrem Tod hatten. ${ }^{34}$

Aus alldem folgt, daß Dostoevskij Fedorovs Projekt, wäre es ihm bekannt und einsichtig geworden, gar nicht hätte akzeptieren können. ${ }^{35}$ Doch wurde es ihm - wahrscheinlich - nicht bekannt. Peterson hatte Fedorov sofort von Dostoevskijs Brief unterrichtet, worauf dieser beschloß, eine "vollständige Darlegung seiner Lehre" zu Papier zu bringen und als Antwort an Dostoevskij zu schikken. ${ }^{36}$ Im Juni 1878, als Fedorov für zwei Wochen zu Peterson nach Kerensk kam, begannen beide mit der Abfassung. ${ }^{37}$ Die Arbeit zog sich jedoch hin und konnte, wie Peterson berichtet, "in den Ferien 1878 nicht beendet werden; sie

34 FOD I, S. 439, 441f; Hervorhebungen im Orig.

35 In der Literatur werden aus Dostoevskijs Brief wiederum mit Vorliebe die zustimmenden Äußerungen zitiert ("Dann mochte ich Ihnen sagen, daß ich im wesentlichen mit diesen Gedanken vollig einverstanden bin. Ich habe sie gelesen als wăren sie meine eigenen." - Dieses $\mathrm{Zi}$ tat fand auch Verwendung für eine Postkarte mit Fedorovs Portrăt, die ein Anhănger des Philosophen 1926 in großer Auflage zu Werbezwecken herstellen ließ!); dagegen werden die Passagen, in denen Dostoevskij seine Unkenntnis des zentralen Gedankens Fedorovs beweist und seine eigene, stark abweichende Position formuliert, zumeist gănzlich unterschlagen! So zuletzt bei Semenova (wie Anm. 1), S. 186, die von Dostoevskijs "Einverstăndnis im kühnsten und 'verrücktesten' Punkt" der Lehre Fedorovs spricht.

Dank dieses Verfahrens kommen so abstruse Behauptungen zustande wie: "Dostoevskij war allein schon deshalb hocherfreut, da er von einem Menschen erfuhr, der genau so dachte, wie er selbst. Und er war doppelt erfreut, da Fedorov nicht nur ein Gleichgesinnter war, sondern ihre gemeinsame Theorie [!] auch noch durch wissenschaftlich-technische Berechnungen untermauerte." Bursov (wie Anm. 1), S. 77. Oder: "Fedorovs Philosophie" habe Dostoevskij "vor allem durch die Übereinstimmung mit seinem eigenen Gedanken von der Notwendigkeit des obšce delo" geradezu "erschüttert". Ju.I. SelEZNEv, Dostoevskaj, M. 1981, S. 480. Die Zahl der Beispiele ließe sich vermehren.

Dagegen hatte bereits 1913 A.S. Pankratov richtig beobachtet: "Die Ähnlichkeit zwischen den Weltanschauungen Dostoevskijs und Solov'evs einerseits und der Fedorovs andererseits ist nur eine auBerliche. In Wirklichkeit loste Fedorov das Problem von Leben und Tod selbstăndig und originell, und weder Dostoevskij noch Solov'ev konnten ihm darin zustimmen. Sie teilten vielmehr die gewöhnliche Ansicht der orthodoxen Kirche. Fedorovs Auferweckung ist dagegen für die orthodoxe Kirche nicht annehmbar." A.S. PanKRatov, "Filosof-pravednik." In: Novoe Slovo, 5 (1913), 8, S. 22f. Und unlăngst stellte V.A. Nikitin fest: "Dostoevskij blieb der traditionellen Lehre der orthodoxen Kirche von der Auferstehung als einem mystischen, eschatologischen, weltweiten Akt, der durch die Macht Gottes geschieht, nicht aber den Höhepunkt des obšzee delo bildet, treu. Darüber schreibt Fedorov selbst in einer unveroffentlichten $\mathrm{Be}$ merkung 'O Dostoevskom i dolge noskrešenija' (GBL, f. 657, Peterson-Archiv)." V.A. NIKITIN, "Dostoevskij, pravoslavie i 'russkaja ideja'." In: Vestmik RChD, 155, 1989, S. 135.

36 Peterson, "Pis'mo..." (wie Anm. 24), S. 301. - Vgl. Ders., Fedorov (wie Anm. 24), S. 90.

37 N.[P.] PEterson, "Predislovie." In: N.F. FeDorov, Filosofija obšcego dela, t. 1, Vernyj 1906 [1907], S. XII. - Im Sommer des Jahres 1878 traf Peterson wăhrend einer Bahnfahrt mit L.N. Tolstoj zusammen. Er erzăhlte ihm von Fedorov und las ihm Dostoevskijs Brief und den Anfang des Antwortschreibens vor. Letzteres, so Peterson, habe Tolstoj "nicht sympathisch" gefunden. Peterson, "Pis'mo..." (wie Anm. 24), S. 301. Ders., Fedorov (wie Anm. 24), S. 90. 
nahm immer mehr an Umfang zu und wurde auch 1879 und 1880 nicht fertig; da aber starb Dostoevskij.... ${ }^{38}$ Ausdrücklich stellt Peterson fest: "... an Dostoevskij ist keinerlei Antwort geschickt worden. ${ }^{39}$

In merkwürdigem Widerspruch dazu stehen Angaben in einem Brief Petersons an K.P. Pobedonoscev vom 14. März $1881 .^{40}$ Aus AnlaB der Ermordung Alexanders II. (am 1. März 1881) legt der Verfasser seine Gedanken über die Ursachen terroristischer Neigungen unter der studentischen Jugend dar, die er vor allem im Mangel an Orientierung und straffer geistiger Führung sieht. Als Lösung schlägt er eine tiefgreifende Reform des bislang nach fremden Vorbildern gestalteten Erziehungswesens vor, die in einer Vereinigung von Museen, Bibliotheken und Universitäten zu einer universalen, patriarchalisch organisierten Bildungseinrichtung bestehen solle. Damit werde die Voraussetzung für eine breite Umgestaltung der Gesellschaft nach dem Vorbild der Heiligen Dreifaltigkeit (deren Teile unterschieden und doch eins seien) geschaffen. Danach fährt der Verfasser fort:

... wenn Sie die hier geăuBerten Gedanken für beachtenswert halten, wăre es Ihnen dann nicht möglich, unter den [nachgelassenen] Papieren von Fedor Michajlovið [Dostoevskij] das Manuskript herauszusuchen, das ich ihm im letzten Drittel des vergangenen Jahres [also 1880] geschickt habe; dieses Manuskript konnte teiłweise das erhellen, was in diesem Brief enthalten ist; ich sage teilweise, weil dieses Manuskript erst der Anfang einer ziemlich umfangreichen, aber noch nicht vollig zu Ende geführten Arbeit ist; falls Sie das Heftchen interessiert, das sich unter den Papieren von Fedor Michajlovið befinden muB, so könnte ich [Ihnen] noch ein Heftchen schicken, welches weit klarer die Gedanken darlegt, die sowohl in diesem Brief wie auch in dem an Fedor Michajloviz geschickten Manuskript enthalten sind.

Ich muB erwăhnen, daB ich im Jahre 1877 ein kleines Manuskript an Fedor Michajlovið geschickt habe, das ihn so sehr interessierte, daß er mir am 24. Mărz 1878 einen langen Brief schrieb, in dem er sagte, er habe die in dieser Schrift dargelegten Gedanken "gelesen als wären sie [seine] eigenen". Im Zusammenhang damit stellte er einige Fragen. Das Heftchen, das ich ihm gegen Ende des vergangenen Jahres schickte, ist eigentlich der Anfang, das Vorwort zu jener Arbeit, die die Antwort auf die von inm gestellten Fragen sein wird. Dostoevskijs Brief an mich hoffe ich dieser Arbeit

38 Peterson, "Pis'mo..." (wie Anm. 24), S. 301. - Dostoevskij starb am 28. Januar (a.St.) 1881.

Zum Inhalt des als Antwort an Dostoevskij verfaBten Schreibens bemerkt Peterson in seinem Vorwort zum ersten Band der Filosofija obšego dela: "... auf Seite 64 beginnt mit den Worten '1. Nachodjas' Zut' ne nysjacu let' usw. das eigentliche Werk. So war im Juni 1878 die Antwort auf den Brief Dostoevskijs vom 23. [sic] Mărz 1878 begonnen worden..." PETERSON, "Predislovie" (wie Anm. 37). Den auf den folgenden etwa 20 Seiten der Filosofija obszego dela abgedruckten Text hatte Peterson bereits im Sommer 1878 Tolstoj vorlesen konnen. PETERSON, Fedonov (wie Anm. 24), S. 90. Dieser Text, so Peterson, habe die Keimzelle aller weiteren Schriften Fedorovs gebildet, aus ihm habe sich alles entwickelt, was spăter in der Werkausgabe veroffentlicht worden sei. PETERSON, "Predislovie" (wie Anm. 37).

39 Peterson, "Pis'mo..." (wie Anm. 24), S. 300.

40 Pobedonoscev (wie Anm. 24), S. 281-286. - Der Brief trăgt Namen und Anschrift Petersons. Im anonymen Kommentar (er stammt von Fedorovs ehemaligem Mitarbeiter G.P. Georgievskij) heiBt es ohne năhere Begründung, dieser Brief sei "vom ersten bis zum letzten Wort von Nikolaj FedoroviC [Fedorov] verfaBt" worden. Ebd., S. 414. 
voranzuschicken, die, obschon ihr Anfang vor mehr als zehn Jahren niedergelegt worden ist, unter dem gegenwärtigen Gesichtspunkt als unmittelbaren AnlaB diesen Brief hat.

Sollten die Angaben in diesem Brief zutreffen, so hat Dostoevskij kurz vor seinem Tod noch ein drittes Manuskript von Peterson erhalten. Das Manuskript wurde nicht gefunden. Unklar bleibt, ob es mit dem in Petersons Brief erwähnten "Heftchen" identisch ist, das Dostoevskij gegen Ende des Jahres 1880 erhalten haben soll. In jedem Falle bleibt der Widerspruch zu Petersons späterer Behauptung bestehen, an Dostoevskij sei "keinerlei Antwort" geschickt worden. ${ }^{42}$

Dostoevskijs Begegnung mit Fedorov fällt in die Zeit, da er an dem Roman Brat'ja Karamazovy arbeitete. Wiederholt ist deshalb versucht worden, Spuren oder Einflüsse Fedorovs in diesem Werk nachzuweisen. ${ }^{43}$ In der Tat finden sich

41 Ebd., S. 285f.; Hervorhebungen im Orig. - Ober eine Antwort Pobedonoscevs ist nichts bekannt.

42 In der Literatur blieb der Brief an Pobedonoscev und der sich daraus ergebende Widerspruch unbeachtet. Siehe zuletzt SEMENOVA (wie Anm. 1). Einzig Komarovic geht davon aus, daB Dostoevskij mit Fedorov in direktem Briefwechsel gestanden und von diesem ein drittes Manuskript erhalten habe. Komarowrtsch (wie Anm. 1), S. 28f. Dabei beruft sich Komarovit auf den zitierten Brief an Pobedonoscev, ohne freilich zu erwahnen, daB dieser Brief Namen und Anschrift Petersons trăgt, Fedorov hingegen an keiner Stelle erwăhnt wird. Es ist also (zumindest dem Namen nach) Peterson, der Pobedonoscev von seiner Korrespondenz mit Dostoevskij berichtet. Außerdem, so Komaroviz, habe Fedorov in seinem Artikel "Die Unsterblichkeit als Privileg der Ubermenschen" geschrieben: "Dostoevskij versicherte mir in einem seiner Briefe usw." Ein solches 'Zitat' lăßt sich jedoch weder in Fedorovs Aufsatz "Bessmertie, kak privilegija sverchcelovekov" (FOD II, S. 122-126) noch an anderer Stelle nachweisen.

43 Erstmals und mit Nachdruck in den Arbeiten von GoRNOSTAEv [GoRsKu] (wie Anm. 1) und KOMAROWITSCH (wie Anm. 1), auf die sich noch G.M. Fridlender bei seinen Hinweisen zu Dostoevskij und Fedorov im Kommentar zu den Brat'ja Karamazovy stützt. DOSTOEvSKU (wie Anm. 5), t. 15, L. 1976, S. 469-472.

Wăhrend Gorskijs Arbeit keinerlei wissenschaftlichen Wert besitzt, bietet Komarovið immerhin ansonsten unzugangliche Materialien. Seine These freilich, "Fjodoroffs Gedanken" hătten sich mit denen Dostoevskijs "gedeckt" und diesen "măchtig beeinfluBt" (S. 28), ist ebenso unhaltbar wie die daran anschließenden ÄuBerungen von SL. Frank, Dostoevskij sei "zur Zeit der Ausarbeitung der 'Brüder Karamazov' ein leidenschaftlicher Anhănger der ... Fedorovschen Deutung des Sinnes des Christentums gewesen" (S.[L.] FRANK, "Aus Dostojevskijs geistiger Werkstatt." In: ZfslPh, 7, 1930, S. 140), oder von G.V. Florouskij, "Fedorovs Ideen" hătten "auf Dostoevskij einen ausgeprägten und tiefen Eindruck gemacht" (G.V. FLoRovSKU, [Rez.] "Die Urgestalt der Brüder Karamasoff." In: Put', 1930, 23, S. 122).

Früh schon wurde dieser Darstellung widersprochen: So betonte S.I. Hessen, Komarovið habe "den wesentlichen Unterschied in der Weltanschauung der beiden Denker" grundsatzlich verkannt (S.[I.] HESSEN, "Der NachlaB von Dostojevskij in deutscher Sprache." In: Slavische Rundschau, 1, 1929, 8, S. 690). D.I. Tschižewskij warnte davor, Fedorovs EinfluB auf Dostoevskij zu überschătzen, und verwies statt dessen mehrmals auf den EinfluB Schillers (D. ČYZEVŚKYJ [TSCHZZEWSKU], "Schiller und die 'Brüder Karamazov'." In: ZfSIPh, 6, 1929, 1-2, S. 14, 39. DERS., [Rez.] "W. Schümer, Tod und Leben bei Dostojevski." In: Zeitschr. f. Kirchengeschichte, 53, 1934, S. 698f. DERS., "Siller v Rossii." In: Novyj Zumal, 45, 1956, S. 132f.). - Unter den jüngsten Arbeiten vgl. KRAG (wie Anm. 32), S. 249, 278-281. S. HACKEl, The religious dimension: vision or evasion? Zosima's discourse in The Brothers Karamazor'." In: New Essays on Dostoyevsky, Cambridge 1983, bes. S. 151f. SeMENova (wie Anm. 1). Dies., Idei neizvestnogo myslitelja v 'Brat'jach Karamazovych', [Vortrag im Dostoevskij-Museum Leningrad, ca. 1981], Ms. [Masch.] $18 \mathrm{Bl}$. Ausfuhrlich, wenn auch kaum unit Bezug auf Dostoevskij, sondern 
sowohl im Roman selbst, vor allem aber in den Entwürfen und Notizen einzelne Motive und Gedanken, die mit Fedorovs Ideen in Verbindung gebracht werden können. Dies gilt vor allem für das zentrale Thema des Vatermordes ${ }^{44}$ sowie für das - freilich auf die Entwürfe beschränkte - Thema der Auferstehung der Vorfahren. Zu letzterem finden sich in Dostoevskijs Notizbüchern Sätze wie:

Die Auferstehung der Vorfahren (voskresenie predkov) hăngt von uns ab.

Die Auferstehung der Vorfahren. Der Gutsbesitzer über Il'inskij: der wird nicht nur nicht auferwekken (voskresit'), sondern zum Teufel schicken (upe'̌et).

Il'inskij ist gegen die Verwandten. (...) Nun, der wird die Verwandten nicht auferwecken (roskresit' $^{45}$. $^{45}$

Diese Formulierungen (es ist stets von voskresenie, voskresit' die Rede), von denen keine in die Endfassung des Romans aufgenommen worden ist, lassen sich freilich eher im Sinne der von Solov'ev gelehrten mystischen Überwindung des Todes durch die Liebe interpretieren, als mit Rückgriff auf Fedorovs Vorstellung einer Auferweckung (voskresenie) mit wissenschaftlich-technischen Mitteln. ${ }^{46}$ Zum Beweis einer Beeinflussung Dostoevskijs durch Fedorov reichen sie jedenfalls nicht aus. ${ }^{47}$

vielmehr "dla kolorytu epoki" werden Fedorov und seine Lehre behandelt von D. KUZA. kowsKA, Dostojewski. Antynomie humanizmu wedrug 'Braci Karamazowbw'. Wrootaw 1987, S. 249-257.

44 Wahrend beispielsweise Mocul'skij das Thema des Vatermordes mit dem Einfluß Fedorovs in Zusammenhang bringt (K. MoCUr'sKU, Dostoevskij, Paris 1947, S. 466-468), glaubt Tschižewskij beweisen zu kőnnen, "daß dieses Sujet sehr stark mit Schillers 'Răubern' zusammenhăngt" (ČYŽEv śkY] [TschiŽEwSKU], "Schiller...", wie Anm. 43, S. 14. Vgl. auch H. LYNGSTAD, Dostoevskij and Schiller, The Hague, Paris 1975, S. 66f.). - Biographische Motive, auf die sich noch Freud in seiner berühmten Studie stützte, haben sich inzwischen als unhaltbar enwiesen. Siehe E. KRAG, "Zur Frage von Dostojevskijs Vater und dem Vatermorde in den Brüdern Karamazov." In: Studi in onore di Ettore Lo Gatto e Giovanni Maver, Roma 1962, S. 361-367.

45 Dostroevsku (wie Anm. 5), t. 15, L. 1976, S. 204, 203, 208; Hervorhebung im Orig.

46 Auch alle anderen im Zusammenhang mit Dostoevskij genannten 'Fedorovschen Themen' (Überwindung der Vereinzelung und freie allmenschliche Einigung im gemeinsamen Werk, Erløsung und Umgestaltung der Welt, Gottmenschentum) finden sich - so allgemein formulier - auch bei Solov'ev, der im Gegensatz zu Fedorov mit Dostoevskij personlich bekannt und freundschaftlich verbunden war (gemeinsam hatten sie im Juni 1878 das Optina-Kloster besucht). Davon zeugen nicht zuletzt Solov'evs berühmte Tri reci v pamjat' Dostoevskogo (18811883). Vgl. dazu G. CHETSO [KJETSAA], "Neopublikovannaja rec' Vladimira Solov'eva o Fedore Dostoevskom." In: Scando-Slavica, 31, 1985, S. 109-116. T. MADJARODY, "Tri rełi v pamjat' Dostoevskogo' V1. Solov'eva." In: Slavica, 21, 1984, S. 229-245. Solov'evs EinfluB auf das Spătwerk Dostoevskijs müBte freilich noch genauer untersucht werden. Siehe DosToEvSKu (wie Anm. 5), t. 15, L. 1976, S. 471-473.

$47 \mathrm{Zu}$ diesem Ergebnis gelangen unabhăngig voneinander PLETNEV (wie Anm. 1), bes. S. 237, und LINNÉR (wie Anm. 1), bes. S. 202f. Vgl. auch M.T. NAUMANN, "Death in the Brothers Karamazov." In: St. Vadimir's Theological Quarterty, 25 (1981), 3, S. 161: "... at best Fedorov's influence on Dostoevskii's understanding of the resurrection was minimal." - Koehlers Behauptung, bei einigen der von ihr angeführten Formulienungen in Dostoevskijs Entwürfen zu Brat'ja Karama- 
Die geistige Verwandtschaft zwischen Dostoevskij und Fedorov (die bereits von Dostoevskij bemerkt worden war, während Fedorov das Gegensätzliche hervorhob) läßt sich ohne Mühe auf die gemeinsame slavophile Denktradition zurückführen. Dagegen dürfte der Einfluß origineller Ideen Fedorovs - falls überhaupt wirksam - sehr gering gewesen sein. Größer war die Bedeutung, die Dostoevskij für Fedorov erlangen sollte - freilich nicht als Ideengeber, sondern als Vorwand, um die eigene Lehre zu propagieren und zum obščee delo aufzurufen.

Im Sommer des Jahres 1897 veröffentlichte Fedorov Dostoevskijs Brief an Peterson (vom März 1878) zusammen mit einem langen, von ihm selbst verfaßten anonymen Artikel in der Voronežer Zeitung Don. ${ }^{48}$ In diesem offenbar als Einleitung vorgesehenen Artikel schreibt Fedorov, er sei "zufällig an einen Brief Dostoevskijs gelangt, der sehr wichtig für die Charakterisierung seiner religiösen Überzeugung" sei, und fährt - sich selbst verleugnend - fort:

In diesem Brief ist die Rede von irgendeinem unbekannten Denker, von denen es heutzutage so viele in RuBland gibt, die uns aber nicht weiter interessieren. Wichtig für uns ist der Gedanke von Fedor Michajloviz [Dostoevskij] selbst, ein Gedanke von wundervoller Erhabenheit, - dieser Gedanke gibt dem menschlichen Leben einen Sinn und ein Ziel und damit das, was gerade unsere Zeit braucht, da durch den Verlust von Sinn und Ziel das Leben allen Wert verloren hat. ${ }^{49}$

Fedorov scheut sich nicht, sein eigenes Projekt Dostoevskij zuzuschreiben, indem er dessen Worte aus dem Zusammenhang reißt und ihren Sinn verdreht:

Dostoevskij sagt in seinem Brief, daB "das Wesentlichste die Pflicht der Auferstehung der Vorfahren, die früher gelebt haben," sei; d.h. unsere Pflicht, unsere Schuldigkeit, unsere Aufgabe besteht folglich in der Auferweckung von allem, was verstorben ist, was verlorengegangen ist durch uns als Söhne, als Nachkommen unserer Vater und Vorfahren. ${ }^{30}$

Unter dem Vorwand, die Ausführungen Dostoevskijs zu kommentieren und zu interpretieren, legt Fedorov dann seine eigene Lehre von der Pflicht zur Auferweckung aller Verstorbenen, zur Beherrschung und Verwandlung der Natur und zur Besiedlung des Weltalls dar, wobei er, an einzelne Äußerungen Dostoevskijs anknüpfend, immer wieder versichert, es handle sich um Gedanken Dostoevskijs beziehungsweise um die einzig möglichen Schlußfolgerungen aus ihnen. Dabei entfernt er sich rasch vom Wortlaut des Briefes - aus "dolg voskresenija" wird alsbald "dolg voskrěenija" -, so daß Dostoevskij schließlich zum bloßen Sprachrohr Fedorovs wird.

zovy handele es sich um "direct quotations from Fedorov" (KOEHLER, "Renan...", wie Anm. 1, S. 370), låBt sich in keinem Falle belegen!

48 Don, No. 80, 1897; die Zeitung war unzugănglich. - Im folgenden zitiert nach FEDOROV (wie Anm. 30), S. 24-31. Wieder abgedruckt in: Sever, 1989, 2, S. 115-118. - Siehe auch Young (wie Anm. 1), S. 47-49. - Die Veroffentlichung geschah mit Hilfe Petersons, der von 1894 bis 1899 am Stadtgericht von Voronež tătig war und in dieser Zeit anonyme Artikel Fedorovs in der Lokalzeitung Don unterbrachte.

FEDOROV (wie Anm. 30), S. 24.

Ebd.; Hervorhebung im Orig. 
$\mathrm{DaB}$ es sich bei diesem Verfahren keineswegs um einen Ausdruck extremer Bescheidenheit handelt, ${ }^{51}$ sondern um geschicktes Kalkül, geht aus einem unveröffentlichten Brief Fedorovs an Koževnikov vom 19. August 1897 hervor. ${ }^{52}$ Fedorov bedankt sich, daß Koževnikov ihm Dostoevskijs Brief nach fast zwanzig Jahren wieder zugänglich gemacht habe, und fährt fort: "Als ich ... den Brief Dostoevskijs sah, da entschied ich sofort, Dostoevskij zum Verkünder der großen Pflicht zu machen (sdelat' Dostoevskogo provozvestnikom velikogo dolga)." Die einleitenden ironischen Bemerkungen über den "unbekannten Denker" stammten, so Fedorov weiter, ausschließlich von ihm, doch müsse man jenen Denker "zum Nutzen der Sache" hinter Dostoevskij zurückstellen.

Fedorov bediente sich der Autorität Dostoevskijs, um seine eigenen Ideen zu propagieren, obwohl er wußte, daß Dostoevskij sie niemals geteilt hatte. Zur gleichen Zeit, da Fedorov Dostoevskij zum "Verkünder der großen Pflicht" machte, warf er ihm an anderer Stelle vor, "nirgends und niemanden zu ihrer Erfüllung aufgerufen" zu haben; ja er habe "wahrscheinlich gar nicht ernsthaft daran gedacht, da er ... mit Solov'ev der Ansicht" gewesen sei, die Auferstehung werde von selbst, ohne menschliches Zutun "in 25000 Jahren erfolgen. ${ }^{53}$

51 Wie z.B. Koehler vermutet: "How very much like Fedorov to conceal the true originator of the 'stunning idea' and to pass it off as a creation of Dostoevsky's! In this way he practiced the outmost modesty..." KOEHLER, Fedorov (wie Anm. 1), S. 50.

52 N.F. Fedorov an V.A. Koževnikov, 19.8.1897; Peterson-Archiv, GBL f. 657, k. 4, ed. chr. 6; nach einer Abschrift in Moskauer Privatbesitz.

FOD I, S. 441. 


\section{VON DER JAHRHUNDERTWENDE BIS ZUR OKTOBERREVOLUTION}

\subsection{Zwischen Fortschrittsglauben und Endzeiterwartung - Das Problem des Todes im russischen Denken um die Jahrhundertwende}

\subsubsection{Das Problem des Todes im idealistischen und religiösen Denken}

Gegen Ende des 19. Jahrhunderts erlebte Rußland einen ökonomischen und industriellen Aufschwung, der verbunden war mit tiefgreifenden politischen und sozialen Veränderungen; gleichzeitig brach eine Periode geistig-kultureller Blüte an - das 'Silberne Zeitalter' der russischen Kunst und Kultur. ${ }^{1}$ In dieser Zeit vollzog sich in weiten Kreisen der Intelligenz eine weltanschauliche Neuorientierung, eine 'geistige Renaissance' (duchovnyj renessans oder duchovnoe vozroždenie), ${ }^{2}$ die gekennzeichnet war durch eine Abkehr von den bis dahin vorherrschenden materialistisch-deterministischen, positivistischen und utilitaristischen Denkrichtungen und eine Hinwendung zu verschiedenen Formen des philosophischen Idealismus sowie ein - zumeist als 'religiöses Suchen' (religioznoe iskanie) bezeichnetes - neues Interesse an Fragen der Religion und Metaphysik. ${ }^{3}$ Dieses Interesse äußerte sich etwa in den Religiös-Philosophischen Versammlungen und Vereinigungen, die zwischen der Jahrhundertwende und dem Beginn des Ersten Weltkriegs in Petersburg und Moskau Vertreter der In-

1 Die Literatur ist nahezu unübersehbar. 'Klassisch' die essayistische Darstellung der geistigen Strömungen dieser Epoche von N.[A.] BERDJAEV, Russkaja ideja. (Osnovnye problemy russkoj mysli XIX veka i nacala XX veka). Paris 1946, S. 220-248. Vgl. auch DERS., Samopoznanie. Opyt filosofskoj avobiografii. Paris ${ }^{2} 1983$, Kap. 6. Unter den neueren Arbeiten sei besonders hervorgehoben M. DEPPERMANN, "RuBland um 1900: Reichtum und Krise einer Epoche im Umbruch." In: Musik-Konzepte, 37/38, München 1984, S. 61-106.

2 Zum Begriff 'geistige Renaissance' siehe J. SCHERRER, Die Petersburger Religiös-Philosophischen Vereinigungen. Die Entwicklung des religiösen Selbstverständnisses ihrer Intelligencija-Mitglieder (1901-1917). Berlin, Wiesbaden 1973, S. 12.

3 Vgl. N. ZERNOV, The Russian Religious Renaissance of the Twentieth Century, London 1963. P.C. BORI, P. BETTTOLO, Movimenti religiosi in Russia prima della rivoluzione (1900-1917). Brescia 1978. G.F. PUTNAM, Russian Altematives to Maxaism. Christian Socialism and Idealistic Liberalism in Twentieth Century Russia. Knoxville 1977. SCHERRER (wie Anm. 2). - Knappe und prägnante Darstellungen der idealistischen Stromungen um die Jahrhundertwende auch bei $L$. KolAKowsKI, Die Hauptströmungen des Manaismus, Bd. 2, München, Zürich 1978, S. 469-474. H. DAнM, Grundzüge russischen Denkens. Persönlichkeiten und Zeugnisse des 19. und 20. Jahrhunderts. München 1979, S. S0-57. - Aus sowjetmaxistischer Sicht: M.I. SACHNOVIC, Lenin i problemy aseizma. Kritika religii v trudach V.I. Lenina. M.-L. 1961. E.F. GREKULOv, Cerkov', samoderzavie, nanod (2-ja polovina XIX - natala XX v.), M. 1969. E.S. LUKASEVSKU, "Osnovnye napravlenija v russkom bogoiskatel'stve v načale XX v." In: Aleizm, religija, sovremennost', L. 1973, S. 47-66. M.P. LASKovaJA, Bogoiskatel'stuo i bogostroirel'stro prezde i teper', M. ${ }^{2}$ 1976. N.S. SEMENKIN, Filosofija bogoiskatel'stva. Kritika religiozno-filosofskich idej sofiologov. M. 1986. 
telligenz und der orthodoxen Geistlichkeit zusammenführten, ${ }^{4}$ im Entstehen christlicher Gruppen und Bewegungen, deren sozialpolitisches Engagement einem 'neuen religiösen Bewußtsein' (novoe religioznoe soznanie) entsprang, ${ }^{5}$ sowie in der Entdeckung der bis dahin fremden Welt der Sektierer und Altgläubigen, deren endzeitlich gefärbte Religiosität einer weit verbreiteten apokalyptischen Stimmung entgegenkam, der Erwartung einer nahen Katastrophe, eines erlösenden Umbruchs und einer Erneuerung von kosmischem Ausmaß ${ }^{6}$

So verschieden die Ursachen für diesen geistigen Wandel waren und so vielfältig seine Äußerungen, allgemein war die Absage an Materialismus, Positivismus und Determinismus sowie die damit verbundene Vorstellung eines unaufhaltsamen, rein innerweltlichen Fortschritts der Menschheit. Anknüpfend an die Fortschrittskritik des 19. Jahrhunderts, ging man daran, die Aporien dieses Denkens aufzuzeigen, und nichts war dazu besser geeignet als der Hinweis auf die Hinfälligkeit des menschlichen Individuums und die sich daraus ergebende Frage nach Sinn und Zweck seines Daseins in der Geschichte. Das Problem des Leidens und des Todes und die Frage nach dem letzten Sinn und Ziel des Lebens wurden zentrale Themen in Dichtung, Kunst und Philosophie. ${ }^{7}$ Namhafte

4 Ausführlich beschrieben von SCHERRER (wie Anm. 2). Vgl. ferner P. SCHEIBERT, "Die Petersburger religios-philosophischen Zusammenkünfte von 1902 und 1903." In: JfGO, NF 12 (1964), 4, S. 513-560. Putnam (wie Anm. 3), Kap. 3 (S. 56-92).

5 Über die sozialrevolutionăren Elemente im 'neuen religiðsen Bewußtsein' siehe insbes. J. SCriERRER, "Pour une théologie de la révolution." In: Archives de Sciences sociales des Religions, 45 (1978), 1, S. 27-50. Aus marxist ischer Sicht I.P. CUEVA, Genezis i filosofskie osnovy 'novogo religioznogo soznanija', Diss. doktora filos. nauk, Leningrad 1971, [Masch.]. - Hierzu gehörten die 'Christliche Bruderschaft des Kampfes' (Christianskoe bratstwo bor'by) und die Bewegung des sog. 'Golgatha-Christentums' (golgofskoe christianstwo). Ausführlich dazu unten und II: 2.3.1.

6 Siehe auch II: 2.3 .1$.

7 In seiner Aufsatzsammlung $O$ pricinach upadka i o noyych tecenijach sorremennoj nusskoj literatury, deren Veroffentlichung 1893 mit dem Beginn der 'geistigen Renaissance' zusammenfällt, bemerkte D.S. Merežkovskij, daß metaphysische Fragen über die Unendlichkeit, über den Tod und über Gott, die von den Positivisten bislang unterdrückt worden seien, die unruhevolle Sehnsucht der "neuen Menschen" kennzeichneten. D.S. MEREŽKovSKU, PSS, t. 18, M. 1914, S. 264f. Und gegen Ende dieser Epoche konstatiente Fedor Sologub, in dessen Werk das Todesthema (als Todessehnsucht) an zentraler Stelle steht: "Die Frage nach dem Tod zieht viele zeitgenossische Dichter mit der gleichen unwiderstehlichen Macht an, wie die Frage nach dem Sinn des Lebens." F. SOLOGUB [TETERNIKOV], "Iskusstvo nałich dnej." In: Russkaja Mysl', 36, 1915, 12, S. 57.

Das Problem des Todes wurde in der Literatur auf vielfaltige Weise behandelt: So erschien der Tod einmal als unbegreifliches Schrecknis, als 'Nihilist', der das Leben vergiftet und sinnlos macht (so etwa bei N.M. MINSKU [VILENKIN], Religija buduszego, SPb. 1905, und V.P. Svencickij, siehe unten Anm. 34), ein andermal als Befreier aus einem bedrückenden oder langweiligen irdischen Dasein (so etwa bei G.I. Culkov und F. Sologub) oder als schreckliche, aber unumgängliche Notwendigkeit, die es gefaßt hinzunehmen gilt (so etwa bei SA. ANDREEVSKU, Kniga o smerti, verfaßt zwischen 1891 und 1910, postum veroffentlicht Reval, Berlin 1922; ein wenig bekanntes Werk, das wahrscheinlich unter dem EinfluB Schopenhauers entstanden ist; oder in dem Beitrag von I.E. REPIN, "Smert" in dem gleichnamigen Almanach, SPb. 1910, S. 265-267). Effektvoll-oberflăchlich, oftmals in Verbindung mit Motiven der Sexualităt und Grausamkeit, 
Denker - darunter die ehemaligen 'kritischen Marxisten' N.A. Berdjaev, P.B. Struve und S.N. Bulgakov, die um die Jahrhundertwende unter dem EinfluB Kants "vom Marxismus zum Idealismus" 8 konvertiert waren, sowie religiöse Schriftsteller und Philosophen wie V.P. Svencickij und V.F. Ėrn - kritisierten die Vorstellung eines innerweltlichen Reiches vollkommener Glückseligkeit als immanentes Ziel der Geschichte, indem sie dem Fortschrittsbegriff einer monistisch-deterministischen Geschichtsteleologie, der sich auf eine abstrakte Menschheit bezieht, das Schicksal des einzelnen, die Frage nach seiner Freiheit und Gleichheit, nach dem Sinn des historischen Leidens und den 'Opfern der Geschichte' und - all dem zugrundeliegend - das Problem des Todes entgegenhielten. ${ }^{9}$

findet sich das Motiv des Todes hăufig in den Werken seinerzeit erfolgreicher Schriftsteller wie M.P. Arcybasev und L.N. Andreev. Vgl. dazu M. MoROzov, Pred licom smerii. Iz sovremennych mistiteskich i érotiteskich iskanij. SPb. 1908, bes. S. 37-54. V.G. MALACHIEVA-MIROviC. "O smerti v russkoj poezii. In: Zavery, 1912, 7,3, S. 98-108. A.M. RED'Ko, "Problema smerti i duŠepereselenija (1909-1910)." In: DERS., Literatumo-chudožestvennye iskanija v konce XIX nacala XX v.v., L. 1924, S. 187-198. Der Literaturwissenschaftler Mirskij unterscheidet zwischen einer metahistorischen, ontologischen Behandlung des Todesthemas (etwa bei Tolstoj) und einer historischen, aus dem Vorgefühl des drohenden Untergangs einer Kultur erwachsenden; letztere sei kennzeichnend gewesen für die russische Literatur zwischen 1894 und 1917. (D.[P.] SVJATOPOLK-MIRSKU, "Vejanie smerti v predrevoljucionnoj literature." In: Versty, 2, 1927, S. 247-253). Siehe ferner P. BRANG, "Zur Todesmotivik in der russischen Moderne." In: Schweizerische Beirnäge zum VIII. Intemationalen Slavistenkongreß in Zagreb und Ljubljana 1978, Bern 1978, S. 23-58. Zur Geschichte des Todesmotivs in der Kunst in Verbindung mit Sexualităt und Grausamkeit siehe auch das grundlegende Werk von M. PrAZ, Liebe, Tod und Teufel, München 1963. - Rückblickend läßt sich über die Zeit um die Jahrhundertwende feststellen: There does not seem to have been any period in Russian thought when death had such a strong hold

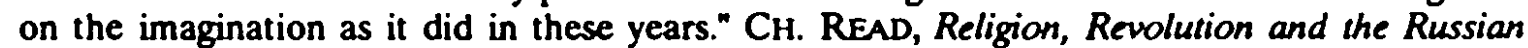
Intelligentsia 1900-1912, London 1979, S. 32.

8 Or marksizma $k$ idealizmu lautete der Titel eines 1903 erschienenen Sammelbandes von S.N. Bulgakov, der einer ganzen Bewegung den Namen gab. Ihre Anhănger veröffentlichten im selben Jahr den Sammelband Problemy idealizma, M. 0.J. [1903]; dazu eine maxxistische Kritik von N.A. RozKov, "Znatenie i sud'by novejక̌̉ego idealizma v Rossii." In: Voprosy Filosofii $i$ Psichologii, 14 (1903), 2 (67), S. 314-332. - Uber die (gescheiterten) Versuche von Berdjaev, Struve und Bulgakov, den klassischen Marxismus in enger Anlehnung an Kant ethisch zu begründen bzw. zu 'ergănzen', siehe L. KLINE, Theoretische Ethik im russischen Frühmanxismus." In: Forschungen zur Osteuropäischen Geschichte, Bd. 9, Berlin, Wiesbaden 1963, S. 269-274.

9 Hierzu die beachtliche Arbeit aus maxistischer Sicht: L. TUREK, Kultura i rewolucja. Wroctaw u.a. 1973; bes. S. 195-207 ("Liberalno-burziuazyjna i konsenwatywno-neostowianofilska krytyka etycznych aspektów posytywistycznej doktryny postępu").

Die ethisch motivierte, sich am Ideal einer allumfassenden ErIosung (vseobšce spasenie) orientierende Kritik an Geschichtskonzeptionen, die uber dem Fortschreiten einer abstrakten Menschheit (oder des absoluten Geistes) das Schicksal des einzelnen vergessen, hat im russischen Denken eine weit zurückreichende Tradition. Bereits Belinskij hatte - in einem oft zitierten Brief - gegen Hegel erklărt, das Schicksal des Individuums sei "wichtiger als das Schicksal der ganzen Welt"; falls es ihm gelănge, "die höchste Stufe der Entwicklungsleiter zu erklimmen", so werde er für alle dieser Entwicklung zum Opfer Gebrachten Rechenschaft fordern, und falls er dann über das Schicksal auch nur eines seiner Brüder nicht beruhigt werden könne, so wolle er sich "kopfüber von dieser hochsten Stufe hinabstürzen". "Man sagt", so Belinskij weiter, "Disharmonie sei eine Bedingung für Harmonie; mag sein, daB das sehr vorteilhaft und erfreulich ist für Melomanen, doch keinesfalls für jene, denen es beschieden ist, durch ihr Schicksal đie Idee der Disharmonie zu verkorpern." Denn, so fragt er, "... was habe ich davon, 
Für S.N. Bulgakov (1871-1944) ${ }^{10}$ war die Vorstellung von einem Geschichtsverlauf, der sich kontinuierlich mit objektiver Notwendigkeit und immanenter Gesetzmäßigkeit auf einen vollkommenen Endzustand zubewegt, nur scheinbar wissenschaftlich begründet; in Wirklichkeit, so Bulgakov, handele es sich dabei um den "alten chiliastischen Glauben an den Anbruch des irdischen Paradieses", der nun gänzlich ins Diesseitige gewendet worden sei. ${ }^{11}$ Damit entfalle die "Perspektive einer kommenden Auferstehung der Toten". Wenn aber alle vorangegangenen Geschlechter unwiederbringlich vergangen seien, so werde es niemals der ganzen Menschheit, sondern bestenfalls einigen Generationen gelingen, das Ziel des historischen Fortschritts zu erreichen: "... das zweifelhafte Glück, die sozialistische Seligkeit des Zukunftsstaates auf den Gebeinen der hi-

daB ich überzeugt bin, daB die Vernunft triumphieren wird, daB es in Zukunft gut sein wird, wenn das Schicksal mir befohlen hat, Zeuge zu sein des Triumphs des Zufalls, der Unvernunft, der viehischen Grausamkeit? Was habe ich davon, daß es meinen oder deinen Kindern gutgehen wird, wenn es mir schlechtgeht und es nicht meine Schuld ist, daB es mir schlechtgeht?" V.G. BeunSKU, PSS, t. 12, M. 1956, S. 22f.; Brief an V.P. Botkin, 1.3.1841. Für Belinskij wird deshalb die Frage der persönlichen Unsterblichkeit zum "Alpha und Omega der Wahrheit". Ebd., t. 11, M. 1956, S. 552f.; Brief an Botkin, 5.9.1840. - Kritisch dazu L. SEstov [ŠvaRCMAN], Dobro v uěenii gr. Tolstogo i F. Nitse, SPb. 1900, S. V-XVI. Siehe auch V.V. ZEN'KovSKU, Istorija russkoj filosofii, t. 1, Paris 1948, S. 273-276.

Auch Herzen verwarf den Gedanken eines zukünftigen Fortschritts, um dessentwillen der einzelne geopfert werde: Er nannte ihn einen Moloch, der stets zurückweiche, wăhrend er den geschundenen und zum Untergang verurteilten Menschen hohnisch zurufe, nach ihrem Tode werde es auf Erden herrlich sein. Siche A.I. GERCEN, "S togo berega" [1849]. In: DERS., SS v 30i tomach, t. 6, M. 1955; hier S. 34. Der Gedanke wurde wieder aufgegriffen von A.[V.] LUNACARSKU, "Mestanstvo i individualizm." In: Ocenki filosofii kollektivizma, sb. pervyj, SPb. 1909, S. 248.

Fragen nach dem Sinn der Geschichte und der ethischen Rechtfertigung ihres Zieles sind, so der Philosoph L.P. Karsavin, charakteristisch für das russische geschichtsphilosophische Denken des gesamten 19. Jahrhunderts: "Warum sollen wir unser kleines Glück, uns selbst dem Wohl der Zukunftsmenschen aufopfern? Gibt es einen Sinn unseres ethischen Tuns, unserer Anstrengung und Selbsthingabe, wenn wir selbst an dieser dazu problematischen Seligkeit keinen Anteil haben werden, wenn wir unglücklich und lacherlich sterblich sind?" L.P. KARSAVIN, "Der russische geschichtsphilosophische Gedanke." In: Ethos, 1 (1925), 2, S. 267. - Zur russischen Fortschrittskritik im 19. Jahrhundert siehe auch A. WALICKI, "L'idée de progrès dans la pensee russe au XIX ${ }^{\mathrm{e}}$ siecle." In: Rossija-Russia, 1, 1974, S. 41-91; 2, 1975, S. 129-161.

10 Vgl. zu Bulgakov in diesem Zusammenhang: B. WIELENGA, Lenins Weg zur Revolution. Eine Konfrontation mit Sergej Bulgakov und Petr Struve im Interesse einer theologischen Besinnung. München 1971, bes. S. 97-105, 241-247. Eine traditionelle theologische (Gegen-)Position vertritt H.-J. RUPPERT, Die Kosmodizee S.N. Bulgakous als Problem der christlichen Weltanschauung. Theol. Diss. Heidelberg 1977 [Masch.], bes. S. 51, 271-273. Siehe auch SCHERRER (wie Anm. 2), bes. S. 80-83.

11 S.[N.] Burgakov, "Apokaliptika i socializm." [1910] In: DERs., Dva grada. Issledovanija o prirode obšzestvennych idealov. T. 2, M. 1911, S. 116. Vgl. auch DERS., "Osnovnye problemy progressa" [1902]. In: DERS., Ot marksizma $k$ idealizmu. Sb. statej (1896-1903). SPb. 1903, S. $128 f$. DERS., "Voskresenie Christa i sovremennoe soznanie." [1906] In: DERs., Dva grada, a.a.O., S. 168. - Ähnlich auch Berdjaevs Charakterisienung eines Sozialismus, der, wie im Marxismus, weit über die Regulierung okonomischer Verhalltnisse hinausgehend, metaphysische Fragen - nach dem Sinn des Lebens, dem Ziel der Geschichte - mit Hilfe einer innerweltlichen Eschatologie zu beantworten sucht und damit zu einer Ersatzreligion wird. NA. BERDJAEV, Novoe religioznoe soznanie i obšestvennost', SPb. 1907, Kap. 3: "Socializm kak religija", S. 69-101. 
storischen Vorfahren zu genießen und dies zudem mit der Aussicht, jenen auch die eigenen Gebeine hinzufügen zu müssen."12 Im Namen dieses 'zweifelhaften Glücks', so Bulgakov weiter, würden zahllose Opfer gefordert und gebracht.

Die Leiden der einen Generationen sind gleichsam die Brücke zum Glück für die anderen; die einen Generationen müssen aus irgendeinem Grunde leiden, damit die anderen glücklich sind, müssen durch ihr Leiden "die künftige Harmonie düngen", wie es Ivan Karamazov formuliert hat. ${ }^{13}$

Aber, so fragt Bulgakov,

... weshalb muB Ivan sich dem künftigen Glück eines Petr opfern? Hat nicht Ivan als ein menschliches Individuum ... das gleiche Recht auf Glück wie der zukünftige Petr? ${ }^{14}$

Wenn das Ziel einer auf dem Positivismus gegründeten hedonistisch-utilitaristischen Ethik darin besteht, dem einzelnen größtmögliches Glück zu verschaffen, und wenn jeder ursprünglich ein gleiches Recht auf Glück mitbringt, so ist es geradezu widersinnig, von den jetzt Lebenden zu erwarten und zu fordern, daß sie für das Glück künftiger Generationen leiden und sich opfern ohne Aussicht, selbst daran teilhaben zu können. ${ }^{15}$ Falls sie aber dennoch dazu bereit wären, würde dann ihr Opfer das Ziel, um dessentwegen es gebracht wurde, nicht korrumpieren? - denn "... welchen ethischen Wert stellt dieses künftige Glück dar, das erkauft wurde mit fremdem Schweiß und Blut; kann durch irgend etwas ein solcher Preis gerechtfertigt werden? ${ }^{\text {16 }}$ Die Antwort lautet 'nein'; das erreichte

12 Burgakov, "Apokaliptika..." (wie Anm. 11), S. 118.

13 Burgakov, "Osnovnye problemy..." (wie Anm. 11), S. 136.

14 Ebd.

15 "Aus welchem Grunde soll ich meine Person in Schăndung und Tod führen, nur damit die Arbeiter des 32. Jahrhunderts keinen Mangel an Nahrung und Geschlechtsgenüssen leiden?", fragt Sanin, der Held von Arcybasevs gleichnamigem Erfolgsroman (ersch. 1907), und verweigert die Selbstaufopferung im Namen einer fernen Zukunft zugunsten des Genusses in der $\mathrm{Ge}$ genwart. Siehe die aufschluBreiche Deutung von S. NoLDA, 'M.P. Arcybasevs Roman 'Sanin'. Zur Aktualităt eines vergessenen Skandals." In: ZfSlPh, 43 (1983), S. 387-399.

16 Buzgakov, "Osnovnye problemy..." (wie Anm. 11), S. 136. - Für Dostoevskijs Ivan Karamazov ist die künftige Weltharmonie "nicht einmal der Trănen auch nur eines gequălten Kindes wert", weshalb er Gott die "Eintrittskarte zu dieser Weltharmonie" zurückgibt. F.M. DOSTOEVSKu, PSS v 30 $i$ tomach, t. 14, L. 1976, S. 223. Ivans Haltung erinnert an Schopenhauer, auch dieser verwirft die Vorstellung vom Glück spăterer Generationen, das auf dem Leiden der früheren sich gnündet. "Daß Tausende irgendwann und anderswo 'in Wonne lebten, hobe nicht die Todesmarter und Angst eines Einzigen' hier und jetzt auf. Kein 'Glück eines Individuums' kann 'das Leiden eines anderen' kompensieren; kein Obel kann durch seine postumen Folgen gerechtfertigt werden." L. LOTKEHAUS, "Pathodizee und Mitleidsethik." In: H. EBELING, L. LÓT. KEHAUS (Hgg.), Schopenhauer und Maxx Philosophie des Elends - Elend der Philosophie? Konigstein/Ts. 1980, S. 190. Für den in der Tradition von Marx und Schopenhauer stehenden Philosophen Max Horkheimer kønnen deshalb wahres Glück und vollendete Gerechtigkeit "in der Geschichte niemals ganz verwirklicht werden; denn selbst wenn eine bessere Gesellschaft die gegenwartige Unordnung ablost und sich entfaltet haben wird, ist das vergangene Elend nicht gutgemacht..." Die Leiden der verflossenen Geschlechter finden keinen Ausgleich: "Was den Menschen, die untergegangen sind, geschehen ist, heilt keine Zukunft mehr. Sie werden 
Glück und der dafür bezahlte Preis werden sich stets gegenseitig in Frage stellen:

Entweder werden die künftigen Menschen mit einem schärferen Gewissen und einem höher entwikkelten Gefühl allmenschlicher Solidarităt und Liebe sich quălen in dem BewrBtsein, daB ihr Wohlergehen so teuer erkauft wurde - dann werden sie tausendmal trauriger und unglücklicher sein als wir ... oder, im entgegengesetzten Falle, wenn sie alles vergessen und sich selbst alles zuschreiben, so würde dies etwas abstoßend HäBliches sein, vor dem es uns ekelt und übel wird bei dem Gedanken, daß fur die spießige Zufriedenheit und das Wohlergehen dieser Herrschaften ein solcher Preis bezahlt und Märtyrerblut vergossen worden ist. ${ }^{17}$

Im einen Falle würden "unsere Nachfahren Vampire sein, die sich von unserem Blut ernähren," ${ }^{18}$ unwürdig, die Früchte einer qualvollen Geschichte zu genießen, im anderen Falle aber würden sie zum Genuß gar nicht fähig sein.

Die Prognose eines Reiches vollendeter Gerechtigkeit und Glückseligkeit innerhalb der Grenzen der Geschichte erweist sich mithin als Illusion. Sie scheitert letztlich am Faktum des Todes, das für den Positivismus unüberwindbar ist. Der Tod - dieser "schreckliche Nihilist"19 - macht nicht nur das Leben des einzelnen zu "etwas Zeitlichem und Zufälligem" und damit "wert- und sinnlos", 20 sondern zerstört auch die Einheit der Menschheit, indem er sie in Generationen spaltet, ${ }^{21}$ und verhindert damit, daB alle am Fortschritt teilhaben und daB die historischen Opfer und Anstrengungen sinnvoll werden, indem ihre Ergebnisse für die gesamte Menschheit Bedeutung erlangen. ${ }^{22}$

niemals aufgerufen, um in der Ewigkeit beglückt zu werden." M. HORKHEIMER, Kritische Theorie, Frankfurt/M. 1968, S. 374f., 198.

17 Bulgakov, "Voskresenie..." (wie Anm. 11), S. 170.

18 Bulgakov, "Osnownye problemy..." (wie Anm. 11), S. 136. - Spăter spricht Bulgakov in diesem Zusammenhang von "geistigem Kannibalismus" (duchovnyj kannibalizm) der zukünftigen Generationen, die, "nachdem sie das sozialistische irdische Paradies errichtet haben und dabei auf den Schultern der gesamten vorhergehenden Menschheit ruhen, sich ihrer dumpfen Glückseligkeit hingeben werden, indem sie auf egoistische und gotteslästerliche Weise den Wert dieses Paradieses, jene zahllosen Mühen und Opfer, die für seine Errichtung gebracht wurden, vergessen. (...) Dieses Bild eines Festmahls der Nachkommen auf den Gräbern der Vorfahren (pirśestuo potomkov na mogilach predkov) ist abstoßend durch seine Grobheit und seinen Zynismus..." S.[N.] Burgakov, Christianstvo i socializm, M. 1917, S. 20f. Siehe auch II: 2.2.1.

19 S.[N.] BuLgaKov, "Voskresenie Christa i sovremennoe soznanie." In: DERS., Intelligencija i religija, M. 1908, S. 43 (die in Anm. 11 zitierte Fassung dieses Aufsatzes enthălt an dieser Stelle eine abweichende Formulierung).

20 Bulgakov, "Voskresenie..." (wie Anm. 11), S. 170.

21 Ebd. - Für den Positivismus bezeichnet der Begriff 'Menschheit' deshalb nur eine Abstraktion, von der allenfalls metaphorisch gesagt werden kann, daB sie "unsterblich" sei und "făhig zu endloser Vervollkommnung". S.[N.] BurGakov, "Religija relovekobožija u L. Fejerbacha." [1907] In: DERS., Dva grada (wie Anm. 11), t. 1, S. 59. Sinnvoll werden solche Attribute erst unter der Annahme persönlicher Unsterblichkeit. Auf diesen Gedanken kommt Bulgakov im Zusammenhang mit seiner Auseinandersetzung mit Fedorov noch einmal zurück in seinem Spătwerk Nevesta agnca. O bogotelovectestve. C. 3, Paris 1945; dort S. 372f.

22 Burgakov, "Religija..." (wie Anm. 21), S. 61. - Solange der Tod herrscht, kann in der Geschichte von keinem Fortschritt die Rede sein, denn "es gibt niemanden, der fortschreiten 
Den "einzig denkbaren Ausweg aus diesen tragischen Widersprüchen" eröffnet für Bulgakov der auf Christi Auferstehung gegründete Glaube an die künftige Überwindung des Todes und die Auferstehung der ganzen Menschheit. Er allein ermöglicht die Vorstellung von Fortschritt, dessen Ziel freilich jenseits der säkularen Geschichte liegt - doch nur von dorther erhält menschliches Handeln und Leiden Rechtfertigung und Sinn. ${ }^{23}$

In dieser maximalistischen Haltung traf sich Bulgakov mit anderen Denkern seiner Zeit. So sah D.S. Merežkovskij (1866-1941), einer der führenden Vertreter des 'neuen religiösen Bewußtseins', in der Verwirklichung eines 'Paradieses auf Erden', in dem alle leiblichen und geistigen Bedürfnisse des Menschen befriedigt seien, keinen Fortschritt, solange in ihm der Tod herrsche und jede Möglichkeit seiner Überwindung ausgeschlossen bleibe. ${ }^{24}$ Nur in Verbindung mit dem Glauben an eine physische Überwindung des Todes sei, so Merežkovskij, die Vorstellung von einem Fortschreiten der Menschheit überhaupt sinn-

kann", solange es keinen "einheitlichen, ununterbrochenen, keinem zeitlichen Ende unterworfenen Menschen" gibt. Bulgakov, Nevesta agnca (wie Anm. 21), S. $372 f$.

23 Bulgakov, "Voskresenie..." (wie Anm. 11), S. 171. - Eine athnliche Argumentation findet sich bereits in Hermann Lotzes metaphysischer Geschichtsteleologie (H. LOTZE, Mikrokosmos. Ideen zur Naturgeschichte und Geschichte der Menschheit. Bd. 3, Leipzig 1864, bes. S. 49-53): "Der Sinn der Welt" würde "sich in Widersinn verkehren", wenn, so Lotze, "ins Endlose die Arbeit vergehender Geschlechter nur denen zu Gut komme, die ihnen folgen, für sie selbst aber unwiederbringlich verloren gehe" (ebd., S. 50). Es sei deshalb vollig sinnlos, von einem Ziel zu sprechen, dem das Menschengeschlecht in seiner Geschichte zustrebe oder das es erlange, solange nicht geklärt sei, in welcher Weise das Individuum, d.h. jedes Individuum, dieses Zieles für sich selbst habhaft werde. Zwar könne ein jeder auf seinen Anteil an dem verwirklichten Ziel verzichten, doch dürfe niemand solchen Verzicht von anderen fordern. Es gebe nur eine Voraussetzung, unter der alle zur Teilnahme am Fortschritt zu bewegen seien, da ihnen die Teilhabe am Ziel der Menschheitsgeschichte versichert werde - nămlich die Annahme personnlicher Unsterblichkeit. - Lotzes Werk fand in RuBland starke Beachtung; bereits $1866-67$ erschien in Moskau eine Obersetzung des Mikrokosmos.

Die Forderung nach einer Uberwindung des Todes ist seit je fester Bestandteil in der Auseinandersetzung mit innerweltlichen Fortschrittsauffassungen. So behauptet der katholische Theologe Johann Baptist Metz, sảkulare Heilslehren müBten Utopien bleiben, da schlieBlich "kein Glück der Enkel das Leid der Văter" wiedergutmache; einzig der christliche "Gott der Lebenden und der Toten" verheiße mit der Auferweckung aller Verstorbenen Sinn und universale Gerechtigkeit nicht nur den künftigen Geschlechtern, sondern auch den "längst Vergessenen", den "ungesühnten Opfern und Besiegten der Geschichte". J.B. METZ, Glaube in Geschichte und Gesellschaft, Mainz 1977, S. 72-74, 99. Unter ausdrücklicher Berufung auf Lotze verteidigte auch Walter Benjamin in seinen 1940 entstandenen "Geschichtsphilosophischen Thesen" den Glauben an die Unabgeschlossenheit der Vergangenheit und die mogliche Erlosung auch der Toten: Wahres Glück sei nur dort müglich, wo der unfaßliche Gedanke an eine Erlosung, ja Wiederauferstehung all jener, die jemals umgekommen sind, aufrechterhalten bleibe. Siehe W. BENJAMIN, Illuminationen. Ausgewählie Schrifien. Frankfurt/M. 1969, S. 268 271.

24 D.S. MEREZKKovsKu, "O voskresenii." In: Živaja Żizn', 1 (27.11.1907), S. 3. 
voll, ${ }^{25}$ denn "... kein unkörperlicher Idealismus kann den Realismus des körperlichen Todes überwinden. ${ }^{\text {26 }}$

Auch N.A. Berdjaev (1874-1948), der sich, ebenso wie Bulgakov, um die Jahrhundertwende vom Marxismus abgewandt hatte, ${ }^{27}$ verwarf eine final-utopische Sinngebung der Geschichte: Es sei keine Lösung für die Qual und Tragödie aller vergangenen Geschlechter, wenn eine Generation Auserwählter in einer unbekannten Zukunft höchste Lebensfülle und Seligkeit erlange. Es hieße das auf der "Gleichheit absolut aller Menschen" beruhende Recht der jetzt Lebenden wie auch der bereits Verstorbenen mißachten, würden diese zum bloßen Mittel und Werkzeug (sredstvo) für jene. ${ }^{28}$ Das Ziel der Geschichte, die künftige Gesellschaft, der "vollkommene und gute Zustand, zu dem der Fortschritt führt," sei in Wahrheit ein "Ungeheuer, das das Blut der vergangenen und gegenwärtig lebenden Geschlechter trinkt". ${ }^{29}$ Der Irrtum der "Religion des Sozialismus und des Fortschritts" besteht für Berdjaev darin, Gerechtigkeit im Diesseits herbeiführen zu wollen, ${ }^{30}$ doch lasse sich Gerechtigkeit niemals in der Zeit verwirklichen, da alles Glück künftiger Generationen das geschehene Unrecht und Leid nicht wiedergutzumachen und moralisch zu rechtfertigen vermöge. ${ }^{31}$ Wahrer Fortschritt ziele nicht auf das beste, sondern auf das absolute Leben, bedeute Überwindung der Zeit und damit des Kreislaufs von Leben und Tod; wahre Gerechtigkeit könne somit "nicht positivistisch, sondern nur religiös verwirklicht werden ${ }^{\text {32 }}$ durch eine die Geschichte transzendierende Revolution zugunsten aller, auch der Toten. ${ }^{33}$

25 Für Merezkkovskij stützt sich der Glaube an die Moglichkeit einer Obenwindung des Todes allein auf das einmalige Ereignis der physischen Auferstehung Christi. Wird dieses Ereignis geleugnet, so ist die Welt ein Chaos, das menschliche Leben sinnlos (ebd., S. 4-8). Den gleichen Gedanken entwickelt Merezkovskij im ersten Kapitel ("Mex") seines Buches Ne mir, no med (1908); siehe MEREZKovskU (wie Anm. 7), t. 13, M. 1914, S. 5-35. Siehe auch J.P. SCANLAN, The New Religious Consciousness: Merezhkovsky and Berdyaev, Aix-en-Provence 1968, [Masch.] bes. S. 7.

26 MEREZKovsKu (wie Anm. 25), S. 21.

27 Vorausgegangen war dieser Abwendung der an Kant orientierte Versuch, den marxistischen Begriff 'sozialer Gerechtigkeit' und das zu seiner Verwirklichung dienende Handeln ethisch zu begründen. Siehe dazu A. HAARDT, "Marxismus und Ethik im Frühwerk Nikolaj Berdjaevs." In: Wiener Slavistischer Almanach, 2, 1978, S. 97-113.

28 Berdjaev (wie Anm. 11), S. 78f. - Zur Kritik an Berdjaev von marxistischer Seite vgl. Moro. zov (wie Anm. 7), S. 12f. LAskovana (wie Anm. 3), S. 43.

29 Berdjaev (wie Anm. 11), S. 77.

30 Ebd., S. 80.

31 Ebd., S. 78. - Auch hier ein Anklang an Schopenhauer (vgl. oben Anm. 16), dessen EinfluB auf den jungen Berdjaev belegt ist (BERDJAEv, Samopoznanie, wie Anm. 1, S. 50, 54, 98).

32 BerdjaEV (wie Anm. 11), S. 79.

33 Ausfürlich entwickelt Berdjaev seine Kritik an der "Religion des Fortschritts" als einer "Religion des Todes", welche das Problem der Zeit ignoriere und damit die Opfer der Geschichte der ewigen Verdammnis preisgebe, in seinem Werk Smysl istorii, Berlin 1923, S. 222-248 (Kap. 
Auch der religiöse Schriftsteller und Publizist V.P. Svencickij (1879-1931) ${ }^{34}$ wandte sich gegen die Vorstellung, künftige Generationen könnten oder dürften ein besseres Leben genießen im Bewußtsein der dafür gebrachten Opfer. Den "künftigen Menschen" rief Svencickij zu:

Ich kann nicht zulassen, daß Ihr leichten Herzens, so als ob nichts geschehen ware, Eure Freiheit genieBt, wenn Euch bekannt ist, daB diese Freiheit erkauft wurde um den Preis von Foltern, Scheiterhaufen, Kriegen und Blutgerüsten. Vergiftet nicht der Gedanke, daß ein jedes Eurer Hăuser auf einem menschlichen Leichnam erbaut ist, Euer seelisches Wohlbefinden? Kann Euer Schlaf ruhig sein, wenn Ihr wiBt, daB diese Ruhe erkauft wurde durch lange schlaflose Năchte Euch unbekannter

10: "Urenie o progresse i konec istorii"). - Ein Jahr zuvor hatte Karsavin geschrieben: Für den Positivismus "ist der Fortschritt ein künftiger Zustand, der den gegenwărtigen ablost, wobei das Gegenwărtige für immer und unwiederbringlich untergeht, wie auch das Vergangene fur immer untergegangen ist. Für den ... Positivismus ist die Gegenwart nur eine Stufe, ein Mittel zu einer besseren Zukunft und besitzt an sich keinen Wert." Dagegen ist der "christliche Idealzustand" die "Verwandlung und Rettung alles Seienden, auch dessen, was offensichtlich, empirisch untergegangen ist. Die Aufgabe der [christlichen] Kultur besteht im Sieg über das Vergessen und die Zeit, über die Vergangenheit und Zukunft, über den Tod." L.P. KARSA vin, Vostok, Zapad $i$ russkaja ideja, Pb. 1922, S. 36f.

34 Valentin Pavlovit Svencickij (der im Rahmen dieser Arbeit noch mehrmals genannt wird; unten und bes. II: 2.3.1.) wurde 1879 in Kazan' geboren. Nach dem Besuch des 1. Moskauer Gymnasiums studierte er an der Philologischen Fakultăt in Moskau und an der Juristischen Fakultăt in Petersburg. Zwischen der Jahrhundertwende und dem Beginn des Ersten Weltkriegs war Svencickij eine bekannte, wenn auch sehr umstrittene Figur in den Kreisen der religiosen Intelligenz, wo er durch die Radikalităt seiner Anschauungen, seinen Fanatismus und sein oftmals exzentrisches Benehmen auffiel - Zinaida Hippius verglich ihn mit Savonarola, Bełyj und Zen'kovskij nannten ihn hysterisch. Z. [N.] GIPPIUs, Literatumyj dnemik (1899-1907), SPb. 1908, S. 359. A. BELY], "Vospominanija o A.A. Bloke." In: Epopeja, 2, 1922, S. 239. V.V. ZEN'KovSKU, "Iz vospominanij." In: Vestnik $R C h D, 139,1983, S$. 120. Von Jugend an beschăftigte sich Svencickij mit dem Problem des Todes und der Unsterblichkeit, das er immer wieder in seinen Schriften behandelte; so schildert er in seinem Roman Antichrist. Zapiski strannogo celoveka (SPb. 1907, 21908), der offenbar autobiographische Züge trăgt, einen Menschen, der von stăndiger Todesfurcht gequâlt wird (ebd., S. 9-18). Mirskij nannte dieses "totgeschwiegene Buch" "eines der bezeichnendsten Dokumente jener Zeit", ein "Denkmal von erstrangiger Bedeutung für die Charakterisierung der 'religios-philosophischen Bewegung'." SVJATOPOLK-MIRSKU (wie Anm. 7), S. 252. Das Thema des Todes steht im Mittelpunkt auch von Svencickijs Drama Smert' (1910), das in vielem an Ibsens "Wenn wir Toten erwachen" erinnert. Um 1912/13 gehorte Svencickij einem Kreis religioser Intellektueller an, die sich auch mit Fedorows Ideen beschăftigten. 1917 wurde er zum Priester geweiht und lebte in den zwanziger Jahren von seiner Gemeinde verehrt in Moskau. Wiederholt verhaftet und verbannt, starb Svencickij am 20.10. 1931 in Sibirien; sein Grab auf dem Moskauer Vvedenskij-Friedhof wird noch heute von seinen Anhăngem besucht und gepflegt.

Erst in jüngster Zeit wurde Năheres über Svencickijs Leben bekannt; siehe insbes. AA. SoLo. DOVNIKOV [?], "Sokroviša Vvedenskich gor." In: Nadezda, vyp. 9, Frankfurt/M. 1983, S. 219222. N. SVENCICKANA, "Otec Valentin." Ebd., vyp. 10, 1984, S. 183-220. V.P. SVENTICKU [sic], "Predsmertnye pis'ma." In: Minuvsee. Istoriceskij al'manach. 1, Paris 1986, S. 294-298. Vgl. ferner die Erinnerungen seines Schulkameraden, des spăteren Sekretărs der Partei der Sozialrevolutionăre M.V. Vissuak, Dan' proslomu, New York 1954, S. 29-32, 98f., 166-170, der auch Svencickijs asketische, an Fedorov erinnernde Lebensweise beschreibt; ferner die Erinnenungen von A. BELYJ, Nacalo veka, M.-L. 1933, bes. S. 270-275, die Erinnerungen von S.I. FUDEL', "U sten cerkvi." In: Nadezda, vyp. 2, 1979, S. 231, 233f., 317, 326, 332f. (Predigten Svencickijs aus dem Jahre 1926: ebd., S. 105-178), und die Erinnerungen von V. ALEKSEEV, "Moskovskie propovedniki." In: Novyj Zumal, 121, 1975, S. 208f. Zahlreiche Angaben auch bei SCHERRER (wie Anm. 2), s.v. 'Svencickij'. 
Menschen? Konnt Ihr Euch an einem opulenten Mahl erfreuen, wenn dafür Menschen erschossen und gehenkt werden? Könnt Ihr Euch von allen Leiden distanzieren, wenn Ihr von den Leiden der Millionen wiBt, die sich abgeplagt haben, indem sie Euer Leben schufen? ${ }^{35}$

Für Ivan Karamazov war bereits eine einzige Träne eines unschuldig leidenden Kindes ein zu hoher Preis für künftiges Glück; die gegenwärtige Zivilisation, so Svencickij, beruhe indessen auf einem "Meer von Tränen". ${ }^{36}$ Es hieße, den Menschen zum Mittel zu machen, würde man Leiden und Opfer als notwendigen Preis für den Fortschritt akzeptieren und somit historisch rechtfertigen. ${ }^{37}$ Vor der Amoralität einer solchen Geschichts- und Weltauffassung, die diese - schlechte - Welt als notwendige Vorstufe einer künftigen besseren akzeptiert und rechtfertigt, wird das menschliche Gewissen allein durch die Idee der Unsterblichkeit bewahrt; doch bedarf dieser Idee auch der menschliche Verstand, soll die Rede von künftiger Glückseligkeit und Freiheit sinnvoll sein, denn "am Rande des Grabes ist Glück nicht möglich und Freiheit nicht im zugenagelten Sarg". ${ }^{38}$

Auch für den zu jener Zeit mit Svencickij eng verbundenen Philosophen V.F. Érn (1882-1917) ${ }^{39}$ sind Zeit und Tod die entscheidenden Hindernisse, die dem Menschen Freiheit und Glückseligkeit verwehren. Wenn sie - wie im Falle des Positivismus und den auf ihm beruhenden innerweltlichen Fortschrittskonzeptionen - als grundsätzlich unüberwindbare Gegebenheiten angesehen werden, so ist es unsinnig, den Gedanken an eine Befreiung der Menschheit überhaupt zu verkünden, denn "Freiheit und Tod sind absolut unvereinbar, ... der Tod ist die höchste Form der Knechtschaft" ${ }^{40}$

Von Fortschritt kann keine Rede sein, solange die Geschichte der Menschheit allenfalls auf eine Perfektion des Gegebenen hinausläuft, ohne jemals die Grenzen der empirischen Wirklichkeit, die den Bedingungen von Zeit und Tod unterworfen ist, zu überschreiten:

35 V.[P.] SVEncicku, Pis'ma ko usem, M. 1907, S. 72f. - Das Kapitel trăgt die Oberschrift "Pis'mo V. K budušim ljudjam".

36 V.[P.] SVENCiCKU, "Smert' i bessmertie." In: Svobodnaja sovest', kn. 1, M. 1906, S. 59.

37 Eben dies tue beispielsweise der Terrorist, der einen politischen Mord verübe. Indem er sich selbst dem Wohle anderer opfere, beweise er - wenn auch unwissentlich - die Notwendigkeit der Idee der Unsterblichkeit. V.[P.] SVENCICKU, "Terror i bessmertie." In: Voprosy religii, vyp. 2, M. 1908, S. 3-28.

38 SVENCICKU (wie Anm. 35), S. 76.

39 Vgl. hierzu D. STÅGLKC, Vadimir F. Ėm (1882-1917). Sein philosophisches und publizistisches Werk. Diss. Bonn 1967. A. RovNER, "V.F. Em." In: N.P. POLTORACKU (Hg.), Russkaja religiozno-filosofskaja mysl' XX veka. Sb. statej. Pittsburgh 1975, S. 383-391.

40 V.[F.] ERN, "Socializm i problema svobody." In: Živaja Zizn', 2 (20.12.1907), S. 86. Auch in DERS., Borba za Logos. Opyry filosofskie i kriticeskie. M. 1911, S. 232; im folgenden wird nach beiden Ausgaben zitiert. - Dem Problem des Todes ist das gesamte dritte Kapitel dieses Aufsatzes gewidmet (ebd., S. 68-87 [212-233]). - An anderer Stelle wirft Ern dem Positivismus vor, alles der menschlichen Erkenntnis Zugăngliche dem Gesetz der Kausalităt zu unterwerfen und damit Freiheit prinzipiell unmoglich zu machen (ebd., S. 42 [183f.]). 
Eine positivistische Auffassung, die durch ihre Grundprinzipien gefesselt ist, kann sich die Zukunft der Menschheit, ihren weiteren progressiven Gang nur in jenen Formen vorstellen, in denen er sich bisher vollzogen hat. Die Entwicklungslinie der Menschheit verlăuft [dieser Auffassung zufolge] stets ununterbrochen und wird auch weiter sich fortsetzen; nie wird sie sich in andere Daseinsformen verwandeln, plotzlich abreißen und die Menschheit in andere Dimensionen hinüberführen konnnen. Aus dieser unserer langweiligen, bösen und leidenden Welt, die sich unter dem Joch von Zeit und Tod befindet, gespalten, chaotisch, stets trăge und unfrei, konnen uns keinerlei weitere Phasen des Fortschritts hinausführen. ${ }^{41}$

Je weiter der Fortschritt gelangt, desto klarer treten die unverrückbaren Grenzen dieser Welt hervor, und das unüberwindliche Faktum des Todes wird um so bedrückender, je günstiger sich die Bedingungen des Lebens gestalten. ${ }^{42}$ Selbst der von allen gesellschaftlichen und ökonomischen Abhängigkeiten befreite Mensch wird ein zum Tode Verurteilter bleiben, und das künftige 'Paradies auf Erden' - errichtet auf den Gräbern der Vorfahren - wird nur ein besonders komfortables Gefängnis sein, in dem er auf seine Hinrichtung wartet. ${ }^{43}$

Mag auch der Sozialismus verwirklicht werden, das Reich okonomischer Gerechtigkeit, ja vielleicht allmenschlicher Solidarităt anbrechen, die Welt wird doch immer ein Sarg bleiben, denn immer werden in ihr die Sterbenden faulen; immer wird sie ein Gefängnis bleiben, denn immer werden in ihr in "freier Erwartung" die dem Tode Verfallenen sitzen; worin dieser Zustand besser sein soll als der von Hohlenmenschen, weiß ich nicht; ich weiß nur, daß es für die positivistische Fortschrittsauffassung keine anderen Perspektiven gibt. ${ }^{44}$

Eine ganz andere Perspektive eröffnet dagegen die von Érn entwickelte "Idee des katastrophischen Fortschritts" (ideja katastroficeskogo progressa). ${ }^{45}$ Danach werden natürliche Prozesse, die unter den Bedingungen dieser Welt kausal und kontinuierlich verlaufen, durch das plötzliche Eindringen der jenseitigen, noumenalen Welt in einer rational nicht zu begreifenden Weise unterbrochen, auf eine qualitativ neue, höhere Stufe gehoben und damit dem Absoluten nähergebracht (als Beispiele für solche bereits erfolgten sprunghaften Veränderungen, die sich rational nicht erklären lassen, nennt Érn u.a. die Entstehung der Welt, das Erscheinen des Organischen, des Bewußtseins und des Selbstbe-

41 V.[F.] ERN, "Ideja katastrofizeskogo progressa." In: Russkaja Mysl', 30 (1909), 10, S. 157. Auch in DERS., Borba (wie Anm. 40), S. 258.

42 ERN (wie Anm. 40), S. 78f., 84 [223-225, 230]. - Dieser Gedanke kehrt wieder bei Ernst Bloch, der über die "befreite Menschheit" schreibt, daß "... nach abgeschaffter Armut und Lebenssorge sich die Todessorge besonders hart erhebt..." E. BLOCH, Das Prinzip Hoffnung, Bd. 3, Frankfurt/M. 1959, S. 1381. Der Tod ist für Bloch denn auch "die hărteste Gegenutopie". E. BLOCH, Tendenz - Latenz - Utopie, Frankfurt/M. 1978, S. 359.

43 ERn (wie Anm. 41), S. 82f. [228f.].

44 Wie Anm. 41. - Vermutlich geht dieses Bild der Seinslage des Menschen als eines zum Tode Verurteilten, der im Gefángnis auf seine Hinrichtung wartet, auf Pascal (Pensées, III, 199) zurück. 
wußtseins sowie die Geburt des ersten Übermenschen Jesus Christus). ${ }^{46}$ Für die Geschichte der Menschheit bedeutet die Möglichkeit einer künftigen Intervention jenseitiger Art, der Einbruch des Absoluten, daß sie nicht kausal, kontinuierlich und endlos unter den jetzt gegebenen Bedingungen - das heißt auch, unter der Herrschaft von Zeit und Tod - verlaufen, sondern abreißen und sich in anderen Dimensionen fortsetzen wird.

Die menschliche Geschichte, diese unsere Welt muß ihr Ende haben. (...) Der Tag wird kommen, da ... die alte Welt untergehen, ... die Zeit verschwinden und der Tod besiegt werden wird; und aus der Flamme der Verwandlung wird eine neue Erde unter einem neuen Himmel entstehen. ${ }^{4}$

Fortschritt, wie Ėrn ihn versteht, ist die Verwirklichung des Absoluten in der Welt, sein Ziel die consummatio mundi, das Reich Gottes auf Erden, in dem der Tod nicht mehr sein wird.

Diese religiös-eschatologische Geschichtsauffassung mit ihrem ausgeprägten Katastrophenbewußtsein bildete die Grundlage für das sozialpolitische Engagement einer Vereinigung, die unter der Bezeichnung "Christliche Bruderschaft des Kampfes" (Christianskoe bratstvo bor'by) im Februar 1905 von Ėrn, Svencickij und (wahrscheinlich) P.A. Florenskij (1882-1937) - der "Troika der Apokalyptiker", wie Belyj sie nannte ${ }^{48}$ in Moskau gegründet wurde. ${ }^{49} \mathrm{Zu}$ ihren Mitgliedern zählten A.V. El'Caninov (1881-1934) und der Priester I.P. Brichničev

46 ERN (wie Anm. 41), S. 156 [256f.]. - Auch die Theoretiker des Marxismus bezeichnen den plotzlichen Ubergang in einen neuen qualitativen Zustand als 'Sprung' (man denke an Engels' berühmtes Diktum vom "Sprung aus dem Reich der Notwendigkeit in das Reich der Freiheit"), doch gehorchen diese 'Sprünge' den (erkennbaren) 'Gesetzen der Dialektik'.

47 Ebd., S. 158 [259]; in Anlehnung an den Wortlaut der Apokalypse "Und ich sah einen neuen Himmel und eine neue Erde" (Off. 21:1), "Und der Tod wird nicht mehr sein" (Off. 21:4). - Auf den moglicherweise bestehenden Zusammenhang zwischen der von Ern formulierten Annahme einer "Diskontinuităt der Geschichte" (prenyrnost' istonii) und den seinerzeit aktuellen Diskussionen über Kontinuităt und Diskontinuităt von Raum und Zeit (an denen auch Erns Freund Florenskij maßgeblich beteiligt war) kann hier nur hingewiesen werden.

48 BeLY\}, NaCalo (wie Anm. 34), S. 263

49 Siehe das Programm der "Christlichen Bruderschaft des Kampfes": Val.[P.] SVENCICKuJ, 'Christianskoe bratstuo bor'by' $i$ ego programma, M. 1906.

Vgl. SCHERRER (wie Anm. 2), S. 144-152. Dies., "Intelligentsia, religion, révolution: Prèmieres manifestations d'un socialisme chrétien en Russie. (1905-1917)." In: Cahiers du Monde russe et soviérique, 17 (1976), 4, S. 427-466; bes. S. 438-453, 458-466. PuTNAM (wie Anm. 3), S. 58-60, 72-78. StÁguch (wie Anm. 39), S. 10-14, 24f. ROVNER (wie Anm. 39), S. 384-386. Zernov (wie Anm. 3), S. 101-106. VišnjaK (wie Anm. 34), S. 99. SVENTICKIJ (wie Anm. 34), S. 294-296. - Aus sowjetmarxistischer Sicht: N.F. PLATONOv, 'Pravoslavnaja cerkov' v bor'be s revoljucionnym dviženiem v Rossii." In: Ezegodnik Muzeja istonii religii $i$ ateizma, t. 4, M.-L. 1960, S. 132f. SACHNoviC (wie Anm. 3), S. 365-367. GREKulov (wie Anm. 3), S. 95f. M.M. SEJNMAN, Christianskij socializm, M. 1969, S. 130-145; bes. S. 131f. SEMENKIN (wie Anm. 3), S. 165-167. Unlängst wurden sogar Spekulationen über eine Verbindung dieser Gruppe zu dem berühmtberüchtigten Okkultisten Georgij Ivanovið Gjurdžiev (Gurdjieff, 1872[1877?]-1949) angestellt (J. WEBB, The Harmonious Circle. The Lives and Work of G.I. Gurdjieff, P.D. Ouspensky, and Their Followers. London 1980, S. 36); sie entbehren jedoch jeder Grundlage. 
$(1879-1968)^{50}$ und wahrscheinlich auch Bulgakov und Berdjaev. ${ }^{51}$ Entstanden als Reaktion auf die Ereignisse des 9. Januar 1905 und auf die Haltung der offiziellen Kirche dazu, rief die "Christliche Bruderschaft" in ihrem von Svencickij verfaßten Programm zum Kampf gegen die Autokratie (die "gottloseste Erscheinungsform der weltlichen Macht") und die sie stützende Geistlichkeit auf und forderte eine tiefgreifende Erneuerung der Kirche sowie die Lösung der sozialen Probleme unter Anwendung christlicher Prinzipien. ${ }^{52}$ Soziale Gerechtigkeit für alle lasse sich durch das Zusammenwirken der Christen bereits hier und jetzt verwirklichen und nicht erst, "wie dies durch die Arbeiterparteien geschieht", in ferner Zukunft. ${ }^{53}$ "Allgemeines Wohlergehen" (vseobšee blagopolucie) könne es hingegen auf dieser Erde niemals geben", da das unerbittliche Gesetz des Todes herrsche, gegenüber dem auch der Sozialismus machtlos sei. ${ }^{54}$ Doch eröffne das Christentum einen Weg, auf dem im Zusammenwirken mit Gott schließlich auch die Naturgesetze verwandelt, der Tod überwunden und das Reich Gottes herbeigeführt werden könnten. ${ }^{55}$ Durch den Kampf für soziale Gerechtigkeit und eine kirchliche Erneuerung hofften die Anhänger der "Christlichen Bruderschaft" eine Voraussetzung für den Sieg des Guten im apokalyptischen Endkampf gegen die Mächte der Finsternis zu schaffen, von dem sie glaubten, er stehe kurz bevor. ${ }^{56}$ "Die Zeit ist nahen, verkündete Svencickij, "wir treten in die letzte, apokalyptische Periode der Weltgeschichte ein." ${ }^{57}$

Die "Christliche Bruderschaft" bestand nur kurze Zeit, doch wirkten ihre Ideen und Zielsetzungen in anderen religiösen Erneuerungsbewegungen weiter, insbesondere im "freien" oder "sozialen Christentum" (svobodnoe, obšcestvennoe christianstvo) des Archimandriten Michail und im sogenannten "Golgatha-Christentum" (golgofskoe christianstvo), einer religiös-sozialrevolutionären Bewegung, die wahrscheinlich um 1905 in Petersburger Arbeiterkreisen entstanden

so Ober ihn ausfuhrlich unten II: 2.3.1.

51 Siehe SCHERRER (wie Anm. 2), S. 150 .

52 SVENCICKU (wie Anm. 49), S. 9. - Vgl. auch Val.[P.] SVENCICKI, "Christianskoe otnołenie k vlasti i nasiliju." In: Voprosy religii, vyp. 1, M. 1906, S. 5-37 (bes. S. 19f.: gegen Cäsaropapismus; die Anerkennung der zarischen Selbstherrschaft bedeutet Abfall von Christus).

53 SVEncicku (wie Anm. 49), S. 20, Punkt 2. - Voraussetzung dafür ist - in Verwirklichung der christlichen Prinzipien der Liebe und Freiheit - der gemeinsame Besitz an Grund und Boden und an den Produktionsmitteln und damit die Abschaffung der Ausbeutung des Menschen durch den Menschen. Besitzstreben und Egoismus haben die Menschen einander feindlich werden lassen und alle Bereiche des Lebens korrumpiert. Vgl. dazu auch V.F. ERN, "Cerkovnoe vozroždenie." In: Voprosy (wie Anm. 52), S. 102-142; bes. S. 131f. - Die Kritik der "Bruderschaft" an der bürgerlich-kapitalistischen Gesellschaft gleicht bis in Einzelheiten der Fedorovs.

54 Svencicku (wie Anm. 49), S. 20, Punkt 6.

55 Ebd., S. 21, Punkte 7-9.

56 Ebd., S. 20, Punkt 5.

57 Ebd., S. 21, Punkt 10. 
war; 58 für sie war Golgatha "nicht das Symbol einer Religion der Trauer und des Leidens, sondern einer siegreichen Religion der Auferstehung". ${ }^{59}$ An die Spitze dieser Bewegung traten um das Jahr 1910 mit Svencickij und Brichnicev zwei ehemalige Mitglieder der "Christlichen Bruderschaft".

Apokalyptische und chiliastische Stimmungen und Strömungen hatten um die Jahrhundertwende und besonders nach den gesellschaftlichen Erschütterungen des Jahres 1905 sowie in der darauf folgenden Phase der Reaktion weite Kreise der russischen Intelligenz erfaßt. ${ }^{60}$ Dabei wurden die Erscheinungen des politischen, ökonomischen und sozialen Umbruchs, in dem sich Rußland seit Ende des 19. Jahrhunderts befand, in religiösen Kategorien interpretiert - als Vorzeichen des nahenden Untergangs der alten, vertrauten (oder verhaßten) Welt und des Anbruchs einer neuen, besseren Ordnung, eines 'Gottesreichs auf Erden'. ${ }^{61}$ Eine eschatologische Geschichtsauffassung - das Nichtakzeptieren der 'Welt, wie sie ist', und die Erwartung eines 'katastrophisch' anbrechenden Reiches vollkommener Gerechtigkeit und Glückseligkeit - verband religiös gesinnte Intellektuelle mit Sektierern und Revolutionären. ${ }^{62}$ Mit der Hoffnung auf einen

58 Die 'Programme' dieser Bewegungen weisen zahlreiche Ubereinstimmungen mit den Ideen Fedorovs auf. Ausführlich dazu unten II: 2.3.1.

59 So ein nicht năher bekannter Anhănger dieser Bewegung (1910). Zitiert nach K.M. AZADov. SKU, "Rannec tvortestvo NA. Kljueva. (Novye materialy)." In: Russkaja Literatura, 1975, 3, S. 209.

60 Vgl. dazu B.G. Rosentral, "Eschatology and the Appeal of Revolution: Merezhkovsky, Bely, Blok." In: California Slavic Studies, 11 (1980), S. 105-139. S. HACKEL, The Poet and the Revolurion: Aleksandr Blok's 'The Twelve'. Oxford 1975, S. 2-4. J.H. BilungTON, The Icon and the Axe. An Interpretive History of Russian Culture. New York 1970, S. 504-509, 514. SCHERRER (wie Anm. 2), s.v. 'Apokalyptische Erwartungen'.

Das wohl folgenreichste literarische Produkt dieser verbreiteten apokalyptischen Strömungen erschien im Dezember 1905 in Carskoe Selo unter dem bezeichnenden Titel Velikoe v malom, ili Antichrist, kak blizkaja politixeskaja vozmozmost'. Das offenbar unter dem Eindruck von Solov'evs Tri razgovora entstandene Werk, das bis 1917 noch mehrere Auflagen erlebte, stammte aus der Feder des religiosen Fanatikers und Obskuranten Sergej Aleksandrovið Nilus (28.8.1862-14.1.1929; neue Daten und Erkenntnisse zu seiner Person sollen an anderer Stelle veroffentlicht werden); es enthalt die berüchtigten "Protokolle der Weisen von Zion", die in dieser Fassung weltweite Verbreitung fanden.

61 Davon zu unterscheiden sind die pessimistischen Fin-de-Siècle-Stimmungen der Dekadenten, die den Untergang der Kultur und das bevorstehende Ende der Menschheit beschworen, jedoch ohne eine sich daran anschließende Erwartung eines universalen Umbruchs und einer kosmischen Erneuenung; derartige Krisen- und Untergangsstimmungen waren auch in Westeuropa verbreitet. Vgl. SCHERRER (wie Anm. 2), S. 417-419, und zu Westeuropa W. Wrora, "'Die Kultur kann sterben.' Reflexionen zwischen 1880 und 1914." In: Fin de Siecle. Zur Literanur und Kunst der Jahrhundertwende. Frankfurt/M. 1977, S. 50-72. - Ober KrisenbewuBtsein, Kulturpessimismus und Apokalyptik als Kennzeichen des spätbürgerlichen Lebensgefühls in Westeuropa (Wagner, Nietzsche) und RuBland (Skrjabin, Rozanov, Leont'ev) siehe auch A.F. LOSEv, "Gibel' buržuaznoj kul'tury i ee filosofii." [Nachwort] In: A. CHUUBSER [HOBSCHER], Mysliteli našego vremeni, M. 1962, S. 310-354; hier S. 313-320.

62 Vgl. RosentTal (wie Anm. 60), S. 111-113 und pass. SCHERRER (wie Anm. 5). Bereits BerdJAEV (wie Anm. 11), S. 80-83, 101, hatte die marxistische Lehre vom notwendigen Zusammenbruch des Kapitalismus und dem nachfolgenden Reich der Freiheit mit religioser Eschatologie 
radikalen Wandel ging eine eigentümliche Kompromißlosigkeit des Wollens gegenüber der empirischen Wirklichkeit einher, ein Glaube, da $B$ das, was sein solle, auch sein könne und sein werde. Diese Haltung begegnete sogar gegenüber der Wirklichkeit des Todes. So weigerten sich beispielsweise die Anhänger der Sekten der "Unsterblichen" (bessmertniki) und der "Jehovisten" (iegovisty), den Tod als unabwendbar zu akzeptieren. Christi Sieg über den Tod war für sie der Beweis, daß Unsterblichkeit möglich sei; die Menschen starben nur deshalb, weil sie an den Tod glaubten und nicht an die Unsterblichkeit. Selbst der Tod eines "Unsterblichen" bewies nur dessen Glaubensschwäche. ${ }^{63}$

Einen neuen Aufschwung erlebte diese sektiererisch-fanatische Kompromißlosigkeit gegenüber der empirischen Wirklichkeit des Todes in den Jahren nach der Revolution, als sich mit der Erwartung einer totalen Befreiung der Menschheit die Forderung nach sofortiger Abschaffung des Todes verband. - Davon wird noch eigens zu sprechen sein.

\subsubsection{Das Problem des Todes im marxistischen (revisionistischen) Denken}

Um die Jahrhundertwende wies der russische Marxismus zwei revisionistische Strömungen auf, eine neukantianische und eine, deren Anhänger sich an Nietzsche und an der Lehre des Empiriokritizismus orientierten. Die neukantianischen Revisionisten (Bulgakov, Berdjaev, Struve u.a.) waren mit ihren Versuchen, die Freiheit des einzelnen - als Voraussetzung moralischer Autonomie und die Auffassung vom Menschen als höchstem Wert und Selbstzweck im Rahmen eines monistisch-deterministischen Systems zu verankern, gescheitert: Die vom Marxismus behauptete Einheit von theoretischer und praktischer Wahrheit, von Sein und Sollen, ließ keinen Raum für eine autonome Personal-

verglichen. Zur apokalyptischen Geschichtsauffassung (im Unterschied zur evolutionistischen) als dem wichtigsten Merkmal des russischen religiösen BewruBtseins ausführlich DERs., "Russkaja religioznaja ideja." In: Problemy nusskogo religioznogo soznanija. Sb. statej. Berlin 1924, S. $102-129$.

Aus den chiliastischen und apokalyptischen Strömungen der Jahrhundertwende hat noch die Revolution von 1917 starke Antriebe erfahren: "Die emotionale Romantik der sozial gefarbten Erwartungen der Sektierer berührte sich mit der eschatologischen Besessenheit des Kommunismus, der Traum vom Gottesreich auf Erden verwob sich ununterscheidbar mit der kommunistischen Projektion einer künftigen klassenlosen und herrschaftsfreien Gesellschaft." I. LA. GovSKu, "Bog i social'naja pravda v SSSR." In: Novyj,Grad, 4, 1932, S. 44. Vgl. auch R. FOLOPMILLER, Geist und Gesicht des Bolschewismus, Wien ${ }^{2} 1928$ [1'1926], S. 100-121. E. SARKISYANZ, Rußland und der Messianismus des Orients, Tübingen 1955, S. 87f., 95-106. V. MURVAR, "Messianism in Russia: Religious and Revolutionary." In: Joumal for the Scientific Study of Religion, 10 (1971), 4, S. 277-338. E. MOLLER, "Opportunismus oder Utopie? V.D. Bon丈-Bruevi飞 und die russischen Sekten vor und nach der Revolution." In: JfGO, NF 35 (1987), 4, S. 509-533.

63 Siehe Berdjaev, Samopoznanie (wie Anm. 1), S. 229. Ders., Russkaja ideja (wie Anm. 1), S. 200. - Ober die 'Unsterblichen' auch Burgakov, "Apokaliptika..." (wie Anm. 11), S. 114f. A.S. PANKRATOV, ISCuš́tie boga. OXerki sovremennych religioznych iskanij i nastroenij. Kn. 1, M. 1911 [recte 1910], S. 13. E.K. GERCYK, Vospominanija, Paris 1973, S. 121. - Ober die 'Jehovisten' FOLOP-MILLER (wie Anm. 62), S. 111. 
ethik, und der durchgängige ökonomisch-historische Determinismus degradierte den einzelnen zum Transmissionspunkt objektiv wirkender Kräfte. ${ }^{64} \mathrm{Zu}$ dem hatte sich - wie im vorangegangenen Abschnitt dargelegt - die naturgesetzliche Fortschrittsauffassung mit ihrer Verheißung eines innerweltlichen Idealzustandes angesichts der Endlichkeit des Individuums und des akkumulierten historischen Leidens als illusionär und moralisch nicht zu rechtfertigend erwiesen - ein Problem, das nur durch die Forderung nach persönlicher Unsterblichkeit lösbar zu sein schien. Die so entstandenen theoretischen Schwierigkeiten zwangen die neukantianischen Revisionisten schließlich zur Abkehr vom orthodoxen Marxismus und zur Weiterentwicklung dualistischer und indeterministischer Konzeptionen.

Auch der zweiten revisionistischen Strömung innerhalb des russischen Marxismus - ihre wichtigsten Vertreter waren A. Bogdanov (d.i. A.A. Malinovskij, 1873-1928), V.A. Bazarov (d.i. V.A. Rudnev, 1874-1939), S.A. Vol'skij (d.i. A.V. Sokolov, 1880-1936?), A.V. Lunačarskij (1875-1933) und zeitweilig M. Gor'kij (d.i. A.M. Peškov, 1868-1936) - lag letztlich die gleiche Problematik zugrunde: auch hier ging es um den Versuch, das Ideal einer harmonischen, integralen Persönlichkeit ${ }^{65}$ mit dem Anspruch einer allumfassenden monistischen Weltauffassung $\mathrm{zu}$ versöhnen ${ }^{66}$ und die Vorstellung eines innerweltlichen Fort-

64 Demgegenüber bezweifelten die Neukantianer die Ableitbarkeit der Werturteile (des Sollens) aus der wissenschaftlichen Analyse der Gesellschaft und ihrer historischen Bewegungsgesetze (des Seins). "Für Marx ist Sozialismus eine soziologische Unausweichlichkeit: aber folgt daraus, daß er auch ein Gut ist?", fragte Berdjaev, "... ist es møglich, zu beweisen, daß der Sozialismus das gegenwărtig denkbar höchste Gesellschaftsideal ist, ungeachtet der Interessen bestimmter Klassen und unabhăngig von der Frage der Unvermeidbarkeit seines Eintretens?" N.A. BERD. JAEV zitiert nach A.V. LuNACARSKU, Religija i socializm, t. 1, SPb. 1908, S. 13f.; Hervorhebungen von mir; $M . H$.

65 Dieses Personlichkeitsideal war - in unterschiedlichem Maße - an Nietzsche orientiert, wobei an die Stelle des elităren Obermenschen eine kollektive 'Obermenschheit' als Ziel der Geschichte gesetzt wurde. Kline bezeichnet die Gruppe deshalb (im Unterschied zu den kantianischen) als nietzscheanische Manxisten. KLINE (wie Anm. 8.). DERS., "Nietzschean Marxism in Russia." In: Demythologizing Marxism. Boston College Studies in Philosophy, 2, 1969, S. 166-183. Vgl. ferner die für die Erforschung der Nietzsche-Rezeption in RuBland grundlegende Arbeit von A.M. LANE, Nietzsche in Russian Thought 18901917. Ph.D. diss., Univ. of Wisconsin, Madison 1976; Ann Arbor, Mich. 1981, S. 494-578. B.G. RosentHAL (Hg.), Nietzsche in Russia, Princeton, New Jersey 1986, bes. Teil 3 mit Beitrăgen über Nietzsches EinfluB auf Gor'kij, Lunatarskij und Bogdanov. - Nietzsches Individualismus am năchsten stand SA. Vol'skij, der sich in seiner "Philosophie des Kampfes" gegen das von den übrigen nietzscheanischen Revisionisten verkündete Aufgehen des Individuums im Kollektiv wandte. Man dürfe, so Vol'skij, "das Konkrete nicht im Abstrakten ausloschen, die Personlichkeit nicht im Kollektiv auflosen..." S.A. Vol'sku [A.V. SOKOLOV], Filosofija bor'by. Opyt postroenija étiki marksizma. M. 1909, S. 268. $\mathrm{Zu}$ Vol'skijs Position, die im folgenden unberücksichtigt bleibt, siehe auch G.L. KLINE, The Nietzschean Marxism of Stanislav Volsky." in: A.M. Muxotin (Hg.), Westem Philosophical Systems in Russian Literature, Los Angeles 0.J. [1979], S. 177-195.

66 Siehe A. KELIY, "Empiriocriticism: a Bolshevik Philosophy?" In: Cahiers du Monde russe et soviétique, 22 (1981), 1, S. 89f., 101 und pass. - Eine gute Darstellung der Philosophie Bogdanovs, insbesondere ihrer erkenntnistheoretischen Grundlagen, gibt KotAKowskI (wie Anm. 3), $S$. 483-498. Vgl. auch TUREK (wie Anm. 9), bes. S. 208-226. 
schritts angesichts der Endlichkeit des Einzelmenschen zu retten und zu rechtfertigen. ${ }^{67}$

Dabei wurde freilich der von den Neukantianern vertretene Individualismus und Dualismus als ein Rückfall in bürgerliches Denken verworfen. ${ }^{68}$ Dualistische Konzeptionen, so lautete der Vorwurf, spiegelten den autoritären und antagonistischen Charakter des Kapitalismus wider, den Gegensatz von Herrschenden und Beherrschten, während die Verherrlichung des Individuums in Wahrheit Ausdruck der durch Arbeitsteilung, Spezialisierung, Privateigentum und Klassengegensätze verursachten Zersplitterung und Atomisierung der bürgerlichen Gesellschaft sei, in der die Interessen und Wünsche der einzelnen, isolierten Menschen auseinanderstrebten und einander zuwiderliefen. Das Individuum, vorgestellt als eine von der Gesellschaft, vom allgemeinen Leben abgesonderte Wesenheit, sei in Wirklichkeit ein 'bürgerlicher Fetisch', ein Trugbild, das individuellem Besitzdenken und einer dualistischen Weltauffassung entstamme, welche auch die Vorstellung persönlicher Unsterblichkeit durch ein Fortdauern der Seele im Jenseits hervorgebracht hätten. Demgegenüber komme es in der sozialistischen Gesellschaft durch kollektiv organisierte Arbeit zu einer Vereinheitlichung der Denk- und Erfahrungsweise, die zu einem geschlossenen monistischen Weltbild führe, welches die vormals individuellen Interessen und Wünsche der Menschen auf allgemeine reduziere. Im Bemühen um ein allen Menschen gemeinsames Ziel - vorgestellt als eine gewollte Möglichkeit, nicht als etwas, das ohnehin (gesetzmäßig) eintreten wird - werde der einzelne sich als Teil des umfassenden Ganzen (Kollektiv, Gattung, Menschheit) erfahren, seine Isolierung und Beschränkung überwinden, seine Kräfte vervielfachen und schließlich Unsterblichkeit erlangen.

Besonders prägnant dargelegt finden sich diese Gedanken in einer erstmals 1906 erschienenen anonymen Schrift "Über proletarische Ethik" (O proletarskoj $\left.e^{e t i k e}\right)^{69}$, auf die sich die folgenden Ausführungen stützen: Motiv aller menschli-

$67 \mathrm{DaB}$ und weshalb auch dieser Versuch scheiterte, kann im folgenden nur angedeutet werden. Ausführlich hierzu Kelly (wie Anm. 66). Vgl. auch TUREK (wie Anm. 9), bes. S. 208-226.

68 Auch die nietzscheanischen Revisionisten lehnten den orthodox-marxistischen Geschichtsdeterminismus als 'fatalistisch' ab.

69 N.N., O proletarskoj èrike. (Proletarskoe mortéestwo s toxki zrenija realisticeskoj filosofii). S predisloviem i pod redakciej priv.-docenta N.A. Rožkova. M. 1906.

Ober den Verfasser dieser Schrift, die den Standpunkt der nietzscheanischen Revisionisten zum Problem des Todes besonders gut wiedergibt, herrscht Unklarheit; genannt werden "an early Russian Marxist" (G.L. KLINE, Religious and Anti-Religious Thought in Russia, Chicago, London 1968, S. 164), "one of Bogdanov's followers" (R.C. WILLIAMS, "Collective Immortality: The Syndicalist Origins of Proletarian Culture, 1905-1910." In: Slavic Review, 39, 1980, 3, S. 392), "Bogdanov, or perhaps [L.B.] Krasin" (DERS., The Other Bolsheviks. Lenin and His Critics, 1904-1914. Bloomington, Indianapolis 1986, S. 204; 79), A. Bogdanov (E. TolstANA-SEGAL, "Ideologiteskie konteksty Platonova." In: Russian Literature, 9, 1981, S. 240, 274), A.V. Lunatarskij (FOLOP-MıLLE, wie Anm. 62, S. 12f., 502) sowie ein gewisser Nikolaj Nikolaevið Koskarev, von dem nichts weiter bekannt ist (I.F. MASANOv, Slovar psevdonimov, t. 3, M. 1958, S. 323). 
chen Tätigkeit ist der "Wille zum Leben" (volja $k$ žizni), der "Selbsterhaltungstrieb" (instinkt samosochranenija), das Streben letztlich nach unbegrenzter Fortdauer (stremlenie $k$ procnosti, $k$ večnosti žizni). ${ }^{70}$ In der bürgerlichen Gesellschaft, in der das Individuum sich als abgesonderte Wesenheit und sein Leben als Privatbesitz betrachtet, ${ }^{71}$ äußert sich dieser Lebenswille im Kampf der einzelnen oder Gruppen um die Erhaltung der je eigenen, partikularen Existenz auf Kosten anderer und in Konkurrenz mit ihnen. Die Menschheit verausgabt somit einen Großteil ihrer Kräfte zur wechselseitigen Paralysierung ihrer Aktivitäten; die Herrschaft der Natur bleibt ungebrochen, das isolierte Ich am Ende weiterhin der völligen Vernichtung preisgegeben. Damit aber besitzt es nicht einmal Individualität, denn "individuell ist in Wahrheit [nur] dasjenige, was feststehend, ewig ist", 72 während das, was verdinglichendem Denken als Individualität erscheint - das bloße sinnlich-empirische Einzeldasein -, nur "eine zufällige Konzeption von Elementarkräften [ist], die bis dahin im Raum zerstreut waren und sich nur vorübergehend in Form eines lebenden Organismus kristallisiert haben" ${ }^{73}$ Unvergänglich ist dagegen das "allgemeine Leben", das "Leben der Menschheit" ${ }^{74}$ sowie die menschliche Schöpferkraft und ihre Objektivationen, die ins Leben einfließen und zu seiner Steigerung beitragen. ${ }^{75}$ Wahre Individualität und mithin Dauer liegen deshalb nicht in der partikularen Existenz, sondern im "allgemeinen Leben der Menschheit", dem der einzelne sich hingibt,

Was die Verfasserschaft Bogdanovs betrift, so findet sich in der neueren einschlägigen Literatur (den Arbeiten von Grille, Yassour und Jensen) kein Hinweis auf diese Schrift; und in der bislang ausführlichsten Bogdanov-Bibliographie von A. YASSOUR, "Bogdanov et son oeuvre." In: Cahiers du Monde nusse et soviétique, 10 (1969), S. 546-584, wird O proletarskoj ètike nicht aufgeführt. Auch Lunąarskij dürfte als Verfasser ausscheiden: die ausführliche Bibliographie seiner Werke (Anatolij Vasil'evit Lunatarskij. Ukazatel' unudov... T. 1, M. 1975) enthalt keinen Hinweis auf die genannte Schrift. Allerdings weist $O$ proletarskoj ètike sprachliche und inhaltliche Obereinstimmungen mit bekannten Werken Lunatarskijs aus jener Zeit auf (von denen noch dazu mehrere im selben Verlag erschienen sind). Unzutreffend ist jedoch Fülöp-Millers Angabe, die Schrift sei im bolschewistischen RuBland verboten worden, weshalb Lunałarskij sie anonym in Berlin veroffentlicht habe: Erstmals 1906 erschienen, erlebte $O$ proletarskoj erike im nachrevolutionăren RuBland mindestens zwei Neuauflagen (M. 1918, Char'kov 1923) und fand, vor allem wegen der darin enthaltenen kühnen Zukunftsvisionen, nachweisbare Resonanz. Eine deutsche Übersetzung (N.N., Uber proletarische Ethik. Das proletarische Schaffen vom Standpunkt der realistischen Philosophie) liegt in zwei Ausgaben vor (Zürich 1920, Hamburg 1921). Im folgenden wird die Schrift unter ihrem Titel nach der russischen Ausgabe von 1906 zitiert.

O proletarskoj ètike (wie Anm. 69), S. $12 f ., 17$.

71 Ebd., S. 49, 60.

72 Ebd., S. Sor.

73 Ebd., S. 59 .

74 Ebd., S. $50 f$.

75 Ebd., S. 50f., 59 . 
dem er schöpferisch handelnd 'dient' und seinen Stempel aufdrückt, und in dem er schließlich aufgeht. ${ }^{76}$

Voraussetzung dafür ist, daß die subjektiven Wünsche des einzelnen mit den objektiven Interessen der Allgemeinheit, der Gattung, zusammenfallen. 77 Diese Voraussetzung wird in der sozialistischen Gesellschaft dadurch erfüllt, daß die Bemühungen aller Menschen auf ein Ziel gelenkt werden, das ein jeder als sein eigenes und zugleich als ein allen gemeinsames erkennt ${ }^{78}$ - nämlich die Entfaltung und Steigerung des allgemeinen Lebens durch zunehmende Beherrschung und Umwandlung der Natur, um ein "Maximum an Leben" (maximum Zizni),

76 Ebd., S. 60f. - Dieser Gedanke, der in den Schriften der nietzscheanischen Revisionisten - insbesondere der Anhänger des bogostroirel'stwo (siehe unten Anm. 103) - immer wiederkehrt, erinnert an Comtes Lehre von der fortschreitend sich vervollkommnenden unbegrenzten, ewigen "Menschheit" (Humanite), dem "Großen Wesen" (le Grand Etre), dem der einzelne (für sich, in seiner Gesondertheit nur eine Abstraktion) sich "dienend" hingibt, mit dem er verschmilzt. Nach Comte sind der bedeutendste Bestandteil des "Großen Wesens" die Verstorbenen, freilich nur diejenigen, die sich durch ihr Mitwirken an der Vervollkommnung der Weltordnung als "würdig" erwiesen haben, in dieses "Große Wesen" aufgenommen zu werden (auch dieser 'elităre' Gedanke findet sich bei den Russen wieder). - Die Frage eines Einflusses von Comte auf die genannten Denker und ihre Konzeptionen hat bislang so gut wie keine Aufmerksamkeit gefunden. (Siehe auch unten Anm. 98).

\begin{abstract}
Ähnliche Gedanken - möglicherweise von Comte beeinfluBt - finden sich im Entwurf einer "Religion des Fortschritts der Menschheit", mit der der englische Freidenker William Winwood Reade (1838-1875) den Glauben an einen personalen jenseitigen Gott zu ersetzen suchte. Im SchluBkapitel seines Hauptwerks The Mantyrdom of Man (1872), das erstaunliche Ubereinstimmungen mit einzelnen Gedanken Fedorovs und der nietzscheanischen Revisionisten aufweist, forderte Reade die Vereinigung aller Menschen im Dienst an der Gesamtmenschheit (mankind as One), ihrer Hobherentwickung und Vervollkommnung, die totale Beherrschung der Natur durch Wissenschaft und Technik, die Ausrottung von Hunger, Seuchen und Krankheiten, die "Erfindung der Unsterblichkeit" (invention of immonality) und die Eroberung des Weltalls: "... all men can join in that gigantic and godlike work, the progress of creation." "... men will... give up all for all mankind. With one faith, with one desire, they will labor together in the Sacred Cause..." W.W. READE, The Martyrdom of Man, New York ${ }^{20} 1923$, S. 538, 537. Ob Reades seinerzeit in zahlreichen Auflagen verbreitetes, heute jedoch gănzlich vergessenes Werk jemals auch in RuBland rezipiert worden ist, ließ sich nicht feststellen.
\end{abstract}

77 Ebd., S. 39.

78 In der antagonistischen Gesellschaft verhindert der "Kampf der Klassen, Gruppen und Individuen" die "Idee des [gemeinsamen] Zieles" (A. BogDANov, Krasnaja zvezda, L. 1929 [11908], S. 100 [Nachdruck Hamburg 1979]). Die Vereinigung (Organisation) der Interessen der Menschen auf ein gemeinsames Ziel und damit die Koordinienung der menschlichen Tătigkeiten zu einem schøpferischen Gesamtwerk war die Aufgabe der von A. Bogdanov entwickelten 'Allgemeinen Organisationslehre' (Tektologie), die in ihren Grundzügen 1913 vorlag. (Siehe dazu II: 3.1.1.). Zum Problem der Vereinigung divergierender Interessen durch das Aufstellen eines gemeinsamen verbindlichen Zieles vgl. auch A. BOGDANOV, "Celi i normy Żizni." [1905] In: DERS., Noyyj mir, M. 1905, S. 111 f. 
eine "maximale Lebensfülle" (maksimal'naja polnota žizni), ${ }^{80} \mathrm{zu}$ erreichen, einschließlich allgemeiner Unsterblichkeit. ${ }^{81}$

Angesichts dieses allgemeinen Zieles wird der einzelne den "Zusammenhang [seines Lebens] mit dem Leben der Menschheit ${ }^{m 82}$ erkennen; er wird sich "von den engen Interessen seiner Individualität" lösen und beginnen, "in der Kollektivseele zu leben". ${ }^{83}$ Die sozialistische Gesellschaft, in der alle am Leben bauen, wird nicht mehr zerteilt sein in die "elenden winzigen Zellen (kletuski) selbstgenügsamer Vereinzelter ${ }^{84}$, vielmehr werden der persönliche Instinkt und der Instinkt der Gattung miteinander verschmelzen.$^{85}$ An die Stelle des individuellen wird der "gesellschaftliche Selbsterhaltungstrieb" (instinkt obščestvennogo samosochranenija $)^{86}$ treten und den Einzel- und Gruppenkampf um das Dasein in einen gemeinsamen Kampf für das Dasein verwandeln. Das Individuum wird sich selbst als ein "Moment im großen Leben der Gattung" ${ }^{87}$ begreifen, als "Glied einer großen Kette, [als] Einheit des in sich ganzheitlichen kollektiven Schaffens" ${ }^{\text {88 }}$. Individualität im bürgerlichen Sinne als Abgeschlossenheit wird es nicht mehr geben; sie wird ausgelöscht werden durch die gemeinsame Schaffenskraft:

Die Persönlichkeit, die zuvor verloren war und ohnmăchtig inmitten eines Ozeans von physischen und sozialen Elementargewalten, ... es wird sie nicht mehr geben als einzelnes, abgesondertes Zentrum von Interessen und Bestrebungen; [statt dessen] lebt sie in tausend Leben als bewuBter, organischer Teil des vernünftigen, unteilbaren Ganzen; sie ist nicht verloren - [denn] sie kennt ihren

80 A.V. LunaCarsku, "Osnnyy pozitivnoj estetiki." In: Ozenki realisticeskogo mirovozzrenija. Sbornik statej po filosofii, obszestvennoj nauke $i$ żizni. SPb. 1904, S. 137.

$81 \mathrm{Vgl.O}$ proletarskoj ètike (wie Anm. 69), S. 47f. - Im kollektiven Kampf gegen die Natur zur Sichenung der menschlichen Existenz wird schließlich auch der alte Gegensatz von Sein und BewuBtsein überwunden: "Das Sein erhălt hier Sinn, und zwar diesen: Die Menschheit organisien das Universum durch den Kampf mit seinen Elementen. Das Denken bekommt hier eine reale Kraft, nămlich: Das Denken organisien die Arbeitsenergie der Menschheit im Kampf mit den Elementen. Es verschwindet die absurde Unvergleichbarkeit der beiden Pole: das Denken, verwirklicht in der Tătigkeit des Kollektivs, ist ein măchtiges Sein; und das Sein, widergespiegelt in dieser Tătigkeit, ist ein 'lichtes Denken' (svetloe mystenie)." A. BogDANov, Padenie veli. kogo fetisizma. (Sovremennyj krizis ideologii). M. 1910, S. 113; Hervorhebungen im Orig.

82 O proletarskoj ètike (wie Anm. 69), S. 25.

83 Ebd., S. 26. - Ebenso Bogdanov: "Der Mensch, der sich bewuBt wird, ein integraler Teil eines großen Ganzen zu sein und ein mit diesem untrennbar verbundenes Leben zu führen, wird bereits die bloße Vorstellung von egoistischen und eng-individualistischen Zielen verlieren." (Bogdanov, "Celi...", wie Anm. 78, S. 122). - Wie Fedorov lehnt auch Bogdanov alle Formen geistigen Eigentums mit Hinweis auf kollektive Erzeugerschaft und Nützlichkeit ab.

84 V. BAZAROV [V A. RUDNEV], Na dva fronta, SPb. 1910, S. 140.

85 LunaCarsku (wie Anm. 80), S. 136f. - Zum Wachsen des "GattungsbewuBtseins" und "Gattungsinstinktes" siehe auch DERS. (wie Anm. 9), S. 334f.

86 O proletarskoj ètike (wie Anm. 69), S. 38.

87 Lunacarsku (wie Anm. 80), S. 136.

88 LunaCarsKu (wie Anm. 9), S. 342. 
Platz im System des Ganzen; sie ist nicht ohnmáchtig - [denn] sie stützt sich auf dieses System. 'Alle für einen jeden und ein jeder für alle', so lautet die Formel, welche die Mauern und Gitter ihrer alten Einzelzelle zerbricht.

Der einzelne wird, indem er sich dem Leben und Schaffen der Gattung hingibt, sich also für Ziele einsetzt, die jenseits seiner konkreten und unmittelbar erfahrbaren Wirklichkeit liegen, ${ }^{90}$ eine "höhere Individualität" (vysšaja individual'nost') erlangen; ${ }^{91}$ er wird "in tausend Leben leben", seine Kräfte vervielfachen $^{92}$ und sein Bewußtsein und Empfinden so weit über die zeitlichen und räumlichen Grenzen seines physischen Daseins ausdehnen, da $B$ in ihm schließlich die gesamte vergangene und zukünftige Geschichte der Menschheit anwesend sein wird.

Das Leben des Menschen wird den Charakter eines schøpferischen Prozesses annehmen; nicht nur das Gefühl seiner Einheit mit der Vergangenheit wird ihm zugänglich werden, sondern er wird ebenso eine klare Vorstellung vom EinfluB seines Geistes auf die Zukunft haben. Man darf die Tatsache nicht vergessen, daß unser BewuBtsein ins Unendliche erweitert werden kann. ${ }^{93}$

Das Leben eines Menschen zu leben, bedeutet, seine Vergangenheit bereits vor dem Tag der eigenen Geburt zu sehen und zu empfinden und seine, wirklich seine Zukunft auch hinter dem Grabe; es bedeutet, sich selbst als sterblichen Teil einer unsterblichen Elementarkraft zu erkennen - des kollektiven Lebens.

89 Bogdanov (wie Anm. 81), S. $113 f$.

900 proletarskoj étike (wie Anm. 69), S. 25. - Der Mensch, der bereit ist, nichts mehr für sich selbst zu wollen, und ganz aufgeht im Dienst an der zukünftigen Menschheit, übt "Fernstenliebe" (ljubov' $k$ dal'nemu; dieser Begriff, der Nietzsches Zarathustra entlehnt ist, findet sich hăufig in Lunatarskijs Schriften). Die gleiche Haltung spricht auch aus Trockijs Bekenntnis: "Solange ich atme, werde ich für die Zukunft kămpfen, jene glănzende, lichte Zukunft (svetloe buduscee), da der Mensch, stark und schön, den elementaren Lauf seiner Geschichte beherrschen und auf den grenzenlosen Horizont von Schönheit, Freude und Glück lenken wird." L.D. TroCKU, "O pessimizme, optimizme, XX stoletii i mnogom drugom." [1901] In: DERs., Soxinenija, t. 20, M.-L. 1926, S. 78.

91 O proletarskoj èrike (wie Anm. 69), S. 58.

92 "Sozialismus ist Zusammenarbeit in Zeit und Raum. Indem das Individuum sich um der Gattung willen verleugnet, findet es sich zehnmal so stark." A.V. LUNACARSKU, "Budušce religii" [Teil 1]. In: Obrazovanie, 16, 1907, 10, S. 24; dieselbe Formulierung auch in DERS., Religija (wie Anm. 64), S. 45. Vgl. KeLLY (wie Anm. 66), S. 103.

93 A.M. GoR'Ku [Antwort auf die Umfrage der Zeitschrift Mercure de France: "La question religieuse"]. In: Mercure de France, 61 (15.4.1907), S. 595. - Auch bei Bogdanov findet sich die Vorstellung einer durch alle Zeiten gehenden Zusammenarbeit der Menschen (die auch die Verstorbenen umfaBt): "Alle hervorragenden Kampfer der Vergangenheit, alle arbeitenden Menschen, welcher Klasse auch immer sie angehort haben mogen, sind unsere Genossen." A. BoGDANOV, Vseobscaja organizacionnaja nauka (Teksologija), c. 1, SPb. 1913, S. 107. "Der Proletarier darf niemals die Mitarbeilesschaft der Generationen vergessen..." DERS., "Kritika proletarskogo iskusstva" [1918]. In: DERs., O proletarskoj kul'ture 1904 1924, L.-M. 1924, S. 173; Hervorhebung im Orig.

94 A.[V.] LUNACARSKU, "Dvadcat' tretij sbornik 'Znanija'." In: Literatumyj raspad, kn. 2, SPb. 1909, S. 87. 
Das "kleine Ich" wird sich entgrenzen und aufgehen im "großen Wir", von dem es heißt: Es vergrößert tausendfach die Oberfläche des Empfindens (poverchnost' ošcušcenija), es gibt die Möglichkeit, sich an Siegen zu erfreuen, die erst hundert Jahre nach dem Tod des 'kleinen Ich' errungen werden, und das Leben längst untergegangener Geschlechter zu leben, die ebenfalls dem 'Wir' angehörten, ein Teil von ihm waren. ${ }^{95}$ In der Überwindung der individuellen Begrenztheit "durch die Verlagerung des Schwerpunktes von sich selbst, seinem physischen 'Ich' auf das große 'Wir' der schöpferischen, kämpfenden, fortschrittlichen Menschheit" liegt schließlich auch die "Rettung vor dem Tode"

... der Mensch kann den Tod besiegen und besiegt ihn ... durch die Liebe zu seiner Gattung ... ${ }^{97}$

Für den wahren Sozialisten ... ist die Realităt - die Gattung, die Menschheit, und das Individuum ist bloB ein besonderer Ausdruck dieses Wesens. Sozialismus ist Zusammenarbeit in Zeit und Raum. ${ }^{98}$

Im gemeinsamen zielgerichteten Schaffen verwirklicht sich die Einheit der Menschheit, werden die Individuen gleichsam zu Zellen eines "unsterblichen Überorganismus" (bessmertnyj sverchorganizm).$^{99}$ Damit aber verliert der "persönliche Tod" (licnaja smert') seine Bedeutung - und seinen Schrecken; er wird, mit den Worten Bazarovs, "so geringfügig sein wie das Absterben einer meiner Gehirnzellen"100. Das Individuum, das aufgeht in der unendlichen Gesamt.

95 A.V. LunaCarsku, "Voprosy morali i M. Meterlink." In: Ders., Etjudy kritixeskie i po. lemiceskie, M. 1905, S. 175. - Dieses Aufgehobensein des 'Ich' im 'Wir' bezeichnet Lunazarskij als "makrophysischen Individualismus", Weitherzigkeit, im Unterschied zum Egoismus, der, wie 'vernünftig' auch immer er sein mag, stets eine Art "Mikropsychik", Engherzigkeit, bleibe (ebd.).

96 A.V. LuNaCARsKU, "V mire nejasnogo." In: Ders., Otkliki ¥izni. Sb. statej. SPb. 1906, S. 71.

97 Lunacarsku, Religija (wie Anm. 64), S. 44. - Ganz ahnlich. Ders. (wie Anm. 94).

98 LuNACARSKu, Religija (wie Anm. 64), S. 45. - Hierzu noch einmal Comte: "Volle Lebensintensităt" (louse l'intensité de vie) und "subjektive Unsterblichkeit" (immonalité subjective) erlangt der einzelne durch die "große Verschmelzung" (grande identification) mit der Gesamtmenschheit. Das "Betreiben des offentlichen Wohls" ist die "Hauptquelle des persönlichen Glücks" und gewăhrt zudem die "Befriedigung des Strebens nach unsterblichem Leben": "Da das Individuum sein Leben nur durch die Gattung zu verlăngem vermag, wird es so dazu geführt, sich moglichst vollstăndig in sie einzugliedern, indem es sich zutiefst mit deren nicht allein gegenwărtiger, sondern auch vergangener und zukünftiger Existenz verbindet." A. COMTE, Rede über den Geist des Positivismus [Discours sur l'esprit positif, 1844], Hamburg 21966, S. 154-157.

99 Dies wird eine Wiederherstellung - auf hoherer Ebene - der Bedingungen des Urkommunismus sein, unter denen das "persornliche Interesse vom kollektiven nicht getrennt und der Mensch organisch mit dem Ganzen - der Gruppe oder der Kommune - verbunden war wie Zellen im lebenden Gewebe." Bogdanov, "Celi..." (wie Anm. 78), S. 121 .

100 V. Bazarov [V A. Rudnev], Versiny, SPb. 1909, S. 360; zitiert nach KuINe (wie Anm. 8), S. 278. - Mit dem gleichen Bild hatte bereits Winwood Reade 1872 die Bedeutung des Individuums und seines Todes für die fortschreitend sich vervollkommnende Gesamtmenschheit beschrieben: There is onty One Man upon the earth; what we call men are not individuals, but components; what we call death is merely the bursting of a cell..." READE (wie Anm. 76), S. 521. - Gegen eine solche 'Losung' des Todesproblems gab es freilich auch von marxistischer Seite Widerspruch; so versicherte der Literaturkritiker und Soziologe Juskevix: "Das BewuBtsein des 
menschheit wie eine Welle im Meer, ${ }^{101}$ braucht keine persönliche Unsterblichkeit, da "seine Unsterblichkeit das Leben der Gattung ist". ${ }^{102}$ Diese, ein überindividuelles, allmächtiges und unendliches Wesen, wird für den einzelnen zum Gegenstand des Glaubens und der Verehrung und nimmt damit den Platz des von Nietzsche für tot erklärten - Gottes in der atheistischen "Religion des Fortschritts" (Lunacarskij) ein: ${ }^{103}$

eigenen 'Ich' wird in der Gesellschaft der Zukunft nicht erloschen, und die Personlichkeit wird nie anfangen, sich als Zelle oder Neuron des kollektiven Gehirns zu empfinden..." P.S. JUSKEVIC, Novye vejanija, SPb. 1910, S. 194.

101 Vergleich von LUNACARSKU (wie Anm. 94).

102 Ebd., S. 87f. Siehe auch KEILY (wie Anm. 66), S. 104. - Von orthodox-maxxistischer Seite wurde freilich jegliche Annahme einer Unsterblichkeit - egal ob personlich, innerhalb eines Kollektivs oder der Gattung - als Verrat am Materialismus kritisiert und verworfen: "Seine [Lunatarskijs] 'Philosophie des Kollektivismus' ist die Philosophie eines reuigen Individualisten, der nach Unsterblichkeit strebt mittels eines übernatürlichen Großen 'Ich' (ebenso wie Bulgakov und Co. ihre Unsterblichkeit mittels eines transzendenten Gottes verwirklichen wollen)." N. GRABOVSKU [d.i. V.F. GALKIN], 'Doloj materializm!' (Kritika empiriokriticeskoj kritiki). SPb. 1910, S. 276.

103 Zur Vergottlichung der kollektiven Menschheit im sog. 'Gotterbauertum' (bogostroitel'stwo; der Begriff wurde 1908 von Gor'kij geprägt) vgl. R. SESTERHENN, Das Bogostroitel'stwo bei Gorkij und Lunacarskij bis 1909, München 1982. D.G. RowLEY, Millenarian Bolshevism: Empiriomo nism, God-Building, Proletarian Culture. Ph.D. diss. Michigan 1982 (oft ungenau und gegenüber Sesterhenn weit weniger ergiebig). Zur Begriffsbestimmung J. SCHERRER, "La 'construction de Dieu' marxiste ou la 'recherche de Dieu' chrétienne: les termes bogostroitel'stuo et bogoiskatel'stro." In: Rossija - Russia, 4, Torino 1980, S. 173-198, und die dort angegebene Literatur. Nachklănge des bogostroirel'stwo finden sich zu Beginn der zwanziger Jahre u.a. in den Allmachts- und Unsterblichkeitsvisionen Gor'kijs und der Proletkul't-Dichter sowie in A.K. Gastevs Plănen zur Schaffung mechanisierter kollektiver Ubermenschen. Siehe II: 3.1.

In diesem Zusammenhang müBte einmal den auffallenden Parallelen zu Comte ("Religion der Menschheit"; siehe oben Anm. 76 und 98), Guyau und Renan ("Religion der Wissenschaft") nachgegangen werden. In L'Avenir de la Science (entstanden 1848/49; vollstăndig veroffentlicht 1890) deutet Renan den Fortschritt der Menschheit und ihrer Wissenschaft als ProzeB der Realisienung der absoluten Vernunft, d.h. Gottes; die Opfer des Fortschritts fanden sich dereinst wieder im vollkommenen Wissen, ihre Unsterblichkeit liege in ihrem Beitrag zur Selbstwerdung der Gottheit. Auch Winwood Reade (siehe oben Anm. 76 und 100) schwarmt von der Selbstvervollkommnung und Vergöttlichung der unsterblichen Gesamtmenschheit: "... the One of whom we are the elements, ... though we perish, never dies, but grows from period to period, and by the united efforts of single molecules called men ... is raised toward the Divine power which he will finally attain. Our religion therefore is Virtue; our Hope is placed in the happiness of our posterity; our Faith is the Perfectibility of Man." READE (wie Anm. 76), S. 536f. Unbeachtet blieb bislang auch die Frage nach einem EinfluB Bergsons, der in seiner 1907 erschienenen und - nach dem Zeugnis A.F. Losevs - auch in RuBland alsbald stark beachteten Evolution creatrice mit ganz ahnlichen Worten und Bildern wie die bogostroiteli das Eintauchen des Menschen in den unendlichen Strom des Lebens beschreibt, sein Verschmelzen mit der Gesamtmenschheit, die vielleicht sogar den Tod überwinden werde: "... l'humanité entière, dans l'espace et dans le temps, est une immense armée qui galope à côté de chacun de nous, en avant et en arrière de nous, dans une charge entraînante capable de culbuter toutes les résistances et de franchir bien des obstacles, même peut-être la mort." H. BERGSON, L'evolution creatrice, Paris 1911, S. 294. - Schließlich soll, wenn auch als bloße Vermutung, auf die Moglichkeit eines Nachwirkens der von den Slavophilen formulierten (und auf die Gemeinschaft der Rechtglăubigen bezogenen) sobormost'-Idee in săkularisierter Form hingewiesen werden: sobomost', verstanden als das Gefühl der harmonischen Eingebundenheit des einzelnen in eine 
Der Glaube des aktiven Menschen ist der Glaube an die künftige Menschheit, seine Religion ist die Gesamtheit jener Gefühle und Gedanken, die ihn zum Teilnehmer am Leben der Menschheit machen und zu einem Glied in der Kette, die sich zum Obermenschen hin spannt, zu einem schonen und măchtigen Geschøpf, einem vollendeten Organismus, in dem Leben und Vernunft ihren Sieg über die Elemente feiem werden. ${ }^{104}$

Der einzelne - mit Nietzsche aufgefaßt als "Brücke zum Übermenschen"105 - besitzt in dieser Sicht lediglich "historisch-instrumentellen Wert ${ }^{106}$, doch ist er mit dieser seiner Rolle versöhnt in dem Bewußtsein, durch die gemeinschaftliche Arbeit zu einem Teil der fortschreitenden Menschheit zu werden und damit Anteil am zukünftigen Glück zu erlangen, einem Glück, das vollkommen sein wird durch den "völligen Triumph über die Natur"107 und den realen Sieg über den Tod.

... wir alle werden unausweichlich verschwinden, um auf Erden Platz zu machen für Menschen, die ... ein neues, schønes, strahlendes Leben schaffen und - moglicherweise - durch die wunderbare Kraft ihres vereinten Willens den Tod besiegen werden. ${ }^{108}$

'Vereinter Wille' bedeutet gesellschaftliche Organisation. Von dem Grad ihrer Entwicklung hängen die intellektuellen Fähigkeiten und die technischen Möglichkeiten und damit die Macht der Menschen über die Natur ab. Diese Macht ist um so größer, je höher der 'gesellschaftliche Organismus' entwickelt ist, d.h.

Gemeinschaft, einen sozialen Organismus, sowie der Teilhabe an und der Úbereinstimmung mit einem überindividuellen kollektiven Bewußtsein, beschreibt auch das Ideal der bogostroiteli.

104 LuNACARSKU (wie Anm. 80), S. 181. - Das - auf Nietzsche zurückgehende - Bild vom Einzelmenschen als einem (Ketten-)Glied (zveno) wurde zur beliebten Metapher in den Schriften der bogostroiieli; so heiBt es noch zwei Jahrzehnte spater bei Bogdanov, der Arbeiter erkenne sich selbst als "lebendiges Glied eines großen, allesbesiegenden Ganzen" (A. BOGDANov, "Zakony novoj sovesti." [1924] In: DERS., O proletarskoj..., wie Anm. 93, S. 343); und Lunatarskij: der "neue Mensch" empfinde sich als "Glied einer groBen Kette", als Teil eines ewigen Ganzen" (A. LUNACARSKU, "O prepodavanii istorii v kommunistiCeskoj Skole." [1918] In: DERS., Prosuescenie i revoljucija. Sb. statej. M. 1926; hier S. 105f.).

105 "Der Mensch ist die Brücke zum Ubermenschen" - diese, Nietzsches Zarathustra entlehnte Formel hatte Bogdanov seinem Aufsatz "Sobiranie reloveka" (1904) als Motto vorangestellt. Nietzsches 'Ubermensch' wird bei Bogdanov zur vollkommen vereinten 'Ubermenschheit' (svenchielovecestio).

106 Vgl. KuINe, "Nietzschean Marxism in Russia" (wie Anm. 65), S. 166. Ders., The Nietzschean Marxism..." (wie Anm. 65), S. 177f. - Eben diese Sicht hatte S.N. Bulgakov kritisiert, als er davon sprach, daB "die Leiden der einen Generationen ... gleichsam die Brücke zum Glück für die anderen" seien (siehe oben Anm. 13).

$107 \mathrm{Vgl.} \mathrm{O}$ proletarskoj érike (wie Anm. 69), S. 46-53.

108 M. GoR'kw, "RazruŠnie litnosti." In: Oxenti (wie Anm. 9), S. 396. Auf den "Geist der Gattung" (LUNACARSKI, wie Anm. 64, S. 73) und den Glauben an die Zukunft der Menschheit gründet sich auch die Opferbereitschaft, die aus den berühmten Worten Rybins spricht: "Mogen Tausende sterben, damit das Volk auf der ganzen Erde zum Leben aufersteht! Das ist es: Sterben ist leicht, wenn sie dann nur auferstehen!" M. GoR'KU, "Mat'." [1906] In: DERS., PSS. Chudotestvennye proizuedenija v dvadcati pjati ıomach. T. 8, M. 1970, S. 136. Weitere Beispiele für Gor'kijs Glauben an die Oberwindbarkeit des Todes durch die 'Energie des Kollektivs' bei S.G. SEMENOVA, "Ne vižu predela moši razuma'." In: Literatumaja UČeba, 1984, 3, S. 150-156. 
je weiter die Vereinigung der Menschen vorangeschritten ist. Mit zunehmender Vervollkommnung der gesellschaftlichen Organisation wird es der Menschheit gelingen, nicht nur die unbelebte Natur, sondern auch die "organischen Elementarkräfte immer mehr zu beherrschen" und nach und nach "die einzelnen Organismen unsterblich zu machen ${ }^{109}$. Für die vollkommen vereinte und damit utopisch perfekte "Übermenschheit" (sverchCeloveלestvo) wird schließlich nichts mehr unmöglich sein, ihre Schöpferkraft wird keine Grenzen kennen:

Wir kð̋nnen uns nicht einmal auch nur vorstellen, wie măchtig der Mensch der Zukunft werden kann, wie groB seine Macht über die Natur sein wird. Er wird der Herr der Welt werden und sein Geschlecht im weiten Weltraum verbreiten, er wird das Planetensystem beherrschen. Die Menschen werden unsterblich sein. ${ }^{110}$

Ein detailliertes Bild der Möglichkeiten künftiger Naturbeherrschung, wie sie sich einer sozialistisch-kollektivistischen Gesellschaft bieten, entwirft A. Bogdanov in seinem im November 1907 erschienenen utopischen Roman "Der Rote Stern" (Krasnaja zvezda). ${ }^{111}$ Zwar spricht Bogdanov nicht von der Überwindung des Todes (die von ihm geschilderte fortgeschrittene Mars-Zivilisation jedenfalls kennt sowohl den natürlichen wie auch den - durch Sterbehilfe erleichterten - selbstgewählten Tod), ${ }^{112}$ doch beschreibt er, wie es den vorbildlichen Marsmenschen gelungen ist, den Prozeß des Alterns zu verlangsamen und die

109 O proletarskoj etike (wie Anm. 69), S. 52.

110 Ebd.

111 A. Bogdanov, Krasnaja zvezda. (Utopija). SPb. 1908 [recte 1907]. Das Werk erlebte nach der Revolution mehrere Neuauflagen (Pg. 1918, L.-M. 1924 u.a.) Im folgenden zitiert nach der Ausgabe L. 1929 (Nachdruck Hamburg 1979).

Eine positive Würdigung erfahrt Bogdanovs Roman in der ausführlichen Monographie von A.F. BRrTikov, Russkij sovetskij naudno-fantastikeskaj roman, L. 1970, S. 49-55. Vgl. auch DERS., "Zaroždenie sovetskoj nauťnoj fantastiki." In: Istonja nusskogo sovetskogo romana. Kn. 1, M.-L. 1965, S. 373f. Vgl. ferner G. Maniscalco Basile, The Utopia of Rebirth: Aleksandr Bogdanov's Krasnaja Zvezda." In: Canadian-American Slavic Studies, 18 (1984), 1-2, S. 54-62. R.-D. KLUGE, "Lenins Rivale als Science Fiction-Autor. Alexander Bogdanovs utopische Romane." In: Aspekte der Science Fiction in Ost und West, Tübingen 1985, S. 14-26, 134-136. Kluge vermutet (ebd., S. 135), Bogdanov habe seine "ungehemmte Technik-Euphorie" auch von Fedorov "bezogen", "mit dem er in den Argumentationsmustern und vorrangigen Projekten und Zielen übereinstimm[e]." Die von Kluge genannten Beispiele kőnnen jedoch nicht uberzeugen: Nie ging es Fedorov darum, "Kontakte zu AuBerirdischen her[zu]stellen" oder mittels "medizinischer und psychologischer Forschung ... das Leben unendlich zu verlăngern". Für eine Beeinflussung der frühen Werke Bogdanovs durch Fedorov, die unlăngst auch von Heller behauptet wurde (L. GELLER [HELLER], Vselennaja za predelom dogmy, London 1985, S. 45, 50), gibt es keinerlei Anhaltspunkte.

Auffallend ist dagegen die Āhnlichkeit zwischen Krasnaja zvezda und den seinerzeit populăren Marsromanen von K. Laßwitz Auf zwei Planeten (1897) und H.G. Wells War of the Worlds (1898). Zu der v.a. durch die astronomischen Forschungen und Spekulationen G. Schiaparellis im letzten Viertel des 19. Jahrhunderts ausgeloste 'Marsbegeisterung' und ihrem reichen literarischen Niederschlag siehe den instruktiven Aufsatz von $\mathbf{K}$. DEBUS, "Weltraumschiffahrt, ein poetischer Traum und ein technisches Problem der Zeit." In: Hochland, 24 (1927), S. 356-371.

112 Siehe das Kap. "V lečebnice", ebd., S. 102-109. 
Lebensdauer des einzelnen erheblich zu verlängern. $\mathrm{Zu}$ diesem $\mathrm{Zweck}$ bedienen sie sich der "Transfusion des Blutes zwischen zwei menschlichen Wesen, von denen jedes dem anderen eine gesteigerte Lebenskraft $\mathrm{zu}$ geben vermag ${ }^{\text {1113. }}$. Dieses Verfahren beruht auf dem (für Bogdanovs Organisationslehre grundlegenden) Prinzip, wonach "Komplizierung" (usložnenie) und "Differenzierung" (differenciacija) innerhalb eines Systems eine "Verdünnung" (utoncenie) und Schwächung zur Folge haben, während der umgekehrte Vorgang - Bogdanov nennt ihn später "Kontradifferenzierung" (kontra-differenciacija) -, nämlich die Angleichung zweier Systeme und ihre Vereinigung, zu einer Stärkung und $\mathrm{Zu}$ nahme an Dauerhaftigkeit führen. ${ }^{114}$ Die Natur bedient sich dieses Prinzips, indem sie durch die Vereinigung und Kreuzung zweier verschiedener Wesen die Lebensfähigkeit des Organismus steigert und durch die Verschmelzung der Zellen die "Unsterblichkeit' des Protoplasmas" sichert. ${ }^{115}$ Analog dazu vermag der Mensch mit Hilfe gegenseitiger Blutübertragungen die Lebenskraft und -dauer der Individuen zu steigern und damit den Fortbestand der Gattung zu sichern. Überdies - und das ist nicht minder wichtig - kommt es zu einer physischen Annäherung der Individuen; die Grenzen der Individualität werden überwunden, ${ }^{116}$ die Einzelwesen gleichen sich einander an, ${ }^{117}$ werden zu "klei-

113 Ebd., S. 107. - Ob auf diesem Wege schließlich auch der Tod überwunden werden kann, bleibt offen. Unzutreffend ist deshalb die Behauptung. "...Bogdanov imagined indefinite [!] longevity ... by means of collective blood transfusion." WILLLAMs, "Collective Immortality..." (wie Anm. 69), S. 392. Der Verfasser von Krasnaja zvezda war, wie Jensen richtig bemerkt, kein "Fedorovist", kein "searcher after immortality". K.M. JENSEN, "Red Star: Bogdanov Builds a Utopia." In: Studies in Soviet Thought, 23, 1982, S. 327. Der Autor korrigiert damit seine frühere Behauptung in DERs., Beyond Marx and Mach. Aleksandr Bogdanov's Philosophy of Living Experience. Dordrecht 1978, S. 1. KLUGE (wie Anm. 111) bemerkt richtig, daß durch die von Bogdanov beschriebene Bluttransfusion eine "Verlăngerung des Lebens möglich [sei], jedoch keine Unsterblichkeit" (S. 20), was ihn freilich nicht hindert, diesen Gedanken "mit Fedorovs Ziel in Zusammenhang" zu bringen (S. 135). Vgl. auch II: 3.13. Anm. 89.

114 Ein Ergebnis von Kontradifferentiation ist beispielsweise die Einheitssprache der Marsianer, die durch gegenseitige Annaherung und Angleichung zahireicher Dialekte entstanden ist. - Der Gedanke einer Universalsprache als Mittel und Ausdruck allmenschlicher Vereinigung wurde von Bogdanov spăter weiter ausgeführt (siehe z.B. A. BogDANov, "Proletarskaja kul'tura i meždunarodnyj jazyk." [1919] In: DERS., O proletarskoj.., wie Anm. 93, S. 328-332); dieser Gedanke findet sich auch bei Fedorov und anderen Verkündern einer săkularisierten sobornost'Idee (Ciolkovskij, Chlebnikov, Biokosmisten) sowie bei russischen Sektierern; siehe FOLOPMILLER (wie Anm. 62), S. 111.

115 BogDanov (wie Anm. 111), S. 107. - Natur und Mensch bedienen sich derselben Organisationsmethoden - auf dieser Grundannahme beruht Bogdanovs monistische Universalwissenschaft. Siehe auch II: 3.1.1.

116 Dies erklărt auch, weshalb Bluttransfusionen bei den Erdenmenschen so selten vorgenommen werden: Die "Psychologie des Individualismus", die "so sehr den einen Menschen vom anderen trennt", läßı bei ihnen den "Gedanken an ihre lebendige Verschmelzung" kaum aufkommen; BOGDANOV (wie Anm. 111), S. 108.

117 So sind die Marsmenschen außerlich nach ihrem Geschlecht kaum zu unterscheiden; auch ihre Namen lassen nicht erkennen, ob es sich um månnliche oder weibliche Wesen handelt. 
nen Zellen des großen Organismus"118, und verschmelzen schließlich im Kollektiv. 119

Ein noch kühneres Verfahren, mit dessen Hilfe nicht nur Krankheiten beseitigt und das Leben des einzelnen verlängert, sondern auch der Tod überwunden und bereits Verstorbene wiederhergestellt werden sollen, skizziert ein Anhänger Bogdanovs, der als Historiker und Soziologe bekannt gewordene N.A. Rožkov (1868-1927). ${ }^{120}$ In seinem 1911 erschienenen Buch "Grundlagen einer wissenschaftlichen Philosophie" (Osnovy naǔ̌noj filosofii) ${ }^{121}$ verwirft Rožkov sowohl die religiöse Vorstellung einer Fortdauer der Seele im Jenseits wie auch die herkömmlichen idealistischen und materialistischen Versuche zur Lösung des Todesproblems (Aufgehen des einzelnen im 'Allgemeinen', Fortdauer in den Nachkommen, im Bewußtsein künftiger Generationen, in den eigenen Werken) als "klägliche und lächerliche Surrogate wirklicher Unsterblichkeit, die nur persönlich (ližnyj) sein kann und darf ..." ${ }^{122}$ Reale, diesseitige Unsterblichkeit werde, so Rožkov, in einer künftigen, planmäßig organisierten, klassenlosen Gesellschaft mit Hilfe einer dann allmächtigen Wissenschaft verwirklicht werden. Sobald es gelinge, die Verbindungen aller Elektronen innerhalb eines jeden (menschlichen) Organismus genau zu bestimmen, sie durch eine mathematische Formel vollständig darzustellen und beliebig zu manipulieren, werde es ein leichtes sein, Krankheiten zu heilen oder ihnen vorzubeugen, das Leben unbegrenzt zu verlängern und sogar den "Traum von ewiger Jugend" zu verwirklichen; ${ }^{123}$ doch damit nicht genug:

118 "... in jedem von uns, den kleinen Zellen des großen Organismus, lebt das Ganze, und ein jeder lebt durch dieses Ganze", lăßt Bogdanov einen Marsianer verkünden; BogDANOv (wie Anm. 111), S. 100.

119 Der Gedanke, durch fremdes Blut die eigene Vitalităt zu steigern und den ProzeB des Alterns zu verzogern, ist uralt (Vampirismus, Kannibalismus). Seine moderne Version, nămlich dieses durch Bluttransfusion zu bewerkstelligen, findet sich frühestens bei Francis Bacon (History of Life and Death). Im 17. Jahrhundert wurde das Verfahren praktisch erprobt. Ausführlich hierzu G.J. GRUMAN, A History of Ideas about the Prolongation of Life. The Evolution of Prolongevity Hypotheses to 1800. Philadelphia 1966, S. 82f. Vgl. auch A. BogDaNov, Bor'ba za Ziznesposobnost', M. 1927, S. 104f. Originell ist Bogdanovs Bestreben, durch wechselseitige Blutübertragungen die 'Verbrüderung' der Menschen zu fordern und sie einander anzugleichen. Bogdanov hat diese Gedanken weiterverfolgt und spăter im Rahmen seiner 'Allgemeinen Organisationslehre' philosophisch zu begründen versucht. Siehe auch II: 3.1.1.

120 Ein biographischer Abriß von R. HELLE, "Rozhkov, Nikolai Aleksandrovich." In: MERSH, 31, 1983, S. 217-221. Vgl. auch Pamjati Nikolaja Aleksandrovica Rozkova. Sb. statej. M. 1927. A. VUCINICH, Science in Russian Culture 1861-1917, Stanford 1970, S. 455f. - Rožkov, der sich selbst als Marxist bezeichnete (und als solcher auch in der westlichen Literatur figuriert), gilt in der Sowjetunion als 'Eklektiker'; siehe O.V. VOLOBUEV, "Voprosy social'noj psichologii v trudach NA. Rožkova." In: Istorija i psichologija, M. 1971, S. 296-318. - Rožkov war seit 1903 mit Bogdanov bekannt; er verfaBte das Vorwort zur ersten Ausgabe von $O$ proletarskoj étike und besorgte die Redaktion (siehe oben Anm. 69).

121 N.[A.] Rožkov, Osnovy naư̌noj filosofii, SPb. 1911.

122 Ebd., S. 130.

123 Ebd., S. 131. 
Wir dürfen die Hoffnung haben, als Tote zu neuem Leben zu erwachen. Wenn die Typen der physiologischen Strukturen (fiziologiceskie organizacii), auf die sich alle individuellen Organismen zurückführen lassen, genau bestimmt sein werden, dann wird ein Portrăt, eine Photographie, die einfache Beschreibung einer Person, sogar nur von zwei oder drei ihrer physiologischen Merkmale, Eigenschaften oder Besonderheiten, ausreichen, um aufgrund dieser Fragmente und Ausschnitte die Strukturformel (formula stroenija) dieses oder jenes Menschen aufzustellen. ${ }^{124}$

Da zwischen der Geistesverfassung eines Menschen und seiner physiologischen Konstitution ein gesetzmäßiger Zusammenhang bestehe, genüge, so Rožkov, bereits ein Ausschnitt aus einem beliebigen Schriftstück, einem Buch etwa oder einem Brief, um danach die individuelle Strukturformel des jeweiligen Autors $\mathrm{zu}$ ermitteln und diesen physisch zu rekonstruieren: ${ }^{125}$

Dann wird der, welcher vor vielen Jahrhunderten gelebt hat, in einem chemischen Laboratorium auferstehen. Natürlich wird er dann [seinerseits] diejenigen auferwecken, die er gekannt und geliebt hat. Das Problem der Unsterblichkeit wird endgültig gelost sein. Man muß nur einer künftigen Auferst ehung würdig sein. ${ }^{126}$

Der aus diesen Zeilen sprechende Glaube an eine Überwindung des Todes und eine Wiederherstellung längst Verstorbener fand insbesondere in den ersten Jahren der Sowjetmacht weite Verbreitung; bemerkenswert ist dabei der Umstand, daß die von Rožkov gemachte Einschränkung, wonach Unsterblichkeit und Auferstehung einer 'Elite' vorbehalten bleiben (man muß ihrer "würdig sein"), bei den Propheten einer klassenlosen Zukunftsgesellschaft weit mehr Anklang fand als Fedorovs Forderung nach Teilhabe ausnahmslos aller am ewigen Leben. ${ }^{127}$

124 Ebd.

125 Ebd., S. 132. - Auch Fedorov glaubte, daB es nur weniger Informationen über einen Menschen bedürfe, um diesen in seiner psychischen und physischen Individualităt zu rekonstruieren, und $\mathrm{daB}$ diese Informationen in allem enthalten seien, was Menschen je hervorgebracht hatten. Fedorov hielt es deshalb fur eine "heilige Pflicht", alle Artefakte (insbesondere jegliche schriftliche Hinterlassenschaft) zu sammeln und in Museen aufzubewahren. - Wiederholt wurde Rozkov mit Fedorov in Verbindung gebracht. Vgl. D. CYŽEvs'KYJ [TSCHLzEWSKU], [Rezension von] "Fedorov, N.F., Filosofija obsxego dela..." In: Slawische Rundschau, 2, 1930, S. 515. DERS., "Die russische Philosophie der Gegenwart." In: ebd., S. 739. SARKISYANZ (wie Anm. 62), S. 41. KLINE, Religious and Anti-Religious Thought (wie Anm. 69), S. 165f. Für einen direkten EinfluB Fedorovs gibt es jedoch keinen Beleg.

126 Roźxov (wie Anm. 121), S. 132.

127 So außerte 1921 der Volkskommissar Leonid Krasin die Oberzeugung, daß es der befreiten Menschheit mit Hilfe der Technik dereinst moglich sein werde, die "großen Persönlichkeiten" der Geschichte aufzuerwecken (siehe II: 3.13.). Auch die von Majakovskij in seinem Poem Pro éto geschilderte künftige Auferweckung einiger Auserwahlter erinnert weit mehr an Rožkov denn an Fedorov (siehe II: 3.2.1). Rozkov selbst wiederholte zu Beginn der zwanziger Jahre seine Oberzeugung, daB "in ferner Zukunft" die Menschen Unsterblichkeit erlangen und die Auferweckung Verstorbener bewerkstelligen würden (siehe II: 3.1.3.). 


\subsubsection{Das Problem des Todes im naturwissenschaftlichen Denken}

Das Problem des Todes beschäftigte in Rußland um die Jahrhundertwende nicht nur Philosophen und Schriftsteller, es war auch Gegenstand exakter Forschung und darauf sich gründender Theorien.

Dies gilt insbesondere für die Arbeiten des Biologen und Nobelpreisträgers I.I. Mečnikov (1845-1916), eines überzeugten Darwinisten und langiährigen Mitarbeiters von Pasteur in Paris. ${ }^{128}$ Auf der Grundlage naturwissenschaftlichpositivistischer Erkenntnisse über die "Natur des Menschen" entwarf Með̌nikov eine "optimistische Philosophie", deren Hauptanliegen es war, das Problem des Todes zu lösen. ${ }^{129}$ Mečnikov sah dieses Problem im wesentlichen darin, daß der Tod "... in einem Augenblick [eintritt], in dem der Mensch seine physiologische Entwicklung nicht abgeschlossen hat, und in dem er im Vollbesitz des Lebensinstinkts (instinkt zizni) ist ${ }^{130}$. Die gegenwärtige Lebensdauer reicht nicht aus, um den Lebensinstinkt soweit zu befriedigen, daß er von selbst erlischt und durch den "Instinkt des natürlichen Todes" (instinkt estestvennoj smerti) ersetzt wird. Diese "Disharmonie" von Lebensinstinkt (dem Verlangen, zu leben) und Lebensdauer (der Möglichkeit, zu leben) war für Meそ̌nikov die Hauptursache für Pessimismus, Todesfurcht und die naive Sehnsucht nach Unsterblichkeit und leiblicher Auferstehung. ${ }^{131}$ Die Lösung des Problems sah Mexnikov nicht in

128 Einen guten Überblick über Leben und Werk Mě̌nikovs gibt H. Zerss, Elias Metschnikow, Jena 1932. Neuerdings auch VA. FroLov, Operedivsij vremja, M. 1980. Vgl. ferner I.E. AMLINSKU, "Naužnyj traktat o relovečeskoj prirode i sredstvach izmenit' ee." [Nachwort zu] I.I. MECNIKOV, Etjudy optimizma, M. 1964, S. 294-333. Im geistes- und wissenschaftsgeschichtlichen Kontext behandelt Metnikovs Philosophie N.F. UTKINA, Pozitivizm, antropologiceskij materializm i nauka v Rossii, M. 1975, S. 286-294. Siehe auch A. ASNAGH, Storia ed escatologia del pensiero russo, Genova 1973, S. $229 f$.

129 Die Titel der beiden wichtigsten naturwissenschaftlich-philosophischen Werke von I.I. Meřnikov, die zuerst in franzosischer Ausgabe in Paris erschienen, lauten: Etudes sur la nature humaine. Essai de philosophie optimiste (1903; russ.: Etjudy o prirode Celoveka. Opyt optimisticeskoj filosofii. M. 1904) und Essais optimistes (1907; russ.: Etjudy optimizma, M. 1907). Die Arbeiten erregten großes Aufsehen und wurden alsbald in mehrere Sprachen übersetzt. Im folgenden wird nach den deutschen Ausgaben zitiert.

130 E. MetschnKoff [MECNKov], Studien über die Natur des Menschen. Eine optimistische Philosophie. Leipzig 1904, S. 379.

131 Ebd., S. 149-246, 346-399; hier bes. S. 377. - Ausführlich behandelt Metnikov in diesem Zusammenhang Religionen und philosophische Systeme als ÄuBerungen der Todesfurcht und zugleich untaugliche Versuche, die 'Disharmonien' der menschlichen Natur zu bekämpfen. Vgl. UTKINA (wie Anm. 128), S. 287-289. Frolov (wie Anm. 128), S. 232, $236 f$.

In seiner Schrift Literatura i revoljucija (M. 1923), die stark utopische Züge trägt, wiederholt Trockij diesen Gedanken, wobei er Mecnikovs Begriffe benutzt, ohne diesen jedoch zu erwăhnen: "Der befreite Mensch wird ein großeres Gleichgewicht in der Arbeit seiner Organe erreichen wollen ..., um schon allein dadurch die Angst vor dem Tode in die Grenzen einer zweckmåBigen Reaktion des Organismus auf Gefahr zu verweisen, weil ... gerade die ăuBerste Disharmonie [!] des Menschen - die anatomische und physiologische - die außerordentliche UngleichmäBigkeit der Entwicklung und Abnutzung der Organe und Gewebe dem Lebensinstinkt [!] eine verklemmte, krankhafte und hysterische Form der Angst vor dem Tode verleiht, die 
der Überwindung des Todes - ihn hielt er für unausweichlich und notwendig -, vielmehr zielten seine Forschungen über den Prozeß des Alterns und Sterbens darauf ab, Leiden, Krankheiten und Siechtum zu beseitigen, um auf diese Weise ein "pathologisches Alter" und den anormalen "vorzeitigen Tod" (preždevremennaja smert') zu verhindern, damit der Mensch zu einem seiner Anlage und seinem Lebensinstinkt entsprechenden "physiologischen Alter" und zu einem "natürlichen Tod" (estestvennaja smert') gelange. ${ }^{132}$ Das "Ziel der menschlichen Existenz" sah Meðnikov "im Vollenden des normalen Lebenszyklus, der [schließlich] zum Erlöschen des Lebensinstinkts führt und zu einem Alter ohne Krankheit, das [den Menschen] mit dem Tode aussöhnt ${ }^{\text {133 }}$. Die natürliche, (d.h. durch keine äußere Einwirkung verkürzte) Lebensdauer schätzte Mečnikov auf mindestens 100 bis 120 Jahre. Dieses Alter könne jedoch nur dann erreicht werden, wenn alle Ursachen für einen "vorzeitigen Tod" beseitigt würden, insbesondere Krankheiten und physische Defekte, aber auch schädliche Gewohnheiten und soziale Mißstände. Es sei, davon war Mečnikov überzeugt, mit Hilfe ausschließlich wissenschaftlicher Erkenntnisse und Methoden möglich, "die menschliche Natur zu modifizieren, ... ihre Disharmonien in Harmonien zu verwandeln ${ }^{\text {134 }}$ und damit die Bedingungen für ein "normales Leben" zu schaffen (Mě̌nikov prägte hierfür den Begriff "Orthobiose" [ortobioz]). ${ }^{135} \mathrm{Die}$ Beseitigung aller Krankheiten, Leiden und Defekte sowie, damit einhergehend, die Zunahme der Solidarität unter den Menschen ${ }^{136}$ und eine optimistische Le-

den Verstand trübt und dummen und erniedrigenden Phantasien von einem Leben nach dem Tode Nahrung gibt." L. TROCKע, Literatura i revoljucija, M. 1923, S. 189.

132 Vgl. MECNIKov (wie Anm. 130), S. 346-348, 366-399. DeRs., Beirnäge zu einer optimistischen Weltauffassung, München 1908, S. $132 \mathrm{f}$.

133 I.I. MEČnIKov, Akademiðeskoe sobranie sotinenij, t. 11, M. 1956, S. 29; zitiert nach I.T. Fro. LoV, "O Zizni, smerti i bessmertii. Etjudy novogo (real'nogo) gumanizma." In: Voprosy Filosofii, 1983, 1, S. 92. Vgl. MEČnIKOV (wie Anm. 130), S. 3796.

134 MEČNIKov, Beirräge (wie Anm. 132), S. 309.

135 MEĆnIKov (wie Anm. 130), S. 381. - In dieser Hinsicht vertraute Mečnikov - wie hundert Jahre zuvor Condorcet in seiner berühmten Esquisse d'un tableau historique des progrès de l'esprit humain - auf die "Allmacht der Wissenschaft" (ebd., S. 396); sie allein konne das Ziel des menschlichen Daseins erkennen und die Mittel bereitstellen, es zu erreichen. Vgl. UTKINA (wie Anm. 128), S. 292. M.J.A. CONDORCET, Entwurf einer historischen Darstellung des Fortschritts des menschlichen Geistes, Frankfurt/M. 1976, S. 219 (über die biologische Vervollkommnung des Menschen). Fedorov hatte Condorcets Gedanken einer individuellen Lebensverlăngerung "auf unbestimmte Zeit" (indefini) abgelehnt und "endloses" Leben (infini) for alle Menschen gefordert (FOD I, S. 429).

Wahrscheinlich unter dem Einfluß von Mečnikovs Theorie der "Orthobiose" (und vielleicht auch der Ideen William Godwins von der Macht des Geistes uber den Korper) entstand M.M. Zoszenkos 1933 veroffentlichte Novelle Vozuraszennaja molodost', in der es einem alten Astronomieprofessor gelingt, durch eigene Willensanstrengung seine verlorene Jugend wiederzuerlangen. Dasselbe Thema begegnet auch in Zostenkos postum (1972) erschienener Povest' o razume.

136 MeCnikov (wie Anm. 130), S. 392f., 397f. - Vgl. Utkina (wie Anm. 128), S. 291; Frolov (wie Anm. 128), S. 93. 
benseinstellung eröffneten die Aussicht auf einen vollkommenen, "physiologischen Lebensablauf" und einen "natürlichen Tod", dessen Eintritt mit dem Erlöschen des Lebensinstinkts und dem Erwachen des "Todesinstinkts" zusammenfalle, weshalb er seinen Schrecken verlieren und als natürlicher Abschluß eines erfüllten Lebens akzeptiert, ja geradezu herbeigesehnt werden würde. ${ }^{137}$

Mečnikovs Theorie der "Orthobiose" stieß bei den Zeitgenossen auf lebhaftes Interesse, rief aber auch vielfach Kritik hervor. So meinte Tolstoj ironisch, Mexnikov sei zwar ein "sehr gebildeter und gelehrter Mann", doch habe er keine Ahnung von dem, was die Menschen wirklich brauchten: "Das Übel liegt nicht darin, da $\beta$ wir zu kurz leben, sondern darin, da $\beta$ wir gegen uns und unser Gewissen leben. ${ }^{138}$ Der Moskauer Moraltheologe M.M. Tareev (1866-1934) bestritt

137 MeĆnikov (wie Anm. 130), S. 380. - Vgl. Utkina (wie Anm. 128), S. 290. Meðnikovs hier sehr verkürzt wiedergegebene Konzeption laßt sich schematisch folgendermaBen darstellen:

\section{Ist-Zustand}

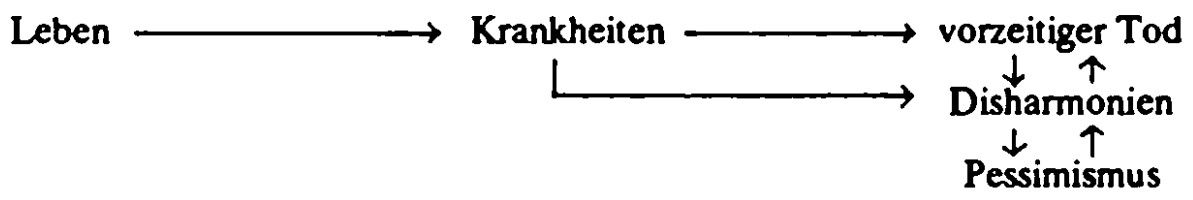

Soll-Zustand

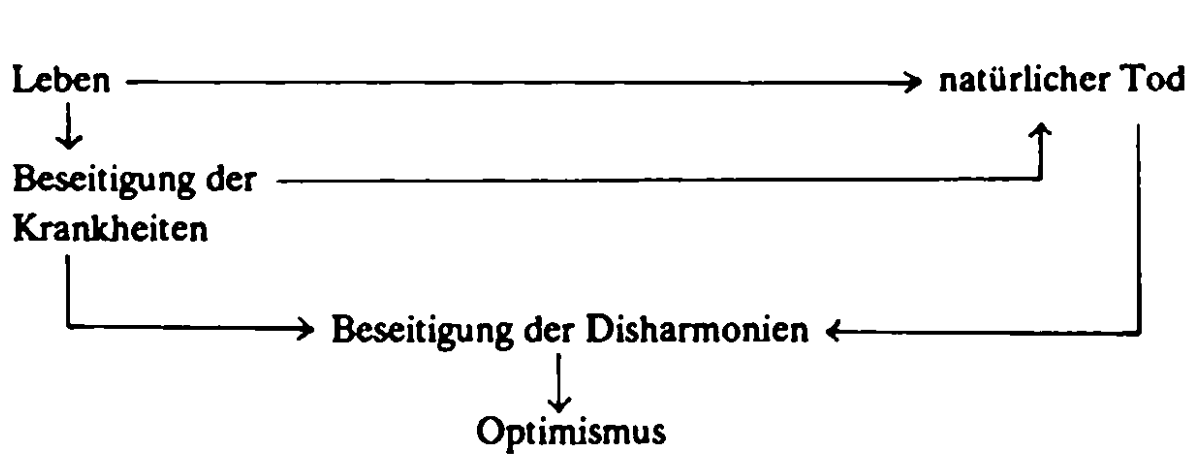

Nach Frolov (wie Anm. 128), S. 238.

Auf die weitgehend in der Tradition Meznikous stehenden Bemühungen russischer und sowjetischer Gerontologen, das menschliche Leben zu verlăngern und Gesundheit bis ins hohe Alter zu erhalten, braucht hier nicht naher eingegangen zu werden. Verwiesen sei in diesem Zusammenhang auf die anregende (wenn auch in den Details oftmals ungenaue und fehlerhafte) Studie von Peter Wiles, der in RuBland eine besondere Tradition des Interesses an Fragen der Langlebigkeit und physischen Unsterblichkeit feststellen zu konnen glaubt und dieses mit Hilfe oft kühner Spekulationen zu erklăren versucht. P. WILES, "On Physical Immortality." In: Survey, 1965, 56, S. 125-143; 57, S. 142-161. Vgl. ferner L. LIPEROVSKIJ, "Voprosy žizni i smerti v nauke i religii." In: VRSChD, 1930, 1, S. 9-17; 4, S. 6-14.

138 L.N. Tolstoj (1905); zitiert nach VolžsKu [d.i. A.S. GuNKA], "Problema smerti u prof. Mecnikova." In: DERS., Iz mira literatumych iskanij. Sb. statej. SPb. 1906, S. 264. Tolstoj wies Melnikovs Theorie der "Orthobiose" scharf zurück, da sie nur auf eine physische, nicht aber auf 
Með̌nikovs Anspruch, auf der Grundlage positivistischer Wissenschaft die Frage nach Sinn und Ziel des menschlichen Daseins beantworten und Regeln für ein 'richtiges Leben' begründen zu können. ${ }^{139}$ Unter Hinweis auf Mex̌nikovs Bemühen, das menschliche Leben zu verlängern, behauptete der Philosoph V.F. Ėrn, die Wissenschaft strebe danach, den Menschen unsterblich zu machen, doch werde ihr dies niemals gelingen. ${ }^{140}$ S.N. Bulgakov wandte sich gegen den Versuch, einen "spießigen Sieg über den Tod" zu erringen, indem man ihn "schmerzlos und bequem" mache und ihm damit seine "tragische Spitze" nehme. ${ }^{141}$ Von seinen Kritikern wurde Mečnikov oft mißverstanden, ging es ihm doch nicht wie immer wieder behauptet oder unterstellt wurde - nur darum, den Tod möglichst lange hinauszuzögern, und schon gar nicht darum, ihn zu überwinden. ${ }^{42}$ Die Verlängerung des Lebens war für Mečnikov kein Selbstzweck, sondern diente als Mittel, dem Menschen die Furcht vor dem (vorzeitigen) Tod zu nehmen. Fedorov, dem es um die Überwindung des Todes ging, nicht aber um eine Versöhnung mit ihm, ${ }^{143}$ hat diese Absicht Mečnikovs klar erkannt:

Das intellektuelle Europa hat sich vier Jahrhunderte lang bemüht und alle Kraft darauf verwendet, sich einzureden - wie dies auch Tolstoj tut -, daß der Tod eine gute Sache sei; doch hat es dabei offenbar keinen Erfolg gehabt, wenn es der Lehre von Mernikov bedurfte, wonach der Tod [dann] erwünscht wăre, wenn das Leben eine normale Dauer erreichen würde. ${ }^{144}$

eine sittliche Vervollkommnung des Menschen abziele. Bei einem von der Öfentlichkeit stark beachteten Besuch Mečnikovs in Jasnaja Poljana im Mai 1909 herrschte eine gespannte, fast feindselige Stimmung (ausführlich dazu Frolov, wie Anm. 128, S. 217-225). - Bemerkenswert ist in diesem Zusammenhang, daß Mecnikovs äterer Bruder Ivan Il'ið, ein Jurist, mit Tolstoj eng befreundet war; sein früher Tod im Jahre 1881 gab den AnstoB und Teile des Sujets für Tolstojs berühmte Erzăhlung Smert' Ivana Il'ica (1884-1886). Vgl. hierzu AMuINSKU (wie Anm. 128), S. 302. Frolov (wie Anm. 128), S. 218.

139 M.[M.] TAREEv, "Ortobioz. (Optimistizeskaja nauka i nravstvennost')." In: Bogoslovskij Vestnik, 17 (1908), 3,12, S. 560-582; hier bes. S. 578ff. - Tareev wies ferner darauf hin, daB der von . Metnikov behauptete "Todesinstinkt" eine bloße Annahme sei, deren Richtigkeit sich unter den gegebenen Bedingungen (vorzeitiger Tod) gar nicht nachprüfen lasse. Im übrigen enthălt Tareevs Aufsatz eine gute Darstellung der Grundgedanken der Theorie der "Orthobiose"; die Kritik ist sachlich, der Stil unpolemisch.

140 ERN (wie Anm. 40), S. 84f. [229-231].

141 S.N. Burgakov (wie Anm. 19), S. 43f. - Den gleichen Vorwurf erhob der Literaturkritiker Volžskij (Glinka) in seiner Auseinandersetzung mit Měnikov; siehe VolŽskJ (wie Anm. 138), S. 250-266.

142 So etwa R.C. WILllams, Artists in Revolution. Portraits of the Russian Avantgande, 1905-1925. London 1978, S. 19. BILLINGTON (wie Anm. 60), S. 486.

143 Es ist deshalb abwegig, Mecnikov mit Fedorov in Verbindung zu bringen; so BILLINGToN (wie Anm. 60), S. 486. V.I. MiL'DoN, "Besedy o paraliterature." In: Voprosy Filosofii, 1972, 1, S. 151. G.M. Young, The Philosopher of the Common Task. A Study in the Life and Thought of Nikolaj Fedorov. Ph.D. diss. Yale 1973, S. 205f. S.F. STARR, Melnikov. Solo Architect in a Mass Sociery. Princeton 1981, S. 253.

144 N.F. FEDOROV, Saxinenija, M. 1982, S. 637. - Hierbei handelt es sich um die einzige bekannte Äußerung Fedorovs zu Metnikov; sie findet sich in Fedorovs nachgelassenen philosophischen Fragmenten, die erstmals in der Moskauer Ausgabe von 1982 veröffentlicht wurden. 
Im Unterschied zu Mečnikov befaßte sich sein Schüler S.I. Metal'nikov (18711946) mit der Frage der realen Überwindung des Todes. Einen Weg dorthin sah er in der Erforschung der - erstmals von dem Zoologen August Weismann beschriebenen - potentiellen Unsterblichkeit einzelliger Lebewesen (Bakterien, Protozoen, einige Algen), die sich ungeschlechtlich durch anscheinend unbegrenzte Teilung fortpflanzen, ohne je eines natürlichen Todes zu sterben, die also im Gegensatz zu den höher entwickelten Arten keine 'Leiche' hinterlassen. ${ }^{145}$

Einen anderen Weg zur Überwindung des Todes beschritt der Biologe und Physiker P.I. Bachmet'ev (1860-1913): Er setzte Organismen niedrigen Temperaturen (zwischen $-4^{\circ} \mathrm{C}$ und $-10^{\circ} \mathrm{C}$ ) aus, bis sie keinerlei Anzeichen von Leben mehr zeigten, um sie dann mit Hilfe spezieller Verfahren wiederzubeleben. Berichten zufolge seien künstlich eingefrorene Fische und Amphibien nach dem Wiederauftauen und einer entsprechenden Behandlung "fröhlich im Aquarium herumgeschwommen"146. Durch die Erfolge dieses als "Anabiose" (anabioz) bezeichneten Phänomens glaubten Bachmet'ev und seine Mitarbeiter, das Problem der Unsterblichkeit seiner endgültigen Lösung nähergebracht zu haben; ein Glaube, der offenbar auch von einigen Anhängern Fedorovs geteilt wurde. ${ }^{147}$ Die geschilderten Versuche, die seinerzeit großes Aufsehen erregten, muten freilich recht primitiv an und wirken wenig überzeugend; dennoch dürften sie - insbesondere in den ersten Jahren der Sowjetmacht - die Phantasie fortschrittsgläubiger Autoren nicht unbeträchtlich angeregt haben. ${ }^{148}$

145 Moglicherweise unbegrenzte Teilungsfahigkeit und daumit potentielle Unsterblichkeit wird auch bei Tumorzellen beobachtet. - Zu Metal'nikovs Ansichten über die "Unsterblichkeit der Zelle" siehe den Bericht von V.S., "Sušestvuet li telesnoe bessmertie?" In: Nov' (Moskva), 9.3.1914, S. 3f. Vgl. ferner S.[I.] METAL'NKOV, Immonalite el rajeunissement dans la biologie moderne, Paris 1924. DERS., La lutte contre la mon, Paris ${ }^{4} 1937$. - Die auf Weismann zurückgehenden Theorien und Forschungen von Sergej Ivanovi Metal'nikov fanden in den zwanziger Jahren in der Sowjetunion großen Anklang und wurden dort insbesondere von A.V. Nemilov und I.I. Smal'gauzen fortgeführt. Vgl. LIPERovsku (wie Anm. 137). METAL'NKov, La lutte, a.a.O. Siehe auch II: 3.1.3.

146 [Bericht in:] Nov' (Mostva), 8.2.1914, S. 1 (mit Abb.!).

147 Vgl. A.I. BurSTtesn, Anabioz i ego prakticeskoe primenenie. Po professonu Bachmet'evu. Odessa 1913. P.I. BACHMET'EV, "Sedališe duSi. (Anabioz)." In: Vselenskoe delo, sb. 1, Odessa 1914, S. 59-85. L.M. LUCENKo, "Predely žizni. (Cholod i ego vlijanie na žizn')." Ebd., S. 99-104 (zum Problem der Unsterblichkeit bes. S. 101). Bei Vselenskoe delo handelt es sich um ein von Anhăngern Fedorovs herausgegebenes Sammelwerk (siehe II: 23.2.). - Zu Porfirij Ivanoviz Bachmet'ev siehe auch den entsprechenden Artikel in BSE (1-oe izd.), t. 5, M. 1927, Sp. 96f., aus dem hervorgeht, daß 1926 in der Sowjetunion Anstalten getroffen wurden, die unterbrochenen Forschungen zur Anabiose wiederaufzunehmen. Ähnliche Experimente mit dem Ziel einer "human hibernation" werden (mit freilich ungleich gröBerem technischen Aufwand) seit Jahren in den USA durchgeführt. Siehe R.C.W. ETtinger, The Prospect of Immortality, New York 1964.

148 So wird, um nur zwei Beispiele zu nennen, der Held in Majakovskijs Theaterstuck Klop (1928) - wenn auch versehentlich - eingefroren, um fünfzig Jahre spăter in einem "Institut für menschliche Auferweckungen" wiederbelebt zu werden; in Boris Pil'njaks Erzăhlung Delo smerti (1927) bittet der Leiter eines "Lebens-Instituts", seinen Korper einzufrieren und so lange aufzubewahren, bis die Wissenschaft imstande sein werde, ihn wiederzubeleben. (Siehe II: 3.2.1.). 


\section{2. Überblick über die Fedorov-Rezeption 1904-1917}

\subsubsection{Philosophen und Theologen}

Glaubt man dem Maler Leonid Pasternak, so wurde "der so lange unbekannte Name Fedorovs nach seinem Tode ... in ganz Rußland berühmt, und es gab ... keinen gebildeten Menschen, der nicht von ihm gehört hätte."1 - In Wirklichkeit verhielt es sich jedoch anders, ${ }^{2}$ wie im folgenden zu zeigen sein wird.

Am 16. Dezember 1903, einen Tag nachdem Fedorov gestorben war, erschien in der konservativen Tageszeitung Moskovskie Vedomosti der erste Nachruf auf ihn. Weitere Nekrologe und Gedenkartikel folgten. ${ }^{3}$ Sie alle zeugen von der hohen Wertschätzung, die der ehemalige Bibliothekar des Rumjancev-Museums in den Kreisen des gelehrten Moskau genossen hatte. Die Gründe dafür lagen in Fedorovs Persönlichkeit, seiner Bescheidenheit und Anspruchslosigkeit, seinem immensen Wissen und seiner unermüdlichen Hilfsbereitschaft. Eher beiläufig wurde hingegen bemerkt, daß Fedorov auch ein "origineller Denker" gewesen sei, der "eigenartige Ideen" vertreten und "getreu seiner Theorie" gelebt habe. Nur Jurij Bartenev und Nikolaj Černogubov gingen in ihren kurzen Gedenkartikeln auch auf Fedorovs Lehre ein und versuchten, ihre Grundzüge wenigstens zu skizzieren. ${ }^{4}$

Im Februar 1904 begann in der renommierten historischen Zeitschrift Russkij Archiv Koževnikovs großangelegte Studie über Fedorov zu erscheinen. Die fortsetzungsweise Veröffentlichung zog sich mit Unterbrechungen bis 1906 hin und brach dann $a b .^{5} 1908$ erschien die Arbeit, um einige Seiten erweitert, jedoch unvollendet, in einer Buchausgabe, die nur sehr geringe Verbreitung

1 L.O. Pasternak, Zapisi raznych let, M. 1975, S. 144. Vgl. DeRs., "Iz zapisok Leonida Pasternaka." In: Novyj Zumal, 77, 1964, S. 208.

2 Bereits Pasternak selbst enweist sich als nicht besonders gut informiert: Fedorovs Todesjahr gibt er mit 1904 an. (Ebd.).

3 Folgende Nachrufe und Gedenkartikel wurden ermittelt und waren zugănglich: G.G. [d.i. G.P. GeORGIEvSKU], "Pamjati Nikolaja Fedoroviza." In: Moskovskie Vedomosti, 344 (16.12.1903), S. 3. ANON., "N.F. Fedorov (Nekrolog)." In: Russkie Vedomosti, 346 (17.12.1903), S. 4. E.[S.] NEKRASOVA, "Pamjati N.F. Fedorova." In: Russkie Vedomosti, 353 (24.12.1903), S. 4. P.JA. Po. KROVSKIJ [d.i. G.P. GEORGIEVSKU], "Iz vospominanij o Nikolae Fedorovize. (K 40 dnju konđiny)." In: Moskouskie Vedomosti, 23-26 (23.-26.1.1904), S. 4f., 4f., 5, 4. JU.P. BARTENEV, "Pamjati Nikolaja Fedorovita Fedorova." In: Russkij Archiv, 1904, 1, S. 191f. (datiert 17.12.1903). N. [d.i. N.N. CERNOGUBOV], "Nikolaj Fedorovið Fedorov (15-go dekabrja 1903 g.)." In: Vesy, 1 (1904), 1, S. 54. V.I. SENROK, "Pamjati N.F. Fedorova i A.E. Viktorova." In: Istoriceskij Vestnik, 25 (1904), 95,2, S. 663-670. A. BASARgIN, "Myslitel'-samorodok." In: Moskovskie Vedomosti, 8 (8.1.1905).

4 Bartenev (wie Anm. 3). Cernogubov (wie Anm. 3).

5 Genaue bibliographische Angaben I: 2. Anm. 15. - Die Veröffentlichung stieß bei einem Teil der Abonnenten des Russkij Archiv auf Ablehnung. Siehe A.D. ZAJCEv, Petr Ivanovic Bartenev, M. 1989, S. 117. 
fand. ${ }^{6}$ Koževnikov, der fast dreißig Jahre mit Fedorov befreundet gewesen war, und einen großen Teil des schriftlichen Nachlasses besaß, teilte in seiner Studie viele Einzelheiten zu Leben und Werk mit, die sich nirgendwo sonst finden; es gelang ihm jedoch nicht (oder scheint nicht seine Absicht gewesen zu sein), Fedorovs Lehre in systematischer Weise so darzulegen, da $B$ ihre Grundzüge klar erkennbar werden: die zentralen Gedanken des obš̌ee delo gehen in einer Flut von Nebensächlichkeiten unter, und Fedorovs kühner Zukunftsentwurf wird mit keinem Wort erwähnt!

Im April 1904 erschien in Vernyj der erste Band der gesammelten Schriften, herausgegeben und eingeleitet von Koževnikov und Peterson. ${ }^{8}$ Die niedrige Auflage von 480 Exemplaren sollte unentgeltlich an Bibliotheken, gelehrte Gesellschaften und interessierte Privatpersonen abgegeben werden. ${ }^{9}$ Die Nachfrage war jedoch gering: Fünf Jahre später beklagte Peterson, das Buch habe noch immer keine Aufmerksamkeit auf sich gezogen; Gratisexemplare waren noch immer erhältlich. ${ }^{10}$

Entsprechend schwach war auch die Resonanz. Die erste und für lange Zeit einzige Rezension erschien Ende 1908 im Moskovskij Eženedel'nik. ${ }^{11}$ Verfaßt hatte sie Sergej Bulgakov, wahrscheinlich auf Wunsch Koževnikovs, mit dem er kurz zuvor bekannt geworden war. ${ }^{12}$ Fedorov, der "Moskauer Sokrates", ist für Bulgakov ein "rätselhafter Denker" (zagadoznyj myslitel'). ${ }^{13}$ Noch nie sei er "einem so unliterarischen, seltsamen, schwierigen und unsystematischen Schrift-

6 VA. KozeVnIKov, Nikolaj Fedorovic Fedorov. Opyt izloženija ego ucenija po izdannym i neizdannym proizvedenijam, perepiske $i$ liznym besedam. C. 1, M. 1908. - Das Werk ist außerst selten; in Westen ist nur ein Exemplar in der Universitătsbibliothek Basel ("Sammlung Lieb") bekannt.

7 Um die Leser des Russkij Archiv unit Fedorovs Lehre von der Auferweckung der Verstorbenen wenigstens in groben Zügen bekannt zu machen, bat der Herausgeber P.I. Bartenev seinen Sohn Sergej, eine kurze Darstellung darüber zu verfassen. Diese erschien in der 1 . Nummer des Russkij Archiv vom Jahre 1909. S.P. BARTENEv, "Nikolaj Fedorovið Fedorov. Dva razgovora o voskrełenii mertvych. " In: Russkij Archiv, 1909, 1, S. 119-122.

8 Siehe dazu auch I: 2.

9 N.P. PETERSON, "Predislovie." In: FOD I, XIf. - Auch Pankratov berichtet, daß der Band kostenlos angeboten wurde unter der Bedingung, daß der Leser über die 'Wirkung' berichte. A.[S.] PankRatov, "Filosof-pravednik." In: Novoe Slovo, 5 (1913), 8, S. 17.

10 N.P. PETERson, N.F. Fedorov $i$ ego kniga 'Filosofija obstego dela' v protivopolotnost' uXeniju L.N. Tolstogo 'o neprotivlenii' i drugim idejam naśego vremeni, Vernyj 1912, S. 20, 139. - Damit wird der immer wieder geăußerten Behauptung widersprochen, das Buch sei innert kürzester Zeit zu einer gesuchten Rarităt geworden.

11 S.N. Bulgakov, "Zagadołnyj myslitel'. (N.F. Fedorov)." In: Moskouskij Eženedel'nik, 48 (5.12.1908), S. 28-46; im folgenden nach dem Wiederabdruck in DERS., Dva grada. Issledovanija o prinade obstestvennych idealov. T. 2, M. 1911, S. 260-277.

12 Siehe Ders., "Pamjati Vladimira Aleksandrovił̌a Koževnikova." In: Christianskaja Mysl', 1917, $11-12$, S. 77 .

13 Bulgakov (wie Anm. 11), S. 260f; beide Bezeichnungen werden bis heute in der Fedorov-Literatur mit Vorliebe zitiert. 
steller begegnet"; gleichwohl gehörten Fedorov und sein Werk zu den "originellsten Erscheinungen des russischen Lebens der neueren Zeit". ${ }^{14} \mathrm{Da}$ es unmöglich sei, Fedorovs Lehre in kurzen Zügen darzustellen, beschränkt sich Bulgakov auf eine Skizze der Gedanken über die allumfassende Verwandtschaft und die daraus erwachsende Pflicht zur Auferweckung der Verstorbenen. Fedorovs "schwindelerregend kühnes 'Projekt" will Bulgakov religiös verstanden wissen, und er warnt davor, "Fedorovs religiöse Idee im Geiste der gegenwärtigen wissenschaftlichen Positivisten à la Meénikov zu interpretieren und [dadurch] ein religiöses Ideal in eine unerträgliche Banalität zu verwandeln.. ${ }^{15}$ Ausführlich behandelt er Fedorovs Einfluß auf Dostoevskij und Solov'ev; ${ }^{16}$ mancher Gedanke Solov'evs werde erst vor dem Hintergrund der Lehre Fedorovs verständlich.

Bulgakovs Aufruf, sich ernsthaft und intensiv mit Fedorovs Ideen auseinanderzusetzen, fand in den Kreisen der philosophischen und literarischen Intelligenz zunächst keinen erkennbaren Widerhall. Die wenigen Beiträge, die zu Fedorov erschienen, stammten aus der Feder unbekannter Autoren; sie zeichneten die bereits legendären Züge Fedorovs und befaßten sich, wo es um seine Lehre ging, mit Peripherem, ohne die zentralen Themen des Fedorovschen Denkens - Überwindung des Todes, Auferweckung der Verstorbenen und Umwandlung des Universums - auch nur zu berühren. ${ }^{17}$ So schilderte der Musikwissenschaftler A.A. Ginken (1847-1913) Fedorov als "idealen Bibliothekar", 18 und die Publizisten A. Beljaev und S.I. Matveev, beide aus Char'kov, begeisterten sich für die slavophilen und autoritären Elemente in Fedorovs Werk: Or-

14 Ebd., S. 261.

i5 Ebd., S. 268; Hervorhebung im Original. - Bulgakovs Warnung beweist sein Mißverstăndnis: Fedorov selbst bezeichnete seine Lehre als positivistisch - er nannte sie, im Unterschied zu reiner Theorie, einen "Positivismus des Handelns" (FOD I, S. 26) - und wollte seinen Begriff der Auferweckung im "tatsăchlichen und allereinfachsten Sinne" verstanden wissen (FOD I, S. 434).

16 Ebd., S. 268-274.

17 Eine Ausnahme bildet der in Anm. 5 genannte Aufsatz von S.P. Bartenev im Russkaj Archiv, der als Korrektur und Ergånzung zu Koževnikovs Studie gedacht war. - Dagegen beschrănkte sich der unbekannte Verfasser eines Artikels in der Petersburger Tageszeitung Novoe Vremja auf die Schilderung von Fedorovs asketischem Lebenswandel und behauptete, Fedorov habe (im Gegensatz zu Tolstoj) "nichts gelehrt, nichts gepredigt und keinerlei moralische oder soziale Ideen propagiert..." M. BA-N, "Dva bogoiskatelja." In: Novoe Vremja, 12471, 29.11.(12.12.) 1910, S. 3. Nicht zugánglich war mir ein Artikel über Fedorov, der unter dem Pseudonym "Kreslavskij" in Novoe Vremja erschienen sein soll (der einzige Hinweis darauf findet sich in einem Brief von N.P. Peterson an V.V. Rozanov vom 15.3.1914; nach einer Abschrift in Moskauer Privatbesitz).

18 A.[A.] GinKEN, "Ideal'nyj bibliotekar' - Nikolaj Fedorovið Fedorov. (Kratkaja charakteristika pokojnogo, kak reloveka i bibliotekarja, po literaturnym dannym)." In: Bibliotekar, 1911, 1, S. 12-26 (wieder abgedruckt in DERS., $O$ cienii $i$ knigach, SPb. 1914). - 1910 hatte Ginken einen Vortrag über Fedorov gehalten; siehe den Bericht darüber ANON., "Ideal'nyj bibliotekar'." In: Novoe Vremja, 12438, 27.10.(9.11.)1910, S. 4. 
thodoxie, Autokratie und Volkstum. ${ }^{19}$ Das obšcee delo wurde allenfalls am Rande erwähnt und vage als "Vereinigung der Menschheit in einer Familie" und "Kampf gegen das Böse" umschrieben. ${ }^{20}$

Hauptursache für dieses verzerrte Bild von Fedorov und seiner Lehre war die einseitige Darstellung, die Koževnikov in seiner Studie gegeben hatte. Hinzu kamen mehrere Veröffentlichungen aus der Feder Petersons, in denen die Filosofija obšcego dela als christliche Heilslehre gepredigt und - häufiger noch - gegen Tolstoj und dessen Ethik polemisiert wurde. ${ }^{21}$ Zur Erhellung der Grundgedanken Fedorovs tragen diese sektiererisch-eifernden Artikel und Traktate nichts bei (immerhin enthalten sie einige biographische Informationen und beleuchten Fedorovs Verhältnis zu Tolstoj). ${ }^{22}$

Wie sehr Koževnikov und Peterson bestrebt waren, von den zentralen Gedanken der Filosofija obščego dela abzulenken, bzw. sie zu 'entschärfen' und einer 'positivistischen' oder 'materialistischen' Deutung entgegenzuwirken, zeigt sich auch an ihrem Verhalten gegenüber einer kleinen Gruppe von Anhängern der religiös-revolutionären Bewegung des golgofskoe christianstvo. Diese waren in den Jahren 1912/13 auf Fedorov und seine Lehre aufmerksam geworden und hatten die Absicht geäußert, zum zehnten Todestag Fedorovs einen Sammelband herauszugeben, in dem das Problem des Todes und Möglichkeiten seiner Überwindung erörtert werden sollten. Koževnikov und Peterson befürchteten jedoch (nicht ganz zu Unrecht), Fedorovs Idee des obšcee delo werde von den golgofcy 'materialistisch' verstanden: Sie lehnten eine Mitarbeit ab und warnten andere vor dem Unternehmen. ${ }^{23}$

1913 veröffentlichen Koževnikov und Peterson in Moskau den zweiten Band der Werke Fedorovs. ${ }^{24}$ Die Resonanz war auch diesmal gering. Dabei hatten es die Herausgeber nicht an Werbung fehlen lassen: In der Presse waren Anzeigen erschienen, und dem zur gleichen Zeit in Petersburg veröffentlichten volkstümlichen Geschichtswerk Skazanija o Russkoj Zemli des Generals A.D. NeXvolodov

19 A. BeluaEv, "Vzgljad na samoderžavie episkopa Feofana i N.F. Fedorova." In: Vera i Razum [Char'kov], 1906, S. 313-331; zu Fedorov S. 319-330. S.[I.] MATVEEv, Filosofija obscego dela. (UČenie N.F. Fedorova). Char'kov 1912. Verănderter und ergănzter Wiederabdruck unter demselben Titel in der Moskauer Zeitschrift Svetod i Dnewnik Pisatelja, 1913, kn. 1, S. 123-129; kn. 2, S. 57-65. - Uber die Verfasser ist nichts Naheres bekannt.

20 Beluaev (wie Anm. 19), S. 321. MatVeev, Filosofija (wie Anm. 19), S. 9.

21 Vgl. N.[P.] PETERson, "Pis'mo k izdatelju Russkogo Archiva. Po povodu otzyva F.M. Dostoevskogo o N.F. Fedorove." In: Russkij Archiv, 1904, 2, S. 300f. DERS., "Predislovie." In: FOD I, S. V-XII. DERS., Pravda o velikom pisatele zemli nusskoj, gr. L.N. Tolstom k 55-letnemu jubileju ego literatumoj dejatel'nosti, Novozerkassk 1908 (wieder abgedruckt in DERS., wie Anm. 10, S. 66-82). DERS., "Iz zapisok byvsego utitelja." In: PA. SERGEENKo (Hg.), Mezdunarodnyj tolstovskij al'manach, M. 1909, S. 257-268 (erweiterte und verănderte Fassung in DERS., wie Anm. 10, S. 83-93). DERS. (wie Anm. 10).

Ausführlich dazu II: 1.1 .

Ausföhrlich dazu II: 2.3.

Siehe I: 2. 
lag in großer Auflage ein Prospekt der Filosofija obščego dela bei. ${ }^{25}$ Aleksandr Dmitrievic Nečolodov, ein Vertreter konservativer, monarchistischer Kreise, der sich auch als Antisemit hervortat, war mit Koževnikov befreundet und von diesem auf Fedorov aufmerksam gemacht worden. Im Vorwort zu seinen Skazanija rühmte der General Fedorov als einen der größten russischen Patrioten und betonte seine völlige Übereinstimmung mit dessen Ansichten über die führende Rolle Rußlands und seines Herrschers bei der Einigung und Erlösung der Menschheit. ${ }^{26}$

An Fedorovs Messianismus und seine geschichtsphilosophischen Spekulationen erinnerte auch der Artikel eines gewissen A. Moscanskij, der Ende 1914 in der Zeitschrift Russkaja Mysl' erschien: Fedorov, ein "wenig bekannter, aber höchst genialer russischer Denker", habe den Ausbruch des Krieges und die von den Deutschen verübten Bestialitäten lange vorausgesehen, als er vor dem Militarismus des "Schwarzen Kaisers" (Wilhelm II.) und der Übermensch-Lehre des "Schwarzen Philosophen" (Nietzsche) gewarnt habe. Den Voraussagen des "genialen Fedorov" zufolge, werde Rußland als Sieger aus dem Krieg hervorgehen und zum Initiator einer weltweiten Befriedung werden. ${ }^{27}$

Ausführlich behandelt wurden Fedorovs Gedanken in zwei anonymen Artikeln, die 1912 und 1914 in den Bjulleteni Literatury $i$ Żizni erschienen. ${ }^{28}$ Während sich der Verfasser des ersten Artikels bei seiner Darstellung von "Fedorovs Projekt" lediglich auf eine Schrift Petersons und die darin enthaltenen FedorovZitate stützen konnte, lagen dem zweiten Artikel beide Bände der Filosofija obš̌ego dela zugrunde: Durch gut ausgewählte Zitate wurde der Leser nicht nur mit den zentralen Gedanken - Tod und Auferweckung -, sondern auch mit einzelnen Vorschlägen - wie dem Einsatz der Streitkräfte und Kriegsgeräte im Kampf gegen die Natur - bekannt gemacht.

Eine knappe und im wesentlichen treffende Darstellung von Fedorovs Leben und Werk gelang auch dem Schriftsteller und Journalisten A.S. Pankratov in einem Aufsatz, der 1913 in der liberalen Petersburger Zeitschrift Novoe Slovo er-

25 V.A. Koževnikov an N.P. Peterson, 14.6.1913; Peterson-Archiv, GBL f. 657, k. 4: Pis'ma V.A. Koževnikova k N.P. Petersonu 1902-1916 gg.; nach einer Abschrift in Moskauer Privatbesitz. Der Prospekt lag mir nicht vor.

26 A.[D.] NECVolodov, Skazanija o Russkoj Zemle, $x .1$, izd. 4-oe, SPb. 1913, S. IIIf. - Das aufwendig gestaltete Werk hatte eine Auflage von 160.000 Exemplaren; hinzu kam noch eine Luxusausgabe.

27 A. Moscansku, "Mysli i predskazanija N.F. Fedorova." In: Russkaja Mysl', 35 (1914), 12, S. 140-145. - Uber den Verfasser ist nichts Năheres bekannt.

Auch Peterson widmete (kurz vor seinem Tod) Fedorovs geschichtsphilosophischen Spekulationen über das Verhältnis zwischen Rußland und Deutschland eine eigene Darstellung, die jedoch ungedruckt blieb: N.P. PETERSON, Kratkoe izlożenie principov 'Filosofii obšzego dela' v svjazi s vojnoj s Germaniej v 19141918 g.g., Ms. [Masch.], 31 Bl.; Privatarchiv Moskau. - Zum selben Thema siehe auch den Artikel von BERDJAEV (Anm. 65).

28 ANON., "Ideja vseobšego spasenija ot smerti." In: Bjulleteni Literatury i Žizni, 7, 1912 (dekabr'), S. 301-308. ANON., "Ideja vseobšcego spasenija ot smerti." Ebd., 12, 1914 (fevral'), S. 687-692. 
schien. $^{29}$ Zwar überwog auch bei Pankratov das Anekdotisch-Biographische, dennoch vermochte er auf wenigen Seiten, die der Filosofija obšcego dela gewidmet waren, die immanente Auferweckung aller Verstorbenen als Fedorovs zentrales Anliegen herauszustellen, dem alle übrigen Projekte (Raumfahrt, meteorologische Regulierungen, politische und soziale Veränderungen) untergeordnet seien. Anders als seine Vorgänger, hob Pankratov die Originalität und Kühnheit dieses Gedankens hervor und betonte - im Unterschied etwa zu Koževnikov und Peterson - den Gegensatz zur traditionellen Orthodoxie. ${ }^{30}$ Zwar sei Fedorov "in seinem Herzen ein Orthodoxer" gewesen, doch habe "sein philosophischer Verstand das Fundament der kirchlichen Orthodoxie gesprengt. ${ }^{n 1}$ Fedorovs Konzeption der Auferweckung könne von der Orthodoxie niemals akzeptiert werden; für sie bleibe er ein Häretiker. Um so mehr sei Fedorov ein "Philosoph der Zukunft": Dereinst würden Materialisten und Positivisten seine Lehre würdigen und erkennen, $\mathrm{da} B$ es "nie einen kühneren und genialeren Versuch gegeben habe, den Mystizismus in den Mauern seiner eigenen Behausung zu zerstören. ${ }^{\text {32 }}$ Fedorovs Lehre nehme einen "bedeutenden Platz im philosophischen Denken der Welt" ein und werde zweifellos schon bald "ihren Systematisator und Popularisator" finden. ${ }^{33}$

Nun meldeten sich auch die Theologen zu Wort: Vom Dezember 1913 an veröffentlichte die von der Moskauer Geistlichen Akademie herausgegebene Zeitschrift Bogoslovskij Vestnik eine Reihe von Aufsätzen, in denen Fedorovs Lehre dargestellt und vom Standpunkt der Orthodoxie bewertet wurde. Verfasser war S.A. Golovanenko, ein junger, philosophisch gebildeter Theologe, der 1912 als Schüler von Pavel Florenskij die Akademie absolviert hatte. ${ }^{34}$

29 Pankratov (wie Anm. 9), S. 17-25. - Aleksandr Savvic Pankratov (1872-1922) arbeitete als Schriftsteller und Journalist für die Zeitschriften Russkoe Slovo und Russkoe Bogatstvo; ausführlich schilderte er das zeitgenठssische Sektenwesen und Gottsuchertum, verfaBte mehrere Aufsătze über L.N. Tolstoj und beteiligte sich an dem zum Andenken Fedorovs herausgegebenen Sammelband $V$ selenskoe delo, sb. 1 (siehe II: 2.3.2.). Pankratov soll auch eine Biographie Fedorovs verfaBt haben. Sie ist jedoch nie erschienen. Das druckfertige Manuskript des Buches soll in den Wirren der Revolution und des Bürgerkriegs verlorengegangen sein. Wann und wo Pankratov von Fedorov und seinem Werk erfuhr, ist nicht bekannt. Siehe I.[P.] KozodoEv [N.A. SETNICKU ?], "Bibliografija Filosofii Obšzego Dela." In: Vselenskoe delo, sb. 2, Riga 1934, S. 187. Siehe auch den Hinweis bei A.K. GoRnostaev [GoRsKU], Pered licem [sic] smerti, 0.0 . [Harbin] 1928, S. 5.

30 Und damit auch den Gegensatz zu Dostoevskij und Solov'ev: "Die Ähnlichkeit zwischen den Weltanschauungen Dostoevskijs und Solov'evs einerseits und der Fedorovs andererseits ist nur eine ăußerliche. In Wirklichkeit loste Fedorov das Problem von Leben und Tod selbstăndig und originell, und weder Dostoevskij noch Solov'ev konnten ihm darin zustimmen. Sie teilten vielmehr die einfache Ansicht der orthodoxen Kirche." (PANKRATov, wie Anm. 9, S. 22f.).

31 Ebd., S. 25.

32 Ebd., S. 23.

33 Ebd., S. 25.

34 Sergej Alekseevix Golovanenko (1888-1938) hatte mit einer Dissertation über "Das Problem der Erfahrung" bei PA. Florenskij promoviert. Er gehorte zum engen Schülerkreis Florenskijs. Forenskij war es auch, der als Redakteur des Bogoslouskij Vestnik die Veroffentlichung der 
Im ersten Beitrag ${ }^{35}$ gibt Golovanenko - in Form einer Rezension der beiden Bände der Filosofija obš̌ ego dela - einen Überblick über die Grundgedanken der Fedorovschen Lehre. Fedorov sei ein "tiefgründiger Denker" gewesen, sein Werk, "fast unbekannt", sei der "Versuch einer neuen Auslegung des Christentums". Im Zentrum stehe die Idee der Auferweckung, verstanden nicht als Neuschöpfung, sondern als immanente, mit wissenschaftlichen Mitteln zu bewerkstelligende Wiederherstellung des durch den Tod zeitweilig zerstörten Ganzen. In diesem Konzept fehlten, so Golovanenko, die christlichen Momente der Hoffnung und der Freiheit. Fedorovs 'Erlösung' sei determiniert: Sie werde ausschließlich zum Ergebnis des 'richtigen' Verhaltens der Lebenden gegenüber den Verstorbenen. Die Aufforderung zur Wiederherstellung des Vergangenen in der Zukunft (eine ausschließlich quantitative Veränderung) schließe schöpferisches Tun (eine qualitative Veränderung) - und damit Hoffnung und Freiheit aus.

In den beiden folgenden Beiträgen unternimmt Golovanenko den Versuch, Fedorovs Philosophie systematisch darzulegen, ${ }^{36}$ um sie dann in weiteren drei Artikeln aus der Sicht des orthodoxen Theologen einer Kritik zu unterziehen. ${ }^{37}$

Knapp und präzise werden zunächst die philosophischen Prämissen benannt, auf denen Fedorov sein Denkgebäude errichtet: die Identifizierung des Guten mit dem Leben, des Bösen mit dem Tod, des Bewußten mit dem Menschen, des Unbewußten mit der Natur; die Bedingtheit der Sterblichkeit, die sittliche Pflicht zur Beseitigung des Todes, die Welt als Projekt. Sodann wird Fedorovs Auffassung vom Wesen der Religion - Ahnenkult und Aufstand gegen den Tod und des Christentums, welches sich unverfälscht nur in der russischen Orthodoxie erhalten habe, dargestellt: Im orthodoxen Dogma sei das Gebot des obšcee delo als Gedanke enthalten, im orthodoxen Ritus manifestiere es sich in symbolischer Form, um schließlich als künftige außerkirchliche Liturgie verwirklicht zu werden. Die "allumfassende Auferweckung" wird als "äußere Regulierung" (der Natur) und als "innere Regulierung" (des Menschen) beschrieben; die Auffassung von samoderžavie (als Vater-Kind-Verhältnis) und von narodnost' (als Überlegenheit des Dorfes) skizziert. Fedorovs philosophische Begriffe von Sein und Wissen, von Subjekt und Objekt, theoretischer, praktischer und projektiver Vernunft werden an Beispielen seiner Auseinandersetzung mit Kant und Nietz-

Aufsătze Golovanenkos über Fedorov gegen den Widerstand des Rektors der Akademie, Bischof Feodor, durchgesetzt hatte. Zu Florenskijs Interesse an Fedorov siehe unten.

35 S.[A.] Golovanenko, "Filosofija obšege dela." In: Bogoslovskij Vestnik, 22 (1913), 12, S. 832 844.

36 Ders., "Filosofija smenti i voskresenija. (Proektivizm N.F. Fedorova)." Ebd., 23 (1914), 4, S. 664-688. DeRs., "Pravoslavie i kul't predkov." Ebd., 23 (1914), 5, S. 83-109.

37 DERS., "Immanentizm i christianskaja filosofija. (O real-filosofskich predposylkach N.F. Fedorova)." Ebd., 23 (1914), 7-8, S. 569-592. DERS., "Tajna synovstva. (O christianstve N.F. Fedorova)." Ebd., 24 (1915), 3, S. 498-516. DERs., "Proekt ili simvol? (O religioznom proektivizme N.F. Fedorova)." Ebd., 24 (1915), 6, S. 294-314. 
sche erläutert, seine Ablehnung von Rationalismus und Mystizismus am Beispiel Tolstojs und Solov'evs dargestellt.

Den zentralen Mangel der Fedorovschen Lehre sieht Golovanenko in der willkürlichen und unbegründbaren - Nichtannahme einer Transzendenz. Die Folge sei ein geschlossenes, mechanistisches Weltbild, in dem 'Freiheit' sich in der Kenntnis und Anwendung der Naturgesetze erschöpfe. Der Sinn der Geschichte (des wahren Fortschritts) sei die Wiederherstellung des Vergangenen als Verwirklichung der menschlichen Alleinheit. Wenn die 'Väter' wirklich tot seien (und nicht in einer 'anderen Welt' fortdauerten), so geschehe alles Bemühen um ihre Auferweckung einzig um der 'Söhne' willen: ihr Befinden solle gebessert, ihre Einsamkeit erleichtert, ihre Todesfurcht gemindert werden. Die immanente Auferweckung sei "im Grunde der extremste Ausdruck des natürlichen Kampfes ums Dasein, menschlicher Selbstschut $z^{n},{ }^{38}$ nicht aber geistige Erlösung, wie sie allein im Zusammenwirken von Menschlichem und Göttlichem, Immanenz und Transzendenz, verwirklicht werden könne.

Golovanenkos Artikel, die sich durch solide Kenntnis des Gegenstandes und eine objektiv-leidenschaftslose Darstellung auszeichnen, ${ }^{39}$ riefen heftige Kritik durch N.P. Peterson hervor. In einer rasch publizierten Broschüre ${ }^{40}$ sowie in einem Artikel, der 1916 im Bogoslovskij Vestnik erschien, ${ }^{41}$ versuchte Peterson, eifernd und gelegentlich gehässig, den "Verleumdungen" Golovanenkos entgegenzutreten und mit weitschweifigen Zitaten aus der Filosofija obšcego dela den "tief religiösen Charakter der gesamten Lehre Fedorovs" ${ }^{42}$ zu beweisen. ${ }^{43}$

Koževnikov war demgegenüber zurückhaltender, wenngleich auch er sich um die Propagierung Fedorovs als eines rechtgläubigen und national gesinnten Denkers bemühte. Doch war ihm bewußt, daß Fedorovs Lehre, sollte sie für Christen akzeptabel sein, einer "gründlichen Überarbeitung" bedurfte. Die Filosofija obščgo dela, so erklärte er gegenüber dem Theologen Anatolij Žurakovskij, ${ }^{44}$ sei "kein starres System", in dem nichts verändert werden" dürfe;

38 Ders., "Tajna synovstva..." (wie Anm. 37), S. 511.

39 Aus diesem Grunde wurde auf Golovanenkos Artikelserie unlängst hingewiesen - mit polemischer Spitze gegen die sowjetische Fedorov-Forschung. L. KELER [KoEHLER], "N.F. Fedorov i kritiki." In: Vexe, 13, 1984, bes. S. 69-73.

40 N.P. PETERson, O religioznom charaktere utenija N.F. Fedorova. (Po povodu statej SA. Golovanenki v 'Bogoslovskom vestnike' 1914 g.). M. 1915.

41 DeRs., "Christianstvo N.F. Fedorova, avtora Filosofii Obšrego Dela." In: Bogoslovskij Vestmik, 25 (1916), 1, S. 119-130.

42 Ders. (wie Anm. 40), S. 30 und pass.

43 In seiner kurzen Replik wandte sich Golovanenko vor allem gegen das - nicht nur von Peterson angewandte - Verfahren, Fedorovs christliche Lebensweise zur Charakterisierung seiner Lehre heranzuziehen. S.[A.] GolovanENKo, "Otvet N.P. Petersonu." In: Bogoslovskij Vestnik, 25 (1916), 1, S. 130-135.

44 A. Żurakovsku, Tajna ljubvi i tainstvo braka." In: Christianskaja Mysl', 1917, 3-4, S. 53. Żurakovskij bezieht sich auf ein "personliches Gesprăch" mit Koževnikov. 
vielmehr "könne und müsse sie überprüft und überarbeitet" werden, wobei insbesondere die von Fedorov vernachlässigte Frage der "Mitwirkung Jesu beim obšcee delo" in den Vordergrund zu rücken sei. Eine solche "Frage" hatte für Fedorov freilich gar nicht existiert. Indem Koževnikov sie stellte, wies er den Weg, auf dem in der Folge eine der zentralen Ideen Fedorovs immer wieder mißverstanden und verfälscht wurde: Aus dem kühnen Projekt einer Selbsterlösung der Menschheit wurde eine "göttlich-menschliche Angelegenheit ${ }^{n 45}$, bei der allenfalls der jeweilige Anteil strittig blieb. ${ }^{46}$

In den Jahren vor dem Ersten Weltkrieg gehörte Koževnikov dem "Kreis der nach christlicher Erleuchtung Suchenden" (Kružok išcušcich christianskogo prosvešcenija) an, einer konservativ-orthodoxen und neoslavophilen Vereinigung, die um das Jahr 1907 von dem Altphilologen und ehemaligen Tolstoj-Anhänger M.A. Novoselov (1864-1938), dem Gründer und Herausgeber der "Religiös-Philosophischen Bibliothek", und dem Zemstvo-Abgeordneten F.D. Samarin (1858-1916), dem ältesten Neffen des berühmten Slavophilen, in Moskau gegründet worden war. Zu den prominentesten Mitgliedern dieses Kreises, der sich als Gegenpol zu den 'modernistischen' Petersburger Religiös-Philosophischen Vereinigungen verstand, zählten die Philosophen und Theologen S.N. Bulgakov, P.A. Florenskij, G.A. Racinskij (1859-1939) und Fürst E.N. Trubeckoj (1863-1920), die religiösen Intellektuellen P.B. Mansurov (1860-?), S.N. Durylin (1877-1954) und Graf Ju.A. Olsuf'ev (1878-1939), der Rektor der Moskauer Geistlichen Akademie Bischof Feodor (Pozdeevskij) sowie der ehemalige Terrorist Lev Tichomirov (1852-1923) und der Priester Iosif Fudel' (1864-1918), einer der Führer des rechtsextremen "Bundes des russischen Volkes". 47 Auch Berdjaev und die Schriftstellerin Mariètta Šaginjan (1888-1982) verkehrten eine Zeitlang im Kreis um Novoselov, doch fühlten sie sich schon bald von dem dort herrschenden klerikalen Obskurantismus abgestoßen. ${ }^{48}$

Es kann als sicher gelten, daß in diesem Kreis - dem außer 12 bis 15 festen Mitgliedern jeweils 60 bis 80 Gäste angehörten - auch Fedorovs Gedanken rezipiert und diskutiert wurden. Der Anstoß dazu dürfte von Koževnikov ausgegan-

So ŽURAKovsKu (wie Anm. 44).

46 Siehe die 'Interpretationen' von Berdjaev und Bulgakov in diesem Kapitel.

47 Im Gegensatz zu den 'progressiven' Petersburger Religios-Philosophischen Vereinigungen wurde der konservative Kreis um Novoselov und Samarin von der Forschung bislang kaum beachtet. - Vgl. VA. Kožnvnkov u.a., "Feodoru Dmitrieviťu Samarinu ot druzej." In: Ba goslouskij Vestnik, 25 (1916), 10-12, S. 543-581. "Perepiska F.D. Samarina i svjasx. P.A. Florenskogo." In: Vestnik $R C h D, 125,1978$, bes. S. 252. Ausfürlich, aber nicht immer zuverlässig, die Erinnerungen von N.S. ARSEN'Ev, Das Heilige Moskau, Paderbom 1940, S. 185-193. DeRS., "Iz junosti. (Kartiny moskovskoj žizni)." In: Vozrożdenie, 18, 1951, S. 79-81. DERS., Iz nusskoj kul'tumoj i tworteskoj tradicii, Frankfurt/M. 1959, S. 105f. Siehe auch N. ZERNov, Russkoe religioznoe vozrozdenie XX veka, Paris 1974, S. 121f., sowie das wenig beachtete Werk des zeitgenossischen Beobachters A. GRATIEUX, Le mouvement slawophile d la veille de la revolution, $\mathrm{Pa}$ ris 1953.

48 NA. Berduat, Samopoznanie, Paris ${ }^{2}$ 1983, S. 212-214. M.S. SAGInjan, Čelovek $i$ rremja, M. 1980, S. 251f., 274-302; bes. S. 286. 
gen sein. Im Novoselov-Kreis hatte er Bulgakov kennengelernt, der damals noch von der "Errettung der Welt durch eine 'christliche Politik" träumte, und ihn mit Fedorovs Werk bekannt gemacht. ${ }^{49}$ Auch Florenskij, Trubeckoj und Berdjaev begannen sich zu jener Zeit für Fedorov zu interessieren und konnten in Koževnikov einen kompetenten Gesprächspartner finden. Es ist bekannt, daß Koževnikov Ausgaben der Filosofija obš̌̌ego dela sowie seine eigene Monographie über Fedorov an Mitglieder des Novoselov-Kreises verschenkte. Mariëtta Šaginjan erinnert sich:

Der schwerfällige und schweigsame Kožcunikov schenkte mir die beiden Bănde der Filosofija obšego dela von Fedorov. Darin waren erstaunliche ... weit vorausblickende Aufsătze. (...) Năchtelang sowie zwischen den Vorlesungen ließ ich mich durch ihre Lektüre faszinieren. ${ }^{50}$

Von Florenskijs Beschäftigung mit Fedorov zeugen gelegentliche Hinweise auf den "tiefgründigen" Denker sowie Zitate aus der Filosofija obščego dela in Florenskijs theologischem Hauptwerk Stolp $i$ utverždenie istiny und in den (noch unveröffentlichten) Vorlesungen zur Geschichte der Philosophie, die Florenskij 1916/17 an der Moskauer Geistlichen Akademie gehalten hat. ${ }^{51}$ Fedorovs zentrales Anliegen bleibt darin freilich unerwähnt, da eine materialistische, wissenschaftlich-technische Auffassung des obšcee delo für Florenskij unannehmbar war: In einem Brief an Koževnikov wies Florenskij die Idee einer "chemischen Auferweckung" entschleden zurück. ${ }^{52}$

49 Siehe Bulgakov (wie Anm. 12).

50 Saginjan (wie Anm. 48), S. 287. In ihren Erinnerungen (die zuerst in Novyj Mir erschienen) kommt Saginjan wiederholt auf Koževnikov und Fedorov zu sprechen; siehe ebd., S. 238, 252, 300, 440, 465. - Ein Exemplar von Koževnikovs Monographie über Fedorov mit handschriftlicher Widmung des Verfassers an F.D. Samarin aus dem Jahre 1908 befindet sich heute in der "Sammlung Lieb" der Universitătsbibliothek Basel.

51 Siehe P.[A.] FLoRENSKI, Stolp i utverzdenie istiny, M. 1914, bes. S. 459f.; ferner S. 614, 643, 703, 744, 789, 807. - VA. Nıkmin, "Chramovoe dejstvo kak sintez iskusstv. Svjašx. Pavel Florenskij i Nikolaj Fedorov." In: Vestmik RChD, 153, 1988, S. $41 f$.

52 Mitgeteilt in einem Brief von V.A. Koževnikov an N.P. Peterson, 14.6.1913; Peterson-Archiv, GBL f. 657, k. 4; nach einer Abschrift in Moskauer Privatbesitz. Vgl. auch Nikrtin (wie Anm. 51), S. $42 f$.

Der Maler Žegin, der Florenskij zu Beginn der zwanziger Jahre kennenlernte, berichtet von dessen ablehnender Haltung gegenüber Fedorovs Ideen. L. ŻEGIN [L.F. ŠECHTEL'], "Vospominanija o PA. Florenskom." In: Vestnik RChD, 135, 1981, S. 63. Demgegenüber spricht der Theologe Troickij wiederholt vom EinfluB Fedorovs auf Florenskij. Vgl. G.[F.] TROITSKY [Trolcku], "Florensky Alexandrobits Paulos." In: Thréskeutiké kai Ëthiké Enkyklopaideia, 11, Athēnai 1967, Sp. 1179. DERS., "In Memory of the Reverend Pavel Florensky." In: JMP, 1972, 11, S. 77. Für B. LuUBIMOV, 'Zagadka dlja issledovatelej i Citatelej." In: Teatral'naja Žizn', 1988, 20, S. 17, steht Florenskij mit seiner Auffassung vom Menschen als Verwandler der Wirklichkeit und Vollender der Schøpfung in der Tradition Fedorovs und des "russischen Kosmismus". Eine "gewisse ideologische Verwandtschaft zwischen beiden Philosophen" konstatiert auch N. KAUCHTSCHISCHWIL, "Pavel Florenskij teologo e cultore di cose artistiche." In: Strumenti Critici, 21 (1987), 1, S. 130. Ähnlich vage außert sich NikrnN, a.a.O., S. 41f. - Die Frage kann nach gegenwărtiger Quellenlage nicht geklărt werden. AufschluB konnte ein kürzlich aufgefundenes umfangreiches Manuskript Florenskijs geben, eine Rezension des Buches von A.M. TUBE- 
Anfang 1913 veröffentlichte Evgenij Trubeckoj im Moskauer religiös-philosophischen Verlag Put' (in dem auch Florenskijs opus magnum erschien), eine breit angelegte Studie über die Weltanschauung Vladimir Solov'evs. Ein Kapitel des zweibändigen Werkes war dem Verhältnis zwischen Solov'ev und Fedorov gewidmet. ${ }^{53}$ Trubeckoj begrenzt den Einfluß Fedorovs auf die mittlere Periode im Schaffen Solov'evs: beide hätten damals - unabhängig voneinander - die Grundzüge ihrer Weltanschauungen bereits entwickelt gehabt und seien dabei zu gewissen Übereinstimmungen gelangt. So habe Solov'ev, als er mit Fedorovs Projekt der allumfassenden Auferweckung und der Herbeiführung des Gottesreichs auf Erden bekannt geworden sei, dieses ohne weiteres in sein Gedankengebäude einfügen können. Dagegen sei Fedorovs Absicht, das obšee delo allein durch den Menschen und mit technisch-wissenschaftlichen Mitteln zu verwirklichen, dem Mystiker Solov'ev unverständlich und "organisch fremd" geblieben. ${ }^{54}$ Auf Petersons - wie immer heftigen - Einwand, Solov'ev selbst habe Fedorov als seinen "Lehrer und geistigen Vater" bezeichnet und mithin nicht nur dessen Projekt, sondern auch die Mittel zu seiner Verwirklichung akzeptiert, ${ }^{55}$ verweist Trubeckoj auf gegenteilige Äußerungen Solov'evs; zudem habe auch Fedorov

RovsKU, Voskresenie Christovo. Opyt mistiCeskoj ideologii paschal'nogo dogmata. Sergiev Posad 1916. Das Manuskript war mir nicht zugănglich.

Mit Florenskij personlich und geistig eng verbunden war der Philosoph Aleksej Losev (18931988), ein christlicher Neuplatoniker, der zu den bedeutendsten russischen Denkern dieses Jahrhunderts zăhlt. Losev war - und dies dürfte auch für Florenskij gelten - ein entschiedener Gegner der Fedorouschen Auferweckungslehre: In einem Gespräch mit mir (am 9.3.1984 in Moskau) bestritt Losev, daß es sich bei der Filosofija obšzego dela überhaupt um Philosophie handele und nannte Fedorovs Ideen "dumm" und "lăcherlich". Losevs einzige schriftliche Äußerung zu Fedorov findet sich in einem kurz vor seinem Tod verfaBten und erst postum veröffentlichten Aufsatz über Solov'ev; darin ist vom "schresklichen und ungeheuer ungeistigen Charakter" der Fedorovschen "Lehre von der physischen Aufenweckung der Verstorbenen" die Rede. A.F. LOSEv, "I ne pogasnet to, tto raz v duše zažglos'." In: Junost', 1989, 6, S. 63.

53 E.N. TRUBeckoJ, Mirosozercanie V.S. Solov'eva, t. 1, M. o.J. [1913], S. 78-85. Teilw. Vorabdruck unter dem Titel "Žiznennaja zadaca Solov'eva i vsemirnyj krizis Žizneponimanija." In: Voprosy Filosofii i Psichologii, 1912, 4 (114), S. 224-287 (zu Fedorov: S. 272-279). - Siehe auch die Rezension von N.[A.] BERDJAEV, "O zemnom i nebesnom utopizme." In: Russkaja Mysl', 34 (1913), 9, S. 46-54.

54 Diese Einschătzung teilt auch der Solov'ev-Biograph und -Herausgeber Radlov: Fedorovs Projekt habe Solov'ev nur kurze Zeit fasziniert; das Unmethodische, Phantastische und Wirre im Denken Fedorovs sei dem Philosophen fremd geblieben. E.L. RADLov, Vadimir Solov'ev. Żizn'i ǔ̉enie. SPb. 1913, S. 80.

55 N.[P.] PETERSON, "Zametka po povodu stat'i kn. E. Trubeckogo - 'Žiznennaja zadaca Solov'eva i vsemirnyj krizis žizneponimanija', - v 'Voprosach Filosofii i Psichologii', sentjabr'-oktjabr' 1912 goda." In: Voprosy Filosofii i Psichologii, 1913, 3 (118), S. 405-411. - Auf Florenskijs Veranlassung erweiterte Peterson seine Replik zu einem Aufsatz, der im Bogoslovskij Vestnik erscheinen sollte. Dies scheiterte jedoch am Einspruch des Rektors der Geistlichen Akademie. Daraufhin schickte Peterson seinen Aufsatz an Rozanov mit der Bitte um Veroffentlichung in der Petersburger Tageszeitung Novoe Vremja. Die Veroffentlichung kam nicht zustande. Angaben nach einem Brief Petersons an V.V. Rozanov, 15.3.1914; nach einer Abschrift in Moskauer Privatbesitz. Siehe auch II: 2.2.2. 
wiederholt auf die tiefen Meinungsverschiedenheiten hingewiesen, die zwischen ihm und Solov'ev in dieser Frage bestanden hätten. ${ }^{56}$

Fedorovs "bornierter (durnoj) Naturalismus und Materialismus" wurde auch von Berdjaev kritisiert. In einem langen Aufsatz, der im Sommer 1915 in der Zeitschrift Russkaja Mysl' erschien, setzte sich Berdjaev eingehend mit Fedorovs Werk auseinander. ${ }^{57}$ Dabei äußerte er durchaus Sympathie für den Verfasser: Fedorov sei ein "geniales Naturtalent" gewesen, ein "Original und Sonderling", ein "typisch russischer Sucher nach einer allumfassenden Erlösung", getrieben von grenzenlosem Mitleid und Verantwortungsgefühl. Auch einzelne Gedanken der Filosofija obščego dela fanden Berdjaevs Zustimmung, insbesondere Fedorovs "originelle Eschatologie", die Auffassung von der Bedingtheit der apokalyptischen Prophezeiungen, verstanden als Drohung, die durch kollektives menschliches Handeln abgewendet werden müsse. Diese "geniale Einsicht" in die Bedeutung der menschlichen Aktivität bei der Erlösung und Vollendung der Schöpfung werde jedoch korrumpiert durch einen geradezu anachronistischen Materialismus und Szientismus. Fedorovs "naiver Glaube" an die Allmacht positiven Wissens und seine "bornierte Verachtung (durnoe prenebreženle) jeglicher Mystik und Gnostik" hätten ihn gehindert, das "innere geheimnisvolle Leben der Natur", die "Irrationalität des Bösen" und die Bedeutung göttlicher Gnade für die Erlösung der Menschheit zu erkennen. Fedorov rationalisiere selbst das "Geheimnis des Todes", indem er die "religiöse Idee der Auferweckung" in eine "materialistische Utopie" verwandele, eine konservative zudem, da es ihm nicht um Erschaffung (tvorčestvo) eines neuen, sondern um die Wiederherstellung (vosstanovlenie) des alten Lebens gehe. Unannehmbar seien nicht nur die Mittel und Methoden, sondern auch das Ziel - die physische, materielle Auferweckung. Christus sei in einem "verklärten", "schwerelosen", "vergeistigten" Leib auferstanden, und auch die künftige Auferstehung sei nur in einem "mystischen Leib" denkbar. Fedorov aber fordere "eine physische, grob materialistische Auferwekkung der Toten. Er - ein gläubiger orthodoxer Christ - philosophier[e] wie ein reiner Materialist. ${ }^{n 8}$

In seinem 1916 erschienenen Werk Smysl tvorčestva versuchte Berdjaev sodann, Fedorovs Forderung ins Geistige zu wenden; das Ergebnis ist ein bemerkenswertes Beispiel gedanklicher Vernebelung:

Der Mensch ist schuld am Tode seiner Eltern und Vorfahren, und er muß sie auferwecken. Doch ist diese Auferweckung selbst nur außerhalb der Gattung möglich, in einer Verbindung dem Geiste

56 E.[N.] TRUBECKOJ, "Neskol'ko slov o Solov'eve i Fedorove. (Otvet N.P. Petersonu)." Ebd., S. 412-426.

57 N.[A.] BERDJAEV, "Religija voskrełenija. 'Filosofija obšcego dela' N.F. Fedorova." In: Russkaja Mysl', 35 (1915), 7, S. 75-120. - Bereits 1913 wird Berdjaev in einer Anzeige des Verlags Put' (am Ende des Buches von TRUBECKOJ, wie Anm. 53) als Verfasser einer Monographie über Fedorov genannt, die in der Reihe "Russkie mysliteli" erscheinen sollte, doch ist das Projekt, an dem auch Andrej Belyj beteiligt war (siehe unten Anm. 104), offenbar nicht über das Stadium der Planung hinausgelangt.

Ebd., S. 117. 
nach ( $v$ svjazi po duchu). Ein mystisch-aktives Verhalten gegenüber den Vorfahren verwandelt die Verbindung der Gattung in eine geistige, die sterbliche in eine unsterbliche. (...) Im Leben der Gattung ist der Tod unvermeidlich. Nur im Geiste ist ein Sieg über den Tod, eine Auferstehung der Toten möglich. 59

Abgesehen davon, daß Fedorovs materialistische Konzeption der traditionellen christlichen Lehre von der 'Auferstehung des Fleisches' (wie sie von Augustin und Thomas von Aquin vertreten wurde) näher kommt als Berdjaevs mystische 'Wiedergeburt im Geiste', ${ }^{60}$ zeugt Berdjaevs Kritik von einem erstaunlichen Mangel an Bereitschaft, sich auf Fedorovs monistisches Welt- und Menschenbild einzulassen. Erübrigt hätte sich dann die Frage, ob Fedorov an die Unsterblichkeit der Seele geglaubt habe, ${ }^{61}$ oder der Vorwurf, er spreche über Mystizismus genauso "wie irgendein beliebiger Marxist-Materialist". ${ }^{62}$ Von einem tiefen Mißverständnis zeugt schließlich Berdjaevs Behauptung, Fedorov zufolge hänge "die allumfassende Erlösung und Auferstehung nicht nur von Gott, sondern auch vom Menschen, von seiner eigenen Aktivität" ab. ${ }^{63}$ Von einem Beitrag Gottes zum obšcee delo ist bei Fedorov nicht die Rede. ${ }^{64}$

59 NA. Berdjaev, Smysl tvortestva. Opyt opravdanija ceioveka. M. 1916, S. 189f. Zu Fedorov auch S. 194, 336, 342f., 345, 358.

Auf der Grundlage vor allem dieses Werkes weist Boris Paramonov in einer originellen Studie, die der Herkunft utopischer Motive in Platonovs Roman Cevengur gewidmet ist, eine Reihe von Ubereinstimmungen im Denken Berdjaevs und Fedorovs nach: Wie Fedorov stellte Berdjaev das (projektive) Schaffen uber das (faktische) Dasein, das technisch-maschinell Erzeugte über das natürlich-geschlechtlich Gezeugte, Organische, den schøpferischen ganzheitlichen Androgyn über das gespaltene, zeugende und gebărende Geschlechtswesen. Paramonov deutet diese Ubereinstimmungen psychologisch - als Ausdruck der Misogynie und latenten Homosexualităt beider Autoren. B.[M.] PARAMONov, "Čevengur i okrestnosti." In: Kontinent, 54, 1987, S. 333-372; bes. S. 344-353. - Berdjaevs Streben nach Vergeistigung prägte auch seine positive Einstellung zum technischen Fortschritt: In dem 1915 entstandenen Aufsatz "Geist und Maschine" verherrlichte er die Maschine als Hervorbringung des Geistes und Wegbereiterin zu seiner Befreiung aus der Knechtschaft durch die Materie. NA. BERDJAEV, "Duch i masina." In: DERS., Sud'ba Rossii, M. 1918, S. 233-240.

60 Bereits 1905 hatte Berdjaev in seinem Entwurf einer idealistischen Ontologie fur das 'neue religiose BewuBtsein' zwischen "phănomenalem" und "noumenalem Leib" (oder Fleisch) unterschieden und nur letzterem "wahres", nămlich transzendentes Sein zuerkannt. N.A. BERDJAEV, "O novom religioznom soznanii." [1905] In: DERS., Sub specie aetemitatis, SPb. 1907, bes. S. 349-352. Spăter suchte Berdjaev dieses Konzept auch Fedorovs Lehre zu oktroyieren.

61 Berdjaev (wie Anm. 57), S. 116.

62 Ebd., S. 113.

63 Ebd., S. 78; Hervorhebung von mir; M.H.

64 Berdjaevs Mißverstăndnis rührt offenbar daher, daß er ganz der Solov'evschen Auffassung von der "freien Theurgie", d.h. der aktiven Mitwirkung der Menschheit mit Gott bei der Verwandlung der Welt, verhaftet bleibt. - Wann immer Berdjaev spăter auf Fedorov zu sprechen kam, wiederholte er zum Teil wörtlich das in "Religija voskrešenija" Gesagte - einschlieBlich aller Mißverstăndnisse. Freilich maßigte er im Laufe der Zeit seine Kritik und hob die ihm positiv erscheinenden Aspekte - Fedorovs "außerordentlich hohes sittliches BewuBtsein" und sein aktives Verstăndnis der Apokalypse als Drohung und Aufruf zum Handeln - stărker hervor. Ausführlich dazu II: 4.3.4. 
Fast gleichzeitig mit dem Aufsatz in Russkaja Mysl' veröffentlichte Berdjaev einen Artikel in den Birževye Vedomosti, in dem er einen ganz anderen Ton anschlug: ${ }^{65}$ Fedorov wird darin als weitsichtiger Warner vor dem deutschen Militarismus und Imperialismus geschildert, der früh schon auf die Bedrohung Rußlands durch das Bündnis des "Schwarzen Kaisers" mit dem Islam hingewiesen habe. Dem deutschen Willen zu Macht und Weltherrschaft habe Fedorov den russischen Willen zu weltweiter Einigung und Erlösung entgegengestellt und damit den "tiefen Unterschied zwischen dem Geist der slawischen und dem der germanischen Rasse" zum Ausdruck gebracht. ${ }^{66}$

Sergej Bulgakov, der schon früh vor einem positivistischen Verständnis der Filosofija obščego dela gewarnt hatte, unternahm in seinem 1917 erschienenen religiös-philosophischen Werk Svet neveðernij den Versuch, Fedorovs Lehre in einer Weise zu interpretieren, die dem tief christlichen Geist und der wahren Absicht ihres Verfassers gerecht werden sollte. ${ }^{67}$ Dabei konnte weder die Vorstellung einer rein physischen Auferweckung noch die Forderung, diese müsse ausschließlich das Ergebnis menschlichen Bemühens sein, bestehen bleiben.

Die materialistisch-mechanistische Annahme, wonach der Mensch eine Maschine sei, die durch den Tod zerstört werde, lasse, so Bulgakov, "streng genommen den Gedanken einer Auferweckung, d.h. einer Rückkehr desselben lebendigen Wesens ins Leben, überhaupt nicht $\mathrm{zu}{ }^{{ } 68}$ Mit wissenschaftlich-technischen Mitteln könnten allenfalls ähnliche "Doppelgänger" konstruiert werden, perfekt ausgeführte Nachahmungen, die in Wirklichkeit jedoch monströse Fälschungen seien. Auferweckung erfordere nämlich "nicht nur vollkommenste Ähnlichkeit, sondern auch numerische Identität. ${ }^{69}$ Einheit und Identität der Persönlichkeit würden jedoch nicht durch den sich ständig erneuernden und verändernden materiellen Organismus, sondern allein durch den überzeitlichen und unsterblichen Geist (oder die Seele) konstituiert. ${ }^{70}$ Auch Fedorov glaube an eine Seele, von der er jedoch lediglich sage, daB sie bei der Wiederherstel-

65 N.[A.] BerdjaEv, "Prorozestva N.F. Fedorova o vojne." In: Biržeyye Vedomosti, 15027 (15.8. 1915).

66 Dieser stark nationalistisch tơnende Artikel, in dem Fedorovs zentrales Anliegen nur am Rande enwahnt wird, bildet freilich eine Ausnahme unter Berdjaevs Äußerungen zu Fedorov.

67 S.[N.] BULGakov, Svet nevečemij. Sozercanija i umozrenija. O.O. [M.] 1917, S. 360-368.

68 Ebd., S. 360.

69 Ebd., S. 361.

70 Wie schon Berdjaev, hălt auch Bulgakov Fedorovs monistischer Konzeption eine eigene dualistische entgegen, ohne deren Uberlegenheit durch Argumente zu beweisen. Ungeklărt bleibt beispielsweise die Frage, wie eine geistige oder korperlose Substanz die Basis für personale Identităt bilden kann und welches die Kriterien zur Feststellung der Identităt solcher Substanzen sind. - Zum Identitătsproblem ausführlich T.D. ZAKYDALSKY, N.F. Fyodorov's Philosophy of Physical Resumection, Ph.D. diss. Bryn Mawr 1976. Zu Bulgakovs Ansichten über Unsterblichkeit und Auferstehung siehe L.J. SHEIN, "Sergius Bulgakov's Critique of Conditional Immortality." In: Abba Salama, 10 (1979), S. 245-256. 
lung des Körpers in diesen zurückkehre. ${ }^{71}$ In der Zwischenzeit, so mutmaßt Bulgakov, befinde sie sich offenbar in einer Art anabiotischem Zustand reiner Potentialität, was mit der christlichen Vorstellung einer Fortdauer im Jenseits nicht vereinbar sei. Schließlich könne die Seele nur in einen "vergeistigten", "verklärten" Körper zurückkehren, nicht aber in einen "wiederbelebten Leichnam". "Der Tod ... ist ein Akt, der viel zu weit über die Grenzen dieser Welt hinausgeht, als daß man ihn allein durch eine 'Regulierung der Natur', mit den Methoden einer physischen Wiederherstellung eines Körpers, bezwingen könnte ... ${ }^{72}$ Auferweckung und Geburt seien dem menschlichen Denken unbegreifbare schöpferische Akte göttlicher Allmacht.

Nachdem Bulgakov die Gegensätze zwischen Fedorovs Denken und der traditionellen christlichen Glaubenslehre formuliert hat, schlägt er eine erstaunliche Interpretation vor, durch die Fedorovs Idee auch für Christen akzeptabel gemacht werden soll. Fedorovs Projekt dürfe "nicht buchstäblich", sondern müsse "seinem Geiste nach" verstanden werden, "nicht naturalistisch, sondern religiös-symbolisch":

Vielleicht entspricht folgender Gedanke eher seinem [Fedorovs; M.H.] hohen religiosen Geist: Die Auferstehung der Toten ist ein gottlich-menschlicher Akt (akt bogoxeloveceskij), der die Vereinigung göttlicher Gnade und menschlichen Handelns verlangt. Wăhrend der göttliche Aspekt der Auferweckung voll anerkannt bleibt, soll der Mensch seinen Anteil daran durch entsprechende Bemühung, durch sein eigenes Streben nach Auferweckung beweisen. ${ }^{73}$

Durch diesen Kompromiß wird die ethische Begründung des obšcee delo weitgehend aufgegeben. ${ }^{74}$ Gerade sie ist es aber, die - wie Bulgakov an anderer Stelle hervorhebt - Fedorovs Utopie vor den säkularen Fortschrittslehren auszeichnet: In seiner 1917 erschienenen Schrift Christianstvo i socializm ${ }^{75}$ geißelt Bulgakov die Vorstellung eines künftigen sozialistischen Paradieses auf Erden, das durch Mühen und Opfer zahlloser Generationen geschaffen wurde, die dem Vergessen anheimgefallen sind:

Dieses Bild eines Festmahles der Nachkommen auf den Gräbern der Vorfahren ist abstoßend durch seine Grobheit und seinen Zynismus; faktisch wird hier eben jene Menschheit ausgeloscht, in deren

71 Fedorov spricht von "BewuBtsein"; die betreffende Stelle lautet: "... der Organismus ist eine Maschine, und ... das BewuBtsein verhălt sich zu ihm wie die Galle zur Leber; setzt die Maschine zusammen, und das BewuBtsein kehrt in sie zurück!" FOD I, S. 288; siehe auch I: 3. Anm. 180.

72 Bulgakov (wie Anm. 67), S. 361.

73 Ebd., S. 364.

74 So auch ZAKYDALsKY (wie Anm. 70), S. 104f.

75 S.N. Burgakov, Christianstwo i socializm, M. 1917 Moskovskaja prosvetitel'naja komissija pod red. N.N. Alekseeva). - Diese kleine Schrift, die eine unmittelbare Reaktion auf die revolutionăren Ereignisse darstellt, ist heute eine bibliographische Rarităt. Benutzt wurde ein Exemplar in der Lenin-Bibliothek, Moskau. 
Namen die Werke des Fortschritts vollbracht werden, sie wird in einzelne, abgesonderte, einander nicht kennende Generationen zerrissen. ${ }^{76}$

Im Unterschied zum Sozialismus, dessen Interesse allein auf das Wohlergehen der letzten Generationen gerichtet sei, erinnere Fedorov an die Schuld gegenüber den Vorfahren und fordere deren Rückerstattung. Damit aber sei sein Projekt - wenn auch praktisch undurchführbar - den sozialistischen Phantasien moralisch weit überlegen. ${ }^{7}$

\subsubsection{Symbolisten}

In den Jahren vor der Revolution waren es zumeist religiöse Philosophen und Theologen, die Fedorovs Werk rezipierten und sich öffentlich mit ihm auseinandersetzten. Eine - wenn auch erheblich geringere - Resonanz fanden Fedorovs Gedanken darüber hinaus bei einigen symbolistischen Dichtern und Schriftstellern, vor allem bei Brjusov, Belyj und dem wenig bekannten Valerian Borodaevskij.

Valerij Brjusov hatte (wohl als einziger unter den Symbolisten) Fedorov noch persönlich gekannt. Über eine Begegnung, die am 20. April 1900 im Haus von Jurij Bartenev stattfand, notierte er:

Freitag abend ... war ich bei Ju. Bartenev. Sah dort außer Koževnikov auch Nikolaj Fedoroviz [Fedorov], den großen Lehrer des Lebens, den unbăndigen Alten, unter dessen scharfer Zunge auch Solov'ev und Tolstoj zu leiden hatten. Von Beginn des Gesprăchs an attakierte er mich.

"Wie auch immer, sterben müssen wir doch", sagte ich. "Haben Sie sich denn die Mühe gemacht, daruber nachzudenken, ob das wirklich so ist?", fragte Nikolaj Fedoroviz.

76 Ebd., S. 21. - Siehe auch Bulgakovs frühe Kritik an innerweltlichen Fortschrittskonzeptionen in II: 2.1.1.

$77 \quad \mathrm{Zu}$ Fedorov ebd., S. 20-23.

In spatteren Arbeiten kam Bulgakov gelegentlich auf Fedorov zurück, ohne jedoch dem hier Gesagten Wesentliches hinzuzufügen. Vgl. z.B. S.[N.] Bulgakov, "Duła socializma." [1] In: Novyj Grad, 1, 1931, bes. S. 54, 57f. [DERS.], "Ideja obšego dela." [Vosproizvedenie po pamjati nekotorych myslej doklada ... S. Bulgakova]. In: Vestnik RSChD, 9 (1934), 10, bes. S. 17f. DERS., Social Teaching in Modem Russian Orthodax Theology, Evanston, III. 1934, bes. S. 17-20. DERS., Nevesta agnca. O bogacelovedestue. C. 3, Paris 1945, bes. S. 372-374. DERS., "Sofiologija smerti." In: Vestnik RChD, 128, 1979, S. 29. Siehe auch II: 4.3.4. - Zu Bulgakov und Fedorov vgl. L.A. ZANDER, Bog i mir. (Mirosozercanie otca Sergija Bulgakova). T. 1, Paris 1948, S. 386f. H.-J. RUPPERT, "Religioser Utopismus und Eschatologie im russischen Denken." In: Materialdienst, 44 (1981), 10, bes. S. $281-286$.

Auch Bulgakov konnte der Kritik des eifernden Peterson nicht entgehen: In einem Schreiben an den Patriarchen Tichon aus AnlaB des Allrussischen Landeskonzils beklagte sich Peterson, daß mehrere Mitglieder des Konzils - danunter Bulgakov und E.N. Trubeckoj - Fedorovs Werke zwar besäben, sie jedoch nicht gründlich genug gelesen und deshalb nicht verstanden und entsprechend gewürdigt hătten. N.P. Peterson an Patriarch Tichon, 20.3.(2.4.)1918; Peterson-Archiv, GBL f. 657; nach einer Abschrift in Moskauer Privatbesitz. 
Das Gesprăch kam auf Nietzsche, und wie immer fiel Nikolaj Fedoroviz heftig über mich her. Ich blieb ihm gegenüber sehr freundlich, und als ich aufbrach (ich beeilte mich), dankte ich ihm. Jurij Bartenev aber dachte, ich sei beleidigt, und schickte mir ein Entschuldigungsschreiben. ${ }^{78}$

Um die Jahrhundertwende war Brjusov leitender Mitarbeiter des Moskauer Symbolistenverlags Skorpion (1900-1916), in dem, mit Unterstützung N.N. Cernogubovs und finanziert durch den Großfürsten Konstantin Konstantinovið, eine Ausgabe der Schriften Fedorovs erscheinen sollte; das Vorhaben wurde nicht verwirklicht. ${ }^{79}$ Nach Fedorovs Tod veröffentlichte Brjusov in der von ihm herausgegebenen Zeitschrift Vesy (1904-1909), dem 'Zentralorgan' des russischen Symbolismus, Černogubovs Nachruf, in dem dieser auch Fedorovs Anliegen skizzierte. ${ }^{80}$ Im Februar und Juli 1904 erschienen in Vesy die ersten namentlich gezeichneten Auszüge aus Fedorovs Schriften, ${ }^{81}$ die Zeichnungen von Šesterkin und Leonid Pasternak ${ }^{82}$ sowie ein Hinweis Brjusovs auf Koževnikovs Studie im Russkij Archiv. ${ }^{83}$

Auch in den folgenden Jahren zeigte Brjusov Interesse an Fedorov: Im Jahre 1908 wandte er sich an Koževnikov mit der Bitte, ihm den ersten Band der Werkausgabe und die soeben erschienene Monographie über Fedorov zu schikken. Koževnikov antwortete sofort und äußerte seinerseits den Wunsch, Brjusov möge beide Veröffentlichungen in Vesy besprechen, wobei er ihn bat, den "sehr

78 V.[JA.] Bruusov, Dnevniki 1891-1910, M. 1927, S. 85. - Am folgenden Tag erhielt Brjusov eine schriftliche Entschuldigung von Jurij Bartenev: "Es ist mir ăußerst unangenehm, daß Sie sich gestern bei uns einem so wütenden Angriff dieses zweifellos bedeutenden, jedoch unbeherrschten Alten aussetzen mußten. Beklagen Sie sich nicht über mich und seien Sie nachsichtig gegenüber einem achtzigjăhrigen [sic] Denker, unter dem auch Solov'ev und Tolstoj zu leiden hatten. Seine ungezăumte Zunge und sein hitziges Gemüt sind durch nichts zu bändigen." Ju.P. Bartenev an VJa. Brjusov; 21.4.1900; Archiv von VJa. Brjusov, GBL f. 386; zitiert nach S.S. GRECISKIN, A.V. LAVRov, "Andrej Belyj i N.F. Fedorov." In: Twortestvo AA. Bloka i nusskaja kul'tura XX veka. Blokovskij sbomik 3. Tartu 1979, hier S. 149.

Brjusov arbeitete von 1899 bis 1902 als Redaktionssekretăr bei P.I. Bartenev, dem Herausgeber des Russkaj Archiv und Vertrauten Fedorovs. In diese Zeit fällt die anonyme Veröffentlichung von Fedorovs Aufsatz "Cemu nauZaet drevnejక̌ij christianskij pamjatnik v Kitae?" (Russkij Archiv, 1901, 4, S. 631-637). Brjusov dürfte die Autorschaft Fedorovs bekannt gewesen sein. Siehe V.[JA.] BruUsov, Iz moej zizni, M. 1927, S. 93ff. Die betreffenden Angaben bei K.[V.] MoCur'SKU, Valerij Brjusov, Paris 1962, S. 60, sind nicht ganz zuverlässig.

79 S.G. Semenova, "Primełanija." In: N.F. Fedorov, Soxinenija, M. 1982, S. 695. Private Mitteilung, Moskau. - Năheren Aufschluß könnte der Briefwechsel zwischen Brjusov und Cernogubov aus den Jahren 1900 bis 1903 geben, der sich in der GBL befindet; er war mir nicht zugănglich.

80 Cernogubov (wie Anm. 3).

81 N.F. FEDORov, "Astronomija i architektura." In: Vesy, 1 (1904), 2, S. 20-24. DeRs., "O pis'menach. Posmertnaja stat'ja." Ebd., 6, S. 1-5.

82 In: Vesy, 1 (1904), 2, S. 20 (Pasternak). Ebd., 6, vor dem Titel (Pasternak); S. 1 (Sesterkin). Brjusov hatte sich selbst bei Pasternak um die Druckvorlagen bemüht (Mitteilung von E.B. Pasternak, Moskau).

83 ANON. [V.JA. Bruusov], "V Żumalach i gazetach. Russkij Archiv." In: Vesy, 1 (1904), 6, S. $65 f$. 
dezidierten Standpunkt [Fedorovs] hinsichtlich der Aufgabe der Kunst" nicht als "Vorwurf gegen die neue Kunstrichtung" aufzufassen. ${ }^{84}$

Brjusovs Interesse an Fedorovs Werk richtete sich auf zwei Themen: das Ausgreifen der Menschheit in den Weltraum und die Überwindung des Todes als Aufgabe der Wissenschaft. Die Vorstellung interplanetarischer Flüge hatte Brjusov seit seiner Kindheit fasziniert. Zunächst unter dem Einfluß der in Rußland enorm populären Werke Camille Flammarions und Jules Vernes, später dann angeregt durch Fedorovs und Ciolkovskijs Ideen, feierte Brjusov in Romanen, Novellen und vor allem in zahlreichen Gedichten die "Eroberung der Luft" und den Vorstoß in den Weltraum als Ausdruck eines 'prometheischen' Lebensgefühls. ${ }^{85}$ Wiederholt war dabei die Rede von einer Umwandlung der Erde in ein vom Menschen gesteuertes Raumschiff - ein Gedanke, der unmittelbar auf Fedorov zurückging, worauf Brjusov in einem Gespräch mit Emile Verhaeren im Jahre 1909 hinwies:

Wir sprechen über Aeroplane. (...) Ich bin froh, sagt Verhaeren, daß ich die Eroberung der Luft noch erlebe. Der Mensch muß über die Elemente herrschen, über Wasser, Feuer und Luft. Er muß lernen, sogar die Erdkugel zu lenken. Zum Erstaunen Verhaerens teilte ich ihm mit, daB diesen Gedanken bereits ein russischer Denker vorweggenommen hat, der alte Fedorov. ${ }^{86}$

Über Fedorovs Projekt schreibt Brjusov wenig später in seinem Aufsatz "Die Grenzen der Phantasie":

Der russische Philosoph Fedorov plante ernsthaft, die Bewegung der Erde im Raum dadurch zu steuern, daß man sie in einen riesigen Elektromagneten verwandele. Die Menschen könnten mit der

84 V.A. Koževnikov an V Ja. Brjusov, 9.12.1908; unveroffentlichter Brief im Archiv von V.Ja. Brjusov, GBL f. 386, k. 89, ed. chr. 55; nach einer Abschrift in Moskauer Privatbesitz. - Brjusov erhielt die genannten Werke mit Widmungen Koževnikovs, doch scheint er sie nicht besprochen zu haben. Unter den von Koževnikov an Brjusov geschickten Büchern befindet sich auch ein Widmungsexemplar des 2. Bandes der Filosofija obščego dela; GBL f. 386, knigi, ed. chr. 1129.

85 Vgl. K.S. Gerasimov, "'Sturm neba' v poėzii Valerija Brjusova." In: Brjusouskie ctenija 1963 goda, Erevan 1964, S. 130-153. A.F. BRTTKOV, Russkj sovetskij naulno-jantasticeskij roman, L. 1970, bes. S. 35-45. M.V. VASIL'EV, "Brjusov - poèt kosmonavtiki." In: V mire knig, 1972, 1, S. 12f. DERs., "Pervyj poèt nauťnoj kosmonavtiki." In: Brjusovskie čtenija 1971 goda, Erevan 1973, S. 19-32. V.B. MURAV'EV, "Neopublikovannye i nesoverక̌nnye povesti i rasskazy." In: $\mathrm{Li}$ teratumoe nasledstvo, t. 85 [Valerij Brjusov], M. 1976, hier S. 70-72. F.PH. INGOLD, Literatur und Aviatik, Basel 1978, bes. S. 181-189. GRECISKIN, LAVRov (wie Anm. 78), S. 150f. I.G. PANKENKo, "Kosmireskaja' tema v romanach V. Brjusova 'Gora Zvezdy' i A. Tolstogo 'Aèlita'." In: Briusovskie cienija 1983 goda, Erevan 1985, S. 248-258. - Mit Ausnahme von Gerasimov weisen alle genannten Autoren auf Fedorovs Einfluß hin. Mit Ciolkovskijs Arbeiten zur Raumfahrt wurde Brjusov erst relativ spăt - wahrscheinlich um 1919/20 - bekannt; siehe hierzu A.L. C'žzEVSKU, Vsja Lizn', M. 1974, S. 7479. In der Folge verfaßte er eine unvollendet gebliebene Erzăhlung über einen Flug der Erdenbewohner zum Mars ("Pervaja mežduplanetnaja èkspedicija", erstmals veroffentlicht in: Literatumoe nasledstvo, a.a.O., S. 103-113). Bereiis 1899 war der Raumfahrtroman "Gora Zvezdy" entstanden (erstmals veroffentlicht in: Fantastika 73-74, M. 1975, S. 191-236).

86 V.[JA.] BRuUsov, "Literaturnaja žizn' vo Francii. IV. Novye knigi Émilja Vercharna." In: Russkaja Mysl', 1910, 8; hier S. 6. 
Erde, wie mit einem gigantischen Schiff, nicht nur andere Planeten, sondern auch andere Sterne besuchen. Einmal habe ich versucht, diesen Traum des Philosophen in Verse umzusetzen, in meiner 'Hymne an den Menschen':

Ich glaube - Kühner! -, du wirst auf der Erde

Reihen von Segeln setzen.

Du wirst mit eigener Hand lenken

Den Lauf des Planeten zwischen den Gestimen ... ${ }^{87}$

Mehrmals noch kam Brjusov auf diesen Gedanken zurück, insbesondere in seiner "wissenschaftlichen Poesie"; so heißt es in dem Gedicht "Die junge Erden (1913):

Lenkt die Bewegungen des Planeten,

Seinen Lauf im Himmelsraum ...! ${ }^{88}$

In dem Gedicht "Die Jugend der Welt" (1922):

Ist es nicht an der Zeit, ...

die Erdkugel auf eine beliebige Umlaufbahn

zu lenken?

Und in dem Gedicht "Wie Blätter im Herbst" (1924), das wohl am stärksten von Fedorovs Gedanken beeinflußt ist:

Verbiegen wollen wir die Krümmungen der Umlaufbahnen,

Der Erde eine neue Drehung geben. ${ }^{90}$

Mit großer Anteilnahme verfolgte Brjusov die Fortschritte in Naturwissenschaft und Technik, ${ }^{11}$ doch bewahrte er daneben ein ausgeprägtes Interesse für magische und okkulte Theorien und Praktiken - er besuchte nicht nur Flugveranstal-

87 Zitiert nach Literatumoe nasledstwo (wie Anm. 85), S. 70f. - Vgl. auch - jeweils etwas abweichend - BRrnKov (wie Anm. 85), S. 43, und GRECISKIN, LAVROV (wie Anm. 78), S. 151. - Der unvollendete und bislang nur auszugsweise veroffentlichte Aufsatz ist zwischen 1911 und 1913 entstanden. Das Gedicht Gimn Celoveku (spăterer Titel Chvala Celoveku) wurde 1906 verfaBt moglichenweise unter dem EinfluB von Fedorovs Aufsatz "Astronomija i architektura" (siehe Anm. 81).

88 "Zemlja molodaja." In: V.[JA.] BRusov, SS v 7 t., t. 2, M. 1973, S. 100.

89 "Molodost' mira." Ebd., t. 3, M. 1974, S. 140.

90 "Kak list'ja v osen'." Ebd., S. 174.

91 Dabei ist Brjusov keineswegs der blinde Fortschrittsoptimist, als den ihn beispielsweise INGOLD (wie Anm. 85) zeichnet. Im Gegensatz zu seiner meist optimistischen 'Wissenschaftsdichtung' thematisiert Brjusov in seiner Prosa die Bedrohung des Menschen durch die Maschine (z.B. in den unvollendeten Erzahlungen Vosstanie masin [1908] und Mjaseż masin [1915]) oder schildert den katastrophischen Untergang hochtechnisierter Zukunftsgesellschaften (in dem Drama Zemlja [1904] und in der Erzăhlung Respublika Jutnogo Kresta [1904/5]). Ausführlich zu diesem Aspekt Brrnkov (wie Anm. 85). 
tungen, sondern auch spiritistische Sitzungen. ${ }^{92}$ Von einer Verbindung der strengen Methodik der "Universitätswissenschaften" mit den Erfahrungen und Traditionen der Geheimlehren (Magie, Okkultismus, Theosophie) versprach sich Brjusov eine Klärung der Frage, was der Tod sei und unter welchen Bedingungen Verstorbene fortdauerten oder ins Leben zurückkehrten. ${ }^{93}$

Ausführlich äußerte er sich dazu in einem Beitrag für den Sammelband $V$ selenskoe delo, der 1914 zum Gedenken an Fedorov von dessen Anhängern A.K. Gorskij und I.P. Brichnicev in Odessa herausgegeben wurde. ${ }^{94}$ Es sei, so Brjusov, durch Beobachtungen und Experimente bewiesen, daß die menschliche Persönlichkeit mit dem Tod nicht aufhöre zu existieren und da $\beta$ es Kontakte zwischen Lebenden und Verstorbenen gebe. Nunmehr müsse untersucht werden, welchen Bedingungen die postmortale Existenz gehorche, ob sie befristet sei (als "jenseitiges Leben") oder unendlich (Unsterblichkeit) oder ob es eine Möglichkeit gebe, in den Kreis der Lebenden zurückzukehren (Metempsychose). Die Klärung dieser Fragen sei Aufgabe der Wissenschaft unter Hinzuziehung der Arkandisziplinen.

Als "mögliche Aufgabe der Wissenschaft, die sie sich zu Recht stell[e]", bezeichnet Brjusov auch die Auferweckung (voskrešenie) - verstanden entweder als "Wiederherstellung der körperlichen Hülle einer Person, obwohl deren [höhere] Existenzbedingungen eine solche Hülle nicht [mehr] erforder[te]n" oder, wahrscheinlicher, als "Rückkehr einer Person ins Dasein nach Ablauf einer uns unbekannten Frist", die als "Wiedersein" (pakibytie) bezeichnet werden könne. ${ }^{95}$

Beide Auffassungen haben mit der von Fedorov geforderten Auferweckung nichts gemein, da sie eine wie auch immer geartete, in jedem Falle aber ununterbrochene Fortdauer nach dem Tode voraussetzen. Zwar betonte auch Brju-

92 Siehe Bruusov, Dnevniki (wie Anm. 78), S. 90. - Zwischen 1900 und 1902 schrieb Brjusov mehrere Artikel über Spiritismus, Mediumismus und Somnabulismus, die in der russischen Spiritistenzeitschrift Rebus erschienen; u.a. forderte er darin die Anerkennung des Spiritismus als Wissenschaft. Von Brjusovs Interesse an Magie, Alchimie und Dămonologie zeugt auch der 1907 erschienene historische Roman Ognennyj angel.

93 Mit dem Problem des Todes hatte sich Brjusov schon in jungen Jahren literarisch auseinandergesetzt, noch bevor er mit Fedorov und dessen Ideen bekannt wurde, wie die um 1890 entstandenen unveroffentlichten Skizzen Iz zapisok und Smert' zeigen. Siehe N. GuDZU, "Junołeskoe tvoræestvo Brjusova." In: Literatumoe nasledstwo, t. 27-28, M. 1937; hier S. 234.

94 V.[JA.] BRJusov, "O smerti, voskresenii $i$ voskresenii. (Pis'mo $v$ otvet na vopros)." In: Vselenskoe delo, sb. 1, Odessa 1914, S. 49f. (datiert: November 1913). - Es handelt sich um die Antwort auf eine Anfrage Brichnitevs vom Mai 1913. Fedorov wird in Brjusovs Beitrag nicht erwăhnt. Der erste Kontakt zwischen Brichnitev und Brjusov fallt in das Jahr 1910; seitdem hatte Brichnitev immer wieder versucht, Brjusov zur Mitarbeit an seinen religios-philosophischen und gesellschaftskritischen Zeitschriften zu bewegen. Siehe V.G. BAZANOV, "Razrußenie legendy." In: Russkaja Literatura, 1980, 3, bes. S. 97-99. Ausführlich unten II: 23.1., zu Vselenskoe delo II: 23.2. Im Archiv von V Ja. Brjusov (GBL f. 386) werden 11 Briefe der Korrespondenz zwischen Brichnizev und Brjusov aus den Jahren 1911 bis 1915 aufbewahrt (k. 78, ed. chr. 18); sie waren mir nicht zugănglich.

95 Bruusov (wie Anm. 94), S. 50. - Die erstgenannte Form der Auferweckung hălt Brjusov für überflüssig; sie gleiche der Rückverwandlung eines Schmetterlings in eine Larve. Die zweite Form der Auferweckung sei wissenschaftlich noch ungesichert. 
sov, Tod und Auferweckung seien "natürliche Phänomene", deren Erforschung und Erklärung Aufgabe der Wissenschaft sei, doch wollte er dabei - im Gegensatz zu Fedorov - okkulte Erfahrungen und magische Praktiken mit einbeziehen. Schließlich fehlt bei Brjusov die für Fedorov charakteristische ethische Begründung der Auferweckung aller Verstorbenen als höchster moralischer Pflicht. ${ }^{96}$

Satirisch behandelt Brjusov das Thema in der 1918 entstandenen Erzählung "Triumph der Wissenschaft" ${ }^{27}$ Ein "Theurgisches Institut" befaßt sich mit der Auferweckung Verstorbener durch Materialisation ihrer "psychischen Zentren", von denen es heißt, daß sie die Persönlichkeit konstituierten und nach dem Tode fortdauerten. Da hierzu möglichst viele und genaue biographische Daten benötigt werden, kommen nur berühmte Persönlichkeiten in den Genuß einer solchen Rückkehr ins Leben. Als das Verfahren - mit mäßigem Erfolg - an Hegel, Ninon de Lenclos und Judas Ischariot demonstriert wird, ist der Erzähler entsetzt und bittet, man möge ihm eine Auferweckung "mit wissenschaftlichen Methoden" ersparen.

Noch einmal kommt Brjusov auf die Überwindung des Todes zu sprechen: In dem bereits genannten Gedicht "Wie Blätter im Herbst" (1924) feiert er die Menschen als "Herren über das Leben", deren Aufgabe es sei, den Tod zu richten. In einer Anmerkung verweist Brjusov auf Fedorov, der "die Möglichkeit eines mit wissenschaftlichen Methoden geführten Kampfes gegen den Tod" untersucht habe. ${ }^{98}$

Andrej Belyj, der führende Theoretiker des russischen Symbolismus, dürfte schon früh mit Fedorovs Gedanken bekannt geworden sein. ${ }^{9}$ In der Zeit, da in Vesy Fedorovs Artikel erschienen, war Belyj ein enger Mitarbeiter des Blattes und verkehrte mit Brjusov und Cernogubov; letzteren nannte er in seinen Erinnerungen einen "Kenner Fets und Fedorovs" und bezeichnete ihn an anderer Stelle als fedorovec. ${ }^{100}$ Im Unterschied zu Brjusov, der von Fedorovs wissenschaftlich-technischen Projekten angezogen wurde, ordnete Belyj den Philosophen dem religiös-mystischen Denken zu und stellte ihn in eine Reihe mit Vladimir Solov'ev. ${ }^{101}$

96 Dazu auch GreCišrin, LAVROV (wie Anm. 78), S. 150.

97 V.[JA.] BRuUsov, Toržestvo nauki. (Zapiski posešcenija Teurgiłeskogo Instituta)." [1918] Erstveroffentlichung unter dem Titel "Ne voskrešajte menja!" In: Technika - Molodež, 1963, 12, S. 16-18.

98 BRusov (wie Anm. 88), t. 3, M. 1974, S. 174, 584. - Moglicherweise hatte Brjusov damals Kontakt zum Kreis der Moskauer Fedorov-Anhănger um NA. Setnickij und A.K. Gorskij (siehe II: 4.1.). Gorskij nahm im Oktober 1924 an Brjusovs Begrabnis teil. Bericht darüber in Gorskijs Brief an M.M. Skapskaja, 4.1.1925; CGALI f. 2182, op. 1, ed. chr. 280; Abschrift in Moskauer Privatbesitz.

99 Zum folgenden grundlegend GRECISKIN, LAVROV (wie Anm. 78).

100 A. BELYJ, Nacalo veka, M-L.1933, S. 168. DeRS., Mezdu dvuch revoljucij, L. 1934, S. 219.

101 So schreibt Belyj in seinem Nachruf auf Aleksandr Blok (1921), dieser habe in seinem Werk die "Themen Vl. Solov'evs und Fedorovs" und des gesellschaftskritischen Denkens von Lavrov, 
Wiederholt ist vermutet worden, Belyj habe in seiner "Zweiten (dramatischen) Symphonie" Fedorov in der Gestalt des "leidenschaftlichen Mystikers" Bars Ivanovic karikiert: dieser erscheint im letzten Bild auf dem Friedhof des Novodevicij-Klosters, auf dem Solov'ev begraben liegt, und "lehrt, die Toten aufzuerwecken". ${ }^{102}$ Es gibt jedoch keinerlei Hinweise darauf (und ist zudem sehr unwahrscheinlich), daß Belyj zu der Zeit, da er die "Zweite Symphonie" schrieb, nämlich im Sommer 1901, bereits eine Vorstellung von Fedorov und dessen Ideen hatte. ${ }^{103}$

Hingegen plante Belyj im Jahre 1912, ein ganzes Buch über Fedorov zu schreiben, das in der Reihe "Russische Denker" des religiös-philosophischen Verlags Put' erscheinen sollte. Der einzige Hinweis darauf findet sich in einem Brief an den Philosophen und Kritiker E.K. Metner (Medtner) vom Dezember 1912. Belyj, der sich damals in großen Geldnöten befand, kündigte an, er wolle, nachdem er den Roman Peterburg beendet habe, $21 / 2$ bis 3 Monate an einer Monographie arbeiten. Zunächst hatte er an ein Buch über A.A. Fet gedacht. Im Brief an Metner war dann von einer "Monographie über den ehrwürdigen 'Fedorov" ( $o$ starce 'Fedorove') die Rede. Der Gedanke schien Belyj freilich nicht zu begeistern, denn er fuhr fort: "... über den alten Fedorov zu schreiben, wird für mich eine moralische Qual sein (denn genauso wie eine Monographie über 'Schluchten', kann ich eine Monographie über 'Fedorov' schreiben: das eine wie das andere interessiert mich bis zu einem gewissen Grade, ganz ergriffen bin ich hingegen von etwas anderem, Fundamentalem). ${ }^{104}$ Das Buch - bereits

Herzen und Bakunin miteinander verbunden. A. BELYJ, "[Pamjati A. Bloka]." In: Literatumoe nasledstvo, t. 92 [Aleksandr Blok. Novye materiały i issledovanija], kn. 3, M. 1982, S. 829. Ähnlich auch A. BELYJ, "Vospominanija o Bloke." In: Epopeja, kn. 2, M.-Berlin 1922, S. 119. Dort heißt es weiter: "Das năchste Stadium ist die Verbindung der Philosophie Fedorovs (individuelle Auferstehung [sic]) mit der vertieften Problematik des nanodnitestvo, der Auferstehung des Volkskollektivs als Chor, als Orchester..."

102 A. BELYJ, "Simfonija (2-ja, dramatiðeskaja)." [1902] In: DERS., SS, t. 4, M. 1917, hier S. 286; zitiert nach dem Reprint: A. BELY, Cetyre simfonii, München 1971 ( = Slavische Propyläen; 39).

Als erster vermutete Mocul'skij in Bars Ivanovic eine Anspielung auf Fedorov. K.[V.] Mocuz'sKu, Andrej Belyj, Paris 1955, S. 38; siehe auch ebd., S. 118. Die Vermutung wurde übernommen und ausgeführt von V. GLoSKA, "Simfonija' (2-ja, dramatiłeskaja)." In: Zbomik Pedagogickej Fakulty v Banskej Bystrici, 17, Ruský jazyk a literatúra. Bratislava 1969, hier S. 217f. Ohne Hinweis auf Možl'skij spricht Tschižewskij davon, daß Bars Ivanovið wohl der "phantastische Moskauer Philosoph N.F. Fedorov" sei. D. TsCHIŽEWSKU, "Andrej Belyjs 'Symphonien'." In: BELYJ, Cetyre simfonii, a.a.O.; hier S. XVII. Was bis dahin nur Vermutung war, wird bei Koehler schließlich - ohne năhere Begründung - zur Gewißheit: "It is clearly [!] Fedorov (or one of his followers [!], possible V1. Solov'ev [!]) who is ment here, although Fedorov hardly could be described as a mystic." L. KOEHLER, N.F. Fedorov: The Philosophy of Action, Pittsburgh 1979, S. 90.

103 So Grečliskin, LAVRov (wie Anm. 78), S. 152.

104 Belyj an E.K. Metner, Berlin, 26.12.1912 (Archiv von E.K. Metner, GBL f. 167); zitiert nach A. BELYJ, Pelerturg, M. 1981, S. 514; siehe auch ebd., S. 691 Anm. 73. Mit einer Arbeit über Schluchten hatte Belyj 1903 sein naturwissenschaftliches Studium an der Moskauer Universităt abgeschlossen. Im Mai 1912 war er in Koln Rudolf Steiner begegnet, der in den folgenden Jahren sein geistiger Mentor wurde. - Zum Brief an Metner siehe auch GRECISKIN, LAVROV (wie 
1913 mit Berdjaev als Verfasser angekündigt ${ }^{105}$ ist nie erschienen, und es ist unbekannt, ob Belyj je daran gearbeitet hat.

In den Jahren 1916 und 1917 war Belyj häufig mit Berdjaev zusammen, der damals gerade seinen umfangreichen Aufsatz über Fedorov veröffentlicht hatte. Im Juni 1917 las er Bulgakovs Buch Svet neveðernij - auch dort war ausführlich von Fedorov die Rede. Im Februar 1918 erwähnte er schließlich "Anhänger $\mathrm{Fe}$ dorovs (fedorovcy) und Biokosmisten", mit denen er zusammengetroffen sei. ${ }^{106}$ Dennoch scheint sich Belyj in all den Jahren nicht näher mit Fedorov befaßt zu haben: Die bislang veröffentlichten Tagebuchaufzeichnungen, Briefe und Erinnerungen enthalten jedenfalls keine diesbezüglichen Hinweise.

Eine Ausnahme bildet - möglicherweise - die Erzählung Iog, die im August 1918 entstand, als Belyj einige Wochen im Moskauer Staatsarchiv als Hilfskraft arbeitete. ${ }^{107}$ Der Held dieser Erzählung, der Moskauer Bibliothekar Ivan Ivanovið Korobkin, weist - vor allem in seiner äußeren Erscheinung - bemerkenswerte Ähnlichkeit mit Fedorov auf: Seit fast vierzig Jahren arbeitet der inzwischen über 70jährige in der Bibliothek eines Moskauer Museums. Den Benutzern und Kollegen ist der gebückte, bärtige Mann mit dem "strengen, hageren Gesicht, das an Porträts des Dichters und Zensors Majkov erinnert", und der stets in abgetragener Kleidung erscheint, seit langem als Sonderling und Exzentriker bekannt. Korobkin ist ein "altmodischer Mensch", konservativ und eigenbrödlerisch, mit einem streng geregelten Tagesablauf und festen Gewohnheiten. ${ }^{108}$ Die weitere Handlung läßt dann freilich keinen Vergleich mit Fedorov zu: Korobkin erweist sich als Jogi, der mystische Literatur liest und durch Meditation und Kontemplation sein Bewußtsein erweitert. Nach einem Auftritt als apokalyptischer Prediger stirbt er, einsam und verkannt, im Juni 1918; er wird auf dem Friedhof beim Novodevicij-Kloster begraben. ${ }^{109}$

Anm. 78), S. 154f., M. LuUNGgren, The Dream of Rebinh. A Study of Andrej Belyj's Novel 'Pererburg'. Stockholm 1982, S. 81 f.

105 Siehe oben Anm. 57.

106 A. BELYJ, "Rakurs k Dnevniku" [recte: Rakkurs dnevnika]; zitiert nach GRECISKIN, LAVROV (wie Anm. 78), S. 155. - $\mathrm{Zu}$ den Biokosmisten ausführlich II: 3.3.

107 A. BELYJ, "Iog." Erstveroffentlichung in der Voronežer Zeitschrift Sirena, 1918, 2-3, Sp. 17-30. Wieder abgedruckt in DeRs., Rasskazy, München 1979, S. 63-79 (= Slavische Propyläen; 141). Erläuterungen und Interpretation bei R.E. PETERSON, Andrei Bely's Shon Prose, Birmingham 1980, S. $63-70$.

108 Die (außere) Ähnlichkeit zwischen Korobkin und Fedorov behandeln ausführlich GRECISKIN, LAVrov (wie Anm. 78), S. 155-159, um dann freilich festzustellen: "Aus diesen Beobachtungen folgt nicht, daB A. Betyj in der Gestalt Korobkins ein genaues Portrăt Fedorovs gegeben hat." (Ebd., S. 159). Vielmehr gehorre Korobkin in die lange Reihe der Cudaki in Belyjs Prosa. "Korobkin" heißt später der Held in dem Roman Moskva (1925), doch taucht der Name schon viel früher auf: "Von ... Ivan Ivanyと Korobkin erzahlte ich Vjareslav Ivanov im Jahre 1909 (als ich die '[Silberne] Taube' schrieb); letzterer bat mich, eine Erzăhlung über diese Figur zu schreiben, die so lebhaft meine Phantasie beschaftigte." A. BELYJ in: Kak my pisem, L. 1930, S. 13f. Weder hier noch an anderer Stelle gibt Belyj einen Hinweis auf Fedorov.

109 Zu den Gegensătzen Korobkin - Fedorov siehe GreCıISKIN, LAVROv (wie Anm. 78), S. 160-162. 
Aus dem Kreis um Belyj ist der Dichter Valerian Valerianovix Borodaevskij (1874-1923) als Verehrer Fedorovs bekannt. ${ }^{110}$ Mit Belyj teilte er das Interesse für Anthroposophie und Mystik und arbeitete wie dieser für den Verlag Put': Für die Serie "Russische Denker" plante er eine Arbeit über Konstantin Leont'ev, die jedoch - ebenso wie Belyjs Monographie über Fedorov - nie erschienen ist. ${ }^{11}$ Borodaevskijs Beschäftigung mit Fedorov fand ihren Ausdruck in dem Gedicht Pamjati N.F. Fedorova, das im Sommer 1913 fertiggestellt und im darauffolgenden Jahr in dem Fedorov-Gedenkband Vselenskoe delo erstmals veröffentlicht wurde. ${ }^{112}$ Den symbolistischen Dichter mit starkem Hang zum Mystischen faszinierte vor allem die legendenumwobene 'Mönchs'-Gestalt des alten Fedorov: In Borodaevskijs Gedicht wird er zum "Asketen" und "Gerechten" stilisiert, zum "weisen und heiligen greisen Bibliothekar", der in seiner "armseligen, kargen Kammer" als "unverstandener Alchimist [!]" wirkte.

Borodaevskij war mit Vjaceslav Ivanov befreundet und seit 1909 häufiger Gast im 'Turm', der so genannten Dachwohnung der Ivanovs an der Taurischen Straße in Petersburg, in der sich Dichter und Literaten, Künstler und Philosophen regelmäßig zu Gesprächen und Lesungen zusammenfanden. Möglicherweise wurden in diesem Kreis auch Fedorovs Ideen diskutiert. Mehrere Teilnehmer an Ivanovs Empfängen kannten Fedorovs Werk und hatten sich mit ihm auseinandergesetzt. Dies gilt vor allem für Berdjaev, der eine Zeitlang regelmäßig im 'Turm' verkehrte, ${ }^{113}$ aber auch für die sporadischen Besucher aus Moskau - Brjusov, Belyj ${ }^{114}$ und Florenskij. ${ }^{115}$ Im 'Turm' könnte Maksimilian Vološin mit Fedorovs Werk bekannt geworden sein, ${ }^{116}$ ebenso Chlebnikov, der im Herbst 1908 aus Kazan' nach Petersburg gekommen war. ${ }^{117}$ Majakovskij soll

110 GRECISKIN, LAVROV (wie Anm. 78), S. 148. - Uber Borodaevskij, der ein gelernter Bergbauingenieur war, ist nur sehr wenig bekannt. Siehe die biographische Notiz von JU. Bugrov, "Pevec kurskogo kraja." In: Lileratumaja Rossija, 28.10.1983, sowie die Angaben in Vselenskoe delo (wie Anm. 29), S. 184, und A.K. TARASENKOV, Russkie poity XX veka, M. 1966, S. 68.

111 Siehe den Hinweis in Vestnik RChD, 121, 1977, S. 191.

112 V. BorodaevsKu, "Pamjati N.F. Fedorova." [Datiert: 7. November 1910 - 21. Juli 1913] In: Vselenskoe delo (wie Anm. 94), S. 32. Auch in DERS., Uedinennyj dol [ursprünglicher Titel: $\mathrm{Na}$ lone rodimoj zemli]. Vionaja kniga stichov. M. 1914, S. 10f. Wieder abgedruckt in A. OsTRoMIROV [A.K. GoRSKU], Nikolaj Fedorovic Fedorov $i$ sovremennost', vyp. 4, Charbin 1933, S. 51.

113 Siehe N.[A.] BERDJAEV, "Ivanovskie sredy." In: Russkaja literatura XX veka. Pod red. SA. Vengerova. T. 3, vyp. 8, M. 1916, S. 97-100.

114 Siehe BeLYJ, Nacalo veka (wie Anm. 100), S. 319-328.

115 Vgl. VA. Nikrtin, V.P. KUPCENKo, "K istorii vzaimootnosenij P.A. Florenskogo i MA. Volosina." In: Minuvsee. Istoriteskij al'manach. 6, Paris 1988, S. 325. L.V. IVANOVA, "Vospominanija o Vjareslave Ivanove." In: Noryj Zumal, 149, 1982, S. 100.

116 Zavalishin nennt Fedorov einen der Mentoren von Volosins "mystical [!] thought", ohne dies jedoch năher zu begründen. V. ZaVAuISHan, Earty Soviet Writers, New York 1958, S. 25.

$117 \mathrm{Zu}$ Chlebnikov und Fedorov ausführlich II: 3.2.2. 
- einer unbestätigten Version zufolge - durch den Dichter Boris Šmankevič, der dem Kreis um Ivanov angehörte, von Fedorovs Ideen erfahren haben. ${ }^{118}$

Ob Ivanov selbst sich eingehend mit Fedorov beschäftigt hat, ist nicht bekannt, erscheint aber angesichts der Hinneigung des Dichters und Gelehrten zur klassischen Antike und zu einem christlichen Humanismus (schließlich zum Katholizismus) als wenig wahrscheinlich. ${ }^{119}$ Allerdings gibt es in Ivanovs Werk ein immer wiederkehrendes Thema, das sich - freilich abgewandelt und mit anderer Konsequenz - auch bei Fedorov findet: das Thema Erinnerung. ${ }^{120}$ "Ewige Erinnerung", die večnaja pamjat' der Totenmesse als Treueschwur der Lebenden an die Verstorbenen, stiftet und garantiert als "sammelnde und vereinigende Energie" (énergija sobornaja) die wahre Gemeinschaft aller Menschen, eine "Gemeinschaft im Geiste". ${ }^{121}$ Kultur ist immer "Kult der Verstorbenen" (kul't otšedsich), während jene Unternehmungen, die "auf den namenlosen, dem Erdboden gleichgemachten Gräbern der Vergangenheit ... im Namen der Kommenden" versucht werden, scheitern müssen. ${ }^{122}$ Erinnerung ist die Waffe des Menschen gegen die Zeit oder, wie es in einem Gedicht Ivanovs heißt, "das Pfand der Unsterblichkeit" (bessmertija zalog). ${ }^{123}$

Häufige Gäste im 'Turm' waren auch Vasilij Rozanov und Fedor Sologub, zwei Schriftsteller, in deren Werk das Thema des Todes eine herausragende, wenn nicht sogar zentrale Stellung einnimmt, was den Gedanken an eine Rezeption Fedorovs nahelegt.

118 Siehe Vselenskoe delo (wie Anm. 29), S. 184. S.G. SEMENOVA, "Celovek, priroda, bessmeriie v poèzii Nikolaja Zabolockogo." In: Literatumaja Gruzija, 1980, 9, S. 142. Zu Boris Ivanovi Smankevix, der zusammen mit seinem Bruder Vsevolod in den zwanziger Jahren zum Kreis der Moskauer Fedorov-Anhănger gehorte, siehe II: 4.1. Anm. 17. Zu Majakovskij und Fedorov ausführlich II: 3.2.1.

119 Eine kurze Erwăhnung Fedorovs findet sich in V.I. IVANov, "Kruci. O krizise gumanizma." [1919] In: DERS., SS, t. 3, Brüssel 1979, S. 379. Der Hinweis auf Fedorov in der deutschen Ausgabe von V.I. IVANOV, "O russkoj idee" [1909] - W. IWANOw, Die nussische Idee, Tübingen 1930, S. 40 Anm. 4 - stammt wahrscheinlich vom Ubersetzer; in der russischen Fassung ist er nicht enthalten. In den zwanziger Jahren hatte Ivanow, der seit 1924 in Rom lebte, moglicherweise Kontakt zu dem Fedorov-Anhănger N.A. Setnickij in Harbin (siehe II: 4.2.2.).

120 Siehe hierzu aus der Zeit des Turmes' v.a. Ivanovs glănzenden Essay "Drevnij užas" [1909] in: DERS., SS (wie Anm. 119), S. 92-110. Vgl. auch D.[V.] IVANov, "Recurrent Motifs in Ivanov's Work." In: Vyacheslav Ivanov: Poet, Critic and Philosopher, New Haven 1986, bes. S. 382-384.

121 V.I. IVanov, SS (wie Anm. 119), S. 93.

122 Ebd., S. $92 f$.

123 "Derev'ja." [1917-1918] Ebd., S. 533. 
Persönlich waren Rozanov und Fedorov nicht miteinander bekannt, ${ }^{124}$ doch besa $B$ Rozanov Fedorovs Werke; als einer der ersten hatte er ein Exemplar des ersten Bandes aus Vernyj erhalten. ${ }^{125}$ Auch läßt die nach Fedorovs Tod einsetzende Korrespondenz Rozanovs mit dem Fedorov-Anhänger N.P. Peterson auf ein gewisses Interesse am Autor der Filosofija obšcego dela schließen. ${ }^{126}$ In Rozanovs veröffentlichtem Werk wird Fedorov hingegen nur kurz erwähnt. ${ }^{127}$

An dieser Stelle kann nicht geklärt werden, ob Fedorovs Ideen Spuren in Rozanovs weit verstreutem, unsystematischem und in sich oftmals widersprüchlichem schriftstellerischem und philosophischem Werk hinterlassen haben. ${ }^{128}$ Auf einen Gegensatz im Denken beider sei allerdings hingewiesen, betrifft er doch das Kernstück der Fedorovschen Philosophie, das Problem des Todes und seiner Überwindung: Auch Rozanov wendet sich gegen den Tod - "Den Tod

124 Das geht aus einem Brief Petersons an Rozanov vom 19.2.1906 hervor: Peterson schickt Rozanov einige Seiten aus dem im Druck befindlichen ersten Band der Filosofija obšcego dela und stellt den Autor als "einen bereits verstorbenen, zu Lebzeiten unbekannten Menschen" vor. (Nach einer Abschrift in Moskauer Privatbesitz). - Die im Archiv von V.V. Rozanov (GBL) nachgewiesenen Briefe an einen N.F. Fedorov (siehe die knappe Angabe in Kratkij ukazatel' archivnych fondov ordela rukopisej [GBL], M. 1948, S. 161) sind höchstwahrscheinlich nicht an den Philosophen gerichtet, sondern an einen Schauspieler gleichen Namens (private Mitteilung).

1251915 schrieb Rozanov: "... ich erinnere mich, daß ich vor etwa 10, 12 Jahren erstaunt war über die mir zugeschickten Werke des Moskauer Philosophen Fedorov, die zuerst in der Stadt Vernyj erschienen sind..." V.[V.] Rozanov, "Turkestanskie proizrastanija." In: Novoe Vremja, 14269, 29.11.(12.12.)1915, S. S.

126 Im Archiv von V.V. Rozanov (CGALI f. 419) befinden sich - einer privaten Mitteilung zufolge 11 Briefe Petersons aus der Zeit vom 19.2.1906 bis 15.3.1914 (op. 1, ed. chr. 569). Eine unbekannte Anzahl von Schreiben Rozanovs an Peterson befindet sich im Peterson-Archiv, GBL f. 657 (siehe Zapiski otdela nukopisej, 39, M. 1978, S. 143). - Nur ein kleiner Teil dieser Korrespondenz war mir in Abschriften in Moskauer Privatbesitz zugănglich; siehe Anm. 17, 55, 124, 127 und II: 2.3.2. Anm. 91.

127 Es handelt sich um zwei Enwăhnungen in Aufsătzen in der Petersburger Tageszeitung Novoe Vremja. In einem 1913 erschienenen Aufsatz zitiert Rozanov aus Strachovs Brief an Tolstoj vom 6.2.1882 (bei Rozanov irrtümlich 5.2.1892) jenen Abschnitt, in dem Strachov erklärt, er werde Kunst und Wissenschaft mit allen Kräften gegen Tolstoj, Solov'ev und Fedorov verteidigen. V.[V.] Rozanov, "Idejnye spory L.N. Tolstogo i N.N. Strachova." In: Novoe Vremja, 13548,1913 , S. 5. Wegen dieses unkommentierten Zitats wurde Rozanov von Peterson kritisiert: In einem Schreiben vom 15.11.1913 halt Peterson Rozanov entgegen, Fedorov habe die Wissenschaft stets hochgeschătzt und Tolstoj wegen dessen wissenschaftsfeindlicher Haltung wiederholt angegriffen. (Nach einer Abschrift in Moskauer Privatbesitz). - Zur zweiten Enwahnung Fedorovs durch Rozanov siehe oben Anm. 125.

128 Erschwert wird eine solche Spurensuche durch Rozanovs Originalitătssucht und seine notorische Verlogenheit: Ideen anderer gab er skrupellos als eigene aus, wăhrend er ihren wahren Ursprung zu verschleiern suchte (so behauptete er beispielsweise, niemals Hegel und Schopenhauer gelesen zu haben). - In der Literatur zu Rozanov findet sich in der Regel kein Hinweis auf Fedorov. Dies gilt z.B. für das noch immer grundlegende Werk von E. [F.] GollerbaCH, V.V. Rozanov. Žizn'i tvoréestvo. Pb. 1922, wie auch für die jüngsten materialreichen Untersuchungen. Vgl. H.A. STAMMLER, Vasilij Vasil'evic Rozanov als Philosoph, Gießen 1984. H. DAHM, Grundzüge nussischen Denkens, München 1979, S. 161-195. J.A.S. ROMANOFF, Vasilij Rozanov - The Jurodivyj of Russian Literature, Ph.D. diss. Stanford Univ. 1974; Ann Arbor 1975. 
fürchte ich, den Tod will ich nicht, vor dem Tode graut mir. ${ }^{\text {129 }}$ Im Gegensatz zu Fedorov aber, der die Ursache des Todes in der naturhaft-geschlechtlichen Fortpflanzung sieht und deshalb fordert, Zeugung und Geburt durch die künstliche Wiederherstellung der Vorfahren zu ersetzen, verherrlicht Rozanov Geschlechtlichkeit und Sinnenlust als Ausdruck elementarer Lebensintensität und betrachtet die Zeugung von Nachkommen als Mittel zur Verewigung der Gattung und damit zur Überwindung des Todes. Der Tod, so Rozanov, werde durch Kindergebären besiegt:

Der Tod ist kein endgültiger Tod, sondern nur ein Mittel der Emeuenung: denn in meinen Kindern lebe ich, in ihnen lebt mein Blut, mein Körper, und folglich sterbe ich keineswegs, es stirbt lediglich mein heutiger Name. Mein Körper aber und mein Blut werden weiterteben auch in ihren Kindern und Kindeskindern und so fort - ewig! $!^{130}$

Mehr noch: Indem das Individuum in der Gattung aufgehe, werde es nicht nur Unsterblichkeit erlangen, sondern auch sein Bewußtsein und Empfinden unendlich erweitern:

Als Einzelperson (litno) bin ich nicht imstande, Wissenschaft und Krieg, Kultur und Religion zu umfassen, selbst wenn ich ewig leben und superklug sein würde! Aber ich habe mich vervielfacht: und in meinen Kindern, Enkelkindern, in Hunderten von Generationen arbeite ich mit tausend Händen in der Menschheit, rieche ich alle Düfte der Welt, übe ich alle Benfe aus, bin ich Sklave und Zar, Genie und Wahnsinniger. Was für ein Reichtum, verglichen mit jeglicher individuellen Existenz! ${ }^{131}$

Rozanovs kosmisch-vitalistische Vision eines Sieges der Gattung über den Tod die, möglicherweise inspiriert von Bergson, zu jener Zeit eine bemerkenswerte Entsprechung im Denken der russischen revisionistischen Marxisten, der sog. bogostroiteli um Bogdanov, Lunacarskij und Gor'kij, hatte $-{ }^{132}$ erweist sich als unvereinbar mit Fedorovs Sorge um die personale Wiederherstellung eines jeden einzelnen, der untergegangen ist. ${ }^{133}$

129 V.[V.] Rozanov, Opavsie list'ja [1913], Berlin 1929, S. 8. - Zur Todesfurcht bei Rozanov siehe auch A. RIPEllino, "Rozzanov." In: DeRS., Saggi in forma di ballate, Torino 1978, S. $73 f$.

130 V.V. Rozanov, Ljudi lunnogo svela. Metafizika chntstianstva. SPb. 1911, S. 68; Hervorhebung im Original. - Rozanov hielt dieses Buch in gedanklicher Hinsicht für eines seiner zentralen Werke. Gollerbach (wie Anm. 128), S. 67f. Kritiker sahen in der darin entfalteten "Metaphysik des Geschlechts" freilich nichts weiter als eine Mystifizierung kleinbürgerlicher Begierden; so A.F. LOSEV, Dialektika mifa, M. 1930, S. 92 f.

131 Rozanov (wie Anm. 130), S. 147; Hervorhebung im Orig.

132 Ausführlich dazu II: 2.1.2. - Gor'kij hat Ljudi lunnogo sveta - wie auch die meisten anderen Werke Rozanovs - kurz nach dem Erscheinen gelesen. Siehe "Pis'ma A.M. Gor'kogo k V.V. Rozanovu..." In: Kontekst 1978, M. 1978, S. 305, 324.

133 Bereits Berdjaev bemerkt, die von Fedorov und Rozanov geăuBerten Gedanken seien "einander polar entgegengesetzt". N.[A.] BERDJAEv, $O$ naznacenii celoveka, Paris 1931, S. 278. Auf den Gegensatz weisen auch Schultze und Ripellino hin. B. SCHULTZE, Russische Denker, ihre Stellung zu Christus, Kirche und Papsttum, Wien 1950, S. 201, 214. DERS., "Christozentrik im russischen Gedanken." In: Ostkirchliche Studien, 8, 1959, S. 113. RuPELIINo (wie Anm. 129), S. 43, 50. Für Sinjavskij besteht eine Ähnlichkeit zwischen Rozanov und Fedorov in der "Kühnheit, Extremheit und Globalităt, mit der sie die 'letzten Fragen' gestellt" hătten. A.[D.] SiN. 
Eine ganz andere Haltung gegenüber Leben und Tod begegnet im dichterischen Werk Fedor Sologubs. Das irdische Dasein, die reale Welt, werden als armselig, häßlich und böse verworfen, die Sehnsucht gilt der Nacht und dem Traum, der ewigen Ruhe des Nichts, dem Tod. Sologub, der "Sänger des Todes" (A. Belyj) oder, wie Chlebnikov ihn abschätzig nannte, der "Totengräber" (grobokopatel'), ist der Antipode Fedorovs. ${ }^{134}$

Dennoch gibt es ein Werk Sologubs, in dem sich Ideen und Motive finden, die von einigen Interpreten mit Fedorov in Verbindung gebracht worden sind. Es handelt sich um die zwischen 1907 und 1914 erschienene großangelegte Romantrilogie Tvorimaja legenda, ein "literarisch dürftiges, philosophisch jedoch höchst komplexes - rein eklektisches - work in progress" ${ }^{n}{ }^{135}$ das von der zeitgenössischen Kritik als "mystisch" und "dekadent" bezeichnet wurde. ${ }^{136} \mathrm{Die}$ Hauptgestalt, der Satanist und Alchimist Georgij Trirodov, ein ehemaliger Privatdozent der Chemie, besitzt als eine Art symbolistischer Übermensch die Fähigkeit, Verstorbene zu beschwören und wiederzuerwecken - freilich nicht mit Hilfe der Wissenschaft, sondern der Magie. ${ }^{137}$ Zum Antrieb eines von ihm konstruierten Raumschiffs, mit dem er der banalen Wirklichkeit zu entfliehen sucht, plant Trirodov, die "psychischen Kräfte der Verstorbenen" zu nutzen: Menschen werden verbrannt, kondensiert und zu Prismen gepreßt ("schwer von Gewicht und manchmal etwas fettig beim Anfühlen") ${ }^{138}$; ihre "psychischen Kräfte", die imstande sind, "Materie in Energie [zu] verwandeln", ${ }^{139}$ bleiben dabei erhalten und lassen sich zur Überwindung der Schwerkraft einsetzen.

JAVSKII, 'Opavsie List'ja' V.V. Rozanova, Paris 1982, S. 15; zu den unterschiedlichen Antworten beider auf die "letzten Fragen" siehe ebd., S. 38. Zen'kovskij vergleicht Rozanov und Fedorov auf der gemeinsamen Grundlage eines "christlichen Naturalismus". V.V. ZEN'KOVSKU, Russkie mysliteli i Evropa, Paris 1934, S. 215-217.

134 In der Literatur wird in diesem Zusammenhang immer wieder auf den starken EinfluB Schopenhauers hingewiesen, doch fehlt bislang eine genauere Untersuchung. Siehe S. MCLAugh. LIN, Schopenhauer in Rußland, Wiesbaden 1984, S. $35 f$.

135 INGOLD (wie Anm. 85), S. 152.

136 Nachfolgend zitient nach der von Sologub autorisierten (und einzig vollstăndigen) Fassung in deutscher Sprache F. SsOLOGUB [SOLOGUB], Totenzauber. Eine Legende im Wenden. 5 Teile [in 2 Bdn.], München 1913. - Zur Entstehung und zur philosophischen Konzeption siehe J. HOLTHUSEN, Fedor Sologubs Roman-Trilogie (Tvorimaja legenda), 'S-Gravenhage 1960. Zur zeitgenठssischen Rezeption und Kritik H. BARAN, "Fedor Sologub and the Critics: The Case of Nav'i Cary." In: Studies in 20th Century Russian Prose, Stockholm 1982, S. 26-58.

137 SOlogub (wie Anm. 136), Teil 1, S. 127-134; Teil 2, S. 238-246. - KoEHLER (wie Anm. 102), S. 94, sieht darin einen moglichen Einfluß Fedorovs. Dem widerspricht freilich das rein Magische der beschriebenen Vorgănge. Hinzu kommen Elemente der Schauerliteratur: So erinnert die Schilderung des Zombie-gleichen Egorka im Grab an Poes Erzăhlung The Premature Burial. Egorkas Wiedererweckung durch Trirodov wird gedeutet als Ausdruck von Sologubs Glauben an die Allmacht des künstlerischen Schøpfungswillens. Siehe die Interpretation von S.J. RABINOWITZ, Sologub's Literary Children, Columbus 1980, S. 120-122.

138 SOLOGUB (wie Anm. 136), Teil 2, S. 178.

139 Ebd., Teil 5, S. 60. 
Die Annahme, diese Ideen könnten sich "auf die materialistische Apologie des Ahnenkults und die Resurrektionstheorie" Fedorovs beziehen, ${ }^{140}$ erweist sich bereits aufgrund des Gesagten als abwegig: Für die von Sologub geschilderten "rein magischen Vorstellungen"141 und Praktiken gibt es keinerlei Entsprechungen in Fedorovs Werk. ${ }^{142}$

Die Resonanz, die Fedorovs Ideen bei den russischen Symbolisten hervorgerufen haben, war insgesamt sehr gering. Wichtige Vertreter dieser Strömung wie z.B. der für sein philosophisches Interesse bekannte Merežkovskij - scheinen Fedorov überhaupt nicht zur Kenntnis genommen zu haben. ${ }^{143}$ Sein Name taucht weder in den Diskussionen der Religiös-Philosophischen Vereinigungen auf, noch spielt er irgendeine Rolle in den kunsttheoretischen Diskussionen jener Zeit (obwohl gerade Fedorovs Kunstauffassung dem symbolistischen Streben nach universaler Synthese - bei gleichzeitigem Krisenbewußtsein - entgegenkam). Auf fruchtbaren Boden fielen Fedorovs Gedanken hingegen in Kreisen religiöser Denker (zu nennen sind insbesondere Berdjaev und Bulgakov) sowie im Milieu sektiererischer Intellektueller, aus dem - wie im folgenden Kapitel zu zeigen sein wird - die 'zweite Generation' der Anhänger Fedorovs hervorgegangen ist.

140 IngOLd (wie Anm. 85), S. 155. - Auch Koehler vermutet, daB sich Trirodovs Plan, "to utilize the mystical [sic] powers of the dead", auf Fedorov zurückführen lasse. KOEHLER (wie Anm. 102), S. 95.

141 Holthusen (wie Anm. 136), S. 46. Als moggliche Quelle nennt Holthusen Poes phantastischen Dialog The Power of Words.

142 Gemeinsam ist beiden der - zu Beginn dieses Jahrhunderts kaum mehr originelle - Raumfahrtgedanke, der im Falle Sologubs wohl auf H.G. Wells zurückgeht; in Sologubs Roman wird der auch in RuBland überaus populäre Verfasser phantastischer Erzählungen namentlich genannt (Trirodov: "... wir lieben Utopien. Wir lesen Wells."). SolOGUB (wie Anm. 136), 1. Teil, S. 108.

143 Seine Frau, Zinaida Hippius, scheint sich immerhin mit Fedorov befaßt zu haben, wenn auch mit gănzlich negativem Ergebnis, wie aus ihren Briefen an V.A. Mamæenko hervorgeht. Am 26. Oktober 1936 schreibt sie: "Keiner sagt einem heute, wie man leben soll: weder Hegel noch Sestov (und am wenigsten von allen Fedorov)." Und am 17. September 1937: "... Fedorov spricht nicht von der Auferstehung der Person, er begreift sie [die Person; M.H.] überhaupt nicht. Abgesehen davon, daB er sich selbst vollig unüberlegt als 'Christ' bezeichnet, behauptet er irgendeine Auferweckung von Geschlechtem, ja ganzer Herden, was weder nötig noch verlockend ist. Denken Sie nicht, daB ich mich nicht auskenne; interessiert hat mich letztlich die Hypnose, die Fedorov bei einigen seiner Zeitgenossen bewirkt hat, und ich beschloB, mir eine Meinung über ihn und seine 'Ideen' zu bilden. Was man verstehen kann, habe ich verstanden, und das hat mir vollig gereicht, um ihn mitsamt seinen Auferweckungen beiseite zu tun..." T. PACHMUSS (Hg.), Intellect and Ideas in Action. Selected Correspondence of Zinaida Hippius. München 1972, S. 449, 452. Die Anmerkungen der Hg. zu Fedorovs Werk (ebd., S. 459f.) sind fehlerhaft. 


\section{Die Anfänge der Fedorov-Bewegung}

\subsubsection{I.P. Brichničev und die Zeitschrift 'Novoe Vino' (1912-13)}

Im Jahre 1912 fand sich in Moskau eine kleine Gruppe von Intellektuellen zusammen, schwärmerisch religiös gesinnte Literaten und Publizisten, die im Zuge des 'religiösen Suchens' und im Bemühen um eine 'christliche Erneuerung' auf Fedorovs Ideen gestoßen waren und sich mit ihnen auseinanderzusetzen begannen. Die Hauptvertreter dieser Gruppe waren I.P. Brichniとev und A.K. Gorskij, ihre wichtigsten Publikationen die kurzlebige Zeitschrift Novoe Vino (Moskau 1912-13) und der Sammelband Vselenskoe delo (Odessa 1914). Obwohl ihr Einfluß auf die Verbreitung und Wirkung Fedorovscher Ideen zunächst eng begrenzt blieb, sollen Brichnið̌ev und Gorskij ausführlich vorgestellt werden; zum einen, weil ihre Tätigkeit später an Bedeutung gewann Gorskij wurde in den zwanziger Jahren zu einem der aktivsten Propagandisten des obš̌ee delo -, zum anderen, um am Beispiel ihrer Biographien die Entstehung jenes geistigen Milieus zu skizzieren, in dem Fedorovs Ideen in den Jahren vor dem Ersten Weltkrieg Widerhall fanden.

Über den Priester, Schriftsteller und Publizisten Iona Pantelejmonovic Brichnixev (1879-1968), der um das Jahr 1912 mit den Ideen Fedorovs bekannt wurde, liegen neben autobiographischen Aufzeichnungen ${ }^{1}$ zahlreiche, jedoch weit verstreute Nachrichten vor; trägt man sie zusammen, so ergibt sich ein überaus schillerndes Lebens- und Charakterbild.

I.P. Brichnicev wurde am 15.(27.) Juni 1879 als Sohn eines Schmiedes in Tiflis geboren. ${ }^{2}$ Nach der Grundausbildung in der kirchlichen Gemeindeschule in Kutaisi besuchte er gemeinsam mit dem gleichaltrigen Iosif (Soso) Džugažvili (Stalin) das Priesterseminar in Tiflis ${ }^{3}$ und wurde anschließend Geistlicher, zunächst in der Ortschaft Pasanauri, danach an der "Eisenbahnkirche" in Tiflis. Als Tiflis 1905 zum Schauplatz heftiger politischer Unruhen wurde, schloß sich Brichnicev unter dem Eindruck des von Obrigkeit und Kirche geförderten Treibens der rechtsradikalen "Schwarzhunderter" (Cernosotency) sowie staatlicher

1 I.P. BRICHNICEv, SluŽebnaja avtobiografija (1879-1937), Ms., 5 Bl.; GBL f. 516, k. 3, ed. ehr. 39; das Original war mir nicht zugänglich, benutzt wurde eine Abschrift in Moskauer Privatbesitz. Die Zeit vor 1917 wird von Brichnitev nur kurz behandelt; insbesondere fehlen jegliche Angaben über seine religiös-sektiererischen Aktivităten, auch sein Interesse für Fedorov wird nicht erwähnt. Zu Brichnitevs Biographie vgl. ferner EZ., "Iona Brichnitev." In: Vselenskoe delo, sb. 2, Riga 1934, S. 184 (fehlerhaft!). V.G. BAZANov, "Trudnaja biografija." In: Zvezda, 1979, 12, S. 176-188. V. SuMOV, "Iz prichodskich batjuß̌ek - v buntari." In: Nauka i Religija, 1980, 11, S. 22. K.M. AZADOvSKU, "Pis'ma N.A. KJjueva k Bloku. Vstupitel'naja stat'ja..." In: Literatumoe nasledstwo, t. 92 [Aleksandr Blok. Novye materialy i issledovanija], kn. 4, M. 1987, S. 445-450.

2 BRICHINICEV (wie Anm. 1).

3 Ebd. - Eine Zeitlang waren Brichnižev und Džugašvili Klassenkameraden. Siehe auch (ohne Hinweis auf Brichničev) M.[S.] AGURSKIJ, "Stalin's Ecclesiastical Background." In: Survey, 28 (1984), 4, S. 1-14. 
Repressionsmaßnahmen, die sich auch gegen Teile der Geistlichkeit richteten, der regimefeindlichen Bewegung an. ${ }^{4}$ Er fand Kontakt zu einer Gruppe junger Intellektueller um V1.F. Ėrn, A.V. El'Caninov und P.A. Florenskij, die, ausgehend von christlichen Prinzipien, tiefgreifende politische, soziale und kirchliche Reformen forderten, wobei sie die Autokratie und die sie stützende Geistlichkeit ablehnten und sich zu einer Art christlichem Sozialismus bekannten. ${ }^{5}$ Insbesondere richtete sich ihre Kritik gegen die Vertreter der offiziellen Kirche, denen sie vorwarfen, das Evangelium zur Rechtfertigung der "byzantinisch-tatarischen Selbstherrschaft" mit all ihren Greueln und Ungerechtigkeiten zu mißbrauchen. ${ }^{6}$

Um solcher Kritik an Kirche und Staat Gehör zu verschaffen, gründete Brichnicev Ende April 1906 in Tiflis die religiös-politische Wochenschrift Vstan', Spjjašzij!! die sich an breite Leserkreise wandte. ${ }^{7}$ In scharf formulierten Artikeln forderten er und seine Mitautoren - unter ihnen Vladimir Ėrn - die Beseitigung jeglicher Form von Herrschaft (gospodstvo) und Gewalt (nasilie) im Namen eines richtig verstandenen Christentums: Gott habe alle Menschen frei

4 Siehe V.[F.] E[RN], "O dviženii sredi gruzinskogo duchovenstva." In: Voprosy Żizni, 1905, 8, S. 273-291.

5 In einem Brief an A. Belyj vom 21.5.1904 nennt Florenskij die Mitglieder dieser "Gruppe" (kružok): Ern, Svencickij und El'Zaninov sowie "den einen oder anderen (koe-kio), den Sie nicht kennen". P.A. FloRENSKU, "Pis'ma P.A. Florenskogo k B.N. Bugaevu [A. Belomu]." In: Vestnik $R C h D, 114,1974$, S. $150 f$.

Zen'kovskij gibt an, Brichnizev habe zusammen mit Em, Florenskij und V.P. Svencickij die "Christliche Bruderschaft des Kampfes" (Christianskoe bratstwo borby) gegründet, die für eine radikale christ liche Erneuerung in enger Verbindung mit politischer Emanzipation und sozialer Gerechtigkeit eintrat. V.V. ZEN'KovSKU, Istonija nusskoj filosofii, t. 2, Paris 1950, S. 415; ohne Beleg. Zen'kovskij spricht irtümlich von einem Sojuz christianskoj bor'by. In der von der "Christlichen Bruderschaft" herausgegebenen Schriftenreihe Religiozno-obšestvennaja biblioteka ist Brichnitev mit einer Veroffentlichung vertreten. - Über die "Christliche Bruderschaft" und ihre Mitglieder siehe II: 2.1.1.

Moglicherweise hatte Brichnirev schon früher Kontakt zu Florenskij und Em gefunden: Die beiden letztgenannten besuchten bis 1900 das 2 . Klassische Gymnasium in Tiflis und verkehrten in einem Schülerzirkel, der von Florenskij und seinem Klassenkameraden Lev Borisoviz Rozenfel'd (1883-1936) geleitet wurde (Rozenfel'd wurde später unter dem Pseudonym Kamenev als Bolschewik und Vertrauter Lenins bekannt). Auch Džugašvili hatte um 1899/1900 Kontakt zu diesem Zirkel, und es ist denkbar, daß dies auch für seinen Klassenkameraden Brichnitev gilt. Vgl. AGURSKU (wie Anm. 3), S. 11, sowie die Erinnerungen eines Mitglieds dieses Zirkels J. DAVRICHEWY, Ah! Ce qu'on rigolait bien avec mon copain Staline. Paris 1979, S. 11, 111 .

6 Vl.[F.] ERN, Pastyr' novogo tipa, M. 1907, S. 9. - In dieser Broschüre, die in der Reihe Religiozno-obšcestvennaja biblioteka erschien, zeichnet Em ein lebendiges Bild der frühen politischen und publizistischen Aktivităten Brichnizevs. Verbindungen Brichnirevs zur "Christlichen Bruderschaft" werden jedoch nicht erwathnt.

7 Vstan', Spjašij!, Tiflis, 1-3 (27.4., 7.5., 14.5.1906). Der Titel der Zeitschrift ist ein Zitat von Eph. 5:14. Die vierte Nummer erschien am 21.5.1906 unter dem Titel Naša Mysl'. Vgl. L.N. BEL. JAEVA, Bibliografija periodiceskich izdanij v Rossii 1901-1916, t. 1, L. 1958, S. 360, Nr. 1736. Ausführlich über Vstan', Spjascij! Bazanov (wie Anm. 1), S. 178-181. ERn (wie Anm. 6), S. 1017. DERS., "Staroobrjadcy i sovremennye religioznye zaprosy." In: Zivaja Zizn', 1908, 1, S. 15. Mir waren nur die ersten zwei Nummern von Vstan', Spjastij!' zugănglich. 


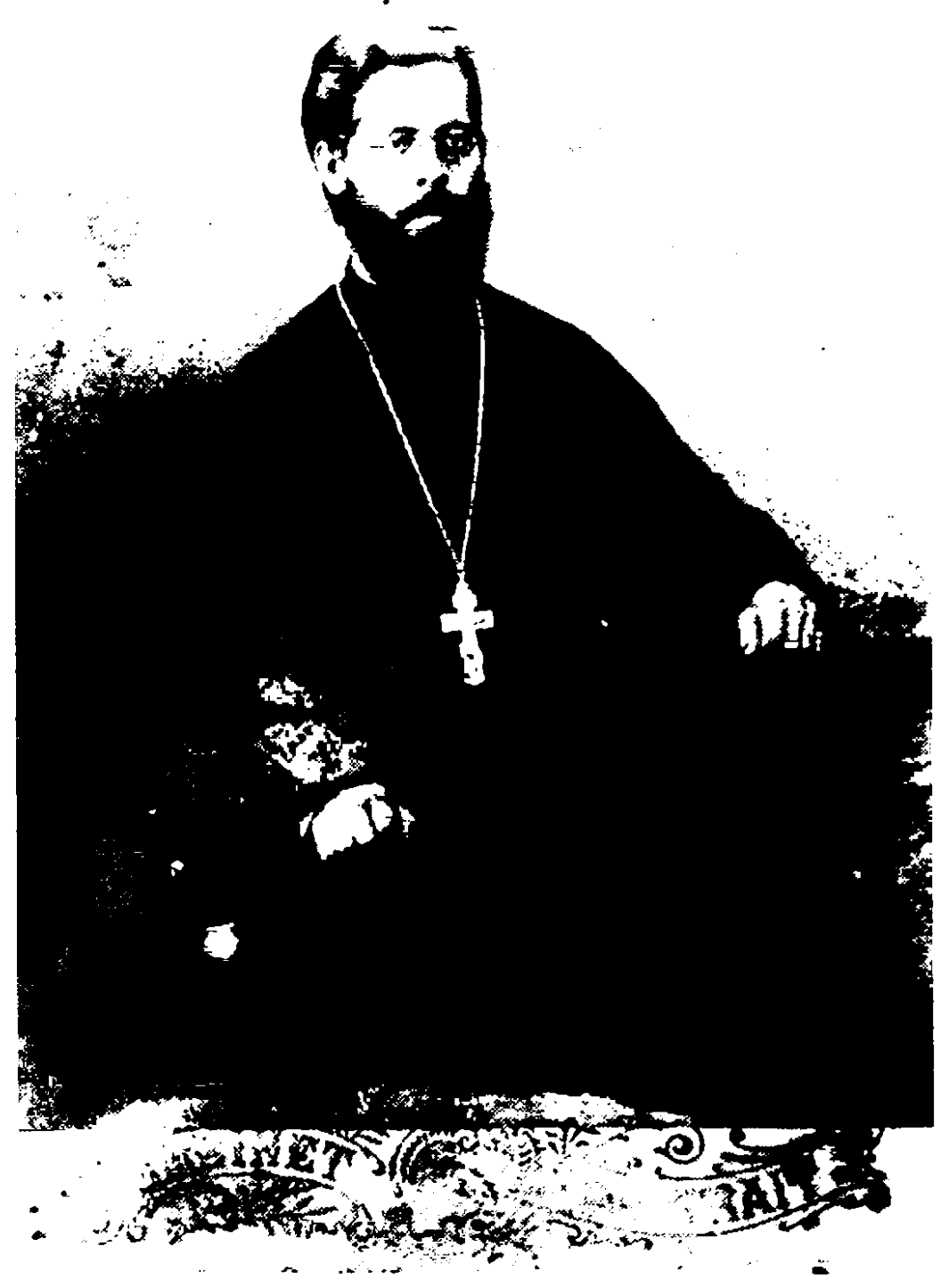

IP. Brichničev, Aufnahme um 1905 
geschaffen, und es sei mithin die Pflicht eines jeden wahren Christen, für die Freiheit aller zu kämpfen und sich notfalls dafür zu opfern. ${ }^{8}$

Der Erfolg von Vstan', Spjaščij! übertraf alle Erwartungen. Die erste Nummer mit einer Auflage von 10.000 Exemplaren war bereits am Erscheinungstag ausverkauft, die zweite Nummer schon nach wenigen Stunden. Nach der dritten Nummer, die eine Auflage von 18.000 erreichte, wurde die Zeitschrift vom Generalgouverneur verboten. ${ }^{9}$ Unter dem Vorwurf revolutionärer Agitation wurde Brichničev im Juni 1906 verhaftet und wegen seiner Angriffe auf die Geistlichkeit seines Priesteramtes enthoben. ${ }^{10}$

Nachdem er ein Jahr in den Festungen Kars und Metechi (Tiflis) eingesessen hatte, ${ }^{11}$ wandte sich Brichnicev im August 1907 aus Železnovodsk in einem Brief an Tolstoj mit der Bitte, ihm eine Anstellung zu verschaffen; Tolstoj lehnte jedoch ab. ${ }^{12}$ Im selben Jahr beteiligte sich Brichniðev zusammen mit El'caninov an einem literarischen Sammelband, dessen Erlös der hungernden Bevölkerung Südrußlands zugute kommen sollte. ${ }^{13}$

Anfang 1908 veröffentlichte Brichniðev in der Moskauer Zeitschrift Živaja Žizn', die dem Kreis um Ėrn, Svencickij und El'Caninov nahestand, einen kurzen Beitrag über Ibsens Drama Brand, das in den Kreisen der russischen Intelligenz

8 In anderen Beitrăgen wurde das russische Volk aufgerufen, sich allen imperialistischen Bestrebungen seiner Machthaber zu widersetzen; selbst ein Sklavendasein führend, dürfe es nicht teilnehmen an der Unterwerfung und Knechtung anderer Völker. Die Geistlichkeit dürfe sich nicht lănger an der Unterdrückung des Volkes beteiligen oder diese dulden. Die Kirche, bislang willfahriges Instrument der Obrigkeit, sei vom Staat zu trennen. Die Todesstrafe sei Mord und müsse abgeschafft werden. Unter der Rubrik "Nützliche Kenntnisse" wurden Begriffe wie "Konstitution", "Bürokratie" und "Aufrührer" erlăutert und das Budget der Zarenfamilie mit den Einkünften eines Arbeiterhaushaltes verglichen. In seinem Beitrag "Graždanskie svobody i christianstvo" (2, S. 7-13) suchte Em nachzuweisen, daB die bürgerlichen Grundrechte, die im Oktobermanifest von 1905 gewahrt worden waren, auf dem Evangelium beruhten. Die in Vstan', Spjascij! erhobenen Forderungen glichen in vielem denen der "Christlichen Bruderschaft des Kampfes", wie sie von Svencickij in der programmatischen Schrift 'Christianskoe bratstvo bor'by' i ego programma, M. 1906, dargelegt worden waren (siehe II: 2.1.1.). Ein Zusammenhang liegt nahe, wenngleich er sich unmittelbar nicht nachweisen lăBt (vgl. oben Anm. 5).

9 Siehe ERN (wie Anm. 6), S. 14-17. BAZANOv (wie Anm. 1), S. 180. - Unter stăndig wechselnden Namen erschienen von dieser Zeitschrift zahlreiche Fortsetzungen, die jedoch zumeist schon nach der ersten Nummer verboten wurden. Siehe BeLJAEVA (wie Anm. 7), t. 1 (1958), S. 360, Nr. 1735; S. 362, Nr. 1744. T. 2 (1959), S. 304, Nr. 4625; S. 419, Nr. 5213. T. 3 (1960), S. 563, Nr. 9118. Vgl. auch ERN (wie Anm. 6), S. 17-19. BAzANOv (wie Anm. 1), S. 181f. AZADOVSKu (wie Anm. 1), S. 446.

10 Vgl. Bazanov (wie Anm. 1), S. 182. Azadovsku (wie Anm. 1), S. 446. ERn, "Staroobrjadcy..." (wie Anm. 7).

11 Brichilicev (wie Anm. 1). Vgl. auch das autobiographische Gedicht "Ot sten Metechi..." In: I.P. BRICHNICEV, Puti Zivye. (Cvetopesni - kniga tret'ja). M. 1916, S. 3. ERN (wie Anm. 6), S. 20.

12 L.N. TolstoJ, PSS, t. 77, M. 1956, S. 179. - Brichnirev veroffentlichte Tolstojs ablehnende Antwort in der Presse und beklagte sich darüber.

13 Siehe O.D. GOLUBEVA, Literatumo-chudotestvennye al'manachi i sbomiki $1900-1911$ gady, M. 1957, S. 110. 
tiefen Eindruck gemacht hatte. ${ }^{14}$ In Rostov am Don gab BrichniCev die religiöse Wochenschrift Pojdem Za Nim heraus. ${ }^{15}$ Im Sommer 1908 suchte er Tolstoj in Jasnaja Poljana auf, schilderte ihm seine Erlebnisse während der Festungshaft und seine schwierigen Lebensbedingungen und wiederholte seine Bitte um Arbeit. ${ }^{16}$ Obwohl Tolstoj sich 'beeindruckt' zeigte, blieb auch dieser Vorstoß Brichnixevs ohne Erfolg. ${ }^{17}$

1909 lebte Brichnixev in Caricyn, wo er an mehreren Zeitungen und Zeitschriften "für das Volk" mitarbeitete und selbst eine volkstümliche Wochenschrift mit dem Titel Slušaj Zemlja herausgab. ${ }^{18} \mathrm{Zu}$ dieser Zeit stand er offenbar in Verbindung mit Aleksandr Blok; in Bloks Aufzeichnungen findet sich Brichni evs Name im Zusammenhang mit dem Bauerndichter N.A. Kljuev und mit Sektierern. ${ }^{19}$ Während Kljuev dem Milieu der Altgläubigen und Sektierer eindeutig zuzurechnen ist, bleibt unklar, ob auch Brichniðev sich diesen Kreisen - denen zu jener Zeit das besondere Interesse Bloks und vieler Intellektueller galt - angeschlossen oder angenähert hatte. ${ }^{20}$ Immerhin besuchte Brichni飞ev

14 I.[P.] BRICHNICEV, "K pobede putem gibeli." In: Živaja Žizn', 1908, 1, S. 42-47. - Der Titelheld dieses Stücks, ein fanatischer, kompromißloser Pfarrer, vertrat eine Haltung, die unter dem Schlagwort 'religiöser Maximalismus' auch von Svencickij und seinem Kreis propagiert wurde. Siehe N.A. NILsson, Ibsen in Rußland, Stockholm 1958, S. 115-126; bes. S. 121 .

15 Sumov (wie Anm. 1). Vgl. Beluaeva (wie Anm. 7), t. 2 (1959), S. 601, Nr. 6135. Es erschienen 8 Nummern. Als Herausgeber zeichnete ein gewisser I.E. Komar; faktischer Redakteur und Hauptautor aber war Brichnitev.

16 Literatumoe nasledstwo, t. 90 [U Tolstogo 1904-1910. 'Jasnopoljanskie zapiski' D.P. Makovickogo], kn. 3, M. 1979, S. $143 f$.

17 Als Tolstoj ein dreiviertel Jahr spăter auf Brichnizev angesprochen wurde, konnte er sich nicht mehr an ihn erinnern (ebd., S. 355).

18 AzAdovsku (wie Anm. 1), S. 446f. - Die Zeitschrift brachte es nur auf sechs Nummern (Jan.Feb. 1909). Vgl. BeluaEva (wie Anm. 7), t. 3 (1960), S. 246, Nr. 7706 (Brichnitev wird hier nicht genannt).

19 A.A. Blok, Notiz vom 16./17.2.1909: "Man könnte nach Caricyn an der Wolga fahren, zu Iona Brichnicev. Ins Gouvernement Olonec, zu Kljuev. Mit Prisvin sich herumtreiben. $\mathrm{Zu}$ den Sektierem - nach RuBland." A.A. BLoK, Zapisnye knizki 1901-1920, M. 1965, S. 131. Ausführlich zu Brichnirev, Kljuev und Blok AZADOvskI (wie Anm. 1). Vgl. auch V.G. BAzANov, "Razrußenie legendy." In: Russkaja Literatura, 1980, 3, S. 97-99. DERS., "K tvorZeskim iskanijam Bloka." In: A. Blok i sovremennost', M. 1981, bes. S. 212-217. Zu Kljuev DerS., "Oloneckij krest'janin i peterburgskij poet." In: Sever, 1978, 8, S. 93-112; 9, S. 91-110.

20 Filippov und Azadovskij geben an, Brichniðev habe wegen seiner Affinităt zu Altglăubigen und Sektiererkreisen sein Priesteramt verloren. BA. FiuPPOV, "Materialy k biografii." In: N. KLJU. Ev, PSS, t. 1, New York 1954, S. 54. Ders., "Nikolaj Kljuev. Materialy dlja biografii." In: N. KLUUEv, Soxinenija, Bd. 1, München 1969, S. 43. K.M. AZADovsKu, "Blok i A.M. Dobroljubov." In: Tezisy I vsesojuznoj (III) konferencii 'Twortestvo AA. Bloka $i$ russkaja kul'tura XX veka', Tartu 1975, S. 100. Uber das Interesse der Intellektuellen an den verschiedenen Formen der Volksfrömmigkeit und des religiösen Sektierertums allgemein J. SCHERRER, Die Petersburger Religiös-Philosophischen Vereinigungen, Berlin, Wiesbaden 1973, S. 122-124, 418; im Falle Bloks S. HACXEI, The Poet and the Revolution: Aleksandr Blok's 'The Twelve', Oxford 1975, S. 35-42. AzADOVSKU, a.a.O. M. NiqueuX, "Blok et l'appel de Kljuev." In: Revre des Etudes slaves, 54 (1982), 4, S. 617-630 (zu Brichnirev bes. S. 621); im Falle von M.M. Prił̌vin V.D. Prisvina, Put' k slovu, M. 1984, bes. S. 184-198 (zu Brichnizev S. 188). 
damals die Versammlungen religiöser Sektierer, die regelmäßig im Moskauer Gasthaus "Jama" (Grube, Gruft) stattfanden. ${ }^{21}$ Neben 'Gottsuchern', 'Propheten' und Straßenphilosophen der verschiedensten Richtungen dürfte er dort auch den sogenannten "Unsterblichen" (bessmertniki) begegnet sein, Anhängern einer Sekte, die davon überzeugt waren, daß allein der feste Glaube an Christi Sieg über den Tod genüge, um selbst physische Unsterblichkeit zu erlangen; starb dennoch einer aus ihren Reihen, so sahen sie darin nur einen Beweis seiner Glaubensschwäche. 22

Gegen Ende des Jahres 1910 wurde Brichnicev Mitarbeiter und bald darauf leitender Redakteur der Moskauer literarischen und religiös-philosophischen Wochenschrift Novaja Zemlja; ein Jahr später übernahm seine Frau Valentina Maksimovna die Herausgabe der Zeitschrift, ${ }^{23}$ in der Beiträge von Svencickij, I.I. Gorbunov-Posadov, dem Altgläubigenbischof Michail, dem symbolistischen Dichter und Sektierer A.M. Dobroljubov sowie Gedichte von Blok, Brjusov und Kljuev erschienen. ${ }^{24}$ Novaja Zemlja war das Organ des sogenannten golgofskoe christianstvo (etwa "Golgatha-Christentum"), einer religiös-sozialen Erneuerungsbewegung, an deren Spitze zu jener Zeit der Bischof Michail stand. ${ }^{25}$ Ziel

21 A.S. PANKRATOV, IsCustie boga. Ozenki sovremennych religioznych iskanij i nastroenij. Kn. 1, M. 1911 [recte 1910], S. 13. - Der Journalist und Sektenforscher A.S. Pankratov, der in dem genannten Buch ausführlich über den Moskauer Sektierertreffpunkt berichtet (das Kapitel "Jama" erschien zuerst in Russkoe Bogatstvo, 1910, 4), war auch ein Kenner Fedorovs und seiner Philosophie. Aus seiner Feder stammt ein Aufsatz über Leben und Werk Fedorovs sowie eine offenbar verschollene Fedorov-Biographic (siehe II: 2.2.1.). - Uber die "Jama" auch A.I. KIJBA. Nov, Istorija religioznogo sektantstva v Rossii (6a. gady XIX v. - 1917 g.), M. 1965, S. $266 \mathrm{f}$.

22 Neben Brichnicev erwähnt Pankratov als prominente Besucher der "Jama" u.a. S.N. Bulgakov und N.A. Berdjaev. Letzterer berichtet in seiner Autobiographie ausführlich von seinen Besuchen, wobei ihn besonders die "Unsterblichen" interessierten. N.[A.] BERDJAEV, Samopoznanie, Paris ${ }^{2} 1983$, S. 227-229. DeRs., Russkaja ideja, Paris 1946, S. 200. - Uber Berdjaevs Besuche in der "Jama" und über die "Unsterblichen" berichtet auch die Schriftstellerin und Ubersetzerin E.K. Gercyk in ihren Erinnerungen. E.K. GerCYK, Vospominanija, Paris 1973, S. 121. Vgl. auch II: 2.2.1.

23 Beluaeva (wie Anm. 7), t. 2 (1959), S. 450, Nr. 5366. - Die Zeitschrift war mir nicht zugănglich. Ausführlich über Novaja Zemlja und ihr Programm BazAnov (wie Anm. 1), S. 183-188. DeRs., "Razruß̌enie..." (wie Anm. 19), S. 96-99. DERS., "K tvorteskim..." (wie Anm. 19), S. 206-218. AZADOVSKIJ (wie Anm. 1), S. 447-449.

24 Dazu ausführlich K.M. AzAdovsKu, "Rannee tvorzestvo N.A. Kljueva. (Novye materialy)." In: Russkaja Literatura, 1975, 3, S. 208-211. DERS. (wie Anm. 1), S. 447-450. Vgl. ferner FilipPov, "Nikolaj Kljuev..." (wie Anm. 20), S. 25f. V.G. Bazanov, "Poézija Nikolaja Kljueva." In: N.A. KuUUEV, Stichorvorenija i poemy, L. 1977, S. 21. DERS., Sergej Esenin i krest'janskaja Rossija, L. 1982, S. 123f. - Kljuev schrieb über Novaja Zemlja an A.V. Rumanov: 'Zuurnal 'Novaja Zemlja' oxen' beden i Brichnižev izdajuščij ego edva kormitsja s ženoj i tremja detjami..." Undatierter Brief, veröff. von G. MCVAY, "Unpublished Texts of Nikolay Klyuyev." In: SEER, 63 (1985), 4, S. 561. Uber Brichnizevs Bemühungen, Blok und Brjusov zur Mitarbeit an Novaja Zemlja zu bewegen, BAZANOV (wie Anm. 19).

25 Archimandrit Michail (Pavel Vasil'evic Semenov, 1874-1916), Professor an der Geistlichen Akademie in Petersburg, hatte sich unter dem Eindruck des Arbeiterelends 1906 dem rechten Flügel der Sozialrevolutionäre, den Volkssozialisten, angeschlossen, war aus der Staatskirche ausgetreten und Bischof der Altgläubigen geworden. In der Folge trat er als Propagandist eines 
dieser stark endzeitlich gestimmten Bewegung war die Heraufführung einer "neuen Erde ${ }^{\text {n26 }}$ auf dem Wege einer religiösen Erneuerung und eines "sozialen Christentums" (obšcestvennoe christianstvo). Dabei wurde jede Form privaten Heilstrebens verworfen; die Vorstellung einer individuellen Erlösung, so hieß es, sei eine betrügerische Erfindung derer, die im Namen Christi soziale Ungerechtigkeit sanktionieren wollten. ${ }^{27}$ Auch Svencickij und Brichnicev hatten sich dem golgofskoe christianstvo angeschlossen, und Brichnicev, der zwischen 1911 und 1913 zum führenden Propagandisten dieser Bewegung wurde, forderte in Novaja Zemlja "die volle und endgültige Befreiung der Welt von Knechtschaft, Sünde, Leiden und Tod $^{\text {n28 }}$. Aufrufe dieser Art führten schließlich dazu, daß die Zeitschrift, von der immer wieder einzelne Nummern beschlagnahmt worden waren, Anfang 1912 endgültig verboten wurde; auch eine Fortsetzung unter dem Titel $K$ Novoj Zemle wurde sofort unterdrückt. ${ }^{29}$

Für Brichniłev war 1912 ein Jahr intensiver publizistischer Tätigkeit. Er veröffentlichte seinen ersten Gedichtband, ${ }^{30}$ gab zwei Anthologien geistlicher Ly-

"freien" oder "sozialen Christentums" (svobodnoe, obšcestvennoe christianstvo) hervor. Gemeinden "freier Christen" gab es u.a. in Tiflis und Caricyn, so daß Brichnizev bereits dort mit Anhăngern Michails zusammengekommen sein konnte. A. MiCHAIL [P.V. SEMENOV], Kak ja stal narodnym socialistom, M. 1907. DERS. (Hg.), Christos $v$ vek masin (Voprosy religii $i$ obštesivennoj zizni). SPb. 1907. Vgl. auch PaNkRatov, wie Anm. 21, S. 123-127. "Michail [Pavel Vasil'evic Semenov]." In: Novyj énciklopediceskij slovar', t. 26, Pg. 0.J., Sp. 729. Zwischen 1906 und 1907 gab Michail in Petersburg die Wochenschrift Vek heraus, die für eine kirchliche Erneuerung und eine Verbindung christlicher und sozialistischer Ideen eintrat; zu ihren Mitarbeitern zăhlten u.a. Ern, Svencickij und Florenskij. SCHERRER (wie Anm. 20), S. 139-144. Um diese Zeit trat Michail an die Spitze des sogenannten golgofskoe dviženie, einer religiös-sozialrevolutionăren Bewegung, die nach den Ereignissen von 1905 unter der Petersburger Arbeiterschaft entstanden war (moglichenweise nicht ohne Michails EinfluB, doch ist über ihren Ursprung nichts bekannt). Die golgofcy (etwa "Golgatha-Christen"), wie sich ihre Anhănger nannten, lehnten Kirche und Staatsmacht ab und beriefen sich bei ihren sozialrevolutionăren Forderungen allein auf das Evangelium. - Uber Michail und die Petersburger golgofcy berichtet ausführlich M. SAGINJAN im vierten Teil ihrer Memoiren "Čelovek i vremja. Vospominanija." In: Novyj Mir, 1975, 3, S. 132-211; bes. S. 181-211. Vgl. ferner Z.[N.] GIPPIUS, Sinjaja kniga. Peterburgskij dnemik 1914-1918. Belgrad 1929, S. 54-56. M.P. LASKOVAJA, Bogoiskatel'stvo i bogostroirel'stro prezde i leper, M. ${ }^{2}$ 1976, S. 39f. AzADOVSKU (wie Anm. 24), S. 208f. BAZANov (wie Anm. 1), S. 182-188. DeRS., "K tvorkeskim..." (wie Anm. 19), S. 206-218.

26 Novaja Zemlja - so auch der Titel der Zeitschrift. Dabei handelt es sich um eine Anspielung auf die Ankündigung der Offenbarung des Johannes, es werde "ein neuer Himmel und eine neue Ende" sein nach der zweiten eschatologischen Schlacht und dem Weltgericht (Off. 21:1) "und der Tod wird nicht mehr sein" (Off. 21:4).

27 Vgl. Pankratov (wie Anm. 21), S. 123-127.

28 "My chotim polnogo i okončatel'nogo osvoboždenija mira ot rabstva, grecha, stradanij i smerti." I.P. BRICHNICEV in: Novaja Zemlja, 1911, 2; zitiert nach O.N. SETNICKAJA, Aleksandr Konstantinovic Gorskj. Biografija. Ms. [Masch.] Siehe auch unten Anm. 58.

29 BeLjaEVA (wie Anm. 7), t. 2 (1959), S. 110, Nr. 3681 . Vgl. auch - aus den Zensurakten - BAZA. Nov, "K tvorzeskim..." (wie Anm. 19), S. $215 f$.

30 I.[P.] BRICHNICEV, Kaplja krovi. Stichorworenija. Vyp. 1, M. 1912. - Kljuev besprach den Band in der Moskauer Wochenschrift Stolitnaja Molva, 4.6.1912, S. 247, S. 3. 
rik $^{31}$ und zwei Bände mit biographischen Skizzen ${ }^{32}$ heraus, die in populärer Form die Ideen einer religiösen Erneuerung befördern sollten. Ausführlich dargelegt wurden diese Ideen in Zeitungsartikeln und einer Reihe von Traktaten, die Brichnicev unter dem Titel Biblioteka 'Novaja Zemlja' herausgab. ${ }^{33}$ Darin entwarf er eine aktiv-schöpferische, auf allumfassende Erlösung abzielende Eschatologie, die bemerkenswerte Übereinstimmungen mit den Grundgedanken der Filosofija obščego dela aufweist: Im Zentrum des von Brichničev propagierten golgofskoe christianstvo sollten nicht, wie bisher, Furcht vor ewiger Verdammnis sowie Streben nach "persönlicher Selbsterrettung" (licnoe samospasanie) und Fortdauer im Jenseits stehen, sondern die Errettung aller Menschen ohne Ausnahme und die Erlösung der gesamten Schöpfung. Die alte Welt sollte in eine neue (novaja zemlja) verwandelt werden durch die gemeinsame Anstrengung der gesamten Menschheit in der Nachfolge Christi. Noch liege die Welt im argen, doch habe Christus auf Golgatha durch seinen Sieg über den Tod den Grund gelegt für ihre Erlösung (daher der Begriff golgofskoe christianstvo). Christi Vorbild (obraz) folgend und mit seiner Hilfe würden die Menschen, vereinigt in gegenseitiger Liebe und dem Bewußtsein, für alles Übel auf der Welt verantwortlich zu sein, schließlich den Sieg über Zeit und Tod erringen:

... das einzige Gebot des golgofskoe christianstvo ist die allgemeine Verantwortlichkeit für das Bobse in der Welt. Christus hat die Welt nicht erlठst, sondern den Grund gelegt für die gemeinsam und mit uns zu verwirklichende Erlosung. (...) Aus dem Feuer der brennenden, flammenden Menschenherzen, vereint in dem Wunsch, alles aufzuerwecken, entsteht jene kosmische Flamme, in der, wie es heißt, die alte Welt und alles Alte verbrennt. ${ }^{34}$

Neben Brichnixevs eigenen Traktaten erschienen in der Biblioteka 'Novaja Zemlja' religiöse und religiös-philosophische Schriften von Valentina Maksi-

31 Christos v mirowoj poezzii, M. 1912. DERs., Moliny uselenskoj cerkvi, M. 1912. - Der überwiegende Teil der Beitrăge stammt von zeitgenössischen russischen Dichtern.

32 I.[P.] BRICHNICEV, Apostoly reformacii, M. 1912. DERS., Apostoly gumannosti $i$ suobody, M. 1912.

33 Vor allem in I.[P.] BRICHNICEv, "Novoe religioznoe soznanie. (C'to takoe golgofskoe christianstvo?)." In: Rul', 358 (9.7.1912). DERS., Clo takoe golgofskoe christianstuo?, M. 1912 (= Biblioteka 'Novaja Zemlja'; 13); wieder abgedruckt in DERS., Ognennyj sejatel', M. ${ }^{2} 1913$, S. $49-55$.

34 BRICHNICEV, "Novoe religioznoe soznanie..." (wie Anm. 33). - Man vergleiche hierzu, was Berdjaev über Fedorov sagte: "Er war ein russischer Sucher nach allumfassender Errettung. In ihm erreichte das Gefühl der Verantwortlichkeit aller für alle seinen schărfsten Ausdruck: Ein jeder ist für die ganze Welt und für alle Menschen verantwortlich, und ein jeder muB danach trachten, alle und alles zu erretten." BERDjAEV, Russkaja ideja (wie Anm. 22), S. 210. - Ob Fedorovs Gedanken einen unmittelbaren EinfluB auf die Konzeption des golgofskoe christianstwo hatten, läßt sich nicht klăren, zweifellos aber besteht eine 'geistige Venwandtschaft'. 
movna Brichnixeva, Svencickij und Bischof Michail sowie Kljuevs Gedichtzyklus Bratskie pesni. ${ }^{35}$

Im August 1912 wandte sich Brichnicev in einem Brief an Aleksandr Blok und berichtete ihm von einer geplanten Zeitschrift, die unter dem Titel Novoe Vino die verbotene Novaja Zemlja ersetzen sollte. Er bat Blok, für die erste Nummer eine Rezension der Bratskie pesni beizusteuern. ${ }^{36}$ Blok lehnte ab. ${ }^{37}$ Im Dezember erschien die erste Nummer von Novoe Vino. ${ }^{38}$ Sie enthielt unter anderem Gedichte von Kljuev (eines davon war Brichnicev gewidmet), Brjusov, Blok und Gorodeckij sowie eine Besprechung der Bratskie pesni von Ljubov' Stolica. Als Herausgeberin und Redakteurin zeichnete Vera Nikandrovna Mironovič-Kuznecova (1880er Jahre - 1931), die später zum Kreis der Moskauer Fedorov-Anhänger zählte. ${ }^{39}$ Sie selbst trat allerdings nur mit einem kurzen Gedicht in Erscheinung. Novoe Vino war im wesentlichen das Sprachrohr von Brichniðev und Svencickij.

Das Programm dieser Zeitschrift lag wiederum auf der Linie des von Brichniðev bereits früher propagierten golgofskoe christianstvo, doch werden hier die Anklänge an Gedanken Fedorovs noch deutlicher. Der "neue Wein", die Lehre Christi vom Reich Gottes auf Erden und vom Sieg über Zeit und Tod, sei, so Brichnicev, von den Menschen verfälscht worden; ihnen gehe es nicht mehr um die "Rettung des Ganzen" (spasenie Celogo) und die Auferweckung aller Kreatur" unter "Anspannung aller Kräfte des ganzen Menschengeschlechts" (naprjaženie vsech sil vsego ¿eloveð̌eskogo roda $k$ voskrešeniju vsej tvari), sondern nur noch um die "Rettung der eigenen Seele" (spasenie sobstvennoj dusi). Einer solchen Haltung, die gekennzeichnet sei durch passive Jenseitssehnsucht und

35 N.[A.] KuJuEv, Bratskie pesni. Kniga vtoraja. M. 1912 (= Biblioteka 'Novaja Zemlja'; 16). - Das Gedicht auf S. 39 ist Valentina Brichniceva gewidmet. Ein Verzeichnis der in dieser Reihe erschienenen Veroffentlichungen findet sich in Nowe Vino, 1913, 2, S. 15.

36 Unveroffentlichter Brief Brichnitevs vom 12.8.1912. Angabe nach AA. BLok, SS v \&-i ti., t. 8, M.-L. 1963, S. 611 Anm. 326. Vgl. auch Bazanov (wie Anm. 19), S. 99. Ders., Sergej Esenin (wie Anm. 24), S. 123-126.

37 Brief vom 26.8.1912, BLoK (wie Anm. 36), S. 400-402. - Blok schrieb, es sei ihm gegenwartig unmoglich, mit irgend jemandem "gemeinsame Sache zu machen" (delat' obszee delo), auch eigne er sich nicht zum Prediger. Blok hatte wohl bemerkt, daB Brichnicev ihn als prominenten Propagandisten für die Sache des golgofskoe christianstwo zu gewinnen suchte. Bloks Brief an Brichnizev wurde erstmals 1922 von dem Fedorov-Anhănger A.K. Gorskij veroffentlicht und kommentiert. A. GoRnOSTAEV [d.i. A.K. GoRSKU], "Golos iz kletki. Neizdannoe pis'mo A. Bloka." In: Segadnja, 1922, 2-3, S. 4f. Siehe auch AzADovsku (wie Anm. 20), S. $100 f$.

Trotz seiner reservierten Haltung gegenüber Brichnitev scheint Blok sich dem EinfluB der religiós-sozialsevolutionăren Bewegungen jener Zeit nicht entzogen zu haben. Bazanov vermutet sogar, daB noch die in ihrer Bedeutung bis heute umstrittene Gestalt Christi am SchluB von Bloks Poem Dvenadcat' (1918) im Sinne des golgofskoe christianstwo aufzufassen sei, d.h. als Kämpfer für Freiheit und scziaie Gerechtigkeit. Buzanov, "Razrusenie... (wie Anm. 19), bes. S. 99-101. DERS., "K tvorteskim..." (wie Anm. 19), bes. S. 219-221.

38 Novoe Vino. Druchnedel'nyj Zumal. M., 1 (Dez. 1912), 2 und 3 (Jan. 1913). 
religiösen Egoismus, gelte es sich zu widersetzen - die Herrschaft von Zeit und Tod könne und müsse hier auf Erden durch die im wahren, das heißt aktiven Glauben vereinigte Menschheit gebrochen werden. ${ }^{40}$

Diese Gedanken könnten bereits direkt von Fedorov inspiriert gewesen sein; über ihre Nähe zu Fedorovs Lehre war sich Brichnicev zu diesem Zeitpunkt jedenfalls im klaren, wie aus einem Brief hervorgeht, den er im Dezember 1912 an N.P. Peterson schrieb:

Ich schicke Ihnen die Zeitschrift Nowoe Vino, aus der Sie ersehen, wie viel unsere Lehre mit der Lehre Fedorovs gemein hat. Ich bitte Sie deshalb sehr, uns (moglichst rasch) ein Portrăt des verstorbenen Philosophen zur Veroffentlichung in der Zeitschrift zu schicken sowie sein Buch und das Ihre über ihn (zur Besprechung) ... ${ }^{41}$

Peterson scheint Brichniłevs Bitte umgehend erfüllt zu haben: Bereits in der zweiten Nummer von Novoe Vino, die im Januar 1913 erschien, finden sich unter der Rubrik "Zolotye slova" drei kurze Auszüge aus Fedorovs Schriften ${ }^{42}$ sowie ein Beitrag, in dem auf Petersons soeben erschienenes Buch über Fedorov und Tolstoj hingewiesen wird. ${ }^{43}$ Von Fedorovs Lehre heißt es, sie enthalte "erstaunliche und blendende Einsichten" (udivitel'nye $i$ slepitel'nye prozrenija), zugleich aber auch "schreckliche und verhängnisvolle Irrtümer" (užasnye, gibel'nye zabluždenija). ${ }^{44}$ Verfasser dieses mit "A.K." gezeichneten Beitrags war der Fedorov-Anhänger A.K. Gorskij, zu jener Zeit Lehrer in Odessa, ${ }^{45}$ der unter dem Pseudonym "A. Gornostaev" auch mit mehreren Gedichten in der zweiten und dritten Nummer von Novoe Vino vertreten war. ${ }^{46}$ Er dürfte es gewesen sein, der die Mitarbeiter dieser Zeitschrift - insbesondere Brichnicev und die Herausgeberin Mironovǐ̌-Kuznecova - mit den Ideen Fedorovs bekannt gemacht hat.

Auch Nikolaj Kljuev, der mit Brichnicev befreundet war, zum engen Mitarbeiterkreis von Novoe Vino gehörte und dem golgofskoe christianstvo eine Zeitlang anhing, ${ }^{47}$ soll sich für Fedorovs Ideen interessiert haben. ${ }^{48}$ Kljuevs

40 I.B. [d.i. I.P. BRICHNICEV], "Novoe vino." In: Novoe Vino, 1912, 1, S. 2; wieder abgedruckt in Ders., Ognennyj sejasel' (wie Anm. 33), S. 9f.

41 'Posylaju Vam žurnal 'Novoe Vino' - iz nego Vy uvidite, kak mnogo v nǎ̌em utenii obšzego s ư̌eniem Fedorova. Poétomu oxen' prošu Vas vyslat' nam (vozmožno skoree) portret pokojnogo filosofa dlja pomescenija v žumale, ego knigu i Vał̌ o nem (dlja otzyva)..." I.P. Brichnizev an N.P. Peterson, Dezember 1912; Original im Peterson-Archiv, GBL f. 657; nach einer Abschrift in Moskauer Privatbesitz.

42 Nowa Vino, 1913, 2, S. 14.

43 A.K. [d.i. A.K. GorSKU], "O kliłkach. (lz bratskoj perepiski)." In: Novoe Vino, 1913, 2, S. 9 .

44 Ebd., S. 10.

45 Uber ihn ausführlich II: 23.2 .

46 Siehe die Angaben in der Bibliographie dieser Arbeit.

47 Die erste Ausgabe von Kljuevs Bratskie pesni (1912) trug den Untertitel Pesni golgofskich christian. Brichnirev nannte Kljuev einen "poet golgofskogo christianstva" (in: Novaja Zemlja, 1912, 


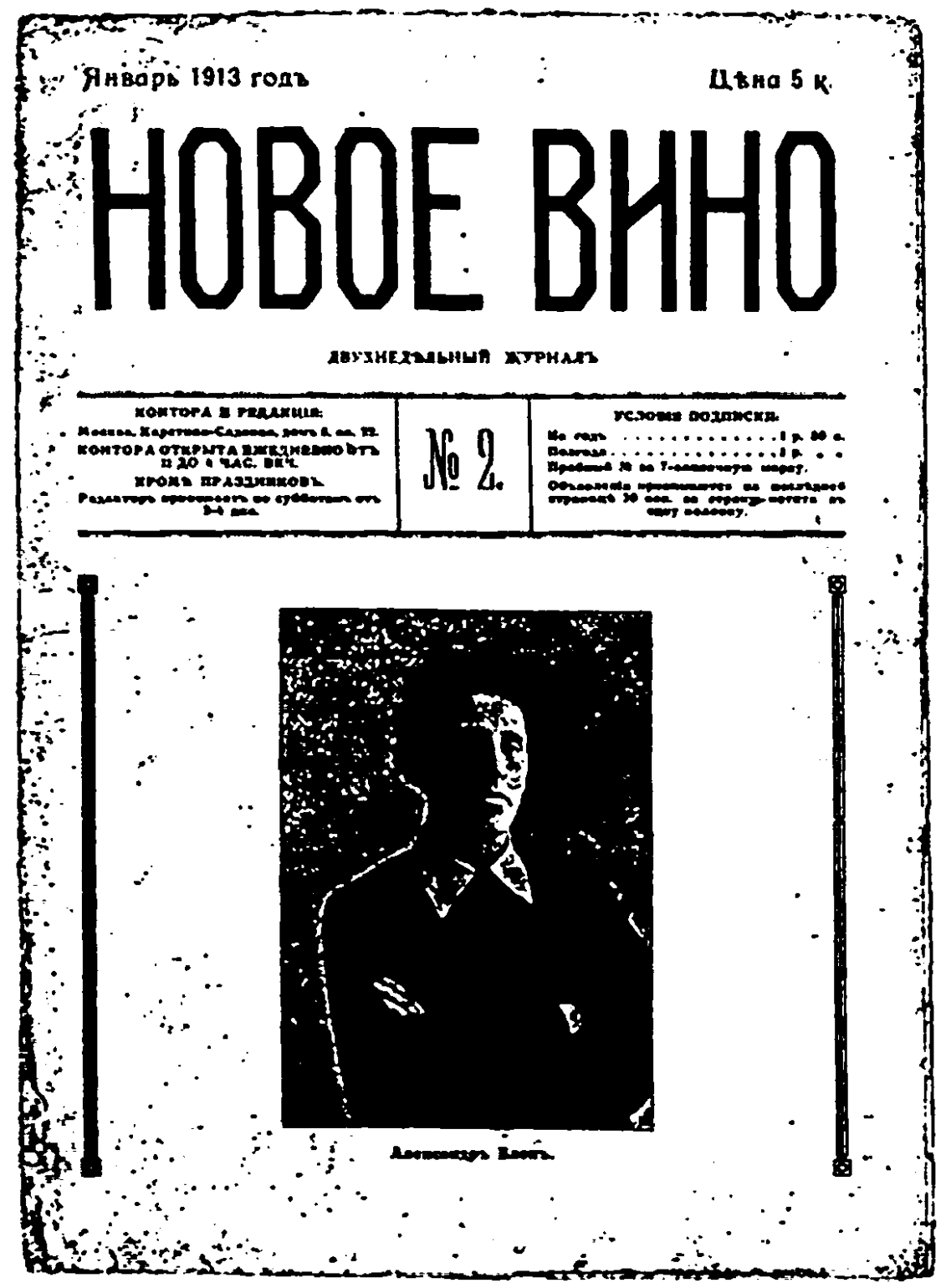

1-2, S. 3). - Siehe insbesondere AZADOVSKU (wie Anm. 1 und 24); ferner K.L. ZELINSKU, Na rubeže druch epoch, M. 1959, S. 200f. BAzANov (wie Anm. 23), S. 21. DERS., "K tvorteskim..." (wie Anm. 19), S. 212-214. Niqueux (wie Anm. 20), S. 621, 624 Anm. 3.

Als Kljuev versuchte, sich der sektiererischen Enge des golgofskoe christianstwo zu entziehen, kam es - offenbar gegen Ende des Jahres 1912 - zum Bruch mit Brichnirev, wie aus einem 1913 veroffentlichten Gedicht Brichnitevs hervorgeht ("Nikolaju Kljuevu" in: I.[P.] BRICHINIEV, Osanna. (Vtoraja kniga stichov). Odessa 1914 [recte 1913], S. 115). Wahrscheinlich war Brichnitev auch jener von Sergej Gorodeckij erwahnte "Genosse B.", der ein gegen Kljuev gerichtetes Pamphlet "Pravda o Nikolae Kljueve" verfaBt hatte, das handschriftlich verbreitet war. Siehe S. GORODECKu, "O Sergee Esenine. Vospominanija." In: Noyyj Mir, 2 (1926), 2, S. 137. 146; hier S. 139. Gorodeckij gehorte zu den Autoren von Novoe Vino und war mit Kljuev seit 1911 bekannt. Hierzu K.[M.] AZADOvSKU, "N.A. Kljuev i 'Cech poetov'." In: Voprosy Literatury, 1987,4 , S. 269-278.

48 Filippov, der wiederholt auf thematische Gemeinsamkeiten in den Werken von Fedorov und Kjuev hinweist, zitiert eine mündliche ÄuBenung des Philosophen S.A. Alekseev-Askol'dov, Kljuev habe Fedorovs Lehre "ganz ausgezeichnet gekannt" (znal prevoschodno). FilipPov, "Nikolaj Kljuev..." (wie Anm. 20), S. 50. Dafür gibt es allerdings keinen Beleg! 
vielbewunderte Belesenheit und eine gewisse Geistesverwandtschaft lassen diese Vermutung jedenfalls zu. So traf er sich mit Fedorov beispielsweise in der Identifizierung von 'Volk' und Bauern und in der Verherrlichung der patriarchalischen Ordnung des russischen Dorfes sowie in der Ablehnung der städtischen Zivilisation und ihres 'künstlichen' Lebens. In seinem Antiurbanismus ging Kljuev so weit, das Bild einer glücklichen Zukunft zu entwerfen, in der die Stadt - dieses "steinerne Gefängnis" (kamennaja tjur'ma) - gänzlich abgeschafft sein würde. ${ }^{49}$

Zu einer intensiveren Rezeption und Auseinandersetzung mit der Lehre Fedorovs oder gar zu einer Verschmelzung mit verwandten Ideen des golgofskoe christianstvo ist es auf den Seiten von Novoe Vino nicht mehr gekommen; mit der dritten Nummer stellte die Zeitschrift im Januar 1913 ihr Erscheinen ein. ${ }^{50}$ Ihre Bedeutung für die Wirkungsgeschichte Fedorovs liegt vor allem darin, da $B$ sich um sie ein kleiner Kreis von Intellektuellen gesammelt hatte, deren Aufmerksamkeit auf das Problem des Todes und seiner immanenten Überwindung gerichtet war und die deshalb aufgeschlossen waren für Fedorovs Ideen und sich mit seinem Werk zu beschäftigen begannen. Ihren Niederschlag fand diese Beschäftigung bereits ein Jahr später in dem von Gorskij gemeinsam mit Brichnißev herausgegebenen Sammelband Vselenskoe delo. ${ }^{51}$

Brichnicev selbst war in dieser Zeit zu einem begeisterten Anhänger Fedorovs geworden, wie seine Gedichte beweisen, die er Ende 1913 in Odessa veröffentlichte. 52 Sie sind Fedorov und seinen Ideen gewidmet und rufen auf zum gemeinsamen Kampf gegen den Tod, zur Erschaffung einer neuen Welt und eines neuen, "göttlichen" Menschen. Als Beispiel für Brichniðevs Auffassung von Fedorov (und zugleich für seinen schwülstigen Stil) sei das Gedicht "An N.F. Fedorov" zitiert:

49 So Kljuev in scinem Aufsatz "Plenniki goroda" in Novaja Zemlja (1911); nach AZADovskus (wie Anm. 24), S. 206. Zu Kljuevs Antiurbanismus im Zusammenhang mit Fedorov auch B.A. Fiup. POV, "Potomok Awakumov." In: DeRS., Mysli naraspasku, Washington 1979, S. 149-157. - Die Idee einer Abschaffung der Städte findet sich ein Jahrzehnt später in A.V. Cajanovs băuerlicher Utopie.

50 Man kann Novoe Vino also kaum als "Fedorovian publication" bezeichnen. ST. LUKASHEVICH, N.F. Fedorov (1828-1903). A Study in Russian Eupsychian and Utopian Thought. Newark, London 1977, S. 29. Ebensowenig war die Zeitschrift gegründet worden "for the explicit purpose of addressing the issue of man's mortality". S.F. STARR, Melnikov. Solo Architect in a Mass Sociery. Princeton 1981, S. 245. - Keinem der beiden Autoren scheint Novoe Vino vorgelegen zu haben, da beide die falsche Angabe des Erscheinungsdatums aus Vselenskoe delo (wie Anm. 1), S. 183, übernehmen. Vollige Unkenntnis offenbart schließlich die Behauplung:"... the first known group of committed 'Fedorovists' was a band of unknown [!] poets who wrote for Novoe vino, a small Kiev [!] magazine started in 1909 [!] by Vera Kuznetsova". G.M. Young, Nikolai F. Fedorov: An Introduction. Belmont, Mass. 1979, S. 181 .

51 Siehe II: 2.3 .2 .

52 BRICHNICEV, Osanna (wie Anm. 47). - Der im November/Dezember 1913 in Odessa erschienene Band enthălt u.a. Gedichte an Fedorơ, Gornostaev [Gorskij], V.N. Mironovic, Stolica, Kogan, Kljuev, Svencickij und P.I. Bachmet'ev. - Brichnicev war Anfang 1913 nach Odessa übergesiedelt. 
Am wenigsten von allen kannte und las ich Dich,

Als ich meinen unruhigen Weg ging...

Doch da - in der Ferne erblickte ich die Sonne...

Und mit dem ahnenden Herzen erkannte ich plotzlich

Dich, Weiser, Dich, gestrenger Eremit!..

Wachsen wir gemeinsam, verwandter Kristall.

Unser Banner: Von der Verwesung zur Auferweckung.

Du standest auf der Spitze aller Grabhügel..

Du - liebtest alles. Und alle riefest Du zur Tat

Und alles zur Vereinigung zusammen..

Dein Platz ist das Zollamt, das Archiv..

Du bist das Geflecht aller Welten und aller Zeiten..

In den Bücherkammern hast Du das Gras vertrockneter Wiesen

Gesammelt, und in Krăfte umgewandelt

Hast Du es von neuem zu ewiger Blüte gerufen..

Wir werden den Aufruf der großen Seele erfüllen..

Die Auftrăge des Ewigen verwirklichen..

Und wenn wir die zăhneknirschenden Feinde versöhnt haben,

So werden wir aus allen lebendigen Hörnern zu posaunen beginnen

Und den Schmutz der Erde in Topase verwandeln.

Und wie Konige, IHM gleich,

Werden alle den Thron besteigen zur Rechten der wunderbaren Kräfte..

Und unsere Mutter - das Gefăngnis des Universums,

Werden wir umgestalten - Unvergănglichkeit allem!

Wir, die auf himmlischen Wolken Kommenden... ${ }^{53}$

Fedorovs Einfluß, sein Glaube an die unbegrenzten Möglichkeiten technischen Fortschritts bei gleichzeitiger Pflicht, die Schuld gegenüber den Vorfahren zu erstatten, kommt deutlicher noch zum Ausdruck in dem Gedicht "An P. Bachmet'ev" aus demselben Band:

Keine Märchen mehr... Nein...

Alles wird klar und wahr...

Da ist auch schon die Antwort:

Straßenbahn und Automobil!...

Und morgen - sind die Segel in der Luft gespannt

Und morgen - gibt es Telegraphen ohne Drăhte und Masten...

Was für ein Tag, da neu ist die entzauberte Kraft

Und nah' der süße Augenblick, da wir auferstehen werden aus den Grăbern...

Keine Mărchen mehr... Nein

Und keine Hindernisse dem Glauben...

Gruß dem Kommenden...

Und Wiederbringung dem Vergangenen. ${ }^{54}$

53 "N. Fedorovu." Ebd., S. $111 f$.

54 "P. Bachmet'evu." Ebd., S. 98. - Uber den Biologen und Physiker P.I. Bachmet'ev, der sich mit dem Problem der Anabiose beschäftigte und mit Brichnizev korrespondierte, siehe II: 2.1.3. und 2.3.2. 
Und in einem anderen Gedicht "An P.I. Bachmet'ev" heißt es:

(...)

Vor der Macht des Verstandes und des menschlichen Willens

Fallen, sinken in den Staub

Die alten Trugbilder, die seit Urzeiten quălen

Schrecken des Universums...

Gottmensch auch DU! ER befahl zu erfüllen,

Du vollendetest -

Ein stolzer Beginn. Und glücklich, wer fortführt, Was Du entdeckt.

(...)

Steh auf, o Fedorov. Zu Ende sind die Tage des Umherirrens,

Das Land ist getrostet.

Wir werden nicht sterben wie Moses beim Lager

Am Abhang des Gebirges

Als man im Morgenrot bereits das Hosianna vernahm

Und sichtbar war die lichte Stadt. ${ }^{55}$

Die Jahre des Ersten Weltkriegs verbrachte Brichni Stadt zu Stadt wandernd in der Ukraine und im Kaukasus, dann, ab Dezember 1915, wieder in Moskau. In dieser Zeit veröffentlichte er zwei weitere Gedichtbände, ${ }^{56}$ in denen sich jedoch keine deutlichen Anklänge an Fedorovsche Themen finden. ${ }^{57}$

\subsubsection{A.K Gorskij und der Sammelband 'Vselenskoe delo' (1914)}

Über den Fedorov-Anhänger Aleksandr Konstantinovix Gorskij (1886-1943) liegen nur verstreute und teilweise schwer zugängliche Informationen vor. ${ }^{58}$ Offensichtlich war Gorskij - darin Fedorov gleich - bestrebt, als Persönlichkeit ganz hinter sein Werk zurückzutreten und die eigene Lebensgeschichte zu verschleiern. Wie Fedorov publizierte er nie unter seinem eigenen Namen, sondern

55 "P.I. Bachmet'evu." Ebd., S. 966.

56 Puti żiye, M. 1916. Liturgija celomu, M. 1917. - Letztgenannter Band erschien in einem Verlag Bessmertie, uber den nichts weiter bekannt ist. Der Name läBt vermuten, daB es sich um ein Unternehmen der Biokosmisten gehandelt haben könnte. Ausführlich dazu II: 3.3.

57 Ober Brichnixevs Karriere unter den Sowjets II: 4.1.

58 Die Angaben zur Biographie von A.K. Gorskij stammen, sofern nichts anderes angegeben, aus einem unveroffentlichten Manuskript von O.N. SETNICKAJA, Aleksandr Konstantinovic Gorskij. Biografija. Ms. [Masch.] 0.O. 0.J., $47 \mathrm{Bl}$., sowie aus privaten Mitteilungen der Verfasserin. Ol'ga Nikolaevna Setnickaja (5.4.1916-10.2.1987), Tochter des Fedorov-Anhăngers N.A. Setnickij (über ihn ausführlich II: 4.1.) und selbst seit ihrem sechzehnten Lebensjahr Anhängerin der Ideen Fedorovs, war mit Gorskij in den dreiBiger und vierziger Jahren eng befreundet. 
verbarg sich hinter wechselnden Pseudo- und Kryptonymen. ${ }^{59}$ Seine zahlreich erhaltenen Manuskripte und Briefe, ${ }^{60}$ in eigenartiger, äußerst schwer zu entziffernder Schrift verfaßt, enthalten kaum Angaben zu seiner Person oder Hinweise auf seine Lebensumstände. Aus Gorskijs literarischer Hinterlassenschaft, vor allem aber aus Schilderungen derer, die ihn kannten, entsteht das Bild eines Sonderlings, der ganz seiner selbstgewählten Aufgabe lebte, die darin bestand, Fedorovs Gedanken weiterzuentwickeln und zu verbreiten, wobei sein Enthusiasmus bisweilen durchaus sektiererische Züge annahm.

A.K. Gorskij wurde am 18.(30). Dezember 1886 als Sohn eines Geistlichen in Starodub (Gvt. Cernigov) geboren. ${ }^{61}$ Er besuchte die Schule seiner Geburtsstadt (1897-1902), dann das Geistliche Seminar in Černigov (1902-1906) und studierte anschließend an der Moskauer Geistlichen Akademie und, möglicherweise, auch an der Moskauer Universität. Im Winter 1906/7 nahm Gorskij an Zusammenkünften der Moskauer Religiös-Philosophischen Gesellschaft teil. Zu seinen Bekannten zählten V.A. Ternavcev und L.I. Šestov; einer seiner Lehrer an der Akademie war Pavel Florenskij, der ihn hoch schätzte. Eine längere Reise führte Gorskij im Jahre 1908 nach Bulgarien, Griechenland, Serbien, Kroatien, Österreich-Ungarn und Polen. 1911 absolvierte er die Geistliche Akademie, ohne jedoch die Priesterweihe empfangen zu haben. 1913 ging er als Lehrer nach Odessa. ${ }^{62}$ Offenbar gehörte Gorskij - wie Brichničev - zu jenen jungen, theologisch gebildeten Intellektuellen, die, angesichts der revolutionären Ereignisse von der starren, regimetreuen Haltung der offiziellen Kirche enttäuscht, außerhalb der traditionellen Orthodoxie nach neuen Formen für ihre Religiosität und ihr soziales Engagement suchten.

Bereits während seines Studiums an der Geistlichen Akademie hatte Gorskij Fedorovs Werk kennengelernt ${ }^{63}$ und begonnen, sich mit ihm zu beschäftigen; $a b$

59 Folgende Pseudonyme konnten aufgelరst und Gorskij zugeschrieben werden: A.[K.] Gornostaev, A. Grobov, A. Ostromirov, Pavel Lutickij, Zin. Gerv. Jachontov. - Siehe auch die Angaben in der Bibliographie dieser Arbeit.

6033 Briefe Gorskijs an N.A. Setnickij aus den Jahren 1925 bis 1928 befinden sich im FedorovArchiv in Prag (siehe auch II: 4.2.2. und 4.3.2.). Zahlreiche weitere Briefe und unveroffentlichte Manuskripte Gorskijs haben sich in mehreren privaten Archiven in Moskau erhalten und konnten dort eingesehen werden (siehe auch II: 4.2. Anm. 59).

61 SETNICKAJA (wie Anm. 58), Bl. 1. - Dagegen nennt N.A. Setnickij als Geburtsdatum Gorskijs den 24.10. (a.St.) 1887. Brief Setnickijs an das Tschechische Nationalmuseum Prag, 5.6.1933; FAP I, 328.

62 Dort unterrichtete er Latein und Russische Literatur an einem Priesterseminar und einem Gymnasium. Zu seinen Schülern zählten die später als Schriftsteller berühmt gewordenen Brüder Kataev - Valentin (1897-1986) und Evgenij (1903-1942) - sowie der Dichter Eduard Bagrickij [d.i. E. Dzjubin, 1895-1934]. In Valentin Kataevs autobiographischer Erzăhlung Trava zabven'ja (1967) findet sich kein Hinweis auf Gorskij. Auch in der sehr detaillierten Kataev-Biographie von L.I. Skorino, Pisatel'i ego vremja. Zizn'i tvontestvo V.P. Kataeva. M. 1965, wird Gorskij nicht erwähnt.

63 In Gorskijs Notizbüchern taucht der Name Fedorov erstmals 1910 auf im Zusammenhang mit Dostoevskij und Solov'ev. SETnICKAJA (wie Anm. 58), Bl. 7f. Vielleicht war Gorskij durch P.A. Florenskij auf Fedorov aufmerksam gemacht worden. 
1913 widmete er sich intensiv seiner Auslegung und Weiterentwicklung. ${ }^{64}$ Daneben schrieb und veröffentlichte er Gedichte, ${ }^{65}$ begann eine breit angelegte vergleichende Untersuchung über Leben und Werk von Vladimir Solov'ev und Fedorov, ${ }^{66}$ befaßte sich mit der Psychoanalyse Sigmund Freuds und geriet unter den Einfluß der metaphysisch-panpsychischen Spekulationen Gustav Theodor Fechners (1801-1887) sowie der Popularphilosophie des amerikanischen Pragmatisten Prentice Mulford (1843-1891), dessen "praktischer Optimismus" die Natur durch den Geist aufbrechen und den "Unfug des Sterbens" kurzerhand abschaffen wollte.

$\mathrm{Zu}$ Beginn des Jahres 1913 veröffentlichte Gorskij seine ersten Beiträge in Novoe Vino und machte vermutlich die übrigen Mitarbeiter dieser Zeitschrift mit den Ideen Fedorovs bekannt. Wahrscheinlich auf seine Anregung hin wurde der Plan gefaßt, zu Ehren Fedorovs an dessen zehntem Todestag am 15.12.1913 einen Sammelband mit dem Titel Vselenskoe delo herauszugeben. Die Redaktion übernahmen Gorskij und Brichnicev; beide hatten sich zu Beginn des Jahres 1913 in Odessa niedergelassen. Im Mai 1913 veröffentlichten sie im Moskauer Verlag N.I. Dorofeeva einen Prospekt, der ein Zitat aus Fedorovs Filosofija obščego dela, Koževnikovs Gedicht Da priidet Čarstvie Tvoe, eine Inhaltsangabe des geplanten Bandes sowie eine Aufforderung zur Beteiligung enthielt. ${ }^{67}$ Bis zur Fertigstellung verging freilich noch ein Jahr, und als Vselenskoe delo schließlich im Sommer 1914 in Odessa erschien, gelangten infolge des Kriegsausbruchs nur noch wenige Exemplare in Umlauf. ${ }^{6}$

64 Brief von N.A. Setnickij (wie Anm. 61). - Bestătigt wird dies durch einen Brief Gorskijs an Maksim Gor'kij vom 19.3.1923, in dem er schreibt: "Ja už okolo 10 let zanjat razrabotkoj voprosov svjazannych s liŁnost'ju i ǔeniem Fedorova." Unveroff. Brief im Gor'kij-Archiv Moskau; nach einer Abschrift in Moskauer Privatbesitz.

65 Der erste Bard seiner Gedichte, der ermittelt werden konnte, erschien 191.3 unter dem Titel Glubokim utrom. (Pesnopenija) in Moskau bei N.I. Dorofeeva, dem Verlag, der auch die bereits enwähnte Biblioteka 'Novaja Zemlja' mit den Werken von Brichnitev, Svencickij und Kljuev herausgegeben hatte. In der Einleitung schreibt Gorskij, offenbar bereits unter dem Einfluß der Ideen Fedorovs, er wolle seine Gedichte verstanden wissen als "Einladung zur Liturgie", als "Aufruf zur allumfassenden, gemeinschaftlichen Tat der Umwandlung alles Toten in Lebendiges und alles Vergänglichen in Unvergängliches." (Ebd., S. X). Die Gedichte selbst verraten den Einfluß von Vl. Solov'ev und Blok.

66 "Tjaga zemnaja." Auszugsweise veroffentlicht in Vselenskoe delo, sb. 1, Odessa 1914, S. 140-207. - Von Solov'evs Werken hatten Gorskij besonders die unter dem Titel Smysl ljubvi veröffentlichten Aufsätze beeindruckt, die von der Übenwindung des Todes durch die Liebe handeln. SETNICKAJA (wie Anm. 58), Bl. 3.

67 Angaben nach Setnicknja (wie Anm. 58), Bl. 15f., und Brief von V.A. Koževnikov an N.P. Peterson, 14.6.1913; Peterson-Archiv, GBL f. 657, k. 4; nach einer Abschrift in Moskauer Privatbesitz.

68 Vselenskoe delo, vypusk 1 [so das Titelblatt; auf dem Umschlag: sbornik 1], Odessa 1914. XIII, 208, 42 [priloženija], II, (4)S.

Gedruckt und herausgegeben vom Verlag Vencke $i$ Ljubek in Odessa, war der Sammelband bereits bei seinem Erscheinen eine bibliographische Rarităt. Da sich der Verlag in deutschosterreichischem Besitz befand, wurde er bei Kriegsausbruch geschlossen, seine Besitzer 


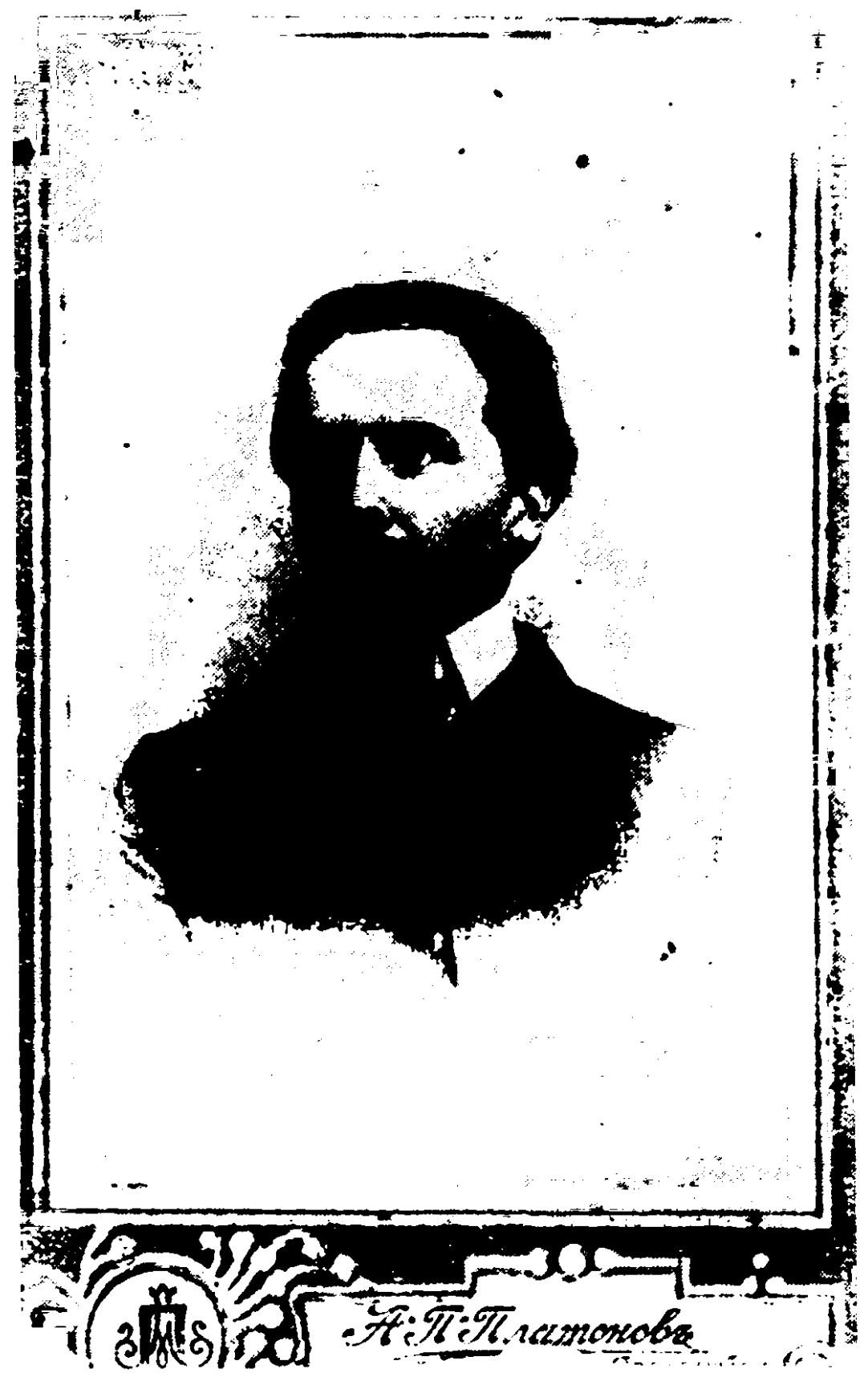

A.K. Gorskij, Aufnahme um 1905

verhaftet und nahezu die gesamte Auflage von Vselenskoe delo beschlagnahmt. Lediglich einige Rezensionsexemplare waren bereits ausgeliefen worden. Eines davon jefindet sich heute in der "Sammlung Lieb" der Universitătsbibliothek Basel (Sign.: Lieb Eb 219). Im Westen ist m.W. nur noch ein weiteres Exemplar zugănglich, das sich im Besitz der Universitătsbibliothek Helsinki befindet. - Zur Entstehungsgeschichte des ersten Bandes von Vselenskoe delo siehe ZET. [d.i. NA. SETNICKU], "Vselenskoe Delo' v proslom." In: Vselensioe delo (wie Anm. 1), S. 107-115. 
Der Band umfaßt 34 Beiträge, davon 13 Gedichte. Zu 13 der insgesamt 19 Autoren konnten biographische Daten ermittelt werden. ${ }^{69}$ Neben A.K. Gorskij (unter den Pseudonymen "A. Gornostaev" und "Pavel Lucickij"), I.P. Brichnicev und N.F. Fedorov waren dies die Schriftsteller V.Ja. Brjusov und V.V. Borodaevskij $^{70}$, der Pädagoge und Tolstoj-Anhänger I.I. Gorbunov-Posadov (18641940), die Dichterinnen L.N. Stolica $(1884-1934)^{71}$ und F.I. Kogan (1891$1974)^{72}$, der Journalist und Sektenforscher A.S. Pankratov $(1872-1922)^{73}$, der Schriftsteller A.S. Sorokin (1884-?) ${ }^{74}$, der Odessaer Psychoanalytiker M. Wulff (Vul'f) $^{75}$ sowie die Naturwissenschaftler P.I. Bachmet'ev $(1860-1913)^{76}$ und V.A. Chludov (1840-1913) ${ }^{7}$. Bei fünf der genannten Autoren - nämlich Gorskij, Brichnicev, Stolica, Kogan und Brjusov - handelte es sich um ehemalige Mitarbeiter von Novoe Vino; Gorbunov-Posadov hatte in Brichnicevs Novaja Zemlja publiziert. $^{78}$

Aufgabe von Vselenskoe delo - dem ersten Band sollten halbjährlich weitere folgen - war es, die von Fedorov erhobene Forderung nach Überwindung des Todes und Auferweckung aller Verstorbenen zu verbreiten sowie Mittel und Wege vorzustellen, die geeignet erschienen, diese Forderung zu verwirklichen.

69 Keine biographischen Daten wurden gefunden zu: R. Mannovskij, Vladimir Kedrov, I.M. Lucenko, Apollon Vodlinger, V.K. Nedzveckij sowie dem Odessaer Dichter Oleg Vostokov. Letzterer ist wohl kaum, wie Ol'ga Setnickaja in einem Schreiben vom 30.8.1985 vermutete, mit dem Wirtschaftswissenschaftler und Eurasier P.N. Savickij (1895-1968) identisch, der seit den dreißiger Jahren gelegentlich unter dem Pscudonym P. Vostokov publizierte (siche II: 4.3.2.).

70 Valerian Valerianovic Borodaevskij, ein gelernter Bergbauingenieur, galt als Verehrer Fedorovs. Er war mit Vjareslav Ivanov und Rozanov befreundet und mit Belyj bekannt und beschăftigte sich wie dieser mit Anthroposophie und Mystik. Wahrscheinlich unterhielt er auch Kontakte zu Brichnizev und Gorskij. In der von Brichnizev 1912 herausgegebenen Anthologie Christos v mirovoj poezii war Borodaevskij mit einem Gedicht vertreten. Zu Borodaevskij auch II: 2.2.2.

71 L.N. Stolica debütierte 1908 mit der Gedichtsammlung Rainja, 1912 erschien ihre zweite Gedichtsammlung Lada und 1915 die Sammlung Rus'. Ihr groBer Roman in Versen Elena Deeva wurde 1916 in Moskau und 1923 in Berlin herausgegeben. Seit 1921 lebte Stolica in Bulgarien.

72 F.I. Kogan debütierte 1912 mit dem Gedichtbăndchen Moja duša. 1920 gehörte sie dem von Vjareslav Ivanov geleiteten Kruzok poezii in Moskau an.

73 Möglicherweise hatten sich Pankratov und Brichnicev in der "Jama", dem Moskauer Sektierertreffpunkt, kennengelernt. Siehe oben Anm. 21.

74 I.F. MASANOv, Slovar' psevdonimov nusskich pisatelej, uČenych i obšrestvennych dejatelej, t. 4, M. 1960, S. 449.

75 Siehe unten Anm. 83.

76 BSE (1-oe izd.), t. 5, M. 1927, Sp. 96f. BSE (3-e izd.), t. 3, M. 1970, S. 54.

77 Vselenskoe delo (wie Anm. 68), [prilož.] S. $25 f$.

78 Diesem Kreis dürfte mindestens noch ein weiterer Autor von Vselenskoe delo zuzurechnen sein, nămlich ein gewisser Vladimir Kedrov, von dem der bereits mehrfach enwăhnte Moskauer Verlag N.I. Dorofeeva 1913 einen Band mit dem Titel Evangelie voskrešenija angekündigt hatte, der jedoch nie erschienen ist. 
In dem von Gorskij verfaßten programmatischen Aufruf zu Beginn des Bandes heißt es dazu:

(...) Sterbliche aller Lănder, Stămme und Vőlker, aller Berufe, Rănge, Stănde, aller Glaubensrichtungen, Meinungen und Oberzeugungen - vereinigt Euch!

Nur im gemeinsamen und einmütigen Kampf mit dem allgemeinen Feind, im unversöhnlichen und bestăndigen Kampf, in dem keine einzige Kraft entbehrlich ist, keine einzige Waffe ungenutzt bleibt, werden wir unser angeborenes Recht erringen - das Recht auf Unsterblichkeit.

Alle, die den Sieg über den Tod nicht nur im mystischen oder irgendwie metaphorischen, sondern im direkten, einfachen und präzisen Sinne für möglich und wünschenswer halten, rufen wir auf, zusammenzukommen und sich zu vereinigen. [S. IIX]

(...) Die Aufgabe des Kampies mit dem Tod ist eine gemeinsame Aufgabe (delo obšcee), eine Aufgabe der gesamten Menschheit; die Verbannung des Todes aus der Welt ist nicht mit vereinzelten Kraften zu erreichen. [S. IX]

(...) Das BewuBtsein allumfassender Verbundenheit, der Verantwortung aller für einen jeden und eines jeden für alle, die weltweite Gesamtbürgschaft (vsemimaja krugovaja poruka) ist die erste Bedingung für den Sieg.

Wir sind überzeugt, daß der Kampf gleichzeitig geführt werden muB, in der Betrachtung und im Handeln, in Theorie und Praxis, in Begeisterung und Anspannung, im Geheimen und im Wachen, in der Mystik und in der Wissenschaft. [S. X]

$(\ldots)^{79}$

Im Kampf gegen den Tod war offenbar jeder als Verbündeter willkommen, wie das breite Spektrum der Beiträge beweist. Neben einem pathetischen Aufruf von Brichnið̌ev, in dem die Überwindung des Todes, die Auferweckung aller Verstorbenen und die Errichtung des Reiches Gottes auf Erden proklamiert und als eigentliche Aufgabe der Menschheit in der Nachfolge Christi dargestellt wird, ${ }^{80}$ finden sich naturwissenschaftliche Aufsätze des seinerzeit bekannten Biologen und Physikers P.I. Bachmet'ev und seiner Mitarbeiter über physiologische Experimente zur Anabiose ${ }^{81}$ und zur Konservierung lebender Materie durch Unterkühlung ${ }^{82}$. Eine psychoanalytische Studie des Freudianers Mosche Wulff über Todesfurcht ${ }^{83}$ steht neben Beiträgen über Seelenwanderung ${ }^{84}$ und

79 [A.K. GoRsKU], "Ot redakcii." In: Vselenskoe delo (wie Anm. 68), S. VII-XII; wieder abgedruckt in: Vselenskoe delo (wie Anm. 1), S. 109-112. Zur Verfasserschaft Gorskijs SETNICKANA (wie Arm. 58), Bl. 16.

80 I.[P.] BRichniCev, "Delo Iisusa. (Nad Evangeliem)." In: Vselenskoe delo (wie Anm. 68), S. 122.

81 P.I. BAChMet"Ev, "Sedališe duSi. (Anabioz)." Ebd., S. 59-85. Der Autor selbst soll kurz vor seinem Tod diesen Artikel der Redaktion von Vselenskoe delo übergeben haben. SETNICKAJA (wie Anm. 58), Bl. 17. - Zu Bachmet'ev II: 2.1.3.

82 I.M. LUCENKo, "Predely żizni. (Cholod i ego vlijanie na žizn')." In: Vselenskoe delo (wie Anm. 68), S. 99-104.

83 M.[V.] VUL'F, "O strache smerti, idee bessmertija i samoubijstve. (Psichoanalitiðeskij eskiz)." Ebd., S. 108-116. - Mosche Wulff, aus Odessa gebürtig, hatte seine Ausbildung in Berlin unter Karl Abraham erhalten; seit 1910 praktizierte er in seiner Heimatstadt und war bis zu seiner 
Mystik $^{85}$. Die Gedichte, die zumeist aus der Feder von Brichnicev oder Gorskij stammen, sind Personen gewidmet, denen sich die Herausgeber von Vselenskoe delo besonders verbunden fühlten: Fedorov, Tolstoj, Solov'ev, Bachmet'ev und Prentice Mulford.

Um auch prominente Autoren als Beiträger zu gewinnen, hatten sich Brichničev und Gorskij im Frühjahr und Sommer 1913 an "bekannte Persönlichkeiten" gewandt und diese gebeten, ihre Ansichten über den Tod und die Möglichkeit seiner Überwindung mitzuteilen. ${ }^{86}$ Die Resonanz war jedoch enttäuschend gering: ${ }^{87}$ Ausführliche Stellungnahmen kamen lediglich von Pankratov, ${ }^{88}$ Gorbunov-Posadov ${ }^{89}$ und Brjusov ${ }^{90}$. Hingegen hatten Fedorovs engste Vertraute, Koževnikov und Peterson, ebenso wie P.A. Florenskij ihre Mitarbeit von Anfang an verweigert, da sie eine materialistische Interpretation des obšcee delo (als "chemische Auferweckung") und damit eine 'Vulgarisierung' der Fedorovschen Ideen befürchteten. Insbesondere störte sie die Teilnahme führender Vertreter des golgofskoe christianstvo: Es sei zu bedauern, so erklärten sie, da $B$ der Aufruf zum obšcee delo ausgerechnet von so zweifelhaften Gestalten wie Brichnicev und Svencickij ausgehe. ${ }^{91}$

Emigration nach Palăstina Ende 1927 einer der bedeutendsten Psychoanalytiker Rußlands. Siehe J. MART, "La psychoanalyse en Russie et en Union soviétique de 1909 à 1930." In: Criti. que, 32 (1976), 346, S. 199-236.

84 V.K. NeDzVECKU, "Metémpsichoza." In: Vselenskoe delo (wie Anm. 68), [prilož.] S. 31-42.

85 Ders., "Misticizm ili realizm?" Ebd., S. 35-41.

86 Siehe ZET. [SEINICKU] (wie Anm. 68), S. 108. - Wer die von den Herausgebern angeschriebenen Persönlichkeiten waren, wird nicht mitgeteilt.

87 Vselenskoe delo (wie Anm. 68), [prilož.] S. 25.

88 "Žizn' ne prekraš̌aetsja." Ebd., S. 43f.

89 "Čto ja dumaju o voskreß̌enii. (Pis'mo k redaktoram sbornika 'Vselenskoe delo')." Ebd., S. $46 \mathrm{f}$. (datiert: 2. Nov. 1913).

90 "O smerti, voskresenii i voskrě̌enii. (Pis'mo v otvet na vopros)." Ebd., S. 49f. (datiert: November 1913). Ausführlich dazu II: 2.2.2.

91 Brief von Koževnikov an Peterson, 14.6.1913 (wie Anm. 67); darin werden auch die gleichlautenden Befürchtungen Florenskijs wiedergegeben (Florenskij war von Gorskij zur Mitarbeit an Vselenskoe delo aufgefordert worden).

Negative Äußerungen uber Brichnizev und Svencickij finden sich auch in anderen Briefen Koževnikovs und Petersons aus jener Zeit. In einem Brief vom 15.11.1913 warnt Peterson V.V. Rozanov vor Brichniðev und dem Sammelband zu Ehren Fedorovs: "Sčitaju nužnym predupredit' Vas, to nekto Iona Brichnið̌ev, odin iz rasstrižennych svjaš̌ennikov, izdavavšij v Moskve 'Novoe Vino', pozemu-to proniksja uvaženiem k N.F. Fedorovu i gotovit kakoj-to sbornik v pamjat' ego. I my s V.A. Koževnikovym imeli neostorožnost' dat' Brichnizevu odnu statejku, nape ‘atannuju v 1897 godu $v$ Voronežskoj gazete 'Don' i kotoraja budet napecatana $v 3$ tome i este odno pis'mo ko mne, napisannoe $v$ 70-ch godach prošlogo stoletija. Dali my éto Brichnitevu potomu, cto v kampanii s nim po izdaniju sbornika uČastvuet nekto Gorskij, o kotorom izvestnyj Vam Florenskij otzyvalsja ozen' choroso, kak o ¿cloveke neobyčajno cistom. No potom ja prozital proizvedenie Brichniceva 'Ognennyj Sejatel", proizv[edeni]e besso-

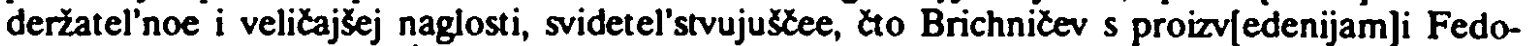
rova sovsem neznakom. Eto zastavljaet opasat'sja, čto obraz N.F. Fedorova v sbornike, izda- 
Obwohl Vselenskoe delo dem Andenken Fedorovs und der Propagierung seiner Ideen gewidmet war, ging nur einer der Autoren ausführlicher auf ihn und seine Lehre ein, nämlich Gorskij, der im weitaus längsten Beitrag dieses Bandes das Verhältnis zwischen Fedorov und Solov'ev untersuchte. ${ }^{92}$ Von Fedorov selbst wurde ein ausführlicher Kommentar zu Dostoevskijs Brief an Peterson sowie ein bis dahin unbekanntes Fragment "Über das Krankenhaus" publiziert. ${ }^{93}$ Dem Andenken Fedorovs waren ein Gedicht von Valerian Borodaevskij ${ }^{94}$ und eine kurze Fabel von Anton Sorokin ${ }^{95}$ gewidmet. Außerdem enthielt der Band eine ganzseitige Wiedergabe von Fedorovs Totenmaske nach der Zeichnung von Leonid Pasternak. ${ }^{96}$

Wenn auch nur wenige Autoren Fedorov ausdrücklich erwähnten, so darf doch davon ausgegangen werden, da $B$ die meisten Mitarbeiter von Vselenskoe delo mit den Grundgedanken der Filosofija obš̌ego dela vertraut waren, ${ }^{97}$ sei es, $\mathrm{da} B$ sie, wie Brjusov ${ }^{98}$ und Chludov ${ }^{99}$, Fedorov persönlich gekannt hatten, oder aber $\mathrm{da} B$ sie, wie im Falle von Brichnixev, Gorskij und Borodaevskij, gleiche Ideale und Ziele verfolgten. Allen scheinbar so disparaten Beiträgen von Vselenskoe delo lag denn auch ein gemeinsames Motiv zugrunde - die Auflehnung gegen den Tod und der Glaube an seine immanente Überwindung. Der Einfluß und damit die wirkungsgeschichtliche Bedeutung dieser Veröffentlichung blieb freilich infolge der genannten äußeren Umstände gering.

Für den geplanten zweiten Band von Vselenskoe delo waren unter anderem Beiträge von Brichničev über "Lermontov und das Problem des Todes" und über

vaemom Brichniとeyym, budet iskažen. O rem ja i š̌el nužnym predupredit' Vas." (Archiv von V.V. Rozanov, CGALI f. 419; nach einer Abschrift in Moskauer Privatbesitz).

Vielleicht haben Zweifel an der Person Brichnitevs und an der Seriosităt von Vselenskoe delo auch andere prominente Autoren von einer Mitarbeit abgehalten. Aufschluß darüber könnte der Briefwechsel zwischen Brichnitev und Peterson geben, der sich im Peterson-Archiv befindet.

92 Tjaga zemnaja." In: Vselenskoe delo (wie Anm. 68), S. 140-207. - Es handelt sich um Auszüge aus einer längeren Untersuchung zu diesem Thema, deren übrige Teile unveröffentlicht geblieben sind.

93 'Pis'mo N.F. Fedorova k redaktoru gazety 'Don' po povodu pis'ma F.M. Dostoevskogo k N.P. Petersonu ob utenii N.F. Fedorova." Ebd., S. 24-30. (Abdruck des Briefes S. 30f.). "Iz perepiski N.F. Fedorova. O bol'nice." Ebd., S. 97f. Es handelt sich um den Auszug aus einem Brief an N.P. Peterson aus den siebziger Jahren. Beide Texte hatte Brichnicev von Peterson erhalten. (Siehe oben Anm. 91).

94 "Pamjati N.F. Fedorova." Ebd., S. 32. - Siehe II: 2.2.2.

95 "I plakal v tot den' Satana. (Pamjati N.F. Fedorova)." Ebd., S. 33f.

96 Ebd., nach S. 32.

97 So wird Fedorov beispielsweise im Beitrag von A.S. Pankratov nicht erwăhnt, obwohl derselbe Verfasser kurz zuvor einen Aufsatz über Leben und Werk Fedorovs verfaBt hatte. Siehe II: 2.2.1.

99 Hierzu Vselenskoe delo (wie Anm. 68), [prilož.] S. 25. 
"Die Idee der Auferweckung in der russischen Dichtung" vorgesehen, ferner Essays von Prentice Mulford sowie weitere Kapitel aus Gorskijs Studie über Fedorov und Solov'ev. ${ }^{100}$ Der Ausbruch des Krieges verhinderte jedoch das Erscheinen dieses Bandes. ${ }^{101}$

Die wichtigsten Mitarbeiter von Vselenskoe delo und Novoe Vino vereinigte noch einmal eine Gedichtsammlung, die unter dem Titel Solnečnyj put' im Sommer 1914 in Odessa erschien. ${ }^{102}$ In ihr finden sich Beiträge von Brichnixev, Gorskij, Kogan, Stolica, Vostokov, Kljuev und Gorodeckij. Einflüsse Fedorovs sind nicht erkennbar.

Gorskij lebte während des Krieges in Odessa. Er schrieb Beiträge für den Južnyj Muzykal'nyj Vestnik, unter anderem über Skrjabin, Wagner und Nietzsche sowie über den Komponisten V.I. Rebikov (1866-1920), mit dem er befreundet war. Für kurze Zeit schloß er sich einer Gruppe junger Dichter an, die dem Futurismus nahestanden. ${ }^{103}$ In ihrem 1916 erschienenen Sammelband Sed'moe pokryvalo war Gorskij mit sieben freilich eher konventionellen Gedichten vertreten. ${ }^{104} \mathrm{Zu}$ seinen Bekannten zählten in jener Zeit der Dichter A. Fioletov und der Schriftsteller Jurij Olesa. ${ }^{105} 1918$ veröffentlichte Gorskij mehrere Ge. dichte und einen Aufsatz über Aleksandr Blok in der Odessaer Zeitschrift Južnyj Ogonek. ${ }^{106}$ Obwohl er in keiner der genannten Veröffentlichungen Fedorov erwähnte, galt Gorskijs Hauptinteresse nach wie vor der Filosofija obščego dela und ihrer Wirkung. So verfaßte er in jenen Jahren eine längere Studie über Fedorov und Dostoevskij, hielt Vorträge über Leben und Werk Fedorovs - bei-

100 Siehe die Ankündigung ebd., [prilož.] S. II.

101 Erst 1934 erschien in Riga ein weiterer Sammelband unter dem Titel Vselenskoe delo, der an die Tradition des Odessaer Bandes anknüpfte. Darüber, wie auch über Versuche, zu Beginn der zwanziger Jahre einen zweiten Band von Vselenskoe delo herauszubringen, siehe II: 4.1 und 4.3.3.

102 Solneðnyj put'. Južnyj al'manach. Kn. 1, Odessa 1914. Für den zweiten (nicht erschienenen) Band des Jużnyj al'manach waren u.a. Beiträge von Vodlinger, Vul'f und Gornostaev [Gorskij] angekündigt.

103 Uber die Odessaer Dichtergruppe, die in den Jahren 1914 bis 1917 fünf Sammelbănde herausgab, vgl. V. MARKov, Russian Futurism: A History, Berkeley 1968, S. 378f., und SKORINO (wie Anm. 62), S. 37-49, 64f. Der dritte Sammelband mit dem Titel Avto v oblakach wurde von Gorskij rezensiert.

104 Sed'moe pokryvalo. Stichi. Odessa 1916. - Dieser Band enthielt ferner Beitrăge von E. Bagrickij, I. Bobovix, P. Storicyn (von diesem ein Gedicht "Aleksandru Gornostaevu"), S. Tret'jakov, A. Fioletov, G. Cagareli, V. Serß̌enevic. (Viele dieser Gedichte, allerdings ohne einen Beitrag Gorskijs, auch in Cudo v pustyne. Stichi. Odessa 1917).

105 Setnickaja (wie Anm. 58), Bl. 23.

106 Wahrscheinlich trug Gorskij 1918 auch zu einer der ersten Veroffentlichungen von Bloks Poem Skify in Odessa bei. G.D. ZLENKo, "Neučtennye publikacii proizvedenij A. Bloka." In: Russkaja Literatura, 1983, 1, S. 252. Eine Zeitlang gehörte Gorskij dem Redaktionskollegium des Južnyj Ogonek an. Siehe G.D. STEJNVAND, Odes'ka periodična presa nokiv revoljucii ta hromadjans'koi vijni 1917-1921, Odesa 1929, S. 145, Nr. 416. Im Južnyj Ogonek publizierte 1918 auch B.I. Smankevix, der in den zwanziger Jahren zum Kreis der Moskauer Fedorov-Anhănger gehठrte. Siehe II: 4.1 . 
spielsweise Anfang 1917 vor der Odessaer "Bibliographischen Gesellschaft" _.107 und sammelte Material für eine breit angelegte Untersuchung, in der er die Aktualität des Fedorovschen Denkens aufzuzeigen versuchte; ${ }^{108}$ die Ergebnisse all dieser Arbeiten konnten freilich erst ein Jahrzehnt später im Ausland veröffentlicht werden. ${ }^{109}$

107 Setnickaja (wie Anm. 58), Bl. 29.

108 Gorskij unterhielt Kontakt zu Fedorovs engem Vertrauten V.A. Koževnikov (gest. 1917), von dem er Einzelheiten über Fedorovs Biographie erfuhr. Siehe A. OSTROMIROV [A.K. GoRSKU], Nikolaj Fedorovic Fedorov. 1828-1903-1928. Biografija. O.O. [Harbin] 1928, S. 8. - Zu Brichnirev hatte Gorskij keinen Kontakt mehr. Erst 1940 sollen beide sich noch einmal begegnet sein. Briefl. Mitteilung von O.N. Setnickaja, 25.2.1981.

109 A. Gornostaev [Gorski], Raj na zemle. K ideologii mortestua F.M. Dostoevskogo. F.M. Dostcevskaj i N.F. Fedorov. O.O. [Harbin] 1929. A. OsTromIROV [GoRSKH], Nikolaj Fedorovix Fedorov i souremennost'. Oxerki. Vyp. 1-4, Charbin 1928-1933. Siehe dazu II: 4.2. 


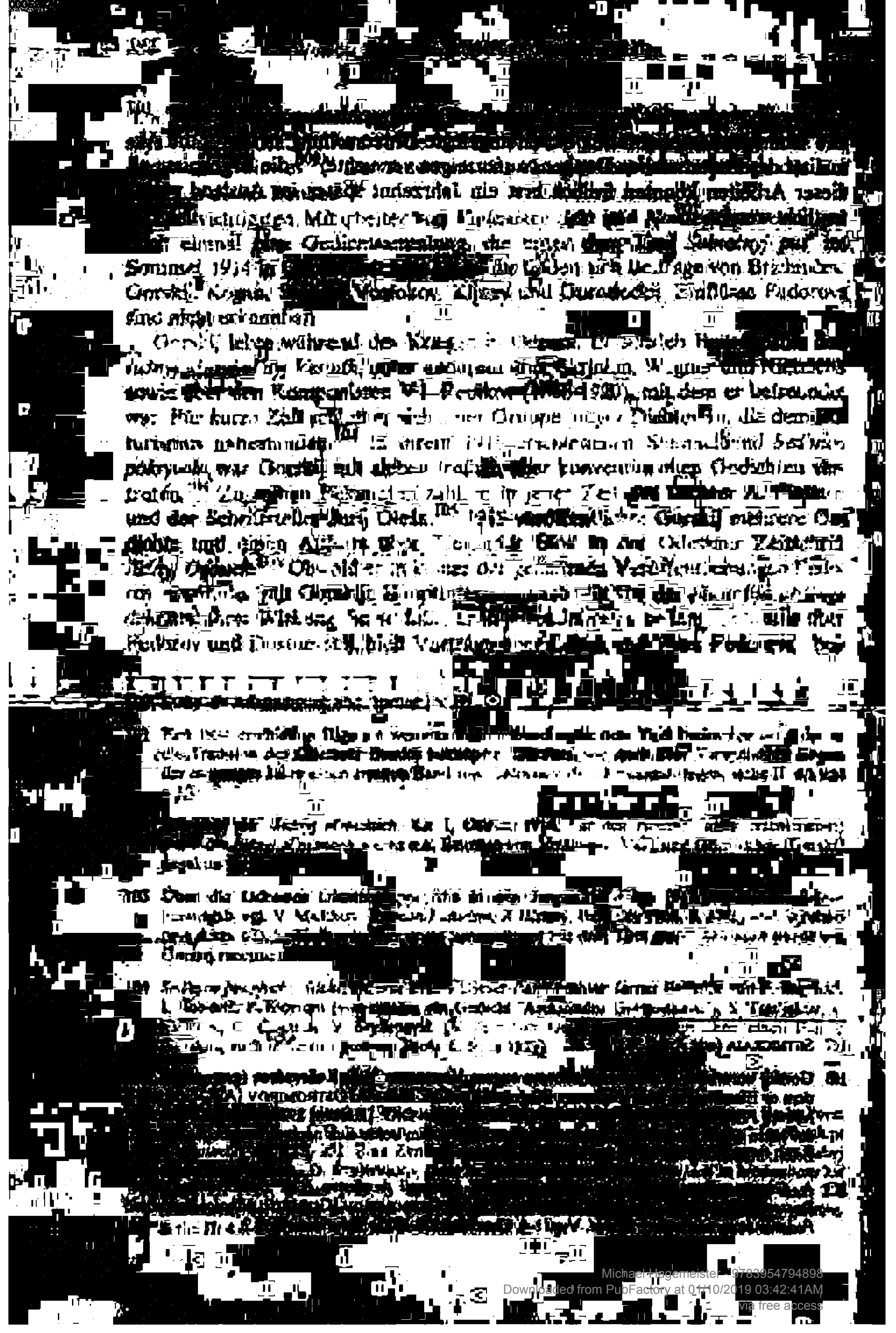




\section{DIE FRŪHE SOWJETZETT}

\subsection{Der 'Prometheismus' der frühen Sowjetzeit}

\subsection{0. 'Prometheismus'}

'Prometheismus' bezeichnet den Glauben an die unbegrenzte Schöpferkraft und Macht des Menschen über die Natur sowie die daraus erwachsende Haltung, die sich mit der Welt, wie sie ist, nicht abfindet, die sich gegen die empirische Wirklichkeit auflehnt, keine Verbesserung des Bestehenden, sondern dessen totale Umgestaltung durch Wissenschaft und Technik will: Welt, wie sie sein soll. Im Unterschied zur utopischen Haltung, die sich mit dem Bild des Gewünschten zufriedengibt, geht es der 'prometheischen' um die tatsächliche Veränderung, um Mittel und Wege, wie das Gewollte verwirklicht werden kann. ${ }^{1}$

Als Verbindung von Materialismus und Szientismus, Fortschrittsglauben und Technikbegeisterung mit orthodox-christlichen und sektiererischen Heilsvisionen und Endzeiterwartungen war 'Prometheismus' bereits im vorrevolutionären Rußland vielfältig verbreitet. ${ }^{2}$ Die Revolution verschaffte ihm zusätzlichen Auftrieb: Weithin herrschte die Erwartung, Wissenschaft, Kunst und Technik würden - aus den Fesseln widerstreitender partikularer Interessen befreit und erstmals dem Wohle der gesamten Menschheit dienend - einen ungeahnten Aufschwung nehmen, den Weg in eine 'lichte Zukunft' bereiten und endlich auch die letzten Barrieren vor dem Tor zum 'Reich der Freiheit' - die Begrenzungen des Menschen in Raum und Zeit - überwinden. Damit verbunden waren Vorstellungen und Pläne eines Ausgreifens in den Weltraum, der Regulierung geologischer, meteorologischer und kosmischer Vorgänge bis hin zu der Vision ei-

1 Die Begriffe 'Prometheismus' (russ. prometeizm; engl. prometheanism) und 'Utopismus' lassen sich nicht immer scharf gegeneinander abgrenzen. Nach Kline umfaßt 'Prometheismus': "rebelliousness, theomachy and 'Baconianism' - the attempt to subdue nature through science and technology". G.L. KLINE, Soviet Prometheanism and its Roots in Russian Thought. [Abstract; Ms. Masch.] 0.O. O.J. [ca. 1975]. Vgl. auch DERS., Religious and Anti-Religious Thought in Russia, Chicago 1968, s.v. "prometheanism". J.H. BiLungTon, The Icon and the Axe, New York 1970, s.v. "prometheanism". Verwiesen sei ferner auf die Arbeiten von P.S. Boraneckij, dessen von Fedorov stark beeinflußtes - philosophisches Gesamtwerk den Versuch darstellt, eine "prometheisch-titanische Weltanschauung" zu entwickeln. Siehe dazu II: 4.3.4. Der wohl berühmteste "moderne Prometheus" war Victor Frankenstein, Held des gleichnamigen Romans von Mary Shelley (1818), dem es gelang, ein aus Leichenteilen zusammengesetztes Monster zu beleben. - Zur Geschichte der Begriffe 'Prometheismus' und 'Titanismus' siehe V.V. GoGUADZE, Titanizm i neotitanizm." In: A.F. Losevu k 9a-letiju so dnja rozdenija, Tbilisi 1983, S. 131-141; Prometheus, heißt es dort, sei "das Symbol für Zivilisation und technischen Fortschritt." (S. 134)

2 Hierzu gehören Erscheinungen wie das bogosiroitel'stwo, in dem sich unter dem starken Einfluß Nietzsches sozialistisches Gedankengut mit religiosem Pathos verband (siehe II: 2.1.2.), Ciolkovskijs 'Kosmismus' und nicht zuletzt das Werk Fedorovs. Reiches Belegmaterial bei E. SARkisyanz, Rußland und der Messianismus des Orients, Tübingen 1955, erster Teil. 
ner völligen Umgestaltung und Beherrschung des Universums, der Schaffung eines übermächtigen 'neuen Menschen', der Beseitigung des Todes und der Wiederherstellung Verstorbener. ${ }^{3}$

"Wir können alles, wir müssen es nur wagen!"4 lautete die weitverbreitete Parole, mit der sich kühne Antizipationen einer besseren Zukunft verbanden, die angesichts der mangelhaften Gegenwart zugleich als Trost und Ansporn dienten. Rožkov (der bereits 1911 ein technisches Verfahren zur Wiederherstellung Verstorbener vorgeschlagen hatte) sprach von der Möglichkeit künftiger "Allmacht" (vsemoguščestvo) "... bis hin zum Verkehr mit anderen Welten, zur Unsterblichkeit, zur Auferweckung jener, die früher gelebt haben, und sogar zur Schaffung neuer Planeten und Planetensystemen. ${ }^{5}$ Der sonst eher nüchterne Trockij schwärmte von einer Zeit, da man "die Welt als gefügigen Ton zum Formen immer vollkommenerer Lebensformen" betrachten und lernen werde, "Flüsse und Berge zu versetzen und Volkspaläste auf dem Gipfel des Montblanc oder auf dem Grund des Atlantiks zu errichten. ${ }^{.6}$ Der Mensch werde nicht nur die Erde "nach seinem Geschmack umbauen", sondern auch sich selbst "harmonisieren", die "unbewußten Prozesse im eigenen Organismus ... der Kontrolle

3 Detaillierte Beschreibungen vieler Bereiche des 'kunftigen Lebens' enthălt der (bislang unbeachtet gebliebene) Sammelband A. A[RKA]N [d.i. A.I. ANEkSTEJN], E. Kol'MAN (Hgg.), Żizn'i rechnika budušcego. (Social'nye i naư̌no-lechnixeskie uropii). M.-L. 1928. Vgl. ferner SARKssYANZ (wie Anm. 2). KLINE, Religious ... Thoughe (wie Anm. 1). P. SCHEIBERT, "Revolution und Utopie. Die Gestalt der Zukunft im Denken der russischen revolutionăren Intelligenz." In: Epirthosis. Festgabe für Cart Schmitt. Bd. 2, Berlin 1968, S. 633-649. P. BRang, "Fortschrittsglauben in RuBland einst und jetzt." In: Das Problem des Fortschrits - heute, Darmstadt 1969, S. 29-53. Biluington (wie Anm. 1), bes. Kap. "Prometheanism" (S. 478-492). R. Pethybridge, The Social Prelude to Stalinism, New York 1974, bes. Kap. 2: "Social visions 1917-1921". R.C. Williams, Artists in Revolution, London 1977, pass. R. StTrEs, Utopia and Experiment in the Russian Revolution: Some Preliminary Thoughts. Washington ( = Kennan Institute for Advanced Russian Studies, Occasional Paper No. 152). DERS., "Utopias of Time, Space, and Life in the Russian Revolution." In: Revue des Etudes slaves, 56 (1984), 1, S. 141154. DERS., "Utopias in the Air and on the Ground: Futuristic Dreams in the Russian Revolution." In: Russian History / Histoire Russe, 11 (1984), 2-3, S. 236-257. DERS., "Hopes and Fears of Things to Come: The Foreshadowing of Totalitarianism in Russian Fantasy and Utopia." In: Nordic Joumal of Soviet and East European Studies, 3 (1986), 1, S. 1-20. H. GONTHER, "Utopie nach der Revolution. (Utopie und Utopiekritik in Rußland nach 1917)." In: Utopieforschung, Bd. 3, Stuttgart 1982, S. 378-393. M. HELLER, "Utopija v sovetskoj ideologii." In: Revue des Etudes slaves, 56 (1984), 1, S. 105-113. Noch immer unentbehrlich, wenn auch in Einzelheiten bisweilen unzuverlässig, der materialręiche Augenzeugenbericht von R. FOLOP-MILLER, Geist und Gesicht des Bolschewismus, Wien ${ }^{2} 1928$.

Die utopisch-prometheische 'linke' Phase der Revolution dauerte etwa ein Jahrzehnt, doch setzte bereits wăhrend dieser Zeit ein immer rascher fortschreitender Utopieverlust ein, erlahmte der 'prometheische' Schwung infolge der 'eschatologischen Verzogerung' (die hochgesteckten Erwartungen erfüllten sich nicht) und der zunehmend repressiven $\mathrm{MaBnahmen}$ einer prinzipiell utopiefeindlichen Obrigkeit; Beispiele dafür in den folgenden Abschnitten.

4 So der Proletkul't-Dichter M.P. Gerasimov, zitiert nach S.G. SEMENOVA, "Čelovek, priroda, bessmertie v poezii Nikolaja Zabolockogo." In: Liseratumaja Gnuzija, 1980, 9, S. 140.

5 N.A. Rožxov, Smysl i krasota žizni, Pg.-M. 1923, S. 19. - Zu Rožkov ausführlich II: 2.1.2.

6 L. TrockI, Literatura i revoljucija, M. 1923, S. 185, 188. 
durch Vernunft und Willen" unterwerfen und dadurch "unvergleichlich viel stärker, klüger und feiner" werden. ${ }^{7}$ Das Bild eines künftigen Übermenschen begegnet auch bei Gor'kij, der "alle Völker der Welt" aufrief, sich "zu einer einzigen Familie" zu vereinigen und gemeinsam danach zu streben, die Naturkräfte dem Verstand und dem Willen des Menschen zu unterwerfen. ${ }^{8}$ Mit der Begeisterung des wissenschaftsgläubigen Autodidakten verkündete er, es gebe auf Erden nichts, was auf Dauer dem menschlichen Verstand unzugänglich sei und der Beherrschung und Veränderung durch menschliche Tätigkeit widerstehen könne:

... Arbeit und Wissen besiegen alles. (...) ... zweifellos wird eine Zeit kommen, da der Mensch Herr über die Natur sein wird und vielleicht ein solcher Wundertăter, daß es für ihn keinerlei Hindernisse mehr geben wird. Vielleicht wird er auch die interplanetaren Raume erobern, den Tod besiegen und all seine Krankheiten und inneren Măngel, und dann wird hochstwahrscheinlich das Paradies auf Erden sein. ${ }^{9}$

7 Ebd., S. 186, 188-190. - Auf die Verwandtschaft dieser Gedanken mit Mexnikovs Theorie der 'Orthobiose' wurde oben hingewiesen (II: 2.1.3.). - Bereits 1793 hatte William Godwin, Vater der "Frankenstein"-Erfinderin Mary Shelley, in seinem Hauptwerk An Enquiry conceming Polirical Justice, and its Influence on General Virue and Happiness (8. Buch, Kap. 7) die Uberzeugung geäußert, "that mind will one day become omnipotent over matter". Der vernunftbegabte Mensch sei imstande, alle physiologischen Vorgănge im eigenen Korper zu begreifen und zu beherrschen und auf diese Weise schlieBlich Schlaf, Krankheit, Altern und Tod (und damit auch alle Zwistigkeiten) zu überwinden. Siehe P.H. MARSHALL, William Godwin, New Haven, London 1984, bes. S. 95, 157. - Die Făhigkeit des kommunistischen Zukunftsmenschen zur "willentlichen Selbstregulierung" (volevoe samoregulirovanie) seiner Korperfunktionen beschreibt der Arzt und Psychotherapeut A.[B.] ZALKIND, "Psichologija celoveka budušego." In: A[RKA]N [ANEKSTEjN], Kol'man (wie Anm. 3), S. 486f. Für die Gegenwart propagierte Zalkind vor allem geschlechtliche Selbstbeherrschung: die sublimierten Energien sollten dem kommunistischen Aufbau zugute kommen. Siehe Strtes, "Hopes and Fears..." (wie Anm. 3), S. 19.

8 M. GoR'KIJ, "Svobodnaja associacija položitel'nych nauk." [Novaja Žizn', 35, 30.5./12.6.1917]. In: M. GOR'KIJ, Neswoevremennye mysli, Paris 1971, S. 61.

9 M. GoR'KI, "O znanii." [Vortrag an der Arbeiter-und-Bauern-Universităt in Petrograd, Mărz 1920] In: Archiv A.M. Gor'kogo, t. 12, M. 1969, S. 107. - Siehe dazu S.G. SEMENOVA, "Ne vižu predela mošci razuma'." In: Literatumaja Užeba, 1984, 3, S. 155.

Gor'kijs prometheische Visionen der zwanziger Jahre und sein Interesse für Fedorov (dazu ausführlich II: 4.1. und 4.2.) knüpfen an das bogostroitel'stvo der Jahre vor dem Ersten Weltkrieg sowie an die frühe (bereits zu Beginn der 1890er Jahre einsetzende) Beschăftigung mit Nietzsche an. Für Gor'kijs mitunter naive Wissenschaftsgläubigkeit finden sich v.a. in seinem publizistischen Werk zahlreiche Beispiele. So schwărmte Gor'kij im April 1917 vor Mitgliedern der mit seiner Hilfe gegründeten "Freien Vereinigung zur Entwicklung und Verbreitung der positiven Wissenschaften": "Mir schwebt eine Einrichtung vor, die ich 'Stadt der Wissenschaft' nennen möchte - eine Reihe von Tempeln, in denen jeder Gelehrte als Priester unabhăngig seinem Gott dienen würde. Es wăre dies eine Reihe herrlich eingerichteter technischer Laboratorien, Kliniken, Bibliotheken und Museen, in denen tagein, tagaus das scharfe, kühne Auge des Gelehrten in das Dunkel der furchtbaren Geheimnisse eindringen würde, die unseren Planeten umgeben." M. GOR'KJ, "Re飞' na publið̌nom zasedanii Svobodnoj associacii dlja razvitija i rasprostranenija položitel'nych nauk." In: Letopis', 5-6, 1917, S. 226. 
Während jedoch Gor'kij hinzufügte, dies alles sei noch "sehr fern und ganz phantastisch" ${ }^{10}$ und auch Rožkov und Trockij bei ihren Prognosen von "ferner Zukunft" sprachen, riefen andere zur sofortigen Befreiung des Menschen aus allen natürlichen Abhängigkeiten auf. So forderte der proletarische Dichter Ivan Filipcenko, "die Gesetze der Natur in ein Gesetz für die Natur zu verändern" (inaxit' zakony prirody v zakon dlja prirody), Gott zu stürzen und durch das allmächtige Kollektiv der vereinten Menschheit zu ersetzen. ${ }^{11}$ Der Kuznica. Dichter Grigorij Sannikov proklamierte die bevorstehende Befreiung aller Verstorbenen, ${ }^{12}$ und die sogenannten Biokosmisten, eine Gruppe anarchistischer Dichter und Literaten, forderten unter der Parole "Immortalismus und Interplanetarismus" die unverzügliche Beseitigung der Knechtschaft durch Zeit und Raum: Nachdem die soziale Revolution verwirklicht worden sei, müsse nun die Abschaffung des Todes, die Besiedlung des Weltalls und die Auferweckung der Verstorbenen 'auf die Tagesordnung gesetzt' werden. ${ }^{13}$

Wieder anderen genügte weder die Vision eines künftigen Paradieses, noch die von 'revolutionärer Ungeduld' zeugende bloße Forderung nach dessen sofortiger Verwirklichung. Statt vom Sternenflug nur zu träumen, stellte der Schriftsteller und Erfinder Ciolkovskij astronautische Berechnungen an und erprobte seine Raketenmodelle im selbstgebauten Windkanal. ${ }^{14}$ Im Institut des Biophysikers P.P. Lazarev (1878-1942) suchte man nach Wegen, die vom (menschlichen) Organismus in Form elektromagnetischer Wellen freigesetzte "Nervenenergie" in Licht oder Wärme zu verwandeln, sie zur unmittelbaren Kommunikation (Gedankenübertragung) und sogar zur Überwindung der Schwerkraft (Telekinese) einzusetzen, um - so ein Schüler Lazarevs - den Menschen an die

10 GoR'KU, "O znanii" (wie Anm. 9).

11 I.[G.] Filuptenko, "Poema slavy." [1917] In: DeRs., Era slavy, M. 1918, S. 39-67; hier S. 52.

12 GA. SANNIKov, "Kogda mertye voskresnut." Unveroffentlichtes Gedicht; Abschrift in Moskauer Privatbesitz.

13 Siehe II: 3.3. - Nach der Revolution wurden maximalistische Forderungen nach sofortiger totaler Befreiung auch von anderen Anarchistengruppen erhoben: So verwarfen die Führer der "Pananarchisten", die Brüder Gordin, kurzerhand die Gesetze der Physik, da diese nur zur Rechtfertigung gesellschaftlicher Herrschaftsverhältnisse dienten: Newtons Gravitationsgesetz beispielsweise war für sie "kosmische Konterrevolution". Brat'ja GoRDINY, Manifest pananarchistov, M. 1918, bes. S. 46. Vgl. P.V. ALEKSEEv, Revoljucija i naǔnaja intelligencija, M. 1987, S. 45f. - Der "Neonihilist" Andrej Andreev propagierte die 'Befreiung der Menschen von der Geschichte', d.h. von jeglicher Verpflichtung gegenüber vergangenen und kommenden Generationen. In den Opfern, die im Glauben an ein künftiges Paradies auf Erden gefordert und gebracht wurden, sah er "die schlimmste Form von Gotzendienst". A. ANDREEv, Neonigilizm, M. 1922, S. 46. Dies hinderte Andreev jedoch nicht, im Rahmen einer utopischen Erzahlung das paradiesische Leben im Jahre 2089 zu schildern, kurz vor der Erlangung der Unsterblichkeit durch die Entdeckung und Vernichtung der "Mikroben des Todes" (Utopija v krasnom dome", ebd., S. 91-101).

14 Siehe II: 3.1.2. 
"Grenze zur Allmacht" zu führen. ${ }^{15}$ Auf exakte Forschungen gründeten sich auch die Spekulationen des Geochemikers und Naturphilosophen V.I. Vernadskij (1863-1945) über die technische Nutzung der "inneratomaren Energie", ${ }^{16}$ die Möglichkeiten einer elementaren Regenerierung des Menschen (Autotrophie) und über die Rolle des menschlichen Verstandes bei der Umgestaltung der Erde (Übergang von der Bio- zur Noosphäre, Schaffung einer 'zweiten Natur' durch den Menschen). ${ }^{17}$ Selbst die überspannt anmutenden Forderungen nach Überwindung des Todes, ewiger Jugend und Auferweckung Verstor-

15 Siehe S.A. BEXNEv, Gipoteza o nervnoj energii i ee znacenie v dele obrazovanija raboxich kollektivov maksimal'noj proizuoditel'nosti truda, M. 1923, bes. S. 16-19. - In dieser lăngst in Vergessenheit geratenen Schrift eines Schülers von Lazarev werden naturwissenschaftliche Forschungsergebnisse mit kühnen Spekulationen verbunden: Der Mensch der Zukunft, der die Transformation seiner Nervenenergie in andere Energieformen beherrsche, werde sich nicht nur nach Belieben in eine Licht- und Wărmequelle verwandeln, sondern auch unmittelbar durch bloße Gedankenarbeit - auf die Materie einwirken und ihre Struktur verăndern kőnnen. Bezeichnend für das fast schon religiose Pathos dieser Zukunftsvisionen ist ein Zitat Maeterlincks, das der wissenschaftsglaubige Marxist Beknev seinen Ausführungen vorangestellt hat: "Wir leben in der Erwartung, vielleicht den letzten Minuten der Erwartung... Wir horen schon, so scheint es, das Stampfen übermenschlicher Schritte, den Lărm riesiger sich offnender Pforten..." (ebd., S. 7).

Die Vorstellung von einer wirkmăchtigen "psychophysischen" oder "Nerven-Energie" war um die Jahrhundertwende v.a. durch die naturphilosophischen Schriften Wilhelm Ostwalds in RuBland populăr geworden. Angeregt durch die Forschungen des Moskauer Physiologen Naum Kotik über "psychophysische Gehimstrahlung" schrieb Maksim Gor'kij 1912: "Jedes Jahr hăuft sich in der Welt mehr Gedanken-Energie an, und ich bin überzeugt, daB diese Energie, die vielleicht physikalisch mit dem Licht und der Elektrizităt verwandt ist, aber ausschließlich ihr eignende Făhigkeiten besitzt, in der Lage sein wird, mit der Zeit Dinge zu verwirklichen, die wir uns bis jetzt nicht vorstellen können." M. GoR'Ku, "Izdaleka." [1912] Zitiert nach: H. SETZER, "Die Bedeutung der Energielehre für die Literaturkonzeption Maksim Gor'kijs nach der ersten russischen Revolution." In: WdSI, 25 (1980), 2, S. 417. Auf die Annahme physikalisch meßbarer Gehirnstrahlen ("Gehirnradio") gründete in den zwanziger Jahren der Leningrader Physiologe Leonid Vasil'ev seine spăter berühmt gewordenen Experimente zur "Mentalsuggestion". Das Thema fand auch Eingang in die Wissenschaftliche Phantastik; siehe z.B. A.P. Platonov, Efimyj trakt (1926/27), A.R. Beljaev, Vastelin mira (1929). - Bereits Fedorov hatte vermutet, daB "Nervenenergie" der Elektrizităt vergleichbar oder gar mit ihr identisch sei (FOD I, S. 331) und daß physische Äußerungen psychischer Vorgănge mit Hilfe des elektrischen Stroms übertragen werden kơnnten (FOD I, S. 328).

16 "Die Zeit ist nicht mehr fern, da der Mensch die Atomenergie in seine Hand bekommt, eine Kraftquelle, die ihm die Möglichkeit gibt, sein Leben nach seinen Wünschen aufzubauen. (...) Wird der Mensch diese Kraft zu gebrauchen wissen, sie zum Guten anwenden und nicht zur Selbstzerstorung? (...) Die Gelehrten dürfen nicht die Augen verschließen vor den möglichen Folgen ihrer wissenschaftlichen Arbeit... (...) Sie müssen ihre Arbeit mit der besten Organisation der gesamten Menschheit verbinden." V.I. VERNADSKJ, Ocenki i reci, t. 1, Pg. 1922, S. 37; siehe auch ebd., S. 31-44. Solche Skrupel blieben den Fortschrittsfetischisten aus dem Lager der ehemaligen bogostroiteli fremd; sie verbanden mit der Nutzung der Atomenergie ausschließlich positive Erwartungen. Vgl. A. BOGDANOV, "Oðerki organizacionnoj nauki." In: Proletarskuja Kul'tura, 13/14, 1920, S. 17. GoR'KU, "O znanii" (wie Anm. 9), S. 108f.

17 Vgl. V.I. VERNADSKH, Biogeochimiceskie ocerki 1922-1932 gg., M.-L. 1940, S. 47-58. DERS., Biosfera, L. 1926. DERS., "Neskol'ko slov o noosfere." [1944] In: DERS., Filosofskie mysli naturalista, M. 1988, S. 503-512. 
bener fanden bei einigen Wissenschaftlern Resonanz und brachten eine Reihe mehr oder weniger seriöser Theorien und Experimente hervor. ${ }^{18}$

In der vom 'prometheischen' Überschwang geprägten Aufbruchstimmung der frühen Sowjetzeit erschienen auch Fedorovs Ideen nicht länger phantastisch und unrealisierbar. Vieles von dem, was revolutionärer Fortschrittsenthusiasmus in jenen Jahren verkündete, erinnert denn auch an die Projekte der Filosofija obščego dela, deren Themen und Motive nun gleichsam 'in der Luft lagen', geistiges Gemeingut waren. Gerade dadurch aber wird es oft schwierig, zwischen Rezeption und Antizipation zu unterscheiden, wenn es darum geht, Fedorovs Einfluß im Einzelfall nachzuweisen. Bevor dies in den folgenden Kapiteln versucht wird, sollen drei Themenkomplexe skizziert werden, die sowohl im Mittelpunkt des Fedororschen Denkens stehen als auch in den Jahren nach der Revolution die Diskussion beherrschten und damit den Boden bereiteten für eine mögliche Aufnahme und Wirkung Fedorovscher Ideen. Es handelt sich um:

1) Die Steigerung menschlicher Macht durch Vereinigung des Denkens und Handelns in der Ausrichtung auf ein gemeinsames Ziel (Allorganisation, Universalwissenschaft, Monismus);

2) Das Ausgreifen der Menschheit in den Weltraum mit dem Ziel der völligen Umgestaltung und Beherrschung des Universums ('Kosmismus');

3) Die Überwindung des Todes und die Wiederherstellung der Verstorbenen.

\subsubsection{Allorganisation, Universalwissenschaft, Monismus}

Fedorov hatte gefordert, die menschlichen Energien, die unter den herrschenden 'unbrüderlichen' Verhältnissen für partikulare Zwecke eingesetzt und in gegenseitiger Konkurrenz verausgabt würden, zu vereinigen und auf ein allen Menschen gemeinsames Ziel auszurichten - den Kampf gegen die 'blinden Kräfte der Natur'. Durch planmäßig-organisierte, zielgerichtete Zusammenarbeit aller lasse sich die Macht der Menschheit gegenüber der elementaren Natur in bislang ungekanntem Maße steigern und schließlich die vollständige Beherrschung und Umwandlung des Universums einschließlich der Überwindung des Todes und der Wiederherstellung aller Verstorbenen herbeiführen. Als Beispiel für eine bereits bestehende 'Vereinigung' von Menschen, die aufgrund ihres gut organisierten Zusammenwirkens besonders effektiv handelten, nannte Fedorov die Armee; diese Institution würde auch in der künftigen 'brüderlichen' Gesellschaft keineswegs überflüssig werden, sondern im Gegenteil eine führende Rolle im organisierten Kampf gegen die Natur übernehmen.

Ähnliche Überlegungen begegnen in den Jahren nach der Revolution: Mit der Überwindung der antagonistischen Gesellschaft und ihrer Interessengegensätze schien erstmals die Voraussetzung für ein geordnetes Zusammenwirken aller gegeben zu sein. Hinzu kam, daß die siegreiche Klasse, das Proletariat, bisher schon Hauptträger des Kampfes gegen die Natur, infolge spezifischer 
Lebens- und Arbeitsbedingungen prädestiniert zu sein schien für kollektives Denken und Handeln und deshalb zum Vorbild für eine im Kampf gegen die Natur vereinte Menschheit werden konnte:

Heute führt die Menschheit ihren kollektiven Kampf gegen die Natur vor allem mit den Krăften des Industrieproletariats. Wenn aber alle Menschen ein proletarisches Bewußtsein erlangen, so wird die Macht des menschlichen Genius ungeheuer anwachsen. Die feindlichen Naturgewalten werden besiegt, die Macht des Menschen wird sich uber den weiten Weltraum erstrecken. ${ }^{\text {9 }}$

Und Gor'kij ließ (in einer der letzten Szenen seiner Romanchronik Žizn' Klima Samgina) einen jungen Arbeiter am Vorabend der Revolution ausrufen:

Die kosmischen Fragen werden wir losen, nachdem wir die sozialen gelöst haben. Und lossen werden sie nicht einzelne, die durch das BewuBtsein ihrer Einsamkeit, ihrer Schutzlosigkeit in Schrecken versetzt sind, sondern Millionen von Hirnen, die von der Sorge, ein Stückchen Brot zu beschaffen, befreit sind ... 20

Dem Glauben an die Allmacht des Kollektivs stellte sich der Kampf der Menschheit gegen die Natur und die damit verbundene planmäßige Umgestaltung der Welt im wesentlichen als eine Organisationsaufgabe dar, bei der es darum ging, die bislang divergierenden Interessen der einzelnen durch Festlegung auf den Entwurf einer zukünftigen Welt einander anzugleichen und ihre Bemühungen zu koordinieren. Zur Lösung dieser Aufgabe wurden unterschiedliche Wege vorgeschlagen. Während beispielsweise Bogdanov an die "kameradschaftliche Zusammenarbeit" (tovarišceskoe sotrudniČestvo) des proletarischen Kollektivs glaubte, d.h. an die Fähigkeit, sich und seine Aktivitäten selbst zu organisieren, ${ }^{21}$ favorisierte Trockij in den Jahren des Kriegskommunismus eine Organisation der Arbeit nach militärischem Muster, indem er die Schaffung fremd-

19 P. IVAnicki, "Proletarskaja etika." In: A. Svjatogor [AgIENKo], P. IVANICKI, Biokosmizm (Materialy - No. 1), M. 1921, S. 13. Siehe auch II: 33. - Im Unterschied dazu setzte Fedorov, was den Initiator des obscee delo, also des gemeinsamen Kampfes gegen die Natur betraf, seine Hoffnung auf die Landbevolkerung, auf das in ihr noch lebendige Verwandtschaftsgefühl und das immer wieder wachgerufene BewuBtsein ihrer Abhăngigkeit von der Natur.

20 M. GoR'KIJ, PSS. ChudoĽestvennye proizvedenija v 25-i tomach. T. 24, M. 1975, S. 522.

21 "Das proletarische Kollektiv unterscheidet und definiert sich durch eine besondere organisatorische Verbindung, die kameradschaftliche Zusammenarbeit. Dabei handelt es sich um eine Art der Zusammenarbeit, bei der die Rolle des Organisierens und die des Ausführens nicht getrennt ist, so daß es keine auf Macht gegründete Autorităt und keine unüberlegte Unterordnung gibt, sondern einen gemeinsamen Willen (vseobstaja volja), der die Entscheidungen trifft, und die Teilnahme eines jeden an der Ausführung [Erfüllung] der allgemeinen Aufgabe (obšcee delo). Dort, wo die Arbeit die unmittelbare Anleitung einer einzelnen Person erfordert, tritt anstelle von Autorităt und Macht die kameradschaftlich akzeptieite Kompetenz hervor. Und derjenige, der bei dem einen Unternehmen der Leiter war, kann schon beim năchsten den Anweisungen seines Genossen folgen, den er soeben noch angeleitet hat: Organisator und Ausführender tauschen hăufig die Plătze." A. BOGDANOV, "O tendencijach proletarskoj kul'tury." [1919] In: DERS., O proletarskoj kul'ture 1904-1924, L.-M. 1924, S. 324; Hervorhebung im Orig. 
bestimmter, hierarchisch gegliederter 'Arbeitsarmeen' forderte. ${ }^{22}$ Gemeinsam war beiden der Gedanke, daß allein rationell organisierte, auf ein Ziel ausgerichtete und von Gemeinschaftsgeist durchdrungene Kollektive zu höchster Leistung fähig seien.

Weiterentwickelt und - zumindest theoretisch - auf die Spitze getrieben wurde der Gedanke rationeller Organisation menschlicher Arbeit, ja des gesamten Denkens und Handelns, im Programm der sogenannten "Wissenschaftlichen Arbeitsorganisation" (NauCnaja organizacija truda; NOT), wie es seit 1920 im Moskauer Zentralen Arbeitsinstitut (Central'nyj institut truda; CIT) entwickelt wurde. ${ }^{23}$ Leiter dieses Instituts war der ehemalige Metallarbeiter, Altbolschewik und Proletkul't-Dichter A.K. Gastev (1882-1941), der, von der kalten Rationalität der Technik fasziniert, in seiner Dichtung wie in seinen theoretischen Schriften die Welt der Maschinen verherrlichte. ${ }^{24}$ Der Mensch, so Gastev, habe

22 Zur "Militarisierung der Arbeit" (militarizacija truda) und zu den "Arbeitsarmeen" (trudovye amii) siehe L. TroCKU, "Terrorizm i kommunizm." (Kap. 8: "Voprosy organizacii truda"). In: Ders., Soxinenija, t. 12, M. 1926, S. 152-167. Vgl. auch PETHYBRIDGe (wie Anm. 2), S. 104-109. L. HeLler, "Zamjatin: prophète ou témoin? Nous autres et les réalités de son époque." In: Cahiers du Monde russe et soviétique, 22 (1981), 2-3, S. $146 \mathrm{f}$.

Bogdanov vergleicht das Zusammengehörigkeitsgefühl des gemeinsam schaffenden und kămpfenden Proletariats mit dem "Geist einer Armee" (duch armii) im Krieg. A. Bogdanov, "Zakony novoj sovesti." [1924] In: DeRs. (wie Anm. 21), S. 338. Auch in den Werken der Proletkul't-Dichter finden sich hăufig militărische Ausdrücke zur Bezeichnung kollektiver Arbeitsorganisation wie z.B. batalliony truda, legiony truda, jady, armii truda. - Der Gedanke einer militărischen Organisation der Arbeit hat seit jeher radikale Reformer und utopische Denker fasziniert; er findet sich in den Entwürfen von Fourier, Cabet und Bellamy, bei Fedorov und, von diesem beeinfluBt, bei Murav'ev (II: 3.4.), in Bogdanovs utopischem Roman Krasnaja zvezda (1907/08) und in Ciolkouskijs utopischen Schriften wie z.B. Vne Zemli $(1918,1920)$ und Budušce Zemli $i$ celovedestva (1928). Einen frühen Versuch, diesen Gedanken zu verwirklichen, stellen die Militarkolonien des Generals AA. Arakceev (1769-1834) dar; an dieses berüchtigte Experiment aus der Zeit Alexanders I. mußte sich hundert Jahre spăter Trockij von den Gegnern seiner 'Militarisierung der Arbeit' erinnern lassen.

23 Vgl. F. Baumgarten, Arbeitswissenschaft und Psychotechnik in Rußland, München, Berlin 1924, S. 12-36 und pass. FOLOP-MiLlER (wie Anm. 3), S. 281-287. CIT i ego metody NOT, M. 1970, bes. Kap. 1 und 2 (S. 3-59). M. TATUR, 'Wissenschaflliche Arbeitsonganisation.' Arbeitswissenschafien und Abeilsorganisation in der Sowjetunion 1921-1935. Wiesbaden 1979, S. 41-44 und pass. A. EbBInghaUs, Taylor in RuBland." In: Autonomie. Materialien gegen die Fabrikgesellschaft. Bd. 1, München o.J. [1975],S. 3-15. HelleR (wie Anm. 22), bes. S. 144-153. A. SALOMON, "Una fonte per lo studio del taylorismo nella Russia sovietica." In: Classe, 13 (1982), 22, S. 245-263. A. CESARETT, A. JELL, "NEP e scienca del lavoro. Un libro di Ossip A. Ermanskij (1866-1941)." Ebd., S. 265-272. - Eine ironische Schilderung des CIT gibt E. TollER, Quer durch. Reisebilder und Reden. Berlin 1930, S. 121-124.

24 Ausfuihrlich K. Johansson, Aleksej Gastev. Proletarian Bard of the Machine Age. Stockholm 1983. Vgl. ferner SARKISYANZ (wie Anm. 2), S. 42-45, 404. K.L. ZeLINSKU, Na rubete dvuch epoch, M. 1959, S. 63-71. A.N. MEN'SUTIN, A.D. SinjavSKIJ, Poezija peryych let revoljucii, M. 1964, bes. S. 153-155. L. GELLER [HELLER], Vselennaja za predelom dogmy, London 1985, S. 51f., 55, 62. - Maschinenkult war eines der Hauptthemen der Dichtung des Proletkul',, insbesondere der Moskauer Kuznica, doch linden sich entsprechende Motive bereits bei den Futuristen (Marinetti, Majakovskij) und Symbolisten (Verhaeren, Bal'mont, Brjusov). Ober Gastevs theoretische Konzeption und über seine Rolle als Direktor des CIT in den frühen 
sich der Rationalität der Maschine zu unterwerfen, müsse selbst zu einem reibungslos funktionierenden Teil der Maschinerie werden, zum "Nerven-MuskelAutomaten". ${ }^{25}$ In seinen Schriften über 'wissenschaftliche Arbeitsorganisation' entwarf Gastev ein von der Maschine geprägtes seelenloses Menschenbild des zukünftigen Arbeitskollektivs, dessen psychische Verfassung er als "mechanisierten Kollektivismus" beschrieb:

Die Erscheinungsformen eines solchen mechanisierten Kollektivismus sind so weit entfernt von jeder Personalităt und derart anonym, daB die Bewegung dieser Kollektivkomplexe sich der Bewegung von Gegenstănden annăhert, in denen es schon keine menschliche Individualităt mehr gibt, sondern nur gleichförmige, genormte Schritte, Gesichter ohne Ausdruck, eine Seele, die der Lyrik entbehr, ein Empfinden, das nicht durch Schreien oder Gelächter gemessen wird, sondern mit Manometer und Taxameter. ${ }^{26}$

Das "mechanisierte Kollektiv", so Gastev, dulde keine Individualität; sie werde ausgelöscht durch das Zusammenwachsen aller im gemeinsamen Schaffen und durch die vollständige Rationalisierung, das heißt "Maschinisierung" allen Handelns und Denkens, auch des alltäglichen (masinizirovanie obydennobytovogo myslenija). In der auf solche Weise normierten Psyche des Kollektivs

... fließen von einem Ende der Welt zum anderen măchtige schwere psychologische Strome, für die es nicht Millionen von Kopfen zu geben scheint, sondern einen einzigen Welt-Kopf (mirovaja golova). Diese Tendenz wird mit der Zeit unmerklich individuelles Denken unmoglich machen; dieses

zwanziger Jahren siehe die aufschluBreiche Studie von K.E. BAILES, "Aleksej Gastev and the Soviet Controversy over Taylorism, 1918-1924." In: Soviet Studies, 29 (1977), 3, S. 373-394.

25 Die 'wissenschaftliche Arbeitsorganisation', hatte Gastev erklärt, betrachte "auch den Menschen als Maschine, und zwar als die beste Maschine, die es auf der Welt gibt". A. GASTEV, "Kak nado rabotat'" [1922]; zitiert nach K. HIELSCHER, "Futurismus und Kulturmontage." In: Altemative, 21 (1978), 122-123, S. 231. Vgl. auch Johansson (wie Anm. 24), S. 112f. - Demzufolge lassen sich Menschen 'reparieren' und 'verjüngen' ("Otremontirovat' 20 millionov beznogich. [...] Omolodit' na 30 let kanadcev." A.K. GASTEv, "Packa orderov." [1921]. In: DERS., Poezija rabocego udara, M. 1971, S. 219). Ermanskij bemühte sich um die "Verbesserung" des Arbeiters als einer rabozaja masina (CESARETT, JELU, wie Anm. 23, S. 270), Ciolkovskij beschrieb die Vervollkommnung des Menschen als dessen Umwandlung in eine mysljastaja masina (K.E. Clolkovsku, Um i strasti, Kaluga 1928, S. 8). - Bekanntlich hatten - in der Tradition des mechanistischen Naturmodells - auch Fedorov und vor ihm Descartes, La Mettrie, Zedler u.a. den Menschen als eine (besonders komplizierte) Maschine aufgefaBt. Zur Geschichte der Vorstellung vom Korperautomaten und vom Homme machine in 17. und 18. Jahrhunder ausführlich A. SUTTER, Götliche Maschinen, Frankfurt/M. 1988.

26 A. GASTEv, "O tendencijach proletarskoj kul'tury." In: Proletarskaja Kul'tura, 1919, 9/10, S. 45. Auch in: Literatumye manifesty. Ot simvolizma do 'Oktjabrja'. M. 1924, S. 132f. - Gedanken, wie sie Gastev hier vortrăgt, waren seinerzeit weit verbreitet. So erklărte beispielsweise der Schriftsteller Andrej Platonov in einem Ende 1920 erschienenen Aufsatz über den "vereinheitlichten Arteiter": "Es ist Aufgabe der sozialen kommunistischen Revolution, die Persönlichkeit zu vernichten und durch ihren Tod ein neues, lebendiges, măchtiges Wesen hervorzubringen - die Gesellschaft, das Kollektiv, den einheitlichen Organismus der Erdoberflăche, den einen Kămpfer mit der einen Faust gegen die Natur." A.[P.] PLATONOV, "Normalizovannyj rabotnik." [1920] In: Russian Literature, 23, 1988, S. 430. 
wird zur objektiven Psychologie einer ganzen Klasse mit Systemen psychologischer Schalter und Riegel. $^{27}$

Zur Bildung effizienter Kollektive wurde vorgeschlagen, die von jedem Organismus ausgehenden elektromagnetischen Wellen gleichzuschalten, was zu einer enormen Steigerung der "Nervenenergie" des Kollektivs und damit seiner Produktivität führen würde. ${ }^{28}$

Zwar beschränkte sich die Tätigkeit des Zentralen Arbeitsinstituts in den ersten Jahren seines Bestehens weitgehend darauf, einfache Arbeitsabläufe nach der Methode des amerikanischen Ingenieurs F.W. Taylor durch Berechnung des geringsten Zeit- und Kraftaufwandes zu rationalisieren, doch gingen Gastevs Pläne weit darüber hinaus: Durch Mathematisierung und Formalisierung sollten weite Bereiche des menschlichen Lebens erfaßt und manipulierbar gemacht werden, um sie dann einer vollständigen Rationalisierung zu unterwerfen; dabei träumte Gastev von einer Art 'social engineering' (social'nyj inženerizm):

Auf sozialem Gebiet muß eine Ära ... genauer Messungen, Formeln, Schablonen, Eichungen und sozialer Normen beginnen. ... wir müssen uns die Frage einer völligen Mathematisierung der Psychophysiologie und der Ökonomie stellen, um mit bestimmten Koeffizienten der Erregung, Stimmung und Ermüdung einerseits und direkten und indirekten bkonomischen Anreizen andererseits operieren zu k8nnen. 29

Die "Menschen der Zukunft", so die Vision eines gewissen E.. Enčmen, würden vom "Revolutionären Wissenschaftsrat der Weltkommune" "physiologische Pässen erhalten, in denen mit Ziffern die Intensität der wichtigsten Reaktionen sowie der "Koeffizient der freudigen Erregbarkeit" (radostnost') vermerkt seien; diese Pässe dienten dann zur Festsetzung der Arbeit und zur Regelung aller Bedürfnisse. ${ }^{30}$

27 Gastev, "O tendencijach..." (wie Anm. 26), S. 44. Siehe auch den Gedichtzyklus Packa orderov (1920), bes. "Order 05" in: GASTEv, Poezija (wie Anm. 25), S. 217f. - Zu Gastevs Konzeption der 'Mechanisierung des Menschen' vgl. Balles (wie Anm. 24), S. 377-379; TATUR (wie Anm. 23), S. 14-20; Johansson (wie Anm. 24), S. 66-71. Parodien wurde diese Vision in Zamjatins 1920 verfaßter berühmter Anti-Utopie My. Vgl. K. LEWIS, H. WEBER, "Zamyatin's 'We', the proletarian poets and Bogdanov's 'Red Star'." In: Russian Literature Triquarterty, 12, 1975, S. 253-278. Heller (wie Anm. 22), bes. S. 148-151. P. CARDEN, "Utopia and Anti-Utopia: Aleksei Gastev and Evgeny Zamyatin." In: Russian Review, 46 (1987), S. 1-18.

28 Siehe BEKNEV (wie Anm. 15), bes. S. 20-36. - Beispiele für vorbildlich organisierte Kollektive findet Beknev bei Bienen und Ameisen!

29 A. Gastev, Organizacija truda, M. 1921, S. 11. - Stalin bezeichnete spăter (1932) die Schriftsteller als "Ingenieure der menschlichen Seele". J.W. STALIN, Werke, Bd. 13, Berlin 1955, S. 362. Es wăre freilich eine unzulässige Vereinfachung, in Gastev einen Vorlăufer und Wegbereiter (und in Zamjatin den visionăren Kritiker) der totalitären Gesellschaft des Stalinismus zu sehen.

30 E. Encmen in seinem Anfang der zwanziger Jahre erschienenen Buch Teorija novoj biologii; zitiert nach Oxenki istonii nusskoj sovetskoj Zumalistiki 1917-1932, M. 1966, S. 92. Zu Encmen und seiner radikalen "Theorie der neuen Biologie", die eine Zeitlang als enčmenizm Aufsehen erregte, siehe auch ALEKSEEV (wie Anm. 13), S. 47-49, 66. 
Das Bestreben, die oberflächliche Vielfalt der empirischen Wirklichkeit zu vereinheitlichen - sei es durch mathematische Verfahren, sei es durch spekulative Reduktion auf eine tieferliegende allumfassende ontologische Einheit -, war in den Jahren nach der Revolution weit verbreitet. Der Drang zu Reduktionismus und Monismus und die Vorliebe für bis ins letzte Detail durchkonstruierte Weltentwürfe gipfelte in der Vorstellung einer möglichen Universalwissenschaft, die alle Einzelerkenntnisse in Weltformeln zusammenfassen und damit für die totale Umwandlung und Beherrschung der Welt nutzbar machen würde. ${ }^{31}$

Der Dichter Velimir Chlebnikov versuchte den Eintritt bestimmter historischer Ereignisse mittels algebraischer Systeme zu erfassen, um auf diese Weise die gesamte Menschheitsgeschichte berechenbar und somit "durchsichtig" (prozracnyj) zu machen; ${ }^{32}$ Chlebnikov war überzeugt, daß alle Gesetzmäßigkeiten schließlich auf eine "einzige Weltformel" zurückzuführen seien. ${ }^{33}$ (Mit derselben Methode, nämlich der der Reduktion, suchte Chlebnikov auch eine Universalsprache zu re-konstruieren). ${ }^{34}$ V.N. Murav'ev, ein Mitarbeiter Gastevs und Anhänger der Ideen Fedorovs, entwarf eine "Allgemeine Produktionsmathematik" (vseobšcaja proizvoditel'naja matematika) als Synthese aller Wissenschaften, eine Art mathesis universalis, von der er glaubte, daß sie das Universum verwandeln und sogar die Zeit beherrschen und überwinden könne. ${ }^{35}$ Ein Verfahren zur 'Umkehrung der Zeit' erwartete man von Einsteins Relativitätstheorie, wobei die historische Gleichung $E=m c^{2}$ von manchen als eine Art Weltformel mit beinahe magischer Kraft angesehen wurde. ${ }^{36} \mathrm{Um}$ eine grundlegende Rückführung der Welt ging es auch den Philosophen und Universalgelehrten P.A. Florenskij und A.F. Losev: Durch Forschungen auf den verschiedensten Gebieten suchten sie die Gesamtheit der Elemente des Weltganzen und ihre Wechselbeziehungen zu erfassen; Florenskijs Ziel war es, zu einer "synthetischen", "monistischen Weltanschauung" zu gelangen und den "Zusam-

31 Eine umfassende Darstellung dieses Phănomens fehlt, doch liegen mit der ideengeschichtlichen Studie von I. SusILUOTO, The Origins and Development of Systems Thinking in the Soviet Union, Helsinki 1982, erste Forschungsansătze vor.

32 Siehe besonders V. ChLEBNikov, Doski sud'by, 1-3, M. [1921-22]; $4-7$ liegen im Manuskript vor. - Chlebnikovs mathematische Spekulationen stießen bei seinen Zeitgenossen auf Unverstăndnis und Ablehnung. Siehe etwa die scharfe Kritik von I.A. AKSENOV, "Velimir Chlebnikov. Otryvok iz dosok sud'by." In: Pecar' i Revoljucija, 1923, 5, S. 277-279. Erst in jüngster Zeit werden sie ernsthaft erforscht. Vgl. etwa R.V. DugANov, "Poet, istorija, priroda." In: Voprosy Literatury, 1985, 10, bes. S. 139-141. E. ARENZoN, "K ponimaniju Chlebnikova: nauka i poezija." Ebd., S. 163-169. V.P. GRIGOR'EV, Grammatika idiostilja. V. Chlebnikov. M. 1983, bes. S. 46, $117,119-130,165$. V.V. Ivanov, "Chlebnikov i nauka." In: Puti v neznaemoe, M. 1986, S. 382440. - Ausführlich zu Chlebnikov II: 3.2.2.

33 GRIGOR'EV (wie Anm. 32), S. 128.

Siehe II: 3.2.2.

Zu Murav'ev ausführlich II: 3.4 .

Siehe II: 3.2.1. 
menhang der Grundgesetze des Universums" zu formulieren, ${ }^{37}$ während Losev sich bemühte, die Einheit der Welt durch dialektische Integration der Gegensätze aufzuzeigen. ${ }^{38}$

Den wohl aufwendigsten und wirkungsvollsten Versuch, eine Universalwissenschaft zu begründen, unternahm Aleksandr Bogdanov (Malinovskij) mit seiner "Allgemeinen Organisationswissenschaft (Tektologie)" ${ }^{n 9}$ Bogdanov ging davon aus, da $B$ alle menschliche Tätigkeit mit dem Ziel, die Natur zu beherrschen, auf organisatorische Prozesse hinauslaufe: Organisation der äußeren Kräfte der Natur - durch die Technik; Organisation der menschlichen Kräfte - durch Ökonomie und Politik; Organisation der gesellschaftlichen Erfahrung - durch Ideologie, Kunst und Kultur. ${ }^{40}$ Auch die Natur erweise sich als Organisator, und der Mensch sei nichts anderes als eines ihrer organisiertesten Erzeugnisse. ${ }^{41}$ Zwar handele er im Unterschied zur Natur bewußt planmäßig, dennoch bestehe zwischen der spontanen Organisationsarbeit der Natur und der bewußt planmäßigen Arbeit des Menschen kein prinzipieller Gegensatz - beide, Mensch und Natur, seien nach denselben Gesetzmäßigkeiten organisiert, und beide organisierten nach parallelen Methoden (Monismus): ${ }^{42}$

Es existieren allgemeine Methoden und Gesetzmäßigkeiten, nach denen die verschiedenen Elemente des Weltalls sich zu Komplexen organisieren. ${ }^{43}$

37 ANON., "'Stroenie slova' PA. Florenskogo." In: Kontekst 1972, M. 1973, S. 344. P.[V.] PA. LIEVSKu, [Einleitung zu] PA. FLoRENSKIJ, "Pristan' i bul'var." In: Prometej, 9, 1972, S. 138. - Zu PA. Florenskij siehe auch II: 2.2.1. und 3.4.

38 Dies wird bereits an den Titeln der in den zwanziger Jahren verfaBten Werke Losevs erkennbar: Dialekrika imeni (1923; ersch. 1927 unter dem Titel Filosofija imeni), Dialektika chudotestvennoj formy (1927), Dialektika cisla u Plotina (1927), Dialektika mifa (1930). Siehe auch D.V. DZZOCHADZE, "Aleksej Fedoroviz Losev." In: A.F. Losevu... (wie Anm. 1), bes. S. 13-20.

39 Dargelegt in Bogdanovs philosophischem Hauptwerk Vseobszzaja organizacionnaja nauka (Tektologija), dessen drei Teile zwischen 1913 und 1922 erschienen (vollstăndig erst 1929), sowie in zahlreichen anderen Schriften. Eine knappe, gute Darstellung der Grundgedanken gibt G. Go. REUK, "Bogdanov's Tectology: Its Nature, Development and Influence." In: Studies in Soviet Thought, 26 (1983), S. 39-57. Vgl. ferner A. VUCINICH, Social Thought in Tsarist Russia. The Quest for a General Science of Society, 1861-1917. Chicago, London 1976, S. 226-230. Susiluo. To (wie Anm. 31), S. 36-69 und pass. Zu den Anfängen und Vorlăufern (Spencer, Haeckel, Mach, Noiré, Ostwald, Avenarius) D. GRILLE, Lenins Rivale. Bogdanov und seine Philosophie. Koln 1966, S. 171-204 und pass. - Erstaunlicherweise ist der offensichtliche Zusammenhang zwischen Bogdanovs Organisationslehre und der 'wissenschaftlichen Arbeitsorganisation' in der einschlăgigen Literatur bislang nicht năher untersucht worden.

40 A. Bogdanov, Vseobšaja organizacionnaja nauka (Tekeologija), c. 1 [1913], M. ${ }^{3} 1925$, S. $27 f$. DERS., Nauka ob obscestvennom soznanii [1914], M. ${ }^{2} 1918$, S. 25.

41 Bogdanov, Vseobsčaja..., (wie Anm. 40), S. 28.

42 Ebd., S. 32, 37.

43 A. Bogdanov, Filosofija zivogo opyra. Populjamye očerki. Pb. 1913, S. 271; Hervorhebung im Orig. (Weitere Ausgaben erschienen 1920 und 1923). 
Die Erforschung und Formulierung dieser allgemeinen Organisationsmethoden mit dem Ziel der Schaffung einer "Weltmethodologie" (mirovaja metodologija) bezeichnete Bogdanov als Aufgabe der "Allgemeinen Organisationswissenschaft" (vseobšcaja onganizacionnaja nauka), einer neuen, die gesamte organisatorische Erfahrung der Menschheit vereinenden Universalwissenschaft. ${ }^{44}$ Mit ihrer Hilfe werde

... die Menschheit ihre schopferischen Kräfte, ihr Leben auf der ganzen Linie planmäBig organisieren können... Diese Wissenschaft wird zum ersten Male echte Weltformeln stiften ... praktische Formeln: solche, die es ermøglichen, planmăBig jede beliebige Gesamtheit gegebener Elemente des Weltprozesses zu beherrschen. 45

Bogdanovs Entwurf einer Universalwissenschaft, welche die organisatorische Erfahrung der Menschheit vereinen und in ein mächtiges Instrument zur Naturbeherrschung verwandeln würde, fand in den Jahren nach der Revolution vielfältige Resonanz. ${ }^{46}$

44 Bogdanovs Konzeption beruht also auf der Sammlung, Bewahrung und Weiterentwicklung (Nutzbarmachung) des Wissens und der Erfahrungen der Vergangenheit und steht damit im Gegensatz zu jenen kulturrevolutionăren Bestrebungen, die unter Hinweis auf den Klassencharakter aller kulturellen Hervorbringungen (einschlieBlich der exakten Wissenschaften) den Bruch mit der Tradition und eine tabula rasa für den Aufbau der neuen proletarischen Kultur forderten: "Im Namen unseres Morgen verbrennen wir Raffael / Zerstoren die Museen, zertrampeln die Bluten der Kunst." V.[T.] KIRILlov im Gedicht "My" [1917] in: DERS., Stichotworenija, Pb. o.J. [1918], S. 9. Gegen diese Haltung wandte sich Bogdanov mit aller Schărfe, wobei er nicht nur pragmatische Gründe anführte (auch Marx habe sich erfolgreich bürgerlicher Wissenschaft bedient), sondern auch an das proletarische Gewissen appellierte: "Der Proletarier darf niemals die Mitarbeiterschaft der Generationen vergessen, die der Zusammenarbeit der Klassen in der Gegenwart gegenübersteht, - er hat kein Recht [!], die Achtung gegenüber den großen Toten zu vergessen, die uns den Weg gebahnt und ihre Seele vermacht haben und die uns aus dem Grabe die helfende Hand reichen bei unserem Streben nach dem Ideal." A. Bogdanov, "Kritika proletarskogo iskusstva." [1918] In: DERs. (wie Anm. 21), S. 173; Hervorhebung im Orig.

45 Bogdanov (wie Anm. 43), S. 271f.; Hervorhebung im Orig. - Vgl. auch ebd., S. 259-272 (Kap.: "Nauka budušcego"). Ausführlich dazu K.M. JENSEN, Beyond Marx and Mach. Aleksandr Bogdanov's 'Philosophy of Living Experience'. Dordrecht 1978, S. 148-159. Vgl. ferner GRILLE (wie Anm. 39), S. 171-176.

46 So führte etwa die Aufhebung der Trennung von Wissenschaft, Kunst und Technik durch ihre gemeinsame Bestimmung als Organisationsmittel im Bereich der Ästhetik zu Vorstellungen einer Verschmelzung von Kunst und Technik, Kunst und Produktion, wie sie in den zwanziger Jahren in Kreisen der Avantgarde verbreitet waren, aber auch von TROCKU (wie Anm. 6), S. 210f., vertreten wurden. Von Bogdanov offensichtlich beeinfluBt war auch V.N. Murav'evs Auffassung von Kunst als Organisationsinstrument (dazu II: 3.4.) sowie die Konzeption künstlerischer Tătigkeit ais ziznestrcenie ('Lebenbauen', d.h. Organisation des Lebens) des LEF-Theoretikers N. Cužak. Dazu ausführlich H. GONTHER, "Proletarische und avantgardistische Kunst. Die Organisationsăsthetik Bogdanovs und die LEF-Konzeption der 'lebenbauenden' Kunst." In: Ästhetik und Kommunikation, 4 (1973), 12, S. 62-75. Auf den Zusammenhang mit Gastevs NOT wurde bereits hingewiesen. 


\subsubsection{Kosmismus}

Im "Vorwort" zu seinem letzten (unverwirklicht gebliebenen) Gedichtband Planetaria schrieb Valerij Brjusov 1922/23:

... es besteht kein Zweifel, daB im Leben der Menschheit eine Etappe anbricht, in der die gesamte Erde vereinigt sein wird, sei es in der Art eines einheitlichen 'Staates' (einer weltweiten sozialistischen Republik), sei es in einer anderen Form, die die Arbeit und Krafte aller Menschen, die auf dem Planeten leben, für gemeinsame Ziele vereinigt. Dann bricht eine neue Periode des Lebens an: die Eroberung seines Platzes im Sonnensystem... ${ }^{47}$

Kennzeichnend für die Aufbruchstimmung und den 'Prometheismus' der frühen Sowjetzeit war ein Denken und Fühlen in kosmischen Maßstäben, das in der Forderung gipfelte, das ganze Weltall zu erobern und zum Nutzen der Menschheit umzugestalten. Die Dichter des Proletkul't, die Mitglieder der Moskauer Kuznica und die Petrograder 'Kosmisten' feierten die Revolution als Ereignis von kosmischer Bedeutung und besangen den "Sturm des Himmels" (šturm neba) als Vorwegnahme der künftigen Allmacht einer vereinten Menschheit: "Für unseren Planeten werden wir einen anderen, blendend hellen Weg finden" (V.T. Kirillov); "Die Sterne stellen wir in Reihen auf, dem Mond legen wir Zügel an" (ders.); "Über den Kanälen des Mars werden wir den Palast der Weltfreiheit errichten" (M.P. Gerasimov) ${ }^{48}$ Brjusov schlug vor, die Bahn der Erde zu verändern, ihr eine neue, vom menschlichen Willen bestimmte Richtung zu geben. ${ }^{49}$ Chlebnikov sprach vom anbrechenden "kosmischen Zeitalter". kovskij feierte den Sieg der Kommune im Weltall. ${ }^{51}$ Malevic entwarf Raumschiffe und extraterrestrische Wohnanlagen. ${ }^{52}$ Der Maler Vladimir Ljusin schuf das Modell einer "Station für Weltraumkommunikation" (stancija mežplanet-

47 VJA. BRusov, "Predislovie" [zu Planetaria]. In: Literatumoe nasledstwo, t. 85 [Valerij Brjusov], M. 1976, S. 238; Hervorhebung im Orig.

48 Alle Zitate nach K.V. Druagin, Pateticeskaja lirika proletarskich poetov épochi voennogo kommunizma, Vjatka 1933, S. 19 und 38. - Zum 'Kosmismus' in der Lyrik der proletarischen Dichter siehe auch Z.[S.] PAPERNYJ, "Proletarskaja poezija pervych let sovetskoj epochi." In: Prodetarskie poiry peryych let sovetskoj epochi, L. 1959, S. 46-48. V. ZAvaluSHIN, Earty Soviet Writers, New York 1958, S. 147-150. S.[G.] SEMENOvA, "Masterovye ideala. Poezzija pervogo posleoktjabr'skogo desjatiletija." In: Oktjabr', 1987, 11, S. 190-198. Vgl. ferner die Artikel "Kosmizm" in: Literatumaja énciklopedija, t. 5, M. 1931, Sp. 501f., und "Cosmism" in: MERSL, 4 (1981), S. 244246.

49 In den Gedichten "Molodost' mira" (1922) und "Kak list'ja v osen"" (1924) in: V.JA. BRJUsov, SS v 7 tt., t. 3, M. 1974, S. 139f., 174. Das Gedicht "Kak list'ja..." entstand, wie Brjusov selbst anmerkt, unter dem EinfluB Fedorovscher Gedanken (ebd., S. 584). Vgl. auch II: 2.2.2.

50 So ein Ausspruch aus dem Jahre 1921; zitiert nach N.I. CHARDŽıEv, "Majakouskij i Chlebnikov." In: N.I. ChARDŽiev, V.V. TRENIN, Poeticeskaja kul'tura Majakovskogo, M. 1970, S. 121.

51 Zum 'Kosmismus' bei Majakovskij siehe insbesondere K. PoMORSKA, The Utopian Future of the Russian Avant-Garde." In: American Contributions to the Ninth Intermational Congress of Slavists, Kiev, September 1983, vol. 2, Columbus, Ohio 1983, S. 371-386. Ausführlich II: 3.2.1.

52 Siehe II: 3.2.3. 
nych soobščenij). ${ }^{53}$ Die Mitglieder der Moskauer Künstlergruppe Amaravella riefen dazu auf, die Vereinigung der Menschheit mit dem Universum in einer großen künstlerischen Synthese zu gestalten. ${ }^{54}$ Der Imaginist Gruzinov proklamierte eine "kosmische Dichtung" (poezija kosmičeskaja) und forderte "gebieterisch die Herstellung einer Verbindung zum allerfernsten Stern, zum allerfernsten Boliden, der durch die himmlischen Weiten irrt. " 55 "Die Dichter", so ein Zeitgenosse, "flogen über die Grenze der Erde hinaus und erzeugten Revolutionen im Planetensystem, auf den Sternen, der Milchstraße und in den Weiten des Weltalls. ${ }^{56}$

Das kosmische Welt- und Lebensgefühl der ersten Jahre nach der Revolution speiste sich aus vielerlei Quellen. Neben Einflüssen des Symbolismus und Futurismus sowie prometheischer und pantheistischer Unterströmungen (bogostroitel'stvo, imjaslavie, Theosophie) waren es vor allem die Werke Bogdanovs und Ciolkovskijs, denen der Gedanke eines Ausgreifens der Menschheit in den Weltraum und der Beherrschung und Verwandlung des Universums starke Impulse verdankte. ${ }^{57}$ Bogdanovs 'Kosmismus', von dem bereits die Raumfahrtromane Krasnaja zvezda (1907/8) und Inžener Mènni (1913) zeugen, 58 wirkte in den Jahren nach der Revolution vor allem im Bereich der Kunst. Als Theoreti-

52 V.I. Kostin, OST (obšcestwo stankovistov), L. 1976, S. 25f. (mit Abb.).

54 Dies geschah v.a. unter dem EinfluB von E.P. Blavackaja, M.K. Ciurlionis, A.N. Skrjabin und spăter N.K. Rerich; auch Fedorov wurde in diesem Zusammenhang genannt, doch laßt sich sein EinfluB nicht nachweisen. JU.V. LINNIK, "Amaravella'." In: Sever, 1981, 11, S. 108-114; hier S. 111. Ders., "Amaravella': nesusšij svet." In: Leningradskaja Pravda, 12.12.1987, S. 4. Ders., "Amaravella." In: Punalippu [Petrozavodsk], 1989, 4, S. 112-127 (m. zahir. Abb.). Zur Geschichte und zum Programm der Gruppe, die von 1922 bis 1928 bestand, vgl. auch V. KLENOV, "Amaravella'." In: Dekorativnoe Iskusstvo SSSR, 1981, 11, S. 16-19. Zur 'Synthese der Künste' siehe auch II: 3.2.4.

S5 I. GRUZINov, Imazinizma osnomoe, M. 1921, S. 19.

56 DRJAGIN (wie Anm. 48), S. 19. - Ihre Kritiker sahen darin bloßen Eskapismus, "Fahnenflucht in interstellare Sphären, um den komplizierten und für die Kunst schwierigen irdischen Dingen auszuweichen." Trocku (wie Anm. 6), S. 155f.; zur Kritik am 'Kosmismus' vgl. ebd., S. 155-157. Kritik am Kosmismus findet sich auch in Zamjatins anti-utopischem Roman My, in dem der totalitäre Einheitsstaat als gigantisches Projekt den Bau eines Raumschiffs betreibt.

57 Dies zeigt sich besonders deutlich am Beispiel der sowjetischen Science Fiction bzw. Wissenschaftlichen Phantastik, die in den zwanziger Jahren eine Blüte erlebte. So ist etwa A.N. Tolstojs Roman Aelita (1922/23) stark von Bogdanovs Krasnaja zvezda abhăngig, und A.B. Jaroslavskij übernimmt in seinem Roman Angonavty uselennoj (1926) viele technische Details aus Ciolkovskijs Schriften. Ausführlich hierzu A.F. BRrTIKov, Russkij sovetskij naučna-fantasticeskij moman, L. 1970. GELLER [HEL LER] (wie Anm. 24).

58 Siehe II: 2.1.2. - Von Krasnaja zvezda erschienen zwischen 1918 und 1925 mehrere Ausgaben (die genaue Anzahl lieB sich nicht feststellen); Intener Mènni lag 1923 in 5. Auflage vor. Bibliographische Angaben bei A. YAssour, "Bogdanov et son oeuvre." In: Cahiers du Monde russe et soviétique, 10 (1969), 3-4, S. 563, 565. Zur Bedeutung von Krasnaja zvezda siehe A. A[RKA]N [d.i. A.I. ANEKSTEJN], "Social'nye utopii." In: A[RKA]N [ANEKSTTEJN], Kol'MAN (wie Anm. 3), S. 166-174. NA. RYNIN, Kosmiceskie konabli. (Mežplanetnye soobšzenija v fantazijach romanistov). L. 1928, S. 35-41 (mit einer genauen technischen Beschreibung des Raumschiffes [èreronef]). 
ker des Proletkul't regte Bogdanov die proletarischen Dichter zu ihrer kosmischprometheischen Lyrik an. ${ }^{5}$

Ciolkovskijs Einfluß reichte weiter und bestimmte für lange Zeit die sowjetische Weltraumforschung und Kosmonautik. ${ }^{60}$ Bis zum Beginn der zwanziger Jahre hatte Ciolkovskij bereits an die fünfzig Arbeiten vorgelegt, in denen er nicht nur technische Probleme der Luft- und Raumfahrt behandelte, sondern sich auch zur Frage der Stellung und Aufgabe der Menschheit im Weltraum äußerte. ${ }^{61}$ Der Grundgedanke seiner "kosmischen Philosophie" (kosmiceskaja filosofija) lautete: Da das Leben auf Erden durch Übervölkerung und Katastrophen gefährdet sei und ihm durch die Abkühlung der Sonne der 'Kältetod' drohe, müsse die Menschheit, um ihren Fortbestand zu sichern und sich weiterentwickeln zu können, in den Weltraum 'auswandern'.62 Bereits 1911 hatte Ciolkovskij erklärt:

... die Menschheit wird nicht ewig auf der Erde bleiben, vielmehr wird sie bei ihrem Streben nach Licht und Weite, zunăchst noch bescheiden, über die Grenze der Atmosphäre hinausdringen, um sich dann den gesamten Raum des Sonnensystems zu erobern. ${ }^{63}$

Ciolkovskijs Ideen waren 1915 von dem Wissenschaftsjournalisten IJa. Perel'• man in einem Buch "Interplanetarische Reisen" in allgemeinverständlicher

59 "Der künftige Dichter-Kollektivist ... wird den Zusammenhang der Welten fühlen und erkennen, die, durch Abgründe getrennt, einander doch so ăhnlich sind wie die Kinder ein und derselben Mutter Natur, verbunden durch ihre Lichtstrahlen und den ewigen Austausch ihres kosmischen Lebens. (...) Der Dichter-Kollektivist, wie auch jeder Künstler-Kollektivist, wird nicht nur vom proletarischen Leben und nicht nur vom menschlichen Kollektiv des Kampfes oder der Arbeit reden. Nein, das ganze Leben und die ganze Welt werden zum Inhalt seiner Dichtung; alles wird er mit den Augen des Kollektivisten betrachten und das Band des Zusammenhanges auch dort sehen, wo es der Individualist nicht zu erkennen vermag. Das ganze Universum wird er als ein Feld der Arbeit wahrnehmen, als ein Feld des Kampfes zwischen den Krăften des Lebens und den Elementargewalten, den Kräften, die zur Einheit des BewuBtseins drăngen, und den finsteren Krăften der Zerstörung und der Desorganisation." A. BOGDaNov, "Proletariat $i$ iskusstvo." [1918]. In: Ders. (wie Anm. 21), S. 120. - Zu Bogdanovs EinfluB auf 'Kosmismus' und Kollektivismus in der "pathetischen Lyrik der proletarischen Dichter" ausführlich DRJAGIN (wie Anm. 48), S. 138-140, 146f. Zurückhaltender außern sich dazu MEN'SUtTN, SinjavsKu (wie Anm. 24), S. 172.

60 Erste Hinweise auf eine Beschăftigung Ciolkovskijs mit dem Raumfahrtgedanken reichen bis auf das Jahr 1878 zurück.

61 Ein großer Teil dieser Schriften - darunter fast alle philosophischen Arbeiten - ist nicht wieder veroffentlicht worden und in den seltenen Originalausgaben nur schwer zugănglich. Dies gilt auch fur den Wiederabdruck einiger philosophischer Traktate Ciolkovskijs in einem editorisch ganz unzulănglichen Sammelband, der 1986 in einem Provinzverlag erschienen ist und sofort vergriffen war. K.E. Clolkovsk山, Grezy o zemle i nebe: Naučno-fantasticeskie proizvedenija, Tula 1986.

62 Siehe z.B. K.E. ClolkovSKU, "Issledovanie mirovych prostranstv reaktivnymi priborami." [Teil 2, 1911] In: DERS., SS, t. 2, M. 1954, S. 139.

63 Ciolkovskij in einem Brief an den Aviatiker B.N. Vorob'ev, 12.8.1911. In: CloLkovsky (wie Anm. 62), S. 3. - Bereits 1892 hatte Ciolkovskij das Weltall zum "Eigentum der menschlichen Nachkommenschaft" erklărţ. K.E. ClolkovskJ, Prostce ủenie o vozduśnom korable $i$ ego postroenii, Kaluga 1892, M. ${ }^{2}$ 1904; zitiert nach A. Flusprov, "Kryl'ja." In: Vesy, 1906, 5, S. 40. 
Form dargelegt worden. ${ }^{64}$ Das Buch hatte großen Erfolg - 1919 erschien es bereits in zweiter und dritter, 1923 in vierter Auflage -65 und trug in den Jahren nach der Revolution wesentlich zur Verbreitung des Raumfahrtgedankens bei. ${ }^{66}$ Auf Perel'mans Anregung veröffentlichte Ciolkovskij 1918 die romanhafte Raumfahrtdarstellung "Außerhalb der Erde", die zu seinem populärsten Werk werden sollte. ${ }^{67} \mathrm{Er}$ schildert darin mit einer Fülle technischer, physikalischer und astronomischer Details, wie im Jahre 2017 (also hundert Jahre nach der Oktoberrevolution) eine Gruppe von Gelehrten unter Führung des Russen Ivanov Raumschiffe baut und mit ihnen das Sonnensystem bereist, Raumstationen, sogenannte "Kosmokolonien", errichtet und künstliche Gewächshäuser, "Orangerien", anlegt, während auf der Erde die Menschheit vereint in Frieden und dank des wissenschaftlich-technischen Fortschritts - in Wohlstand lebt und die Heere in Arbeitsarmeen umgewandelt sind.

Zu Beginn der zwanziger Jahre soll Ciolkovskij im Kalugaer Proletkul't-Studio Vorlesungen über Raumfahrt gehalten und dadurch zahlreiche proletarische Schriftsteller, unter ihnen Vladimir Kirillov, zu ihrer Himmelsstürmerlyrik angeregt haben. ${ }^{68}$ Ein enger Vertrauter Ciolkovskijs, der Biophysiker, Weltraumexperte und Dichter A.L. Čiževskij (1897-1964), wirkte zu jener Zeit im Auftrag Lunacarskijs wahrscheinlich im Rahmen des Proletkul't in Kaluga als "literarischer Instrukteur" (literaturnyj instruktor). ${ }^{69}$ Seinem Bericht zufolge äußerte Brjusov, damals stellvertretender Leiter des literaturnyj otdel beim Volkskom-

64 Ja.I. Perel'man, Mezplanetnye puteśestrija, Pg. 1915. - Ausführlich hierzu A. Gluchov, "Meł.planet nye putesestvija'." In: Al'manach bibliofila, vyp. 2, M. 1975, S. 51-57.

65 Insgesamt erlebte das Werk - immer wieder ergănzt und úberarbeitet - bis 1935 zehn Auflagen. Die 2. und 3. Auflage erschien unter dem Titel Putesestrija na planety.

66 A.L. ČİEvSKJ, Vsja żizn', M. 1974, S. 114.

67 K.E. Clolkovsku, "Vne Zemli." [Teilweise] in: Priroda i Ljudy, 1918, 2-14 (mit dieser Nr. muBte die Zeitschrift ihr Erscheinen einstellen). Vollstăndig als Einzelveroffentlichung: Kaluga 1920. Die zweite Ausgabe erschien 1958 in Moskau mit einer Aunage von 250.000 Exemplaren; danach zahlreiche weitere Veröffentlichungen. - Die ersten 11 Kapitel des Romans waren bereits 1896 verfaßt worden.

68 Zavalushin (wie Anm. 48), S. 148f. - Zavalishin gibt hierfür keine Quellen an, sondern spricht lediglich von "meager records available of his [Ciolkovskijs] association with the group [Kalugaer Proletkul't]." (Ebd., S. 148).

Ciolkovskijs Einfluß auf den 'Kosmismus' der frühen Sowjetzeit ist bislang nicht năher untersucht worden. Vgl. die überaus spärlichen und nicht selten ungenauen Angaben zu Ciolkovskij in den ansonsten gründlichen und materialreichen einschlăgigen Arbeiten: ZAVALISHIN (wie Anm. 48), S. 148f. R. NUDEL'MAN, "Fantastika, roždennaja revoljuciej." In: Fantastika 1966, vyp. 3, M. 1966, S. 339. D. SUVIN, The Utopian Tradition of Russian Science Fiction." In: The Modem Language Review, 66 (1971), S. 150. B. RULLKOTTER, Die wissenschaftliche Phantastik in der Sowjetunion, Bern, Frankfurt/M. 1974, S. 26f. GELlER (wie Anm. 24), S. 64. - Von Ciolkovskijs (und Fedorovs) 'bestimmendem EinfluB' auf Majakouskij spricht Ingold, ohne jedoch dafür Belege beizubringen. F.PH. INGOLD, Literatur und Aviatik. Europäische Flugdichrung 1909-1927. Basel 1978, S. 210.

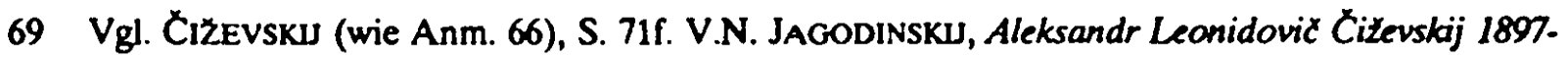
1964, M. 1987, S. 41 . 
missariat für Bildungswesen (Narkompros), lebhaftes Interesse für Ciolkovskij und dessen Raumfahrtprojekte. ${ }^{70}$ 1920/21 verfaßte Brjusov eine unvollendet gebliebene Erzählung über "Die erste interplanetare Expedition" zum Mars, ${ }^{71}$ und es ist sehr wahrscheinlich, da B er Anregungen dazu aus Ciolkovskijs Schriften empfangen hat. ${ }^{72}$ Ausdrücklich auf Ciolkovskij beriefen sich die Petrograder Biokosmisten; ihr Anführer, A.B. Jaroslavskij, veröffentlichte 1926 einen phantastischen Roman "Argonauten des Weltalls", der sich besonders in der Beschreibung technischer Details eng an Ciolkovskijs Raumfahrtprojekte anlehnte. ${ }^{73}$ Belegt ist Ciolkovskijs Einfluß auch auf den Maler Ivan Kudrjašev, dessen Vater für den "Sonderling aus Kaluga" (kalužskij cudak) hölzerne Raketenmodelle angefertigt hat. ${ }^{74}$

Das Streben nach der Eroberung des Weltalls blieb in den Jahren nach der Revolution keineswegs auf den Bereich der Kunst beschränkt, sondern führte früher als in den westlichen Ländern - auch zur Förderung einer wissenschaftlich-institutionalisierten Beschäftigung mit dem Raumfahrtgedanken. Bereits 1921 wurde in Moskau ein 'Gasdynamisches Laboratorium' (Gazodinamiceskie laboratorii) zur Entwicklung von Raketentriebwerken gegründet und zwei Jahre später ein 'Büro zur Erforschung von Strahltriebwerken' (Bjuro po izučeniju reaktivnych dvigatelëj). 1924 veröffentlichte der Raketentechniker V.P. Gluskko (geb. 1908) eine Studie "Über die Notwendigkeit des interplanetaren Verkehrs" und gab eine "Geschichte der Entwicklung der Idee interplanetarer und interstellarer Reisen" heraus. Zur selben Zeit hielt der Aerodynamiker V.P. Vetčinkin (1888-1950) eine Vorlesung über "Reisen zu anderen Planeten". Im Mai 1924 wurde in Moskau die erste Raumfahrtgesellschaft gegründet. ${ }^{75} 1925$ schlo $B$ Vetčinkin eine Untersuchung "Über die Möglichkeit eines Fluges zum Mond mit Raketenhilfe" ab. Im Jahr darauf plante Glusko den Bau von Orbitalstationen für Erdbeobachtungen. Zwischen 1928 und 1932 veröffentlichte N.A.

70 Ciževsku (wie Anm. 66), S. 75-79. - Brjusov plante sogar, ein Buch über Ciolkovskij zu schreiben. Eine Begegnung zwischen ihnen kam jedoch nicht zustande. Siehe Literatumoe nasledsruo (wie Anm. 47), S. 14, 71.

71 V.JA. BRusov, "Pervaja mežduplanetnaja ekspedicija." In: Literatumoe nasledstvo (wie Anm. 47), S. 103-113.

72 Der Kommentar in Literatumoe nasledstuo (wie Anm. 47), S. 70f., nennt in diesem Zusammenhang als moggliche Anreger neben Ciolkovskij auch Fedorov und Perel'man; der naheliegende Hinweis auf Bogdanov und seinen Marsroman Krasnaja zvezda unterbleibt.

73 Siehe II: 3.3.

74 Siehe Kostin (wie Anm. 53), S. 25.

75 Obscestwo izuCenija mežplanetnych soobstenij. Siehe JAGODINSKu (wie Anm. 69), S. 290. - Dies geschah früher als in den westlichen Ländem (Österreich 1926, Deutschland 1927, Großbritannien und USA 1930). 
Rynin (1877-1942) eine zehnteilige Enzyklopädie über "Interplanetaren Verkehr" (Mežplanetnye soobščenija). ${ }^{76}$

\subsection{3. Überwindung des Todes}

Mit dem Ausgreifen ins Weltall verband sich nicht nur die Hoffnung, die Kontinuität der menschlichen Generationen zu sichern, sondern auch die Vorstellung einer Selbstvervollkommnung der Menschheit durch Ausdehnung ihrer Herrschaft über die Natur, die zu einer Befreiung aus den Fesseln von Raum und Zeit, zu einer Verlängerung der Lebensdauer und schließlich zur Überwindung des Todes führen würde. Durch die Eroberung der interplanetaren und intergalaktischen Sphären werde die Menschheit, so Ciolkovskij, die lebensbedrohenden kosmischen Schadensbedingungen beseitigen, neue Lebensräume und Energiequellen erschließen und im Weltall unaustilgbar werden. Damit einher gehe eine biologische Steigerung der Lebensfähigkeit im Sinne einer Vervielfachung der Lebensdauer ${ }^{77}$ sowie einer Zunahme der intellektuellen Fähigkeiten, die schließlich einen "überneuen Menschen" (sverchnovyj človek) hervorbringe, der sich zum heutigen Menschen verhalte, wie dieser zu einem einzelligen Lebewesen. ${ }^{78}$ Zuletzt werde die Menschheit ihre Körperlichkeit verlieren, sich in eine Art Strahlung verwandeln und damit "unsterblich in der Zeit und unendlich im Raum" werden. ${ }^{79}$ Bereits 1911 hatte Ciolkovskij geschrieben:

Der beste Teil der Menschheit wird høchstwahrscheinlich niemals untergehen, sondern wird von einer Sonne, wenn sie erlischt, zu einer anderen wandern. (...) Es gibt kein Ende für das Leben, kein Ende für den Verstand und die Vervollkommnung der Menschheit. Ihr Fortschritt ist ewig. Wenn das so ist, kann es auch keinen Zweifel an der Erlangung der Unsterblichkeit geben. ${ }^{80}$

76 Angaben nach W. PETRI, "Raumfahr in der Sowjetunion. Historisch-ideologischer Rahmen und praktische Erwartungen." In: Studies in Soviet Thought, 18 (1978), S. 45-55. S.V. ORLOV, "Astronomizeskie utopii." In: A[RKA]N [ANEKSTEJN], KOL'MAN (wie Anm. 3), S. 286-336. Einschlägige Artikel in der dritten Ausgabe der $B S E$.

77 Hierzu bes. I.V. VIŠEv, "Metodologiłeskie obosnovanija idej K.E. Ciolkovskogo i vozmožnosti radikal'nogo prodlenija žizni zeloveka." In: Trudy zerymadcanych Črenij KE. Ciolkouskogo (Ka. luga 1979 g.). Sekcija 'KE. Ciolkouskij i filosofskie problemy osvoenija kosmosa.' M. 1980, S. 101-107. Vgl. auch CIŽEVSKJ (wie Anm. 66), S. 145-148.

78 So Ciolkovskij in einem Gesprăch mit A.L. Ciževskij im Jahre 1932; siehe A.L. ČlžEvskIJ, "Stranicy vospominanij o K.E. Ciolkovskom." In: Chimija i Żizn', 1977, 1, S. 30. - Unlăngst wurde die Echtheit dieses inzwischen vielzitierten Berichts angezweifelt und vermutet, Ciževskij habe in fingierte Äußerungen Ciolkovskijs seine eigenen Ideen eingeflochten. T.N. ŽELNINA, [Rezension] "K.E. Ciolkovskij, Grezy o zemle i nebe, Tula 1986." In: Voprosy Istorii Estestvoznanija i Techniki, 1987, 3; hier S. 154.

79 ČlžEvsKu (wie Anm. 78). - Ciolkovskij spricht von luxistoe celovečestwo, vielleicht als Folgerung aus der speziellen Relativitătstheorie, wonach die Ausdehnung eines mit Lichtgeschwindigkeit bewegten Korpers gleich Null ist; wahrscheinlich aber handelt es sich hier um einen Reflex buddhistischer bzw. theosophischer Vorstellungen.

80 Ciolkovsku (wie Anm. 62). - Zur Idee der Unsterblichkeit bei Ciolkovskij und zur Konzeption der 'sozialen Unsterblichkeit' vgl. E.T. FADDEEv, "Ideja bessmertija Zelovetestva u K.E. 
Während Ciolkovskij das Problem des 'Kältetodes' (den beispielsweise Engels in seiner Dialektik der Natur [1873-83] für unausweichlich gehalten hatte) durch Auswanderung der Menschheit in andere Sonnensysteme lösen zu können glaubte, versuchte er der Prognose eines 'Wärmetodes' des gesamten Universums, wie sie aus dem zweiten Hauptsatz der Thermodynamik (Entropiesatz) abgeleitet wurde, mit dem Hinweis auf die "antientropische Wirkung" der vernunftgeleiteten Tätigkeit der Menschheit zu begegnen. ${ }^{81}$ Der gleiche Gedanke findet sich auch bei Florenskij. Für das "Grundgesetz der Welt" hielt Florenskij "das [zweite] Prinzip der Thermodynamik - das Gesetz der Entropie, des allgemeinen Ausgleichs (Chaos)." Ihm entgegen wirke die menschliche Kultur, die auf dem "Gesetz der Ektropie (Logos)" beruhe. Menschliche Kultur sei mithin nichts anderes als "Kampf gegen den Ausgleich in der Welt - den Tod". 82

Der Tod, dieser letzte 'Rest' unbezwungener Natur, der den Menschen daran hindert, gottgleich zu werden, stellte die größte Herausforderung für den 'Prometheismus' der frühen Sowjetzeit dar; doch glaubte man auch hier, durch vernunftgelenkte kollektive Anstrengung Natur in Kultur verwandeln und damit die Macht der blinden Elementargewalten zurückdrängen und schließlich über-

Ciolkouskogo." In: Naucnye doklady vysšej skoly. Filosofskie nauki. M. 1975, 2, S. 58-66. A.D. URSU, JUA. SKOLENKo, Obitaemaja veselennaja, M. 1976, S. 53-55. A.D. URSUL, "Al'ternativa grjadušccgo: gibel' ili bessmertie? (O prognozirovanii dlitel'nosti social'nogo progressa)." In: Trudy desjarych i odinnadcatych Ctenij KE. Ciolkovskogo (Kaluga 1975, 1976 gg.). Sekcija 'KE. Ciolkovskij i filosofskie problemy osvoenija kosmosa.' M. 1978, S. 20-31.

81 Siehe K.E. ClOLKovSKIJ, Vtoroe nacalo termodinamiki, Kaluga 1914.

82 [P.A. FlorenSKU], "Florenskij, Pavel Aleksandrovic." In: Enciklopediceskaj slovar' Granal, t. 44, M. o.J. [1927], Sp. 144. Vgl. etwas abweichend, DERS., "Biograficeskie svedenija (avtoreferat)." In: Vestnik RChD, 135, 1981, S. 55f.

Die Deutung des zweiten Hauptsatzes der Thermodynamik als 'wissenschaftlichen Beweis' für die Unausweichlichkeit des Weltendes - und damit als 'Beweis' gegen alle universellen Fortschrittslehren - ist seit der zweiten Hälfte des 19. Jahrhunderts Gegenstand lebhafter kontroverser Diskussionen von Naturwissenschaftlem (v. Helmholtz, Maxwell, v. Bertalanffy) und Philosophen (Engels, E. v. Hartmann, Spengler, Scheler, Teilhard de Chardin, Bloch). Die Einwănde gegen die Annahme eines unaufhaltsamen, gleichsam kosmischen Todestriebes reichen von der Behauptung einer notwendigen Wiedererzeugung, wenn schon nicht der menschlichen Gattung, so doch zumindest des "denkenden Geist[es] ... anderswo und in anderer Zeit" (F. ENGEls, "Einleitung zur 'Dialektik der Natur'." In: K. MARX, F. ENGEls, Werke, Bd. 20, Berlin 1962, S. 327), über den weit ausholenden Nachweis einer antientropischen Wirkung der "menschlichen Energie" (P. TEILHARD DE CHARDIN, L'Energie humaine, Paris 1962) bis zur Hoffnung auf eine neue "kommunistische Kosmologie", auf "Ektropie' als human-kosmische Neuschöpfung" (E. BLoCH, Das Prinzip Hoffnung, Bd. 3, Frankfurt/M. 1959, S. 1383. DERS., Tendenz - Latenz - Utopie, Frankfurt/M. 1978, S. 306). - In RuBland wurde die Auffassung von Kultur als Sphäre bewußter, schøpferischer Energie und damit als Widerstand des Menschen gegen die dem Chaos (oder Stillstand) zustrebenden Naturprozesse u.a. von dem Physiker NA. Umov (1846-1915), dem Geochemiker und Naturphilosophen V.I. Vernadskij und dem Fedorov-Ashănger V.N. Murav'ev (dazu II: 3.4.) vertreten. Vor einer wachsenden Entropie auch der Kultur warnten der Philosoph N.A. Berdjaev ("Predsmertnye mysli Fausta." In: Osval'd Spengler i zakat Evropy, M. 1922, S. 71) und der Schriftsteller E.I. Zamjatin (O liverature, revoljucii, entropii i o protem, 1924). - Die Rezeption des Entropiegedankens in RuBland und seine Anwendung (auch in Literatur in Kunst) warten noch darauf, erforscht zu werden. 
winden zu können. ${ }^{83}$ "Leicht und schnell," so der Schriftsteller und Ingenieur Andrej Platonov, werde "der Gedanke den Tod vernichten durch seine systematische Arbeit, die Wissenschaft. ${ }^{\text {}}{ }^{84}$

Besonders ausgeprägt war diese Zuversicht bei den ehemaligen Anhängern des bogostroitel'stvo. So bemühte sich Bogdanov bei seinen Forschungen und Experimenten zur Bluttransfusion ${ }^{85}$, die 'Lebensfähigkeit' (Ziznesposobnost') des Organismus zu stärken, Krankheiten und Defekte zu beseitigen und die Lebensdauer zu verlängern. ${ }^{86}$ Durch die Ausdehnung der Wachstumsphase sollte die

83 Unter dem Eindruck der herrschenden wissenschaftlich-technischen Fortschrittsbegeisterung scheint der Gedanke einer diesseitigen Uberwindung des Todes auch in religiosen Kreisen diskutiert worden zu sein. So kündigte der Herausgeber der in Moskau erscheinenden religiossen Zeitschrift Vertograd, V.G. Senatov, im Frühjahr 1918 einen Vortrag mit dem Titel "Der Sieg über den Tod" an, dessen Themen lauteten: "Die Lehre von der Evolution der verborgenen Krafte des Menschen. Seine physische und sittliche Wiedergebur. Die vollstăndige Erneuerung des Menschen und die Erlangung unbegrenzter Lebensdauer." Siehe Veriograd, 4, 26.3./ 8.4.1918, S. 1. (Von dieser ăußerst seltenen Zeitschrift war mir außerdem nur noch die Nr. 1 vom 19.2./4.3.1918 zugănglich). Weitere Mitarbeiter von Vertograd waren P.I. Ivanickij, der einige Jahre spăter als Mitglied der Biokosmisten die Abschaffung des Todes und die Auferweckung der Verstorbenen forderte (siehe II: 3.3.), sowie - möglicherweise - V.N. Murav'ev, der die Idee einer totalen kosmischen Umwandlung, eines Sieges über Zeit und Tod propagierte (siehe II: 3.4.); beide gehorten in den zwanziger Jahren zum Kreis der Moskauer Fedorov-Anhänger (siehe 4.1.). Zu den Mitarbeitern von Verrograd zăhlte ferner N.N. Rusov (1884 nach 1934), "ein Freund Rozanovs und Berdjaevs, Mystiker, Slavophile und Anhănger der Philosophie Vl. Solov'evs" (E.L. MINDLIN, Neobyknovennye sobesedniki, M. 1968, S. 122). Wahrscheinlich durch seine Vermittlung erschienen in Veriograd die ersten Abschnitte von Rozanovs berühmter Apokalipsis našego vremeni (1917-1918), einer Folge von Artikeln und Essays, die um die Frage von Vergănglichkeit, Ewigkeit und Unsterblichkeit kreisen.

84 A.P. Platonov, "Kul'tura proletariata." [1920] Zitiert nach $\$. LuUBUSKuNA, "Ideja bessmertija u rannego Platonova." In: Russian Literature, 23, 1988, S. 412. Vgl. auch N.M. MALYGINA, "Idejno-éstetiそeskie iskanija A. Platonova v nałale 20-ch godov." In: Russkaja Literatura, 1977, 4, S. 163. DIES., "Estestvennonautnye istocniki predstavlenija o prirode Andreja Platonova." In: Celovek i priroda v chudožestuennoj proze. Meturuzovskij sbomik. Syktyvkar 1981, S. 49-64, bes. S. 54-57.

In einer 1923 erschienenen phantastischen Erzahlung schildert Platonov eine "Masterskaja Bessmertnoj Ploti", in der die durch "Anthropotechnik" und durch die Vernichtung "todbringender Mikroben" mittels elektromagnetischer Wellen unsterblich gemachten "neuen Menschen" leben und arbeiten; sie kennen keinen Schlaf und zeichnen sich durch völlige geschlechtliche Enthaltsamkeit aus. A.[P.] PLATONOV, "Rasskaz o mnogich interesnych vešach." In: DerS., Starik i stanucha. Poterjannaja proza. München 1984, S. 43-92; bes. S. 71-77. - Die Idee, durch Vernichtung todlicher Mikroben den Menschen unsterblich werden zu lassen, findet sich mehrfach in der utopischen Literatur jener Zeit (vgl. oben Anm. 13).

85 Erstmals beschrieben in Krasnaja zvezda (1907/8). Siehe II: 2.1.2. - 1926 gründete Bogdanov in Moskau ein Institut für Bluttransfusion, das erste seiner Art. Er starb 1928, nachdem er sich bei einem Selbstversuch mit dem Blut eines Malaria- und Tuberkulosekranken infiziert hatte. Einzelheiten dazu - aufgrund eines Interviews mit Bogdanovs Sohn - erstmals bei L.R. GrAHAM, "Bogdanov's Inner Message." In: A. Bogdanov, Red Star. The First Bolshevik [sic] Utopia, Bloomington 1984, S. 252. Siehe auch V. DorofEev, "Opponent..." In: Literatumaja Gazeta, 49, 7.12.1988, S. 13 .

86 Hierzu insbesondere A. Bogdanov, Bor'ba za Ziznesposobnost', M. 1927. Vgl. femer Ders., "Oterki organizacionnoj nauki." In: Proletarskaja Kul'tura, 1920, 15/16; darin das Kap.

"Tektologija bor'by so starost'ju." S. 27-31. 
Menschheit in ein "Geschlecht von Riesen" verwandelt werden, das stärker sei und länger lebe als die heutigen Menschen. ${ }^{87}$ Bogdanovs Ziele gleichen denen Mecnikovs; im Gegensatz jedoch zur Theorie der 'Orthobiose', derzufolge die Verbesserung und Verlängerung des Lebens von einer Stärkung des Individuums durch Mobilisierung ausschließlich eigener Kraftreserven erwartet wurde, stand hinter Bogdanovs Methode des wechselseitigen (Blut-)Austausches der Gedanke kollektiver Solidarität und Unterstützung sowie die Absicht, den herrschenden Individualismus zu überwinden und durch "physiologischen Kollektivismus" (fiziologiceskij kollektivizm) zu ersetzen. 88

Wenngleich es Bogdanov bei seinen Experimenten zur Bluttransfusion nicht um eine Methode zur Erlangung realer Unsterblichkeit ging, ${ }^{89}$ so eröffnet der Gedanke des "physiologischen Kollektivismus" doch, wie Lunačarskij gezeigt hat, auch eine 'Lösung' des Todesproblems: Durch das Verschmelzen des individuellen Ich mit dem "unsterblichen Überorganismus" des Kollektivs, dem "ewigen Ganzen" der Gesamtmenschheit,, ${ }^{90}$ verlieren Zeit und Tod ihren Schrecken - das "universelle Ich" weiß sich unendlich im "realen Bewußtsein der

Das Thema fand auch literarische Bearbeitung: In seinem 1930 entstandenen Drama My budem Eit' schildert Boris Lavrenev die heroischen Bemühungen einer Gruppe sowjetischer Wissenschaftler, Krankheit und "sinnlosen vorzeitigen Tod" durch Bluttransfusionen zu überwinden. In: B.L. LAVRENEV, SS v 6-i tt., t. 5, M. 1956, S. 161-241; hier S. 173. Möglicherweise in Anlehnung an Bogdanov beschreibt Aleksej Tolstoj in seiner 1925 erschienenen Erzăhlung Golu. bye gornda in einer Zukunftsvision des Jahres 2024 die technischen Moglichkeiten einer "totalen Verjüngung", die allerdings das Privileg weniger bleibt.

87 Siehe Bogdanov, Borba (wie Anm. 86), S. 52.

88 Siehe ebd., S. 153f. - Ins Kosmische gewendet wird dieser Gedanke in einem 1920 entstandenen Gedicht Bogdanovs: "Ein Marsianer, den es auf die Erde verschlagen hat", trăumt von seinem Heimatplaneten, "wo Brüderlichkeit und Vernunft herrschen". Doch auch die Erdenbewohner sind "Kinder der allmăchtigen Natur", den Marsianern "blutsverwandt", und werden wie diese den Weg zur universellen Harmonie beschreiten. "Dereinst, wenn Raum und Zeit beherrscht / und die Elemente und der Tod überwunden sein werden / werden beide Rassen zu einem einzigen Geschlecht verschmelzen / einem Geschlecht von Erbauern neuer Welten." ("Marsijanin, zabrosennyj na Zemlju." [Erstmals] in: A. BogDANOV, Krasnaja zvezda, izd. vtoroe [6. Ausgabe?], L.-M. 1924, S. 167-169. In der Ausgabe L. 1929 [Nachdruck Hamburg 1979] ist dieses Gedicht nicht mehr enthalten).

89 Abwegig sind Behauptungen wie: "[Bogdanov] believed that eternal [!] life could be achieved through transfusions of blood." N.A. Tumarkin, Lenin lives! The Lenin Cult in Soviet Russia. Cambridge, Mass., London 1982, S. 22. Vgl. DiEs., "Religion, Bolshevism, and the Origins of the Lenin Cult." In: Russian Review, 40 (1981), S. 43f. "A central [!] theme in Bogdanov's writings was the possibility of scientifically overcoming [!] death, or at least persuading people of this possibility." R.C. WiLliAMS, "Collective Immortality: The Syndicalist Origins of Proletarian Culture, 1905-1910." In: Slavic Review, 39 [1980], 3, S. 392. "... influenced by Fedorov's ideas [!] ... [Bogdanov] may have hoped to create, quite literally, in the laboratory, an immortal [!] superman." B.G. ROSENTHAI, "Introduction." In: DIES. (Hg.), Nietzsche in Russia, Princeton, New Jersey 1986, S. 42. - Von "ewigem Leben", "Uberwindung des Todes" oder der Schaffung eines "unsterblichen Übermenschen" ist bei Bogdanow nirgends die Rede! (Vgl. auch II: 2.1.2, Anm. 113).

90 A.[V.] LunaČRSKU, "O prepodavanii istorii v kommunistiðeskoj łkole." [1918] In: DERS., Prosvestenie i revoljucija. Sb. statej. M. 1926, S. 105. 
Unsterblichkeit des Menschengeschlechts. Das ist der Sieg über die Zeit, das ist der Sieg über den Raum ... ${ }^{n 1}$ Und Gastev dichtete:

GroB in der Vergangenheit, unendlich in der Zukunft ist mein Leben.

(...)

Ich lebe nicht Jahrhunderte, Jahrtausende lang.

Ich lebe seit der Erschaffung der Welt.

Und ich werde noch Millionen Jahre leben.

Mein Lauf kennt keine Grenzen. ${ }^{2}$

Um eine Überwindung des Todes im Sinne individueller Unsterblichkeit ging es anderen ehemaligen Anhängern des bogostroitel'stvo. So äußerte Gor'kij in einem Vortrag an der Arbeiter-und-Bauern-Universität in Petrograd im März 1920 die Überzeugung, daß es dem menschlichen Verstand gelingen werde, alle Geheimnisse der Natur zu entdecken und zum Nutzen des Menschen zu beherrschen. Unter Hinweis auf die Bemühungen russischer Physiologen, die Dauer des menschlichen Lebens zu verlängern, rief er seinen Hörern zu:

Wenn ihr darüber nachdenkt, Genossen, so werdet ihr sehen, daß in diesem Falle der menschliche Verstand dem Tod als einer Naturerscheinung den Krieg erkărt - sogar dem Tod. Meine innere Überzeugung ist die, daß früher oder spăter, vielleicht in zweihundert Jahren, vielleicht in tausend, der Mensch tatsăchlich die Unsterblichkeit erlangen wird. ${ }^{93}$

"Individuelle Unsterblichkeit" verhieß auch die aus dem Kreis der bogostroiteli stammende Schrift $O$ proletarskoj ètike (1906), die in den Jahren nach der Revolution mehrere Neuauflagen erlebte. ${ }^{94}$

Noch einen Schritt weiter ging der ebenfalls dem Kreis der bogostroiteli nahestehende Rožkov, der nicht nur an die Unsterblichkeit künftiger Generationen, sondern auch an die Möglichkeit einer Auferweckung Verstorbener mit wissenschaftlich-technischen Mitteln glaubte. ${ }^{95}$ Nahrung und Bestätigung fand

91 Ebd., S. 106. - Lunacarskij vergleicht den "neuen Menschen" mit einem Soldaten, der begeistert kămpfe, obwohl er wisse, daB er den Sieg selbst nicht erleben werde. Im Kampf für den Fortschritt der gesamten Menschheit suche und finde der "neue Mensch" Unsterblichkeit (ebd.). Das Thema der Unsterblichkeit und des Sieges über die Zeit behandelt Lunatarskij auch in seinen Theaterstücken Faust $i$ gonod (1910-1916) und Magi $(1919,1923)$. Am SchluB des Stückes Faust $i$ gorod läbt der Autor, nachdem der Arzt Fausts Tod festgestellt hat, Gabriel ausrufen: "Faust lebt in allen Dingen! Er lebt in uns! Er lebt fur immer!" Zum Sieg über die Zeit siehe auch Magi (13. Aufzug).

92 A.[K.] Gastev, "Moja Žizn'." [Gedicht] In: Ders., Poizija rabočego udara, Pg. 1918, S. 143f. Den Gedanken einer 'Úberwindung' des Todes durch völlige Identifizierung des einzelnen mit der als unsterblich gedachten Menschheit hat Gastev von den bogostroiteli übernommen, zu denen er schon vor dem Ersten Weltkrieg enge Beziehungen unterhielt (siehe II: 2.1.2.). In den Jahren nach der Revolution findet sich die Konzeption einer 'sozialen Unsterblichkeit' auch bei Ciolkovskij (siehe oben Anm. 80) und ZALkIND (wie Anm. 7), S. 468.

93 GOR'KU, "O znanii" (wie Anm. 9).

94 Siehe II: 2.1.2. Anm. 69ff. Zur Wirkung dieser Schrift siehe die Rezension von Ivanickij 1921 im Organ der Moskauer Biokosmisten (II: 3.3.).

Siehe oben Anm. 5 und ausführlich II: 2.1.2. 
solcher Glaube in den Experimenten zur biologischen Verjüngung, Lebensverlängerung und Wiederbelebung, mit denen, etwa seit der Jahrhundertwende, die russischen Physiologen und Genetiker P.I. Bachmet'ev, I.I. Mexnikov, S.I. Metal'nikov, N.K. Kol'cov, N.P. Kravkov, S. Voronov und andere sowie die Wiener Paul Kammerer und Eugen Steinach Aufsehen erregten. ${ }^{96}$ Zwar zielten die meisten dieser Bemühungen auf eine - bestenfalls beliebige - Verlängerung des menschlichen Lebens, ${ }^{97}$ doch gab es auch Versuche, die Folgen des bereits eingetretenen Todes rückgängig zu machen: Allein die 'Auferweckung Verstorbener' gelangte in der Praxis nie über die Wiederbelebung von Pantoffeltierchen oder - falls man entsprechenden Berichten glauben darf - von tiefgefrorenen Fischen und Amphibien hinaus. ${ }^{98}$ Im übrigen blieb sie Gegenstand bloßer Spekulation. Zumeist wurde dabei das - für Fedorov zentrale - ethische Moment durch eine deterministische Fortschrittsauffassung ersetzt, was zur Folge hatte, $\mathrm{da} B$ Unsterblichkeit und Auferweckung einer Elite - den 'roten Helden', den 'Siegern der Geschichte', den 'großen Persönlichkeiten' oder aber den 'Mühseli-

96 Aus der Vielzahl einschlägiger Veroffentlichungen, die in den frühen zwanziger Jahren in der Sowjetunion erschienen sind und die auf ein großes Interesse deuten, seien nur die folgenden genannt: N.K. Kol.'CoV (Hg.), Omolożenie. Vionoj sbomik statej. M.-Pg. 1924. A.V. NEMLOV, 'Zizn' i smert', L. 1924. P. KAMMERER, Omolotenie i prodlenie liznoj zizni, M. 1922. Ders., Omolotenie i dolgovetnost', Pb.-Berlin 1922. Ders., Smert' i bessmertie, M.-L. 1925. Vgl. ferner N.S. MELuK-PASAEv, "Čelovek buduš́cgo (v svete sovremennych dostiženij biologii $i$ mediciny)." In: A[RKa]N [ANEKStejn], Kol'man (wie Anm. 3), S. 388-396. Zalkind (wie Anm. 7), S. 492f.,sowie den Rezensionsartikel von V. ZaVADOVSKL, "Obzor inostrannoj i russkoj literatury po voprosu ob omoloženii." In: Pečat' i Revoljucija, 1921, 2, S. 78-89. - Im einzelnen oft ungenau und fehlerhaft ist die in diesem Zusammenhang hăufig zitierte Studie von P. WILES, "On Physical Immortality." In: Survey, 1965, 56, S. 125-143; 57, S. 142-161. - Zu Mečnikov siehe auch II: 2.1.3. und die dort angegebene Literatur.

Steinach, der sich mit Experimenten zur Wiederbelebung und Verjüngung von Organismen befaßte, wurde in den zwanziger Jahren zum Idol der Petrograder Biokosmisten. Siehe z.B. A. JAROSLA vSKu, Poema anabioza, Pg. 1922. Ders., "Kosmo-chronika." In: DerS., Koren' iz Ja, L.M. 1926, S. 7-9. Bessmertie, 1922, 1, S. 3f., 6, 11f. Ausführlich II: 3.3. In diesen Zusammenhang gehorr auch M.A. Bulgakovs 1925 entstandene Satire Sobac'e serdce, in der ein Professor Preobraženskij (!) - eine Mischung aus Faust und Frankenstein - auf der Suche nach einer Methode zur Verjüngung und Verbesserung des Menschen einen Hund durch Transplantation der Hoden und Hypophyse eines jungen Mannes in ein menschenăhnliches Wesen verwandelt.

97 Siehe in diesem Zusammenhang die Bemerkung Emst Blochs, daß dem "Kampf gegen das Altern" insgeheim die "Abschaffung des Todes" vorschwebe. BLOCH, Prinzip Hoffnung (wie Anm. 82), Bd. 2, S. 535f., 541; mit Hinweisen auf Mežnikov, Voronov und Steinach sowie auf sowjetische Experimente.

98 Siehe I.I. SMal'Gauzen, Problema smerti i bessmerija, M.-L. 1926. N.P. KRavkov, "Dannye i perspektivy po ožjvleniju tkanej umeršich." In: Bessmertie (wie Anm. 96), S. 2f. Zu den Wiederbelebungsversuchen von Bachmet'ev und Metal'nikov auch II: 2.1.3. und die dort angegebene Literatur (Anm. 145-147). - Solženicyn berichtet von einem Physiologen Michajlovskij, der in den zwanziger Jahren Leichen zersetzungshemmende Lösungen injizjert habe, was in der sowjetischen Presse als eine "von Menschenhand bewirkte Auferweckung" gefeiert worden sei. A.I. SolZzencrN, Archipelag GULag 1918-1956, t. 3-4, Paris 1974, S. 305. 
gen und Beladenen', den 'vergessenen Opfern der Geschichte' - vorbehalten blieben. ${ }^{99}$

1921 verkündete der Volkskommissar und Diplomat L.B. Krasin aus Anlaß des Todes von L.Ja. Karpov:

Ich bin überzeugt, die Zeit wird kommen, da die Wissenschaft so măchtig sein wird, daß sie einen zugrundegegangenen Organismus wiederherstellen kann. Ich bin überzeugt, die Zeit wird kommen, da es möglich sein wird, mit Hilfe der Elemente des Lebens eines Menschen den physischen Menschen selbst zu rekonstruieren. Und ich bin überzeugt, wenn diese Zeit kommen wird, da die befreite Menschheit fähig sein wird, unter Einsatz der ganzen Macht von Wissenschaft und Technik, deren Stărke und Größe man sich jetzt noch gar nicht vorstellen kann, die großen Persönlichkeiten [!], die Kămpfer für die Befreiung der Menschheit, wiederzuerwecken - ich bin überzeugt, daB dann unter den großen Persönlichkeiten auch unser Genosse Lev Jakovlevið sein wird. ${ }^{100}$

Drei Jahre später war Krasin verantwortlich für die Konservierung von Lenins Leichnam. ${ }^{101}$ Es ist denkbar - und wurde wiederholt geäußert -, daß diese Maßnahme im Hinblick auf eine mögliche Auferweckung erfolgte. ${ }^{102}$ K.S. Mel'ni-

99 So trăgt die von dem bibelfesten proletarischen Dichter Filipłenko geschilderte Auferwekkungsszene durchaus elităre Züge: "Wie Hesekiel" erblickt er ein Feld, auf dem Knochen bleichen und faulen, die "von der götlichen Messe zurückgewiesen worden sind"; es sind die "Knochen der Beladenen" (kosti obremennych). Der Dichter - mit dem "Herzen des Prometheus" verspricht: "Ich werde sie mit einem Korper bekleiden und ihnen eine Seele eingeben. Ich werde sie auferwecken." I.[G.] FILIPCENKo, [Gedicht] "Eta kniga - otdel'nye zvuki edinoj..." [1917] In: DERS. (wie Anm. 11), S. 8. - Vgl. auch die satirische Darstellung der Auferweckung berühmter Personlichkeiten (Hegel, Ninon de Lenclos, Judas Ischariot) in Brjusovs phantastischer Erzählung Torzestio nauki (1918). Ausführlich II: 2.2.2.

100 L.B. Krasin zitiert nach M.[S.] OL'MINSKU, "Kriticeskie stat'i i zametki." In: Proletarskaja Revoljucija, 1931, 1, S. 149f. (Ungenaue Übersetzung bei TUMARKIN, "Religion...", wie Anm. 89, S. 44. DiES., Lenin lives!, wie Anm. 89, S. 181). Vor der Revolution hatte Krasin enge Kontakte zu Bogdanov und Rožkov gehabt. Von letzterem scheint er den Gedanken einer technischen Wiedererweckung großer Persónlichkeiten übernommen zu haben. Auf die elităren Züge dieses Denkens hat bereits S.V. UtECHIN, "Bolsheviks and Their Allies After 1917: The Ideological Pattern." In: Soviet Studies, 10 (1958), 2, S. 130, hingewiesen.

101 S.O. Chan-Magomedov, Mavzolej Lenina, M. 1972, S. 55f. - Auf Krasin soll auch die Idee der Konservierung und stăndigen Ausstellung von Lenins Leichnam zurückgehen. Vgl. B. SvANIDZE, Im engsten Kreis, Stuttgart 1953, S. 189. S.F. STARR, Melnikov. Solo Architect in a Mass Sociery. Princeton 1981, S. 248f. Auch Lenins Gehirn wurde konserviert und einer gründlichen anatomischen Untersuchung unterzogen, glaubte man doch, in ihm "zweifellos den Prototyp des Gehirns des künftigen Ubermenschen" vor sich zu haben; so MELIK-PASAEV (wie Anm. 96), S. 368. Nach Ansicht des Physiologen Bechterev, der in Leningrad ein Institut für Hirnforschung leitete, sollten die Gehirne der "großen Mănner" als "wertvolle Reliquien" erhalten und zum Zwecke der "Propaganda der materialistischen Anschauungen über die Entwicklung der schðpferischen Tătigkeit des Menschen" in einem "Pantheon" (!) ausgestellt werden. W. BECHTEREW [V.M. BECHTEREV], "Bechterew über das Pantheon." In: Wochenbericht der Gesellschaft für kulturelle Vertindungen der Sowjetunion mit dem Auslande, 2, 14.1.1928, S. 4f. Die Reduzierung des Genies auf Materie und Mechanik des Gehirns hat Roland Barthes eindrücklich am Beispiel des Einsteinmythos beschrieben. R. BARTHES, "Le cerveau d'Einstein." In: DERS., Myrhologies, Paris 1957, S. 103-105. Bereits 1929 sprach Majakovskij vom "futuristischen Gehim Einsteins". V.V. MAJAKOVSKU, PSS v 13-i th., t. 11, M. 1958, S. 280.

102 So meinte der Fedorov-Anhănger N.A. Setnickij, "die Tatsache der Einbalsamierung und Aufbewahrung des Leichnams von V.I. Lenin (die im Gegensatz steh[e] zu seinen eigenen bekann- 
kov, der Architekt, der den gläsernen Sarkophag zur "ewigen Erhaltung" von Lenins Leichnam entwarf, ${ }^{103}$ hatte sich seit langem mit der Frage der Überwindung des Todes beschäftigt und die entsprechenden Diskussionen in den Jahren nach der Revolution verfolgt. ${ }^{104}$ Das Problem von Lenins Tod 'löste' er, indem er ihn (wie im Märchen von Dornröschen) 'schlafend' präsentierte, unverweslich, ${ }^{105}$ auf seine Wiedererweckung wartend... ${ }^{106}$ So verstand es auch Žacev, der Held in Platonovs Novelle Kotlovan (1929-30):

"PruSevskij! Werden die Errungenschaften der hochsten Wissenschaft imstande sein, verweste Menschen wiederzuerwecken?"

"Nein," sagte Pruševskij.

"Du lügst," warf Žatev ein, ohne die Augen zu offnen, "der Marxismus kann alles. Warum liegt dann Lenin unversehrt in Moskau? Er wartet auf die Wissenschaft, er will auferstehen. ${ }^{107}$

ten Äußerungen über das Zurschaustellen von Leichen [imupoložstvo]" konne "nur mit dem Gedanken an eine notwendige und unausbleibliche Auferweckung" erklärt werden. NA. S[ETNIC]KIJ, "O smerti i pogrebenii." In: Vselenskoe delo, 2, Riga 1934, S. 145. Vgl. auch SARKISYANZ (wie Anm. 2), S. 41. Starr (wie Anm. 101), S. 247-250. Heller (wie Anm. 3), S. 111.

Tumarkin vermutet hinter den von Krasin getroffenen Maßnahmen sogar einen direkten Einnuß Fedorovs: "His [Fedorov's] work appeared to have profoundly [!] influenced Leonid Krasin..." TUMARKIn, Lenin lives! (wie Anm. 89), S. 19; "Krasin ... may have been influenced ... by Fedorow, the respected [!] philosopher..." (ebd., S. 181). Für Grygar wird dies zur Gewißheit: Krasin sei, so schreibt er, "fasziniert gewesen von der utopischen Prophezeiung des Kazaner [!] Philosophen N.F. Fedorov..." M. GRYGAR, "Leninizm i bespredmetnost': roždenie mifa." In: Russian Literature, 25 (1989), 3, S. 386. Start verweist in diesem Z.usammenhang auf "the resurgent popularity of Fedorov's vision during the early 1920s, the attraction that it held for several [!] leading [!] Bolsheviks..." S.F. STARR, [Rezension von] "N. Tumarkin, Lenin lives!" In: Russian Review, 43 (1984), S. 286. - Für alle diese Vermutungen und Behauptungen gibt es freilich keinerlei Beweise.

103 Von einem "sarkofag dlja sochranenija na večnye vremena tela V.I. Lenina" sprechen noch heute sowjetische Reiseführer. - Viel metaphorischer dagegen Bertolt Brecht: "Lenin ist eingeschreint [!] / In dem großen Herzen der Arbeiterklasse." ("Kantate zu Lenins Geburtstag." Svendborger Gedichle, Mitte der dreißiger Jahre).

104 Ausführlich dazu STARR (wie Anm. 101), S. 245-250. - Mel'nikov hatte u.a. einen im Dezember 1923 verfaßten Traktat des Fedorov-Anhăngers V.N. Murav'ev gelesen, in dem von einer künftigen Auferweckung der Verstorbenen mit wissenschaftlich-technischen Mitteln die Rede war. (Ebd., S. 248) Zu Murav'ev ausführlich II: 3.4.

105 In der orthodoxen Kirche als Zeichen für Heiligkeit gedeutet. - Zum 'Reliquien'-Kult um Lenins Leichnam ausführlich, wenn auch bisweilen überinterpretierend und faktisch nicht immer genau, die Arbeiten von TUMARKIN (wie Anm. 89).

106 Den Vergleich mit dem Mărchen von Dornroschen wollte Mel'nikov, wie sein Biograph berichtet, wortlich verstanden wissen. STARR (wie Anm. 101), S. 249.

107 A.P. Platonov, Kollovan. Juvenil'noe more. M. 1987, S. 97. 


\subsection{Die künstlerische Avantgarde}

\subsubsection{Fedorov und die Avantgarde}

Die Kunstauffassung der russischen Avantgarde ${ }^{1}$ weist eine Reihe von Merkmalen auf, die an eine Beeinflussung durch Fedorovs Ideenwelt denken lassen. Gemeinsam sind beiden utopische und totalitäre Züge, die Absage an die Welt, wie sie ist, und der auf ein hohes Ideal bezogene Anspruch zur radikalen und umfassenden "Umgestaltung der Wirklichkeit" (preobraženie dejstvitel'nosti) durch eine aktive, "lebenbauende" Kunst (bei Fedorov moralisch begründet, bei den Avantgardisten eher ästhetisch motiviert). Beide verwerfen die kontemplative Haltung und die traditionelle mimetische Funktion, indem sie Kunst bestimmen als Projekt der Welt, wie sie sein soll, und als dessen planmäßige Verwirklichung im žiznetvorčestvo oder žiznestroenie. ${ }^{2}$ Die Schaffung eines 'neuen Menschen' und eines 'neuen kebens', der Glaube an die gottgleiche, Ordnung und Einheit stiftende Allmacht des menschlichen Verstandes, an Wissenschaft und Technik, die Überwindung von Zeit und Raum, von Schwerkraft und Tod, der Vorstoß in neue Dimensionen, das Ausgreifen ins All - alle diese 'Fedorovschen Motive' finden sich auch in den Werken der Avantgardisten. So allgemein formuliert entsprechen sie freilich dem Zeitgeist und müssen nicht notwendig auf die Filosofija obščego dela zurückgeführt werden; ${ }^{3}$ als Beweis für eine Beeinflussung reichen sie nicht aus. ${ }^{4}$

1 Dieser Terminus hat sich als zusammenfassende Bezeichnung einer Reihe unterschiedlicher Kunstrichtungen der 1910er und 1920er Jahre (Kubo-Futurismus, Suprematismus, Konstruktivismus u.a.) eingebürgert. Er wird hier mit den von Bowlt geăußerten Vorbehalten verwendet. J.E. BowlT, "Art in Exile: The Russian Avant-Garde and the Emigration." In: Ant Joumal, 41 (1981), 3, S. $215 f$.

2 Siehe FOD II, S. 152. - Zur engen Verwandtschaft zwischen der Kunstauffassung des ziznestroenie der russischen Avantgarde (Čužak u.a.) und der des ziznervortestvo, wie sie von Solov'ev und den Symbolisten (und man könnte ergănzen: von Fedorov) vertreten wurde, siehe H. GONTHER, "Žiznestroenie." In: Russian Litenature, 20 (1986), S. 41-48. B. Groys nennt als Hauptmerkmal der (russischen) Avantgarde die Forderung, von der Darstellung der Welt überzugehen zu ihrer Umgestaltung im Rahmen eines totalen ăsthetisch-politischen Plans. B. GroYs, Gesamtkunstwerk Stalin, München 1988, bes. S. 19-38. Genau dies trifft - mit moralischer Begründung - auch für Fedorovs Kunstauffassung zu.

3 Die genannten Motive finden sich - um nur ein Beispiel zu nennen - auch bei den italienischen Futuristen, insbesondere bei Marinetti, der bereits 1902 in La Conquête des Etoiles verkündet hatte: "L'heure est venue de conquérir l'espace et de monter à l'assaut des Etoiles." Mittels der Technik wird Marinettis 'neuer Mensch' seinen Willen der Materie aufzwingen, sich ihrer bemächtigen und, indem er sie nach seinem Belieben formt, die ganze Welt neu gestalten; schlieBlich wird er künstliche Lebewesen schaffen, die, da sie nicht gezeugt und geboren, sondem mechanisch konstruiert sind, unsterblich und allmăchtig sein werden. Ausführlich dazu CH. BAUMgARTH, Geschichte des Futurismus, Reinbek 1966; hiei S. 12, 136-138.

4 Siehe beispielsweise die unbegründet hohe Einschätzung des Fedorovschen Einflusses durch Kovtun und Povelichina: "Devançant leur temps, les idées de Fedorov, le tableau grandiose qu'il créa de la lutte titanique contre la chute-attraction, de l'humanité débouchant sur le cosmos, des envols interplanétaires, ont eu une énorme action sur les esprits et l'imagination de la 
Fedorovs Einfluß auf die künstlerische Avantgarde, insbesondere auf den russischen Futurismus und Kubofuturismus, wird in der Literatur sehr unterschiedlich veranschlagt; eingehend untersucht wurde er noch nicht. ${ }^{5} \mathrm{Im}$ folgenden soll ihm am Beispiel der Dichter V.V. Majakovskij und V.V. Chlebnikov sowie der Maler K.S. Malevi乏 und V.N. Čekrygin nachgegangen werden, jener Vertreter der künstlerischen Avantgarde, die immer wieder mit Fedorov in Verbindung gebracht werden, obwohl - außer Cekrygin - keiner von ihnen Fedorov jemals namentlich erwähnt hat.

Nur einmal taucht Fedorovs Name in den Schriften eines Futuristen auf, nämlich bei Nikolaj Burljuk, ${ }^{6}$ der in seinem 1914 erschienenen programmatischen Aufsatz Poèticeskie nacala auf die angeblich lange vernachlässigte ästheti-

génération suivante. (...) Il ne fait aucun doute que des fils encore invisibles partent de Fedorov, menant à de nombreux faits de la culture artistique russe du début du $X X^{e}$ siècle." $E$. Kovtoune [E.F. Kovtun], A. Povelikhina [A.V. Povelichina], "La ville futuriste de Sant'Elia et les idées architecturales de Xlebnikov." In: Présence de F.T. Marinetri, Lausanne 1982, S. 271.

Bei der Frage nach einem möglichen EinfluB dürfen auch nicht (was durchweg geschieht) die wesentlichen Differenzen zwischen Fedorov und den Vertretern der Avantgarde (insbesondere den Futuristen) übersehen werden. So war etwa die in den futuristischen Manifesten und Auftritten provokant vorgetragene Verherrlichung der Jugend und der Zukunft (so schon in der programmatischen Eigenbenennung: futuristy, budetljane) und die Auflehnung gegen Traditionsgebundenheit, gegen alles 'Gestrige', das den Fortschritt lahmt, gegen die Toten, die die Lebenden unterdrücken, der Grundintention von Fedorovs rückwărtsgewandter Utopie, der es um die Bewahrung und Wiederherstellung alles Gewesenen (und sei es zunăchst nur in Bibliotheken und Museen) ging, geradezu entgegengesetzt. "Das Vergangene ist eng. [...] Puß̌kin, Dostoevskij, Tolstoj etc. etc. sind vom Dampfer der Gegenwart zu werfen", hieB es in dem berühmten futuristischen Manifest Pošcetina obšestvennomu vkusu von 1912; und 1909 hatte Marinetti im Gründungsmanifest des italienischen Futurismus seinen $\mathrm{HaB}$ gegen Museen und Bibliotheken - diese "Friedhöfe vergeblicher Anstrengungen, diese Kalvarienberge gekreuzigter Trăume" - proklamiert und gefordert: "Legt Feuer an die Regale der Bibliotheken!... Leitet den Lauf der Kanăle ab, um die Museen zu überschwemmen!" Zitiert nach BAUMGaRTH (wie Anm. 3), S. 28. Unvereinbar mit Fedorovs Lehre war ferner die bei den Avantgardisten vorherrschende Begeisterung für die GroBstadt und ihre Zivilisation sowie ihr ausgeprăgtes Elitedenken.

5 Für sehr bedeutend hălt z.B. Tolstaja-Segal Fedorous EinfluB auf den russischen Futurismus, insbesondere auf Chlebnikov und Majakovskij. E. TOLSTANA-SEGAL, "Ideologiteskie konteksty Platonova." In: Russian Literature, 9 (1981), S. 246f. In dem Standardwerk von V. MARKov, Russian Futurism. A History. Berkeley, Los Angeles 1968, wird Fedorov hingegen überhaupt nicht enwăhnt. Noch immer gilt die Feststellung von Igor' Smimov: "Die Frage nach den Verbindungen zwischen dem Futurismus und der ideologischen Hinterlassenschaft des originellen russischen Denkers N.F. Fedorov wartet darauf, behandelt zu werden." I.P. SMIRNov, Chudotestvennyj smysl i èvoljucija poèticeskich sistem, M. 1977, S. 110.

6 Der Maler Cekrygin (zu ihm ausführlich unten) hing nur kurze Zeit dem Futurismus an und wurde erst viel spăter mit Fedorovs Werk bekannt. Er kann also nicht als Beispiel für eine Fedorov-Rezeption der Futuristen angeführt werden; so z.B. bei SMIRNov (wie Anm. 5). Gleiches gilt für den Dichter und Publizisten Aleksandr Emmanuiloviz Belenson, der eine Zeitlang den Futuristen nahestand (die er zusammen mit Symbolisten in den von ihm herausgegebenen Sammelbănden Strelec druckte). Ein 1922 entstandenes Gedicht Belensons mit dem Titel Nicse - Spengler - Fedorov ist nichts weiter als ein unbeholfener Versuch, Schlagworte und Klischees wie "Zarathustra", "Untergang Europas", "Sohnespflicht - Auferweckung" und dgl. 'poetisch" einzukleiden und laßrt sich keiner Stilrichtung zuordnen. In: Strelec. Sbomik tretij i poslednij. SPb. 1922, S. 112. Zu Belenson auch MARKov (wie Anm. 5), S. 278-281, 410 f. 
sche Wirkung von Schriftzeichen einging und zu kalligraphischen und typographischen Experimenten anregte. In diesem Zusammenhang erinnerte Burljuk - eher beiläufig - an Fedorov, einen "Moskauer Gelehrten", der "unlängst verstorben" sei; dieser habe "in der schweren Zeit des Symbolismus und der 'Dekadenz' vergeblich auf die Rolle der Schriftzeichen in der Ästhetik hingewiesen". 7 Gemeint waren Fedorovs Gedanken über den Verfall der Schreibkunst, dargelegt in einem kurzen Auszug aus seinem nachgelassenen Werk, der unter dem Titel $O$ pis'menach 1904 in der Symbolisten-Zeitschrift Vesy erschienen war. $^{8}$

\subsubsection{V.V. Majakovskij}

Von allen Vertretern der russischen Avantgarde wird am häufigsten V.V. Majakovskij (1893-1930) mit Fedorov in Verbindung gebracht. ${ }^{9}$ Zwar hatte Majakovskij - nach einer Aussage von Osip Brik - Fedorovs Werke nicht gelesen, ${ }^{10}$ doch könnte er mit einzelnen Gedanken der Filosofija obš̌̌ego dela durch die Vermittlung anderer bekannt geworden sein. Einer Version zufolge soll Majakovskij in den 1910er Jahren durch den Dichter Boris Šmankevic, der dem

7 N.[D.] BuRusuk, "Poètiteskie nacala." In: Futurist. Penyj Zumal Russkich Futuristov. M. 1914, 1-2, S. 82; wieder abgedruckt in: Ot simvolizma do 'Okrjabrja'. Literatumye manifesty. M. 1924, S. 103. - Zu Burljuks Hinweis auf Fedorov vgl. auch N.I. CHARdžlev, "Poezija i zivopis'. (Rannij Majakovskij)." In: $K$ istonii russkogo avangarda. The Russian Avant-Gande. Stockholm 1976, S. 56. DERS., "Majakovskij i żivopis'." In: N.I. ChardžIEv, V.V. TrENIN, Pó́ticeskaja kul'tura Majakovskogo, M. 1970, S. 37. G. JANECEK, The Look of Russian Literature, Princeton 1984, S. 16. - Zur Bedeutung der Schriftzeichen bei den Futuristen vgl. neben dem grundlegenden Werk von JANECEK auch E.F. KovTUN, "Das Antibuch der Warwara Stepanowa." In: Von der Fläche zum Raum. Rußland 1916-24. Köln o.J. [1974], S. $57-63$ (zu Burljuks Hinweis auf Fedorov, S. 59). Siehe auch unten Anm. 72.

8 Siehe I: 2. Anm. 14. - Die kurze Erwăhnung durch Burljuk als Beweis für den "EinfluB Fedorovs auf die Grundlagen des russischen Modernismus" zu deuten - so TOLSTAJA-SEGAL (wie Anm. 5), S. 246 - dürfte wohl übertrieben sein.

9 Aus der umfangreichen Literatur zu Majakovskij seien folgende Werke genannt, die von einem starken EinfluB Fedorovs auf Majakovskij ausgehen: V. ZAvALISHIN, Earty Soviet Writers, New York 1958, S. 83-86. A.M. RIPELliNo, Majakovskj e il teatro russo d'avanguardia, Torino 1959, S. 60f., 118, 208. DERS., "Play Majakovskij. (Divagazioni su La cimice)." In: Rossija - Russia, 3, 1977, S. 15-28. EJ. Brown, Majakovsky. A Poet in the Revolution. Princeton 1973, S. 122, 253256. V.D. BarooshIAN, Russian Cubo-Futurism, 1910 1930. A Study in Avant-Gandism. The Hague 1974, S. 43f., 49, 52f. (Verf. behauptet, Majakovskij habe Fedorovs Werk gelesen!). R.C. Willuams, Arists in Revolution. Pontraits of the Russian Avant-garde, 1905-1925. London 1978, S. 129-131, 135, 140, 145f., 149f. - Auch in Arbeiten, die Majakovskij nur am Rande behandeln, finden sich nicht selten dezidierte Äußerungen über Fedorovs Einfluß. So heißt es bei $\mathrm{L}$. Heller, De la Science-Fiction soviétique, Lausanne 1979, S. 41: "C'est de Fiodorov que vient la foi de Maiakovski en la résurrection et l'immortalité." Und F.PH. INGOLD, Literatur und Aviatik. Europäische Flugdichtung 1909-1927. Basel 1978, S. 210, spricht vom "bestimmenden - bisher noch kaum untersuchten EinfluB Nikolaj Fedorovs" auf Majakovskij.

10 N.[I.] ChardžIev, "Majakovskij i Chlebnikov." In: To Honor Roman Jakobson, vol. 3, The Hague, Paris 1967, S. 2321. Dieser Aufsatz erschien leicht verăndert und ohne Hinweis auf die Erstveroffentlichung in CHARDZZIEv, TRENIN (wie Anm. 7), S. 96-126; hier S. 120. 
Kreis um Vjaceslav Ivanov angehörte, von Fedorovs Ideen erfahren haben; ${ }^{11}$ andere nennen als mögliche Vermittler Valerij Brjusov oder den 1914 von Fedorov-Anhängern in Odessa herausgegebenen Sammelband Vselenskoe delo. ${ }^{12}$ Auch Osip Brik ${ }^{13}$ sowie nicht näher bekannte "Moskauer Fedorov-Anhänger"14 werden in diesem Zusammenhang angeführt - doch sind all dies Spekulationen, für deren Richtigkeit es keinerlei Beweise gibt. Zweifelhaft bleibt auch die häufig geäußerte Vermutung, wonach Majakovskij von Fedorov und dessen Ideen durch den Maler Vasilij Nikolaevič Čekrygin erfahren haben soll, den er 1912 als Student an der Moskauer Hochschule für Malerei, Bildhauerei und Baukunst kennengelernt hatte. ${ }^{15}$ Von Čekrygin ist inzwischen bekannt, daß er wahrsçheinlich erst in der zweiten Hälfte des Jahres 1921 mit Fedorovs Werk in Berührung gekommen ist, ${ }^{16}$ sich dann allerdings bis zu seinem frühen Tod, im Juni 1922, intensiv mit der Gedankenwelt der Filosofija obščego dela auseinanderge-

11 Siehe Vselenskoe delo, 2, Riga 1934, S. 184. - S.G. SemENova, "Čelovek, priroda, bessmertie v poezii Nikolaja Zabolockogo." In: Literatumaja Gruzija, 1980, 9, S. 142. - Uber den Kreis um V.I. Ivanov, in dem möglicherweise Ideen Fedorovs rezipiert und diskutiert wurden, siehe II: 2.2.2.; zu B.I. Šmankevix II: 4.1 .

12 K.A. CCHEIDzE, "Komentáł k Majakovskému." In: Rozhledy po Literatuře a Uměnl [Praha], 8-9, 1933, S. 58. (Dass. russ.: "Kommentarij k Majakovskomu." [1932] In: DERS., O sovremennoj nusskoj literature, Prag 1933, Ms. [Masch.], Bl. 13-24; hier Bl. 22).

13 N.S. TALBOTT, Mayakovsky Agonistes. The Myth of Self in the Poetry of Vladimir Mayakovsky. Unveroff. B.Litt. thesis Oxford 1972, Ms. [Masch.], S. 116, 234.

14 K.A. Čcheidze teilt in einem Zusatz zur russischen Fassung seines Aufsatzes über Majakovskij (siehe Anm. 12, dort Bl. 24) mit, er habe unlăngst "ganz eindeutige Hinweise" erhalten, wonach Majakovskij mit "einigen Moskauer Fedorov-Anhängern" (nekotorye fedonovcy-moskvici) engen Umgang gehabt und mit ihnen mehrmals über "Fedorovsche Themen" (fedorovskie temy) gesprochen habe. In den Schriften der bekannten Moskauer Fedorov-Anhănger finden sich jedoch keine entsprechenden Hinweise.

15 Vgl. L.F. ŻEGIN [d.i. L.F. SECHTEL'], "Vospominanija o Majakovskom." [1935] In: V. Majakovskij v vospominanijach sovremennikov, M. 1963, S. 99-102. V.O. PERCov, Majakovskaj. Zizn' itvoriestvo. T. 1, M. 1950, S. 223f. - Ausführlich zu Cekrygin unten 3.2.4.

16 Siehe unten Anm. 96. - Hingegen schreibt Viktor Šklovskij über Majakovskijs Studienzeit an der Moskauer Kunsthochschule: "Čekrygin sprach mit den Worten des alten Bibliographen aus dem Rumjancev-Museum, Fedorov, von der Auferweckung der Toten. Er malte Engel, Majakovskij aber wollte, daB er eine Fliege male." V.B. SKLOVSKU, "O Majakovskom." [1940] In: DERS., SS v 3-ch tr., t. 3, M. 1974, S. 25. Der letzte Satz geht - was Šklovskij nicht enwăhnt - zurück auf die Erinnerungen von Lev Žegin (Šchtel', 1892-1969) und bezieht sich - auch das bleibt bei Sklovskij unerwăhnt - auf die Arbeit an Majakovskijs erstem Gedichtband Ja!, den Žegin gemeinsam mit Cekrygin im Jahre 1913 illustrierte: "Nun, Vasja - brummt Majakovskij du hast ja schon wieder einen Engel gemalt. Warum nicht eine Fliege? Hast schon lange keine Fliege mehr gemalt." ŻEIN (wie Anm. 15), S. 101. Von Fedorov ist in diesem Zusammenhang nicht die Rede! - Ebenfalls im Zusammenhang mit der Arbeit an Majakovskijs erstem Gedichtband enwähnt Percov (wie Anm. 15), S. 224, Cekrygins Bilderzyklus "Die Auferwekkung der Toten"; tatsăchlich entstand dieser Zyklus unter dem Einfluß Fedorovs doch wurde er erst im Jahre 1921 begonnen! - Auf die genannten irreführenden Angaben bei Sklovskij und Percov stützen sich alle späteren Behauptungen und Vermutungen, wonach Majakovskij bereits um das Jahr 1913 durch Cekrygin mit den Theorien Fedorovs bekannt geworden sei. So RI. PELLINo (wie Anm. 9), S. 63, 315. Brown (wie Anm. 9), S. 122, 235f. WiLliams (wie Anm. 9), S. $135,145 f$. 
setzt hat. ${ }^{17}$ Gerade in dieser Zeit aber soll Majakovskij keinen Kontakt zu Cekrygin gehabt haben. ${ }^{18}$

Auch die Suche nach 'Fedorovschen Motiven' im Werk Majakovskijs erwies sich bislang als wenig geeignet, Zeitpunkt und Umstände einer möglichen Rezeption zu erhellen. So können Versuche, Fedorovs Einfluß in frühen Werken wie Oblako v stanach (1914/15) und Vojna i mir (1915-17) nachzuweisen, nicht überzeugen, da sie sich darauf beschränken, futuristische Hyperbolik, Gigantomanie und Omnipotenzgebaren mit dem Geist der Filosofija obš̌ego dela in Verbindung zu bringen, wobei allenfalls oberflächliche Ähnlichkeiten erkennbar werden. ${ }^{19}$ Sogar das Motiv der Überwindung des Todes und der mit technischen Mitteln bewerkstelligten Auferweckung Verstorbener, das sich vor allem in den zwanziger Jahren in unterschiedlicher Gestaltung in mehreren Werken Majakovskijs findet, ${ }^{20}$ muß nicht notwendig auf Fedorov zurückgeführt werden, wie die folgenden Beispiele zeigen.

In der 1928 entstandenen satirischen Komödie Klop ${ }^{21}$ wird der Spießer Prisypkin bei einem Brand im Löschwasser der Feuerwehr versehentlich eingefroren. Fünfzig Jahre später findet man ihn in einem Keller in einem Eisblock er-

17 Siehe unten 3.2.4.

18 Mit der Begründung, er habe schon lange keinen Kontakt mehr zu Cekrygin gehabt, soll Majakovskij im Juni 1922 in einem Telephongesprăch mit Žegin seine Teilnahme an Cekrygins Begrăbnis abgesagt haben. Mitteilung von A.A. Dorogov, Moskau, 5.4.1984; Dorogov beruft sich auf eine Mitteilung Žegins. - Siehe in diesem Zusammenhang auch Cekrygins abfallige ÄuBerungen über Majakovskij ("ja ... ego stichov ne vynoš") in einem Brief an M.F. Larionov vom 9.12.1921. [V.N. CekRYGIN], "Pis'ma V. Cekrygina k M. Larionovu." In: $A$ - Ja, 4, 1982, S. 40-43; hier S. 42. Dagegen behauptet Chardžiev, es sei ihm "gelungen, Tagebuchaufzeichnungen (dnevnikorye zapisi) über Begegnungen Majakovskijs mit Cekrygin im Jahre 1920 zu entdekken". ChaRDŽiev (wie Anm. 10). In der spăteren Veröffentlichung dieses Aufsatzes spricht Chardžiev statt von "Tagebuchaufzeichnungen" nur noch von "Nachrichten" (svedenija), ohne năhere Angaben darüber zu machen. CHARDŽIEv, TRENIN (wie Anm. 7), S. 120.

19 Vgl. z.B. Barooshian (wie Anm. 9). Semenova (wie Anm. 11). - Brown (wie Anm. 9), S. 122, beispielsweise vermutet Fedorovs EinfluB in folgender Strophe von Oblako v stanach: "Sehnen und Muskeln sind zuverlässiger als Gebete. / Oder sollen wir etwa die Gnade der Zeit erflehen! / Wir halten / ein jeder / in unserer Faust / die Treibriemen der Welten!" V.V. MWAKovSKu, PSS v 13-i tt., t. 1, M. 1955, S. 184. Diese Zeilen enthalten jedoch nichts, was nur durch Rückgriff auf Fedorov erklărt werden könnte.

20 Als einer der ersten hat Roman Jakobson dieses Motiv in seinem 'Nachruf auf Majakovskij behandelt. R. JAKOBSON, "O pokolenii, rastrativకem svoich poetov." In: R. JAKOBSON, D.S. Mirsku, Smen' Vadimira Majakovskogo, Berlin 1931, S. 7-45; hier S. 24-28. Deutsch "Von einer Generation, die ihre Dichter vergeudet hat", erstmals vollstăndig, wenn auch oft ungenau, in: R. JAKOBSON, Poetik. Ausgewählte Aufsätze 1921-1971. Frankfurt/M. 1979, S. 158-191. Vgl. ferner WiLliaMs (wie Anm. 9), S. 128-150, - Majakovskijs lebenslange Beschäftigung mit dem Problem des Todes und der Unsterblichkeit sei, so Williams, außer durch Fedorov v.a. durch Verhaeren, Maeterlinck und Walt Whitman angeregt und beeinfluBt worden - und RIPELUINO, "Play Majakovskij" (wie Anm. 9), der die Auferweckung (la risurrezione) als "ein wesentliches Element in Majakovskijs Werk" bezeichnet (S. 16).

21 Majakovsku (wie Anm. 19), t. 11 (1958), S. 215-276. 
starrt. Das "Institut für menschliche Auferweckungen" (Institut celoveðeskich voskresenij) ${ }^{22}$ unternimmt es, ihn wiederzubeleben.

Das Motiv der Auferweckung wird (ähnlich dem der von Wells, Einstein und Chlebnikov inspirierten 'Reise in der Zeit' in Banja [1929]) ${ }^{23}$ vor allem wegen seines satirischen Effektes eingesetzt: Im Verlauf des Stücks kommt es zwischen dem wiederbelebten 'Fossil' Prisypkin und den Angehörigen einer perfekten, aber technizistisch-sterilen Zukunftsgesellschaft zu mancherlei Konflikten und damit zur wechselseitigen Entlarvung ihrer Unzulänglichkeiten. Prisypkins Auferweckung erinnert denn auch weit mehr an die bizarren Projekte der Biokosmisten ${ }^{24}$ und an den Anfang von Edward Bellamys Looking Backward 2000$1887^{25}$ als an Fedorovs moralische Forderung nach universeller Überwindung des Todes.

Das Verfahren selbst hat keinerlei Ähnlichkeit mit dem von Fedorov beschriebenen, sondern gleicht dem der Anabiose-Experimente eines Bachmet'ev, wie sie in den zwanziger Jahren in der Sowjetunion betrieben wurden ${ }^{26}$ und auch in der Literatur ihren Niederschlag fanden: So berichtet Boris Pil'njak in seiner Erzählung Delo smerti (1927) ${ }^{27}$ von einem "Lebens-Institut [Institut Žizni] der Moskauer Kommunistischen Akademie", dessen Mitarbeiter die "Fragen der Unsterblichkeit" durch Einfrieren und Wiederbeleben von Organismen zu lösen versuchen. Als der Leiter des Instituts Selbstmord begeht, hinterläßt er die Bitte, seinen Körper einzufrieren und so lange aufzubewahren, bis die Wissenschaft imstande sein werde, ihn wiederzubeleben. ${ }^{28}$ Pil'njaks Erzählung nur wenige Monate vor Entstehung der Komödie Klop (Herbst 1928) in der Zeitschrift Novyj Mir erschienen - könnte Majakovskij ebenso als Anregung gedient haben wie A. Jaroslavskijs Poema anabioza (1922), in dem geschildert wird, wie der verspießerte Teil der Menschheit durch Einfrieren und späteres Wiederauftauen in die perfekte Welt der Zukunft versetzt wird. ${ }^{29}$

22 Ebd., S. 246. - Es erinnert an das Teurgiceskij institut zur Auferweckung Verstorbener in Brjusovs 1918 entstandener Satire Torkesmo nauki (siehe II: 2.2.2.).

23 Ausführlich hierzu R. Duganov, "Zamysel 'Bani'." In: $V$ mire Majakovskogo. Sb. statej. M. 1984, S. 394-434. Duganov weist in Banja starke Einflüsse von Chlebnikovs Spekulationen über die Natur der Zeit und ihre Beherrschung nach (ebd., bes. S. 419-430).

24 Siehe II: 3.3.

25 Bellamys Looking Backward (russ. erstmals als Budušij vek und Cerez sto let, SPb. 1891) war wohl die populărste Utopie im vorrevolutionăren Rußland. Fedorov hat sich wiederholt kritisch über sie geăußert. Siehe FOD I, S. 140. N.F. FEDOROV, Soxinenija, M. 1982, S. 614-621.

26 Siehe II: 2.1.3. und 3.1.3.

27 B. Pil'njak [d.i. B.A. Vogau], N.M. Fedorovsku, "Delo smerti." In: Novyj Mir, 4 (1928), 2, S. 133-140.

28 Ebd., S. 140.

29 Siehe II: 3.3. - Dennoch wird das Motiv der Auferweckung in Klop immer wieder ausschlieBlich auf Fedorov zurückgeführt. Vgl. RIPELLINo, Majakovskij (wie Anm. 9), S. 208. DERS., "Play 
Ohne alle Komik behandelt Majakovskij das Thema der Auferweckung in der um die Jahreswende 1922/23 entstandenen Dichtung Pro èto. ${ }^{30}$ Gegen Ende des deutlich autobiographischen Poems wendet sich der Dichter mit einer "Bittschrift" an den "Genossen Chemiker" des 30. Jahrhunderts, der darüber entscheidet, wer von den Verstorbenen auferweckt werden soll:

Ich sehe,

Luft auf Luft,

sehe klar, bis zu den Details.

wie wenn Stein auf Stein [sich fügte],

unerreichbar für Verwesung und Zerbröckeln,

strahlend

erhebt sich mit den Jahrhunderten

die Werkstatt der Menschenauferweckungen (masterskaja Xelove' ich voskrešenij).

Da ist er, der großstimige stille Chemiker,

vor dem Experiment hat er die Stirn gerunzelt.

Ein Buch -

"Die ganze Erde", -

er sucht einen Namen heraus.

Das zwanzigste Jahrhundert.

Wen soll man auferwecken?

Da wăre Majakovskij...

Suchen wir markantere Gesichter -

der Dichter ist nicht schön genug. -

Ich schreie

von dieser

Blăttere die Seite nicht um!

von der jetzigen Seite:

Erwecke!

(...)

Erwecke

und sei es bloß dafür,

daB ich

als Dichter

dich enwartet,

den Alltagsunsinn verworfen habe!

Erwecke mich

Enwecke wenigstens dafür!

das Meine will ich zu Ende leben! ${ }^{31}$

Majakouskij" (wie Anm. 9), S. 18f. Brown (wie Anm. 9), S. 254. WILLIAMS (wie Anm. 9), S. 149. Zurückhaltender ăußert sich INGOLD (wie Anm. 9), S. 155 Anm. 254.

30 Was die beiden vorliegenden Obersetzungen dieses Poems ins Deutsche von H. Huppert und A.E. ThoB nicht erkennen lassen; sie sind durchweg in einer witzigen Diktion gehalten.

31 MajaKovsku (wie Anm. 19), t. 4 (1957), S. 181f., 184; wörtliche Übersetzung. - Zur Entstehung siehe auch Z.S. PAPERNY\}, "Majakouskij v rabote nad poémoj 'Pro eto'." In: Literatumoe 
Auch in dieser apokalyptisch anmutenden Szene, ${ }^{32}$ da es um eine individuelle Auferweckung geht, deren man noch würdig zu sein hat, ${ }^{33}$ sind Hinweise auf Fedorov $^{34}$ wenig überzeugend, ist doch der Gedanke einer Rückkehr ins Leben, sofern diese einer 'Elite' vorbehalten bleibt, der Absicht des obš̌ee delo geradezu entgegengesetzt. ${ }^{35}$ Vorstellungen, wie sie Majakovskij vertritt, finden ihre Parallele (und mögliche Herkunft) vielmehr in den Utopien eines Rožkov, der bereits 1911 die künftige Wiederherstellung Auserwählter in einem chemischen (!) Laboratorium vorhergesagt hatte ${ }^{36}$ sowie - in den Jahren nach der Revolution - in den Proklamationen der Biokosmisten und des Volkskommissars Krasin, in denen von einer technischen Auferweckung der 'teuersten Söhne des Proletariats' und der 'größten Gestalten der Geschichte' die Rede ist. ${ }^{37}$

Der Gedanke einer Überwindung des Todes mit wissenschaftlich-technischen Mitteln war in den Jahren nach der Revolution weit verbreitet. Auftrieb erhielt er nicht zuletzt durch die damals gerade bekannt gewordene Allgemeine Relativitätstheorie, die nicht nur von Wissenschaftlern und Philosophen, son-

nasledstvo, t. 65 [Novoe o Majakovskom], M. 1958, S. 217-284; hier S. 256-262, ohne Hinweis auf Fedorov.

32 Das Buch des Chemikers erinnert an das "Buch des Lebens" aus der Offenbarung des Johannes.

33 Ähnlich das Thema in Banja: Aus der Zukunft erscheint mittels der Zeitmaschine eine "phosphoreszierende Frau", bevollmächtigt zur Auswahl der Besten (!), die in das kommunistische Jahrhundert versetzt werden sollen. MAJAKovSKIJ (wie Anm. 19), t. 11 (1958), S. 322.

34 CCheidze (wie Anm. 12). Brown (wie Anm. 9), S. 253f. Ripellino, "Play Majakovskij" (wie Anm. 9), S. 17. Williams (wie Anm. 9), S. 145. L.L. STAHLBERGER, The Symbolic System of Majakovskaj, The Hague 1974, S. 142. A. FlAKER, Poetika osporavanja, Zagreb 1982, S. 69. K. POMORSKA, "Majakovskij i vremja. (K chronotopiteskomu mifu russkogo avangarda)." In: Slavica Hierosolymitana, 5-6, 1981, S. 352f. Dies., The Utopian Future of the Russian AvantGarde." In: American Contributions to the Ninth Intemational Congress of Slavists, Kiev, September 1983, vol. 2, Columbus, Ohio 1983, S. 382f,; dass. geringfügig erweitert auch unter dem Titel "Majakovskij's Cosmic Myth." In: A. KodjaK u.a. (Hgg.), Myth in Literature, Columbus, Ohio 1985, S. 183f. DiEs., "Majakovskij and the Myth of Immortality in the Russian Avant-garde." In: N.A. NILSSON (Hg.), The Slavic Literatures and Modemism, Stockholm 1986, S. 59-61. - Kritisch dazu G. CEREMIN, "Mistiそeskaja 'utopija' pod flagom nauki. (Ob odnoj amerikanskoj koncepcii tvorkestva V.V. Majakovskogo)." In: Voprosy Literatury, 1984, 9, S. 185194; zu Fedorov, dessen EinfluB auf Majakouskij bestritten wird, S. $191 f$.

35 Daß Majakovskijs Vorstellung einer künftigen Auferweckung elităre Züge trägt, wurde wiederholt bemerkt; vgl. S.V. UTECHIN, "Bolsheviks and Their Allies After 1917: The Ideological Pattern." In: Soviet Studies, 10 (1958), 2, S. 130. Tolstaua-Segal (wie Anm. 5), S. 247, doch wies zuerst POMORSKA, "Majakovskij i vremja" (wie Anm. 34), S. 353, auf den dadurch entstandenen Gegensatz zu Fedorov hin. Diesen Punkt hebt auch Karabcievskij in seiner unlăngst erschienenen polemischen Auseinandersetzung mit Majakovskij hervor. JU. KA. RABCIEVSKU, Voskresenie Majakouskogo, München 1985, bes. S. 199-211: Majakovskij habe sich nur oberflăchlich mit Fedorovs Projekt befaBt, dessen totalităre und technizistische Züge ihm imponiert hătten. Im Gegensatz zu Fedorov sei es Majakovskij jedoch nur um die eigene Fortdauer (sowie die einiger Auserwăhlter) gegangen; Fedorovs moralischer Rigorismus - die selbstlose Liebe zu allen Verstorbenen - sei Majakovskij fremd geblieben.

Siehe II: 2.1.2.

37 Siehe dazu II: 3.1.3. und 3.3. 
dern auch in Kreisen der künstlerischen Avantgarde intensiv rezipiert wurde und zu kühnen Spekulationen Anlaß gab. ${ }^{38}$ Mit ihrer Hilfe, so glaubten einige, werde es gelingen, die Zeit zu beherrschen, die Menschen unsterblich zu machen und sogar - durch eine 'Umkehrung der Zeit' - die Toten ins Leben zurückzuholen. ${ }^{39}$ Auch Majakovskij interessierte sich, wie Roman Jakobson berichtet, gerade für diesen Aspekt der neuen Lehre:

Im Frühjahr 1920 kehrte ich in das von der Blockade eingeschlossene Moskau zurück. Ich brachte neue europäische Bücher mit, Nachrichten über die wissenschaftliche Arbeit des Westens. Majakovskij zwang mich, meinen verwortenen Bericht über die Allgemeine Relativitătstheorie und die zu jener Zeit zunehmende Diskussion darüber mehrere Male zu wiederholen. Die Freisetzung der Energie, das Problem der Zeit, die Frage, ob eine Geschwindigkeit, die die des Lichtstrahls übertrift, nicht eine entgegengesetzte Bewegung in der Zeit sei - all das faszinierte Majakouskij. Selten habe ich ihn so aufmerksam und begeistert gesehen. "Glaubst du nicht," fragte er mich plotzlich, "daß man auf diese Weise die Unsterblichkeit erringen kann?" Ich sah ihn erstaunt an und murmelte zweifeinde Worte. Darauf begann er mit der hypnotisierenden Beharrlichkeit, die wahrscheinlich allen bekannt ist, die Majakovskij näher kannten, die Backenknochen zu bewegen. "Ich bin dagegen vollkommen überzeugt, daß es keinen Tod mehr geben wird. Man wird die Toten auferwecken. Ich werde einen Physiker ausfindig machen, der mir Einsteins Buch Punkt für Punkt erklăren soll. Es kann doch nicht sein, daß ich das nicht verstehen werde. Ich werde diesem Physiker eine Akademiker-Ration bezahlen." In jenem Augenblick offenbarte sich mir ein ganz anderer Majakouskij: die Forderung nach der Überwindung des Todes nahm ihn gefangen. (...) Majakovskij trug sich damals

38 Der 'Panfuturist' Ippolit Vasil'evið Sokolov (1902-1974) feierte Einstein als Futuristen und "neuen Newton des 20. Jahrhunderts". I.[V.] Soxolov, Renessans XX veka, 0.O. 0.J. [M. ca. 1920], S. 3f. Valerij Brjusov lieB sich durch die Relativitătstheorie zu einer Reihe von Gedichten inspirieren, z.B. "Princip otnositel'nosti" [1922] in: VJA. BRussov, SS, t. 3, M. 1974, S. 136; "Beskonęnost" [1924] in: Literatumoe nasledstvo, t. 85, M. 1976, S. 62-64. Zu Brjusovs Einstein-Rezeption auch K.L. ZeLINSKIJ, Na nubeže dvuch époch, M. 1959, S. 273f. Vgl. ferner POMORSKA, "Majakovskij" (wie Anm. 34) und L.D. HENDERSON, The Founh Dimension and Non-Euclidean Geometry in Modem Ant, Princeton 1983, S. 241-244, 291-299. Aus manxistischer Sicht: K.CH. Delokarov, Filosofskij analiz teonii omosirel'nosti (na materiale filosofskich diskussij v 20 - 30-e gody), M. 1973, bes. S. 107-109, 145f. - Einsteins "Relativitătsprinzip" wurde sogar zur Erklărung "religiöser Phănomene" (etwa der durch Ekstase verănderten Wahrnehmung von Raum und Zeit) herangezogen; siehe die originelle, heute fast verschollene Arbeit des Ethnographen V.G. BOGORAZ (TAN), Ėinštejn i religija. Primenenie principa omositel'nosti $k$ issledovaniju religioznych javlenij. M.-Pg. 1923.

39 Siehe die 1924 erschienene Schrift von V.N. MURAV'EV, Ovladenie vremenem (ausführlich dazu II: 3.4.). Bereits zwei Jahre zuvor hatte Florenskij in einer aufsehenerregenden Abhandlung von der möglichen Umkehrung der Zeit gesprochen, wonach die Wirkung ihrer Ursache vorausgehe. P.A. FLORENSKU, Mnimosti v geometrii, M. 1922 [Nachdruck München 1985], S. 52. Siehe auch die Einleitung von M. HAGEMEISTER, "P.A. Florenskij und seine Schrift 'Mnimosti $\checkmark$ geometrii' (1922)." Ebd., bes. S. 17f., 47. - Das Thema des Sieges über die Zeit, ihre "Nichtumkehrbarkeit", behandelt im Zusammenhang mit Einstein auch Brjusovs Gedicht "Nevozvratnost" [1923] in: Brussov (wie Anm. 38), S. 171f. Vgl. auch das Gedicht des Biokosmisten Jaroslavskij "Kosmochronika", in dem es heiBt: "... na granicach vselennoj 3irokich / vysjatsja bjusty Enštejna [sic] / na poljusach krajnich planet." In: A.[B.] JAROSLAvSKU, Koren' iz $J a$, L.-M. 1926, S. 8. - Durch seinen Nachweis der Relativităt der Zeit habe Einstein, so der Fedorov-Anhănger A.K. Gorskij, die Behauptung eines 'absoluten Todes' widerlegt. A. Ostromirov [A.K. GorSKIJ], Nikolaj Fedorovic Fedonov i sovremennost'. Ozerki. Vyp. 2, Charbin 1928, S. 13. 
mit der Absicht, an Einstein ein Gruß-Radiogramm zu schicken 'Der Wissenschaft der Zukunft von der Kunst der Zukunft'.

Noch im selben Jahr entwarf Majakovskij den Plan zu einem Drama, dessen Hauptpersonen Lenin und Einstein sein sollten sowie ein Dritter, dessen Namen er jedoch nicht verraten wollte. Das Drama wurde nie geschrieben, und es bleibt der Spekulation überlassen, ob es sich bei dem geheimnisvollen Dritten um Fedorov gehandelt haben könnte. ${ }^{41}$

\subsubsection{V.V. Chlebnikov}

Neben dem Werk Majakovskijs sind es vor allem die Schriften von Velimir (Viktor) Chlebnikov (1885-1922), in denen immer wieder Anklänge oder Einflüsse Fedorovscher Gedanken vermutet werden. ${ }^{42}$ Zwar gibt es keine eindeuti-

40 Jakobson (wie Anm. 20), S. 24f. - Bei seinem Versuch, die geistesgeschichtlichen Wurzeln der Dichtung Majakovskijs darzulegen, spricht Jakobson davon, daB Majakovskijs "Vision der künftigen Auferweckung der Toten im Fleische der materialistischen Mystik Fedorovs konvergent [!]" sei. (Ebd., S. 24). Diese - nicht năher begründete - Äußerung wird in der spăteren Majakovskij-Literatur hăufig als Behauptung (bei manchen Autoren sogar als Beweis) einer direkten Beeinflussung Majakovskijs durch Fedorov angeführt! Siehe zuletzt W. WOROSZYLSKI, "Vladimir Maïakovski (1893-1930)." In: E. ETKIND u.a. (Hgg.), Histoire de la linterature nusse Le XX' siecle [2]: La Revolution et les années vingt. O.O. [Paris] 1988, S. 299. - Jakobson selbst war mit Fedorows Gedanken durch den Linguisten M.N. Peterson bekannt geworden (siehe I: 2.).

Zu Majakovskijs Interesse an Einstein und der Relativitătstheorie vgl. CHARDŽIEv (wie Anm. 10), S. 2321f. POMORSKA, "Majakorskij" (wie Anm. 34). R. JAKOBSON, K. POMORSKA, Dialogues, Cambridge 1983, S. 142. G.V. BEBUTOv, Majakovskij vstrecaet vek dvadcat' penyj, Tbilisi 1984, S. 11, 36-40 (dort S. 37 der Hinweis, Majakovskij habe eine Ausgabe der Speziellen Relativitătstheorie [Pg. 1916] besessen). Vom "futuristischen Gehim Einsteins" spricht in Banja der Erfinder einer wundersamen Maschine zur völligen Beherrschung der Zeit: "Ich werde die Zeit zwingen stiltzustehen oder dahinzueilen in jeder beliebigen Richtung und mit jeder beliebigen Geschwindigkeit." MNAKOVSKU (wie Anm. 19), t. 11 (1958), S. 280.

41 Der m.W. einzige Hinweis auf dieses Drama findet sich bei L. MatthIAs, Genie und Wahnsinn in Rußland, Berlin 1921, S. 45.

42 Vel.. [Pseud.], "Chlebnikow - osnovatel' budetljan." In: Kniga i Revoljucija, 1922, 9-10 (21-22), S. 22, 25. (Chlebnikovs Glaube an eine Uberwindung des Todes und seine Skepsis gegenüber dem Westen rückten ihn, so der Verf., in die Năhe Fedorovs. Uber den Verf. dieses Artikels, in dem erstmals Chlebnikov und Fedorov verglichen werden, herrscht Unklarheit; genannt werden N.N. Punin, S.P. Bobrov, R.V. Ivanov-Razumnik und Lev Arens). V. MARKOV, The Longer Poems of Velimir Khlebnikov, Berkeley, Los Angeles 1962, S. 15, 148. A.M. RIPELLINo, Chlébnikov. Saggio, antologia, commento. Torino 1968, S. VIII, XXXIII, XXXVII, XL, LXIf., LXX-LXXII, LXXIXf., LXXXII, XCI, 178, 190, 199, 202, 207, 210f., 217, 245, 248f. (Hinweise auf motivische Anklănge). DERS., Tentativo di esplorazione del continente Chlébnikov." In: DERS., Saggi in forma di ballate, Torino 1978, S. 78, 99f., 106f., 124, 132, 134, 140-142, 150. S. MIRSKY, Der Orient im Werk Velimir Chlebnikovs, München 1975, S. 80. E.F. KovruN, A.V. POVELICHINA, "Utes iz budušego'. (Architekturnye idei Velemira Chlebnikova)." In: Techniteskaja Esterika, 1976, 5-6, S. 40-42. DeRs., Dies. (wie Anm. 4). L. KoEHIER, N.F. Fedorov: The Philosophy of Action, Pittsburgh 1979, S. 103-105. A A. URBAN, "Filosofskaja utopija. (Poetiteskij mir V. Chlebnikova)." In: Voprosy Literatury, 1979, 3, S. 155f. DERs., Obraz 
gen Beweise für eine Rezeption, und Fedorovs Name taucht in den bislang zugänglichen Schriften Chlebnikovs nirgends auf, ${ }^{43}$ doch ist bekannt, daB Chlebnikov ein umfassendes Interesse für die naturwissenschaftlichen, philosophischen und künstlerischen Strömungen seiner Zeit hegte und vielseitig belesen war. ${ }^{44}$ Mit Fedorovs Gedanken könnte er bereits um 1909 im 'Turm' von Vjačeslav Ivanov bekannt geworden sein oder durch Pavel Florenskij, den er 1916 in Sergiev Posad aufsuchte, um mit ihm über die 'Gesetze der Zeit' zu diskutieren, ${ }^{45}$ oder aber, gegen Ende seines Lebens, als er im Winter 1921/22 an der Kunsthochschule VChUTEMAS unterkam, an der damals neben Florenskij auch der Fedorov-Anhänger Čekrygin tätig war. ${ }^{46}$

celoveka - obraz vremeni, L. 1979, S. 50. J.C. LANNE, Velimir Khlebnikov, Paris 1983, t. 1, S. 50; t. 2, S. 308, 346. L. HELLER, "Les chemins des artisans du temps: Filonov, Platonov, Hlebnikov et quelques autres..." In: Cahiers du Monde nusse ef soviétique, 25 (1984), S. 361-365, 370. DERS., Vselennaja za predelom dogmy, London 1985, S. 47, 64, 78. C. SOLIVETT, "Azbuka uma' Velimira Hljebnikova." In: Pojmovnik nuske avangarde, 3, Zagreb 1985, S. 228f., 231f. M.JA. Poluakov, "Velimir Chlebnikov. Mirovozzrenie i poetika." In: V. Chlebnikov, Tvorenija, M. 1986, S. 13f., 19. N.[V.] BASMAKova, Slovo $i$ obraz. $O$ tvorteskom mystenii Velimira Chlebnikova. Helsinki 1987, bes. S. 24f., 27f., 55-58, 94, 240. R. GoLDT, Sprache und Mythos bei V. Chlebnikov, Mainz 1987, S. 42f., $87 f$.

Wăhrend sich die genannten Autoren darauf beschrănken, Anklănge und Parallelen aufzuzeigen, und eine Beeinflussung allenfalls vermuten, spricht TolsTAJA-SEGAL (wie Anm. 5), S. 247, von einem "direkten EinfluB der Ideologie Fedorovs auf die Ideen Chlebnikovs. Praktisch alle Grundthemen von Chlebnikovs synthetischem Schaffen [seien] auf Fedorov zurückzuführen: die Themen der Einheit der Menschheit und der Rolle der Binnenkontinente (Asiens), Hunger und Ernăhrungsproblem, die Verdammung der Stadt und der künstlichen Produkte des Fortschritts, die Idee der Raumfahr, das Interesse an den Metamorphosen der Materie, das Problem der Umkehrbarkeit der Zeit, die Einheit von Theorie und Praxis, die Begeisterung für die Archaik (Ahnenkult)." In der Tat finden sich diese Themen (mit Ausnahme der "Umkehrbarkeit der Zeit") - so allgemein formuliert - auch bei Fedorov, zudem aber auch bei vielen Zeitgenossen Chlebnikovs: Antiurbanismus und Fortschrittskritik etwa bei den 'Bauerndichtern' Kljuev, Esenin und Klyzkov sowie in A.V. Cajanovs băuerlicher Utopie; Raumfahrtprojekte bei Ciolkovskij, Brjusov, den Kosmisten und Proletkul't-Dichtern; die Orientierung nach Asien bei den 'Skythen' um Ivanov-Razumnik und bei Kljuev (Belaja Indija) sowie spăter bei den Eurasiern, um nur einige Beispiele zu nennen. Zudem läßt eine genauere Untersuchung der $\mathrm{Be}-$ handlung dieser Themen bei Chlebnikov erhebliche Unterschiede zur Filosofija obšcego dela deutlich werden: so versteht Chlebnikov beispielsweise die "Metamorphosen der Materie" im Sinne der Reinkarnationslehre, was Fedorovs Auffassung völlig zuwiderlăuft (dazu ausführlicher unten).

43 Allerdings ist ein "bedeutender Teil seines literarischen und wissenschaftlichen Nachlasses noch unveroffentlicht." R.V. Duganov, "Poet, istorija, priroda." In: Voprosy Literatury, 1985, 10, S. 130. Siehe auch die Angaben bei R. VROON, Velimir Xlebnikov's Shoner Poems, Ann Arbor 1983, S. $25,33 f$.

44 O.M. Brik zufolge verfügte Chlebnikov über "ein riesiges Wissen und einen sehr scharfen Sinn für die Wirklichkeit." O.M. BRIK, "O Chlebnikove." In: Russian Literature, 9, 1981, S. 60.

45 Uber diesen Besuch berichtet D. PETRovsku, "Vospominanija o Velemire Chlebnikove." In: LEF. Zumal Levogo Fronta Iskussiv. 1923, 1, S. 145-148 (Nachdruck München 1970). - Zu dem noch lange nicht ausreichend erforschten Verhăltnis zwischen Chlebnikov und Florenskij vgl. HAGEMEISTEK (wie Anm. 39), S. 7, 36f. BASMAKOVA (wie Anm. 42), bes. S. 18f., 101-104, 115117, 142f. V.V. BABKoV, "Meždu naukoj i poeziej: 'metabioz' Velimira Chlebnikova." In: Voprosy Istonii Estestvoznanija i Techniki, 1987, 2, bes. S. 144-147.

Siehe unten Anm. 131. 
Hinzu kommen Anzeichen, die auf eine gewisse Wesensverwandtschaft zwischen Chlebnikov und Fedorov deuten: Beide galten als kauzige Sonderlinge, als cudaki; beide suchten ihre Herkunft zu verschleiern (was zur Bildung von Legenden führte); beide waren zeitlebens arm, haßten Geld und trugen zumeist abgerissene Kleidung. ${ }^{47}$ Chlebnikovs Werk ist, wie das Fedorovs, fragmentarisch - Notizen und Verse schrieb er auf Zettel, die er gerade zur Hand hatte und die er dann in einen Sack stopfte. Die Verbreitung seiner Schriften überließ er Freunden, was zur Folge hatte, daß der gröBte Teil seines Werkes erst postum erscheinen konnte (ein Teil des Nachlasses ist noch unveröffentlicht; viele Manuskripte gelten als verloren). Wie Fedorov befaBte sich Chlebnikov mit utopisch anmutenden Projekten, die dem Wohl der Menschheit dienen sollten: Er erforschte die 'Gesetze der Zeit', versuchte auf der Grundlage eigenwilliger mathematischer Berechnungen Voraussagen über das Weltgeschehen zu treffen, um schließlich Vergangenheit und Zukunft "durchsichtig" (prozrąnyj) werden zu lassen, er arbeitete an der Entwicklung einer Universalsprache, um die Menschheit zu einen und die "Geißel des Krieges" zu verbannen, und bemühte sich um die Lösung des Ernährungsproblems, indem er vorschlug, das Wasser planktonreicher Seen zum Kochen zu bringen und daraus eine Suppe zu machen, die jedermann zugänglich sei. ${ }^{48}$

In Chlebnikovs Dichtung finden sich Bilder einer idealen Zukunftswelt, in der Mensch und Natur miteinander versöhnt sind, Geld keine Macht mehr besitzt und Freiheit und brüderliche Eintracht unter allen Kreaturen herrschen ("Ich sehe die Freiheit der Pferde / Und die Gleichberechtigung der Kühe") ${ }^{49}$.

47 "Chlebnikov hatte nie eine Kopeke, nur eine Garnitur Wassche, zerrissene Hosen und statt eines Kissens einen Uberzug, der mit Manuskripten vollgestopft war." Lili Briks Beschreibung, zitiert nach L.N. STEPanov, Velimir Chlebnikov. Žizn' i mortestvo. M. 1975, S. 155, k8nnte auch Fedorov gegolten haben. Siehe 2.B. "'Proroxeskaja dußa.' V. Chlebnikov v vospominanijach sovremennikov." In: Literatumoe Obozrenie, 1985, 12, S. 93-104; viele der dort geschilderten Eigenheiten werden auch von Fedorov berichtet.

48 Vgl. V.V. Manakovsku, "V.V. Chlebnikov." In: Majakovsku (wie Anm. 19), t. 12 (1959), S. 23-28. VEL. (wie Anm. 42), S. 21. JU.K. OLESA, Izbrannye soxinenija, M. 1956, S. 447f. URBAN, Obraz celoveka (wie Anm. 42), S. 49-80. - Der letztgenannte Vorschlag findet sich in Sojuz izobretaselej [1918]. CHLEBNIKOV (wie Anm. 42), S. $615 f$.

49 So in dem 1920 entstandenen utopischen Poem Ladomir. CHLEBNikov (wie Anm. 42), S. 289. In der Utopie Lebedija budušcego (1918/19) heißt es: "Es wurde die Vorschrift erlassen, daB kein einziges Tier verschwinden dürfe" - und in der Utopie Utes iz buduscego (1921/22): Tieren und Pflanzen wurde ihr Recht auf Leben zurückgegeben, ein herrliches Geschenk. Auch wir sind wieder glücklich: Ein Löwe schlăft auf meinen Knien..." (ebd., S. 615, 567).

Mirsky (wie Anm. 42), S. 81-83, führt diese Vorstellungen auf die Lehre Buddhas zurück, mit der Chlebnikov sich eingehend befaBt hatte; sie konnten aber auch von den utopischen Idyllen der Frühsozialisten - etwa Ch. Fouriers "Theorie des quatre mouvements" (1808) - angeregt sein. Gleiche Gedanken einer Befreiung und Hoherentwicklung der Tiere finden sich etwas spăter auch in den naturphilosophischen Gedichten N.A. Zabolockijs, die wahrscheinlich unter Chlebnikovs EinfluB entstanden sind. Ausführlich dazu D. Goldstrin, In Pursuit of Harmony: The Long Poems of Nikolaj Zabolockij, Ph.D. diss. Stanford 1982; Ann Arbor 1983, Kap. 6: S. 161-209; zu Fedorov bes. S. 175. Vgl. ferner URBAN, Obraz celoveka (wie Anm. 42), S. 91-101. SEMENOVA (wie Anm. 11), bes. S. 148f. - Hinweise auf Fedorov sind in diesem Zusammenhang 
In dieser idealen Welt würde auch der Tod seinen Schrecken verlieren ${ }^{50}$ - ein Gedanke, der das Bild idealer Zukunft bei Chlebnikov begleitet und von einigen Interpreten mit Fedorov in Verbindung gebracht wurde. ${ }^{5 f}$

Eine genauere Untersuchung zeigt indessen, daß Chlebnikovs Vorstellung von einer Lösung des Todesproblems mit dem Projekt des obšcee delo nichts gemein hat, ja ihm geradezu entgegengesetzt ist. Sie beruht, wie inzwischen nachgewiesen wurde, auf einer "eigenartige[n] Synthese von wissenschaftlichem Denken und dem Glauben an die buddhistische bzw. hinduistische Lehre von der Reinkarnation. ${ }^{\text {} 52}$ Chlebnikov war überzeugt, da $B$ das Leben des einzelnen

allerdings unangebracht. So ist es beispielsweise abwegig, Chlebnikovs Vorstellungen von einer künftigen "Brüderlichkeit aller Lebewesen" oder von der Natur als "Weltorganismus" in die Năhe Fedorovs zu rücken. BASMAKova (wie Anm. 42), S. 94. Scharf unterscheidet Fedorov zwischen dem "einzig vernunftbegabten Wesen auf Erden" und dem "Reich der Tiere" als einer "Karikatur" oder "Parodie" des Menschen (FOD I, S. 344f.); Ziel ist für Fedordov die Beherrschung der Natur durch den Menschen und ihre Verwandlung in ein Kunstwerk unter Beseitigung alles Organischen.

50 Chlebnikov (wie Anm. 42), S. 283.

51 Markov (wie Anm. 42), S. 148, und - ihm folgend - Mirsky (wie Anm. 42); ferner Solivetrn (wie Anm. 42), S. 228f. - Markovs Interpretation von Ladomir stieß bei sowjetischen Forschern auf heftige Kritik: Statt einer "Verkorperung der religios-philosophischen Ideen Fedorovs" handele es sich um "eine dichterische Vorausschau der kommunistischen Zukunft". A.L. GRIGOR'EV, Russkaja literatura v zanubetnom literaturovedenii, L. 1977, S. 167; ahnlich auch STEPANOV (wie Anm. 47), S. 189-196. Den naturphilosophischen Gehalt von Ladomir, insbesondere die Vorstellung einer 'Wiedergeburt', 'Auferstehung', 'Resurrektion' der Natur, die eher an Fourier und an den jungen Marx als an Fedorov erinnert, untersuchte unlăngst Duganov (wie Anm. 43), bes. S. 147-156.

52 Mirsky (wie Anm. 42), S. 80. Vgl. auch Stepanov (wie Anm. 47), S. 196. - Zu Chlebnikovs Interesse an Indien und an der Reinkarnationslehre vgl. auch V.V. IVANOV, "Kategorija vremeni v iskusstve i kul'ture XX veka." In: Structure of Texts and Semiotics of Culture, The Hague, Paris 1973, S. 105f. DERS., "Struktura stichotvorenija Chlebnikova 'Menja pronosjat na slonovych...:" In: Trudy po znakovym sistemam, 3, Tartu 1967, S. 156-171. Ivanovs Angaben zufolge kannte Chlebnikov den ersten Band eines umfangreichen Werkes über den Buddhismus, das aus der Feder von V.A. Koževnikov stammte, des engen Vertrauten von Fedorov. Ebd., S. 163; siehe auch I: 1. Anm. 59.

Mit der Idee einer zyklischen Wiedergeburt und dem Vordringen in höhere Dimensionen konnte Chlebnikov auch durch die Schriften der (russischen) Theosophen und Esoteriker (v.a. P.D. Uspenskijs Cervenoe izmerenie [1909] und Tertium Organum [1911] sowie A.N. Smidts Tretij zavet [1916]) vertraut geworden sein. Uber den EinfluB dieser Strömungen auf die russische Avantgarde (insbesondere auf Malevix) liegen mittlerweile mehrere gründliche Untersuchungen vor. Vgl. Henderson (wie Anm. 38), Kap. 5 (S. 238-299). Dies., The Merging of Time and Space: The 'Fourth Dimension' in Russia from Ouspensky to Malevich." In: Soviet Union / Union Soviétique, 5 (1978), 2, S. 171-203. Willums (wie Anm. 9), S. 101-127. Ferner die Beitrăge von J.E. Bowl, CH. Douglas, L.D. HENDERSON, E. KASINEC und B. KERDIMUN in: The Spiritual in Ant: Abstract Painting 18901985, Los Angeles, New York 1986. Dagegen freilich wenig kompetent und überzeugend - R. CRONE, "Zum Suprematismus - Kazimir Malevið, Velimir Chlebnikov und Nicolai [sic] Lobaלesvskij." In: Wallmaf-Richantz-Jahrbuch, 40 (1978), S. 129-162; bes. S. 141, 144f., 147, 158. Zum gesamteuroparischen Kontext siehe auch die anregende Studie von F.W. FischER, "Geheimlehren und moderne Kunst. Zur hermetischen Kunstauffassung von Baudelaire bis Malewitsch." In: Fin de siecle. Literatur und Kunst der Jahrthundertwende. Frankfurt/M. 1977, S. 344-377. 
ebenso wie die Natur und die Geschichte der Menschheit zyklischen Rhythmen unterworfen sei, deren Phasen sich als "Gleichungen des Schicksals" genau berechnen ließen. ${ }^{53}$ Tod und Wiedererstehen seien somit nichts Zufälliges, sondern gehorchten den berechenbaren 'Gesetzen der Zeit'. Der Gedanke, die 'Gesetze der Zeit' zu suchen, sei ihm, so Chlebnikov, erstmals im Mai 1905, am Tage nach der Seeschlacht bei Tsushima gekommen: Er habe damals "eine Rechtfertigung für jene Tode finden" wollen. ${ }^{54}$ Über das Ergebnis seiner Bemühungen schreibt er 1917 an G.N. Petnikov: "... der Sieg über die Zeit wird erreicht durch die Reduktion und Übertragung des Bewußtseins bei der zweiten Wiedergeburt. Wir beabsichtigen zu sterben in Kenntnis der Sekunde unserer zweiten Geburt. ${ }^{.55}$ Bereits in dem 1916 entstandenen Fragment Otryvok iz p'esy hatte Chlebnikov angedeutet, daß sich der Zeitpunkt des Todes und der Wiedergeburt genau berechnen lasse. ${ }^{56}$ Ausführlich ging er darauf in seiner 1920 entstandenen Schrift Naša osnova ein:

Heute kann man, dank der Auffindung der Welle des Geburtenstrahls (volna luča rożenija), allen Ernstes sagen, daß in einem bestimmten Jahr ein Mensch geboren werden wird, sagen wir ein 'Jemand', mil einem Schicksal, das dem Schicksal dessen gleicht, der 365 Tage vor ihm geboren wurde. Auf diese Weise wird sich auch unser Verhăltnis zum Tode ăndern; wir stehen an der Schwelle zu einer Welt, in der wir Tag und Stunde wissen, da wir wiedergeboren werden, und den Tod als ein zeitweiliges Baden in den Wellen des Nichtseins betrachten. ${ }^{57}$

In diesem Zusammenhang ist bemerkenswert, daB Fedorovs Lehre (trotz des ihr bisweilen nachgesagten mystischen Charakters) keinerlei Resonanz unter den russischen Okkultisten, Spiritisten und Esoterikern hervorgerufen hat. Erst in den sechziger Jahren weist der Esoteriker Boris Murav'ev, ein Schüler Uspenskijs, gelegentlich auf Fedorov hin. B. MouraviefF [MURAV'EV], Gnosis, étude et commentaires sur la tradition ésotérique de l'orthodaxie orientale, t. 1, Paris 1961 , S. 294; t. 2, Paris 1962, S. 189.

53 Nur wenig spăter begann der Biophysiker A.L. Čiževskij mit der Erforschung des Einflusses der zyklisch schwankenden Sonnenaktivităt auf das irdische Leben und die Geschichte der Menschheit; siehe z.B. A.L. CiŻEVSKU, Zemnoe ècho solneznych bur, M. ${ }^{2} 1976$.

54 V. Chlebnikov, "Otryvok iz dosok sud'by." [1922]. In: DeRS., SS, 3, München 1972, S. 472; Hervorhebung von mir; M.H.

55 V.V. Chlebnikov an G.N. Petnikov, Anfang 1917 (?). In: Chl.EBnikov (wie Anm. 54), S. 314.

56 ChLEbikov (wie Anm. 54), S. 142.

57 Chlebnikov (wie Anm. 42), S. 631. - Vgl. auch Vel. (wie Anm. 42), S. 21f., der dieses Zitat mit Fedorov in Verbindung bringt. Tatsáchlich zeigt sich hier jedoch ein Gegensatz: Wăhrend bei Fedorov die Zeit am Ende (wenn alle auferweckt sein werden) zum Stillstand kommt, 'besiegt wird' und sich gleichsam verrăumlicht, ist die Wiedergeburt bei Chlebnikov an die lineare Fortdauer der Zeit gebunden. Siehe VA. AL'FONsov, "Čtoby slovo smelo poslo za Zivopis'ju' (V. Chlebnikov i živopis')." In: Literatura i zivopis', L. 1982, S. 206f. - Der Gedanke einer zyklischen Wiedergeburt (statt einmaliger Auferweckung) liegt wohl auch jenen Zeilen in Chlebnikous Gedicht $O$ swobode zugrunde, die lauten: "Wir werden zu Erde - wir werden wiedererstehen, / Ein jeder wird wieder lebendig werden!" (Stanem zemleju - voskresnem, / Každyj potom oživet!). ChLEBNIKov (wie Anm. 42), S. 112; das Gedicht ist 1918 entstanden, 1922 verăndert. 
Chlebnikovs 'Wissenschaft', seine eigenartigen mathematischen Konstruktionen, die von ihm durchaus ernst gemeint waren und die er kurz vor seinem Tod in den "Tafeln des Schicksals" (Doski sud'by) darlegte, dienten also nicht der Bekämpfung und Abschaffung des Todes, sondern seiner Berechenbarmachung, seiner 'Entschleierung': "Die Zahl hilft, den Schleier des Geheimnisses vom Antlitz des Todes zu reißen (den Tschador des Todes). ${ }^{58}$ Dabei wurde der Tod als Naturgesetz akzeptiert ${ }^{59}$ und durch den Nachweis einer zyklischen Wiedergeburt verharmlost. ${ }^{60}$

Auch in der Bewertung der Technik unterscheidet sich Chlebnikov von Fedorov. In einem Brief an M.V. Matjušin von 1913 heißt es: "Wenn die Schwerkraft vieles lenkt, dann sind Luftfahrt und relative Unsterblichkeit (otnositel'noe bessmertie) miteinander verbunden. ${ }^{61}$ Das Motiv des Fliegens und Schwebens wird hier allenfalls zur Auferstehungsparabel; von einer realen Überwindung des Todes mit Hilfe der Technik ist nicht die Rede. In der 1909 entstandenen Dichtung Žuravl' zeichnet Chlebnikov die apokalyptische Vision einer entfesselten Technik, eines 'Aufstandes der Dinge', die sich mit den ihren Gräbern entstiegenen Toten gegen die Menschen verbinden. ${ }^{62}$ Die Vermutung, dieses Bild

58 Chlebnikov, zitiert nach V.V. Ivanov, "Chlebnikov i nauka." In: Puti v neznaemoe, M. 1986, S. 394.

59 In einer (besonders knappen) Formulierung des von ihm 'entdeckten' "Grundgesetzes der Zeit" machte Chlebnikov den Tod sogar zum Faktor für Harmonie: " $3^{n}$ - Tod, $2^{n}$ - Leben, $3^{n} \cdot 2^{n}$. Harmonie..." (aus Chlebnikovs unveroffentlichtem NachlaB in CGALI, f. 527; zitiert bei V.P. GRIGOR'EV, Grammatika idiostilja. V. Chlebnikov. M. 1983, S. 146).

60 Ähnliche Vorstellungen finden sich - wahrscheinlich beeinflußt durch den Theosophenkreis seiner Heimatstadt Kaluga - bei Ciolkovskij: Der Tod verlien seinen Schrecken durch die Einsicht, daß es sich beim Entstehen und Vergehen des Lebens um bloße Metamorphosen der unvergănglichen Materie handelt. "Das Atom ist immer lebendig und immer glücklich, trotz der - absolut gesehen - riesigen Unterbrechungen des Nichtseins oder des Seins im anorganischen Zustand. Für die Toten gibt es keine Zeit, sie zăhlt nicht. Da aber eine neue Verkörperung [roplošenie] notwendig stattfindet, ... so fließen alle diese Verkörperungen subjektiv zu einem einzigen, subjektiv-ununterbrochenen, herrlichen und unendlichen Leben zusammen." K.E. ClOLKovsKU, Monizm Vselennoj [1925]; hier nach DERS., Grezy o zemle i nebe. Nautnofantasticeskie proizvedenija. Tula 1986, S. 292. - Weitere Gemeinsamkeiten zwischen Chlebnikov und Ciolkovskij erwăhnt G.S. GoR, "Zamedlenie vremeni." In: Zvezda, 1967, 4, S. 189.

Das Thema der Seelenwanderung behandelt Chlebnikov in der 1915 entstandenen surrealistischen Erzăhlung $\mathrm{Ka}$ (gemeint ist die Seele nach altăgyptischer Vorstellung: ein Doppelgănger im Jenseits). Vgl. zum selben Thema FOD II, S. 228-235. Zu Chlebnikovs lebenslangem Interesse am Problem der Zeit, ihrer GesetzmäBigkeit und Beherrschbarkeit, vgl. Ivanov, "Kategorija vremeni..." (wie Anm. 52), S. 103-107. DUganov (wie Anm. 23), S. 419-430. Ders. (wie Anm. 43), bes. S. 139-141. E. ARENZON, "K ponimaniju Chlebnikova: nauka i poezija." In: Voprosy Literatury, 1985, 10, S. 163-169. GRIGOR'EV (wie Anm. 59), S. 46, 117, 119-130, 165.

61 V.V. Chlebnikov an M.V. Matjusin, 18.6.1913. In: V. ChLEBNIKoV, Neizdannye proizvedenija, M. 1940, S. 365 (Nachdruck München 1971). - An anderer Stelle findet sich märchenhaftphantastisch der Gedanke einer Vereinigung aller Volker mit Hilfe der Fliegerei ( $O$ pol'ze izucenija skazok [1915]). CHLEBNIKOV (wie Anm. 42), S. 594f.

ChILEBnikov (wie Anm. 42), S. 189-192. 
könne von Fedorov angeregt sein, ${ }^{63}$ ist wenig plausibel; zu sehr widerspricht die Vorstellung einer Kapitulation des Lebens vor dem "Bund der Leiche und des Dinges ${ }^{164}$ dem Projekt des obšcee delo: Fedorovs Vision einer Auferweckung der Toten weist durchaus keine dämonischen Züge auf. Für das Motiv des 'Aufstandes der Dinge' und der Auferstehung der Toten gibt es hingegen zahlreiche Belege in der zeitgenössischen Literatur. ${ }^{65}$

In einem Bereich allerdings entwickelte Chlebnikov Gedanken, die bis zu einem gewissen Grade denen Fedorovs verwandt sind. ${ }^{66}$ Wie Fedorov sah auch er in der Vielfalt der menschlichen Sprachen eine der Ursachen für Trennungen und Feindschaft und damit ein Hindernis auf dem Weg zur erstrebten friedlichen Vereinigung der Menschheit. Früher, "als die Wörter Feindschaft zerstörten $^{n 67}$, habe Sprache die Menschen vereint; jetzt aber, "da sie ihre Vergangenheit verraten haben", dienten die verschiedenen (National-)Sprachen der "Sache der Feindschaft" und führten zur "Desintegration der Menschheit" (raz-edinenie Celove`estva) ${ }^{68}$. Chlebnikov plädiert deshalb für die Schaffung einer globalen Einheitssprache, denn, so fragt er, "was ist besser, eine Weltsprache oder ein Weltkrieg?" ${ }^{69}$ Dabei dachte er zunächst an eine "panslavische Sprache ${ }^{m 70}$ im Sinne von Juraj Križanić oder an eine "gemeinsame, wissenschaftlich aufgebaute Schriftsprache der Arier ${ }^{m 71}$, doch sah er die Lösung schließlich - ähnlich wie Fedorov - in der Schaffung einer "allgemeinen Schrift-Sprache" (obšcij

63 INGOLD (wie Anm. 9), S. 164. - Vgl. auch - ohne Hinweis auf Fedorov - Ders., "Zur Komposition von Chlebnikovs Kranich-Poem ('Zuravl")." In: Schweizerische Beitrüge zum VIII. Intemationalen Slavistenkongress in Zagreb und Ljubljana, September 1978, Bern 1978, S. 59-76. STEPANOV (wie Anm. 47), S. $97 f$.

64 ChI Ebnikov (wie Anm. 42), S. 191. Die Verse lauten: "Da geschah der Umsturz. Das Leben übergab die Macht / dem Bund der Leiche und des Dinges."

65 Hingewiesen sei auf Brjusovs Erzählungen Vosstanie mašin (1908) und Mjateż mašin (1915), auf M.A. Vološins Artikel "Bunt mašin" (in: Moskovskaja gazeta, 111, 20.9.1911, S. 2) sowie auf die belebten Maschinen-Monstren in den expressionistischen Prosastücken und Gedichten von A.K. Gastev (an Chlebnikovs Zuravl' erinnert insbesondere Gastevs "Kran" in: A.K. GASTEv, Poezija rabox'ego udara, Pg. 1918, S. 91-93). Majakovskijs Tragödie Vadimir Majakovskij trug ursprünglich den Titel Vosstanie vešej. Die Reihe der Beispiele ließe sich fortsetzen.

66 Vgl. zum folgenden Mirsky (wie Anm. 42), S. 59-66. A.A. HANSEN-LOVE, Der russische Fomalismus, Wien 1978, S. 115-119. GRIGOR'EV (wie Anm. 59), bes. S. 74-83. GoldT (wie Anm. 42), S. 87f. Auf Analogien in Chlebnikovs Konzept einer Universalsprache und den Gedanken Fedorovs haben bislang nur Grigor'ev und Goldt hingewiesen.

67 Dieses und die folgenden Zitate aus "Chudožniki mira!" [1919] In: CHL EBNIKov (wie Anm. 42), S. 619-621.

68 Für Fedorov ist die Sprachenverwirnung als Zeichen der Entfremdung eine Folge des Vergessens der Pflicht gegenüber den Vătern (FOD I, S. 253).

69 "Iz zapisnych knižek." In: V.V. Chlebnikov, Sobranie proizvedenij, t. 5, L. 1933, S. 266 (Nachdruck München 1972).

70 V.V. Chlebnikov an V.I. Ivanov, 31.3.1908. In: CHLEBNIKov (wie Anm. 47), S. 354.

71 "Predloženija." [1915/16] In: ChLEBNikov (wie Anm. 69), S. 157. 
pis'mennyj jazyk) ${ }^{72}$ sowie in der Rekonstruktion der "Ur-Sprache" (pra-jazyk) mit Hilfe des korneslovie, d.h. der (von Chlebnikov als wissenschaftlich verstandenen) Reduktion aller "homophonen Worte bzw. Wurzeln auf 'Urwurzeln'"73. Die so rekonstruierte "Universalsprache würde die Grenzen der Nationalsprachen ebenso aufheben wie die zwischen ihren Benützern, da - nach der Vorstellung Chlebnikovs - in der Universalsprache (dem 'vselenskij jazyk') die universellen Gesetzmäßigkeiten des gesamten Kosmos im Redeakt wirksam werden $^{\text {74 }}$. Im Unterschied zu den weitaus meisten Vorschlägen zur Schaffung einer Universalsprache, ${ }^{75}$ ging es Chlebnikov nicht um eine mehr oder minder willkürliche Neuschöpfung, sondern um die Erforschung und Wiederherstellung eines als ursprünglich und universal angenommenen Sprachzustandes. Auf demselben Weg wollte auch Fedorov zu einer die Menschheit vereinenden Universalsprache (vsečelovečeskaj, vsenarodnyj jazyk) gelangen:

... damit diese Vereinigung [der Menschen] weltweit ist, bedarf es einer Vereinigung in der Sprache aller Volker, jedoch nicht in einer künstlichen Sprache wie Volapük, sondern in einer natürlichen Sprache, d.h. der urvăterlichen (jazyk praoteceskij). Die Linguistik, die Wissenschaft, die alle Sprachen erforscht, kann keine andere Anwendung erfahren als die Ausarbeitung einer allgemeinen Sprache für alle Volker. Gegenwartig gibt es den Etymologen (komeslov) für die Sprachen arischer Abstammung, es wird aber den Etymologen für alle Sprachen geben [müssen]. Infolge der allgemeinen Bildungspflicht wird sich die Erforschung der Wortwurzeln überallhin erstrecken; und das Stu-

72 "Chudožniki mira!" In: ChLEBNIKov (wie Anm. 42), S. 621. - In diesem Essay beschreibt Chlebnikov "Aussichten auf das allgemeinmenschliche Alphabet" (obšeželovereskaja azbuka), das aus Schriftzeichen besteht, die allen Menschen verständlich sind. Eine solche allgemeine "Schrift-Sprache" würde zum "Sammler des Menschengeschlechts" (sobiratel' celoveceskogo roda) werden. Dies erinnert an Fedorovs Ausführungen uber Ideogramme und Hieroglyphen als 'belebte Schrift' (Zivopis') (vgl. FOD I, S. 25; II, S. 223) sowie an die kalligraphischen und typographischen Experimente der Futuristen; siehe oben Anm. 7 und RIPELLINO (wie Anm. 42), S. LXI-LXIV. - Im Zusammenhang damit stehen Versuche zu Beginn der zwanziger Jahre, eine 'universale Sprache der Kunst' zu schaffen: Chlebnikovs enger Freund P. Mituriz entwikkelte ein 'graphisches Alphabet', und P.A. Florenskij begann damit, ein Lexikon der universalen graphischen Symbolsprache der Menschheit zusammenzustellen. Siehe N. LAPSIN, "Chlebnikov - Mituric." In: Russkoe Iskusstvo, 1923, 2-3, S. 99-101. EA. NEKRASOVA, "Neosuscestvlennyj zamysel 1920-ch godov sozdanija 'Symbolarium'a' (Slovarja simvolov) i ego pervyj vypusk Tocka'." In: Pamjatriki kul'tury. Norye otkrytija. Ežegodnik 1982. L. 1984, S. 99-115. HAGEMEISTER (wie Anm. 39), S. 13, 44.

73 HaNSEN-LOVE (wie Anm. 66), S. 117.

74 Ebd., S. 116.

75 Vgl. etwa die universalsprachlichen Theorien und Entwürfe des 17. und 18. Jahrhunderts (Francis Bacon, Descartes, Leibniz); einen guten Úberblick gibt E.K. DREZEN, Za useobscim jazykom, M.-L. 1928. Chlebnikovs Interesse für Descartes und besonders für Leibniz ist nachgewiesen. GRIGOR'EV (wie Anm. 59), S. 77. - Von Chlebnikovs Zeitgenossen propagierte beispielsweise K.E. Ciolkovskij die Schaffung einer künstlichen Einheitssprache als Mittel zur Wiederherstellung der ursprünglichen Einheit der Menschheit. Vgl. K.E. CloLKovsKu, Obrazovanie zemli $i$ solnetnych sistem, Kaluga 1915. DERS., Obšij alfavit $i$ jazyk, Kaluga 1915. Hier nach M.S. ARLAzorov, Ciolkovskij, M. ${ }^{2}$ 1963, S. 287. Dagegen vertrat Stalin (in Anlehnung an N.Ja. Marr) die Ansicht, die gemeinsame Sprache der kommunistischen Gesellschaft werde sich durch Kreuzung und Verschmelzung der Nationalsprachen herausbilden. Siehe 2.B. I.V. Staun, "Die nationale Frage und der Leninismus." [1929] In: Ders., Werke, Bd. 11, Berlin 1954, S. 312. 
dium der eigenen und fremder Sprachen wird zu der Erkenntnis dessen führen, was in ihnen gemeinsam, verwandt und urvăterlich ist. Bereits in der Fibel werden Lautgruppen und Silben durch die gemeinsamen Wurzeln ersetzt, wodurch sie von selbst verstăndlich werden. ${ }^{16}$

Die auf diese Weise geschaffene Universalsprache der Brüder würde sich, so Fedorov, im gemeinsamen Bemühen um das obš̌ee delo immer mehr der Sprache der Väter (vor der babylonischen Sprachverwirrung) annähern und schließlich mit ihr zusammenfallen. 77

Ob Chlebnikov bei seinen - im übrigen sehr vielfältigen - Entwürfen einer Universalsprache ${ }^{78}$ von Fedorovs Überlegungen beeinflußt worden ist, läßt sich nicht nachweisen. Vielleicht vermögen weitere Veröffentlichungen aus dem umfangreichen Nachla $B$ Chlebnikovs sowie die inzwischen verstärkt betriebene $\mathrm{Er}$ forschung seines Werks darüber einmal Aufschluß zu geben. Beim gegenwärtigen Stand der Forschung müssen freilich alle Versuche, Chlebnikov in die Tradition Fedorovs zu stellen, als unbegründet angesehen werden. ${ }^{79}$

\subsubsection{K.S. Malevix}

Zweifelhaft ist Fedorovs Einfluß auch im Falle des Malers, Architekten und Kunsttheoretikers K.S. Malevic (1878-1935). Wiederholt wurden Malevǐ̌s architektonische Utopien - seine Entwürfe schwebender Wohnanlagen, bemannter Orbitalstationen und interplanetarer Raumschiffe - mit Fedorov in Verbindung gebracht. ${ }^{80}$ Bereits 1913 hatte Malevix von einer Zeit geträumt, "da große

76 FOD I, S. 367; Hervorhebung im Orig. - Dieselbe Passage findet sich mit geringfügigen Abweichungen auch in Fedorovs Schrift "C to takoe dobro?" In: Put', 40, 1933, S. 10f. Vgl. auch FOD I, S. 253-256 und S. 348f.: "Man muB die Urvătersprache studieren, um in einer einzigen Bridersprache zu sprechen; (...) Die Entdeckung der gemeinsamen Wurzeln aller Sprachen der arischen Familie konnen wir mit vollem Recht als philologische Auferstehung bezeichnen." (Hervorhebung im Orig.) Nun gelte es, ein "Lexikon der Wurzeln aller Sprachen" zu erstellen (FOD I, S. 256).

77 FOD I, S. 367.

78 "Chlebnikov entwickelte nie eine kohärente, konsequent durchgeführte Theorie der 'einen Weltsprache', sondern beschäftigte sich vielmehr mit mehreren Möglichkeiten zur Verwirklichung dieses Ideals..." MIRSKY (wie Anm. 42), S. 60. Hier wurde nur diejenige vorgestellt, die der Fedorovs gleicht.

79 S. KALmYKov [d.i. S.B. DŹIMBINOV], "V poiskach 'zelenoj palocki'. In: Veðnoe solnce. Russkaja social'naja utopija i naužnaja fantastika vtoroj poloviny $X I X$ - nazala $X X$ veka. M. 1979, S. 36. Dagegen GRIGOR'EV (wie Anm. 59), S. 32.

80 E.F. Kovtun, "K.S. Malevic. Pis'ma k M.V. Matjuß̌inu." In: EŽegadnik rukopisnogo oldela Puskinskogo doma na 1974 god, L. 1974, S. 183 (dass. franz. E. KovTouNE, "Introduction à la publication des lettres de Malevitch à Matiouchine." In: Malevitch 1878-1978. Actes du colloque intermational. Lausanne 1979, S. 176). DERS., Povelichina (wie Anm. 42). DERS., "Kazimir Malevich." In: Ant Joumal (wie Anm. 1), S. 236. M.E. ARCHANGEL'SKI, "Maleviz, dejstvitel'nost' i kul'tura." In: Gnozis, 1978, 3-4, S. 32-69; zu Fedorov und Malevix S. 41-47. Ju.V. LINNIK, "Kosmiðeskij dizajn Kazimira Malevica." In: Komsomolec [Petrozavodsk], 18.2.1989, S. 8. 
Städte und die Ateliers moderner Künstler an riesigen Zeppelinen hängen wer$\operatorname{den}^{m 81}$. Zu Beginn der zwanziger Jahre schlug er vor, die "neuen Behausungen der neuen Menschen ${ }^{\text {n82 }}$ in den Weltraum zu verlegen:

Die Erde wird für sie [die neuen Menschen] zu einer Zwischenstation, und dementsprechend müssen Flugplătze angelegt werden ... Die provisorischen Behausungen der neuen Menschen müssen sowohl im Weltraum als auch auf der Erde den Aeroplanen angepaBt sein. ${ }^{83}$

Schwebende Planiten [planity, von russ. aeroplan] werden den neuen Plan der Städte und die Form der Hăuser der 'Semljaniten' [zemljanity, etwa 'Erdbewohner'] bestimmen. ${ }^{84}$

In einer 1920 erschienenen programmatischen Schrift entwarf Malevið den Bau eines "neuen suprematistischen Trabanten" (novyj sputnik suprematiceskij), der sich in einem Orbit zwischen Erde und Mond bewegen sollte; auch war die Rede von interplanetaren Flügen und einer Besiedlung des Weltalls. ${ }^{85}$ Die genannten Projekte erinnern zwar an Fedorov, ${ }^{86}$ doch sind die Anklänge so allgemein und vage, daß sie als Nachweis einer Beeinflussung nicht ausreichen. ${ }^{87}$

Bereits 1974 hatte Bowlt festgestellt, Malevils architektonische Konstruktionen erinnerten an die "technologischen Utopien" Fedorovs. D.E. Boult [J.E. BowLT], "Kazimir Maleviz: ego putešestvie v bespredmetnyj mir." In: Russkaja Mysl', 2991, 21.3.1974, S. 8. Dem widersprach mit aller Entschiedenheit Chardžiev: Malevið habe sich nie für Fedorov interessien. N.I. ChARDŹIEv, "Detstvo i junost' Kazimira Maleviza." In: $K$ istorii nusskogo avangarda (wie Anm. 7), S. 89 (dass. fanz. N. KHARDJIEV, "En giuse d'introduction à l'Autobiographie de Malevitch." In: Malevitch 1878-1978, a.a.O., S. 143). Bowlt gab daraufhin in einer Rezension des Aufsatzes von Chardžiev (in: Slavic Review, 37, 1978, S. 353) zu bedenken: "When many (!) members of the avant-garde such as Chekrygin, Punin and Tatlin were discussing the ideas of Nikolaj Fedorov, why assume that Malevich 'was never interested in him'?" - Nun trifft aber Bowlts Behauptung (die im Falle Malevits nichts beweist) nachweislich nur auf Cekrygin zu (über ihn und Punin unten 3.2.4.); von einer Beschäftigung Tatlins oder anderer Avantgardisten - genannt wird noch der Maler Pavel Filonov - mit Fedorovs Ideen ist nichts bekannt. Zu Filonov, einem Vertreter des "utopisch-religiösen Kommunismus", der "genetisch verbunden [sei] mit den Ideen N.P. [sic] Fedorovs" siehe N.N., "Pavel Filonov (1883-1941)." In: $A$ - Ja, 2, 1980, S. $35,37,40$.

81 K.S. Malevic an M.V. MatjuŠin, 9.5.1913; zitiert nach Kovtun, "Maleviz..." (wie Anm. 80).

82 [K.S. MALEVIC], "Suprematistisches Manifest Unowis." [1924]. In: K. Malewtrsch [MALEVIC], Suprematismus - die gegensiandslose Welt, Koln 1962, S. 285.

83 Ebd.

84 [K.S. MALEVIC], "Suprematismus I/46." [1923]. Ebd., S. 274. - Zu Maleviłs Idee der "kosmischen Stadt" siehe auch S.O. Chan-Magomedov, Pioniere der sowjetischen Architektur, Wien, Berlin 1983, S. 282.

85 K.[S.] MALEVIC, Suprematizm. 34 risunka. Vitebsk 1920, S. 1. (Eine deutsche Übersetzung dieser sehr seltenen Schrift erschien in: L.A. SHADOWA [Z̈ADOVA], Kasimir Malewitsch und sein Kreis, München 1982, S. 284-287; hier S. 284f.).

$86 \mathrm{Zu}$ Fedorovs 'nebesnaja archirektura' vgl. FOD II, S. 248-253, 350.

87 Bei der Suche nach Vorbildern für die architektonischen Utopien der russischen Avantgarde müBte auch - was bislang nicht geschehen ist - der mögliche EinfluB des Symbolismus berücksichtigt werden. Zu verweisen wăre etwa auf die kühnen "architectures aériennes", schwebende Metallkonstruktionen und hochstrebende Türme, die bereits gegen Ende des 19. Jahrhunderts die imaginären Stadtlandschaften Rimbauds und Moreaus prägten. Dazu L. FORESTIER, 


\subsubsection{V.N. Čeknygin}

Der einzige Vertreter der russischen Avantgarde, der sich nachweislich mit Fedorovs Werk auseinandergesetzt hat und intensiv von ihm beeinflußt wurde, ist der früh verstorbene Maler und Kunsttheoretiker Vasilij Nikolaevið Čekrygin. ${ }^{88}$

"Symbolist Imagery." In: The Symbolist Movement in the Literature of European Languages, Budapest 1982, S. $111 \mathrm{f}$.

Die Idee einer architektonischen Uberwindung der Schwerkraft (Luftstraßen, fliegende Gebăude) begegnet auch bei Chlebnikov ("Utes iz budušego." [1921/22] In: CHLEBNIKOV, wie Anm. 42, S. 566). Vgl. hierzu Kovtun, Povelichina (wie Anm. 4), S. 266-274. Ders., Dies. (wie Anm. 42). Ripeluino, "Tentativo..." (wie Anm. 42), S. 139-141. Ch. LoDDER, Russian Constructivism, New Haven, London 1983, S. 208f., 298f. Zahlreiche weitere Beispiele für Projekte fliegender oder schwebender "Stådte der Zukunft" in Architektur und Literatur der frühen Sowjetzeit finden sich in der anregenden Studie von E.K. BEAUJOuR, "Architectural Discourse in Early Soviet Literature." In: Joumal of the History of Ideas, 44 (1983), 3, S. 477. 495. Vgl. ferner M. BuIzNaKov, "The City of the Russian Futurists." In: Canadian-American Slavic Studies, 20 (1986), 1-2, S. 89-110. Siehe auch die Entwürfe einer "fliegenden Stadt der Zukunft" des Architekten G.T. Krutikov. Ausführlich dazu mit zahlr. Abb. CHAN-MAGOMEDOV (wie Anm. 84), S. 284, 307f., 333.

Der von Kovtun unternommene Versuch, Malevixs Begriff 'Supranaturalismus' mit Fedorovs 'Supramoralismus' in Verbindung zu bringen, wurde von Chardžiev mit Recht zurückgewisen. Vgl. E.[F.] KovtuN, "Die Entstehung des Suprematismus." In: Von der Fläche zum Raum (wie Anm. 7), S. 38. Chardžılev (wie Anm. 80), S. 125 Anm. 12. Maleviles assthetische Konzeption des 'Suprematismus' hat mit Fedorovs Philosophie nichts gemein; sie steht vielmehr in der Tradition theosophischer und kabbalistischer Spckulationen. Uber Ursprünge und Einflusse siehe insbesondere die in Anm. 52 genannten Arbeiten von HENDERSON sowie FISCHER, bes. S. 367-370.

88 Im Westen nach wie vor kaum bekannt, ist Cekrygin in der Sowjetunion keineswegs 'vergessen', wie gelegentlich behauptet wird. Ausstellungen seiner Werke in Moskau (1957, 1964, 1970, 1981) sowie zahlreiche Veröffentlichungen zeugen nicht nur von regem Interesse, sondern auch von offizieller Anerkennung (siehe auch unten Anm. 135).

Zu Cekrygin siehe insbesondere den Ausstellungskatalog Vasilij Nikolaevic Čekrygin (1897. 1922). Risunki. M. 1969. V.I. RAKInN, "Sila obraznogo dramatizma." In: Iskusstvo, 1971, 10, S. 33-39. E.M. BoGAT, Veðnyj Celovek, M. 1973, darin Kap. "Čekrygin", S. 153-168 (mehrmals wieder abgedruckt, u.a. in: DERS., Četvertyj list pergamenta, M. 1983, S. 176-188; zu Čekrygin auch ebd., S. 121). JUA. MOLOK, V.I. KostiN, "Ob odnoj idee "buduscego sinteza zivych iskusstv'. (Po materialam pisem V.N. Cekrygina k N.N. Puninu nacala 20-ch godov)." In: Soverskoe iskusstwoznanie 76, 2, M. 1977, S. 287-336. Vgl. ferner ANON., "Nekrolog." In: Makovec, 1922, 2, S. 3f. A.[V.] BAKUŠINSKU, "V puti k velikomu iskusstvu." In: Žizn', 1922, 3, S. 132-135. DERS., "Vystavka proizvedenij V.N. Cekrygina." In: Russkoe Iskusstuo, 1923, 2-3, S. 15-20. Ostromirov [Gorsku] (wie Anm. 39), vyp. 3, Charbin 1932, S. 17-20. "Cekrygin, V.N." In: BSE (1-oe izd.), t. 61, M. 1934, Sp. 117. A. SALTYKov, "Pervyj illjustrator Majakovskogo." In: Twortestuo, 1965, 12, S. 15. A.A. SIDOROV, Zapiski sobiratelja, L. 1969, S. 208, 210. JU. GERCUK, "Pereselenie reloveka na zvezdy." In: Dekoratimoe Iskussivo SSSR, 1971, 4, S. 25. DERS., "Vasilij Cekrygin." In: Tvořestuo, 1974, 10, S. 10-12. V.P. LAPSIN, "Iz istorii chudožestvennoj Zizni Moskvy 1920-ch godov. 'Makovec'." In: Sovetskoe iskusstwoznanie 79, 2, M. 1980, S. 355391. V. PaCjukov, "Proekt - mif - koncept." In: $A$ - Ja, 2, 1980, S. 3f. CeKRYGIN (wie Anm. 18). N. MisLer, "Il rovesciamento della prospettiva." In: P.[A.] FlORENSKU, La prospertiva rovesciata e altri scritti, Roma 1984, S. 3-51; bes. S. 8-16 und pass. Unlängst erschienen die ausführlichen Erinnerungen von L.F. ŽEGIN [ŠECHIEL'], "Vospominanija o V.N. Čekrygine." In: Panorama iskusstv, vyp. 10, M. 1987, S. 195-232 [Vorwort und Kommentar von N.I. Chardžiev]. 
Am 6.(18.) Januar 1897 in Žizdra (Gvt. Kaluga) geboren, wuchs Čekrygin in einfachen Verhältnissen auf. In Kiev, wohin seine Eltern übergesiedelt waren, besuchte er die Ikonenmalschule der Pecerskaja Lavra. 1910 erhielt er ein Levitan-Stipendium und schrieb sich an der Moskauer Hochschule für Malerei, Bildhauerei und Baukunst ein. Dort lernte er im Jahre 1912 Majakovskij kennen und schloß sich dem Kreis der Futuristen um Majakovskij, David Burljuk, Žegin und Malevið̌ an. ${ }^{89}$ Obwohl sich Čekrygin später als "einen der ersten russischen Anhänger des Futurismus" ${ }^{\prime 90}$ bezeichnete, galt sein Hauptinteresse der altrussischen Malerei, den biblischen Themen eines A.A. Ivanov und den Fresken Vrubel's. Auch in seinem eigenen Werk bevorzugte er religiöse Motive, wie die Illustrationen zu Majakovskijs erstem Gedichtband Ja! beweisen. ${ }^{91}$ Im Januar 1914 traf Cekrygin in Moskau mit Marinetti zusammen, der ihn nach Mailand einlud, ${ }^{92}$ doch wandte sich der junge Maler schon bald vom Futurismus ab ${ }^{93}$ und begann eine eigene, religiös orientierte Kunstkonzeption zu entwickeln. Anfang 1914 verlor er sein Stipendium und mußte die Moskauer Hochschule verlassen. Zusammen mit Lev Žegin reiste er nach Westeuropa, wo er die Kunstzentren München, Wien, Paris und London besuchte, bis ihn der Ausbruch des Krieges zur Rückkehr nach Rußland zwang. Nach der Revolution arbeitete er zunächst in der Moskauer Kommission zum Schutz der Kunstwerke, gab Malunterricht und hielt. Vorträge über Malerei im Atelier von Aleksandra Ékster in Kiev; ${ }^{94}$ er entwarf Kostüme für das Moskauer Kindertheater, arbeitete in der Abteilung für Plakate der Sektion für bildende Künste (IZO) beim Volkskommissariat für Bildungswesen und wirkte mit bei der Dekoration öffentlicher Gebäude, Straßen und Plätze.

Zu Beginn der zwanziger Jahre beteiligte sich Cekrygin intensiv an den kunsttheoretischen Auseinandersetzungen, die in den Kreisen der Avantgarde geführt wurden. Dabei ging es um eine neue Bestimmung des Verhältnisses von ästhet ischer und Lebens-Praxis, um die Klärung der Frage, welche Funktion die Kunst bei der Schaffung eines 'neuen Lebens' übernehmen solle, und um die Anwendung neuer Ausdrucksformen, wie sie insbesondere der Gedanke einer 'Synthese der Künste' zu eröffnen schien. Im Winter 1920 hielt Čekrygin im

89 Ein Photo, das Cekrygin, Žegin [Šechtel'] und Majakovskij 1913 in Moskau zeigt, ist abgebildet bei ZEGIN (wie Anm. 88), S. 201. - Uber Cekrygins künstlerische Anfänge siehe die Erinnerungen seiner Freunde ZEGIN (wie Anm. 88) und K.N. RED'KO, "Vospominanija o V.N. Cekrygine." In: Iskusstwo, 1971, 10, S. 391. DERS., "Zratki solnca." In: V.I. KostiN, Kliment Red'ko. Dnemiki. Vospominanija. Stat'i. M. 1974, S. 23-61; hier S. 23-32.

90 Brief an N.N. Punin, 6.12 .1920 (offenbar nicht abgeschickt); nach MoLoK, Kostin (wie Anm. 88), S. 310. Vgl. ebd., S. 292.

91 Die biblischen Szenen der Zeichnungen Cekrygins weisen keinen Zusammenhang mit dem Inhalt von Majakovskijs Werk auf. Vgl. hierzu oben Anm. 16 und SALTYKov (wie Anm. 88).

92 Siehe Cekrygin nach Molok, Kostnx (wie Anm. 88), S. 310. Vgl. ebd., S. 331f. Anm. 3.

93 Ebd., S. 310.

94 Ebd., S. 334f. Anm. 3. 
Moskauer Künstlercafé "Domino", dem Treffpunkt der Avantgarde, einen vielbeachteten Vortrag über "Die Kunst des Bildes" (iskusstvo obraza) und bereitete eine Vorlesungsreihe zu Fragen der Kunstphilosophie für die Höheren künstlerisch-technischen Werkstätten (VChUTEMAS) vor. Zu den Hörern des damals Dreiundzwanzigjährigen zählten so bedeutende Experten wie P.A. Florenskij und V.A. Favorskij. ${ }^{9}$

In jener Zeit - wahrscheinlich in der zweiten Hälfte des Jahres 1921 - stieß Čekrygin "überraschend", wie er später berichtete, auf das Werk Fedorovs. ${ }^{96} \mathrm{Er}$ fand darin seine eigenen, seit langem gehegten Vorstellungen über Art und Aufgabe einer 'neuen Kunst' formuliert und in einen umfassenden theoretischen Zusammenhang gestellt. ${ }^{97}$ Am 9. Dezember 1921 berichtete er dem in Paris lebenden Maler Michail Larionov:

Meine künstlerischen Ansichten haben sich zu einer klaren und präzisen Form entwickelt, von der ich behaupte, daB sie niemand sonst in Europa hat. Für Sie werden sie wahrscheinlich (zweifellos) völlig unerwartet und neu sein, wie auch für alle Franzosen und Russen. Dieser Weg (nicht meiner, sondern der meines philosophischen Lehrers) soll alles künstlerische und philosophische Suchen zum Abschlu $B$ bringen, ihm Sinn verleihen und die ungewöhnliche Klarheit der Synthese, er soll die Lehren des Spiritualismus und des Materialismus miteinander versöhnen, indem er die Widersprüche des Panpsychologismus, Panvoluntarismus und Panästhetizismus lost. Die Philosophie hört auf, kontemplativ und abstrakt zu sein und geht in die Realităt über, die Wissenschaft vereint sich in der Astronomie und gelangt zur Vollendung durch die reinen Künste in der Synthese des Ursprungs.

95 Ebd., S. 295, 304f. Anm. 22. - Florenskij hielt zwischen 1921 und 1924 Vorlesungen an den Moskauer VChUTEMAS über die Analyse der Răumlichkeit in Kunstwerken. Der mit ihm eng befreundete Xylograph und Maler VA. Favorskij (1886-1964) war Professor und zeitweilig Rektor der VChUTEMAS. Siehe auch HAGEMEISTER (wie Anm. 39), S. 11.

96 So Cekrygin in einem Brief an N.N. Punin vom 7.2.1922; darin heißt es, er sei überraschend erst vor kurzem (!) auf Fedorovs Lehre gestoßen ("... vstretil éto uťenie neožidanno nedavno..."). Molok, Kostin (wie Anm. 88), S. 327. - Dazu berichtet Žegin, er habe zu Beginn der zwanziger Jahre Fedorovs Werke auf dem Sucharev-Markt in Moskau erstanden und Cekrygin mit innen bekannt gemacht. Mitteilung von A.A. Dorogov, Moskau, 5.4.1984; Dorogov bezieht sich auf eine Mitteilung von Zegin. Vielleicht war auch P.A. Florenskij, der Fedorovs Werk seit langem kannte und der sich zu jener Zeit intensiv mit kunstphilosophischen Fragen befaBte, der Vermittler.

Wann genau Čekrygin mit Fedorous Werk bekannt wurde, lăßt sich nicht feststellen. Der Ausstellungskatalog (V.N. Cekgygin. Risunki, wie Anm. 88, o.S. [10]) nennt das Jahr 1921, MoloK, Kostin (wie Anm. 88), S. 335 Anm. 2, hingegen das Jahr 1920, wobei sie sich auf Tagebucheintragungen und (wenig überzeugend) den Inhalt von Cekrygins erstem Brief an Punin vom November/Dezember 1920 berufen. Cekrygins Briefe an Punin vom November und Dezember 1920 und an Larionov vom Februar 1921 enthalten jedoch keinerlei Hinweise auf eine Beschăftigung mit Fedorov, wohl aber die Briefe an Punin und Larionov vom Dezember 1921 und Februar 1922. Siehe unten Anm. 110 und CEKR YGIN (wie Anm. 18).

97 In dem bereits zitierten Brief an Punin vom 7.2.1922 heißt es: "... v kruge že odnorodnych idej žil samostojatel'noj mysl'ju (pravda, menee oformlennych) očen' davno, s $1913 \mathrm{~g}$...." (ebd., S. 327). Möglicherweise hatte Cekrygin seit langem - unabhăngig von Fedorov - den Gedanken einer Rückkehr der Verstorbenen ins Leben entwickelt. So ließe sich auch die von Žegin mitgeteilte Äußerung Florenskijs über Čekrygin erklăren, man könne über die Idee der Auferwekkung ein zwei Jahre sprechen, nicht aber zehn Jahre; dann sei es bereits leeres Geschwătz. L.F. ŻEGIN [SECHTEL'], "Vospominanija o PA. Florenskom." In: Vestnik RChD, 135, 1981, S. 63 [anscheinend unvollstăndig]. 
Der neue Weg ist die Forderung nach tiefer Sittlichkeit, auf ihm enthüllt sich der wahre Sinn der Arbeit. Mein Lehrer ist der großBte Menschensohn nach Sokrates, doch weiser als dieser. Seine Lehre wird, so glaube ich, die Aufgabe des künftigen Menschen werden. ${ }^{98}$

Die Idee des obšcee delo und die Rolle, die der Kunst im Rahmen dieses Projekts zugewiesen wurde, nahm Čekrygin mit Begeisterung auf und legte sie nicht nur seinem eigenen künstlerischen Schaffen zugrunde, sondern formulierte sie auch in Briefen und Abhandlungen und suchte sie bei jeder sich bietenden Gelegenheit zu verbreiten:

Die Filosofija obšxego dela wurde für ihn zu einer Art Katechismus. Sie nahm ihn ganz und gar gefangen und erklärte ihm vieles in seinem eigenen Werk, was er selbst nie hatte erklären kơnnen. ${ }^{99}$

Uber die Ideen Fedorovs ... konnte er immer und überall sprechen, unter allen nur moglichen Umstănden. Er konnte einen zufällig irgendwo auf der Straße treffen und ... endlos reden, indem er die einzig wertvolle und notwendige philosophische Doktrin des obšcee delo bewies... Weggehen war nicht moglich - er lieB einen nicht fort, bevor er nicht jenen Gedanken bewiesen hatte, den man schon tausendmal von ihm gehort hatte und der sich auf geradezu monomanische Weise seines ganzen Wesens bemăchtigt hatte. ${ }^{100}$

Cekrygin hatte die Absicht, die Idee des obšcee delo in einem riesigen Freskogemälde zu gestalten und damit ein Vorbild für die zu erstrebende Synthese aller Künste zu schaffen; dereinst verwirklicht, sollte diese Synthese die reale Auferweckung der Verstorbenen sein. ${ }^{101}$ Der Plan wurde nicht ausgeführt. Am 3. Juni 1922 starb Čekrygin, nachdem er unter ungeklärten Umständen in der Nähe von Moskau von einem Zug überfahren worden war. ${ }^{102}$ Er hinterließ etwa 1500 Zeichnungen, von denen die meisten erst kurz vor seinem Tod entstanden waren. Titel wie "Beginn der außerkirchlichen Liturgie", "Anbruch des kosmischen Zeitalters", "Beherrschung der kosmischen Vorgänge", "Übersiedlung der Menschen auf die Gestirne", "Auferstehung" lassen Fedorovs Einfluß erkennen. Ein großer Teil dieser Zeichnungen stellt Vorarbeiten für das geplante Monumentalgemälde dar, ${ }^{103}$ über das B.V. Šaposnikov schrieb:

Besonders gern sprach er [Čekrygin] über N.F. Fedorov, dessen Philosophie auf ihn als Künstler großen EinfluB hatte. Das Thema der 'Auferweckung' sah er als sein Hauptthema an, und alle seine

98 ČEKRYGIN (wie Anm. 18), S. 42.

99 ŽEGIN (wie Anm. 88), S. 227.

100 Žegin nach Molok, Kostin (wie Anm. 88), S. 303 Anm. 6. Vgl. etwas abweichend Žgin (wie Anm. 88), S. 227. Bestattigt wird dies von N.M. Rudin: "Der 'fanatische' Cekrygin ... sprach nur über den Philosophen Fedorov." LAPŠIN (wie Anm. 88), S. 366.

101 Molok, Kostin (wie Anm. 88), S. 296.

102 Siehe ZEGIN (wie Anm. 88), S. 229r. - Wie Fülop-Miller berichtet, wurde Cekrygin nach seinem Tode von einer "große[n] Gemeinde" verehrt. R. FOLOP-MILLER, Geist und Gesicht des Bolschewismus, Wien ${ }^{2} 1928$, S. 134. Ähnlich wie bei Chlebnikov, der zwei Monate spăter starb, ranken sich auch um Cekrygins Biographie zahlreiche Legenden.

103 Vgl. Molok, Kostin (wie Anm. 88), S. 297, 305 Anm. 23. V.N. Cekrygin. Risunki (wie Anm 88), Zeichnungen Nr. 103, 104, 109-115, 174-178, 208-211, 250-260. 
in jüngster Zeit entstandenen Zeichnungen waren Fragmente eines grandiosen Gemăldes, das er über dieses Thema zu schaffen beabsichtigte. Dieses Thema war für ihn das Symbol seiner Kunst oder sogar aller Kunst. 'Die Synthese der lebendigen Künste ist die Auferweckung der Toten', schrieb er sechs Tage vor seinem Tod in mein Album...

Seine Gedanken über die künftige 'neue Kunst' und ihre Aufgabe legte Čekrygin in Vorträgen, Abhandlungen und Briefen dar, von denen jedoch nur ein kleiner Teil zugänglich ist. ${ }^{105}$ In dem bereits zitierten Brief an Larionov vom 9. Dezember 1921 heißt es:

Ich habe ein kleines Büchlein geschrieben, in dem ich seine [Fedorovs] Worte fast wörtlich wiederhole (da ich es nicht für nottig halte, ein eigenes System zu entwickeln), doch habe ich darin (in dem Buch) seine Lehre systematisiert und versucht, sie anschaulicher darzulegen. Außer dem Buch habe ich einen kurzen Aufsatz verfaßt, den ich demnăchst veroffentlichen werde... ${ }^{106}$

Der Aufsatz ist 1922 - bereits postum - in der Zeitschrift Makovec erschienen. ${ }^{107}$ Bei dem erwähnten Büchlein handelt es sich um die dem Andenken Fedorovs gewidmete Schrift "Die Kathedrale des auferweckenden Museums", von der bislang nur kurze Auszüge veröffentlicht worden sind. ${ }^{108}$ Aufschluß über Cekrygins Kunstauffassung geben ferner die Briefe an Larionov ${ }^{109}$ und an den

104 B.[V.] SAPOŠNIKov, "Apostol bol'Sogo iskusstva. Vospominanija o V.N. Cekrygine." In: Makovec, 2, S. 8.

Cekrygins Thema, die Auferweckung der Verstorbenen, sei gar nicht anders als durch skizzenhafte Annăherung zu bewăltigen gewesen, meinte A.D. Sinjavskij. Möglicherweise sei Cekrygin gar nicht zu früh gestorben, sondern habe an der Grenze der Skizze angehalten, ohne sie zu überschreiten. "Der Maler hat offenbar verstanden, daß Malerei eine Skizze der Auferstehung [sic] jst, und hinterlieB uns - eine Skizze." A.TERC [d.i. A.D. SINJAvSKU], Golos iz chora, London 1974, S. 313; die Aufzeichnung ist datiert: 19. Mai 1971. - AnlaßBlich einer Retrospektive im Jahre 1923 schrieb der Kunstwissenschaftler A.V. Bakusinskij über Cekrygins Werk, es sei "... die Vorahnung eines neuen Himmels und einer neuen Erde sowie eines neuen Menschen in neuen, noch nie gesehenen gesellschaftlichen und kosmischen Verhaltnissen." BAKUSINSKIJ, "Vystavka..." (wie Anm. 88), S. 16.

105 Siehe MoloK, Kostin (wie Anm. 88), S. 289.

106 Cekrygin (wie Anm. 18), S. 42.

107 V.[N.] CEKRYGIN, "O nameðajuŠcemsja novom etape obšcevropejskogo iskusstva." In: $M a$ kovec, 1922, 2, S. 10-14. (Eine franz. Ubersetzung unter dem Titel "De l'ébauche d'une nouvelle étape d'un art paneuropéen." In: An et poésie nusses 1900-1930. Texaes choisis. Paris 1979, S. 194-199). Siehe auch unten Anm. 135.

108 Sobor voskresajušcego muzeja. O buduscem iskusstve: muzyki, zivopisi, skul'prury, architektury i slova. Die Widmung lautet: "Pamjati velikogo pravednika i utitelja Nikolaja Fedorovita Fedorova." Das Manuskript dieses Werkes, dessen Erscheinen 1922 in der Zeitschrift Makovec angekündigt worden war, ist erhalten; Zitate daraus in Makovec, 1922, 2, S. 6, und MoLoK, Ko. STIN (wie Anm. 88), S. 300, 333 Anm. 6. 
futuristischen Kritiker und Theoretiker der 'linken Kunst' N.N. Punin ${ }^{110}$ sowie einige verstreute Zitate aus Briefen und Aufzeichnungen. ${ }^{111}$

Ausgehend von einer Kritik der zeitgenössischen Kunstrichtungen (Kubismus, Suprematismus, Konstruktivismus), denen er vorwarf, "analytisch" und "wesenlos" zu sein und die "lebendige Verbindung zum Leben" verloren zu haben, entwickelte Cekrygin - in enger Anlehnung an Fedorov - die Vorstellung einer Synthese der Künste, die dazu dienen sollte, das Universum umzugestalten, es aus einem Produkt der Natur in ein Werk des Menschen, d.h. in ein Kunstwerk zu verwandeln, um es auf diese Weise vor dem drohenden Untergang $\mathrm{zu}$ bewahren und seiner Vollendung zuzuführen. ${ }^{112} \mathrm{Zu}$ eben diesem Zweck, so Čekrygin, habe die Natur den Künstler-Menschen geschaffen, der über die Fähigkeit verfüge, ideale Bilder zu entwerfen, die die Natur selbst nicht hervorbringen könne; er vermöge damit jene Vollkommenheit zu antizipieren, die in der Natur nicht vorhanden sei und die nur durch menschliches Handeln in sie hineingetragen werden könne. ${ }^{113}$

In einer zersplitterten, im Werden begriffenen, sich verwirklichenden Welt lebend, ist der Mensch der höchste Aufschwung (pod-em) der Natur... Die Bestimmung und der Sinn seiner Arbeit, der Kunst, ist es, die Naturelemente zu befreien und zu organisieren (und dadurch sich selbst wiederherzustellen) und durch die eigene Umgestaltung in der Welt den Frieden wiederherzustellen. ${ }^{114}$

Der Mensch als Schöpfer seiner selbst sei die "Synthese der lebendigen Künste" (sintez Zivych iskusstv), er sei "lebendige Malerei, Skulptur, Architektur und Musik". ${ }^{115}$ Zwar sei auch er noch nicht vollendet, da noch immer dem Tode unterworfen, ${ }^{116}$ doch gebiete er über Kräfte, die dem Zerfall und der Zerstörung entgegenwirkten.

110 Molok, Kostin (wie Anm. 88), S. 306-330. - Cekrygin versuchte in diesen Briefen, Punin für seine Kunstauffassung zu gewinnen. Die ersten beiden Briefe vom November und Dezember 1920 sind offenbar nicht abgeschickt worden. Die übrigen drei Schreiben (eines vom 29.12.1921 und zwei vom 7.2.1922), die an Punin gelangten, zeigen einen starken EinfluB Fedorovscher Ideen. In den beiden Briefen vom 7.2.1922 werden Fedorov und sein Werk mehrmals genannt; außerdem verspricht Cekrygin, seinem Adressaten ein Heft mit Exzerpten aus Fedorows Schriften zu schicken.

111 LAPSIN (wie Anm. 88), S. 367, 371.

112 Aus den wenigen zugänglichen Schriften Cekrygins läBt sich keine in sich geschlossene Theorie rekonstruieren; vielmehr handelt es sich um unsystematische Entwürfe, oftmals aphoristisch und mit Zitaten durchsetzt, 'unklar' und 'chaotisch', wie Cekrygin selbst schreibt. Cekrygin nach Molok, Kostin (wie Anm. 88), S. 327. Bei aller Verworrenheit lassen Cekrygins Ausfuhrungen dennoch eine enge Anlehnung an Fedorov erkennen, zu dem er sich wiederholt als seinem 'großen Lehrmeister' bekennt. Ebd., S. 323, 327.

113 Ebd., S. 308, 315.

114 Cekrygin (wie Anm. 10'), S. 14.

115 Cekrygin nach Molok, Kostin (wie Anm. 88), S. 330. Vgl. FOD II, S. 155.

116 Ebd., S. 325, 330. 
Der Künstler-Mensch, der Vermittler organisierender Krăfte inmitten eines zu volliger Gestaltlosigkeit neigenden Chaos, der Mitleidende des Weltkorpers, aus dessen Elementen er zusammengesetzt ist, ist die vollkommenste Synthese der lebendigen Künste und der Vollbringer ihrer auferweckenden Krafte im Kreise der Welterbauung. ${ }^{117}$

Als Bewahrer des Vergangenen sei der Mensch ein 'Museum'; indem er als 'Synthese der lebendigen Künste' das Vergangene wiederherstelle, werde er zum "auferweckenden Museum" (muzej voskrešajuščlj). ${ }^{118}$ Im Unterschied zu den "illusionistischen Künsten" (illjuzornye iskusstva), die sich mit einer scheinbaren Wiederherstellung begnügten, bestehe die Aufgabe der "lebendigen Künste" (Zivye iskusstva) in der "Auferweckung der toten Väter in der Wirklichkeit", der "Umgestaltung des Kosmos (des Weltalls)" sowie der "Beherrschung der kosmischen Vorgänge", insbesondere der Schwerkraft, die, unbezähmt, zum Untergang des Weltalls führen würde. ${ }^{119}$ Gelänge diese Aufgabe, dann würden die "belebten, beseelten Himmelskörper des vom Untergang-Tode erlösten Weltalls" zum Material für die "wahre kopernikanische Himmelsarchitektur". ${ }^{120}$ Das "Hineintragen lebendiger Architektur in das Weltall" und damit die "'Errichtung des Paradieses" werde der "letzte Akt lebendiger Kunst" sein. ${ }^{121}$

Die Verwirklichung der "großen Synthese" (velikij sintez) liege in der Zukunft; Aufgabe der gegenwärtigen Kunst müsse ihre Vorbereitung (predvaritel'noe dejstvo) sein, ${ }^{122}$ wobei sie "teilweise die künftige Erneuerung des Universums enthüllen, d.h. seine Vollendung antizipiere. ${ }^{123}$ Dann, so Čekrygin, "wird die Kunst auch in der Wirklichkeit die verborgenen Kräfte beherrschen und wird die siegreiche Erschaffung einer himmlischen Architektur sein, die den Himmel baut und die in der Erde verborgenen Körper wiederherstellt ${ }^{\text {124 }}$. Der Mensch werde zugleich Subjekt und Objekt einer allumfassenden Umgestaltung. Erneuerung und Vervollkommnung sein, einer "Selbsterschaffung" (samosozdanie), die ihn aus einem natürlichen (geborenen) in ein künstliches (und damit unsterbliches) Wesen verwandele. ${ }^{125}$

117 Cekrygin (wie Anm. 107), S. 14.

118 Cekrygin nach MoloK, Kostin (wie Anm. 88), S. $325 f$.

119 Ebd., S. 326, 329. - Dies entspricht genau Fedorovs Unterscheidung von "ptolemåischer" und "kopernikanischer Kunst".

120 Ebd.

121 Ebd., S. 330. - Vgl. auch: "Das Ziel der Künste ist die Wiederherstellung des Vaters durch den Sohn und die Emeuerung [des Universums] durch die universale, lebendige Himmelsarchitektur." Brief Cekrygins an N.M. Cernyక̌ev, 1922; nach LAPŠIN (wie Anm. 88), S. 371. Fedorov: "Die Umwandlung aller Welten in solche, die vom Verstand der wiedererweckten Geschlechter gelenkt werden, ist das hochste Ziel der Kunst." FOD II, S. 240.

122 Cekrygin nach Molok, Kostin (wie Anm. 88), S. 296.

123 Cekrygin (wie Anm. 107), S. 14.

124 Ebd.

125 Vgl. Molok, KostnN (wie Anm. 88), S. 300. FOD II, S. 239. 
Die kirchliche Liturgie (chramovoe dejstvo), die Pavel Florenskij in einem bemerkenswerten Aufsatz als einen durch rituelle Gestik, Gesang, Licht, Weihrauch, Ikonen usw. gebildeten "lebendigen, ganzheitlichen Organismus" und also bereits verwirklichte Synthese der Künste beschrieben hatte, ${ }^{126}$ blieb für Cekrygin ein unvollkommener Versuch zur Wiederherstellung der Verstorbenen, da sie nicht über den Entwurf eines Vor-Bildes hinausgelange:

Beim Singen der Totenmesse [er]fand die Kirche die Stimme der belebenden Musik (entsprechend der künftigen Musik, welche die Uberreste der Verstorbenen beleben wird). Nachdem sie die Vater und Vorvăter als Mitlebende imaginient hatte (Ikone), erhob sie sie in Gedanken ins Sternen-Vaterland (zvezdnoe otecestwo) (Ikonostase) und schuf [damit] den Plan zum Sieg über die trăge Macht des Todes durch die Gesamtheit der lebendigen Künste. ${ }^{12 T}$

Die Verwirklichung dieses Planes erfordere die Vereinigung aller schöpferischen Kräfte und gehe damit weit über den Bereich der kirchlichen Handlung hinaus, weshalb Cekrygin sie - mit den Worten Fedorovs - als "außerkirchliche Liturgie" (vnechramovoe dejstvie, vnechramovaja liturgija) bezeichnete.

Cekrygins Vorstellungen von einer syntheseschaffenden oder synthetischen Kunst reichten weit über die Entwürfe der Symbolisten (Belyj, Kandinskij, Čiurlionis, Vjaceslav Ivanov u.a.) hinaus. ${ }^{128}$ Am nächsten kam ihnen vielleicht Aleksandr Skrjabin (1872-1915), der gegen Ende seines Lebens versucht hatte, die Vereinigung aller Künste in einem (unvollendet gebliebenen und wohl auch unaufführbaren) "Mysterium" (Misterija) zu verwirklichen, einer weltumspannenden künstlerisch-liturgischen "Vorbereitenden Handlung" (Predvaritel'noe Dejstvo), welche den Untergang der 'alten Welt' begleiten und eine 'neue Welt' heraufführen sollte, als deren Messias er sich sah. Wie Fedorov und Cekrygin glaubte auch Skrjabin an die Unbegrenztheit der menschlichen Schöpferkraft

126 P.[A.] FLORENSKU, "Chramovoe dejstvo, kak sintez iskusstv." [1918] In: Makovec, 1922, 1, S. 2832. Siehe auch unten Anm. 135. Eine ăhnliche Auffassung der Liturgie begegnet bereits in Florenskijs Stolp i utverzdenie istiny (M. 1914). - Florenskij war mit Cekrygin gut bekannt und schătzte dessen künstlerisches Werk hoch. Den Ideen Fedorovs stand er zu jener Zeit ablehnend gegenüber. Vgl. dazu ŻEIN (wie Anm. 97). LAPSIN (wie Anm. 88), S. 367, 389. HA. GEMEISTER (wie Anm. 39), S. 11, 42f. Siehe auch II: 2.2.1. Die Konzepte einer Synthese der Künste bei Forenskij und Fedorov sowie der russischen Avantgarde der zehner und zwanziger Jahre skizziert und vergleicht L. GELLER, "Estetika i utopija: dve teorii iskusstva o. Pavla Florenskogo." In: Russkaja Mysl', 3711 (12.2.1988), S. 12, 14. Siehe auch VA. NikrTIN, "Chramovoe dejstvo kak sintez iskusstv. Svjaßz. Pavel Florenskij i Nikolaj Fedorov." In: Vestmik RChD, 153, 1988 , S. $40-56$.

127 V.[N.] CEKRYgIN, "Sobor voskreక̌ajušego muzeja." Zitiert nach Makovec, 1922, 2, S. 6; Hervorhebung im Orig.

128 Siehe 2.B. L.[A.] ŽAdova, "Poiski chudožestvennogo sinteza na rubeže stoletij." In: Dekorativnoe Iskusstuo SSSR, 1976, 8, S. 38-43. Und mit Hinweis auf Fedorov V.[P.] RAKOv, "Somatizeskie intuicii v sovetskom literaturovedenii 1920-ch godov." In: Tvortestvo pisatelja i literatumyj process, Ivanovo 1986, S. 66-78; zu Fedorov S. 70-72. - In diesem Zusammenhang ist der EinfluB der deutschen Romantik (Schelling, A.W. Schlegel) wohl noch nicht hinlănglich untersucht. 
und an die theurgische Macht der Kunst, mit deren Hilfe der Mensch sich selbst vergöttlichen werde. ${ }^{129}$

Der Gedanke einer großen Synthese der Künste findet sich, wenn auch nur vage, in dem Programm der Moskauer Künstlervereinigung "Makovec (Kunst ist Leben)", die im Dezember 1921 unter maßgeblicher Beteiligung Čekrygins gegründet worden war. Ihr gehörten, neben anderen, die Maler N.M. Černyšev und L.F. Žegin (Šechtel') sowie der Priester, Kunsttheoretiker und Universalgelehrte P.A. Florenskij an. ${ }^{130}$ Das Manifest von "Makovec", das in der ersten Nummer der gleichnamigen Zeitschrift erschien, weist die Gruppe deutlich als post-avantgardistisch aus. ${ }^{131}$ Kritisiert wurden Subjektivismus und ästhetische Isolierung der zeitgenössischen (avantgardistischen) Künstler: Sie hätten den Blick für die "ewige Ordnung, die sich in allen Dingen widerspiegelt" verloren

129 Auf die Verwandtschaft zwischen Skrjabins "Mysterium" und Fedorovs Projekt des obšzee delo hat schon früh Bulgakov hingewiesen. S.N. Burgakov, Svet nevecemij. Sozercanija i umozrenija. M. 1917, S. 368 Anm. 1; vgl. ebd., S. 390 Anm. 1. Mit Fedorov und dessen Werk war Skrjabin nicht bekannt. Seine Konzeptionen entstanden unter dem EinfluB von Nietzsche ('Ubermensch'), Wagner (Gesamtkunstwerk), Vjaz. Ivanov (kollektives Theater als Kunst und religioses Ritual) sowie den theosophischen und apokalyptischen Strömungen seiner Zeit. Vgl. B. SLfeCER [SChLOEZER], "Zapiska B.F. Slecera o Predvaritel'nom Dejstvii." In: Russkie propilei, t. 6, M. 1919, S. 98-119. M. COOPER, "Scriabin's Mystical Beliefs." In: Music and Letters, 16, 1935, S. 110-115. L. HofFMANN-ERBRECHT, "Alexander Skrjabin und der russische Symbolismus." In: Musik des Ostens, 6, 1971, S. 185-196. S. SCHibli, Alexander Skrjabin und seine Musik, München, Zürich 1983, bes. 3. Teil (S. 265-363). Zu den Gemeinsamkeiten und Unterschieden zwischen Skrjabin und Fedorow sowie zum geistesgeschichtlichen Kontext des Skrjabinschen "Mysteriums" ausführlich B. DE SCHLOEZER, Alexandre Scriabine, Paris 1975, S. 193-197 [russ. Erstausgabe Berlin 1923]. Vgl. auch OstromiRov [GORSKU] (wie Anm. 88), S. 16f. Nikrtin (wie Anm. 126), S. 47-49. - Zur Synthese der Künste bei Skrjabin und Ciurlionis siehe die Beiträge in Materialy usesojuznoj skcty molodych utenych po probleme 'Svet i muzyka' (tret'ja konferencija), Kazan' 1975, S. 13-42; sowie zu Skrjabin und Fedorov den Beitrag von JU.V. LINNIK, "Problemy sinestezii i recepcija gravitacii." Ebd., S. 208-212.

130 Ausführlich hierzu LAPSIN (wie Anm. 88), S. 355-391. Ders., "VA. Favorskij i N.M. Cernyšsev. Nabrosok k dvojnomu portretu." In: Panorama iskusstv, sb. 7, M. 1984, bes. S. 22-26, $46 f$. Misler (wie Anm. 88), bes. S. 4-19 und pass. Vgl. ferner Molok, Kostin (wie Anm. 88), S. 287f., 302 Anm. 1. ŻEGIN (wie Anm. 97), S. 60-63, 70. N.M. CERNYSEV, "Istorija 'Makovca'." In: Narodnyj chudotnik RSFSR professor Nikolaj Michajlovic Cemysev 1885-1973. Sb. materialov. M. 1978, S. 176-178. HAGemeister (wie Anm. 39), S. 11, 42f. [Artikel] "Makovec." In: BSE (1-oe izd.), t. 37, M. 1938, Sp. 756. - Die Vereinigung "Makovec" bestand bis Anfang 1927. Benannt war sie nach dem Hügel, auf dem Sergej von Radoneż im 14. Jahrhundert das Dreifaltigkeitskloster (Troice-Sergieva-Lavra) gegründet hatte.

131 "Naš prolog." In: Makovec, 1922, 1, S. 3f. - Vgl. auch LAPSIN (wie Anm. 88), S. 356f., 368f. MisLER (wie Anm. 88), S. 9. Von dieser Zeitschrift liegen nur zwei Nummern vor (Moskva 1922); die dritte Nummer (1923), für die Favorskij das Titelblatt entworfen hatte, ist nicht mehr erschienen. - Unter den Mitarbeitern der Zeitschrift Makovec wird neben Pasternak, Aseev und anderen auch Chlebnikov genannt; er ist mit mehreren Gedichten vertreten. Chlebnikov war nach seiner Rückkehr aus Persien Ende Dezember 1921 ins Studentenheim der VChUTEMAS gezogen, an der die Makovec-Mitarbeiter Favorskij und Florenskij lehrten und an der auch Cekrygin auftrat. Siehe ANON., "I vojsko pesen povedu...'" In: Literatumaja Gazeta, 46, 12.11.1975, S. 7. Im Juni 1922 ist Chlebnikov im Gut. Novgorod gestorben. 
und gäben infolgedessen in ihren Werken die Welt als eine "ungestalte Masse unverbundener Einzelteilen wieder. $^{132}$

Wir [so die Verfasser des Manifests] sehen das Ende der analytischen Kunst, und es ist unsere Aufgabe, ihre zerstreuten Elemente in einer machtvollen Synthese zusammenzufassen. (...) Die Aufgabe unseres Schaffens besteht darin, die unbewußten Stimmen der Natur, die in die höchste Sphăre des geistigen Lebens aufgestiegen sind, mit diesem in eins zu verschmelzen und sie in măchtigen, diese Zustănde in einer Synthese zusammenfassenden, ganzheitlichen Bildern einzufangen. ${ }^{133}$

Zwar gewährt die begriffliche und inhaltliche Unschärfe solcher Formulierungen breiten Raum für Interpretationen, doch kann sie nicht darüber hinwegtäuschen, daB Fedorovs Kunstauffassung, die auf Čekrygin so stark gewirkt hatte, von den übrigen Mitgliedern der Gruppe "Makovec" kaum übernommen worden ist. ${ }^{134}$ Auch in diesem Falle blieb Fedorovs Wirkung auf einen einzelnen beschränkt, dem es nicht gelang, andere für das obšcee delo zu gewinnen. ${ }^{135}$

132 "Naš prolog" (wie Anm. 131), S. 3.

133 Ebd., S. 4.

134 Im Gegensatz zu Bowlt kann ich in diesem Manifest eine "Verpflichtung gegenüber dem prophetischen Denken des russischen Philosophen Nikolaj Fedorov" nicht erkennen. Siehe J.E. Bowlt, "Expression und Abstraktion. Die Kunst der russischen Avantgarde." In: Werke aus der Sammlung Costakis. Russische Avantgande 1910 1930. Düsseldorf 1977, S. 14. Möglicherweise beruht Bowlts Urteil auf einer mangelhaften Kenntnis des Fedorovschen Werkes; an anderer Stelle wird nămlich von Fedorov gesagt, er habe "sich mit der Wanderung der Seelen im Kosmos [!]" beschåftigt. Ebd., S. 98. Ebenso unzutreffend sind auch Bowlts Bemerkungen über Cekrygins Werk; die Rede ist von "psychischen' Themen" und "irrsinnigen Motiven". Ebd., S. $13 f$.

135 Cekrygins künstlerisches Werk und seine theoretischen Schriften werden in der Sowjetunion auch in religiös-philosophischen Zirkeln hoch geschătzt. So beschaftigten sich die Mitglieder des 1974 gegründeten "Christlichen Seminars zu Problemen der religiosen Wiedergeburt in RuBland" (Christianskij seminar po problemam religioznogo vozrozdenija $v$ Rossii) mit den Werken Cekrygins und nannten als eine ihrer "Quellen" den in Makovec veroffentlichten Aufsatz "O namezajušemsja novom étape obšceevropejskogo iskusstva" (wie Anm. 107). Siehe hierzu Christianskij seminar, Frankfurt/M. 1981, S. 51, 94. - Auch Florenskijs Aufsatz "Chramovoe dejstvo, kak sintez iskusstv" (wie Anm. 126) wurde erstmals wieder im Samizdat herausgebracht. Sobranie dokumentov samizdata, t. 26, ¿. 2, München 1978, S. 445-458. Inzwischen liegen mehrere Veroffentlichungen und Ubersetzungen vor; siehe M. HAGEMEISTER, "PA. Florenskijs 'Wiederkehr': Materialien zu einer Bibliographie (1985-1989)." In: Ostkirchliche Studien [im Druck]. 


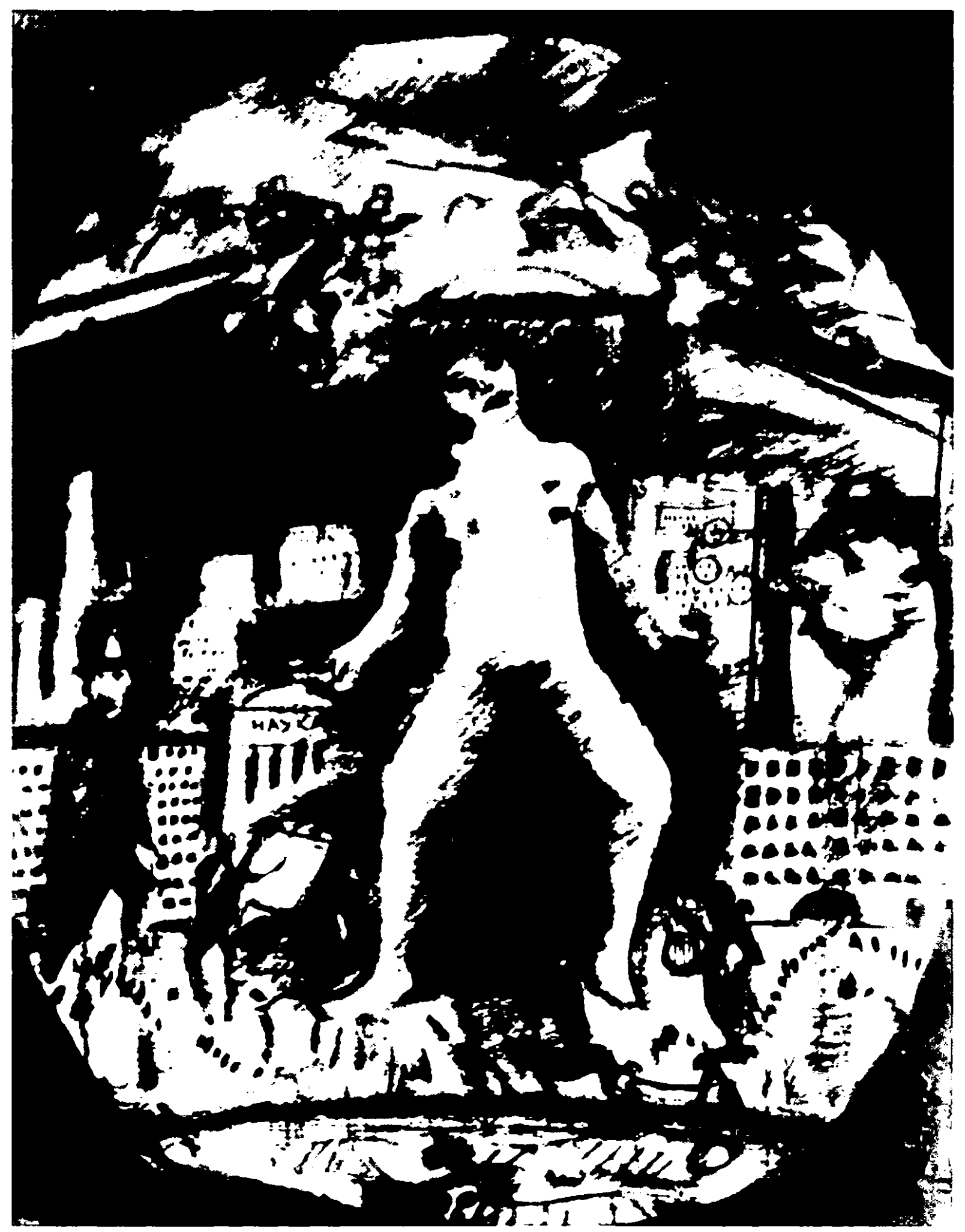

VN. Čekrygin: Der Kult der Frau 


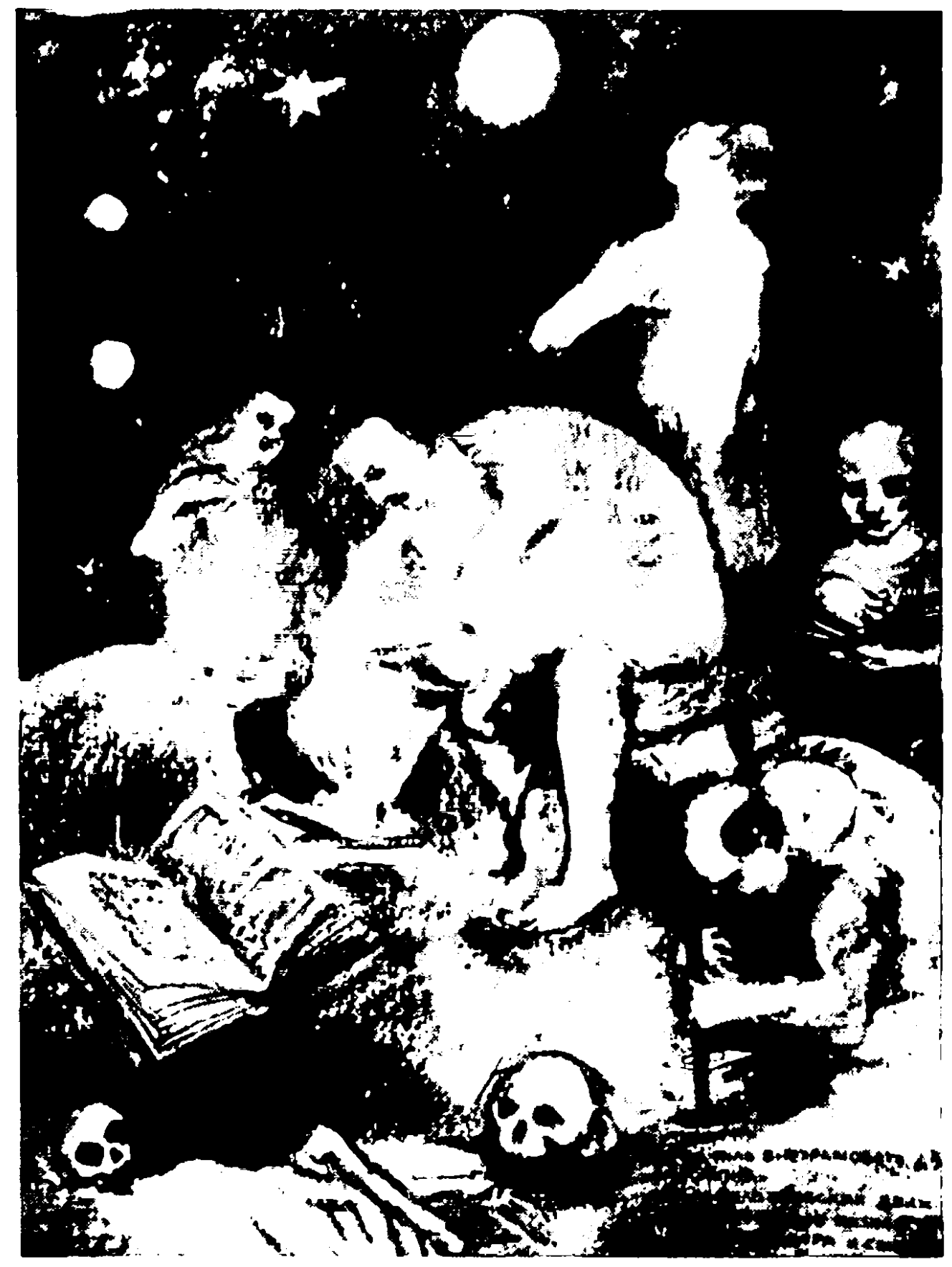

VN. Čekrygin: Beginn der außerkirchlichen Liturgie 


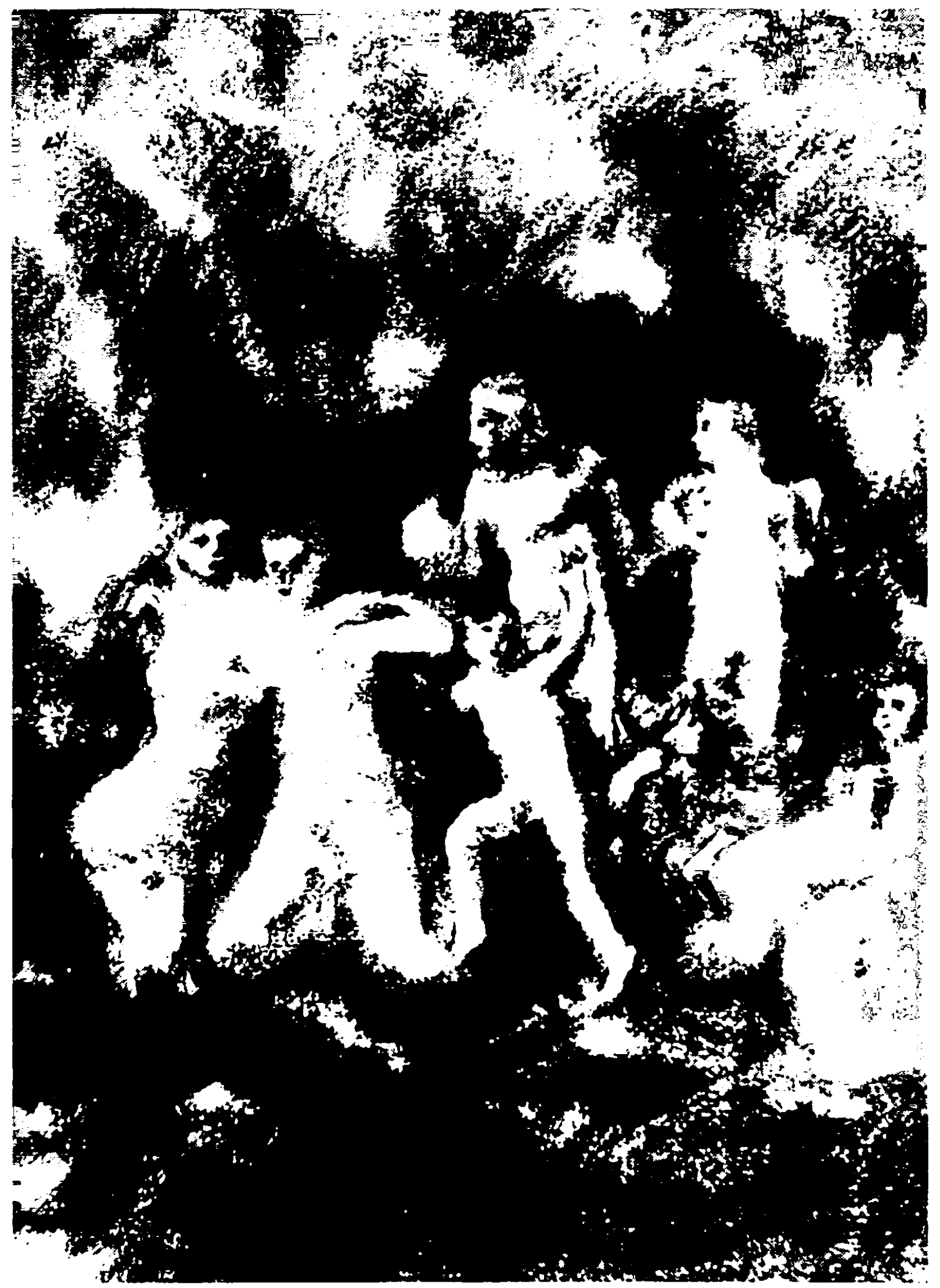




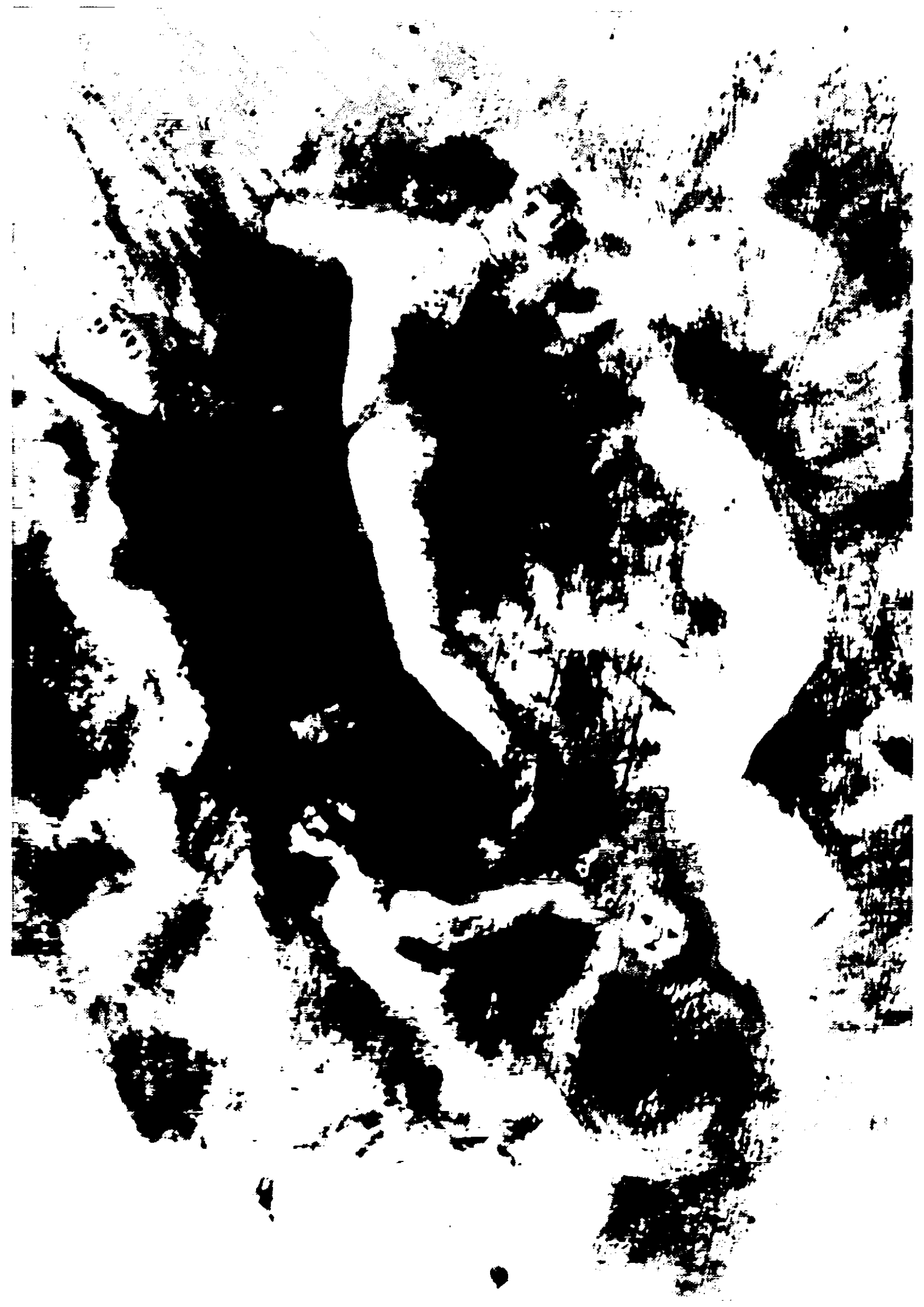

V.N.Čekrygin: Auferweckung 


\subsection{Die Biokosmisten ${ }^{1}$}

"Immortalismus und Interplanetarismus" (immortalizm $i$ interplanetarizm), die Überwindung der Grenzen von Zeit und Raum, - mit dieser Losung traten gegen Ende des Jahres 1920 in Moskau (später auch in Petrograd) die sogenannten Biokosmisten (biokosmisty) an die erstaunte Öffentlichkeit und verkündeten ein Programm, dessen zahlreiche Übereinstimmungen mit der Lehre Fedorovs den Gedanken an eine Beeinflussung nahelegen. ${ }^{2}$ Hervorgegangen aus Kreisen probolschewistischer Anarchisten, forderten sie die völlige Befreiung des Menschen, das heißt die sofortige Beseitigung nicht nur der sozialen, politischen und ökonomischen, sondern auch aller "natürlichen" Fesseln. Konkret verstanden sie darunter die Abschaffung des Todes, die Eroberung des Weltalls und die Auferweckung der Verstorbenen. Erst dann, so erklärten sie, sei der Mensch wirklich frei, wenn er die volle Herrschaft über Zeit und Raum errungen habe. ${ }^{3}$

Die Anfänge dieser Bewegung liegen im Dunkeln. Wahrscheinlich bestand bereits in den ersten Jahren der Sowjetmacht in Moskau eine Gruppe, deren Mitglieder sich selbst als Biokosmisten bezeichneten, während sie von Außenstehenden für Anhänger Fedorovs gehalten oder mit diesen in Verbindung gebracht wurden. Die früheste Erwähnung der Biokosmisten findet sich in einer

1 Dieses Kapitel ist die überarbeitete und erheblich erweitene Fassung meines Aufsatzes "Die 'Biokosmisten' - Anarchismus und Maximalismus in der frühen Sowjetzeit." In: G. FrEIDHOF u.a. (Hgg.), Studia Slavica in Honorem Vini Doctissimi Olexa Horbatsch. I: Beiträge zur ostslawischen Philologie, 1, München 1983, S. 61-76.

2 In der Literatur finden sich nur vereinzelt Hinweise auf die Biokosmisten und ihr Programm. Nikitina und - ihr folgend - Goriêly und Eimermacher nennen sie beilăufig unter den literarischen Gruppen der zwanziger Jahre. E.F. NikrtiNA, Russkaja literatuma ot simvolizma do nasich dnej, M. 1926, S. 141. B. GoRIELY, Le avanguardie letlerarie in Europa, Milano 1967, S. 115. K. EIMERMACHER, Dokumente zur sowjerischen Literaturpolitik 1917-1932, Stuttgart 1972, S. 307f. DERS., "Zur Frage des Zusammenhangs von literaturpolitischen Entscheidungen ..." In: Russian Literature, VI-2, 1978, S. 135. Bei G. MAXIMOFF [MAKSIMOV; d.i. G.P. LAPOT'], The Guillotine at Work: Twenty Years of Terror in Russia, Chicago 1940, S. 362, werden sie im Zusammenhang mit dem Schicksal des nachrevolutionăren russischen Anarchismus kurz erwăhnt. Jeweils sehr knappe Hinweise im Zusammenhang mit Fedorov finden sich bei G. KRAISKI, Le poetiche nusse del Novecento dal simbolismo alla poesia proletaria, Bari 1968, S. 286. JUA. MoLoK, V.I. KostrN, "Ob odnoj idee 'budušrego sinteza živych iskusstv'." In: Sovetskoe iskusstwoznanie "76, 2, M. 1977 , S. 299, 333f. Anm. 6. M. Ripellino, "Play Majakovskij." In: Rossija - Russia, 3, Torino 1977, S. 17. L. HeLleR, De la Science-Fiction soviérique, Lausanne 1979, S. 41 (dass. russ. Vselennaja za predelom dogmy, London 1985, S. 63). S.I. SUCHICH, "M. Gor'kij i N.F. Fedorov." In: Russkaja Literatura, 1980, 1, S. 160. S.G. SEMENOVA, "Čelovek, priroda, bessmertie v poezii Nikolaja Zabolockogo." In: Literatumaja Gruzija, 1980, 9, S. 140f. DiES., "Kosmos i chudožestvennoe tvorCestvo." In: Dekorativnoe Iskusstvo SSSR, 1981, 11, S. 11f. G.V. FILIPPOV, Russkaja sovetskaja filosofskaja poezija, L. 1984, S. 18f. - Weitgehend auf meinem in Anm. 1 genannten Aufsatz basien S.G. Semenova, "Masterovye ideala. Poczija pervogo posleoktjabr'skogo desjatiletija." In: Oktjabr', 1987, 11, S. 196f.

3 Vgl. Fedorovs Kritik an allen bloß sozialreformerisch oder -revolutionär begründeten Verheißungen eines freien und glücklichen Daseins bei ungebrochener Herrschaft des Todes. FOD I, S. 320; II, S. 204. 
Tagebuchaufzeichnung von Andrej Belyj; danach ist Belyj im Februar 1918 mit "Anhängern Fedorovs" (fedorovcy) und "Biokosmisten" zusammengetroffen. ${ }^{4}$

Nachweisbare Aktivitäten entfalteten die Moskauer Biokosmisten jedoch erst mit Beginn der zwanziger Jahre unter ihrem Führer und Theoretiker, dem Dichter und Anarchisten Aleksandr Agienko, der zumeist unter dem Pseudo-

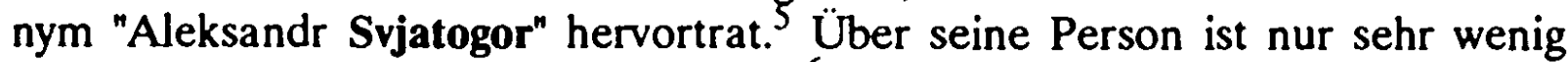
bekannt. "Arm wie eine Kirchenmaus", 6 dafür aber von sich selbst und der Bedeutung seiner Ideen überzeugt, verband Svjatogor Sendungsbewußtsein mit einem ausgeprägten Hang zur Selbstdarstellung. Seit dem Erscheinen seines ersten Gedichtbändchens im Jahre $1907^{7}$ war er um Anerkennung als Dichter und weltverbessernder Denker bemüht, wenn auch ohne erkennbaren Erfolg. Seine politischen und künstlerischen Vorstellungen waren exzentrisch und radi$\mathrm{kal}$, nicht selten jedoch bis zur Unverständlichkeit verworren. So forderte er in seinem 1917 erschienenen Gedicht- und Aufsatzband Petuch revoljucii unter der Parole "Es lebe der Vulkanismus!" (Da zdravstuuet Vulkanizm!) die Abschaffung der gesamten bürgerlichen Kultur und ihre Ersetzung durch eine nicht näher bestimmte "Vulkankultur" (vulkankul'tura): "Allen Ländern, allen Völkern, allen Bewohnern ferner Planeten, dem ganzen grenzenlosen und unsterblichen Kosmos verkünde ich den Vulkanismus! ${ }^{\text {8 }}$ Diesem Thema widmete er auch eine Reihe von Aufsätzen, die im folgenden Jahr in der Moskauer Zeitung Anarchija erschienen; ${ }^{9}$ über eine Resonanz ist nichts bekannt.

Erst als Svjatogor gegen Ende des Jahres 1920 damit begann, seine Ideen - nun unter dem Begriff "Biokosmismus" ${ }^{\text {n10 }}$ - auf öffentlichen Kundgebungen und

4 A. BELYJ, "Rakurs k Dnevniku" [recte: Rakkurs dnevnika]; zitiert nach S.S. GRECISKIN, A.V. LAvrov, "Andrej Belyj i N.F. Fedorov." In: Blokovskij sbomik, 3, Tartu 1979, S. 155. Năheres ist nicht bekannt. - Möglicherweise gibt es noch einen früheren Hinweis auf die Biokosmisten: 1917 veröffentlichte der Fedorov-Anhänger I.P. Brichnizev seinen Gedichtband Liturgija celomu in einem Moskauer Verlag Bessmerrie; der Name könnte auf ein Unternehmen der Biokosmisten deuten. Siehe II: 2.3.1. Anm. 56.

$5 \mathrm{DaB}$ es sich bei Aleksandr Svjatogor um ein Pseudonym von A. Agienko handelt, geht aus mehreren Beitrăgen der Zeitschrift Bessmentie, 1922, 1, hervor; vgl. dort S. 9, 11 .

6 So schildert ihn sein Moskauer Verleger I.N. Kuznecov in einem Widmungsschreiben an Gor'kij im Dezember 1916, in dem er diesen um eine wohlwollende Äußerung über Svjatogor bittet. Licnaja biblioteka A.M. Gor'kogo, kn. 1, M. 1981, S. 162 f.

7 Es trug den Titel Vzmachi. Ihm folgte das Gedichtbändchen [A.] SVjaTogor [AGIENKo], Stichery o vertikali, M. 1914, und die Abhandlung O. AGlENKO, Vil'nij leatr [ukr.], M. 1917.

8 A. Svjatogor [Aglenko], Petuch revoljucii, M. 1917, S. 16.

9 Siehe A. AGIENKo, "Iz našej letopisi." In: Biokosmist, 1922, Nr. 1, S. 2. - Anarchija, das Organ der "Moskauer Föderation anarchistischer Gruppen", wurde herausgegeben von G.K. Askarov [Jakobson], dem spăteren Mitbegründer der Anarchisten-Universalisten (siehe unten). Vgl. auch Gonenija na anarchizm v Sovetskoj Rossii, Berlin 1922, S. 19. Die Zeitung Anarchija war mir nicht zugănglich.

10 Wann und von wem dieser Begriff geprägt wurde, konnte nicht festgestellt werden. - Der Begriff "Kosmismus" effreute sich unter den russischen Anarchisten seinerzeit großer Beliebtheit, wenn er auch mitunter in recht eigenwilliger Bedeutung gebraucht wurde; die "Pananarchisten" 


\section{Diskussionsveranstaltungen vorzutragen, erregte er Aufsehen. Der Dichter Mat- vej Rojzman erinnerte sich}

... an den Auftritt eines Biokosmisten, der nach Moskau gekommen war und seine geschmacklosen Verse zur Probe vortrug. Brjusov stand unter dem Bogen des zweiten Saales zusammen mit jungen Dichtern und Dichterinnen. Alle bogen sich vor Lachen. Da erhob sich von einem Tischchen ein Rotarmist mit drei Balken am Kragenspiegel und wandte sich an Valerij Jakovlevic: "Könnte man nicht, Genosse Brjusov, dem Bürger Biokosmisten vorschlagen, seinen Vortrag im zweiten Stock, über uns, fortzusetzen?" - Im zweiten Stock befand sich, wie auf einem riesigen Schild zu lesen stand, eine Heilanstalt für Geisteskranke..."

\section{Der Schriftsteller und Kritiker Boris Agapov beschreibt Svjatogor als}

... eine[n] kleinen Mann[...] in billiger Tweedjacke, Stiefelgamaschen, Breeches und zerlöcherten Schuhen, der vor seinen wildblickenden Augen alle zehn Finger spreizte und mit ihnen hin und her fuhr, als suche er nach passenden Worten. $\mathrm{Zu}$ jeder Zeit und bei jeder Gelegenheit erklärte er, es sei für die Menschheit die Zeit gekommen, den Weltraum zu besiedeln, Leben auf tote Planeten zu bringen. Einzig darin liege Poesie, alles andere sei Schwachsinn. Deshalb nannte er sich Biokosmist. $^{\text {2 }}$

Einen Auftritt Svjatogors im Moskauer Anarchistenklub schildert Nikolaj Berdjaev, wobei er den Biokosmisten bezeichnenderweise für einen Anhänger Fedorovs hält:

Der Klub der Anarchisten (die damals noch erlaubt waren) hatte einen Disput über Christus angekündigt. Man hatte mich eingeladen, daran teilzunehmen. Auch Bischöfe und Geistliche waren eingeladen worden, aber nicht erschienen. Es waren da: Tolstojaner ${ }^{13}$ ], Anhänger N. Fedorovs, die Fedorovs Idee der Auferstehung [sic] mit einem Anarcho-Kommunismus zu verbinden suchten, fer-

beispielsweise verwendeten ihn anstelle von "Kosmopolitismus" zur Bezeichnung des apolitischen brüderlichen Zusammenlebens aller Menschen. Siehe Brat'ja GoRdiNY, Manifest pananarchistov, M. 1918, S. 21-26.

11 M.D. Rojzman, Vse, cto pomnju o Esenine, M. 1973, S. 88. Aus dem Bericht geht nicht hervor, ob es sich bei dem genannten Biokosmisten um Svjatogor gehandelt hat. Vgl. auch AGIENKo (wie Anm. 9). V. ANIST, "Dviženija biokosmizma." Ebd., S. 6. - Bevorzugter Schauplatz von Svjatogors Auftritten war zu jener Zeit das Künstlercafé "Domino", über das der Konstruktivist K.L. Zelinskij schreibt: "Ins 'Domino' ging man, um Diskussionen über die phantastischsten Themen zu hören und sich beim Klappern des Geschirrs die Reihe der niemandem bekannten Neoklassiker, Biokosmisten, Efuisten, Niðevoken, Präsentisten, Expressionisten, Egokubo- und Pseudofuturisten sowie anderer Versemacher anzusehen, die einander Abend für Abend seelenruhig und selbstbewuBt auf der Bühne ablösten." K.L. ZelinskJ, Na rubeže dvuch époch, M. 1959, S. 209. Wie die Biokosmisten, so wollte auch Zelinskij sich nicht mit der bloßen Verheißung von Freiheit zufriedengeben: "... ich will kein Leben im Vorzimmer eines künftigen Palastes. Mein Leben vollzieht sich hier und heute." DERS., "Bod." In: Oktjabr, 1929, 6, S. 186.

12 B.N. Agapov, "Wo sind Sie, Blom?" In: Sowjetische Erzählungen heute, München 1979, S. 241. (Die Originalveröffentlichung konnte nicht ermittelt werden). - Agapov, Mitglied der literarischen Gruppe der Konstruktivisten, lebte seit 1922 in Moskau, wo er vermutlich Svjatogor begegnet ist.

13 Hierbei handelt es sich offenbar um Anhänger einer Fraktion der Anarchisten, die sich, unter Berufung auf Tolstoj, zu den Prinzipien eines kompromißlosen Pazifismus und vőlliger Gewaltlosigkeit bekannten. Zur Geschichte dieser Bewegung siehe M. POPOVsKu, Russkie muziki rasskaryvajut. Posledovateli L.N. Tolstogo v Sovetskom Sojuze 1918-1977. London 1983. 
ner einfache Anarchisten und einfache Kommunisten. (...) Es sprach ein Anhänger Fedorovs (fedorovec), der sich selbst einen Biokosmisten nannte. Er trug einen unglaublichen Unsinn vor über ein Stutenevangelium. Zum Schluß erklărte er, das soziale Programm sei bereits maximal verwirklicht und nun bliebe nur noch, die kosmische Auferstehung [sic] auf die Tagesordnung zu setzen. Dies loste im Auditorium lautes Gelächter aus. ${ }^{14}$

Berdjaevs Bericht (etwa zwei Jahrzehnte nach dem geschilderten Ereignis ver$\mathrm{fa} B \mathrm{t}$ ) bedarf einiger Korrekturen und Ergänzungen. Wie Fedorov forderte Svjatogor die tätige Auferweckung der Verstorbenen (voskrešenie) im Gegensatz zur passiven Auferstehung (voskresenie), von der Berdjaev spricht. Dabei betonte er jedoch die Originalität dieser Idee und wehrte sich vehement dagegen, als Anhänger Fedorovs bezeichnet zu werden. ${ }^{15}$ Auf der von Berdjaev besuchten Veranstaltung sprach Svjatogor über das Thema "Der Christus des Biokosmisten" (Christos biokosmista). Von ihm stammt auch der Begriff "Stutenevangelium" (Evangelie ot kobyly). Der dreitägige Disput, an dem auch S.N. Bulgakov teilnahm, fand nicht, wie Berdjaev schreibt, um die Wende des Jahres 1918/19, sondern wohl erst 1921 statt. $^{16}$

$\mathrm{Zu}$ dieser Zeit hatten Svjatogor und eine kleine Gruppe von Biokosmisten auch politisch Position bezogen, indem sie sich zu Beginn des Jahres 1921 den sogenannten Universalisten angeschlossen hatten, einer neugegründeten Anarchistenvereinigung, die im Gegensatz zu anderen Anarchistengruppen die Sowjetmacht als notwendiges Stadium auf dem Weg zu einer herrschaftsfreien Gesellschaft ausdrücklich befürwortete. ${ }^{17}$ Eine Zeitlang gehörte Svjatogor dem Sekretariat der Universalisten an. In ihrer Zeitschrift, Universal, veröffentlichte er im Laufe des Jahres 1921 mehrere Artikel, in denen er das Programm des Biokosmismus zu erläutern suchte. ${ }^{18}$ Neben Svjatogor trat zu jener Zeit noch ein anderer Biokosmist hervor, Pavel Ivanovix Ivanickij, der auch zum Kreis der

14 N.[A.] Berdjaev, Samopoznanie, Paris ${ }^{2}$ 1983, S. 273f. - Öffentliche Streitgespräche über 'theologische' Fragen, an denen Atheisten, religiöse Intellektuelle und Kirchenmånner teilnahmen, waren in den Jahren nach der Revolution durchaus keine Seltenheit. Bekannteste Beispiele: die Diskussionen zwischen Lunacarskij, Vjareslav Ivanov und dem Metropoliten A.I. Vvedenskij (1888-1946), dem ideologischen Führer der 'Lebendigen Kirche', in Moskau, bei denen es um nichts Geringeres ging als die Klärung der Frage nach der Existenz Gottes. Siehe z.B. die anschauliche Schilderung eines solchen Streitgesprächs im Augenzeugenbericht des Jesuitenpaters M. D'HeRBIGNY, L'aspect religieux de Moscou en octobre 1925, Roma 1926, S. 222 231 [38-47].

15 Siehe unten.

16 Siehe ANIST (wie Anm. 11).

17 Siehe Aglenxo (wie Anm. 8), S. 3. - Der vollstăndige Name dieser Organisation lautete Vserossijskaja [bzw. Moskovskaja] sekcija anarchistov-universalistov (VSAU [bzw. MSAU]). Sie war im Dezember 1920 von A.L. Gordon, G.K. Askarov und anderen in Moskau gegründet worden. Vgl. H.J. GoldBerg, The Anarchists View the Boishevik Regime, 1918-1922, Ph.D. diss. Univ. of Wisconsin 1973; Ann Arbor 1974, S. 200-207. P. AVRICH, The Russian Anarchists, Princeton 1967, S. 201-203. V.V. KoMiN, Anarchizm v Rossii, Kalinin 1969, S. 168-178.

Vgl. ANIST (wie Anm. 11), S. 7. - Die Zeitschrift Universal war mir nicht zugänglich. 
Moskauer Fedorov-Anhänger gehörte. ${ }^{19}$ Zusammen mit Svjatogor repräsentierte Ivanickij die Biokosmisten bei zahlreichen öffentlichen Auftritten, darunter den Veranstaltungen der Moskauer Sektion der "Freien philosophischen Assoziation" (Vol'fila). ${ }^{20}$

Am 17. April 1921 gründeten 26 Biokosmisten, angeführt von Svjatogor und Ivanickij, in Moskau einen Klub mit dem Namen "Kreatorium der Biokosmisten" (Kreatorij biokosmistov); der Anklang an 'Krematorium' war beabsichtigt und programmatisch: Am Beginn der neuen Ära des Biokosmismus sollte alles in der Vergangenheit Hervorgebrachte durch Feuer vernichtet werden. ${ }^{21}$

Als im Oktober und November 1921 auch die Universalisten von der allgemeinen Anarchistenverfolgung erfaßt wurden - obwohl prosowjetisch, hatten sie den Aufstand der Kronstädter Matrosen begrüßt ${ }^{22}$, distanzierten sich die Biokosmisten von ihnen und beeilten sich, der Sowjetmacht ihre Loyalität zu versichern. Auf einer gemeinsamen Sitzung von Vertretern der Universalisten und des "Kreatoriums der Biokosmisten", die am 29. Dezember 1921 in Moskau

19 Wann Ivanickij mit Fedorovs Ideen bekannt wurde, ließ sich nicht feststellen. Ein 1918 erschienener Artikel Ivanickijs "K bratskomu edinstvu" (in: Ventograd, 4, 26.3./8.4.1918, S. 2f.) enthălt zwar Anklănge an die Filosofija obšxego dela - so ist u.a. davon die Rede, die Menschheit durch "Religion und Wissenschaft, Kultur im allgemeinsten und weitesten Sinne," zu einer "Brüderschaft" zu vereinigen -, doch reichen solche Formulierungen nicht aus, um einen Einfluß Fedorovs nachzuweisen. Ivanickijs spătere Zugehörigkeit zum Kreis der Moskauer Fedorov-Anhănger ist hingegen belegt. Siehe II: 4.1. und unten Anm. 51.

20 Siehe ANIST (wie Anm. 11), S. 7. - Die Vol'fila war 1918 konzipiert und im folgenden Jahr von Belyj, Blok, Ivanov-Razumnik und anderen in Petrograd gegründet worden, um, wie es hieB, neue Ansătze zur Lösung sozialer und kultureller Fragen zu diskutieren; sie bestand bis 1924, die Moskauer Sektion, der u.a. Berdjaev und Florenskij angehorten, von 1921 bis 1924 . Siehe ANON., "Vol'naja filosofskaja associacija." In: Kniga i Revoljucija, 1920, 2, S. 91f. A. BELYJ, "Vol'naja filosofskaja associacija." In: Novaja Russkaja Kniga, 1922, 1, S. 32f. Eine geheime "Splittergruppe" der Vol'fila soll in Moskau bis 1932 existiert haben. Siehe V.P. EFrormson, "Avtoritet, a ne avtoritarnost'." In: Ogonek, 11, 1989, S. 12.

21 Siehe Agienko (wie Anm. 9), S. 3. - Diese mit Fedorovs Lehre völlig unvereinbare Haltung erinnert an den bilderstürmerischen Bruch der Futuristen, Suprematisten und Proletkul't-Dichter mit der Vergangenheit, der seinen Ausdruck in der Symbolik des Krematoriums und Verbrennens fand. Siehe V.[Z.] PAPERNYJ, Kul'rura 'Dva', Ann Arbor 1983, S. 31f., mit der bemerkenswerten Vermutung, daß die in den zwanziger Jahren verbreitete Propagierung der Kremation als 'fortschrittlicher' Bestattungsart - verbunden mit einer Verachtung der Friedh $\delta$ fe Elemente einer unbewuBten Polemik gegen Fedorovs Lehre enthalte. Der Gedanke, das Alte durch Feuer restlos zu vernichten, um dem Neuen Platz zu schaffen und gleichzeitig Erinnerung und Rekonstruktion zu verhindern, hat auch in RuBland Tradition. So hatte Bakunin davon geträumt, "ganz Rußland niederzubrennen". Die 'mystischen Anarchisten' um 1905 hofften auf ein "herrliches Feuer, das die alte Welt verzehren werde," und forderten, "die ganze Geschichte [müsse] verbrannt werden." Ausführlich dazu R. STTrEs, "Iconoclastic Currents in the Russian Revolution: Destroying and Preserving the Past." In: Bolshevik Culture, Bloomington 1985, S. 1-24. Siehe auch L. LowENTHAL, "Calibans Erbe. Bücherverbrennungen und Verdrăngungsmechanismen." In: Kanon und Zensur, München 1987, S. 227-236. Zu ergănzen wäre, daß das Bild des Weltenbrandes sich verbindet mit der Auffassung der Revolution als apokalyptisches Ereignis, als Anbruch eines neuen Äons der Eschatologie; so etwa bei Blok und nach dem Zeugnis von Losev - bei Florenskij. Erinnert sei auch an das Gegenbild des konservativen K.N. Leont'ev, RuBland "einzufrieren" (podmonozit').

Vgl. GoldBERG (wie Anm. 17), S. 205-207. AVRICH (wie Anm. 17), S. 230 f. 
stattfand, kam es dann zum endgültigen Bruch zwischen beiden Gruppen und anschließend zur Gründung eines "Kreatoriums der Russischen und Moskauer Anarchisten-Biokosmisten" (Kreatorij Rossijskich $i$ Moskovskich anarchistov-biokosmistov; KR i MA-B). ${ }^{23}$ Das Sekretariat des "Kreatoriums", dem neben Svjatogor und Ivanickij der Proletkul't-Dichter und Mitbegründer der Kuznica Nikolaj Semenoviz Degtjarev ${ }^{24}$ sowie die nicht näher bekannten V. Zikeev und É. Grozin angehörten, beschloß eine Deklaration, die am 4. Januar 1922 von der Regierungszeitung Izvestija veröffentlicht wurde. ${ }^{25}$ Darin hieß es, die Position des klassischen Anarchismus, nämlich die bedingungslose Ablehnung jeglicher Form von Herrschaft, habe sich gegenüber der revolutionären Sowjetmacht als unhaltbar und anachronistisch erwiesen. Bislang sei es jedoch der anarchistischen Bewegung einschließlich der Universalisten nicht gelungen, eine den neuen Verhältnissen entsprechende ideologische Konzeption zu entwickeln, die von der Sowjetmacht als einem positiven Faktor ausgehe. Die anarchistische Bewegung sei somit in eine Sackgasse geraten, aus der allein die neue Ideologie des Biokosmismus einen Ausweg weise. Mit wenigen Sätzen wurden sodann die Prinzipien und Ziele dieser neuen Ideologie skizziert:

Biokosmismus ist eine neue Ideologie, die als Grundprinzip einen Begriff von der Persönlichkeit hat, die in ihrer Kraft und in ihrer Kreativităt heranwăchst bis zur Selbstbestătigung in der Unsterblichkeit und im Kosmos. Für wesentliche und reale Rechte der Persönlichkeit halten wir das Recht auf Sein (Unsterblichkeit, Auferweckung und Verjüngung) und auf freie Fortbewegung im Kosmos (nicht aber die Scheinrechte, die in der Deklaration der bürgerlichen Revolution von 1789 verkündet wurden). Dabei stützt sich der Biokosmismus auf die jüngsten Errungenschaften von Wissenschaft und Technik, die er freilich ebenso wie die Errungenschaften auf den Gebieten der Philosophie, Soziologie, Okonomie, Kunst und Ethik entsprechend seiner großen Teleologie umzugestalten sucht. $^{26}$

Nachdrücklich betonten die Biokosmisten ihre positive Einstellung gegenüber der Sowjetmacht, in der sie eine Staatsform sahen, die "mit revolutionärer Geschwindigkeit [übergehe] von der Herrschaft des Menschen über den Menschen zur Herrschaft des Menschen über die Natur" und damit dem "großen Ziel des Biokosmismus" diene. ${ }^{27}$

23 Vgl. "Iz protokola No. 1." In: Biokosmist, 1922, 1, S. 2. AgIEnko (wie Anm. 9), S. 3.

24 Zu N.S. Degtjarev siehe G. KRATZ, Die Geschichle der 'Kuznica' (1920-1932), Gießen 1979, S. $39,59,73,113$.

25 Kreatorij Rossijskich i Moskovskich anarchistov-biokosmistov, ["Deklarativnaja rezoljucija"]. In: Izvestija VCIK, 4 (4.1.1922), S. 3. Wieder abgedruckt in: Biokosmist, 1922, 1, S. If.

26 Ebd.

27 Ebd. - Wie die sowjetischen Machthaber auf diese Deklaration reagierten, ist nicht bekannt, doch dürften sie in den verstiegenen, gănzlich irrealen Forderungen kaum eine akute Gefahr gesehen haben, bestand doch das Ziel der Biokosmisten, wie der Anarchist G. Maksimov in seinen Erinnerungen sarkastisch bemerkte, darin, "... to bring about the social revolution in the interplanetary spaces but not upon the Soviet territory." MAXIMOFf [MAKsimov] (wie Anm. 2). Bereits Trockij hatte den 'Kosmismus' der Proletkul't-Dichter als eskapistisch ("Fahnenflucht in interstellare Sphären") kritisiert. Siehe II: 3.1.2. Maßgebend für das Verhalten der Obrigkeit 
Ausführlich dargelegt wurde die Ideologie des Biokosmismus von Svjatogor und Ivanickij in einer Broschüre, die im Dezember 1921 vom "Kreatorium der Biokosmisten" herausgegeben wurde, ${ }^{28}$ sowie in dem Organ der Biokosmisten, der Zeitschrift Biokosmist, ${ }^{29}$ die zwischen März und Juni 1922 monatlich mit der für jene Zeit beachtlichen Auflage von 3000-4000 Exemplaren erschien; sie kann als Sprachrohr Svjatogors bezeichnet werden, da die überwiegende Anzahl der Beiträge aus seiner Feder stammt. ${ }^{30}$

Die Grundgedanken des Biokosmismus lassen sich kurz zusammenfassen. ${ }^{31}$ Ausgehend von dem instinktiven Verlangen des Menschen nach Unsterblichkeit (bessmertie) und Unendlichkeit (beskonecnost') formulieren die Biokosmisten zwei fundamentale Rechte: das "Recht auf Sein" (pravo na bytie) und das "Recht auf freie Fortbewegung" (peredviženie). Das "höchste Gut" ist demnach "unsterbliches Leben im Kosmos", das größte Übel die "Begrenztheit in Zeit und Raum" (lokalizm vo vremeni $i$ prostranstve). Alle bisherigen Gesellschaftsordnungen und ihre Ideologien (insbesondere die Religion) beruhen auf der Hinnahme dieser Begrenztheit. Doch auch jene Ideologien, die sich die Befreiung

war das Bekenntnis der Biokosmisten zu uneingeschrănkter Loyalităt sowie der enwünschte Effekt einer Spaltung und Schwăchung der anarchistischen Bewegung. Die durchweg sehr hohen Auflagen der von den Moskauer Biokosmisten veröffentlichten Schriften dürften nicht ohne staatliche Unterstützung möglich gewesen sein. Im Lager der Anarchisten, die trotz zunehmender Verfolgung durch die Sowjetmacht in zahlreiche Fraktionen gespalten waren, stieß die Deklaration der Biokosmisten auf heftige Kritik und loste einige Bewegung aus: So solidarisierte sich die "Allrussische Föderation der Anarchisten-Kommunisten" (Vserossijskaja federacija anarchistov-kommunistov) mit den verbliebenen 'Universalisten' gegen die Biokosmisten. Siehe "Ot sekretariata K.R. i M.A.-B." In: Biokosmist, 1922, 2-3, S. 27f. - Auch in ihren späteren Veröffentlichungen bekannten sich die Biokosmisten vorbehaltlos zur Sowjetmacht und verteidigten die 'Diktatur des Proletariats'. Siehe 2.B. A. Svjatogor [AGIENKo], "Doktrina otcov' i anarchizm-biokosmizm." In: Biokosmist, 1922, 1, S. 5.

28 A. Svjatogor [AgIEnKo], P. IVANicku, Biokosmizm (Materialy - No. 1), M. 1921. Aufl. 2000 Expl.; enthalt: A. SVJATOGOR [AGIENKo], "Biokosmičskaja poetika", S. 3-11 (wieder abgedruckt in: Literatumye manifesty. Ot simvolizma do 'Oktjabrja'. M. 1924, S. 220-224; ital. Úbers. bei KraiskI, wie Anm. 2, S. 291-296) und P. IVANICKU, "Proletarskaja étika", S. 12-14. Bei Ivanickijs Beitrag handelt es sich um eine Rezension der anonymen Schrift $O$ proletarskoj eitike, die erstmals 1906 erschienen war und nach der Revolution mehrere Neuauflagen erlebte. Ausführlich dazu II: 2.1.2. Das revolutionăr-prometheische Pathos dieser Schrift dürfte nicht ohne Einflu $B$ auf die Biokosmisten geblieben sein.

29 Biokosmist. Organ organizacii Kreatorij rossijskich i moskovskich anarchistov-biokosmistov. M. 1922, 1 [Mărz], 2 [April], 3-4 [Mai-Juni]. - Die Doppelnummer 3-4 erschien auch als separate Broschüre unter dem Titel A. Svjatogor [AGIENKo], Dva. (Biokosmizm, materialy No. 2). M. 1922. Die ersten beiden Nummern von Biokosmist hatten die bemerkenswert hohe Auflage von 4000 Exemplaren, die Doppelnummer 3-4 brachte es auf 3000 Exemplare, die inhaltlich identische Broschüre Dva auf 2000 Exemplare.

30 Die übrigen Mitarbeiter waren P.I. Ivanickij, N.S. Degtjarev, V. Anist, E. Grozin und Petr Lidin.

31 Die folgende Darstellung nach Svjatogor [AgIENKo], IVANickU (wie Anm. 28). A. SVjatogor [AGIENKo], "Naši utverždenija." In: Biokosmist, 1922, 1, S. 3-5. AGIENKo (wie Anm. 23), S. 5f. E. Grozin, "Na puti k biokosmizmu." Ebd., S. 6. Svjatogor [AGIENko],(wie Anm. 27), S. 3-21; bes. S. 13ff. - Da die Thesen der Biokosmisten in den genannten Beitrăgen formelhaft wiederkehren, wird auf Einzelnachweise verzichtet. 
des Menschen zum Ziel gesetzt haben (einschließlich des klassischen Anarchismus), akzeptieren sie als "natürliche Notwendigkeit" (estestvennaja neobchodimost'). Einzig der Biokosmismus erkennt in der natürlichen Begrenztheit, namentlich im Tod, die letzte Ursache aller Unfreiheit und Ungerechtigkeit und erklärt ihr deshalb den Krieg. Ziel des Biokosmismus ist die vollständige Beherrschung von Raum und Zeit, das heißt persönliche Unsterblichkeit, Leben im All und Auferweckung der Verstorbenen.

Wir erklären, daß man jetzt die Frage der Verwirklichung persönlicher Unsterblichkeit auf die Tagesordnung setzen muß. (...) Außerdem setzen wir auch den 'Sieg über den Raum' auf die Tagesordnung. Wir sagen: keine Luftfahrt - das ist viel zu wenig, sondern Raumfahrt. (...) Man darf nicht länger nur Zuschauer sein, sondern muß aktiver Teilnehmer am kosmischen Leben werden. Unsere dritte Aufgabe ist die Auferweckung der Toten. Unsere Sorge gilt der Unsterblichkeit der Person im Vollbesitz ihrer geistigen und körperlichen Kräfte. Die Auferweckung der Toten ist die Wiederherstellung der Dahingeschiedenen in eben dieser Vollkommenheit. ${ }^{32}$

Die genannten Ziele können weder auf religiösem oder mystischem Wege noch individuell verwirklicht werden, sondern nur durch die gemeinsame Anstrengung aller zu diesem Zweck miteinander verbündeten Menschen und unter Einsatz der jüngsten Errungenschaften von Wissenschaft und Technik. Da das Ziel des Biokosmismus dem innersten Streben eines jeden Menschen entspricht und somit weder egoistisch noch altruistisch ist, vermag es allein alle sozialen Gegensätze zu überwinden und die Menschheit ohne staatlichen Zwang zu einen. ${ }^{33}$ Während Kommunisten und Anarchisten sich mit dem Umbau der Gesellschaft zufriedengeben, gehen die Biokosmisten viel weiter - sie zerstören das "Gefängnis der Natur" und verwirklichen so die "maximale Freiheit und das maximale Recht der Persönlichkeit"; sie schaffen ein "neues Leben" und eine "neue Kultur" und bilden damit die "Avantgarde der Avantgarde der Weltrevolution". 34

Wie bereits aus dieser Skizze erkennbar ist, weist die Lehre der Biokosmisten eine Reihe von Gemeinsamkeiten mit zentralen Gedanken der Fllosofija obšcego dela auf - bis hin zu gleichen Begriffen und Formulierungen. So findet sich bei Fedorov die Formel 'Zizn' bessmertnaja est' istinnoe dobro, a smert',

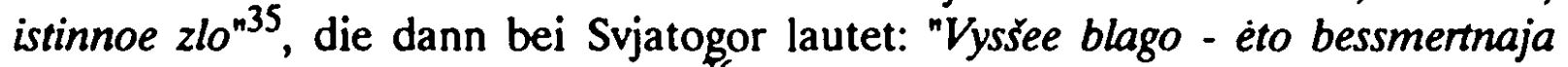
żizn'v kosmose. Vysšee zlo - smert ${ }^{m 6}$, sowie die Aufforderung, die Erde in ein

32 Svjatogor [Agienko] (wie Anm. 28), S. 3f.

33 Dabei fehlt auch nicht der Gedanke einer biokosmistischen Universalsprache; siehe SvjaTOGOR [AGIENKo], ebd., S. 7.

34 Die Selbsteinschătzung der Biokosmisten wird aus einem von Svjatogor angestellten Vergleich deutlich: Bisher habe die Menschheit wie in Platons Hobhle nur die Schatten der Dinge erblickt; nun aber in Gestalt der "biokosmistischen Avantgarde" habe sie die Höhle verlassen und sehe die Dinge selbst, ja wage sogar, in die Sonne zu schauen. SvjATOGor [AGIENKo] (wie Anm. 31), S. 5.

35 FOD I, S. 402. - Um die Ähnlichkeit der Formulierungen deutlich werden zu lassen, werden dieses und die folgenden Zitate nicht übersetzt. 
lenkbares Raumschiff zu verwandeln (Fedorov: "... celoveðestvo dolžno byt' ne prazdnym passažirom, a prislugoju, ékipažem našego zemnogo ... korablja... ${ }^{\text {337; }}$ Svjatogor: "I kosmiceskim korablem, upravljaemym umudrennoj volej biokosmista, dolžna stat' naša zemlja. ${ }^{\text {38 }}$ ). Für die Biokosmisten liegt die "tiefste Ursache der sozialen Ungerechtigkeit, des widerwärtigen Privateigentums sowie der individuellen, nationalen und Klassengegensätze" in der "zeitlichen Begrenztheit", im Tod. ${ }^{39}$ Das Ideal sozialer Gerechtigkeit kann deshalb "noch nicht der Endpunkt auf dem Weg zu einer besseren Ordnung der Dingen sein, es muß vielmehr ergänzt werden durch "das biokosmistische Ideal des Immortalismus, wodurch es in den Massen neue Begeisterung zu entfachen vermag auf dem Weg zu einem besseren Leben"40. "Kampf um individuelle Unsterblichkeit, um ein Leben im Weltall - das ist der allgemeine Willen, der die Menschen in der "neuen Gesellschaft" zusammenschließen wird. ${ }^{41}$ Auch Fedorov führt die soziale Frage und alle Gegensätze und Streitigkeiten auf die natürliche Begrenztheit des Menschen zurück, ${ }^{42}$ und auch er betont, daß nur ein allen gemeinsames Ziel Egoismus und Altruismus zu überwinden und die Menschheit zu einen vermag. Beide unterstreichen schließlich das "Moment des Schaffens" (tvoř̌eskij moment): "Persönliche Unsterblichkeit ist nicht gegeben, sie muß erkämpft, verwirklicht, geschaffen werden" (Svjatogor); ${ }^{43}$ "Die Aufgabe des Menschen besteht in der Umwandlung alles Geborenen, von selbst Entstandenen, Erzeugten und deshalb Sterblichen in Erarbeitetes (trudovoe) und deshalb Unsterbliches" (Fedorov) $^{44}$. Der ètika dela der Biokosmisten entspricht Fedorovs proektivizm: nichts darf empfangen, alles muß geschaffen werden; dem Menschen ist es aufgetragen, durch sein Tun sich und die Welt zur Vollendung zu führen. ${ }^{45}$

Doch gibt es auch gravierende Unterschiede. Sie betreffen insbesondere den für Fedorov wie für die Biokosmisten zentralen Gedanken der Überwindung

37 FOD I, S. 284; vgl. ebd., S. 336. N.[F.] FEDOROV, "Astronomija $i$ architektura." In: Vesy, 1 (1904), 2; hier S. 21. Dieser Gedanke wurde - unter ausdrücklicher Berufung auf Fedorov - von Brjusov in seinem "Preislied auf den Menschen" (Chvala Celoveku, 1906) aufgegriffen. Siehe dazu II: 2.2.2.

38 Svjatogor [AgIENKo] (wie Anm. 28), S. 4. - Dieser Gedanke wurde wiederholt aufgegriffen. Vgl. Brjusovs von Fedorov inspirierte Gedichte Chvala Celoveku (1906), Zemlja molodaja (1913), Molodost' mira (1922), Kak list'ja v osen' (1924) sowie V.T. Kirillovs Proletkul't-Gedicht My (1917). Unter dem Einfluß Fedorovs sprach auch V.N. Murav'ev (1924) von der Umwandlung der Erde in ein "gehorsames Raumschiff". Siehe II: 3.4.

39 Svjatogor [AgIENKo], "NaŠi utverždenija" (wie Anm. 31), S. 4.

40 A. AGIENKo, "Golod i biokosmizm." In: Biokosmist, 1922, 2, S. 3.

41 Svjatogor [Agienko] (wie Anm. 27), S. 17.

42 Vgl. FOD I, S. 402f;; II, S. 204.

43 Svjatogor [AgIenko] (wie Anm. 27), S. 16.

44 FOD I, S. 500.

45 Vgl. Fedorov nach VA. KoŽEVnIKov, "Nikolaj Fedoroviz Fedorov." In: Russkij Archiv, 44 (1906), 2, S. 278. Sviatogor [AgIENKo],"NaŠi utverždenija" (wie Anm. 31), S. 3. 
des Todes. Während die Biokosmisten darunter vor allem die Erlangung individueller Unsterblichkeit verstehen (die erste ihrer Forderungen), steht für Fedorov die Auferweckung aller Verstorbenen im Mittelpunkt. So heißt es bei Fedorov: Vseobšcee voskrešenie est' polnaja pobeda nad prostranstvom $i$ vremenem ${ }^{\text {"46. }}$ bei dem Biokosmisten Ė. Grozin hingegen: "Pobeda nad smert'ju budet pobedoj nad vremenem i prostranstvom. ${ }^{47}$ Der wesentliche Unterschied liegt jedoch darin, da $B$ Fedorov den Kampf gegen den Tod ethisch begründet: Die Aufgabe, den Tod zu überwinden und alles vergangene Leben wiederherzustellen, erwächst aus der sittlichen Pflicht aller Lebenden (der "Söhne"), das von den Vorfahren (den "Vätern") empfangene Leben zurückzuerstatten. Nur im Bewußtsein dieser Pflicht werden die Lebenden einander als "Brüder" erkennen und den gegenwärtigen "unbrüderlichen Zustand" überwinden. Unsterblichkeit ohne die Auferweckung aller Verstorbenen ist für Fedorov nicht nur unmöglich, sie wäre vor allem moralisch verwerflich. ${ }^{48}$ Die Biokosmisten hingegen sehen den Antrieb zum Kampf gegen den Tod im animalischen Selbsterhaltungstrieb eines jeden einzelnen, im instinktiven Streben nach individueller Unsterblichkeit (erst im Bemühen um ein allen gemeinsames Ziel verliert dieser Antrieb seinen egoistischen Charakter). Nicht das passive Gefühl der "Brüderlichkeit" (bratstvo), sondern aktive "Kampfgenossenschaft" (soratniČestvo) werde deshalb die Menschen zusammenschließen. ${ }^{49}$

Fedorovs Vorstellung einer sittlichen Pflicht gegenüber allen Verstorbenen war den Biokosmisten "völlig fremd", wie Svjatogor in einer knappen, polemischen Stellungnahme bemerkte, in der er jeglichen Einfluß der Filosofija obš̌ego dela auf die Ideologie der Biokosmisten bestritt; diese sei "völlig unabhängig" und ohne Berücksichtigung der Lehre Fedorovs entstanden. ${ }^{50}$ Die genannten Parallelen und Übereinstimmungen lassen daran freilich zweifeln.

Immerhin gehörte einer der führenden Biokosmisten, Pavel Ivanovið Ivanickij, nachweislich zum Kreis der Moskauer Fedorov-Anhänger um A.K. Gorskij und N.A. Setnickij. ${ }^{51}$ Ivanickij äußerte sich denn auch am ausführlichsten zur Frage der Auferweckung: ${ }^{52}$ Das Proletariat, durch sein klassenspezifisch kollektives Denken und Handeln prädestiniert für den erfolgreichen Kampf gegen die

46 Siehe FOD II, S. 351.

47 Grozin (wie Anm. 31), S. 6.

48 Siehe FOD I, S. 91.

49 A. SVjatogor [AgIENKo], "Radost' igrajustego zverja." In: Biokosmist, 1922, 2, S. 2. - Der Biokosmist A. Jaroslavskij rief in einem Gedicht den "SpieBbürgern, die sterben wollen," zu: "Uber Eure Leichen werden wir zur Unsterblichkeit gelangen!!" A.[B.] JAROSLAvSKU, "Mešanam želajuscim umeret'." In: Bessmertie, 1922, 1, S. 6.

50 SVjatogor [AGIENKo] (wie Anm. 27), S. 18-20. - Es handelt sich um die einzige Erwăhnung Fedorovs in den Schriften der Biokosmisten!

51 O.N. SETNICKAJA, Nikolaj Aleksandrovic Setnickij. Biografija. O.O. 1965. Ms. [Masch.], Bl. 8f. Kopie im FAP I, 337. Ausführlich II: 4.1.

Das Folgende nach IVANICKU (wie Anm. 28), S. 13 f. 
Natur, wird dereinst, "wenn die Stunde gekommen ist, da der menschliche Verstand über den Tod triumphiert," auch "jene nicht vergessen, die für die Verwirklichung des sozialen Ideals zugrundegegangen sind". Es wird seine "Genossenpflicht" (tovarišceskij dolg) erfüllen und zur "Befreiung der 'letzten Unterdrückten'" schreiten, indem es die Toten auferweckt. Dies wird möglich sein, da die "materielle Grundlage des Menschen - die Atome seines Organismus - prinzipiell nicht verlorengehen" (ein Gedanke, der sich auch bei Fedorov findet). Die so Wiederhergesteliten werden dann die endlosen Weiten des Alls besiedeln (auch dies ein Gedanke Fedorovs). Um die Verstorbenen bis dahin nicht zu vergessen, bestattet das Proletariat seine teuersten Genossen im Zentrum der Städte - auf dem Roten Platz, auf dem Marsfeld (bei Fedorov: im Kreml; auch dieser Gedanke geht möglicherweise auf ihn zurück). Im Unterschied zu Fedorovs ethischem Maximalismus gilt allerdings die von Ivanickij angeführte "Genossenpflicht" nur gegenüber einer Elite, den "teuersten Genossen" des Proletariats, jenen,"die für die Verwirklichung des sozialen Ideals zugrundegegangen sind"; nur sie sind einer künftigen Auferweckung 'würdig'. Diese Haltung erinnert an Rožkov, ${ }^{53}$ an Majakovskij ${ }^{54}$ und Krasin ${ }^{55}$ sowie an den Kult um den verstorbenen Lenin. ${ }^{56}$

Ivanickijs Hauptinteresse galt der Beherrschung des Wetters. Wie Fedorov sahen die Biokosmisten in der Bewältigung dieser Aufgabe nicht nur ein Mittel, um die Abhängigkeit des Menschen von der Natur zu verringern, sondern auch einen wichtigen Schritt auf dem Weg zur Überwindung der irdischen Beschränktheit und zur Eroberung des Weltalls. ${ }^{57}$

Die Regulierung des Wetters stellt bereits eine hohe Stufe auf dem Weg ins Weltall dar. Die Beherrschung des Wetters bedeutet bereits eine teilweise Beherrschung des Weltalls, da die Meteore Himmelskorper sind und die Lenkung der letzteren bereits eine Vorstufe zur Lenkung der kosmischen Körper ist. Die Regulierung des Wetters ist für uns die năchstliegende Aufgabe des Interplanetarismus. Der VorstoB in den Weltraum ist notwendig für den Sieg der Revolution und die Verwirklichung wahrer Glückseligkeit auf Erden. Die Verbindung mit dem Weltall wird unglaubliche Macht gewăhren. (...) Eine Trennung vom Weltall bedeutet Zusammenbruch, Zerstorung, Finsternis und Tod; die Verbindung mit dem Weltall hingegen Vereinigung, Schaffen und Leben im vollen Sinne. Die Regulierung des Wetters ist der Kanal, durch den wir uns mit dem Weltall verbinden. 58

Die durch die Weltrevolution herbeigeführte Einigung der Menschheit werde, so glaubten die Biokosmisten, die Voraussetzungen schaffen für eine weltweite

53 Siehe II: 2.1 .2 . und 3.1.3.

54 Siehe II: 3.2.1.

55 Siehe II: 3.1.3.

56 Siehe II: 3.1.3.

57 Vgl. FOD I, S. 247, 280-283; II, S. 252.

AgIEnko (wie Anm. 40), S. 4f. 
Regulierung des Klimas sowie für die Entwicklung und den Einsatz einer "kosmischen Technik ${ }^{\text {n9 }}$.

Ivanickij befaßte sich insbesondere mit Methoden zur künstlichen Erzeugung von Regen, um auf diese Weise Dürrekatastrophen, wie sie vor allem den Süden Rußlands immer wieder bedrohten, abzuwenden. Seine Hoffnung setzte er dabei - ebenso wie Fedorov - auf die Elektrizität. Von den Möglichkeiten, die ihr planmäßiger Einsatz zu eröffnen schien, ging zu jener Zeit eine große Faszination aus. "Kommunismus - das ist Sowjetmacht plus Elektrifizierung des gesamten Landes", lautete Lenins bekannte Formel aus Anlaß des GOELRO-Planes (1920). Elektrizität sollte nicht nur Licht und Aufklärung in die entlegensten Dörfer bringen, sondern auch die Herrschaft des Menschen über die Natur ermöglichen. In diesem Sinne hatte schon Fedorov die Elektrizität als "wunderbare Kraft" bezeichnet, eine Kraft, die "in den Händen aller" sein werde, "wenn das elektrische Licht aufleuchtet in der Dorfhütte ${ }^{n} .{ }^{60}$ Nach der Revolution schrieb der später als Schriftsteller bekannt gewordene Ingenieur Andrej Platonov: "Kommunismus ist nicht nur Kampf gegen das Kapital, sondern auch gegen die Natur, und die Elektrifizierung ist unsere beste Waffe in diesem Kampf. ${ }^{\text {"61 }}$ Das "goldene Zeitalter" würde, so Platonov, mit Hilfe der Elektrizität geschaffen werden, und eines der ersten Ziele auf dem Weg dorthin sei die Beherrschung des Klimas. ${ }^{62}$ Auch Fedorov hatte diesem Problem größte Bedeutung im Rahmen des obšcee delo beigemessen und - in enger Anlehnung an die Forschungen von V.N. Karazin - Maßnahmen zur Beherrschung des Klimas, insbesondere der Niederschläge, vorgeschlagen, die auf einer künstlichen Regulierung der atmosphärischen Elektrizität beruhten. ${ }^{63}$

In den Jahren nach der Revolution, als witterungsbedingte Mißernten und schwere Hungersnöte vor allem an der unteren Wolga zu einer besonderen Herausforderung an den herrschenden Technik- und Fortschrittsglauben wur-

59 Als Beispiel hierfür nannte Agienko die weltweite Errichtung von Windkraftwerken. A. AGIENKo, "K voprosu o kosmizeskoj technike (anemofikacija)." In: Biokosmist, 1922, 2, S. 6 f.

60 FOD I, S. 328.

61 A.P. Platonov, Elektrifikacija, Voronež 1921, S. 12; zitiert nach A. TESkEY, Platonov and Fyodorov, Amersham 1982, S. 28.

62 Platonovs Prognosen finden sich in Artikeln wie Zolotoj vek sdelannyj iz elektricestva, Ob uluč́enii klimata, Bor'ba s pustynej, die in den frühen zwanziger Jahren in der Zeitung Vononežskaja Kommuna erschienen. Den Einsatz der Elektrizität zur Regulierung des Klimas, aber auch zur Umgestaltung der Erde und zur Erschaffung eines neuen Universums schildert Platonov in den phantastischen Erzählungen Potomki solnca (1922) - eine "Klimakatastrophe" zwingt die Menschheit zum gemeinsamen "Aufstand gegen das Weltall" -, Rasskaz o mnogich interesnych vestach (1923), bes. Kap. 10, souie - wahrscheinlich bereits von Fedorov beeinflußt Efimyj trakt (1926/27). Siehe auch W. ŚLIwOwSKA, R. ŚLIwOwSK, "Filozoficzne inspiracje Andrzeja Pratonowa." In: Przegtad Humanistyczny, 25 (1981), 7-9, S. 9.

Ausführlich dazu I: 3.2 .3 . 
den, griff Ivanickij Fedorovs Ideen auf. ${ }^{64} 1921$ hielt er im Moskauer Klub der Linken Sozialrevolutionäre einen Vortrag "Über künstliches Auslösen von Regen $^{\text {"65 }}$ und veröffentlichte dazu in den folgenden Jahren mehrere Artikel - u.a. in Biokosmist und Izvestija -, in denen er Fedorovs Vorschläge zur Klimaregulierung anführte. ${ }^{66}$ Besonders deutlich wird Fedorovs Einflu $B$ in einer Arbeit über "Die künstliche Regenerzeugung und die Steuerung des Wetters durch Regulierung der atmosphärischen und terrestrischen Elektrizität", die Ivanickij 1925 im Moskauer Landwirtschaftsverlag Novaja derevnja veröffentlichte. ${ }^{67}$ Ausführlich ging er darin auf die meteorologischen Forschungen Karazins ein und beschrieb im Anschluß daran Fedorovs Plan, das Klima durch den Einsatz von Luftschiffen und Blitzableitern zu regulieren und es schließlich durch die Umwandlung der Erde in einen riesigen, vom Menschen zu steuernden Elektromagneten vollständig unter Kontrolle zu bringen. ${ }^{68}$ Vorschläge dieser Art trugen Ivanickij freilich nur Spott ein und den Vorwurf, ein "Vulgärmaterialist" vom "Schlage N.F. Fedorovs" (tipa N.F. Fedorova) zu sein. ${ }^{69}$ Ivanickijs Schriften blieben folgenlos und waren schon bald vergessen. ${ }^{70}$

64 Vgl. NA. SETNICKI, SSSR, Kitaj i Japonija. (NaCal'nye puti reguljacii). Charbin 1933, S. 18-31. A. Ostromirov [A.K. GorskIJ], Nikolaj Fedorovic Fedorov i sovremennost'. Odenki. Vyp. 4, Charbin 1933, S. 3f. Wie sehr seinerzeit die Frage einer Klimaregulierung und Regenerzeugung die Phantasie der Wissenschaftler und Techniker beschäftigte, geht aus der Vielzahl einschlăgiger Arbeiten hervor. Siehe die umfangreiche Bibliographie in: Itogi bor'by $\mathbf{s}$ golodom v 1921-22 8g., M. 1922, S. 478-499; die Vorschlăge reichten von einer künstlichen Verănderung des irdischen Magnetfeldes bis zu der Idee, Schnee aus den nördlichen Regionen auf die Felder in den Trockengebieten zu transportieren und ihn dort schmelzen zu lassen.

65 "Ob iskusstvennom vyzyvanii đoždja." Siehe ANIST (wie Anm. 11), S. 7.

66 P.I. IVANICKU, "Ob iskusstvennom vyzyvanii doždja." In: Biokosmist, 1922, 2, S. Sf. DERS., "Iskusstvennoe vyzyvanie doždja." In: Izvestija VCIK, 114 (25.5.1923), S. 4. DERS., "Iskusstvennoe vyzyvanie dở.dja v Rossii." Ebd., 138 (23.6.1923), S. 5. - Fedorov wird in diesen Artikeln nicht namentlich erwăhnt.

67 P.[I.] IVANICKI, Iskusstvennoe vyzyvanie dozdja i upravlenie pogodoj posredstwom reguljacii atmosfemogo i zemnogo elektricestva, M. 1925. - Im selben Verlag war kurz zuvor P.A. Florenskijs grundlegende Arbeit über Dielektrika erschienen.

68 Ebd., S. 57. - Vgl. FOD I, S. 53f., 280-283. - Auch in V.A. Cajanovs "Land der bäuerlichen Utopie" wird im Jahre 1984 das Wetter durch künstliche Veränderung des irdischen Magnetfeldes gesteuert; sogenannte "Meteorophoren" (meteorofory) losen nach Bedarf Regen und Sturm aus. Siehe Ivan Kremnev [d.i. V.A. Cananov], "Putešestvie moego brata Alekseja v stranu krest'janskoj utopii." [1920] In: Ders., CEuvres choisies, Bd. 3, o.O. [The Hague, Paris] 1967, S. 21, 52f., 60. Vgl. auch die enweiterte deutsche Ausgabe A.W. Tschananow [Caunanov], Reise meines Bruders Aleksej ins Land der bäuertichen Uropie, Frankfurt/M. 1981, S. 41, 71, 80, 85. - Cajanov könnte diesen Gedanken von Fedorov oder von Karazin übernommen haben.

69 Dieser Vorwurf - verbunden mit der Erwăhnung Fedorovs - findet sich in einem Artikel des Philosophen I. Luppol, der zu Beginn der ideologischen Kontroverse über mechanizistischen und dialektischen Materialismus entstand. I.[K.] LUPPOL, "O sinice, kotoraja zažgla more." In: Pod Znamenem Marksizma, 1926, 11, S. 221. Darin greift der 'Dialektiker' und Deborin-Schüler Luppol den 'Mechanizisten' Z. Cejtlin an, der sich auf Ivanickij berufen hatte. Z.[A.] CEJTUN, Karl Marks o spinozizme i istočnikach francuzskogo materializma XVIII veka." Ebd., S. 214.

SETNICKU (wie Anm. 64), S. $19 f$. 
Im August 1922 kam es zur Spaltung der Biokosmisten, als sich in Petrograd unter dem Vorsitz des Dichters und Anarchisten Aleksandr Borisovic Jaroslavskij ${ }^{71}$ eine "Nördliche Gruppe der Biokosmisten-Immortalisten" (Severnaja gruppa biokosmistov-immortalistov) konstituierte. ${ }^{72}$ Zwar bekannten sich auch die Petrograder Biokosmisten zu den Prinzipien des "Immortalismus" und "Interplanetarismus", wie sie in der Deklaration vom Dezember 1921 verkündet worden waren, und betonten ebenso wie seinerzeit die Moskauer Gruppe ihre Loyalität gegenüber der Sowjetmacht, zugleich aber distanzierten sie sich scharf von der Moskauer Gruppe und deren Vorsitzendem Svjatogor (Agienko), dem sie "Egoismus" und "Machthunger" vorwarfen. ${ }^{73}$

Die Moskauer Gruppe scheint bald darauf auseinandergefallen zu sein. Während sich Ivanickij weiterhin dem Problem künstlicher Regenerzeugung widmete, ist das Schicksal von Svjatogor (Agienko) unbekannt. ${ }^{74}$

Indessen entfalteten Jaroslavskij und die Petrograder Biokosmisten eine rege publizistische und propagandistische Aktivität: Sie veranstalteten Dichterlesungen und Vorträge, die nicht selten tumultuarisch verliefen, und gaben eine Zeitschrift mit dem Titel Bessmertie heraus, ${ }^{75}$ in der sich neben zahlreichen Beiträgen von Jaroslavskij und seinen Anhängern, die in Stil und Inhalt zumeist von

71 A.B. Jaroslavskij wurde 1897 in Vladivostok geboren. Nach dem Besuch des Gymnasiums seiner Heimatstadt schloß er sich der revolutionăren Bewegung an. 1919 wurde er von den Interventen verhaftet und verbrachte fünf Monate im Gefängnis. 1920 und $1921 \mathrm{nahm}$ er in den Reihen der Anarchisten am Bürgerkrieg im Fernen Osten und in Sibirien teil. 1922 ging er nach Moskau, spatter nach Petrograd. - Zwischen 1917 und 1921 veroffentlichte Jaroslavskij sieben schmale Bănde mit Gedichten im Stil des Proletkul't. Ein 1920 in Irkutsk erschienener Gedichtband mit dem Titel Krov' i radost' war dem sibirischen Partisanenführer und Anarchisten N.A. Kalandarišili gewidmet. Außerdem war Jaroslavskij mit Beitrăgen in fünf Sammelbănden der "fernosstlichen Futuristen" (N. Aseev, S. Tret'jakov, S. Alymov u.a.) vertreten, die zwischen 1921 und 1922 in Čita erschienen. Vgl. Antologija poezii Dal'nego Vostoka, Chabarovsk 1967, S. 467; dort S. 76-83 auch einige Proben des dichterischen Schaffens Jaroslavskijs aus den Jahren 1918-1919: "Zvezdnyj manifest", "Zvezdnomu bratu", "Krov' i radost", "Leninu". A.K. TARASENKov, Russkie poety XX veka, M. 1966, S. 429. A.M. VITMAN [u.a.], Vosem' let russkoj chudożestvennoj literatury (1917-1925), M.-L. 1926, S. 307. A.N. LUR'E, Poétizeskjj epos revoljucii, L. 1975, S. 95f.

72 Jaroslavskij war zuvor Mitglied des Moskauer "Kreatoriums der Biokosmisten" gewesen. Auch N.S. Degtjarev trat in die "Nørdliche Gruppe" uber, wurde aber schon bald aus dieser ausgeschlossen. Der "Nordlichen Gruppe" schlossen sich alsbald Biokosmisten-Zellen in Irkutsk, Omsk, Kiev und Pskov sowie die 'Antitaxidermisten' (antitaksidermisty) in Boroviti an. Vgl. Bessmertie, 1922, 1, S. 11. I. JAKOVLEV, Bryzgi bestializma, Boroviłi 1923. Über Entstehung. Mitgliederzahl und das weitere Schicksal all dieser Gruppen ist nichts bekannt.

73 Vgl. "Deklaracija severnoj gruppy biokosmistov-immortalistov" [vom 12.8.1922]. In: Bessmertie, 1922, 1, S. 1. "Otkrytoe pis'mo severnoj gruppy" [vom 11.8.1922]. Ebd., S. 11 .

741936 erschien eine ausführlich kommentierte Literaturübersicht zum Thema Astronomie und Raumfahrt von einem gewissen A. Agienko, bei dem es sich möglicherweise um den ehemaligen Biokosmisten handelt: A. AGIENKo, "Solneznoe zatmenie 19 ijunja 1936 g. (Literatura i drugie posobija dlja lekcij i besed)." In: Antireligioznik, 11 (1936), 3, S. $42-45$.

75 Von der allerdings nur eine Nummer erschien: Bessmertie. Organ severnoj gruppy biokosmistov (immonalistov) i komiteta poezii biokosmistov. Pg. 1922, 1, [25. November]; die Auflage betrug 2000 Exemplare. 
sektiererischer Selbstüberschätzung zeugen, auch populärwissenschaftliche Abhandlungen finden. So berichtete etwa der Pharmakologe N.P. Kravkov über Verfahren zur Neubelebung abgestorbener Gewebe, ${ }^{76}$ der Physiologe L.L. Vasil'ev über den Versuch einer Synthese von Wissenschaft und Kunst ${ }^{77}$ und ein gewisser L. Litvinov über Einsteins Allgemeine Relativitätstheorie, in der er den Beweis für die Endlichkeit des Universums sah und folglich (!) für dessen prinzipielle Erkennbarkeit und Beherrschbarkeit mittels eines "allgemeinen Weltgesetzes". ${ }^{78}$ Als Verbündete im Kampf gegen den Tod und bei der Eroberung des Weltraums suchten die Petrograder Biokosmisten den Wiener Physiologen Eugen Steinach zu gewinnen, der sich mit Experimenten zur Neubelebung und Verjüngung von Organismen befaßte, ${ }^{79}$ sowie den in Kaluga lebenden Raumfahrtpionier und wissenschaftlich-phantastischen Schriftsteller K.E. Ciolkovskij. ${ }^{80}$

Besonders taten sich Jaroslavskij und die Petrograder Biokosmisten auf dem Gebiet der Dichtung hervor. In den Jahren 1922 und 1923 erschienen vier Bändchen mit Gedichten von Jaroslavskij und eine schmale Anthologie biokosmistischer Lyrik. ${ }^{81}$ Künstlerisch belanglos, geben diese Werke doch Einblick in

76 N.P. Kravkov, "Dannye i perspektivy po oživleniju tkanej umerకich." Ebd., S. 2f. - N.P. Kravkov (1865-1924) war Professor an der Milităr-Medizinischen Akademie in Petrograd; scine Experimente erregten auch das Interesse Gor'kijs. Siehe II: 4.2. Anm. 155.

77 L.[L.] VASIL'Ev, "Pjatnadcat' tezisov normal'noj ideologii." Ebd., S. 3f. - L.L. Vasil'cv (18911966), der sich ebenso wie Kravkov und der Physiologe Korovin (ein früherer Mitarbeiter des Anabiose-Forschers P.I. Bachmet'ev; siche II: 2.1.3.) den Petrograder Biokosmisten für Vortrăge zur Verfügung gestellt hatte, war Leiter der physiologischen Abteilung des Bechterev-Instituts für Himforschung und wurde spăter weithin bekannt durch seine Forschungen uber "Mentalsuggestion" (Telepathie). Seit den frühen zwanziger Jahren war Vasil'ev mit dem Biophysiker und 'Kosmisten' A.L. Ciževskij befreundet, einem Mitarbeiter und engen Vertrauten von K.E. Ciolkovskij. Čiževskij bemühte sich damals, Ciolkovskijs Raumfahrtprojekte bekanntzumachen; møglicherweise hat er dabei auch Vasil'evs Interesse für die Biokosmisten geweckt. Siehe A.L. CižEvsku, Vsja Zizn', M. 1974, S. 181 f.

78 L. Litvinov, "Ateizm i teorija otnositel'nosti." In: Bessmertie (wie Anm. 75), S. 4 f.

79 Siehe ebd., S. 11 und 12.

80 Siehe ebd., S. 2. - In seinen Erinnerungen an den Raumfahrtpionier bemerkt der Schriftsteller Lev Kassil', Ciolkovskij habe "sich selbst für einen 'Biokosmisten' gehalten". LA. KASSIL', "Zvezdoplavatel' i zemljaki." In: K.E. Ciolkovskij. Sbomik Aeroflora. M. 1939, S. 165. Bereits I925 spricht ein gewisser A.Ć. [d.i. A.L. Ciževskij] von Ciolkovskijs "biokosmischen Ideen" (biokosmizeskie idei). Siehe K.E. CiolkovskJ, Pricina kosmosa, Kaluga 1925, S. 2. Siehe auch II: 3.1.2.

81 A. Jaroslavsku, Poèma anabioza (1922), Svjataja bestial' (1922), Na śturm vselennoj (1922), Mins poceluj (1923). [Versch. Autoren], Biokosmisty desjat' stuk (1923). Alle herausgegeben vom Komiret poezii biokosmistov-immortalistov (sevemaja gruppa) in Petrograd. Die Gedichte tragen Titel wie "Zum Sturm aufs Weltall", "Sternenmanifest", "In Ciolkovskijs Raumschiff", "Kosmochronik", "Tod dem Tode", "Anabiose-Poem"; in ihrer Thematik (Fortschrittsenthusiasmus, Technikkult, Prometheismus, Kosmismus) sowie in ihrer hyperbolischen, euphorischkămpferischen Diktion gleichen diese Gedichte den tyrischen Erzeugnissen der Petrograder 'Kosmisten' (1920-1923) und der Moskauer Kuznica (1920-1932). Personelle Verbindungen zwischen den genannten Gruppen bestanden im Falle des Moskauer Biokosmisten N.S. Degtjarev, 
N21.
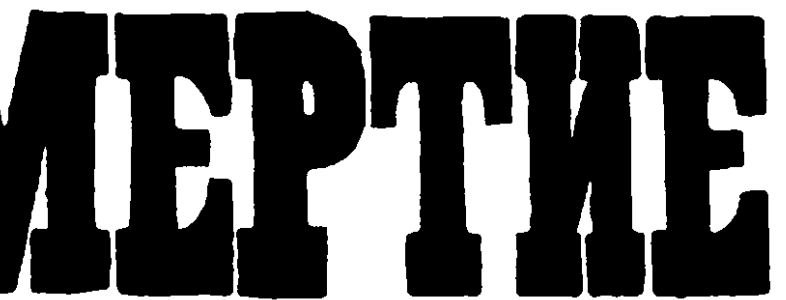

Орган Северной Группн Биокоемистов (Нммортапиетов) и Комитете Позяни Виохоемиетов.

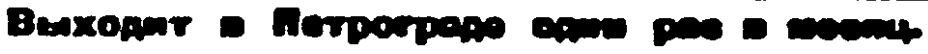

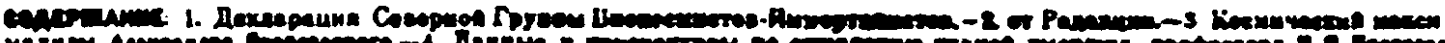

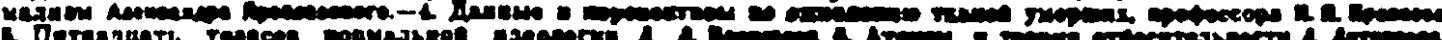

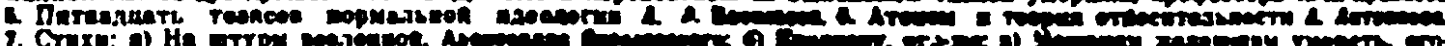

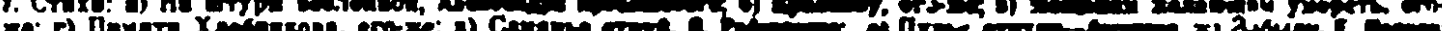

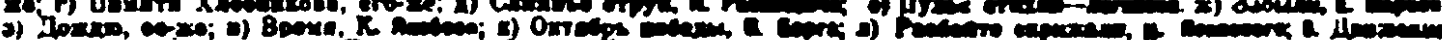

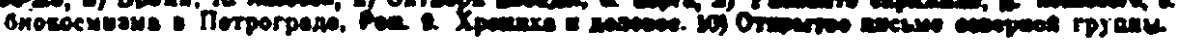

\section{Девлорочня Cesophoủ Tpgnnu Бмовосмистоs-Нимортолнетов.}

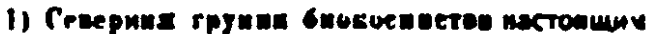

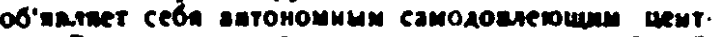

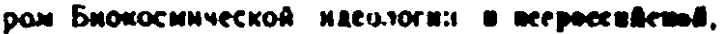

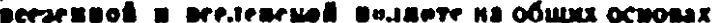

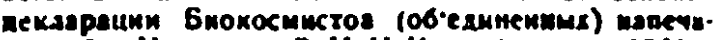

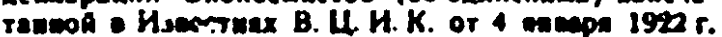

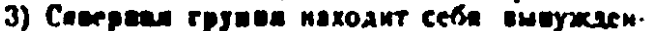

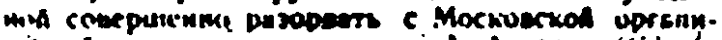

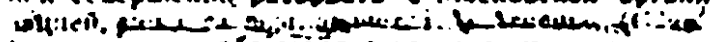

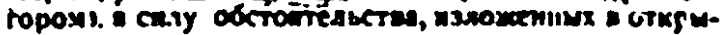
mu nucsure. Notopoe novernewo mume.

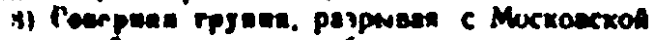
opranusнinef octaninct uesuliemunn ocnomane no-

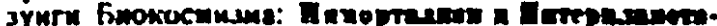

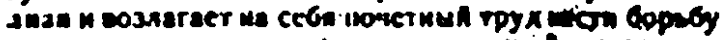

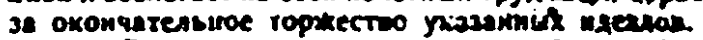

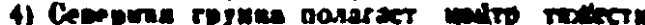

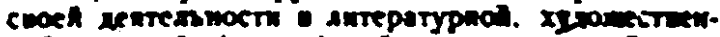

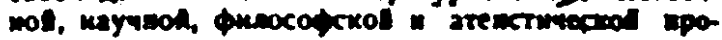

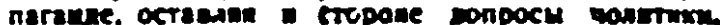

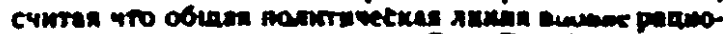

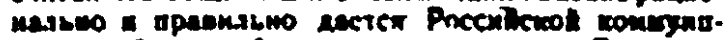

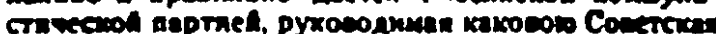
Pocen operonpezenoct remesuc Buenietron.

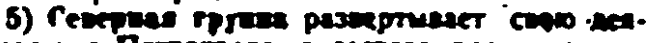

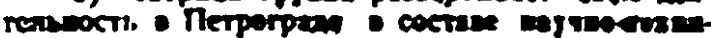

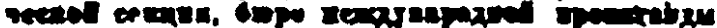

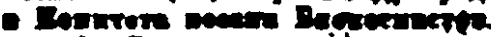

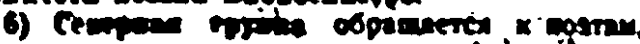

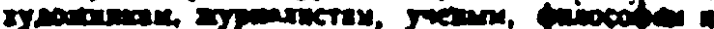

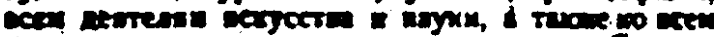

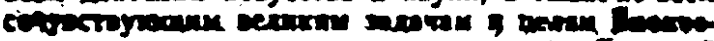

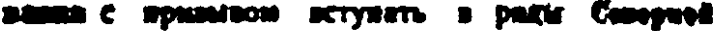
tures.

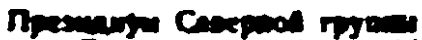

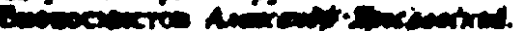

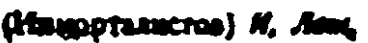

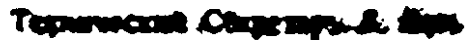

\section{Or Pononquи.}

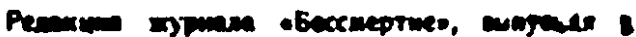

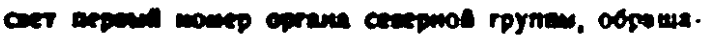

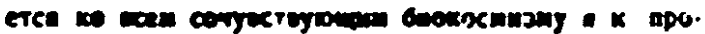

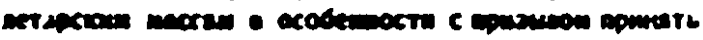

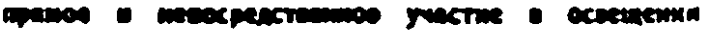

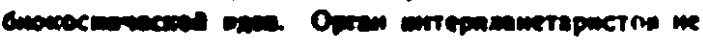

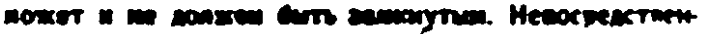

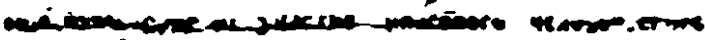

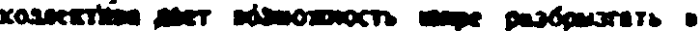

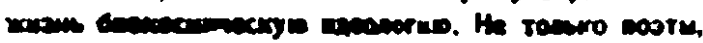
худы.

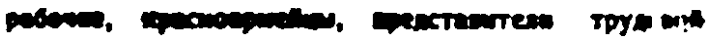

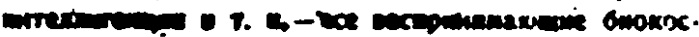

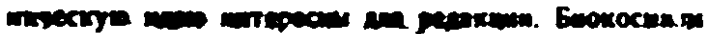

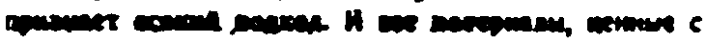

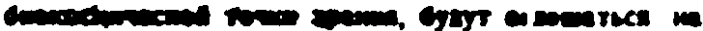

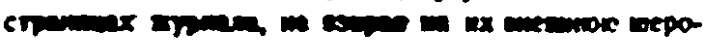

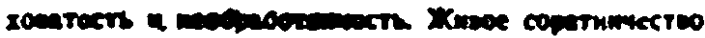

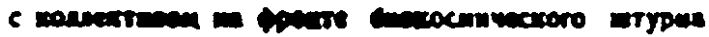

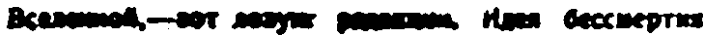

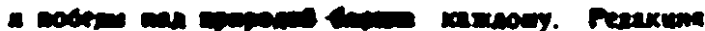

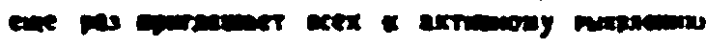
croaro on

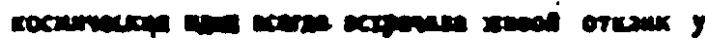

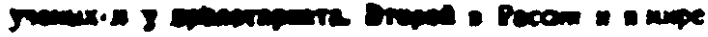

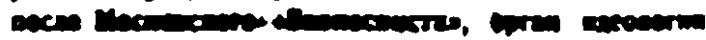

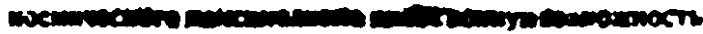

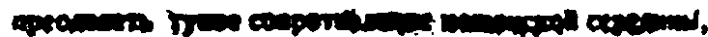
roun yan

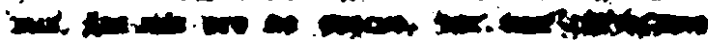

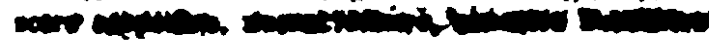
- and

remorin. 
die naiv-fortschrittsgläubige Gedankenwelt ihrer Verfasser. So schildert Jaroslavskij in seinem "Anabiose-Poem" (Poema anabioza, 1922) die Verwandlung der Erde in ein Paradies: Unter Leitung eines "genialen Rates der Weisen" und mit Hilfe des "großartigen Radiums" wird die neue Welt gebaut, das Wetter reguliert, Krankheiten und alle Bazillen ausgerottet und selbst der Tod besiegt. Da aber die meisten Menschen Spießer sind und den Fortschritt behindern, werden sie vom "Heer der Biokosmisten" kurzerhand eingefroren, um dann, "wenn alles fertig ist", aus ihrem anabiotischen Schlaf erweckt zu werden, damit auch sie am Genuß des neuen Lebens teilhaben können. ${ }^{82}$

Nach zwei Jahren hektischer Aktivität verlieren sich auch die Spuren der Petrograder Biokosmisten; viele ihrer angekündigten Veröffentlichungen - darunter Arbeiten von Steinach, Ciolkovskij, Vasil'ev und dem von ihnen als geistesverwandt verehrten Chlebnikov ${ }^{83}$ - sind nicht mehr erschienen. Lediglich Jaroslavskij legte 1926 noch zwei größere Werke in einem Verlag der Biokosmisten in Moskau vor: den umfangreichen Gedichtband Koren' iz Ja und - seine wohl erfolgreichste Veröffentlichung - die "Roman-Utopie" Argonavty vselennoj. In diesem Werk, das sich stark an die populären Raumfahrtromane von Kurd Laßwitz und H.G. Wells anlehnt, während die Beschreibung technischer Details wohl auf Ciolkovskij zurückgeht, werden die Menschen aufgefordert, ihre einzigen Feinde - Alter, Tod, Raum und Zeit - zu überwinden und ins Weltall vorzustoßen, denn auch sie seien "Bürger des Weltalls" (graždane vselennoj). ${ }^{84}$

Damit endet die Bewegung der Biokosmisten, eine der schillerndsten und widersprüchlichsten Erscheinungen der nachrevolutionären Jahre; in ihr verbanden sich Maximalismus und Opportunismus, Sternenflug und sektiererische

der auch der Kuznica angehörte, sowie des Petrograder Biokosmisten Ivan Loginov (18911942), der auch Mitglied der 'Kosmisten' war.

82 A. Jaroslavsku, Poima anabioza, Pg. 1922. Ein kurzer Auszug erschien unlăngst im Rahmen der von E.A. Evtuß̌enko betreuten Serie über vergessene russische Dichter des 20. Jahrhunderts in: Ogonek, 1988, 40, S. 23; mit Hinweis auf Fedorov. - Siehe auch LUR'E (wie Anm. 71), S. 95. Auf ăhnliche Motive in Majakovskijs Komodie Klop (1928) wurde bereits hingewiesen. Siehe II: 3.2.1.

83 Siehe A. Jaroslavskijs Gedicht "Pamjati Chlebnikova" (Bessmertie, wie Anm. 75, S. 6f.), in dem es heißt: "Wir sind nicht nur die Regierung des Erdballs / Wir sind die Verwalter des Weltalls (...) Und Dich, Kampfgenosse (soratnik), verwest, doch flammend / werden wir für neue Kămpfe wiederenwecken!"

84 A.[B.] JaroslavsKu, Argonavty vselennoj, M.-L. 1926; hier S. 165. - In der Dichtung des Proletkul't findet sich diese Formel hăufig; so heißt es beispielsweise in dem Gedicht "Der Proletarier" von A.I. Samobytnik: "Da ist er, der Schöpfer des irdischen Werkes / und der Bürger des ganzen Weltalls..." A.I. SAMOBYTNIK [MASIROV], "Proletarij." In: Literatumyj al'manach, $\mathrm{Pb}$. o.J. [1918], S. 11. - Lasswitz' Roman "Auf zwei Planeten" (1897) erschien russ. 1925 unter dem Titel Na dvuch planetach; H.G. Wells' "First men on the moon" russ. Penye ljudi na Lune (Pg. 1919). Auf Ciolkovskijs Roman Vne Zemli (1918/20) dürfte Jaroslavskijs Beschreibung des Raumschiffs zurückgehen. 
Enge, hochgespannte Erwartungen und fanatische Selbstüberschätzung bei tatsächlicher Ohnmacht. ${ }^{85}$

85 Jaroslavskij, der sich die Befreiung der Menschheit vom Tod zum Ziel gesetzt hatte, endete tragisch: Er wurde verhaftet und in das berüchtigte Konzentrationslager auf den Soloveckij-Inseln eingeliefert; dort soll er Ende der zwanziger Jahre nach einem gescheiterten Fluchtversuch erschossen worden sein. Siehe M. ROZANOV, Soloveckij konclager' v monastyre 1922-1939 gady, kn. 1, 0.O. 1979, S. 150. Vgl. auch A.I. SOLZENICYN, Archipelag GULag, t. 3-4, Paris 1974, S. 46. 


\subsection{V.N. Murav'ev}

Rezipiert und dem prometheischen Geist der nachrevolutionären Jahre entsprechend gedeutet und formuliert wurden Fedorovs Gedanken und Projekte durch den Philosophen und Mathematiker V.N. Murav'ev, der seit den frühen zwanziger Jahren zum Kreis der Moskauer Fedorov-Anhänger gehörte. Murav'evs in jener Zeit entstandene Schriften, von denen nur der Aufsatz "Die universelle Produktionsmathematik" (Vseobšcaja proizvoditel'naja matematika) und die Abhandlung "Die Beherrschung der Zeit als Grundaufgabe der Arbeitsorganisation" (Ovladenie vremenem kak osnovnaja zadaca organizacii truda) im Druck erschienen und zugänglich sind, ${ }^{1}$ stehen weithin unter dem Einfluß der Filosofija obščego dela. Daneben finden sich in ihnen Elemente verschiedener geistiger Strömungen jener Zeit, denen, bei allen Unterschieden im einzelnen, eines gemeinsam ist: der Glaube an die Möglichkeit einer völligen Beherrschung, Umwandlung und Vervollkommnung der Welt durch die organisierte, rationale Tätigkeit der vereinten Menschheit.

Valerian Nikolaevix Murav'ev ${ }^{2}$ entstammte einem alten Adelsgeschlecht. Am 28. Februar 1885 (a.St.) wurde er in dritter Ehe des Juristen und Politikers Ni-

1 V.[N.] MURAV'EV, "Vseobš̌aja proizvoditel'naja matematika." In: Vselenskoe delo, 2, Riga 1934, S. 116-140; nachfolgend zitiert: VPM. Im Dezember 1923 verfaßt, sollte dieser Aufsatz in einem sowjetischen Sammelband veröffentlicht werden, der jedoch kurz vor seinem Erscheinen von den Behörden unterdrückt wurdc. (Angaben ebd., S. 116).

V.[N.] MURAV'Ev, Ovladenie vremenem kak osnovnaja zadača organizacii truda, M. 1924; nachfolgend zitiert: OV. Es handelt sich um eine Broschüre von 127 Seiten, die, vom Verfasser in einer Auflage von 1000 Exemplaren herausgegeben, bald schon zu einer bibliographischen Rarităt wurde. Inzwischen liegt ein Nachdruck vor: V.N. MURAVEV, Ovladenie vremenem, Moskva 1924. Nachdruck nebst einer einführenden Studie von M. Hagemeister. München 1983. Darin M. HAGEMEISTER, "Valerian Nikolaevið Murav'ev und das 'prometheische Denken' der frühen Sowjetzeit." S. 1-27. - Die Publikation hat ein breites Echo hervorgerufen; siehe die ausführlichen Rezensionen von H. GÜNTHER in: WdSl, 29 (1984), 1, S. 219-222. A. TESKEY in: Irish Slavonic Studies, 5 (1984), S. 256f. T.D. ZAKYDALSKY in: Canadian Slavonic Papers, 28 (1986), 1, S. 91-94. G. EjKALoviC, "'Fedoroviana'." In: Noyyj Zumal, 163, 1986, bes. S. 265-272. DeRS., "Ovladenie vremenem." In: Vexe, 25, 1987, S. 69-85. - Vgl. ferner A.V. GuLYGA, "Universitetskij gorod." In: Noyyj Mir, 1984, 12, S. 207f. (auch in DERS., Putjami Fausia, M. 1987, S. 360). L. Heller, "Les chemins des artisans du temps: Filonov, Platonov, Hlebnikov et quelques autres..." In: Cahiers du Monde russe el soviétique, 25 (1984), bes. S. 262. K. HiELSCHER, "Ein Jegliches hat seine Zeit. Von der Technikverherrlichung zur Zivilisationskritik in der SowjetLiteratur." In: L'80, 35, 1985, bes. S. 90, 94-96. G.P. AKSENOV, "Živoe veš̌estvo: meždu večnost'ju i vremenem." In: Prometej, 15, M. 1988, S. 209f., 212, 218, 220 Anm. 15; (Murav'ev, so Aksenov, sei ein "zu Unrecht vergessener", "höchst origineller Philosoph").

Weitere Arbeiten Murav'evs sind wahrscheinlich in sowjetischen Archiven erhalten, dort bislang jedoch unzugănglich. (Siehe unten Anm. 117).

2 Uber Murav'evs Leben ist nur wenig Sicheres bekannt. Einige biographische Angaben, die jedoch nicht immer zuverlässig sind, enthält der Nachruf von G.G.G. [N.A. SETNICKU ?], "Valerian Nikolaevii Murav'ev." In: Vselenskoe delo (wie Anm. 1), S. 181f. Die übrigen Hinweise sind spärlich und liegen an verstreuten Orten vor. Sie wurden erstmals in meiner Einleitung zum Nachdruck von OV zusammengestellt. Siehe HAGEMEISTER (wie Anm. 1). 
kolaj Valerianovix Murav'ev (1850-1908) geboren. ${ }^{3}$ Sein Vater, zu jener Zeit Staatsanwalt am Moskauer Appellationsgericht und ein hervorragender Redner, wurde 1894 Justizminister und ging 1905 als Botschafter nach Rom. ${ }^{4}$ Valerian Nikolaevix verbrachte seine Kindheit in England. 1905 absolvierte er das Kaiserliche Alexander-Lyzeum in Petersburg, die Eliteschule RuBlands, mit Auszeichnung. ${ }^{5}$ Er wurde Jurist, erhielt den Rang eines Kollegienassessors und den Titel eines Kammerjunkers und diente als zweiter Sekretär an der russischen Gesandtschaft in Belgrad. ${ }^{6}$ Politisch stand er der liberal-bürgerlichen Partei der Konstitutionellen Demokraten nahe. ${ }^{7}$ Unter der Provisorischen Regierung leitete er das politische Kabinett im Außenministerium ${ }^{8}$ und schrieb für die Petersburger Wochenschrift Russkaja Svoboda.9 Dem Oktoberumsturz stand er ablehnend gegenüber.

In den Jahren 1917 und 1918 gehörte Murav'ev dem Redaktionskollegium der angesehenen national-liberalen Moskauer Zeitung Utro Rossii an; ${ }^{10}$ außerdem war er Mitarbeiter der von G.I. Čulkov herausgegebenen Moskauer Wochenschrift Narodopravstvo, ${ }^{11}$ der von N.V. Ustrjalov gegründeten kurzlebigen Moskauer Zeitschrift Nakanune ${ }^{12}$ und, möglicherweise, der religiösen Zeit-

3 N. Ikonnixov, La Noblesse de Russie, tome J.2 [Mouraviev], Paris ${ }^{2}$ 1959, No. 356.

4 Vgl. E. AmbURger, Geschichre der Behöndenorganisation Rußlands von Peter dem Großen bis 1917, Leiden 1966, S. 171, 458. Enciklopediceskij slovar', izd. Brokgauz/Efron, t. 20, SPb. 1897, S. 1916.

5 Vgl. Ixonnikov (wie Anm. 3). Imperatorskij Aleksandrovskij Licej 1811-1961. Pamjatnaja knizka liceistov. Neuilly-sur-Seine o.J., S. 139.

6 Almanach de St.-Pétersbourg 1912, S. 350.

7 G.G.G. (wie Anm. 2), S. 181.

8 D.L. Gou Inkov, Krusenie antisovetskogo podpol'ja v SSSR, kn. 2, M. ${ }^{2} 1978$, S. 15.

9 P. Pascal, Mon Joumal de Russie 1916-18, Lausanne 1975, S. 228. - Pierte Pascal (1890-1983), während des Ersten Weltkriegs als französischer Verbindungsoffizier in Rußland, schloB sich der Revolution an, arbeitete spăter für die Komintern; nach seinem Bruch mit dem Sowjetsytem prominenter RuBland-Historiker. Pascal war mit Murav'ev persönlich bekannt und hatte zu ihm langjăhrige Kontakte. Vgl. unten Anm. 15, 17.

10 Bis zum endgültigen Verbot der Zeitung im Juli 1918 schrieb Murav'ev zahlreiche Beitrăge für Utro Rossii, in denen er für einen "patriotischen und nationalen Maximalismus" plädierte und sich für die Entente und gegen den Frieden von Brest-Litovsk aussprach. Siehe H. HaRDEMaN, "A 'bourgeois' newspaper in the Russian revolution. 'Utro Rossii', Moscow 1917-1918." In: Rossija - Russia, 6, Venezia 1988, bes. S. 67f., 73f. Vgl. M.[S.] AGURSKU, "U istokov nacionalbol'Sevizma." In: Minuusee. Istoriceskaj al'manach. 4, Paris 1987, S. 140-165; zu Murav'ev S. 156, 164.

11 Narodopravstvo erschien erstmals am 30.6.1917 und läBt sich bis Nr. 23/24 im Februar 1918 nachweisen. Außer Murav'ev und Culkov zăhlten zu den Beitrăgern N.N. Alekseev, NA. Berdjaev, V.P. Vyšeslavcev, B.K. Zajcev, V.V. Zen'kovskij, M.M. Prił̌vin, A.M. Remizov, S.M. Solov'ev, A.N. Tolstoj, N.N. Fioletov. - Die Zeitschrift war mir nicht zugănglich.

12 Von Nakanune erschienen offenbar nur fünf Nummern im April/Mai 1918. Zu den Beitrăgern zahlten, neben Ustrjalov und Murav'ev, N.A. Berdjaev, P.B. Struve und moglicherweise auch Brjusov. Siehe AGURSKU (wie Anm. 10), S. 155, 164. - Die Zeitschrift war mir nicht zugănglich. 
schrift Vertograd ${ }^{13}$; die genannten Zeitungen und Zeitschriften galten als Sammelbecken der national-liberalen regimekritischen Intelligenz. 1918 gehörte Murav'ev - mit Alekseev-Askol'dov, Berdjaev, Bulgakov, Frank, Novgorodcev, P.B. Struve, Vjaceslav Ivanov und anderen - zu den Autoren des von Petr Struve betreuten Sammelbandes Iz glubiny, der bei seinem Erscheinen im Jahre 1921 in Moskau sofort verboten wurde. ${ }^{14}$ In jenen Jahren unterhielt er enge Kontakte zu der von Berdjaev gegründeten "Freien Akademie für Geisteskultur" (Vol'naja akademija duchovnoj kul'tury) sowie zur Moskauer Sektion der "Freien philosophischen Assoziation" (Vol'fila). ${ }^{15}$ Eine Zeitlang soll er am "Institut des lebendigen Wortes" (Institut Živogo Slova) in der Abteilung für Vortragskunst gearbeitet haben. ${ }^{16}$

13 Ventograd erschien mit wenigen Nummern im ersten Halbjahr 1918. Zu den Autoren zăhlten V.V. Rozanov sowie der spăter als Biokosmist und Fedorov-Anhănger hervorgetretene P.I. Ivanickij. Siehe auch II: 3.1. Anm. 83, 3.3. Anm. 19.

14 Iz glubiny. Sbomik statej o russkoj revoljucii. [Zweite Ausgabe] Paris 1967. Darin: V.N. MURAv'Ev, "Rev plemeni", S. 225-246; zu Murav'ev siehe auch das Vorwort von $N$. Poltoracki, ebd., S. XII. Vgl. ferner I. STAL, "De Profundis' ou la critique de la raison revolutionnaire." In: Cahiers du Monde nusse et sovietique, 24 (1983), 1-2, S. 59-81; bes. S. 61-65. HARDEman (wie Anm. 10), S. 68. Aus sowjetischer Sicht: A.I. Novikov, Nigilizm i nigilisty, L. 1972, S. 181-184. V.A. KUVAKIN, Religioznaja filosofija v Rossii, nacalo XX veka, M. 1980, S. 49-54.

15 Mündliche Mitteilung von A.F. Losev, Moskau, 9.3.1984. Der Philosoph Losev, der in jenen Kreisen verkehrte, war mit Murav'ev gut bekannt. Er schildert ihn als einen außergewöhnlich gebildeten und glăubigen Menschen. Nach der Revolution habe er sich unter anderem mit Sprachunterricht durchgebracht. - Siehe auch P. PASCAL, En Communisme. Mon Joumal de Russie 1918-1921. Lausanne 1979, S. 119-121.

Uber die Tătigkeit der "Freien Akademie", die von 1919 bis 1922 bestand, gibt es bislang nur verstreute Nachrichten; siehe: "Vol'naja Akademija Duchovnoj kul'tury v Moskve." In: Sofija. Problemy duchomoj kul'rury i religioznoj filosofii. Pod red. NA. Berdjaeva. Berlin 1923, S. $135 f$. N.[A.] BERDJAEv, Samopoznanie, Paris 1983, S. 276f. DERS., "Russkij duchownyj renessans XX v. i Żurnal 'Put"." In: Put', 49, 1935, S. 18f. Pxox, "N.A. Berdjaev. (Po ličnym vospominanijam)." In: Vestnik $R C h D, 115,1975, \mathrm{~S}$. 142-150. Zu den Vortragenden auf den äußerst populăren Veranstaltungen der "Freien Akademie" zăhlten neben Berdjaev unter anderen Belyj, Florenskij, V.I. Ivanov, Losev, S.L. Frank, S.M. Solov'ev, B.P. Vyšslavcev und FA. Stepun; siehe "Iz moskouskogo pis'ma. Nacalo ijunja." In: Rul', 489, 29.(16.)6.1922, S. 3.

Die Moskauer Sektion der Vol fila bestand von 1921 bis 1924. Zu ihren Mitgliedern zăhlten unter anderen Berdjaev, Frank, Vyšeslavcev, Florenskij, G.G. Spet, I.A. Il'in; siehe A. BELYJ, "Vol'naja filosofskaja associacija." In: Novaja Russkaja Kniga, 1922, 1, S. 32 f.

16 Briefliche Mitteilung O.N. Setnickaja, Moskau, 29.11.1980. - Das Institut Živogo Slova war im November 1918 in Petrograd eroffnet worden und bestand bis 1923. Zu den Mitarbeitem zăhlten K.A. Erberg, A.V. Lunazarskij, A.F. Koni, F.F. Zelinskij und N.S. Gumilev; letzterer hielt Vorlesungen zur Theorie und Geschichte der Dichtung. Siehe Zapiski Instituta Živogo Slova, 1, Peterburg 1919. Möglicherweise gab es eine Filiale in Moskau, an der Murav'ev arbeitete. Siehe auch Murav'evs Bemerkungen über den Zusammenhang von Sprechen und Gestik in VPM, S. 123f. 
Zu Beginn des Jahres 1920 hatte Murav'ev auf Empfehlung Trockijs eine Anstellung beim Volkskommissariat für auswärtige Angelegenheiten erhalten. ${ }^{17}$ Insgeheim gehörte er dem "Nationalen Zentrum" an, einer antibolschewistischen Vereinigung, die mit anderen regimefeindlichen Gruppen im sogenannten "Taktischen Zentrum" verbunden war. Im Zusammenhang mit der Liquidierung des "Taktischen Zentrums" wurde Murav'ev verhaftet und im August 1920 vom Obersten Revolutionstribunal zum Tode verurteilt. ${ }^{18}$ Auf persönliche Intervention Trockijs wurde das Urteil in eine dreijährige Haftstrafe umgewandelt, die unmittelbar darauf durch eine Amnestie erlassen wurde. ${ }^{19}$

Nach seiner Entlassung aus der Haft fand Murav'ev eine Anstellung an der Bibliothek des Obersten Volkswirtschaftsrates (VSNCh) und trat in enge Verbindung zu Kreisen der Moskauer imjaslavcy. ${ }^{20}$ Diese "Verehrer des (Gottes-) Namens", wie sie sich nannten, waren Anhänger einer mystisch-gnostischen Lehre, wonach der Name Gottes Gott selbst sei und seine Anrufung im Gebet göttliche Energien freisetze. ${ }^{21}$ Kurz vor dem Ersten Weltkrieg in den russischen Athosklöstern entstanden, hatte sich das imjaslavie trotz energischer Bekämp-

17 Pierre Pascal berichtet "... comme chose assez typique, que Valérien Mouraviev ... non socialiste, mais qui comprend que le socialisme est la vérité fatale, entre sur la recommandation de Trotsky et la mienne au Commissariat des Affaires Etrangères ... comme 'rédacteur' des traités de paix futurs, et pour commencer avec l'Estonie. Tchitcherine est heureux d'avoir pour cela quelqu'un qui possède la tradition." PASCAL (wie Anm. 15), S. 126; Eintragung vom 11.1.1920. Vgl. auch ebd., S. 117.

Die Malerin M.V. Vološina bemerkt dazu in ihren Erinnerungen, der "junge, hervorragend begabte" Murav'ev habe durch seine scharfe Kritik an der Milizorganisation das Interesse Trockijs erweckt, worauf dieser ihm leitende Posten in zwei Kommissariaten angeboten habe. Murav'ev, ein "Feind der kommunistischen Regienung", sei fasziniert gewesen von Trockijs Klugheit und Weitsicht. M. Woloschin, Die grüne Schlange, Frankfurt/M. 1982, S. 344. - Bereits 1914 hatte Murav'ev mit seinem Aufsatz "Nevedomaja Rossija" (in: Russkaja Mysl', 35, 1914, 1, S. 24-43) Trockijs Aufmerksamkeit, aber auch heftige Kritik erregt. Siehe L. TROCKע, Soxinenija, t. 20, M.-L. 1926, S. 375-377. - Auch Roman Gul' berichtet, daB Trockij, als er dem Narkomindel vorstand, sich Spezialisten aus dem bürgerlichen Lager gesucht habe, und nennt als Beispiel Murav'ev. R.B. Gul', Ja unes Rossiju, t. 2, New York 1984, S. 255.

18 Golunkov (wie Anm. 8), S. 12-17. - Uber den ProzeB, an dem sie als Beobachterin teilnahm, berichtet ausführlich Woloschin (wie Anm. 17), S. 343-349. Siehe auch S.[P.] MELGUNOV, "Sud istorii nad intelligenciej.' (K delu 'Takticeskogo Centra')." In: Na cužoj storone. Istorikoliteratumye sbomiki. 3, Berlin-Praga 1923, S. 137-163; zu Murav'ev S. 142.

19 Siehe ANON., "Delo 'taktizeskogo centra." In: Izvestija VCIK, 185, 22.8.1920, S. 4. Vgl. HARDEMAN (wie Anm. 10), S. 75f. - Trockijs spektakulăren Auftritt vor Gericht und sein Plădoyer zugunsten von Murav'ev - ein irregeleiteter Intellektueller, der jedoch für die Sowjetmacht nützlich sein konnte - schildert eindrücklich WoLOSCHIN (wie Anm. 17), S. 347-349. Insgesamt fielen die Urteile verhăltnismäBig milde aus, was auch Berdjaev, der den ProzeB beobachtete, in seinen Erinnerungen bestătigt. BERDJAEv, Samopoznanie (wie Anm. 15), S. 280.

20 G.G.G. (wie Anm. 2), S. 181.

21 Zur Entstehung und Verbreitung des imjoslavie siehe K.K. PAPULIDĒs, Hoi Rōsoi Onomatolatrai tu Hagiu Orus, Thessalonikē 1977. Zur Lehre des imjaslavie ausführlich auch B. SCHULTZE, "Der Streit um die Göttlichkeit des Namens Jesu in der russischen Theologie." In: Orientalia Christiana Periodica, 17 (1951), S. 321-394. 
fung durch den Heiligsten Synod in Rußland ausbreiten können und besonders unter der religiösen Intelligenz Beachtung und Anklang gefunden. ${ }^{22}$ Führende Mitglieder des Novoselov-Samarin-Kreises, darunter die Philosophen E.N. Trubeckoj, Ėrn, Bulgakov sowie der Fedorov-Anhänger Koževnikov, aber auch der Dichter Osip Mandel'štam, standen dem imjaslavie nahe. ${ }^{23}$ In den Jahren nach der Revolution flammte die Auseinandersetzung um das imjaslavie erneut auf und zog so bedeutende Denker in ihren Bann wie den Mathematiker D.F. Egorov, der 1929 als 'Idealist' seines Postens als Direktor des Moskauer Instituts für Mathematik enthoben wurde, oder den Philosophen A.F. Losev, der in seiner 1923 verfaßten Filosofija imeni über das Verhältnis von Wesen und Namen schrieb: "... sama suščnost' est' ne čto inoe kak imja". ${ }^{24}$ Auch in Murav'evs Schriften finden sich - obgleich nur vereinzelt - Reflexe der imjaslavie-Diskussion, so wenn von "wirkenden (dejstvennye) Zeichen oder Namen" die Rede ist, "deren Kenntnis Macht über die Natur verleiht". 25

Einer der ersten Verteidiger des imjaslavie war der Priester und Universalgelehrte P.A. Florenskij, der sich zu Beginn der zwanziger Jahre durch mathematische und physikalische Forschungen einen Namen machte, aber auch mit originellen Arbeiten zur Kunsttheorie, Sprachphilosophie und Semiotik hervor-

22 Siehe B. USPENSKU, "Prolegomena k teme: 'Semiotika ikony'." In: Rossija - Russia, 3, Torino 1977, S. 200f. N.S. SEMENKIN, Filosofija bogoiskatel'stva. Kritika religiozno-filosofskich idej sofiologov. M. 1986, S. 46-57. A. Nivière, "Les moines onomatodoxes et l'intelligentsia russe." In: Cahiers du Monde russe et soviétique, 29 (1988), S. 181-194.

23 Vgl. Papulidēs (wie Anm. 21), S. 63-70. SChultze (wie Anm. 21), S. 370-374. SeMEnKin (wie Anm. 22), bes. S. 48-51. NiviÈre (wie Anm. 22). Zu Mandel'stam bes. R. PrZYBYLSKI, "La questione degli onomatodossi del Monte Athos." In: The Common Christian Roots of European Nations, 2, Florence 1982, S. 763-769. Bulgakovs philosophisch-theologische Studien zum imjaslavie-Problem wurden postum unter dem Titel Filosofija imeni (Paris 1953) veroffentlicht. Zum Novoselov-Samarin-Kreis siehe II: 2.2.1.

24 A.F. LOSEv, Filosofija imeni, M. 1927, S. 166; Hervorhebung im Orig. Vgl. auch Losevs Ausführungen über die magische Kraft des Namens; ebd., S. 203f. Bislang unveröffentlicht sind Losevs "Tezisy imjaslavskogo urenija", die dieser mit Schreiben vom 30.1.1923 an P.A. Florenskjj geschickt hatte; Original in Moskauer Privatbesitz. - Auf den Zusammenhang von imjaslavie und Losevs neuplatonisch orientierter Filosofija imeni habe ich unlängst auch an anderer Stelle hingewiesen. M. Chagemejster [HAgemeister], "Slovo o Loseve." In: Literatumaja UZeba, 1988, 1, S. 159.

Die Geschichte des imjaslavie im nachrevolutionăren RuBland ist nicht einmal ansatzweise erforscht. Uber die zwanziger Jahre liegen nur spărliche Informationen vor. Vgl. R. FOLOPMILLER, Geist und Gesicht des Bolschewismus, Wien ${ }^{2} 1928$, S. 374-377. R. MANOVSKI IN.A. SETMICKU ?], "Messianstvo i 'Russkaja Ideja'." In: Vselenskoe delo (wie Anm. 1), bes. S. 91f. D. SKalon [d.i. JU.D. KaSKarov], "A.F. Losev k devjanostoletiju." In: Novyj Zumal, 150, 1983, S. 285f. N. Prat [d.i. A. PartaSnikov], "Orthodox Philosophy of Language in Russia." In: Studies in Soviet Thought, 20 (1979), S. 1-21. P.V. FLORENSKU, P.A. Florenskij po vospominanijam Alekseja Loseva, Ms. [Masch.], M. 1989, Bl. 17-25.

25 VPM, S. 130. - Den EinfluB des imjaslavie verrăt wohl auch die Formulierung "Der Tod ist der Abgrund - die Rückkehr der Person ins formlose Nichts... Das Leben ist das Siegel des Namens über dem Abgrund." (OV, S. 109). 
trat. ${ }^{26}$ Florenskijs überaus vielfältige wissenschaftliche Bemühungen standen im Zeichen einer universalen Theorie der Kultur, einer "Ideologie konkreten, schöpferischen Verhaltens zur Welt" ${ }^{27}$ Menschliche Kultur, so Florenskij, beruhe auf dem "Gesetz der Ektropie (Logos)"; sie sei letztlich nichts anderes als "Kampf gegen den Ausgleich in der Welt - den Tod". 28

Seit 1921 arbeitete Florenskij im Rahmen des GOELRO-Planes in der von Trockij geleiteten Hauptverwaltung der elektrotechnischen Industrie beim Obersten Volkswirtschaftsrat (Glavelektro VSNCh), ${ }^{29}$ jener Behörde, in deren Bibliothek auch Murav'ev eine Zeitlang angestellt war. Beide verkehrten zudem in der "Freien Akademie" und nahmen an den Veranstaltungen der Moskauer Vol'fila teil. ${ }^{30}$ Es ist sehr wahrscheinlich, daß der Autor von Ovladenie vremenem und Vseobšcaja proizvoditel'naja matematika mit Florenskijs mathematischen Spekulationen, seiner Zahlensymbolik und Zeitphilosophie vertraut war. ${ }^{31}$ Florenskijs Auffassung von Kultur als bewußtem Widerstand des Menschen gegen die anscheinend irreversiblen, dem Chaos (oder der Nivellierung, Entropie) zustrebenden Naturvorgänge, findet sich durchgängig auch in Murav'evs Schriften. ${ }^{32}$

26 Siehe M. HAgEmeistrer, "P.A. Florenskij und seine Schrift 'Mnimosti v geometrii' (1922)." In: P.A. FlorenskIJ, Mnimosti v geometrii [Nachdruck], München 1985, bes. S. 9-14, 40-45. Bereits 1913 hatte Florenskij zusammen mit dem Journalisten I.P. Sxerbov, einem Mitarbeiter der rechtsradikalen Zeitung Zemšina, einen anonymen Artikel zur Verteidigung der imjaslavcy veroffentlicht sowie ein ebenfalls anonymes Vorwort zu einer 'Apologie' des imjaslavie verfaßt. Siehe SEMENKIN (wie Anm. 22), S. 51.

27 Brief Florenskijs vom 13.9.1922; zitiert nach K.P. FLORENSKU, "O rabotach P.A. Florenskogo." In: UCenye zapiski Tanuskogo gos. universiteta, vyp. 284, Tartu 1972, S. 502.

28 [P.A. Florensku], "Florenskij, Pavel Aleksandrovic." In: Enciklopediceskij slovar' Granat, t. 44, M. 0.J. [1927], Sp. 144. Siehe auch II: 3.1. Anm. 82.

29 Siehe HAgEMEISTER (wie Anm. 26), S. 9, 41.

30 Siehe oben Anm. 15. - Murav'ev und Florenskij haben noch mehr gemeinsam: Beide gehorten zu jenen Intellektuellen, die aufgrund ihrer sozialen Herkunft, ihres Glaubens und ihrer politischen Uberzeugung die bolschewistische Machtergreifung ablehnten, dann aber als Patrioten ihre Kenntnisse und Făhigkeiten in den Dienst der neuen Ordnung stellten und sich gegenüber der Sowjetmacht loyal verhielten - was beide nicht davor bewahrte, als Opfer des Stalinschen Terrors zu enden.

31 A.F. Losev bittet im Mai 1924 Florenskij um Beteiligung an einem geplanten mathematischphilosophischen Sammelband; unter den Beiträgern, die Florenskij "nahestehen", nennt Losev u.a. Murav'ev mit einem Aufsatz über "den Begriff des GroBen und des Kleinen und über eine hypostatische Konstruktion der Mengenlehre". Florenskij, so Losev, möge "etwas in der Art von Mnimosti v geometri" beisteuem. A.F. Losev an PA. Florenskij, 24.5.1924; Original in Moskauer Privatbesitz. - 1922 hatte Florenskij in seiner Schrift Mnimosti v geometrii in Anlehnung an die Relativitătstheorie Möglichkeit und Folgen einer Umkehrung der Zeit beschrieben. FlORENSKU (wie Anm. 26), bes. S. 52f. Siehe auch HAGEMEISTER (wie Anm. 26), S. 17f., 47f. - Zum Problem der Zeit im Denken Florenskijs insbesondere die Hinweise bei V.V. IVanov, "Kategorija vremeni $v$ iskusstve i kul'ture XX veika." In: Structure of Teas and Semiotics of Culture, The Hague, Paris 1973, S. 108-111.

32 Vgl. VPM, S. 125f., 129f. OV, S. 61. - Dieselbe Auffassung von Kultur vertrat unlängst auch der sowjetische Linguist und Semiotiker V.V. Ivanov: "Menschlicher Kultur liegt die Tendenz zu- 
In der Zeit, als Murav'ev zu den imjaslavcy stieß, waren Bestrebungen im Gange, die ursprünglich mystisch-kontemplative Lehre, die in der Tradition des Hesychasmus stand, in eine aktive, weltbeherrschende und -verwandelnde umzudeuten. ${ }^{33}$ Aus der Teilhabe an den göttlichen Energien durch Aussprechen des Gottesnamens (imjaslavie) glaubte man eine Pflicht des Menschen zu synergetischem Handeln ableiten zu können, d.h. zur tätigen Mitwirkung bei der Verwandlung der Welt und ihrer Vollendung in Gott (imjadejstvie). Das Dogma des imjaslavie, so hieß es, ermögliche und fordere zugleich die "Herrschaft des Menschen", der durch sein Handeln die göttlichen Energien in die Wirklichkeit umsetze, und erweise sich damit als "kosmokratisch und pantokratisch". ${ }^{34}$ Aufgabe der Menschheit sei es, jegliche Trennung zu überwinden, um in gemeinsamer Arbeit die blinden Naturgewalten zu bezwingen und schließlich den Tod zu besiegen.

Vertreten wurde diese Interpretation des imjaslavie als imjadejstvie von einer kleinen Gruppe Intellektueller um A.K. Gorskij und N.A. Setnickij, die sich zu Beginn der zwanziger Jahre in Moskau zusammengefunden hatten, um Fedorovs Ideen weiterzuentwickeln und zu verbreiten. ${ }^{35}$ Möglicherweise war $\mathrm{Mu}$ rav'ev bereits durch die imjaslavcy auf Fedorov und sein Werk aufmerksam geworden; ${ }^{36}$ sicher ist, daß er etwa seit 1923 dem genannten Kreis der Moskauer Fedorov-Anhänger angehörte und sich mit den Gedanken der Filosofija obšcego dela auseinandersetzte. ${ }^{37}$

Davon zeugen die 1923/24 entstandenen Arbeiten Ovladenie vremenem und Vseobšcaja proizvoditel'naja matematika, auch wenn Fedorovs Name in ihnen nur selten und scheinbar beiläufig erwähnt wird: Tatsächlich übernahm $\mathrm{Mu}$ rav'ev von Fedorov nicht nur den Grundgedanken des obšcee delo - die Wiederherstellung der Verstorbenen und die Umwandlung und Beherrschung des Universums durch rationales, zielgerichtetes Handeln der gesamten Menschheit -,

grunde, den Tod zu überwinden... (...) Bis zu einem gewissen Grade bleibt alle menschliche Kultur bis jetzt ein Protest gegen Tod und Zerstörung, gegen zunehmende Unordnung oder zunehmende Vereinheitlichung - Entropie." IVANOV (wie Anm. 31), S. 148f. Vgl. auch II: 3.1. Anm. 82.

33 Siehe MaNovsku (wie Anm. 24), S. 91.

34 Ebd. - Vgl. VPM, S. 140.

35 Ausführlich dazu II: 4.1.

36 In dem bereits zitierten Aufsatz von R. Manovskij, der wie Murav'evs Aufsatz VPM in dem von Fedorov-Anhängern herausgegebenen Sammelband Vselenskoe delo erschienen ist, wird eine Verbindung von imjaslavie und der Lehre Fedorovs ausdrücklich betont: Die Filosofija obszego dela sei "nichts anderes als eine Ubertragung ... der theologischen Kosmokratie des imjaslavie ... in die Sprache der Gegenwart." MANovsku (wie Anm. 24), S. 93. Der zeitgenőssische Beobachter Fülop-Miller bemerkt: "Eng verwandt mit der Onomatodoxie [russ. imjaslavie; M.H.] ist auch ... die Neubelebung der alten Lehre Fjodoroffs..." FOLOP-MiLLER (wie Anm. 24), S. 378.

37 G.G.G. (wie Anm. 2), S. 181. O.N. SetnickAsA, Nikolaj Aleksandrovit Setnickij. Biografija. Ms. [Masch.] 0.O. 1965, Bl. 8f. - Zum Kreis der Moskauer Fedorov-Anhănger ausführlich II: 4.1. 


\section{BAЛЕРИАН МУРАВЬEB}

\section{ОВЛАДЕНИЕ \\ BPEMEHEM}

\section{КАК ОСНОВНАЯ ЗАДАЧА ОРГАНИЗАЦИИ ТРУДА}

Изданме автора

M O С в а - 1924 
sondern auch - wie zu zeigen sein wird - eine ganze Reihe einzelner Ideen und Projekte, Begriffe und Formulierungen.

An den Anfang seiner Überlegungen stellt Murav'ev den Gedanken der Beherrschung der Zeit durch bewußte Lenkung der Naturprozesse. Zeit besitzt für Murav'ev keine absolute Realität, sondern ist an Materie gebunden; sie ist Bewegung und Veränderung in der Welt der Dinge, genauer, "die sich verändernden Beziehungen zwischen den Dingen" ${ }^{38}$ Ein isolierter, unveränderlicher Körper oder ein statisches System sind zeitlos. Jede Handlung, die eine Veränderung bewirkt, "schafft" Zeit. ${ }^{39}$ Geschieht diese Veränderung bewußt und zielgerichtet, so wird der dadurch "geschaffene" Zeitablauf beherrscht: Die beliebige Umkehrung und Wiederholung eines Vorgangs - z.B. die Analyse und Synthese chemischer Verbindungen - bedeutet auch die beliebige Umkehrung und Wiederholung - und damit die Beherrschung - eines Zeitablaufs, wenn auch zunächst nur in einem engen, abgeschlossenen Bereich. ${ }^{40}$ Diesen Bereich gilt es zu erweitern. Mit zunehmender Herrschaft des Menschen über die Dinge wächst auch die Herrschaft über die Zeit::1 "Der Schlüssel zur [Beherrschung und] Überwindung der Zeit liegt in unserer Fähigkeit, die Menge der Dinge zu lenken. ${ }^{42}$ Erreicht wird dies, wie im Falle chemischer Verbindungen, durch die Kenntnis und Anwendung ihrer Formeln.

Die Welt besteht aus einer Vielzahl von Elementen, die sich zu Komplexen verbinden. ${ }^{43}$ Die verschiedenen Kombinationen werden vom menschlichen Verstand mit Hilfe von Symbolen (Namen, Zahlen) begriffen und - am genauesten durch (mathematische) Formeln dargestellt. ${ }^{44}$ Nichts ist deshalb unwiederbringlich verloren. Jeder Gegenstand, der einmal war, hat durch sein Dasein die mathematische Möglichkeit einer bestimmten Kombination einer Menge von

38 "... vremja est' ne to inoe, kak menjajušciesja otnoß̌enija vešcej." (OV, S. 31). Vgl. auch: "Vremja ... est' ne tto inoe, kak izmenenie i dviženie." (Ebd., S. 11). "Vremja est' izmenenie otnoß̌enij vešcej." (Ebd., S. 52). - Murav'evs Terminologie ist oftmals ungenau und inkonsequent, der Stil seiner Darlegungen wortreich, aber nicht immer klar; einzelne Argumente widersprechen einander.

39 OV, S. 17.

40 Vgl. OV, S. 31-33, 57, 65. VPM, S. 135f. - Der von den exakten Wissenschaften erhobene Anspruch auf prinzipielle Wiederholbarkeit ihrer Beobachtungen und Experimente läBt sich nur verwirklichen durch die Isolierung ihrer Objekte, wodurch diese scheinbar unabhăngig werden von der irreversiblen geschichtlichen Zeit.

41 OV, S. 33, 57.

42 OV, S. 11.

43 Vgl. VPM, S. 118-121. OV, S. 11-13.

44 OV, S. 65. Vgl. VPM, S. 118f., 121. - DaB Wissenschaft Beschreibung der Wirklichkeit durch Symbole, Bilder oder Namen sei, hatte zwei Jahre zuvor Florenskij in einem bemerkenswerten Aufsatz nachzuweisen versucht. P.[A.] FLORENSKU, "Simvolizeskoe opisanie." In: Feniks, kn. 1, M. 1922, S. 80-94. Dazu zuletzt V.V. IVANOV, "Nauka kak simvoliłeskoe opisanie v koncepcii Florenskogo." In: PA. Florenskij: filosofija, nauka, sechnika. L. 1989, S. 9-12. 
Elementen bewiesen. ${ }^{45}$ Durch die gezielte Wiederholung dieser Kombination entsprechend ihrer Formel - läßt sich der Gegenstand wiederherstellen (Murav'ev spricht sogar von "wiedererwecken"):

Die Wiederherstellung eines Dinges entsprechend einer Formel ist eine Art wunschgemåßer Wiedererweckung des Gegenstandes durch den Menschen. ${ }^{46}$

Das Vergangene (prostoe) wird wiedererweckt durch die Wiederholung der vergangenen Kombinationen. Sofern es faktisch [noch] nicht wiedererweckt worden ist, bleibt es, wie jetzt, Eigentum allein des Gedăchtnisses. ${ }^{47}$

Auch ein verstorbener Mensch - ein besonders kompliziertes "bewußtes System" (soznatel'naja sistema) - läßt sich durch Wiederholung seiner Kombination wiedererwecken. ${ }^{48}$ Das dabei auftretende Problem der Identität löst Murav'ev, indem er Wesen und Individualität als eine Kombination von Elementen bestimmt, die sich durch eine Formel oder Zahl darstellen läßt:

... das Wesen der Dinge besteht in Zahlen, ... Dinge sind Zahlen. ${ }^{49}$

Der Begriff der Individualităt beschrănkt sich ausschlieBlich auf die Ubereinstimmung mit einer Formel oder Zahl, und nichts anderes als eine solche Zahl oder Kennziffer einer individuellen Kombination läßt sich in einem Individuum finden. so $^{\circ}$

Wie Wasser durch die künstliche Synthese der Elemente Wasserstoff und Sauerstoff entsprechend 'seiner' Formel $\mathrm{H}_{2} \mathrm{O}$ nach Belieben 'wiedererweckt' werden kann (wobei es für Murav'ev unerheblich ist, ob dazu dieselben oder jeweils andere Atome 'verwendet' werden), so wird sich auch jedes menschliche Individuum entsprechend seiner 'individuellen' Kombinationsformel wiederherstellen lassen. ${ }^{51}$

45 Siehe OV, S. 17.

46 OV, S. 21.

47 OV, S. 65.

48 Vgl. OV, S. 53, 105-109.

49 "... sušcnost' vešcej v čislach, ... vešci sut' cisla." (OV, S. 106). - Murav'ev weist in diesem Zusammenhang auf die Lehre der Pythagoreer hin. Wenn Murav'ev an anderer Stelle sagt, die Zahl könne auch durch Zeichen oder Namen ersetzt werden (VPM, S. 130), so gelangt er damit zu der von Losev gegebenen Bestimmung des Wesens als Name. Verwandte Gedanken finden sich auch bei Florenskij sowie in den mathematischen Spekulationen Chlebnikovs. Mögliche Zusammenhănge sind bislang nicht untersucht worden.

50 VPM, S. 135. - Die Reduktion des menschlichen Individuums auf eine Zahl oder Nummer ist in der anti-utopischen Literatur ein verbreitetes Kennzeichen inhumaner, totalitărer Zukunftsgesellschaften (z.B. in Zamjatins 1920 entstandenem Roman My).

51 VPM, S. 135f. OV, S. 105-109. - Die Forderung nach materieller Identităt von Verstorbenem und Wiedererwecktem ('Verwendung' derselben Materieteilchen) weist Murav'ev mit dem Hinweis zurück, daB zwischen jedem lebenden Organismus und seiner Umwelt ein stăndiger Materieaustausch stattfinde, was niemanden daran hindere, eine bestimmte Kombination als Individuum zu erkennen und zu benennen. (OV, S. 106f.). - Die Wiederherstellung eines Verstorbenen aufgrund seiner individuellen "Strukturformel" (formula stroenija) hatte bereits 1911 
Um die Macht des Menschen über die Natur zu erweitern, muß menschliches Handeln organisiert werden. Bislang schon verändert der Mensch durch "projektiv-produktive Tätigkeit" (proektivno-proizvoditel'naja dejatel'nost') die Natur, indem er ihre blinden, zerstörerischen Kräfte (Chaos) seinem Willen unterwirft und sie zwingt, die von seinem Verstand (Logos) gesetzten Ziele zu verwirklichen. Durch bewußte, zielgerichtete Arbeit verwandelt er die "gegebene, primäre Natur" (dannaja, pervicnaja priroda) in "bearbeitete", "sekundäre" (obrabotannaja, vtoritnaja) - in Kultur. ${ }^{52}$ Diese wird definiert als

... die Gesamtheit der Resultate, die vom Menschen bei der Umgestaltung der Welt erreicht werden. Kultur ist die Welt, die vom Menschen verändert wurde und wird, entsprechend den Idealen seines Verstandes. $^{53}$

Jede Tätigkeit, welche die Natur verändert mit dem Ziel, die Herrschaft des Menschen über sie auszudehnen, kann somit als "kulturelle Tätigkeit" (kul'turnaja dejatel'nost') bezeichnet werden.

Murav'ev unterscheidet zwei Formen kultureller Tätigkeit: geistige Arbeit (ihr entspricht die "symbolische Kultur") und physische Arbeit (ihr entspricht die "reale Kultur"). Durch Arbeitsteilung und Spezialisierung haben sich die beiden Bereiche voneinander getrennt, wobei der Begriff Kultur zumeist auf die Ergebnisse geistiger Arbeit (theoretisches Wissen, Werke der Kunst) beschränkt bleibt. Infolge dieser Trennung hat geistige Arbeit weitgehend den Bezug zur materiellen Wirklichkeit und damit den Blick für die Abhängigkeit des Menschen von der Natur verloren. Während sich ein Teil der Menschen in die weltfremden Regionen abstrakter Theorie und passiver Kontemplation zurückgezogen hat, handeln die anderen zwar in der Welt, doch verfolgen sie dabei lediglich partikulare und egoistische Ziele. Die Trennung von physischer und geistiger Arbeit hat das Handeln sinnlos und das Denken folgenlos werden lassen; sie hat zu einer Zersplitterung der Menschheit in Spezialisten und Konkurrenten geführt, zu einer planlosen, irrationalen Entwicklung der Kuitur und damit zur Schwächung der Kräfte im Kampf gegen die Natur. ${ }^{58}$

NA. Rožkov vorgeschlagen. Ausführlich dazu II: 2.1.3. Denselben Gedanken äußerte vierzig Jahre später der amerikanische Mathematiker und Kybernetiker Norbert Wiener: Die körperliche Identităt eines Individuums beruhe, so Wiener, nicht auf der Identităt der materiellen Substanz, aus der es gemacht sei, sondern auf der Identităt der Anondnung seiner Elemente, d.h. seines Schemas (patterm). Dicses - z.B. durch analysierendes Rastern (scanning) gewonnene Schema, also eine bestimmte Menge von Information, ermoggliche es - theoretisch -, einen lebenden Organismus "aus irgendwelchem Material anderswo wiederherzustellen". N. WIENER, The Human Use of Human Beings. Cybemetics and Sociery. Boston 1950, Kap. 6. Die vollstăndige Darstellung der Molekularstruktur eines Organismus mache es, so Wiener an anderer Stelle, "conceptually possible for a human being to be sent over a telegraph line". DERS., God and Golem, Inc., Cambridge, Mass. 1966, S. 36.

52 VPM, S. 116f.

53 VPM, S. 125. Vgl. OV, S. $16 f$.

54 Vgl. VPM, S. 122-128, 138. OV, S. 22-28, 88f., 112. - FOD I, S. 10, 21, 216, 250-253; II, S. 78. Murav'ev folgt hier nicht nur der Argumentation Fedorovs (ohne diesen zu erwăhnen), sondern übernimmt bei der Beschreibung des Zustands allgemeiner Zwietracht und der "unbrüderli- 
Die verderbliche Herrschaft der Natur kann nur gebrochen werden, wenn es gelingt, die Trennung zu überwinden und alle kulturelle Tätigkeit rational zu organisieren.

Es gibt nur einen Weg - man muß eine Kultur schaffen, in der das Bewußtsein nicht vom Leben getrennt ist, sondern es projektiv lenkt und dabei die einzelnen Menschen nicht einander entzweit, sondern sie im Gegenteil soweit wie moglich vereint auf der Grundlage einer gemeinsamen Aufgabe (na osnovach obscego dela). ${ }^{55}$

In dieser neuen Kultur wird die Kluft zwischen Theorie und Praxis, zwischen "symbolischer" und "realer" Kultur, überwunden werden. Die Menschheit wird sich weltweit vereinen, indem sie eine nur gemeinsam zu bewältigende Aufgabe angeht und alle Aktivitäten im Hinblick auf die Erreichung dieses Ziels koordiniert. $^{56}$

Es muß erkannt werden, daß es nur eine einzige Welt gibt und eine einzige Aufgabe - ihre Umwandlung, und daß diese Umwandlung vollbracht werden muß durch die Bemühungen aller Menschen und aller Geschøpfe der Welt. Diese Umwandlung muß jeden Bereich des Lebens ergreifen, den psychischen ebenso wie den gesellschaftlichen und den materiellen, und alle Einrichtungen und Organe betreffen, die der Menschheit dienen. ${ }^{57}$

Die Menschen müssen sich daran gewöhnen, im gemeinsamen Kampf gegen die todbringenden Krăfte der Natur die höchste menschliche Aufgabe zu sehen. ${ }^{58}$

Wer sich hingegen der Erfüllung dieser Aufgabe verweigert oder sie behindert und seien dies selbst Staaten oder Völker - hat, so Murav'ev, "kein Recht auf Leben". 59

Beruhte die alte Kultur auf dem Prinzip des "Kampfes ums Dasein", der auch ein "Kampf aller gegen alle" war, so gründet sich die "neue Weltkultur" (vsemimaja kul'tura) auf die Prinzipien der Symbiose und der Kooperation (sotrud-

chen" Vereinzelung des bürgerlichen Individuums auch Fedorovs Beispiele und Formulierungen. So spricht er von "egoistischer Unverwandtheit" (nerodstvennost') der Menschen als "Folge ihrer Unterwerfung unter blinde Instinkte" (VPM, S. 124). Statt einer Vereinigung zur Verwirklichung des obšce delo herrsche allgemeiner Krieg (obšzaja vojna), in dem es nur einen Sieger gebe - den Tod (OV, S. 27).

VPM, S. 128. Vgl. OV, S. 61.

56 Vgl. OV, S. 86-89. VPM, S. 138-140. - Dem entspricht Fedorovs "Projektivismus", in dem sich theoretische und praktische Vernunft in der Ausrichtung auf das obstee delo verbinden.

Fast gleichzeitig mit Murav'ev erklärte Trockij, zu den "Endzielen der Revolution" gehöre die "völlige Überwindung" der "von der bourgeoisen Gesellschaft geschaffene[n] Trennung der geistigen Arbeit - darunter auch der Kunst - von der physischen." L. TROCKU, Literatura $i$ revoljucija, M. 1923, S. 7. Zwischen Murav'ev und Trockij, die miteinander bekannt waren, gibt es eine Reihe bemerkenswerter gedanklicher Ubereinstimmungen; siehe unten Anm. 81, 85, 90 , 92.

57 OV, S. 86.

58 OV, S. 87. - In einer Anmerkung hierzu nennt Murav'ev mehrere russische Denker des 19. Jahrhunderts, die sich mit dieser Frage befaßt haben, darunter auch Fedorov. (Ebd., S. 127). 
niðestvo), ${ }^{60}$ die verwirklicht werden im Bewußtsein der "ursprünglichen Verwandtschaft" (pervonacal'naja rodstvennost') aller Menschen.

Diese Verwandtschaft, die [zunăchst nur] etwas von der Natur Gegebenes ist, muB in ihrem sekundären, bewußten Stadium schopferisch und aktiv werden und die Welt in eine einzige große kollektiv schaffende Familie verwandeln. ${ }^{61}$

Unter diesen Bedingungen wird die Menschheit zu einem "organischen Ganzen" (organiCeskoe celoe), einem "Sozialkörper" (social'noe telo) verschmelzen. ${ }^{62}$

Die "symbolische Kultur" wird sich, durch "Oberste Räte" gelenkt, planmäßig entwickeln. Die "Gelehrten" werden eine Art "Kommission" bilden, deren Aufgabe es ist, den Plan für das gemeinsame Handeln zu erarbeiten. ${ }^{63}$ Wissenschaft wird nicht länger Angelegenheit von Spezialisten sein (großangelegte Experimente beispielsweise werden von den Volksmassen durchgeführt). ${ }^{64}$ Das "kollektive Bewußtsein" wird das gesamte Wissen und alle "kulturellen Errungenschaften" synthetisieren, organisieren und in Handeln überführen. ${ }^{65}$ Eine "Philosophie des bewußten Handelns ${ }^{\text {}}{ }^{66}$ wird die Aufgabe eines jeden einzelnen bestimmen und sie durch eine Art mathematischer Integration auf das gemeinsame Projekt beziehen. ${ }^{67}$ Dieses wird von der Wissenschaft als ein "System von Formeln oder Zahlen" dargestellt, wobei es darauf ankommt,

60 VPM, S. 138. - Hier klingt ein Gedanke an, der in der russischen Auseinandersetzung mit dem Darwinismus - insbesondere seinen sozialen Varianten - eine wichtige, wenn auch bislang kaum beachtete Rolle spielte: Dem struggle for life und survival of the fittest stellte P.A. Kropotkin das natürliche Prinzip der "gegenseitigen Hilfe" (vzaimnaja pomos't, mutual aid) entgegen, V.V. Dokutaev das natürliche "Gesetz der Zusammenarbeit (zakon sodružestva), der weltweiten Hilfe und Liebe", und V.I. Vernadskij entwickelte das Konzept einer universellen Symbiose (in seiner Lehre von der "Biosphäre"). Für Fedorov kennzeichnen Überlebenskampf und Zuchtwahl die Herrschaft der Natur, die der Mensch in brüderlicher Zusammenarbeit zu überwinden hat. Vgl. FOD I, S. 32; II, S. 332.

61 VPM, S. 138.

62 VPM, S. 124.

$63 \mathrm{Vgl}$. VPM, S. 127. OV, S. 6, 23. - Fast wörtlich FOD I, S. 28.

64 OV, S. 96f. VPM, S. 139. - FOD I, S. 411. - Bereits um die Jahrhundertwende hatte der Soziologe A. Vol'skij (Ja.V. Machajskij, 1867-1926) vor der Gefahr gewarnt, daB die "Geistesschaffenden" nach der Revolution den Platz der Kapitalisten einnehmen würden, wenn es nicht gelănge, ihr Wissensmonopol zu brechen. Dieser Gedanke wurde spăter vor allem von Bogdanov und dem Proletkul't propagiert.

65 VPM, S. 128-130; in diesem Zusammenhang ein Hinweis auf Fedorovs Abhandlung Supramoralizm ili useobszij sintez. Vgl. OV, S. 89-98.

66 OV, S. 89.

67 ov, S. 93. 
... die Formel für eine jede überhaupt mögliche Handlung zu geben. Damit werden die Projekte der Wissenschaft in eine universelle Produktionsmathematik verwandelt, die alle exakten Kenntnisse des Menschen über die Welt beinhaltet unter dem Aspekt der verăndernden Einwirkung auf letztere. ${ }^{68}$

Auf diesem Weg gelangt man zu einer Universalwissenschaft, die mittels einer Art Weltformel dem Menschen die "vollständige Umwandlung und Erneuerung der Welt" (zunächst im planetarischen, schließlich im kosmischen Bereich) ermöglicht. ${ }^{69}$

Im Weltmaßstab würde das die Beherrschung aller Zeit der Welt (ovladenie vsem vremenem mira) bedeuten, eine kosmische Revolution, durch die der Bund aller Lebewesen allmächtig werden würde. Dann würde die Kette von Ursachen und Wirkungen, die jetzt für uns wirksam ist, ersetzt werden durch eine Kette bewuBten Wollens und Handelns aller Erdenbewohner. ${ }^{70}$

... in der Tat ist die letzte Aufgabe des historischen Handelns der Sprung aus dem Reich der Notwendigkeit in das Reich der Freiheit, die Liquidierung der Geschichte mit ihren zerstorrerischen Prozessen und die Ersetzung ihrer blinden Bewegung durch das rationale Handeln der zu einem riesigen Bund vereinten Lebewesen. ${ }^{71}$

In enger Anlehnung an Fedorovs Projekte beschreibt Murav'ev die allmähliche Umwandlung und Beherrschung der Welt durch den Menschen:

Die gesamte Erdoberflăche wird vom Menschen erforscht und seiner wirtschaftlichen Nutzung unterworfen, die Verkehrswege werden vervollkommnet, durch Radio und Telegraph alle Teile des Erdballs in augenblicklicher Nachrichtenubermittlung verbunden. Als Ergebnis menschlicher Einwirkung verändern sich Flora und Fauna der Erde: Schădliche und nutzlose Tier- und Pflanzenarten werden aussterben, andere aber, nutzliche, werden vom Menschen gezüchtet. Infolge von Waldkultivierung, Trockenlegungs- und Bewassserungsarbeiten wird sich das Klima ganzer Landstriche verăndern. Mit der Entwicklung der Meteorologie ist mit der Zeit die völlige Beherrschung des Wetters und dessen wunschgemäße Regulienng zu erwarten. Im Bereich der Okonomie wird die Idee einer erd- oder sogar weltumgreifenden Wirtschaft allmăhlich Wirklichkeit werden. Der Moment läßt sich voraussehen, da die Erde mit all ihren Elementen wirklich den Menschen gehorren und nach ihren rationalen Plănen umgestaltet werden wird. Weiter kann man ... von der völligen Beherrschung der Schwerkraft trăumen und von einer solchen Regulierung der Bewegung der Erde, daß diese sich in

68 VPM, S. 130; Hervorhebung im Orig. - Wie sehr Murav'ev in der Tradition des Systemdenkens steht (er selbst verweist u.a. auf Leibniz' Mathesis universalis, Laplace und Comte; zu ergănzen wăre insbesondere noch Descartes), zeigt auch seine Gleichsetzung von Denken und Mathematik: "Am vollkommensten ist der Gedanke, der sich durch Zahlen ausdrücken läBt..." (VPM, S. 130).

69 OV, S. 88. VPM, S. 119., 130. - Den gleichen Anspruch hatte Bogdanov für die von ihm entworfene Allgemeine Organisationswissenschaft erhoben: "Diese Wissenschaft wird zum ersten Male echte Weltformeln stiften ... praktische Formeln: solche, die es ermöglichen, planmäBig jede beliebige Gesamtheit gegebener Elemente des Weltprozesses zu beherrschen." A. BoGDA. Nov, Filosofija tivogo opyta. Populjamye ocenki. Pb. 1913, S. 271; Hervorhebung im Orig. Siehe auch II: 3.1.1. - Neben Bogdanov zăhlt Murav'ev zu den extremen Vertretern des russischen Systemdenkens. In der einschlägigen Literatur wurde er bislang freilich nicht zur Kenntnis genommen (siehe zuletzt die ausführliche Arbeit von I. SUsILUOTO, The Origins and Development of Systems Thinking in the Soviet Union, Helsinki 1982).

70 OV, S. 67. Vgl. VPM, S. 134-136.

71 OV, S. 81. 
ein gehorsames Raumschiff verwandelt. Dann werden die Menschen nicht nur Dampfer und Aeroplane steuern, sondern die Erde selbst, sie werden Erdenlenker sein. Aber auch dabei bleibt der aus der Wissenschaft erwachsene Traum nicht stehen: Es zeichnen sich die Perspektiven der Kommunikation mit anderen Planeten mittels besonderer, dafür entwickelter Apparate ab. Die Menschen werden nicht nur die Erde beherrschen, sondern das ganze Sonnensystem... 7

Als näherliegende Aufgaben, die durch weltweit organisiertes Handeln in Angriff genommen werden müssen, nennt Murav'ev die vernünftige Nutzung der Naturschätze anstelle des gegenwärtig betriebenen Raubbaus ${ }^{73}$ sowie die Erschließung neuartiger Energiequellen (Beherrschung der "inneratomaren Energie $^{n}$, d.h. kontrollierte Kernreaktionen, ${ }^{74}$ Wasserkraft und Solarenergie). Mit Fedorov kritisiert er die unvernünftige Produktion nutzloser und schädlicher Dinge als eine Verschwendung von Arbeitskraft und Rohstoffen. Eine rational organisierte Wirtschaft würde statt Luxusgütern und Vernichtungswaffen nur Dinge herstellen, die der Verbesserung der menschlichen Lebensbedingungen dienen. ${ }^{75}$ Mit Fedorov wendet sich Murav'ev auch gegen den Plan einer weltweiten Abrüstung. Allgemeine Wehrpflicht und Bewaffnung müssen beibehalten werden - jedoch allein für den Kampf gegen die Natur: Weitreichende Geschütze werden sich auf die Wolken richten, Hagel vertreiben und Regen auslösen, "chemische Erfindungen werden die Menschen nicht mehr töten, sondern sie wiederbeleben und wiedererwecken ${ }^{n}{ }^{76}$ und die Heere aller Nationen werden sich zu einer "weltweiten Arbeitsarmee" (vsemimaja trudovaja armija) vereinigen, zum Einsatz "gegen Tod, Zeit, Armut und Krankheit". 77

Neben Philosophie, Wissenschaft und Technik, wird auch die Kunst zu einem "realen Faktor der Umgestaltung der Welt" werden. ${ }^{78}$ Statt "toter Abbilder"

72 OV, S. 78f. - Vgl. HielsCher (wie Anm. 1), S. 95. Zur Umwandlung der Erde in ein "gehorsames Raumschiff" siehe auch VPM, S. 134 (dort mit Hinweis auf Fedorov). Vgl. FOD I, S. 283f., 336.

73 VPM, S. 136f. - Eindringlich warnt Murav'ev vor den Folgen dieses Raubbaus: "Die [natürlichen] Ressourcen werden, wenn der Mensch sie durch Raubbau verschwendet, bald erschopft sein. In dieser Hinsicht hat menschliche Tătigkeit die Natur auf Erden bereits verăndert, nămlich in Richtung auf eine Verarmung und Zerstörung. Wenn diesem zerstörerischen Tun nicht Einhalt geboten wird, so widerfăhn der [gesamten] Natur allmăhlich das, was mit vielen bewaldeten Gebieten geschehen ist, die zu Wüsten geworden sind, oder mit Tierarten, die ausgerottet worden sind." (Ebd., S. 130).

74 VPM, S. 133, 137. - Die Möglichkeiten einer technischen Nutzung der "inneratomaren Energie" waren damals gerade von dem Geochemiker und Naturphilosophen Vernadskij beschrieben worden und hatten zur Gründung eines Radium-Instituts durch Vernadskij geführt. Siehe V.I. Vernadsku, Oxerki i reci, t. 1, Pg. 1922, S. 31-44. - Wie Murav'ev ein Liberaler und russischer Patriot, hatte Vernadskij als Mitglied der Konstitutionellen Demokraten (er war einer der Gründer dieser Partei) der Provisorischen Regierung angehört.

75 VPM, S. $137 f$.

76 VPM, S. 139. Vgl. FOD I, S. 4, 661-663, 669-676.

77 VPM, S. 140. Vgl. FOD I, S. 371, 423f., 459, 644. - Zur "Militarisierung der Arbeit" und zu den "Arbeitsarmeen" ausfuhrlich II: 3.1. Anm. 22.

OV, S. 99. 
(mertvye podobija) wird sie "lebendige Bilder" (živye obrazy) geben, ein "künstlerisches Projekt der künftigen verwandelten Welt", und sie wird die Menschen "zu wahren Taten massenhaften Charakters begeistern" - also antizipatorisch und mobilisierend wirken. ${ }^{79}$ Offensichtlich denkt Murav'ev an eine Synthese der Künste mit den Mitteln der künstlerischen Avantgarde, wenn er eine "Verbindung des Konstruktivismus mit der Kinematographie oder einen dynamischen Konstruktivismus" vorschlägt: ${ }^{80}$ Riesige "sich bewegende Bilder" sollen, als Vorzeichen kosmischer Konstruktionen auf den Himmel projiziert, den Horizont der Menschen erweitern, während Sphärenklänge die Massen in rhythmische Bewegung versetzen und sie in ihrem kollektiven Handeln beflügeln und harmonisieren. ${ }^{81}$

Besondere Bedeutung kommt der Architektur zu: Sie wird Gebilde schaffen, die ein massenhaftes organisiertes Leben und Arbeiten ermöglichen, bei dem alle Kräfte auf den Kampf gegen die zerstörerischen Naturgewalten, den Tod, gerichtet sind. ${ }^{82}$ Nach dem Vorbild der altrussischen Wehranlagen, insbesondere des Moskauer Kreml, werden "um die Asche der Väter" Festungsstädte entstehen, die als eine Art Vorposten im künftigen "kosmischen Krieg" dienen: ${ }^{83}$ Museen werden alle Informationen (Überreste, Schriften, Symbole) sammeln und speichern, die für die Wiedererweckung der Vorfahren erforderlich sind; Laboratorien und wissenschaftliche Werkstätten werden die Natur erforschen und verändern; Wetterwarten und Observatorien werden meteorologische und kosmische Vorgänge überwachen und regulieren. ${ }^{84}$ Die Massen werden sich in riesigen Tempeln und auf Plätzen versammeln. Zwischen den Städten, die sich um ihre Kreml gruppieren, werden Gärten liegen, und Straßen werden "in die Tiefe der Felder und Wälder führen", um so die gegenwärtige

79 OV, S. 100. - Vgl. VPM, S. 127: "... naznačenie iskusstva - dat' ljudjam ideal luð̌ego mira i pomot' real'nomu pretvoreniju nastojašcego v takoe budušce."

80 OV, S. 100. - Vgl. auch die - von Fedorov beeinflußten - Uberlegungen zu einer Synthese der Künste bei V.N. Cekrygin (II: 3.2.4.).

81 OV, S. 100f. - Murav'ev erinner in diesem Zusammenhang an die organisierende und stimulierende Funktion der Musik und des Tanzes bei kultischen Handlungen. Diese Funktion müsse in großem Maßstab auf den "außerkirchlichen Bereich", die "gesellschaftliche Liturgie" übertragen werden. (Ebd.; vgl. auch S. 87). - Der Gedanke der Theatralisierung des Alltags und der Rhythmisierung des Menschen" findet sich positiv auch in Trockijs Zukunftsentuurf (TROCKU, wie Anm. 56, S. 187-190), wăhrend in Zamjatins kollektivistisch-totalitărem Einheitsstaat die Berieselung mit Marschmusik ein Mittel zur Manipulierung der normierten Nummernmenschen ist.

82 Siehe OV, S. 101-103. - Murav'ev steht hier ganz in der Tradition des klassischen utopischen Denkens, das die Zukunftsgesellschaft vorwiegend in architektonischen Termini imaginiert; erinnert sei an die französischen Revolutionsarchitekten C.-N. Ledoux und E.-L. Boullée, an Fouriers Phalanstère (und deren russische Variante bei Černyševskij) oder an die (utopischen) Projekte der frühen sowjetischen Architektur.

OV, S. 102.

Ebd. 
Trennung von Städtern und Dorfbewohnern zu beseitigen: "Alle Menschen müssen zugleich in der Stadt und auf dem Lande leben. ${ }^{85}$

Der Stil dieser architektonischen Gebilde wird eine Mischung aus babylonischen Zikkurats, ägyptischen Pyramiden, gotischen Kathedralen und altrussischen Kirchen sein, "gekrönt von mächtigen Antennen, die in den Weltraum Signale der Menschheit verbreiten, vielleicht auch wirksame elektrische Bewegungsenergien". ${ }^{86}$ Mit fortschreitender Entwicklung der Technik werden diese Kreml-Komplexe beweglich werden und zuerst "wie gigantische Tanks" über die Erde kriechen, um sich sodann "wie ungeheure Luftschiffe" $z$ u erheben. ${ }^{87}$ Mächtige "Städte-Flugzeuge" (goroda-aèroplany) werden in den Weltraum vorstoßen, um das Feld menschlicher Tätigkeit - und Herrschaft - auszuweiten. ${ }^{88}$

Schließlich wird die ganze Erde in den Prozeß solchen Bauens einbezogen und gănzlich eine Vereinigung solcher Kreml-Organismen sein; sie wird ... enwachen und sich als ein lebendiges Schiff der Menschheit erkennen, das im Kielwasser des Sonnengeschwaders der weltweiten Vollendung entgegenfahrt. Dann wird der Mensch wahrlich zum Architekten des Weltalls werden, sich in einen Weltenbauer verwandeln, und die Menschen werden Erden- und Sonnenlenker werden. ${ }^{89}$

Um das zu erreichen, müssen zuerst die Grenzen zwischen den einzelnen Gattungen der Kunst aufgehoben werden, sodann die Grenzen zwischen der "vereinten Kunst" und allen übrigen schöpferischen Tätigkeiten: Die Kunst wird vollständig ins Leben übergehen und mit der Gestaltung der Wirklichkeit verschmelzen. ${ }^{90}$

85 Ebd. - Das Thema der Uberwindung der Trennung von Stadt und Land(bewohnern) - bereits eine Forderung der Verfasser des Kommunistischen Manifests; Gartenstadtprojekte reichen sogar bis ins 18. Jahrhundert zurück - spielt bei Fedorov eine wichtige Rolle, doch konnte Murav'ev es auch der Tagesdiskussion entnehmen: Trockij z.B. spricht vom "titanischen Bau von Dorf-Stadten" (TROCKU, wie Anm. 56, S. 184). Vgl. auch die "băuerliche Utopie" von Cajanov. Zahlreiche weitere Beispiele für antiurbanistische Garten- und Agrostadtprojekte (zelenye goroda, agrogoroda) bei S.F. STARR, "Visionary Town Planning during the Cultural Revolution." In: S. FitzPATRICK (Hg.), Cultural Revolution in Russia, 1928-1931, Bloomington, London 1978, S. 207-240.

86 OV, S. 102f. - Zur Idee, "mit Hilfe elektrischer Wellen auf weite Entfernung eine zerstörerische oder konstruktive Wirkung" zu erzielen, siehe auch VPM, S. 134.

87 OV, S. 103.

88 Ebd. - Die Uberwindung der Schwerkraft in der Architektur - Ansătze fimden sich bereits bei Ledoux und Boullee - war zu Beginn der zwanziger Jahre ein überaus beliebtes Thema utopischer Spekulationen; erinnert sei nur an die schwebenden Hăuser und Straßen, die Luft-, Aeround Satellitenstădte etwa bei Chlebnikov, Malevið und Tatlin. Weitere Beispiele und Literatur II: 3.2. Anm. 87.

89 OV, S. 103. - Ganz ăhnlich die - auf Fedorov zurückgehenden - Ausführungen Cekrygins über die "wahre kopernikanische Himmelsarchitektur" (siehe II: 3.2.4). Vgl. dazu FOD II, S. 248250. - Eine poetische Vision in Osip Mandel'Stams berühmtem Gedicht "Sumerki svobody" (1918).

90 Vgl. OV, S. 26, 103. - Murav'evs Forderung nach Uberwindung der reinen Kunst zugunsten praktischer Wirklichkeitsverăndenung hat eine zeitgenossische Parallele in der Theorie der sogenannten "Produktionskunst", wie sie von Boris Arvatov, Nikolaj Cužak und anderen Autoren aus dem Umkreis des LEF vertreten wurde. Die Trennung von Kunst und Produktion soll bei 
Der Mensch wird auch sich selbst zum Gegenstand projektiv-produktiver Tätigkeit machen: Mit Hilfe von "Anthropotechnik" und "Anthropourgie" wird er sich selbst vervollkommnen und die Dauer seines Lebens verlängern. ${ }^{91}$ An die Stelle von unkontrollierter Zeugung und Geburt wird die rationelle Züchtung und massenweise "Produktion" eines Geschlechts von "Übermenschen" treten, eines "vollkommenen, mächtigen Wesens mit kosmischem Horizont und kosmischer Macht". 92 Den Sieg über den Tod wird schließlich die "Anastatik" erringen, die "Kunst, verlorenes Leben wiederzuerwecken" ${ }^{93}$ Der Mensch als "Besieger des Todes" wird seine Macht über die irdischen Grenzen ins All ausdehnen und eine wahre "Kosmokratie und Pantokratie" errichten. ${ }^{94}$

Die Geschichte wird mit der Astronomie verschmelzen. (...) Und das Ende der Erdgeschichte in diesem Sinne wird der Beginn der Sonnengeschichte und dann der Geschichte des Kosmos sein. ${ }^{95}$

Außer der Gesamtkonzeption des obšcee delo übernahm Murav'ev auch zahlreiche Einzelgedanken von Fedorov. Wie dieser setzte er der "blinden Natur" als dem Ursprung aller zerstörerischen Kräfte das bewußte menschliche Handeln entgegen. Wie dieser betonte er die Notwendigkeit, Theorie und Praxis zu vereinen und die Trennung von Gelehrten und Ungelehrten, von Stadt und Land zu überwinden. Die phantastische Vision (fliegender) Festungsstädte - nach dem Vorbild des Moskauer Kreml - als Aufbewahrungsort für die Überreste der Ahnen, mit Einrichtungen zur Regulierung des Klimas (Wetterwarten, Observatorien) und zur Wiederherstellung Verstorbener (Museen, Laboratorien) geht

Murav'ev einem twortestuo Eizni weichen (OV, S. 26) - die Produktionskünstler sprachen von tiznestroenie. Auch Trockij erwartete, daB die Scheidung zwischen Kunst und Technik, aber auch zwischen Kunst (im Sinne von Gestaltung) und Natur fallen werde; durch schøpferische Umgestaltung werde die Natur immer "künstlicher" werden. TroCKu (wie Anm. 56), S. 185f. Zur Konzeption des ziznestroenie und zur These vom Ende der Kunst siehe H. GONTHER, "Proletarische und avantgardistische Kunst. Die Organisationsassthetik Bogdanovs und die LEF-Konzeption der 'lebenbauenden' Kunst." In: Ästhetik und Kommunikation, 4 (1973), 12, S. 62-75. DERS., "Die These vom Ende der Kunst in der sowjetischen Avantgarde der 20er Jahre." In: Referate und Beiträge zum VIII. Internationalen Slavistenkongre $\beta$ Zagreb 1978, München 1978, S. 77-94.

91 VPM, S. 131f. - Murav'ev venweist in diesem Zusammenhang auf die "glänzenden Forschungen" von Bachmet'ev, Voronov, Kol'cov und Kravkov. Siehe dazu II: 2.1.3. und 3.1.3.

92 OV, S. 105. - Murav'ev spricht in diesem Zusammenhang von "proizvodstvo ljudej". Vgl. auch Trockijs Vision einer Selbstvervollkommnung des kommunistischen Menschen, der durch "psychophysisches Training" und "künstliche Auslese" einen "hoheren gesellschaftlichbiologischen Typus, und, wenn man will, den Ubermenschen" schaffen wird. TROCKU (wie Anm. S6), S. 188f. Gegen Ende der zwanziger Jahre entwarf der Architekt K.S. Mel'nikov im Rahmen eines Wettbewerbs 'Grüne Stadt' ein "Institut zur Verănderung der menschlichen Gestalt". Mel'nikovs Biograph S.F. Start sieht darin eine Parallele zu den Ideen Murav'evs und Fedorovs, ohne freilich von einem direkten EinfluB zu sprechen. S.F. STARR, Melnikov. Solo Architect in a Mass Sociery. Princeton 1981, S. 254f. Zu Murav'ev auch ebd., S. 248, 253.

VPM, S. 132. Vgi. OV, S. 109.

VPM, S. 140.

OV, S. $81 f$. 
ebenso auf Fedorov zurück ${ }^{96}$ wie die Projekte einer "Synthese der lebendigen Künste", der Verwandlung der Erde in ein "gehorsames Raumschiff" und der architektonischen Umgestaltung des Universums. ${ }^{97}$ Von Fedorov stammt schließlich auch die Bezeichnung des obšcee delo als "außerkirchliche Liturgie" ${ }^{m 88}$ sowie die Deutung der "aufrechten Wächterhaltung" des Menschen als Ausdruck des Aufstandes gegen die Natur. ${ }^{99}$ Allerdings übernahm Murav'ev die Projekte Fedorovs ohne dessen ethische Begründung: War für Fedorov die Auferweckung der Väter die vornehmste sittliche Pflicht der Söhne, so tritt bei Murav'ev unter dem Eindruck des herrschenden Fortschrittsoptimismus die gesellschaftlichpolitische und wissenschaftlich-technische Durchführbarkeit der Projekte in den Vordergrund. 100

Mit seinen radikalen Forderungen und weitreichenden Plänen sah sich $\mathrm{Mu}$ rav'ev - von Hause aus eher national und liberal gesinnt - nunmehr auf dem linken Flügel der nachrevolutionären sowjetischen Kultur. Diesen Eindruck gewann auch N.V. Ustrjalov, Mitbegründer der prosowjetischen Smena-vech-Bewegung, als er während eines Besuchs in Moskau im Sommer 1925 mit Murav'ev, der ihm einst politisch nahegestanden hatte, zusammentraf:

Ein leidenschaftlicher fedorovec, war er zu jener Zeit [auch] ein leidenschaftlicher Anhănger der Sowjetrevolution, und es ist bezeichnend, daß es gerade seine 'Bekehrung' zur Lehre Fedorovs (jedorovskoe ego 'obras'enie') war, die ihn in einen Sowjetophilen verwandelt hatte. Er behauptete und versicherte, daß man das revolutionăre Pathos des Oktober vollstăndig akzeptieren müsse und, mehr noch, daß es nötig sei, 'weiter' zu gehen, als es bislang die Bolschewiki tăten. Ich sagte ihm, halb im Scherz, daß er in seinem luziferischen Eifer [sogar] Majakovskij und Gor'kij in den Schatten stelle... Er aber bestand darauf, daß es notwendig sei, unserer Revolution noch grandiosere sch ̋pferische Perspektiven zu eroffnen: "nous sommes plus bolchevistes que les bolcheviques mêmes", rief er aus... ${ }^{101}$

96 Vgl. OV, S. 102f. FOD I, S. 111, 427, 513; II, 248, 399-404, $463 \mathrm{f}$.

97 Vgl. OV, S. 100-103. FOD I, S. 283f., 412f;; II, S. 347, 350.

98 Vgl. OV, S. 87. FOD I, S. 260; II, S. 269.

99 Vgl. OV, S. 6. FOD II, S. 204.

100 Zakydalsky bemerkt in diesem Zusammenhang zu Recht: "... without Fedorov's moral motivation resurrection is no more than a repetition of a previous state and has less value than the introduction of a new state. The fact that Murav'ev adhered to the idea of resurrection testifies to his lack of critical judgment, as well as to the hold of Fedorov's influence over him." ZAKYDALSKY (wie Anm. 1), S. 93.

101 N.V. Ustrualov, "Iz pis'ma." In: Vselenskoe delo (wie Anm. 1), S. 165. - Der Staatsrechtler und Historiker N.V. Ustrjalov (1890-1938?) war wie Murav'ev ein gelernter Jurist, ehemaliger Anhănger der Konstitutionellen Demokraten und großrussischer Nationalist. Zwischen 1909 und 1918 schrieben beide für die national-liberale Moskauer Zeitung Utro Rossii; 1918 gehorte Murav'ev zu den Autoren der von Ustrjalov herausgegebenen kurzlebigen Zeitschrift Nakanune. Siehe AGURSKIJ (wie Anm. 10). - Nach seiner Emigration nach Harbin rief Ustrjalov Anfang der zwanziger Jahre seine Landsleute zur patriotisch motivierten Zusammenarbeit mit den Bolschewiki auf. 1925 besuchte er die Sowjetunion und traf mit den Moskauer Fedorov-Anhăngern zusammen. Von 1920 bis 1934 lehrte Ustrjalov an der Juristischen Fakultăt in Harbin; 1935 kehrte er in die Sowjetunion zurück. Ausführlich zu Ustrjalov II: 4.2.1. 
Seine 'revolutionäre Ungeduld' rückt Murav'ev in die Nähe der Biokosmisten (einer ihrer Wortführer, P.I. Ivanickij, gehörte wie Murav'ev zum Kreis der Moskauer Fedorov-Anhänger). Mit ihnen teilte er den prometheischen Glauben an die völlige wissenschaftlich-technische Beherrschbarkeit von Zeit und Raum (immortalizm $i$ interplanetarizm in der Sprache der Biokosmisten) und berief sich dabei auf dieselben Autoritäten, die auch den Biokosmisten als Stütze ihrer "großen Teleologie" dienten: auf Einstein, dessen Relativitätstheorie die Beherrschung der Zeit versprach, auf Ciolkovskij, der die Eroberung des Weltraums predigte, und schließlich auf die russischen Physiologen, die mit ihren Experimenten und Theorien zur biologischen Verjüngung, Lebensverlängerung und Wiederbelebung die Überwindung des Todes in Aussicht stellten.

Hinzu kommt noch ein weiterer wesentlicher Einfluß. Um die Mitte der zwanziger Jahre arbeitete Murav'ev im Volkskommissariat für Arbeiter- und Bauerninspektion (NKRKI), danach bis 1929 als wissenschaftlicher Sekretär in dem von A.K. Gastev geleiteten Zentralen Arbeitsinstitut $(C I T) .{ }^{102}$ Beide Einrichtungen befaßten sich im weitesten Sinne mit Fragen der Organisierung und Rationalisierung menschlicher Tätigkeit. ${ }^{103}$ Das dabei angewandte Verfahren, komplexe Vorgänge und Beziehungen durch mathematische Formalisierung und Systematisierung zu vereinheitlichen, sollte - nach den Plänen Gastevs -

102 G.G.G. (wie Anm. 2), S. 181. Postkante von V.N. Murav'ev an NA. Setnickij, 1928; FAP I, 328.

103 Die 1920 gegründete Arbeiter- und Bauerninspektion hatte u.a. die Aufgabe, Vorschriften zur Rationalisierung des staatlichen Verwaltungsapparates zu erlassen und über deren Einhaltung zu wachen. Mit Unterstutzung dieser Behorde entstanden überall im Lande Zellen und Gruppen für "wissenschaftliche Arbeitsorganisation" (naulnaja organizacija truda - NOT), um die zahlreichen Mängel des Funktionierens von Wirtschaft und Verwaltung zu beseitigen. Eng damit verbunden war auch die Tătigkeit der 1923 von P.M. Keržencev gegründeten "Zeitliga" (liga vremeni), die zum bewuBten Umgang mit der Zeit und ihrer rationellen Nutzung aufrief und gegen Unpünktlichkeit und Zeitverschwendung, den sogenannten "organisatorischen Analphabetismus", zu Felde zog. Um das BewuBtsein für Zeit zu entwickeln, wurden die Mitglieder der "Zeitliga" angehalten, Uhren zu tragen und auf sogenannten "Chronokarten", einer Ant Stundenplan, ủber die tägliche Arbeits- und Freizeit Rechenschaft abzulegen. Die "Zeitliga" (spăter "Liga für NOT") wurde binnen kurzem zu einer Massenbewegung. Daneben gibt es zahlreiche Einzelbeispiele für ein geschärftes Zeit-BewuBtsein: So verband der Konstruktivist V. Kuzmin seinen Entwurf für Kommunalwohnungen mit einem genauen Zeitplan für deren Bewohner, in dem die Abfolge und Dauer selbst der kleinsten Verrichtungen (Morgengymnastik, Duschen, Ankleiden, Gang in den Speiseraum usw.) minutios bemessen und vorgeschrieben war. Siehe A. KoPP, Constructivist Architecture in the USSR, New York 1985, S. 81. Einen Fall lebenslanger exakter Buchführung über die verbrauchte Zeit (betrieben von dem Biologen A.A. Ljubišcev) schildert DA. GrANIN in der Novelle Eta strannaja tizn', L. 1976. Siehe auch Murav'evs Bemerkung (OV, S. 7f.), das von ihm behandelte Problem der 'Beherrschung der Zeit' sei aus der 'wissenschaftlichen Arbeitsorganisation' erwachsen.

Zum CIT ausführlich II: 3.1.1., bes. Anm. 23. Vgl. auch P.M. KERŻENCEV, Borba za uremja, M. 1965 (S. 65. Abb. einer "Chronokane"). F. BAUMGARTEN, Arbeitswissenschaft und Psychotechnik in Rußland, Müchen, Berlin 1924, S. 105-113. FUrOP-MILLER (wie Anm. 24), S. 272-277. K.E. B.AILES, "Aleksej Gastev and the Soviet Controversy over Taylorism, 1918-1924." In: Soviet Studies, 29 (1977), 3, bes. S. 386-389. M. TATUR, 'Wissenschaftliche Arbeitsorganisation.' Arbeitswissenschaften und Arbeitsorganisation in der Sowjetunion 1921-1935. Wiesbaden 1979, S. 66-70. R. StTrEs, "Utopias of Time, Space, and Life in the Russian Revolution." In: Revue des Etudes slaves, 56 (1984), 1, S. 151 . 
nicht auf die Arbeitswelt beschränkt bleiben, sondern weite Bereiche des Lebens erfassen: Neben die "wissenschaftliche Organisation der Arbeit" würde dann die "wissenschaftliche Organisation des Alltagslebens" (naucnaja organizacija byta) treten, mit dem Ziel, alle menschliche Tätigkeit vernünftig zu regulieren und planmäßig zu koordinieren. Dahinter stand das von A. Bogdanov entwickelte Konzept einer "Allgemeinen Organisationswissenschaft", die alle Erkenntnisse über die Welt durch Reduktion auf ein Prinzip vereinen und in ein allmächtiges Instrument der kollektiv handelnden Menschheit bei der Umgestaltung der Welt verwandeln sollte. ${ }^{104}$

Dieser Gedanke, von Bogdanov erstmals in seiner 1913 erschienenen Filosofija Zivogo opyta geäußert, wurde allem Anschein nach von Murav'ev rezipiert und in seiner Vseobš̌aja proizvoditel'naja matematika weiterentwickelt. ${ }^{105} \mathrm{Ob}$ wohl Bogdanov von Murav'ev an keiner Stelle genannt wird, deutet eine Reihe von Gemeinsamkeiten (inhaltliche und terminologische) auf eine Beeinflussung hin - angefangen vom monistischen Verständnis der Welt ${ }^{106}$ über die Definition des Begriffs 'Kultur' ${ }^{107}$ und die Auffassung von Kunst als Organisationsmittel ${ }^{108}$ bis zur Forderung nach Vergesellschaftung der Wissenschaft ${ }^{109}$ und der Vorstellung eines "tovariš̌̌eskoe sotrudničestvo" bei der Erfüllung des "obščee delon'110.

Über Murav'evs Tätigkeit am Zentralen Arbeitsinstitut ist nichts Näheres bekannt. ${ }^{111}$ Zwar erschienen 1928 in Organizacija Truda, der Vierteljahresschrift des $C I T$, zahlreiche Beiträge aus seiner Feder, doch handelt es sich dabei fast ausschließlich um Rezensionen ausländischer Veröffentlichungen zu Fragen

$104 \mathrm{Zu}$ Gastev und Bogdanov siehe II: 3.1.1. und die dort angegebene Literatur.

105 Vgl. Bogdanov (wie Anm. 69), S. 259-272. VPM, S. 118-121, 130 und pass.

106 Vgl. A. BogDANOV, Vseobscaja organizacionnaja nauka (Tektologija), c. 1 [1913], M. ${ }^{3} 1925$, S. 137. OV, S. 39ff., 63-66, 90f. und pass.

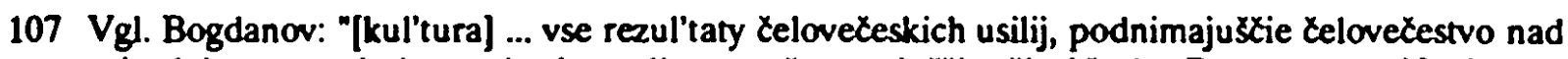
prirodoju, vse plody truda i mysli, soverßenstvujuscie zizn'." A. BOGDANov, Nauka ob obserestvennom soznanii [1914], M. ${ }^{2}$ 1918, S. 8. VPM, S. 125.

$108 \mathrm{Vgl.} \mathrm{A.} \mathrm{BocDanov,} \mathrm{"Proletariat} \mathrm{i} \mathrm{iskusstvo."} \mathrm{[1918]} \mathrm{In:} \mathrm{DeRs.,} \mathrm{O} \mathrm{proletarskoj} \mathrm{kul'ture} \mathrm{19041924,}$ L.-M. 1924, S. 117f. OV, S. 98-100.

109 Vgl. Bogdanov (wie Anm. 69), S. 3ff. OV, S. 96f. VPM, S. 139. - Bogdanovs utopischer Roman Inžener Ménni (1913) enthălt einen Aufruf an die Arbeiterklasse, sich der Wissenschaft zu bemăchtigen, um deren Zersplitterung und Isolierung zu überwinden und sie dem Leben, der Arbeit anzunăhem. A. Bogdanov, Inzener Menni, L.-M. ${ }^{5}$ 1925, S. 76f. (Nachdruck Hamburg 1979).

110 Vgl. A. Bogdanov, "O tendencijach proletarskoj kul'tury." [1919] In: DERS. (wie Anm. 108), S. 324. VPM, S. 138.

111 In neueren sowjetischen Arbeiten über das CIT werden zahlreiche Mitarbeiter genannt, doch finden sich keinerlei Hinweise auf Murav'ev. Siehe z.B. CIT $i$ ego metody NOT, M. 1970. Dasselbe gilt auch für die bislang ausführlichste im Westen erschienene Arbeit von TATUR (wie Anm. 103). 
der Arbeitswissenschaft und Organisation; ${ }^{112}$ eigene Anschauungen kommen darin nicht zum Ausdruck. Unbestätigt bleiben Behauptungen, Murav'ev habe Fedorovsche Ideen in die Arbeit des CIT eingebracht und die (etwa 1924 erfolgte) Umorientierung von einem bloßen Taylorismus in Richtung auf eine Erforschung der "Arbeit in all ihren Erscheinungsformen" sei nicht ohne seinen "starken Einfluß" erfolgt. ${ }^{113}$

1929 wurde Murav'ev - möglicherweise wegen seiner Verbindungen zu Trockij - verhaftet und auf die Soloveckij-Inseln verbannt; dort soll er im Februar 1931 an Typhus gestorben sein. 114

Bis zuletzt - wie es heiBt, noch in der Verbannung - war Murav'ev schriftstellerisch tätig. Den Schwerpunkt bildete offenbar die Behandlung philosophischer Themen (insbesondere die Auseinandersetzung mit dem Werk Fedorovs); daneben schrieb er über politische, wirtschaftliche und organisatorische Fragen und versuchte sich auf dem Gebiet der Belletristik. ${ }^{115} \mathrm{Da}$ diese Arbeiten in der Sowjetunion nicht erscheinen konnten, übersetzte Murav'ev einige von ihnen (darunter auch Ovladenie vremenem) ins Englische und versuchte sie im Ausland $\mathrm{zu}$ veröffentlichen, was jedoch mißlang. ${ }^{116}$ Anscheinend zirkulierten einige seiner Schriften in der Sowjetunion als Manuskript. ${ }^{117}$

Ovladenie vremenem war Murav'evs einzige größere Arbeit, die in der Sowjetunion veröffentlicht werden konnte. Zwar war die Auflage binnen kurzem vergriffen, doch ließ sich im Lande selbst zunächst keine Resonanz feststel-

112 Organizacija muda. Trechmesjacnyj organ Central'nogo Instituta Truda VCSPS. M. 1928, 1, S. 96f., 99-102, 104; 2, S. 51-54, 76f., 79f;; 3, S. 84, 86f.; 4, S. 34f., 94.

113 G.G.G. (wie Anm. 2), S. 182. - Weiter heißt es dort: "Die Fedorovschen Ansichten über die Arbeit, die Murav'ev bereits 1923-24 entwickelt hatte, wurden durch das CIT realisiert und fanden etwa 1928-30 offizielle Anerkennung (freilich ohne Angabe oder sogar Kenntnis ihres Ursprungs)."

114 Laut der von Murav'evs Schwestern veroffentlichten Todesanzeige in der Pariser Emigrantenzeitung Vozrozdenie, 2205 (16.6.1931), S. 1. - Andere Quellen sprechen von einer Verbannung nach Narym, wo Murav'ev in einer meteorologischen Station gearbeitet haben soll; 1932 sei er an Flecktyphus gestorben. Vselenskoe delo (wie Anm. 1), S. 116, 165, 181.

115 G.G.G. (wie Anm. 2), S. $181 f$.

116 Ebd.

117 So erinnerte sich der in Moskau lebende Architekt K.S. Mel'nikov, im Winter 1923/24 ein Manuskript von Murav'ev gelesen zu haben, das damals weit verbreitet gewesen sein soll; offenbar handelt es sich um den Aufsatz Vseobszaja proizuoditel'naja matematika, dessen Veroffentlichung kurzfristig verhindert worden war. STARR (wie Anm. 92), S. 248. - Uber den Verbleib all dieser Schriften, von denen ein Teil sich im Ausland befinden soll, ist nichts bekannt. Ein Archiv von Valerian Murav'ev befindet sich in der Handschriftenabteilung der Lenin-Bibliothek in Moskau, Fond 189. Siehe Lilnye archimye fondy v gosudarstvennych chranilišach SSSR. Ukazatel'. T. 1, M. 1962, S. 470. Das Archiv enwies sich als unzugănglich; über seinen Inhalt liegen keine Angaben vor. Ein Manuskript Murav'evs mit dem Titel Filosofija dejstrija - eine in den zwanziger Jahren entstandene unveroffentlichte Arbeit über Fedorovs Filosofija obsčego dela - soll sich in der Saltykov-Scedrin-Bibliothek in Leningrad befinden. (Private Mitteilung). 
len. ${ }^{118}$ Im Ausland erschienen 1928 zwei Rezensionen, deren Verfasser dem evrazijstvo nahestanden: V.E. Sezeman (1884-1963), Professor für Philosophie an der Universität Kaunas und Schüler Cohens, referierte in einem Beitrag für die Pariser Zeitschrift Versty den Inhalt von Ovladenie vremenem und wies auf einige Irrtümer in Murav'evs Konzeption hin. ${ }^{119}$ Im Ganzen positiv äußerte sich zunächst auch der in Paris lebende Theologe V.N. Il'in (1891-1974) in einer kurzen Besprechung in der Zeitschrift Put' im Jahre 1928, wobei er den Einfluß Fedorovs und des imjaslavie erwähnte. ${ }^{120}$ Doch schon ein Jahr später nannte Il'in Murav'evs Werk ein Beispiel dafür, wie Fedorovs Ideen in einen "kosmischen gottlosen Utopismus mit kommunistischem Beigeschmack" verwandelt würden. ${ }^{121}$ Fedorovs Einfluß wurde auch von Berdjaev und Tschižewskij bemerkt. Während Berdjaev Ovladenie vremenem ein "interessantes Buch" nannte, ohne jedoch näher auf dessen Inhalt einzugehen, ${ }^{122}$ wies Tschižewskij auf die Übernahme des Gedankens der Überwindung der Zeit in Majakovskijs Banja hin. ${ }^{123}$

In den dreißiger Jahren bemühten sich die Fedorov-Anhänger in Moskau, Harbin und Prag, Murav'ev bekanntzumachen und seine Ideen zu verbreiten. So führte A.K. Gorskij (Moskau) im Rahmen seiner umfangreichen Untersuchungen über die Wirkung Fedorovscher Ideen in der Sowjetunion ausführliche Zitate aus Ovladenie vremenem an, ${ }^{124}$ und der von Fedorov-Anhängern und Eurasiern gemeinsam zusammengestellte, 1934 in Riga erschienene Sammelband $V$ selenskoe delo enthielt neben der Veröffentlichung von Vseobšcaja proizvoditel'naja matematika einen Nachruf auf Murav'ev sowie Erinnerungen von N.V. Ustrjalov. ${ }^{125}$ P.N. Savickij, der Führer der Prager Eurasier, ging in einem Artikel über die nachrevolutionäre russische Philosophie, der unter dem Pseudonym "P. Vostokov" 1932 in der Pariser Zeitschrift Le Monde slave erschien, auf Murav'ev und Ovladenie vremenem ein, wobei er den Einfluß Fedorovs und des imjaslavie hervorhob. ${ }^{126}$ K.A. Čcheidze, ebenfalls Prager Eurasier und ein

118 G.G.G. (wie Anm. 2), S. 181.

119 In: Versty, 3, 1928, S. 172-175.

120 In: Put', 9, 1928, S. 94.

121 V.N. IL'IN, "O religioznom i filosofskom mirovozzrenii N.F. Fedorova." In: Evrazijskij sbomik, kn. 6, Prag 1929, S. 20. Siehe auch Ders., Sest' dnej morenija, Paris 1930, S. 211.

122 N.[A.] BERDJAEV, Ja i mir ob-ekıov, Paris 1934, S. 125.

123 D. CYŽEVs'KYJ [TsCHIŽEWSKU], "Die russische Philosophie der Gegenwart." In: Slavische Rundschau, 2 (1930), 10, S. 739.

124 A. Ostromirov [d.i. A.K. GoRSKU], Nikolaj Fedorovic Fedorov i sovremennost', vyp. 3, Charbin 1932, S. 30 .

125 Siehe oben Anm. 1, 2, 101.

126 P. Vostoxov [d.i. P.N. SAvicku], "La philosophie russe durant la période post-revolutionnaire." In: Le Monde slave, 9 (1932), 4, S. 432-457; hier S. 440. Zu Savickij siehe auch II: 4.3.2. 
Anhänger Fedorovs, wies mehrmals auf Murav'ev hin und nannte ihn einen "prominenten Vertreter der Lehre Fedorovs". ${ }^{127}$ Wahrscheinlich war es der in Harbin lebende Fedorov-Anhänger N.A. Setnickij, der Gor'kij auf Murav'ev und sein Werk aufmerksam machte; im November 1934 wandte sich Gor'kij an seinen Sekretär P.P. Krjuckkov mit der Bitte, ihm Ovladenie vremenem zu schicken. ${ }^{128}$

Damit erschöpfen sich die - insgesamt spärlichen - Zeugnisse einer Rezeption. Murav'evs Ende markiert zugleich das Ende dessen, was (am Beginn dieses Kapitels) als "prometheisches Denken" bestimmt wurde; 129 oder, wie es N.V. Ustrjalov formulierte:

... die Revolution ist erbarmungslos nicht nur gegen den, der mit ihr nicht Schritt hält, sondern auch gegen den, der sie 'überholt'. ${ }^{138}$

127 K.A. ČCHEIDZE, "N. Fjodorovið Fjodorov." In: Ruch filosofický, 11 (1936), 3-4, S. 114. DERS., "N.F. Fedorov v proslom i nastojašcem. (K poznaniju religioznych motivov russkoj revoljucii)." In: Znamja Rossii, 12 (100), 1937, S. 12.

128 Siehe Letopis' Zizni i tvortestva A.M. Gor'kogo, vyp. 4, M. 1960, S. 424. - Ein Exemplar dieses Buches wurde unlängst in Gor'kijs Privatbibliothek nachgewiesen. Siehe Licnaja biblioteka A.M. Gorkogo v Moskve. Opisanie. Kn. 1, M. 1981, S. 326, Nr. 5634. - Gor'kijs Bitte an Krjuckov erfolgte unmittelbar auf einen Brief Setnickijs (vom 29.10.1934), in dem dieser auf den verbannten Murav'ev, einen "sehr interessanten Denker", und dessen Buch hingewiesen hatte. Siehe II: 4.2., Anm. 150ff.; dort auch ausführlich zur Korrespondenz zwischen Gor'kij und Setnickij.

$129 \mathrm{Zu}$ der Zeit, da Murav'ev verhaftet wurde, gelang es einem gewissen P.S. Boraneckij, die Sowjetunion zu verlassen. Mit seiner "prometheischen Weltanschauung", die im einzelnen stark an Fedorov, Murav'ev und die Biokosmisten erinnert, erregte er in den dreißiger Jahren in Pariser Emigrantenkreisen Aufsehen. Siehe II: 4.3.4.

130 Ustrualov (wie Anm. 101). - In jüngster Zeit wird im Zusammenhang mit der Erforschung des utopischen Denkens in Rußland und der Wirkung des Fedorovschen Werkes auch Murav'ev gelegentlich enwăhnt. Vgl. P. SCHEIBERT, "Die Besiegung des Todes." In: Glaube, Geist, Geschichte. Festschrift für Emst Benz. Leiden 1967, S. 445f. DERS., "Revolution und Utopie. Die Gestalt der Zukunft im Denken der russischen revolutionăren Intelligenz." In: Epinhosis. Festgabe für Cart Schmitt. Bd. 2, Berlin 1968, S. 648. ST. LukASHEVICH, N.F. Fedorov (1828-1903). A Study in Russian Eupsychian and Utopian Thought. Newark, London 1977, S. 28f. L. KoEHLER, N.F. Fedorov: The Philosophy of Action. Pittsburgh 1979, S. 78. G.M. Young, Nikolai F. Fedorov: An Introduction, Belmont 1979, S. 187f. - Alle genannten Autoren stützen sich ausschließlich auf die spärlichen und zum Teil fragwürdigen Angaben in Vselenskoe delo, die zudem oft ungenau wiedergegeben werden. So heißt es bei Young (um nur das jüngste Beispiel zu zitieren), Murav'ev sei der Sohn des Außenministers (!) gewesen. 1917 (!) verhaftet, sei er zu einer fünfjährigen (!) Gefăngnisstrafe verurteilt worden. Danach habe er in verschiedenen Ministerien einflußreiche (!) Stellungen innegehabt. 1932 sei er im Alter von 37 (!) Jahren gestorben.

In der sowjetischen Literatur wurde Murav'ev zuerst mit Ciolkovskij in Verbindung gebracht: "Bliže vsego $k$ idejam Ciolkovskogo - neobyknovennaja kniga maloizvestnogo filosofa V.N. Murav'eva 'Ovladenie vremenem' ... prosla nezametno." I.A. Kol'CENKO, KE. Ciolkovskij kak myslitel', Kand. diss., Ms. [Masch.], M. 1968, Bl. 233. Siehe ferner den Hinweis im Zusammenhang mit Fedorov bei S.G. SEMENOVA, 'TvorZestvo Żizni. Filosofskaja mysl' N.F. Fedorova i russkaja literatura." In: Naš Sovremennik, 1981, 6, S. 183; und - im Zusammenhang mit V.I. Vernadskij und der Theorie der "lebenden Materie" (zivoe vestestvo) als "zeitbildendem Faktor" (rremjaobrazujustij faktor) - bei AKSENOV (wie Anm. 1). 


\section{DIE ZWANZIGER UND DREISSIGER JAHRE}

\subsection{Die Fedorov-Anhänger in Moskau}

Fedorovs Bedeutung für die sowjetische Kultur der zwanziger Jahre läßt sich nicht allein durch den Nachweis der Rezeption in einigen 'prominenten' Fällen ermessen. Zu fragen ist auch nach der allgemeinen Verbreitung seiner Ideen sowie nach der Zahl seiner Anhänger, ihrer Organisation, gesellschaftlichen Stellung und ihrem Einfluß.

In der neueren Literatur finden sich dazu erstaunlich dezidierte Äußerungen: So ist, um nur einige Beispiele zu nennen, die Rede von der "herausragenden Rolle", die "Fedorovs Ideen in der sowjetischen Kultur gespielt" hätten, und von der "massenhaften Begeisterung (poval'noe uvlečnie) der prosowjetischen Intelligenz" für Fedorovs Werk. ${ }^{2}$ Anhänger Fedorovs seien, so heißt es, auf "verantwortungsvolle Regierungsposten" gelangt und hätten einige seiner Ideen und Projekte in die offizielle Politik einbringen können. ${ }^{3}$ Formulierungen wie "Fedorovian movement", "organized Fedorovism", "center of Fedorovism" lassen an eine breite, wohlorganisierte Bewegung denken. 4

Dem stehen die überaus spärlichen Angaben in den zeitgenössischen Quellen gegenüber, die zudem vage und widersprüchlich sind. Der einzige, der von einer weiten Verbreitung der Lehre Fedorovs berichtet, ist der österreichische Schriftsteller und Kulturhistoriker René Fülöp-Miller (1891-1963), der in den frühen zwanziger Jahren die Sowjetunion bereiste und sich dabei nicht nur für den kommunistischen Aufbau interessierte, sondern auch für dissidente Strömungen im geistigen und religiösen Untergrund. Als einen der vielfältigen Versuche, "die geistige Wiedergeburt Rußlands aus den religiösen Tiefen der Rechtgläubigkeit abzuleiten", nennt Fülöp-Miller: "Die Neubelebung der alten Lehre Fjodoroffs von der 'wahren Kollektivität', die früher nur wenigen bekannt gewesen war, gerade unter der 'materialistischen Diktatur' der Bolschewiken jedoch neu aufflammte, in weite Kreise eindrang und gegenwärtig einen großen

1 M. AgURSKU, Ideologija nacional-bol'sevizma, Paris 1980, S. 30.

2 Ebd., S. 46.

3 G.M. Young, Nikolai F. Fedorov: An Introduction, Belmont 1979, S. 182, 184, 188, 222.

4 Vgl. S.V. UTECHIN, "Bolsheviks and Their Allies After 1917: The Ideological Pattern." In: Soviet Studies, 10 (1958), 2, S. 131. ST. LuKASHEVICH, N.F. Fedorov (1828-1903). A Study in Russian Eupsychian and Utopian Thought. Newark, London 1977, S. 30. Young (wie Anm. 3), S. 183-185. - Siehe dazu meine Kritik M. HAGEMEISTER, [Rez.] "L. Koehler, N.F. Fedorov: The Philosophy of Action ... Pittsburgh 1979." In: ZfSIPh, 43 (1983), S. 207. DERS., [Rez.] "G.M. Young, Nikolai F. Fedorov: An Introduction, Belmont 1979." Ebd., 44 (1984), S. 446f. - Der Ausdruck fedonovskoe tečenie findet sich bereits 1932 bei N. BERDJAEv, [Rez.] "N.A. Setnickij, O konetnom ideale, 1932." In: Put', 36, 1932, S. 93. 
Teil der russischen Geistigkeit in ihrem Banne hält.." ${ }^{55}$ Da jedoch, so fügt er hinzu, "alle nichtmaterialistischen Richtungen ... den rücksichtslosesten Verfolgungen ausgesetzt" seien, könnten sie sich "nur im Verborgenen entwickeln, ihre Anhänger sich nur in geheimen Konventikeln zusammenfinden. ${ }^{66}$ - Unter solchen Umständen dürfte es aber auch für Fülöp-Miller schwierig gewesen sein, einen verläßlichen Überblick über die Verbreitung der Ideen Fedorovs zu gewinnen.

Bemerkungen, die auf eine heimliche Beschäftigung mit Fedorov deuten, finden sich vereinzelt auch an anderen Orten: So spricht ein pseudonym veröffentlichter Bericht über die "unterirdische Literatur im heutigen Rußland" (der späten zwanziger Jahre) vom neuerwachten Interesse russischer Intellektueller an Fedorov, ${ }^{7}$ und V.S. Varšavskij erinnert sich an "Zeugnisse für die Existenz geheimer Fedorov-Anhänger (tajnych 'fedorovcev')" in Sowjetrußland, ohne jedoch auf diese Zeugnisse näher einzugehen. ${ }^{8}$ Bei der Erwähnung von fedorovcy ist freilich auch mit Verwechslungen zu rechnen: So wurden Anhänger Fedorovs mit den ebenfalls als fedorovcy bezeichneten Mitgliedern einer weit verbreiteten apokalyptischen und militant-antibolschewistischen Sekte gleichgesetzt. ${ }^{9}$

Berdjaev, der selbst immer wieder auf Fedorov hingewiesen hat, schrieb 1927, "auf dem Höhepunkt der bolschewistischen Revolution" habe sich "unter der Jugend ein Interesse für Fedorovsche Ideen bemerkbar gemacht, wenn auch bisweilen leider in entstellter Form". ${ }^{10}$ Gemeint waren die Biokosmisten. Ihr Anführer, Aleksandr Svjatogor, glaubte indes schon 1922 feststellen zu können: "Von dem 'Philosophen' [Fedorov; M.H.] ist nichts geblieben, abgesehen von

5 R. FULOP-MILLER, Geist und Gesicht des Bolschewismus, Wien ${ }^{2} 1928$ [1'1926], S. 378; Hervorhebung von mir; M.H. - Auf diese Behauptung Fülop-Millers stützt sich wahrscheinlich Nikolaj Arsen'ev, der in seiner 1929 erschienenen Geschichte der russischen Literatur erklărt, Fedorovs Philosophie finde "... gerade jetzt, 25 Jahre nach seinem Tode ... einen besonders starken Anklang ... bei vielen religiős denkenden und dabei kirchlich-glăubigen Menschen unter den Gebildeten in SowjetruBland." N.v. ARSENIEw [N.S. ARSEN'Ev], Die nussische Literatur der Neuzeit und Gegenwan in ihren geistigen Zusarnmenhängen, Mainz 1929, S. 363.

6 FOLOP-MILLER (wie Anm. 5).

7 M. ARTEMjew [ARTEM'Ev; Pseud.], "Unterirdische Literatur im heutigen RuBland." In: Orient und Occident, 7, 1931, S. 16.

8 V.S. VARSA VSKIJ, Nezamečennoe pokolenie, New York 1956, S. 260.

9 "Fleeing Lenin's success in Russia, Fedorov's followers attempted to settle in Manchuria [gemeint ist offenbar der Fedorov-Anhänger N.A. Setnickij in Harbin; dazu II: 4.2.], while some sects still carry his name in the present Soviet Union." V. MURVAR, "Messianism in Russia: Religious and Revolutionary." In: Joumal for the Scientific Study of Religion, 10 (1971), 4, S. 301; Hervorhebung von mir; M.H.

Die Sekte der fedorovcy, benannt nach ihrem Gründer Fedor Rybalkin, war in den zwanziger Jahren vor allem im Zentralen Schwarzerdegebiet verbreitet und soll sich trotz massiver Verfolgung bis in die Gegenwart gehalten haben. Siehe dazu I.V. REUTSKI, "Razoblexennoe gnezdo sektantskoj kontrrevoljucii." In: Bednota, 3455 (2.11.1929). A. SESTAKov, "Krestonoscy CCO." In: Novyj Mir, 1929, 12, S. 148-154. R. STUPPERICH, "Russische Sektenbewegungen der Nachrevolutionszeit." In: Zeitschrift für systematische Theologie, 13 (1936), 2, S. 259-261. W. KoLARZ, Religion in the Soviet Union, London 1961, S. 358-361. 
jenen lebenden Leichnamen aus der Intelligenz, die trostlos auf der Pfeife einer national-konstitutionell-demokratischen 'Philosophie' spielen, sowie einigen Fedorov-Anhängern (fedorovcy) ... Epigonen, ... gezwungen zum aussichtslosen Balancieren zwischen Orthodoxie und Atomismus." ${ }^{11}$

Aussagen dieser Art erlauben es nicht, ein klares und gesichertes Bild vom Ausma $B$ der sowjetischen Fedorov-Rezeption in den zwanziger Jahren zu zeichnen. Angesichts der in der neueren Literatur verbreiteten weitreichenden Mutmaßungen und Behauptungen ist allerdings vor einer Überschätzung zu warnen: Noch 1933 beklagte der Fedorov-Anhänger N.A. Setnickij mit Blick auf die Sowjetunion, daß "die Ansichten Fedorovs zu einer ganzen Reihe von Fragen nicht nur nicht bekannt, sondern sogar unzugänglich [seien], und zwar nicht nur für den Durchschnittsleser, sondern auch für die leitenden Kreise... ${ }^{12}$

In den Jahren nach der Revolution scheint man sich mit Fedorov am intensivsten in Moskau beschäftigt zu haben. Hier hatte Fedorov die längste Zeit seines Lebens verbracht und die meisten Spuren hinterlassen. Hier wurde - nach dem Tod Koževnikovs (1917) und Petersons (1919) - sein Nachlaß aufbewahrt. Hier fand sich schließlich eine Gruppe von Intellektuellen zusammen, die es sich zur Aufgabe machte, Fedorovs Erbe zu bewahren und weiterzuentwickeln, seine Schriften herauszugeben und seine Ideen zu propagieren. Die Entstehung dieser Gruppe geht möglicherweise auf jene zahlreichen halböffentlichen oder privaten Zirkel und Vereinigungen zurück, in denen zu Beginn der zwanziger Jahre religiöse, philosophische und künstlerische Fragen jenseits der herrschenden Ideologie diskutiert wurden. $\mathrm{Zu}$ den bedeutendsten dieser Vereinigungen zählten in Moskau die "Freie Akademie für Geisteskultur" (1919-1922) und die "Freie philosophische Assoziation" (1921-1924). ${ }^{13}$ Es ist anzunehmen, wenngleich nicht nachweisbar, daB im Rahmen ihrer Veranstaltungen auch über Fedorov gesprochen worden ist; immerhin gehörten zu den regelmäßig Vortragenden Berdjaev, Belyj und Florenskij, die mit Fedorovs Werk gut bekannt waren.

11 A. SVJATOGOR [AGIENKo], "'Doktrina otcov' i anarchizm-biokosmizm." In: Biokosmist, 1922, 34, S. 20.

12 N.A. SETNICKU, SSSR, Kitaj i Japonija. (Načal'nye puti reguljacii). Charbin 1933, S. 27.

13 Die Geschichte dieser mehr oder weniger exklusiven Vereinigungen, Zirkel, 'Bruderschaften' und 'Akademien', zu denen die traditionsreiche Moskauer "Religios-Philosophische VladimirSolov'ev-Gesellschaft" und die "Psychologische Gesellschaft der Moskauer Universitat" (beide bestanden bis 1921) ebenso gehorten wie der "L.-M.-Lopatin Kreis" und die Gemeinde von Aleksej Metev (1860-1923), ist noch weitgehend unerforscht. Ihre Bedeutung für das Geistesleben in den Jahren nach der Revolution kann jedoch nicht hoch genug eingeschătzt werden. Zur "Freien Akademie" und zur Moskauer Sektion der Vol'fila (von der eine geheime "Splittergruppe" bis 1932 existiert haben soll) siehe die Literaturangaben in II: 3.3 Anm. 20 und 3.4. Anm. 15. 
Die Gruppe der Moskauer Fedorov-Anhänger trat erstmals zu Beginn des Jahres 1923 in Erscheinung; ihr gehörten an: der Biokosmist und Fachmann für "Meteorourgie" P.I. Ivanickij, ${ }^{14}$ der Mitarbeiter an Gastevs Arbeitsinstitut V.N. Murav'ev, ${ }^{15}$ die ehemalige Herausgeberin von Novoe Vino V.N. MironovicKuznecova, ${ }^{16}$ die Brüder B.I. und V.I. Smankevic ${ }^{17}$ sowie G.V. Postnikov und V.P. Savel'ev, über die nichts weiter bekannt ist. ${ }^{18}$ Initiatoren und treibende Kraft der Gruppe waren A.K. Gorskij ${ }^{19}$ und N.A. Setnickij ${ }^{20}$.

14 Siehe II: 3.3. - "Meteorourgie" (meteorourgija), eine Wortbildung Fedorovs (vgl. FOD II, S. 275).

15 Siehe II: 3.4.

16 Siehe II: 2.3.1. - Vera Nikandrovna Mironoviz-Kuznecova (1870 - 4.4.1932), Witwe eines im Weltkrieg gefallenen Offiziers, war Artzhelferin und Hebamme in Moskau, lebte dann als Rentnerin im Dorf Bogorodskoe nordøstlich von Moskau (dort lebte auch Gorskij). Bis zuletzt unterhielt sie enge Kontakte zu den Fedorov-Anhängern in Moskau und Harbin (im Prager Fedorov-Archiv sind 126 Briefe von ihr an N.A. Setnickij aus den Jahren 1925-1931 erhalten). Selbst nicht schriftstellerisch tătig, kopierte sie eine Reihe von Arbeiten über Fedorov und bewahrte sie so vor der Vernichtung. Siehe die spärlichen und teilweise fehlerhaften Angaben von N.[P.] M[IRONOvik. "Vera Nikandrovna Kuznecova (Mironovið)." In: Vselenskoe delo, 2, Riga 1934, S. 182f. Ergănzend briefl. Mitteilungen von O.N. Setnickaja, Moskau, 19.1.1981.

17 Zu Boris Ivanoviそ̌ Šmankevił̌ liegen nur ăußerst spărliche Informationen vor. Ein Dichter, der im Kreis um Vjačeslav Ivanov verkehrte, soll er (ab wann, ist nicht bekannt) ein leidenschaftlicher Anhănger der Ideen Fedorovs gewesen sein und diese in Literatenkreisen propagien haben. Auch Majakovskij soll - einer unbestătigten Version zufolge - durch Šmankeviž von Fedorovs Ideen erfahren haben. Smankevits Gedichte, die in den literarischen Almanachen Gjulistan (1 und 2, M. 1916) sowie im August 1918 in einigen Nummern der Odessaer Zeitung Južnyj Ogonek (deren Redaktion Gorskij angehorte) erschienen, lassen allerdings (noch?) keinen EinfluB Fedorovs erkennen. B.I. Smankevið soll 1932 in der Verbannung in Turkestan gestorben sein. - Biographische Angaben nach Vselenskoe delo (wie Anm. 16), S. 184. Siehe auch II: 2.2.2. - Uber den Bruder Vsevolod Ivanovit Smankevið ließen sich keine Angaben ermitteln.

18 Angaben über den Kreis der Moskauer Fedorov-Anhănger in O.N. SETNICKAJA, Aleksandr Konstantinoviz Gorskij. Biografija. Ms. [Masch.] o.O. o.J., Bl. 33f. DIEs., Nikolaj AleksandroviC Setnickij. Biografija. Ms. [Masch.] 0.O. 1965, Bl. $8 \mathrm{f}$.

Ober die Tătigkeit des Kreises teilt Setnickaja mit: "Murav'ev ... hielt Ubungen mit einigen Studenten [genannt werden die Brüder Šmankeviz, Postnikov, Savel'ev], die sich entschlossen hatten, das russische philosophische Denken von Herzen und den Slavophilen bis zu N.F. Fedorov zu studieren. Alle Teilnehmer schrieben Referate und diskutierten sie. (...) Wie V.P. Savel'ev berichtet, hatte man eine Karikatur gezeichnet, die einen liegenden Leichnam zeigte und um ihn herum die Mitglieder des Kreises, wie sie sich bemühten, ihn wiederzuerwecken." SET. NICKAJA, Gorskij, a.a.O., Bl. 34.

19 Uber ihn ausführlich II: 2.3.2.

20 Zur Biographie von N.A. Setnickij vgl. die Aufzeichnungen seiner Tochter O.N. SEINICKAJA (wie Anm. 18) sowie ergänzend G.[K.] GINs, "Spisok professorov, prepodavatelej i lektorov Juriditeskogo Fakul'teta ... (1920 g. - 1931 g.)." In: Izv.Jur.Fak., 9, 1931, S. 353. Biographische Angaben enthălt ferner ein von N.A. Setnickij beantworteter Fragebogen, der ihm 1928 von dem Geographen und Statistiker Andrej Andreevi Dostoevskij (1863-1933; ein Neffe des Schriftstellers) zugeschickt worden war. (Privatarchiv O.N. Setnickaja).

N.A. Setnickij wurde am 12.12.1888 in Ol'gopol' (Podolien) geboren. Von 1908 bis 1913 besuchte er die Petersburger Universităt, zunăchst die Abteilung für orientalische Sprachen, dann die Juristische Fakultăt. Seit 1917 lebte er in Odessa, wo er an der Juristischen Fakultăt der 
Gorskij hatte Setnickij um das Jahr 1918 in Odessa kennengelernt und für die Ideen Fedorovs gewonnen. ${ }^{21} \mathrm{Zu}$ Beginn der zwanziger Jahre hatten sie gemeinsam unter dem Eindruck der herrschenden Hungersnot in der Odessaer Zeitung Na Pomošc'? zum Kampf gegen die Naturgewalten aufgerufen und dabei - Fedorov folgend - vor allem Maßnahmen zur Beherrschung des Wetters gefordert. $^{22}$ Ausführlich sollte dieses Thema in einem Sammelband Vselenskoe delo erörtert werden, mit dem Gorskij und Setnickij an die gleichnamige Odessaer Veröffentlichung von 1914 anknüpfen wollten. ${ }^{23}$ Um die Mittel durch Pränumeration aufzubringen, verfaßten sie einen Prospekt, in dem sie unter der Parole "Sterbliche aller Länder, vereinigt euch!" zum "letzten Kampf" gegen den "uralten, mächtigen Feind", die noch unbezwungene, blinde Natur aufriefen. ${ }^{24}$ Da sich jedoch keine Subskribenten fanden, mußte das Vorhaben aufgegeben werden. Auch spätere Versuche (bis ins Jahr 1923), einen zweiten Band von Vselenskoe delo herauszubringen, scheiterten. ${ }^{25}$

Als 1923 Fedorovs Todestag sich zum zwanzigsten Male jährte, nahmen seine Moskauer Anhänger dies zum Anlaß, um eine rege propagandistische Tätigkeit zu entfalten: Sie organisierten Gedenkveranstaltungen, hielten Vorträge und trafen sich auf dem Skorbjašcenskij-Friedhof, wo sie auf Fedorovs Grab ein neues Kreuz errichteten. ${ }^{26}$ Vor allem aber wollten sie durch Veröffentlichungen

Neurussischen Universităt (dem ehemaligen Richelieu-Lyzeum!) sowie an den Instituten für Volkswirtschaft und für Landwirtschaft unterrichtete. Uber seine Bekanntschaft mit den Ideen Fedorovs schreibt er (in dem o.g. Fragebogen): "... von 1918 an lernte ich die Filosofija obšrego dela von N.F. Fedorov kennen, die all mein weiteres Tun bestimmte." 1923 ging Setnickij nach Moskau, wo er als Statistiker im Volkskommissariat für Post- und Fernmeldewesen (Narkompoctel') tătig war. Neben wissenschaftlichen Arbeiten zur Nationalökonomie verfaßte er in dieser Zeit zahlreiche literarische Werke (Gedichte, Dramen) sowie eine Studie über die "Statistik als einen der Wege zur Erklärung der Elementarkraft des Wortes". N.[A.] SETNICKJ, Statistika, literatura i poezija. K voprosu o plane issledovanija. Odessa 1922; hier S. 18.

21 Setnickaja, Gorskij (wie Anm. 18), Bl. 32.

22 Vgl. SetnickiJ (wie Anm. 12), S. 19. A. Gornostaev [d.i. A.K. Gorsku], "Pustynja." [Gedicht] In: Vselenskoe delo (wie Anm. 16), S. 10. - Von der Zeitung Na Pomoš'! erschien nur eine Nummer (mir nicht zugänglich). Während Setnickij als Erscheinungsjahr 1920 angibt, findet sich andernorts folgende Angabe: "Na pomost'! V pol'zu golodajušcich. Izd. Od. Profsojuza poligraf-proizv. Odnodnevnaja gazeta. 15-VIII-21." G.D. STEJNVAND, Odes'ka periodicna presa rokiv revoljucii ta hromadjans'koi vijni 1917-1921, Odesa 1929, S. XIII, Nr. 29.

23 Vgl. dazu ZET. [d.i. NA. SETNICKI], "'Vselenskoe Delo' v prołlom." In: Vselenskoe delo (wie Anm. 16), S. 113-115. - Zum ersten Band von Vselenskoe delo ausführlich II: 2.3.2.

24 Ebd., S. 114f. - In dem geplanten Sammelband sollten Möglichkeiten diskutiert und Wege aufgezeigt werden, wie Fedorovs Idee eines allumfassenden Kampfes gegen die Natur unter Anwendung der neusten wissenschaftlichen Erkenntnisse verwirklicht werden könne. Geplant waren u.a. Beitrăge zu folgenden Themen: "Kămpferische Biologie. (Das gegenwărtige Problem des Kampfes gegen den Tod)." "Die Relativitătstheorie und die Praxis planetarisch-kosmischen Handelns." "Die Agonie des Planeten und die Aufgabe der Metenrourgie." (Ebd., S. 113).

25 SETNICKu (wie Anm. 23), S. 115.

26 SetNickaja, Gorskij (wie Anm. 18), S. 35. - Das alte Holzkreuz wurde durch ein schwarzes guBeisernes Kreuz ersetzt, das Fedorovs Namen und seine Lebensdaten trug; als Geburtsjahr 
auf Fedorov und sein Werk aufmerksam machen und suchten dazu einflußreiche Unterstützung. Diese hofften sie bei Maksim Gor'kij zu finden.

Gor'kij hatte - wohl noch vor seiner Abreise aus Rußland im Oktober 1921 Interesse an Fedorov und dessen Nachla B gezeigt. ${ }^{27}$ Am 19. März 1923 wandte sich deshalb A.K. Gorskij unter dem von ihm häufig benutzten Pseudonym "A. Gornostaev" in einem Brief an Gor'kij, der zu jener Zeit in Saarow bei Berlin lebte. ${ }^{28}$ Er habe, so Gorskij, von der Witwe Koževnikovs und aus anderen Quellen erfahren, daß Gor'kij sich für die Filosofija obščego dela interessiere. $\mathrm{Er}$ selbst, so Gorskij weiter, beschäftige sich bereits seit etwa zehn Jahren mit Fedorov und dessen Werk und habe darüber ein Buch für die "Biographische Bi-

war 1824 angegeben! Auf dem Querbalken stand: Christos Voskres. Siehe A. Ostromirov [Gorsku], Nikolaj Fedorovic Fedorov. 1828-1903-1928. Biografija. O.O. [Harbin] 1928, S. 20.

27 Der Schriftsteller S.T. Grigor'ev schrieb am 4.3.1926 an Gor'kij, die Witwe Koževnikovs habe ihm "vor etwa drei, vier Jahren" gesagt, daß Gor'kij sich für den literarischen Nachlaß Fedorovs interessiert habe. Literatumoe nasledstio, t. 70 [Gor'kij i sovetskie pisateli. Neizdannaja perepiska.], M. 1963, S. 134.

Wann Gor'kij zum ersten Mal mit der Philosophie Fedorovs in Berührung kam, lăßt sich nur annăhernd bestimmen. Zwar ăußerte Gor'kij 1926, er habe Fedorov einmal gesehen und auch dessen Bücher gelesen (siehe II: 4.2. Anm. 35), doch ist es unwahrscheinlich, daß der für sein MiBtrauen bekannte Bibliothekar mit Gor'kij über seine Lehre gesprochen hat. In einem Brief an B.M. Ejchenbaum (14.3.1933) berichtet Gor'kij von seinen Gesprăchen mit L.N. Tolstoj, wobei dieser auch Fedorov enwahnt habe (siche II: 4.2. Anm. 147). Mit der Filosofija obscego dela dürfte Gor'kij sich kaum vor Beginn der zwanziger Jahre beschăftigt haben. Ein im Mărz. 1920 an der Arbeiter-und-Bauern-Universităt in Petrograd gehaltener Vortrag Gor'kijs enthălt zwar zahlreiche motivische Anklănge an Fedorovs Werk (Selbsterkenntnis und Selbstvervollkommnung der Natur durch den Menschen; Allmacht der Menschheit durch Wissen und Arbeit; Raumfahrt; Uberwindung von Krankheit und Tod), doch lassen sich alle diese Motive auch bei zeitgenossischen Autoren - insbesondere aus dem Umkreis des bogostroirel'stwo (Bogdanov, Rožkov) - finden; zum Nachweis einer Beeinflussung durch Fedorov reichen sie nicht aus. M. GoR'ku, "O znanii." In: Archiv A.M. Gor'kogo, t. 12, M. 1969, S. 101-111. Als "bedeutendes Dokument des gedanklichen Einflusses der Filosofija obšcego dela auf die Bildung der Ansichten Gor'kijs" deutet diesen Vortrag S.G. SEMENOVA, "Celovek, priroda, bessmertie v poezii Nikolaja Zabolockogo." In: Literatumaja Gruzija, 1980, 9, S. 141f. - In Gor'kijs Privatbibliothek sind beide Bănde der Erstausgabe der Filosofija obšego dela nachgewiesen, doch ist nicht bekannt, wann sie in Gor'kijs Besitz gelangten. Siehe Liznaja biblioteka A.M. Gor'kogo v Moskve. Opisanie. Kn. 1, M. 1981, S. 31. Der Schriftsteller und Journalist Ivan Rachillo bemerkt dazu lediglich, Gor'kij habe die Werke Fedorovs "irgendwie aufgestరbert". I.[S.] RACHILLO, "Predutrennie zvezdy." In: My nas, my novyj mir postroim, M. 1967, S. 541.

Zum Thema Gor'kij und Fedorov liegen mehrere zum Teil ausführliche Arbeiten vor. Vgl. S.I. SuCHICH, "Zizn' Klima Samgina' M. Gor'kogo i 'Filosofija obšego dela' N.F. Fedorova." In: M. Gor'kij i voprosy literatumych zannov. Mezvuzovskij sbomik. Gor'kij 1978, S. 3-38. DERS., "M. Gor'kij i N.F. Fedorov." In: Russkaja Literatura, 1980, 1, S. 160-168. M. HAGEMEISTER, "Neue Materialien zur Wirkungsgeschichte N.F. Fedorovs: $M$. Gor'kij und die Anhänger Fedorovs in Moskau und Harbin." In: Studia Slavica. Beiträge zum VIII. Intermationalen Slawistenkongre $\beta$ in Zagreb 1978. Gießen 1981, S. 219-244. S.[G.] Sem'onova [SEmenova]-GaCeva, "Prevăzmogvane na esnafa. Otnoふ̌enieto kăm smărtta u Maksim Gorki." In: Literaturen Front, 38 (17.9.1981), S. 7.

28 Unveroffentlichter Brief im Gor'kij-Archiv, IMLI, KG-P-21-10-1; nach einer Abschrift in Moskauer Privatbesitz. - Vgl. Suchich, "M. Gor'kij..." (wie Anm. 27), S. 160. 
bliothek" des Petrograder Verlags Kolos fertiggestellt; ${ }^{29}$ neben biographischen Angaben enthalte es eine "Charakteristik der wissenschaftlich-philosophischen Seite von Fedorovs Lehre und ihrer Bedeutung für die Gegenwart." Man habe ihm geraten, die Arbeit Gor'kij zur Veröffentlichung in Deutschland anzubieten. Außerdem besitze er Materialien über Fedorovs Verhältnis zu Tolstoj und Dostoevskij, von denen ein Teil bereits bearbeitet sei. Aus den veröffentlichten und unveröffentlichten Schriften Fedorovs - letztere befänden sich im Besitz von M.N. Peterson - ließe sich eine Chrestomathie zusammenstellen.

Gor'kij antwortete zustimmend und sprach von der Möglichkeit, die genannten Materialien in der Zeitschrift Beseda zu veröffentlichen, ${ }^{30}$ einer literarischwissenschaftlichen Rundschau, die von Gor'kij gemeinsam mit Vladislav Chodasevic in Berlin herausgegeben wurde und auch in der Sowjetunion verbreitet werden sollte. ${ }^{31}$

Dadurch ermutigt, schrieb Gorskij im April 1923 an Gor'kij, er sei unverzüglich darangegangen, die Studie über Fedorov und Dostoevskij auszuarbeiten und eine Fedorov-Chrestomathie zusammenzustellen, wofür ihm M.N. Peterson den unveröffentlichten dritten Band der Filosofija obščego dela zur Verfügung stellen wolle. ${ }^{32}$

Die genannte Studie über Fedorov und Dostoevskij hat Gor'kij offenbar nie erhalten. Im August 1923 schrieb er an Chodasevix: "Ich habe eine telegraphische Anfrage: Ist der Artikel über Dostoevskij und Fedorov angekommen? Er ist nicht angekommen. ${ }^{33}$ Bekanntlich sind mehrere Beiträge sowjetischer Autoren, die zur Veröffentlichung in Beseda bestimmt waren, von der sowjetischen Zensur abgefangen worden. ${ }^{34}$ In den sieben Nummern dieses kurzlebigen Periodikums findet sich jedenfalls kein Artikel über Dostoevskij und Fedorov. ${ }^{35}$

29 In einem Brief an die in Petrograd lebende Dichterin M.M. Skapskaja schreibt Gorskij am 28.3.1923, sein "Buch über Fedorov" werde "in 2 bis 3 Monaten" herauskommen. (CGALI, f. 2182, op. 1, ed. chr. 280; nach einer Abschrift in Moskauer Privatbesitz). Siehe auch II: 4.2. Anm. 66. Das Programm der "Biographischen Bibliothek" der Petrograder Verlagskooperative Kolos umfaßte Lebensbeschreibungen russischer Gelehrter und Künstler. Mehrere der angekündigten Werke - darunter eine von Florenskij verfaßte Biographie V.V. Rozanovs sowie eine Biographie V.S. Solov'evs aus der Feder seines Neffen S.M. Solov'ev - sind wegen der Schließung des Verlags nicht mehr erschienen.

30 Suchich, "M. Gor'kij..." (wie Anm. 27), S. 160f.

31 Was jedoch am Widerstand der sowjetischen Behörden scheiterte. Vgl. S. YakoBson, [Einleitung zu] "The Letters of Maksim Gor'kij to V.F. Xodasevic. 1922-1925." In: Harvand Slavic Studies, 1 (1953), S. 282f. R.C. WiLlams, Culture in Exile. Russian Emigres in Germany, 1881-1941. Ithaca, London 1972, S. 278-280.

32 Unveroffentlichter Brief im Gor'kij-Archiv, IMLI, KG-P-21-10-2. Inhalt nach SUCHCH, "M. Gor'kij..." (wie Anm. 27), S. 161.

33 [M. GoR'KI], "Pis'ma Maksima Gor'kogo k V.F. Chodaseviłu." In: Novyj Zumal, 30, 1952, S. 192.

34 Vgl. Yakobson (wie Anm. 31), S. 282. Williams (wie Anm. 31), S. 280.

35 Gorskijs Studie über Dostoevskij und Fedorov wurde erst 1929 von Setnickij in Harbin veroffentlicht: A.K. GoRnOSTAEv [GoRSKu], Raj na Zemle. $K$ ideologii tvoréestva F.M. Dosto- 
Auch die von Gorskij verfaßte Arbeit über Leben und Werk Fedorovs fiel offenbar der Zensur zum Opfer. Sie soll zwar von Gorskij rechtzeitig abgeschickt worden sein, damit Gor'kij sie zum zwanzigsten Todestag Fedorovs veröffentlichen konnte, doch ist auch sie nicht erschienen, und Gorskij erhielt auf seine diesbezüglichen Anfragen keine Antwort. ${ }^{36}$

Über das Schicksal der von Gorskij zusammengestellten Chrestomathie, in der auch bislang ungedruckte Schriften aus Fedorovs Nachlaß veröffentlicht werden sollten, ist nichts weiter bekannt; das Werk ist nie erschienen.

Damit waren die Bemühungen der Moskauer Fedorov-Anhänger gescheitert, zum zwanzigsten Todestag des Philosophen ihn und sein Werk durch Veröffentlichungen bekannt zu machen und zu würdigen. Als Erfolg mußte ihnen schließlich gelten, daß Fedorovs Name wenigstens einmal und noch dazu in einer offiziellen Publikation erwähnt wurde: Iona Brichnicev, der inzwischen zum Sekretär der Zentralen Kommission für die Hungerhilfe (CKPomgol) avanciert war, schrieb im Rechenschaftsbericht, den die Kommission 1923 herausgab, da $B$ es "im Zusammenhang mit der durchgemachten schweren Hungersnot und Mißernte an der Zeit [sei], sich der Ideen des großen alten Fedorov zu erinnern. ${ }^{\text {37 }}$

evskogo. F.M. Dosıoevskij i N.F. Fedorov. O.O. [Harbin] 1929. In seinem Vorwort weist der Herausgeber (Setnickij) darauf hin, daß die Arbeit bereits 1918 verfaßt worden sei.

36 Im Sommer 1926 schrieb Setnickij an Gor'kij, die Biographie Fedorovs sei "rechtzeitig für die Beseda auf Ihren Wunsch hin (soweit ich verstanden habe) geschrieben" worden, doch habe der Verfasser, Gorskij, auf seine Briefe keine Antwon erhalten. "Jetzt befindet sich das Manuskript bei mir." (Unverơffentlichter Brief von N.A. Setnickij an Gor'kij, Sommer 1926, Gor'kij-Archiv, IMLI, KG-P-71-4-2; nach einer Abschrift in Moskauer Privatbesitz). Das Manuskript ist erhalten, war mir jedoch nicht zugänglich: A.K. GoRNOSTAEv [GoRSKI], Nikolaj Fedoroviz Fedorov. Biograficeskij očerk. Datien 1923. Ms. [Masch.], 57 Bl.; CGALI, f. 1435, op. 1, ed. chr. 147. (Private Mitteilung).

Weitere Versuche, das Manuskript zu veröffentlichen (u.a. im Verlag Z.I. Gržebin) schlugen ebenfalls fehl. Erst 1928, zu Fedorovs hunderstem Geburstag, konnte Setnickij in Harbin mit der Herausgabe einer inzwischen erheblich erweiterten Fassung dieser Arbeit beginnen; sie erschien in einzelnen Lieferungen unter dem Titel A. OsTromirov [GoRSKI], Nikolaj Fedorovic Fedorov i sovremennost'. Ozerki. Vyp. 1-4, Charbin 1928-1933. Zur Geschichte dieser Veröffentlichung vgl. Setnickijs Vorwort zur vierten Lieferung (1933) und HAGEMEISTER (wie Anm. 27), S. 222.

37 Zitiert nach SETNICKU (wie Anm. 12), S. 24. - Sofort nach der Revolution hatte sich Brichnizev (zu ihm ausfuihrlich II: 2.3.1.) auf die Seite der Bol'seviki geschlagen. Ihren Sieg feierte er in schwülstigen Gedichten, in denen Lenin als bizarre Mischung aus Christus und Heiligem Georg auftritt. Siehe Proletarskij sbomik, kn. 1, M. 1918, S. 18-20. Während des Bürgerkriegs war Brichnirev Leiter des Amtes für Volksaufklärung in Mogilev und Gomel', wo er sich insbesondere der Agitationskunst widmete, indem er Gebăude mit revolutionăren Parolen verzieren ließ. Siehe A.V. LuNACARSKI, SS v 8-i tt., t. 7, M. 1967, S. 402.1920 trat er in das Volkskommissariat für das Bildungswesen (Narkompros) ein und wurde in das Führungsgremium der 'Allrussischen auBerordentlichen Kommission zur Liquidierung des Analphabetentums' (VCKLN) berufen. Vgl. V A. KuMANEV, Socializm i vsenaradnaja gramolnost', M. 1967, S. 75, 131. Likvidatoram negramotnosti, M. 1921, S. 134f., 137f., 142. 1921/22 war Brichnicev als sowjetischer Bevollmächtigter in verschiedenen Funktionen in Georgien tătig. Als solchen erwähnt ihn Nadežda Mandel'štam in ihren Memoiren. N. MaNDEL'STAM, Vtoraja kniga, Paris 1972, S. 77. Ab Mai 1922 arbeitete er als Sekretăr der Zentralen Kommission für die Hungerhilfe. In der Folgezeit trat er mit antireligioser Propaganda hervor; so publizierte er auf dem 
In das Jahr 1923 fällt auch eine - freilich erst viel später veröffentlichte - Bemerkung Gor'kijs über Fedorov (ausgelöst wahrscheinlich durch die Korrespondenz mit Gorskij). In den sogenannten "Freiburger Aufzeichnungen" (Frejburgskie zametki) aus der Zeit, als Gor'kij (von Juni bis Mitte November) in Güntersthal bei Freiburg im Breisgau lebte und an dem Roman Delo Artamonovych arbeitete, findet sich die Notiz: "Unsere russische - besonders bei N.F. Fedorov - Sicht der Frau. Seine Worte von der [zwar] 'nicht drückenden, aber verderblichen Herrschaft der Frauen'. ${ }^{38}$

Das Zitat entstammt Fedorovs Aufsatz über die Pariser Weltausstellung von 1889, der im ersten Band der Filosofija obščego dela abgedruckt ist ${ }^{39}$ - ein Hinweis darauf, daß Gor'kij den ersten Band der Werke Fedorovs gekannt hat. ${ }^{40}$ In der Pariser Weltausstellung zum hundertsten Jahrestag der Französischen Re-

Höhepunkt der Auseinandersetzung zwischen der alten Kirche des Patriarchen Tichon und den prosowjetischen Schismatikern ein Pamphlet Patriarch Tichon i ego cerkov' (M. 1923), in dem er die Konfiszienung der Kirchenschätze durch die Sowjetmacht als notwendige MaBnahme im Kampf gegen den Hunger verteidigte. Um die Mitte der zwanziger Jahre war Brichnizev Sekretăr des Zentralrates des Bundes kämpferischer Atheisten und gehörte der Redaktion der Zeitschrift Bezbożnik an. 1926 veroffentlichte er eine Broschüre mit Äußerungen Lenins zu Fragen der Religion. Siehe M.SACHNOVIC, Lenin i problemy ateizma, M.-L. 1961, S. 639. Von 1926 bis 1928 war Brichniðev Mitarbeiter der Gesellschaft 'Nieder mit dem Analphabetentum!' (ODN), von 1928 bis 1929 des Narkompros von Kazachstan. 1929 verlieB er die Kommunistische Partei und versuchte, sich als Schriftsteller durchzubringen. 1932 wurde er Mitarbeiter der Belorussischen Akademie der Wissenschaften. Nachrichten über sein gewaltsames Ende im Jahre 1931 (Vselenskoe delo, wie Anm. 16, S. 184; von don wiederholt übernommen) treffen somit nicht zu: Brichnitev starb am 28.3.1968 in einem Moskauer Altersheim. Briefliche Mitteilungen von O.N. Setnickaja, Moskau, 20.5.1980 und 25.2.1981. - Biographische Angaben, wenn nicht anders vermerkt, nach I.P. BRICHNICEV, Služebnaja aviobiografija (1879-1937), Ms.; GBL f. 516, k. 3, ed. chr. 39; nach einer Abschrift in Moskauer Privatbesitz. V.G. BAZANOV, Trudnaja biografija." In: Zvezda, 1979, 12, S. 188. V. Sumov, "Iz prichodskich batjuక̌ek - v buntari." In: Nauka i Religija, 1980, 11, S. 22. S. FrtzPATRICK, The Commissariat of Enlightenment, Cambridge 1970, S. 176, 297.

Allem Anschein nach hatte Brichnicev keinen Kontakt zum Kreis der Moskauer Fedorov-Anhänger, doch blieb er zeitlebens ein Verehrer des Philosophen, den er zu den großen Aufklärem der Menschheit zăhlte. In einer 1931 veröffentlichten populärwissenschaftlichen Abhandlung über die Lesegewohnheiten berühmter Persönlichkeiten und ihren Umgang mit Büchern enwăhnte Brichnizev auch Fedorov, von dem er zu berichten wuBte, er habe in Büchern eine Reihe wertvoller Randbemerkungen und Notizen hinterlassen. I.P. BRICHNICEV, Kniga v Zizni velikich ljudej, M. 1931, S. 23. Auf Fedorovs Bedeutung im Zusammenhang mit der "Regulierung der Natur" wies Brichnitev 1949 in einem Brief an einen Lektor des sowjetischen Schriftstellerverbands hin. Siehe BAZANOV, a.a.O., S. 177. Mündlichen Mitteilungen zufolge soll Brichnirevs umfangreicher literarischer NachlaB, der sich in der Lenin-Bibliothek Moskau (f. 516) befindet, weitere Zeugnisse für seine Beschäftigung mit Fedorov enthalten.

38 Vgl. Archiv A.M. Gor'kogo, t. 12, M. 1969, S. 230. M. GoR'Ku, PSS. Varianty k chudotestvennym proizvedenijam. T. 5, M. 1977, S. 599.

"Vystavka 1889 goda..." In: FOD I, S. 492-519; hier S. 495.

40 In seinem Aufsatz $O$ zenscine (1930) erwăhnt Gor'kij, er habe sich mit dem ersten Band der Filosofija obsžego dela "vertraut gemacht" (oznakomilsja), gibt aber nicht an, wann dies geschehen ist. M. GOR'KJ, $S S$ v 30-i tt., t. 25, M. 1953, S. 162. Ein Exemplar des ersten Bandes der Filosofija obstego dela mit Anmerkungen von fremder Hand ist in Gor'kijs Privatbibliothek nachgewiesen (siehe Anm. 27). 
volution hatte Fedorov den Geist des Wirtschaftskapitalismus beispielhaft verkörpert gesehen und vorgeschlagen, die Ausstellung in ein ständiges Museum der Industriegesellschaft zu verwandeln. Ursprung und Antrieb der Industrieproduktion, ja der gesamten bürgerlichen Kultur, sei, so Fedorov, die "Idolatrie der Frau". Ihre zwar "nicht drückende, aber verderbliche Herrschaft" habe zur Hypertrophie der Sexualität geführt und eine Flut unnützer und schädlicher Luxusgüter erzeugt, die zur Erregung und Befriedigung von Eitelkeit und Rivalität dienten. Fedorovs Kulturkritik hat Gor'kij beeindruckt; auf sie ist er noch mehrmals zurückgekommen, in Briefen, vor allem aber in seinem Roman Žizn' Klima Samgina. ${ }^{41}$ Dabei versäumte er nie, Fedorovs Ausspruch von der "nicht drückenden, aber verderblichen Herrschaft der Frauen" zu zitieren.

Die Jahre 1923 bis 1925 sahen eine rege schriftstellerische Tätigkeit der Moskauer Fedorov-Anhänger: Im Dezember 1923 verfaßte Murav'ev den Aufsatz Vseobšcaja proizvoditel'naja matematika (der freilich erst zehn Jahre später veröffentlicht werden konnte) und brachte im folgenden Jahr die Arbeit Ovladenie vremenem heraus. ${ }^{42}$ Ivanickij schrieb mehrere Artikel über die Beherrschung des Wetters und ging in seiner 1925 erschienenen Broschüre auch auf Fedorovs diesbezügliche Vorschläge ein. ${ }^{43}$ Gorskij veröffentlichte den Brief, den Aleksandr Blok am 26. August 1912 an Brichnixev geschrieben hatte, und kommentierte ihn. ${ }^{44}$ Außerdem arbeitete er an einer breit angelegten Untersuchung, in der er die Aktualität des Fedorovschen Denkens aufzuzeigen suchte; das Werk erschien mit mehrjähriger Verzögerung in Harbin. ${ }^{45}$

Unveröffentlicht blieb hingegen ein 1924 abgeschlossenes Manuskript Gorskijs mit dem Titel Ogromnyj oðerk, das trotz des vergleichsweise geringen Um. fangs als sein Hauptwerk gilt. ${ }^{46}$ In eigenartiger Weiterentwicklung des Fedorovschen Gedankens der "positiven Keuschheit" (polozitel'noe celomudrie) ${ }^{47}$ speku-

41 Vgl. Suchich (wie Anm. 27). Hagemeister (wie Anm. 27). Siehe II: 4.2. Anm. 145.

42 Siehe II: 3.4.

43 Siehe II: 3.3. Anm. 66f.

44 Siehe II: 2.3.1. Anm. 37.

45 A. Ostromirov [Gorsku], Nikolaj Fedorovix Fedorov i sovremennost'. Oxerki. Vyp. 1-4, Charbin 1928-1933.

46 Das Manuskript, datien 1924 (in der vorliegenden Fassung freilich Ergebnis spăterer Uberarbeitungen; siehe II: 4.2. Anm. 227), hat einen Umfang von 110 Schreibmaschinenseiten. Es befindet sich in Moskauer Privatbesitz und war mir nur für eine kurze Durchsicht zugănglich; auf Wunsch der Besitzerin wurden keine Exzerpte angefertigt. - Der Titel der Arbeit geht zurück auf EA. Baratynskijs Gedichtzeilen "I poétizeskogo mira ogromnyj ozerk ja uzrel..." ( $V$ dni bezgraniinych uvletenij..., 1831).

47 Fedorov hatte zwischen "positiver" und "negativer Keuschheit" unterschieden: letztere sei bloß passive Enthaltsamkeit und, wie jede Form selbstgenügsamer Askese, im Grunde lebensfeindlich; erstere dagegen liefere die Energie zur (Selbst-)Vervollkommnung und Auferweckung. "Die gewaltige Kraft, die sich [bislang] in der Wollust zeigt, wird gleichwertigen Ausdruck im Wiederherstellen [des Untergegangenen] finden." FOD II, S. 13; siehe auch bes. FOD I, S. 315318. 
lierte Gorskij darin über geschlechtliche Enthaltsamkeit als Bedingung für Unsterblichkeit sowie über eine Transformierung und Sublimierung der "sexuellen

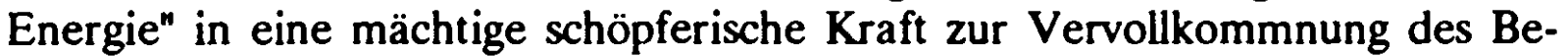
stehenden und zur Wiederherstellung des Vergangenen. Dabei ließ er sich auch von zeitgenössischen Theorien anregen: Unübersehbar ist der Einfluß der Freudschen Trieblehre (mit Moshe Wulff, einem der führenden Freudianer, stand Gorskij 1923 in Kontakt); die Annahme einer regulierbaren "sexuellen Energie" erinnert an Wilhelm Reichs "Orgon"-Theorie, ${ }^{48}$ und der von Gorskij in Anlehnung an Fedorov entwickelte Gedanke einer Verwandlung der menschlichen Wahrnehmungsorgane in schöpferische Organe gleicht Florenskijs Theorie der "Organprojektion"49. Nachweislich kannte Gorskij das seinerzeit vielgelesene Buch des deutschen Chemikers Ludwig Staudenmeier Die Magie als experimentelle Naturwissenschaft (1912), in dem magische Phänomene auf die Umwandlung von Nervenenergie zurückgeführt wurden, ${ }^{50}$ und es kann als wahrscheinlich gelten, daß er mit den Forschungen und Theorien von Kotik, Lazarev

48 Zum Einfluß Reichs in der Sowjetunion siehe M.A. MiLlER, "Freudian Theory Under Bolshevik Rule." In: Slavic Review, 44 (1985), S. 640 f.

49 P.A. Florensku, "Organoproekcija." [1919] In: Dekorativnoe Iskusstvo SSSR, 145, 1969, S. 3942. - In dieser bemerkenswerten Schrift entwickelt Florenskij Ansätze zu einer Philosophie der Technik: Technische Werkzeuge sind - worauf bereits die Doppelbedeutung des griechischen organon hinweist - Fortsetzungen (prodolzenija) oder Projektionen von Teilen des menschlichen Korpers. Die Vereinigung aller Werkzeuge ist das Haus (eigentlich der Tempel) als Projektion des ganzen menschlichen Korpers. Die "historische Aufgabe der Technik" besteht in der bewuBten "Organprojizierung", wobei auch Werkzeuge geschaffen werden konnen, deren organische Prototypen bislang nur rudimentär oder noch gar nicht entwickelt (aber potentiell vorhanden) sind. - Ob diese Ideen Florenskijs seinerzeit bekannt waren, laßi sich nicht feststellen, doch sei auf zwei Analogien (Einflüsse?) hingewiesen: Nach dem Prinzip der Organprojektion konstruierte Vladimir Tatlin zwischen 1929 und 1932 seinen Flugapparat 'Letatlin', und der Fedorov-Anhänger Vasilij Cekrygin forderte zu Beginn der zwanziger Jahre die Rekonstruktion des Himmelsgebăudes nach dem Vorbild des menschlichen Korrpers. Siehe II: 3.2.4. Cekrygin und Tatlin waren ebenso wie Gorskij mit Florenskij persönlich bekannt.

Fedorov hatte davon gesprochen, daB die Werkzeuge des Menschen, mit denen er seine Hertschaft über die Natur ausdehnt, zunăchst nur gedacht und projektiert, im Verlauf der Selbsterschaffung und Vervollkommnung zu künstlichen Leibesorganen werden: "die Schwingen der Seele werden zu korperlichen Flügeln werden." (FOD I, S. 318). Den im Protest gegen den Tod aufgerichteten Körper des Menschen hatte Fedorov einen Tempel und ein Modell des vollkommenen Universums genannt. (Vgl. z.B. FOD I, S. 512f.; II, S. 267). - Ähnliche Gedanken finden sich auch bei dem Futuristen Marinetti: Offenbar in Anlehnung an Lamarcks Theorie von der aktiven, 'willentlichen' Organbildung aufgrund eines dringenden Verlangens sprach er davon, daß "im Fleisch des Menschen Flügel ruhen", die der Wille zur Herrschaft und Weltgestaltung nach außen wenden werde; dann "werden Traum und Wunsch, die heute leere Worte sind, souverăn über den bezwungenen Raum und die bezwungene Zeit regieren." F.T. MA. RINETT, Le Fururisme, Paris 1911; zitiert nach CH. BAUMGaRTH, Der Futurismus, Reinbek 1966, S. 135. Unter Hinweis auf Fedorov und Florenskij wurde die Idee der Organprojektion unlängst im Weik von Velimir Chlebnikov nachgewiesen. N.[V.] BASMAXOVA, Slowo i obraz. $O$ norteskom myslenii Velimina Chlebnikova. Helsinki 1987, S. 24f., 55-59, 101-104.

50 Mitteilung von O.N. Setnickaja, Moskau. - Das Buch enthielt sogar Anleitungen zur praktischen Durchführung magischer Experimente. 
und Beknev über die "psychophysische Gehirnstrahlung" und die Transformation der menschlichen "Nervenenergie" vertraut war. ${ }^{51}$

Besonders auffallend sind freilich Übereinstimmungen, die zwischen Gorskij und dem Schriftsteller Andrej Platonov in der Frage eines Zusammenhangs zwischen Sexualität, Enthaltsamkeit und Unsterblichkeit bestehen. ${ }^{52}$ Platonov hatte seit Beginn der zwanziger Jahre diesem Thema breiten Raum in seinen publizistischen und belletristischen Arbeiten gewidmet. ${ }^{53}$ Er vertrat die Ansicht, $\mathrm{da} B$ alle zivilisatorischen Leistungen, die "im Kampf gegen den großen Feind, den Tod," errungen wurden, das Ergebnis geschlechtlicher Enthaltsamkeit (celomudrie) seien, das heißt der Verwandlung jener "mächtigen inneren Körperkraft", die gewöhnlich "zur Erzeugung von Nachkommen verwendet" wird, in schöpferische Aktivität. Während die bürgerliche Gesellschaft ganz der Sexuali-

51 Siehe II: 3.1. Anm. 15.

52 Seit geraumer Zeit ist bekannt, daB Platonov Fedorovs Lehre kannte und daB die Filosofija obščego dela zu seinen Lieblingsbüchern zählte; ein Exemplar mit eigenhăndigen Anmerkungen Platonovs ist erhalten. Vgl. S.|G.] SEMENOVA, "'V usilii k buduszemu vremeni...' (Filosofija Andreja Platonova)." In: Literatumaja Gruzija, 1979, 11, S. 107. DiEs., "'Ideja Żizni' Andreja Platonova." In: A. Platonov, Kollovan, M. 1988, S. S. N.G. Poltavceva, Filosofskaja proza Andreja Platonova, Rostov-na-Donu 1981, S. 132. V.V. VASIL'EV, Andrej Platonov. Orerk Zizni i norkestva. M. 1982, S. 41. - In Platonovs bislang veröffentlichtem Werk werden die Filosofija obšcego dela und ihr Verfasser freilich mit keinem Won enwähnt, doch soll Fedorovs Name - einem einzigen, unbestătigten Hinweis zufolge - in Platonovs Manuskripten vorkommen. N.[V.] KornienKo, [Rez.] "V. Vasil'ev, Sopriłastnost' Zizni, M. 1977." In: Zvezda, 1978, 7, S. 220.

Fedorovs Einfluß auf Platonov wurde vielfach untersucht - mit sehr unterschiedlichem Ergebnis. Aus der umfangreichen Literatur sei, neben den bereits genannten, noch an folgende Arbeiten erinnert: J.W. SHEPARD, The Origin of a Master. The Eanty Prose of Andrej Platonov. Ann Arbor 1974. E. TOLSTAJA-SEgAL, "Ideologiteskie konteksty Platonova." In: Russian Literature, 9, 1981, S. 231-280. W. ŚLwWowSKA, R. ŚLIWOWSKI, "Filosoficzne inspiracje Andrzeja Pratonowa." In: Przegrgd Humanistyczny, 25 (1981), 7-9, S. 1-23. A. TESKEY, Platonov and Fyodorov: The Influence of Christian Philosophy on a Soviet Writer. Amersham 1982. M.JA. GELLER [HELLER], Andrej Platonov v poiskach stast'ja, Paris 1982, bes. S. 30-54. A. SPROEDE, Roman et utopie. 'Cevengur' d'Andrej Platonov dans le contexe linéraire et philosophique. Diss. phil. Konstanz, Ms. [Masch.] o.J. [1982], bes. S. 142-191. B.[M.] PARAMONOv, "Cevengur i okrestnosti." In: Kontinent, 54, 1987, S. 333-372. Paramonov entdeckt in Platonovs utopischem Roman Cevengur Grundzüge, die auch für das Denken Fedorovs, Solov'evs und Berdjaevs charakteristisch seien: Misogynie, Sexualfeindlichkeit und Todesfaszination als Ausdruck einer latenten Homosexualităt.

Ungeklärt und umstritten ist insbesondere die Frage, wann und auf welche Weise Platonov erstmals mit Fedorovs Gedanken in Berührung gekommen ist. Während SEMENOVA ("Ideja Zizni'...", a.a.O.) von einem "EinfluB" der Filosofija obšcego dela "auf die Bildung der Weltanschauung des noch ganz jungen Platonov" spricht und GELLER (a.a.O., S. 33) vermutet, dieser habe "möglicherweise schon vor der Revolution" stattgefunden, gibt Ljubuskina dafür die Zeit nach 1923 an, denn man könne "mit Bestimmtheit sagen, daB bis 1923 in keinem Werk Plato-

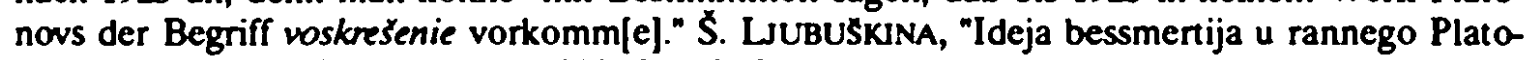
nova." In: Russian Literature, 23, 1988, S. 419. Siehe auch die vage Angabe bei TESKEY (a.a.O., S. 139): "... at a relatively early stage in his literary career." - Im folgenden sei auf eine mögliche EinfluBquelle hingewiesen, die bislang keine Beachtung gefunden hat.

53 Ausführlich und mit Hinweisen auf Fedorov E. NaIMAN, "Andrej Platonov and the Inadmissibility of Desire." In: Russian Literature, 23, 1988, S. 319-366. Vgl. auch GELLER (wie Anm. 52), S. 27-30, 42-44. LuUBuSKina (wie Anm. 52), S. 401-404, $407 f$. 
tät und dem Kult des Weibes verfallen sei und damit dem Tod, beruhe die nun anbrechende "Kultur des Proletariats" auf dem "Bewußtsein" (soznanie) und werde zusammen mit der Sexualität auch den Tod überwinden:

Das BewuBtsein wird das Geschlecht besiegen und vernichten und es wird zum Zentrum des Menschen und der Menschheit. (...) Der Gedanke wird leicht und schnell den Tod vernichten durch seine systematische Arbeit, die Wissenschaft. ${ }^{54}$

Jetzt aber ist die Zeit des völlig keuschen Menschen (soversenno celomudrennogo celoveka) angebrochen, und er wird eine große Zivilisation schaffen, er wird die Erde und alle übrigen Gestirne lenken, alles Sichtbare und Unsichtbare mit sich vereinen und vermenschlichen und schlieBlich Zeit und Ewigkeit in eine Kraft verwandeln, und er wird die Erde und selbst die Zeit überdauern. ${ }^{55}$

Obwohl diese Gedanken an Gorskij und Fedorov erinnern, könnte Platonov sie auch aus der Ideenwelt der russischen Sektierer übernommen haben: Die Vorstellung vom Sieg des Geistes über das Fleisch - und damit über den Tod - ist ein besonders auffallendes Motiv der apokalyptisch-chiliastischen Bewegungen, wie sie in Rußland im 19. und frühen 20. Jahrhundert verbreitet waren.

Die Frage muß offenbleiben, ob und inwieweit Platonov und Gorskij füreinander vorbildlich gewesen sind; die Möglichkeit eines Kontaktes und einer gegenseitigen Beeinflussung war jedenfalls schon dadurch gegeben, da $B$ beide im Jahre 1924 Beiträge für die eher obskure Moskauer Zeitschrift Oktjabr' Mysli verfaßten; diese Zeitschrift, von der nur sechs Nummern mit kleiner Auflage erschienen sind, stand offenbar dem $L E F$, der "Produktionskunst" und der linken Opposition nahe. ${ }^{56}$ Platonov veröffentlichte vier Rezensionen in den ersten

54 A.[P.] Platonov, "Kul'tura proletariata." [1920]; zitient nach LuUbUSkina (wie Anm. 52), S. 412.

55 A.[P.] Platonov, "Rasskaz o mnogich interesnych vešzach." [1923] In: Ders., Starik $i$ stanucha. Poterjannaja proza. München 1984, S. 73. Der zitierte Abschnitt findet sich auch im Rahmen des Zyklus "Rodonacal'niki nacii ili bespokojnye proisłestvija." In: A.[P.] PLATONOV, Epifanskie sljuzy, M. 1927, S. 236f. - In der 1922 entstandenen Erzăhlung Potomki solnca rettet "keusche Brüderlichkeit" (celomudrennoe bratstwo) die Menschheit vor dem drohenden Untergang in einer gewaltigen Klimakatastrophe.

56 Angaben nach T. LANGeraK, "Andrej Platonov v Voroneže." In: Russian Literature, 23, 1988, S. 459f. - Die Zeitschrift Oktjabr' Mysli ist außerhalb der Sowjetunion offenbar nicht vorhanden; sie war mir trotz intensiver Bemühungen nicht zugănglich.

Aus den Materialien über Gorskij und die Gruppe der Moskauer Fedorov-Anhănger lăßt sich ein Kontakt zu Platonov nicht belegen. Es ist jedoch bekannt, daß Platonov, der in den frühen zwanziger Jahren als Ingenieur bei Meliorations- und Elektrifizierungsprojekten im Gouvernement Voronež arbeitete, in dieser Zeit mehrmals nach Moskau reiste, wo er Kontakte zu literarischen Gruppen anknüpfte (siehe LANGERAK, a.a.O.). Dabei könnte er über die Zeitschrift Oktjabr' Mysli mit Gorskij und Setnickij bekannt geworden sein. Denkbar wäre auch eine Verbindung zu dem Biokosmisten, Fedorov-Anhănger und Fachmann für "Meteorourgie" P.I. Ivanickij, der zu dieser Zeit - ebenso wie Platonov - mit Vorschlăgen zur Regulierung des Klimas durch den Einsatz von Elektrizităt hervortrat. Siehe II: 3.3. - Diesen Spuren sollte nachgegangen werden. 
beiden Nummern; ${ }^{57}$ Setnickij und Gorskij waren mit insgesamt vier Beiträgen zu Fragen der wissenschaftlichen Organisation geistiger Arbeit vertreten. ${ }^{58}$

Ebenfalls 1924 verfaßten Setnickij und Gorskij einen Aufruf zur "Liquidierung der passiven Haltung ... gegenüber der Frage von Leben und Tod", in dem sie die Selbsterlösung der Menschheit forderten; das Manuskript wurde, einer Schlußbemerkung zufolge, handschriftlich verbreitet. ${ }^{59}$

In den genannten Zeitraum fält auch eine intensive Auseinandersetzung der Moskauer Fedorov-Anhänger mit der - damals vieldiskutierten - Lehre des imjaslavie. Besonders Gorskij und Setnickij bemühten sich, die Auffassung vom Namen als Offenbarung des Wesens (suščnost') und als Ausdruck seiner Wirkkraft (énergija) mit den Zielen der Filosofija obščego dela zu verbinden, indem sie die ursprünglich mystisch-kontemplative Lehre (imjaslavie) in ein weltverwandelndes Programm (imjadejstvie) umdeuteten. ${ }^{60}$ Der Name (imja), so formulierten sie in ihren "Thesen über das imjaslavie ${ }^{\text {m61 }}$, sei die Einheit von Wort (slovo) und Tat (delo). Als "lebendiges", "wirkendes Wort" (zivoe, dejstvennoe slovo) dränge der Name auf Verwirklichung (osušcestulenie). Diese beginne damit, da $B$ jeder einzelne seinen (eigenen) Namen verwirkliche, indem er die durch den Namen gegebene Bestimmung in der Welt erfülle. Bislang seien die Versuche zur Verwirklichung des Namens weitgehend unbewußt verlaufen, ungeordnet und oftmals im Widerstreit miteinander. Durch die Einbindung ins Kollektiv werde dies verhindert: Das Kollektiv bestimme den Namen des einzelnen und weise ihm damit Aufgabe und Ziel seines Handelns zu. Durch die "Harmonisierung der individuellen Namen" würden die Handlungen aller koordiniert und auf ein gemeinsames Ziel gelenkt werden - die Verwirklichung des Namens Gottes als des Inbegriffs der Vollkommenheit. ${ }^{62}$

57 Siehe LANGERAK (wie Anm. 56), S. 464, 466.

58 NA. SEtnickis, "Edinstvo trudovogo processa." In: Oktjabr' Mysli, 1924, 1-2. Ders., "NOT i NOUT." Ebd. DERS., "Trud uzenogo." Ebd., 5-6. A. GORNOSTAEV [GORSKU], "Ekonomika nautnogo proizvodstva. $K$ istorii voprosa." Ebd., 3-4, S. 43-57; 5-6, S. 59-72. Alle Angaben nach SETNICKNA, Gorskij (wie Anm. 18), BI. 35.

59 [A.K. GoRSKU, NA. SETNICKI], Tezisy o lajne bezzakonija, Ms. [Masch.], datiert 1924, 9 Bl.; in Moskauer Privatbesitz.

60 Siehe II: 3.4. und die dort (Anm. 21ff.) angegebene Literatur. - "Die Frage nach dem imjaslavie und imjadejstvie tauchte 1923 in Moskau auf, als man (natürlich ganz im geheimen...) Moglichkeiten zu erortern begann, wie der Streit zwischen imjaslavcy und imjaboncy beigelegt werden könne." R. MANOvsku [N A. SETNICKu ?], "Messianstvo i 'Russkaja Ideja'." In: Vselenskoe delo (wie Anm. 16), S. 91. In dem genannten Jahr verfaßte A.F. Losev seine Filosofija imeni; als das Werk 1927 veroffentlicht werden konnte, soll das imjaslavie Hauptthema heimlicher Diskussionen in Moskauer Theologenkreisen gewesen sein - so Gorskij in einem Brief aus Starodub vom 26.8.1927 an Setnickij in Harbin; FAP I, 328.

61 [A.K. GoRSKu, NA. SETNICKu], Tezisy ob imjaslavii, Ms. [Masch.], undatiert [um 1924], 5 Bl.; in Moskauer Privatbesitz.

62 Den magischen Zusammenhang zwischen dem (Vor-)Namen und dem Wesen seines Trăgers hatte Florenskij in den frühen zwanziger Jahren in einer (unveroffentlicht gebliebenen) hochspekulativen sprachphilosophischen Abhandlung darzulegen und am Beispiel von 19 Vornamen 
Die in den "Thesen über das imjaslavie" nur skizzierte theologische Begründung des obšcee delo wurde breit ausgeführt in einer 1925 von Gorskij und Setnickij wiederum gemeinsam verfaßten Schrift, die ein Jahr später anonym unter dem Titel Smertobožničestvo von Setnickij in Harbin veröffentlicht wurde. ${ }^{63}$ Obwohl Fedorov in dieser Schrift nicht genannt wird, ist sein bestimmender Einfluß klar erkennbar. ${ }^{64}$

Die Menschheit, so die Verfasser, stehe heute vor ihrer weltweiten äußeren Vereinigung. Damit eröffne sich ihr die Möglichkeit - und stelle sich zugleich als Aufgabe -, durch planmäßig koordiniertes Handeln die blinden, zerstörerischen Kräfte der Natur zu besiegen, die Herrschaft schließlich über das gesamte Universum zu erringen, es zu einen und mit Vernunft zu erfüllen. ${ }^{65}$ Dies gelinge jedoch nur, wenn auch der Tod - die einzige Begrenzung menschlicher Macht bekämpft und überwunden und nicht, wie bisher, als notwendig anerkannt oder als schicksalhaft hingenommen und damit "vergottet" werde. 66 "Todesvergottung" (smertobožnicestvo) sei jede Anerkennung der Macht der Natur und der 'natürlichen' Begrenztheit des Menschen - vom Kult der Magna Mater bis zur positivistischen Naturwissenschaft als bloßer Weltbeschreibung. ${ }^{67}$ "Todesvergottung" folge aus dem Dualismus von Leib und Seele und der damit verbundenen Geringschätzung des Leibes, der abgetötet werde, um die - je eigene - Seele zu retten. Auch die Vorstellung von einer Erlösung durch Leiden und Tod sowie einer Auferstehung in einem verwandelten, verklärten Leib sei "Todesvergot-

(Aleksandr, Aleksandra, Aleksej, Anna usw. bis Michail) zu erläutern versucht. P.A. FLoREN. SKU, Imena, Ms. [Masch.], 254 Bl.; Abschrift in meinem Besitz. Siehe auch M. HAGEMEISTER, "P.A. Florenskij und seine Schrift 'Mnimosti v geometrii' (1922)." In: PA. FLoRENSKL, Mnimosti v geometrii [Nachdruck], München 1985, S. 12f., 43f.

63 Der vollstăndige Titel lautet: Smenoboznizesrvo. Koren' eresej, razdelenij $i$ izvnašenij istinnogo ǔenija cerkvi. Dogmaticeskie oxerki. Cast' 1. Borba slovom. O.O. [Harbin] $1926 \mathrm{~g}$. Pascha 19 aprelja - 2 maja.

Zur - lange unbekannten - Verfasserschaft berichtet SETnICKAJA, Gorskij (wie Anm. 18), Bl. 37: "Alle Thesen von Smenobożnicestro waren gemeinsam überlegt worden; die Darstellung stammte von Setnickij mit einigen Korrekturen Gorskijs." - Zur Entstehung: "Geplant und vollendet wurde der Traktat in Moskau in der ersten Hălfte des Jahres 1925." A.K. GoRskJ, POsleslovie k traktatu 'SmenobożniXestuo', Ms. [Masch.] 1926-1942; in Moskauer Privatbesitz. - Die 81 Seiten umfassende Schrift war Teil eines geplanten, jedoch nie erschienenen Sammelbandes. Materialien dazu befinden sich im Fedorov-Archiv Prag (FAP I, 338). In einem Brief an Setnickij berichtet Gorskij am 11.5.1927 von der Arbeit an einem zweiten Teil von Smertoboznitestvo (FAP I, 328).

64 Dies wurde auch von den beiden Rezensenten der Schrift hervorgehoben. Siehe BERDJAEV (wie Anm. 10), S. 122-124; Smenoboznizestur sei "zweifellos von einem Schüler Fedorovs verfaBt" worden (ebd., S. 122). A. MiRoluUbov [Pseud.?] in: Vselenskoe delo (wie Anm. 16), S. 198-200. - Zum Inhalt vom Smenobožnixestvo und zum geistesgeschichtlichen Kontext siehe P. SCHEIBERT, "Die Besiegung des Todes - Ein theologisches Programm aus der Sowjetunion (1926)." In: Glaube, Geist, Geschichte. Festschrift für Emst Benz. Leiden 1967, S. 431-447.

65 Smenotoznicestuc (wie Ann. 63), S. 3-5.

Ebd., S. $5 f$.

Ebd., S. 11. 
tung ${ }^{n}{ }^{68}$ Ein Christentum, das passiv die Befreiung vom Tod als göttliches Gnadengeschenk für wenige Auserwählte erwarte und den verworfenen Rest ewiger Verdammnis überlasse, anstatt die Welt in gemeinsamer Tat zu verwandeln ( $\mathrm{Li}$ turgie im eigentlichen Sinne), sei "Todesvergottung".69

Die Kraft dieser Häresie liege in ihrer Schwäche: Sie bestätige die Unendlichkeit des Sterbens und führe damit die Menschheit allmählich zur Verzweiflung, zum Bewußtsein völliger Ausweglosigkeit, zu Nihilismus, Katastrophismus, Todeskult (smertopoklonstvo), kollektivem Mord und Selbstmord; die Vernichtungskriege des 20. Jahrhunderts - von der Kirche nicht nur geduldet, sondern sogar mit ihrem Segen versehen - seien schrecklicher Ausdruck solcher Geistesverwirrung, die mit Wort und Tat bekämpft werden müsse. ${ }^{70}$ Dabei gelte es zunächst, die vielfältigen Erscheinungsformen der "Todesvergottung" in der Geschichte des christlichen Glaubens aufzudecken ${ }^{71}$ - z.B. im Ikonoklasmus, der mit dem Bild auch den Plan zur Verwandlung bekämpft habe, ${ }^{72}$ in der katholischen Kirche, die die Menschen zwar geeint und ihre schöpferischen Kräfte wachgerufen, ihnen aber keine gemeinsame Aufgabe (obšcee delo) gestellt habe, ${ }^{73}$ und schließlich im Protestantismus mit seiner Irrlehre vom Gottsuchen des einzelnen. ${ }^{74}$ Immerhin habe der Westen in seinem Abfall von der unverkürzten Lehre jene Seiten menschlicher Tätigkeit gefördert, aus denen die neuzeitliche Wissenschaft erwachsen sei. Diese könnte - göttlichem Plan entsprechend - die Welt verwandeln und erretten; statt dessen aber werde sie zu ihrer Vernichtung mißbraucht. ${ }^{75}$

Die Ostkirche kenne hingegen Formen göttlich-menschlichen Zusammenwirkens - so z.B. im Sichtbarmachen des Urbildes durch den inspirierten Maler der Ikone, in der mystischen körperlichen Wahrnehmung des weltverändernden Taborlichts, vor allem aber im Aussprechen des göttlichen Namens, der, nach der Lehre des imjaslavie, Gott selbst sei. ${ }^{76}$ Damit diese Einsicht in die Möglichkeit synergetischen Handelns nicht zur bloßen dogmatischen Formel erstarre und damit zu einer weiteren Form von "Todesvergottung" -, müsse das imjaslavie unverzüglich in die Tat umgesetzt, zum imjadejstvie werden, zum organisier-

68 Ebd., S. 12-15, 73.

69 Ebd., S. 15-18.

70 Ebd., S. 25-28, 63.

71 Ebd., S. 30-67.

72 Ebd., S. 44-47, 65f. - Die Auffassung der Ikone als Plan und Projekt der Verwandlung der Welt geht auf Fedorov zurück.

73 Ebd., S. 56f., 62.

74 Ebd., S. 24.

75 Ebd., S. 63.

76 Ebd., S. 6468. 


\section{СМЕРТОБОЖНИЧЕСТВО.}

КОРЕHЬ ЕPECEИ, РАЗАЕАЕНИЙ И ИЗВРАШЕНИЙ - . ИСТИННОГО . . . УЧЕНИЯ ЦЕРКВН.

АОГМАТИЧЕСКИЕ ОЧЕРКИ.

Чacts 1.

Борьба словом.

1926 r.

I ACXA

19 anpess-2 мex. 
ten Kampf aller Menschen gegen die blinde Natur, gegen Zerfall und Tod. ${ }^{77}$ Von der Erfüllung dieser gemeinsamen Aufgabe unter Einsatz aller Kräfte und Mittel hingen die Rettung der Welt und das Heil der Menschheit ab. ${ }^{78}$ - Den Schluß der Schrift bilden fünf Anathemata gegen die Anhänger jedweder "Todesvergottung". ${ }^{79}$

Welche Resonanz Smertobožnizestvo in religiösen und philosophischen Kreisen hervorgerufen hat, ist unbekannt. Einer kurzen Vorbemerkung zufolge soll der Text in der Sowjetunion handschriftlich verbreitet gewesen sein; auch die gedruckte Fassung gelangte schon bald nach ihrem Erscheinen in illegalen Umlauf. ${ }^{80}$ Lediglich von Florenskij wird berichtet, daß er sich - in einem Gespräch mit dem Fedorov-Anhänger Postnikov - zu den Thesen von Smertobožnicestvo geäußert habe. ${ }^{81}$ Im Westen wurde die Schrift kaum beachtet: Abgesehen von Berdjaevs Rezension ${ }^{82}$ sowie einem kurzen Hinweis des religiösen Philosophen V.N. Il'in ${ }^{83}$ finden sich ihre Spuren nur noch im Briefwechsel zwischen Gor'kij und Ol'ga Fors. ${ }^{84}$

Ein bemerkenswertes, jedoch ganz vereinzeltes Zeugnis für den Widerhall, den Fedorovs Gedanken in Moskauer religiösen Kreisen in den zwanziger Jahren gefunden haben, wurde durch eine Veröffentlichung in der Pariser Emigrantenzeitschrift Put' bekannt. Es handelt sich um die Predigt eines unbekannten Moskauer Priesters - er wird "Aleksej B." genannt - aus dem Jahre 1928 sowie um Erläuterungen zu den Sakramenten, die nach Gesprächen mit "Aleksej B." von einem Mitglied seiner Gemeinde aufgezeichnet worden waren. ${ }^{85}$ Aus beiden Texten, in denen zum Kampf gegen die "blinden Kräfte der Natur", zur Überwindung des Todes und zur Wiederherstellung der Verstorbenen aufgerufen wird, spricht - kaum verhüllt - die Stimme Fedorovs; so heißt es in der Predigt:

77 Ebd., S. 68-76.

78 Ebd., S. 76-79. - Fedorovs Einfluß wird hier besonders deutlich, wenn z.B. von der "gemeinsamen Aufgabe (obšzee delo) der gesamten, in kirchlicher und außerkirchlicher Liturgie vereinten Menschheit" (S. 79) die Rede ist oder der Einsatz des "christusliebenden Heeres im Kampf gegen die Natur" gefordert wird (S. 78).

79 Ebd., S. 79-81. - In seiner ansonsten wohlwollenden Besprechung kritisiert Berdjaev diesen Schluß. Berdjaev (wie Anm. 10), S. 124.

80 Siehe Smenoboznizestuo (wie Anm. 63), S. 2. A.K. Gorskij [unter dem Pseud. Ostromirov], Moskau, an N.A. Setnickij, Harbin, 29.6./12.7.1926; FAP I, 328.

81 Setnickaja, Gorskij (wie Anm. 18), S. 38. Die Verf. bezieht sich auf einen Brief Gorskijs vom 12.7.1939.

82 Siehe oben Anm. 10, 64.

83 V.N. IL'IN, "O religioznom i filosofskom mirovozarenii N.F. Fedorova." In: Evrazijskij sbomik, kn. 6, Prag 1929, S. 20 Anm.

84 Siehe II: 4.2.2.

85 Ot. Aleksej B., "'Az esm' chleb životnyj'." In: Put', 42, 1934, S. 68-79. 
Wir werden nicht, wie bisher, für uns selbst leben und nicht für die anderen, die auch nur für sich selbst leben, für gegenseitigen Kampf, Bedrăngung und Verdrăngung, sondern wir werden zusammen mit allen Lebenden so leben, daB wir ... schlieBlich das Leben denen zurückerstatten, die es uns gegeben haben, die selber aber untergegangen sind und deshalb mit Recht von uns die Rückgabe des Lebens erwarten. ${ }^{86}$

In enger Anlehnung an Fedorov werden die Sakramente gedeutet als "Projekten, die es mit vereinten Kräften zu verwirklichen gelte: Taufe, Firmung und Salbung seien Aufrufe zur Vereinigung der Menschen und zum Kampf gegen die Natur, Aufgabe der Ehe sei es, Fortpflanzung durch Wiederherstellung (vossozdanie) zu ersetzen, die Eucharistie schließlich sei das Projekt der tätigen Auferweckung der Verstorbenen. ${ }^{87}$ Über den Verfasser wird lediglich mitgeteilt, da $\beta$ er von 1925 bis zu seiner Verhaftung im Jahre 1930 in Moskau als Priester gewirkt habe; ${ }^{88}$ eine Verbindung zu den Moskauer Fedorov-Anhängern konnte nicht nachgewiesen werden.

Ohne Beteiligung der Fedorov-Anhänger scheint in den frühen zwanziger Jahren in Moskau die Arbeit an einem Slovar' russkich myslitelej vonstatten gegangen zu sein. ${ }^{89}$ Das Werk, in das auch Fedorov aufgenommen werden sollte, ging auf ein Projekt aus dem Jahre 1918 unter Beteiligung von Rozanov zurück. Nach dessen Tod stand es unter der Leitung des Slavophilen N.N. Rusov (1884 nach 1934); Mitarbeiter waren unter anderen Berdjaev, G.G. Špet (1878-1937) und É.F. Gollerbach (1895-1942). Über das weitere Schicksal dieser Unternehmung ist nichts bekannt.

Unabhängig von den Moskauer Fedorov-Anhängern entstand auch der kurze Namenartikel zu Fedorov, der 1926 oder 1927 im Énciklopediceskij slovar' Granat erschien. ${ }^{90}$ Fedorov wird darin als "eigenartiger und tiefsinniger Philosoph und religiöser Denker" vorgestellt, sein Geburtsdatum in die "1840er Jahre" verlegt. Verfasser des nur mit Initialen gezeichneten Artikels ist wahrscheinlich der Philosoph und Cohenschüler G.O. Gordon, über den nichts Näheres bekannt ist.

Immer wieder erwiesen sich die Möglichkeiten der Moskauer Fedorov-Anhänger, innerhalb der Sowjetunion publizistisch wirksam zu werden, als eng begrenzt. Sie verschlechterten sich sogar noch, als etwa seit Mitte der zwanziger Jahre die ideologische Gleichschaltung verstärkt wurde; damit einher ging die Liquidierung des privaten Verlagswesens, das nach der Revolution in der Phase

\section{Ebd., S. 71.}

87 Ebd., S. 71-79.

88 Ebd., S. 68 (Anm. des Herausgebers).

89 Dieses und das Folgende nach E.[F.] Gollerbach, "Russkaja filosofija i ee sud"ba." In: No vaja Russkaja Kriga, 5, 1922, S. 1-4.

90 G. GN. [G.O. GORDON ?], "Fedorov, Nikolaj Fedorovix." In: Enciklopedixeskij slovar nusskogo bibliograficeskogo instituta Granat, 7-e izd., t. 43, M. o.J. [nicht vor 1926], Sp. 102. 
der NEP eine kurzzeitige Blüte erlebt hatte. ${ }^{91}$ Von der noch bis zum Beginn der dreißiger Jahre bestehenden Möglichkeit, eigene Werke legal im Selbstverlag (izdanie avtora) herauszubringen, ${ }^{2}$ hatte aus dem Kreis der Moskauer FedorovAnhänger nur Murav'ev einmal, im Falle seines 1924 erschienenen Ovladenie vremenem, Gebrauch gemacht. Setnickij und Gorskij hatten mehrere umfangreiche Arbeiten zu Fedorov verfaßt; ihre Bemühungen, sie zu veröffentlichen, waren jedoch erfolglos geblieben. Da trat - im Jahre 1925 - unerwartet eine Wende ein.

91 Im Mărz 1922 zăhlte man allein in Moskau 143 private Verlage, 1924 waren es bereits 220; in Anlehnung an die NEP (Novaja Ekonomiceskaja Politika) sprach man deshalb auch von Nep (nezavisimaja pe ¿at'). Unter den Moskauer Verlagen, die in den frühen zwanziger Jahren nichtmarxistische philosophische Werke herausbrachten, sind v.a. zu nennen: Primor'e, Sipownik, Bereg, GA. Leman i S.A. Sacharov.

92 Im Selbstverlag und mit staatlicher Druckerlaubnis hatte beispielsweise der Moskauer Philosoph A.F. Losev seit 1927 acht umfangreiche Werke veroffentlicht, in denen er eine idealistische, bisweilen sogar offen antimarxistische Position einnahm; zuletzt mit aller Schärfe in dem Anfang (?) 1930 erschienenen, dann freilich sofort verbotenen Werk Dialektika mifa, wo es auf S. 147 heiBt: "dialektischer Materialismus ist schreiender Unsinn" (vopijustaja nelepost'). Losev wurde am 18. April 1930 verhaftet und zusammen mit dem Mathematiker D.F. Egorov und dem Bischof Feodor (Pozdeevskij) im ProzeB gegen das sog. "Religiös-politische Zentrum" zu 10 Jahren Lagerhaft verurteilt. 


\subsection{N.A. Setnickij in Harbin}

\subsubsection{Der Weg nach Harbin: N.V. Ustrjalov und das 'smenovechovstvo'}

Im Sommer 1925 besuchte der in der Emigration in Harbin lebende Staatsrechtler und Historiker N.V. Ustrjalov die Sowjetunion und traf in Moskau auch mit Anhängern Fedorovs zusammen.

Ustrjalov, ein ehemaliger Funktionär der Konstitutionellen Demokraten und großrussischer Nationalist, ${ }^{1}$ gehörte zu den Initiatoren und Wortführern der sogenannten Smena-vech-Bewegung, die zu Beginn der zwanziger Jahre in der Emigration entstanden war und sich, von sowjetischer Seite eine Zeitlang gefördert, darum bemühte, ehemalige Gegner der Bolschewiki für eine Zusammenarbeit mit der Sowjetmacht zu gewinnen. Begründet wurde diese - von

1 Nikolaj Vasil'evit Ustrjalow wurde am 25.11.1890 in Sankt Petersburg geboren. 1913 schloB er sein Studium an der Juristischen Fakultăt der Moskauer Universităt ab und hielt sich im folgenden Jahr zur Weiterbildung in Paris und Marburg auf. 1916 wurde er Privatdozent am Lehrstuhl für Staatsrecht in Moskau. Er verkehrte in der Moskauer Religiös-Philosophischen Vladimir-Solov'ev-Gesellschaft und stand unter dem EinfluB der geschichtsphilosophischen Konzeptionen Leont'evs und Danilevskijs. Wahrend der Zeit der Provisorischen Regierung nahm Ustrjalov in den Reihen der Konstitutionellen Demokraten (Kadetten) aktiv am politischen Leben teil. Im April 1918 gründete er in Moskau die kurzlebige Zeitschrift Nakanune, die eine an den nationalen Interessen RuBlands orientierte Position vertrat (zu den Autoren zăhlten N.A. Berdjaev, V.N. Murav'ev, A.A. Kizevcıter, P.B. Struve und möglicherweise auch Brjusov). Ende 1918 ging Ustrjalov über Perm' nach Omsk, wo er im folgenden Jahr zum Vorsitzenden des "Ostlichen Büros" der Kadetten gewăhlt wurde und der Regierung des Admirals KolZak als Leiter ihrer Propagandaabteilung diente. Nach dem Sturz Koltaks und der Niederlage des Atamans Semenov bei Irkutsk foh Ustrjalov über Cita nach Harbin, wo er im Mărz 1920 Professor für Staatsrecht an der neugegründeten Juristischen Fakultăt wurde (bis 1934). Im selben Jahr legte er seine politischen Anschauungen in einer Reihe von Aufsătzen in der Zeitung Novosti Zizni nieder, die er Ende 1920 in dem Buch V bor'be za Rossiju zusammenfaBte. 1921 gehörte er zu den Autoren des in Prag erschienenen Sammelbandes Smena vech. 1922 trat er in den Dienst der in sowjetischem Besitz befindlichen Ostchinesischen Eisenbahn (als Leiter ihrer Bibliothek). Im Zusammenhang mit dem Verkauf der Eisenbahn an Japan im Jahre 1935 entschloB sich Ustrjalov, in die Sowjetunion zurückzukehren. Nach kurzer Tătigkeit als Professor an der Moskauer Staatsuniversităt wurde er 1937 verhaftet. Ustrjalov ist wahrscheinlich 1938 gestorben.

Zu Ustrjalovs (intellektueller) Biographie vgl. G.[K.] Gins, "Spisok professorov, prepodavatelej i lektorov Juridizeskogo Fakul'teta ... (1920 g. - 1931 g.)." In: Izv.Jur.Fak, 9, 1931, S. 356f. BSE, 1-e izd., t. 56, M. 1936, Sp. 392f. M.[S.] AGURSKI, Ideologija nacional-bol' 'Sevizma, Paris 1980, S. 64-69 und pass. DeRs., "Perepiska I. Ležneva i N. Ustrjalova." In: Slavica Hierosolymitana, 56, 1981, bes. S. 543-545. DeRS., "Defeat as Victory and the Living Death: The Case of Ustrjalov." In: History of European Ideas, 5, 1984, 2, S. 165-180. Ders., The Third Rome. National Bolshevism in the USSR. Boulder, London 1987, bes. S. 185-187, 240-266, 309-315, 330-334. DERS., "U istokov nacional-bol'Sevizma." In: Minuvsee. Istoriteskij al'manach. 4, Paris 1987, S. 140-165. J. BURbank, Intelligentsia and Revolution, New York, Oxford 1986, S. 222-237. - Der groBte Teil von Ustrjalovs Archiv befindet sich heute in der Hoover Institution, Stanford, Kalifornien (siehe AGURSKI, "Perepiska...", a.a.O., S. 550f.). Ein von der Forschung bislang nicht beachteter Teil von Ustrjalovs Archiv gelangte Mitte der dreiBiger Jahre nach Prag, wo er als Teil der sog. "Fedoroviana Pragensia" gegenwărtig im Literarischen Archiv der Gedenkstătte für Nationales Schrifttum aufbewahrt wird (FAP I, 335-336). 
Ustrjalov als "Nationalbolschewismus" bezeichnete - Haltung mit der Überzeugung, da $B$ die nationalen Interessen Rußlands gegenwärtig am besten bei den Bolschewiki aufgehoben seien. Bereits in den Jahren der Revolution und des Bürgerkriegs habe sich, so Ustrjalov, die Sowjetmacht als einzig wirksamer Ordnungsfaktor erwiesen und als Garant für die territoriale Integrität Rußlands: Es sei das nationale Verdienst der Bolschewiki, Staatlichkeit und Disziplin wiederhergestellt und eine Auflösung des russischen Reiches verhindert zu haben. Nationale Züge seien auch in der gegenwärtigen sowjetischen Außenpolitik zu erkennen, die, vor allem in Asien, traditionelle Ziele russischer Großmachtpolitik wiederaufgegriffen habe. Dies deute auf eine "Nationalisierung des Bolschewismus" hin (der als rein russisches Phänomen zu unterscheiden sei vom unrussischen "internationalistischen" Kommunismus), auf eine nationale "Evolution der Revolution". Um diesen Prozeß zu fördern und zu beeinflussen, riefen Ustrjalov und die smenovechovcy die nichtbolschewistische Intelligenz auf, ihren Widerstand gegen die Sowjetmacht zu beenden und als wahre Patrioten am Aufbau eines mächtigen und geeinten russischen Staatswesens mitzuwirken. ${ }^{2}$

2 Siehe N.[V.] Ustrualov, $V$ bor'be za Rossiju. (Sbomik statej). Charbin 1920. Ders., Na novom etape, Sanchaj ${ }^{2} 1930$. Eine knappe, gute Darstellung der Smena-vech-Bewegung bietet E. OBERLÃNDER, "Nationalbolschewistische Tendenzen in der russischen Intelligenz." In: JfGO, 16 (1968), S. 194-211. Materialreich, wenn auch bisweilen spekulativ, AGURSKI, Ideologija (wie Anm. 1). Ders., The Third Rome (wie Anm. 1), bes. S. 240-266. Burbank (wie Anm. 1). Vgl. ferner G.[P.] STRUVE, Russkaja literatura v izgnanii, Paris ${ }^{2}$ 1984, S. 30-35. - Aus sowjet ischer Sicht V.P. KOSARNYJ, "Iz istorii bor'by s buržuazno-restavratorskoj sociologiej smenovechovstva v pervye gody nepa." In: Aktual'nye problemy istorii filosofii nanodov SSSR, vyp. 4, M. 1977, S. 105-117. L.K. SKARENKov, Agonija beloj émigracii, M. 1981, S. 83-93.

Der wohl prominenteste smenovechovec-vozvrascenec war der Schriftsteller A.K. Tolstoj, der 1923 aus der Berliner Emigration in die Sowjetunion zurückkehrte. - Auch der Schriftsteller B.A. Pil'njak (Vogau) stand eine Zeitlang unter dem Einfluß der Ideologie des smenovechovstvo. Bereits in seinem kurz nach der Revolution entstandenen Roman Golyj god hatte er zwischen russischem "Bolschewismus" und westlichem "Kommunismus" unterschieden. Wie die smenovechovcy verglich Pil'njak die Revolution mit einem Naturereignis, deutete sie als einen Aufstand des bäuerlichen Volkes gegen alles Fremde und vertraute darauf, daB sich im Laufe der weiteren Entwicklung dieses nationalrussische Element gegen die fremden Einflüsse durchsetzen werde. Siehe V.T. RECK, Boris Pil'njak. A Soviet Writer in Conflict with the State. Montreal, London 1975, S. 95-100. Agursku (wie Anm. 1), S. 126-128. Im Mărz 1926 traf Pil'njak auf einer Reise nach Japan in Harbin mit Ustrjalov zusammen. Schriftliche Zeugnisse darüber im Fedorov-Archiv Prag (FAP I, 336). Ob Pil'njak damals auch mit Setnickij und den Ideen Fedorovs bekannt geworden ist, lieB sich nicht feststellen. Abwegig ist die Vermutung, Pil'njaks 1927 veröffentlichte Erzăhlung Ivan Moskva sei durch "N. Fedorov's philosophy of reincarnation [sic!]" beeinfluBt worden. P. A. JENSEN, Nature as Code. The Achievement of Boris Pilnjak 1915-1924. Copenhagen 1979, S. 281. Das Thema der wissenschaftlich-technischen Wiederherstellung individuellen Lebens (durch zeitweiliges Einfrieren der Verstorbenen) behandelt Pil'njak in der 1927 entstandenen Erzählung Delo smerti (siehe II: 3.2.1.).

Den smenovechovcy geistig verwandt waren die Eurasier (evrazijcy), deren prosowjetische Fraktion unter D.P. Svjatopolk-Mirskij und S.Ja. Efron sogar eine ideologische Verbindung von Marx und Fedorov versuchte (ausführlich II: 4.3.1.), sowie die mladorossy, eine Bewegung in der Pariser Emigration der zwanziger und dreiBiger Jahre, die ausgeprägt faschistische Züge aufwies; ihr "Führer" (vozd'), A.L. Kazem-Bek (1902-1977), ein Bewunderer Mussolinis und Stalins, kehrte (wie vor ihm Svjatopolk-Mirskij, Efron und Ustrjalov) 1956 in die Sowjetunion zurück. Siehe N. HAYEs, "Kazem-Bek and the Young Russian's Revolution." In: Slavic Review, 
Wie die smenovechovcy hatten auch die Moskauer Fedorov-Anhänger die Revolution akzeptiert und die durch sie geschaffene neue Ordnung als verbesserte Möglichkeit erkannt, Rußlands welthistorische Mission voranzutreiben. Auf dieser Basis - eines ursprünglich slavophilen Messianismus - konnten sie sich mit Ustrjalov verständigen. Über seine Begegnungen mit den Moskauer Fedorov-Anhängern im Juli und August 1925 berichtete Ustrjalov später:

Die originelle Lehre [Fedorovs; M.H.] wird, soviel ich bemerken konnte, ziemlich hăufig in vertraulichen Gesprächen erwähnt. Im Licht dieser Lehre erscheint die gegenwărtige Epoche als Beginn einer Art universaler Verwandlung und Wiedergeburt des Menschengeschlechts. ${ }^{3}$

Es ist bemerkenswert, daß die Fedorovsche Konzeption, russisch ihren Wurzeln und ihrem Stil nach, in ihrer praktischen Einstellung ganz besonders der sowjetischen Geisteshaltung in ihrem objektiven Wesen entspricht. Nicht von ungefăhr machen die Fedorov-Anhänger kein Hehl aus ihren sowjetischen Sympathien und korrigieren in dieser Hinsicht ausdrücklich die antisozialistischen und altmodischen Ansichten ihres Lehrers. ${ }^{4}$

Fedorovs Lehre habe, so Ustrjalov, mit ihrem dynamischen Optimismus den prometheischen Geist der Zeit getroffen, ihr Glaube an die Allmacht der Vernunft komme dem Bedürfnis nach einem neuen Mythos entgegen:

Man muß nicht unbedingt ein Fedorov-Anhănger sein, um in diesem eigenartigen System etwas Außergeworhnliches und Faszinierendes zu verspüren. Ich denke, es wird sich nicht als Irrtum erweisen, wenn ich sage, daß Fedorovs System die Voraussetzung für einen großen gesellschaftlichen Erfolg in sich birgt. Sein beispielloser, schwindelerregender Optimismus ist geeignet, die Gemüter zu erobern. Es ist in ihm etwas Modernes, etwas, das dem Zeitalter der Massen entspricht. Fedorovs System verlangt gleichsam nach Tribünen und Mikrophonen, und man spürt, daß es ihm zu eng ist in seinem jetzigen intellektuell-akademischen Rahmen. Ja, es ist sozusagen mythentrăchtig (mifonosna) und damit verheißungsvoll, besonders für unser Jahrhundert, da die Menschheit sich offensichtlich nach einem neuen oder emeuerten Mythos sehnt. ${ }^{5}$

Ustrjalov selbst blieb freilich distanziert; er kritisierte die Vergötzung von Rationalismus und Materialismus und die damit verbundene "bis zur Barbarei naive Wissenschaftsgläubigkeit", wie sie vor allem der Fedorov-Anhänger Murav'ev an den Tag legte. Zugleich aber würdigte er Fedorovs Werk als gedanklich originellen, wenn auch praktisch undurchführbaren Versuch, innerweltlichen Fortschritt durch eine ausschließlich sittlich begründete Zielsetzung zu definieren und zu rechtfertigen: Ewiges Fortschreiten sei absurd; wahrer

39 (1980), 2, S. 255-268. Den genannten Bewegungen gemeinsam war die Verabsolutierung des Nationalen und seiner greifbarsten Ausdrucksform, des Staates. Siehe auch M. GoRLIN, "Die philosophisch-politischen Stromungen in der russischen Emigration." In: Osteuropa, 8 (193233), S. 279-289.

3 N.[V.] UstRullov, Rossija (u okna vagona), Charbin 1926, S. 46.

4 N.V. Ustrualov, "Iz pis'ma." In: Vselenskoe delo, 2, Riga 1934, S. 164f. Gekürzt auch unter dem Titel "O filosofii N.F. Fedorova v svete sovremennosti." In: DERS., Naše vremja. Sb. statej. Sanchaj 1934, S. 197-202; hier S. 200 f.

5 Ustrualov, "Iz pis'ma" (wie Anm. 4), S. 162.

6 Ebd., S. 162f., 165. Zu Ustrjalovs Begegnung mit Murav'ev auch II: 3.4. 
Fortschritt erfordere die Ausrichtung auf ein "letztes Ideal", nach Fedorov die Auferweckung aller Verstorbenen als "vollständigen Triumph des Sittengesetzes über die physische Notwendigkeit". Da dieses Ziel jedoch, so Ustrjalov, innerhalb der Grenzen dieser Welt nicht zu verwirklichen sei, habe Fedorov - mit genialer Konsequenz, wenn auch entgegen seiner Absicht - die Idee eines innerweltlichen Fortschritts und einer Selbstvervollkommnung (oder Selbstvergottung) des Menschen ad absurdum geführt. ${ }^{7}$

Während seines Moskauer Aufenthalts traf Ustrjalov auch mit dem Weltkriegsgeneral A.A. Brusilov zusammen, den die smenovechovcy als großen $\mathbf{P a -}$ trioten verehrten, da er schon zu Beginn der ausländischen Intervention zur Unterstützung der Roten Armee aufgerufen hatte. ${ }^{8}$ Brusilov, der seit langem eine starke Neigung zum Okkultismus und zur Theosophie der Elena Blavackaja bewies, ${ }^{9}$ begann sich - möglicherweise durch Ustrjalov angeregt - für die Lehre Fedorovs zu interessieren und suchte den Kontakt zu den Moskauer FedorovAnhängern. Im Mai 1926 berichtet Gorskij an Setnickij:

An Ostern war ich sehr betrübt über die Nachricht, daß General Brusilov wăhrend der letzten Monate ständig auf mich gewartet hat, da er die Lehre $\mathbf{N}$. F[edorovs] kennenlernen wollte (ich erfuhr davon durch S.P. Bartenev), doch ist es nicht mehr dazu gekommen, da er unerwartet [am 17.3.1926; M.H.] gestorben ist. ${ }^{10}$

Im August 1925 kehrte Ustrjalov nach Harbin zurück. Zwei Monate später folgte ihm Setnickij, um an der Juristischen Fakultät, an der Ustrjalov lehrte, eine Stelle als Privatdozent anzutreten. ${ }^{11}$ Unmittelbar vor Setnickijs Abreise entstand ein Photo, das ihn zusammen mit Gorskij und Kuznecova-Mironoviz sowie einem unbekannten Popen an Fedorovs Grab auf dem Skorbja:̌̌enskijFriedhof in Moskau zeigt. ${ }^{12}$

7 N.[V.] UstRJalov, "Problema progressa." In: IzvJur.Fak., 9, 1931, hier S. 59-62. Siehe auch unten Anm. 169. - Vgl. DERS., "Iz pis'ma" (wie Anm. 4), S. 162-166. DeRs., Naše vremja (wie Anm. 4), S. 88f., 134f.

8 Ustrjalov hatte seinen Sammelband $V$ bor'be za Rossiju (1920) General Brusilov gewidmet, "dem tapferen und treuen Diener des Großen Rußland in der Zeit seines Ruhmes und in den schweren Tagen des Leidens und Unglücks".

9 Siehe A.A. Brusilov, Moi vospominanija, M.-L. 1929, S. 31, 33-35.

10 A.K. Gorskij, Moskau, an N.A. Setnickij, Mai 1926; FAP I, 328. - Der erwăhnte Sergej Petrovic Bartenev (1863-1930), Pianist und Musiklehrer in Moskau, hatte Fedorov persönlich gekannt.

11 O.N. SETniCKaja, Nikolaj Aleksandrovic Setnickij. Biografija. Ms. [Masch.] 0.O. 1965, B1. 9. $\mathrm{DaB}$ Setnickijs Ubersiedlung nach Harbin auf seine Bekanntschaft mit Ustrjalov zurückzuführen ist, wurde von O.N. Setnickaja bestätigt. Neben der Möglichkeit zu wissenschaftlicher Arbeit soll Setnickij v.a. die Aussicht verlockt haben, Fedorovs Werk durch ungehinderte Publikationstătigkeit bekanntmachen zu können.

12 Aufnahme vom Oktober 1925. - Nach einem Abzug im FAP I, 327. 


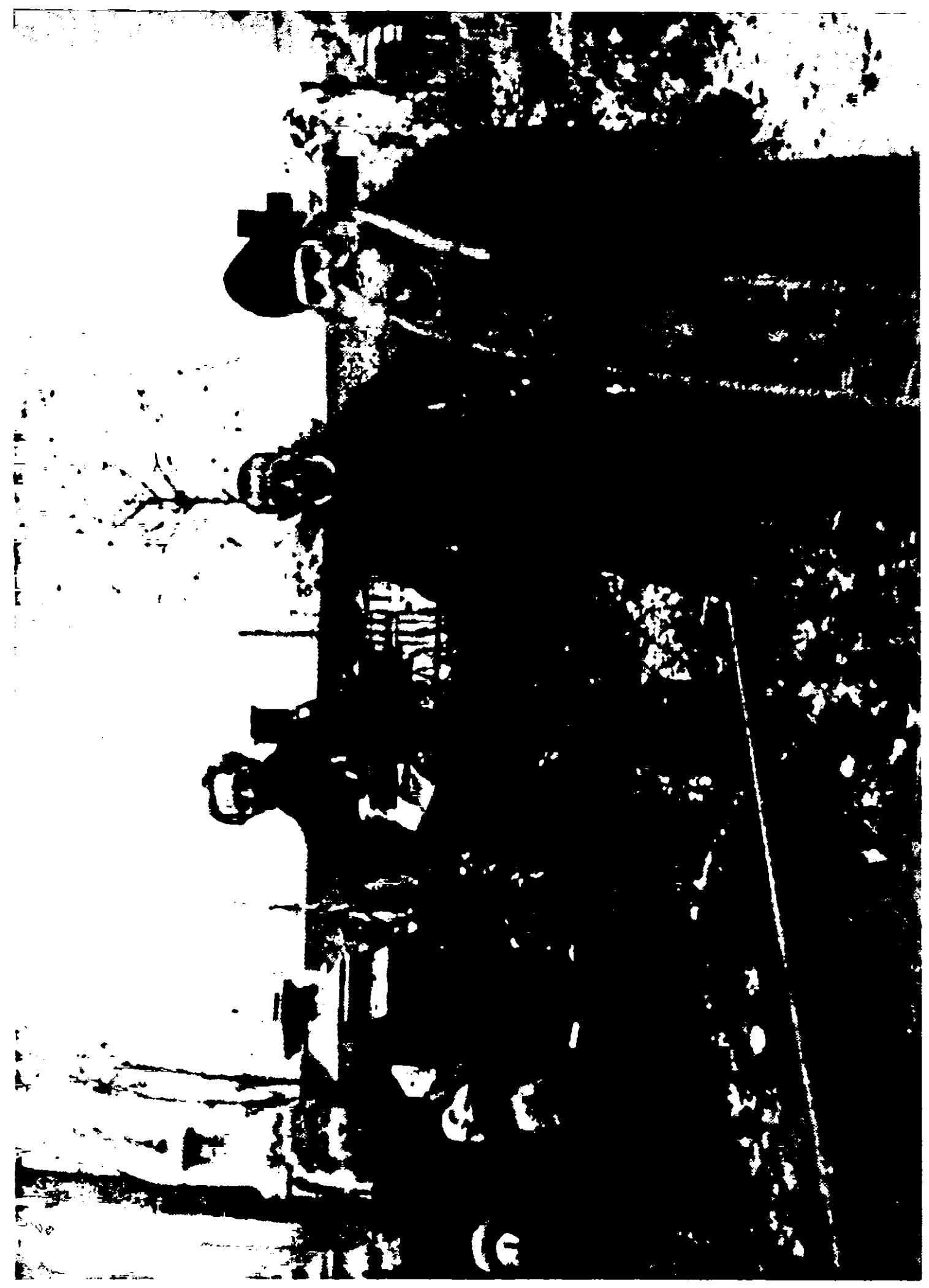

V.N. Kuznecova-Mironovič, A.K. Gorskij, NA. Setnickij und ein unbekannter Geistlicher (von links nach rechts) am Grab von N.F. Fedorov auf dem Friedhof des Skorbjaščenskij-Klosters in Moskau, Aufnahme vom Oktober 1925 


\subsubsection{Setnickij und Maksim Gor'kij (I)}

Harbin, von wo aus Setnickij zwischen 1925 und 1935 Fedorovs Ideen propagierte, war in den zwanziger und dreißiger Jahren eine Vielvölkerstadt, in der freilich noch immer das russische Element dominierte. ${ }^{13}$ Schon bald nach ihrer Gründung - im Jahre 1898 beim Bau der Ostchinesischen Eisenbahn - war die Stadt zur Metropole des russischen Einflusses in der Mandschurei geworden und, nach dem Sieg der Bolschewiki in Sibirien, zu einem Zufluchtsort für Zehntausende russischer Emigranten. Als 1924 die Ostchinesische Eisenbahn unter gemeinsame sowjetisch-chinesische Verwaltung gestellt wurde (deren Sitz sich in Harbin befand), erlebte die Stadt den Zuzug einer großen Zahl sowjetischer Staatsbürger (auch viele Emigranten nahmen damals die sowjetische Staatsbürgerschaft an). Hinzu kamen, angelockt durch einen enormen wirtschaftlichen Aufschwung, Abenteurer und Geschäftsleute aus aller Welt. $\mathrm{Zu}$ Beginn der dreißiger Jahre galt Harbin als das 'Chicago des Fernen Ostens'; von seinen rund 400.000 Einwohnern waren etwa 60.000 Sowjetbürger und etwa 45.000 staatenlose russische Emigranten; es gab 15 Konsulate, 63 Restaurants, 5 Theater und 118 Bars und Opiumhöhlen. Harbin besaß die größte sowjetische Kolonie im Ausland und war zugleich Zentrum des russischen Faschismus. ${ }^{14}$

$\mathrm{Zu}$ Harbins Ruf als Zentrum russischer Kultur im Fernen Osten trug wesentlich die Juristische Fakultät bei, die 1920 von emigrierten Wissenschaftlern unter ihnen Ustrjalov und G.K. Gins - gegründet worden war. ${ }^{15}$ Ab 1924, d.h. mit Beginn der gemeinsamen sowjetisch-chinesischen Verwaltung der Bahn, wurden auch sowjetische Staatsbürger als Studenten und Dozenten aufgenom-

13 Die kurze, aber ereignisreiche Geschichte Harbins, das uberaus vielfaltige politische, wirtschaftliche und kulturelle Leben in dieser Stadt, hat bislang keine wissenschaftlichen Ansprüchen genugende Darstellung gefunden. Erinnerungen an das alte (russische) und eine Schilderung des modemen (chinesischen) Harbin enthält V.[P.] PETROV, Gorad na Sungari, Washington, D.C. 1984. Zum Schicksal der 'weißen' Emigration siehe P. BaLAKSIn, Final v Kitae, t. 1, San Francisco 1958, bes. S. 105-111. Aus sowjetischer Sicht SKARENKov (wie Anm. 2), S. 133144. Ober das kulturelle Leben berichten V.F. SALATKO-PETRISCE, "Russkie na Dal'nem Vostoke." In: V.F. Kovalevski, Zanubetnaja Rossija, Paris 1971, S. 324-332. N.[S.] ReZNIKova, "V russkom Charbine." In: Novyj Zumal, 172-173, 1988, S. 385-394. Ein detailliertes Bild des Alltagslebens der Harbiner Russen in den zwanziger und dreißiger Jahren zeichnet die heute in Moskau lebende Schriftstellerin N.I. Il'ina in ihrer "autobiographischen Prosa". N.I. IL'INA, Vozuraštenie, M. 1957. Dies., Sud'by, M. 1980. Dies., Dorogi i sud'by, M. 1985.

14 Ausführlich hierzu J.J. STEPHAN, The Russian Fascists. Tragedy and Farce in Exile 1925-1945. New York 1978. Dem Verf. gelingt es, nicht nur die politischen und sozialen Verhältnisse in Harbin wăhrend der zwanziger und dreiBiger Jahre anschaulich darzustellen, sondern auch ein eindrückliches Bild der Atmosphăre dieser Stadt zu zeichnen. Vgl. ferner E. OBfeRLANDER, The All-Russian Fascist Party." In: Joumal for Contemporary History, 1 (1966), 1, S. 158-173. Zum - einzigen bekannten - Versuch, Fedorov als Vordenker für die Ideologie des russischen Faschismus zu reklamieren, siehe unten Anm. 208.

15 Auch die Geschichte der Juristischen Fakultăt, die von 1920 bis 1937 bestand und eine Reihe angesehener Wissenschaftler aufwies - neben Ustrjalov und Gins ist v.a. V.A. Rjazanovskij als Spezialist für chinesisches und mongolisches Recht zu nennen -, verdiente eine ausführlichere Darstellung. Vgl. G.[K.] Gins, "Juriditeskij Fakul'tet v g. Charbine 1920-1930." In: Izv.Jur.Fak., 9, 1931, S. 308-314. DeRS. (wie Anm. 1), S. 337-361. KovaleVsKIJ (wie Anm. 13), S. 103-107. 
men. ${ }^{16} \mathrm{Zu}$ dieser Gruppe, deren zahlenmäßiger Anteil rasch wuchs, gehörte Setnickij. ${ }^{17}$ Er unterrichtete an der neu gegründeten wirtschaftswissenschaftlichen Abteilung, hielt Vorlesungen über Politökonomie, Wirtschaftsgeographie und Statistik, und betrieb Forschungen v.a. zu Fragen des chinesischen Außenhandels, wovon eine ansehnliche Reihe einschlägiger Veröffentlichungen zeugt. ${ }^{18}$

Setnickijs Hauptinteresse galt indessen der Verbreitung von Fedorovs Ideen. Aus Moskau hatte er Manuskripte mitgebracht, die unter den Bedingungen der sowjetischen Zensur nicht veröffentlicht werden konnten. ${ }^{19}$ Neben eigenen Arbeiten und solchen von Gorskij handelte es sich dabei vor allem um unveröffentlichte Schriften Fedorovs, die von Koževnikov und Peterson für den dritten Band der Filosofija obšcego dela vorbereitet worden waren. Im März 1926 unterrichtete Setnickij den Dekan der Juristischen Fakultät V.A. Rjazanovskij von seiner Absicht, einen (dritten) Band mit bislang unbekannten Schriften Fedorovs herauszubringen, und gab eine kurze Beschreibung der ihm vorliegenden Materialien. ${ }^{20}$ Der Großteil bestand demnach aus Briefen, die Fedorov zwischen 1890 und 1903 an Koževnikov und Peterson gerichtet hatte: sie enthielten Fedorovs Vorschläge für die Haager Friedenskonferenz (1899), Bemerkungen zu den Ereignissen in China (1900), zum Gottesdienst in der Karwoche, zum Kalender und zum "Zodiacus vitae"; ferner Briefe aus Turkestan über Turkestan und über den Kampf gegen die Natur sowie Bemerkungen zu den Abschriften der Manuskripte der Filosofija obšcego dela; schließlich zwei Aufsätze: über das Christentum in China und über die Frage Čto takoe dobro? Insgesamt, so Setnickij, lägen ihm etwa 300 Seiten Typoskripte vor, wovon er etwa 250 Seiten veröffentlichen wolle. Dabei dachte er an eine Auflage von 1000 Exemplaren. Auf seine diesbezügliche Anfrage bei dem Verleger und Buchhändler Telberg in Tsingtau erhielt Setnickij dann jedoch die enttäuschende Auskunft, daß bei realistischer Einschätzung des Marktes sich allenfalls 150 bis 200 Exemplare würden verkaufen lassen, weshalb eine Ausgabe der Werke Fedorovs nur möglich

16 Dies führte v.a. unter der Studentenschaft zur Spaltung in eine pro- und eine antisowjetische Fraktion; letztere bildete den Kern der 1925 gegründeten "Russischen Faschistischen Organisation", aus der 1931 die von K.V. Rodzaevskij geführte "Russische Faschistische Partei" hervorging. Ausführlich dazu STEPHAN (wie Anm. 14). - Unter Setnickijs Papieren, die heute im Fedorov-Archiv Prag aufbewahrt werden, finden sich auch bislang unbeachtete Hinweise auf die Aktivităten der Harbiner Faschisten, wie z.B. ein Unteil des Disziplinargerichts der Juristischen Fakultắt vom 11.4.1927 gegen Rodzaevskij; FAP 1, 342.

17 Setnickij lebte zusammen mit seiner Familie in Harbin als sowjetischer Staatsbürger, nicht als Füchtling oder Emigrant, wie gelegentlich behauptet wird. Siehe unten Anm. 192.

18 Siehe die Liste seiner Publikationen bei GiNs (wie Anm. 1), S. 353. Als Setnickijs wirtschaftswissenschaftliches Hauptwerk gilt die umfangreiche Arbeit Soevye boby na mirovom rynke, Charbin 1930. - Anfang der dreißiger Jahre unterrichtete Setnickij auch am Polytechnischen Institut in Harbin.

Mitteilung von O.N. Setnickaja, Moskau, 29.11.1980.

NA. Setnickij an VA. Rjazanovskij, Mărz 1926, sowie Aufzeichnungen Setnickijs; FAP I, 338. 
sei, wenn von dritter Seite Zuschüsse gegeben würden. ${ }^{21}$ Dies war nicht der Fall, und die bereits angekündigte 22 Veröffentlichung kam nicht zustande. Immerhin gelang es Setnickij in den folgenden Jahren, einen Teil der genannten Materialien nach und nach in der russischen Emigrantenpresse Westeuropas zu publizieren. $^{23}$

Geringere Probleme bereitete Setnickij die Veröffentlichung seiner eigenen Arbeiten über Fedorov, stand ihm hierfür doch das angesehene Publikationsorgan der Fakultät, die Izvestija Juridiceskogo Fakul'teta, zur Verfügung. Etwa jede zweite der zwischen 1926 und 1933 erschienenen acht Nummern enthielt einen längeren Beitrag, in dem Fedorovs Ideen diskutiert wurden. ${ }^{24}$

Eröffnet wurde die Reihe mit dem 1926 erschienenen Aufsatz Kapitalisticeskij strö v izobraženii N.F. Fedorova. ${ }^{25}$ Darin behandelt Setnickij Fedorovs Kritik der bürgerlich-kapitalistischen Gesellschaft, ihrer Wirtschaftsweise und Kultur, wie sie vor allem in der Schrift über die Pariser Weltausstellung von 1889 dargelegt ist: Ausgehend von Fedorovs Vorschlag, die Ausstellung in ein ständiges Museum der Industriegesellschaft zu verwandeln, erläutert Setnickij anhand einer genauen Beschreibung dieses Museums-Projekts ausführlich Fedorovs Bild einer Gesellschaft, die geprägt ist durch die "nicht drückende, aber verderbliche Herrschaft der Frauen" und durch eine hypertrophe Sexualität. Merkwürdig vage bleibt hingegen - in der Darstellung Setnickijs - Fedorovs Gegenentwurf: Da alle Probleme sich auf die "Frage von Leben und Tod" reduzierten, bestehe ihre Lösung im obšcee delo, der - wie Setnickij sehr abstrakt formuliert - "immanenten Wiederherstellung der durch die blinden Naturkräfte zerstörten Ganzheit [der gesamten Menschheit]. ${ }^{26}$

21 G. Telberg, Tsingtau, an N.A. Setnickij, Harbin, 11.6.1926; FAP I, 330.

22 Zum Beispiel in Izv Jur.Fak., 3, 1926, S. 9, 332.

23 Siehe unten Anm. 111, 112 und I: 2. Anm. 39. - Die Materialien - in verschiedenen Stufen redaktioneller Bearbeitung - befinden sich in FAP I, 320.

24 N.A. SETNICKU, "Kapitalistiðeskij stroj v izobraženii N.F. Fedorova." In: Izv.Jur.Fak., 3, 1926, S. 9-25. DeRs., "Russkie mysliteli o Kitae (V.S. Solov'ev i N.F. Fedorov)." Ebd., S. 191-222. DERS., "Eksploatacija (Orerk 1)." Ebd., 5, 1928, S. 215-257. DERS., "O konęnom ideale." Ebd., 7, 1929, S. 191-255. DERS., "SSSR, Kitaj i Japonija. (Nacal'nye puti reguljacii)." Ebd., 10, 1933, S. 187. 247. - Alle genannten Beitrăge Setnickijs sind auch als Sonderdrucke (ottiski) erschienen. AuBerdem veroffentlichte Setnickij in den Izv.Jur.Fak. Fedorovs Aufsatz "Cemu nautaet drevnej3ij christianskij pamjatnik v Kitae?" (ebd., 3, 1926, S. 223-229) sowie einen Gedenkartikel für Koževnikov (ebd., 4, 1927, S. 323-328). - Die Izv.Jur.Fak. erschienen zwischen 1925 und 1937 mit insgesamt 12 Nummern.

25 Siehe Anm. 24. Wieder abgedruckt 1928 in der Pariser Zeitschrift Versty; siehe unten Anm. 111. Einer Anmerkung zufolge handelt es sich um ein Kapitel einer großeren Arbeit mit dem Titel Eksploatacija ili reguljacija. Diese Arbeit ist nie erschienen. Weitere Teile daraus sind die später in den Izv.Jur.Fak veröffentlichten Aufsätze "Eksploatacija" und "SSSR, Kitaj i Japonija"; siehe Anm. 24. Siehe auch die Rezension von V.[K.] OBUCHOV in: Vselenskoe delo (wie Anm. 4), S. 201-203.

SETNICXu, "Kapitalistiteskij stroj..." (wie Anm. 24), S. 25. Zwar betonte Setnickij die praktische Orientierung der Fedorovschen Lehre, doch war er zugleich bestrebt, Fedorovs kühne Forde- 
In derselben Nummer der Izvestija veröffentlichte Setnickij noch einen Beitrag mit dem Titel Russkie mysliteli o Kitae, in dem er Äußerungen Fedorovs und Vladimir Solov'evs über China zusammenstellte; im Anhang dazu findet sich Fedorovs Aufsatz Čemu nauCaet drevnejSij christianskij pamjatnik v Kitae?27

Bereits zu Ostern 1926 hatte Setnickij seine gemeinsam mit Gorskij verfaßte Schrift SmertobožniČestvo auf eigene Kosten in Harbin drucken lassen. ${ }^{28}$ Einige Exemplare schickte er an Gorskij, mit dem er seit seiner Abreise aus Moskau in brieflicher Verbindung stand. ${ }^{29}$ Am 12 . Juli 1926 bestätigte Gorskij den Empfang und nannte weitere Adressaten. ${ }^{30}$ Setnickij ging nun daran, Smertobožnicestvo sowie Sonderdrucke seiner Aufsätze in alle Welt zu versenden. - Die Resonanz war freilich enttäuschend gering: Einige Bibliotheken schickten Empfangsbestätigungen oder förmliche Dankschreiben, ${ }^{31}$ die Emigrantenpresse vermerkte die Titel unter der Rubrik 'Eingegangene Bücher', und nur Smertobožnixestvo fand in Berdjaev schon bald einen Rezensenten. ${ }^{32}$

Wieder einmal zeigte es sich, daß die Bemühungen der Anhänger Fedorovs, seine Ideen bekannt zu machen, erfolglos blieben, da es ihnen an namhafter Unterstützung mangelte; und wieder versuchten sie, diese bei Gor'kij zu erlangen. ${ }^{33}$

rungen und Projekte - insbesondere die "Auferweckung aller Verstorbenen" - durch vage Umschreibungen zu 'entschărfen'.

27 Siehe Anm. 24. - Fcdorovs Aufsatz "Čemu naucaet..." war zuerst erschienen in: Russkij Archiv, 1901,4, S. $631-637$.

28 Siehe II: 4.1 .

2933 Briefe von Gorskij an Setnickij aus den Jahren 1925 bis 1928 befinden sich im Fedorov-Archiv Prag; FAP I, 328 (in Abschrift FAP I, 324). - Da die Korrespondenz durch die sowjetische Zensur offenbar stark behindert wurde - immer wieder ist davon die Rede, da $B$ angekündigte Briefe, beigelegte Zeitungsausschnitte oder Büchersendungen unterwegs 'verlorengegangen' seien -, enthalten die langen, schwer lesbaren Briefe Gorskijs zahlreiche verschlüsselte Hinweise, Anspielungen und Abkürzungen. Unterzeichnet sind sie mit "Ostromirov", "Gornostaev" oder "Jachontov" oder den entsprechenden Initialen.

30 Ostromirov [A.K. Gorskij], Moskau, an N.A. Setnickij, Harbin, 29.6./12.7.1926; FAP I, 328.

31 Zu den Emprängern der von Setnickij auch in den folgenden Jahren gratis versandten Schriften über Fedorov zählten u.a. die New York Public Library, das British Museum und die Bibliothèque Nationale sowie zahlreiche groBe Bibliotheken in der Sowjetunion. Sogar ein Dankschreiben des Vatikans (in lateinischer Sprache, unterzeichnet von Kardinal Pacelli) findet sich unter Setnickijs Papieren; FAP I, 330.

32 Siehe II: 4.1. Anm. 10, 64. - Auch der Buchhändler und Verleger Telberg in Tsingtau, der Setnickijs Publikationen teils auf eigene Rechnung, teils in Kommission auch nach Europa vertrieb, berichtete immer wieder über mangelndes Interesse und schleppenden Absatz. Mehrere Schreiben an Setnickij aus den Jahren 1926 und 1927; FAP I, 330.

33 Vgl. zum Folgenden $M$. HAGEMEISTER, Neue Materialien zur Wirkungsgeschichte N.F. Fedorovs: M. Gor'kij und die Anhänger Fedorovs in Moskau und Harbin." In: Studia Slavica. Beiträge zum VIII. Intemationalen Slawistenkongre $\beta$ in Zagreb 1978. Gießen 1981, S. 219-244. 
Am 4. März 1926 wandte sich Sergej Grigor'ev, ein mit Gorskij und Setnickij befreundeter Schriftsteller, der in jener Zeit in Sergiev Posad wohnte, mit einem Brief an Gor'kij, in dem er ihn - am Ende und fast beiläufig - an sein einstiges Interesse für Fedorov erinnerte:

(...) Vor etwa drei, vier Jahren sagte mir die Witwe Koževnikovs, daB Sie, Aleksej Maksimoviž, sich für den literarischen Nachlaß N.F. Fedorovs interessiert hătten. Ich halte das für wahrscheinlich. Wenn Sie (als Schriftsteller) niemals mit dem Tod geliebäugelt haben, steht Ihnen der philosophische Bolschewismus Fedorovs und seine Einstellung zum Tode năher als Lev Tolstojs Angst vor dem Tode. $(. . .)^{34}$

Doch die erhoffte Reaktion blieb aus; Gor'kij antwortete nur kurz (15.3.1926):

(...) N.F. Fedorov habe ich einmal gesehen. Seine Bücher habe ich natürlich gelesen. Sie haben mir nicht gefallen. $(. . .)^{35}$

Nun wandte sich Setnickij selbst an Gor'kij. Im Sommer 1926 schickte er Sonderdrucke seiner Aufsätze Kapitalisticeskij stroj... und Russkie mysliteli... sowie Exemplare von SmertobožniCestvo nach Sorrent.

Auf Bitten einiger meiner Freunde, die in Moskau leben, und insbesondere auf Weisung von $\mathrm{Al}$. Konst. Gorskij (Gornostaev) schicke ich Ihnen die Broschüre Smentobožnitestvo, die vielleicht für Sie interessant sein könnte.

Er erinnerte Gor'kij an die im Manuskript vorliegende Biographie Fedorovs, die 1923 für die Beseda verfaßt, jedoch nicht gedruckt worden war, ${ }^{37}$ berichtete von seinem Vorhaben, einen Teil der unveröffentlichten Materialien des dritten Bandes der Filosofija obšcego dela herauszubringen, ${ }^{38}$ und äußerte den Wunsch, Gor'kij möge zum 100. Geburtstag Fedorovs (1928) etwas über ihn schreiben. Um Gor'kijs Interesse zu wecken, erwähnte Setnickij, daß sich unter den unveröffentlichten Schriften Fedorovs auch Äußerungen über Gor'kij befänden.

34 Literatumoe nasledstvo, t. 70 [Gor'kij i sovetskie pisateli. Neizdannaja perepiska.], M. 1963, S. 134; Hervorhebung im Orig. - Sergej Timofeevic Grigor'ev (1875-1953) schrieb u.a. mehrere wissenschaftlich-phantastische Erzăhlungen. 1926 erschien seine utopische povest' Gibel' Britanii, die auch Gor'kijs Beifall fand. Der darin enthaltene Gedanke, den "Untergang Britanniens" als des Hortes der Reaktion mit wissenschaftlich-technischen Mitteln herbeizuführen, geht moglicherweise auf Fedorov zurück. - Zu Grigor'evs Freundschaft mit den Moskauer FedorovAnhängern Gorskij und Setnickij - briefliche Mitteilung von O.N. Setnickaja, Moskau, 19.1.1981. Im Fedorov-Archiv Prag befindet sich ein Brief von Grigor'ev an N.A. Setnickij aus dem Jahre 1927 sowie ein Exemplar von Gibel' Britanii; FAP I, 328, 332.

35 Gor'kij, Neapel, an Grigor'ev, 15.3.1926. In: Literatumoe nasledstvo (wie Anm. 34), S. 136.

36 Setnickij, Harbin, an Gor'kij, Sorrent, Sommer 1926; Gor'kij-Archiv, IMLI, KG-P-71-4-2; nach einer Abschrift in Moskauer Privatbesitz.

37 Ebd. - Siehe auch II: 4.1. Anm. 36.

38 Ebd. - Ihm liege, so Setnickij, der dritte Teil dessen vor, was von Koževnikov und Peterson zur Verơffentlichung im 3. Band der Filosofija obšzego dela vorgesehen gewesen sei. 
Schließlich bat er Gor'kij, ein Exemplar von Smertobožnicestvo an Vjaceslav Ivanov in Rom zu schicken. 39

Gor'kij antwortete höflich (31.8.1926), ${ }^{40}$ wenn auch zurückhaltend, dankte für die Sonderdrucke, teilte die Adresse von Ivanov mit und meinte, was die Biographie Fedorovs betraf,

... selbstverstăndlich sind Sie vollig im Recht, über ihr Manuskript zu verfügen, wie es Ihnen beliebt; mir bleibt nur, Sie um Entschuldigung zu bitten, daB ich Ihnen Mühe bereitet habe, doch konnte ich Ihre wertvolle Arbeit nicht verwenden. Das ist übrigens nicht allein meine Schuld.

Ausweichend antwortete er auch auf die Bitte, über Fedorov zu schreiben:

Anläßlich des Jubilăums von N.F. Fedorov wird es mir kaum gelingen, etwas zu schreiben. Doch wird, wie es scheint, vom Herbst an in Petersburg eine Zeitschrift herauskommen, in der ich vielleicht eine Notiz veroffentlichen werde, was ich sehr gern tun würde.

Mit Interesse reagierte Gor'kij hingegen auf die Bemerkung, Fedorov habe sich über ihn geäußert, und er bat Setnickij, ihm das Zitat zugänglich zu machen.

Am 27. September 1926 antwortete Setnickij, ${ }^{41}$ er sei noch mit dem Kopieren der Fedorovschen Manuskripte beschäftigt, doch wolle er den Auszug aus einem Brief Fedorovs, in dem Gor'kij erwähnt werde, in den nächsten Tagen abschicken. ${ }^{42}$ Die Postkarte, mit der diese Nachricht erfolgte, zeigt Fedorovs

39 Ebd. - Die Korrespondenz zwischen Setnickij und Gor'kij dauerte bis 1934. Siehe auch Literatumoe nasledstro (wie Anm. 34), S. 589 Anm. 1. In diesem Zeitraum lassen sich 9 Schreiben Setnickijs (davon eines nicht abgeschickt) und zwei Schreiben Gor'kijs nachweisen. Ausführlich HAgemeister (wie Anm. 33). Zu Gor'kijs Briefen auch M. HeŘman, "Dva neznámé dopisy Maxima Gorkêho (A.M. Pěskova)." In: Sbornik Národntho muzea v Praze, ř. C, sv. 8 (1963), 4, S. 221-224.

40 A. Peskor (A.M. Gor'kij), Sorrent, an N.A. Setnickij, Harbin, 31.8.1926. Original in FAP I, 328. Russ. Text und Abb. dieses Briefes bei HAGEMEIster (wie Anm. 33), S. 224, 242 . Vgl. auch Heřman (wie Anm. 39). Laut S.I. Suchich, "M. Gor'kij i N.F. Fedorov." In: Russkaja Lireratura, 1980, 1, S. 161, ist dieser Brief (in Abschrift?) auch im Gor'kij-Archiv, IMLI, PG-rl39-8-2, vorhanden.

41 Setnickij, Harbin, an Gor'kij, Sorrent, 29.9.1926; Gor'kij-Archiv, IMLI, KG-P-71-4-1; nach einer Abschrift in Moskauer Privatbesitz.

42 Die versprochene Abschrift hat Gor'kij erhalten: Am 16.3.1927 dankt er Setnickij für den "sehr interessanten Brief" Fedorovs (siehe unten Anm. 55). Nach Suchich handelt es sich dabei um einen Brief aus dem Jahre 1900 an VA. Posse, in dem Fedorov Gor'kijs "Widerwillen gegen den Tod als dem tatsăchlichen Bösen" hervorhebt und dies mit einem Zitat aus Gor'kijs Vagabundenerzăhlung Prochodimec (1898) belegt. SuCHCH (wie Anm. 40), S. 164f.; der Brief befindet sich laut Suchich im Gor'kij-Archiv, IMLI, Ptl-16-8/1.

Suchichs Angaben über den Inhalt dieses Schreibens decken sich vollstăndig mit dem Inhalt eines Briefes von Fedorov an V.A. Koževnikov vom 3.7.1900, den Setnickij spăter in der Zeitung Evrazija, 24 (4.5.1929), S. 8, veroffentlichte. Darin zitiert Fedorov einen kurzen Auszug aus Prochodimec, in dem das Streben eines jurodivyj nach Selbstvervollkommnung bespottelt wird (Fedorov vermutet dahinter eine Kritik an Tolstoj), um dann den Autor gegen Vonwürfe zu verteidigen, die der Kritiker M.A. Protopopov wegen dieser Szene erhoben hatte. Ihm scheine, so Fedorov, daB bei Gorkaj der Widerwille gegen das tatsächliche Böse (den Tod) sehr viel stärker [sei] als die Liebe zum scheinbar Guten (Macht und Reichtum)." Ebd.; Hervorhebungen 
Porträt nach dem Gemälde von L.O. Pasternak; - Setnickij hatte sie in großer Auflage zu Werbezwecken drucken lassen. ${ }^{43}$

Durch Setnickijs Initiative wurde Gor'kijs Interesse offenbar von neuem geweckt. In den folgenden Monaten finden sich in Gor'kijs Briefen an sowjetische Schriftsteller immer wieder Hinweise auf Fedorov und auf die Aktivitäten seiner Anhänger. ${ }^{44}$

Nur wenige Tage nach seinem Schreiben an Setnickij fragte Gor'kij in einem Brief an Ol'ga For' (5.9.1926):

(...) Kennen Sie die Filosofija obšrego dela von N.F. Fedorov? Es scheint so, ja? In Harbin erscheint jetzt der 3. Band seiner Schriften. (...)

Und ein Brief an den Literaturwissenschaftler Il'ja Gruzdev (13.9.1926) beweist, daß Gor'kij Setnickijs Aufsatz Russkie mysliteli.. gelesen hat:

(...) Seltsam, daß einige seiner [gemeint: S.G. Somov; M.H.] Ideen - zum Beispiel über China - mit den Ideen N.F. Fedorovs übereinstimmten. $(. . .)^{46}$

Unter dem Eindruck von Setnickijs Schrift Kapitalisticeskij stroj... schrieb Gor'kij (17.10.1926) an Michail Prišin:

(...) Da gab es bei uns einen höchst originellen Denker, N.F. Fedorov; der hat nachgewiesen, daß nicht nur die gesamie Industrie, sondern auch die gesamte Zivilisation das Werk der Frau sei. "Die Frau und die von ihr provozierte sexuelle Kraft" schafft diese Ordnung, die "verweichlicht und demoralisiert und zu Dekadenz und zum Untergang führt". Die Herrschaft der Frau nannte Fed[orov] "nicht drückend, aber verderblich", und die soziale Welt teilte er nicht in Reiche und Arme, sondern in Gelehrte und Ungelehrte. "Diese Aufspaltung", sagte er, "stellt das größte Übel dar, ein unvergleichlich größeres als das Auseinanderfallen der Menschen in Reiche und Arme". Ein sehr interessanter alter Mann. Wertvoll und nahe ist mir seine Predigt eines "aktiven" Verhälınisses zum Leben. $(\ldots)^{47}$

Die zitierten Äußerungen Fedorovs konnte Gor'kij der genannten Schrift Setnickijs entnehmen. ${ }^{48}$

Ende Oktober 1926 antwortete Prišvin:

im Orig. - Es ist sehr wahrscheinlich, daß es sich bei dem von Suchich als Adressaten genannten V[ladimir] A[leksandrovit] Posse (1864-1940, ein linksgerichteter Petersburger Journalist, Bekannter Gor'kijs, ging 1901 ins Ausland) um eine Verwechslung mit Vladimir Aleksandrovic Koževnikow handelt, der von Setnickij 1927 veröffentlichte Brief also mit dem im Gor'kij-Archiv aufbewahrten identisch ist.

43 Siehe die nebenstehende Abb.

44 Siehe zum folgenden HAGEMEISTER (wie Anm. 33), S. 225-229.

45 Gor'kij an O.D. Forక, 5.9.1926. In: Literatumoe nasledstvo (wie Anm. 34), S. 584.

46 Gor'kij an IA. Gruzdev, 13.9.1926. In: Archiv A.M. Gor'kogo, t. 11 [Perepiska A.M. Gor'kogo s IA. Gruzdevym], M. 1966, S. 82.

47 Gor'kij an M.M. Prišin, 17.10.1926. In: Literatumoe nasledstvo (wie Anm. 34), S. 335.

48 SETNICKU, "Kapitalistiteskij stroj..." (wie Anm. 24); dort, in der Reihenfolge der Zitate Gor'kijs, S. 22, 14, 19. 


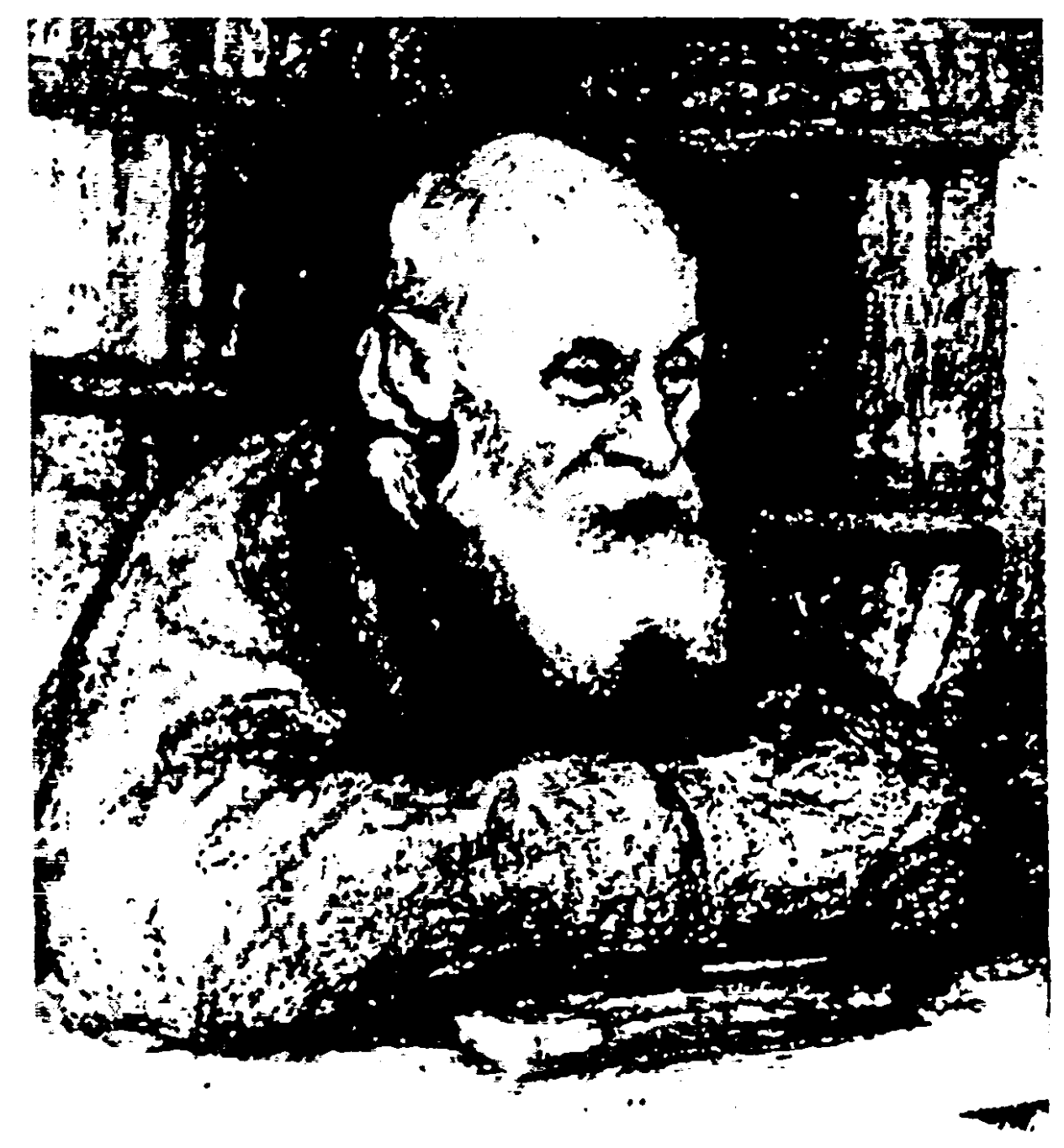

Николай Федорович ФЕДОРОВ $1823-+1903$.

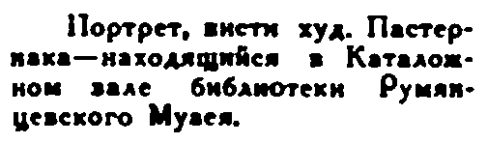
$=$

Первым делом вопрос-кто өтот мысаитель, мысли „которото Вы передали? Если мохете, то сообщите его на- стоящее имя. Он слишком заннтересовая меня. По крайней "мере, сообщите хоть что нибудь о нем подробнее. как о - лице... Затем скажу, что в сушности совершенно согласен „с әтими мыслями. Их я прочел как 6 а аа свон“.

(Hs виesme Ф. M. Aocroenckoro H. П. Петерсоny-i874 roA). 
Von Fedorov war ich früher selbst einmal begeistert, doch dann bin ich abgekühlt, und diese Abkühlung hing zusammen mit einem Umstand, den ich von jemandem erfuhr, daß nămlich Fedorov hinsichtlich seiner Lebensweise ein richtiger Asket gewesen ist, Läuse hatte er in rauhen Mengen, und geschlafen hat er auf Brettern, und dabei arbeitete er im Rumjancev-Museum. Im "Einsiedler" sind Läuse durchaus angebracht (...), aber im Museum..., so wurde er mir zuwider (obschon ein verlauster Junggeselle angenehmer ist als ein übermaßig sauberer), und seitdem betrachte ich Fedorov mit schiefem Blick (ich durchlebe innerlich die "Aufenweckung der Văter"). Ich kenne auch seine Meinung über die Frau und rege mich bis heute darüber auf. Sie ist mir (unbewuBt) in die "Schuhe" [eine Erzăhlung Prišvins; M.H.] eingeflossen... (... $)^{49}$

\section{Am 20. September 1926 schrieb Ol'ga For $§$ an Gor'kij:}

(...) Darüber läßt sich nicht mit zwei Worten sprechen, auch nicht über Fedorov, wobei es mich wundert, daß Sie sich seiner erinnert haben. Soeben lese ich seinen 2. Band (die anderen kenne ich nicht). Es stehen da inakzeptable Dinge, doch gibt es dafür etwas so Erstaunliches wie das Leben, etwas, das einem bei VI. Solov'ev nio begegnet. Dieser ist neben Fedorov ein hochgebildeter Führer durch die "heiligen Stătten", ganz und gar kein Teilhaber und Entdecker der schopferischen Kräfte, die von unserem AlltagsbewuBtsein noch nicht erkannt worden sind. Deshalb beeindruckt das Ungereimte Fed[orovs] mehr als das Ausgeklügelte Solov'evs. Falls es Sie interessiert, werde ich ausführlicher darüber schreiben. $(. . .)^{50}$

49 M.M. Prišvin an Gor'kij, Ende Oktober 1926. In: Literatumoe nasledstvo (wie Anm. 34), S. 336. - S.G. Semenova hat den Versuch unternommen, den unterschwelligen EinfluB der "Fedorovschen Ideenwelt" in Prišvins Werk, v.a. in den philosophischen Aphorismen und Miniaturen seiner spăten autobiographischen Prosa (Glaza zemli, Nezabudki) nachzuweisen. S.G. SEME. NOVA, "'Serdečnaja mysl" M. Prišvina." In: Volga, 1980, 3, S. 162-170. Die angeführten Zitate zumeist aus den vierziger Jahren - lassen denn auch eine geistige Verwandtschaft erkennen; sie geben jedoch keinerlei Aufschluß darüber, wann und in welchem Umfang sich Priłvin mit $\mathrm{Fe}$ dorovs Werk beschäftigt hat. Die einzige bislang bekannte Äußerung Prisvins zu Fedorov - in dem zitierten Brief an Gor'kij, Ende Oktober 1926 - wird von Semenova stark verkürzt, das Negative fast gănzlich unterschlagend, wiedergegeben. Ebd., S. 163. Vgl. auch DIEs., Tvor testvo žizni." In: Nas Sovremennik, 1981, 6, S. 184. Nach Ansicht des Dichters und Philosophen Ju.V. Linnik verbindet Prišvin und Fedorov eine synthetische Weltauffassung, das Streben nach Vereinigung von Wissenschaft (Logik) und Kunst (Intuition) sowie der beiden eigene Kosmismus. JU.V. LINNIK, "Kosmos Michaila Prišvina." In: Sever, 1980, 10, S. 109-114. Immer hăufiger wird Prišvins Werk mit den "ethisch-philosophischen Konzeptionen" des in jüngster Zeit modisch gewordenen russischen Kosmismus in Verbindung gebracht, als dessen Vertreter, neben Vernadskij, Čiževskij und Ciolkovskij, auch Fedorov und Losev (!) genannt werden. Siehe z.B. V. FATEEV, "Chudožnik sveta." In: NaŠ Sovremennik, 1988, 3, S. 184.

Aufschluß über eine Beschäftigung Prišvins mit Fedorovs Werk könnten Prišvins fast lebenslange Tagebuchaufzeichnungen geben, von denen bisher jedoch nur ein kleiner Teil veröffentlicht worden ist. Aus ihnen geht hervor, daB Prišin sich in den späten zwanziger Jahren für (natur)philosophische Arbeiten russischer Autoren wie Florenskij, Losev und Vernadskij interessierte (Prišvins Frau Valerija Dmitrievna [1899-1979] war eine Schülerin Losevs). Prišvin lebte damals in Sergiev Posad, wo er hăufig mit Sergej Grigor'ev zusammentraf. In diese Zeit făllt auch seine Bekanntschaft mit A.K. Gorskij; siehe die Tagebuchaufzeichnungen vom 28.7. und 4.10.1928. M.[M.] PriSvin, "Zapisi o tvortestve." In: Kontekst 1974, M. 1975, S. 344f., $348 f$. Prišvin beabsichtigte, im dritten (unausgeführt gebliebenen) Teil seines autobiographischen Romans Kaseeva cep' unter den für die Epoche charakteristischen Kulturschaffenden "unbedingt auch ... Fedorovs Schüler und bewuBten Nachfolger (Gorskij) vorzustellen." Tagebuchaufzeichnung vom 30.9.1928; zitiert nach SEMENOVA, "Serdežnaja mysl"...", a.a.O., S. 164.

50 O.D. Forš an Gor'kij, 20.9.1926. In: Literatumoe nasledstvo (wie Anm. 34), S. 588; Hervorhebung im Orig. - Ol'ga Forక̌ hatte - insbesondere in den Jahren vor dem Ersten Weltkrieg ein starkes Interesse für die Lehre Solov'evs gezeigt und sich auch mit Buddhismus, Theoso- 


\section{Gor'kij war interessiert und antwortete am 27. September 1926:}

... ich wăre Ihnen sehr dankbar, wenn Sie eine freie Stunde fănden, um mir Ihre Gedanken über Fedorov mitzuteilen. Der erste Band seiner Schriften ist eine Rarităt; er wurde vor etwa 20 Jahren in Vernyj herausgegeben. Der dritte [Band] wird von Verehrern Fedorovs in Harbin zur Publikation vorbereitet; an ihrer Spitze steht ein gewisser N.A. Setnickij. Diese Gruppe [!] hat unter dem Titel SmenobożniZestvo ein anonymes Büchlein von 80 Seiten veröffentlicht; Ziel dieses Büchleins ist eine Reform der Orthodoxie im Geiste der "Aktivităt". Der Gedankengang lăßi deutlich den EinfluB Fed[orovs] erkennen und meines Erachtens auch etwas vom Heidnischen V.V. Rozanovs. Im kritischen Teil des Büchleins steht nicht wenig Interessantes, doch leider wird der "neue Glaube" mit einem fünffachen Bannfluch gegen die Andersgläubigen beschlossen. Das klingt so:

1. Jeden, der die Teilnahme des Menschen am göttlichen Werk einschrănkt, treffe der Bann.

2. Jeden, der sich vor dem Tod ais solchem beugt und in ihm keine Schande erblickt, treffe der Bann.

3. Wer von der Mühe und dem Kampf bei der Umgestaltung seines Leibes ablăßt, den treffe der Bann.

4. Wer den Tod rechtfertigt, anstatt ihn zu bekămpfen;

5. wer nicht zum aktiven Kampf strebt, sei ebenfalls verflucht.

Das hat schon etwas vom Protopopen Avvakum und vom vemünftigen Fanatismus und ist deshalb für mich unannehmbar. Doch insgesamt ist es als ein Zeichen des nicht erloschenen Denkens mit dem Herzen (serdelnaja mysl') außerordentlich interessant und viel wertvoller als die blutarmen Gedanken des Fürsten Trubeckoj über das "Eurasiertum", Gedanken, die ebenfalls von Fedorov entlehnt sind, was der Fürst und seine Genossen verschweigen. (.... $)^{51}$

In ihrem Brief an Gor'kij vom 3. November 1926 legte Ol'ga Forš offenbar ausführlich ihre Gedanken zu Fedorov und zu der Schrift seiner Anhänger dar; 52

phie, Gnosis und Okkultismus beschăftigt. Siehe A.V. TAMARCENKo, Ol'ga For', M.-L. 1966, S. $31-42,47-49$.

51 Gor'kij an O.D. Forక̌, 13.11.1926. In: Lireratumoe nasledstwo (wie Anm. 34), S. 588f.; Hervorhebungen im Orig. - Scharfsichtig und erstaunlich früh erkannte Gor'kij die Verwandtschaft zwischen der Lehre der Eurasier und Ideen Fedorovs - wenn auch zunächst nicht infolge einer 'Entlehnung', sondern aufgrund gemeinsamer Ursprünge. Erst gegen Ende des Jahres 1928 berief sich die linke, prosowjetische Fraktion der Eurasier, die "Bewegung von Clamart", ausdrücklich auf die Lehre Fedorovs in der Hoffnung, sich auf dieser Basis mit den Marxisten arrangieren und in der Sowjetunion legal tătig werden zu können. Da aber war es N.S. Trubeckoj, der das Eurasiertum mit den Lehren sowohl von Marx wie von Fedorov für unvereinbar erklärte und sich deshalb von der Bewegung, die er selbst initiiert hatte, trennte. Ausführlich dazu II: 4.3.1.

Zu Smenoboznitestuo ist noch eine weitere Äußerung Gor'kijs erhalten (undatierte Aufzeichnung im Gor'kij-Archiv, IMLI): "Ein interessanter Versuch, die 'Orthodoxie' monistisch aufzufassen. Die Kapitel IV-V kőnnen als Beweis für die Tatsache der Rückständigkeit der Theologie und Metaphysik dienen, d.h. nicht einmal der Rückstăndigkeit, sondern des Nachfolgens auf den Wegen der experimentellen Wissenschaft. Denn die Idee der Unsterblichkeit des Leibes ist offensichtlich wissenschaftlicher Herkunft und wurde meines Erachtens in dieser Form hervorgerufen durch die Ideen Mečnikovs und Metal'nikovs und durch die Arbeiten von Steinach, Voronov usw. Verschweigen der Trinităt Gottes." Literatumoe nasledstvo ('vie Anm. 34), S. 591 Anm. 1.

52 Unveröffentlichter Brief. Siehe die Angabe in Literatumoe nasledstvo (wie Anm. 34), S. 591 Anm. 1. 
freilich, so fügte sie hinzu, werde es einem "von Fedorov ... irgendwie übel, wie wenn man Chloroform einatme". 53

Gor'kij antwortete am 13. November 1926:

(...) Alles, was Sie über die "Smertobožcy" gesagt haben, ist meines Erachtens zweifellos richtig; richtig ist auch der Hinweis, daß es einem von Fedorov "übel wird" wie von Chloroform. Es stimmt, daß er ein höchst origineller Denker ist, doch hasse ich seine Sicht der Frau, eine kirchliche Sicht, die er so formuliert hat: Kultur ist das Ergebnis der Herrschaft der Frauen, die "nicht drückend, aber verderblich" ist. Ich denke darüber anders, kurz gesagt so: Die Menschheit muB unbedingt zum Matriarchat zurückkehren, der Mann hat seine Rolle ausgespielt. Leider kann ich Ihnen nicht die Harbiner Broschüre der Anhänger Fedorovs schicken, doch habe [!] ich diesen geschrieben, da B sie sie Ihnen schicken. Die Broschüre ist bei Danzas. ${ }^{54}$

Am 16. März 1927 wandte sich Gor'kij mit einigen wenigen Zeilen an Setnickij: Er dankte für eine "Broschüre N.F. Fedorovs" und für Fedorovs "sehr interessanten Brief" (gemeint war das Schreiben aus dem Jahre 1900 an V.A. Koževnikov [Posse?], in dem Fedorov sich über Gor'kij äußert) und bat Setnickij, ein Exemplar von Smertobožnicestvo an die Leningrader Adresse von Ol'ga Forš zu schicken. 55

Setnickij hat die Bitte umgehend erfüllt, was er Gor'kij am 5. April 1927 mitteilte; er hoffe, so Setnickij, daß die Sendung Ol'ga Forš erreichen werde, da seine Versuche, etwas nach Moskau oder Leningrad zu schicken, gewöhnlich scheiterten. $^{56}$

In diesem Falle war Setnickijs Sorge unbegründet, wie aus einem Brief von Ol'ga Forš an Gor'kij vom 2. Juni 1927 hervorgeht:

[Mein] Sohn schrieb mir, daß nach meiner Abreise [nach Paris; M.H.] jene Broschüre aus Harbin eingetroffen sei, die Sie für mich bestellt hatten. Vielen Dank. Fedorovs Ideen sche ich in den jüngsten Arbeiten unserer russischen rel[igiösen] Philosophen, wenn auch vereinfacht, verkümmert. ${ }^{37}$

53 Ebd.

54 Gor'kij an O.D. Fors, 13.11.1926. In: Literatumoe nasledstvo (wie Anm. 34), S. 590. Gor'kijs langjăhrige Bekannte Julija Nikolaevna Danzas (1879-1942), Religionswissenschaftlerin, Historikerin, beschäftigte sich mit Theosophie und Freimaurertum, verfaßte ein grundlegendes Werk über die Gnosis ( $V$ poiskach boťestva, SPb. 1913); begrüBte die Revolution und erhielt eine Professur für Religionskritik. Anfang der zwanziger Jahre Vorträge an der Petrograder Vol'fila; Konversion zum Katholizismus. 1923 Verhaftung, Lagerhaft. 1929 (oder 1932) Emigration nach Italien. - Ob und auf welchem Wege die von Gor'kij erwăhnte "Harbiner Broschüre" (Smerroboznicestvo) an Danzas gelangte, die sich damals im Lager auf den Soloveckij-Inseln befand, läBt sich nicht feststellen; vielleicht durch die Vermittlung von E.P. Peskova (1876-1965), der ersten Frau Gor'kijs und Vorsitzenden des Politischen Roten Kreuzes.

55 A. Peskov (Gor'kij), Sorrent, an N.A. Setnickij, Harbin, 16.3.1927. - Original im FAP I, 328. Russ. Text und Abb. dieses Briefes bei HAgemeister (wie Anm. 33), S. 228, 243. Vgl. auch Heřman (wie Anm. 39). Laut SUCHICH (wie Anm. 40), S. 161, 164, ist dieser Brief (in Abschrift?) auch im Gor'kij-Archiv, IMLI, PG-rl-39-8-3, vorhanden.

56 Setnickij, Harbin, an Gor'kij, Sorrent, 5.4.1927; Gor'kij-Archiv, IMLI, KG-P-71-4-4; nach einer Abschrift in Moskauer Privatbesitz.

57 O.D. Forక̌, Paris, an Gor'kij, Sorrent, 2.6.1927. In: Literatumoe nasledstvo (wie Anm. 34), S. 396. 


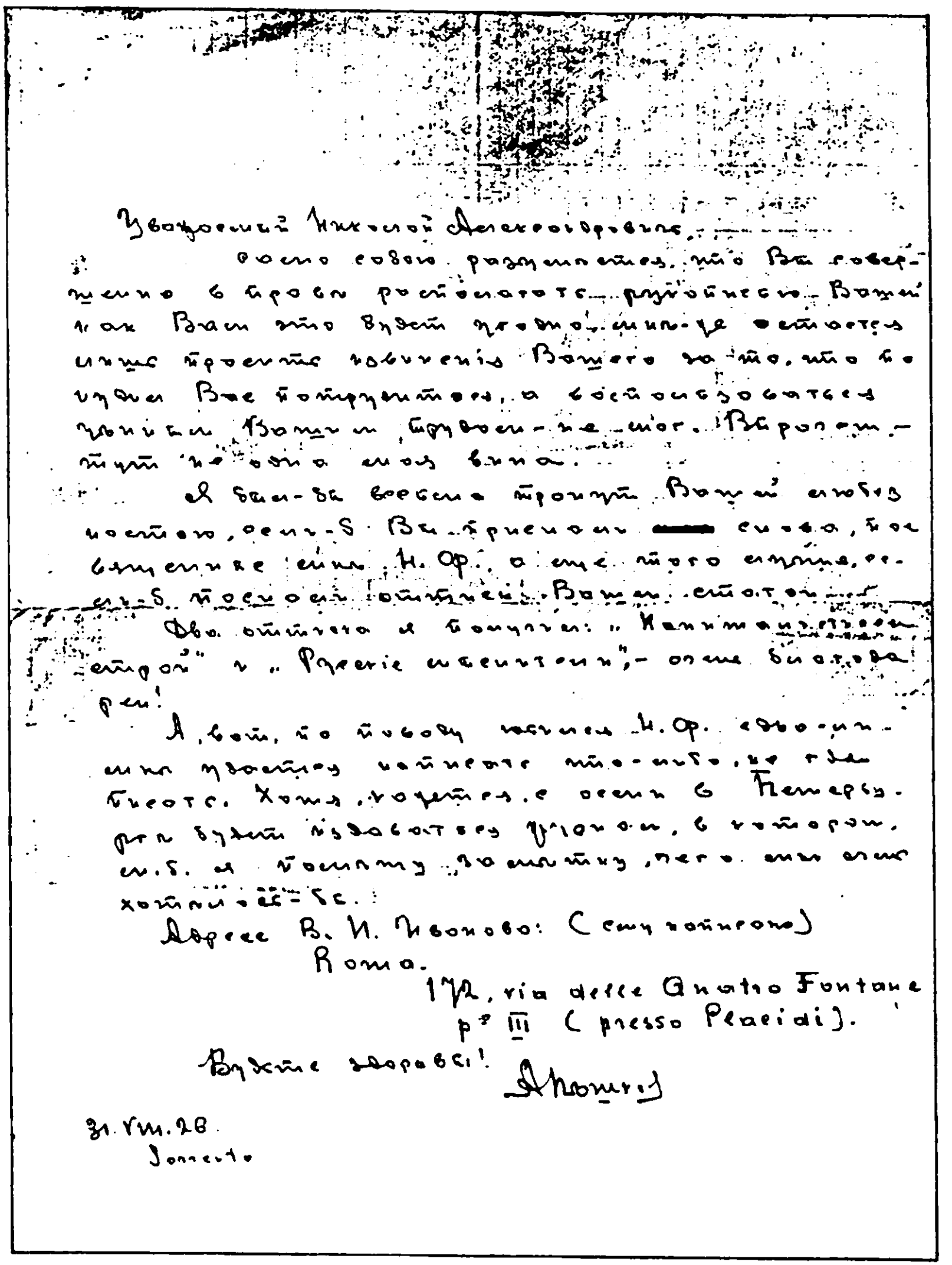

Autograph des Briefes von M. Gor'kij an N.A. Setnickij vom 31.8.1926.

Fedorov-Archiv, Prag (1, 328). 


\subsubsection{Setnickij und Gorskaj}

Bei seinen Bemühungen, Fedorovs Ideen von Harbin aus zu verbreiten, stand Setnickij - wie aus den im Prager Archiv erhaltenen Briefen hervorgeht - mit den Moskauer Fedorov-Anhängern Mironovič-Kuznecova, Murav'ev und vor allem mit Gorskij in Verbindung. 58

Über Gorskijs Tätigkeit in jenen Jahren ist nur sehr wenig bekannt. Er lebte zurückgezogen im Dorf Bogorodskoe am nordöstlichen Stadtrand von Moskau in äußerst bescheidenen Verhältnissen und widmete sich, während seine Frau als Musikerin für den Unterhalt sorgte, seinen Studien, in deren Mittelpunkt Fedorovs Leben und Werk standen. ${ }^{59}$ In der zweiten Hälfte der zwanziger Jahre trat Gorskij einige Male bei Veranstaltungen der G.A.Ch.N. (Gosudarstvennaja akademija chudožestvennych nauk) in Erscheinung ${ }^{60}$ - offenbar war er eine Zeitlang Mitarbeiter der Literatursektion, die von dem Schriftsteller und ehemaligen 'mystischen Anarchisten' G.I. Čulkov geleitet wurde: ${ }^{61} 1925$ sprach Gorskij vor der "Moskauer Vereinigung zur Erforschung des Werks von A. Blok", einer Abteilung der G.A.Ch.N., über Bloks Gedichtzyklus Meri, ${ }^{62}$ Ende

58 Siehe oben Anm. 29. Briefe von Mironovic-Kuznecova und Murav'ev im FAP I, 329. - Setnickij hielt sich wăhrend einer Dienstreise nach Westeuropa (Hamburg, Den Haag, Paris) im Mai und August 1928 auch in Moskau auf, wo er mit den dortigen Fedorov-Anhängern zusammentraf. Siche FAP I, 324.

59 O.N. Setnickana, Aleksandr Konstantinovic Gorskij. Biografija. Ms. [Masch.], Bl. 40. Private Mitteilungen. - Gorskij soll Mitglied des Artels Kooperativnaja pecat' gewesen sein, doch ist darüber nichts Năheres bekannt.

Gorskijs umfangreicher schriftlicher NachlaB aus den zwanziger und dreißiger Jahren befindet sich heute in mindestens vier privaten Archiven in und in der Năhe von Moskau. Drei der Archive waren mir zugănglich, wobei ich jedoch nur einen (kleinen?) Teil der dort enthaltenen Materialien einsehen konnte (unter Bedingungen zudem, die ein gründliches Studium nur selten gestatteten). Hinzu kommen noch jene Briefe und Manuskripte, die sich im FedorovArchiv Prag befinden und ohne Einschrănkungen ausgewertet werden konnten. - Aus den mir zugänglichen Schriften Gorskijs sowie den Schilderungen seiner Persönlichkeit entsteht das Bild eines Sonderlings mit sektiererischen Zügen. Beeindruckend bleiben Gorskijs moralische Integrităt und die selbstlose Hingabe, mit der er seine Mission betrieb, hingegen werden seine intellektuelle Bedeutung wie auch sein dichterisches Talent von seinen Verehrem und Nachlaßbewahrem offensichtlich stark überschätzt.

60 Aufgabe dieser 1921 gegründeten Institution war eine im weitesten Sinne synthetische Erforschung der Künste. Zu den prominentesten Mitarbeitern gehörten der Maler V.V. Kandinskij, der Literatur- und Kunstsoziologe V.M. Friče, der Kunsthistoriker und Bücherkundler A.A. Sidorov und der Literaturwissenschaftler M.O. Geršnzon. Umstritten war v.a. die philosophische Abteilung, die unter der Leitung des Husserlianers G.G. Spet stand (von 1923 bis 1929 auch Vizepräsident der GA.Ch.N.); prominentester Mitarbeiter dieser Abteilung, die sich um die Erarbeitung einer synthetischen Kunstphilosophie bemühte, war der in der Tradition von Platon, Hegel und Husserl stehende A.F. Losev, der auch als Musikologe und Altertumswissenschaftler hervortrat. 1930 wurde die G.A.Ch.N. aufgelठst. Die Geschichte dieser Institution wartet noch auf ihre Erforschung.

61 Culkov erwähnt Fedorov kurz in seinen Erinnerungen Gody stranstvij, M. 1930, S. 83.

62 Siehe die Notiz in: Pe`at' i Revoljucija, 5 (1925), 5-6, S. 562. 


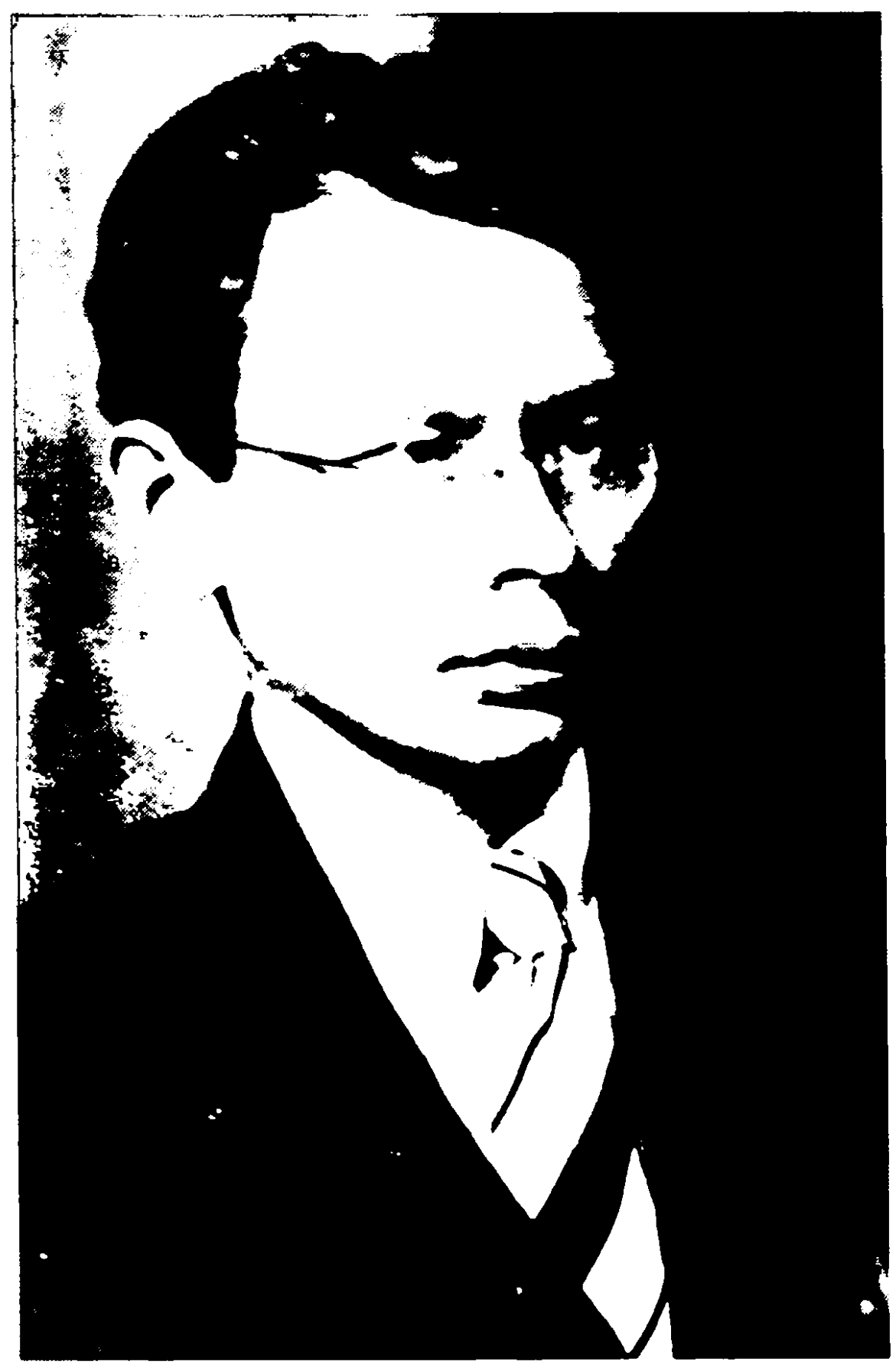

N.A. Setnickij, Aufnahme von 1928 
1927 nahm er an den Diskussionen der von Čulkov geleiteten DostoevskijKommission teil, ${ }^{63}$ und am 10. Februar 1928 hielt er einen Vortrag über "Lev Tolstoj und N.F. Fedorov", in dem er Fedorovs Einfluß auf Tolstoj hervorhob; dies löste, wie das "Bulletin der G.A.Ch.N." vermerkt, bei den Hörern "erheblichen Widerspruch" aus: Dem Referenten wurde vorgeworfen, "Fedorovs Bedeutung für die geistige Entwicklung Tolstojs übertrieben" zu haben. ${ }^{64}$

In Gorskijs Briefen finden sich, wenn auch selten, Hinweise auf Personen, die sich für Fedorovs Werk interessierten. So berichtete er 1926 über den vergeblichen Versuch General Brusilovs, mit den Moskauer Fedorov-Anhängern in Kontakt zu treten. ${ }^{65} 1922$ hatte Gorskij die Petrograder Dichterin Marija Škapskaja (1891-1952) kennengelernt und war mit ihr in einen Briefwechsel getreten. ${ }^{66}$ Zwar läßt die Thematik des lyrischen Werks der Škapskaja - geschlechtliche Liebe, Empfängnis, Schwangerschaft, Geburt und Abtreibung eher an eine geistige Verwandtschaft mit Vasilij Rozanov denken, ${ }^{67}$ doch könnte die von der Dichterin immer wieder eindrucksvoll beschriebene Auflehnung einer Mutter gegen den Tod ihres Kindes auf die Beschäftigung mit Fedorovs Lehre von der Überwindung des Todes zurückzuführen sein. 68

1928 wurde Gorskij mit Michail Prišvin bekannt - möglicherweise durch die Vermittlung Sergej Grigor'evs; beide Schriftsteller lebten damals in Sergiev Posad (seit 1930 Zagorsk). ${ }^{69}$ Dort könnte Gorskij auch mit seinem ehemaligen Lehrer Pavel Florenskij zusammengetroffen sein; ${ }^{70}$ dieser wiederum verkehrte

63 Siehe Bjulleren' G.A.Ch.N., 10, M. 1927/28, S. 27.

64 Bjulleten' GA.Ch.N., 11, M. 1928, S. 31. - Im Fedorov-Archiv Prag sind zwei Thesenpapiere Gorskijs erhalten: A.K. GoRnOSTAEv [GoRSKu], Tezisy $k$ dokladu A.K Gomostaeva 'L.N. Tolstoj i N.F. Fedorov'. GA.Ch.N. Lireratumaja sekcija. Ms. [Masch.] datiert: 10/II-1928, 1 Bl.; FAP I, 334. DeRS., Blok i Gogol'. Tezisy doklada. Ms. [Masch.] 1927, 2 Bl.; ebd. - Außer den genannten, enthalten die Bjulleteni GA.Ch.N., M. 1 (1925) - 11 (1928), sowie der Otלet 1921 . 1925, M. 1926, keine weiteren Hinweise auf Gorskij.

65 Siehe oben Anm. 10.

66 Gornostaev [Gorskij] an Setnickij, 12.8.1926; FAP I, 328. - Briefe von Gorskij an Škapskaja aus der Zeit vom 24.11 .1922 bis 4.1 .1925 (insges. 34 Bl.) befinden sich im Archiv von M.M. Skapskaja, CGALI f. 2182; einige davon waren mir in Abschriften in Moskauer Privatbesitz zugänglich. Siehe auch II: 2.2. Anm. 98, 4.1. Anm. 29.

67 So B. Filippov, der Skapskaja als die "Vasilisa Rozanova der russischen Dichtung" bezeichnet. B.[A.] FILIPPOV [FILISTINSKIJ], "O zamolZannoj. Neskol'ko slov o poezii Manii Skapskoj." In: M.[M.] SKaPSKaJA, Srichi, London 1979, S. 16.

68 Leider ließ sich darüber nichts in Erfahrung bringen. Von der Literaturwissenschaft wurde M.M. Skapskaja bislang kaum beachtet.

69 Siehe oben Anm. 49.

70 Bis zu seiner Verhaftung am 25.2.1933 lebte Florenskij mit seiner Familie in Sergiev Posad (Zagorsk). Sein Haus in der Dvorjanskaja ulica (später ul. Pionerskaja, 19) war ein Treffpunkt religiöser Intellektueller. Ausführlich dazu M.S. TRUBACEVA, S.Z. TRUBACEV, Sergiev Posad v Zizni P.A. Florenskogo, Ms. [Masch.] [Zagorsk 1988], $28 \mathrm{Bl}$. In den zwanziger Jahren gehörten Florenskij und Prišvin einem literarisch-künstlerischen und philosophischen Kreis an, der sich im Haus des Literaten A.A. Aleksandrov (1861-1930) in Sergiev Posad versammelte und in 


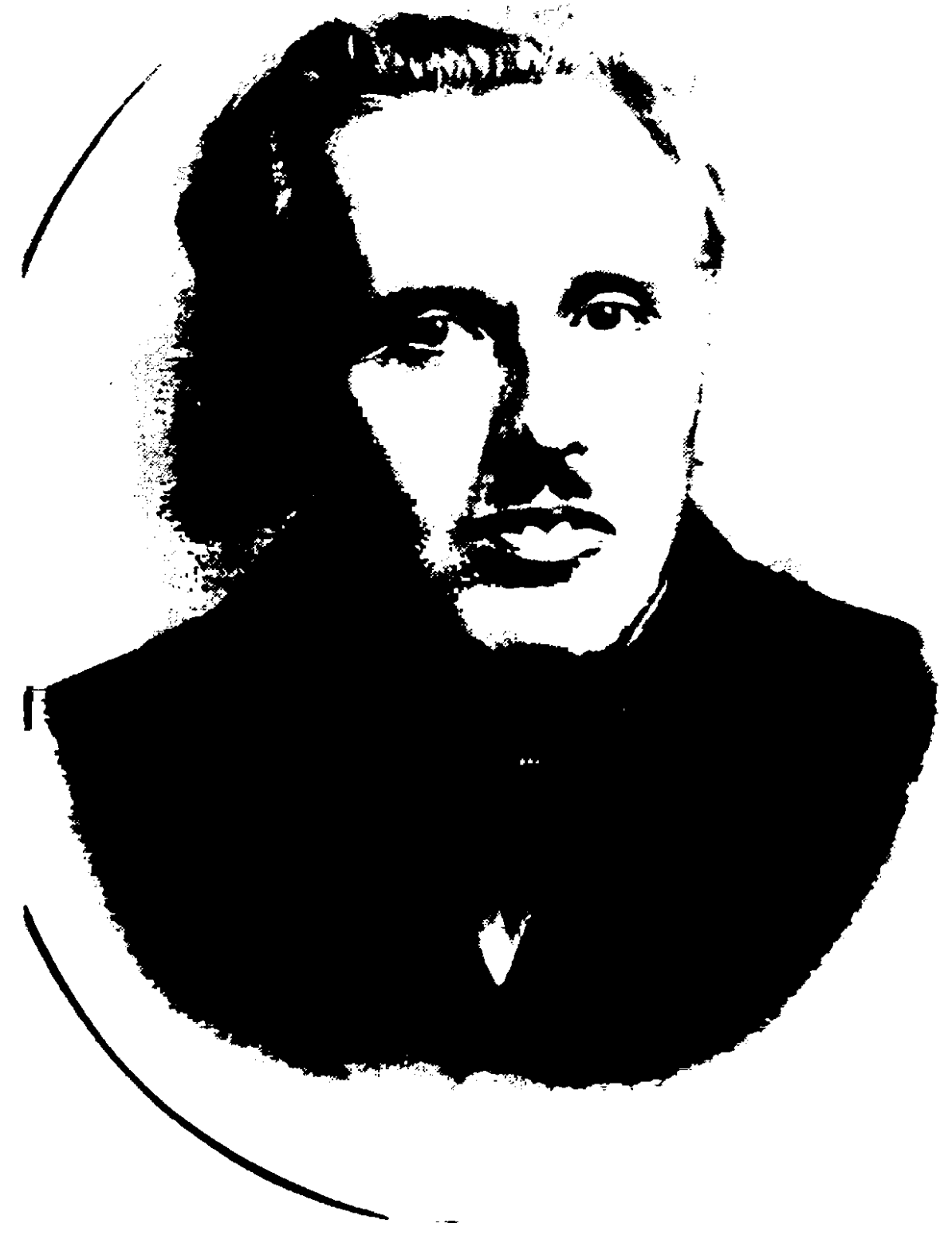

A.K. Gorskij, Aufnahme von 1928

dem, moglicherweise, Fedorovs Ideen diskutiert wurden; auch über diesen Kreis ist nur sehr wenig bekannt. Siehe die Angaben bei E.V. KUCENKo, [Vstupitel'naja stat'ja] in: M.V. Boskin. Katalog vysıavki. Zagorsk 1987, S. S. A.U. GREKOV, "Chudožestvennaja žizn' Zaugorska." In: Pamjatniki otecestva, 2 (16), 1987, S. 33-43. 
zu jener Zeit mit dem Schriftsteller Vsevolod Ivanov (1895-1963), der Fedorovs Werke besaB, ${ }^{71}$ und hatte möglicherweise Kontakt zu Ol'ga Forš, seiner Cousine zweiten Grades, die sich damals mit Fedorov beschäftigte. ${ }^{72}$ Enge Verbindung unterhielt Florenskij zu einem Kreis religiöser Künstler und Wissenschaftler, von denen der Geochemiker und Naturphilosoph V.I. Vernadskij (1863-1945), der Xylograph und Kunsttheoretiker VA. Favorskij (1886-1964) sowie die Pianistin M.V. Judina (1899-1970) mit Fedorovs Ideen bekannt waren. ${ }^{73}$ In Gorskijs Briefen ist von alldem keine Rede, was jedoch mit Rücksicht auf die Zensur erklärt werden kann.

Um so bedeutender ist eine knappe Bemerkung Gorskijs in einem Brief an Setnickij vom September-Oktober 1926: "In Piter [Petersburg] gibt es eine ganze Gruppe leidenschaftlichster Fedorov-Anhänger (otzajannejsich fedorovcev). ${ }^{{ }^{74}}$ Zwar nennt Gorskij keine Namen, noch enthalten seine Briefe Hinweise auf die Mitglieder dieser Gruppe; dennoch läßt sich auf der Grundlage dessen, was heute über die halboffiziellen und geheimen intellektuellen Zirkel in Leningrad in den zwanziger Jahren bekannt ist, zumindest das Milieu skizzieren, in dem Fedorovs Ideen rezipiert und diskutiert worden sind. ${ }^{75}$

Das größte, eine Zeitlang auch offiziell geduldete Forum zur freien Diskussion weltanschaulicher, kultureller und sozialer Fragen bildete die 1918 konzipierte und im folgenden Jahr von Belyj, Blok, Ivanov-Razumnik und anderen in Petrograd gegründete "Freie philosophische Assoziation" (Vol'naja filosofskaja associacija; Vol'fila). ${ }^{76}$ Es ist möglich, wenngleich nicht belegt, da $B$ bei den zahlreichen öffentlichen und intimen Veranstaltungen der Vol'fila, ihren Vorträgen, Kursen und Zirkeln auch Fedorovs Ideen zur Sprache kamen (Andrej Belyj, der

71 Siehe die Erinnerungen seines Sohnes VJAC. Vs. IVANoV, "Prostranstvom i vremenem polnyj." In: Vsevolod Ivanov - pisatel' i Celovek. Vospominanija sovremennikov. M. ${ }^{2} 1975$, S. 349. - Aus dem Jahre 1941 ist eine Äußerung Ivanovs über Gor'kij und Fedorov überliefert; siehe unten A.nm. 123.

72 Siehe TrubaCeva, TrubaCev (wie Anm. 70), Bl. 11. O.D. Forš wird unter den Besuchern Florenskijs in Sergiev Posad genannt, jedoch ohne Zeitangabe.

73 TrubaCeva, TrubaCev (wie Anm. 70). Private Mitteilungen. - Die veröffentlichten Schriften von Favorskij und Judina enthalten keinen Hinweis auf Fedorov, doch könnten in den - mir unzugănglichen - Archiven diesbezügliche Materialien vorhanden sein. Die einzige bislang publizierte Sammlung autobiographischer Schriften von Judina (M.V. JUDINA, Stat i, vospominanija, materialy, M. 1978) weist zahlreiche Auslassungen auf.

74 Ostromirov [Gorskij] an Setnickij, Sept.-Okt. 1926; FAP I, 328; Hervorhebung von mir; M.H.

75 Einen guten Uberblick über die wichtigsten religios-philosophischen Zirkel und Vereinigungen in Petrograd/Leningrad im ersten Jahrzehnt nach der Revolution geben K. CLARK, $M$. Holoust, Mikhail Bakhtin, Cambridge, Mass., London 1984, S. 123-142.

76 Siehe ANON., "Vol'naja filosofskaja associacija." In: Kniga i Revoljucija, 1920, 2, S. $91 f$. ANON., "Vol'fila." In: Russkaja Kniga, 1921, 1, S. 14. A. BELYu, "Vol'naja filosofskaja associacija." In: Novaja Russkaja Kniga, 1922, 1, S. 32f. Ders., Poxemu ja stal simvolistom..., Ann Arbor 1982, S. 109-111. A.V. LAVRov, "Vstupitel'naja stat'ja." [Zu] "Perepiska s R.V. Ivanovym-Razumnikom." In: Literatumoe nasledstwo, t. 92 [Aleksandr Blok. Novye materialy i issledovanija.], kn. 2, M. 1981, S. 380f. Clark, Holquist (wie Anm. 75), S. 125f. - Eine Moskauer Sektion der Vol'fila bestand von 1921 bis 1924. Siehe II: 3.3. Anm. 20, 3.4. Anm. 15. 
Vorsitzende der Petrograder Vol'fila, war mit Fedorovs Werk wohlvertraut). Da die Vol'fila aber schon 1924 ihre Arbeit einstellen mußte, kommt sie als organisatorischer Rahmen für die von Gorskij zwei Jahre später erwähnten Leningrader Fedorov-Anhänger nicht in Frage. Diese sind vielmehr in jenen mehr oder weniger geheimen religiös-philosophischen Zirkeln zu suchen, die teils aus der Vol'fila hervorgegangen, teils unabhängig von ihr entstanden sind. Zwischen den Mitgliedern dieser verschiedenen Zirkel gab es zahlreiche Verbindungen. ${ }^{7}$

Bereits im Herbst 1917 hatte der Philosoph A.A. Mejer (1875-1939) einen religiös-philosophischen Kreis gegründet, der später - nach dem Wochentag, an dem seine Mitglieder regelmäßig zusammenkamen - den Namen Voskresenie erhielt. ${ }^{78}$ Mejer, ein ehemaliger 'mystischer Anarchist' und führendes Mitglied der Petersburger Religiös-Philosophischen Vereinigungen, gehörte zu den Gründern der Vol'fila und leitete seit 1921 ihre Sektion für Geschichte der Philosophie. ${ }^{79}$ In den Jahren 1919 und 1920 arbeitete er am "Institut des lebendigen Wortes" (Institut Živogo Slova), wo er eine Reihe von Vorträgen hielt, die auf eine Beschäftigung mit dem imjaslavie deuten. ${ }^{80}$ Möglicherweise wurde Mejer damals mit Murav'ev bekannt. ${ }^{81}$ Mejer und die Mitglieder seines Kreises standen der Revolution und ihren Zielen anfangs nicht ablehnend gegenüber, doch glaubten sie - wie schon die 'christlichen Sozialisten' und die bogostroiteli zu Beginn des Jahrhunderts -, daß die sozialökonomische "Wahrheit des Sozialismus" um eine religiöse Dimension ergänzt werden müsse, da nur eine Verbindung von Wissen und Glauben imstande sei, die "Welt zu erretten" und den "neuen Menschen" hervorzubringen. ${ }^{82} \mathrm{Zu}$ den prominentesten Mitgliedern des

77 ClaRk, Holouist (wie Anm. 75), S. 138.

78 Vgl. N.P. ANCIFERov, 'Tri glavy iz vospominanij." In: Pamijat'. Istoriceskij sbomik. Vyp. 4, Paris 1981, S. 57-110. S. ElENIN, Ju. OVCINNKKOv, "Primetanija." [Zum vorangegangenen Beitrag]. Ebd., S. 111-145. [E.N. FeDotovA], "Georgij Petrovic Fedotov (1886-1951)." In: G.P. FEDOTOV, Lico Rossii, Paris 1967, S. X-XX.

79 Zur Biographie von Aleksandr Aleksandroviz Mejer ausführlich S. DALINSKu, "Vstupitel'naja stat'ja." In: A.A. MEJER, Filosofskie soxinenija, Paris 1982, S. 7-21. Vgl. Elenin, OvčInNIKov (wie Anm. 78), S. 111 .

80 Die Titel der Vortrăge lauten: "Simvolizeskoe dejstvie i simvol-slovo. (Opyt wedenija v filosofiju slova)." "Slovo u srednevekovych realistov." "Sila slova. (Roždenie dejstvija i slova)." DALINSKU (wie Anm. 79), S. 17. Leider sind diese Vortrăge bislang nicht veroffentlicht worden. Zum imjaslavie siehe II: 3.4. Anm. 21ff., 4.1. Anm. 60. Uber das im November 1918 eröffnete Institut Zivogo Slova ist nur wenig bekannt; siehe II: 3.4. Anm. 16.

81 Zu Beginn der zwanziger Jahre soll Murav'ev am Institut Zivogo Slova in der Abteilung für Vortragskunst gearbeitet haben; auch hatte er enge Kontakte zu Kreisen der imijaslavcy. Siehe II: 3.4 .

82 G.P. Fedotov, Gründungsmitglied des Kreises um Mejer, schrieb 1918: "Wir glauben und wissen: im Sozialismus lebt eine ewige Wahrheit, deren vollen Sinn er selbst noch nicht begreift. Die Menschheit muB die mit dem Verstand erfaßbare Bruderschaft in die Praxis umsetzen. (...) Ein neues Denken muB das BewriBtsein der Werktătigen erleuchten und ein neuer Glaube ihre Herzen entzünden. (...) Kühn ist das Ziel, doch die Zeit erfordert eine große Tat: die Wahrheit des Sozialismus zu retten durch die Wahrheit des Geistes und durch die Wahrheit des Sozialismus die Welt zu retten." FEDOTOv (wie Anm. 78), S. 10f. Zu Fedotov 
Mejer-(Voskresenie-)Kreises gehörten der Historiker und Philosoph G.P. Fedotov (1886-1951), der 1925 nach Frankreich emigrierte, der Historiker und Literaturwissenschaftler N.P. Anciferov (1889-1958), Verfasser der berühmten literatur- und kulturgeschichtlichen Studie Duša Peterburga (1922), die Pianistin Judina sowie der Philosoph Alekseev-Askol'dov.

S.A. Alekseev-Askol'dov (1871-1945), ${ }^{83}$ Sohn des Philosophen A.A. Kozlov (1831-1901), hatte sich 1918 mit einem Aufsatz über "die religiöse Bedeutung der russischen Revolution" an dem anti-bolschewistischen Sammelband Iz glubiny, zu dessen Beiträgern auch Murav'ev gehörte, beteiligt. ${ }^{84} 1921$ gründete Alekseev-Askol'dov in Petrograd eine religiös-philosophische Vereinigung, die 1926 den Namen Bratstvo Serafima Sarovskogo annahm. ${ }^{85}$ Im Vergleich zum Voskresenie-Kreis war das Bratstvo konservativer und stärker orthodox-theologisch orientiert. Es organisierte religiöse Diskussionen und Vortragsreihen, an denen Studenten, junge Wissenschaftler und Geistliche teilnahmen. Zu den Mitgliedern des Bratstvo gehörten die Historiker S.F. Platonov (1860-1933) und E.V. Tarle (1875-1955), die Philologen V.L. Komarovic (1894-1942) und D.S. Lichacev (geb. 1906) sowie der Philologe, Psychiater und Kirchenhistoriker I.M. Andreevskij (ca. 1890-1976). Dieser hatte 1923 mit seinen Studenten die literarisch-philosophische Kosmičeskaja akademija nauk gegründet, die offenbar enge Verbindungen zum Bratstvo unterhielt: Zu den Vortragenden im Kreis um Andreevskij gehörten Alekseev-Askol'dov und Komarovic. ${ }^{86}$

Im Milieu dieser Zirkel sind auch die von Gorskij erwähnten Leningrader Fedorov-Anhänger zu suchen: Andreevskij, der Vorsitzende der Kosmiðeskaja akademija, war ein Bruder der Dichterin M.M. Škapskaja, ${ }^{87}$ die mit Gorskij im Briefwechsel stand. Komarovix, einer der führenden Dostoevskij-Forscher seiner Zeit, hatte Mitte der zwanziger Jahre eine ausführliche Studie zur Frage von Fedorovs Einfluß auf Dostoevskij und dessen Roman Brat'ja Karamazovy verfaßt, die 1928 von Fülöp-Miller im Rahmen der deutschen Dostoevskij-Aus-

siehe V. TOPOROV, "O russkom myslitele Georgii Fedotove i ego knige." In: Naše Nasledie, 1988, 4, S. 45, 50. Ausführlich über den Mejer-(Voskresenie-)Kreis auch ClaRK, HolQUIST (wie Anm. 75), S. 126-132.

83 Zu Sergej Alekseevix Alekseev (Pseud. Askol'dov) vgl. N.O. Lossky [Losski], History of Russian Philosophy, London 1952, S. 381-383. V.V. ZEN'KOVSKU, Istorija russkoj filosofii, t. 2 , Paris 1950, S. 183-187. B. [A.] Filippov [FIlistinsku], "S.A. Alekseev-Askol'dov." In: Russkaja religiozno-filosofskaja mysl' XX veka, Pittsburgh 1975, S. 186-189. DERS., "Askoldov, Sergei." In: Handbook of Russian Literature, New Haven, London 1985, S. 26 f.

84 Siehe II: 3.4 .

85 Siehe Clark, Holquist (wie Anm. 75), S. 132-135. - Der hl. Serafim von Sarov (1760-1833) wurde (und wird) v.a. in konservativ und nationalistisch gesinnten Kreisen verehrt. Fedorov schătzte ihn als einen Verkünder des Auferstehungsgedankens.

86 Vgl. Elenin, OvCinnikov (wie Anm. 78), S. 128f. Z.V. TRIfUnOViC, "I.M. Andreevskij." In: Russkoe Vozrożdenie, 1 (1978), 4, S. 212f. OA. Bogdanova, "Vasilij Leonidovið Komaroviz." In: Voprosy Literatury, 1988, 9, S. 133 f.

87 Elenin, OVCINNIKOV (wie Anm. 78), S. 128. 
gabe im Münchner Piper-Verlag veröffentlicht wurde. ${ }^{88}$ Gorskij wußte von Komarovie' Beschäftigung mit Fedorov; unklar bleibt, ob er zu ihm Kontakt gehabt oder sogar mit ihm zusammengearbeitet hat. ${ }^{89}$ Von Alekseev-Askol'dov schließlich ist eine Äußerung über Kljuevs ausgezeichnete Kenntnis der Lehre Fedorovs überliefert. Mitgeteilt hat diese Äußerung der Schriftsteller und Literaturwissenschaftler B.A. Filippov (eigentl. Filistinskij, geb. 1905), selbst ein Kenner des Fedorovschen Werkes. ${ }^{90} 1924$ war Filistinskij-Filippov aus der Provinz nach Leningrad gekommen, wo er in den folgenden Jahren am Orientalistischen Institut studierte. In dieser Zeit wurde er mit Fedorovs Werk bekannt; ${ }^{91}$ möglicherweise im Rahmen eines der genannten religiös-philosophischen Kreise, vielleicht aber auch einfach dadurch, da $B$ ihm das Buch bei einem Bukinisten in die Hände gefallen war: Mit einigem Glück konnte man nämlich - wie er in seinen Erinnerungen an das "Leningrader Petersburg" des Jahres 1924 schrieb unter den Bücherbergen, die auf dem Litejnyj- und Vladimirskij-Prospekt zum Verkauf angeboten wurden, auch Fedorovs Filosofija obšcego dela entdecken. ${ }^{92}$ $\mathrm{Zu}$ denen, die möglicherweise in den zwanziger Jahren in Leningrad mit Fedorovs Werk bekannt wurden, gehört schließlich auch der Schriftsteller und Essayist G.S. Gor (1907-1981). Während seines Studiums an der Philologischen Fakultät könnte Gor durch seinen Lehrer Komarovið auf Fedorov aufmerksam gemacht worden sein. ${ }^{93}$ Vielleicht gehörte Gor auch der Kosmiceskaja akade-

88 W. KomarowtrsCH [V.L. KomaroviC], "Der Vatermord und Fjodoroffs Lehre von der 'Fleischlichen Auferstehung'." In: F.M. Dostojewski. Die Urgestalt der Brüder Karamasoff. München 1928, S. 3-58. Zum Inhalt des Aufsatzes, der nie in russischer Sprache veroffentlicht worden ist, siehe II: 1.2. Komarovit hatte bereits an dem 1926 bei Piper erschienenen Materialband Der unbekannte Dostojewski maßgeblich mitgewirkt. Zu seiner Biographie vgl. A. IVANov, "V.L. Komarovið o christianstve i socializme u F.M. Dostoevskogo." In: Novyj Zumal, 136, 1979, S. 203-212. Bogdanova (wie Anm. 86), S. 130-151.

89 In einem Brief an Setnickij vom 11.5.1927 schreibt Gorskij, im Piper-Verlag solle in der Reihe (!) "Der unbekannte Dostocvskij" eine von Komaroviz herausgegebene und eingeleitete Anthologie (!) der Schriften Fedorovs erscheinen. Gorskij schlägt Setnickij vor, in dieser Sache an Fülöp-Miller zu schreiben, ihm Materialien zu schicken und eine Zusammenarbeit anzubieten. FAP 1, 328. Weiteres ist nicht bekannt.

90 B.A. Filuppov [Filistinsku], "Nikolaj Kljuev. Materialy dlja biografii." In: N.[A.] KLUUEv, Soxinenija, t. 1, München 1969, S. 50.

Im Jahre 1941 lebten Filistinskij-Filippov und Alekseev-Askol'dov in Novgorod (beide hatten mehrjăhrige Lageraufenthalte hinter sich). Nach der Eroberung der Stadt durch die deutsche Wehrmacht im August 1941 gelangten sie über Pskov und Riga nach Deutschland. AlekseevAskol'dov starb 1945 in Potsdam; Filistinskij-Filippov ging 1950 in die USA. Seither hat er in zahlreichen, zumeist unter dem Namen Filippov veroffentlichten literaturwissenschaftlichen Arbeiten, Kommentaren, Kritiken und Essays immer wieder auf Fedorov hingewiesen (insbesondere im Zusammenhang mit Nikolaj Kljuev). Siehe Literaturverzeichnis.

91 Siehe die (etwas vage) Angabe in B.[A.] Fil.IPPOV [FiLustinsku] Skatulka s dvojnym dnom, o.O. [Washington] 1977, S. 155.

92 G. PEtrov [d.i. BA. FILISTINSKIJ], "Leningradskij Peterburg." In: Grani, 8 (1953), 18, S. 40.

93 Siehe die (etwas vagen) Angaben in dem autobiographischen Essay G.[S.] GoR, "Zamedlenie vremeni." In: Zvezda, 1968, 4, S. 185, $187 f$. 
mija oder dem Bratstvo Serafima Sarovskogo an. Letzteres stand unter dem starken Einfluß Florenskijs, ${ }^{94}$ - und Gor hat später wiederholt (und als einer der ersten in der Sowjetunion) auf die Bedeutung Florenskijs und Fedorovs hingewiesen. ${ }^{95}$

Im Laufe des Jahres 1928 wurden die genannten Kreise - Voskresenie, Bratstvo Serafima Sarovskogo und Kosmiðeskaja akademija - entdeckt und zerschlagen. ${ }^{96}$ Die meisten ihrer Mitglieder wurden verhaftet und viele von ihnen - darunter die Gründer Mejer, Alekseev-Askol'dov und Andreevskij, aber auch Lichacev, Anciferov u.a. - zu langjährigen Strafen in den berüchtigten Lagern auf den Soloveckij-Inseln und an den Baustellen des Weißmeerkanals verurteilt. 97

In seinen Briefen an Setnickij äußerte sich Gorskij gelegentlich auch über den Stand seiner Arbeiten zu Fedorov. Zunächst ging es um die Biographie: Im August 1926 sprach Gorskij von Fortschritten bei seinen Recherchen ${ }^{98}$ und im April 1927 davon, daß es ihm gelungen sei, Fedorovs Vater zu ermitteln. ${ }^{99} \mathrm{Im}$ Mai 1927 erwähnte er die Arbeit an einem zweiten Teil von SmertobožniCestvo; ${ }^{100}$ einige Tage später berichtete er vom Abschluß eines Aufsatzes Pered licom smerti, der das Verhältnis zwischen Fedorov und Tolstoj behandelte und in einem sowjetischen Sammelband erscheinen sollte. ${ }^{101}$

94 Siehe Clark, Holquist (wie Anm. 75), S. 135.

95 Siehe GOR (wie Anm. 93), S. 188 [Fedorov]. Ders., "Ol'ga Nsu." In: Ders., Glinjanyj papuas, M. 1966, S. 159-177 [Fedorov S. 164f., 174]. Ders., Geometrixeskij les, L. 1975, S. 58-60, 205-207 [Florenskij]. - Uber G.S. Gor als Science-fiction-Autor siehe auch AA. URBAN, Fantastika i nas' mir, L. 1972, S. 109-152.

96 Zahlreiche prominente Mitglieder dieser Kreise - darunter Alekseev-Askol'dov, Mejer, Andreevskij und Komarovic - hatten gegen den im Juli 1927 vom Metropoliten Sergij erlassenen Aufruf zur Zusammenarbeit mit der Sowjetmacht protestiert (zu den Protestierenden gehorten auch die Moskauer Pavel Florenskij, Aleksej Losev, Michail Novoselov und Valentin Svencickij). Siehe I.M. ANDREEV [ANDREEVSKU], Kratkij obzor istorii nusskoj cerkvi ot revoljucii do našich dnej, Jordanville, N.Y. 1951, S. 51.

97 Vgl. Elenin, Ovénnikov (wie Anm. 78), S. 113, 129 und pass. Dalinski (wie Anm. 79), S. 19f. Clark, HolQuist (wie Anm. 75), S. 140 f.

In Medvez'ja gora, einem der Lagerzentren am Weißmeerkanal, trafen 1931 Anciferov, der wegen seiner Teilnahme an den Sitzungen des Mejer-(Voskresenie-)Kreises verurteilt worden war, und der Moskauer Fedorov-Anhănger Gorskij zusammen. Siehe unten Anm. 134.

98 Gorskij an Setnickij, 12.8.1926; FAP I, 328.

99 Gorskij an Setnickij, 20.4.1927; ebd.

100 Gorskij an Setrickij, 11.5.1927; ebd.

101 Gorskij an Setnickij, 31.5.1927; ebd. - Pered licom smeni ist in der Sowjetunion nicht erschienen; die Arbeit wurde spăter von Setnickij in Harbin veröffentlicht. Siehe unten Anm. 121. 
Immer wieder drängte Gorskij seinen Briefpartner, an prominente Persönlichkeiten in aller Welt heranzutreten, ihnen die Harbiner Publikationen zu schicken und sie zu Äußerungen über Fedorov zu bewegen, die sich dann zu Propagandazwecken verwenden ließen. Genannt wurden u.a. H.G. Wells in London, Romain Rolland in Villeneuve am Genfer See, Zinaida Gippius und Marina Cvetaeva in Paris, Vjaceslav Ivanov in Rom und Nikolaj Rerich "in der Mongolei". ${ }^{102}$ Von Fülöp-Miller erhoffte sich Gorskij Unterstützung bei der Veröffentlichung des dritten Bandes der Filosofija obšcego dela, der in diesem Fall zuerst in deutscher Sprache und später auf Russisch erscheinen sollte; ${ }^{103}$ und über Ol'ga Forక̌ wollte er versuchen, auf die "Pseudo-Solov'evschen Kreise in Paris einzuwirken". 104

Die höchsten Erwartungen richtete er indessen auf Gor'kij. "Ich bin sehr froh," schrieb Gorskij am 20. April 1927 an Setnickij, "daß Sie zu Gor'kij Kontakt aufgenommen haben"; und am 11. Mai: "vertiefen Sie den Kontakt auf jede Art und Weise!"105 Ungeduldig bat er Setnickij, ihm mitzuteilen, wie Gor'kij auf Smertobožničestvo reagiert habe, ${ }^{106}$ und immer wieder riet er ihm, auf Gor'kij einzuwirken, daß dieser sich über Fedorov äußere. Gorskij hatte eine großangelegte Studie Nikolaj Fedorovic Fedorov $i$ sovremennost' verfaßt, mit deren Veröffentlichung (in mehreren Lieferungen) im Jahre 1928 begonnen werden sollte; er hoffte, Gor'kij werde das Vorwort dazu schreiben. ${ }^{109}$ Eine entspre-

102 Gorskij an Setnickij, 17.2.1928; ebd. - Zwischen N.K. Rerich (1874-1947) und Fedorov gibt es gewisse, wenn auch sehr allgemeine geistige Gemeinsamkeiten. Beide trăumten von einer paradiesischen Zukunft, die durch das Zusammenwirken aller Menschen herbeigefuhrt werde, wobei der weltverwandelnden Kunst besondere Bedeutung zukomme. Niemand dürfe, so Rerich, "nur ein kalter Betrachter" sein, vielmehr müßten "alle zu Mitwirkenden bei der [gemeinsamen] Arbeit" werden. N.K. RERICH, SS, t. 1, M. 1914, S. 117; zitiert nach L.V. KOROTKINA, Tvortestwo N.K. Rericha (1890-e gg. - 1916). Avtoreferat dissertacii. L. 1977, S. 11. Gemeinsam war beiden ein Denken in kosmischen Dimensionen und das Streben nach allumfassender Synthese. Rerich, so wird berichtet, habe den Plan gehabt, im Norden Rußlands ein "Museum der Synthese" zu errichten, in dem Kunsterzeugnisse ausgestellt werden sollten, in denen sich die "kosmische Erweiterung des menschlichen BewuBtseins" außere. JU.[V.] LINNIK, "Amaravella'." In: Sever, 1981, 11, S. 114. Rerich unterschied sich von Fedorov v.a. durch seine Skepsis gegenüber Wissenschaft und Technik und seine starke Neigung zum Buddhismus. Über eine Beschăftigung Rerichs mit Fedorovs Werk ist nichts bekannt.

Was H.G. Wells betrifft, so sind im Fedorov-Archiv Prag mehrere Entwürfe zu einem Otkrytoe pis'mo g. Uèlsu aus dem Jahre 1928 erhalten; FAP I, 338. Der Verfasser ist offenbar Setnickij. Von einer Korrespondenz mit Wells ist nichts bekannt. - Zu Vjareslav Ivanov und Zinaida Gippius siehe II: 2.2. Anm. 119 und 143.

103 Gorskij an Setnickij (wie Anm. 100).

104 Gorskij an Setnickij (wie Anm. 101).

105 Gorskij an Setnickij (wie Anm. 99, 100).

106 Gorskij an Setnickij (wie Anm. 101).

107 Gorskij an Setnickij (wie Anm. 100). 
chende Bitte hat Setnickij am 31. Mai 1927 an Gor'kij gerichtet, doch ist sie unerfüllt geblieben. ${ }^{108}$

Im Jahre 1928 jährte sich Fedorovs Geburtstag zum hundertsten und sein Todestag zum fünfundzwanzigsten Mal. Für Setnickij war dies Anlaß, eine rege publizistische Aktivität zu entfalten. Bereits im Januar und Februar 1928 erschienen in Harbiner Zeitungen Artikel, in denen er - unter Hinweis auf das Jubiläum - die Aktualität Fedorovscher Ideen hervorhob. ${ }^{109}$ In den Izvestija der Juristischen Fakultät veröffentlichte Setnickij ein weiteres Kapitel seiner Arbeit Eksploatacija ili reguljacija, in dem er, Fedorov folgend, das Verhältnis des Menschen zur Natur als ein parasitäres und ausbeuterisches beschrieb, das zwangsläufig in den Untergang führen müsse. ${ }^{110}$ Die Pariser Emigrantenzeitschrift Versty brachte einen Wiederabdruck von Setnickijs Aufsatz Kapitalisticeskij stroj v izobraženii N.F. Fedorova sowie eine von Setnickij eingeleitete Veröffentlichung von drei Briefen Fedorovs an Koževnikov über Turkestan. ${ }^{111}$ Die Briefe, aus dem Jahr 1899, gehörten zu jenen Materialien, die im dritten Band der Filosofija obščego dela veröffentlicht werden sollten. Aus derselben Quelle stammten auch mehrere kurze Abhandlungen und Skizzen, die Setnickij - wiederum unter Hinweis auf Fedorovs hundertsten Geburtstag - in der Pariser religiösen Zeitschrift Put' veröffentlichen ließ. ${ }^{112}$

Auch der Plan, einen zweiten Sammelband mit dem Titel Vselenskoe delo herauszubringen, wurde aus Anlaß des Jubiläums wieder aufgegriffen, doch ließ

108 N.A. Setnickij an M. Gor'kij, 31.5.1927; Gor'kij-Archiv, IMLI, KG-P-71-4-3; nach einer Abschrift in Moskauer Privatbesitz. - In der Hoffnung, Gor'kij als Verfasser eines Vorworts zu gewinnen, schrieb Setnickij: "Im übrigen ist in diesem Buch eine große Anzahl von Seiten Ihnen gewidmet und Ihrem Kampf für den Frieden..." Eine Antwor Gor'kijs auf diesen Brief ist nicht bekannt.

109 N. SETNICKu, "N.F. Fedorov o razoruženii." In: Den' Jurista, 7, 1928, S. 4; siehe auch Anm. 163. DERS., "Nauka i trud." In: Novosti Żizni, 28.2.1928, S. 2; diese Tageszeitung war ein Organ der Smena-vech-Bewegung.

110 N.A. SETNICKU, "Eksploatacija..." (wie Anm. 24). Auch als Separatdruck erschienen.

111 NA. SETNICKI, "Kapitalističeskij stroj v izobraženii N.F. Fedorova." In: Versty, 3, 1928, S. 259. 277. [N.F. FEDOROv], "Iz perepiski N.F. Fedorova s V.A. Koževnikovym o Turkestane." Ebd., S. 278-288. [Einleitung von] "S" [d.i. N.A. SETNICKJ]], ebd., S. 278f. - Die Zeitschrift Versty erschien von 1926 bis 1928 mit insgesamt nur drei Nummern unter der Redaktion von D.P. Svjatopolk-Mirskij, P.P. Suvtinskij und S.Ja. Efron. Mit dem faktischen Chefredakteur, dem Musikwissenschaftler und Schriftsteller P.P. Suvtinskij (1892-1985), hat Setnickij 1927 korrespondiert; FAP I, 33O. Siehe auch II: 4.3.1.

112 [N.F. Fedorov], "Iz tret'ego toma 'Filosofii obsčego dela'." In: Put', 10, 1928, S. 3-42. [Einleitung von] N. [d.i. N.A. SETNICKu], ebd., S. 3f. - Chefredakteur von Put' war N.A. Berdjaev. Im Fedorov-Archiv Prag sind zwei kurze undatierte Briefe Berdjaevs an Setnickij erhalten (FAP I, 328), die jedoch keinen Aufschluß über eine Zusammenarbeit geben. Hingegen geht aus den Notizen Setnickijs (FAP I, 320) eindeutig hervor, daß er es war, der die in Versty und Put' publizierten Materialien des dritten Bandes der Filosofija obšcego dela an die betreffenden Redaktionen geschickt hat. 
er sich zu diesem Zeitpunkt noch nicht verwirklichen. ${ }^{113}$ Mehr Erfolg hatte hingegen ein anderes, ebenfalls seit langem verfolgtes Vorhaben: die Neuausgabe der Filosofija obšcego dela. Gorskij hatte vorgeschlagen, mit dem Druck des dritten Bandes zu beginnen, um das noch unveröffentlichte Material vor einem möglichen Verlust zu bewahren. ${ }^{114}$ Statt dessen begann Setnickij 1928, eine unveränderte Neuausgabe des ersten Bandes in einzelnen Lieferungen herauszubringen. Bis 1930 erschienen drei Lieferungen, die zusammen etwa ein Drittel des ersten Bandes umfassen; dann mußte Setnickij das Unternehmen aus finanziellen Gründen abbrechen. 115

Der Neuausgabe der Filosofija obščego dela vorangestellt war ein von Gorskij verfaßter Abriß der Biographie Fedorovs, dessen erste Fassung auf das Jahr 1923 zurückging. ${ }^{116}$ Separat und mit verändertem Titel 1928 veröffentlicht, bildete er zugleich die erste Lieferung von Gorskijs mehrteiliger Studie Nikolaj Fedorovic Fedorov $i$ sovremennost, ${ }^{1} \$$ ' Lieferung erschien; ${ }^{118}$ zwei weitere folgten 1932 und $1933 .{ }^{119}$ Ebenfalls im Jubiläumsjahr 1928 brachte Setnickij noch zwei Werke Gorskijs heraus: das Gedichtbändchen Lico èry, in dem sich unter anderem ein Gedicht mit dem Titel "Anabiose" findet, ${ }^{120}$ sowie die Studie Pered licom smerti, die dem Verhältnis

113 Siehe ZET. [d.i. N.A. SETNICKU], "'Vselenskoe Delo' v proslom." In: Vselenskoe delo (wie Anm. 4), S. 115.

114 Gorskij an Setnickij, 11.10.1927; FAP I, 328.

115 Siehe ausführlich I: 2. Anm. 46. - Die Auflage der ersten Lieferung betrug 750 Exemplare. Setnickij hat offenbar die gesamten Druckkosten selbst bestritten. Siehe Rechnung der Druckerei L.M. Abramovic, Harbin; FAP I, 342. - Irreführend ist die Äußerung von L. Sestov, die Neuausgabe der Filosofija obscego dela habe "trotz Gor'kijs Protektion" in RuBland nicht erscheinen können. L. SEsTOV, "N.F. Fedorov." In: DeRs., Umozrenie i otkrovenie, Paris 1964, hier S. 127. Es gibt keinen Anhaltspunkt für eine Unterstutzung Gor'kijs bei der Veröfentlichung der Werke Fedorous.

116 A. Ostromirov [A.K. GoRsku], "Nikolaj Fedoroviz Fedorov. (Biografizeskij ozerk)." In: N.F. FEDOROV, Filosofija obszego dela, t. I, vyp. 1, Charbin 1928, S. V-XX. Siehe auch II: 4.1. Anm. 36.

117 A. Ostromirov [A.K. GorsKu], Nikolaj Fedorovic Fedorov. 1828-1903-1928. Biografija. O.O. [Harbin] 1928. ( = A. Ostromirov [A.K. GORSKU], Nikolaj Fedonovic Fedorov $i$ sovremennost'. Oxerki. Vyp. 1).

118 A. Ostromirov [A.K. Gorsku], Nikolaj Fedonoviz Fedonov i sovremennost'. Oxenki. Vyp. 2, Charbin 1928. Enthălt die Kapitel "Proektivizm i bor'ba so smert'ju" und "Bogoslovie Obšcego Dela".

119 A. Ostromirov [A.K. GorSKU], Nikolaj Fedorovic Fedorov $i$ sovremennost'. Ocenki. Vyp. 3, Charbin 1932. Enthălt das Kapitel "Organizacija mirovozdejstvija.". Vyp. 4, Charbin 1933. Enthalt das Kapitel "Ostrie mirovogo krizisa."

120 A.K. Gornostaev [GoRsku], Lico ery. Stichi. Charbin 1928. Darin das Gedicht "Anabioz", S. 12f. - Die Auflage betrug 500 Expl. Das Werk wurde kaum beachtet; die einzige Rezension erschien in einer unbedeutenden Pariser Emigrantenzeitschrift: F. O[CHOTNIKOV], "A. Gornostaev. Lico ery." In: Zveno, 1928, 4, S. 225. 
zwischen Fedorov und Tolstoj gewidmet war und, in den folgenden Jahren in mehrere Sprachen übersetzt, relativ breite Beachtung fand. ${ }^{121}$

\subsubsection{Setnickij und Maksim Gor'kij (II)}

Aus Anla $B$ des hundertsten Geburtstags Fedorovs schienen seine Anhänger sich verstärkt bemüht zu haben, Gor'kij für ihre Sache zu gewinnen, zumal sich bereits zu Beginn des Jahres in Moskau herumgesprochen hatte, daß Gor'kij in die Sowjetunion zurückkehren wollte. ${ }^{122}$ Am 2. Februar 1928 schrieb Gorskij an Setnickij:

Soeben habe ich mich mit jemandem getroffen, der im Ausland war und drei Monate in der Umgebung Gor'kijs verbracht hat, wobei er in engem Kontakt zu ihm stand. Nach seinen Worten äußert sich Gor'kij über Fedorov geradezu überschwenglich (govorit zachlebyvajas') - schätzt ihn überaus hoch, hat alles genau gelesen, was über ihn geschrieben wurde - usw. ${ }^{123}$

Setnickij wandte sich im Laufe des Jahres 1928 mindestens zweimal an Gor'kij. ${ }^{124}$ Am 2. August 1928 teilte er ihm mit, er habe "in diesen Tagen an Ekaterina Pavlovna [Peškova; M.H.] einige Broschüren und Sonderdrucke geschickt, die mit den Ideen N.F. Fedorovs zu tun" hätten, und er bat um Bestätigung des Empfangs. In der Presse, so Setnickij weiter, habe man viel von Gor'kijs Absicht lesen können, nicht nur eine, sondern sogar zwei Zeitschriften

121 A.K. Gornostaev [GorskiJ], Pered licem [sic] smeni. L.N. Tolstoj i N.F. Fedonov 1828-19031910-1928. O.O. [Harbin] 1928. - Siehe auch oben Anm. 101. Einer unbestătigten Angabe zufolge soll es sich um ein Kapitel aus einer umfangreichen unveroffentlichten Studie des Verfassers über L.N. Tolstoj handeln, die den Titel trägt Na kraju starngo zaprela; siehe Vselenskoe delo (wie Anm. 4), S. 196. Von dem Ms. fehlt bislang jede Spur.

Pered licom smerti wurde auszugsweise veroffentlicht in der Harbiner Tageszeitung Novosti Zizni, 1928, 20-22. 1933 erschienen Ausgaben in Tschechisch (Před rvăr̆ smri, Praha) und Japanisch. Ubersetzungen ins Deutsche ("Im Angesicht des Todes") und Englische ("At the face of Death") blieben unveroffentlicht, sind aber als Manuskripte im Fedorov-Archiv Prag erhalten (FAP I, 334, 338); dort auch Rezensionen der japanischen Ausgabe in mehreren japanischen Zeitungen (FAP I, 334). Für 1935 war anläßlich des 25. Todestages Tolstojs eine Veroffentlichung in Amerika geplant (Setnickij an Gor'kij, 29.10.1934; siehe unten Anm. 150). Zur Resonanz unten Anm. 189-191.

122 Gorskij an Setnickij, 2.2.1928; FAP I, 328.

123 Ebd. - Um wen es sich bei der von Gorskij erwähnten Person handelt, konnte nicht festgestellt werden. - Daß Gor'kij Fedorov offenbar hochschätzte, geht auch aus einem Bericht der Moskauer Bibliothekarin Ekaterina Aleksandrovna Krašeninnikova hervor: "Im Jahre 1941 aßen wir zusammen mit dem Vater unserer Kommilitonin, dem Schriftsteller Vs[evolod] Vją̌[eslavoviz] Ivanov, zu Mittag. Er erzăhlte von Gor'kij, es gab etwas Wein, und er sagte: 'Und jetzt trinken wir auf das, worauf auch Gor'kij vorgeschlagen hat zu trinken, wie mir jemand - Gor'kijs Sekretăr oder ein Freund von ihm - erzählt hat. Also, Gor'kij hat vorgeschlagen, sich an Fedorov zu erinnern und auf die Verwirklichung seiner Idee zu trinken." Aufzeichnungen von E.A. Krašeninnikova, Ms. in Moskauer Privatbesitz.

124 Am 30.1.1928 mit einer Postkarte, über deren Inhalt nichts bekannt ist; am 2.8.1928 mit einem Brief. 
herauszugeben. Ob man dort auch über Fedorov und die Filosofija obščego dela schreiben könne? Als erstes schlug Setnickij Gorskijs Aufsatz über Fedorov und Tolstoj, Pered licom smerti, vor; falls Gor'kij ihn nicht veröffentlichen wolle, so möge er wenigstens einige Exemplare an Interessenten - z.B. an M.M. Prišvin weiterleiten. ${ }^{125}$

Gor'kij jedoch ließ sich nicht zu einer öffentlichen Äußerung über Fedorov bewegen, noch schien er bereit zu sein, einen Artikel über ihn zu schreiben. Deshalb beschloß Gorskij, sich nach Gor'kijs Rückkehr in die Sowjetunion (Ende Mai 1928) persönlich an ihn zu wenden. Eine Begegnung scheint stattgefunden zu haben, doch ist über sie nichts Näheres bekannt. ${ }^{126}$ Am 27. November 1928 ging Gorskijs Wunsch in Erfüllung: Gor'kij äußerte sich öffentlich wenn auch nur mit wenigen Worten - über Fedorov. In dem von Pravda und Izvestija gleichzeitig abgedruckten Artikel Ešce o mechaničeskich graždanach schrieb er:

Es gab bei uns den bemerkenswerten, jedoch wenig bekannten - weil eigenartigen - Denker N.F. Fedorov. Unter der Vielzahl seiner originellen Spekulationen und Aphorismen ist auch folgender: "Freiheit ohne Macht über die Natur ist das gleiche wie Befreiung der Bauern ohne Land." Das ist meines Erachtens unbestreitbar. ${ }^{127}$

Nur wenige Tage darauf, am 11. Dezember 1928, wurde dieses Zitat von M.I. Kalinin in einer Rede vor dem Zentralkomitee aufgegriffen und in der Pravda am 14. Dezember veröffentlicht:

Genossen, in einer der letzten Nummern der Izvestija ist ein Artikel Gor'kijs Esze o mechanizeskich grazdanach erschienen, und er zitiert dort einen Aphorismus von N.F. Fedorov, dem bekannten [!] Denker, Verfasser zahlreicher Aphorismen, der als Bibliothekar des Rumjancev-Muscums gearbeitet hat. Das also sagt Fedorov: "Freiheit ohne Macht über die Natur ist das gleiche wie Befreiung der Bauern ohne Land. ${ }^{128}$

Nunmehr sah auch Gorskij seine Chance gekommen; und tatsächlich gelang es ihm - unter ausdrücklichem Hinweis auf die Äußerungen Gor'kijs und Kalinins am 28. Dezember 1928 einen Artikel über Fedorov in die Izvestija zu lancie-

125 Setnickij an Gor'kij, 2.8.1928; Gor'kij-Archiv, IMLI, KG-P-71-4-7; nach einer Abschrift in Moskauer Privatbesitz. - Der Brief ist in einem fordernden Ton verfaBt, weshalb Gorskij ihn spăter als "polemisch" (svartivoe pis'mo) bezeichnete. Gorskij an Setnickij, 22.9.1928; FAP I, 328.

126 Der einzige Hinweis ist eine Bemerkung Setnickijs in einem Brief vom 29.10.1934 an Gor'kij über dessen Begegnung mit Gorskij im Jahre 1928. Siehe unten Anm. 150.

127 M. GOR'ku, SS v 30i tt., t. 24, M. 1953, S. 454. Das Fedorov-Zitat in FOD II, S. 48. - Zum Zeitpunkt der Veröfentlichung des Artikels hielt sich Gor'kij bereits wieder in Sorrent auf, wo er bis 1933 regelmaßig die Wintermonate verbrachte.

128 M.I. KALININ, "O vyborach v Sovety v 1928/1929 g. Doklad na retvertoj sessii CIK SSSR IV sozyva 11 dekabrja 1928 g." In: DERS., Izbrannye proizvedenija v Eetyrech tomach, t. 2, M. 1960, hier S. 283f. 
ren. ${ }^{129}$ Der Anlaß war freilich konstruiert: An diesem Tage, so behauptete Gorskij einleitend, jähre sich zum hundertsten Male der "Geburtstag des originellen Denkers" (in Wahrheit jährte sich Fedorovs Todestag). Nach einigen Worten zu Fedorovs Person und seinem Einfluß auf berühmte Zeitgenossen nannte Gorskij einzelne Projekte der Filosofija obščego dela - etwa den "Kampf organisierter Kollektive gegen Epidemien und blinde Naturgewalten" oder die "allgemeine Abrüstung und die Umwandlung aller Kriegsheere in Arbeitsarmeen" -, vermied dabei aber jeden Hinweis auf die zentralen Gedanken, die Überwindung des Todes und die Auferweckung der Verstorbenen. Fast wurde Fedorov zu einem Vorläufer der Bolschewiki, als Gorskij schrieb:

Er erwartete eine grandiose technische Revolution und kämpfte dafür sein Leben lang. Diese Revolution sollte alle sozialen Verhăltnisse verändern, die alte Familienstruktur zerschlagen, nationale und klassenmaßige Trennungen beseitigen und die territorialen Grenzen wegwischen. ${ }^{130}$

\section{Und an anderer Stelle:}

Fedorovs Gedanken, die die größten seiner Zeitgenossen überraschten und faszinierten, erschienen dem damaligen reaktionăren Spießertum als Utopie und Phantasterei. Nun aber hat der gigantische Umschwung des Oktober und die ihm folgende kulturelle und technische Revolution vieles von dem, worüber Fedorov sprach, auf die laufende Tagesordnung gesetzt. ${ }^{131}$

\section{Gorskij schloß mit den Worten:}

Viele von Fedorovs Gedanken befinden sich im Einklang mit dem heutigen Tag. Ist es nicht an der Zeit, das geistige Erbe dieses außergeworhnlichen und für uns interessanten Denkers besser und gründlicher zu erforschen? ${ }^{132}$

Wenige Tage nach dem Erscheinen dieses Artikels, am 10. Januar 1929, wurde Gorskij verhaftet. ${ }^{133}$ Im Juli 1929 verurteilte ihn ein Kollegium der GPU nach Paragraph 58,11 (antisowjetische Propaganda und Agitation) zu zehn Jahren Lagerhaft, die er an den Baustellen des Weißmeerkanals ableisten mußte. ${ }^{134}$

129 A. Gornostaev [A.K. GoRSKIJ], "N.F. Fedorov." In: Izvesija CIK SSSR i VCIK, 300 (3534), 28.12.1928, S. 4.

130 Ebd.

131 Ebd.

132 Ebd.

133 SetNiCKasa (wie Anm. 59), Bl. 44. - N.A. Setnickij nennt als Datum von Gorskijs Verhaftung die "Nacht auf den 7.1.1929". Siehe Setnickijs Schreiben vom 5.6.1933 an das Tschechische National-Museum Prag anläßlich der Ubergabe der Briefe Gorskijs an das dortige FedorovArchiv (FAP I, 328). Gorskijs letzter Brief an Setnickij trägt das Datum vom 28.12.1928; beigefügt ist der an diesem Tag erschienene Izvestija-Artikel über Fedorov.

134 Von 1929 bis 1934 arbeitete Gorskij vor allem in Medvežja gora (heute Medvež'egorsk) am Nordufer des Onega-Sees; eine Zeitlang soll er auf den berüchtigten Soloveckij-Inseln inhaftiert gewesen sein. Gorskij versah verschiedene Tătigkeiten zumeist in der Verwaltung (Buchhaltung, Rechnungswesen), führte einen Buch- und Zeitschriftenkiosk und arbeitete in der Lagerbibliothek. Seine Haftbedingungen seien "entrăglich" (nedumo), schreibt am 7.4.1932 ein 


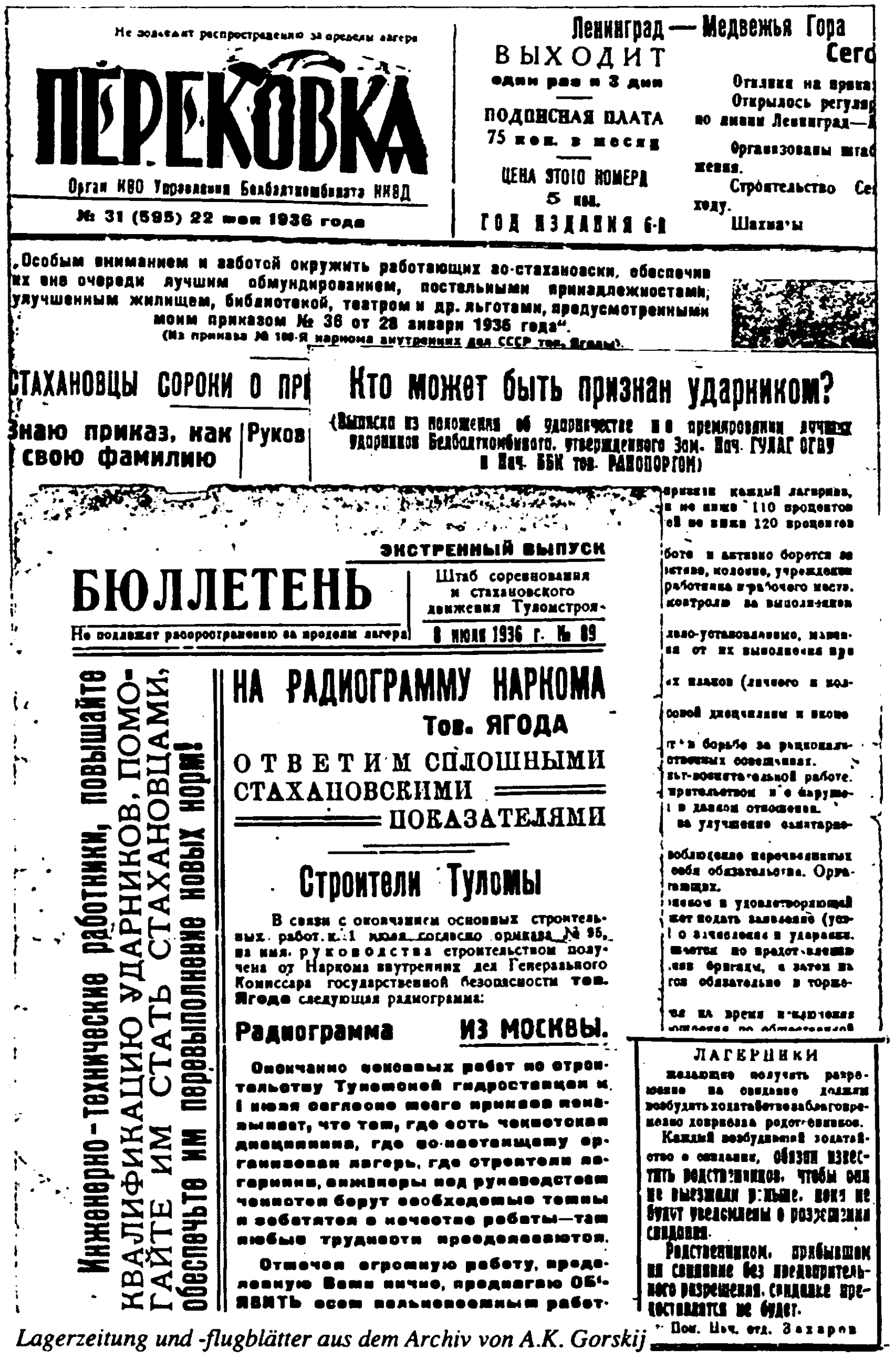


Der Anlaß für Gorskijs Verhaftung ist unbekannt. Setnickij bemerkte dazu später, es bestehe Grund zu der Annahme, daß Gorskijs Verhaftung im Zusammenhang mit der Erwähnung Fedorovs durch Gor'kij und Kalinin und der dadurch ermöglichten Veröffentlichung des Izvestija-Artikels erfolgt sei. Dieser Artikel habe großes Aufsehen erregt und zu zahlreichen Anfragen bei der Redaktion der Izvestija geführt. Schließlich habe ein gewisser Znamenskij, ein Moskauer Jurist und späterer Diplomat, die Redaktion darüber aufgeklärt, daß Fedorov in Wirklichkeit ein leidenschaftlicher Konterrevolutionär gewesen sei und die Redaktion sich über ihn habe täuschen lassen. Es heiße, so Setnickij, auch Gor'kij habe daraufhin seine früheren Äußerungen über Fedorov widerrufen und erklärt, sie seien ihm von Gorskij unterschoben worden. ${ }^{135}$

Tatsächlich scheint Gor'kij sich von weiteren Äußerungen über Fedorov zunächst distanziert zu haben, wie aus den Mitteilungen des in Bogorodsk bei Moskau lebenden Ingenieurs und Heimatforschers I.I. Alekseev an Setnickij hervorgeht. ${ }^{136}$

gewisser E. Pamirskij (offenbar ein von Fedorov inspiriertes Pseudonym; vgl. FOD I, S. 354f.) aus Moskau an N.A. Setnickij; FAP I, 328. Im Sommer 1933 erkrankte Gorskij an Skorbut. Im August 1934 wurde er an den Bauplatz des Tuloma-Wasserkraftwerks (Tulomstroj) im Norden der Halbinsel Kola verlegt, wo er dem leitenden Ingenieur als technischer Archivar zugewiesen wurde. Gorskij war Stoßarbeiter (udamik) und erlangte die damit verbundenen Vergünstigungen (Besuchserlaubnis für Frau und Schwester, bessere Verpflegung und Unterkunft, Haftreduzierung). Im Frühjahr 1937 wurde er vorzeitig entlassen. SETNICKAJA (wie Anm. 59), Bl. 44 f. - Über die Vergünstigungen für die udamiki und stachanovcy berichtet ausführlich die Lagerzeitung Perekovka (in Nr. 31 (595) vom 22.5.1936 findet sich S. 4 ein Hinweis auf "A.K. GorskijGornostaev").

1931 begegnete Gorskij in Medvežja gora dem ebenfalls inhaftienten Leningrader Historiker und Literaturwissenschaftler N.P. Anciferov. Dieser berichtete spăter in seinen Erinnerungen: "Er [Gorskij] war ein ganz außergewöhnlicher Mensch. (...) Durch innere Arbeit erlangte er ein Glücksempfinden, das von nichis Äußerem abhängig war. In jeder Lage und unter allen Umstănden bewahrte er nicht nur frohen und klaren Mut, sondern auch eine unauslöschliche Begeisterung. (...) Er war ein überaus eifriger Anhänger der Lehre Fedorovs, seiner Theorie des obšcee delo. Der Tod ist kein Gesetz des Lebens. Er muß überwunden werden. Der Mensch muß keusch leben. Keuschheit ist die Bedingung für physische Unsterblichkeit. Doch geht es nicht nur darum, persönliche Unsterblichkeit zu erlangen. Der Tod muß endgültig überwunden werden, und es ist die Pflicht der Lebenden, die Toten aufzuerwecken. Das ist auch das obšcee delo. Und Gorskij bewahrte Keuschheit, mehr noch, er bewahrte ... Keuschheit in seiner Ehe... (...) Wenn ein Mensch starb, so beging er in den Augen Gorskijs eine unwürdige Handlung. Er selbst glaubte fest, daß er nicht sterben werde. Er hatte daran nicht den geringsten Zweifel. (...) Die Revolution akzeptierte er auf seine Art. Er schătzte an ihr den Schwung des Aufbaus, die Kraft ihres Tempos. Ihn freute die Arbeit am Kanal..." N.P. ANCIFEROV, Medvez'ja gora. 1931., Ms. [Masch.] 3 Bl. - Es handelt sich um ein Kapitel aus dem in den fünfziger Jahren verfaßten, bislang nur auszugsweise veröffentlichten Buch Put' moej Zizni; Originalmanuskript in GPB f. 27; nach einer Abschrift in Moskauer Privatbesitz. Siehe auch ANCIFEROV (wie Anm. 78).

135 In seinem Schreiben vom 5.6.1933 (wie Anm. 133).

136 Neun Schreiben von Ivan Ivanovic Alekseev an N.A. Setnickij (1928-1929) im FAP I, 328. Siehe auch HEŘMAN (wie Anm. 39), S. 223. - Alekseev arbeitete in den zwanziger Jahren als Ingenieur in der Fabrik Elekstrostal' in Bogorodsk (heute Noginsk, Geb. Moskau) und war aktives Mitglied des Bogorodsker Instituts für Heimatforschung. 
Alekseev, der sich nach eigenen Worten seit langem mit Fedorovs Werk beschäftigt hatte und mit Koževnikov und Peterson persönlich bekannt gewesen war, ${ }^{13}$ hatte bereits 1927 mehrmals mit Gor'kij über Fragen der Heimatforschung (kraevedenie) korrespondiert; Fedorov war dabei nicht erwähnt worden. ${ }^{138}$ Wahrscheinlich war Alekseev Anfang 1928 mit Gorskij zusammengetroffen und hatte von ihm erfahren, daß Gor'kij sich für Fedorov interessiere und beabsichtige, einen Aufsatz über ihn zu schreiben. Daraufhin wandte sich Alekseev am 6. März 1928 an Gor'kij und bat ihn um nähere Auskünfte. ${ }^{139}$ Gor'kij scheint nicht geantwortet zu haben, denn am 15. Mai fragte Alekseev bei Setnickij nach, ob ihm ein Aufsatz Gor'kijs über Fedorov bekannt sei. Er selbst, Alekseev, beabsichtige, einen populären Artikel über Fedorov für die Zeitschrift Krasnaja Niva zu schreiben und wolle sich dabei auf Gor'kij berufen. ${ }^{140}$ Als Ende November Gor'kijs Artikel mit dem Hinweis auf Fedorov in Pravda und Izvestija erschienen, hat Alekseev offenbar seine Bitte an Gor'kij wiederholt. Am 9. Dezember teilte er Setnickij mit: "Ich habe Gor'kij geschrieben und ihn gebeten, sich über Fedorov zu äußern, denn wenn man sich auf

137 Alekseev an Setnickij, 27.3.1928; FAP I, 328. - Briefe von Alekseev an Peterson befinden sich im Peterson-Archiv, GBL f. 657; siche Zapiski ordela rukopisej, 39, 1978, S. 143.

Fedorov war von 1858 bis 1864 in Bogorodsk Lehrer gewesen und hatte dort 1864 Peterson kennengelernt. - Daß man in dieser Stadt das Andenken an Fedorov bewahrt, beweist ein Artikel, den der Direktor des Heimatkunde-Museums von Noginsk 1959 in der Lokalpresse veroffentlichte: A. SMiRnov, "Nikolaj Fedorovi飞 Fedorov." In: Znamja Kommunizma, 227 (10036), 19.11.1959, S. 4.

$138 \mathrm{Vgl}$. V.[I.] ALeKSEEv, "Kraevednaja konferencija v Bogorodske, Moskovskoj gub." In: Kraevedenie, 5 (1928), 2, S. 108f. Ders., "Maksim Gor'kij o kraevedenii. (Moja perepiska s A.M. Gor'kim)." In: Soverskoe Kraevedenie, 1936, 8, S. 4-8. ANON., "... Zemlju vsju, do poslednego atoma." In: Soverskaja Kul'tura, 26 (5138), 28.3.1978, S. 5.

Mit dem Begriff kraevedenie verband sich in den zwanziger und frühen dreißiger Jahren eine breite Bewegung zur Erforschung und Bewahrung kultureller und natürlicher Besonderheiten eines Ortes oder einer Region. Organisiert durch das Central'noe Bjuro Kraevedenija (CBK), gab es Ende der zwanziger Jahre etwa 2000 lokale Vereinigungen und Institute mit etwa 50.000 Mitgliedern. Vor allem in der Provinz bot das kraevedenie der alten Intelligenz (Lehrem, Geistlichen u.ä.) ein willkommenes Betătigungsfeld und zugleich ein weitgehend unpolitisches Refugium. In den dreißiger Jahren verlagerte sich das Schwergewicht des kraevedenie auf die Suche nach neuen Energie- und Rohstoffquellen. Das historisch-kulturelle kraevedenie lebte als Massenbewegung seit den sechziger Jahren wieder auf und hat (seit 1966) seinen organisatorischen Rahmen im Vserossijskoe obšestvo ochrany pamjatnikov istorii i kul'tury (1981: 14 Millionen Mitglieder).

Gelegentlich ist versucht worden, das kraevedenie der zwanziger Jahre mit Fedorov in Verbindung zu bringen; so spricht Utechin von "organized Fyodorovism", und Young nennt die Zeitschrift Kraevedenie "a forum for the discussion of Fedorovist projects". S.V. UTECHIN, "Bolsheviks and Their Allies After 1917: The Ideological Pattern." In: Soviet Studies, 10 (1958), 2, S. 131. G.M. YouNG, Nikolai F. Fedorov: An Introduction. Belmont, Mass. 1979, S. 184. Es gibt jedoch keinerlei Hinweise, die derartige Behauptungen stützen würden.

139 Alekseev an Gor'kij, 6.3.1928; Gor'kij-Archiv, IMLI, KG-uc-1-8-7; Hinweis bei SUCHICH (wie Anm. 40), S. 161.

140 Alekseev an Setnickij, 15.5.1928; FAP I, 328. 
Gor'kij berufen kann, wird es einfacher sein, etwas über Fedorov zu schreiben. ${ }^{1141}$ Ende Dezember erschien Gorskijs aufsehenerregender Artikel in der Izvestija; Anfang Januar erhielt Alekseev Gor'kijs Antwort: Er habe, so Gor'kij, überhaupt keine Zeit, über Fedorov zu schreiben oder sich über ihn zu äußern, und er habe auch nirgends einen Artikel über ihn veröffentlicht. ${ }^{142}$ Noch einmal scheint Alekseev seine Bitte wiederholt zu haben, denn am 6. Juli 1929 teilte er Setnickij den Inhalt eines Briefes mit, den Gor'kij ihm am 9. Mai aus Sorrent geschrieben hatte; er lautet:

Verehrter Ivan Ivanoviz!

Ich werde über Fedorov nicht schreiben, ich habe überhaupt keine Zeit für eine solche Arbeit, ja ich konnte noch nicht einmal die Literatur über ihn durchlesen, die Harbiner Veroffentlichungen. Überdies reise ich in einigen Tagen nach Rußland ab.

Alles Gute

A. Pełkov ${ }^{143}$

Gor'kijs Absage blieb freilich nicht sein letztes Wort. Zwar hat er nie den gewünschten Artikel verfaßt, doch ist er noch mehrmals auf Fedorov und dessen Werk zurückgekommen; insbesondere im Zusammenhang mit jener Theorie, die Gor'kij offenbar am stärksten beeindruckt hatte, derzufolge nämlich die letzte Ursache für die Entstehung und Entwicklung der bürgerlichen Kultur die Frau sei und der hypertrophe Geschlechtstrieb die Grundlage der kapitalistischen Wirtschaft bilde.

In dem Anfang 1930 verfaßten und im März desselben Jahres in der Zeitschrift Naši Dostiženija veröffentlichten Aufsatz $O$ ženš̌ine behandelt Gor'kij die Rolle der Frau in der bürgerlichen Gesellschaft; dabei verwies er auch auf Fedorov, einen "wenig bekannten Schriftsteller", der zu dem Ergebnis gelangt sei, "daß die Grundlage des wirtschaftlichen Lebens der Bourgeoisie der hypertrophe, d.h. krankhaft übersteigerte, in Hochspannung versetzte Geschlechtstrieb sei, und daß das Leben das 'Reich der Frauen' sei, der allseitige Ausdruck ihrer 'nicht drückenden, aber verderblichen Herrschaft'." Die "kirchliche Herkunft dieser Idee" sei, so Gor'kij, "völlig klar", doch enthalte sie in diesem Falle "ein gut Teil 'häßlicher Wahrheit". 144

Im gleichen Zusammenhang - nämlich der Diskussion der 'Frauenfrage' wird Fedorov auch in Gor'kijs großer, zwischen 1925 und 1936 entstandener 'Romanchronik' Žizn' Klima Samgina mehrmals erwähnt:

141 Alekseev an Setnickij, 9.12.1928; ebd.

142 Alekseev an Setnickij, 8.1.1929; ebd. - Gor'kijs Brief ist unveroffentlicht; in der Literatur findet sich kein Hinweis auf inn.

143 Alekseev an Setnickij, 6.6.1929; ebd. - Russ. erstmals bei HaGemeister (wie Anm. 33), S. 231. Auch auf diesen Brief Gor'kijs findet sich in der Literatur kein Hinweis.

144 GoR'k山 (wie Anm. 127), S. 161f. 
Er [Markov] hatte den Abdruck eines Artikels von dem Samgin unbekannten Philosophen N.F. Fedorov mitgebracht und las einige in sonderbar schwerfalliger Sprache verfaßte Sătze vor, die besagten, daß die ganze Grausamkeit der kapitalistischen Gesellschaftsordnung eine Folge der übermäßigen und krankhaften Anspannung des Geschlechtstriebes und das Ergebnis der Unbăndigkeit des durch nichts zu zügelnden und veredelten Fleisches sei. Er schwenkte den Abdruck des Aufsatzes hin und her ... und sagte: "Ja, hier stammt vieles von der Kirche... Der Verfasser ist ein kluger Feind, und er hat recht, wenn er von der 'nicht drückenden, aber verderblichen Herrschaft der Frau' spricht. Ich denke, er hat bei uns als erster so entschieden und richtig darauf hingewiesen, daB die Frau unbewußt ihre Herrschaft, ihren zentralen Platz in der Welt empfindet. Daß jedoch gerade sie die Grundursache und Erweckerin der Kultur sei, konnte er freilich nicht sagen. ${ }^{145}$

In beiden Fällen - dem Aufsatz $O$ ženšcine und dem Roman Žizn' Klima Samgina - stützte sich Gor'kij auf Setnickijs Arbeit KapitalistiČeskaj stroj v izobraženii N.F. Fedorova, die ihm seinerzeit vom Verfasser zugeschickt worden war. Auch die angeführten Zitate aus Fedorovs Abhandlung über die Pariser Weltausstellung von 1889 sind der Arbeit Setnickijs entnommen. ${ }^{146}$

Die letzte bekannte Äußerung Gor'kijs über Fedorov findet sich in einem Brief an B.M. Éjchenbaum vom 14. März 1933:

... wenn Lev Nikolaevi飞 [Tolstoj] über N.F. Fedorov, über V.V. Rozanov, über VI. Solov'ev, Nikolaev und andere solche Leute sprach, so schien es mir, als denke er von jedem: gut, aber - kein Tolstoj! $!^{147}$

Auch in den dreißiger Jahren fuhr Setnickij fort, Gor'kij zu schreiben und ihm die Harbiner Veröffentlichungen zu schicken. ${ }^{148}$ So erhielt Gor'kij mit einem Schreiben vom 3. Mai 1932 Setnickijs Buch $O$ konexnom ideale mit der Bemerkung, es sei "nicht für eine weite Verbreitung bestimmt", doch sei dem Autor sehr an Gor'kijs Urteil gelegen (vsjakoe Vaše suždenie ja primu s ogromnym interesom); Setnickij bat, das Buch auch dem Historiker M.N. Pokrovskij zu zeigen. ${ }^{149}$

145 M. GoR'kJ, PSS. Chudožestvennye proizvedenija v 25-i n. T. 22, M. 1974, S. 123. - Fedorovs Ausspruch von der 'nicht drückenden, aber verderblichen Herrschaft der Frau(en)', wird noch an drei weiteren Stellen des Romans zitiert: t. 22, S. 134, 291; t. 23 (M. 1975), S. 35. Darüber hinaus wird Fedorov erwăhnt: t. 22, S. 147; t. 24 (M. 1975), S. 78, 107. - Ausführlich hierzu Sucrnch (wie Anm. 40), S. 165-168.

146 In seinem Aufsatz $O$ Zenscine verweist Gor'kij selbst auf Setnickijs Aufsatz. Zu Zizn' Klima Samgina siehe den Kommentar in GoR'Ku (wie Anm. 145), t. 25, M. 1976, S. $243 f$.

147 Gor'kij an B.M. Ejchenbaum, 14.3.1933. In: Literatumyj Sorremennik, 5 (1937), 6, S. 28.

148 In Moskauer Privatbesitz befinden sich Abschriften von drei Briefen Setnickijs an Gor'kij aus den dreißiger Jahren: 3.5.1932, 29.10.1934 und Mai 1936 (nicht abgeschickt).

149 Setnickij an Gor'kij, 3.5.1932; Gor'kij-Archiv, IMLI, KG-P-71-4-8; nach einer Abschrift in Moskauer Privatbesitz. - In Gor'kijs Privatbibliothek sind alle separat erschienenen Harbiner Veröffentlichungen zu Fedorov nachgewiesen; die letzten stammen aus dem Jahre 1933. Siehe Liðnaja biblioteka A.M. Gorkogo v Moskve. Opisanie. Kn. 1, M. 1981, S. 28 [Ostromirov, d.i. 
Am 29. Oktober 1934 wandte sich Setnickij erneut an Gor'kij, ${ }^{150}$ wobei er zunächst dessen "Verdienste" um das obšcee delo hervorhob. Es sei, so Setnickij, für ihn "außerordentlich wichtig" gewesen, daß Gor'kij "in den vergangenen fünf Jahren zweimal den Namen Fedorovs in der Presse erwähnt" habe. ${ }^{15}$ Während er und seine Freunde, so Setnickij weiter, zwischen 1918 und 1928 vergeblich versucht hätten, die "Losung des Kampfes gegen die Natur als Hauptaufgabe der Gegenwart" auszugeben, sei es Gor'kijs Verdienst, daß diese Losung inzwischen nicht nur verkündet werde, sondern bereits zu einem programmatischen Element des Aufbaus im Lande geworden sei. Nunmehr müsse sich der Kampf gegen die Natur auf den Kampf gegen den Tod konzentrieren, wobei man sich nicht auf die gelehrten Spezialisten verlassen dürfe, die selbst vom Tod hypnotisiert seien.

Im zweiten Teil seines Briefes wies Setnickij auf das Schicksal von Gorskij und Murav'ev hin. Gorskij, den Gor'kij 1928 kennengelernt habe, sei 1929 verhaftet worden und befinde sich in der Verbannung. Er habe jeden Kontakt zu ihm verloren. "Es kam mir der Gedanke, daß Sie vielleicht eine Erleichterung seiner Lage erwirken oder ihn einfach ausfindig machen könnten, falls er diese Jahre überlebt hat. Er ist ein sehr talentierter Mensch, und ich glaube nicht, da B er irgendwelcher besonderer Vergehen schuldig ist." Gorskijs Arbeit Pered licom smerti, von der "Prof. Gudzij" im Jahre 1928 gesagt habe, sie stelle "einen Wendepunkt in der Erforschung L.N. Tolstojs" dar, ${ }^{152}$ liege inzwischen in einer japanischen und einer tschechischen Ausgabe vor, sei ins Deutsche und Englische übersetzt und solle 1935 anläßlich des 25. Todestages Tolstojs in Amerika erscheinen. Ebenfalls in der Verbannung, in Narym, befinde sich Valerian Murav'ev, ein "sehr interessanter Denker", dessen Werk Ovladenie vremenem 1924 in Moskau erschienen sei.

Was den Kampf gegen die Natur betraf, so war Gor'kij durchaus geneigt, auf die Naturwissenschaftler zu zählen, von deren Erfolgen er sich die Befreiung der Menschheit von Krankheit und Leiden, die Verlängerung des Lebens und

Gorskij], 29 [Setnickij], 31 [Fedorov], 175 [Geželinskij, d.i. Setnickij], 177 [Gornostaev, d.i. Gorskij], 341 [Setnickij].

150 Setnickij an Gor'kij, 29.10.1934; Gor'kij-Archiv, IMLI, KG-P-71-4-9; nach ciner Abschrift in Moskauer Privatbesitz. - Siehe auch die knappen Angaben bei Suchich (wie Anm. 40), S. 164, der den Brief ungenau auf "Anfang der dreißiger Jahre" datiert.

151 Gemeint waren Gor'kijs Artikel Eš̌e o mechaničskich grażdanach (1928) und $O$ žensicine (1930); siehe oben Anm. 127 und 144.

152 N.K. Gudzij (1887-1965), Philologe, Professor an der MGU, Spezialist für altrussische Literatur und für das Werk L.N. Tolstojs. Die Gudzij zugeschriebene Äußerung ist nicht belegt; in Gudzijs Arbeiten zu Tolstoj findet sich kein Hinweis auf Gorskij! 
schließlich sogar die Überwindung des Todes erhoffte. ${ }^{153}$ Im Entwurf eines Antwortschreibens an Setnickij äußerte er sich denn auch wie folgt:

... als Materialist kann ich mir den Kampf gegen den Tod nur als eine praktische Sache vorstellen, die experimentelle Forschung verlangt. Unsere Regierung, die sehr aufmerksam gegenüber Ideen mit "phantastischem" Charakter ist, hat 1932 beschlossen, ein "Allunionsinstitut für experimentelle Medizin" (VIEM) zu gründen. Ziel des Instituts ist die komplexe Erforschung des Lebens, der Arbeit und der Abnutzung des menschlichen Organismus. Erstmals in der gesamten Geschichte der medizinischen Wissenschaften werden hierzu Physiker und Chemiker hcrangezogen, und zum ersten $\mathrm{Mal}$ ist die nơtige Aufmerksamkeit auf die Medizin gerichtet. ${ }^{154}$

Das genannte "Allunionsinstitut für experimentelle Medizin" war Ende 1932 unter starker Anteilnahme Gor'kijs gegründet worden, um die vielfältigen Forschungen auf den verschiedenen Gebieten der Medizin zu koordinieren und auf ein gemeinsames Ziel - die Erhaltung und Verlängerung des menschlichen Lebens - auszurichten. ${ }^{155}$ In seiner propagandistischen Bedeutung den 'Großbauten des Sozialismus' vergleichbar, sollte das Institut, mit den Worten seines Direktors L.N. Fedorov, ein "Dneprostroj der Wissenschaft" werden. ${ }^{156}$

153 Das Thema des Kampfes gegen den Tod findet sich häufig und zu allen Zeiten in Gor'kijs Werk - allerdings nie mit Hinweis auf Fedorov! Gor'kijs ausgeprägte Făhigkeit zum Mitleiden ließ ihn den Tod hassen; beim Anblick eines sterbenden Freundes dachte er: "... eines Tages werden die Menschen den Tod besiegen. Ich habe keinen anderen Grund, an einen Sieg über den Tod zu glauben, als diesen einen - hier stirbt ein Mensch, und das ist so gemein, so unnötig." $M$. GOR'KIJ, "Iz vospominanij." [1917] In: DeRs. (wie Anm. 145), t. 16, M. 1973, S. 396. Wie für Fedorov, so war auch für Gor'kij der Kampf gegen den Tod ein Teil des organisierten Kampfes gegen die Natur. Als Themen, die in Kinderbüchern behandelt werden sollten, schlug er vor: "Die Macht des Menschen über die Natur. Die planmäBige, organisierte Arbeit der sozialistischen Gesellschaft. Der Sieg über die Naturgewalten, über Krankheit und Tod." Und wie Fedorov bezeichnete er in diesem Zusammenhang den Menschen als "Träger jener Energie, die die Welt organisiert und eine 'zweite Natur', die Kultur, erschafft; der Mensch ist das Organ der Natur, das diese gleichsam zur Erkenntnis ihrer selbst und zu ihrer Umwandlung hervorgebracht hat." M. GOR'KJ, "O temach." [1933] In: DeRs. (wie Anm. 127), t. 27, M. 1953, S. 106, 100. - Siche auch S.[G.] SEM'OnOva [SEMENOVA]-GaCEVA, "Prevăzmogvane na esnafa. Otnošenieto kăm smărtta u Maksim Gorki." In: Literaturen Front, 38, 17.9.1981, S. 7. DiEs., "Ne vižu predela mošci razuma'." In: Literatumaja Ǔeba, 1984, 3, S. 150-156.

154 Literatumoe nasledstvo (wie Anm. 34), S. 589 Anm. 3. - Der Entwurf von Gor'kijs Antwortschreiben an Setnickij ist dort auf das Jahr 1933 datiert; offensichtlich handelt es sich jedoch um eine Antwort auf Setnickijs Schreiben vom 20.10.1934. Ob Gor'kijs Schreiben abgeschickt wurde, ist nicht bekannt.

155 Siehe Letopis' Zizni i tvortestva A.M. Gor'kogo, vyp. 4, M. 1960, S. 118, 120, 138, 227, 243, 245, 257, 270. M. GoR'ku, "O nauke." [1932] In: Archiv A.M. Gor'kogo, t. 3, M. 1951, S. 197f. - Aufmerksam hat Gor'kij die Erfolge der Medizin im Kampf gegen den Tod registriert und kommentiert. So schlug er beispielsweise 1925 in einem Brief an den Verleger A.E. Kogan vor, unter dem Titel "Die Auferweckung der Toten" (Voskrešenie mertyych) einen Artikel über die erfolgreichen Reanimationsversuche des russischen Chirurgen V.A. Oppel' zu verfassen und über N.P. Kravkovs Experimente zur Neubelebung abgestorbener Gewebe zu berichten. Siehe L. FlejSMAN, "Gor'kij i žurnal'nyj proekt A.E. Kogana." In: Slavica Hierosolymitana, 4, 1979, S. 271.

156 Siehe E. Herriot, "La Russie: l'intelligence nouvelle." In: Conferencia, 1934, 9 (15 avril), S. 478. - Zur Begegnung des ehemaligen französischen Ministerpräsidenten Edouard Herriot mit Gor'kij und L.N. Fedorov am 5.9.1933 siehe auch Letopis' (wie Anm. 155), S. 322. 
Ob Gor'kij sich für den verbannten Gorskij eingesetzt hat, ist nicht bekannt. Murav'ev war zu dieser Zeit schon tot. Mitte November 1934 bat Gor'kij seinen Sekretär P.P. Krjuckov, ihm Murav'evs Ovladenie vremenem zu schicken. 157

Setnickij kehrte im Juni 1935 nach Moskau zurück. Als er bald darauf erkrankte, schickte Gor'kij ihm einen Arzt. ${ }^{158}$

Noch einmal hat Setnickij an Gor'kij geschrieben. Im Mai 1936 verfaßte er einen 7-seitigen Brief, ${ }^{159}$ in dem er über Vereinsamung und Depressionen klagte, Gor'kij für die erwiesene Aufmerksamkeit und Hilfe dankte und dessen Verdienste im Kampf gegen den Tod hervorhob:

Ich denke, daß Sie, A[leksej] M[aksimovix], auf dem Weg dieses Kampfes sehr viel getan haben. Für einen Außenstehenden ist das nicht erkennbar, doch Ihre Analyse der Figur L.N. Tolstojs, unübertroffen in ihrer Genauigkeit und Schărfe, die Gestalt des [Egor] Bulyžov, Ihre Aufsătze aus dem Jahre 1928 über den Kampf gegen die Natur mit dem Zitat N.F. Fedorovs und auch Ihre jüngste Erwăhnung dieses Namens in einem Ihrer Bücher [wahrsch. Žizn' Klima Samgina; M.H.] all das sind Dinge von großer Bedeutung. ${ }^{160}$

Heute, da "der Faschismus den Untergang der Welt und der Menschheit" vorbereite, sei es notwendiger denn je, einen "wirklichen Kampf für das Leben" zu führen und "alle Masken des Todes herunterzureißen". Ohne Kampf gegen den Tod könne der Kommunismus nicht erbaut werden. Gor'kij aber sei "gegenwärtig der einzige Mensch in der [Sowjet-]Union", der "direkt und klar" den Feind erkenne, mit dem man kämpfen müsse. Wie dieser Kampf "allein" (v odinocku) geführt werden könne, wolle er Gor'kij bei einer persönlichen Begegnung mitteilen. ${ }^{161}$ Der Brief wurde nicht abgeschickt; ein Treffen mit Gor'kij kam nicht mehr zustande. Am 18. Juni 1936 ist Gor'kij gestorben.

Überblickt man Gor'kijs Äußerungen zu Fedorov, so fällt auf, daß sie um lediglich zwei Themen, genauer, zwei kurze Zitate kreisen: Fedorovs Ausspruch von der 'nicht drückenden, aber verderblichen Herrschaft der Frau' und seine Behauptung, 'Freiheit ohne Macht über die Natur [sei] das gleiche wie eine Befreiung der Bauern ohne Land'. Wo immer Gor'kij sich zu Fedorov äußerte, berührte er mit keinem Wort das zentrale Thema der Filosofija obščego dela, die Überwindung des Todes und die Auferweckung der Verstorbenen. Zwar sprach Gor'kij wiederholt von der Möglichkeit, das menschliche Leben zu verlängern, und er schloß nicht aus, daß es dem menschlichen Verstand gelingen werde,

157 Siehe Letopis' (wie Anm. 155), S. 424. - Gor'kij lebte damals in Tesseli auf der Krim.

158 SETNICKAJA (wie Anm. 11), Bl. 10. - Vermittler war möglicherweise der Schriftsteller S.G. Skitalec (eig. Petrov), der, 1934 aus dem Exil in Harbin nach Moskau zurückgekehrt, sowohl mit Gor'kij wie auch mit Setnickij bekannt war. Mitteilung O.N. Setnickaja.

159 Setnickij an Gor'kij, Mai 1936; nach einer Abschrift in Moskauer Privatbesitz. - Siehe auch unten Anm. 211.

160 Ebd. - In dem 1930/31 entstandenen Bühnenstück Egor Bulycov $i$ drugie schildert Gor'kij den Kampf gegen den Tod als - freilich vergebliche - Auflehnung eines einzelnen gegen sein Sterben.

161 Ebd. 
einst sogar physische Unsterblichkeit zu verwirklichen, doch knüpfte er derlei Spekulationen an die seinerzeit vieldiskutierten gerontologischen Forschungen und Theorien eines Mečnikov oder Steinach; Fedorov wurde in solchem Zusammenhang nie erwähnt. Insgesamt vermitteln Gor'kijs Äußerungen nicht den Eindruck einer auf intensiver Beschäftigung beruhenden gründlichen Kenntnis des Fedorovschen Werkes; oft sind sie nur Reaktion auf die hartnäckigen Versuche der Fedorov-Anhänger, den prominenten und einflußreichen Schriftsteller zum Fürsprecher ihrer Sache zu gewinnen.

\subsubsection{Setnickij 1928-1937}

Das Jubiläumsjahr 1928 hatte den Höhepunkt der Publikations- und Propagandatätigkeit Setnickijs gesehen. Doch auch in den folgenden Jahren nutzte er alle Möglichkeiten, die ihm ein freies Verlags- und Pressewesen sowie seine Stellung als Dozent an der Juristischen Fakultät boten, um Fedorovs Ideen und die seiner Anhänger zu verbreiten. Wiederholt machte Setnickij von der Möglichkeit Gebrauch, Fedorovsche Gedanken im Rahmen eigener Aufsätze in den Izvestija JuridiCeskogo Fakul'teta zu propagieren. ${ }^{162}$ Auch die von der Studentenschaft der Fakultät einmal jährlich herausgegebene Zeitung Den' Jurista diente ihm als Forum. ${ }^{163}$

Den gewichtigsten eigenen Beitrag zur Interpretation und Weiterentwicklung Fedorovscher Gedanken legte Setnickij 1932 mit dem Buch $O$ konecnom ideale vor. ${ }^{164}$ Im ersten Teil dieser umfangreichen Studie versuchte er, Grundlagen einer Lehre vom "letzten Ideal" als Anweisung zur innerweltlichen Verwirkli-

162 Siehe oben Anm. 24. - Ein Aufsatz Setnickijs Materialy po perepiske N.F. Fedorova, VA. Koteunikova i N.P. Petersona, der als Beilage zu Bd. 10 der Izv.Jur.Fak. (1933) angekündigt war (ebd., S. 378), ist offenbar nicht erschienen.

163 In den Jahren nach 1928 lassen sich zwei Beitrăge Setnickijs nachweisen: N.[A.] SETNICKIJ, "Central'naja ideja N.F. Fedorova." In: Den' Jurista, 8, 1929, S. 5. DERS., "Sovremennost' na putjach bor'by so smert'ju." Ebd., 13, 1934, S. 3f. Die tatsăchliche Zahl der Beitrăge Setnickijs in dieser heute kaum noch zugănglichen Zeitung dürfte jedoch erheblich großer sein. Mitteilung O.N. Setnickaja.

Bei seinen Bemühungen, Fedorovs Werk zu propagieren, scheint Setnickij bisweilen die Toleranz seiner Vorgesetzten stark beansprucht zu haben. So weigerte sich der Rektor der Fakultăt, N.V. Ustrjalov, mit Schreiben vom 15.7.1929, die Druckkosten für drei Arbeiten über Fedorov aus der Fakultătskasse zu bestreiten. Setnickij sei Geld für eine Studie Očerki kitajskich finansov bewilligt worden; die genannten Titel hătten damit jedoch nichts zu tun. Setnickij wird sie dann wohl aus eigener Tasche bezahlt haben. FAP I, 342.

164 N.A. SETNICKI, $O$ konexnom ideale, Charbin 1932. - Die Auflage betrug 250 Exemplare. Das Buch war, wie Setnickij selbst bemerkte, "nicht für eine weite Verbreitung bestimmt". Brief an Gor'kij vom 3.5.1932; siehe oben Anm. 149. Fünf der insgesamt 16 Kapitel waren vorab erschienen: N.A. SETNICKU, "O koneznom ideale." In: Izv.Jur.Fak., 7, 1929, S. 191-255 (auch als Sonderdruck). Im folgenden wird nach der Ausgabe von 1932 zitiert. - Setnickij arbeitete an einer Fortsetzung des Buches; erhalten ist ein Manuskript mit dem Titel Ob-edinenie celovecestva. Dogmat i opyt, Ms. [Masch.], 49 Bl.; Exemplare in zwei Moskauer Privatarchiven. 
chung idealer Vollkommenheit zu formulieren und gegen Einwände zu verteidigen, wie sie vor allem der Rechts- und Sozialphilosoph P.I. Novgorodcev (18661924) in seinem großen ideologiekritischen Werk Ob obščstvennom ideale (1917) erhoben hatte.

Novgorodcev hatte behauptet, daß der Anspruch innerweltlicher Heilslehren, die Antithese von Freiheit und Ordnung aufzuheben und absolute Harmonie in den Grenzen des irdischen Seins zu verwirklichen, die transzendente Natur des Absoluten mißachte. Innerhalb der Geschichte gebe es keinen Sinn, keine bestimmte Richtung, kein letztes Ziel. Daraus folge, so Novgorodcev, der "Zusammenbruch [aller] Utopien vom Erdenparadies". ${ }^{165}$ Das 'letzte' absolute Ideal verliere damit freilich nicht seine historische Bedeutung und objektive Geltung: Zwar gebe es keine "Hoffnung auf die konkrete Erlangung (dostiženie) idealer Vollkommenheit" in der Geschichte, möglich aber bleibe "sittlicher Fortschritt" als unendliche Annäherung an das Absolute. Das "absolute Ideal" sei "die Grenze, auf die man auf den Wegen der Geschichte zugehen" müsse. ${ }^{166}$

Demgegenüber vertrat Setnickij die Überzeugung, die Menschheit sei in ihrer Gesamtheit in der Lage, ideale Vollkommenheit auf Erden zu verwirklichen, wenn sie sich an einem "ganzheitlichen Ideal" (celostnyj ideal) orientiere. Ein solches "ganzheitliches Ideal" sowie der Weg zu seiner Verwirklichung seien am klarsten von Fedorov beschrieben worden, nämlich als Schaffung einer vollkommenen Gesellschaft freier und unsterblicher Personen einschließlich aller wiedererweckten Verstorbenen durch die gemeinsame Arbeit aller Menschen. ${ }^{167}$ Als nächstliegende Aufgaben habe Fedorov genannt: die Vereinigung der Menschheit im Kampf gegen die Natur, die Beherrschung des Klimas als Vorstufe kosmischer Regulierung und die elementare Regenerierung des menschlichen Organismus als Vorstufe zu dessen künstlicher Konstruktion. ${ }^{168}$ Alle diese Aufgaben - von manchen als 'unwissenschaftlich' und 'phantastisch' abge$\tan -{ }^{169}$ seien, so Setnickij, mittlerweile in der Sowjetunion angegangen worden:

165 Siehe P.[I.] NovgorodCEv, Ob obscestvennom ideale, yyp. 1 [mehr nicht erschienen], izd. tret'e, Berlin 1921; Kapitel "KruSenie utopii zemnogo raja", S. 143-386; bes. S. 143-146.

166 Ebd., S. 79. - Novgorodcevs Buch bietet - fast dreißig Jahre vor Karl Löwiths Weltgeschichte und Heilsgeschehen (Meaning in History, 1949) - eine glänzende Kritik innerweltlicher Heilslehren dargestellt als săkularisiente Formen der Erlösungshoffnung - durch den Nachweis, daß es aufgrund der Begrenztheit dieser Welt keine Selbsterlösung, keine absolute Rechtfertigung geben kann, weder des Bestehenden, noch des durch Menschenmacht in der Zukunft je zu Erreichenden. - Lange Zeit fast unbekannt, finden Novgorodcev und scin Werk erst allmählich die ihnen gebührende Beachtung. Siehe G.F. PUTnAM, Russian Altematives 10 Marxism, Knoxville 1977, bes. S. 122-176. A. WALICKI, Legal Philosophies of Russian Liberalism, Oxford 1987, S. 291-341.

167 SETNICKIJ (wie Anm. 164); zu Fedorov S. 66-88, zur Kritik an Novgorodcev S. 3-16.

168 Ebd., S. $76 f$.

169 Ebd., S. 79f. - Hier wendet sich Setnickij v.a. gegen Ustrjalov, der in scinem Aufsatz Problema progressa (1931; siehe oben Anm. 7) zwar eine "glänzende Skizze" der Fedorovschen Theorie gegeben, jedoch ihre Umsetzbarkeit in die Praxis bestritten habe; zur Kritik an Ustrjalov auch ebd., S. 17-30. - Sehr viel schärfer als Ustrjalov hatte ein anderer Kollege Setnickijs, der 
Man kann mit Gewißheit sagen, daß es keinen oder fast keinen Tătigkeitsbereich in der heutigen UdSSR gibt, in dem nicht offen oder verdeckt Fedorovs Ideen verwirklicht wïrden. ${ }^{170}$ (...) ... Fedorov selbst würde im gegenwärtigen sowjetischen Aufbau den Beginn der Verwirklichung des obšcee delo sehen... ${ }^{171}$

Noch mangele es vielfach an der wirksamen Koordinierung aller Aktivitäten, da das Endziel, das "letzte Ideal", noch nicht klar erkannt und begriffen worden sei, doch hoffte Setnickij - und versuchte auch mit seiner Arbeit dazu beizutragen -, daß Gosplan (die oberste sowjetische Planungsbehörde) dereinst das "Projekt der universellen Errettung" entwerfen und realisieren werde. ${ }^{172}$

Mit eschatologischem Blick auf die Perfektibilität der Welt bot Setnickij im zweiten Teil seiner Arbeit ("Materialien zu einer Lehre vom letzten Ideal") eine aktuelle, auf konkrete Probleme der Gegenwart und Zukunft bezogene Auslegung der Apokalypse des Johannes, aufgefaßt - im Sinne Fedorovs - nicht als Vorhersage eines unabwendbaren schicksalhaften Ereignisses, das es abzuwarten und ergeben hinzunehmen gelte, sondern als Aufruf und Anleitung zur aktiven Gestaltung der Zukunft durch den Menschen. "Hauptthema der Apokalypse" sei, so Setnickij, "das Entstehen der schöpferisch-umgestaltenden Tätigkeit der Menschheit und ihre Ausrichtung auf die völlige Verwandlung aller Bereiche des Kosmos..." ${ }^{173}$

In seiner Rezension nannte Berdjaev Setnickijs Buch "das vielleicht interessanteste und wichtigste" der bisherigen Fedorov-Literatur und hob besonders die - von ihm selbst geteilte - aktive Auffassung der Apokalypse als Aufruf zum Handeln hervor, während seine Kritik sich vor allem gegen die - vermeintliche Minderung des göttlichen Anteils am Sieg über den Tod richtete. ${ }^{174}$ Dagegen bemerkte Bulgakov zu Recht und kritisierte, daß der Kampf gegen den Tod bei

Anthropologe E.M. Cepurkovskij, Fedorovs Idee einer Auferweckung mit wissenschaftlichen Mitteln kritisiert und sie als "absurde Phantasie" und "völligen Unsinn" bezeichnet. E.M. CEPURKovsku, "Absoljutnyj mir $\mathrm{i}$ individu[a|l'noe bessmertie $s$ to Kki zrenija sovremennogo estestvoznanija." In: Izv.Jur.Fak., 9, 1931, S. 89-91.

170 SETNICKU (wie Anm. 164), S. 81.

171 Ebd., S. 83. - Als Beispiele für die Verwirklichung Fedorovscher Ideen und Projekte (wobei der Zusammenhang freilich kaum jemandem bewußt sei!) nannte Setnickij u.a. den Kampf gegen die Dürre, das "Große-Wolga-Projekt", Versuche zur Verjüngung von Organismen und zur Wiederbelebung Verstorbener.

172 Ebd., S. 84.

173 Ebd., S. 321. - Der Kampf um die Verwandlung der Welt werde, so Setnickij, auch "mit dem Wort" geführt (bor'ba slovom), ebd., S. 178; hier klingen Vorstellungen des imjaslavie an, wie sie in der Schrift Smentobożnizestvo skizziert worden waren. Siehe II: 4.1.

174 N.[A.] Berdjaev, [Rez.] "N.A. Setnickij, O koneלnom ideale. 1932 g." In: Put', 36, 1932, S. 9395. - Berdjaevs Kritik, Setnickij verwandle den Sieg über den Tod "vor allem [!] in ein (im weitesten Sinne) technisches Problem", beruht auf der Annahme, daß der Sieg über den Tod eine gemeinsame "göttlich-menschliche Aufgabe" sei; diese Annahme wird jedoch weder von Fedorov noch von Setnickij geteilt. Setnickij zufolge ist die Auferweckung eine "erarbeitete, immanente, reale und körperliche, durch den Menschen zu verwirklichende". SETNICKU (wie Anm. 164), S. 77. 
Setnickij zur reinen Menschensache werde; die Apokalypse, das Vorbild Christi, ja selbst die Idee Gottes seien für ihn lediglich Allegorien jener Aufgaben und Ziele, die die Menschheit, ganz auf sich allein gestellt, "in grenzenlosem Naturalismus" zu verwirklichen habe. ${ }^{175}$ Florovskij zufolge habe das - für Fedorov und dessen Anhänger typische - Bedürfnis nach Endlichkeit und Abgeschlossenheit (žažda koncov, volja $k$ okončaniju) Setnickij daran gehindert zu begreifen, daß sich das Ideal nicht an einem bestimmten (End-)Punkt der Geschichte verwirkliche, sondern zu jeder Zeit im endlosen Streben nach Vervollkommnung. ${ }^{176}$ Als positiv bewertete Losskij, daß Setnickijs "Aufruf zur Verwirklichung idealer Vollkommenheit" sich vom sowjetischen Fortschrittskonzept wesentlich dadurch unterscheide, da $B$ er nicht zulasse, "daß ganze Bevölkerungsgruppen mißbraucht würden zur Düngung von Feldern, von deren Ernte künftige Generationen sich ernährten". ${ }^{17}$

1933 veröffentlichte Setnickij unter dem Pseudonym "G.G. Geželinskij" ein schmales Bändchen mit Reflexionen über Ursprung, Entwicklung und Aufgabe der Kunst. ${ }^{178}$ Obwohl Fedorov namentlich nicht genannt wurde, sind die zentralen Gedanken - etwa über den religiösen Ursprung der Kunst, über ihr Streben nach Verwirklichung von Harmonie und Ganzheitlichkeit in der Welt oder ihre künftige Bestimmung als "Liturgie" - der Filosofija obščego dela entnommen.

Setnickij bemühte sich auch, die in seinem Besitz befindlichen Manuskripte Gorskijs zu veröffentlichen. 1929 ließ er auf eigene Kosten 500 Exemplare der bereits 1918 entstandenen Untersuchung über Fedorov und Dostoevskij drukken, deren Veröffentlichung 1923 in Gor'kijs Zeitschrift Beseda vorgesehen, dann aber nicht zustande gekommen war. ${ }^{179}$ Ebenfalls auf eigene Kosten gab Setnickij in den Jahren 1928 bis 1933 in vier Lieferungen Gorskijs mehrteilige Studie über 'Fedorov und die Gegenwart' heraus. ${ }^{180}$ Das zwischen 1923 und 1927 verfaßte Werk sollte im Anschluß an einen biographischen Abriß (vyp. 1) die Aktualität des Fedorovschen Denkens auf den Gebieten der Philosophie

175 [S.N. BuLgaKov], "Ideja obšego dela." [Vosproizvedenie po pamjati nekotorych myslej doklada ... S. Bulgakova]. In: Vestnik RSChD, 9 (1934), 10, S. $17 \mathrm{f}$.

176 G.[V.] Florovsku, "Proekt mnimogo dela. (O N.F. Fedorove i ego prodolžateljach)." In: Sovremennye Zapiski, 59, 1935, S. 410.

177 N.[O.] Lossku, [Rez.] "N.A. Setnickij, O koně̌nom ideale. Charbin 1932." In: Noyyj Grad, 9, 1934, S. 89-92; hier S. 92. - Losskij spielt damit auf Ivan Karamazovs Vorwurf an, die "künftige Harmonie" werde mit menschlichen Leiden "gedüngt".

178 G.G. GeŽelinsku [d.i. N.A. Setnicku], Zametki ob iskusstve, o.O. [Harbin] 1933. Das Băndchen umfaBt 32 Seiten, die Auflage betrug 150 numerierte Exemplare. Ein geplanter zweiter Band ist nicht erschienen. Siehe auch die Rezension von Ja. Kalouskova in: Vselenskoe delo (wie Anm. 4), S. 203-205.

179 A.K. Gornostaev [GoRsku], Raj na zemle. $K$ ideologii tvortestva F.M. Dostoevskogo. F.M. Dostoevskij i N.F. Fedorov. O.O. [Harbin] 1929. 87 Seiten. Rechnung der Druckerei L.M. Abramovic an Setnickij vom 11.5.1929 im FAP 1, 342. Siehe auch II: 4.1. Anm. 32-35.

180 Siehe oben Anm. 117-119. 
und Theologie (vyp. 2), der Wissenschaft und Kunst (vyp. 3) sowie der Politik (vyp. 4) nachweisen. Dabei gab es kaum ein Ergebnis zeitgenössischen Denkens und Forschens, das von Gorskij nicht zu Fedorov in Beziehung gebracht oder gar als Beweis für dessen geniale Voraussicht gedeutet wurde - von Skrjabins Konzeption des Gesamtkunstwerks über Einsteins Relativitätstheorie und Freuds Psychoanalyse bis zu Ciolkovskijs Raumfahrtprojekten! Setnickijs Bemühungen verdanken sich wahrscheinlich auch die japanische und die tschechische Ausgabe von Gorskijs Studie über Fedorov und Tolstoj, die 1933 erschienen sind. ${ }^{181}$ Schließlich brachte Setnickij 1935 noch zwei Werke aus Gorskijs umfangreichem dichterischem CEuvre heraus, die jedoch keinen direkten Bezug zu Fedorov erkennen lassen. ${ }^{182}$

Wie sehr Setnickij sich auch um die Verbreitung der genannten Publikationen kümmerte, zeigen Briefe aus aller Welt, die sich im Fedorov-Archiv erhalten haben. $\mathrm{Zu}$ den regelmäßigen Empfängern der Sendungen aus Harbin gehörten der in Prag lebende georgische Schriftsteller und Eurasier K.A. Čcheidze $(1897-1974),{ }^{183}$ der Soziologe und Harvard-Professor Pitirim Sorokin (18791968) ${ }^{184}$ sowie der Basler Theologe, christliche Sozialist und Exeget russischer Philosophie Fritz Lieb (1892-1970) ${ }^{185}$ In mehreren Briefen aus München und Berlin bedankte sich der Maler L.O. Pasternak für zugesandte Bücher und äußerte sich zufrieden über die Qualität, mit der sein Fedorov-Porträt auf Postkarten reproduziert worden war, die Setnickij zu Werbezwecken in großer Auflage hatte herstellen lassen. ${ }^{186}$ Unter Setnickijs Korrespondenten befand sich auch der englische Staatsbeamte und Kenner der russischen Religions- und Geistesgeschichte A.F. Dobbie-Bateman (1897-1974), der in einem Leserbrief an die Londoner Times vom 10.1.1933 auf die herausragende Bedeutung Fedorovs hingewiesen und eine Übersetzung seines Werks angeregt hatte. ${ }^{187}$

181 Siehe oben Anm. 121.

182 A.K. Gornostaev [GoRsKu], Odigirnja. Sonety iz cikla 'Velikaja cep". O.O. [Harbin] 1935. Auflage: 120 numerierte Exemplare. ZIN. GERV. JACHONTOV [A.K. GORSKIJ], Vyskazyvanija $i$ kartiny. Poima v 3-ch Castjach. C. 1-2, 0.O. [Harbin] 1935.

183 Ausführlich II: 4.3.2.

1845 Briefe von PA. Sorokin an Setnickij aus den Jahren 1929-1932 im FAP I, 330. - In seinen Schreiben geht Sorokin kaum auf den Inhalt der zugesandten Bücher ein.

185 Lieb war von 1930 bis 1933 Professor der Theologie in Bonn, ab 1937 in seiner Heimatstadt Basel. Von 1934 bis 1937 lebte er in Clamart bei Paris, wo er engen Kontakt zu Berdjaev, Bulgakov, Sestov, Fedotov und anderen (meist linken) russischen Emigranten hatte. Zusammen mit Berdjaev gab er die Zeitschrift Orient und Occident heraus. Unter den rund 12000 Büchern, die Lieb 1951 der Universitătsbibliothek Basel schenkte ("Sammlung Lieb"), befinden sich alle in Harbin erschienenen Fedoroviana, darunter ein Widmungsexemplar von Setnickijs $O$ konetnom ideale.

1866 Schreiben von L.O. Pasternak an Setnickij aus den Jahren 1928-1934 im FAP I, 330.

187 "... this rare and Christian philosopher is practically unknown. His 'Philosophy of the Common Task' awaits a translator." A.F. DOBBIE-BATEMAN, Technocracy." [Leserbrief] In: The Times, 
Solcher Enthusiasmus blieb freilich die Ausnahme; er kann nicht darüber hinwegtäuschen, da $B$ die Resonanz auf die Harbiner Publikationen insgesamt schwach war und für Setnickij deprimierend gewesen sein muB. ${ }^{188}$ Zwar wurde der Versuch, Fedorovs Werke in einer neuen, erweiterten Ausgabe wieder zugänglich zu machen, von mehreren Rezensenten begrüßt, doch stießen Setnickijs und vor allem Gorskijs Arbeiten auf zum Teil schroffe Kritik. Der Prager Slawist Dmitrij Tschižewskij nannte Gorskijs Darstellung "vollkommen unkritisch"; seine Studie über Dostoevskij und Fedorov sei "als völlig miBlungen ... zu betrachten". ${ }^{189}$ Lev Šstov kritisierte die Neigung der Fedorov-Anhänger, die Ideen ihres Lehrers zu vereinfachen und krampthaft zu aktualisieren. ${ }^{190}$ Noch negativer äußerte sich der berühmte Philologe und Eurasier Fürst N.S. Trubeckoj in einem Brief vom 1. Januar 1933 an seinen Gesinnungsgenossen, den in Prag lehrenden Wirtschaftsgeographen und Kulturtheoretiker P.N. Savickij:

Sie wünschen mein Urteil über die Harbiner Fedorov-Anhănger. Da ich selbst kein Philosoph bin, kann ich natürlich nicht besonders kompetent urteilen. Die Arbeit von A.K. Gornostaev 'Dostoevskij und Fedorov' ist unter aller Kritik. Das ist eine völlig unzulăssige Art des Herangehens an Literatur. Seine andere Arbeit, 'Tolstoj und Fedorov', ist etwas besser, doch nur deshalb, weil sie nicht mit literarischen Werken, sondern mit biographischen Daten operiert. Im ganzen aber ist das stăndige Bestreben der Fedorov-Anhănger, einen bestimmenden EinfluB Fedorovs auf alle russischen Denker seiner Zeit nachzuweisen, völlig unhistorisch. Es gibt viel zu wenig positive Zeugnisse für einen solchen Einfluß, und nur wenn man sie durch die Lupe eines sektiererischen Fanatismus betrachtet, kann man in ihnen das erkennen, was die Fedorov-Anhänger zu sehen vermeinen. Außer acht bleibt dabei der außerst labile und zu augenblicklicher Begeisterung neigende Charakter der russischen 'Berufsgottsucher' (bogoiskateli-pmfessionaly) jener Zeit. Sowohl Dostoevskij wie auch Tolstoj und ganz besonders Vladimir Solov'ev waren damals durchaus imstande, irgend jemandem einen begeisterten Brief zu schreiben, ihm mitzuteilen, daß sie mit ihm in allem übereinstimmten, und sich ein, zwei Wochen intensiv mit einem Denker zu beschaftigen, den sie gerade entdeckt hatten, - um diesen dann schon ein Jahr später so gründlich vergessen zu haben. $\mathrm{daB}$ man nicht mehr die geringste Spur von ihm findet... ${ }^{191}$

10.1.1933. Dobbie-Bateman wurde später Geistlicher und schrieb ein Buch über Serafim von Sarov.

188 Dies bestătigt auch SETNICKAJA (wie Anm. 11), Bl. 9.

189 D. ČŽEvs'KY] [TsChiZEwSKu], [Rez.] "Fedorov, N.F.: Filosofija obšego dela. T. I, yyp. 1 i 2. Charbin 1928/29. [...] Ostromirov, A.: N.F. Fedorov i sovremennost'. Charbin 1928. [...] Gornostajev, A.K.: Pred licom smerti. Charbin 1929. [...] Gornostajev, A.K.: Raj na zemle. 1929. [...]." In: Slavische Rundschau, 2 (1930), S. 515f.

190 L. Chestov [ŠEstov, d.i. L.I. Śtarcman], [Rez.] "N.F. Fedorov, Filosofija obšcego dela [...], fasc. I a III, Kharbin, 1928, 1929, 1930. - A. Ostromirov, N.F. Fedorov i sovremennost' [...), Kharbin, 1928, 1932, 1933. - A.K. Gornostaev, Pred licom smerti [...] Kharbin, 1929." In: Le Monde slave, 11 (1934), 2, S. 155-158. Dass. russ. unter dem Titel "N.F. Fedorov." In: L. SEsTOV, Umozrenie i otkrovenie, Paris 1964, S. 125-130; deutsch in: L. SCHESTOW [SEETOV], Spekulation und Offenbanung, Hamburg, München 1963, S. 179-184.

191 N.S. Trubeckoj, Wien, an P.N. Savickij, Prag, 1.1.1933; nach einer Abschrift im FAP I, 328. Trubeckojs Onkel, der Philosoph Evgenij Trubeckoj, hatte in seiner 1913 erschienenen großen Arbeit über die Weltanschauung Vladimir Solov'evs auch das Verhăltnis zwischen Solov'ev und Fedorov untersucht. Siehe II: 2.2.1. 
Bisweilen ist vermutet (oder behauptet) worden, in Harbin habe es eine ganze Gruppe von Anhängern Fedorovs gegeben, die sich - einer religiösen Gemeinde gleich - der Propagierung seiner Ideen gewidmet hätten. ${ }^{192}$ Dies war nicht der Fall. Setnickij fand zwar Interesse und gelegentlich Unterstützung, jedoch niemanden, der seine Überzeugung in vollem Umfang geteilt hätte. ${ }^{193}$ In Briefen klagte er über geistige Einsamkeit und gedachte der Moskauer Jahre, da er von einem Kreis Gleichgesinnter umgeben gewesen war. ${ }^{194}$

Zeit seines Lebens dichterisch tätig (wovon zahlreiche Gedichte und Dramen in seinem Nachlaß zeugen, von denen freilich der größte Teil unveröffentlicht geblieben ist), ${ }^{195}$ suchte Setnickij, wie zuvor schon in Odessa und Moskau,

Mehrere Rezensenten der Harbiner Publikationen verzichteten auf eine Bewertung und beschrănkten sich auf eine Wiedergabe des Inhalts. Vgl. L.[I.] KEL'BERIN, [Rez.] "Fedorov i sovremennost'. (A. Ostromirov. Charbin)." In: Cisla, sb. 9, Paris 1933, S. 181-183. I.P. Kozo. DOEV [d.i. N.A. SETNICKU], "K tridcatiletiju so dnja smenti N.F. Fedorova. (Bibliografizeskaja zametka)." In: Vrata, kn. 1, Sanchaj 1934, S. 183-187. I. K-V [d.i. N.A. SETNICKIJ], [Rez.] "18281903-1928 g.g. Filosofija Obšcego Dela. [...] T. 1, vyp. 1-3 [Harbin] 1928-1930." In: Vselenskoe delo (wie Anm. 4), S. 188. I. K-V [d.i. N.A. SetNiCKU], [Rez.] "A. Ostromirov, Nikolaj Fedorovil Fedorov i sovtemennost" [yyp. 1-4]." Ebd., S. 194-196. ŽEL'. [d.i. N.A. SETNCKU], [Rez.] "A.K. Gornostaev. Pered licom smerti [...] A.K. Gornostaev. Raj na zemle [...]." Ebd., S. 196198. Berdjaev ging in seiner 'Rezension' von Raj na zemle nicht auf den Inhalt des Buches ein, sondern wiederholte seine Einwănde gegen die Idee einer universellen Auferweckung als Menschenwerk. N.[A.] Berdjaev, [Rez.] "A.K. Gornostaev. Raj na zemle [...]." In: Put', 19, 1929, S. 114-116.

192 So heißt es bei Billington: "[Fedorov's] most inspired followers [!] fled [!] ... from Bolshevik Russia to Harbin, Manchuria, to form a quasi-religious commune [!], which was in tum engulfed when the wave of Leninist, political revolution [!] spread from their native to their adopted land." J.H. BiLungton, The Icon and the Axe, New York 1970, S. 43. Ähnlich auch Koehler: "... some [!] of Fedorov's most devoted followers found temporary refuge [!] in China after the Russian Revolution..." L. KOEHLER, N.F. Fedorov: The Philosophy of Action. Pittsburgh 1979, S. 129. Ganz abwegig schließlich Young: "... the world center for Fedorovism [!] in the late twenties was ... in Manchuria. There, at the Harbin School of Law, a young professor, N.A. Setnitskii had gathered a circle [!] of true believers who were prepared to devote everything to the common task." Young (wie Anm. 138), S. 185. Und Vagin: "In der zweiten Hăffte der zwanziger Jahre entstand in Kreisen der russischen Emigration in Harbin die eigenartige 'Sekte' der Fedorov-Verehrer - die 'Todesvergotter' [!] (smeriobozniki)." E.[A.] VAGIN, "Sovetskoe izdanie N.F. Fedorova." In: Vete, 11, 1983, S. 118. - Von "Verehrem [!] Fedorovs in Harbin" spricht auch Gor'kij in seinem Brief vom 27.9.1926 an Ol'ga Forš (siehe oben).

Der Eindruck, es gebe in Harbin eine (größere) Anzahl von Anhängem Fedorovs, wurde nicht zuletzt durch die wechselnden Pseudonyme hervorgerufen, unter denen Setnickij seine und Gorskijs Werke veröffentlichte, und war durchaus beabsichtigt. Als Setnickij einmal vorschlug, eines seiner Werke anonym herauszubringen, widersprach Gorskij: "Je mehr [verschiedene] Autorennamen, desto besser." Gorskij an Setnickij, 17.2.1928; FAP I 328.

193 Briefliche Mitteilung von O.N. Setnickaja, Moskau, 12.7.1980.

194 Briefliche Mitteilung von O.N. Setnickaja, Moskau, 19.1.1981.

195 Setnickijs dichterische Erzeugnisse, viele davon bereits vor und wăhrend des Ersten Weltkriegs entstanden, füllen allein im Prager Fedorov-Archiv fünf Kartons (FAP I, 318, 319, 323, 325, 
auch in Harbin die Begegnung mit Dichtern und Schriftstellern und verkehrte in literarischen Zirkeln. Es scheint, daß sein Engagement für Fedorov in diesem Milieu eine gewisse Resonanz fand; die Zeugnisse dafür sind allerdings spärlich und vage. ${ }^{196}$

Immerhin kann als sicher gelten, daß der wohl bedeutendste russische Dichter in Harbin, Arsenij Ivanovic Nesmelov (eigentl. Mitropol'skij, 1891-1945), mit Setnickij bekannt war und von diesem in die Gedankenwelt Fedorovs eingeführt worden ist. ${ }^{197}$ Nesmelov, der unter dem Einfluß der russischen Futuristen (Severjanin, Majakovskij, Aseev, Tret'jakov) stand und einen langjährigen Briefwechsel mit Marina Cvetaeva unterhielt, könnte von Fedorovs 'prometheischen' Projekten angezogen worden sein; wie es heißt, soll er einige Ansichten Fedorovs geteilt haben. ${ }^{98}$ Das bislang einzige Zeugnis für Nesmelovs Be-

326). Veröffentlicht wurden: ANON., Epafrodit. Epopeja. O.O. [Harbin] 1927. Eine umfangreiche Versdichtung über das Moskauer Leben in den frühen zwanziger Jahren. Unter dem Pseudonym Jakov Kormé, Valaam. (Poemy). Sanchaj 1931. Ein Werk mit dem Titel Poèma soll Anfang der dreißiger Jahre in Harbin erschienen sein.

196 Das allem Anschein nach überaus rege literarische Leben der Russen in Harbin (wie auch im übrigen Fernen Osten) ist, von wenigen Ausnahmen abgesehen, bislang unerforscht. Selbst zu den bedeutendsten Dichtern liegen nur spärliche Informationen vor. Ihre verstreuten Werke sind bibliographisch kaum erfaßt und lassen sich oftmals nur unter großem Aufwand ermitteln und beschaffen. Die bislang ausführlichste Schilderung des literarischen Lebens in Harbin bieten die unlängst veröffentlichten Memoiren des Dichters V. Perelešin [d.i. V.F. SalatkoPetrišce]; J.P. HinRichs [Hg.], Russian Poetry and Literary Lufe in Harbin and Shanghai, 1930 1950. The Memoirs of Valerij Perelesin. Amsterdam 1987. Vgl. auch V. PERELESIN IV.F. SALAT. KO-PETRISCE], "Russkie dal'nevost ocnye poety." In: Novyj Zumal, 107, 1972, S. 255-262. M. Vo. LIN [d.i. VolodCENKo], "Russkie poéty v Kitae." In: Kontinent, 34, 1982, S. 337-357. - Uberaus knappe und mitunter falsche Angaben in dem 'Standardwerk' von STRUVE (wie Anm. 2), S. 173f., 370. Fehlerhaft auch die Bibliographie von E.[A.] STEJN, Poezija nusskogo massejanija 1920 1977, Ashford, Conn. 1977. In dem von N.P. Poltorackij herausgegebenen Sammelband Russkaja literatura v emigracii, Pittsburgh 1972, sind den "vielen begabten Dichtern" in Harbin von über 400 Seiten ganze zwei Zeilen gewidmet! (Ebd., S. 67). - Einige Proben aus dem Schaffen sowjetfreundlicher Dichter sowie knappe bio-bibliographische Angaben in Antologija poezii Dal'nego Vostoka, Chabarovsk 1967, und "O Rodine - vdali ot nee." In: Golos Rodiny, 1987, 31, S. 8f.

197 O.N. Setnickaja, Moskau, an K.A. Čcheidze, Prag, Sept. 1965; FAP I, 333. - Zu A.I. Nesmelov vgl. die Angaben bei HinRICHS (wie Anm. 196), siche Register. PERELESIN (wie Anm. 196), S. 257, 259, 261. Volin (wie Anm. 196), S. 344-352. Antologija... (wie Anm. 196), S. 459. L. Chalndrov, [Vorwort zu] "Arsenij Nesmelov, Vozvrašženie." In: Znanija, 1988, 9, S. 76-78. E. VrrKovSKJ,, "Arsenij Nesmelov. Iz literaturnogo nasledija." In: Oktjabr', 1988, 11, S. 144-149. Aus Moskau gebürtig, lebte Nesmelov seit Mitte der zwanziger Jahre in Harbin, wo er eine rege literarische Aktivität entfaltete. Unter dem Pseudonym "N. Dozorov" erschien 1936 in Bern scin Poem Georgij Semena - die Hymne der russischen Faschisten. Nach der Eroberung Harbins durch die Rote Armee im August 1945 wurde Nesmelov verhaftet und starb im September (oder November) 1945 in einem sowjetischen Durchgangsgefăngnis. Datum und Umstände seines Todes wurden erstmals mitgeteilt bei VrrkovsKIJ, a.a.O., S. 145. Eine ăußerst dürftig kommentierte Auswahl aus Nesmelovs Prosaschriften erschien unter dem Titel A. Nesmelov, Izbrannaja proza, Orange, Conn. 1987.

198 SETNICKAJA (wie Anm. 197). 
schäftigung mit Fedorov ist ein Gedicht, das dieser im Dezember 1933 aus Anla $B$ des dreißigsten Todestages des Philosophen verfaßt hat. ${ }^{199}$

Auch der Dichter, Schriftsteller und Journalist Vsevolod NikanoroviC Ivanov (1888-1971) könnte durch Setnickij mit Fedorovs Ideen bekannt geworden sein. ${ }^{200}$ Ivanov, der sich mit geschichtsphilosophischen Fragen beschäftigte und eine Zeitlang dem evrazijstvo nahestand, veröffentlichte 1933 unter dem Titel Delo celoveka einen kulturphilosophischen Essay, der, obwohl Fedorov darin nicht genannt wird, deutliche Spuren seines Denkens trägt: Der biblische Auftrag, die Schöpfung zu vollenden, gewinne, so Ivanov, erst jetzt, im 20. Jahrhundert, an Bestimmtheit; erst jetzt eröffneten wissenschaftlicher Fortschritt und das erreichte Niveau der materiellen Kultur der Menschheit die Möglichkeit, das Ziel der Geschichte, "Gerechtigkeit und Unsterblichkeit" (pravednost' $i$ bessmertie), nicht nur zu erkennen, sondern auch den Weg zu seiner tätigen Verwirklichung - unter Einsatz des "ganzen Arsenals der Wissenschaft" und "aller Gaben der Kunst" - zu beschreiten. ${ }^{201}$ Zwar spricht Ivanov nur von menschlicher "Mitwirkung" (sodejstvie) bei der Heraufführung des Gottesreichs, doch deutet der besondere Anteil, den er dabei der "schöpferischen Kraft der Wissenschaft" zumißt, auf Fedorovs Einfluß hin. Namentlich genannt wurde Fedorov in einem kurzen Artikel Voskresenie i zizn', den Ivanov 1934 in der Harbiner Tageszeitung Zarja veröffentlichte. ${ }^{202}$

$\mathrm{Zu}$ Beginn der dreißiger Jahre bestand in Harbin der literarische Zirkel Čuraevka, eine Vereinigung vorwiegend junger Dichter und Literaten, die sich regelmäßig trafen, um Vorträge zu halten und aus ihren Werken zu lesen. ${ }^{203} \mathrm{Zu}$ den Mitgliedern gehörten die jungen Dichter V.K. Obuchov und Boris Beta (d.i. B.V. Butkevic); beide studierten an der Juristischen Fakultät und waren mit Setnickij bekannt. ${ }^{204}$ Wahrscheinlich gehörte auch Setnickij diesem Kreis an und trug dazu bei, daß der Dichter G.G. Satovskij-Rževskij in einem Vortrag im

199 A. NeSMELoV, [Gedicht] "Pered poslednim boem." In: Vselenskoe delo (wie Anm. 4), S. 3-6.

200 V.N. Ivanov, 1888 in Volkovysk (Gvt. Grodno) geboren, hatte vor dem Ersten Weltkrieg bei Windelband in Heidelberg und bei Rickert in Freiburg/Br. studiert. Im Bürgerkrieg war er weißgardist ischer Offizier; von 1922 bis 1945 lebte er in der Mandschurei, wo er seit 1925 für die TASS arbeitete. Anfang der dreißiger Jahre war Ivanow Redakteur der Harbiner Tageszeitung Gun-bao, 1931 veröffentlichte er in Harbin eine Arbeit über die Philosophie Vladimir Solov'evs und nahm im selben Jahr die sowjetische Staatsbürgerschaft an. 1939 erschien in Riga seine Monographie über den Maler-Philosophen Nikolaj Rerich. 1945 kehrte Ivanov in die Sowjetunion zurück. 1971 ist er in Chabarovsk gestorben.

201 V.N. Ivanov, Delo Celoveka. Opyt filosofii kul'tury. Charbin 1933, S. $151 f$.

202 V.[N.] IVANov, "Voskresenie i žizn'." In: Zajja, 93, 8.4.1934, S. 4.

203 Siehe hierzu insbesondere die Erinnerungen der ehemaligen Mitglieder Perelesin und Kruzenstern-Peterec: PERELESIN (wie Anm. 196), S. 258-260. HinRICHS (wie Anm. 196), pass. JU.[A.] KRUZENSTERN-PETEREC, "Curaevskij pitomnik." In: Vozrozdenie, 204, 1968, S. 45-70. Vgl. ferner N.S. "'Curaevka' " In: C'isla, sb. 10, Paris 1934, S. 245f.; siehe auch ebd., S. 234.

204 Briefliche Mitteilung O.N. Setnickaja, Moskau, 12.2.1981. - Vasilij Konstantinovi Obuchov rezensierte Setnickijs Schriften über Fedorov in dem 1934 erschienenen Sammelband Vselenskoe delo; siehe oben Anm. 25 und II: 4.3.3. 
Mai 1933 aus Anlaß des dreißigsten Todesjahres an Fedorov erinnerte. ${ }^{205}$ Aus demselben $A$ nla $B$ veröffentlichte ein gewisser $P$. Trubnikov - hinter dem sich möglicherweise Setnickij verbirgt - im Juli 1933 zwei Artikel über Fedorov in der Harbiner Tagespresse. ${ }^{206}$ Setnickij war auch mit dem Schriftsteller. S.G. Skitalec (eigentl. Petrov, 1869-1941) bekannt, der von 1922 bis zu seiner Rückkehr in die Sowjetunion im Jahre 1934 in Harbin lebte, dabei jedoch stets Kontakt zu sowjetischen Zeitschriften und Verlagen unterhielt. Möglicherweise spielte Skitalec eine Mittlerrolle zwischen Setnickij und Gor'kij. ${ }^{207}$ Über ein Interesse Skitalec' für Fedorov ist nichts bekannt.

Im Jahre 1934 fanden schließlich zwei Vorträge über Fedorov im Rahmen der wöchentlichen Zusammenkünfte der literarisch-künstlerischen Vereinigung Vostok in Schanghai statt: Der Vorsitzende dieser Vereinigung, der Dichter, Schriftsteller und Monarchist Michail Vasil'evic Šcerbakov, sprach über "Die Lehre N.F. Fedorovs: Projektivismus, die Rolle der Wissenschaft, die Rolle der Kunst" und ein gewisser A.G. Kol'cov-Mosal'skij über "Fedorovs Theologie". ${ }^{208}$ Auch in diesen Fällen geht die Anregung wahrscheinlich auf Setnickij oder dessen Harbiner Dichterfreunde zurück, von denen mehrere - nämlich Nesmelov, Ivanov, Obuchov und Boris Beta (Butkevic) - auch der Vereinigung Vostok angehörten.

All das deutet auf ein - wenn auch langsam - erwachendes Interesse an Fedorov unter der russischen Intelligenz im Fernen Osten hin. Allerdings blieb diesem Interesse keine Zeit mehr, sich zu entwickeln. Politische Ereignisse in der

205 Siehe A.G., "Mudrejకij iz. mudrych. Doklad g. Satovskogo-Ržcuskogo o N.F. Fedorove v 'Curacuke'." In: Zarja, 125, 11.5.1933, S. 2. D. GREJ [d.i. G.G. SATOVSKuJ-RZEvSKU], "Na vtornike Curaevki." In: Russkoe Slovo, 2156, 11.5.1933, S. 6. - Uber den Dichter Grigorij Grigor'eviž Satovskij-Rževskij ist lediglich bekannt, daß er in den vierziger Jahren in äußerster Armut in Harbin gestorben ist.

206 P. TRubnikov [N.A. SETNICKus ?], "Voskrełat' mertych ili zvat' smert'?" In: Gun-bao [Harbin], 2042, 14.7.1933, S. 2. Dass. auch in: Segodnja [Riga], 178, 30.6.1933. DERS., "Armii narodov na bor'bu so smert'ju." In: Zarja [Harbin], 190, 16.7.1933, S. 6.

207 Siehe oben Anm. 158.

208 M.V. Šcerbakov: "Ǔenie N.F. Fedorova: proektivizm, rol' nauki, rol' iskusstva." A.G. Kol'covMosal'skij: "Bogoslovie N.F. Fedorova." - Angaben nach Vrata, kn. 1, Sanchaj 1934, S. 195. In den von der Vereinigung Vosiok herausgegebenen Sammelbänden Vrata wurde wiederholt auf die Harbiner Fedorov-Publikationen hingewiesen. Siehe die Sammelrezension von Kozodoev [SETNICKU] (wie Anm. 191). M.[V.] SCERBAKOV, "Literatura i knigoizdatel'stvo." In: Vrata, kn. 2, Sanchaj 1935, S. 237-242; hier S. 241. Szerbakov spricht vom fedorianstvo [sic] als einer "philosophisch-religiösen Strömung, die sowohl in der Sowjetunion wie in der Emigration großen Erfolg" habe.

Aus Schanghai, dessen russische Kolonie in den dreißiger Jahren bis zu 50.000 Menschen zăhlte, erklang auch das letzte Echo, das Fedorovs Lehre im Fernen Osten hervorrief. Im Jahre 1941 erschien in der Berliner Tageszeitung Novoe Slovo, einem Organ der russischen Faschisten, der Artikel eines gewissen Michail Nedzveckij aus Schanghai, in dem dieser auf Fedorov und dessen Lehre hinwies: sie sei, so der Autor, geeignet, die durch den verderblichen Geist des "Judaismus" gelăhmte orthodoxe Theologie zu erneuern und ein modernes, weltzugewandtes arisches Christentum zu befordern, das die "jüdisch-freimaurerischen Măchte" überwinden werde. M. NeDzVECKI, "Nała liturgija." In: Novoe Slovo, 23 (352), 8.6.1941, S. 4 . 
ersten Hälfte der dreißiger Jahre führten dazu, daß sich die Lage der Russen in jener Region drastisch verschlechterte und damit auch ihre kulturelle Bedeutung schwand. Im September 1932 hatte Japan die Mandschurei besetzt und ein halbes Jahr später den Satellitenstaat Mandschukuo proklamiert. Damit war auch Harbin unter japanische Oberhoheit geraten. Die - zumeist sowjetischen Angestellten der Ostchinesischen Eisenbahn und ihrer zahlreichen Institutionen versuchten eine Zeitlang, mit den Japanern zusammenzuarbeiten. Als sich jedoch die Konflikte häuften, erklärte Moskau sich bereit, die Bahn an Mandschukuo (d.h. de facto an Japan) zu verkaufen. Der Vertrag wurde im März 1935 in Tokio unterzeichnet. In den folgenden Monaten verließen fast alle Angestellten der Ostchinesischen Eisenbahn, die sowjetische Pässe besaßen - es soll sich um mehrere Zehntausend gehandelt haben -, die Mandschurei und gingen in die Sowjetunion. ${ }^{209}$ Darunter war auch Setnickij; im Juni 1935 kehrte er mit seiner Familie nach Moskau zurück. ${ }^{210}$

Vor seiner Abreise hatte Setnickij einen Teil seines privaten Archivs (etwa 3000 Seiten) vernichtet, ${ }^{211}$ den größten Teil jedoch, der die Zeugnisse seiner Bemühungen um die Verbreitung des Fedorovschen Werkes enthielt, nach Prag geschickt, wo er dem dortigen Fedorov-Archiv eingegliedert wurde, das 1933 auf Initiative von K.A. Čcheidze im Tschechischen Nationalmuseum eingerichtet worden war. ${ }^{212}$ Cheidzes Vermittlung ist wahrscheinlich auch zu verdanken, $\mathrm{da} B$ in dem 1934 in Riga zu Ehren Fedorovs veröffentlichten (zweiten) Sammelband $V$ selenskoe delo neben mehreren Beiträgen Setnickijs auch zahlreiche Materialien aus Setnickijs Archiv sowie einige kürzere Beiträge von Harbiner Autoren der literarischen Zirkel Curaevka und Vostok erschienen. ${ }^{213}$

Nach seiner Rückkehr mußte Setnickij sich in Moskau mit schlechtbezahlten Gelegenheitsarbeiten durchschlagen, zuerst als Angestellter bei einer Bahnverwaltung, dann als wissenschaftlicher Mitarbeiter am Institut für Weltwirtschaft der Akademie der Wissenschaften. ${ }^{214}$ Seine Stimmung war depri-

209 Siehe IL'INA, Dorogi $i$ sud'by (wie Anm. 13), S. 43-48. - Zwischen 1930 und 1940 ging die russische Bevölkerung in der Mandschurei von etwa 150.000 auf 54.000 zurück. Noch schneller schwand ihr EinfluB. Siehe G.C. GuINS [G.K. GINS], "Russians in Manchuria." In: The Russian Review, 2 (1943), 2, S. 81-87.

210 Setnickana (wie Anm. 11), Bl. 10.

211 So Setnickij in einem nicht abgeschickten Brief an Gor'kij vom Mai 1936 (siehe oben Anm. 159): "Vor meiner Abreise in die UdSSR habe ich etwa 3000 Seiten von den Sachen vernichtet, die ich nicht in fremde, der [Sowjet-] Union vielleicht feindliche Hănde fallen lassen wollte, die mitzunehmen ich aber auch Bedenken hatte. Manuskripte zu verbrennen - diese qualvolle Erfahrung Gogol's und N.F. Fedorovs - ist nun auch mir bekannt, und ich muB sagen, daB es furchtbar schwer ist."

212 Zum Prager Fedorov-Archiv ausführlich II: 43.2. - Auch ein Teil des Archivs von N.V. Ustrjalow, der ebenfalls 1935 in die Sowjetunion zurückkehrte, gelangte ins Prager FedorovArchiv; siehe auch oben Anm. 1.

213 Siehe II: 4.3 .3 .

214 Setnickaja (wie Anm. 11), Bl. 10. 
miert; Setnickij fühlte sich isoliert und sah keine Möglichkeit, sein Lebenswerk, den Kampf gegen den Tod, voranzubringen. 215

Im Frühjahr 1937 traf er in Moskau mit Gorskij zusammen, der vorzeitig aus der Lagerhaft entlassen worden war. ${ }^{216}$ Die Begegnung beflügelte beide. Gemeinsam planten und begannen sie eine Arbeit, in der sie das Verhältnis des Marxismus zu Leben und Tod untersuchen und theoretisch weiterentwickeln wollten. Die Grundlage dafür bildete Friedrich Engels' Dialektik der Natur, eine Sammlung von Artikeln, Skizzen und Fragmenten, die zuerst 1925 in russischer Sprache in Moskau veröffentlicht worden war. Ausgehend von dem von Engels formulierten zweiten Grundgesetz der materialistischen Dialektik - dem "Gesetz vom Umschlagen von Quantität in Qualität" - stellten Setnickij und Gorskij die These auf, daß das Leben in der Phase seiner "bewußten Entwicklung" einen neuen "qualitativen Charakter" annehmen, d.h. aus dem Zustand passiver Naturverfallenheit in aktives Schaffen (tvoř̌estvo) übergehen werde: "Je energischer und stetiger dieses Schaffen sein wird, desto mehr wird im Prozeß des Lebens jener Raum abnehmen, der dem Tod verbleibt. ${ }^{217}$ - Den ganzen Sommer des Jahres 1937 widmeten sich Setnickij und Gorskij dieser Arbeit, doch blieb sie unvollendet. Erhalten ist lediglich ein Manuskript Setnickijs mit dem Titel "der schöpferische Marxismus und die Liquidierung des 'untätigen Hinterherhinkens' in der Biologie ${ }^{n}{ }^{218}$ Darin heißt es:

Aufgabe (delo) des Kommunismus ist die Abschaffung (unižoženie) aller Leiden, darunter der Quelle des großten Leids - des Todes naher Menschen. Dies kann und muß verwirklicht werden. Der Kampf gegen den Tod und der Sieg über inn ist Sache der vom Joch des Kapitalismus befreiten Menschheit, unsere Aufgabe aber ist, schon jetzt zu diesem Kampf aufzurufen. ${ }^{21}$

Setnickij war damit seiner Überzeugung treu geblieben, die er elf Jahre zuvor in einem Kondolenzschreiben an M.A. Rejsner aus AnlaB des Todes seiner Tochter Larisa geäußert hatte:

... unbestreitbar und sicher ist, daß es heute nicht nur um den Schutz und die Verlăngerung des Lebens geht, sondern darum, den bereits nahen und von unserem Willen abhăngenden Zeitpunkt zu erleben (dotit'), da alles, was uns teuer ist, wiederhergestellt werden wird, wiederhergestellt nicht durch einen fremden, transzendenten Akt, sondern durch unser immanentes Handeln, durch die Arbeit der vereinten Menschheit. Danach streben wir jetzt... ${ }^{220}$

215 So Setnickij in einem nicht abgeschickten Brief an Gor'kij vom Mai 1936 (siehe oben Anm. 159).

216 Dieses und das Folgende nach einer brieflichen Mitteilung von O.N. Setnickaja, Moskau, 13.4.1981.

217 Ebd.

218 N.A. SETNICKH, Tvorieskij marksizm i likvidacija 'chvostizma' v biologii, Ms. [Masch.] 1937, 36 Bl.; FAP I, 337.

219 Ebd., Bl. 15.

220 N.A. Setnickij, Harbin, an M.A. Rejsner, Moskau, 12.3.1926 (Datum des Poststempels); Archiv von L.M. Rejsner, GBL f. 245, k. 8, ed. chr. 15; nach einer Abschrift in Moskauer Privatbesitz. 
Am 1. September 1937 wurden Setnickij und seine Frau verhaftet ${ }^{221}$ - ein Schicksal, das sie mit der Mehrzahl derer teilten, die aus der Mandschurei in die Sowjetunion zurückgekehrt waren.222 Am 7. Dezember 1940 ist Setnickij gestorben, "wahrscheinlich irgendwo in der Gegend von Norilsk". 223

Gorskij hatte sich unterdessen mit seiner Frau in Kaluga niedergelassen, wo er, äußerst bescheiden lebend, versuchte, seine Arbeiten zu Fedorovs Werk fortzusetzen. Als 1938 Gor'kijs Märchen Devuska i Smert' (1892) erschien, von dem Stalin sagte, es sei "stärker als Goethes 'Faust' (die Liebe besiegt den Tod)", 224 reagierte Gorskij mit einer Abhandlung Preodolenie Fausta, in der er, unter Hinweis auf die Idee des Kampfes gegen den Tod, auch Fedorov ins Gespräch zu bringen suchte. ${ }^{225}$ Die Veröffentlichung stieß jedoch auf Schwierigkeiten und scheiterte schließlich. ${ }^{226}$ Auch von den zahlreichen Gedichten, Poemen und Rezensionen, die Gorskij in jenen Jahren verfaßte, konnte keine Zeile gedruckt werden. Besondere Bedeutung maß Gorskij seinem in den zwanziger Jahren entstandenen Hauptwerk Ogromnyj očerk bei, das er nunmehr zu einer "streng wissenschaftlichen, exakten, experimentellen Ästhetik" erweitern wollte. ${ }^{27}$ Über seine Pläne und Arbeiten berichtete Gorskij seinen beiden Vertrauten Ol'ga (Ljalja) Nikolaevna Setnickaja und Ekaterina (Katja) Aleksandrovna Kraseninnikova in ausführlichen Briefen, die zum Teil ganze Abhandlungen enthielten. ${ }^{228}$

Ganz seiner Arbeit hingegeben, scheint Gorskij die Gefahr kaum bemerkt zu haben, in die er durch äußere Umstände geriet: Als im Oktober 1941 Kaluga von den Deutschen erobert wurde, hatte Gorskij die Stadt nicht verlassen. Nach der Befreiung durch die Rote Armee um die Jahreswende 1941/42 wurde er unter dem Verdacht der Spionage und Kollaboration verhaftet und ins Gefängnis

Mit dem Juristen und Kenner der Freudschen Psychoanalyse Michail Andreevix Rejsner (18681928) und dessen Tochter, der Schriftstellerin Larisa Michajlovna Rejsner (1895-1926), war Setnickij freundschaftlich verbunden gewesen. Mitteilung ON. Setnickaja.

221 Setnickaja (wie Anm. 11), Bl. 10.

222 Auch Ustrjalov wurde 1937 verhaftet. Siehe AGURSku, "Perepiska..." (wie Anm. 1), S. 545.

223 SETNICKNA (wie Anm. 11), Bl. 10. - 19 Jahre spăter wurde Setnickij postum rehabilitiert. Ebd.

224 GOR'Xu (wie Anm. 127), t. 1, M. 1949, S. 497.

225 [A.K. Gorsku], Preodolenie Fausta, Ms. [Masch.], 94 Bl.; Privatbesitz Moskau; das Werk war mir nur für eine kurze Durchsicht zugänglich.

226 Davon zeugt ein umfangreicher Briefwechsel Gorskijs mit Redakteuren verschiedener Zeitschriften; Privatbesitz Moskau.

227 Mitteilung Setnickaja (wie Anm. 216). - Siehe auch II: 4.1. Anm. 46.

228 Privatbesitz Moskau. Das letzte dort erhaltene Manuskript Gorskijs trägt den Titel A. Ostromirov, Pesni bez nedomolvok. Popravki, pojasnenija $i$ dodelki. 1941. 20-j vek. Kaluga 1942. Das Archiv von EA. Krašeninnikova war mir nicht zugănglich. 
nach Tula gebracht. Dort fand er am 24. August 1943 den Tod. ${ }^{229}$ N.P. Anciferov, der Gorskij im Lager kennengelernt hatte, schreibt in seinen Erinnerungen:

Weshalb hat man ihn vernichtet, diesen völlig harmlosen Trăumer? Er hatte Solovki hinter sich. Folglich war er verdăchtig. Sollte dies wirklich Anlaß gewesen sein, ihn zu verdăchtigen ... Sympathie mit den Deutschen zu haben, die das russische Volk versklaven wollten? - Gorskij war ein Messianist des russischen Volkes. Er hielt das russische Volk für berufen, der Welt neues Heil zu offenbaren. $^{230}$

229 Mitteilung O.N. Setnickaja, Moskau. - Auf einer Photographie Gorskijs im FAP I, 327, ist als Todesdatum der 23.8.1943 vermerkt. - In einer sowjetischen atheistischen Propagandabroschüre aus dem Jahre 1978 heißt es (ohne nähere Angaben): Wăhrend des Krieges, im Jahre 1943, sei von der sowjetischen Abwehr eine Anthroposophen-Gruppe entdeckt worden, die im Auftrag der Deutschen Spionage und antisowjetische Propaganda betrieben habe; an ihrer Spitze habe A. Gorskij-Gornostaev gestanden, der als "Verbindungsmann des faschistischen Nachrichtendienstes" enttarnt worden sei. A.V. BELOV, DA. KARPOV, Mistika na slutbe antikommunizma, M. 1978, S. 19f. (den Hinweis verdanke ich Renata v. Maydell).

230 ANCIFEROV (wie Anm. 134), BI. 3. 


\section{Die europäische Emigration}

\subsubsection{Die "nachrevolutionären" Bewegungen}

Von der russischen Emigration in Europa, die in den zwanziger und dreißiger Jahren in eine Vielzahl - zumeist publizistisch - aktiver und zum Teil einander heftig befehdender Gruppierungen und Strömungen zerspalten war, ${ }^{1}$ wurden die Ideen Fedorovs und seiner Anhänger in sehr unterschiedlichem Maße beachtet und aufgenommen. So finden sich auf dem weiten Feld der politischideologischen Publizistik, dort, wo es sich um Vertreter traditioneller Parteien und Bewegungen handelt - seien es Monarchisten oder Sozialisten, Sozialrevolutionäre oder Liberale -, keinerlei Hinweise auf eine Beschäftigung mit Fedorov. Weitgehend ignoriert wurde Fedorov auch von den zahlreich im Exil in Berlin, Paris, Prag oder Belgrad lebenden professionellen Philosophen und Theologen - allerdings gab es hier Ausnahmen. ${ }^{2} \mathrm{Zu}$ einer eigentlichen Rezeption, verbunden mit einer gewissen Wirkung kam es hingegen bei führenden Vertretern und Anhängern der sogenannten "nachrevolutionären Strömungen" (porevoljucionnye tečenija).

Dabei handelt es sich um Gruppierungen und Bewegungen, die zu verschiedenen Zeiten an verschiedenen Orten der Emigration entstanden waren, jedoch eine Reihe ideologischer Gemeinsamkeiten aufweisen, durch die sie sich von den übrigen Emigrantengruppen unterscheiden: Hauptmerkmal war die porevoljucionnost', d.h. die Anerkennung der Revolution mit allen ihren Folgeerscheinungen als historisch notwendiges und irreversibles Faktum und ihre Erhebung zum Ausgangspunkt einer geistigen, kulturellen und historischen Identitäts- und Standortbestimmung Rußlands, aus der sich seine Zukunftsperspektive ableiten ließ. Hieraus folgte - als zweites Merkmal - die Entwicklung eines neuen, umfassenden und den Besonderheiten Rußlands entsprechenden Weltanschauungssystems, das als zukunftgestaltendes politisches Programm mit dem Bolschewismus in Konkurrenz treten und das noch nicht konsolidierte Sowjetsystem auf evolutionärem Wege "geistig überwinden" sollte. Die Umsetzung eines neugewonnenen theoretischen Konzepts in politisches Handeln mit dem

1 Der Stand der Erforschung ist uneinheitlich. Wăhrend über die rechten und rechtsextremen Stromungen und Gruppierungen (mladorossy, Faschisten) detaillierte Untersuchungen vorliegen (Arbeiten von HAYES, OBERLÁNDER, STEPHAN) und auch die "nachrevolutionären" Bewegungen des smenovechoustvo und evrazijstwo inzwischen ins Blickfeld der Forschung geriuckt sind (siehe v.a. die Arbeiten von AGURSKY [AGURSKU], ferner BOSS, LUKS), sind die meisten der kleineren und auch geographisch peripheren Gruppen (z.B. im Baltikum) gănzlich unerforscht. Erschwert wird die Arbeit durch die zumeist rege publizistische Tătigkeit der Emigrantenvereinigungen, deren Produkte weit verstreut und in der Regel schwer zugănglich sind. Ihre bibliographische Erfassung steht erst am Anfang. Die Schwierigkeiten der Forschung werden deutlich auch an den zahlreichen Unzulänglichkeiten und Fehlern solcher an sich verdienstvollen Bibliographien wie L.A. FostER, Bibliografija nusskoj zanubetnoj kul'tury 1918. 1968, 2 Bde. Boston 1970; T. OssoRgUINE-BAKOUNINE, L'émigration russe en Europe. Catalogue collectif des périodiques en langue nusse 1855-1940. Paris 1976.

2 Als solche sind zu nennen N.A. Berdjaev, S.N. Bulgakov, G.V. Florovskij, V.N. Il'in. 
Ziel der Errichtung einer "Ideokratie" bildete das dritte Merkmal der porevoljucionnye tecenija. ${ }^{3}$

Am Anfang dieser Strömungen standen Ustrjalov und das smenovechovstvo mit der weitgehend taktisch, realpolitisch motivierten Anerkennung der Sowjetmacht und dem Aufruf zur Förderung nationaler Entwicklungstendenzen innerhalb des Systems. ${ }^{4}$ Freilich erwies sich das Konzept eines großrussischen Nationalismus bald schon als zu eng. Eine erhebliche Erweiterung der ideologischen Basis gelang den sogenannten Eurasiern, die in den zwanziger Jahren zur erfolgreichsten unter den "nachrevolutionären" Bewegungen wurden, sich dann aber in inneren ideologischen Auseinandersetzungen aufrieben. Zu Beginn der dreißiger Jahre entstanden in der Pariser Emigration "nachrevolutionäre" Gruppierungen um die Zeitschriften Utverždenija, Novyj Grad und Tret'ja Rossija, von denen sich die beiden letztgenannten bis gegen Ende des Jahrzehnts halten konnten. Allen diesen Gruppen war gemeinsam, daß sie - insbesondere bei dem Versuch, eine neue Weltanschauung zu erarbeiten - auch Ideen Fedorovs und seiner Anhänger aufnahmen oder sich mit ihnen auseinandersetzten.

\subsubsection{Die Eurasier in Paris}

Die Bewegung der Eurasier ${ }^{5}$ nahm ihren Anfang 1921 in Sofia mit der Veröffentlichung einer Sammlung von Essays unter dem programmatischen Titel Is-

3 Als Gesamterscheinung sind die porevoljucionnye tecenija bis heute unerforscht. Das ist um so bedauerlicher, als viele der damals formulierten Gedanken und Positionen im heutigen sowjetischen Dissidentenmilieu wieder auftauchen und Anklang finden. Genannt sei beispielsweise Gennadij Simanovs Theorie des "idealen Staates", d.h. der geistigen Umgestaltung des Sowjetregimes in eine Theokratie und der ideokratischen KPdSU in eine orthodoxe Partei. Siehe J.B. DUNLOP, The Face of Contemporary Russian Nationalism, Princeton, N.J. 1983, S. 187. - Inzwischen mehren sich die Anzeichen für eine Neubewertung der porevoljucionnye rečenija (insbesondere des evrazijstro) auch in der offiziellen sowjetischen Presse; manche Positionen der porevoljucionniki werden sogar als diskussionswürdige Alternativen vorgestellt. Siehe 2.B. den instruktiven Artikel von S.S. ChORUZu, "Karsavin i de Mestr." In: Voprosy Filosofii, 1989, 3, S. 79-92.

4 Siehe II: 4.2 .1 .

5 Das Eurasiertum zählt zu den relativ gut erforschten Erscheinungen der russischen Emigration. Zur Lehre der Eurasier und ihren geistesgeschichtlichen Wurzeln liegen mehrere Untersuchungen vor: O. BOSs, Die Lehre der Eurasier. Ein Beitrag zur nussischen Ideengeschichte des 20. Jahrtiunderts. Wiesbaden 1961. N.V. RIASANOVSKY, "The Emergence of Eurasianism." In: Califomia Slavic Studies, 4, 1967, S. 39-72. L. LuKS, "Die Ideologie der Eurasier im zeitgeschichtlichen Zusammenhang." In: JfGO, NF 34 (1986), S. 374395. Die letztgenannte Arbeit unternimmt den bemerkenswerten Versuch, die Lehre der Eurasier in das "politisch-ideologische Spektrum Europas in der Zwischenkriegszeit" einzuordnen, wobei Parallelen zur sogenannten konservativen Revolution der Weimarer Republik wie auch zum italienischen Faschismus erkennbar werden. Darüber tritt freilich etwas spezifisch Russisches, nămlich die kompensatorische Funktion, die das Eurasiertum mit den slavophilen Positionen des 19. Jahrhunderts verbindet, zu sehr in den Hintergrund. Ein künftiger Ideologievergleich sollte auch die übrigen "nachrevolutionăren" Strömungen einbeziehen, von Kazem Beks offen faschistischen mladorossy und den - angeblich auch in der Sowjetunion konspirativ tătig gewesenen - narodnikimessianisty über die nacionalisty-christiane, die cetvertorossy, belokrestovcy, nacional-maksima- 
chod $k$ Vostoku. Darin versuchten vier junge aus der Sowjetunion emigrierte Intellektuelle - der Philologe N.S. Trubeckoj (1890-1938), der als der eigentliche Initiator der Bewegung gilt, ${ }^{6}$ der Wirtschaftswissenschaftler P.N. Savickij (18951968), der Theologe G.V. Florovskij (1893-1971) und der Musikwissenschaftler P.P. Suvčinskij (1892-1985) -, Rußlands Eigenart und künftigen Weg zu bestimmen. Durch die Revolution habe sich, so die Autoren, Rußland von der europäischen Welt getrennt und sein wahres Wesen offenbart: Rußland sei weder ein Teil Europas, noch gehöre es zu Asien, vielmehr bilde es eine besondere historisch-geographische und ethnisch-kulturelle Einheit - Eurasien. Nachdem diese Einheit politisch verwirklicht worden sei (durch die Expansion des Russischen Reiches im 19. Jahrhundert und die Verteidigung seines territorialen Bestandes durch die Sowjetmacht), komme es nun darauf an, den eurasischen Raum auch kulturell und ideell zu einen. Unter diesem Aspekt wurde die russische Revolution begrüßt als Aufstand des in der autochthonen Kultur verwurzelten Volkes gegen die europäisierte und somit als wesensfremd empfundene Oberschicht, als der Beginn einer "Kulturrevolution", deren weitere Entwicklung es zu beeinflussen gelte. Ihr Ziel müsse - nach der evolutionären "geistigen" Überwindung des ebenfalls westlich-europäischen Kommunismus - die Ausbildung eines russisch-eurasischen Kulturtypus sein, der Umbau Rußlands zu einer eigenen, nicht länger am "romano-germanischen" Vorbild orientierten Kulturwelt. Hierzu sollte die von den Eurasiern erarbeitete "ganzheitliche" Ideologie und ihre politische Herrschaft in Form einer die eurasische Nation einenden "Ideokratie" dienen.?

listy und smenovechovcy (ustrialovcy) bis zu den neodemokraty, neonarodniki (novogradcy) und urverzdency.

Weitgehend unerforscht ist bislang die Geschichte der eurasischen Bewegung, ihre Struktur und Organisation, ihr Mitgliederbestand, ihre vielfăltige propagandistische und publizistische Tătigkeit, ihre Kontakte in die Sowjetunion und die Zusammenarbeit einiger ihrer Mitglieder mit der monarchistischen Geheimorganisation Trest.

6 Sein Vater und sein Onkel, Sergej und Evgenij Trubeckoj, waren Philosophen slavophiler Ausrichtung gewesen; letzterer hatte in seiner großen Arbeit über VI. Solov'ev auch dessen Verhälınis zu Fedorov untersucht. Siehe II: 2.2.1.

7 Die Lehre der Eurasier ist kein geschlossenes ideologisches System, eher ein Konglomerat verschiedener wissenschaftlicher und wissenschaftsformiger Theorien, verbunden mit geschichtsund gesellschaftsphilosophischen Spekulationen. Besonders hervorstechend sind Einflüsse der Slavophilen (Chomjakov, Dostoevskij, Solov'ev, Leont'ev), der Kulturtypenlehre N.Ja. Danilevskijs (ergänzt durch Spengler), der Völkerpsychologie und der stark naturphilosophisch geprägten "Bodenkunde" V.V. Dokuzaevs, aber auch zeitgenössischer Strömungen: Mit dem italienischen Faschismus beispielsweise teilten die Eurasier einen ausgeprägten Etatismus (der den frühen Slavophilen fremd gewesen war) und die Konzeption eines korporativen Staatswesens, Rückwărtsgewandtheit bei gleichzeitigem Fortschrittsenthusiasmus, Jugendkult und Technikverherrlichung, was in einer zeitweiligen Annäherung an den künstlerischen Futurismus (bei Faschisten wie Eurasiern) zum Ausdruck kam. Dagegen waren Nationalismus und Rassismus unvereinbar mit der "Universalităt" (uselenskost') der Eurasier, ihrem Ansprich, dic gcsamte Menschheit von der Vorherrschaft des "Westens" zu befreien. Der Philosoph Stepun nannte die Eurasier treffend "die Slavophilen der Epoche des Futurismus". F.A. STEPUN, "Ob obšcestvenno-polititeskich putjach 'Puti'." In: Sovremennye Zapiski, 29, 1926, S. 445. 
Die Thesen der Eurasier erregten in den Kreisen der russischen Emigration alsbald großes Aufsehen und wurden heftig diskutiert. ${ }^{8}$ Die Eurasier selbst entfalteten eine rege propagandistische und publizistische Tätigkeit, hielten Vorträge und Seminare und gaben vor allem in den zwanziger und frühen dreißiger Jahren zahlreiche Bücher, Broschüren und Periodika heraus, in denen sie ihrer Vision eines neuen Rußland-Eurasien Konturen zu geben versuchten. ${ }^{9}$ Die Zentren ihrer Aktivität waren Paris und Prag; daneben gab es "eurasische Kreise $^{n}$ in Berlin, Brüssel, Belgrad und Warschau, später auch im Baltikum. Noch vor der Mitte der zwanziger Jahre verließ Florovskij die Bewegung, ${ }^{10}$ neu hinzu kamen die religiösen Philosophen L.P. Karsavin (1882-1952) und V.N.

Vgl. D.S. Mirsky [SvjatopolK-MIRSXu]], "The Eurasian Movement." In: The Slavic Review, 1927, 6, S. 311-320. S. LUBENSKJ [d.i. P.N. SAVICKIJ], "L'Eurasisme." In: Le Monde Slave, 8 (1931), 1, S. 69-91. N.N. ALEXEJEW [ALEKSEEV], "Die geistigen Voraussetzungen der eurasischen Kultur." In: Orient und Occident, 17, 1934, S. 20-30. DERS., "Duchovnye predposylki evrazijskoj kul'tury." In: Evrazijskaja chronika, vyp. 11, Berlin 1935, S. 13-28. Uber die Anfünge des Eurasiertums, insbesondere über N.S. Trubeckoj, siehe J. BURBANK, Intelligentsia and Revolution, New York, Oxford 1986, S. 208-222.

Anklănge an Ideen der Eurasier finden sich gegenwărtig in der überaus spekulativen biologistischen Geschichtskonzeption des Leningrader Orientalisten und Ethnographen L.N. Gumilev (geb. 1912, Sohn von Nikolaj Gumilev und Anna Achmatova) über Entstehung, Entwicklung und Niedergang historisch-kultureller Volkstypen (ethnē, ètnosy) in Abhängigkeit von geographischen Milieus. An den eurasischen Standpunkt erinnert auch Gumilevs Kritik der "Mongolophobie" der bürgerlich-liberalen Geschichtsschreibung, wăhrend seine eher skurrilen Ideen über den Einfluß der "biogeochemischen Energie der lebenden Materie" sowie kosmischer Vorgänge auf den Geschichtsverlauf sich den Spckulationen V.J. Vernadskijs und A.L. Ćiževskijs verdanken. Siehe Gumilevs unveroffentlichtes Hauptwerk Etnogenez $i$ biosfera Zemli, Leningrad 1979, Typoskript, deponien in VINITI, Ljubercy, Mosk. obl. (auch im Samizdat verbreitet), sowie zahlreiche Aufsătze v.a. in Priroda und Vesmik LGU; zuletzt L.N. GUMLEv, "Etnos: mify i real'nost'." In: Druzba Narodov, 1988, 10, S. 218-231. Im Westen unbeachtet, finden die Ideen dieses wissenschaftlichen Außenseiters in der Sowjetunion seit den spăten siebziger Jahren starke Resonanz in nationalistischen Intellektuellenkreisen. Vgl. dazu J.B. DuNLOP, The Faces of Contemporary Russian Nationalism, Princeton, N.J. 1983, S. 141, 145, 258f. L. GRAHAM, Science, philosophy, and human behavior in the Soviet Union, New York 1987, S. 250257.

8 Eine detaillierte Öbersicht über die - zumeist ablehnenden - Reaktionen auf die Eurasier in den zwanziger Jahren gibt P.N. SAviCKU, "V bor'be za evrazijstvo. Polemika vokrug evrazijstva v 1920 godach." In: Tridcarye gody, Paris 1931, S. 1-52.

9 Siehe insbesondere die anonym veröffentlichten programmatischen Schriften Evrazijstvo. (Opyt sistematizeskogo izloženija). Paris 1926. Evrazijstvo. Deklaracija, formulirovka, tezisy. Prag 1932. Evrazijstwo i kommunizm, 0.O. o.J. - Fortlaufend erschienen: Evrazijskaja chronika, 12 Bände, Prag, Paris, Berlin 1925-1937. Utverzdenie evrazijcev, 7 Bände mit wechselnden Titeln, Sofia, Berlin, Paris, Prag 1921-1931. Evrazija, Wochenzeitung, 35 Nummern, Clamart [Paris] 19281929. Evraziec, 25 Hefte, Brüssel 1929-1934. Evrazijskie tetradi, 6 Hefte in 5, o.O. [Prag] 19341936. - Das umfangreiche, weit verstreute Schriftum der Eurasier, das vom aufwendig gedruckten Sammelband bis zur litho- oder hektographierten Broschüre reicht, ist bislang nur unvollstăndig verzeichnet. Siehe die Bibliographie bei BOSS (wie Anm. 5), S. 125-127, sowie S. LUBENSKU [d.i. P.N. SAVICKU], "Evrazijskaja bibliografija 1921-1931." In: Tridcatye gody (wie Anm. 8), S. 285-317 (annotierte Bibliographie).

10 Siehe seine scharfe 'Abrechnung': G.V. FLOROvSKIJ, "Evrazijskaja soblazn." In: Sovremennye Zapiski, 34, 1928, S. 312-346. Vgl. DeRs., "Iz pisem o. Georgija Florovskogo Ju. Ivasku." In: Vestnik RChD, 130, 1979, S. 45-47. - Zu Florovskij und Fedorov unten Anm. $190 f$. 
Il'in (1891-1974), der Literaturwissenschaftler Fürst D.P. Svjatopolk-Mirskij (1890-1939), die ehemaligen Offiziere der Weißen Armee P.S. Arapov und S.Ja. Efron (1893-1941), der Rechtswissenschaftler N.N. Alekseev (1879-1964) und der Historiker G.V. Vernadskij (1887-1973). - Zahlenmäßig war es freilich stets nur eine kleine Minderheit der russischen Intelligenz, die sich zum Eurasiertum bekannte; die große Mehrheit der Emigranten lehnte die neue Lehre ab.

In der zweiten Hälfte der zwanziger Jahre kam es zu einer wachsenden Politisierung und damit verbunden zu Differenzen innerhalb der Bewegung. ${ }^{11}$ Die Bemühungen um tiefschürfende historiosophische und kulturphilosophische Analysen wurden überlagert von dem Bestreben eines Teils der Eurasier, politischen Einfluß zu gewinnen, um auf die innersowjetische Entwicklung einwirken zu können. Obwohl die Eurasier ihre Lehre als Alternative zum Bolschewismus verstanden, gab es eine Reihe von Berührungspunkten: So verurteilten sie das vorrevolutionäre Rußland, die Bourgeoisie und den Kapitalismus und kritisierten die parlamentarische Demokratie nach westlichem Vorbild, die sie durch die Herrschaft einer alle Lebensbereiche durchdringenden "synthetischen" Ideologie ersetzen wollten. Die künftige ideokratische Staatsform Rußland-Eurasiens sahen sie ansatzweise bereits im Sowjetsystem verwirklicht, allerdings sollte an die Stelle des materialistischen und atheistischen Bolschewismus allmählich die eurasische Staatsidee treten, die auf den religiösen Prinzipien der sobornost' und des obšcee delo beruhte.

Der Wunsch, an der politischen Gestaltung Rußlands mitzuwirken, führte bei einigen Eurasiern - insbesondere Svjatopolk-Mirskij, Ėfron, Arapov und Suvcinskij - zu einer immer unkritischeren Haltung gegenüber dem bolschewistischen Regime und zu Versuchen einer ideologischen Annäherung. ${ }^{12}$ In dieser Situation wurden die Eurasier mit den Ideen Fedorovs bekannt.

Vermittler war auch hier Setnickij. Bereits um die Mitte der zwanziger Jahre hatte es Kontakte zwischen dem Pariser Eurasier und Orientalisten V.P. Nikitin

11 In einem Brief vom 24.4.1926 schreibt Svjatopolk-Mirskij an Fürst D.A. Sachovskoj: "Das Eurasiertum durchlebt zur Zeit eine schwere Krise, und es ist möglich, daß es sich in eine 'rechte' und in eine 'linke' Gruppe spaltet (Savickij - und Suvcinskij)." I. [D.A.] SACHOVSKOJ, Biografija junosti, Paris 1977, S. 212.

12 Roman Gul', der Kenner der russischen Emigrantenszene der zwanziger und dreißiger Jahre, behauptet in seinen Memoiren, die Annăherung eines Teils der eurasischen Bewegung an die Sowjetunion sei vom sowjetischen Geheimdienst provoziert worden. So habe die GPU mittels fingierter "Briefe" und "Dokumente" angeblicher Gesinnungsgenossen den Emigranten die Existenz einer wachsenden Eurasierbewegung in der Sowjetunion vorgetăuscht. Der Pariser Eurasier P.S. Arapov sei daraufhin mehrmals "geheim" nach Moskau gereist, um sich vor Ort von der Richtigkeit dieses Eindrucks überzeugen zu lassen. Auf dem Hohepunkt dieser Kampagne, die der Infiltration und Zersetzung der eurasischen Bewegung gedient habe, sei 1926 sogar ein "eurasischer KongreB" in Moskau inszenient worden, an dem der Führer der Prager Eurasier, P.N. Savickij; teilgenommen habe. R. Gur', Ja unes Rossiju, t. 1, New York 1984, S. 173f. Ausfuhrlich dazu auch der Bericht eines anonymen Insiders A.B., "Evrazijoy i Trest." In: Vozrożdenie, 30, 1953, S. 117-127, sowie S.L. VOJCECHOVSKIJ, Trest. Vospominanija i dokamenty. London, Ont. 1974, S. $28 f$. 
(1885-?) und dem in Harbin lebenden Schriftsteller V.N. Ivanov gegeben. ${ }^{13}$ 1927 traten Suvcinskij und Setnickij in einen Briefwechsel. ${ }^{14}$ Als Setnickij im Sommer 1928 im Rahmen einer Dienstreise, die ihn durch die Sowjetunion nach Westeuropa führte, auch Paris besuchte, ${ }^{15}$ könnte er sich dort mit Eurasiern getroffen und über Formen einer Zusammenarbeit verständigt haben. Jedenfalls finden sich von da an in den Publikationen der Eurasier regelmäßig Hinweise auf die Harbiner Veröffentlichungen zu Fedorov, die über den Verlag der Eurasier in Clamart bei Paris vertrieben wurden.

Setnickijs Pariser Briefpartner Suvxinskij war damals faktischer Chefredakteur der seit 1926 erscheinenden literarischen Zeitschrift Versty (Mitherausgeber waren die 'linken' Eurasier Svjatopolk-Mirskij und Ėfron), die neben Beiträgen von Emigranten (v.a. von Efrons Frau Marina Cvetaeva, von Remizov und Sestov) auch beifällig Werke von in der Sowjetunion lebenden Autoren (Pasternak, Sel'vinskij, Babel', Tynjanov, Artem Veselyj u.a.) veröffentlichte, was in konservativen Emigrantenkreisen auf geradezu wütende Ablehnung stieB. ${ }^{16}$ In der dritten (und letzten) Nummer dieser bedeutenden und originellen Zeitschrift erschienen 1928 unter der Rubrik "Materialien" Setnickijs Aufsatz über Fedorovs Kapitalismuskritik sowie - von Setnickij eingeleitet - drei Briefe Fedorovs an Koževnikov über Turkestan aus dem Jahre 1899. ${ }^{17}$

Beide Themen waren für die Eurasier von besonderem Interesse: Wie Fedorov sahen sie die Lösung des sozialen Problems weder im Kapitalismus - mit seiner Vergötzung des Individuums, seinem Gesetz des Kampfes und der Kon-

13 Siehe V.P. NikrnN, "Perepiska s 'aziatom' V. Ivanovym." In: Evrazijskaja chronika, 6, Paris 1926, S. 6-12. - Zu V.N. Ivanov siehe II: 4.2.5.

14 Siehe FAP I, 330.

15 Hinweise in FAP I, 324.

16 Siehe Versty, 1-3, Paris 1926-1928. Siche auch G.[P.] StRLVE, Russkaja literanuma v izgnanii, Paris ${ }^{2}$ 1984, S. 45, 73-75. - Der Musikwissenschaft ler, Schriftsteller und Philosoph Petr Petrovix Suvzinskij, einer der Begründer der eurasischen Bewegung (der er bis 1929 angehörte), wurde 1892 in Petersburg geboren und lebte vom Anfang der zwanziger Jahre bis zu seinem Tod 1985 in Paris. Er war mit Stravinskij und Prokofev befreundet und korrespondierte mit Boris Pasternak. In den spăten zwanziger Jahren scheint sich Suvtinskij mit den Ideen Fedorovs beschäftigt zu haben (laut einer ÂuBerung des Prager Eurasiers Ccheidze; siehe unten Anm. 61). Siehe auch die sehr negative Charakterisienng Suvðinskijs durch A.B. (wie Anm. 12), S. 126.

17 N.A. SETNICKU, "Kapitalistizeskij stroj v izobraženii N.F. Fedorova." In: Versty, 3, 1928, S. 259277. [N.F. FEDOROv], "Iz perepiski N.F. Fedorova s V.A. Koževnikovym o Turkestane." Ebd., S. 278-288. [Einleitung von] " $S$ " [d.i. N.A. SETNICKIJ], S. 278f. In einer Vorbemerkung der Redaktion hieB es, Fedorows Schriften hinterließen zwar den Eindruck "muffiger Provinzialităt" und vieles in seinen Ansichten sei antiquiert und sogar offen reaktionăr, hochst aktuell aber sei der zentrale Gedanke seiner Lehre, die "Unzertrennbarkeit des einzelnen und des Kollektivs, die Idee des obstee delo". "Ot redakcii." Ebd., S. 6.

In derselben Nummer von Versty findet sich - möglichenweise von Setnickij angeregt - auch eine wohtwollende Besprechung von V.N. Murav'evs Ovladenie vremenem durch den Philosophen V.E. Sezeman, der mit Savickij befreundet war und eine Zeitlang dem evrazijstuo nahestand (ebd., S. 172-175), sowie ein Aufsatz von N.A. BERDJAEv, "Russkaja religioznaja mysl' i revoljucija" (ebd., S. 40-62) mit gelegentlichen Hinweisen auf Fedorov. 
kurrenz, seinem krassen Egoismus, Materialismus und Warenfetischismus (vešepoklonstvo) eine der unheilvollsten Erscheinungen der westlichen Welt noch in dessen scheinbarer Antithese, dem kollektivistischen und klassenegoistischen Kommunismus, der den einzelnen entmündige und die Masse - nach bourgeoisem Vorbild - zu materieller Bereicherung aufrufe, sondern in der Synthese einer gesellschaftlichen Ordnung, die auf der Anerkennung der sobomaja lixnost' des Volkes als der organischen Einheit des Ganzen und des einzelnen, des obšcee delo und der persönlichen Autonomie beruhe. Wie alle Lebensbereiche, so sollte nach dem Willen der Eurasier auch die Wirtschaft auf eine ideokratische Basis gestellt werden, d.h. sich nach einem allgemeinen Plan entwikkeln, der die individuellen Interessen mit den Zielen des "gesellschaftlichen Organismus" harmonisiere. ${ }^{18}$ Das zweite Thema, Turkestan und seine - von Fedorov hervorgehobene - geopolitische und kulturgeschichtliche Bedeutung, war für die Eurasier insofern von Bedeutung, als sie durch die Angliederung dieser Region an das Russische Reich im letzten Viertel des 19. Jahrhunderts (auf dem Pamir wurde die Grenze zwischen Rußland und Afghanistan 1895/96 festgelegt) die politische Einigung Eurasiens verwirklicht sahen. ${ }^{19}$

Als erstes Echo der Eurasier auf Fedorovs Ideen erschien 1928 in der Pariser Evrazijskaja Chronika ein kurzer Aufsatz, in dem ein gewisser A.S. Adler die "bislang von niemandem gewürdigte Filosofija obšcego dela" als hochaktuelles und zukunftsweisendes Werk pries. ${ }^{20}$ Fedorov habe das Verhältnis von Individuum und Kollektiv und von geistiger und materieller Kultur neu bestimmt und

18 Ausführliche - und in vielem an Fedorov erinnernde - Kritik an Kapitalismus und Kommunismus sowie Erlăuterung der eurasischen "Synthese" in den anonymen Schriften Evrazijstvo $i$ kommunizm (wie Anm. 9) und Evrazijstvo. Deklaracija... (wie Anm. 9). Hier wie auch an anderer Stelle fallt auf, daß die Kritik der Eurasier am Kapitalismus wesentlich schärfer formuliert ist und breiteren Raum einnimmt, wăhrend dem Sowjetsystem auch positive Züge bescheinigt werden. So sahen die Eurasier in der sowjetischen Kollektiv- und Planwirtschaft, die auf ein gemeinsames Ziel, nămlich die Venwirklichung einer Idee, gerichtet sei und damit eine enthusiastische Aufbaustimmung hervorgerufen habe, einen bedeutenden und erhaltenswerten Fortschritt gegenüber dem durch Individualismus, okonomische Anarchie und entfremdete Arbeit gekennzeichneten System des Kapitalismus. - Die Gesellschaftslehre der Eurasier traf denn auch auf besonders heftige Kritik. So warnte der in Paris lebende Philosoph und Theologe V.V. Zen'kovskij in einem Aufsatz, der 1933 in der liberalen Rigaer Zeitung Segodnja erschien, eindringlich vor dem totalităren, freiheitsfeindlichen Charakter eines "organischen", "ganzheitlichen" Gemeinwesens, wie es den Eurasiern vorschwebte, und nannte die "Ideokratie" die schlimmste - weil geistige - Form der Despotie. In diesem Zusammenhang enwăhnte Zen'kovskij auch die Lehre Fedorovs als eine "eigenartige Verflechtung rein religiöser Motive mit seltsamen Nachklăngen des Okkultismus und der Magie". V.V. ZeN'KovsKIJ, "Evrazijcy." In: Segodnja, 290 (20.10.1933).

19 Siehe z.B. P.[N.] SAviCkU, "Glavy iz 'Orerka geografii Rossii'." In: Tridcatye gody (wie Anm. 8), S. 87-101. - Erstaunlicherweise gibt es keine Reaktion der Eurasier auf Fedorovs historiosophische Spekulationen über die Bedeutung Turans und des Pamir als 'Wiege der Menschheit' und Grabstătte des Urvaters Adam; es scheint, als sei dieser Teil der Lehre Fedorovs nicht rezipiert worden.

20 A.S. ADler, "N.F. Fedorov." In: Evrazijskaja chronika, 10, Paris 1928, S. 101f. Dem Artikel vorangestellt ist ein Portrăt Fedorovs. Uber den Verfasser ist nichts weiter bekannt; møglichenweise handelt es sich um ein Pseudonym. 
mit seinem Aufruf zur vernunftgeleiteten Umgestaltung der Welt und zur Überwindung ihrer verhängnisvollen Gespaltenheit die "absoluten Grundlagen" der "neuen ideokratischen Kultur" gelegt. Mit seinem Entwurf einer "Psychokratie" habe Fedorov die von den Eurasiern geforderte geistige Begründung einer künftigen Ordnung des Lebens vorweggenommen.

Fedorovs Ideen scheinen zunächst von den Anhängern des 'linken' Flügels der Eurasier aufgenommen worden zu sein. Erkennbar wird dies in der Auseinandersetzung um den ideologischen Standpunkt der in Clamart bei Paris wöchentlich erschienenen Zeitung Evrazija, die um die Wende des Jahres 1928/29 zum offenen Konflikt und zur endgültigen Spaltung der Bewegung führte. 21

Die erste Nummer von Evrazija erschien am 24. November $1928 .^{22}$ Ihr Motto lautete: "Das Rußland unserer Zeit wird die Geschicke Europas und Asiens entscheiden. Als sechster Erdteil ist Eurasien Knotenpunkt und Anbeginn einer neuen Weltkultur." Das von 'linken' Eurasiern dominierte Redaktionskollegium bestand aus Arapov, Karsavin, A.S. Lur'e, P.N. Malevskij-Malevic, Nikitin, Svjatopolk-Mirskij, Suvcinskij und Ėfron. Bereits in der ersten Nummer wies Svjatopolk-Mirskij, im Rahmen eines Artikels über Tolstoj, auf Fedorov hin und erwähnte in diesem Zusammenhang die "bemerkenswerte Broschüre von A.K. Gornostaev" über Fedorov und Tolstoj. ${ }^{23}$

In der dritten Nummer erschienen dann die ersten jener umstrittenen "Briefe aus Rußland", in denen offen zu einer Vereinigung des Eurasiertums mit den Lehren von Fedorov und Marx aufgerufen wurde. ${ }^{24}$ Verfasser dieser anonym veröffentlichten und von der Redaktion jeweils beifällig eingeleiteten Schreiben soll - einer unbestätigten Angabe zufolge - Setnickij gewesen sein. ${ }^{25}$ Die durch die russische Revolution entfesselten Kräfte und einander widerstreitenden Bestrebungen müßten, so der Verfasser, reguliert, koordiniert und auf ein letztes, absolutes Ziel gerichtet werden. Ein solches Ziel habe Fedorov gewiesen. Zwar habe Fedorov Revolutionen (als Ausdruck blinder Elementargewalt) abgelehnt, doch würde er den gegenwärtig sich vollziehenden Untergang

21 Siehe zum folgenden auch Boss (wie Anm. 5), S. 118-120.

22 Insgesamt erschienen 35 Nummern (bis 7.9.1935). Wie die meisten Veröffentlichungen der Eurasier ist auch diese Zeitung inzwischen eine Rarităt und nur in wenigen Bibliotheken vollstăndig vorhanden; benutzt wurden Exemplare der Universitătsbibliothek Basel.

23 D.[P.] Svjatopolk-Mirskis, "O Tolstom. 1828-1928." In: Evrazija, 1 (24.11.1928), S. 6 f. $\mathrm{Zu}$ Fedorovs EinfluB auf Tolstoj auch Ders., "Some Remarks on Tolstoy." In: The London Mercury, 1929, 20, S. 174.

24 AnOn., "Pis'ma iz Rossii." In: Evrazija, 3 (8.12.1928), S. 8. "Ot redakcii." Ebd. Siehe auch ANON., "Pis'mo iz Rossii." In: Evrazija, 22 (20.4.1929), S. 6 f.

25 Notiz von A.K. Ccheidze; FAP I, 237. - Zwar sind die Briefe so formulier, als lebte der Verfasser in der Sowjetunion, doch konnte Setnickij sie wăhrend seines dortigen Reiseaufenthaltes im Sommer 1928 geschrieben haben. Nicht auszuschließen ist freilich auch, daB es sich bei den Briefen um jene von Gur' (wie Anm. 12) erwăhnten Fälschungen der GPU handelt; immerhin forderten sie die Polarisierung innerhalb der eurasischen Bewegung und trugen zu deren Spaltung bei. Unbegründet ist hingegen der Verdacht, Setnickij, der ja stets sowjetischer Staatsbürger war, habe die Briefe im Auftrag der GPU verfaßt. 
des Kapitalismus und der Monarchie gutgeheißen haben (Fedorov sei kein Monarchist gewesen; unter samoderžavie habe er eine "Diktatur der Errettung" [diktatura spasenija] verstanden, wobei er das "Wir" im Titel des samoderžec als Hinweis auf eine kollektive Herrschaft gedeutet wissen wollte). Auch den sozialistischen "großen Aufbau" würde Fedorov begrüßt haben, wenngleich seine Pläne weit darüber hinausgegangen seien, denn anstatt sich nur an eine Klasse zu wenden, habe Fedorov die "Sterblichen aller Länder" aufgerufen, sich zu vereinigen im Kampf gegen den letzten Feind - die blinde, todbringende Natur. In allem sei Fedorov konsequenter und radikaler gewesen als die heutigen Kommunisten. Was schließlich den Atheismus in der Sowjetunion betreffe, so seien "aufrechte Atheisten" weit eher bereit, am obšcee delo mitzuwirken, als verstockte Mystiker und Heuchler.

Solche Äußerungen mußten auf orthodoxe Eurasier - und diese dürften die Mehrheit gewesen sein - provozierend gewirkt haben. In der siebten Nummer vom 5. Januar 1929 erschien denn auch ein Brief des Fürsten Trubeckoj, in dem dieser der Redaktion vorwarf, sie gebe "fast ausschließlich" die Ansichten jener Strömung wieder, welche dahin tendiere, bisherige ideologische Grundsätze des Eurasiertums durch Elemente anderer, mit dem Eurasiertum unvereinbarer Lehren - nämlich denen von Marx und Fedorov - zu ersetzen. Damit sei die Spaltung der Bewegung vollzogen, weshalb er, Trubeckoj, seine Mitarbeit aufkündige und seinen Austritt aus der Organisation der Eurasier erkläre. ${ }^{26}$

In einer ersten Stellungnahme bedauerte die Redaktion diesen Schritt, wies aber zugleich darauf hin, da $B$ die eurasische Bewegung, wolle sie nicht in Stagnation verfallen, sich auch mit dem Marxismus und "einem so bemerkenswerten Gedankengebäude wie dem Fedorovs" auseinandersetzen müsse. ${ }^{27}$ Dargelegt und näher begründet wurde dies in einer Reihe von Artikeln, die in den folgenden Nummern von Evrazija erschienen. ${ }^{28}$

Notwendig, so hieß es, sei eine kritische Auseinandersetzung mit den Lehren von Marx und Fedorov, die darauf ziele, die "ursprünglichen richtigen Ideen und Intuitionen" beider freizulegen; insbesondere müßten Materialismus und Klassendenken der Marxisten überwunden werden. Vorbildlich sei in dieser Hinsicht die "synthetische Konzeption" Fedorovs, der jeglicher einseitiger Monismus - materialistisch oder idealistisch - fremd sei. Bei allen Unterschieden seien Marxismus und fedorovstvo dem Eurasiertum näher und verwandter als etwa der "demokratische Relativismus". Schließlich habe die - von den Eura-

26 N.S. TRUBECKOJ, "Pis'mo v redakciju." In: Evrazija, 7 (5.1.1929), S. 8; der Brief ist datiert vom 31.12.1928. - Trubeckoj hat sich nicht endgültig von der eurasischen Bewegung abgewandt, wie Veroffentlichungen aus der Mitte der dreißiger Jahre beweisen. Hingegen blieb seine Einstellung zu Fedorov und dessen Anhăngern reserviert; siehe Trubeckojs Schreiben an P.N. Savickij vom 1.1.1933, II: 4.2.5.

"Ot redakcii." In: Evrazija, 7 (5.1.1929), S. 8.

28 ANON., "Put' evrazijstva." In: Evrazija, 8 (12.1.1929), S. 1. "Ot redakcii." Ebd., 10 (26.1.1929), S. 1. D.[P.] Svjatopolk-Mirsku, "Nas marksizm." Ebd., 11 (2.2.1929), S. 3. ANoN., "Problema ideokratii." Ebd., 15 (2.3.1929), S. 1. 
siern von Anfang an positiv bewertete - russische Revolution den "Primat des Allgemeinen (obšcee) vor dem Privaten (Castnoe) ${ }^{n}$ bekräftigt. Bei dieser Erkenntnis, die zugleich eine Selbsterkenntnis des Eurasiertums gewesen sei, habe Fedorov "eine nicht geringe Rolle" gespielt:

Für viele von uns war die Filosofija obšcego dela ein Schlüssel, der uns den wahren Inhalt unserer eigenen Philosophie eröffnet hat. (...) Natürlich sind wir keine fedorovcy, und in der zentralen Idee Fedorovs können wir nicht mehr sehen als den genialen Zugriff auf einen Mythos. Dennoch erkennen wir ihn als unseren Lehrer, und von allen russischen Denkern ist er uns der năchste. Dem Kreis seiner Ideen sind wir auch deshalb besonders verpflichtet, weil uns von allen westlichen Denkern Marx mittlerweile am năchsten steht - eine Feststellung, die noch vor zwei, drei Jahren die Mehrheit der Eurasier erstaunt haben würde. $\mathrm{Zu}$ Marx zieht uns ... vor allem die auch für Fedorov charakteristische Ausrichtung auf das Handeln, auf eine Philosophie, die gemacht, nicht gedacht wird. (...) Freilich müssen sowohl Fedorow wie Marx überwunden werden, doch bleiben sie in der Dialektik der weiteren Entwicklung des Eurasiertums Momente von entscheidender Bedeutung. Im Eurasiertum muß vollstăndig das zutage treten, was bei Fedorov und Marx nur teilweise und einseitig hervortritt - die Idee des obsčee delo und die Idee der Weltgestaltung (mirodelanie) anstelle der Weltanschauung. ${ }^{29}$

Noch deutlicher wurde der anonyme Verfasser (Setnickij?) eines weiteren "Briefes aus Rußland", der, wiederum mit einer beifälligen Einleitung der Redaktion, am 20.4.1929 in Nr. 22 von Evrazija erschien: $:^{30}$ Allein der schöpferischaktive Projektivismus Fedorovs könne die elementare Aktivität, die durch den gottlosen Marxismus freigesetzt worden sei, bändigen, indem er ihr eine höchste, letzte Aufgabe weise - die schöpferische Umgestaltung des Universums. Mit Marx müsse man beginnen, mit Fedorov müsse man enden. Der Marxismus sei die einzige Lehre, "die Betrachten und Erkennen mit der Verpflichtung zum Handeln" verbinde, doch bleibe dieses Handeln blind und zerstörerisch. Allein die Lehre Fedorovs sei imstande, die blinde Dialektik des Marxismus in eine "konstruktive, projektive Dynamik" zu verwandeln und damit den von der russischen Revolution eingeschlagenen Weg fortzusetzen und zu vollenden. Die Verbindung von Marx und Fedorov biete die "einzig annehmbare" Perspektive, auch für die Eurasier, und verhindere ein Abgleiten in Faschismus und Reaktion.

$\mathrm{Zu}$ diesem Zeitpunkt war die Spaltung der Eurasier freilich schon besiegelt. Zu Beginn des Jahres 1929 hatten Alekseev, Il'in und Savickij in Paris eine Broschüre veröffentlicht, in der sie die Zeitung Evrazija für "nicht-eurasisch" erklärten. ${ }^{31}$ Die Leitartikel, so Savickij, ${ }^{32}$ stellten großenteils eine Apologie des Marxismus dar und propagierten eine Weltanschauung, die man als "Salonkommu-

29 ANON., "Put' evrazijstva" (wie Anm. 28).

30 ANON., "Pis'mo iz Rossii" (wie Anm. 24).

31 N.N. Alekseev, V.N. IL'IN, P.N. SA viCkIJ, $O$ gazele "Evrazija". (Gazeta "Evrazija" ne est' evrazijskij organ). Paris 1929. - Die Broschüre war allen Abonnenten von Evrazija zugeschickt worden.

32 P.[N.] SAvicku, "Gazeta 'Evrazija' ne est' evrazijskij organ." Ebd., S. 3-10; zu Fedorov bes. S. Sf. 
nismus" bezeichnen müsse. Anstatt den Marxismus zum Objekt kritischer Analyse zu machen, werde er auf den Seiten von Evrazija zum Subjekt ideologischer Konstruktionen. Fedorovs Ideen, die an sich nicht uninteressant seien, würden in einigen Leitartikeln im Ton eines "Fedorovschen Sektierertums" (fedorovskoe sektantstvo) propagiert. Auch der kritiklose Abdruck der "Briefe aus Rußland", deren Inhalt für einen orthodoxen Gläubigen - und das heiße, für einen echten Eurasier - unannehmbar sei, beweise, daß die Zeitung Evrazija nicht nur "nichteurasisch", sondern sogar "anti-eurasisch" sei. "Oberflächlich und vergeblich" nannte Alekseev in seinem Beitrag den Versuch, Fedorov und Marx zu verbinden; Fedorov werde nur deshalb herangezogen, weil man "auf seltsame Weisen Marxismus, d.h. Kommunismus, mit dem obšcee delo identifiziere..$^{33}$ Die Broschüre enthielt ferner Erklärungen der Prager und Belgrader sowie eines Teils der Pariser Gruppe der Eurasier, in denen diese sich von der prosowjetischen und "marxistoiden" Linie der Gruppe um Evrazija - der "Bewegung von Clamart", wie sie nach dem Erscheinungsort der Zeitung auch genannt wurde distanzierten. ${ }^{34}$

Die Spaltung von Clamart bedeutete eine erhebliche Schwächung der eurasischen Bewegung. Nach Trubeckoj zog sich im August 1929 auch Suvcinskij aus der Bewegung zurück. Karsavin war 1928 an die Universität Kaunas gegangen, ${ }^{35}$ Vernadskij bereits 1927 einem Ruf nach Yale gefolgt.

Die 'linken' Eurasier fuhren indessen fort, Fedorovs Ideen zu propagieren. So erschienen in Nr. 24 von Evrazija sechs zum Teil umfangreiche Briefe Fedorovs an Koževnikov, die von Setnickij zur Publikation vorbereitet worden waren. ${ }^{36} \mathrm{Da}$ freilich der Inhalt dieser Briefe weitgehend aus umständlich vorgetragenen Bagatellen bestand und kaum die zentralen Gedanken der Fedorovschen Lehre erkennen lie $B,{ }^{37}$ sah sich die Redaktion veranla $B t$, in einem einleitenden Artikel $^{38}$ darauf hinzuweisen, daß zwischen Fedorovs "genialer innerer Erfahrung" und seiner Fähigkeit, diese gedanklich zu fassen und angemessen zu formulieren, eine "krasse Diskrepanz" bestanden habe. Durch den Einfluß des zutiefst kulturlosen konservativen Milieus, in dem Fedorov gelebt und gewirkt habe, seien seine 'Projekte' deformiert, ja oftmals zur "peinlichen Groteske" (mučitel'nyj grotesk) verzerrt worden. Dennoch habe Fedorov wie kein anderer

33 N.N. AlekseEv, "O gazete 'Evrazija'." Ebd., S. 12-20; zu Fedorov S. 18.

34 Ebd., S. 24-31.

35 Dort lehrte er an der historischen Fakultăt. Von 1940 bis 1946 unterrichtete er an der Universităt Wilna. 1949 wurde er verhaftet. Im Juli 1952 ist er in einem sowjetischen Lagerkrankenhaus gestorben.

36 [N.F. FEDOROv], "Pis'ma N.F. Fedorova k V.A. Koževnikovu." In: Evrazija, 24 (4.5.1929), S. 7 f. - Fünf der sechs Briefe sind datiert; sie stammen aus der Zeit vom 27.12.1895 bis 3.7.1900. Dazu erlăuternde Anmerkungen von Koževnikov, Peterson und Setnickij.

37 Der letzte Brief (vom 3.7.1900) verdient ein gewisses Interesse durch die darin enthaltenen Bemerkungen Fedorovs über Cechov und Gor'kij; siehe II: 4.2. Anm. 42.

ANON., "Po povodu pisem N.F. Fedorova." In: Evrazija, 24 (4.5.1929), S. $2-4$. 
das "Problem der Revolution" auf die Ebene ihrer "metaphysischen Bedeutung" gehoben: "mit beispielloser Kraft" habe er "das Thema des revolutionären Projektivismus aufgeworfen und damit dem russischen Bewußtsein den religiösen Sinn der Revolution eröffnet und eine Rechtfertigung ihres historischen Zieles gegeben." ${ }^{39}$

Näher erläutert wurde dieser Gedanke in einem anonymen Leitartikel, der in Nr. 33 (10.8.1929) von Evrazija erschien: ${ }^{40}$ Die Revolution habe den Menschen aus Entfremdung und Passivität befreit und zur aktiv-projektiven Umgestaltung der Natur aufgerufen, das aber heißt, zur Erfüllung seines ursprünglich religiös sanktionierten Auftrags (der in der bürgerlich-kapitalistischen Gesellschaft verraten und vergessen worden sei). Die "organische Tradition" der Religiosität der "neuen Arbeitskultur" hergestellt zu haben, sei das Verdienst Fedorovs, des "neben Marx größten Propheten und Verkünders einer neuen Epoche der Geschichte."

Vier Wochen später, am 7.9.1929, stellte Evrazija ihr Erscheinen ein. Mit ihrem Versuch, Marx und Fedorov zu verbinden, um auf der so konstruierten ideologischen Basis in der Sowjetunion legal tätig zu werden, hatte sich die "Bewegung von Clamart" selbst ins Abseits manövriert. "Es war," wie Alekseev 1934 schrieb, "die Tragödie von Clamart, daß die [nach Moskau] 'ausgestreckte Hand' doch in der Luft hängen blieb. Das Politbüro war ebenso wenig geneigt, die eurasische Bewegung von Clamart wie die Fedorov-Bewegung zu legalisieren, deren Anhänger in Rußland auch verfolgt wurden. Infolge seiner Taktik blieb Clamart vollkommen isoliert. Zugleich war auch das eine Wesentliche verloren: die eurasische Idee selbst. Dies erklärt das traurige Ende des Eurasiertums von Clamart." ${ }^{41}$

Tragisch war auch das Schicksal der Protagonisten dieser Bewegung. Sergej Éfron, den manche als den Hauptschuldigen an der Spaltung der Eurasier ansahen, ${ }^{42}$ wurde in den dreißiger Jahren einer der Organisatoren des "Bundes zur Rückkehr in die Heimat" und war für den sowjetischen Geheimdienst tätig. Nach der Verwicklung in einen politischen Mordfall setzte er sich, möglicherweise über Spanien, in die Sowjetunion ab. Dort wurde er 1941 für seine Dienste erschossen. Svjatopolk-Mirskij trat 1931 in die Kommunistische Partei

39 Ebd., S. 3; Hervorhebung im Orig.

40 ANON., "Ot neobchodimosti - k svobode." In: Evrazija, 33 (10.8.1929), S. 1f.

41 N.[N.] AlEXEJEw [AlekseEv], "Geschichte und heutiger Zustand der eurasischen Bewegung." In: Orient und Occident, 17, 1934, S. 4. - Positiver urteilte Setnickij: Hinter dem Versuch einer Verbindung von Marx und Fedorov sah er das Bemühen um eine neue große ideologische Synthese, die "Revolution und Tradition" einschließe. Es bleibe das unbestreitbare Verdienst der Eurasier von Clamart, erstmals Fedorovs Namen zur Losung und seine Lehre zur Grundlage eines auf die aktuelle Wirklichkeit bezogenen Handelns gemacht zu haben. D.S. KoNONOv [d.i. N.A. SETNICKU], "Evrazijstvo i porevoljucionniki." In: Vselenskoe delo, 2, Riga 1934, S. 39, 37.

42 Siehe den Brief von Marina Cuetaeva an Anna Tesková, 22.1.1929. In: M. CveTAEva, Pis'ma k A. Teskovoj, Prag 1969, S. 71. Siehe auch M. RazumovskAuA, Marina Cveraeva. Mif i dejstvitel'nost'. London 1983, S. 260 f. 
Großbritanniens ein, erwarb im Jahr darauf die sowjetische Staatsbürgerschaft und kehrte in die Sowjetunion zurück. 1937 verhaftet, soll er 1939 in einem Lager in der Nähe von Magadan umgekommen sein. ${ }^{43}$ Auch der 'linke' Eurasier und ehemalige Garderittmeister Arapov kehrte in die Sowjetunion zurück; er endete, dem Vernehmen nach, im Lager von Solovki. ${ }^{44}$

Von den in Paris verbliebenen 'rechten' Eurasiern war V.N. Il'in der bedeutendste. Naturwissenschaftlich, philosophisch und theologisch gebildet, trat er mit Vorträgen und Veröffentlichungen zu religiös-philosophischen Themen hervor. ${ }^{45}$ Im Zuge der Auseinandersetzung mit dem 'linken' Eurasiertum von Clamart richtete Il'in seine Aufmerksamkeit auch auf Fedorov. Am 10. Februar 1929 hielt er in Paris einen öffentlichen Vortrag über "Karl Marx, Fedorov und das Eurasiertum", in dem er den Vorwurf, die Eurasier seien den Bolschewiki geistig verwandt, zurückwies; die Eurasier seien, so Il'in, "Kinder der Slavophilen". 46

In dieser Tradition sah Il'in auch Fedorov, dessen Leben und Werk er in einem Aufsatz würdigte, der 1929 im 6. Band der Evrazijskaja Chronika erschien. ${ }^{47}$ Fedorovs Lehre sei tief religiös, doch enthalte sie Ideen, die durch ihre Kühnheit zur Parodie, zum Sektierertum, ja sogar zur Häresie verführten. Fedorov selbst habe, einem Heiligen gleich, dieser Versuchung widerstanden, seine Nachfolger aber seien ihr erlegen: so sei Fedorovs christliche Anthropologie von Murav'ev in einen "kosmischen gottlosen Utopismus mit kommunistischem Beigeschmack" verwandelt und der "Kampf gegen den Tod" in der Schrift SmertobožniCestvo in einen Kampf gegen das Dogma von der Erlösung durch Christi Kreuzestod verkehrt worden. ${ }^{48}$ In einer erweiterten Fassung dieses Artikels, die 1931 im Vestnik RSChD erschien, ${ }^{49}$ nannte Il'in Fedorov einen "Pro-

43 Zur Biographie von D.P. Svjatopolk-Mirskij siehe N. LAVRoukine [LAVRUCHINa], L. TChertKov [C'ERTKov], D.S. Mirsky. Profil critique et bibliographique. Paris 1980, bes. S. 38-40, 4450.

44 Siehe Gur' (wie Anm. 12), S. 174.

45 Siehe z.B. V.N. IL'IN, Sest' dnej tworenija. Biblija i nauka o tvorenii i proischozdenii mira. Paris 1930. - Versuch einer christlichen Kosmologie unter Einbeziehung moderner naturwissenschaftlicher Erkenntnisse und Theorien; mit Hinweisen auf Murav'ev (S. 211), Losev und Florenskij (S. 212-215), Vernadskij (S. 226-229).

46 Siehe die Tagebuchaufzeichnung von V.N. Bunina vom 10.2.1929: "... gingen zu einer Abendveranstaltung der Eurasier. Erfuhr einiges Neue: die Eurasier sind für eine orthodoxe Weltkirche. Sie haben Fedorov entdeckt..." [V.N. BUNINA], Ustami Buninych, t. 2, Frankfurt/M. 1981, S. 197. Siehe auch M. BEYSSAC, La vie culturelle de l'émigration nusse en France. Chronique (1920 1930). Paris 1971, S. 216. An der Diskussion nahmen Berdjaev, Vyšslavcev, Fedotov und Ju A. Sirinskij-Sichmatov teil.

47 V.N. IL'IN, "O religioznom i filosofskom mirovozzrenii N.F. Fedorova." In: Evrazijskij sbomik, kn. 6, Prag 1929, S. 17-23.

Ebd., S. 20.

49 V.N. IL'IN, "Etjudy o russkoj kul'ture. Etjud V. N. Fedorov i prep. Serafim Sarovskij." In: Vestnik RSChD, 1931, 7, S. 8-13; 8-9, S. 19-26; 11, S. 13-16. 
pheten (!) der Unsterblichkeit und der Auferweckung", ohne jedoch auch nur mit einem Wort zu erwähnen, wie Fedorov zufolge Auferweckung und Unsterblichkeit bewerkstelligt werden sollten. Hier wie auch in späteren Artikeln hat Il'in es verstanden, die zentralen Gedanken des "genialen Fedorov" bis zur Unkenntlichkeit zu verschleiern und zu verzerren. ${ }^{50}$

\subsubsection{Die Eurasier in Prag: K.A. Čcheidze}

Mit der Spaltung von Clamart verlor das Eurasiertum in Paris an Bedeutung. Der Schwerpunkt der Bewegung verlagerte sich nach Prag, das in den zwanziger Jahren neben Paris, Berlin und Harbin zum bedeutendsten Zentrum der russischen Emigration geworden war. Unterstützt durch die "russische Aktion" des Präsidenten der Ersten tschechoslowakischen Republik, T.G. Masaryk, hatten zahlreiche aus der Sowjetunion emigrierte oder ausgewiesene Intellektuelle, darunter mehrere namhafte Philosophen, in der Stadt an der Moldau Aufnahme gefunden und innerhalb kurzer Zeit eine effiziente soziokulturelle Infrastruktur geschaffen, die neben Schulen aller Stufen, einer Vielzahl von Verlagen sowie diversen künstlerischen und literarischen Vereinigungen auch eine Reihe wissenschaftlicher Einrichtungen umfaßte: es gab eine "Russische Universität" (später "Russische Freie Universität") und eine "Russische Bibliothek", eine "Russische philosophische Gesellschaft" und, seit Oktober 1925, auch ein "Eurasisches Seminar"."

'Führer' der Prager Eurasier war P.N. Savickij, der seit 1922 an verschiedenen wissenschaftlichen Institutionen tätig war (u.a. als Dozent an der "Russischen Freien Universität" und als Lektor an der Karls-Universität) und eine überaus rege publizistische Aktivität entfaltete. Im Oktober 1926 soll Savickij an einem - von der GPU inszenierten - "eurasischen Kongre $B^{n}$ in Moskau teilge-

50 Vgl. V.N. IL'IN, "Profanacija tragedii. (Utopija pered licom ljubvi i smerti)." In: Put', 40, 1933, S. 63. Ders., Technika i christianstvo." In: Noyyj Grad, 7, 1933, S. 64. DerS., "Velikaja subbota. (O tajne smerti i bessmertija)." In: Put', 57, 1938, S. 48. DERS., Arfa Davida. Religioznofilosofskie motivy russkoj literatury. T. 1, San Francisco 1980, S. 31, 211, 231, 319, 443. - In einer wahrscheinlich Anfang der dreißiger Jahre verfaßten, jedoch erst postum veroffentlichten Streitschrift polemisierte Il'in gegen die "absurden modischen Versuche", Fedorovs Lehre mit den Doktrinen der Revolution zusammenzubringen; in Wirklichkeit seien beide einander diametral entgegengesetzt: so gelte Fedorovs Sorge nicht künftigen Generationen, sondern den vergangenen; Fedorovs Ziel sei Auferweckung und Leben, das Ziel der Revolution sei der Tod. V.N. IL'IN, Religija revoljucii i gibel' kul'tury, Paris 1987, S. 15, 43f., 74, 133, 135. - 1934 verließ Il'in die Eurasier, denen er eine "offene Neigung zum Bolschewismus" vorwarf.

51 Uber die russische Emigration in Prag gibt es umfangreiche Literatur. Siehe 2.B. T. RiHA, "Russian Emigré Scholars in Prague after World War I." In: Slavic and East European Joumal, 16 (1958), 1, S. 22-26. D.I. MEJSNER, Minazi i dejstvitel'nost'. Zapiski emigranta. M. 1966, bes. S. 124-137; über die Prager Eurasier ebd., S. $187 f$. 
nommen haben. ${ }^{52}$ Trotz seiner Kritik an der Zeitung Evrazija wird Savickij allenfalls den gemäßigt 'rechten' Eurasiern zuzurechnen sein. Der Lehre Fedorovs stand er indifferent gegenüber. Ihre Annahme, so Savickij, stehe nicht "in Widerspruch zur Gesamtheit der eurasischen Ideen"; sie sei deshalb "Sache der persönlichen Überzeugung eines jeden einzelnen Eurasiers. ${ }^{n 53}$ In einem bemerkenswert informativen Aufsatz über die russische nachrevolutionäre Philosophie, der unter dem Pseudonym "P. Vostokov" 1932 in Le Monde Slave erschien, ${ }^{54}$ ging Savickij auch auf das Fortwirken Fedorovscher Ideen in der Sowjetunion ein: als Beispiele nannte er Murav'evs Ovladenie vremenem sowie die zahlreichen Arbeiten von Gornostaev (Gorskij), insbesondere dessen IzvestijaArtikel. Die Haltung der Obrigkeit charakterisierte Savickij mit der Bemerkung, beide Verfasser befänden sich inzwischen in Lagerhaft. 55

Ein weiteres prominentes Mitglied der Prager Eurasier war N.N. Alekseev, der seit 1922 an der von P.I. Novgorodcev gegründeten Russischen Juristischen Fakultät unterrichtete, bis er zu Beginn der dreißiger Jahre über Berlin nach Straßburg ging. In mehreren Aufsätzen, die Alekseev in den dreißiger Jahren in der Emigrantenpresse veröffentlichte, finden sich - allerdings nur sehr knappe Hinweise auf Fedorov. ${ }^{56}$ Gründlichere Kenntnis der Filosofija obšcego dela verrät hingegen sein Aufsatz über das Verhältnis des russischen religiös-philosophischen Denkens zur Natur, der 1959 in der Emigrantenzeitschrift Grani erschien. $^{57}$

Der einzige erklärte Anhänger der Lehre Fedorovs unter den Prager Eurasiern (und, soweit feststellbar, unter den in Prag lebenden Russen überhaupt) ${ }^{58}$

52 Siehe Anm. 12. Vgl. auch MejSNer (wie Anm. 51), S. 192, und A.B. (wie Anm. 12), der Savickij als talentiert, ehrgeizig und fanatisch schildert (bes. S. 126f.). Zur Biographie Savickijs siehe auch G.V. VeRNADSKIJ, "P.N. Savickij (1895-1968)." In: Novyj Zumal, 92, 1968, S. 273-277.

53 "Protokol sovešzanija naličnych v Prage členov Prezidiuma CK s predstaviteljami Pražskoj EA gruppy." In: Evrazijskie tetradi, o.O. [Prag] 1934, S. 11; Sitzung vom 9.7.1934.

54 P. Vostokov [d.i. P.N. SAvicku], "La philosophie russe durant la période post-révolutionnaire." In: Le Monde Slave, 9 (1932), 4, S. 432-457.

55 Ebd., S. 440.

56 N.N. Alekseev, "Svoboda, ravenstvo i bratstvo." In: Tret'ja Rossija, 3, 1933, S. 33f. DeRs. (wie Anm. 41). DERS., Puti i sud'by marksizma. Ot Marksa i Éngel'sa k Leninu i Stalinu. O.O. [Berlin] 1936, S. 87.

57 N.[N.] ALEkSEEv, "Priroda i Zelovek v filosofskich vozzrenijach russkoj literatury." In: Grani, 42, 1959, S. 187-204; zu Fedorov bes. S. 199-203.

58 Einige der (zeitweise) in Prag lebenden Gelehrten haben sich gelegentlich zu Fedorov geäußert, so der Philosoph und Philosophiehistoriker B.V. Jakovenko (1884-1948) in seinem Werk Déjiny ruské filosofie (Praha 1938; zu Fedorov S. 343-346), der Philosoph und Pădagoge S.I. Hessen (1887-19.50) in mehreren Aufsätzen zu Dostoevskij, der Philosoph und Literaturwissenschafiler R.V. Pletnev (geb. 1903) in einem 1934 veröffentlichten Beitrag "Grundlinien der philosophischen Lehre N.O. [sic] Fiodorows" (in: Festschrifi N.O. Losskij, Bonn 1934, S. 133-140) sowie Roman Jakobson (1896-1982) im Zusammenhang mit Majakovskij. 
war der Schriftsteller Konstantin Aleksandrovið Čcheidze (1897-1974). ${ }^{59}$ Aus einer altadeligen georgischen Familie stammend und politisch den Sozialrevolutionären nahestehend, war er während des Bürgerkriegs emigriert und hatte sich schließlich in Prag niedergelassen. Um die Mitte der zwanziger Jahre findet sich sein Name unter den Mitarbeitern der linken Studentenzeitschrift Svoimi Putjami, die mit revolutionär-aktivistischen Parolen wie "Wir träumen von der Verwandlung der Welt" und "Die Väter wollen die Welt restaurieren, wir aber wollen sie transformieren" die konservative Emigrantenschaft provozierten. ${ }^{60}$ Einer der Redakteure war der damals noch in Prag lebende Sergej Ėfron. Durch ihn wurde Čcheidze in den Kreis der 'linken' Eurasier eingeführt und lernte dort die Ideen Fedorovs kennen. Anfangs, so Čcheidze, habe er sie abgelehnt, da sie ihm in der Interpretation von Suvčinskij begegnet seien. ${ }^{61}$ Später dann, nachdem er mit Setnickij in Briefwechsel getreten war, hat Čcheidze seine Haltung geändert.

Die Korrespondenz zwischen Čcheidze und Setnickij begann Ende 1929 und dauerte bis zur Rückkehr Setnickijs in die Sowjetunion im Sommer 1935; aus diesen knapp sechs Jahren sind 78 Briefe von Setnickij und 69 von Čcheidze erhalten. ${ }^{62}$ Ähnlich intensiv war der Briefwechsel zwischen Čcheidze und Ustrjalov, der in die Zeit zwischen 1930 und 1933 fällt. ${ }^{63}$ Mit beiden Briefpartnern wußte Čcheidze sich einig in dem Bemühen um die "Wiederherstellung einer lebendigen psychologischen Verbindung zur Heimat", eines der Grundanliegen auch des Eurasiertums. ${ }^{64}$ Durch Setnickij, der ihm geistig besonders nahe stand, lernte Čcheidze Fedorovs Lehre genauer kennen und gelangte zu der Überzeugung, daß sie einen wesentlichen Beitrag zu einer künftigen Ideokratie leisten könne. Mit Beginn der dreißiger Jahre war Čcheidze zu einem eifrigen Anhänger der Lehre Fedorovs geworden. Allerdings trat er weniger als origineller Denker, denn als rühriger Organisator und Propagandist hervor.

Zwischen 1932 und 1937 wies Čcheidze in zahlreichen Artikeln, die zumeist in tschechischen Zeitschriften erschienen, auf Fedorov hin, skizzierte die

59 Materialien zur Biographie von K.A. Ccheidze (19.9.1897 [n.St.] - 29.7.1974) im FAP, bes. I, 341. Siehe auch LV, "75 let K.A. Ccheidze." In: Svobodné Slovo [Praha], 19.9.1972. In den zwanziger und dreißiger Jahren sollen Čcheidzes Romane und Erzăhlungen recht populăr gewesen sein; als sein Hauptwerk gilt der Kaukasus-Roman Strana Prometeja, der 1932 in Schanghai erschien.

60 Siehe I.V. Kudrova, "Polgoda v Pariže. (K biografii Mariny Cvetaevoj)." In: Marina Cvetaeva. Studien und Materialien. Wien 1981, S. 141f. ( = Wiener Slawistischer Almanach; Sonderbd. 3).

61 Siehe "Protokol..." (wie Anm. 53), S. 9.

62 FAP I, 341, Setnickij an Čcheidze, 1929-1934. - FAP I, 328, Ccheidze an Setnickij, 1930-1935. Von 1965 bis zu seinem Tod korrespondierte Ccheidze regelmäßig mit Setnickijs Tochter Ol'ga Nikolaevna Setnickaja (Ljubimovka bei Moskau); von ihr sind etwa 50 Briefe im FAP I, 341, erhalten.

63 FAP I, 341, Ustrjalov an Čcheidze, 44 Briefe 1930-1933; ¿cheidze an Ustrjalov, 27 Briefe 19301933.

64 Siehe "Protokol..." (wie Anm. 53), S. 9. 
Grundgedanken seiner Lehre und hob ihre Bedeutung für die russische Kultur in Vergangenheit und Gegenwart hervor. Dabei stützte er sich weitgehend auf Mitteilungen und Materialien, die er von Setnickij aus Harbin erhielt. So findet sich bereits im ersten Beitrag über Fedorov, der 1932 in der Prager Kulturzeitschrift Rozhledy po literature a umění erschien, ein langes Zitat aus Gorskijs Izvestija-Artikel. ${ }^{65}$ Es folgten mehrere Aufsätze zur zeitgenössischen russischen $\mathrm{Li}$ teratur, insbesondere zum Werk Majakovskijs, in denen Čcheidze - wenn auch nur kurz - auf die Frage nach einem Einfluß Fedorovscher Ideen einging. ${ }^{66} 1933$ veröffentlichte er in der Brünner Zeitschrift $A k c e$ aus Anla $B$ des 30. Todestages Fedorovs einen Artikel, in dem er die geistesgeschichtliche Tradition und die aktuelle Bedeutung der Filosofija obš̌̌ego dela aufzuzeigen versuchte. ${ }^{67}$

Bei seiner Darstellung der Lehre Fedorovs, der mehrere Artikel 1934 und 1935 gewidmet waren, ${ }^{68}$ wandte sich Čcheidze vor allem gegen den immer wieder - und nicht zuletzt aus den Reihen der Eurasier - erhobenen Verdacht und Vorwurf des Materialismus. ${ }^{69}$ Die Behauptung, Fedorov propagiere eine "chemische Auferweckung der Verstorbenen" gehöre, so Čcheidze, ins Reich der Legenden. Fedorov sei "kein 'Chemiker', kein 'Materialist', sondern ein 'Spiritualist'(!) und Christ". ${ }^{70}$ Er lehre eine "christliche Ethik", die in völligem Einklang mit dem Dogma stehe. Auferweckung, wie Fedorov sie fordere, sei das gemeinsame Werk Gottes und der vereinigten Menschheit, der Mensch also nicht selbstherrlich, sondern Mitarbeiter (sotrudnik) Gottes auf Erden. Fedorovs aktives Christentum mit seinem Streben nach universaler Organisation und Synthese erweise sich als Vorläufer der eurasischen Weltanschauung und als

65 K.A. CCHEIDZE, "Nikolaj Fedorovið Fedorov." In: Rozhledy po Literatuř a Uměnl, 1 (1932), 12, S. 91.

66 K.A. ČCHEIDzE, "Komentár̆ k Majakovskêmu." In: Rozhledy po Literatuře a Umént, 2 (1933), 89, S. 57f. DERS., "O soudobé ruské literatuře." Ebd., 15, S. 105f.; 16-17, S. 115f. (Dass. russ.: $O$ sovremennoj nusskoj literature, Ms. [Masch.], Prag 1933). Siehe auch II: 3.2. Anm. 12, 14.

67 K.A. CCHEIDzE, "N.F. Fedorov a naše doba. (K třicátému výrołi dne jeho úmrtí 15.-28. prosince roku 1903)." In: Akce, 1933, 11-12, S. 171-174. - Im selben Jahr erschienen in eurasischen Publikationen zwei Beitrăge von Ccheidze, in denen Fedorov jeweils kurz erwăhnt wird. K.A. CCHEIDZE, "K probleme ideokratii." In: Novaja epocha. Ideotoatija. Politika-ekonomika. Ob. zory. Narva 1933, S. 15-22; Fedorov S. 17. DeRs., "Science." In: P. MALEVSKY-Mallevich [Hg.], Russia U.S.S.R. A Complete Handbook. New York 1933, S. 677-687; Fedorov S. 678.

68 K.A. С [CHEIDZE], "Zapiska K.A.C. o filosofii N.F. Fedorova." In: Evrazijskie tetradi (wie Anm. 53), S. 30-34. Siehe auch "Protokol..." (wie Anm. 53), S. 28f. (Sitzung vom 11.7.1934). Evrazijskie tetradi, 1934, 2-3, S. 21; 4, S. 9-11, 24-28. DERS., "N.F. Fedorov." In: Acta Academiae Velehradensis, 12, 1934, fasc. 3-4, S. 135-141. Ders., "Idea-projekt." In: Akce, 1934, 5-6, S. 47f. DERS., "Idea-obraz." Ebd., 7-8, S. 64f. DeRS., "Fedorovova filosofie." Ebd., 1935, 1-2, S. $18 f$.

69 Auf die Frage nach ihrer Einstellung zur Lehre Fedorovs gaben Teilnehmer einer Konferenz der Prager Eurasier am 9.7.1934 zu Protokoll: "Die Lehre Fedorovs ist für mich akzeptabel mit Ausnahme der Auferweckung der Toten." (A.P. Antipov) "Stehe der Lehre Fedorovs ablehnend gegenüber." (A.A. Sepovalov) "Was die Lehre Fedorovs betrifft, so bin ich gegen die Auferweckung der Toten. Die Anhänger Fedorovs sind heilige Sektierer, die den tiefen und weisen Sinn des Todes nicht begreifen." (I.S. Beleckij). "Protokol..." (wie Anm. 53), S. 10.

CCHEIDZE, "Zapiska..." (wie Anm. 68), S. 31. 
eine der geistigen Grundlagen einer künftigen Ideokratie. - Inwieweit es Čcheidze gelang, mit dieser Umdeutung die "Legende" von der "chemischen Auferweckung" zu zerstören und die Skeptiker vom christlichen Charakter der Fedorovschen Lehre zu überzeugen, ist nicht bekannt. Ganz auf Setnickijs Materialien beruhten schließlich zwei Aufsätze von 1936 und 1937, in denen Čcheidze die Rezeption und Wirkung der Fedorovschen Ideen nachzeichnete. ${ }^{71}$ Immer wieder verwies Čcheidze auf die Harbiner Veröffentlichungen; er selbst besorgte eine tschechische Ausgabe von Gorskijs Studie über Tolstoj und Fedorov, die 1933 unter dem Titel Před tvár̆ smrti in Prag erschien. ${ }^{72}$

Čcheidzes publizistische Bemühungen um Fedorov fanden nur äußerst schwache Resonanz; ${ }^{73}$ nichts deutet darauf hin, daß es ihm gelang, dem Fedorovschen Denken neue Anhänger zu gewinnen. Wie stark die Vorbehalte waren, mußte Čcheidze erfahren, als er vor der "Russischen philosophischen Gesellschaft" in Prag einen Vortrag über Fedorov halten wollte. Über ein Gespräch mit dem Vorsitzenden dieser Gesellschaft, dem angesehenen Neukantianer I.I. Lapsin (1870-1952), berichtete er:

Lapšin: Sie wollen bei uns über Fedorov sprechen? Aber was ist das denn für ein Philosoph? Ein verrückter Alter, ein Graphoman, dem man nie eine Feder hătte in die Hand geben dürfen.

Ccheidze: Aber Solov'ev, Tolstoj, Dostocvskij und eine ganze Reihe zeitgenössischer Denker waren da anderer Meinung. Anderer Meinung sind auch Bulgakov, Losskij, Berdjaev und Setnickij; dieser hat kürzlich ein Buch veroffentlicht...

L.: Das ist ganz egal. Fedorov wollte alle Kants verhaften lassen. Und diese seine Auferweckung der Toten - kompletter Unsinn! Dummes Zeug! Und zu sagen, er sci ein Philosoph, auch das ist dummes Zeug... Wie kann man nur Solov'ev mit Fedorov vergleichen. Der eine ist ein Philosoph mit enormer Bildung, der andere aber - irgend so ein Bibliothekar!

C.: Nun, wenn Sie wollen, werde ich über Fedorovs Kritik an Kant sprechen oder über den EinfluB des einfachen Bibliothekars auf den brillanten Vl. Solov'ev.

71 KA. CCHEJdzE [CCHEIDZE], "N. Fjodorovið Fjodorov." In: Ruch Filosofický, 11 (1936), 3-4, S. 112-115. DERS., "N.F. Fedorov $v$ prołlom i nastojascem. (K poznaniju religioznych motivov russkoj revoljucii)." In: Znamja Rossii, 12 (100), 1937, S. 10-14.

In Ccheidzes Beitrăgen fallen immer wieder ungenaue oder fehlerhafte Angaben auf, bei denen es sich zumeist um Ubertreibungen handelt. So heißt es beispielsweise im letztgenannten Aufsatz, Gor'kij habe "bei der Eröffnung des Weißmeerkanals [!] über Fedorov geschrieben und gesprochen"; Fedorov seien "Aufsătze [!] in der Izvestija gewidmet" gewesen; in Harbin gebe es einen "Kreis [!] von Fedorov-Anhängern", und ein dortiger Verlag habe "etwa 15-20 Bücher und Broschüren" Fedorovs und seiner Schüler veröffentlicht. CCHEIDZE, "N.F. Fedorov...", a.a.O., S. 12.

72 A.K. Gornostaev [GoRsku], Před ruár̆ smrii, Praha 1933; 36 S.; FAP I, 339.

73 Siehe A. ROM[ANICKU], "K llánku 'Pele-mele' o jezdecké akademii v Ceřanech." In: Jezdec a Chovarel, 3, 1935, 68, S. 803. DERS., "Rab. Rasskaz sportsmena." In: Illjustrirovannaja Rossija, 1936, 27, S. 8. - In beiden Făllen erfolgt die Erwăhnung Fedorovs, die offenbar auf Čcheidze zurückgeht, ganz unpassend, nămlich in Zusammenhang mit Sport! 
L.: Da hat es überhaupt keinen Einfluß gegeben, es konnte gar keinen geben! (...) Was für ein Unsinn, was für dummes Zeug... 74

Doch Čcheidze ließ sich nicht beirren; er war vielmehr überzeugt, daß bald schon die volle Bedeutung der Ideen Fedorovs für die Gegenwart hervortreten werde. Bis dahin galt es, alles, was in irgendeiner Weise Fedorov und sein Werk betraf, zu sammeln und an einem allgemein zugänglichen Ort zu bewahren. So entstand die Idee eines Fedorov-Archivs. Die Initiative ging von Čcheidze aus; sie fand Unterstützung bei Josef Wolf, dem Direktor des Prager NationalMuseums, und dem Leiter der dortigen Handschriftenabteilung Novotný. (Beide dürften mit der Filosofija obš̌ego dela nicht vertraut gewesen sein, glaubten sie doch, in Fedorov einen "Verfechter der Idee der slavischen Einheit" zu ehren). ${ }^{75} 1932$ wandte sich Wolf an Gor'kij, erläuterte das Vorhaben und bat um entsprechende Materialien. ${ }^{76}$ Hauptlieferant war freilich Setnickij, der regelmäßig Exemplare der Harbiner Veröffentlichungen nach Prag schickte. Im Laufe des Jahres 1933 wurde das Archiv mit der Nummer 142 und der Bezeichnung "Fedoroviana Pragensia" im National-Museum eingerichtet und in den folgenden Jahren ständig ergänzt. Neben veröffentlichten und unveröffentlichten Schriften Fedorovs und seiner Anhänger enthält es vielfältige Zeugnisse zur Wirkungsgeschichte der Fedorovschen Ideen. Hinzu kommen Teile der Privatarchive von Setnickij und Ustrjalov, die diese vor ihrer Rückkehr in die Sowjetunion 1935 in Prag deponierten, sowie schließlich das Privatarchiv Čcheidzes mit Zeugnissen auch zur eurasischen Bewegung. ${ }^{77}$ Einige der Archivalien wurden im Mai 1934 der Öffentlichkeit vorgestellt, als auf Anregung Čcheidzes in den Räumen des National-Museums eine Ausstellung zu Ehren Fedorovs veranstaltet wurde. ${ }^{78}$

74 K.A. Ccheidze an N.A. Setnickij, 14.11.1932; FAP I, 328. 1933 hat Ccheidze dann offenbar doch einen Vortrag über Fedorov vor der "Russischen philosophischen Gesellschaft" gehalten; Hinweis FAP I, 328.

75 O. D-A., "Fedoroviana Prahensia." In: Vselenskoe delo (wie Anm. 41), S. $176 f$.

76 S.I. Suchich, "M. Gor'kij i N.F. Fedorov." In: Russkaja Literatura, 1980, 1, S. 161. - Uber eine Reaktion Gor'kijs ist nichts bekannt.

77 Siehe das Verzeichnis von M. Bradová, J. Loužlh, Literámi archiv Nánadního muzea v Praze. Literimi poziustalost cis. 142. Fedoroviana Pragensia. Praha 1962 [Masch. vervielf.]. - Bis in die frühen siebziger Jahre wurden die Bestănde des Fedorov-Archivs von Čcheidze ergănzt. Siehe auch LV (wie Anm. 59). Heute befindet sich das Fedorov-Archiv im Literarischen Archiv der Gedenkstătte für Nationales Schrifttum (Památnîk národního pisemnictvi) im ehemaligen Kloster Strahov in Prag.

78 Siehe die Berichte über die Erbffnung der Ausstellung am 24.5.1934 in der Prager Tagespresse: Národni Politika, 23.5.1934. Pražské Noviny, 24.5.1934. Venkov, 24.5.1934. FAP I, 328. 


\subsubsection{Der Sammelband 'Vselenskoe delo' (1934)}

Mit der Einrichtung und Betreuung des Prager Fedorov-Archivs hat Čcheidze sich in besonderem Maße um das obšcee delo verdient gemacht, doch tritt daneben noch eine andere Leistung: Genau zwanzig Jahre nachdem Fedorov zu Ehren in Odessa der Sammelband Vselenskoe delo erschienen war, gelang es 1934, einen zweiten Band unter demselben Titel in Riga zu veröffentlichen, und obgleich die genauen Umstände seines Zustandekommens unbekannt sind, spricht vieles dafür, daß Čcheidze einen entscheidenden Anteil daran hatte.

In den dreißiger Jahren gab es im Baltikum Eurasier, die gute Kontakte zur Prager Gruppe und insbesondere zu Čcheidze unterhielten. So gab ein gewisser V.A. Pejl' 1933 im estnischen Narva einen Sammelband Novaja épocha heraus, in dem drei Prager Eurasier vertreten waren, neben A.P. Antipov und P.N. Savickij auch Čcheidze, der in seinem Beitrag zum "Problem der Ideokratie" kurz auf Fedorov einging. ${ }^{79}$ Offenbar auf Anregung Čcheidzes erinnerte Pejl" im selben Jahr in einer Narvaer Zeitung an den 30. Todestag Fedorovs. ${ }^{80}$ In Riga erschien 1933 ein Zeitungsartikel über Fedorov, dessen Verfasser "P. Trubnikov" möglicherweise Setnickij war; immerhin wurde derselbe Artikel wenig später von einer Harbiner Tageszeitung veröffentlicht. ${ }^{81}$ Auch hier dürfte Ccheidze Vermittler gewesen sein. Von Čcheidzes Verbindungen zu Eurasiern im Baltikum zeugt schließlich seine Beteiligung an dem Sammelband Potok Evrazii, der 1938 in Tallinn erschien. ${ }^{82}$

79 CCheidze, "K probleme..." (wie Anm. 67). - V.A. Pejl' besuchte eine russische Oberschule in Narva und studierte spăter bei P.N. Savickij in Prag, wo er 1937 promovierte. In scinc Heimat zurückgekehrt, wurde er 1940 von den Sowjets verhaftet und erschossen. Ober die guten Beziehungen zwischen Pejl' und den Prager Eurasiern siehe auch "Protokol..." (wie Anm. 53), S. $27 f$. (Sitzung vom 11.7.1934).

80 V. ORg [d.i. V.A. PEJL'], "Kogda my, mertvye, voskresnem?.. K 30-letiju so dnja smerti myslitelja N.F. Fedorova." In: Staryj Nanskij Listok, 145 (1211), 21.12.1933, S. 3.

81 P. Trubnikov [N.A. Sfetnicku ?], "Voskrełat' mertvych ili zvat' smert'." In: Segodnja [Riga], 178, 30.6.1933. Dass. auch in: Gun-bao [Harbin], 2042, 14.7.1933, S. 2.

82 Siehe K.A. CCHEIDZE, "Bor'ba meždu obrazami i za obraz." In: Potok Evrazii, kn. 1 [mehr nicht erschienen], Tallinn 1938, S. 48-70. Siehe auch V.[E.] Guscik, "Potok Evrazii." Ebd., S. 3-48; mit Hinweis auf Fedorow, "den 99\% nicht kennen" (S. 43). Der Schriftsteller V.E. Guscik lebte in Tallinn; Anfang der vierziger Jahre wurde er in die Sowjetunion verschleppt und hingerichtet.

Ebenfalls in Tallinn lebte von 1922 bis 1940 der Dichter, Essayist und Graphiker K.K. Hoerschelmann (1899-1951), der sich bei seinen Reflexionen über Tod und Unsterblichkeit auch mit Fedorov beschaftigte. In grotesk-phantastischer Weise behandelte Hoerschelmann das Thema in einer 1934 veroffentlichten Erzăhlung: Der Held - ein Philosoph und offenbar Anhänger Fedorovs - wird im Jahre 3107 von der "Südlichen Auferweckungs-Compagnie" als besonders Begabter ausgewăhlt und mit technischen Mitteln wiedererweckt, um in einer hochentwickelten Zukunftsgesellschaft (mit künstlicher Ernahrung, Flugapparaten und Raketen) am Projekt der "allgemeinen Auferweckung und Unsterblichkeit" mitzuarbeiten, d.h. "gutes und ewiges Leben zu schaffen". K. GerSEL'MAN [HoERschelmanN], "Korobka vtoraja. Fantastizeskij rasskaz." In: Nov', 7, Tallinn 1934, S. 23-44. - Zu Hoerschelmanns Beschäftigung mit Fedorov siehe auch den Hinweis bei T. PACHMuss, "Iz archiva K.K. Geršel'mana: 'O bessmertii' i 'Ton mira'." In: Melboume Slavonic Studies, 17 (1983), S. 82. 
¿cheidzes baltische Verbindungen bildeten wahrscheinlich den Grund dafür, daß der zweite Band von Vselenskoe delo in Riga veröffentlicht wurde. ${ }^{83}$ Der Band selbst enthält keinerlei Angaben zu seiner Entstehungsgeschichte. Auch über den Verlag, Oriens, und den Redakteur, R.K. Manovskij, ist nichts weiter bekannt. Für eine maßgebliche Beteiligung Čcheidzes am Zustandekommen von Vselenskoe delo spricht neben seiner Mitarbeit als Autor vor allem die Tatsache, daß die Manuskripte einer Reihe von Beiträgen anderer Autoren im Prager Fedorov-Archiv vorhanden sind. Zudem hatte Čcheidze beste Verbindungen nach Harbin - und von dort stammte mehr als die Hälfte der Beiträge: dabei handelte es sich um Aufsätze von Setnickij (unter verschiedenen Pseudonymen, Kürzeln und Initialen), um Materialien aus Setnickijs Archiv sowie um Beiträge verschiedener Autoren aus Setnickijs Umkreis. Unklar bleibt, ob Setnickij selbst an der Redaktion des Bandes beteiligt gewesen ist. ${ }^{84}$

Vselenskoe delo ist im März oder Anfang April 1934 erschienen. Das anonyme Vorwort - datiert vom 28.(15.) Dezember 1933, dem 30. Todestag Fedorovs - knüpft ausdrücklich an die Tradition des Odessaer Bandes von 1914 an und erklärt die Absicht, "die Grundfragen der Gegenwart unter dem Aspekt (...) der Idee des obščee delo sowie der Aufgabe der Verwandlung der Welt und der Auferweckung der Verstorbenen zu beleuchten" 85

Der Band ist in sechs Abschnitte unterteilt: Gedichte, Aufsätze, Materialien, Notizen, Nekrologe, Bibliographie.

Das einleitende Gedicht stammt von dem Harbiner Dichter Arsenij Nesmelov. Es trägt den Titel "Pered poslednim boem" und ist dem 30. Todestag Fedorovs gewidmet. ${ }^{86}$ Das folgende Gedicht, "Zakljatie ognej", ist mit "Pavel Luxickij" gezeichnet, einem Pseudonym Gorskijs; gewidmet der Fedorov-Anhängerin V.N. Mironovic-Kuznecova, die am 4. April 1932 in Moskau gestorben war, trägt es den Entstehungsvermerk "Sommer 1932 am Polarkreis", ein Hinweis auf Gorskijs Lagerhaft in Karelien. ${ }^{87}$ Das dritte Gedicht, "Pustynja", ist mit "A. Gornostaev" gezeichnet und war zuerst 1920 in der Odessaer Zeitung $\mathrm{Na}$ Pomos't! erschienen. ${ }^{88}$

Der Abschnitt 'Aufsätze', der etwa die Hälfte des Bandes umfaßt, besteht aus sechs Beiträgen; zwei stammen von Setnickij (unter den Pseudonymen "G.G. Geželinskij" und "D.S. Kononov"), einer von Ćcheidze; über die Verfasser

83 Vselenskoe delo. Sbornik 2, Riga 1934. VI, 208 S. - Das Werk ist sehr selten und nur in wenigen Bibliotheken vorhanden. Benutzt wurde ein Exemplar der Universitătsbibliothek Basel (Sign.: Lieb Eb 219).

84 Dagegen spricht eine distanzierende Anmerkung der Redaktion zu einem der Beiträge Setnickijs. Vselenskoe delo (wie Anm. 83), S. 28.

Ebd., S. IV.

86 Ebd., S. 3-6. - Zu Nesmelov siehe II: 4.2.5.

87 Ebd., S. 7-9. - Zu V.N. Mironovic-Kuznecova siehe II: 4.1. Anm. 16.

88 Ebd., S. 10. - Zu der Eintagszeitung Na Pomost?, an der auch Setnickij mitarbeitete, siehe II: 4.1. Anm. 22. 
der übrigen drei Beiträge - V. Aleksandrov, R.K. Manovskij und S.I. Čuev - ist fast nichts bekannt. 89

In seinem Beitrag "Die Verehrung Christi und der Krieg"90 erörtert Setnickij die Frage einer christlichen Rechtfertigung des Krieges. Während Kriege früherer Zeiten mit dem Schutz des Lebens und der Verteidigung des Christentums gerechtfertigt werden konnten, gelte dies nicht mehr für den Krieg der Zukunft, der, vor allem durch den Einsatz chemischer Waffen, zu einem allgemeinen Vernichtungskrieg zu werden drohe. Setnickij ruft deshalb die "Chemiker des Todes", die Wissenschaftler und Techniker auf, sich zu einem "christlichen Heer" zu vereinigen zur Verteidigung des Lebens aller gegen den gemeinsamen Feind, die Natur.

Der darauf folgende Artikel Setnickijs ist dem "Eurasiertum und den Anhängern der nachrevolutionären Strömungen" ${ }^{n}$ gewidmet. ${ }^{91}$ Die Hauptaufgabe dieser Strömungen bestehe in der Entwicklung einer "synthetischen Ideologie", die auf der Grundlage der durch die Revolution geschaffenen historischen Fakten einen Entwurf zur aktiven Gestaltung der Zukunft biete. Bislang sei diese Aufgabe noch nicht erfüllt. Zwar sei die enge ideologische Basis eines großrussischen Nationalismus, wie sie für Ustrjalov und die von ihm ausgehenden nationalbolschewistischen Bewegungen kennzeichnend gewesen sei, mittlerweile durch das Eurasiertum erweitert worden, doch sei der Versuch (der linken Eurasier), durch eine Verbindung von Marx und Fedorov eine "große Ideologie" zu schaffen, nicht zuletzt an mangelnder Kenntnis gescheitert. Trotz ihrer Bedeutung als Grundlage einer übernationalen, synthetischen und aktiven Ideologie habe die Lehre Fedorovs bei den Vertretern der "nachrevolutionären Strömungen" noch nicht die entsprechende Beachtung gefunden.

Um die Schaffung einer synthetischen, schöpferischen Ideologie geht es auch in Čcheidzes Beitrag "Das Problem der Ideokratie".92 Nachdem das ganzheitliche Weltbild und die geschlossene, in ihren Überzeugungen einheitliche Gesellschaft des Mittelalters mit ihren allgemeinen Normen und Bindungen durch analytisches Denken und einen negativ verstandenen Freiheitsbegriff (Freiheit von etwas) zerstört worden sei, was zur schmerzhaften Erfahrung von Klassenspaltung, Vereinzelung und Orientierungslosigkeit geführt habe, mache sich

89 Der Beitrag von Vladislav Aleksandrov (siehe unten Anm. 97) ist datiert "Paris, 27. Juli 1933"; über den Verfasser ist nichts weiter bekannt. Rafail K. Manovskij wird als Redakteur von Vselenskoe delo genannt (ebd., S. 208); da dieser Name nirgendwo sonst auftaucht, handelt es sich wahrscheinlich um ein Pseudonym (vielleicht von Setnickij). Sergej Ivanovic Cuev lebte 1933 in Estland, spăter soll er in die USA ausgewandert sein; Mitteilung O.N. Setnickaja, 29.11.1980. Von ihm befinden sich mehrere Manuskripte sowie zwei Briefe an Setnickij (1934, 1935) im FAP I, 334, 328.

90 G.G. GežzLunSKu [d.i. N.A. SETNICKU], "Christoljubie i vojna." In: Vselenskoe delo (wie Anm. 83), S. 13-27.

91 D.S. Kononov [d.i. N.A. SETNICKU], "Evrazijstvo i porevoljucionniki." Ebd., S. 28-43. Siehe auch oben Anm. 41.

K.[A.] ČHEIDZE, "Problema ideokratii." Ebd., S. 44-60. 
nun, verstärkt durch die "Krise der Demokratie", eine Gegentendenz bemerkbar: ein Streben nach Synthese, nach Einordnung in höhere Zusammenhänge, die Suche nach einem "Einheitsideal" (edinyj ideal). ${ }^{93}$ Der gegenwärtige Erfolg der kommunistischen, faschistischen und nationalsozialistischen Bewegungen sei Ausdruck dieses Strebens, wenngleich es sich bei diesen ideologisch begründeten Einparteiensystemen wegen ihrer klassen- und rassenmäßigen $\mathrm{Be}$ schränktheit nur um unzulängliche "Pseudoideokratien" handele. Zur Bewältigung der anstehenden globalen und kosmischen Aufgaben bedürfe es jedoch einer wahrhaft universalen Ideokratie, zu deren philosophischer Grundlegung Fedorov mit seinem Werk beigetragen habe.

In dem Aufsatz von Rafail Manovskij "Der Messianismus und die 'Russische Idee $^{\text {m94 }}$ geht es um den religiösen Auftrag des russischen Volkes, d.h. seinen Beitrag zur Erlösung der Welt. In einer Zeit scheinbarer Lähmung der orthodoxen Kirche (vom Raskol bis zur Revolution) habe Rußland drei - bislang freilich kaum beachtete - geistige Erscheinungen hervorgebracht, die zusammengenommen einen Weg zur universalen Erlösung wiesen. So habe der heilige Serafim von Sarov beispielhaft den Übergang von individueller zu kollektiver Erlösung vollzogen, indem er die verwandelnde und erlösende Wirkung seiner eigenen asketischen Erfahrungen - vor allem der Schau des unerschaffenen Lichtes vom Tabor - praktisch-altruistisch auf seine Umgebung übertragen habe. ${ }^{95}$ Das Dogma des imjaslavie von der verwandelnden und erlösenden Energie des unerschaffenen Namens Gottes dränge auf kollektives Handeln (imjadejstvie) und erweitere die Erlösung in kosmische Bereiche. ${ }^{96}$ Beide Ansätze hätten schließlich in der Lehre Fedorovs ihre methodische Vollendung und ihren zeitgemäßen Ausdruck gefunden: Wissenschaft und Technik, die die Menschheit gegenwärtig mit totaler Vernichtung bedrohten, würden im Rahmen des obščee delo zu Mitteln einer Verwandlung und Erlösung kosmischen Ausmaßes.

Zwei kürzere Beiträge behandeln die Beziehungen zwischen Religion und Wissenschaft sowie zwischen Mensch und Natur: Der Konflikt zwischen Religion und Wissenschaft werde überwunden, indem die Wissenschaft ihren religiösen Auftrag erkenne und, ihm folgend, die Welt nicht länger in ein "analyti-

93 Ausführlich entwickelt wurden diese Gedanken von N.A. Berdjaev in seinen 1924 unter dem Titel Novoe srednevekov'e veroffentlichten geschichts- und kulturphilosophischen Studien, die Ccheidze, obwohl er sie nicht erwähnt, offenbar als Vorlage gedient haben.

94 R.[K.] ManovskiJ [N.A. SEtnickIJ ?], "Messianstvo i 'Russkaja Ideja'." In: Vselenskoe delo (wie Anm. 83), S. 70-99.

95 Ebd., S. 87-89. - Serafim von Sarov (eig. Prochor Moß̌in, 1759-1833), 1903 kanonisiert, galt den einen als ein Symbol RuBlands, anderen als Obskurant; in den Jahren nach der Revolution war er unter religiosen Intellektuellen überaus popular (siehe etwa das Bratstvo Serafima Sarovskogo in Leningrad; II: 4.2.3.).

96 Ebd., S. 89-92. - Die Ausführungen des Verfassers über das imjaslavie und seine Anhănger unter den Intellektuellen (E.N. Trubeckoj, Em, Losev, Egorov, Florenskij) deuten auf eine intime Kenntnis der Diskussionen in den zwanziger Jahren; dieses sowie der Hinweis auf die Schrift Smernoboznixestvo (S. 91) stützen die Vermutung, daB es sich bei dem Verfasser um Setnickij handeln könnte. 
sches Chaos", sondern in einen "synthetischen Kosmos" verwandele. ${ }^{97}$ Nicht der Mensch sei des Menschen Feind, sondern die Natur. ${ }^{98}$

Der Abschnitt "Materialien" enthält einen Beitrag Setnickijs zur Geschichte des ersten Bandes von Vselenskoe delo und zu den erfolglosen Bemühungen um die Herausgabe eines zweiten Bandes in den zwanziger Jahren. ${ }^{99}$ Es folgt V.N. Murav'evs Aufsatz über "Die universelle Produktionsmathematik", der bereits 1923 verfaßt worden war, jedoch in der Sowjetunion nicht hatte erscheinen können. ${ }^{100}$

Ein weiterer Beitrag Setnickijs beschäftigt sich mit dem Thema Tod und Bestattung. ${ }^{101}$ Der Glaube an die Unausweichlichkeit des Todes sei, so Setnickij, eine vom Menschen geschaffene Illusion, um das Faktum des Todes leichter ertragen und die eigene Untätigkeit rechtfertigen zu können. In Wirklichkeit sei der Tod, d.h. Zerfall und Auflösung eines Körpers, ein mechanischer Vorgang und somit prinzipiell umkehrbar. Die Wissenschaft müsse sich um die Erforschung dieses Prozesses bemühen mit dem Ziel, Verstorbene in physischer und psychischer Vollkommenheit wiederherzustellen. Im Hinblick darauf sollten schon jetzt "vernünftige Bestattungsformen" gewählt werden, die eine künftige Auferweckung ermöglichten und erleichterten. Dies bedeute insbesondere eine Abkehr von der modernen Praxis der totalen Beseitigung des Leichnams aus Hygienegründen (Kremation, Bestattung außerhalb der Städte) und eine Rückkehr zu älteren konservatorischen Bestattungsformen, in denen der Glaube an eine Wiederbelebung Ausdruck gefunden habe. Beispielhaft hierfür seien die Einbalsamierung der Leiche Lenins und ihre Beisetzung im Zentrum Moskaus, eine Maßnahme, die sich "nur mit dem Gedanken an eine notwendige und unausbleibliche Auferweckung" erklären lasse. ${ }^{102}$ Weniger prominente Zeitgenossen könnten künftig auch auf einem "Weltfriedhof" (mirovoj nekropol'), der in der Region des Dauerfrostbodens anzulegen sei, ihrer Auferweckung entgegensehen.

Bei den übrigen "Materialien" handelt es sich um Briefe, die offenbar alle aus dem Archiv Setnickijs stammen: Ein Brief Vladimir Solov'evs aus dem Jahre 1884 , in dem dieser Konstantin Leont'ev gegenüber äußert: "... die Ansichten

97 V. AleKSANDROV, "Religija i nauka." Ebd., S. 61-69.

98 S.[I.] CuEV, "Celovek i priroda." Ebd., S. 100-104.

99 ZET. [d.i. N.A. SETNICKU], "Vselenskoe Delo' v proslom." Ebd., S. 107-115.

100 V.[N.] MURAV'Ev, "Vseobక̌aja proizvoditel'naja matematika." Ebd., S. 116-140. - Ein Typoskript (33 Bl.) befindet sich im FAP I, 334. Ausführlich hierzu II: 3.4.

101 N.A. S[ETNIC]Kు, "O smerti i pogrebenii." Ebd., S. 141-146. - Der Beitrag ist datiert: Berlin, 1928. In diesem Jahr unternahm Setnickij von Harbin aus eine Dienstreise, die ihn auch nach Westeuropa führte.

102 Ebd., S. 145. - Siehe auch II: 3.1.3. 
des Bibliothekars Fedorov ... sind noch origineller als die Ihren". ${ }^{103} \mathrm{Je}$ zwei Briefe Fedorovs an Peterson und Koževnikov aus den Jahren 1891 bis 1900, in denen es unter anderem um die künstliche Erzeugung von Regen, den Boxeraufstand in China und Fedorovs Verhältnis zu Solov'ev geht. ${ }^{104}$ Ein Brief des Moskauer Lehrers I.M. Ivakin (1855-1910) an Lev Tolstoj aus dem Jahre 1891 über Fedorovs Vorschläge zum Kampf gegen Dürre und Hungersnot sowie zur Einrichtung eines regelmäßigen Bücheraustausches zwischen Rußland und Frankreich. ${ }^{105}$ Ein Brief Petersons aus dem Jahre 1874 an den Dramatiker N.A. Čaev (1824-1914) über Fedorovs regionalgeschichtliche Erforschung des Kerensker Gebiets. ${ }^{106}$ Schließlich Auszüge aus einem Schreiben von N.V. Ustrjalov aus dem Jahre 1933, in dem dieser die Aktualität der Lehre Fedorovs hervorhebt und über deren Resonanz in der Sowjetunion (vor allem bei Murav'ev) berichtet. ${ }^{107}$

Der folgende Abschnitt "Notizen" enthält eine Besprechung des 1928 in München erschienenen Buches Die Urgestalt der Brüder Karamasoff, in dem der sowjetische Forscher V.L. Komarovic den Einfluß Fedorovs auf Dostoevskij nachzuweisen sucht, ${ }^{108}$ sowie einen Bericht über das Fedorov-Archiv im Prager National-Museum. 109

Unter dem Titel "Unsere Verluste" folgen Nachrufe auf prominente Anhänger Fedorovs, darunter Koževnikov, Peterson, Murav'ev und Kuznecova-Mironovic. ${ }^{110}$

Den letzten Abschnitt bildet eine ausführlich kommentierte Bibliographie zu Werk und Wirkung Fedorovs. ${ }^{111}$ Besprochen werden Entstehung und Inhalt der Werkausgaben von Vernyj, Moskau und Harbin sowie einzelner Veröffentlichungen in der Emigrantenpresse. Bei der vorgestellten Sekundärliteratur han-

103 V.S. Solov'Ev, "Pis'mo k K.N. Leont'evu (1884 god)." Ebd., S. 147f. - Dieser Brief ist weder im Sobranie soxinenij Solov'evs enthalten, noch wurde er in dessen erweiterte Neuausgabe (Brüssel 1966-1970) aufgenommen.

104 N.F. FEdorov, "Iz perepiski s N.P. Petersonom i V A. Koževnikovym." Ebd., S. 149-155.

105 I.M. IVAKJN, "Pis'mo k L.N. Tolstomu o doždevanii i knižnom obmene." Ebd., S. 156-159.

106 N.P. Peterson, "Pis'mo k NA. Čaevu o N.F. Fedorove." Ebd., S. $160 f$.

107 N.V. Ustrualov, "Iz pis'ma." Ebd., S. 162-166. - Das Schreiben ist datiert: Harbin, 22. Oktober 1933. Gekürzt auch unter dem Titel "O filosofii N.F. Fedorova v svete sovremennosti." In: DERS., Naše uremja. Sb. statej. Sanchaj 1934, S. 197-202. Zum Inhalt siehe II: 4.2.1. und 3.4.

108 N.N. TR-v, "Zametki po povodu materialov k 'Brat'jam Karamazovym'." In: Vselenskoe delo (wie Anm 83), S. 169-175.

109 O. D-A. (wie Anm. 75).

110 "Naక̌i poteri." Ebd., S. 178-184. - Verfasser der nur mit Initialen gezeichneten Artikel sind Gorskij (A. G-v.), Michail Nikolaeviz Peterson (M. P-s.), Setnickij [?] (G.G.G.), Nadežda P. Mironoviz (N. M-z.) sowie ein Unbekannter (Ež.).

111 Ebd., S. 185-205. 
delt es sich ausschließlich um Arbeiten von Gorskij und Setnickij, darunter auch die gemeinsam verfaßte Broschüre Smertobožnicestvo. ${ }^{112}$

Vselenskoe delo fand - offenbar infolge sehr niedriger Auflage - nur geringe Verbreitung und blieb weitgehend unbeachtet; Rezensionen sind nicht bekannt, und auch sonst verzeichnet die Emigrantenpresse keinerlei Echo. Eine Ausnahme bildete lediglich die kleine Gruppe der Eurasier in Brüssel, die der nationalbolschewistischen Position Ustrjalovs nahestand, deren Mitglieder aber auch Kontakte zu den Prager Eurasiern unterhielten: ${ }^{113}$ In ihrem internen Diskussionsorgan Evraziec setzten sie sich im Rahmen mehrerer Beiträge zu Fedorov auch mit dem Inhalt von Vselenskoe delo auseinander. ${ }^{114}$

Mit dem raschen Niedergang des Eurasiertums um die Mitte der dreißiger Jahre ${ }^{115}$ verlieren sich dann freilich die letzten Spuren einer Rezeption. Besondere Bedeutung hatten Fedorovs Ideen nur für die 'linken' Eurasier von Clamart erlangt, als diese sich darum bemühten, den als wesensfremd empfundenen Marxismus durch eine autochthone Philosophie des Handelns aufzuheben. Fedorovs geschichtsphilosophische Spekulationen über Rußlands Stellung zwischen Ost und West fanden hingegen keine nachweisbare Resonanz. ${ }^{116}$ Čcheidze, dem es nicht gelungen war, seine eurasischen Gesinnungsgenossen in Prag für Fedorov zu gewinnen, publizierte noch bis $1937,{ }^{117}$ um dann im stillen

112 Die Verfasser der einzelnen Beitrăge waren neben Setnickij (Pseud.: I. Kozodoev, I. K-v., Žel'.) zwei sciner Studenten an der Juristischen Fakultăt in Harbin: der Dichter V.K. Obuchov (siehe II: 4.2.5.) und N.G. Tretcikov, der auch den Vertrieb der Harbiner Publikationen besorgte (briefliche Mitteilung O.N. Setnickaja, Moskau, 29.11.1980); ferner ein gewisser A. Miroljubov, der unter dem Pseudonym "Anatolij Kazanskij" im Sammelband Vrata, kn. 2, Sanchaj 1935, veroffentlichte, sowie eine gewisse Ja. Kalouskova, über die nichts weiter bekannt ist.

113 Uher die Brüsseler Gruppe der Eurasier (Vorsitzender bis 1934 I.V. Stepanov) ist nur sehr wenig bekannt. Siehe die Angaben in "Protokol..." (wie Anm. 53), S. $5 f$.

114 Evraziec. Diskusionnyj vnutri-evrazijskij organ. [Hektograph.] Brüssel, 22, 1933 - 25, 1934.

115 Am längsten blieb Savickij seinen eurasischen Ansichten treu; er publizierte noch bis in die frühen vierziger Jahre. Nach der Eroberung Prags durch die Rote Armee wurde er verhaftet und in die Sowjetunion verschleppt, wo er zehn Jahre in Gefängnissen und Lagern verbrachte. Seine während dieser Zeit entstandenen Gedichte, die unter dem Pseudonym "P[avel] Vostokov" im Westen veröffentlicht wurden, lassen bisweilen eurasische Motive erkennen. P. Vosto. KOV [P.N. SAVICKIJ], Stichi, Boulogne sur Seine 1960. Nach seiner Haftentlassung kehrte Savickij 1956 nach Prag zurück, wo er 1968 krank und in Armut starb. Private Mitteilung; vgl. auch VERNADSKu (wie Anm. 52), S. 275-277, MEJSNER (wie Anm. 51), S. 188, $235 f$.

116 In der neueren Literatur zu Fedorov finden sich in diesem Zusammenhang haltlose und abwegige Behauptungen wie: "It was, however, Fedorov's East-West philosophy that influenced the Eurasians most strongly." L. KoEHLER, N.F. Fedorov: The Philosophy of Action, Pittsburgh 1979, S. 126. Oder: "From the start [!] all [!] the Eurasians viewed Fedorov as the prophet of the new Russia..." Die Spaltung von Clamart, heißt es weiter, sei die Trennung der "pure Fedorovists" [!] von jenen gewesen, die Fedorov mit Marx versöhnen wollten. G.M. YouNG, Nikolai F. Fedorov: An Introduction. Belmont, Mass. 1979, S. 189.

117 Siehe Anm. 71. 
seine Sammeltätigkeit für das Fedorov-Archiv fortzusetzen, dessen Bestände er bis zu seinem Tod im Jahre 1974 regelmäßig ergänzte. ${ }^{118}$

\subsubsection{Kleinere "nachrevolutionäre" Bewegungen in der Pariser Emigration}

Das Eurasiertum war nicht nur die erfolgreichste, sondern wohl auch die originellste und ideologisch am schärfsten profilierte unter den "nachrevolutionären" Bewegungen. Dies wird besonders deutlich im Vergleich mit einer Reihe weiterer "nachrevolutionärer" Gruppierungen, die zu Beginn der dreißiger Jahre in der Pariser Emigration um die Zeitschriften Novyj Grad, Utverždenija und Tret'ja Rossija entstanden waren. Ihnen gelang es nicht, klare soziale und politische Konzepte zu entwickeln, und auch ihre weltanschaulichen Grundlagen blieben verschwommen. So mußte beispielsweise die Forderung nach einem "geistgläubigen, freiheitsliebenden Sozialismus" (Stepun) mit der Vision einer theokratischen Welt und eines "Kirchewerdens" der ganzen Kultur (Fedotov) in Konflikt geraten, und die Verkündung eines "neuen Christentums" (Berdjaev) blieb inhaltlich ebenso vage wie das Konzept eines "titanischen Messianismus" (Boraneckij). Gemeinsam war diesen Strömungen ein - freilich sehr unbestimmtes - Streben nach geistiger, kultureller und sozialer "Erneuerung", nach "Synthese" und "Ganzheitlichkeit", sowie der Umstand, daß sie dabei gelegentlich Anleihen bei Fedorov und seinen Anhängern machten. ${ }^{119}$

118 Auch Ccheikze war nach dem Krieg verhaftet worden und hatte zehn Jahre in sowjetischer Gefangenschaft verbracht. Nach Prag zurückgekehr, scheint seine Lage besser gewesen zu sein als die Savickijs; so konnte er mehrere Kinderbücher veroffentlichen, und aus AnlaB seines 75. Geburtstages erschien in der Prager Presse ein freundlicher Artikel, in dem besonders seine Bemühungen um das Werk Fedorovs und das Prager Archiv hervorgehoben wurden. LV (wie Anm. 59).

Zu den spăten Ergănzungen des Fedorov-Archivs gehören folgende zum Teil umfangreiche Manuskripte, über deren Verfasser nichts Năheres bekannt ist: P. AGAPOV, Vrag smerti (Prag 1937), Masch. $257 \mathrm{Bl}$.; FAP I, 334. K. STTINDL, Edizni návrh na vydáni svazku z dila $N$. Fjodorova (0.O. o.J.), Masch. 7 Bl.; FAP I, 337 [kurzer Abriß von Leben und Werk Fedorovs]. V. VAGNER, Iznacal'nye osnovy useobsčego sinteza drevnosti. Vseobsčij sintez. Ms. [Masch.] Kiev, Moskva 1922 - Prag 1957/58, 122 Bl.; FAP I, 337.

119 Siehe Kononov [SETNICKU] (wie Anm. 41), bes. S. 42f. - In seiner überaus scharfen Kritik an der Verworrenheit und Widersprüchlichkeit der ideologischen Positionen von Novyj Grad und Utverzdenija verstieg sich P.B. Struve, einer der entschiedensten Gegner der "nachrevolutionăren" Strömungen, zu der höhnischen Behauptung, das Christentum dieser "neuen geistigen Führer und Propheten" stütze sich "bestenfalls auf die Phantasmen eines N.F. Fedorov (wahrscheinlich ein Geisteskranker [!]), schlimmstenfalls auf die metaphysischen Hirngespinste N.A. Berdjaevs..." P.[B.] STRUVE, "Dnevnik politika." In: Rossija i Slavjanstvo, [Paris], 164, 16.1.1932, S. 1. Kritisch auch G.[P.] STRUVE (wie Anm. 16), S. 222-231.

Keiner Gruppierung oder Strömung läßt sich eine Studie zu Leben und Werk Fedorovs zuordnen, die 1929 in mehreren Fortsetzungen in der Pariser Zeitschrift Zvezda erschien: O.A. FON Sul'c [v. SChoultz], "N.F. Fedorov. Celovek i myslitel'." In: Zuezda, 1929, 5, S. 9-18; 6, S. 46-56; 7, S. 34-48; 8, S. 36-45. - Oskar von Schoultz (1872-1947), Ubersetzer und Lektor für russische Sprache in Helsingfors, erwies sich als gut vertraut mit der einschlägigen Literatur, den zeitgenössischen Arbeiten von Gorskij ebenso wie den ălteren Veröffentlichungen von 
Die Zeitschrift Novyj Grad wurde 1931 von dem ehemaligen Sozialrevolutionär I.I. Fondaminskij-Bunakov (1880-1942) sowie den Philosophen F.A. Stepun (1884-1965) und G.P. Fedotov (1886-1951) gegründet. ${ }^{120}$ Anliegen der novogradcy, einer eher lockeren Vereinigung, der unter anderen die Philosophen Berdjaev, Bulgakov und Losskij sowie die Schriftsteller und Publizisten V.S. Janovskij und V.S. Varšavskij angehörten, ${ }^{121}$ war die Suche nach einer religiös begründeten "neuen Ordnung", ihr Motiv das Bewußtsein einer tiefen Krise oder, wie es Fedotov in einem anonymen programmatischen Artikel formulierte: "In der alten Stadt zu leben, wird unmöglich. Halb zerstört durch die Katastrophe des Krieges lebt sie im Vorgefühl eines neuen, für sie vielleicht letzten Schlages. ${ }^{122}$ Die ganze Welt werde von Krisen erschüttert, die den Zerfall der gegenwärtigen Ordnung anzeigten. Während sich die Demokratie als schwach und unfähig erweise, die wirtschaftliche Not zu bekämpfen, bereite sich die Arbeiterklasse zum Sturm auf die kapitalistische Gesellschaft vor. Schon überziehe die Aussicht auf einen neuen, noch schrecklicheren Krieg den Horizont mit blutiger Röte. ${ }^{123}$ In dieser Situation erging der Aufruf, eine "neue Stadt" zu bauen, "aus alten Steinen, jedoch nach neuen Plänen"; an die Stelle der "formalen" Demokratie des Kapitalismus oder der kommunistischen Diktatur sollte eine Gesellschaft treten, die sich auf die Achtung der Persönlichkeit und ihrer Freiheit sowie auf die Prinzipien eines sozialen Christentums gründete. $^{124}$

Als "Lehrer" des novogradstvo nannte Varšavskij rückblickend Vl. Solov'ev und N.F. Fedorov. ${ }^{125}$ Während jener für ein "lebendiges, soziales und ökumeni-

Peterson und Koževnikov. Sein eigener Beitrag enthielt freilich nichts Neues (abgesehen von einigen Spekulationen zu Fedorows Kindheit und zur aktuellen Bedeutung seiner Lehre) und scheint nur einen engen Leserkreis erreicht zu haben. Bei Zvezda handelt es sich dem Anschein nach um eine theosophische Zeitschrift; sie ist nur in wenigen Bibliotheken vorhanden. In der Fedorov-Literatur wird von Schoultz' Beitrag nicht erwahnt.

120 Die Zeitschrift erschien zwisihen 1931 und 1939 unregelmåßig mit insgesamt 14 Nummern. Zu Fedotov, der bis zu seiner Emigration nach Frankreich (1925) Mitglied des Petrograder Voskresenie-Kreises um A.A. Mejer war, siehe auch II: 4.2. Anm. 82.

121 Unter den Beitrăgem zu Novyj Grad finden sich u.a. die (ehemaligen) Eurasier P.N. Savickij, V.N. Il'in, N.N. Alekseev sowie M. Cuetaeva.

122 [Redakcija, d.i. G.P. FEDOTov], "Novyj grad." In: Noyyj Grad, 1, 1931, S. 3.

123 Ebd.

124 Ebd., S. 5-7. - Immer wieder betonten die novogradcy, daß mit der "neuen Stadt" nicht das am Ende der Zeiten zu erwartende "himmlische Jerusalem" gemeint sei, sondern eine auf Erden zu erbauende neue Gesellschaft.

125 V.[S.] VARSA vsKU, "Perecityvaja 'Nowyj Grad'." In: Mosty, 11 (1965), S. 267-285; hier S. 272. Vladimir Sergeevið VarŠavskij (1906-1978) trat v.a. mit autobiographischer Prosa und Schilderungen des Emigrantenlebens hervor. Zur Ideologie der novogradcy und zum Einfluß Fedorovs siehe auch DERS., Nezamexennoe pokolenie, New York 1956, S. $277-290$ und pass. DERS., "Cevengur' i 'Novyj Grad'." In: Novyj Zumal, 122, 1976, bes. S. 210-213. DERS., Rodoslovnaja bol'Sevizma, Paris 1982, bes. S. 161-165. Vgl. ferner P. ROSNIANSKY, "La signification sociale du christianisme dans la philosophie religieuse russe des $19^{\mathrm{e}}$ et $20^{\mathrm{e}}$ siecles." In: Contacts, 121, 1983, S. $33-61$; bes. S. $41-43$. 
sches Christentum" eingetreten sei, habe dieser sich als erster um eine religiöse Sinngebung der fortschreitenden Verwandlung der Welt durch Wissenschaft und Technik bemüht. Die säkularisierte Heilslehre des Sozialismus, so Bulgakov in der ersten Nummer von Novyj Grad, ${ }^{126}$ könne positiv nur überwunden werden, wenn es gelinge, ihr eine christliche Deutung der Wirtschaft und ihrer Rolle im Rahmen einer Eschatologie entgegenzustellen. Den Weg dazu habe Fedorov bereitet, indem er "auf eigentümliche Weise die grundlegenden Dogmen des Christentums auf die Wirtschaft" angewendet habe. Allerdings sei ihm auf diesem Weg "mit Ausnahme von Peterson und einigen jungen Fedorovianern" bislang niemand gefolgt. 127

Auch den novogradcy scheint es zunächst schwergefallen zu sein, Fedorov zu folgen: In den folgenden acht Nummern der Zeitschrift tauchte sein Name nur selten und beiläufig auf. ${ }^{128}$ In der 10 . Nummer von Novyj Grad, die 1935 erschien, unternahm dann ein gewisser S. Belozerov den Versuch, mit Hilfe einer an Fedorov angelehnten Konzeption des obščee delo die russische Emigration zur Einheit und Zusammenarbeit aufzurufen: Vorläufiges Ziel der vereinten Bemühungen müsse die Schaffung eines "dritten Rußland" (als Alternative zum alten Regime wie zum Kommunismus) sein, eines Staatswesens, dessen "organische Einheit" aus dem obščee delo des russischen Volkes erwachse, nämlich der "Bestärkung des Lebens" (utverždenie žizni) und der Vorbereitung seiner "Verwandlung" (preobraženie) als Aufgabe der gesamten Menschheit. ${ }^{129}$ Belozerov würdigte Fedorov als den "ersten Denker und Begründer des obščee delo", doch

126 S.[N.] Bulgakov, "Duša socializma." [1] In: Novyj Grad, 1, 1931, S. 49-58. - Bereits in seinem Beitrag zum Sammelband Problemy idealizma (1902) sowie in mehreren Artikeln in Ot marksizma $k$ idealizmu (1903) hatte Bulgakov auf die religiose Natur des Sozialismus hingewiesen. Die religiose "Seele des Sozialismus", schrieb er 1910, sei "der alte chiliastische Glaube an den Anbruch des irdischen Paradieses ... und an die irdische Uberwindung der historischen Tragodie." S.[N.] BulgaKov, "Apokaliptika i socializm." [1910] In: DeRs., Dva grada, t. 2, M. 1911, S. 116.

127 Bulgakov, "Dusa..." (wie Anm. 126), S. 58. - In seiner weitgehend wohlwollenden Besprechung des ersten Bandes von Novyj Grad bestritt Ustrjalov, daB Fedorovs Konzeption der Umgestaltung der Welt der maxxistisch-materialistischen entgegengesetzt sei, vielmehr zielten beide in dieselbe Richtung: "Es macht nichts, daß die russischen Marxisten keine Ahnung von Fedorov haben und sich gegen das Christentum auflehnen - in Wirklichkeit erfüllen sie das Programm einer aktiven Apokalyptik..." N.V. UsTrualov, "Novyj Grad'." [1932] In: DERS., Nase vremja. Sb. statej. Sanchaj 1934, S. 116-142; hier S. 134f. - Zu weiteren Artikeln Bulgakovs, in denen Fedorov enwăhnt wird, siehe II: 2.2. Anm. 77.

128 Siehe IL'IN, "Technika..." (wie Anm. 50). - N.[O.] Lossk山, [Rez.] "N.A. Setnickij, O konečnom ideale, Charbin 1932." In: Novyj Grad, 9, 1934, S. 89-92. - Der Philosoph und Philosophiehistoriker Nikolaj Onufrievið Losskij (1870-1965) hat Fedorov nur selten erwăhnt. Siehe z.B. N.[O.] Lossk山, "Russkaja filosofija v XX veke." In: Zapiski russkogo nauCnogo institula v Belgrade, 1931, vyp. 3, S. 112 (im Zusammenhang mit Berdjaev). Ders., Dostoevskij i ego christianskoe miroponimanie, New York 1953, S. 163 ("Carstvo Božie. Bessmertie"). Austührlich hingegen DERS., History of Russian Philosophy, London 1952, bes. S. 75-80. 
lehnte er dessen "Grundidee", die "Auferweckung von Leichen", entschieden ab. ${ }^{130}$

Gleiches wird auch von den Teilnehmern einer Gesprächsrunde der novogradcy berichtet: Während Fedorovs Hochschätzung der Technik von einigen noch geteilt worden sei, habe seine "Idee der Auferweckung der Toten" keinerlei Anklang gefunden. ${ }^{131}$

Nur wenige freilich dürften mit Fedorovs Ideen durch die Lektüre seiner Werke bekannt geworden sein. Zumeist stützte man sich auf die eine oder andere Darstellung seiner Anhänger, viele kannten Fedorov wohl nur vom Hörensagen. Beklagt wurde dies von V.S. Janovskij in einem kurzen Artikel über die Aktualität der zentralen Gedanken Fedorovs, der in der 13. Nummer von Novyj Grad erschien. "Warum schreibt man nicht über Fedorov?", fragte er einleitend und gab zur Antwort: "Es ist schwierig, über etwas Erstrangiges, Wichtiges zu schreiben, ganz unmöglich aber über etwas, das alles überragt. Man läßt die Finger davon aus Furcht vor Verfälschung und Vereinfachung. Man ahnt die Bedeutung jedes Details und schreckt zurück vor der übergroßen Verantwortung. ${ }^{132}$ Fedorovs Werk sei in den Originalschriften nur schwer zugänglich und werde durch die plumpen Schematisierungsversuche seiner "gelehrten Schüler" entstellt, doch wirkten die Ideen dieses "originellsten russischen Denkers" unterschwellig, so daß man bisweilen Menschen treffe, die sich für Fedorov begeisterten, ohne eine Zeile von ihm gelesen zu haben. Als - unwissentliche "Schüler Fedorovs" erwiesen sich auch die Bolschewiki; ihr Fünfjahresplan sei eine "verkürzte, kastrierte Fedorovsche Idee". ${ }^{133}$

In derselben Nummer von Novyj Grad stellte Fedotov vor dem Hintergrund zunehmender Endzeitstimmungen die Frage nach Sinn und Ziel menschlichen (vor allem sozialen und kulturellen) Handelns und kam zu dem Ergebnis, daß nur eine optimistische Eschatologie - wie Fedorov sie vertreten habe -, die auch die Möglichkeit einer tätig herbeigeführten Erlösung aller eröffne, gemeinsames Bemühen (im Rahmen einer "freien Theokratie") um Verbesserung der irdischen Verhältnisse ermögliche und rechtfertige. ${ }^{134}$ Fedorovs Idee von der Bedingtheit der apokalyptischen Prophezeiungen sei, "wie alle genialen Ideen, so einfach", daß es "unverständlich erschein[e], wie man anders [habe] denken

130 Ebd., S. 120.

131 ANON., "Duchownyj front." In: Noryj Grad, 10, 1935, S. 132-138; hier S. $135 f$.

132 V.S. JanovsKi,, "Obšcee delo." In: Novyj Grad, 13, 1938, S. $172 f$.

133 Ebd., S. 173. - Vasilij Semenovic Janovskij (geb. 1906, seit 1942 in den USA lebend) verfaßte zahlreiche Romane und Erzählungen, in denen religiosse und philosophische Themen behandelt werden. Neben Einflüssen Berdjaevs, Bergsons und Fedotovs sollen dabei auch Ideen Fedorovs ihren Niederschlag gefunden haben. Vgl. L. D[IENES], "Yanovsky, Vasily Semyonovich." In: V. TERRAs [Hg.], Handbook of Russian Literature, New Haven, London 1985, S. 523. VARSA vsKu, NezameXennoe pokolenie (wie Anm. 125), S. 260. In Janovskijs Roman Ponativnoe bessmenie (New York 1953) und in seiner breiten Schilderung des Pariser Emigrantenmilieus (Elysian Fields, DeKalb, Ill. 1987) wird Fedorov jeweils nur beilăufig enwähnt.

134 G.[P.] FEDOTOv, "Eschatologija i kul'tura." In: Noyyj Grad, 13, 1938, S. 45-56. 
können." ${ }^{135}$ Im Gegensatz zu Fedorov sah Fedotov jedoch eine "letzte Schranken für alle Menschenmacht: den Tod; "diesen letzten Feind" könne nur der Erlöser besiegen, weshalb auch die "Idee einer wissenschaftlichen Auferstehung der Toten" nichts weiter sei als ein "törichter Traum" (bezumnaja mexta). ${ }^{136}$

Eng verbunden mit der Zeitschrift Novyj Grad war die 1935 gegründete literarische Vereinigung "Krug", in der sich zumeist junge, religiös gesinnte Schriftsteller zusammenfanden. In der ersten Nummer des gleichnamigen Almanachs veröffentlichte 1936 der Literaturwissenschaftler K.V. Mocul'skij (1892-1948) eine Skizze über Solov'ev und Fedorov, die sich inhaltlich fast identisch auch in Mocul'skijs im selben Jahr erschienener großer Solov'ev-Biographie findet. ${ }^{137}$ Hinweise auf Fedorov enthalten Močul'skijs umfangreiche (z.T. postum veröffentlichte) Biographien Dostoevskijs, Belyjs und Brjusovs sowie ein Aufsatz aus dem Jahre 1939 über die "Idee des sozialen Christentums in der russischen Philosophie" ${ }^{138}$ Der Vereinigung "Krug" gehörte auch der junge Dichter L.I. Kel'berin (geb. 1907) an, der in einem der prätentiösen Sammelbände von Čisla Gorskijs Arbeit über "Fedorov und die Gegenwart" rezensierte. ${ }^{139}$

Einen Versuch, die zahlreichen, sich immer weiter zersplitternden "nachrevolutionären" Gruppierungen zusammenzufassen, unternahm die 1931 von Fürst Ju_A. Sirinskij-Šchmatov unter Mitarbeit von Berdjaev und Stepun gegründete Zeitschrift Utverždenija. ${ }^{140}$ Auf der Grundlage der "ewigen russischen historischen Idee", wie sie von den großen Denkern, Dichtern und Heiligen Rußlands formuliert worden sei - in diesem Zusammenhang wurde auch Fedorov genannt $-{ }^{141}$ sollte eine "einheitliche nachrevolutionäre Ideologie" erarbeitet werden, ein (im Gegensatz zu Reaktion und Revolution) zukunftsgestalten-

135 Ebd., S. $52 f$.

136 Ebd., S. 54, 48. - Zu Fedorovs Apokalypse-Deutung auch DERS., "Reich Gottes und Geschichte." In: Kirche, Staat und Mensch. Russisch-orthodare Studien. Genf 1937, S. 76.

137 K.[V.] Mocur'sKU, "Vl. Solov'ev i N.F. Fedorov." In: Krug. Al'manach. Kn. pervaja, Berlin, Paris 1936, S. 148-151. Ders., Vadimir Solov'ev. Zizn' i ucenie. Paris 1936, hier S. 151-153.

138 K.[V.] Mocul'sku, Dostoevskij. Zizn' i twortestwo. Paris 1947, S. 467f. Ders., Andrej Belyj, Paris 1955, S. 38, 118. DERS., Valerij Briusov, Paris 1962, S. 60. DERS., "Ideja social'nogo christianstva v russkoj filosofii." In: Pravoslamoe delo, sb. 1, Paris 1939, S. 45-61; bes. S. 57-60. Dass. engl:: The Idea of Social Christianity in Russian Philosophy." In: St. Vadimir's Seminary Quarterty, $12,1968,3-4$, S. 157-169.

139 L.[I.] Kel'BERIN, [Rez.] "Fedorov i sovremennost'. (A. Ostromirov. Charbin)." In: Cisla, sb. 9, Paris 1933, S. 181-183.

140 Utverżdenija. Organ ob-edinenija ponevoljucionnych tecenij. Paris, 1, 1931 - 3, 1932. Fürst Jurij Alekseevic Sirinskij-Sichmatov war Führer der russischen "National-Maximalisten" und einer der profiliertesten Vertreter der "nachrevolutionăren" Bewegungen. Seine Korrespondenz mit Ustrjalov (1933-35) befindet sich im FAP I, 336. - Zu Sirinskij-Sichmatov und Utvertdenija ausführlich VARSAvSKI, Nezametennoe pokolenie (wie Anm. 125), S. 4451, und YaNOVSKY [JANOVSKU], Elysian Fields (wie Anm. 133), S. 71 und pass.

141 JU.[A.] SIRINSKu-ŠIchmaTov, "Dva messianizma." In: Utvertdenija, 3, 1932, S. 19-43; Fedorov S. 33f. DERS., "Porevoljucionnye tecenija." Ebd., S. 177-183; Fedorov S. 177. 
des Programm, das in der Lage wäre, alle "nachrevolutionären Kräfte" zu vereinen und den "Weg in eine neue Epoche, 'zu einem neuen Himmel und einer neuen Erde'm zu eröffnen. ${ }^{142}$ Obwohl die von den utverždency formulierten vier Prinzipien - nämlich 1. Primat des Geistigen vor dem Materiellen; 2. Gestaltung des Lebens nach christlichen Grundsätzen; 3. Universalität der geistigen, kulturellen und sozialen Mission Rußlands; 4 . das künftige nachrevolutionäre Rußland als Synthese des vorrevolutionären (These) und des revolutionären (Antithese) ${ }^{143}$ außerordentlich vage waren, kam die angestrebte "Vereinigung der nachrevolutionären Strömungen" nicht zustande; bereits mit der dritten Nummer stellte Utverždenija ihr Erscheinen ein.

Die radikalste - und den Ideen Fedorovs am nächsten kommende - Position innerhalb des "nachrevolutionären" Denkens vertrat P.S. Boraneckij mit seiner "prometheisch-titanischen Weltanschauung", die er in zahlreichen Vorträgen und, seit 1932, in der von ihm gegründeten und geleiteten Zeitschrift Tret ja Rossija darlegte. ${ }^{144}$ Boraneckij war gegen Ende der zwanziger Jahre in Paris aufgetaucht und hatte alsbald durch die Exaltiertheit seiner Ideen und den missionarischen Eifer, mit dem er diese propagierte, unter den Emigranten großes Aufsehen erregt. ${ }^{145}$ Es hieß, er sei aus der Sowjetunion geflüchtet, wo er, aus bäuerlichem Milieu stammend, zunächst in Odessa, später in Moskau eine Hochschule absolviert, dann aber wegen ideologischer Differenzen die eingeschlagene Karriere abgebrochen habe. ${ }^{146}$ Dieser Umstand sowie seine jugendliche Erscheinung (Boraneckij soll 1900 oder später geboren sein) ${ }^{147}$ machten ihn in den Kreisen der Pariser Emigranten zu einem vielbestaunten Exemplar des

142 "Ot redakcii." In: Utverżdenija, 1, 1931, S. $7 f$.

143 Ebd., S. 6.

144 Tret'ja Rossija. [Wechselnde Untertitel: Organ porevoljucionnogo sinteza. Organ iskanij novogo sinteza. Organ osušcestvlenij novogo sinteza]. Paris, 1, 1932 - 9, 1939. - Die gleichnamige Bewegung, deren Mitglieder sich narodniki-messianisty nannten, wurde völlig von Boraneckij beherrscht. Die Zeitschrift diente ihm als Sprachrohr. Der überwiegende Teil der Beiträge stammte aus seiner Feder, wobei Boraneckij auBer mit seinem eigenen Namen auch mit wechselnden Pseudonymen und Initialen zeichnete. Dieses Verfahren, das den Eindruck einer großen Zahl von Mitarbeitern und Anhängern erwecken sollte, war auch bei anderen "nachrevolutionären" Gruppierungen beliebt. Siehe die diesbezügliche Kritik von S̈IRINSKJJŚICHMATOV, "Porevoljucionnye terenija" (wie Anm. 141), S. 181. Siehe auch V.[S.] VARSAVSKU, "Tret'ja Rossija'." In: Novyj Grad, 13, 1938, S. 175-179.

145 Eine eindrückliche Schilderung der Auftritte Boraneckijs gibt der Dichter G.|V.] IVANOV, "O novych russkich ljudjach." In: Cisla, 7-8, 1933, S. 188-194. Siehe auch VARSAvSKU, Nezamedennoe pokolenie (wie Anm. 125), S. 268.

146 Die Angaben zur Biographie Boraneckijs sind ăuBerst spărlich. Vgl. IVANov (wie Anm. 145), S. 191. N.[O.] LossKI [LOssKu], Histoire nusse des origines d 1950, Paris 1954, S. 403. A. ASNAGHI, Storia ed escatologia del pensiero russo, Genova 1973, S. 269.

147 IVANov (wie Anm. 145), S. 188, schildert Boraneckij Anfang der dreiBiger Jahre als einen "jungen Menschen von etwa 26, 27 Jahren". Lossk山 und ASNAGHI (wie Anm. 146) geben als Geburtsjahr 1900 an. 
"neuen russischen Menschen"148 und erweckten das Interesse insbesondere der jungen porevoljucionniki, die sich um die Integration aktueller innerrussischer Geistesströmungen in die große "nachrevolutionäre" ideologische Synthese bemühten. Als vermeintlicher Ausdruck des Bewußtseins einer neuen, aus der Masse des Volkes hervorgegangenen Intelligenz faszinierte manchen von ihnen Boraneckijs "heroische", "prometheisch titanische Weltanschauung" - eine überaus weitschweifig und mit aufdringlichem Pathos vorgetragene, im Grunde jedoch simple Lehre von der Allmacht des Menschen und der totalen Verwandlung der Welt, die neben zentralen Gedanken Fedorovs Einflüsse Nietzsches, Rozanovs, Bergsons, des bogostroitel'stvo und des Proletkul't in sich vereinigte. ${ }^{149}$

Jedes menschliche Wesen sei, so Boraneckij, "ontologisch" Teil des Universums und somit potentiell grenzenlos und ewig. "Phänomenologisch", oberflächlich sei der Mensch hingegen den "negativen Prinzipien" der Natur (Raum) und der Geschichte (Zeit) unterworfen. Seine Aufgabe bestehe darin, durch "schöpferische Verwandlung der Welt", d.h. durch "Organisierung der Natur und der Geschichte", den "raum-zeitlichen Zustand der Endlichkeit und Trennung" zu überwinden und damit die "potentielle ontologische Seinsordnung", die Identität von Mensch und Welt in ihrer Absolutheit zu verwirklichen.

Bislang freilich hätten die Menschen diese ihre Bestimmung nicht erkannt; zerspalten und isoliert, verzehrten sie sich im Kampf gegeneinander und verhinderten die Entfaltung ihrer schöpferischen Kräfte. Die Menschheit stehe vor der Wahl, das "Paradies auf Erden" zu verwirklichen oder sich selbst zu vernichten.

Den "Weg der Rettung" weise allein die "titanische Weltanschauung des Prometheismus". Er führe über die "harmonische Vereinigung der Menschen" durch das obšcee delo der "Verwandlung der Welt" und der "schöpferischen Harmonisierung des Daseins" zur "Verabsolutierung der Welt" (absoljutizacija mira) und damit zur Vergöttlichung des Menschen: "nicht Gott erschuf die Welt,

148 IVanov (wie Anm. 145), S. 189f. - "... dieser Petr Stepanovic [Boraneckij] ist keine Personlichkeit, er ist ein Typ. Er steht heute auf dem Diskussionspodium der Emigration, aber Zehntausende, Hunderttausende, vielleicht Millionen solcher wie er stehen auf der großen russischen Erde, und ... ihre Kopfe, ihre Seelen sind nach demselben Vorbild geformt." (Ebd., S. 192). Vgl. auch VARSAVSKU, Nezamezennoe pokolenie (wie Anm. 125), S. 268-270.

149 Boraneckijs "prometheisch titanische Weltanschauung" war in ihren Grundzügen zu Beginn der dreiBiger Jahre voll ausgebildet; die spăteren Darlegungen (bis Ende der dreißiger Jahre in Tret'ja Rossija, zwischen 1947 und 1965 in umfangreichen Monographien) betonen lediglich einzelne Aspekte, enthalten jedoch keine neuen Gedanken und lassen keinerlei Entwicklung erkennen. "Boraneckijs Werke gleichen sich wie Aufnahmen ein und desselben Gebăudes aus verschiedenen Blickwinkeln und zu verschiedenen Zeiten." Ig. GENNADU [E.A. EJKALOviC], "Prometeizm." In: Zarubeže, 35-36, 1972, S. 2-5; hier S. 2. Zu Boraneckijs Lehre siehe auch VARSA VSKIJ, Nezameiennoe pokolenie (wie Anm. 125), S. 266-273. Lossku (wie Anm. 146), S. 403f. P.[E.] KovalevsKY [Kovalevski], "Messianisme et millénarisme russes?" In: Archives de Sociologie des Religions, 3 (1958), 5, S. 68. 
sondern die Welt schafft Gott", 150 der Mensch ist ein "Gott im Werden" (stanovjaš̌ijsja Bog) $)^{151}$. Die Verwirklichung des "prometheisch furitanischen ${ }^{152}$ Ideals" beruhe auf dem gemeinsam erkämpften Sieg über Raum und Zeit (den Ursachen jeglicher Trennung und Begrenzung) und bedeute allumfassende Einheit (vseedinstvo) und endlose Dauer (beskoneCnost') und, damit verbunden, die Überwindung des Todes und die Auferweckung aller Verstorbenen. ${ }^{153}$

Als "Realisierung des Idealen und Idealisierung des Realen" beschrieb Boraneckij das Ziel seines "synthetischen Ideal-Realismus" 154 und pries die neue "titanische Weltanschauung" als einzigen Ausweg aus den ideologischen Sackgassen theologischer und materialistischer Lehren sowie als gesellschaftliche $\mathrm{Al}$ ternative zu Kapitalismus und Kommunismus. ${ }^{155}$ Die Überwindung des "bürgerlich-marxistischen" Klassenegoismus durch die "demiurgische Brüderlichkeit" (demiungiCeskoe bratstvo) der im obšcee delo vereinten Menschheit werde als "geistige Revolution zur Errettung der Welt" von Rußland ausgehen, genauer, vom ganzheitlich denkenden und empfindenden russischen Bauerntum, der "Avantgarde der neuen synthetischen Menschheit". ${ }^{156}$ Mit dem Sturz der "proletarischen Ochlokratie" werde das "nachrevolutionäre Dritte Rußland" zum "Embryo und Prototyp der künftigen allmenschlichen Vereinigung" und zum "Sprungbrett in die Zukunft".

Bestrebt, seine Ideen als originell und einmalig herauszustellen, mußte Boraneckij in Fedorov seinen Hauptkonkurrenten sehen; nur so läßt sich die bei-

150 P.[S.] BORANECKIJ, "O novom obsxestvennom ideale. Grjadušaja Atlantida." In: Tret'ja Rossija, 6, 1935, S. 55.

151 Ausführlich dazu P.[S.] BoRANECKu, "O novom žiznennom ideale." In: Tret'ja Rossija, 2, 1932, S. $47-60$.

152 Aus "futuristisch" und "titanisch" - eine Wortschopfung Boraneckijs.

153 Dazu besonders P.[S.] BoraneckJ, "Smysl techniki." In: Tret'ja Rossija, 4-5, 1934, S. 17-28. Ders., "O novom celoveke." Ebd., S. 45-52. - Der individuelle "Kampf ums Dasein" verwandle sich in einen kollektiven "Kampf um Unsterblichkeit", wobei nicht, wie bei Fedorov, die "Regulienung der Natur" (des Raumes), sondern die "Beherrschung der Zeit" (ovladenie uremenem), die "Organisierung der Geschichte", entscheidend sei für den "Sieg über den Tod" und die "allgemeine Auferweckung" (natürlich darf in diesem Zusammenhang der Hinweis auf Einstein nicht fehlen!).

154 BoraneckU (wie Anm. 150), S. 56 f.

155 Zur Kritik am Individualismus und Materialismus der bürgerlich-kapitalistischen Zivilisation, am Okonomismus und Antiidealismus der Marxisten sowie insbesondere an der Weltverneinung, Passivităt, der Selbsterniedrigung und "Sklavenmoral" des jenseitsgerichteten "theologischen Bewußtseins" (gemeint ist die Religion) ausführlich P.[S.] BORANECKU, "O geroizeskom mirosozercanii." In: Tretja Rossija, 7, 1936, S. 46-84. DERS., "K organizacii mira." Ebd., 8, 1938, S. 14-24. DERS., "Prometeizm i religija." Ebd., 9, 1939, S. 46-62.

156 BORANECKU (wie Anm. 150), S. 63.

157 Ebd. - Vgl. auch N. [d.i. P.S. BORANECKu], "Zavet nasego vremeni." In: Tret'ja Rossija, 7, 1936, S. 91. 
spiellos heftige Kritik, ja Wut erklären, mit der er über die Filosofija obš̌ego dela herfiel. ${ }^{158}$

In Fedorovs "krankhaft pervertiertem Denken" verbinde sich, so Boraneckij, "in grotesker Weise" ein theologisches, weltverneinendes und lebensfeindliches Bewußtsein mit Elementen eines "kruden Vulgärmaterialismus" und "Ultranaturalismus"; das Ergebnis dieser "schrillen theologisch-materialistischen Kakophonie" sei der "schreckliche Schwachsinn einer Leichenverehrung" (žutkij nekrolatriceskij idiotizm). ${ }^{159}$ Als primitiver Materialist à la Büchner und Moleschott fasse Fedorov den Tod als rein physisches Problem auf, das durch "Regulierung der Natur" zu lösen sei. Mit seiner Aufforderung, die Überreste der Verstorbenen zu sammeln und mit technischen Mitteln ihre Körper wiederherzustellen, verkehre er den ernsten Gedanken der aktiven Überwindung des Todes in eine "närrisch-positivistische Parodie" und gebe ihn der Lächerlichkeit preis. Der Mensch, so Boraneckij, sei unsterblich weder als Leib (Materialismus) noch als Seele ("theologische Weltanschauung"), sondern - nach der Lehre des "Prometheismus" - als "ganzheitliches universales Wesen" (celostnoe universal'noe suščstvo) durch seine Teilhabe am Leben als unendlicher schöpferischer Aktivität. ${ }^{160}$ Der Tod könne deshalb nur durch eine Stärkung des Lebens bekämpft werden. Fedorov aber mit seiner "trostlosen Friedhofskultur" (kladbišenskaja kul'tura) und "finsteren Leichenverehrung" (nekrolatrija) sei durch und durch lebensfeindlich und ganz auf den Tod fixiert; davon zeuge auch seine heftige Ablehnung der geschlechtlichen Liebe, der Zeugung und Geburt von Nachkommen sowie seine "Schmähung der Kinder" (chula na detej). ${ }^{161}$ Anstatt vorwärts zu streben und Neues zu schaffen, gehe es Fedorov einzig darum, das Vergangene wiederherzustellen; ${ }^{162}$ seine "Verehrung der Vorfahren" (kul't predkov) sei ebenso wie sein Begriff der "Bruderschaft" (bratstvo) extrem reaktionär. 163

158 Hierzu v.a. P.[S.] BORANECKJ, "O jurodivych Cudarestvach fedorovstva i o zamysle preodolenija smerti." In: Tret'ja Rossija, 8, 1938, S. 72-124. - Auf 50 engbedruckten Seiten enthălt dieser Aufsatz die schärfste Kritik, die je gegen die Filosofija obšcego dela vorgebracht worden ist. Weitere Einwănde gegen Fedorovs Lehre in Tret'ja Rossija, 2, 1932, S. 59f.; 7, 1936, S. 78; 9 , 1939, S. 52f.

159 BORANECKU (wie Anm. 158), S. 123, 105 und pass.

160 Ebd., S. 88. - Dieser Gedanke (und seine Formulierung) verrät deutlich den EinfluB der Lebensphilosophie Bergsons.

161 Ebd., S. 80f., 106-108. - Die Úberwindung des Todes durch Stărkung ("Maximierung") des Lebens war auch von Anhängern des bogostroitel'stvo propagiert worden (siehe II: 2.1.2.), wăhrend die Verherrlichung der Geschlechtlichkeit und Fortpflanzung als Mittel gegen den Tod an Rozanov erinnert (siehe II: 2.2.2.).

162 Ebd., S. 102-106. - Für Boraneckijs Alleinheitsphilosophie gibt es "strenggenommen" nichts Vergangenes: das 'Vergangene' ist als "Ergebnis" (irog), das 'Künftige' als Potenz im Gegenwărtigen enthalten. Ebd., S. 88.

163 Ebd., S. 102-104, 108. - Bei Fedorov beruhe bratstwo auf der gemeinsamen Herkunft von Vätem, sei also eine "rückwărtsgerichtete, patriarchalische Vorstellung"; für Boraneckij resultiert brat- 
Scharf kritisierte Boraneckij auch die theologischen Elemente in Fedorovs Lehre (Trinität und, besonders abstoßend, Eucharistie als symbolisch verbrämte "Gottesfresserei" [bogoedstvo]). ${ }^{164}$ Hingegen erkannte er die - immer wieder gestellte - Frage nach dem Anteil Gottes am obšcee delo zu Recht als gegenstandslos, da Gott "im ganzen 'Projekt' Fedorovs überhaupt keine Rollen spiele, er "nicht nur nicht nötig" sei, sondern "geradezu störend" wäre. ${ }^{165}$ Mit beißendem Spott mokierte sich Boraneckij schließlich über die Mystifizierung Fedorovs durch seine Anhänger und wies deren Behauptung, Fedorov habe entscheidenden Einfluß auf Tolstoj und Solov'ev gehabt, mit treffenden Zitaten aus der Filosofija obšcego dela zurück. ${ }^{166}$

Bei alldem bewies Boraneckij eine gründliche Kenntnis der Werke Fedorovs sowie des Schrifttums seiner Anhänger. Die Maßlosigkeit seiner Kritik kann freilich nicht darüber hinwegtäuschen - ja unterstreicht vielmehr -, daß Boraneckij mit seinem Projekt - der von Rußland ausgehenden Vereinigung der Menschheit durch das obšcee delo der Verwandlung und Errettung der Welt selbst ein Epigone Fedorovs war. ${ }^{167}$ Auch in seinem Lebenswandel glich er dem gehaßten Vorläufer. Überzeugt von der welterlösenden Bedeutung seiner Botschaft, widmete sich Boraneckij mit monomanischer Besessenheit der Darlegung und Verbreitung seiner "prometheisch titanischen Weltanschauung": Er verfaßte sieben Bücher mit einem Gesamtumfang von mehr als sechseinhalbtausend Seiten, die er zwischen 1947 und 1965 auf eigene Kosten drucken ließ und unentgeltlich an Interessenten abgab. ${ }^{168}$ Die damit verbundenen hohen Ausgaben bestritt er durch eine äußerst bescheidene Lebensführung - wie $\mathrm{Fe}$ dorov hauste er in einem Zimmer - sowie durch harte und gefahrvolle Arbeit als Fensterputzer an Hochhäusern und Bahnhöfen. ${ }^{169}$ Dennoch dürften Boraneckijs

stwo hingegen aus der "schopferisch-ontologischen Einheit des Menschen mit dem Universum" und ist somit "zeitlos".

164 Ebd., S. 94-96, 100.

165 Ebd., S. $98 f$.

166 Ebd., S. 117-121.

167 Auf die Abhängigkeit von Fedorov weisen hin VARŚAvSKJJ, Nezameđennoe pokolenie (wie Anm. 125), S. 266f. Gennady [Ejkalovic] (wie Anm. 149), S. 2.

168 P.S. BORANECKIJ, Filosofija techniki. Technika inovoe mirosozercanie. Paris 1947 (222 S.; Fedorov S. 162). DerS., Cennost' i Celovek. Princip sochranenija cennosti. Paris 1948 (479 S.). DERS., $O$ dostoinstve Celoveka. Osnovanija geroi Ceskoj èriki. Paris 1950 (768 S.). DERS., Religija, materializm i prometeizm. Osnovanija sinterixeskogo mirosozercanija. Paris o.J. [ca. 1953] (1650 S.; Fedorov S. 271f., 444, 791). DERS., O samom vaznom. Konełnoe naznacenie celoveka. Paris 1956 (1208 S.; Fedorov S. 1131-1139). DERS., Osnovnye natala. Ontologija tvorteskogo mirosozercanija. Paris o.J. [ca. 1960] (983 S.; siehe dort insbes. die Abschnitte "Kampf gegen den Tod", "Wahre Unsterblichkeit" und "Allgemeine Auferweckung", S. 743-770). DERS., Social'nyj ideal. Osnovy social'noj filosofii. Paris 1965 (1365 S.). - Aufgrund dieser Werke wurde Boraneckij sogar von der sowjetischen Religionskritik beachtet, wenn auch sogleich als "Pseudoatheist" abgetan. M.I. SACHNOVIC, Novye voprosy areizma, L. 1973, S. 194-196.

169 Knappe Angaben über Boraneckij und seine Lebensumstănde in den fünfziger und sechziger Jahren bei V.[P.] KRYMOV, Portrety neobyenych ljudej, Paris 1971, S. 146-150. 
Werke nur sehr wenige Leser gefunden haben, ist doch ihr Inhalt von kaum zu überbietender Monotonie: Mit immer denselben Worten repetierte Boraneckij das Konzept seiner Weltanschauung, wie er es bereits in den dreißiger Jahren in Tret'ja Rossija dargelegt hatte. Geplant war die Veröffentlichung weiterer fünf Bücher, doch wurde über sie wie auch über das Schicksal ihres Verfassers nichts mehr bekannt.

Mit Boraneckijs Werk reicht die Wirkung Fedorovs bis weit in die Nachkriegszeit, in einer Gestalt freilich, die die Grenze zur Pathologie des Denkens längst überschritten hat.

Weniger spektakulär, dafür um so nachhaltiger wurde das Bild Fedorovs und seiner Lehre von einem anderen Vertreter der Pariser Emigration verzeichnet, nämlich von Nikolaj Berdjaev. Nach seiner Ausweisung aus der Sowjetunion (1922) und einem Aufenthalt in Berlin hatte sich Berdjaev 1924 in Paris niedergelassen, wo er eine überaus rege schriftstellerische und publizistische Tätigkeit entfaltete. ${ }^{170}$ Seine philosophischen und geistesgeschichtlichen Werke wurden in zahlreiche Sprachen übersetzt und fanden weiteste Verbreitung, was dazu führte, daß Berdjaev, wie wohl kein anderer russischer Autor des 20. Jahrhunderts, jahrzehntelang die Vorstellungen vom "russischen Denken" und der "russischen Idee" prägte. ${ }^{171}$ Als Mitarbeiter der Zeitschriften Novyj Grad und Utverždenija stand Berdjaev den porevoljucionniki nahe. 1925 gründete er die religiös-philosophische Zeitschrift Put', von der bis 194061 Nummern erschienen.

Schon früh hatte sich Berdjaev für Fedorov interessiert und bereits 1915 einen langen Artikel über ihn und sein Werk veröffentlicht. ${ }^{172}$ Die darin enthaltenen dezidierten Urteile - und Mißverständnisse - hat Berdjaev später nicht mehr revidiert; wo immer er sich in der Folge zu Fedorov äußerte, kehren sie zum Teil wörtlich wieder. Fedorov war für Berdjaev der "russischste der Russen", ein "genialer Mensch", ein "Naturtalent und Sonderling", ${ }^{173}$ vor allem aber ein Mensch "von außergewöhnlich hohem sittlichem Bewußtsein": 174 "höher er-

170 Siehe T. KLÉPININE, Bibliographie des oeuvres de Nicolas Berdiaev, Paris 1978.

171 Eine kritische Würdigung dieses Umstands fehlt; immerhin dürfte Berdjaev mit seiner ausgeprägten Neigung zu kategorischen und pauschalen Unteilen über "das russische Denken" und "die russische Seele" ("der Russe ist...") viel zur Bildung - oder Bestătigung - von Klischees beigetragen haben. $\mathrm{DaB}$ darin auch ein Grund für seinen großen Erfolg liegt, laß sich freilich nur vermuten.

172 N.[A.] BerdjAEv, "Religija voskrełenija. 'Filosofija obšcego dela' N.F. Fedorova." In: Russkaja Mysl', 35 (1915), 7, S. 75-120. Ausfuhrlich dazu II: 2.2.1.

173 N.[A.] BerdjaEv, Tri jubileja. (L. Tolstoj, Gen. Ibsen, N.F. Fedorov)." In: Put', 11, 1928, S. 76-94; hier S. 88f. Der Abschnitt über Fedorov erschien auch deutsch in: Neue Schweizer Rundschau, 21, 1928, S. 839-846; englisch in: The Russian Review, 9, 1950, S. 124-130.

174 N.[A.] BerdjaEv, O naznacenii celoveka. Opyt paradoksal'noj étiki. Paris 1931, S. 279. Ebenso DERS., Russkaja ideja. Osnovnye problemy nusskoj mysli XIX veka i nacala XX veka. Paris 1946, S. 213. DERS., Samopornanie. (Opyt filosofskoj avtobiografii). Paris ${ }^{2} 1983$ [ ${ }^{1} 1949$ ], S. 347. 
hob sich noch niemand in der christlichen Welt". ${ }^{175}$ Dies, so Berdjaev, äußere sich in Fedorovs unversöhnlicher Haltung gegenüber dem Tod und der kategorischen Forderung nach gemeinsamer, allumfassender (statt persönlicher) Erlösung (sobomost' spasenija, vseobšcee [statt licnoe] spasenie). ${ }^{1 / 6}$ "Völlig originell", "genial und einzigartig" sei Fedorovs "aktive Auffassung" der Apokalypse als bedingte Voraussage, als "drohende Warnung" (ugroza) und Aufforderung, das schicksalhafte Ende der Welt durch gemeinsames Handeln abzuwenden. ${ }^{1} \rightarrow$

Fedorovs obšcee delo beschreibt Berdjaev - analog dem Solov'evschen Konzept des "Gottmenschentums" und der "freien Theurgie" - als "gottmenschliches Werk" (delo bogočelove`eskoe), ${ }^{178}$ als Zusammenwirken von göttlicher Gnade und menschlichem Handeln. Der Mensch sei aufgerufen zur "Mitwirkung" und "aktiven Teilnahme" an der Wiederherstellung des Lebens und der Erlösung der Welt. ${ }^{179}$ Dabei "rationalisiere" Fedorov freilich das "Geheimnis des Todes", und die von ihm vorgeschlagenen Methoden der Auferweckung seien "phantastisch", "naiv" und "unhaltbar": 180

Nach Fedorovs Lehre wird die Auferweckung nicht nur (!) durch die von Christus vollbrachte Tat ..., sondern auch (!) durch die wissenschaftliche, technische und physikalische Aktivităt der Menschen erreicht. (...) Er spricht sogar (!) von physikalisch-chemischen Versuchen der Auferweckung, was einen fast unheimlichen Eindruck macht. (...) Er will eine reale, fast (!) materialist ische Auferwekkung. ${ }^{181}$

175 Berdjaev (wie Anm. 173), S. 92. Ebenso Ders., Russkaja ideja (wie Anm. 174), S. 211.

176 N.[A.] BerdjaEv, "Christianstvo i revoljucija." In: Novyj Grad, 12, 1937, S. 57. Ders., "Russkaja religioznaja ideja." In: Problemy nusskogo religioznogo soznanija. Sb. statej. Berlin 1924, S. 123-129. - Berdjaev konfrontierte die sobomost' der Erlosung mit der Lehre des Thomas von Aquin, wonach sich die Seligen im Paradies an den Qualen der Verdammten in der Holle weiden. Ebd., S. 124. Vgl. auch DERS., O naznacenii... (wie Anm. 174), Kap. "Ad", S. 286303; bes. S. 293f. Fedorov verbindet diese Vorstellung mit Tertullian (FOD II, S. 43).

177 Vgl. N.[A.] BerdjaEv, Filosofija neravenstva. Pis'ma $k$ nedrugam po social'noj filosofii. Berlin 1923, S. 242. DERS. (wie Anm. 173), S. 93f. DERS., "O charaktere russkoj religioznoj mysli XIXgo veka." In: Sovremennye Zapiski, 42, 1930, S. 325. DeRs., "Čelovek i masina." Put', 38, 1933, S. 32f. DERS., Sinn und Schicksal des nussischen Kommunismus, Luzem 1937, S. 99-101 (die russ. Ausgabe dieses Werks erschien erst 1955). DERS., $O$ mabstve $i$ swobode celoveka, Paris o.J. [1939], S. 219f. Ders., "Vojna i eschatologija." In: Put', 61, 1939-40, S. 12. DerS., Russkaja ideja (wie Anm. 174), S. 211-213. DERS., Opyt eschatologiceskoj metafiziki. (Tvortestro i ob-ektivacija). Paris 1947, S. 201. DeRs., Samopoznanie (wie Anm. 174).

178 BERDJAEv, Russkaja ideja (wie Anm. 174), S. 213.

179 Ebd., S. 211. - BeRdjAEV (wie Anm. 173), S. 89, 91.

180 BerduaEv, Russkaja ideja (wie Anm. 174).

181 Berdjaev (wie Anm. 173), S. 92f. - An anderer Stelle heiBt es: "Die Aufgabe der allumfassenden Auferweckung darf nicht nur [!] auf religiosem Wege erfüllt, sondern muB auch [!] mit physikalisch-chemisch-physiologischen Methoden vollbracht werden." BERDJAEV, "Russkaja religioznaja ideja" (wie Anm. 176), S. 128f. 
Obwohl Berdjaev Fedorovs Philosophie für "völlig ungenügend" hielt, ${ }^{182}$ imponierte ihm die aktive Haltung gegenüber dem Tod und dem Ende der Welt: Mit Fedorov glaubte er die Überzeugung zu teilen, daß der Mensch um seine Unsterblichkeit kämpfen müsse ${ }^{183}$ und $\mathrm{da} B$ die passive Erwartung des schrecklichen Endes der Welt mit der Idee der menschlichen Freiheit unvereinbar sei. Fedorov, so erklärte er, stehe ihm "in vielem sehr nahe" ${ }^{n}{ }^{184}$ und es heißt, daß in Berdjaevs kleiner Wohnung in Clamart auch ein Porträt des alten Bibliothekars gehangen habe. ${ }^{185}$

In den späten zwanziger und frühen dreißiger Jahren wirkte Berdjaev vor allem in seiner Zeitschrift Put' für die Verbreitung Fedorovscher Ideen: Er veröfentlichte Materialien aus dem dritten Band der Filosofija obš̌ego dela ${ }^{186}$ und rezensierte drei der Harbiner Publikationen, die ihm Setnickij zugeschickt hatte. ${ }^{187}$ Außerdem hielt er Vorträge über Fedorov vor verschiedenen Emigrantenvereinigungen. ${ }^{188}$ Am wirkungsvollsten waren jedoch die Hinweise auf Fedorov und dessen Ideen, die Berdjaev in seinen zahlreichen Aufsätzen und Büchern gab. Bedenkt man den einzigartigen Erfolg, den Berdjaevs Werk vor allem in den dreißiger, vierziger und fünfziger Jahren hatte, so dürften die meisten westeuropäischen Leser hier zum ersten - und wohl auch einzigen - Mal dem Namen Fedorovs begegnet sein und vielleicht eine Ahnung von der kühnen Radikalität seines Denkens bekommen haben. ${ }^{189}$

182 Berdjaev, Samopoznanie (wie Anm. 174).

183 Dazu ausfuhrlich N.[A.] BERDJAEV, Ekzistencial'naja dialektika boťestvennogo i celoveceskogo, Paris 1952, S. 183-202; dort heißt es im Gegensatz zu Fedorov, man müsse "die Auferstehung des Leibes geistig verstehen", als "Auferstehung eines geistigen Leibes" (ebd., S. 199, 201). - Zu Berdjaevs Ansichten über Persönlichkeit, Tod und Unsterblichkeit siehe auch F. STEPUN, Mystische Weltschau. Fünf Gestalien des nussischen Symbolismus. München 1964, S. 184-196.

184 BERDJAEV, Ekzistencial'naja dialekrika (wie Anm. 183), S. 187. Vgl. auch ebd., S. 347: "Nahe stehen mir weder VI. Solov'ev noch K. Leont'ev, nahe steht mir N. Fedorov..."

185 J. ChaiX-RuY, "Nicolas Berdiaeff." In: M.F. Sclacca [Hg.], Les grands courants de la pensée mondiale contemporaine. Pontraits. Bd. 1, Milano 1964, S. 118.

186 In: Put', 10, 1928, S. 3-42; 18, 1929, S. 3-24; 40, 1933, S. 3-15. Siehe auch II: 4.2. Anm. 112.

187 Smentobożnicestvo in: Put', 7, 1927, S. 122-124; Gornostaev [Gorskij], Raj na zemle, ebd., 19, 1929, S. 114-116; Setnickij, O koneðnom ideale, ebd., 36, 1932, S. 93-95.

188 Z.B. im Mărz 1930 vor der Religiös-Philosophischen Akademie in Paris über das Thema Rozanov und Fedorov. Siehe BEYSSAC (wie Anm. 46), S. 237, 269.

189 Als Beispiel einer auf Berdjaev beruhenden Darstellung Fedorovs sei genannt H.U.v. BALTHASAR, Apokalypse der deutschen Seele. Studien zu einer Lehre von letzten Haltungen. Bd. 3: Die Vergöttlichung des Todes. Salzburg, Leipzig 1939, S. 410, 412.

In der umfangreichen Literatur zu Berdjaev wird Fedorov nur selten und eher beilăufig enwăhnt, wobei seine Gedanken stets nach der Darstellung Berdjaevs wiedergegeben werden. Siehe z.B. E. PORRET, La philosophie chrétienne en Russie. Nicolas Berdiaeff. Neuchâtel 1944, S. 92-95; deutsch: Nikolaj Berdjajew und die christliche Philosophie in Rußland, Heidelberg 1950. S. 118-121. C.S. Callan, The Significance of Eschatology in the Thought of Nicolas Berdyaev, Leiden 1965, S. 4f., 391., 99, 109; dass. auch unter dem Titel Berdyaev's Philosophy of Hope. A Contribution to Maxist-Christian Dialogue. Minneapolis, Minn. o.J. [ca. 1968]. Ausführlicher 
Während Berdjaev in Fedorov stets einen - wenn auch radikalen - christlichen Denker sehen wollte, dem es um die Erlösung der Welt durch ein gemeinsames gottmenschliches Werk gegangen sei, ist es das Verdienst von Georgij Florovskij, in einem Aufsatz, der 1935 in den Sovremennye Zapiski erschien, die Unhaltbarkeit einer solchen Interpretation aufgezeigt zu haben. ${ }^{190}$

Man dürfe sich, so Florovskij, nicht durch das "christliche Gewand" der Lehre Fedorovs "irreführen lassen"; wichtig sei nicht so sehr, woher die Worte und Bilder stammten, wichtig seien vielmehr die Grundlagen und Prämissen. Diese aber hätten mit dem Christentum nichts gemein: "leicht" könne man aus Fedorovs System "die 'Hypothese Gott' entfernen, ohne da $B$ sich in ihm etwas ändern" würde. ${ }^{191}$

Fedorovs Anliegen sei nicht die Erlösung der Welt von der Sünde (beide Begriffe seien ihm ganz fremd), sondern die technische Bemächtigung und vernunftgemäße Regulierung der Natur. Der Mensch stehe der Natur alleine gegenüber und könne im Kampf gegen sie nur auf seine Arbeit, nicht aber auf göttliche Gnade vertrauen; Gott sei nicht in dieser Welt. ${ }^{192}$ Fedorovs "Religion" sei in Wirklichkeit eine "Religion der Menschheit", ein "sublimierter Humanismus". ${ }^{193}$ Seine weltanschauliche Position könne man allenfalls als Deismus bezeichnen, in der Praxis unterscheide sie sich jedoch nicht vom Atheismus. ${ }^{194}$

Unchristlich (trotz "christlicher Terminologie") sei auch Fedorovs Konzept der Auferweckung. Dabei gehe es ihm nur um eine "neue Zusammensetzung des Leibes"; völlig unklar bleibe hingegen das "Schicksal der Seele", das "jenseitige Leben der Verstorbenen". "Unklar bleibt auch, was der Tod ist... Unklar bleibt, wer stirbt und wer aufersteht - der Leib oder der Mensch... ${ }^{195}$ Fedorovs Projekt der "Belebung von Leichen" habe, so Florovskij, einen "gewissen Beigeschmack von Nekromantie" und erwecke den Eindruck, als beabsichtige er die

behandelt Berdjaevs Auseinandersetzung mit Fedorov W. DieTrICH, Provokation der Person. Nikolaj Berdjajew in den Impulsen seines Denkens. Bd. 3, Gelnhausen, Beriin 1975, S. 126-142, doch wird auch hier die Position Fedorovs nur mit den Worten Berdjaevs vorgestellt.

190 G.[V.] FlorovsKu, "Proekt mnimogo dela. (O N.F. Fedorove i ego prodolžateljach)." In: Sovremennye Zapiski, 59, 1935, S. 399-414. Gekürzt und leicht verăndert in DERS., Puti nusskogo bogoslovija, Paris 1937, S. 322-330.

191 FloRovSKU, "Proekt..." (wie Anm. 190), S. 401f. - Nachdrücklich warnt Florovskij vor einem verbreiteten 'Argument' für den angeblich religiosen Charakter der Lehre Fedorovs: "Man sagt, Fedorov sei ein kirchlich gesinnter Mensch (cerkomyj celovek) gewesen, doch war seine Weltanschauung in der Mehrzahl ihrer Voraussetzungen überhaupt nicht christlich und steht in scharfem Widerspruch zur christlichen Offenbarung und Erfahrung." Ebd., S. 406. "Fedorovs persठ̋nliche Religiosităt macht sein System keineswegs religios." Ebd., S. 408.

192 Ebd., S. 406, 412.

193 Ebd., S. 406, 413.

194 Ebd., S. 412

195 Ebd., S. 403; Hervorhebungen im Orig. - Im Rahmen von Fedorovs monistischer Anthropologie sind diese Fragen freilich irrelevant: die 'Seele' ist nur eine Funktion des Leibes, mit dem Leib stirbt (und wiederersteht) auch der Mensch. 
Herstellung "neuer homunculi in vitro". ${ }^{196}$ Tatsächlich wollte Fedorov den "kosmischen Organismus" in einen "Mechanismus" verwandeln. ${ }^{197}$

Mit seinem naiven Glauben an die "magische" Allmacht der Wissenschaft und Technik (Szientismus und Technizismus), dem Willen zu einer totalen Rationalisierung und Beherrschung des für endlich und überschaubar gehaltenen Universums sowie seinen Bemühungen um eine allgemeinverbindliche "herrschende" Weltanschauung (Ideokratie) sei Fedorov ganz dem Geist der Aufklärung verhaftet und eng verwandt mit den französischen Utopisten (Saint-Simon, Fourier, Leroux) und Positivisten (Comte, Guyau). ${ }^{198}$ Isoliert, zurückgezogen, sich dem "falschen Leben" verweigernd, entwerfe er eine Gegenwelt, träume er - und darin zeige sich sein Grundwiderspruch - "den einsamen Traum vom gememsamen Werk". ${ }^{199}$

Florovskij glaubte 1935 noch vor der "Anziehungskraft" der Fedorovschen Ideen warnen zu müssen, ${ }^{200}$ doch hatte deren Rezeption und Diskussion den Höhepunkt bereits überschritten und sollte in den folgenden Jahren stark nachlassen. ${ }^{201}$ Daran wird deutlich, wie sehr die Resonanz auf Fedorovs Werk von der Aktivität seiner wenigen Anhänger abhängig gewesen war: 1935 kehrte Setnickij aus Harbin nach Moskau zurück, Gorskij war bereits 1929 verstummt, und Ccheidze hatte in Prag keine Mitstreiter gewonnen - gegen Ende des Jahrzehnts war denn auch Fedorovs Name aus der Diskussion verschwunden.

196 Ebd., S. 404 .

197 Ebd., S. 405; Hervorhebungen im Orig.

198 Ebd., S. 401f., 406-408, 410-412.

199 Ebd., S. 401. - Mit dieser Formulierung erliegt freilich auch Florovskij der von inm selbst kritisierten Versuchung, Fedorovs Lehre nach seiner Lebensweise zu beurteilen.

200 Ebd., S. 414.

201 Die Anzahl der Veroffentlichungen zu Fedorov erreichten im Jahre 1933 (30. Todestag) ihren absoluten Hohepunkt. Zumeist handelte es sich um kurze Gedenkartikel in der Emigrantenpresse, wie z.B. ANON., "TridesetogodiY̌njica smrti N.F. Fedorova." In: Svetosavlje [Belgrad], 35, 1933, S. 199. L.N. Gomoucku, "N.F. Fedorov. K 30 letiju so dnja ego smerti (28.XII.1903)." In: Molva [Warschau], 294 (517), 23.-25.12.1933, S. 4. (Lev Nikolaeviz Gomolickij, geb. 1903, ein in Warschau lebender Dichter). I.[S.] LUKAS, "Fedorov." In: Vozrozdenie [Paris], 2788, 19.1.1933, S. 3f., I.L. [I.S. LuKAS ?], N.F. Fedorov." Ebd., 2901, 12.5.1933, S. 2. (Ivan Sozontovic Lukaš, 1892-1940, ein in Paris lebender Prosaiker und Essayist). Mitunter handelte es sich um Auszíge aus Ostromirovs (Gorskijs) mehrteiligem Werk Nikolaj Fedorovit Fedorov i sovremennost': ANON., 'Nikolaj Fedoroviz Fedorov. (1828-1903). (Žizn' i uzenie)." In: Vestnik RSChD, 1933, 5-6, S. 17-23. ANON., "Nikolaj Fedorovic Fedorov. Uzenie." Ebd., 1933, 7-8, S. 1115 ; 9-10, S. 16-22; 11-12, S. 15-21.

Ein weiterer Hőhepunkt der Publikationstătigkeit fallt in das Jahr 1928 (100. Geburtstag). Nach 1934 sind jăhrlich nur noch wenige Veröffentlichungen zu verzeichnen, nach 1939 fast keine mehr. 


\section{BIBLIOGRAPHIE}

I. MANUSKRIPTE

II. BIBLIOGRAPHIEN, NACHSCHLAGEWERKE (AUSWAHL)

III. SCHRIFTEN VON N.F. FEDOROV

IV. Die SAMMELbände "VSELENSKOE Delo", 1 (1914), 2 (1934)

V. ÜBRIGE LITERATUR

BIBLIOGRAPHISCHER NACHTRAG

Schriften, in denen Fedorov genannt wird, sind mit einem Stern ( $\left.{ }^{*}\right)$ gekennzeichnet 


\section{MANUSKRIPTE}

An dieser Stelle werden auch ungedruckte sowjetische Dissertationen aufgeführt, die nur in der Lenin-Bibliothek (GBL) oder Gor'kij-Bibliothek, Moskau, eingesehen werden konnten. Nicht verzeichnet werden Briefe, die sich in staatlichen oder privaten Archiven befinden und mir im Original oder in Abschrift zugănglich waren. Diejenigen Manuskripte, von denen ich eine Abschrift oder eine Xerokopie besitze, sind mit $(A)$ resp. $(X)$ gekennzeichnet.

- ANON., Vecer pamjati N.F. Fedorova, 17 dekabrja 1984 g., v IONCh AN SSSR, Moskva. [Protokoll der Vorträge und Diskussionen] Ms. [Masch.] 4 Bl. (A)

- ANON., Obrašenie ko usem Ziteljam planery Zemlja... [Aufruf zur Gründung einer Vsemimaja organizacija obšzego dela - missija N. Fedorova (VOOD-MNF)]. Ms. [Masch.] M. 1985, 2 S. (A) AgAPOV, Petr, Vrag smerti, Ms. [Masch.] Prag 1937, 257 Bl.; FAP I, 334.

Anciferov, Nikola Pavlovit, Medvežja gora. 1931. Kapitel aus dem Buch Put' moej zizni [1950er Jahre], Ms. [Masch.], 3 Bl.; Original in GPB, f. 27; Abschrift in Moskauer Privatbesitz. (A)

- Borisov, Valeris Semenovic, Kıo Ze byla mat' yydajušcegosja nusskogo myslitelja N.F. Fedorova?, Ms. [Masch.] M. 1986, 3 Bl.; in Moskauer Privatbesitz. (A)

BrichniCev, Iona PANTElejmonovic, Služebnaja avtobiografija (1879-1937), Ms., 5 Bl.; GBL f. 516, k. 3, ed. ehr. 39; Abschrift in Moskauer Privatbesitz.

- ¿cheidze, K[OnStantin] A[Leksandrovic], N.F. Fedorov, Ms. [Masch.] Prag 1932, 6 Bl.; FAP I, 334.

- CCheidze, Konstantin AleksandroviC, $O$ sovremennoj nusskoj literature. Sbomik statej. Ms. [Masch.] Prag 1933, XIX, 24 Bl.; Státni knihovna CSR, Praha. (X)

- Cernogubov, Nikolas NikolaeviC, Nikolaj Fedorovic Fedorov, Ms. 10 Bl.; GBL f. 328, k. 3, ed. chr. 8. [War nicht zugănglich]

- Čuev, S[ERGej] I[VANOVIC], Na knigu 'O konečnom ideale', Ms.; FAP I, 334.

- Dorogov, A A., Dostoevskij i Fedorov. (Doklad na VI-ch Dostoevskich Ctenijach: Dostoevskij i mirovaja kul'tura, Leningrad 11.-13. Nov. 1981). [War nicht zugănglich]

Florensku, PAVel [Aleksandrovic], Imena, Ms. [Masch.] 254 Bl. (A)

Florensku, P[AVEL] V[ASIL'EVIC], P.A. Flonenskij po vospominanijam Alekseja Loseva, Ms. [Masch.] M. 1989, 36 Bl.; in Moskauer Privatbesitz. (A)

- Girenok, F[edor] I[VANovic], Proekt 'Obšcego Dela'v tradicii russkogo kosmizma, Ms. [Masch.] [nach 1981], 36 Bl.; in Moskauer Privatbesitz. (A)

- [Gorsku] Gornostaev, A[LEKSANDR] K[ONSTANTINoviC], Nikolaj Fedorovic Fedorov. Biograficeskıj ačerk. Ms. [Masch.] 1923, 57 Bl.; CGALI f. 1435, op. 1, ed. chr. 147. [War nicht zugănglich]

- Gorski, Aleksandr Konstantinovic, Ogromnyj oxerk, Ms. [Masch.] 1924, 110 Bl.; Privatarchiv Moskau.

[GORSKu] GoRnOSTAEv, A[LEKSANDR] K[ONSTANTINOvic], Blok i Gogol'. Tezisy doklada. Ms. [Masch.] 1927, 2 Bl.; FAP I, 334.

- [GoRSKIJ] GoRnOSTAEV, A[LEKSANDR] K[ONSTANTINOVIC], Tezisy $k$ dokladu A.K Gomostaeva 'L.N. Tolstoj i N.F. Fedorov'. G.A.Ch.N. Litenatumaja sekcija. Ms. [Masch.] datiert: 10/II-1928, 1 Bl.; FAP I, 334.

[GoRski, Aleksandr Konstantinovic], Posleslovie $k$ traktatu 'Smenobożnicestro', Ms. [Masch.] 1926-1942, 1 Bl.; Privatarchiv Moskau. (A)

- [GorskiJ] Gornostaev, A[Leksandr] K[OnSTANTInovic], Im Angesichte des Todes. L.N. Tolstoi und N.F. Fedoroff. Ms. [Masch.] 26 Bl.; FAP I, 334.

- [Gorski] GornostaefF, A[LEKSANDR] K[OnStantinovic], At the face of Death, Ms. [Masch.]; FAP I, 338. 
[Gorsku, Aleksandr Konstantinovic, SETnicki, Nikolas Aleksandrovic], Tezisy o tajne bezzakonija, Ms. [Masch.] M. 1924, 9 Bl.; in Moskauer Privatbesitz. (A)

[Gorski, Aleksandr Konstantinovic, Setnicku, Nikolas Aleksandrovic], Tezisy ob imjaslavii, Ms. [Masch.] [um 1924], 5 Bl.; in Moskauer Privatbesitz. (A)

[Gorsku, Aleksandr Konstantinovič], Duoe. Povest' o greche, o pravde $i$ o sude. Ms. [Masch.] 1933-1943, 219 Bl.; Privatarchiv Moskau.

[Gorski, Aleksandr Konstantinovic], Not' Nikodima. Poima. Ms. [Masch.] 1934-1937, 45 Bl.; Privatarchiv Moskau.

- [Gorski, Aleksandr Konstantinovic], Preodolenie Fausta, Ms. [Masch.] 94 Bl.; Privatarchiv Moskau.

[Gorsku, Aleksandr Konstantinovic] Ostromarov, A., Pesni bez nedomolvok. Popravki, pojasnenija i dodelki. 1941. 20 j vek. Ms. Kaluga 1942; Privatarchiv Moskau.

GuMILEV, Lev NikolaEvic, Emogenez i biosfera Zemli, Leningrad 1979, Ms. [Masch.]; deponient in VINITI, Ljubercy, Mosk. obl., vyp. 1 (No. $1001-79$ Dep.), vyp. 2 (No. 3734-79 Dep.), vyp. 3 (No. 3735-79 Dep.).

- Kune, GeORge L., Soviet Prometheanism and its Roots in Russian Thought, Abstract, Ms. [Masch.] 0.O. 0.J. [ca. 1975]. (X)

- Kol'Cenko, IGOR' AleKseEviC, KE. Ciolkovskij kak myslitel'. Diss. kand. filos. nauk. Institut filosofii AN SSSR, M. 19.12.1968, Ms. [Masch.] 258 Bl.; GBL Sign. Dk 69-9/22. [Fedorov S. 28, 234]

- Kononov, Nikola [Setnicku, Nikolas Aleksandrovic ?], Pafos kul'tury, Ms. [Masch.] 1923, 5 Bl.; FAP I, 334.

- Koutaissoff, Elisabeth, The Noosphere. N.F. Fedorov and P. Teilhard de Chardin. Ms. [Masch.] 0.O. [Oxford] 0.J. [ca. 1982], 24 Bl. (X)

- Krašeninnikova, Ekaterina Aleksandrovina, [diverse Aufzeichnungen über Fedorov und dessen Anhänger]; Privatarchiv Moskau. (A)

Losev, Aleksej Fedorovic, Tezisy imjaslavskogo ucenija, Ms. [Masch.] 1922/23, 4 Bl.; in Moskauer Privatbesitz. (A)

- MuRav'ev, V[ALERLAN] N[IKolaevic], Vseobscaja proizvoditel'naja matematika, Ms. [Masch.] 1923, 33 Bl.; FAP I, 334.

- Nikmin, Valentin ARSen'eviC, Pamjati N.F. Fedorova, [Gedichi] Ms. [Anfang 1980er Jahre] 2 Bl.; in Moskauer Privatbesitz. (A)

- NikTtin, VAlentin ARSEN'EviC, N.F. Fedorov i global'naja futurologija. (Ob uslornom ponimanii apokalipticeskich proročestv). [Vortrag im GIPROMEZ, Moskau, am 27.12.1983, anläßlich des 80. Todestages von N.F. Fedorov] Ms. [Masch.] 9 S.; in Moskauer Privatbesitz. (A)

- Nikrtin, V[ALENTIN] A[RSEN'EVIC], N.V. Gogol' i N.F. Fedorov, Ms. [Masch.] [ca. 1987] 27 Bl.; in Moskauer Privatbesitz. (A)

Paramonov, Boris Michajlovic, Slavjanofil'stwo i krizis russkoj religioznoj filosofii. Diss. kand. filos. nauk, L. 1971, Ms. [Masch.] 361 Bl.; GBL Sign. Dk 71-9/547.

- Paramonov, Boris [Michajlovic], Nikolaj Fedorovic Fedorov, Ms. [Masch.], 10 Bl. Ms. einer Sendung von BBC London, East European Service (Russian), 14.2.1984. (X)

- Pazilova, Valentina Pavlovina, Kriticeskij analiz religiozno-filosofskogo ucenija N.F. Fedorova. Dissertacija na soiskanie urenoj stepeni kandidata filosofskich nauk. Special'nost' - nautnyj ateizm. M. 1981, Ms. [Masch.] 144 Bl.; Gor'kij-Bibliothek, Moskau.

- Peterson, N[ikolaj] P[aviovic], Po povodu stat'i kn. E.N. Trubeckogo 'Neskol'ko slov o Solov'eve i Fedorove', Ms. [Masch.] 26 Bl.; Privatarchiv Moskau.

- Peterson, N[IKoln] P[avlovic], Kratkoe izlozenie principov 'Filosofii obstego dela' v svjazi s vojnoj s Germaniej v 1914 - 1918 g.g., Ms. [Masch.] 31 Bl.; Privatarchiv Moskau.

- RUPPERT, HANS-JORGEN, Die russische religiöse Renaissance des 20. Jahihunderts: Solowjow, Bulgakow, Berdjajew und Florenskij, Ms. einer Sendung des Südwestfunks Baden-Baden vom 23.12.1987, Ms. [Masch.] $65 \mathrm{Bl}$. 
- [Semenova, Svetlana Grigor'evna] Larin, S., Put' $k$ drevu bessmerija, Ms. [Masch.] [Anfang 1980er Jahre] 372 Bl.; in Moskauer Privatbesitz.

- Semenova, S[VETLANA] G[RIGOR'EVNa], Idei neizvestnogo myslitelja v 'Brat'jach Karamazovych', [Vortrag im Dostoevskij-Museum Leningrad, ca. 1981], Ms. [Masch.] 18 Bl.; in Moskauer Privatbesitz. (A)

- Setnickaja, Ol'Ga Nikolaevna, Aleksandr Konstantinovic Gorskij. Biografija. Ms. [Masch.] 47 Bl.; Privatarchiv Moskau. (A)

- Setnickaja, Ol'ga Nikolaevna, Nikolaj Aleksandrovic Setnickj. Biografija. Ms. [Masch.] datiert: 24.3.1965; FAP I, 337.

- [SETNICKu, Nikola Aleksandrovic ?], Otkrytoe pis'mo g. Uelsu, Ms. [Masch.] Charbin 1928, 15 Bl.; FAP I, 338.

- Setnicku, N[IKolaj] A[leksandrovic], Ob-edinenie celovecestua. Dogmat i opyt. Ms. [Masch.] [1930er Jahre] $49 \mathrm{Bl}$.; in Moskauer Privatbesitz.

SETNICKIJ, N[IKOLA]] A[LEKSANDROVIC]], Tvonteskij marksizm i likvidacija 'chvostizma' v biologii, Ms. [Masch.] 1937, 36 Bl.; FAP I, 337.

- SnetKov, S.G., Pamjati Nikolaja Fedoroviza Fedorova. Rex' S.G. Snetkova. Ms. [Masch.] 1 Bl.; FAP I, 334.

- Soxolov, V.V., Janin, V.L., Suchich, S.I., K nasledstvu ne otnosit'sja ne tak..., Ms. [Masch.] M. 1983, 1 BI. (A)

- ŚTINDL, KAREL, Ediěni návrh na yydáni svazku z dila N. Fjodorova, Ms. [Masch.] 7 Bl.; FAP I, 337.

TrubaCeva, M[arua] S[ergeevna], TrubaCev, S[ergej] Z[OSImovic], Sergiev Posad v Zizni $P$ A. Florenskogo, Ms. [Masch.] [Zagorsk 1988] 28 Bl.; in Moskauer Privatbesitz. (A)

VAGNER, VJACESLAV, IznaCal'nye osnovy vseobšcego sinteza drevnosti. Vseobstij sintez. Ms. [Masch.] Kiev, Moskva 1922 - Prag 1957/58, 122 Bl.; FAP 1, 337.

- Volynskis, Akim L'vovic [d.i. Flekser, Chaim LejBovic], Vosknesenie mertyych, Ms. [1920er Jahre ?]; CGALI f. 95. [War nicht zugănglich]

\section{BibliographiEN, NACHSChLAGEWERKE} (Auswahl)

BAKOUNINE, TATIANA, Répertoire biographique des francs-maçons nusses (XVIf et XIX siècles), Paris 1967. ( = Collection historique de l'Institut d'Etudes slaves; 19).

Beiuneva, Lucua NikmCna, Bibliografija periodiceskich izdanij Rossii 1901-1916, t. 1-4, L. 1958-1961.

- Biblioteka L'va Nikolaevita Tolstogo v Jasnoj Poljane. Bibliografizeskoe opisanie. I, Knigi na russkom jazyke. C. 1, M. 1972; ¿. 2, M. 1975.

Biblioteka nusskoj poezii I.N. Rozanova, M. 1975.

- Bradová, MARTA, LOUŽIL, JARomír, Literámi archiv Národniho muzea v Praze. Literámi pozustalost cis. 142. Fedoroviana Pragensia. (NA. Setnickij, N.F. Fjodorov, K. Ćcheidze, N.V. Ustrjalov). [Masch. vervielf.] Praha 1962.

Davies, RIChaRd D., "Nietzsche in Russia, 1892-1919: A Chronological Checklist." In: B.G. Ro. SENTHAL (Hg.), Nietzsche in Russia, Princeton, N.J. 1986, S. 355-392.

- Dejateli revoljucionnogo dviženija v Rossii. Bio-bibliograficeskij slovar. T. 1, દ. 2, M. 1928. [Fedorov S. 427]

- Filosofskaja enciklopedija, t. 1-5, M. 1960-1970.

- Foster, LudDMiLA A., Bibliografija nusskoj zanubeżnoj literatury 1918-1968, t. 1-2, Boston, Mass. 1970. 
GMeline, PATRICK DE, Dictionnaire de la noblesse nusse, Paris o.J. [1978].

GOLUBEVA, OL'GA DMTRIEVNA, Literatumo-chudožestvennye al'manachi i sbomiki 1900-1911 gody, M. 1957.

HAGEMEISTER, MICHAEL, "PA. Florenskijs 'Wiederkehr': Materialien zu einer Bibliographie (1985-1989)." In: Ostkirchliche Studien [im Druck].

Ikonnikov, Nicolas, La noblesse de Russie, tome D.1 [pr. Gagarine], Paris ${ }^{2} 1958$; tome J.2 [Mouraviev], Paris ${ }^{2} 1959$.

Imperatorskij Aleksandrovskij Licej 1811-1961. Pamjatnaja knizka liceistov. Neuilly-sur-Seine o.J.

- KlÉPINIne, TAMARA, Bibliographie des oeuures de Nicolas Bendiaev, Paris 1978. (= Bibliothèque russe de l'Institut d'Études slaves; 43).

Kormin, NA., Serija 'Filosofskoe nasledie'. Katalog izdanij. M. 1981.

Kratkij ukazatel' archivnych fondov otdela nukopisej. Pod red. P.A. Zajonckovskogo i E.N. Konšinoj. M. 1948.

- Liznaja biblioteka A.M. Gor'kogo v Moskve. Opisanie v dvuch knigach. 1-2, M. 1981.

Liznye archivnye fondy v gosudarstvennych chraniliscach SSSR. Ukazatel'. T. 1-3, M. 1962-1980.

LUBENSKU, STEPAN, siehe SAVICKI, P.N.

LUKASKIN, A., "K bibliografii dal'nevostočnoj pressy." In: Novyj Žumal, 114, 1974, S. 252-259.

[LUNACARSKu, A.V.] Anatolij Vasil'eviX LunaCarskij. Ukazatel' trudov, pisem i literatury o zizni i dejatel'nosti. T. 1-2, M. 1975-1979.

MASANOv, IVAN Filuppovic, Slovar' psevdonimov nusskich pisatelej, ucenych i obšcestvennych de. jatelej v cetyrech tomach, t. 1-4, M. 1956-1960.

The Modem Encyclopedia of Russian and Soviet History, 1-49, Gulf Breeze, Flor. 1976-1988.

The Modem Encyclopedia of Russian and Soviet Literatures, 1-4, Gulf Breeze, Flor. 1977-1981.

Muratova, K.D., Peroidika po literalure i iskusstvu za gady revoljucii 1917-1932, L. 1933.

- Naumov, KuIment, Bibliographie des oeuvres de Serge Boulgakov, Paris 1984. (= Bibliothèque russe de l'Institut d'Études slaves; 68/1).

NiKOLA MiChaloviC, VELIKU KNJAZ', Moskovskij nekmopol', t. 1, SPb. 1907.

Ossorguine-BAKounine, TATIANA, L'émigration russe en Europe. Catalogue collectif des périodiques en langue nusse 1855-1940, Paris 1976. ( × Bibliothèque russe de l'Institut d'Etudes slaves; 40/1).

ROGOŽIN, NikolA PETROVIC, Literatumo-chudožestvennye al'manachi i sbomiki 1912-1917 gody, M 1958. (= Literaturno-chudožestvennye al'manachi i sborniki. Bibliografizeskij ukazatel'; 2).

Rogozin, Nikolas PETRovic, Literatumo-chudotestvennye al'manachi i sbomiki 1918-1927 gody, M. 1960. ( = Literaturno-chudožestvennye al'manachi i sborniki. Bibliografǐeskij ukazatel'; 3).

Russkij biograficeskij slovar, t. 4, M. 1914; t. 18, SPb. 1904.

Russkie sovetskie pisareli i poèty. Bibliograficeskij ukazatel'. T. 3, ¿. 2, M. 1980.

STEJNVAND, G.D., Odes'ka periodicna presa rokiv revoljucii ta hromadjans'koi vijni 1917-1921 g.g., Odesa 1929.

[SAvicku, PETr Nikolaevic] LUBEnSKU, StePAN, "Evrazijskaja bibliografija 1921-1931." In: Tridcalye gody, Paris 1931, S. 285-317. DERS., dass. [franz.] in: Le Monde slave, 8 (1931), S. 388 422.

Stejn, Emmanull [Alexseevic], Poezija nusskogo rassejanija 1920 1977, Ashford, Conn. 1978.

TARASENKOV, ANATOLU KuZ'MiC, Russkie poety XX veka, M. 1966.

TJUNIN, M[ICHAIL] S[EMENOVIC], Ukazatel' periodiceskich i povremennych izdanij, vychodivsich v 8. Charbine na nusskom $i$ dr. evropejskich jazykach po l-e janvarja 1927 goda, Charbin 1927. (= Trudy obš̌estva izuそenija man'そ̌̌urskogo kraja. Bibliografija Man'ž̌urii. Vyp. 1, 1927).

[TJUNIN, MICHAIL SEMENOVIC], Ukazatel' perioditeskoj petati g. Charbina yychodivšej na nusskom $i$ dr. evropejskich jazykach. Izdanija, vysedsie s 1 janvarja 1927 goda po 31 dekabrja 1935 goda. Charbin o.J. [1936]. 
VOLKOFF, ANNE-MARIE, L'émigration nusse en Europe. Catalogue collectif des périodiques en langue russe 19401979. Paris ${ }^{2}$ 1981. ( = Bibliotheqque russe de l'Institut d'Etudes slaves; 40/2).

Yassour, Avraham, "Bogdanov et son oeuvte." In: Cahiers du Monde russe el soviétique, 10 (1969), S. 546-584.

- Young, George M., "Fyodorov in Baker Library." In: Dartmouth College Library Bulletin, 16, 1976,2, S. 54-61.

- Young, George M., "Fyodorov in Baker Library: II. The Bibliography." In: Dartmouth College Library Bulletin, 17, 1977, 1, S. 74-88.

- ZaKYDAlsKY, TARAS D., "Fyodorov in Baker Library: II. The Bibliography; an Addendum." In: Dartmouth College Library Bulletin, 17, 1977, 2, S. 16-19.

- Zernov, Nikolas, Russkie pisateli èmigracii: biografizeskie svedenija i bibliografija ich knig po bogosloviju, religioznoj filosofii, cerkomoj istonii i pravoslavnoj kul'ture 1921-1972, Boston, Mass. 1973.

- Žrtomirskaja, S.V. (Hg.), Vospominanija i dnevniki XVII-XX wv. Ukazatel' nukopisej. M. 1976.

\section{SCHRIFTEN VON N.F. FEDOROV}

"Skazanie o postroenii obydennogo chrama v Vologde 'vo izbavlenie ot smertonosnyja jazvy'." [Datiert: sentjabr' 1893 g.] In: Čtenija v Imperatorskom obštestve istorii i drevnostej rossijskich pri Moskovskom universitele $1893 \mathrm{god}$, kn. 3 (166), M. 1893, S. III-X.

"Dolg avtorov po otnoß̌eniju k publixnym bibliotekam." In: Russkie Vedomosti, 1896, 244.

"Pis'mo N.F. Fedorova k redaktoru gazety 'Don' po povodu pis'ma F.M. Dostoevskogo k N.P. Petersonu ob uzenii N.F. Fedorova." [Datiert: 11.7.1897] In: Don, [Voronež] 1897, 80. - Wiederabdr. in: Vselenskoe delo, 1, Odessa 1914, S. 24-30, und in: Sever, 1989, 2, S. 115-118.

"Cemu naucaet drevnejצij christianskij pamjatnik v Kitae? Po povodu stat'i S.S. Sluckogo 'Drevnejకij christianskij pamjatnik v Kitae' ('Russkij Vestnik' 1901 g. No. 1)." In: Russkij Archiv, 1901, 4, S. 631637. - Wiederabdr. in: Izv.Jur.Fak., 3, 1926, S. 223-229.

"Astronomija i architektura." In: Vesy, 1 (1904), 2, S. $20-24$.

"O pis'menach. Posmertnaja stat'ja." In: Vesy, 1 (1904), 6, S. 1-5.

Filosofija obšcego dela. Stat'i, mysli i pis'ma Nikolaja Fedonovica Fedonova, izdannye pod redakciej VA. Kotevnikova i N.P. Petersona. T. 1, Vernyj, 1906. - Nachdruck: Westmead, Famborough, Hants. 1970. Lausanne 1985.

"Zolotye slova." In: Novoe Vino, 2, 1913, S. 14.

Filosofija obšcego dela. Stati, mysli i pis'ma Nikolaja Fedorovita Fedorova, izdannye pod redakciej V.A. Koteunikova i N.P. Petersona. T. 2, M. 1913. - Nachdruck: Westmead, Farnborough, Hants. 1970. Lausanne 1985.

"O bol'nice." In: Vselenskoe delo, 1, Odessa 1914, S. $97 \mathrm{f}$.

"Gramota Carej Ioanna i Petra Alekseevizej Permskomu Voevode Stol'niku Ivanu Savinoviž Cjubarovu. S rukopisi N.F. Fedorova." In: Russkij Archiv, 1915, 11-12, S. 282-295.

"Bytie krestnogo syna." [Einleitung und Abschrift] In: Russkij Archiv, 1915, 11-12, S. 296-303.

Filosofija obsčego dela. Stat'i, mysli i pis'ma Nikolaja Fedonoviza Fedorova, izdannye pod redakciej $V A$. Kotemikova i N.P. Petersona. Izdanie vtoroe. T. I, vyp. 1, s portretom N.F. Fedorova i priloženiem biografizeskogo ožerka, sostavlennogo A. Ostromirovym, Charbin 1928. T. I, vyp. 2, Charbin 1929. T. I, vyp. 3, Charbin 1930.

"Iz perepiski N.F. Fedorova s V A. Koževnikovym o Turkestane." In: Versty, 3, 1928, S. 278-288.

"Iz tret'ego toma 'Filosofii obstego dela'." In: Put', 10, 1928, S. 3-42.

"Pis'ma N.F. Fedorova k VA. Koževnikovu." In: Evrazuja, 24, 4.5.1929, S. 7f.

"Iz posmertnych rukopisej N.F. Fedorova." In: Put', 18, 1929, S. 3-24. 
"C'to takoe dobro?" In: Put', 40, 1933, S. 3-15.

"Iz perepiski s N.P. Petersonom i V A. Koževnikovym." In: Vselenskoe delo, 2, Riga 1934, S. 149-155.

The Question of Brotherhood or Relatedness, and the Reasons for the Unbrotherly, Dis-Related, or Unpeaceful State of the World, and the Means for the Restoration of Relatedness." [Auszug aus FOD I, S. 2-32; gekürzt] In: J.M. EDIE u.a. (Hgg.), Russian Philosophy, vol. 3, Chicago 1965, S. 1654. [Übers. Ashleigh E. Moorhouse, George L. Kline]

"Supramoralizm ih vseobsxij sintez." [Auszug aus FOD I, S. 399-420; gekürzt] In: S.L. FRANK, Iz isto nii nusskoj filosofskoj mysli konca XIX i nacala XX veka. Antologija. Washington, New York 1965, $S$. 51-61. - Dass. [ital.] "Il supramoralismo, ossia la sintesi universale." In: S.L. FraNK, Il pensiero religioso russo. Da Tolstoj a Losskij. Antologia. Milano 1977, S. 53-65. (= Filosofia e scienze umane; 15). [Übers. Pietro Modesto]

The Restoration of Kinship Among Mankind." [Auszüge aus FOD I] In: A. SCHMEMANN, Ulimare Questions. An Anthology of Modem Russian Religious Thought. London, Oxford 1977, S. 175-223. [Übers. Ashleigh E. Moorhouse]

"'Faust' Gete i narodnaja legenda o Fauste." In: Kontekst 1975, M. 1977, S. 315-336.

"Filosofija obšcego dela." [Auszüge aus FOD I und II] In: Vecnoe solnce. Russkaja social'naja utopija i nautnaja fantastika vtoroj poloviny XIX - nacala XX veka. M. 1979, S. 390-398.

"La filosofia dell'opere comune." [Auszüge aus FOD I, S. 2-106; stark gekürzt] In: Occidente, cristianesimo e progresso. Antologia dagli scritti di C. Leont'ev e N. Fedorov. A cura di G. Riconda e N. Bosco. Torino 1981, S. 93-157. (= Collana di studi filosofici). [Übers. Maria Cristina Mignatti, Gian Paolo Marello]

"Proektivnoe opredelenie literatury o 'Mertvych duSach'." In: Literatumaja UCeba, 1982, 3, S. 163 167.

Soxinenija, M. 1982. ( = Filosofskoe nasledie; 85). - Nachdruck USA o.J.

[Iz soxinenij] In: Sovetskaja Rossija, 131 (7882), 6.6.1982, S. 4.

"Parents and Resurrectors." [FOD II, S. 273r.] In: Irish Slavonic Studies, 4 (1983), S. 109-111. [Übers. Marilyn Minto]

"Ni egoizm, ni al'truizm, a rodstvo!" [FOD II, S. 201] "Živoe i mertvoe vosprijatie istorii." [FOD II, S. 211f.] "I7. poslednich rukopiscj N.F. Fedorova." [Put', 18, 1929, S. 14-17]. In: Sever, 1989, 2, S. $118 f$.

\section{Die Sammelbãnde "VSElensKoe Delon", 1 (1914), 2 (1934)}

Vselenskoe delo, ryp. 1 [auf dem Umschlag: sbornik 1], Odessa 1914

- [Gorski, Aleksandr Konstantinovic], "Ot redakcii." S. VII-XII. Brichiniét, lona [Pantelejmonovié], "Delo lisusa. (Nad Evangeliem)." S. 1-22. Gornostaev, A. [d.i. Gorsku, Aleksandr Konstantinovic], "Odno." [Gedicht], S. 23.

- [Fedorov, Nikola FedoroviC], "Pis'mo N.F. Fedorova $k$ redaktoru gazety 'Don' po povodu pis'ma F.M. Dostoevskogo k N.P. Petersonu ob utenii N.F. Fedorova." S. 24-30.

[Dostoevsku, Fedor Michajlovic], "Pis'mo F.M. Dostoevskogo k N.P. Petersonu." S. 30f.

- Borodaevsku, Valerian [Valerianovic], "Pamjati N.F. Fedorova." [Gedicht] S. 32.

- Sorokin, Anton [SemenoviC], "I plakal v tot den' Satana. (Pamjati N.F. Fedorova)." S. 33 f.

NEDZVECKIJ, V.K., "Misticizm ili realizm?" S. 35-41.

KedroV, Vladimir, "Syn Celovereskij." [Gedichit] S. 42.

PanKRatov, A[LEKSANDR SAVVIC], "Žizn' ne prekrašaetsja." S. $43 f$.

Gornostaev, A. [d.i. Gorski, Aleksandr KonstantinoviC], "A.S. Pankratovu." [Gedicht] S. 45. 
Gorbunov-Posadov, I[VAN] I[VANOVIC], "Čto ja dumaju o voskrešenii. (Pis'mo k redaktoram sbornika 'Vselenskoe delo')." S. 46f.

Brichin'ev, IONA [PANTElejmonovic], "L'vu Nikolaevitu Tolstomu. (1908-1913 g.)." [Gedicht] S. 48.

Brussov, Valeru [Jakovlevic], "O smerti, voskresenii i voskreSenii. (Pis'mo v otvet na vopros)." S. 49f.

Stolica, Lubov' [Nikminca], "Iz ciklov 'Strastnye pesni' i 'Dobryj Pastyr"." [Gedichte] S. 51-58. BACHMET'EV, P[ORFIRU IVANOViC], "Sedališce duši. (Anabioz)." S. 59-85.

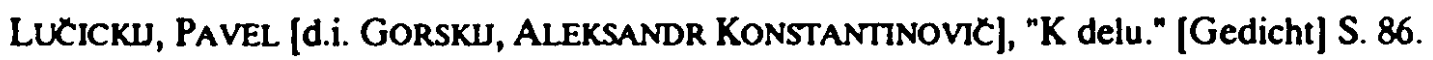

BACHMET'EV, P[ORFIRU] I[VANOVIC], "K biografii P.I. Bachmet'eva." S. 89-91.

Gornostaev, A. [d.i. Gorsku, Aleksandr Konstantinovic], "Novoe nebo. Pamjati P.I. Bachmet'eva." [Gedicht] S. 92-94.

- Fedorov, N[ikolas FedoroviC], "lz perepiski N.F. Fedorova. O bol'nice." S. $97 f$.

LuCENKo, I.M., "Predely žizni. (Cholod i ego viijanie na žizn')." S. 99-104.

Kogan, Fejga [Izrailevina], "Vremeni net." S. 105f.

Gornostaev, A. [d.i. GorskiJ, Aleksandr Konstanttnovic], "Prentis Mjul'ford." [Gedicht] S. 107.

VUL'F, M.[V.], "O strache smerti, idee bessmertija i samoubijstve. (Psichoanalitixeskij eskiz)." S. 108-116.

LUKicku, Pavel [d.i. Gorski, Aleksandr Konstantinovic], "Uchodjašim ot žizni." [Gedicht] S. 117.

MANnovsku, R., "Meterlink o smerti." S. 118-128.

Gornostaev, A. [d.i. GoRsku, AleksandR Konstantinovic], "Vladimiru Solov'evu." [Gedicht] S. 129 .

VODLINGER, APOLLON, "Kogda my mertvye voskresnem?" S. 131-138.

VOSTOKOV, OLEG, [Gedicht ohne Titel] S. 139.

- Gornostaev, A. [d.i. Gorsku, Aleksandr Konstantinovic], "Tjaga zemnaja." S. 140-207.

BrichniCev, Iona [PantelejmonoviC], "V. Chludovu." [Gedicht] S. 208.

Chludov, Vasilus [Aleksandrovic], "Čemu učil Iisus Christos. Carstvie božie." [Prilož.] S. 324.

ANon., "K stat'e Cemu użil Christos." [Prilož.] S. 25f.

NeDzVECKI, V.[K.], "Sv. Grigorij Nisskij o voskresenii tela." [Prilož.] S. 27-30.

NedzVECKu, V.[K.], "Metèmpsichoza." [Prilož.] S. 31-42.

Vselenskoe delo, sbornik 2, Riga 1934

- ANON., "Ot redakcii." S. I-IV.

- Nesmelov [d.i. Mitropol'sku], ARSENu [IVANovic], "Pered poslednim boem." [Gedicht zum 30. Todestag N.F. Fedorovs] S. 3-6.

LUCICKU, PAVEL [d.i. GoRSKI, AleKSANDR KonstaNTINOVIC], "Zakljatie ognej." [Gedicht] S. 79.

Gornostaev, A. [d.i. Gorski, Aleksandr KonstantinoviC], "Pustynja." [Gedicht] S. 10.

GeZelunsku, G.G. [d.i. SetNiCKI, Nikola AleksandroviC], "Christoljubie i vojna." S. 13-27.

- Kononov, D.S. [d.i. SETNICKu, Nikolad AleksandRoviC], "Evrazijstvo i porevoljucionniki." S. 28-43.

- CCifeidze, K[onstantin Aleksandrovic], "Problema ideokratii." S. 4460.

Aleksandrov, Vladislav, "Religija i nauka." S. 61-69. 
- Manovsku, Rafail [K.] [Setnicku, Nikolas Aleksandrovic ?], "Messianstvo i 'Russkaja Ideja'." S. 70-99.

- Cuev, S[ergeu Ivanovic], "Celovek i priroda." S. 100-104.

- Zet. [d.i. Setnicku, Nikola Aleksandrovic]], "'Vselenskoe delo' v prošlom." S. 107-115.

- MuRav'Ev, Valerian [NikolaeviC], "Vseobకtaja proizvoditel'naja matematika." S. 116-140. S[ETNIC]KIJ, N[IKOLA]] A[LEKSANDROVIC], "O smerti i pogrebenii." S. 141-146.

- Solov'ev, V[LAdimir] S[ERgeEviC], "Pis'mo k K.N. Leont'evu (1884 god)." S. 147f.

- Fedorov, N[IKOLAJ] F[edorovic], "Iz perepiski s N.P. Petersonom i VA. Koževnikovym." S. 149-155.

- IVakin, I[VAN] M[IChallovic], "Pis'mo k L.N. Tolstomu o doždevanii i knižnom obmene." S. 156-159.

- Peterson, N[ikolaj] P[avlovic], "Pis'mo k N.A. Caevu o N.F. Fedorove." S. 160 .

- Ustrualov, N[IKolaj] V[asil'evic], "Iz pis'ma." S. 162-166.

- D-A, O., "Fedoroviana Prahensia." S. 176f.

- TR-v, N.N., "Zametki po povodu materialov k 'Brat'jam Karamazovym'." S. 169-175.

- G-V., A. [d.i. GorskiJ, AleksandR Konstantinovic], "Vladimir Aleksandrovič Koževnikov." S. $178 f$.

- P-s., M. [d.i. Peterson, Michall Nikolaevic], "Nikolaj Pavlovið Peterson." S. 179-181.

- G.G.G. [SEtnickiJ, Nixolaj Aleksandrovic ?], "Valerian Nikolaeviz Murav'ev." S. 181f.

- M-C., N. [d.i. Mironovic, NAdežda P.], "Vera Nikandrovna Kuznecova (Mironovic)." S. 182f.

- Ez., [Nachrufe auf V.N. Čekrygin, V A. Brjusov, Valerian Borodaevskij, Iona Brichničev, M.N. Pokrovskij, B.I. Smankevið] S. 183 f.

- Kozodoev, I. [d.i. Setnicki, Nikolaj Aleksandrovic], "Bibliografija Filosofii Obక̌̌̌ego Dela." S. 185-187.

- K-v., I. [d.i. SetNicku, Nikolas AleksandRovic], "1828-1903-1928 g.g. Filosofija Obšego Dela. Stat'i, mysli i pis'ma Nikolaja Fedoroviza Fedorova, izdannye pod redakciej VA. Koževnikova i N.P. Petersona, t. 1, v. 1, s portretom N.F. Fedorova i s A. Ostromirovym [sic], izd. II, s. XX-38, 1928 g. Tože, t. 1, v. 2, s. 75, 1929 g. Tože, t. 1, v. 3, s. 102, 1930 g." [Rezension] S. 188.

- Tretčlikov, N.[G.], "Novye publikacii proizvedenij N.F. Fedorova." S. 189-194.

- K-V., I. [d.i. SETNICKU, NikOla AleKSANDROVIC], "A. Ostromirov. Nikolaj Fedoroviz Fedorov i Sovremennost'.' Vyp. 1. Biografija N.F. Fedorova, str. 16, 1928 g. Tože, vyp. 2-j. Proektivizm i bor'ba so smert'ju, str. 51, izd. 1928 g. Tože, vyp. 3-j. Organizacija mirovozdejstvija, str. $40.1932 \mathrm{~g}$. Tože, vyp. 4-j. Ostrie mirovogo krizisa, str. 51, 1933 g." [Rezension] S. 194-196.

- Žel'. [d.i. SETNICKU, Nikola AleksandroviC], "A.K. Gornostaev. Pered licom smerti (L.N. Tolstoj i N.F. Fedorov). str. 18, 1928 g. A.K. Gornostaev. Raj na zemle (F.M. Dostoevskij i N.F. Fedorov) izd. 1929 g. str. 87." [Rezension] S. 196-198.

- Miroluubov, A[NaTolu], 'Smertobožničstvo. Koren' eresej, razdelenij i izvrašenij istinnogo u飞enija Cerkvi. Dogmatiðeskie oxerki, z. 1. Bor'ba slovom. 1926 g. str. 81. (Avtor ne ukazan)." [Rezension] S. 198-200.

- Obuchov, V[asilu KonstantinoviC], "N.A. Setnickij. KapitalistiZeskij stroj v izobraženii N.F. Fedorova. Otdel'nyj ottisk iz 3-go toma Izvestij Juridireskogo Fakul'teta v Charbine. Str. 47. 1926 g. Ego ze, Eksploatacija. Orerk; iz V-go toma. Str. 45. 1928 g. Ego že, 'SSSR, Kitaj i Japonija' (Nacal'nye puti reguljacii). Orerki; iz X toma. Str. 61. 1933 g." [Rezension] S. 201-203.

Kalouskova, JA., "G.G. Geželinskij. Zametki ob iskusstve." [Rezension] S. 203-205. 


\section{V. ÜBRIGE LTTERATUR}

- ANON., [Nachricht vom Tode N.F. Fedorovs]. In: Moskovskie Vedomosti, 344, 16.12.1903, S. 3.

- ANON., "N.F. Fedorov (Nekrolog)." In: Russkie Vedomosti, 346, 17.12.1903, S. 4.

- ANON., "Pochorony N.F. Fedorova." In: Moskouskie Vedomosti, 346, 18.12.1903, S. 3.

- ANON., "Ideal'nyj bibliotekar'." In: Novoe Vremja, 12438, 27.10.(9.11.)1910, S. 4.

- ANON., "Ideja vseobక̌̌ego spasenuja ot smerti." In: Bjulleteni Literatury i Žizni, 7, 1912 (dekabr'), S. 301-308; 12, 1914 (fevral'), S. 687-692.

ANON., [Bericht über ein Experiment zur Anabiose]. In: Nov', 22, 8.2.1914.

ANON., "Michail (Pavel Vasil'evic Semenov)." [Lexikonartikel] In: Novyj énciklopediceskij slovar, t. 26, Pg. OJ. [ca. 1916], S. 729.

ANON., "Vol'naja filosofskaja associacija." In: Kniga i Revoljucija, 1920, 2, S. $91 f$.

ANON., "Delo 'taktikeskogo centra'." In: Izvestija VCIK, 185, 22.8.1920, S. 4.

ANON., "Vol'fila." In: Russkaja Kniga, 1921, 1, S. 14.

ANON., "V.N. Cekrygin. Nekrolog." In: Makovec, 1922, 2, S. $3 f$.

Anon., "Vol'naja Akademija Duchovnoj Kul'tury v Moskve." In: Sofija. Problemy duchovnoj kul'tury i religioznoj filosofii. Pod red. N.A. Berdjaeva. Berlin 1923, S. $135 f$.

ANON., Evrazijstwo. (Opyt sistematizeskogo izlotenija). Paris 1926.

- ANon., "Pis'ma iz Rossii." In: Evrazija, 3, 8.12.1928, S. 8.

- ANon., "Ot redakcii." In: Eurazija, 3, 8.12.1928, S. 8.

- ANON., "Ot redakcii." In: Evrazija, 7, 5.1.1929, S. 8.

- ANON., "Put' evrazijstva." In: Evrazija, 8, 12.1.1929, S. 1.

- ANON., "Ot redakcii." In: Evrazija, 10, 26.1.1929, S. 1.

- ANON., "Problema idcokratii. 4. Demokratija i progress." In: Evmazija, 15, 2.3.1929, S. 1.

- ANon., "Pis'mo iz Rossii." In: Evrazija, 22, 20.4.1929, S. 6 f.

- ANon., "Po povodu pisem N.F. Fedorova." In: Eurazija, 24, 4.5.1929, S. $2-4$.

- ANON., "Ot neobchodimosti - k svobode." In: Evrazija, 33, 10.8.1929, S. 1 .

ANON., "Ot redakcii." In: Utverzdenija, 1, 1931, S. 3-8.

ANon., Evrazijstro. Deklaracija, formulirovka, tezisy. Prag 1932.

ANON., Evrazijstuo i kommunizm, 0.O. 0.J. [ca. 1932].

- ANON., "Fedorov, Nik. Fedor." [Lexikonartikel] In: Ottưv. Slovnik naucný. Nové doby. Dodatky, Bd. II,1, Praha 1932, S. 518.

- AnON., Tridesetogodišnjica smrti N.F. Fedorova." In: Suetosavlje. Ongan studenata pravoslavnog bogoslovskog fakulteta u Beogradu. 3-5, 1933, S. 199.

- ANON., "Nikolaj Fedorovið Fedorov. (1828-1903). (Žizn' i uðenie)." In: Vestmik RSChD, 1933, 5-6, S. 17-23.

- ANon., Nikolaj Fedorovi飞 Fedorov. Uzenie." In: Vestnik RSChD, 1933, 7-8, S. 11-15; 9-10, S. 1622; 11-12, S. 15-21.

- ANON., "Duchovnyj front." In: Novyj Grad, 10, 1935, S. 132-138. [Fedorov S. 135, 136]

- ANON., "Fiontorōf, F. Nikolai." [Lexikonartikel] In: Thrëskeurikē kai Ëthikē Enkyklopaideia, 11, Athēnai 1967, Sp. 1165f.

- ANon., "Fyodorov." In: The Listener, London, 84, No. 2176, 10.12.1970, S. 813. ANON., "'I vojsko pesen povedu..."' In: Literatumaja Gazela, 46, 12.11.1975, S. 7.

- ANON., "Fedorov, Nikolaj Fedorovic." [Lexikonartikel] In: BSE, tret'e izd., t. 27, M. 1977, S. 260.

- ANon., "O filosofii N. Fedorova." In: Russkaja Zien', San Francisco, 24.1.1978.

ANON., "... Zemlju vsju, do poslednego atoma." In: Sovetskaja Kul'rura, 26 (5138), 28.3.1978, S. 5. 
- ANON., "Fedorov, Nikolaj Fedorovix." [Lexikonartikel] In: Filosofskij enciklopedixeskij slovar, M. 1983, S. 715.

- ANON., "Fedorov, Nikolaj Fedorovit." [Lexikonartikel] In: AteistiZeskij slovar, M. 1983, S. 504. ANON., "O Rodine - vdali ot nee." In: Golos Rodiny, 1987, 31, S. 8 f.

ANON., "Perspektivnyj plan izdanija trudov po otecestvennoj istorii, vidnych russkich i sovetskich filosofov, ekonomistov i juristov, dlitel'noe vremja ne izdavavSichsja v našej strane." In: Knižnoe Obozrenie, 38, 23.9.1988, S. 7-10.

A.B., "Evrazijcy i Trest." In: Vozrozdenie, 30, 1953, S. 117-127.

- A.G., "Mudrejsij iz mudrych. Doklad g. Satovskogo-Rževskogo o N.F. Fedorove v 'Čuraevke'." In: Zarja. Ezenedel'naja demokraticeskaja gazeta. Charbin, 125, 11.5.1933, S. 2.

A.K., siehe GorsKu, A.K.

A.M., steht für Anatolij Sergeevið Mel'nikov, d.i. archiepiskop Antonij; siehe [wirkl. Verfasser] GAVRUUSIN, N.K.

- ADLER, A.S., "N.F. Fedorov (1828-1928)." In: Evnazijskaja chronika. Pod red. P.N. Savickogo. Vyp. 10, Paris 1928, S. 101f.

Agapov, Boris NikolaEvic, "Wo sind Sie, Blom?" In: Sowjetische Erzählungen heute, München 1979, S. 235-249.

AgIENKo, O. [ALEKSANDR], Vil'nij reatr, M. 1917.

Agienko, A[LeksandR], "Iz našej letopisi." In: Biokosmist, 1, 1922, S. 2 f.

AgIENXo, A., "Solnęnoe zatmenie 19 ijunja 1936 g." In: Antireligioznik, 11 (1936), 3, S. $42-45$.

- AgURSku, MichaIl [SAMuIloviC], Ideologija nacional-bol'Sevizma, Paris 1980. [Fedorow S. 29f., 75]

AgURSku, M[ıchail SAmulonic], "Perepiska I. Ležneva i N. Ustrjalova." In: Slavica Hierosolymitana, 5-6, 1981, S. 543-589.

- [Agursku, Michiall Samullovic] Agursky, Miksuil, The Attitude to Religion in the New Russian Literature." In: Religion in Communist Lands, 10 (1982), 2, S. 145-155. - Dass. [ital.] "L'atteggiamento della nuova letteratura russa verso la religione." In: Rivista del Centro Studi Russia Cristiana, 8 (1983), 2, S. 3-15.

[AgURSKu, MichaIl SAMUIovic], AgURSKY, MikhaIL, "Stalin's Ecclesiastical Background." In: Survey, 28 (1984), 4 (123), S. 1-14.

[Agursku, Michall SAmulovic], Agursky, Mikhail, "Defeat as Victory and the Living Death: The Case of Ustrialov." In: History of European Ideas, 5 (1984), 2, S. 165-180.

[AgURSKU, MichaIl SAMUILovic], AGURSKY, MikHall, The Third Rome. National Bolshevism in the USSR. Boulder, London 1987.

AgURSKu, M[ICHAIl SAmUILOVIC], "U istokov nacional-bol'Sevizma." In: Minuusee. Istoriceskij al'manach. 4, Paris 1987, S. 140-165.

- [Aksenov, GenNadu] Axuonow, GenNadi, "Russische Raumfahrtpropheten." In: Sowjetunion heuse, 28 (1983), 2, S. 41 .

AKsenov, G.P., "Živoe vešlestvo: meždu veľnost'ju i vremenem." In: Prometej, 15, M. 1988, S. 202-220.

AKsenov, I.S., "Velemir Chlebnikov. Otryvok iz dosok sud'by. M. 1923." [Rezension] In: Pe`ar' i Rewoljucija, 1923, 5, S. $277-279$.

Aleksandrov, A., siehe KISELEV, A.N.

- Alexsandrova, V., "Neobyčnyj myslitel'." In: Leninec, 3, 2.2.1978, S. 4; 4, 9.2.1978, S. 4.

ALEKSEEV, A[LEKSANDR] A[LEKSEEVIC], "Vospominanija artista imperatorskich teatrov. ¿. IX XI." In: Istoriceskij Vestmik, 49, 1892, S. 94-117.

ALEKSEEV, I[VAN IVANOVIC], "Kraevednaja konferencija v Bogorodske, Moskovskoj gub." In: Kraevedenie, 5 (1928), 2, S. $108 f$. 
Alekseev, I[VAn IVANovic], "Maksim Gor'kij o kraevedenii. (Moja perepiska s A.M. Gor'kim)." In: Sovetskoe Kraevedenie, 1936, 8, S. 4-8.

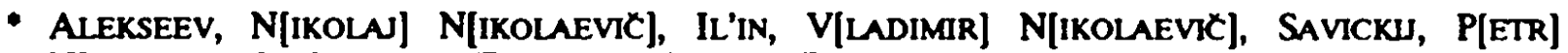
N[IKOLAEviC], $O$ gazele "Evrazija". (Gazela "Evrazija" ne est' evrazijskij organ). Paris 1929. [Fedorov S. 3, 5f., 17f., 23, 25, 30]

- AlEKSEEV, N[IKolas] N[IKolaEVIC], "Svoboda, ravenstvo i bratstvo." In: Tret'ja Rossija, 3, 1933, S. 31-36.

- [Alekseev, Nikolas NikolaeviC], Alexejew, N., "Geschichte und heutiger Zustand der eurasischen Bewegung." In: Orient und Occident, 17, 1934, S. 1-6.

[Alekseev, Nikola Nikolaevic], Alexejew, N., "Die geistigen Voraussetzungen der eurasischen Kultur." In: Orient und Occident, 17, 1934, S. 20-30. - Dass. [russ.] "Duchovnye predposylki evrazijskoj kul'tury." In: Evrazijskaja chronika, vyp. 11, Berlin 1935, S. 13-28.

- Alekseev, N[IKolan] N[IKolaevic], Puti i sud'by marksizma. Or Marksa i Éngel'sa $k$ Leninu $i$ Stalinu. O.O. [Berlin] 1936. [Fedorov S. 87]

* Alekseev, N[IKola NikolaEviC], "Priroda i Celovek v filosofskich vozzrenijach russkoj literatury." In: Grani, 42, 1959, S. 187-204.

ALEKSEEV, P.V., Revoljucija i naučnaja intelligencıja, M. 1987.

Alexseev, V., "Moskovskie propovedniki." In: Novyj Zumal, 121, 1975, S. 200-210.

- AL'Fonsov, VA., "Čtoby slovo smelo poslo za živopis'ju'. (V. Chlebnikov i živopis')." In: Literatura i Zivopis', L. 1982, S. 205-226.

- Allain, Louss, Dostoievski el Dieu. La morsure du divin. Lille 1981. [Fedorov S. 37, 44-47] Almanach de St.-Peiersbourg 1912.

- Altausku, Konstantin [d.i. Korolevv, Konstantin NikolaeviC], "Moskouskaja junost' Ciolkovskogo." In: Moskva, 1966, 9, S. 176-192. [Kap. "Neobyknovennyj bibliotekar'," S. 180-182]. Wiederabdr. in: DERS., Ciolkovskaj rasskazyvaet, M. 1967, S. 223-229.

AMuINSKU, I.E., "Nautnyj traktat o teloveteskoj prirode i sredstvach izmenit' ee." [Nachwort zu] I.I. MECNIKOV, Etjudy optimizma, M. 1964, S. 294-333.

[ANCIFERov], N[IKolA] P[AvloviC], "Epizod iz istorii Solovkov." In: Pamjat'. Istoriceskij sbor. nik. 1, New York 1978, S. 331-336.

ANCIFEROV, N[IKOLA] P[AVLOVIC], "Tri glavy iz vospominanij." In: Pamjat'. Istoriceskij sbomik. 4, Paris 1981, S. 57-110.

ANDREEV [-BOGDANOV], ANDREJ, Neonigilizm, M. 1922.

ANDREEV [d.i. ANDREEVSKU], I[VAN] M[ICHAJLOVIC], Kratkaj obzor istonii nusskoj cerkvi or revoljucii do nasich dnej, Jordanville, N.Y. 1951.

ANDREEVSKU, E.S., "Zapiski." In: Iz archiva KE. Andreevskogo. T. 1, Odessa 1913.

ANDREEVSKU, S[ERGEJ] A[RKAD'EVIC], Kniga o smerti, Reval, Berlin 1922.

- Anelus, Irving H., "A. Teskey, Platonov and Fyodorov: The Influence of Christian Philosophy on a Soviet Writer, Amersham 1982." [Rezension] In: Studies in Soviet Thought, 27 (1984), S. 52 60.

ANIST, V., "Dviženija biokosmizma." In: Biokosmist, 1, 1922, S. $6 f$.

- ANTTPov, GA., "Fenomen prošlogo i fenomen reloveka v učenii N.F. Fedorova." In: Istorija filosofii i sovremennaja ideologiceskaja bor'ba, Novosibirsk 1981, S. 151-163.

Antologija poczii Dal'nego Vostoka, Chabarovsk 1967.

- ANTonov, SERgej, "Ot pervogo lica... (Rasskazy o pisateljach, knigach i slovach)." In: Noyyj Mir, 1972, 11, S. 253-270. [Fedorov S. 268]

ANUFRIEV, JU.E., "Russkaja religioznaja filosofija konca XIX - nałala XX v. i sovremennaja ideologiceskaja bor'ba." In: Social'na-politiceskie reorii sovnemennoj burtuaznoj ideologii. (Kriticeskij analiz). M. 1981, S. 262-293.

- APENCENKo, Ju., "Obitaemyj kosmos." In: Zvezda, 1982, 8, S. 129-160. [Fedorov S. 131f.] 
- ARChangel'sku, M.E., "Maleviz, dejstvitel'nost' i kul'tura. (O filosofii suprematizma)." In: Gnozis, 1978, 3-4, S. 32-69. [Fedorov S. 32, 41-47]

- Archiv A.M. Gorkogo. T. 11 [Perepiska A.M. Gor'kogo s I.A. Gruzdevym], M. 1966. T. 12 [M. Gor'kij, Chudožestrennye proizvedenija. Stat'i i zametki], M. 1969.

AREnzon, E., "K ponimaniju Chlebnikova: nauka i poezija." In: Voprosy Literatury, 1985, 10, S. 163-169.

A[RKA]N, ARK[ADU] [d.i. ANEKSTEJN, A.I.], "Social'nye utopii." In: A. A[RKA]N [ANEKSTEJN], E. Kol'MAN (Hgg.), Żizn'i technika buduscego. (Social'nye i naucno-techniceskie utopii). M.-L. 1928, S. 7-174.

- Arlazorov, Michail Saulovic, Ciolkovskij, M. ${ }^{2}$ 1963. [Fedorov S. 25f.]

- [ARsen'ev, Nikola Sergeevily ARSEniew, Nicolas von, Die russische Literatur der Neuzeit und Gegenwant in ihren geistigen Zusammenhängen, Mainz 1929. [Fedorov S. 358, 360-363]

- [ARSEN'Ev, Nikolas SERGEeviC] ARSENIEw, Nikolaus von, Das heilige Moskau. Bilder aus dem religiösen und geistigen Leben des 19. Jahrhunderts. Paderborn 1940. [Koževnikov, Fedorov S. 189, 211-218] - Dass. [franz.] La Sainte Moscou. Tableau de la vie religieuse et intellectuelle russe au $X I X^{e}$ siecle. Paris 1948.

ARSEN'Ev, N[IKOLA] S[ERGEeVic]], "Iz junosti." In: Vozrozdenie, 18, 1951, S. 796.

ARSEN'EV, N[IKOLA]] S[ERGEEVIC], Iz nusskoj kul'tumoj i tworteskoj tradicii, Frankfurt/M. 1959.

ARSEN'EV, Nikolas [SERgeevic], "A.S. Chomjakov i VA. Koževnikov." In: Vozrożdenie, 216, 1970, S. 35-55. - Wiederabdr. in: DERS., Dary i vstreti tiznennogo puti, Frankfurt/M. 1974.

- [ARSen'ev, Nikolas SergeeviC] ARseniew, Nikolaus v., "Der gottliche Logos in der russischen Religionsphilosophie." In: Kyrios, 14 (1974), S. 129-137.

- ARSEN'EV, NikOLA [SERGEeVIC], "O nekotorych osnownych temach russkoj religioznoj mysli 19go veka." In: N.P. POLTORACKU (Hg.), Russkaja religiozno-filosofskaja mysl' XX veka. Sb. statej. Pittsburgh, Pa. 1975, S. 18-36.

An et potsie nusses 1900-1930. Textes choisis. Paris 1979.

- [ARTem'ev] ARTemev, Mkhall [Pseud.], "Unterirdische Literatur im heutigen RuBland." In: Orient und Occident, 7, 1931, S. 10-20.

- Asnaghi, Adolfo, Storia ed escatologia del pensiero russo, Genova 1973. ( = Critica; 1). [Fedorov S. 133-138]

AVRKCH, PAUL, The Russian Anarchists, Princeton, NJ. 1967.

AZADOVSKU, K[ONSTANTIN] M[ARKOVIC], "Rannee tvorלestvo NA. Kljueva. (Noyye materialy)." In: Russkaja Literatura, 1975, 3, S. 191-212.

AzAdovsKu, K[ONSTANTIN] M[ARKovic], "Blok i A.M. Dobroljubov." In: Tezisy I vsesojuznoj (III) konferencii "Tvortestwo A A. Blaka i nusskaja kul'tura XX veka", Tartu 1975, S. 96-102.

Azadovsku, K[ONSTANTIN MARKoviC], "NA. KJjuev i 'Cech poetov'." In: Voprosy Literatury, 1987,4, S. $269-278$.

AZADOVSKI, K[ONSTANTIN] M[ARKOVIC], "Pis'ma N.A. Kljueva k Bloku. Vstupitel'naja stat'ja..." In: Literatumoe nasledstwo, t. 92 [Aleksandr Blok. Novye materialy i issledovanija], kn. 4, M. 1987, S. $427-462$.

B., AlEkSEJ OT[EC], "'Az esm' chleb Životnyj'." In: Put', 42, 1934, S. 68-79.

- BabaEv, Eduard Girgor'Evic, Tolstoj i kniga, M. 1979. [Fedorov S. 200-207, 221]

Babkov, V.V., "Meždu naukoj i poeziej: 'metabioz' Velimira Chlebnikova." In: Voprosy Istorii Estestwoznanija i Techniki, 1987, 2, S. 136-147.

BAILES, Kendall E., "Aleksej Gastev and the Soviet Controversy over Taylorism, 1918-24." In: Soviet Strudies, 29 (1977), 3, S. 373-394.

BALES, Kendall E., "Science, Philosophy and Politics in Soviet History. The Case of Vladimir Vernadskii." In: Russian Review, 40, 1981, S. 278-299. 
BaILes, Kendall E., "Soviet Science in the Stalin Period: The Case of V.I. Vernadskii and his Scientific School, 1928-1945." In: Slavic Review, 45 (1986), 1, S. 20-37.

BAKUSINSKU, A[NATOLU VASIL'EVIC], "V puti k velikomu iskusstvu." In: Żizn'. Ezemesjąnyj literatumo-chudožestvennyj i naučno-populjamyj zumal. 1922, 3, S. 132-135.

BAKUSINSKu, A[NATOLu VasiL'EVIC], "Vystavka proizvedenij V.N. Čekrygina." In: Russkoe Iskusstwo, 1923, 2-3, S. 15-20.

BALAKSIN, PETr, Final v Kitae. Vozniknovenie, razvitie $i$ isčeznovenie Beloj Emigracii na Dal'nem Vostoke. T. 1, San Francisco 1958.

Balandin, R[UdOL'F] K., "Put' iskanij (polemiceskie zametki)." In: Priroda, 1988, 2, S. 94-98.

- Balandin, Rudol'F [K.], "Nasledie i naslednikj Vernadskogo." In: Druzba Narodov, 1988, 12, S. 169-185.

- Balthasar, Hans Urs von, Apokalypse der deutschen Seele. Studien zu einer Lehre von letzien Haltungen. Bd. 3 [Die Vergöttlichung des Todes], Salzburg, Leipzig 1939. [Fedorov S. 410, 412]

BAMMEL', GR[IGORU KonSTANTINOVIC], "Ob idealistiteskoj filosofii posle Oktjabrja." In: Pod Znamenem Marksizma, 1930, 5, S. 36-55.

- BA-N, M., "Dva bogoiskatelja." In: Novoe Vremja, 12471, 29.11.(12.12.)1910, S. 3.

Baran, Henryk, "Fedor Sologub and the Critics: The Case of Nav'i cary." In: Studies in 20kh Century Russian Prose, Stockholm 1982, S. 26-58. ( = Acta Universitatis Stockholmiensis. Stockholm Studies in Russian Literature; 14).

- Barooshian, Vahan D., Russian Cubo-Futurism 1910 1930. A Study in Avant-Gandism. The Hague, Paris 1974. [Fedorov S. 43, 49, 52, 53]

- Barsukov, Nikola [Platonovic], Zizn' i mudy M.P. Pogodina, kn. 16, SPb. 1902. [Fedorov S. 483]

- Bartenev, Juru [PetroviC], "Pamjati Nikolaja Fedoroviða Fedorova." In: Russkjj Archiv, 42 (1904), 1, S. 191f.

Bartenev, Ju[Ru] P[eTrovic], Pomračennyj ideal, M. 1907.

- B[ARTENEv], P[ETR IVANOviC], [Anmerkung über den Großvater von N.F. Fedorov]. In: Russkij Archiv, 49 (1911), 2, S. 308.

- Bartenev, Sergej [PetroviC], "Nikolaj Fedoroviz Fedorov. Dva razgovora o voskresenii mertvych." In: Russkij Archiv, 47 (1909), 1, S. 119-122.

- Bartenev, S[ergej] P[etrovic], "Iz dnevnika S.P. Barteneva." In: Novyj Zumal, 129, 1977, S. $172-182$.

Barthes, Roland, Mythologies, Paris 1957.

- Basargin, A., "Myslitel'-samorodok." In: Moskouskie Vedomosti, 8, 8.1.1905.

- Basmaxova, Natal'ja [V.], Slovo i obraz. O tvorkeskom mystenii Velimira Chlebnikova. Helsinki 1987. (= Neuvostoliittoinstituutin vuosikirja; 29). [Fedorov S. 24f., 27f., 38, 55-58, 94, 100, 101, 240]

Baumgarten, Franciska, Abeitswissenschaft und Psychosechnik in Rußland, München, Berlin 1924.

BAUMGARTH, CHRISTA, Geschichte des Futurismus, Reinbek 1966.

Bazanov, Vasilu G[RIgor'eVIC], "Poezija Nikolaja Kljueva." In: N. KuJUev, Stichotvorenija i poemy, L. 1977, S. 5-84.

BAzANOV, V[ASILU] G[RIGOR'EVIC], "Oloneckij krest'janin i peterburgskij poet." In: Sever, 1978, 8, S. 93-112; 9, S. 91-110.

- Bazanov, V[asilu] G|RIGoR'EVC], 'Trudnaja biografija." In: Zvezda, 1979, 12, S. 176-188.

BAZANOV, V[AsILU] G[RIGOR'EVIC], "Razruß̌enie legendy." In: Russkaja Literatura, 1980, 3, S. 92 114.

BAZANOV, V[ASILU] G[RIGOR'EVIC], "K tvorČeskim iskanijam Bloka." In: A. Blok i sovremennost', M. 1981, S. 200-226. 
Bazanov, V[asilu] G[RIGoR'evic], "Druz'ja-nedrugi. S. Esenin i N. Kljuev." In: Sever, 1981, 9, S. 95-119.

Bazanov, Vasilu Grigor'eVie, Sergej Esenin i krest'janskaja Rossija, L. 1982.

BAzAROV, V. [d.i. RUdNEv, Vladimir ALEKSANDRoviC], Na dva fronta, SPb. 1910.

BEAUjOUR, ElizABETH KLOSTY, "Architectural Discourse and Early Soviet Literature." In: Journal of the History of Ideas, 44 (1983), 3, S. 477-495.

Bebutov, Garegin Vladimirovic, Majakovskij vstrecaet vek dvadcat' pervyj. Stat'i. Vospominanija. Tbilisi 1984.

[Bechterev, Vladimir Michajlovic] Bechterew, W., "Bechterew über das Pantheon." In: Wochenbericht der Gesellschaft für kulturelle Verbindung der Sowjetunion mit dem Auslande, 2, 14.1.1928, S. 4f.

BEKNEv, S.A., Gipoteza o nervnoj energii $i$ ee znatenie $v$ dele obrazovanija raboxich kollektivov maksimal'noj proizuoditel'nosti truda, M. 1923.

- Belaja, G[Alina] A., "Filosofsko-eticeskaja problematika sovremennoj prozy." In: Sovetskaja literatura i mirovoj literatumyj process, M. 1982, S. 37-58. [Fedorov S. 48f.]

- Belenson, Aleksandr [Emanullovic], "Niçe - Spengler - Fedorov." [Gedicht] In: Strelec. Sbomik tretij i poslednij. SPb. 1922, S. 112.

Belinski, Vissarion Grigor'eviC, Polnoe sobmanie soxinenij, t. 11, M. 1956; t. 12, M. 1956.

- Beluaev, A., "Vzgljad na samoderžavie episkopa Feofana i N.F. Fedorova." In: Vera i Razum, [Char'kov] 1906, S. 313-331.

- B[ELKNAP], R[OBERT] L., "Fyodorov, Nikolai Fyodorovich." [Lexikonartikel] In: V. TERRAS (Hg.), Handbook of Russian Lirerature, New Haven, London 1985, S. 164 f.

BeloV, ANATOLU VASIL'EVIC, KARPOV, DMTTRI, AIEKSANDROVIC, Mistika na službe antikommunizma, M. 1978. ( = NauXnyj at eizm; 1978, 2).

- Belov, Vasilu IVAnoviC, Remeslo olCużdenija. Bjurokratija i ékologija. M. 1988. [Fedorov S. 3, 76f.]

- Belozerov, S., "Obsčee delo." In: Novyj Gmad, 10, 1935, S. 116-128. [Fedorov S. 120, 122]

BELYJ, ANDRfJ [d.i. Bugaev, Boris NikolaEviC], Četyre simfonii. [Nachdruck der Ausgaben Moskau 1917, 1905 und 1908 mit einer Einleitung von Dmitrij Tschižewskij] München 1971. (= Slavische Propylăen; 39).

Belyj, ANDRes [d.i. Bugaev, Boris Nikolaevic], "Volnaja Filosofskaja Associacija." In: Novaja Russkaja Kniga, [Berlin] 1922, 1, S. $32 f$.

Belyu, ANDREj [d.i. Bug.aEv, Boris NikolaeVC], "Vospominanija ob Aleksandre Aleksandrovice Bloke." In: Zapiski mettatelej, 6, 1922, S. 7-122.

- Belyu, ANDRes [d.i. Bugaev, Boris Nikolaevic], "Vospominanija o Bloke." In: Epopeja, kn. 2, M., Berlin 1922. [Fedorov S. 119]

Belyu, ANDRej [d.i. Bugaev, Boris NikolaEvic], [ohne Titel]. In: Kak my pisem, L. 1930, S. 923.

- Belyj, ANDRej [d.i. Bugaev, Boris NikolaeviC], NaCalo veka, M.-L. 1933. [Fedorov S. 168]

- BelyJ, ANDRes [d.i. BugaEv, Boris NikolaeviC], MeZ̃du druch revoljucij, L. 1934. [Fedorov S. 219]

Belyj, ANDRej [d.i. Bugaev, Boris NikolaeviC], Rasskazy, München 1979. (= Slavische Propylăen; 141).

- Belyj, ANDrej [d.i. Bugaev, Boris Nikolatevic], "[Pis'mo] E.K. Metneru [26.12.1912]." In: DERs., Pelerturg, M. 1981, S. 512-515.

BELYJ, ANDREj [d.i. BUgAeV, Boris NikolaeVIC], Poxemu ja stal simuolistom i poxemu ja ne perestal im byt' wo usech fazach moego idejnogo i chudotestvennogo razvitija. [1928] Ann Arbor 1982.

- Belyj, ANdrej [d.i. Bugaev, Boris Nikolaevic], "[Pamjati A. Bloka]." In: Literatumoe nasledstwo, t. 92 [Aleksandr Blok. Novye materialy i issledovanija], kn. 3, M. 1982, S. $829 f$.

Benjaman, Walter, Illuminationen. Ausgewählie Schriften. Frankfurt/M. 1969. 
Berdjaev, Nikolas [Aleksandrovic], "O novom religioznom soznanii." [1905] In: Ders., Sub specie aetemitatis. Opyty filosofskie, social'nye i literatumye (1900 - 1906 8.). SPb. 1907, S. 338-373.

BERDJAEV, NikOLA [ALEKSANDROVIC], Novoe religioznoe soznanie i obšcestvennost', SPb. 1907. BerdjaEv, Nikolaj [AleksandroviC], "O zemnom i nebesnom utopizme. Kn. Evgenij Trubeckoj. Mirosozercanie VI.S. Solov'eva." [Rezension] In: Russkaja Mysl', 34 (1913), 9, S. 46-54.

- Berdjaev, Nikola [AleksandroviC], "Religija voskrełenija. 'Filosofija obకrego dela' N.F. Fedorova." In: Russkaja Mysl', 36 (1915), 7, S. 75-120. - Wiederabdr. in: DERS., Tipy religioznoj mysli $v$ Rossii, Paris 1989, S. 242-301. (= Sobranie soxinenij; 3).

- Berdjaev, Nikolaj [Aleksandrovic], "Prorotestva N.F. Fedorova o vojne." In: Birzevye Ve. domosti, [SPb.] 15027, 15.8.1915.

- Berdjaev, Nikolas [Aleksandrovic], Smysl mor'estva. Opyt opravdanija Celoveka. M. 1916. [Fedorov S. 189f., 194, 336, 342f., 345, 358]

BERDJAEv, N[IKolas AleksandRoviC], "Ivanovskie sredy." In: Russkaja literatura XX veka. Pod red. SA. Vengerova. T. 3, vyp. 8, M. 1916, S. 97-100.

Berdjaev, Nikoln [Aleksandrovic], "Duch i maSina." [1915] In: Ders., Sud'ba Rossii. Opyty po psichologii vojny i nacional'nosti. M. 1918, S. 233-240.

BeRdjaev, Nikoln [AleksandRovic], "Predsmertnye mysli Fausta." In: Osval'd Spengleri zakat Evropy, M. 1922, S. 55-72.

- Berdjaev, Nikola [Aleksandrovic], Filosofija neravenstva. Pis'ma k nedrugam po social'noj filosofii. Berlin 1923. [Fedorov S. 46, 91f., 202, 212, 242]

- Berdjaev, Nikola [Aleksandrovic], Smysl istonii. Opyry filosofii celovečeskoj sud'by. Berlin 1923. [Fedorov S. 268]

- BerdjaEv, Nikolas [Aleksandrovic], "Russkaja religioznaja ideja." In: Problemy nusskogo religioznogo soznanija. Sb. statej. Berlin 1924, S. 52-138. [Fedorov S. 73, 85, 98, 116, 122, 125, 128f.]

- Berdjaev, Nikolas [Aleksandrovic], "Smertobožnitestvo. Koren' eresej, razdelenij i izvraštenij istinnogo urenija cerkvi. Dogmatixeskie oterki. 1926 g." [Rezension] In: Put', 7, 1927, S. 122-124.

- Berdjaev, Nikola [AleksandroviC], "Russkaja religioznaja mysl' i revoljucija." In: Versty, 3, 1928, S. 40-62. [Fedorov S. 45-48, 55]

- Berdjaev, Nikoln [Aleksandrovic], "Tri jubileja. (L. Tolstoj, Gen. Ibsen, N.F. Fedorov)." In: Put', 11, 1928, S. 76-94. - Dass. [dt.] "Drei Gedenktage (Leo Tolstoi, Henrik Ibsen, N.F. Fjedoroff)." In: Neue Schweizer Rundschau, 21 (1928), S. 668-674 [Tolstoj], 743-752 [Ibsen], 839-846 [Fedorov]. Engl. [gekürt] "N.F. Fedorov." In: The Russian Review, 9 (1950), 2, S. 124-130.

- Berdjaev, Nikolas [AleksandroviC], "A.K. Gomostaev. Raj na zemle. K ideologii tvortestva M.F. [sic] Dostoevskogo. F.M. Dostoevskij i N.F. Fedorov. 1929." [Rezension] In: Put', 19, 1929, S. 114-116.

- BerdjaEV, Nikola [ALEKSANDROVIC], "O charaktere russkoj religioznoj mysli XIX-go veka." In: Souremennye Zapiski, 42, 1930, S. 309-343.

- Berdjaev, Nikolas [Aleksandrovic], O naznačenii Celoveka. Opyr paradoksal'noj étiki. Paris 1931. [Fedorov S. 197, 278-280, 283, 285, 292, 302]

- Berdjaev, Nikolaj [Aleksandrovic], "N.A. Setnickij, O konečnom ideale, 1932 g." [Rezension] In: Pur', 36, 1932, S. 93-95.

- Berdjaev, Nikola [AleksandroviC], "Celovek i masina. (Problema sociologii i metafiziki techniki)." In: Put', 38, 1933, S. 3-37. - Wiederabdr. in: Voprosy Filosofii, 1989, 2, S. 147-162.

- Berdjaev, Nikoln [Alexsandrovic], Ja i mir ob-ektov. Opyr filosofii odinozestva i obšenija. Paris 0.J. [1934]. [Fedorov S. 31f., 73]

BERDJAEV, NiKOLAJ [AleKSANDROVIC], "Russkij duchovnyj renessans naCala XX v. i żumal 'Put"." In: Put', 49, 1935, S. 3-22.

Berdjaev, Nikolas [Aleksandrovit], "Christianstvo i revoljucija." In: Novyj Grad, 12, 1937, S. $48-62$. 
- [Berdjaev, Nikolas Aleksandrovic] Berdiajew, Nikolai, Sinn und Schicksal des mussischen Kommunismus, Luzern 1937. [Fedorov S. 44, 99-101, 119, 159]

- Berdjaev, Nikola [Alexsandrovic], $O$ rabstue i suobode Celoveka. (Opyt personalisticeskoj filosofii). Paris O.J. [1939]. [Fedorov S. 189-191, 209, 219f., 222]

- Berdjaev, Nikolas [AleksandroviC], "Vojna i éschatologija." In: Put', 61, 1939-40, S. 3-14. [Fedorov S. 12]

- Berdjaev, Nikola [AleksandroviC], Russkaja ideja. Osnovnye problemy nusskoj mysli XIX veka i nacala XX veka. Paris 1946. [Fedorov bes. S. 209-213]

- Berdjaev, Nikolas [AlEkSANDROviC], Opyt eschatologiceskoj metafiziki. (Tvortestvo i ob-ektivacija). Paris 1947.

- Berdjaev, N[IKOla AleKsandrovic], Ekzistencial'naja dialektika boťestuennogo $i$ celoveceskogo. Paris 1952. [Fedorou S. 197, 200]

- [Berdjaev, Nikolas Aleksandrovic] Berdiajew, Nikolal, Wahiheit und Lüge des Kommunismus, Darmstadt, Genf 1953. [Fedorov S. 84]

- Berdjaev, Nikola [Aleksandrovič], Samopoznanie. (Opyt filosofskoj avtobiografii). Izd. ispr. i dop., Paris ${ }^{2} 1983$ ['1949].

BERELOWTICH, Alexis, "Des slavophiles aux russophiles." In: Revue des Études slaves, 53 (1981), 2, S. 233-244.

BerelowtTCh, Alexis, "L'almanach 'Les Monuments de la Patrie' (Pamjatniki otečestva)." In: Revrue des Études slaves, 54 (1982), 4, S. 767-771.

- Berelowtrch, Alexis, "La place vide de Dieu." In: Cahiers du Monde nusse el soviérique, 29 (1988), 3-4, S. 575-580. [Fedorov S. 576]

Bergson, Henru, L'évolution creatrice, Paris ${ }^{7} 1911$.

Bessmerie. Organ severnoj gruppy biokosmistov (immonalistov) i komiteta poezzii biokosmistov. $\mathrm{Pg}$., 1, 25.11.1922.

- Betrea, David M., The Shape of Apocalypse in Modern Russian Fiction, Princeton, N.J. 1989. [Fedorov S. 23, 30, 36, 39, 113, 154, 160-162, 165f., 169, 177, 182, 184, 241, 257, 268]

- BEYSSAC, MICHELE, Ia vie culturelle de l'émigration nusse en France. Chronique (1920-1930). Paris 1971. [Fedorov S. 216, 237, 269]

- BEZ-JAZYCNYJ, VL[ADIMIR], "Neobyknovennyj bibliotekar' Rumjancevskogo muzeja." In: Ogonek, 1969, 30, S. 20.

- Bilungton, JAMEs H., "The Intelligentsia and the Religion of Humanity." In: The American Histerical Review, 65 (1960), 4, S. 807-821. [Fedorov S. 814, 820]

- Biluington, James H., The Icon and the Axe. An Interpretive History of Russian Culture. New York 1970. [Fedorow S. 43, 443f., 486, 644]

- Biokosmist. Organ organizacii Kreatorij rossijskich i moskovskich anarchistov-biokosmistov. M. 1922, 1 [März], 2 [April], 3-4 [Mai-Juni].

Biokosmisty desjat' stuk, Pg. 1923.

Biokosmizm (Materialy - No. 1), M. 1921.

- BIRuxov, Ju.V., "Razvitie idei rasprostranenija noosfery za predely Zemli v trudach K.E. Ciolkovskogo." In: Trudy pjatych i sestych Crenij KE. Ciolkovskogo (Kaluga 1970, 1971 g8.). Sekcija 'Issledovanie nautnogo twortestva KE. Ciolkovskogo.' M. 1972, S. 91-98. - Wiederabdr. in: Idei KE. Ciolkouskogo i sovremennost', M. 1979, S. 226-232.

- Biruukov, P[avel] I[Vanovic], L.N. Tolstoj. Biografija. T. 2, Berlin 1921. (= Russkaja biblioteka; 31). [Fedorov S. 425-428]

- Brtov, ANDrej Georgievic, "Andrej Platonov segodnja." In: Literatumaja Gazeta, 39 (5157), 23.9.1987, S. 3.

Bjulleten' G.A.Ch.N., 10, M. 1927/1928; 11, M. 1928.

Buznakov, Milka, The City of the Russian Futurists." In: Canadian-American Slavic Studies, 20 (1986), 1-2, S. 89-110. 
BLOCH, ERnst, Freiheil und Ondnung. Abriß der Sozial-Ulopien. New York 1946.

BLoCh, ERnst, Das Prinzip Hoffnung, Bde. 1-3, Frankfurt/M. 1959.

BLOCH, ERNST, Geist der Utopie, Frankfurt/M. 1964. (= Gesamtausgabe; 3).

Bloch, ERNST, Tendenz - Latenz - Utopie, Frankfurt/M. 1978. (= Ergănzungsbd. zur Gesamtausgabe).

Blok, AleksandR Aleksandrovic, Sobmanie soxinenij v vos'mi tomach, t. 7, M.-L. 1963; t. 8, M.-L. 1963.

BLOK, ALEKSANDR ALEKSANDROVIC, Zapisnye knizki 1901-1920, M. 1965.

Bocjanovski, V[LADIMIR] F[eofilovic], Bogoiskateli, SPb.-M. o.J. [1911].

- Bodin, Per ARne, Nine Poems from Dokeor Zivago. A Study of Christian Motifs in Boris Paster. nak's Poetry. Stockholm 1976. (= Acta Universitatis Stockholmiensis. Stockholm Studies in Russian Literature; 6). [Fedorov S. 135]

- BOss, OTto, Die Lehre der Eurasier. Ein Beitrag zur russischen Ideengeschichle des 20. Jahrhunderts. Wiesbaden 1961. ( = Veröffentlichungen des Osteuropa-Institutes München; 15).

- Bogat, Evgenu Michaulovic, Vecnyj celovek, M. 1973. Kap. "Čekrygin", S. 153-168. - Wiederabdr. in: DeRs., Cetvertyj list pergamenia, M. 1983, S. 176-188.

Bogdanov, A. [d.i. Malinovsku, Aleksandr Aleksandrovic], "Celi i normy žizni." [1905] In: DERS., Novyj mir. (Stat'i 1904-1905). M. 1905, S. 55-135.

Bogdanov, A. [d.i. Malinovski, Aleksandr Aleksandrovic], Padenie velikogo fetisizma. (Sovremennyj krizis ideologii). M. 1910.

Bogdanov, A. [d.i. Malinovsku, Aleksandr Aleksandrovic], Filosofija tivogo opyta. Populjamye oxerki. Materializm, èmpiriokriticizm, dialektiŽeskij materializm, émpiriomonizm, nauka buduszego. Pb. 1913.

Bogdanov, A. [d.i. MalinovskiJ, Aleksandr Aleksandrovic], Nauka ob obszestvennom soznanii. (Kratkij kurs ideologiteskoj nauki v vopmsach i orvetach). M. 21918 ['1914].

Bogdanov, A. [d.i. Malinovsku, Aleksandr Aleksandrovic], "Oterki organizacionnoj nauki." In: Proletarskaja Kul'tura, 15/16, 1920, S. 6-38.

Bogdanov, A. [d.i. MALInovskJ, Aleksandr Aleksandrovic], Krasnaja zvezda. Roman-utopija. Izd. vtoroe [6. Ausgabe?], L.-M. 1924.

Bogdanov, A. [d.i. Malinovsku, Aleksandr Aleksandrovic], O proletarskoj kul'ture 1904 1924. L.-M. 1924 [1925?].

BOgDANov, A. [d.i. MALINOVSKU, ALEKSANDR ALEKSANDRoviC], Vseobšcaja organizacionnaja nauka (Tekiologija), ¿. 1, M. ${ }^{3} 1925$ ['1913].

Bogdanov, A. [d.i. MAlinovsku, Aleksandr Aleksandrovic], Bor'ba za Ziznesposobnost', M. 1927.

Bogdanov, A. [d.i. Malinovsku, Aleksandr Aleksanprovic], Krasnaja zvezda. Roman-ulopija. L. 1929. Inżener Ménni. Fantastizeskij roman. L.-M. '1925. [Nachdruck] Hamburg 1979. (= Bibliotheca Russica; 2).

Bogdanova, OA., "Vasilij Leonidoviz Komarovic." In: Voprosy Literatury, 1988, 9, S. 130-151.

Bogoraz (Tan), V[Ladimir] G[ermanovic], Ejnstiejn i religija. Primenenie principa otnosi. tel'nosti k issledovaniju religioznych javlenij. Vyp. pervyj, M.-Pg. 1923.

- BOHATEC, JOSEF, Der Imperialismusgedanke und die Lebensphilosophie Dostojewskijs, Graz, Köln 1951. [Fedorov S. 18, 253, 267]

- BondarCuK, Sergej [Fedorovic]], "Želanie čuda." In: Nă Souremennik, 1980, 7, S. 119-138. [Fedorov S. 129]

- BondarCuK, SERgej [FEdoroviC], "'.. Soderžaniem, važnym dlja žizni ljudej'." In: Literatumaja Gazeta, 39, 24.9.1980, S. 8.

- BorANECKU, P[ETR] S[1EPANOVIC], "O novom žiznennom ideale." In: Tret'ja Rossija, 2, 1932, S. 47-60. [Fedorov S. 59f.]

BORANECKU, P[eTR StEPanovic], "Smysl techniki." In: Tret'ja Rossija, 45, 1934, S. 17-28. 
BoraneckIJ, P[ETR Stepanovic], "O novom reloveke." In: Tret'ja Rossija, 4-5, 1934, S. 45-52.

BORANECKU, P[ETR STEPANOVIC], "O novom obstestvennom ideale. Grjadustaja Atlantida." In: Tret'ja Rossija, 6, 1935, S. 47-63.

- Boranecku, P[ETR StepanoviC], "O geroizeskom mirosozercanii." In: Tret'ja Rossija, 7, 1936, S. 46-84. [Fedorov S. 78]

[Boranecki, Petr Stepanovic] N., "Zavet naß̌go vremeni." In: Tret'ja Rossija, 7, 1936, S. 90 93.

[BORANECKIJ, PeTR STEPanoviC], "K organizacii mira." In: Tret'ja Rossija, 8, 1938, S. 14-24.

- Boranecku, P[ETr STEPANovic], "O jurodivych tudarestvach fedorovstva i o zamysle preodolenija smerti." In: Tret'ja Rossija, 8, 1938, S. 72-124.

- Boranecku, P[etr StePanoviC], "Prometeizm i religija." In: Tret'ja Rossija, 9, 1939, S. 46-62.

- BORANECKU, P[ETR] S[TEPANOVIC], Filosofija techniki. Technika i novoe mirosozercanie. Paris 1947. [Fedorov S. 162]

Boranecku, P[ETR] S[TEPanoviC], Cennost' i Celovek. Princip sochranenija cennosti. Paris 1948.

BORANECKI, P[ETR STEPANOVIC], $O$ dostoinstve celoveka. Osnovanija geroiceskoj ériki. Paris 1950.

- Boranecku, P[eTr StEPanovic], Religija, materializm i prometeizm. Osnovanija sinteticeskogo mirosozercanija. Paris o.J. [ca. 1953]. [Fedorov S. 271f., 444, 791]

- Boranecki, P[etr StePanovic], O samom valnom. Koneznoe naznatenie celoveka. Paris 1956. [Fedorov S. 1131-1139]

BORANECKU, P[ETR StEPANOVIC], Osnovnye nacala. Ontologija tworteskogo mirosozercanija. Paris OJ. [ca. 1960].

Boranecku, P[ETR Stepanovic], Social'nyj ideal. Osnovy social'noj filosofii. Paris 1965.

- Bori, Pier Cesare, Bettiolo, PaOlo, Movimenti religiosi in Russia prima della rivoluzione (1900-1917), Brescia 1978. ( = Dipartimento di scienze religiose; 8). [Fedorov S. 39]

- Borisov, V[ALeRu SEMENoviC], "Idcal'nyj bibliotekar'." In: Al'manach bibliofila, 6, M. 1979, S. 201-206.

- Borodaevski, Valerhan [Valerlanovic], "Pamjati N.F. Fedotova." [Gedicht] In: Ders., Uedinennyj dod. Vtoraja kniga stichov. M. 1914, S. 10 .

- [Borovoj, Vrtalu] Borovoy, VItaly, "Christian Perspectives on Creation in a Time of Ecological Unsustainability." In: Faith and Science in an Unjust World. Report of the World Council of Churches' Conference on Faith, Science and the Future. MIT, Cambridge, USA, 12-24 July 1979. Vol. 1, Geneva 1980, S. 80-86. [Fedorow S. 85f.]

- Bosco, Nynfa, "Introduzione." [Zum Kapitel 'Nicolai Fedorov, La Filosofia dell'opera comune']. In: Occidente, cristianesimo e progresso. Antologia dagli scritti di $C$. Leont'ev e N. Fedorov. A cura di G. Riconda e N. Bosco. Torino 1981, S. 79-91. (= Collana di studi filosofici).

- [Bowlt, John E.] Bourt, Džon E., "Kazimir Malevic: ego putesestvie v bespredmetnyj mir." In: Russkaja Mysl', 2991, 21.3.1974, S. 8.

- Bowlt, Jorrn E., "Expression und Abstraktion. Die Kunst der russischen Avantgarde." In: Werke aus der Sammlung Costakis. Russische Avantgarde 1910-1930. Düsseldorf 1977, S. 12-17.

- Bowlt, JoHN E., "K istorii russkogo avangarda / The Russian Avant-Garde, Stockholm 1976." [Rezension] In: Slavic Review, 37 (1978), S. 351-353.

- Bowlt, Jorn E., "Art in Exile: The Russian Avant-Garde and the Emigration." In: An Joumal, 41 (1981), 3, S. 215-221.

Bowlt, John E., "Esoteric Culture and Russian Society." In: The Spiritual in Ant: Abstract Painting 1890-1985, Los Angeles, New York 1986, S. 165-183.

Borovoj, Lev Jakovievic, Puf' slova, M. 1963.

- Brang, Peter, "Fortschrittsglauben in Rußland einst und jetzt." In: R.W. MEYER (Hg.), Das Problem des Fortschrittes - heute, Darmstadt 1969, S. 29-53. [Fedorov S. 40] 
- Brang, Peter, "Zur Todesmotivik in der russischen Moderne." In: Schweizerische Beiträge zum VIII. Intemationalen Slavistenkongress in Zagreb und Ljubljana, September 1978, Bern 1978, S. 2358. ( = Slavica Helvetica; 12). [Fedorov S. 47]

BrichniCeV, Iona [Pantelejmonovic], "K pobede putem gibeli." In: Živaja Žizn', 1908, 1, S. 42-47.

Brichanicev, Iona [Pantelejmonovic], "Poet golgofskogo christianstva." In: Novaja Zemlja, $1912,1-2$, S. 3-6.

Brichnicev, Iona [Pantelejmonovic], Christos v mirovoj poezii, M. 1912.

BRICHNICEV, IONA [PANTEL EJMONOVIC], Moliny vselenskoj cerkvi, M. 1912.

BRICHINICEV, IONA [PANTELEJMONOVIC], Apostoly gumannosti i svobody, M. 1912.

BrichaniCev, Iona [Pantelejmonovič], Kaplja krovi. Stichotvorenija. Vyp. 1, M. 1912.

BrichniCev, IONa [PANTElejmonoviC], "Novoe religioznoe soznanie. (Čto takoe golgofskoe christianstvo?)." In: Rul', 358, 9.7.1912.

BRICHNICEV, IONA [PANTELEJMONOVIC], Cto lakoe golgofskoe christianstwo? M. 1912. (= Biblioteka 'Novaja Zemlja'; 13).

Brichinicev, Iona [PANTElejmonovic], Ognennyj sejatel', M. ${ }^{2} 1913$.

- Brichnicev, Iona [Pantelejmonovic], Osanna. (Vtoraja kniga stichov). Odessa 1914 [recte 1913].

Brichnicev, Iona [Pantelejmonovic], Puti Zivye. (Cvetopesni - kniga tret'ja). M. 1916.

BrichniCEv, Iona [PANTElejmonoviC], Liturgija celomu. (Četveriaja kniga stichov). M. 1917.

BrichniCev, lona [Pantelejmonovic], [drei Gedichte] in: Proletarskij sbomik, kn. 1, M. 1918, S. 18-20.

BRICHNICEV, I[ONA PANTELEJMonoviC], Metody i formy agitacii v oblasti likvidacii bezgramoinosti, M. 1920.

Bricinicev, I[ONa PantelejmonoviC], Patrianch Tichon i ego cerkov', M. 1923.

- BRICHNICEV, IONa [PANTELEJMONOVIC], Kniga v Zizni velikich ljudej, M. 1931.

BRmKov, A[NATOLU] F[EDOROVIC], "Zaroždenie sovetskoj nauŽnoj fantastiki." In: Istorija russkogo sovetskogo romana, kn. 1, M.-L. 1965, S. 367-392.

- BRTIKov, ANATOLIs FEDOROVIC, Russkij sovetskij nauCno-fantasticeskjj roman, L. 1970.

BrJuchunov, V[ALENTIN] A[NDREEVIC], Mirovozzrenie KE. Ciolkovskogo i ego naučno-rechniCeskoe trontestuo, M. 1959.

- [BRUSOV, VAleRI JakovleviC], "V žumalach i gazetach. Russkij archiv." In: Vesy, 1 (1904), 6, S. $65 f$.

- Bruusov, Valerd [Jakovievic], "Literatumaja Żzn' vo Francii. IV. Novye knigi Émilja Vercharna." In: Russkaja Mysl', 1910, 8, S. 1-17. [Fedorow S. 6]

BruUsov, VAlerU [JAKOVleVIC], Iz moej Zizni. Pamjati. Iz vospominanij za polveka. M. 1927. (= Zapisi proslogo).

- Bruusov, Valerd [Jakovlevic], Dnevmiki 1891-1910. M. 1927. (= Zapisi proslogo).

BRUUSOV, VALERU [JAKOVLEVIC], Toržestvo nauki. (Zapiski posešenija Teurgiceskogo Instituta)." [1918] - ErstveroffentlichunE unter dem Titel "Ne voskrełajte menja! Naučno-fantastið̌eskij rasskaz-pamflet." In: Technika-Molodezi, 1963, 12, S. 16-18.

- Brusov, Valery Jakovlevic, Sobranie soxinenij v semi tomach, t. 1-3, M. 1973-1974.

- Brodsku, Iosif [Aleksandrovic], [Nachwort zu] A. Platonow [Platonov], Das Meer der Jugend, Frankfurt/M. 1984, S. 92-96. (= Ullstein Buch; 20396).

- Brown, Edward J., Mayakorsky. A Poet in the Revolution. Princeton, N.J. 1973. [Fedorov S. 122, 253-256]

- Bubnov, Ig., "Kosmos, Obß̌estvo, Mysl'." In: Noyyj Mir, 1977, 10, S. 272-276.

BOCHNER, LUDWIG, Kraft und Stoff, Leipzig o.J. ( = Kröners Taschenausg.; 102).

Bugrov, JURU, "Pevec Kurskogo kraja." In: Literatumaja Rossija, 28.10.1983. 
Bulgakov, Sergej N[IKolaevic], "Osnownye problemy teorii progressa." [1902] In: DeRs., Ot marksizma $k$ idealizmu. Sb. statej (1896-1903). SPb. 1903, S. 113-160. - Zuerst in: Problemy idealizma. Sb. statej pod red. P.N. Novgorodceva, M. 1902, S. 1-47.

Bulgakov, SERgej N[IKolaEviC], "Voskresenie Christa i sovtemennoe soznanie." [1903] In: DERS., Intelligencija i religija, M. 1908, S. 40-48. - Etwas abweichend auch in: DERS., Dva grada. Issledovanija o prirode obšcestvennych idealov, t. 2, M. 1911, S. 166-176.

Burgakov, Sergej N[IKolaEvič], "Religija celovekobožija u L. Fejerbacha." [1905] In: Ders., Dva grada, t. 1, M. 1911, S. 1-68.

- Burgakov, S[ergej] N[IKolaeviČ], "Apokaliptika i socializm." [1910] In: DeRs., Dva grada, t. 2, M. 1911, S. 51-127. [Fedorov S. 112, 119, 125f.]

- Bulgakov, Sergej [NikolaeviC], "Zagadoðnyj myslitel'. (N.F. Fedorov)." [1908] In: DeRS., Dva grada, t. 2, M. 1911, S. 260-277. Zuerst in: Moskovskij Eženedel'nik, 48, 5.12.1908, S. 28-46.

- Bulgakov, Sergej [Nikolaevic], Svet nevecemij. Sozercanija i umozrenija. O.O. [M.] 1917. [Fedorov S. 360-368]

- Bulgakov, S[ERGE]] N[IKolaeviC], Christianstuo i socializm. M. 1917. [Fedorov S. 20-23]

- Burgakov, S[erges Nikolaevic], "Pamjati Vladimira Aleksandroviła Koževnikova." In: Christianskaja Mysl', [Kiev] 1917, 11-12, S. 75-83.

- Bulgakov, Sergej [NikolaeviC], "Sny Gei". [1915] In: Tichie dumy. Iz statej 1911-15 gg. M. 1918, S. 135-145. [Fedorov S. 139]

- Bulgakov, Sergej [Nikolaevic]], "DuSa socializma." In: Noyyj Grad, 1, 1931, S. 49-58; 3, 1932, S. $33-45 ; 7,1933$, S. 35-43.

- [Burgakov, Sergej Nikolaevic], "Ideja obšcego dela." [Vosproizvedenie po pamjati nekotorych myslej doklada ... S. Bulgakova]. In: Vestnik RSChD, 9 (1934), 10, S. 9-18.

- [Burgakov, Sergej Nikolaevic] Burgakoff, Sergius, Social Teaching in Modem Russian Orthodax Theology, Evanston, III. 1934. [Fedorov S. 17-20]

- Bulgakov, Sergej NikolaeviC, Nevesta agnca. O bogocelove S. 373]

Burgakov, Sergu [Nikolaevic], "Sujašcennik o. Pavel Florenskij." [1943] In: Vesinik RSChD, 101-102, 1971, S. 126-135.

- Bulgakov, Sergej Nikolaevic, Sozialismus im Christentum? Eingel., übers. u. hg. von H.-J. Ruppert, Gơttingen 1977.

- Bulgakov, Sergej Nikolaevic, "Sofiologija smeni." In: Vestnik RChD, 127, 1978, S. 18-41; 128, 1979, S. 13-32.

- [Bunina, Vera Nikolaevna], Ustami Buninych, t. 2, Frankfurt/M. 1981. [Fedorov S. 197] BURBANK, JANE, Intelligentsia and Revolution. Russian Views of Bolshevism 1917-1922. New York, Oxford 1986.

- Burluuk, Nikola [Davidovic], "Poétiteskie natala." In: Futuristy. Pervyj Zumal Russkich Futuristov. M. 1914, 1-2, S. 81-85. - Wiederabdr. in: Ot simvolizma do 'Oktjabria'. Literatumye manifesty. M. 1924.

- Bursov, Boris IVANovic, Lixnost' Dostoevskogo. Roman-issledovanie. L. 1974. - Zuerst in: Zvezda, 1969-70. [Fedorov S. 73-79]

BurStejn, A[RON IOsIfoviC], Anabioz i ego praktileskoe primenenie. Po projessoru Bachmet'evu. Odessa 1913.

Busch, WolfGang, "Konstantin Merežkovskijs Menschheitstraum." In: Archiv für das Studium der neueren Sprachen und Literaturen, Bd. 202, 117 (1966), 6, S. 441-446.

Butorin, Georgu, Pupovina Celoverestva. (Po puti èvoljucii vselennoj). M. 1922.

ČAGIN, BA. (Hg.), Sociologiceskaja mysl' v Rossii. Ocerki istonii nemarksistskoj sociologii poslednej treti XIX-nacala XX veka. L. 1978. 
Čajanov, A[LeKSANDR VASIL'EviC], "Vozmožnoe budušee sel'skogo chozjajstva." In: A. A[RKA]N [d.i. A.I. ANEKSTEJN], E. Kol'MAN (Hgg.), Žizn' i technika budušrego. (Social'nye i naußno-techniZeskie utopii). M.-L. 1928, S. 260-285.

Čananov, Aleksandr VAsil'EVIC, "Putesestvie moego brata Alekseja v stranu krest'janskoj utopii." In: Euvres choisies de A.V. Cajanov, 3, 0.O. [The Hague, Paris] 1967, S. 90-151.

[CAJanov, Aleksandr Vasil'evic] Tschajanow, Alexander W., Reise meines Bruders Alexej ins Land der bäuerlichen Utopie, Frankfurt/M. 1981.

- Calian, Carnegie Samuel, The Significance of Eschatology in the Thoughts of Nicolas Berdyaev, Leiden 1965. [Fedorov S. 4f., 39f., 99, 109]. - Dass. auch unter dem Titel Berdyaev's Philosophy of Hope. A Contribution 10 Marxist - Christian Dialogue. Minneapolis, Minn. o.J. [ca. 1968].

- Ćalmaev, V[IKTOR ANDREeVIC], "Veliðie prostych serdec. K 80-letiju so dnja roždenija Andreja Platonova." In: Ogonek, 36, 1.9.1979, S. 20f.

- Ćalmaev, V[IKTOR] A[NDREeviC], "Istoriko-literatumyj kommentarij." In: A.P. Platonov, Cevengur, M. 1989, S. 373-381.

CARDEN, PATRIClA, "Utopia and Anti-Utopia: Aleksej Gastev and Evgeny Zamyatin." In: The Russian Review, 46 (1987), S. 1-18.

CChejdze, K[Onstantin] A[LeKSAndrovie], Strana Prometeja, Shanghai 1932.

- Coheidze, Konst[ANTIN] AL[exsandrovic], "Nikolaj Fedoroviz Fedorov." In: Rozhledy po Literatuře a Uměni, [Prag] 1 (1932), 12, S. 91.

- CCheidze, Konstantin Alexsandrovic, "Komentáf k Majakovskému." In: Rozhledy po Literatuře a Uměnı, 2 (1933), 8-9, S. 57f. - Dass. [russ.] "Kommentarij k Majakouskomu." In: DERS., $O$ sovremennoj nusskoj literature. Sb. statej. Ms. [Masch.] Prag 1933, Bl. 13-24.

- CChEIdze, KJonstantin] A[LEKSANDRoviC], "O soudobé ruské literatuře." In: Rozhledy po Literatuře a Umění, 2 (1933), 15, S. 105f.; 16/17, S. 115f.

- ¿ChEIDZE, K[ONSTANTIN] A[LeKSaNDROVIC], "N.F. Fedorov a naše doba. (K tȟcátému vyroxi dne jeho úmrí 15.-28. prosince roku 1903)." In: Akce, [Bmo] 1933, 11-12, S. 171-174.

- CCHEIDZE, K[ONSTANTIN] A[LEKSANDRoviC], "K probleme ideokratii." In: Novaja épocha. Ideokrarija. Politika-ikonomika. Obzory. Pod red. V.A. Pejl'. Narva 1933, S. 15-22.

- [CCheidze, Konstantin AleksandroviC] TCheidze, C., "Science." In: P. MalevsKy-Male. vich (Hg.), Russia U.S.S.R. A Complete Handbook. New York 1933, S. 677-687. [Fedorov S. 678]

- Č [CHEIDZE], K[ONSTANTIN] A[LEKSANDROVIC], "Zapiska K.A.Č. o filosofii N.F. Fedorova." In: Evrazijskie tetradi, 0.O. [Prag] 1934, S. 30-34.

- CCheidze, K[ONSTANTIN] A[LEKSANDROVIC], "N.F. Fedorov." In: Acta Academiae Velehradensis, 12, 1934, fasc. 3-4, S. 135-141.

- CChEIDZE, K[ONSTANTIN] A[LEKSANDROViC], "Idea-projekt." In: Akce, 1934, 5-6, S. $47 f$.

- ¿cheidze, K[ONSTANTIN] A[LeksandroviC], "Idea-obraz." In: Akce, 1934, 7-8, S. 64 f.

- ¿ChEIDZE, K[ONSTANTIN] A[LEKSANDRoviC], "Fedorovova filosofie." In: Akce, 1935, 1-2, S. 18 .

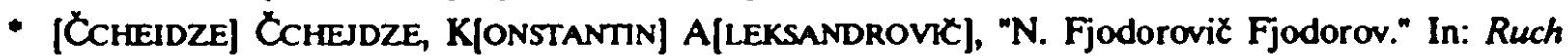
Filosofický, [Prag] 11 (1936), 3-4, S. 112-115.

- CCHEjDZE, K/ONSTANTIN] A[LEKSANDROVIC], "N.F. Fedorov v proslom i nastojašem. (K poznaniju religioznych motivov russkoj revoljucii)." In: Znamja Rossii, [Prag] 12 (100), 1937, S. 10-14.

CErTun, Z.[A.], "Karl Marks o spinozizme i istočnikach francuzskogo materializma XVIII vaka." In: Pod Znamenem Marksizma, 1926, 11, S. 214-220.

Cekrygin, V[asilu NikolaeviC], "O namęajuక̌cemsja novom ètape obšeevtopejskogo iskusstva." In: Makovec, 1922, 2, S. 10-14.

- Cekrygin, Vasilu N[IKolaevic], Risunki, M. 1969.

- [Cekerryin, Vasilu Nikolaevie], "Pis'ma V. Cekrygina k M. Larionovu." In: $A$ - Ja, 4, 1982, S. $40-43$.

- Cepurkovsku, E[FTM] M[IChaloviC], "Absoljutnyj mir $\mathrm{i}$ individu[a]l'noe bessmertie s totki zrenija sovremennogo estestvoznanija." In: Izv.Jur.Fak., 9, 1931, S. 71-101. [Fedorov S. 72, 89-91, 93] 
- Čeremin, G., "Mistiそeskaja 'utopija' pod nagom nauki. (Ob odnoj amerikanskoj koncepcii tvortesva V.V. Majakovskogo)." In: Voprosy Literatury, 1984, 9, S. 185-194.

CERnenko, G., "Raketnyj apparat 'La Russie'." In: Neva, 1966, 7, S. 216.

- Cernenko, G., "Zagadoznyj Fedorov." In: Neva, 1986, 2, S. 188-192.

- [Černogubov, Nikolas NikolaeviC], N., "Nikolaj FedoroviZ Fedorov. (15-go dekabrja 1903 g.)." In: Vesy, 1 (1904), 1, S. 54.

Cesaretti, Anna, Jelli, Alessandra, "Nep e scienza del lavoro. Un libro di Ossip A. Ermanskij (1866-1941)." In: Classe [Milano], 13 (1982), 22, S. 265-272.

Chaindrov, Levan, "Arsenij Nesmelov, Vozvrašcenie." [Vonwort] In: Znamja, 1988, 9, S. 76-78.

- ChaiX-RuY, Jules, "Nicolas Berdiaeff." In: M.F. Sclacca (Hg.), Les grands courants de la pensée mondiale contemporaine. Portraits. Bd. 1, Milano 1964, S. 101-122. [Fedorov S. 118]

ChajRullin, K. CH., "Antropokosmizm K.E. Ciolkovskogo i N.G. Cholodnogo." In: Trudy cetymadcatych Cienij KE. Ciolkovskogo (Kaluga 1979). Sekcija 'KE. Ciolkovskij i filosofskie pro. blemy osvoenija kosmosa.' M. 1980, S. 58-65.

Chan-Magomedov, S[ELIM] O., Mavzolej Lenina. (Istorija sozdanija i archirektura). M. 1972.

Chan-Magomedov, Selim O., Pioniere der sowjerischen Architektur. Der Weg zur newen sowjetischen Architektur in den zwanziger und zu Beginn der dreißiger Jahre. Wien, Berlin 1983.

- Chapman, M.C., "Stephen Lukashevich, N.F. Fedorov (1828-1903): A Study in Russian Eupsychian and Utopian Thought. Newark 1977." [Rezension] In: Studies in Soviet Thought, 20 (1979), S. 295-301.

- Chardžiev, Nikola [IvanoviC], "Majakovskij i Chlebnikov." In: To Honor Roman Jakobson. Essays on the Occasion of his Seventieth Birthday. Vol. 3, The Hague, Paris 1967, S. 2301-2327. [Fedorov S. 2321] - Dass. [leicht verăndent] in: N.I. CilARDZIEv, V.V. TreñN, Poéticeskaja kul'tura Majakovskogo, M. 1970, S. 96-126.

- Chardziev, Nikola [Ivanovic], "Poezija i Żivopis'. (Rannij Majakovskij)." In: K istorii nusskogo avanganda / The Russian Avant-Garde, Stockholm 1976, S. 8-84. [Fedorov S. 56]

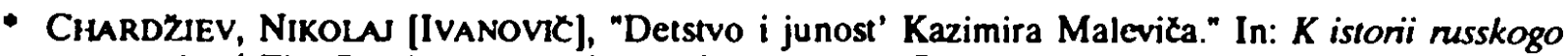
avangarda / The Russian Avant-Gande, Stockholm 1976, S. 85-127. - Dass. [franz.] "En guise d'introduction à l'Autobiographie de Malévitch." In: Malevilch 1878-1978. Actes du colloque inter. national. Lausanne 1979, S. 141-151.

- [Chazanov, Boris, d.i. Fajbusovic, Gennadi Mojseevic] Chasanow, Boris, "Mythos Rußland." In: Merkur, 38 (1984), 3, S. 263-276. - Gekürzt unter dem Titel "Auf halber Strecke fällt der Riese in den Schlaf. Rußlands Trăume und die sowjetische Wirklichkeit." In: Der Spiegel, 1984, 25, S. 114-122.

- Chazanov, Boris [d.i. Fajbusovic, Gennadu Mojseevic], "Ne pojmet i ne ocenit." In: Sirana i Mir, [München] 1984, 6, S. 68-88. - Wiederabdr. in: DERS., Iduscij po vode. Stat'i i pis'ma. München 1985, S. 5-40.

Chilebnikov, Velemir [Viktor Vladimirovic], Otryvok iz dosok sud'by. (List 3-j). M. 1922. [Auf dem Umschlag: Doski sud'by]

ChIebnikov, Velimir [VikTor] V[Ladimirovic], Sobranie soxinenij, 1-4, München 1968-1972. (= Slavische Propyläen; 37, 1-4).

- Chlebnikov, Veumir [Viktor Vladimirovic], Tvorenija, M. 1986.

ChOLOdNYJ, NikOLA GRIGOR'EviC, Izbrannye Irudy, Kiev 1982.

CHORON, JACQUES, "Death and Immortality." [Lexikonartikel] In: Dictionary of the History of Ideas, vol. 1, New York 1973, S. 634-646.

- ChoruŽis, S[ergej] S[ergeevic], "Karsavin i de Mestr." In: Voprosy Filosofii, 1989, 3, S. 79-92.

Christianskj seminar, Frankfurt/M. 1981. ( = Volnoe slovo; 39).

Clolkovsku, K[ONSTANTIN EduardoviC], Gore i genij, Kaluga 1916.

Clolkovsku, K[ONSTANTin Eduardovic], Prizina kosmosa. (Konspekt. Avgust 1925 g.). Kaluga 1925.

Clolkovsku, K[ONSTANTIN EduARDovic], Budušcee zemli i čelovečestva. Kaluga 1928. 
Ciolkovsku, K[ONSTANTIN EdUARdovic], Volja Vselennoj. Neizvestnye razumnye sily. Kaluga 1928.

ClolKovSKU, K[ONSTANTIN EduARDOVIC], Um i strasti, Kaluga 1928.

ClolKovsKu, K[ONSTANTIN EDUARDOVIC], Ljubov' $k$ samomu sebe, ili istinnoe sebjaljubie, Kaluga 1928.

Clolkovsku, K[ONSTANTIN EdUARDOVIC], Obšestvennaja arganizacija Celovečestva, Kaluga 1928.

ClolKovsKu, K[ONSTANTIN ÉdUARDOVIC], Rastenie budušcego. Živomoe kosmosa. Samozaroždenie. Kaluga 1929.

Clolkovsku, K[ONSTANTIN EduARdovic], Souremennoe sostojanie Zemli, Kaluga 1929.

ClolkovsKu, K[ONSTANTIN Éduardovic], Nautnaja ètika, Kaluga 1930.

ClolkovsKu, K[ONSTANTIN EduARDOVIC], Monizm Vselennoj, Kaluga 1931.

Clolkovsku, K[ONSTANTIN EdUARDovic], "Certy iz avtobiografii." In: Konstantin Eduandovic Ciolkouskj 1857-1932. Nautno-jubilejnyj sbomik, posvjastennyj 75-letiju so dnja nożenija KE. Ciolkovskogo i 4 a-letiju so dnja pojavlenija ego pernych peCatnych trudov po dirizablestroeniju. M.L. 1932, S. 7-10.

- Clolkovsku, K[ONSTANTIN ÉduardoviC], "Moja žizn' i rabota." In: KE. Ciolkovskij. Sbomik Aéroflota posvjašcennyj Ciolkovskomu. O.O. [M.] 1939, S. 13-91. Darin "Čerty iz moej žizni." [1932-1935] S. 15-42. [Fedorov S. 27]

CIOLKOVSKU, KONSTANTIN EDUARDOVIC, "Issledovanie miroyych prostranstv reaktivnymi priborami. Reaktivnyj pribor 'raketa' K. Ciolkovskogo." C. 2 [1911]. In: DERS., Sobranie soxinenij, t. 2, M. 1954, S. 100-139.

Clolkovski, Konstantin Eduardovic, Vne Zemli. Nautno-fantasticeskaja povest'. M. ${ }^{2} 1958$ [1920]

- Clolkovsku, K[OnSTANTIN] E[DuardoviC], "Moja žizn'." In: Ogonek, 38 (1960), 37, S. 4f., 10; 38, S. S. 14-16. [Fedorov 37, S. 10]

Clolkovsku, Konstantin Eduardovic, Sobranie soxinenij, t. 4, M. 1964.

Ciolkovsku, Konstantin [EduardoviC], "Kosmizeskaja filosofija." In: Technika - Moloderi, 1981,4, S. 23-26.

CIOLKOVSKU, KONSTANTIN ÉdUARDOVIC, Grezy o zemle i nebe. NauČno-fantasticeskie proizvedenija. Tula 1986.

Cloran, Samuel D., Madimir Solov'ev and the Knighthood of the Divine Sophia, Waterloo, Ont. 1977.

CIT i ego melody NOT, M. 1970.

- Čivilichin, Vladimir Alekseevic, Pamjat'. Roman-èsse. M. 1982. [Fedorov S. 766]

- Civilichin, Vladimir Alekseevic, "Pamjat'." In: Naš Sovremennik, 1983, 10, S. 17-101. [Russ. Kosmismus, Fedorov S. 93-101]

- Čivilichin, Vladimir Alekseevic, "N.F. Fedorov." [1968-1983] In: Ders., Zenkalo dusi, M. 1987, S. 90-110.

CižeVsKu, Aleksandr Leonidovic, Vsja zizn', M. 1974.

ČlzEVSKU, ALEKSANDR LEONIDOVIC, "Stranicy vospominanij o K.E. Ciolkovskom." In: Chimija i Zizn:, 1977, 1, S. 23-32.

ČŽEVSKU, D., siehe TSCHIŽEWSKU, D.

Clark, Katerina, holquist, Michael, Mikhail Bakhtin, Cambridge, Mass., London 1984.

- Clement, Olunier, "Le sens de la terte." In: Ders., Le Christ, terre des vivants. Essais theologiques. Bégrolles en Mauges 1976, S. 81-171. ( = Spiritualité orientale; 17). [Fedorov S. 166-170]

- Clement, Olivier, Les visionnaires. Essai sur le dépassement du nihilisme. Paris 1986. [Fedorov S. 217-221, 222f.j 
CLOWEs, EdTrH WhtreHIL, A Philosophy 'For All and None'. The Earty Reception of Friedrich Nietzsche's Thought in Russian Literature, 1892-1912. Ph.D. diss. Yale Univ. 1981; Ann Arbor, Mich. 1983.

COMTE, Auguste, Rede über den Geist des Positivismus. Discours sur l'Esprit Positif. Ubers., eingel. u. hg. von I. Fetscher, Hamburg ${ }^{2}$ 1966. ( = Philosophische Bibliothek; 244).

CONDORCET, MARIE JEAN ANTOINE, Entwurf einer historischen Darstellung der Fortschritte des menschlichen Geistes, Frankfurt/M. 1976.

COOPER, MARTIN, "Scriabin's Mystical Beliefs." In: Music and Letrers, 16, 1935, S. 110-115.

- Copleston, Frederick C., Philosophy in Russia. From Herzen to Lenin and Bendyaev. Notre Dame, Ind. 1986. [Fedorov S. 228f., 385]

- Cornwell, NeIl, Pastemak's Novel: Perspectives on 'Docior Zhivago', Keele 1986. (= Essays in Poetics Publications; 2). [Fedorov S. 22, 77f., 112]

- Coulson, Jessie, Dostoevsky. A Self-Portrait. London 1962. [Fedorov S. 216f.]

Crone, RAINER, "Zum Suprematismus - Kazimir Malevix, Velimir Chlebnikov und Nicolai [sic] Lobarevskij." In: Wallraf-Richartz-Jahruch, 40 (1978), S. 129-162.

Crouch, Garland E., "Cosmism." [Lexikonartikel] In: MERSL, 4, Gulf Breeze 1981, S. 244-246.

- Cuddakov, A.P., "G.P. Georgievskij. L.N. Tolstoj i N.F. Fedorov. Iz licnych vospominanij." [Vstupitel'naja stat'ja] In: Cetvertye Tynjanovskie crenija, Riga 1988, S. 32-45.

- Cudakova, Mariétta Omarovna, Poétika Michaila Zošcenko, M. 1979. [Fedorov S. 174]

Cueva, Izida Pantelejmonovna, Genezis i filosofskie osnovy 'novogo religioznogo soznanija', Diss. dokt-a filos. nauk, L. 1971.

- Culkov, Georgu [Ivanovic], Gody stmanstvij. Iz knigi vospominanij. M. 1930. [Fedorov S. 83] Cvetaeva, Marina [Ivanovna], Pis'ma k A. Teskovoj, Prag 1969.

CYŽEVS'KYJ, D., siehe TsCHIŽEWSKJ, D.

- Dанм, Helmut, Grundzüge russischen Denkens. Persönlichkeiten und Zeugnisse des 19. und 20. Jahrhunderts. München 1979. [Fedorov S. 547]

DAlINSKu, S., "Vstupitel'naja stat'ja." In: A.A. MEJER, Filosofskie soxinenija, Paris 1982, S. 7-21.

- Dar [d.i. Rrvinin], David JakovieviC, Ballada o zeloveke i ego kryljach, L. 1969. [Fedorov S. 34-36]

DA VRICHEWY, JOSEPH, Ah! Ce qu'on rigolait bien avec mon copain Staline, Paris 1979.

- Davydov, Ju[RU] N[IKolaEvic], "Andrej Platonov i 'russkaja chandra'." In: Literatumaja Gazeta, 42, 19.10.1988, S. 3.

DAVYDOV, JURU NikOLAEVIC, Etika ljubvi $i$ metafizika swoevolija (problemy nravstvennojj filosofii), M. ${ }^{2} 1989$ ['1982].

DEBUS, KARL, "Weltraumschiffahrt, ein poetischer Traum und ein technisches Problem der Zeit." In: Hochland, 24 (1927), S. 356-371.

- Deboser, Lola, "Anmerkungen." In: A. Platonov, Die Epiphaner Schleusen. Frühe Novellen. Berlin 1986, S. 472-484. [Fedorov S. 482-484]

Delo petrasevev, t. 2, M.-L. 1941.

DeloKarov, KADYRBEC ChADŹUMAROVIC, Filosofskij analiz teonii otnositel'nosti (na materiale filosofskich diskussij v SSSR v 20 - 3a e gody), M. 1973.

- Deppermann, Maria, "Rußland um 1900: Reichtum und Krise einer Epoche im Umbruch." In: Musik-Konzeple, 37/38, Aleksandr Skrjabin und die Skrjabinisten II. München 1984, S. 61-106. [Fedorov S. 78f., 85-88, 94]

Dessauer, Friedrich, Philosophie der Technik. Das Problem der Realisierung. Bonn ${ }^{2} 1928$ [1927]. 
- Dieckmann, Eberhard, Polemik um einen Klassiker. Lew Tolstoi im Uneil seiner nussischen Zeitgenossen. Berlin, Weimar 1987. [Fedorov S. 169-171, 174, 300, 324]

- D[IENES], L[ASZLo], "Yanovsky, Vasily Semyonovich." [Lexikonartikel] In: V. TERRAS (Hg.), Handbook of Russian Literature, New Haven, London 1985, S. 523.

- Dietrich, Wolfgang, Provokation der Person. Nikolai Berdjajew in den Impulsen seines Denkens. Bde. 1-3, Gelnhausen, Berlin 1975. [Fedorov Bd. 3, S. 126-142, 176, 253]

" Dobbie-Bateman, A[RThUR] F[rrzRoy], "Technoctacy." [Leserbrief] In: The Times, [London] 10.1.1933.

- Doleżal, ANNA, "Koncepcja przyrody w poezji Mikołaja Zabołockiego." In: Studia z filologii rosyjskiej i stowiañskiej, t. 9, Warszawa 1982, S. 105-124. [Fedorov S. 106]

- DOnOvan, MARgaret Mary, The Role of Russian Religious Thought in the Writings of Nicolas Aleksandrovich Berdiaev, 18741948, Ph.D. diss. Univ. of Wisconsin 1960. [Fedorov v.a. S. $422-$ 427]

DorofEev, VIL', "Opponent, ili Pojasnitel'naja zapiska $k$ rexi N.I. Bucharina na odnoj iz graždanskich panichid 1928 goda." In: Literatumaja Gazeta, 49, 7.12.1988, S. 13.

Dostoevsku, F[eDOR] M[ICHALlovic], "Pis'mo F.M. Dostoevskogo k N.P. Petersonu." In: Russkij Archiv, 42 (1904), 3, S. $402 \mathrm{f}$.

DostoevsKu, FEDOR MICHAJloviC, Materialy i issledovanija, L. 1935.

- Dostoevski, Fedor Michajlovic, Pis'ma v cetyrech tomach, t. 4, M. 1959.

- Dostoevski, FEDOR MichajloviC, Polnoe sobranie soxinenij v tridcati tomach, t. 14-15 [Brat'ja Karamazovy], L. 1976; t. 22 [Dnevnik pisatelja za 1876 god], L. 1981; t. 30,1 [Pis'ma 1878-1881], L. 1988.

- Douglas, Charlotte, "Beyond Reason: Malevich, Matiushin, and their Circles." In: The Spinitual in Ant: Abstract Painting 1890 1985, Los Angeles, New York 1986, S. 185-199. [Fedorov S. 191]

- Dovgallo, G.I., "Iz istorii otdela rukopisej po materialam archiva G.P. Georgievskogo." In: Zapiski otdela rukopisej, vyp. 45, M. 1986, S. 61-87. [Fedorov S. 66, 76]

- Dovgallo, G.I., "G.P. Georgievskij. L.N. Tolstoj i N.F. Fedorov. Iz liznych vospominanij." [Vstupitel'naja stat'ja] In: Cetvertye Tynjanovskie ctenija, Riga 1988, S. 27-31.

- Dowler, WAYNe, Dostoevsky, Grigor'ev, and Native Soil Conservatism, Toronto 1982. [Fedorov S. 178]

DREZEN, E[RNEST] K[ARLovic], Za vseobšim jazykom, M.-L. 1928.

DRJAGIN, K.V., PatetiXeskaja linika prolelarskich poitov épochi voennogo kommunizma, Vjatka 1933. ( = Trudy vjatskogo pedagogizeskogo instituta im. V.I. Lenina; 13).

DUDEK, G[ERHARD], "Chrustal'nyj dvorec - Podpol'e - Zolotoj vek. Zur Metaphorisierung gesellschaftlicher Phånomene bei F.M. Dostoevskij." In: Zeitschrift für Slawistik, 28 (1983), 5, S. $667-$ 682.

- DUdenKov, Vladimir NikolaEviC, Filosofija vechovstva $i$ modemizm. Kritika antigumanizma $i$ éstetizma v Rossii nubeta XX v. L. 1984. [Fedorov S. 125f.]

- DUDKINA, IA., "K voprosu o primenenii principa dejatel'nosti pri rassmotrenii perspektiv razvitija zemnoj civilizacii ('kosmizeskaja filosofija' K.E. Ciolkovskogo i vzgljady N.F. Fedorova, N.A. Umova, V.I. Vernadskogo)." In: Trudy pjatnadcatych Ctenij KE. Ciolkovskogo (Kaluga 1980 g.). Sekcija 'KE. Ciolkouskij i filosofskie problemy oswoenija kosmosa.' M. 1981, S. 11-22.

Duganov, R[UdOL'f] V[AlentinoviC], "Zamysel 'Bani'." In: V mire Majakovskogo. Sb. statej. M. 1984, S. 394-434.

Duganov, R[Udol'f] V[AlentinoviC], "Poet, istorija, priroda." In: Voprosy Literatury, 1985, 10, S. 130-162.

- Dunlop, John B., The New Russian Revolutionaries, Belmont, Mass. 1976. [Fedorov S. 214] DUNLOP, JOHN B., The Faces of Contemporary Russian Nationalism, Princeton, N.J. 1983.

- Dyck, J.W., Boris Pastemak, New York 1972. [Fedorov S. 149f.] 
Ebbinghaus, Angeluka, Taylor in Russland." In: Autonomie. Materialien gegen die Fabrikgesellschaft. 1, München o.J. [1975], S. 3-15.

- Edie, James M., [u.a.], "Nicholas Fyodorovich Fyodorov (1828-1903)." In: J.M. EdiE [u.a.] (Hgg.), Russian Philosophy, vol. 3, Chicago 1965, S. 11-15.

- EFimov, IGoR' [MARKovic], Archiv Straśnogo suda. Roman. Ann Arbor 1982. [Fedorov S. 174176, 181] - Dass. auch in: Vremja i My, 65, 1982, S. 5-89.

EFroimson, Vladimir Pavlovic, "Avtoritet, a ne avtoritamost'." In: Ogonek, 11, 1989, S. 10-13.

- EgEBERG, ERIK, "Kjødets oppstandelse - som ingeniorkunst og moralsk problem. Nikolaj Fjodorovs filosofi." In: DERS., Russiske punktlys, Oslo 1981, S. 68-77.

- Egorov, B[ORIS Fedorovic], "Čto skažet Mar'ja Alekseevna." In: Sovetskaja Kul'tura, 15.3.1988.

- EGOROV, BORIS FEDOROVIC, [Diskussionsbeitrag zu] "Geografija intelligentnosti: eskiz problemy." In: Literatumaja Učeba, 1989, 2, S. 3-17; hier S. 12.

EIMERMACHER, KARh, (Hg.) Dokumente zur sowjetischen Literaturpolitik 1917-1932, Stuttgart 1972.

- Ejkalovic, Gennadi igumen [Evgeni Alexsandrovic], "Prometeizm." In: Zarubez'e, [München] 35-36 (1972), 3-4, S. 2-5.

- EjkaloviC, GenNadu igumen [Evgenu AleksandRovic], "O nekotorych aspektach 'obš̌ego dela' N.F. Fedorova (1828-1903)." In: Golos Zanubez'ja, 1978, 10, S. 12-18.

- Ejkalovic, GenNadu igumen [EvgeniJ AleksandroviC], "Fedoroviana'." In: Novyj Zumal, 163,1986, S. 259-274.

- Ejkalovic, GenNadu igumen [Evgenu Aleksandrovic], "Ovladenie viemenem." In: Vece, [München] 25, 1987, S. 69-85.

EL'CANINOV, A[LEKSANDR] V[IKTOROVIC], Istorija religii, M. 0.J. [1909].

Elenin, S., OVCinnikov, Ju., "Primęanija." [Zu N.P. ANCIFERov, Tri glavy iz vospominanij"] In: Pamjat'. Istoriceskjj sbomik. 4, Paris 1981, S. 111-145.

ELERT, WERNER, "Russische Religionsphilosophie der Gegenwart." In: Zeitschrift für systematische Theologie, 3 (1925), S. 548-588.

- Emel'janova, Tat'jana, "Michail Geller. Andrej Platonov v poiskach stast'ja. Paris 1983." [Rezension] In: Novyj Žumal, 154, 1984, S. 292f.

ERLENBUSCH, Fr., siehe TSCHIZEWSKu, D.

- ERMIEV, AA., KUZnecov, P.V., "V.P. Pazilova, Kriticeskij analiz religiozno-filosofskogo urenija N.F. Fedorova, M. 1985." [Rezension] In: Filosofskie Nauki, 1986, 3, S. 181 .

E[RN], V[LADIMIR FrancEVIC], "O dviženii sredi gruzinskogo duchovenstva." In: Voprosy Zizni, 1905,8 , S. 273-291.

ERn, VLAdimir Francevic], Pastyr' novogo tipa, M. 1907. (= Religiozno-obscestvennaja biblioteka, ser. $1 ; 7)$.

ERN, V[LAdimar Francevic], "Socializm i problema svobody." In: Živaja Žizn', 1907 (20.12.), 2, S. 40-87. - Wiederabdr. in: DeRs., Bor'ba za Logos, M. 1911, S. 181-233.

ERN, V[LADIMIR FRANCEVIC], "Staroobrjadcy i sovtemennye religioznye zaprosy." In: Zivaja Zizn', 1908, 1, S. 9-16.

ERN, V[LADIMIR FrancEVIC], "Ideja katastrofiteskogo progressa." In: Russkaja Mysl', 30 (1909), 10, S. 142-159. - Wiederabdr. in: DERS., Bor'ba za Logos, M. 1911, S. 234-261.

ERn, Vladimar [Francevic], Bor'ba za Logos. Opyty filosofskie i kriticeskie. M. 1911.

ETtINGer, Robert C.W., The Prospect of Immorialin, New York 1964.

- Evdokimov, Paur [Pavel Nikolaevic], Christus im nussischen Denken, Trier 1977. (= Sophia. Quellen 8stlicher Theologie; 12). [Fedorov S. 88-95]

- Euraziec. Diskussionnyj mutri-evrazijskij organ. Bruxelles 22, 1933 - 25, 1934.

- Evrazija. EŽenedel'nik po voprosam kal'tury i politiki. Paris, 24.11.1928 - 7.9.1929. [35 Nummern]

- Evrazijskie retradi, Prag 2-3, 1934; 4, 1934. 
- Evrazijskij sbomik. Politika, filosofija, Rossieveden'e. Kn. 6, Prag 1929.

- EvtuSENKo, EvgenI Aleksandrovic, Jagodnye mesta. Roman. M. 1982. [Fedorov S. 282]

FADDEEv, E.T., "Idea bessmertija Celoverestva u K.E. Ciolkovskogo." In: NauCnye doklady vysšej skoly. Filosofskie nauki. M. 1975, 2, S. 58-66.

Fajbusovic, GenNadu MojseEvic, siehe Chazanov, Boris

FalCo, Marino S., "Veze: il nazionalismo russo ontodosso." In: Russia Cristiana, [Milano] 13 (1972), 126, S. 3-14.

- Fateev, Valeris, "Chudožnik sveta." In: Naš Sornemennik, 1988, 3, S. 183-185.

- FEDOROV, M.G., "Materializm velikich russkich revoljucionnych demokratov i russkij filosofskij idealizm $\mathbf{v}$ ich otnosenii $\mathrm{k}$ klassiðeskoj nemeckoj filosofii. (Postanovka problemy. Kritika idealizma)." In: Istonija filosofii i sovremennaja ideologixeskaja borba. Sb. nautnych tnudov. Novosibirsk 1981, S. 3-37. [Fedorov S. 31-33]

FEDOROV, V.M., "Utenie o biosfere i problema strukturnoj organizovannosti materii." In: Vestmik Moskovskogo universiteta, ser. 7, filosofija, 1981, 6, S. 38-45.

[Fedotov, GeOrgus Petrovic] Redakcija, "Novyj grad." In: Novyj Grad, 1, 1931, S. 3-7.

- Fedotov, G[EORgu PETrovic], "Reich Gottes und Geschichte." In: Kirche, Staat und Mensch. Russisch-orthodaxe Studien. Genf 1937, S. 55-77. ( = Kirche und Welt. Studien und Dokumente; 2). [Fedorov S. 76]

- Fedotov, G[eOrgu Petrovic], "Eschatologija i kul'tura." In: Noyjj Grad, 13, 1938, S. 45-56.

Fedotov, G[EORGIJ] P[ETROVIC], Lico Rossii. Sb. statej (1918-1931). Paris 1967.

Fedotova, E.N., "Georgij Petrovið Fedotov (1886-1951)." In: G.P. Fedotov, Lico Rossii, Paris 1967, S. I-XXXIV.

- FILATov, V[ladimir] P[ETRoviC], "Ob istokach lysenkovskoj 'agrobiologii'. (Opyt social'no-filosofskogo analiza)." In: Voprosy Filosofii, 1988, 8, S. 3-22. [Fedorov S. 19]

FILPCENKo, IVAN [GUR'EVIC], Era slay. Stichi i poimy 1913-1918. M. 1918.

Filuppov, A., "Kryl'ja." In: Vesy, 1906, 5, S. 38-40.

Filuppov, B.A., siehe Filistinsku, B.A.

- Filuppov, G.V., Russkaja sovetskaja filosofskaja poezija, L. 1984.

- [Filustinsku, Boris AndreeviC] Petrov, Georgu, "Leningradskij Peterburg." In: Grani, 8(1953), 18, S. 39-50. [Fedorov S. 40, 45]

- [FILISTINSKIJ, BORIS ANDREEVIC] FILIPPOV, BORIS, "Nikolaj Kljuev. Materialy k biografii." In: N.A. KLuUEv, Polnoe sobranie soxinenij, t. 1, New York 1954, S. 9-114. [Fedorov S. 34f., 41, 58f., $68,90]$

- [Filistinski, Boris ANDReevic] Petrov, Georgu, "Kandidat bylych stoletij, polkovodec novych let (poezija Nikolaja Zabolockogo)." In: Mosty, 1(1958), S. 193-222. [Fedorov S. 215]

- [FILISTINSKu, Boris ANDREeviC] FIlipPOV, Boris, "Razgovor po povodu i bez povoda..." In: Grani, 14 (1959), 44, S. 161-175.

- [FILISTINSKu, Boris ANDREevic] Filippov, Boris A., "'Dom iskusstv' i 'Sumassedšij Korabl"." [Vorwort zu] O. ForS, Sumassedsij korabl', Washington 1964, S. 7-55. [Fedorov S. 26, 28]

- [FILISTINSKI, Boris ANDREEviC] FILIPPOV, BorIS, "Nikolaj Kljuev. Materialy dlja biografii." In: NA. KuUUEV, Soximenija, 1, München 1969, S. 5-182. [Fedorov S. 29-31, 50, 52, 57f., 79, 86, 94, $100,128 f$.

- [FILISTINSKu, Boris ANDreEvic] FilipPov, Boris, "'Javlenie' (Nikolaj Kljuev)." [1964] In: DERS., Mig, k kotoromu ja prikasajus', Washington 1973, S. 53-76. [Fedorov S. 57f., 66f.]

- [FILISTINSKU, BORIS ANDREEVIC] FILIPPOV, BORIS, Skatulka s dvojnym dnom, o.O. [Washington] 1977. [Fedorow S. 79, 86, 151, 155]

- [FILISTINSKU, BORIS ANDREEVIC] FILIPPOV, BORIS, Mysli naraspaska, Washington 1979. [Fedorov und Kljuev S. 149-157] 
- [FILISTINSKU, BORIS ANDREeviC] FILIPPOV, Boris, Stati o literature, London 1981. [Fedorov S. 63f., 172, 179, 225, 231]

[FILISTINSKU, BORIS ANDREEVIC] F.B., "Askol'dov, Sergej." [Lexikonartikel] In: V. TERRAS (Hg.), Handbook of Russian Literanure, New Haven, London 1985, S. $26 \mathrm{f}$.

FISCHER, FRIEDHELM WILHELM, "Geheimlehren und moderne Kunst. Zur hermetischen Kunstauffassung von Baudelaire bis Malewitsch." In: R. BAUER u.a. (Hgg.), Fin de siècle. Zur Literatur und Kunst der Jahrtundertwende. Frankfurt/M. 1977, S. 344-377.

FItZPATRICK, SHEILA, The Commissariat of Enlightenment. Soviet Organization of Education and the Arts under Lunacharsky October 1917-1921. Cambridge 1970.

- Flaker, Aleksandar, Poetika osporavanja, Zagreb 1982. [Fedorov S. 69]

- Fleischer, Helmut, "Die Perestrojka etreicht die Philosophie." In: Das Argument, 167, 1988, S. 9-31. [Fedorov S. 20]

FLEJSMAN, L[AZAR'], "Gor'kij i žumal'nyj proekt A.E. Kogana." In: Slavica Hierosolymitana, 4, 1979, S. 268-273.

FloRENSKU, K[IRILL] P[AVLOVIC], "O rabotach P.A. Florenskogo." In: Utenye zapiski Tartuskogo gos. universitela, vyp. 284, Tartu 1972, S. 501-503.

- Florensku, Pavel [Aleksandrovic], Stolp i utvertdenie istiny. Opyt pravoslavnoj feodicei v dvenadcati pis'mach. M. 1914. [Fedorov S. 459f., 614, 643, 703, 744, 789, 807]

FlorensKu, P[AVEL Al.eKSANDRovic], "Chramovoe dejstvo, kak sintez iskusstv." [1918] In: Makovec, 1922, 1, S. 28-32. - Wiederabdr. in: Sobranie dokumentov samizdata, t. 26, ¿. 2, München 1978, S. 445-458. P.[A.] FlorensKu, Sobranie soxinenij, t. 1, Paris 1985, S. 41-55. Architekrura i Stroitel'stvo Moskvy, 1988, 6, S. 17-20. Sovetskaja Kul'tura, 59, 18.5.1989, S. 6 [gekürzt].

Florenski, PAVel [AleksandroviC], "Simvoliteskoe opisanie." In: Feniks, kn. 1, M. 1922, S. 80-94.

Florenski, PaVel [Aleksandrovic], Mnimosti v geometrii. Rassirenie oblasti dvuchmemych obrazov geometrii. (Opyr novogo istolkovanija mnimostej). M. 1922. - Dass. [Nachdruck] München 1985. ( - Specimina philologiae Slavicae; Suppl. 14).

[Florenskis, Pavel Ai.eksandroviC], "Florenskij, Pavel Aleksandrovic." [Lexikonartikel] In: Enciklopediteskij slovar nusskogo bibliografizeskogo instituta Granat, t. 44, M. o.J. [1927], Sp. $143 f$.

FloRENSKU, P[AVEl] A[LeKSANDROVIC], "Organoproekcija." In: Dekorativnoe Iskusstvo SSSR, 1969,145, S. 39-42.

FLORENSKU, P[AVEL] A[LEKSANDROVIC], "Biograficeskie svedenija (avtoreferat)." In: Vesinik $R C h D, 135,1981$, S. 54-59.

Florovsku, GeORgu [VASIL'EviC], "Evrazijskij soblazn." In: Sovremennye Zapiski, 34, 1928, S. 312-346.

- Florovsku, Georgu [VASIL'EviC], "Die Urgestalt der Brüder Karamasoff ... München 1929." In: Put', 23, 1930, S. 121-125.

- Florovski, Georgu [VAsil'eviC], "Proekt mnimogo dela. (O N.F. Fedorove i ego prodolžateljach)." In: Sorremennye Zapiski, 59, 1935, S. 399-414.

- Florovsku, Georglu [VAsil'evic], Puti russkogo bogoslovija, Paris 1937. [Fedorov S. 322-330]

- [Florovsku, Georgu VAsil'evic] Florovsky, Georges, "Reason and Faith in the Philosophy of Solov'ev." In: E.J. SImmons (Hg.), Continuiry and Change in Russian and Soviet Thought, Cambridge, Mass. 1955, S. 283-297.

[FloRovSKu, GeORgu VASIL'EVIC], "Iz pisem o. Georgija Florovskogo Ju. Ivasku." In: Vestnik $R C h D, 130,1979$, S. 42-52.

- Fomenko, L., "N.G. Poltavceva, Filosofskaja proza Andreja Platonova." [Rezension] In: Voprosy Literatury, 1982, 5, S. 217-223.

FORESTIER, LOUIS, "Symbolist imagery." In: The Symbolist Movement in the Literature of Euma pean Languages, Budapest 1982, S. 101-118. (= A Comparative History of Literature in European Languages; 2). 
Frank, S|EmEn LuUdovigovic], "Die russische Philosophie der letzten fünfzehn Jahre." In: Kant-Studien, 31 (1926), 1, S. 89-104.

Frank, S[EmEn LudDovigovic], "Contemporary Russian Philosophy." In: The Monist, 37 (1927), 1, S. 1-23.

- Frank, S[emen LuUdovigoviC], "Aus Dostojevskijs geistiger Werkstatt." In: ZfslPh, 7, 1930, S. 137-141.

FRANK, S[EMEN] LJUDOVIGOVIC], Eres' utopizma. Kritika idejnych osnov religioznogo, politiceskogo i social'nogo utopizma. San Martin 1954.

Frank, Simon [SEMEN LuUdovigoviC], Die nussische Wellanschauung, Darmstadt ${ }^{2} 1967$ [ $^{1} 1926$ ].

- FRANK, S[EMEN] LJUDOVIGOVIC], Iz istorii nusskoj filosofskoj mysli konca XIX i nacala XX veka. Antologija. Washington, New York 1965. [Fedorov S. 12, 49f.] - Dass. [ital.] Il pensiero religioso nusso. Da Tolstoj a Losskij. Antologia. Milano 1977. (= Filosofia e scienze umane; 15).

- Fridlender, G.M., "Primetanija, \& 8." [Zu F.M. Dostoevskij, Brat'ja Karamazovy, kn. XI-XII, epilog]. In: F.M. DostoEVSKJ, Polnoe sobranie socinenij v tridcati tomach, t. 15, L. 1976, S. 459473. [Fedorov S. 469-471]

- Frolov, I[vaN] T/imofeeviC], "O žizni, smenti i bessmertii. Etjudy novogo (real'nogo) guma. nizma." In: Voprosy Filosofii, 1983, 1, S. 83-98; 2, S. 52-64.

- Frolov, I[VAN TIMOfEEvic], "O teloveke razumnom i gumannom, a takže o biokiborgach, bessmentii i voskreł̌nii mertvych i voobšce o mifologii v vek NTR." In: Nauka i Żizn', 1983, 4, S. $60-66$.

Frolov, IVAN TimpfEEVic, Perspektivy celoveka. Opyr kompleksnoj postanovki problemy, diskussii, obobstenija. M. ${ }^{2} 1983$ [1979].

- Frolov, I[VAN] T[IMOFEEVIC], "Z istorii moral'no-filosofs'kich rozdumiv pro smysl żittja, smert' i bezsmertja: F.M. Dostojevs'kij, V.S. Solovjov." In: Filosofs'ka Dumka, 1985, 2, S. 41-50.

- Frolov, I[VAN] T[IMOFEEVIC], " $Z$ istorii moral'no-filosofs'kich rozdumiv pro smysl zittja, smert' i bezsmertja: M.F. Fedorov, V.I. Vernads'kij, M.M. Prił̌in." In: Filosofs'ka Dumka, 1985, 3, S. 5967.

- Frolov, Ivan [TMmofeEvic], "Prizraki i illjuzii 'večnoj žizni' i 'vseobక̌cego voskrešenija'." In: Sovetskaja Kul'tura, 73, 20.6.1989, S. 6.

Frolov, V|aleru] A[fanas'eviC], "O pnevmatosfere P.A. Florenskogo." In: PA. Flonenskij: $f$ losofija, nauka, technika. L. 1989, S. 31f. (= Preprint; 4).

Frolov, VikTor Alekseevic, Operediusij uremja, M. 1980.

- FudeI', S[ergeJ] I[osifoviC], "U sten cerkvi. Materialy i vospominanija." In: Nadezda. Christianskoe ctenie. Vyp. 2, Frankfurt/M. 1979, S. 214-375. [Fedorov S. 369-371]

- FOLOP-MILlER, RENE, Geist und Gessicht des Bolschewismus. Darstellung und Kritik des kulturellen Lebens in Sowjet-Russland. Wien 1928 [11926]. [Fedorov S. 134, 378f.]

FurMaN, D[MTTRU E.], "Naš put' k normal'noj kul'ture." In: Ju.N. AfaNAS'Ev (Hg.), Inogo ne dano, M. 1988, S. 569-580.

- GaCev, Georgu DmTtrieviC, Cingiz Ajtmalov i mirovaja literatura, Frunze 1982. [Fedorov S. 238]

- Gandenko, P[lama Pavrovina], "Smert'." [Lexikonartikel] In: Filosofskaja énciklopedija, t. 5, M. 1970, S. 34-36.

Galaktionov, ANatolu ANDrianovic, Nikandrov, PEtr Fedotovic, Russkaja filosofija X]. $X I X$ w., L. 1970.

Galas'eva, G.V., "Tema prirody i evoljucija liznosti v proze A.P. Platonova 1920-ch godov." In: Celovek i priroda v chudožestvennoj proze. Metwruzovskij sb. Syktyvkar 1981, S. 33-48.

- Gal'CEVA, R[eNata Aleksandrolna], "Vernadskij, Vladimir Ivanovit." [Lexikonartikel] In: Filosofskaja énciklopedija, t. 5, M. 1970, S. 624f.

GaNCIKov, LEONDA, Orientamenti dello spirito russo, Torino 1958. 
- GANČIKov, L[EONDA], "Fedorov." [Lexikonartikel] In: Enciclopedia filosofica, 2, Firenze 21967, Sp. $1252 f$.

Garibian, V.P., siehe Pazilova, V.P.

GaRmaSEVA, T.V., KaPELJUS, V.N., "Rukopisi i perepiska F.M. Dostoevskogo." In: Bjulleteni rukopisnogo otdela Puskinskogo doma, vyp. 7, M.-L. 1957, S. 5-130.

GASTEV, Alekses [KAPITONovic], Poezija mabočego udara, Pg. 1918.

GaSTEV, A[LEKSEJ KAPITONOVIC], "O tendencijach proletarskoj kul'tury." In: Proletarskaja Kul'tura, 1919, 9-10, S. 35-45.

Gastev, Aleksej KaptTonoviC, Organizacija truda, M. 1921.

- Gavruusin, N[IKOLAJ] K[ONSTANTINOVIC], "Social'nye i esteticeskie motivy v razvitii idei kosmiZeskogo poleta." In: Trudy pjatych $i$ Sestych Ctenij, posvjašennych razmabotke nauZnogo nasledija i rarvitiju idej KE. Ciolkovskogo (Kaluga 1970, 1971 gg.). Sekcija 'Issledovanie nautnogo twortestva K.E. Ciolkouskogo.' M. 1972, S. 50-58.

- GaVRUUSIN, N[IKOLA]] K[ONSTANTINOVIC], Chudožestvennoe tvortestvo i mazvitie nauki (stanovlenie idei osvoenija kosmosa). Avtoreferat kandidatskoj dissertacii, M. 1973.

- [Gavruusin, Nikolas Konstantinovic] A.M. [steht für Anatolu Sergeevic Mel'nikov, d.i. ARCHIEPISKOP ANTONU], "Voskreక̌enie taemoe ili voschišaemoe? (O religioznych vozzrenijach N.F. Fedorova)." In: Bogoslovskie trudy, 24, 1983, S. 242-259.

GELLER, LEOND [MICHAJLOVIC], siehe HELLER, LEONID

Geller, Michail [JAKOVLEVIC], siehe HELLER, Michel

GENNADIJ (EjKaloviC) IGUMEN, siehe EuKaloviC, GENNADI IGUMEN

- Georgieva, EmLla, "Il predecessori dell'avanguardia pittorica russa nel quadro storico del 1898-1908." In: Mir Iskusstva. La cultura figurativa, letteraria e musicale nel Simbolismo russo. Roma 1984, S. 87-95.

- G[eorgievski]], G[RIGoru PetroviC], "Pamjati Nikolaja Fedorovita." In: Moskovskie Vedomosti, 344, 16.12.1903, S. 3.

- [Georgievsku, Grigoru Petrovic] Pokrovsku, P.JA., "Iz vospominanij o Nikolae Fedorovite. (K 40 dnju konciny)." In: Moskovskie Vedomosti, 23-26, 23.-26.1.1904, S. 4f., 4f., 5, 4.

- GeorgievsKu, G[RIGoru PETrovic], "L.N. Tolstoj i N.F. Fedorov. Iz ližnych vospominanij." In: Noyj Zumal, 142, 1981, S. 91-109. [Gekürzte und stellenweise abweichende Fassung des folgenden]

- Georgievsku, G[RIGORI] P[ETRovic], "L.N. Tolstoj i N.F. Fedorov. Iz ličnych vospominanij." In: Cervertye Tynjanouskie ctenija, Riga 1988, S. 46-66.

Gerasimov, K.S., "Šturm neba' v poezzii Valerija Brjusova." In: Brjusovskie čenija 1963 goda, Erevan 1964, S. 130-153.

- Gerasjutin, SERgej [A.], "Pervye tenija N.F. Fedorova." In: Vestnik Prometeja, vyp. 3, M. 1988, S. 289-291.

GERCEN, ALEKSANDR IVANOVIC, Sobranie socinenij v tridcati tomach, t. 3, M. 1954; t. 6, M. 1955.

- GerCUK, JURL, "Pereselenie Celoveka na zvezdy." In: Dekorativnoe Iskusstuo SSSR, 1971, 4, S. 25.

- GerCuK, Ju[Ru], "Vasilij Cekrygin." In: Tvon'estro, 1974, 10, S. 10-12.

GercyK, Evgeniua Kazimirovna, Vospominanija, Paris 1973.

GESSEN, S.I., siehe HeSSEN, S.I.

GEYER, DIETRICH, "Den toten Gott im Herzen tragen. Das Wiederaufleben der idealistischen russischen Philosophie." In: Frankfuner Allgemeine Zeitung, 118, 24.5.1989, S. N3.

GEZELINSKU, G.G., siehe SETNICKU, N.A.

- Ginken, ANTION ANTONoviC], "Ideal'nyj bibliotekar' - Nikolaj Fedorovic Fedorov. (Kratkaja charakteristika pokojnogo, kak celoveka i bibliotekarja, po literatumym dannym)." In: Bibliotekar. Zumal obstestva bibliotekovedenija. [SPb.] 1911, 1, S. 12-26. - Wiederabdr. in: DERS., $O$ ctenii i knigach, SPb. 1914. 
* G[INS], G[EORgu KonstantinoviC], "Juridiðeskij fakul'tet v g. Charbine 1920-1930." In: Izv.Jur.Fak., 9, 1931, S. 308-314. [Fedorov S. 314]

GiNs, G[EORGI] K[ONSTANTINOVIC], "Spisok professorov, prepodavatelej i lektorov Juridiłeskogo Fakul'teta $\mathrm{i}$ ich pełatnye trudy za vremja suscestvovanija Fakul'teta (1 marta $1920 \mathrm{~g}$. 1 ijulja 1931 g.)." In: Izv.Jur.Fak., 9, 1931, S. 337-361.

[Gins, Georgu Konstantinovic] Guins, George C., "Russians in Manchuria." In: The Russian Review, 2 (1943), 2, S. 81-87.

GIPPIUS, Z[INAIDA] N[IKOLAEVNA], Literatumyj dnewnik (1899-1907), SPb. 1908. Nachdruck München 1970. (= Slavische Propyläen; 102).

Gippius, Z[Inalda Nikolaevna], Sinjaja kniga. Peterburgskij dnevnik 1914-1918. Belgrad 1929. (= Russkaja biblioteka; 6 ).

Gippius, Zinaida NikolaeVNa, siehe auch unter Pachmuss, Temira (1972)

- GiRENOK, F[EDOR] I[VANOVIC], "Russkij kosmizm: vsaimosvjaz' filosofskich i estestvennonautnych problem." In: Filosofskie metodologiceskie seminary. Problemy razvitija. M. 1983, S. 262-280.

- GiRENOK, FEDOR IVANOViC, Ekologija civilizacija noosfera, M. 1987. [Fedorov S. 156f., 162, 165, 168-181]

- Glagolev, Vladimir SergeeviC, Religiozno-idealisticeskaja kul'turologija: idejnye tupiki, M. 1985. [Fedorov S. 24, 31, 108, 203f.]

- Glazov, YURI, "Ludmila Koehler. N.F. Fedorov: The Philosophy of Action. Pittsburgh, Pa. 1980." [Rezension] In: Canadian Slavonic Papers, 26 (1984), 1, S. $105 f$.

- G[LEISNER], J[EFF], "Pictures at an Exhibition." In: Detente, [Leeds] 9/10, 1987, S. 40f.

- Gleisner, JefF, "Memoirs of Moscow's 'Pictures at an Exhibition'". In: The Soviet Observer, 10.5.1988, S. 5 .

- Gloska, Vladimir, "Simfonija' (2-ja, dramaticeskaja)." In: Zbomik Pedagogickej Fakulty v Banskej Bystrici, 17, Ruský jazyk a literatúra, Bratislava 1969, S. 207-236. [Fedorov S. 217f.]

Gluchov, A., "Mežplanetnye putesestvija'." In: Al'manach bibliofila, 2, M. 1975, S. 51-57.

GMELINE, PATRICK DE, Dictionnaire de la noblesse nusse, Paris o.J. [1978].

- GN., G. [GoRdon, G.O. ?], "Fedorov, Nikolaj Fedorovic." [Lexikonartikel] In: Enciklopediceskij slovar nusskogo bibliograficeskogo instituta Granat, 7-e izd., t. 43, M. o.J. [nicht vor 1926], Sp. 102. GobZa, I.O., Stoletie Moskouskoj 1-j gimnazii. 18041904 8g. Kratkij istorizeskij acerk. M. 1903.

- GoerdT, WILhelm, Russische Philosophie. Zugänge und Durchblicke. Freiburg/Br., München 1984. [Fedorov S. 475]

GoguAdze, V.V., "Titanizm i neotitanizm." In: A.F. Losevu k 9a-letiju so dnja rotdenija, Tbilisi 1983, S. 131-141.

Goldberg, Harold Joel, The Anarchists View the Bolshevik Regime, 1918-1922. Ph.D. diss. Univ. of Wisconsin 1973; Ann Arbor, Mich. 1974.

- Gol'denvejzer, Alexsandr Borisovic, Vblizi Tolstogo, M. 1959. [Fedorov S. 127f., 130, 413]

- Goldstein, Darra Jane, In Pursuit of Hamony: The Long Poems of Nikolaj Zabolockj. Ph.D. diss. Stanford Univ. 1982; Ann Arbor, Mich. 1983. [Fedorov S. 176-185]

- Goldstein, DaRra [JANE], "Zabolockij and Ciolkovskij." In: Russian Literature, 13, 1983, S. 6580.

- Goldt, Rainer, Sprache und Mythos bei V. Chlebnikov, Mainz 1987. ( = Mainzer Slavistische Veröffentlichungen. Slavica Moguntiaca; 10). [Fedorov S. 42f., 87f., 202, 216]

GOLDT, RAINER, "Aspekte der sowjetischen Idealismusdebatte." In: E. REISSNER (Hg.), Literatur und Perestrojka, Berlin [im Druck].

Golinkov, DAvid L'vovic, Krušenie antisovetskogo podpol'ja v SSSR, kn. 1-2, M. ${ }^{2} 1978$.

- GOLERBACH, E[RiCH] F[ECOROVc]], "Russkaja filosofija i eja sud'ba." In: Novaja Russkaja Kniga, [Berlin] 1922, 5, S. 1-4.

GOLLERBACH, E[RICH] F[EDOROVIC], V.V. Rozanov. Zizn'i wortestuo. Pb. 1922. 
- Goulwitzer, Heinz, Die gelbe Gefahr. Geschichie eines Schlagwonts. Studien zum imperialistischen Denken. Gottingen 1962. [Fedorov S. 97f., 103]

- Golovanenko, S[ergej Alekseevic], "Filosofija obšcego dela." [Rezension] In: Bogoslovskij Vestnik, 22 (1913), 12, S. 832-844.

- Golovanenko, S[ergej] A[LEKSEEviC], "Filosofija smerti i voskreß̌enija. (Proektivizm N.F. Fedorova)." In: Bogoslouskij Vestnik, 23 (1914), 4, S. 664-688.

- Golovanenko, S[ergej] A[LekseeviC], "Pravoslavie i kul't predkov." In: Bogoslovskij Vestnik, 23 (1914), 5, S. 83-109.

- Golovanenko, S[ERGej AlekseeviC], "Immanentizm i christianskaja filosofija. (O real-filosofskich predposylkach N.F. Fedorova)." In: Bogoslouskaj Vestnik, 23 (1914), 7-8, S. 569-592.

- Golovanenko, S[ERgej AlekseeviC], Tajna synovstva. (O christianstve N.F. Fedorova)." In: Bogoslovskij Vestrik, 24 (1915), 3, S. 498-516.

- Golovanenko, S[ERgej AlekseEviC], "Proekt ili simvol? (O religioznom proektivizme N.F. Fedorova)." In: Bogoslovskij Vestnik, 24 (1915), 6, S. 294-314.

- Golovanenko, S[ergej Alekseevic], "Otvet N.P. Petersonu." In: Bogoslouskij Vestnik, 25 (1916), 1, S. 130-135.

- Golovanov, Ja[Roslav Kirillovic], "Real'nost' mečty." In: Komsomol'skaja Pravda, 59, 11.3.1978.

- Golovanov, Jaroslav Kirillovic, Doroga na kosmodrom, M. 1982. [Fedorov S. 135-139] Dass., M. 1983; ohne Hinweis auf Fedorov!

- Golovanov, L[EONID] V[TTAL'EviC], "K voprosu ob idejnych vlijanijach na K.E. Ciolkovskogo." In: Trudy tret'ich Ċenij, posvašennych razrabotke naurnogo nasledija i razvitiju idej $K E$. Ciolkovskogo (Kaluga, 17.19 sentjabrja 1968 g.). Sekcija 'Issledovanie naurnogo tuortestva KE. Ciol. kovskogo'. M. 1969, S. 3-16. [Fedorov S. 9-12]

- Gomolicku, L[EV] N[IKolaEviC], "N.F. Fedorov. K 30 letiju so dnja ego smerti (28. XII. 1903)." In: Molva, [Warszawa] 294, 23.-25.12.1933, S. 4.

Gonenija na anarchizm v Sovetskoj Rossii, Berlin 1922.

GoR, Gennadu [SAmojlovic], "Pobediteli vremeni i prostranstva." In: Zvezda, 1959, 10, S. 151. 158.

- Gor, Gennadu [SAmojloviC], "Zamedlenie vremeni." In: Zuezda, 1968, 4, S. 174-190. - Wiederabdr. in: DeRs., Geometriteskij les, L. 1975, S. 384-423.

- Gor, Gennadu [Samojlovic], "Ol'ga Nsu." In: Ders., Glinjanyj papuas. NauCna-fantasticeskie povesti i masskazy. M. 1966, S. 159-177. [Fedorov S. 164f., 174]

- Gor, Gennadu Samojlovic, Geometrizeskij les, L. 1975.

GORDIENKo, L.N., "Vernadskij i Prišvin. Vzaimodejstvie naučnogo i chudožestvennogo soznanija v formirovanii estetiłeskogo Cuvstva prirody." In: Vestnik Moskovskogo universitera, ser. 7, filosofija, 1980, 1, S. 58-66.

GORDINY [BRAT'JA], Manifest pananarchistov, M. 1918.

Gorelik, GeORGE, "Bogdanov's Tectology: Its Nature, Development and Influence." In: Studies in Soviet Thought, 26 (1983), S. 39-57.

- Goriceva, Tat'jana [Michajlovina], "O religioznom v postmodemizme." In: Kontinent, 53, 1987, S. 277-289. [Fedorov S. 288f.]

- Gorjély, Benjamin, "Les Gagarine. De l'utopiste au cosmonaute." In: Esprit, 29 (1961), 9 (298), S. 274-280.

GORIELY, BENJAMIN, Le avanguardie letreravie in Europa, Milano 1967.

[GoR'Ku, MAKsIM, d.i. PESKov, AleKseJ MAKSIMOVIC] GORK, MAXIME, [Antwort auf die Umfrage des Mercure de France "La question religieuse"]. In: Mercure de France, 61, 15.4.1907, S. 592 595 .

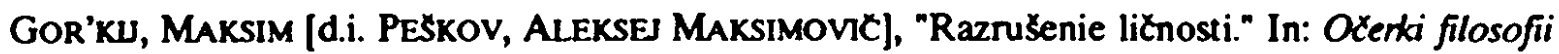
kollektivizma. Sb. pervyj. SPb. 1909, S. 351-403. 


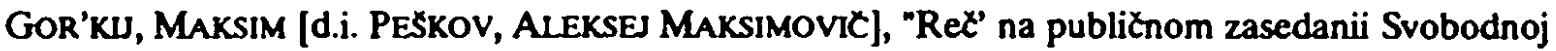
associacii dlja razvitija i rasprostranenija položitel'nych nauk." [April 1917] In: Letopis', 1917, 5-6, S. 223-228.

- GoR'kJ, A.M. [d.i. PeSKov, Aleksej MaksimoviC], "Pis'mo Gor'kogo B.M. Ejchenbaumu." In: Literatumyj Souremennik, 5 (1937), 6, S. $28 \mathrm{f}$.

GoR'ku, Maksim [d.i. Peskov, Aleksej Maksimovic], "Devuska i Smert'." [1892] In: Ders., Sobranie soxinenij v tridcati tomach, t. 1, M. 1949, S. $22-29$.

GoR'ky, Maksim [d.i. PešKov, Aleksej Maksimovic], "O nauke." [1932] In: Archiv A.M. Gorkogo, t. 3, M. 1951, S. 196-198.

- GoR'kU, Maksim [d.i. Peskov, Aleksej Maksimovic], "Pis'ma Maksima Gor'kogo k V.F. Chodasevizu." In: Novyj Zumal, 30, 1952, S. 189-202. [Fedorov S. 193]

- GoR'Ku, Maksim [d.i. PESKov, Aleksej Maksimovic], "Eš̌e o mechanizeskich graždanach." [1928] In: DERS., Sobranie soxinenij v tridcati tomach, t. 24, M. 1953, S. 447-455.

- Gor'xu, Maksim [d.i. Peskov, Aleksej Maksimovic], "O ženšine." [1930] In: Ders., Sobranie soxinenij v tridcati tomach, t. 25, M. 1953, S. 154-166.

GOR'KI, A.M. [d.i. PESKov, Alekses MAKSIMOVIC], "O znanii. (Stenogramma lekcii, procitannoj 30 marta 1920 goda v Rabore-krest'janskom universitete)." In: Archiv A.M. Gorkogo, t. 12, M. 1969, S. 101-111. - Wiederabdr. in: Promelej, 7, M. 1969, S. 136-143.

GoR'ku, Maksim [d.i. PeŠKov, Aleksej MaksimoviC], "Mat'." In: Ders., Polnoe sobranie sotinenij. Chudožestuennye proizvedenija v dvadcati pjati tomach. T. 8, M. 1970.

GoR'Ku, MAKsiM [d.i. PESKov, Aleksej MAKsimovic], Neswoevremennye mysli. Stat'i 1917-1918 8g. Paris 1971.

Gor'Ku, Maksim [d.i. PeSkov, Aleksses MaksimoviC], "Iz vospominanij." [1917] In: Ders., Polnoe sobranie soxinenij. Chudoťestvennye proizvedenija v dvadcati pjati tomach. T. 16, M. 1973, S. 394-397.

- Gor'ku, Maksim [d.i. Peskov, Aleksej Maksimovic], Polnoe sobranie soxinenij. Chudozestvennye proizuedenija v dvadcati pjati tomach. T. 22-25, M. 1974-1976. [Zizn' Klima Samgina und Kommentar]

- Gor'ku, Maksim [d.i. Peskov, Aleksej Maksimovic], Polnoe sobranie soxinenij. Varianty k chudozestvennym proizvedenijam. T. 5, M. 1977. [Fedorov S. 599, 602]

GoR'ki, Maksim [d.i. Peskov, Aleksej Maksimovic], "Pis'ma A.M. Gor'kogo k V.V. Rozanovu i ego pomety na knigach Rozanova." In: Kontekst 1978, M. 1978, S. 297-342.

GORLIN, MiCHAEL [MICHAIL GENRICHOVIC], "Die philosophisch-politischen Stromungen in der russischen Emigration." In: Osteuropa, 8, 1932-1933, S. 279-294.

Gornostaev, A.(K.), siehe Gorski, A.K.

GorodeckI, SERgej [MrtrofaNoviC], "O Sergee Esenine. Vospominanija." In: Novyj Mir, 2 (1926), 2, S. 137-146.

[Gorsku, Aleksandr Konstantinovic] Gornostaev, A., "Utro pjatnicy." [Gedicht] In: Novoe Vino, 2, 1913, S. 5.

" [GoRski, AleKSANDR Konstantinovic] A.K., "O kli飞kach. (Iz bratskoj perepiski)." In: Novoe Vino, 2, 1913, S. 9 f.

[Gorsku, Aleksandr Konstantinovic] Gornostaev, A., "Stichotvorenija." [4 Gedichte] In: Nove Vino, 3, 1913, S. 4f.

[Gorsku, Aleksandr Konstantinovic] Gornostaev, A., Glubokim utrom. (Pesnopenija). M. 1913.

[GORSKU, ALEKSANDR KONSTANTINOVIC] GROBOV, A., "O nestroenijach obšestvennych. (Pis'ma Maks. Iv. Nevzorova knjazju A.N. Golicynu v 1820 g. i mitr. Serafimu 1824 g.)." In: Golos Minuvsego, 1 (1913), 12, S. 270-278.

[GoRsku, Aleksandr Konstantinovic] Gornostaev, Alfiksandr, [Gedichte]. In: Sed'moe pokgrvalo. Stichi. Odessa 1916, S. 15-22. 
[GoRsku, Aleksandr Konstantinovic] GornostaEv, A., "Krasnaja tajna. (Rossija v poézii A. Bloka)." In: Južnyj Ogonek, [Odessa] 1918, 16, S. 8-12.

[GORSKU, AleKSANDR KonstantinoviC] GoRnostaEv, A., "Golos iz kletki. Neizdannoe pis'mo A. Bloka." In: Segodnja, [M.] 1922, 2-3, S. 4 f.

[GORSKU, ALEKSANDR KonSTANTINOVIC] siehe auch Smertobożnižstuo, 1926

- [Gorski, Aleksandr KonstantinoviC] Ostromirov, A., Nikolaj Fedorovic Fedorov. 18281903-1928. Biografija. O.O. [Harbin] 1928. ( = A. OSTROMIROV [A.K. GORSKI], Nikolaj Fedorovic Fedorov i sovremennost'. Oxenki. Vyp. 1). - Dass. [unter dem Titel] "Nikolaj Fedorovii Fedorov. (Biografizeskij ozerk)." In: N.F. FEDOROV, Filosofija obšcego dela. T. I, vyp. 1, Charbin 1928, S. V-XX.

- [Gorski, Aleksandr Konstantinovic] Ostromirov, A., Nikolaj Fedorovit Fedorov $i$ sovremennost'. Oxerki. Vyp. 2-4, Charbin 1928-1933.

[Gorski, Aleksandr Konstantinovic] Gornostaev, A.K., Lico èry. Stichi. Charbin 1928.

- [Gorsku, Aleksandr Konstantinovic] Gornostaev, A.K., Pered licem [sic] smerti. L.N. Tolstoj i N.F. Fedorov. 1828-1903-1910-1928. O.O. [Harbin] 1928. - Dass. [auszugsweise] in: Novosti Žizni, [Harbin] 1928, 20-22. - Dass. [tschech.] Před rvărn smrti, Praha 1933. - Dass. [japan.] 1933.

- [GoRsku, AlEKSANDR KonstantinoviC] GornostaEv, A., "N.F. Fedorov." In: Izvesiija CIK SSSR i VCIK, 300 (3534), 28.12.1928, S. 4

- [Gorski, Aleksandr Konstantinovie] Gornostaev, A.K., Raj na zemle. $K$ ideologii mor'estva F.M. Dostoevskogo. F.M. Dostoevskij i N.F. Fedorov. O.O. [Harbin] 1929.

[Gorsku, Aleksandr Konstantinovie] Gornostaev, A.K., Odigitrija. Sonety iz cikla 'Velikaja cep". O.O. [Harbin] 1935.

[Gorski, Aleksandr KonstantTnovic] Jachontov, Zin. Gerv., Vyskazyvanija i kantiny. Poema v 3-ch Castjach. C. 1-2, 0.O. [Harbin] 1935.

Grabovsku, N. [d.i. GALKIN, VladimiR FILJPPOVIC], 'Doloj materializm!' (Kritika émpiriokririceskoj kritiki). SPb. 1910.

Graham, LoRen R., "Bogdanov's Inner Message." In: A. Bogdanov, Red Star. The First Bolshevik Utopia. Bloomingt on 1984, S. 241-253.

Grahum, Loren R., Science, Philosophy, and Human Behavior in the Soviet Union, New York 1987.

- Granin, DANill AleksandroviC, "Eta strannaja žizn'." [1974] In: DERS., Idu na grozu. Ela strannaja Kizn'. Odnofamilec. Vybor celi. L. 1978, S. 367-477. [Fedorov S. 379f.]

GRATEEUX, A[LBERT], Le mouvement slavophile d la veille de la nevolution. Dmitri A. Khomiakov. Paris 1953.

- GreXiskin, S.S., Lavrov, A.V., "Andrej Belyj i N.F. Fedorov." In: Tvortestuo AA. Bloka $i$ russkaja kul'tura XX reka. Blokovskij sbornik 3. Tartu 1979, S. 147-164. (= UCenye zapiski Tartuskogo gos. universiteta; 459).

- GreCKo, P.K., EPISKoposov, G.L., "N.F. Fedorov: Filosofija dela kak delo filosofii." In: Vestnik Moskovskogo universiteta, ser. 7, filosofija, 1981, 6, S. 66-74.

GREJ, D., siehe SATOVSKU-RŽEVSKU, G.G.

Grekov, A.U., "Chudožestvennaja žizn' Zagorska." In: Pamjaıniki oređestva, 2 (16), 1987, S. 3343.

GrekULov, EFIM FEdOROVIC, Cerkov', samodertavie, narod (2-ja polovina XIX - nacalo XX v.). M. 1969.

- Grigor'Ev, AlEkSEJ L'voviK, Russkaja literatura v zanubeinom literaturovedenii, L. 1977. [Fedorov S. 167]

Grigor'ev, Sergej [TImofeeviC], Gibel' Britanii. Povest'. M.-L. 1926.

- Grigor'ev, Viktor Petrovic, Grammatika idiostilja. V. Chlebnikov. M. 1983.

GRILLE, DIETRICH, Lenins Rivale. Bogdanov und seine Philosophie. Koln 1966. (= Abhandlungen des Bundesinstituts für ostwissenschaftliche und internationale Studien; 12).

Grobov, A., siehe GORSKU, A.K. 
GroYs, BORIS, "Ein neues Heidentum. Die 'russische nationale Wiedergeburt'. - Ein Blick auf jüngste Diskussionen." In: Frankfurter Allgemeine Zeitung, 118, 22.5.1987, S. 27.

GroYs, BORIS, Gesamtkunstwerk Stalin. Die gespaltene Kultur in der Sowjetunion. München 1988.

- Groys, Boris, "Elemente des Gnostizismus im Dialektischen Materialismus (sowjetischen Marxismus)." In: P. KosLowskI (Hg.), Gnosis und Mystik in der Geschichte der Philosophie, Zürich, München 1988, S. 352-367. [Fedorov S. 363f., 367]

- Gruman, Gerald J., A History of Ideas about the Prolongation of Life. The Evolution of Prolongevity Hypotheses to 1800. Philadelphia 1966. (= Transactions of the American Philosophical Society, N.S.; 56,9, 1966). [Fedorov S. 89]

- Gruman, Gerald J., "Longevity." [Lexikonartikel] In: Dictionary of the History of Ideas, 3, New York 1973, S. 89-93.

- Grunwald, Jacoueline, N.F. Fédonov. Diplôme d'études supérieures Univ. de Nancy 1965.

- Grunwald, Jacoueline, "Fédorov et la Philosophie de l'oeuvre commune." In: Contacts, 58, 1967 , S. 147-166.

- Grunwald, Jacqueline, "Fédorov: l'homme et l'oeuvte. II. Le projet fédorovien." In: Contacts, 61, 1968, S. 37-62.

- Grunwald, Jacqueline, "Fedorov: l'homme et l'oeuvte. III. Fédorov et Dostoievski." In: Contacts, 62-63, 1968, S. 198-223.

Gruzinov, IVAN, Imatinizma osnovnoe, M. 1921.

- Grygar, Mojmír, "Leninism i bespredmetnost': roždenie mifa." In: Russian Literature, 25 (1989), 2, S. 383-397. [Fedorov S. 386]

- Guariglia, Guglielmo, Il messianismo nusso, Roma o.J. [1956]. ( = Universale Studium; 47). [Fedorov S. 161-164]

- Gudzu, N[IKola Kallinikovic], Kak rabotal L. Tolstoj, M. 1936. [Fedorov S. 203] GUDZU, N[IKOLAJ KALLINIKOVIC], "Junoß̌skoe tvortestvo Brjusova." In: Literatumoe nasledstio, t. 27-28, M. 1937, S. 198-238.

GONTHER, HANS, "Proletarische und avantgardistische Kunst. Die Organisationsăsthetik Bogdanovs und die LEF-Konzeption der 'lebenbauenden' Kunst." In: Ästhetik und Kommunikation, 4 (1973), 12, S. 62-75.

GONTHER, HANS, "Die These vom Ende der Kunst in der sowjetischen Avantgarde der 20er Jahre." In: Referate und Beiträge zum VIII. Intemationalen Slavistenkongress Zagreb 1978, München 1978, S. 77-94. ( = Slavistische Beitrăge; 119).

- GONTHER, Hans, "Aspekte und Probleme der neueren Utopiediskussion in der Slawistik." In: W. VossKaMP (Hg.), Utopieforschung. Interdisziplinäre Studien zur neuzeitlichen Utopie. Bd. 1, Stuttgart 1982, S. 221-231. [Fedorov S. 226]

- GONTHER, HANS, "Utopie nach der Revolution. (Utopie und Utopiekritik in RuBland nach 1917)." In: W. VosskaMP (Hg.), Utopieforschung. Interdisziplinäre Studien zur neuzeillichen Uta pie. Bd. 3, Stuttgart 1982, S. 378-393. [Fedorov S. 386, 393]

- GONTHER, HANs, "Andrej Platonov und das sozialistisch-realistische Normensystem der 30er Jahre." In: Wiener Slawistischer Almanach, 9, 1982, S. 165-186. [Fedorow S. 169, 172] - Leicht verandert auch in: DERS., Die Verstaatlichung der Literatur, Stuttgant 1984, S. 112-125. [Fedorov S. 114,117

- GONTher, Hans, "Andrej Platonov: 'Unterwegs nach Tschevengur'." In: K.L. BerghahN, H.U. SEEBER (Hgg.), Literarische Utopien von Monus bis zur Gegenwart, Königstein 1983, S. 191-202.

- GONTHER, HaNS, "V.N. Murav'ev, Ovladenie vremenem. Moskva 1924. Nachdruck nebst einer einführenden Studie von Michael Hagemeister. München 1983." [Rezension] In: WdSI, 29 (1984), 1, S. 219-222.

GONTHER, HANs, "Žiznestroenie." In: Russian Literature, 20 (1986), S. 41-48.

Gul', R[OMan Borisov:C], Ja ines Rossiju. Apologija émigracii. 1-2, New Yolk 1984.

- Gulyga, ARSEnU [VladimiroviC], "'Filosofskoe nasledie': 80 tomov." In: Literatumaja Gazeta, 39, 26.9.1979, S. 13. 
- Gulyga, ARSenu [Vladimirovic]], "Universitetskij gorod." In: Novyj Mir, 1984, 12, S. 198-208. [Fedorov S. 207] - Enweiterte Fassung in: DERS., Putjami Fausta. Etjudy germanista. M. 1987, S. 339-364. [Fedorov S. 360]

- Gulyga, ARSEnu [Vladimarovič], "Die ewige Sonne der Liebe." [Nachwort zu] V.[S.] So. LOV'Ev, Der Sinn der Liebe, Hamburg 1985, S. 87-104. (= Philosophische Bibliothek; 373). [Fedorov S. 103f.]

- Gulyga, ARsenu [Vladimarovic], "'Byt' ne prazdnym passažirom.' Russkij kosmizm: nasledie i nasledniki. KritiZeskie zametki." In: Literatumoe Obozrenie, 1987, 7, S. 91-95.

- Gulyga, A[RSEnu] V[LAdimarovic]], "Priblizit' filosofiju k žizni." In: Voprosy Filosofii, 1987, 8, S. 59-61.

Gulyga, ARsenu [Vladimirovic], "Poiski absoljuta." In: Novyj Mir, 1987, 10, S. 245-253.

- Gulyga, ARsenu [VladimaroviC], "Kant als Friedensdenker." In: Stifterverband für die Deutsche Wissenschaft (Hg.), Jahresversammlung des Landeskuratoriums Baden-Würtremberg, Stuttgart, 3. November 1987, Essen 0.J., S. 9-16. [Fedorov S. 16]

GULYGA, A[RSENU] V[LADIMIROVIC], "Stat' zerkalom duSi naroda." In: Voprosy Filosofii, 1988, 9, S. 113-115.

- Gulyga, A[RSEnu] V[ladimirovic], "Filosofija ljubvi." In: V.S. SOlov'ev, Soxinenija v dvuch tomach, t. 1, M. 1988, S. 33-46. [Fedorov S. 45f.]

- Gulyga, Arsenu [VladimiroviC], "Vladimir Sergeevix Solov'ev." In: Literatumaja Gazeta, 3, 18.1.1989, S. 5.

- Gulyga, Ars[enu Vladimarovic], "Revoljucija ducha." In: Zvezda, 1989, 2, S. 173-182. Gumalev, Lev NikolaeviC, "Étnos: mify i real'nost'." In: Druzba Narodov, 1988, 10, S. 218-231.

- GusčIK, Vlad[IMIR E.], "Potok Evrazii." In: Potok Evrazii, kn. 1, Tallinn 1938, S. 3-48. [Fedorov S. 43]

- Gusev, Nikola Nikolaevic, Lev Nikolaevit Tolsioj. Materialy k biografii s 1881 po 1885 god. M. 1970. [Fedorov S. 75-79, 85, 127, 299]

- Gustafson, RichaRd F., "A. Teskey, Platonov and Fyodorov: The Influence of Christian Philosophy on a Soviet Writer. Amersham 1982." [Rezension] In: Slavic Review, 43 (1984), S. $734 f$.

- Gustafson, Ruchard F., Leo Tolstoy. Resident and Stranger. A Study in Fiction and Theoloyy. Princeton, NJ. 1986. [Fedorov S. 458f.]

Guyau, Jean MARIE, L'imeligion de l'avenir, Paris ${ }^{2} 1887$.

HAARDT, AleXANDER, "Marxismus und Ethik im Frühwerk Nikolaj Berdjaevs." In: Wiener Slawistischer Almanach, 2, 1978, S. 97-113.

HACKel, SERged, The Poet and the Revolution: Aleksandr Blok's 'The Twelve'. Oxford 1975.

- HACKEl, SERgej, 'The religious dimension: vision or evasion? Zosima's discourse in The Brothers Karamazov'." In: M.V. JONES, G.M. TERRY (Hgg.), New Essays on Dostoyevsky, Cambridge 1983, S. 139-168. [Fedorov S. 151f.]

- Hagemeister, Michael, "Neue Materialien zur Wirkungsgeschichte N.F. Fedorovs: M. Gor'kij und die Anhắnger Fedorovs in Moskau und Harbin." In: H.-B. HARDER, B.E. SCHOLZ (Hgg.), Studia Slavica. Beiträge zum VIII. Internationalen Slawistenkongre $\beta$ in Zagreb 1978. Gießen 1981, S. 219-244. (= Marburger Abhandlungen zur Geschichte und Kultur Osteuropas; 21).

- Hagemeister, Michael, "Valerian Nikolaevii Murav'ev (1885-1931) und das 'prometheische Denken' der frühen Sowjetzeit." In: VN. MURAv'Ev, Ovladenie vremenem, Moskva 1924. Nachdruck nebst einer einführenden Studie von Michael Hagemeister. München 1983, S. 1-27. (= Specimina philologiae Slavicae; 51).

- Hagemeister, Michael, "Die 'Biokosmisten' - Anarchismus und Maximalismus in der frühen Sowjetzeit." In: G. Freidhof u.a. (Hgg.), Studia Slavica in Honorem Viri Dactissimi Olexa Horbatsch. I: Beitrăge zur ostslawischen Philologie, 1, München 1983, S. 61-76. 
- Hagemeister, Michael, "Kochler, Ludmila, N.F. Fedorov: The Philosophy of Action. Pittsburgh, Pa. 1979." [Rezension] In: ZfslPh, 43,1, 1983, S. 203-210.

- Hagemeister, Michuei, "Young, George M., Nikolai F. Fedorov: An Introduction." [Rezension] In: $Z f_{s} I P h, 44,2,1984$, S. 440-449.

- Hagemejster, Michael, "PA. Florenskij und seine Schrift 'Mnimosti v geometrii' (1922)." In: PA. FLORENSKIJ, Mnimosti v geometrii, Moskva 1922. Nachdruck nebst einer einführenden Studie von Michael Hagemeister. München 1985, S. 1-60. (= Specimina philologiae Slavicae; Suppl. 14). [Fedorov S. 6, 11, 27, 36, 45, 55]

- Hagemeister, MichaeI, "Pavel Florenskij: Zu neuen Ausgaben." In: Ostkirchliche Studien, 36 (1987), S. 45-50. - Dass. [russ.] "Novye izdanija svjaš. P.A. Florenskogo." In: Vestmik RChD, 150, 1987, S. 34-41.

[Hagemeister, Michael] Chagemejster, M., "Slovo o Loseve." In: Literatumaja UČeba, 1988, 1, S. $158 \mathrm{f}$.

HANSEN-LOVE, AMGE A., Der nussische Formalismus. Methodologische Rekonstruktion seiner Entwicklung aus dem Prinzip der Verfremdung. Wien 1978.

HARDEMAN, HILDE, 'A 'bourgeois' newspaper in the Russian revolution. 'Utro Rossii', Moscow 1917-1918." In: Rossija - Russia, 6, Venezia 1988, S. 61-80.

- Hare, Richard, Pontmits of Russian Personalities between Reform and Revolution, London 1959. [Fedorov S. 213, 266-271]

HARRINGTON, Alan, The Immonalist, Millbrae, Cal. 1977.

HARVIE, JA., "A Russian View of Immortality." In: Religious Studies, 10, 1974, S. 479-485.

HAYes, Nicholas, "Kazem-Bek and the Young Russians' Revolution." In: Slavic Review, 39 (1980), 2, S. 255-268.

- Heller, Leonid, De la Science-Fiction soviétique. Par deld le dogme, un univers. Lausanne 1979.

- Heller, Leond, "Zamjatin: prophète ou témoin? 'Nous autres' et les réalités de son époque." In: Cahiers du Monde nusse et soviétique, 22 (1981), 2-3, S. 137-165.

- Heller, Leonid, "Les chemins des artisans du temps: Filonov, Platonov, Hlebnikov et quelques autres..." In: Cahiers du Monde nusse et soviétique, 25 (1984), 4, S. 345-374.

- [HELLER, LEOND] GELLER, LEONID, Vselennaja za predelom dogmy. Razmystenija o sovelskoj fantastike. London 1985. Erweiterte und veränderte Ausgabe von HELLR (1979). [Fedorov S. 20, 37f., 44f., 47, 50, 63f., 78, 349-353, 366, 392]

- [Heller, Leonid] Geller, Leond, "Estetika i utopija: dve teorii iskusstva o. Pavla Florenskogo." In: Russkaja Mysl', 3711, 12.2.1988, S. 12, 14.

- [Heller, Michel] Geller, Michail, "Ob Andree Platonove." In: A. Platonov, Cevengur, Paris 1972, S. 9-22. [Fedorov S. 17]

HELlER, MiCHAEI, "Survivors from Utopia." In: Survey, 21 (1975), 3, S. 155-166.

- [Heller, Michel] Geller, Michail, Andrej Platonov v poiskach scast'ja, Paris 1982.

- Heller, Michel, "Utopija v sovetskoj ideologii." In: Revue des Études slaves, 56 (1984), 1, S. 105-113.

- [Heller, MiChel] Geller, Michall, "Poiski very i sovetskaja literatura." In: Russkaja Mysl', $3729,17.6 .1988$, S. 8 f.

HENDERSON, LINDA DALRYMPLE, The Merging of Time and Space: The 'Fourth Dimension' in Russia from Ouspensky to Malevich." In: Soviet Union / Union Soviétique, 5 (1978), 2, S. 171-203.

HENDERSON, LINDA DALRYMPLE, The Antist, 'The Fourth Dimension', and Non-Euclidean Geometry 1900 1930. A Romance of Many Dimensions. Ph.D. diss Yale Univ. 1975; Ann Arbor, Mich. 1981.

HENDERSON, LiNDA DALRYMPLE, The Fourth Dimension and Non-Euclidean Geometry in Modem An, Princeton, N.J. 1983.

HENDERSON, LINDA DALRYMPLE, "Mysticism, Romanticism, and the Fourth Dimension." In: The Spiritual in Ant: Abstract Painting 1890-1985, Los Angeles, New York 1986, S. 219-237. 
D'HeRBIGNY, MiCHEL, L'aspect religieux de Moscou en octobre 1925, Roma 1926. (= Orientalia Christiana; 5,3 [20], S. 185-280).

Herder, Johann GotTtrRied, Sämtliche Wenke, hg. von B. Suphan, Bde. 13 und 14, Berlin 1887, 1909.

- Her̆man, Miroslav, "Dva neznámé dopisy Maxima Gorkého (A.M. Péskova)." In: Sbomik Na. rodntho muzea v Praze, r. C, sv. 8 (1963), 4, S. 221-224.

HERRIOT, EdouARD, "La Russie: l'intelligence nouvelle." In: Conferencia, [Paris] 1934, 9, S. 469. 482.

Herzen, A., siehe Gercen, A.I.

- [HESSEN, SERGEJ IOSIFOVIC] GESSEN, S.I., "Nemeckoe izdanie neopublikovannych rukopisej F.M. Dostoevskogo." In: Sovremennye Zapiski, 39, 1929, S. 502-515.

- Hessen, S[ERgej IosifoviC], "Der NachlaB von Dostojevskij in deutscher Sprache." In: Slavische Rundschau, 1 (1929), 8, S. 684-690.

- Hessen, Sergius [Sergej Iosifovic], "Der Kampf der Utopie und der Autonomie des Guten in der Weltanschauung Dostojewskis und W. Solowjows." In: Die Pädagogische Hochschule, 1 (1929), 4, S. 247-311. [Fedorov S. 248]

HiElsCHER, KARLA, "Futurismus und Kulturmontage." In: Altemative, 21 (1978), 122/123, S. 226235.

- Hielscher, Karla, "Ein Jegliches hat seine Zeit. Von der Technikverherrlichung zur Zivilisationskritik in der Sowjet-Literatur." In: L'80. Zeitschrift für Politik und Literatur. 35, 1985, S. 89-107.

HildermeIER, MANFred, "Das Privileg der Rückstăndigkeit. Anmerkungen zum Wandel einer Interpretationsfigur der neueren russischen Geschichte." In: Historische Zeitschrift, 244, 1987, 3, S. $557-603$.

Hinruchs, Jan PaUl (Hg.), Russian Poetry and Literary Lefe in Hartin and Shanghai, 1930 1950. The Memoirs of Valerij Perelesin. Amsterdam 1987.

- [Hoerschelmann, Karl KarloviC] GerSEl'man, K., "Korobka vtoraja. Fantastiそeskij rasskaz." In: Nov', 7, Tallinn 1934, S. 23-44. [Fedorov S. 23]

Hoffman, StEFANI HOPE, Scythianism: A Cultural Vision in Rewolutionary Russia. Ph.D. diss. Columbia Univ. 1975; Ann Arbor, Mich. 1975.

HoFFMANN-ERBRECHT, LOTHAR, "Alexander Skrjabin und der russische Symbolismus." In: Musik des Ostens, 6, 1971, S. 185-196.

HOLM, KERSTIN, "Rückwărns-Avantgarden. Das neue Aufleben des russischen Nationalismus." In: Frankfurter Allgemeine Zeitung, 211, 10.9.1988, S. 27.

- Holouist, Michuel, "The Philosophical Bases of Soviet Space Exploration." In: The Key Reporter, 51, 1985, 2, S. 2-4.

Holthusen, JoHANnEs, Fedor Sologubs Roman-Trilogie (Tvorimaja legenda). Aus der Geschichte des nussischen Symbolismus. 'S-Gravenhage 1960. (= Musagetes; 9).

HORKHEIMER, MAX, Kritische Theorie, Bd. 1, Frankfurt/M. 1968.

- IEzurtov, A.N., "Partija i aktual'nye zadaci nauki o literature." In: Russkaja Literatura, 1983, 4, S. 3-8.

- IL'in, V[LAdimiR] N[IKolaeviC], "Valerian Murav'ev, Ovladenie vremenem. Moskva 1924." [Rezension] In: Put', 9, 1928, S. 94.

- IL'IN, V[LADIMIR] N[IKOLAEVIC], "O religioznom i filosofskom mirovozzrenii N.F. Fedorova." In: Eurazijskij sbomik, kn. 6, Prag 1929, S. 17-23.

[IL'IN] ILJIN, VladimiR [NIKolaEVIC], "Die Lehre von Sophia der Weisheit Gottes in der neuesten russischen Theologie. (Im Zusammenhang mit der Onomatodoxie)." In: West-östlicher Weg, 2, 1929, S. 170-185; 225-230.

IL'IN, V[LADIMIR] N[IKOLAEVIC], Sest' dnej tworenuja. Biblija i nauka o tworenii i proischozdenii mira. Paris 1930. 
- Il'in, V[LAdimir] N[ikolaeviC], "Ettjudy o russkoj kul'ture. Étjud V. N. Fedorov i prep. Serafim Sarovskij." In: Vestnik RSChD, 1931, 7, S. 8-13; 8-9, S. 9-26; 11, S. 13-16.

- IL'IN, V[LADIMIR] N[IKOLAEVIC], "Profanacija tragedii. (Utopija pered licom ljubvi i smerti)." In: Pur', 40, 1933, S. 54-65. [Fedorov S. 63]

- Il'in, V[Ladima] N[IKolaevic], "Technika i christianstvo." In: Noyj Grad, 7, 1933, S. 61-65.

- Il'in, Vladimir [Nikolaevic], "Velikaja subbota. (O tajne smerti i bessmertija)." In: Put', 57, 1938, S. 48-57.

- IL'IN, V[LADIMIR] N[IKolaeviČ], Arfa Davida. Religiozno-filosofskie motivy russkoj literatury. T. 1, Proza. San Francisco 1980. [Fedorov S. 31, 211, 231, 319, 443]

- IL'in, V[ladimir] N[IKolaEvic], Religija nevoljucii i gibel' kul'tury, Paris 1987. [Fedorov S. 15, 43f., 74, 133, 135]

IL'iNa, Natal'ja Iosifovina, Vozvrošzenie, M. 1957.

IL'ina, Natal'ja Iosifonna, Sud'by, M. 1980.

Il'iNa, Natal'Ja Iosifovina, Dorogi i sud'by. Avtobiograficeskaja proza. M. 1985.

- Ingold, Felux PhILPP, Literatur und Aviatik. Europäische Flugdichtung 19091927. Basel 1978. [Fedorov S. 105, 155, 164, 182, 210]

INGOLD, FELIX PHILIPP, "Zur Komposition von Chlebnikovs Kranich-Poem ('Zuravl")." In: Schweizerische Beiträge zum VII. Intemationalen Slavistenkongress in Zagreb und Ljubljana, September 1978, Bern 1978, S. 59-76. (= Slavica Helvetica; 12).

- IovCUK, M.T., ANDREEv, A.L., MASUIN, M.A., "Aktual'nye voprosy issledovanija istorii marksizma-leninizma, ego filosofii i filosofskoj mysli narodov SSSR." In: Voprosy Filosofii, 1986, 1, S. 56-73. [Fedorow S. 70f.]

[IZBOLDIN] IsHBOLDIN, BORIS [S.], "The Eurasian Movement." In: The Russian Revue, 5 (1946), 2, S. 6473.

- Istorija gosudarstvennoj ordena Lenina biblioteki SSSR imeni V.I. Lenina za 100 let, 1862-1962, M. 1962. [Fedorov S. 47-49]

- IVAKIN, I[VAN] M[ICHNLoviC], Tolstoj v 1880-e gody. Zapiski I.M. Ivakina." In: Literatumoe nasledsino, t. 69 [Lev Tolstoj], kn. 2, M. 1961, S. 21-124. [Fedorov v.a. S. 45, 51f., 83, 94-100, 105, $112,123]$

IVANICKU, PAVEL. [I.], "K bratskomu edinstvu." In: Venograd, 4, 26.3./8.4.1918, S. $2 f$.

IVANICKU, PAVEL [I.], "Ob iskusstvennom vyzyvanii doždja." In: Biokosmist, 2, 1922, S. $5 f$.

IVANICKU, PAVEL [I.], "Iskusstvennoe vyzyvanie doždja." In: Izvestija VCIK, 114, 25.5.1923, S. 4.

IVANICKU, PAVEI, [I.], "Iskusstvennoe vyzyvanie doždja $\vee$ Rossii." In: Izvestija VCIK, 138, 23.6.1923, S. 5.

- IVANICKU, PAVEL [1.], Iskusstvennoe vyzyvanie dożda i upravlenie pogodoj posredstuom reguljacii atmosfemogo i zemnogo élektritestva. Materialy. M. 1925. (= Biblioteka suchogo zemledelija). [Fedorov S. 57]

- Ivanov, A., "V.L. Komaroviz o christianstve i socializme u F.M. Dostoevskogo." In: Novyj Zumal, 136, 1979, S. 203-212. [Fedorov S. 211]

IVAnov, DMTTRU [VJACESLAvoviC], "Recurtent Motifs in Ivanov's Work." In: R.L. JACKSON, L. Nelson (Hgg.), Vyacheslav Ivanov: Poet, Critic and Philosopher, New Haven 1986, S. 367-389.

Ivanov, Georgu [Vladimarovic], "O novych russkich ljudjach." In: Cisla, Berlin, Paris, 7-8, 1933, S. 184-194.

- [Ivanov, Viaceslav Ivanovic] Iwanow, Wlatscheslaw, Klüfie. Ober die Krisis des Humanismus. Berlin 1921. [Fedorov S. 29f.]

- [Ivanov, Vjaceslav Ivanovic] Iwanow, Wiatscheslaw, Die nussische Idee, Tübingen 1930. [Fedorov S. 40]

- Ivanov, Vjaceslav [Ivanovic], Sobranie socinenij, t. 3, Brüssel 1979. [Fedorov S. 379] 
IVANov, VjaCEslav VsevolodoviC, "Struktura stichotvorenija Chlebnikova 'Menja pronosjat na slonovych...." In: Trudy po znakovym sistemam, 3, Tartu 1967, S. 156-171. (= Urenye zapiski Tartuskogo gos. universiteta; 198).

- IVANov, VjaCeslav V[sevolodovic], "Kategorija vremeni v iskusstve i kul'ture XX veka." In: J. V.D. ENG, M. GRYgar (Hgg.), Siructure of Texts and Semiotics of Culture, The Hague, Paris 1973, S. 103-150. ( = Slavistic Printings and Reprintings; 294). [Fedorov S. 116f.]

- IVANov, V[jaCeslav] V[sEvolodoviC], Toporov, V[LADIMIR] N[ikolaeviX], Issledovanija $v$ oblasti slavjanskich dremostej. Leksiteskie i frazeologizeskie voprosy rekonstrukcii tekstov. M. 1974. [Fedorov S. 13]

- Ivanov, VjaCeslav Vsevolodovic, "Prostranstvom i vremenem polnyj." In: Vsevolod Ivanov . pisatel' $i$ Celovek. Vospominanija souremennikov. M. ${ }^{2} 1975$, S. 342-351. [Fedorov S. 349]

- IVANOV, V[JaCESLAV VSEvolodoviC], "Motivy vostoZno-slavjanskogo jazyCestva $i$ ich transformacii v russkich ikonach." In: Narodnaja gravjura i fol'klor v Rossii XVI-XIX v.v., M. 1976, S. 268287. [Fedorov S. 269]

Ivanov, VjaCeslav Vsevolodovic, "Chlebnikov i nauka." In: Puti v neznaemoe. Pisateli rasskazyvajut o nauke. Sb. 20-j. M. 1986, S. 382-440.

IVANOV, VjaC[ESLAV] Vs[EVOLODOVIC], "Nauka kak simvoliceskoe opisanie v koncepcii Florenskogo." In: PA. Florenskij: filosofija, nauka, technika. L. 1989, S. 9-12. (= Preprint; 4).

IVANOV, Vsevolod N[IKANOROVIC], Delo celoveka. Opyr filosofii kul'tury. Charbin 1933.

- IVANov, Vsevolod [Nikanorovic], "Voskresenie i žizn'." In: Zarja, [Harbin] 93, 8.4.1934, S. 4.

IVANOVa, LIDIJA VjaCESLAvovna, "Vospominanija o Vjaceslave Ivanove." In: Novyj Zumal, 147, 1982 , S. $136-154 ; 149,1982$, S. $100-126$.

JACHONTOV, ZIN. GERV., siehe GORSKU, A.K.

JAGodinSKI, VIKTOR NikolaEviC, Aleksandr Leonidovic CiŽevskij 1897-1964, M. 1987.

- Jakobson, Roman [OsipoviC], "O pokolenii, rastrativsem svoich poctov." In: R. Jakorson, D. SVJatopolk-MIRSkU, Smen' Vadimira Majakovskogo, Berlin 1931, S. 7-45. [Fedorov S. 24] Dass. [dt.] "Von einer Generation, die ihre Dichter vergeudet hat." In: DERS., Poetik. Ausgewählie Aufsätze 1921-1971. Frankfurt/M. 1979, S. 158-191. [Fedorov S. 173]

Jakobson, Roman [Osipovic], Pomorska, Krystrna, Dialogues, Cambridge 1983.

- Jakovenko, B[ORIS Valentinovic], OXenki nusskoj filosofii, Berlin 1922. (= Vseobsčaja biblioteka; 34-35). [Fedorov S. 93f.]

- [Jakovenko] Lakovenko, Boris [Valentinovic], Filosofi russi. Saggio di storia della filosofia nussa. Firenze 1925. [Fedorov S. 149f.]

- JakovenKo, Boris [VAlentinovie], Dějiny nuské filosofie, Praha 1938. [Fedorov S. 19, 252, 274, 343-346, 451f., 504]

JAKOVLEV, ANATOLU, "Vozvrastenie iz nebytija. K vychodu v svet serii 'Iz istorii otecestvennoj filosofskoj mysli'." In: Moskovskie Novosti, 9, 26.2.1989, S. 10.

JaKovlev, IVAN, Bryzgi bestializma, Boroviti 1923.

- JANECEK, GerAld, The Look of Russian Literature. Avant-Gande Visual Experiments, 1900-1930. Princeton N.J. 1984. [Fedorov S. 16, 120]

- Janovsku, V[asilu] S[emenovic], "Obscee delo." In: Noyjj Grad, 13, 1938, S. 172-174.

- Janovski, Vasilu S[emenovic], Portatimoe bessmertie. Roman. New York 1953. [Fedorov S. 170]

- [Janovsku] Yanovsky, V[asilu] S[emenovic], Elysian Fields. A Book of Memory. DeKalb, Ill. 1987. [Fedorov S. 81, 87, 248]

JAROSLAVSKU, ALEKSANDR [BorISOVIC]], Zvezdnyj manifest, o.O. [Vladivostok] o.J. [1918].

JAROSLAVSKIJ, ALEKSANDR [BORISOVIC], Krov' i radost', Irkutsk 1920. 
JAROSLAVSKU, ALEKSANDR [BORISOVIC], Otkrovavlennye trotuary. Stichi. Sb. pjatyj. V.-Udinsk 1921.

Jaroslavsku, Alexsandr [Borisovic], Poima anabioza, Pg. 1922.

JAROSLAVSKIJ, ALEKSANDR [BORISOVIC]], Svjataja bestial', Pg. 1922.

JAROSLAVSKU, ALEKSANDR [BORISOVIC], Na stum vselennoj, Pg. 1922.

Jarosla vSKu, Aleksandr [Borisovic], Miru poceluj, Pg. 1923.

JAROSLAVSKU, ALEKSANDR [BORISOVIC], Argonavty uselennoj. (Roman-utopija). M.-L. 1926.

JAROSLAVSKU, ALEKSANDR [BoRISOVIC], Koren' iz Ja, L.-M. 1926.

JaROSLAVSKU, AleksandR [Borisovic], "Iz 'Poemy Anabioza'. (Fragment)." In: Ogonek, 1988, 40, S. 23.

Jasvilu, Natal'ja, "Moj deduska, Petr Ivanoviz Bartenev." In: Prometej, 7, M. 1969, S. 292-301.

JENSEN, KenNETH MARTIN, Beyond Marx and Mach: Aleksandr Bogdanov's Philosophy of Living Experience. Dordrecht, Boston 1978. (= Sovietica; 41).

- Jensen, K[ENNETH] M[ARTIN], "Red Star: Bogdanov builds a utopia." In: Studies in Soviet Thought, 23, 1982, S. 1-34. [Fedorov S. 32]

- Jensen, Peter Alberg, Nature as Code. The Achievement of Boris Pilnjak 1915-1924. Copenhagen 1979. ( = Kobenhavns Universitets Slaviske Institut. Studier; 6). [Fedorov S. 281]

Johnnsson, KuRT, Aleksej Gastev. Pmletarian Band of the Machine Age. Stockhoim 1983. ( = Acta Universitatis Stockholmiensis. Stockholm Studies in Russian Literature; 16).

Judina, Marua Venjaminovna, Stat'i, vospominanija, materialy, M. 1978.

- JURCENKo, IVAN, "Zagadotnyj starik'. Legendy i fakty ob odnom iz podvižnikov russkoj kul'tury." In: Sovetskaja Rossija, 131 (7882), 6.6.1982, S. 4.

JUSKEVIC, P.S., Noyye vejanija. (Otenki sovremennych religioznych iskanij). SPb. 1910.

Jutnyj Ogonek, [Odessa] 1-16, 1918.

- Kagan, Judifo Matveevna, I.V. Cvetaev, M. 1987. [Fedorov S. 60f.]

- Kalezić, Dimttrue, Ruska filosofija suejedinstva. Istonija i teorija. Beograd 1983. [Fedorov S. 8]

- Kalunin, M[ICHAIL] I[vanoviC], "O vyborach v sovety v 1928/1929 g. Doklad na Cetvertoj sessii CIK SSSR IV sozyva 11 dekabrja 1928 g." In: DERS., Izbrannye proizvedenija v Cetyrech tomach, t. 2, M. 1960, S. 275-298. [Fedorov S. 283]

- Kalmykov [d.i. DŽimbinov], S|tanislav Bemovic], "V poiskach 'zelenoj palozki'." In: Veðnoe solnce. Russkaja social'naja utopija i naucnaja fantastika voroj poloviny XIX - načala XX veka. M. 1979, S. 5-38. [Fedorow S. 10, 33-37]

- Kaltach'́uan, S., "Kuda stremitsja 'edinyj potok'? O leninskoj koncepcii 'dvuch kul'tur' i ego izvrastenijach." In: Sovetskaja Kul'tura, 17.3.1987, S. 6.

Kammerer, Paur', Omolotenie i prodlenie licnoj tizni, M. 1922.

Kammerer, P[AUL], Omolazivanie i dolgovelnost', Pb.-Berlin 1922.

KAMMERER, PAUL', Smert'i bessmertie, M.-L. 1925. ( = Priroda i kul'tura; 17).

- Kantor, K[ARL] M[OISEEviC], "Bez istiny stydno zit'." In: Voprosy Filosofii, 1989, 3, S. 14-21. [Fedorov S. 17-19]

- KarabCIEVSKI, JURU [ARKAD'EVIC], Voskresenie Majakovskogo, München 1985. [Fedorov S. 202-211]

KArazin, V[Asilu] N[AZARovic], Soxinenija, pis'ma i bumagi, Char'kov 1910.

- Karunsky, Simon, "Surrealism in Twentieth-Century Russian Poetry: Churilin, Zabolotskii, Poplavskii." In: Slavic Review, 26 (1967), S. 605-617. [Fedorov S. 616]

Karsavin, Lev] P[Latonovic], Vostok, Zapad i russkaja ideja, Pb. 1922.

KARSAVIN, LEV [PLATONoviC], "Der russische geschichtsphilosophische Gedanke." In: Ethos. Vierieljahrschrift für Soziologie, Geschichts- und Kulturphilosophie, 1 (1925), 2, S. 259-274. 
KASINEC, EDWARd, KERDIMUN, Boris, "Occult Literature in Russia." In: The Spiritual in Art: Abstract Painting 1890-1985, Los Angeles, New York 1986, S. 361-365.

[Kaškarov, JURu DanioviC] SKaLon, D., "A.F. Losev k devjanostoletiju." In: Novyj Zumal, 150,1983, S. 282-292.

KassiL', Lev [ABRAMoviC], "Zvezdoplavatel' i zemljaki." In: KE. Ciolkovskij. Sbomik Aeroflota posvjascennyj Ciolkouskomu. O.O. [M.] 1939, S. 159-172.

Katalog vystavki proizvedenij V.N. Cekrygina (1897-1922), M. 1923.

- Kauchtschischwil, Nina, "Pavel Florenskij teologo e cultore di cose artistiche." In: Strumenti Critici, [Torino] 21 (1987), 1, S. 113-150. [Fedorov S. 130]

- KaVERIN, Ventaman Aleksandrovic, Osvešcennye okna, M. 1977. (= Izbrannye proizvedenija v dvuch tomach; 2). [Fedorov S. 347 ]

KazNaCeev, Vlail' Petrovic, UCenie V.I. Vemadskogo o biosfere i noosfere, Novosibirsk 1989.

- KEDROV, K.A., "Neoslavjanofil'stvo." [Lexikonartikel] In: Kratkaja literatumaja énciklopedija, t. 9, M. 1978, Sp. 557f.

- Kel'berin, Lazar' [IzRailevic], "Fedorov i sovtemennost'. (A. Ostromirov. Charbin)." [Rezension] In: Cisla, sb. 9, Paris 1933, S. 181-183.

KELLY, AILEEN, "Empiriocriticism: a Bolshevik philosophy?" In: Cahiers du Monde russe el sovieique, 22 (1981), 1, S. 89-118.

KERZENCEV, P[LATON] M[ICHAJLOVIC], Bor'ba za vremja, M. 1965.

- Kuko, E.I., "Dostoevskij i Renan." In: Dostoevskij. Materialy $i$ issledovanija. T. 4, L. 1980, S. 106122. [Fedorov S. 119, 121]

KIREEVSKI, I[VAN] V[ASIL'EVIC], Polnoe sobranie soxinenij v dvuch tomach, t. 1, M. 1911.

Kirillov, Vladimir TIIMOFEeViC], Stichotvorenija. 1914 - 1918.j g. Pb. o.J. [1918].

- [Kiselev, Aleksandr NikolaeviC] Aleksandrov, A., "O povesti 'Kotlovan' A. Platonova." In: Grani, 77, 1970, S. 134-143.

- KISELEV, A[LEKSANDR NikolaEVIC], "Utenie Nikolaja F. Fedorova v suete sovremennosti." In: Grani, 81, 1971, S. 122-153. - Dass. [ital.] "Nikolaj Fedorov oggi." In: Russia Cristiana, 12, 1971, 118 , S. 7-28.

- Kiselev, Aleksej [Aleksandr Nikolaevic], "Varsonofev i N.F. Fedorov." In: Noyjj Zumal, 110,1973, S. $296-299$.

- [KJetsaA, GfiR] Chetso, GejR, "Neopublikovannaja rec' Vladimira Solov'eva o Fedore Dostoevskom." In: Scando-Slavica, 31, 1985, S. 109-116.

KIENOV, VALERU, "'Amaravella'. (U istokov kosmizeskoj temy sovetskogo iskussiva)." In: Dekorativnoe iskusstio SSSR, 1981, 11, S. 16-19.

KLeVENSKU, M.M., Kotel'Nikov, K.G., Pokusenie Kanakozova. Stenografixeskij ot'et po delu D. Karakozova, I. Chudjakova, N. Isutina i dr. T. 1, M. 1928. ( = Centrarchiv. PolitiZeskie processy 60 - 80-ch g.g.).

- KLEVENSKU, M.M., Geschichte der staallichen Lenin-Bibliothek der UdSSR, Bd. I [Geschichte der Bibliothek des Moskauer Offentlichen und Rumjancev-Museums], Leipzig 1955. [Fedorov S. 49, $115,135,139,142]$

KLIBANOV, ALEKSANDR IL'IC, Istorija religioznogo sektantstva v Rossii (60.e gody XIX v. - $1917 \mathrm{~g}$ ), M. 1965.

KLIBANOV, ALEKSANDR IL'IC, Religioznoe sektantstvo v prostom i nastojastem, M. 1973.

KLINCIN, A.P., "Provincial'nyj teatr." In: Istonja russkogo dramatiKeskogo teatra, t. 4, M. 1979, S. 220-270.

Kune, George L., Spinoza in Soviet Philosophy, London 1952.

KLINE, GEORGE L., "Theoretische Ethik im russischen Frühmarxismus." In: Forschungen zur Osteuropäischen Geschichte, Bd. 9, Berlin, Wiesbaden 1963, S. 269-279.

- KuINE, GeOrge L., Religious and Anti-Religious Thought in Russia, Chicago 1968. [Fedorov S. 165f.] 
KLINE, George L., "Nietzschean Marxism' in Russia." In: Demythologizing Marxism, Chestnut Hill, The Hague 1969, S. 166-183. (= The Boston College Studies in Philosophy; 2).

- KiINe, George L., "Religious Ferment among Soviet Intellectuals." In: M. HaYward, W.C. FleTCHER (Hgg.), Religion in the Soviet State: A Dilemma of Power. New York, Washington, London 1969, S. 57-69. [Fedorov S. 64-66]

- KuINe, George L., "Religious Motifs in Russian Philosophy." In: Studies on the Soviet Union, 9 (1969), 2, S. 84-96. [Fedorov S. 84, 89-91]

KuINE, GeORGE L., "The Nietzschean Manism of Stanislav Volsky." In: A.M. MLikotin (Hg.), Westem Philosophical Systems in Russian Literature. A Collection of Critical Studies. Los Angeles o.J. [1979], S. 177-195. (= University of Southern California Series in Slavic Humanities; 3).

- KuINE, George L., "Russian Religious Thought." In: Nineteenth Century Religious Thought in the West, vol. 2, Cambridge 1985, S. 179-229. [Fedorov S. 180, 204-208, 216-218, 223, 228]

- Kuine, George L., "Foreword." In: B.G. Rosenthal (Hg.), Nietzsche in Russia, Princeton, NJ. 1986, S. XI-XVI. [Fedorov S. XI]

- Kijuev, Nikola [Alekseevic], Polnoe sobranie soxinenij, t. 1-2, New York 1954.

- Kijuev, Nikolas [Alekseevic], Sodinenija, t. 1-2, München 1969.

- Kluge, Rolf-Dieter, "Lenins Rivale als Science Fiction-Autor. Alexander Bogdanows utopische Romane." In: R.-D. KLUGE, R. KELLNER (Hgg.), Aspekte der Science Fiction in Ost und West, Tübingen 1985, S. 14-26, 134-136. [Fedorov S. 135]

Kóergaina, V.A., "Michail Nikolaevið Peterson (k 100-letiju so dnja roždenija)." In: Vestnik Moskovskogo universiteta, ser. 9, filologija, 1985, 6, S. 48-52.

KodjaK, ANDres, "Tolstoy's Personal Myth of Immortality." In: A. KOdjaK, K. POMORSKA, ST. RUDY (Hgg.), Myth in Literature, Columbus, Ohio 1985, S. 188-207. ( = New York University Slavic Papers; 5).

- Koeriler, Ludmila, N.F. Fedorov: The Philosophy of Action, Pittsburgh, Pa. 1979.

- Koeiner, Ludmila, "Ayleen Teskey, Platonov and Fyodorov: The Influence of Christian Philosophy on a Soviet Writer. 1982." [Rezension] In: Slavic and East European Joumal, 27 (1983), 2, S. $264-266$

- Koehller, Ludmila, "Renan, Dostoevskii, and Fedorov." In: Canadian-American Slavic Studies, 17 (1983), 3, S. 362-371.

- [KoehleR] Keler, L[UdMILA], "N.F. Fedorov i kritiki." In: Vere, [München] 13, 1984, S. 65-74.

- Kogan, L.A., "N.F. Fedorov." In: Istonja filosofii v SSSR v pjati tomach, t. 4, M. 1971, S. 57-64.

- Kogan, LA., "Russkaja filosofija kak sociokul'turnyj fenomen." In: Voprosy Filosofii, 1988, 9, S. 103-106.

KOłAKOWSKI, LESZEK, Die Hauptströmungen des Marxismus. Entstehung, Entwicklung Zerfall. Bd. 2, München, Zürich 1978.

KOLARZ, WALTER, Religion in the Soviet Union, London 1961.

- Kol'CENKo, I[GOR'] A[LEKSEEVIC], "Filosofskie problemy osvoenija kosmosa v tvorלestve K.E. Ciolkovskogo." In: Moskovskij oblasmoj pedagogizeskij institus im. N.K. Krupskoj. Utenye zapiski. T. 168, filosofija, vyp. 8, M. 1966, S. 419-437. [Fedorov S. 420]

- KOL'CENKo, I[GOR'] A[LEKSEEVIC], "K.E. Ciolkovskij o sud'be relovecestva v kosmose." In: Trudy tret'ich Ctenij, posvjašcennych razrabolke naünogo nasledija i razvitiju idej $K$.E. Ciolkovskogo (Kaluga, $17-19$ sentjabrja 1968 g.). Sekcija 'Issledovanie nautnogo tvontestva K.E. Ciolkovskogo'. M. 1969, S. 17-29. [Fedorov S. 28]

- Kol'CENKo, I[GOR'] A[LEKSEEVIC], "K.E. Ciolkovskij o preobrazovanii prirody." In: Trudy sed'mych, vos'mych i devjanych Cienij, posvjaszennych razraboike nauznogo nasledija i razvitiju idej KE. Ciolkouskogo (Kaluga, sentjabr 1972-1974 gg.). M. 1976, S. 15-21.

Kol'Cov, N.K. (Hg.), Omolożenie, M.-Pg. 1924.

- Kolodny, Lev, "lzumitel'nyj filosof." In: Mcskcuskaja Pravda, 137, 13.6.1982, S. 3.

- [KomaroviC, Vasilu LeonidoviC] Komarowitsch, W., "Der Vatermord und Fjodoroffs Lehre von der 'Fleischlichen Auferstehung'." In: R. FOLOP-MILLER, F. ECKSTEIN (Hgg.), F.M. Dosto- 
jewski. Die Urgestalt der Brüder Karamasoff. Dostojewskis Quellen, Entwürfe und Fragmente. München 1928, S. 3-58.

KomIN, V.V., Anarchizm v Rossii, Kalinin 1969.

KOPP, ANATOLE, Constructivist Architecture in the USSR, New York 1985.

KORMCU, JaKoV, siehe SETNICKU, N.A.

- Kornienko, N[ATal'ja] V., "V. Vasil'ev, Sopriłastnost' žizni, M. 1977." [Rezension] In: Zvezda, 1978, 7, S. 219 .

- Kornienko, N[ATal'Ja] V., "V mysli o Rossii. (K istokam filosofsko-istorizeskoj koncepcii tvorそestva Andreja Platonova)." In: Russkaja Literatura, 1985, 1, S. 110-125. [Fedorov S. 114, 118]

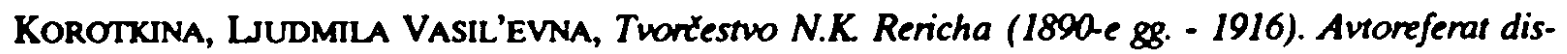
seriacii. L. 1977.

KOSARNYJ, V[ALERU] P[AVLOVIC], "Iz istorii bor'by s buržuazno-restavratorskoj sociologiej smenovechovstva v pervye gody nepa." In: Aktual'nye problemy istorii filosofii narodov SSSR, vyp. 4, M. 1977, S. $105-117$.

KoSARNYJ, VALERU PAVlovic, U istokov sovetskoj filosofskoj nauki (1917.1922 gg.), M. 1981.

Kosmodem'JANSKu, ARKadu AleKSANDroviC, Konstantin Eduardovic Ciolkovskij, M. 1976.

KOSTIN, VLADIMIR IVANOVIC, OST (ObsCestuo stankovistov), L. 1976.

Kostin, Vladimir Ivanovic, Kliment Red'ko. Dnevniki. Vospominanija. Stat'i. M. 1978.

- Koutaissoff, Elisabeth, "Some Futurological Aspects of Fedorov's 'Philosophy of the Common Cause'.' In: Russian Literature Triquarienty, 12, 1975, S. 393-407.

- Koutaissoff, Elisabetr, "Lukashevich, Stephen. N.F. Fedorov (1828-1903): A Study in Russian Eupsychian and Utopian Thought. Newark, London 1977." [Rezension] In: The Slavonic and East Eumopean Review, 58 (1980), 2, S. 287-289.

- Koutaissoff, Elisabeth, "The Philosophy of the Common Cause." [Rezensionsartikel] In: The Slavonic and East European Review, 62 (1984), 1, S. 98-101.

[Kovalevsku] Kovalevsky, PierRe [E.], "Messianisme et millénarisme russes?" In: Archives de Sociologie des Religions, 3 (1958), 5, S. 47-70.

Kovalfuskis, P.E., Zanubetnaja Rossija. Istorija i kul'tumo-prosvetitel'naja rabota nusskogo zanubet'ja za polveka (1920-1970). Paris 1971.

- Kovtun, E[vgenu] F. (Hg.), "K.S. Malevix. Pis'ma k M.V. Matjušinu." In: Eł̌egodnik rukopisnogo otdela Puskinskogo doma na 1974 god, L. 1974, S. 177-195. [Fedorov S. 183] - Dass. [franz.] "Introduction à la publication des lettres de Malévitch à Matiouchine." In: Malévitch 1878-1978. Actes du colloque intemational. Lausanne 1979, S. 171-179.

- Kovrun, Evgenu [F.], "Die Entstehung des Suprematismus." In: Von der Fläche zum Raum. Russland 1916-24. / From Surface to Space. Russia 1916-24. Koln 0.J. [1974], S. 32-47. [Fedorov S. 38]

- Kovtun, Evgenu [F.], "Das Antibuch der Warwara Stepanowa." In: Von der Fläche zum Raum. Russland 1916-24. / From Surface to Space. Russia 1916-24. Köln 0.J. [1974], S. 57-63. [Fedorov S. 59]

- Kovtun, E[vgenu] F., Povelichina, A[Lla] V[Asil'Evina], "Utes iz budušego'. (Architekturnye idei Velemira Chlebnikova)." In: Techničeskaja Éstetika, 1976, 5-6, S. 40-42.

- Kovtun, E[vgenJ] F., "Kazimir Malevich." In: An Joumal, 41 (1981), 3, S. 234-241. [Fedorov S. $236,241]$

- [Kovtun, Evgenu F.] Kovtoune, EugÈne, "Les 'mots en liberté' de Marinetti et la 'transmentalité (zaoum) des futuristes russes." In: Présence de F.T. Marinetti. Actes du Colloque Intemational tenu d I'UNESCO. [1976] Lausanne 1982, S. 234-239. [Fedorov S. 237]

- [Kovtun, Evgeni F.] Kovtoune, Eugène, [Povelichina, Alla Vasil'evna] Povelikhina, Alla, "La ville futuriste de Sant'Elia et des idées architecturales de Xlebnikov." In: Présence de F.T. Marinetti. Actes du Colloque Intemational tenu d I'UNESCO. [1976] Lausanne 1982, S. 266274. [Fedorov S. 271, 274] 
KoZzEVNIKov, V[LADIMIR] A[LEKSANDROVIC], Bezcel'nyj trud, 'ne-delanie' ili delo? Razbor vzgljadov Emilja Zolja, Aleksandra Djuma i grafa L. N. Tolstogo na trud. M. 1893 [2 1894].

- Koževnikov, V[Ladimar] A[Leksandrovic], "Nikolaj Fedorovið Fedorov." In: Russkij Archiv, 42 (1904), kn. 1, vyp. 2, S. 315-325; vyp. 3, S. 390-401; vyp. 4, S. 545-554; kn. 2, vyp. 5, S. 5-26; kn. 3, vyp. 9, S. 106-124; vyp. 10, S. 225-261. 43 (1905), kn. 1, vyp. 1, S. 180-200; vyp. 2, S. 333-365; kn. 2, vyp. 7, S. 417-470. 44 (1906), kn. 1, vyp. 1, S. 63-102; vyp. 2, S. 260-301.

- Kožennikov, Vladimir [Aleksandrovic], "Predislovie." In: N.F. Fedorov, Filosofija obšcego dela, t. 1, Vernyj 1906, S. I-IV.

- KoŽevnikov, V[LAdIMIR] A[Leksandrovic], Nikolaj Fedorovic Fedorov. Opyr izloženija ego uX̌enija po izdannym i neizdannym proizuedenijam, perepiske i litnym besedam. C. 1. S priloteniem pisem F.M. Dostoevskogo, V.S. Solov'eva, AA. Sensina (Fela) i L.N. Tolstogo o N.F. Fedorove $i$ ego uXenii. M. 1908. [Text bis S. 290 identisch mit der Veroffentlichung in Russkij Archiv, 19041906]

- Kozennikov, V[ladimir Aleksandrovic], Peterson, N[ikolas Pavlovic], "Predislovie." In: N.F. FEDOROV, Filosofija obsčego dela, t. 2, M. 1913, S. IIIf.

KoŽEVNIKov, V[LADIMIR] A[LEKSANDROVIC], Buddizm v sravnenii s christianstwom, t. 1-2, Pg. 1916.

[KoZzennikov, Vladimir AleksandroviC, u.a.] "Fedoru Dmitrievicu Samarinu ot druzej." In: Bogoslovskij Vestnik, 25 (1916), 10-12, S. 543-581.

Kožennikov, Vladimir Aleksandrovic, "Pis'ma VA. Koževnikova V.V. Rozanovu." In: Vestnik RChD, 143, 1984, S. 87-100.

- Koźinov, Vadim [VAlERIanovic], "'My menjaemsja'? Polemizeskie zametki o kul'ture, žizni i 'litdejatel'jach'." In: Nas' Souremennik, 1987, 10, S. 160-174.

KozodoEV, I.P., siehe SETNICKU, N.A.

KraG, ErIK, "Zur Frage von Dostojevskijs Vater und dem Vatermorde in den Brudern Karamazov." In: Studi in onore di Ettore Lo Gatto e Giovanni Maver, Roma 1962, S. 361-367.

- KRAg, ERIK, Dostoevsky. The Literary Artist. Oslo, New York 1976.

- Kraisku, Giorgio, Le poetiche nusse del Novecento dal simbolismo alla poesia proletaria, Bari 1968.

Kreatorij Rossijskich i Moskovskich anarchistov-biokosmistov, ["Deklarativnaja rezoljucija"]. In: Izvestija VCIK, 4, 4.1.1922, S. 3. - Wiederabdr. in: Biokosmist, 1, 1922, S. 1 .

KRIstof, LADIS K.D., "Teilhard de Chardin and the Communist Quest for a Space Age World View." In: Russian Review, 28 (1969), S. 277-288.

- Kristof, Ladis K.D., "Koehler, Ludmila. N.F. Fedorov: The Philosophy of Action. Pittsburgh 1979." [Rezension] In: Russian Review, 40 (1981), 4, S. 449-451.

- Krupin, Vladimir Nikolaevic, "Sorokovoj den'. Povest' v pis'mach." In: Ná Sovremennik, 1981, 11, S. 72-117. [Fedorov S. 84]

KRUZENSTERN-PETEREC, JU[STINA VLADIMIROVNA], "Curaevskij pitomnik. (O dal'nevosto nnych poetach)." In: Vozroźdenie, 204, 1968, S. 45-70.

- Krymov, Vl[adimir Pimenovic], Portrety neobyknovennych ljudej, Paris 1971.

- Krzemeñ, Wiktoria, Filozofia w cieniu prawostawia. Rosyjscy mysliciele religijni przetomu XIX i $X X$ wieku. Warszawa 1979. [Fedorov S. 25, 87, 118]

KUCENKo, E.V., [Vstupitel'naja stat'ja] In: M.V. Boskin (1875-1930). Katalog vystavki. Zagorsk 1987, S. $1-6$.

Kudrova, I[RMA] V., "Polgoda v Pariže. (K biografii Mariny Cvetaevoj)." In: Marina Cvetaeva. Studien und Materialien. Wien 1981, S. 129-159.

- Kóenzlen, GotTfried, "Secular Religion and its Futuristic-Eschatological Conceptions." In: Studies in Soviet Thought, 33 (1978), S. 209-228. [Fedorov S. 221, 223]

- Klzakowska, Danuta, Dostojewski. Antymomie humanizmu nedtug 'Braci Karamazombro'. Wroclaw u.a. 1987. (= Prace Slawistyczne; 66). [Fedorov S. 249-256]

KUMANEV, VIKTOR ALEKSANDROVIC, Socializm $i$ usenanodnaja gramotnost', M. 1967. 
- Klrbatov, Valentin, "Živaja duša Rossii. ('... Iz russkoj dumy' chudožnika Jurija Seliverstova)." In: Literanumaja UŽba, 1989, 1, S. 97-110. [Fedorov S. 99, 103, 106f.]

- Kuvakin, V[ALERIJ] A[LEKSANDRoviC], Religioznaja filosofija v Rossii nacalo XX veka, M. 1980.

- KuZin, N.G., "Navstreðu buduščemu. (K 80-letiju Andreja Platonova)." In: Russkaja Literatura. 1979, 3, S. 30-44. [Fedorov S. 32]

Kuz'min-Karavaev, V., "Iz vospominanij o Vladimire Sergeevi飞e Solov'eve." In: Vesinik Eumpy, $35(1900), 11$, S. 443-453.

- Lv, "75 let K.A. Čcheidze." In: Svobodné Slovo, [Prag] 19.9.1972.

LAGovSKIJ, I., "Bog i social'naja pravda v SSSR." In: Novyj Grad, 4, 1932, S. 40-54.

LANE, ANN MARIE, Nietzsche in Russian Thought 1890 1917. Ph.D. diss. Univ. of Wisconsin, Mad. 1976; Ann Arbor, Mich. 1981.

LANGerak, [Thomas] Tomas, "Andrej Platonov v Voroneže." In: Russian Literature, 23, 1988, S. 437-468.

- Lanne, Jean Claude, Velimir Khlebnikov. Poète futurien. T. 1-2, Paris 1983. (= Bibliothèque russe de l'Institut d'études slaves; 64, 1-2).

[LAPSIN, IVAN IVANOVIC] LaPSChIN, IwaN, "Die Metaphysik Leo Tolstojs." In: Fesischrift Th.G. Masaryk zum 80. Geburtstage, 1. Teil, Bonn 1930, S. 179-202.

LAPSin, N., "Chlebnikov - Miturit." In: Russkoe Iskusstwo, M.-Pg. 1923, 2-3, S. 99-101.

- LaPSin, Vladimir P., "Iz istorii chudožestvennoj žizni Moskvy 1920-ch godov. 'Makovec'." In: Sovetskoe iskusstuoznanie 79, vyp. 2, M. 1980, S. 355-391. [Fedorov S. 366]

LAPSIN, V.V., "V.A. Favorskij i N.M. Černyšev. Nabrosok k dvojnomu portretu." In: Panorama iskusstv, sb. 7, M. 1984, S. 18-51.

Laskovaja, Marina Pavlovina, Bogoiskatel'stvo i bogostroitel'stvo prezde i leper', M. ${ }^{2} 1976$.

- Lathoumfre, M[ARIA] A[NTONIUs], "The Idea of the Fulfilment of History in Contemporary Soviet Literature." In: Studies on the Soviet Union, 6 (1966), 1, S. 62-70. [Fedorov S. 70]

LATHouwERS, M[ARIA] A[NTONIUS], "La littérature soviétique à la recherche de la Vérité." In: Irenikon, 39 (1966). S. 325-354.

LATHOUWERS, M[ARIA] A[NTONIUS], "Eléments métaphysiques de la littérature soviétique contemporaine." In: La Table Ronde, [Paris] 233, 1967, S. 128-142.

- Lathouwers, M[ARIA] A[NTONIUS], De Sovjet-literatuur, Utrecht, Antwerpen 1968. ( = Aula-boeken; 386). [Fedorov S. 291]

- Lathouwers, M[ARIA] A[NTONIUS], "Le sens de l'existence humaine dans la littérature soviétique contemporaine." In: Irénikon, 41 (1968), 4, S. 509-542. [Fedorov S. 534f.]

- LATHOUWERS, M[ARIA] A[NTONIUs], "Pour un sens approfondi de l'existence humaine." In: Inénikon, 43 (1970), S. 38-58, 201-228. [Fedorov S. 218f.]

LATHOUWERS, M[ARIA] A[NTONIUS], "La critique de la culture dans la littérature soviétique contemporaine." In: Irénikon, 48 (1975), S. 147-169.

- Lathouwers, M[ARIA] A[NTONIUS], "Religiöse Themen in der zeitgenossischen russischen Literatur." In: G2W - Glaube in der 2. Well, 6 (1978), 7-8, S. 1-16.

- Lauth, Reinhard, Die Philosophie Dostojewskis, München 1950. [Fedorov S. 384, 390, 405, 427, $442,449,512]$

LAVRENEV, BORIS ANDREeVIC, "My budem žit'!" [1930] In: DerS., Sobranie socinenij v sesti tomach, t. 5, M. 1965, S. 161-241.

[Lavruchina] Lavroukine, N., [ČERTkov] TChertkov, L., D.S. Mirsky. Profil critique el bibliographique. Paris 1980. ( = Bibliothèque russe de l'Institut d'études slaves; 58).

LAVRov, A.V., "Vstupitel'naja stat'ja." In: Literatumoe nasledstvo, t. 92 [Aleksandr Blok. Novye materialy $i$ issledovanija], kn. 2, M. 1981, S. 366-391.

- Lazarev, Vladimir JakovleviC, Brat miloserdija. Stichorvorenija. M. 1982. [Fedorov S. 77f.] 
- LAZURSKI, V[LADIMIR] F[eDOROVIC], "Dnemnik V.F. Lazurskogo." In: Literatumoe nasledstro, t. 37/38 [L.N. Tolstoj], kn. 2, M. 1939, S. 443-509. [Fedorov S. 465f.]

Lensku, A[Leksandr] P[avlovic], Stat'i. Pis'ma. Zapiski. M.-L. 1935.

Lensku, Aleksandr Pavlovic, Stat'i. Pis'ma. Zapiski. M. ${ }^{2} 1950$.

- Lepachin, V[Aleru V.], "N.F. Fedorov. Socinenija. M. 1982." [Rezension] In: Acta Universitatis Szegediensis de Attila Jozsef nominatae. Dissertationes Slavicae. Sectio historiae litterarum. 15, Szeged 1982, S. 195-207.

LEPESINSKAJA, O[L'GA] B[ORISOVNA], Voinstvujuscij vitalizm. O knige prof. GurviXa. Vologda 1926.

- Letopis' tizni i tvortestva A.M. Gor'kogo, vyp. 3 (1917-1929), M. 1959; vyp. 4 (1930-1936), M. 1960.

- LeVicku, Sergej [Aleksandrovic], "Svoboda i bessmertie. O romane Pasternaka 'Doktor Živago'." In: Mosty, 2, 1959, S. 224-236. [Fedorov S. 229]

- LeVickH, Sergej A[LeKsandrovic], OXerki po istorii russkoj filosofskoj i obšcestvennoj mysli, Frankfurt/M. 1968. [Fedorov S. 161-164]

LEVICKU, SERgej [ALEKSANDROVIC], "Voskresaemost' Renessansa." In: Noyyj Zumal, 129, 1977, S. 219-230.

- LEVICKU, SERGEJ [AlEKSANDROVIC], "Ob odnoj blagorodnoj utopii. (Nikolaj FedoroviX Fedorov, 1828-1903)." In: Posev, 1980, 1, S. 47-50.

- LeVin, ARThUR A., "Stephen Lukashevich. N.F. Fedorov (1828-1903): A Study in Russian Eupsychian and Utopian Thought. Newark 1977." [Rezension] In: Canadian-American Slavic Studies, $14(1980), 1$, S. 114.

- Levin, Fol'ker [Volker], "Chudožestvennyj mir Andreja Platonova." In: A. Platonov, Starik i stanucha. Poterjannaja proza. München 1984, S. 5-20. (= Arbeiten und Texte zur Slavistik; 33).

- LeVtrin, E.S., "Ob iskusstve V.N. Cekrygina." In: V.N. CEkRYgin, Risunki, M. 1969, S. [5f.]. LEWIS, KATHLEEN, WEBER, HARRY, "Zamyatin's We, the Proletarian Poets, and Bogdanov's Red Star." In: Russian Literature Triquarterty, 12, 1975, S. 253-278.

- LichaCev, DmTtrus [SERGeEviC], "De philologia." In: Ricerche slavistiche, 17-19 [In memoriam G. Maver], 1970-1972, S. 333-337. [Fedorov S. 334, 336]

- LICHACEV, D[MTRRU] S[ERGEEVIC], "Dolžna byt' svoja nravstvennaja tocka zrenija...." In: Literatumaja UCeba, 1987, 4, S. 123-128. [Fedorov S. 128]

Likvidatoram negramotnosti. Prakticeskoe rukovodstwo. M. 1921.

- Lindstrom, Thais, A Concise History of Russian Literature. Vol. 2 [From 1900 to the Present]. New York 1978. [Fedorov S. 216]

- LinnÉR, SVEn, Starets Zosima in The Brothers Karamazov. A Study in the Mimesis of Virtue. Stockholm 1975. (= Acta Universitatis Stockholmiensis. Stockholm Studies in Russian Literature; 4). [Fedorov S. 198-204, 206, 209]

- LinNICEnKo, I[VAN] A[NDREeViC], "Moi vstrexi s L.N. Tolstym." In: DeRs., Reci i pominki. Sb. statej po istoni nusskoj literatury i biograficeskich vospominanij. Odessa 1914, S. 311-319.

- LINNK, JU[RU] V[LADIMIROVIC], "Problemy sinestezii i recepcija gravitacii." In: Materialy usesojuznoj skoly molodych uCenych po probleme 'svet i muzyka'. (Tret'ja konferencija). Kazan' 1975, S. 208-212.

- Linnik, Ju[Ru] V[LadimiroviC], "Kosmos Michaila Prišvina." In: Sever, 1980, 10, S. 109-114.

- Linnik, Ju[Ru] V[LAdimirovic], "Amaravella." In: Sever, 1981, 11, S. 108-114.

LINNIK, JURU [VLADIMIROviC], "Sobranie kosmizeskoj živopisi." In: Dekorativnoe Iskusstvo SSSR, 1981,11, S. 20.

LINNIK, JU[RU] V[LADIMIROVIC], "Amaravella': nesušij svet." In: Leningradskaja Pravda, 12.12.1987, S. 4.

- LinNix, JU[Ru] V[LAdimiroviC], "Nikolaj Fedorovix Fedorov." In: Sever, 1989, 2, S. 112-115.

- LinNik, Ju[Ru Vladimirovic], "Kosmiðeskij dizajn Kazimira Malevita." In: Komsomolec, [Petrozavodsk] 18.2.1989, S. 8. 
- Linnik, Juru [Juru Vladimarovic], "Amaravella." In: Punalippu, [Petrozavodsk] 1989, 4, S. 112127. [Fedorov S. 113]

LIPEROVSKU, LEV [NIKOLAEviC], "Voprosy žizni i smerti v nauke i religii." In: Vestnik RSChD, 1930,1, S. 9-17; 4, S. 6-14.

- LisJUTKIN, O.M., Kritika pravoslavnoj koncepcii kul'tury. Dissertacija na soiskanie urenoj stepeni kandidata filosofskich nauk. M. 1978. [Fedorov S. 16 u.d.?] [War nicht zugănglich]

- LisovoJ, N.N., "Perspektivy sovremennoj fiziki." In: Voprosy Filosofii, 1968, 11, S. 176-180. [Fedorov S. 180]

- Literatumoe nasledstvo, t. 70 [Gor'kij i sovetskie pisateli. Neizdannaja perepiska], M. 1963.

- Literatumoe nasledstvo, t. 83 [Neizdannyj Dostoevskij. Zapisnye knižki i tetradi 1860-1881 gg.], M. 1971.

- Literatumoe nasledstvo, t. 85 [Valerij Brjusov], M. 1976.

- Literatumoe nasledstvo, t. 90 [U Tolstogo 1904-1910. 'Jasnopoljanskie zapiski' D.P. Makovickogo], kn. 1-4, M. 1979. [Fedorov siehe: Ukazateli k knigam 1-4, M. 1981]

Literatumyj al'manach, Pb. o.J. [1918].

- Luaukov, D., "Fedorov, Nikolaj Fedorovic." [Lexikonartikel] In: Filosofskaja énciklopedija, t. 5, M. 1970, S. 308f.

- LuUbimov, B., "Zagadka dlja issledovatelej i Citatelej." In: Teatral'naja Žizn', 1988, 20, S. 17.

- LuUbuskina, S., "Ideja bessmertija u rannego Platonova." In: Russian Literature, 23, 1988, S. 397 424. [Fedorov S. 409, 419]

- LuUnggren, Magnus, The Dream of Rebirh. A Study of Andrej Belyj's Novel 'Peterburg'. Stockholm 1982. (= Acta Universitatis Stockholmiensis. Stockholm Studies in Russian Literature; 15). [Fedorov S. 81, 149f.]

- Lobanov, Michail Petrovic, Razmystenija o literature i zizni, M. 1982. [Fedorov S. 139]

- Lodder, Chiristina, Russian Constructivism, New Haven, London 1983. [Fedorov S. 208, 298f.] LOWENTHAL, LEO, "Calibans Ende. Bücherverbrennungen und kulturelle Verdrängungsmechanismen." In: A. und J. ASSMANN (Hgg.), Kanon und Zensur. Beilrdge zur Archäologie der literarischen Kommunikation. 2, München 1987, S. 227-236.

- LORD, ROBERT, Dostoevsky considered in relation to Apollon Grigorev, Vadimir Solov'yov, and N.F. Fyodorov, M.A. thesis, London 1960.

- LORD, R[OBERT], "Dostoyevsky and N.F. Fyodorov." In: The Slavonic and East European Review, 40 (1962), 95, S. 409-430.

- LORD, ROBERT, "Dostoyevsky and Vladimir Solov'yov." In: The Slavonic and East European Re. view, 42 (1964), 99, S. 415-426.

- LORD, RoBert, Dostoevsky. Essays and Perspectives. London 1970. [Fedorov S. 175-200, 248f.]

LOSEV, A[LEKSE]] F[EDOROVIC], Filosofija imeni, M. 1927.

LOSEV, A[LEKSE]] F[EDOROVIC], Dialektika mifa, M. 1930.

LOSEV, ALEKSEJ FEDOROVIC, "Gibel' buržuaznoj kul'tury i ee filosofii." In: A. CHUUBSER [HOBSCHER], Mysliteli naśego vremeni, M. 1962, S. 310-354.

LOSEV, A[LEKSEJ] F[EDOROVIC], "V poiskach smysla." In: Voprosy Literatury, 1985, 10, S. 205-231.

- LOSEV, A[LEKSEJ] F[EDOROVIC], "I ne pogasnet to, tto raz v duse zažglos'." In: Junost', 1989, 6, S. 61-64. [Fedorov S. 63]

- Lossku, N[IKOLAJ ONUFRIEVIC], "Russkaja filosofija v XX veke." In: Zapiski nusskogo naučnogo institusa v Belgrade, 3, 1931, S. 71-119. [Fedorov S. 112]

- Lossku, N[IKOLAs ONUFRIEVIC], "NA. Setnickij. O konečnom ideale. Charbin 1932." [Rezension] In: Novyj Grad, 9, 1934, S. 89-92.

- [LOSSKU] LOSSKY, N[IKOLA] O[NUFRIEvic], History of Russian Philosophy, London 1952. [Fedorov S. 75-80, 142]

- LOSSKu, Nikola [ONUfRIEviC], Dostoevskij i ego christianskoe miroponimanie, New York 1953. [Fedorov S. 163] 
- [LOSSKU] LOSSKI, N[IKOLA]] O[NUFRIEVIC], Histoire de la philosophie russe des origines a 1950, Paris 1954. [Abweichend von der engl. Fassung]

LOTZE, HERMANN, Mikrokosmos. Ideen zur Naturgeschichte und Geschichte der Menschheit. Bd. 3, Leipzig 1864.

LUBENSKU, StePan, siehe SAVICKU, P.N.

LOTKEHAUS, LUDGER, "Pathodizee und Mitleidsethik." In: H. Ebeling, L. LOTKEHAUS (Hgg.), Schopenhauer und Marx. Philosophie des Elends - Elend der Philosophie? Königstein/Ts. 1980, S. $190-202$.

- Lukas, Ivan [Sozontovic], "Fedorov." In: Vozrozdenie, 2788, 19.1.1933, S. 3f.

- LUKas ?], I[van Sozontovic ?], "N.F. Fedorov." In: Vozrozdenie, 2901, 12.5.1933, S. 2.

LUKASEVSKU, E.S., "Osnownye napravlenija $v$ russkom bogoiskatel'stve $v$ nacale $X X$ v." In: Ateizm, religija, sovremennost', L. 1973, S. 47-66.

- LuKasheVICH, StEPHEN, N.F. Fedonov (1828-1903). A Study in Russian Eupsychian and Utopian Thought. Newark, London 1977.

- LUKashEVICH, STEPHEN, "Fedorov, Nikolai Fedorovich." [Lexikonartikel] In: MERSH, vol. 11, Gulf Breeze 1979, S. 89-93.

- LUKIN, JU[RU] A[NDREEVIC], "Bescennoe oružie. (Leninskoe estetiCeskoe nasledie i metodologileskie problemy sovremennoj literaturnoj teorii i kritiki)." In: Voprosy Literatury, 1980, 4, S. 107-134. [Fedorov S. 125f.]

- LUKIN, JU[RU] A[NDREEVIC], "Chudožestvennaja kul'tura i idejnoe protivoborstvo." In: Znamja, 1983, 1, S. 197-205. [Fedorow S. 203]

- LUXIN, JU[RU] A[NDREEVIC], "Otvetstvennost' chudožnika. Iskusstvo i literatura $v$ formirovanii polititeskoj kul'tury litnosti." In: Znamja, 1983, 9, S. 213-220. [Fedorov S. 219]

- LUKIN, JU[RL ANDREEVIC], "V bor'be za budustee Zelovetestva." In: Literatumaja Gazeta, 44, 2.11.1983, S. 2.

- LUKIN, JURU ANDREEviC, Kul'tura v bor'be idej, M. 1985. [Fedorov S. 78, 205, 207f., 236]

- LUKIN, JU[RU] A[NDREEVIC], "Demokratizacija kul'tury. (XXVII s-ezd KPSS o kul'turnoj politike partii)." In: Voprosy Literatury, 1987, 2, S. 3-32. [Fedorov S. 30]

LUKS, LEOND, "Die Ideologie der Eurasier im zeitgeschichtlichen Zusammenhang." In: JfGO, 34 (1986), S. 374-395.

LUNACARSKU, A[NATOLU VASIL'EviC], "Osnovy pozitivnoj estetiki." In: Ozerki realističeskogo mirovozzrenija. Sb. statej po filosofii, obšcestvennoj nauke i tizni. SPb. 1904, S. 113-182.

LUNACARSKu, A[NATOLu] V[ASIL'EviC], "Voprosy morali i M. Meterlink." In: DeRs., Ejjudy kritiZeskie i polemizeskie, M. 1905, S. 154-178.

LUNACARSKU, A[NATOLU] V[asil'EviC], "V mire nejasnogo." In: DeRs., Otkliki Zizni. Sb. statej. $\mathrm{SPb} ., 1906, \mathrm{~S} .36-72$.

LUNACARSKU, A[NATOLu VASIL'EVIC], "Buduszee religii." In: Obrazovanie, [SPb.] 16 (1907), 10, S. 1-25.

LUNACARSKU, A[NATOLU VASIL'EviC], Religija i socializm, t. 1-2, SPb. 1908, o.J. [1911].

LUNACARSKU, A[NATOLU VASIL'EVIC], "Mesčanstvo i individualizm." In: Ocenki filosofii kollektivizma. Sb. peryyj. SPb. 1909, S. 219-349.

LUNACARSKU, A[NATOLU VASIL'EVIC], "Dvenadcat' tretij sbornik 'Znanija'." In: Literatumyj raspad. Kriticeskij sbomik. Kn. 2, SPb. 1909, S. 84-119.

[LunaCARSkU, ANATOLu VAsiL'EviC] Three Plays of A.V. Lunacharski. Faust and the City. Vasilisa the Wise. The Magi. London, New York 1923.

LUNACARSKI, A[NATOLU] V[ASIL'EVIC], "O prepodavanii istorii v kommunistiZeskoj \$kole." [1918] In: DERS., Prosvešenie i revoljucija. Sb. statej. M. 1926, S. 87-107.

LuNaCARSKu, ANATOI ע VAsIL'EVIC, "Lenin i iskusstvo." [1924] In: Ders., Sobranie sotinenij v vos'mi tomach, t. 7, M. 1967, S. 401-406. 
- Luppol, I[van KaptTonovic], "O sinice, kotoraja ne zažgla morja. (Orerednoj otvet t. Z. Cejtlinu)." In: Pod Znamenem Marksizma, 1926, 11, S. 221-233. [Fedorov S. 221]

LUR'e, ARon Naumovic, Poeitičskij epos revoljucii, L. 1975.

- ŁuŻNY, RYSZARD, "Mikołai Fiodorow - rosyjski mysliciel zapomniany." In: Sprawozdania z posiedzeñ komisji naukowych PAN, 25/2, Wroctaw u.a. 1981, S. 2666 .

- ŁuŻNy, Ryszard, "Myś filozoficzna Mikołaja Fiodorowa w kręgu pisarzy rosyjskich." In: Przegłgd Humanistyczny, 26 (1982), 1-2, S. 99-116.

- L'vov, Vladimir [Evgen'EViC], "Geografija i biologija vychodjat v kosmos." In: Vokrug Sveta, 1959,10, S. 6-8.

- L'vov, Vladimir [Evgen’evic], "Kosmos i my." In: Zvezda, 1961, 5, S. 8-32. [Fedorov S. 9-13, $17,22]$

- L'vov, Vladimir Evgen'eVic, Stranicy Żizni Ciolkovskogo, L. 1963. [Fedorov S. 89-102, 107, 109, $113,126-128,148]$

L'vov, Vladimir [Evgen'evic], "Primety veka." In: Novoe Vremja, 1966, 2, S. 6-8.

- L'vov, Vladimir [Evgen'EviC], "Prjamoe voschoždenie." In: Neva, 1966, 2, S. $130 f$.

- L'vov, Vladimir [Evgen'evic], "Zavtrašnij kosmos." In: Neva, 1966, 7, S. 138-144. [Fedorov S. 139]

- L'vov, Vladimir [Evgen'evic], "Vselennoj tajny rokovye." In: Neva, 1972, 7, S. 167-175. [Fedorov S. 174f.]

- L'vov, Vladimir [Evgen'evic], "Zagadočnyj starik. Povest'-chronika." In: Neva, 1974, 5, S. 65122. - Wiederabdr. in: Ders., Zagadočnyj starik. Povesti. L. 1977, S. 7-192.

- Lyngstad, Alexandra H., Dosioevskij and Schiller, The Hague, Paris 1975. (= Slavic Printings and Reprintings; 303). [Fedorov S. 66f., 109]

McLauginin, Sigrid, Schopenhauer in Rußland. Zur literarischen Rezeption bei Turgenev. Wiesbaden 1984. ( = Opcra slavica; N.F. 3).

- Mclean, Hugh, "The Letters of Maksim Gor'kij to V.F. Xodasevix, 1922-1925." In: Harvard Slavic Studies, 1, 1953, S. 279-334.

MCVAY, GoRdon, "Unpublished Texts of Nikolay Klyuyev." In: Slavic and East European Review, 63 (1985), 4, S. 560-566.

MAdjarody, TAmarA, "Tri reči v pamjat' Dostoevskogo' VI. Solov'eva." In: Slavica. Annales instituti philologiae Slavicae universitatis Debreceniensis de Ludovico Kossuth nominatae. 21, 1984, S. 229-245.

Majakovsku, Vladimir Vladimirovic, Polnoe sobranie soxinenij v trinadcati tomach, M., t. 1 (1955); t. 4 (1957); t. 11 (1958); t. 12 (1959).

- Makedonov, Adrian Vladimirovie, Nikolaj Zabolockij. Žizn'. Tvortestvo. Metamorfozy. L. 1987. [Fedorov S. 311f.]

MAKoVICKU [MAKoVICKÝ], DUSAN PETRoviC, siehe Literatumoe nasledstvo, t. 90, M. 1979.

- Makowiecka, Katarzyna, "Mikołaj Zabołocki i Mikołaj Fiodorow. Między literaturą a filozofią." In: Sprawozdania z posiedzieñ komisji naukowych PAN. Oddz. w Krakowie. 28/1-2, Wroctaw u.a. 1984, S. 122 f.

- Makowiecka, Katarzyna, Pietrzycka-Bohusiewicz, Krystyna, "Motywy filozofii 'wspólnego czynu' M. Fiodorowa w twórczosci M. Zabołockiego i A. Płatonowa." In: Z polskich studiow slawistycznych, ser. 7, literaturoznawstwo, Warszawa 1988, S. 179-192.

MAKRAKĒs, Michaēl K., Hé aisthésis tu thanatu kai ho pothos tès lytroseōs eis ton L. Tolston. En idiaitera anafora pros to ergon autu 'Anastasis'. Athen 1978.

Malachieva-Mirovic, V[arvara] G[RIgor'evNa], "O smerti v russkoj poezii." In: Zavery, $1912,7,3$, S. 98-108. 
- MAl'Cev, Juru Vladimirovic, Volnaja nusskaja literatura 1955-1975, Frankfurt/M. 1976. [Fedorov S. 157ff.]

MAleviC, K[aZimir SeverinoviC], Suprematizm. 34 Risunka. Vitebsk 1920.

[MALEVIC, KaZimir SEVERINOVIC] MALEWITSCH, KAsIMIR, Suprematismus - Die gegenstandslose Weli, Koln 1962.

- MAllac, GUY DE, "Pasternak and Religion." In: The Russian Review, 32 (1973), S. 360-375. [Fedorov S. 367f.]

- Mallac, GuY DE, "A Russian Impressionist: Leonid Osipovich Pasternak, 1862-1945." In: California Slavic Studies, 10, 1977, S. 87-120. [Fedorov S. 113]

- MAllac, GuY DE, Boris Pasternak. His Life and Arr. Norman, Oklah. 1981. [Fedorov S. 332f.] Malygina, N.M., "Idejno-esteticeskie iskanija A. Platonova v nacale 20-ch godov. ('Rasskaz o mnogich interesnych vešach')." In: Russkaja Literatura, 1977, 4, S. 158-165.

- Malygina, N.M., "Estestvennonauðnye istoðniki predstavlenija o prirode Andreja Platonova." In: Čelovek i priroda v chudožestvennoj proze. Meturuzovskij sbomik. Syktyvkar 1981, S. $49-64$.

Malyj teatr. 1824-1974. T. 1, M. 1978.

MANDEL'STAM, NADEŻd, Vtoraja kniga, Paris 1972.

- Mandel'Śtam, Nadeżda, "Mocart i Sal'eri." In: Vesinik RSChD, 1972 (Juni), S. 237-278. [Fedorov S. 241f.]

Maniscalco Basile, Giovanni, "The Utopia of Rebirth: Aleksandr Bogdanov's 'Krasnaja Zvezda'." In: Canadian-American Slavic Studies, 18 (1985), 1-2, S. 54-62.

Manuel, Frank E., Manuel, Frttzie P., Utopian Thought in the Westem Wordd, Cambridge, Mass. 1979.

- Markov, Vladimir, The Longer Poems of Velimir Khlebnikov, Berkelcy, Los Angeles 1962. (= University of California Publications in Modern Philology; 62). [Fedorov S. 15f., 148, 224]

MARKOV, V[LADIMIR] (Hg.), Manifesty i programmy russkich futuristov, München 1967. (= Slavische Propylăen; 27).

MARxov, Vladimir, Russian Futurism: A History, Berkelcy 1968.

- [MARKstein, Elusabeth] MARKSTEjn, Elizabet, "Dom i kotlovan, ili mnimaja realizacija utopii. (C'itaja Andreja Platonova)." In: Rossija - Russia, 4, Torino 1980, S. 245-270. [Fedorov S. 269]

MARKstein, Elisabeth, "Die Russischnationalen." In: Osteuropa, 1984, 3, S. 159-167.

- Marsh, Rosalind, Soviet Fiction since Stalin: Science, Politics and Literature, London, Sydncy 1986. [Fedorov S. 133, 137, 145f., 253, 258, 260, 314] [Siehe auch WELLS, ROSALIND]

Marshall, Peter H., William Godwin, New Haven, London 1984.

MART, JEAN, "La psychoanalyse en Russie et en Union soviétique de 1909 à 1930." In: Critique, 32, 1976, 346, S. $199-236$.

MARX, KARL, Engels, Friedrich, Werke, Bd. 20, Berlin 1962.

MarX, Karl, Engels, Friedrich, Werke, Ergănzungsbd. [Schriften, Manuskripte, Briefe bis 1844], 1. Teil, Berlin 1968.

- Masing-Delic, Irene, "Zhivago as Fedorovian Soldier." In: The Russian Revue, 1981, 3, S. 300316.

- Masing-Delic, IRENE, "Bergsons 'Schopferische Entwicklung' und Pasternaks 'Doktor Shiwago'." In: E. REISSNER (Hg.), Literatur- und Sprachentwicklung in Osteuropa im 20. Jahrhundert, Berlin 1982, S. 112-130. ( = Osteuropaforschung; 4).

- MAsing-Delic, IRENE, "Zoshchenko - Pavlovian, Freudian or Fedorovian?" In: Slavic Symposium. Department of Russian Studies. University of the Witwatersrand, Johannesburg 1982, S. 140-159.

- MAsing-Delic, IRENE, "Zabolockij's The Triumph of Agriculture': Satire or Utopia?" In: The Russian Review, 42 (1983), S. 36G-376. 
- Masing-Deluc, Irene, Teskey, Ayleen. Platonov and Fyodorov. The Influence of Christian Philosophy on a Soviet Writer. Amersham 1982." [Rezension] In: The Russian Review, 42 (1983), 4, S. 449r.

- MAsing-Deluc, IRENe, Capitalist Bread and Socialist Spectacle: The Janus Head of 'Rome' in Pastemak's 'Doctor Zhivago'. Paper presented to the International Symposium 'Boris Pasternak and his Times', Jerusalem, May 19-24, 1984.

- Masing-Delic, Irene, "The Chickens Also Want to Live': A Motif in Zabolockij's 'Columns'." In: Slavic and East Eumopean Joumal, 31 (1987), 3, S. 356-369. [Fedorov S. 356f., 361, 367f.]

- Maslin, Michall Alexsandrovit, Sovremennye burtuaznye koncepcii istorii nusskoj filosofii. Krititeskij analiz. M. 1988. [Fedorov S. 31-34]

MATthIAS, LEO, Genie und Wahnsinn in Rußland. Geistige Elemente des Aufbaus und Gefahrenelemente des Zusammenbruchs. Berlin 1921.

- Matveev, S.[I.], Filosofija obšcego dela. (UCenie N.F. Fedorova). Char'kov 1912.

- Matveev, S.[I.], "Filosofija obšego dela. (Utenie N.F. Fedorova)." In: Svetox i dnevnik pisatelja. Ezemesjacnyj illjustrinovannyj literatumo-nauXnyj zumal dlja usech. M., 1913, kn. 1, S. 123-129; kn. 2, S. 57-65.

[MAKsimov; d.i. LAPOT', GRIGORU PETROVIC] MAXIMOFF, G.P., The Guillotine at Work. Twenty Years of Terror in Russia. Chicago 1940.

- Maynard, John, Russia in Flux. Before October. London 1941. [Fedorov S. 235, 267]

[MECNIKov, Il'Ja Il'JC] METSChNIKOFf, EluAs, Studien über die Natur des Menschen. Eine optimistische Philosophie. Leipzig 1904.

[MECNIKOV, IL'JA IL'IC] METSCHNIKOFF, ELIAS, Beiträge zu einer optimistischen Weltauffassung, München 1908.

Medvedeva, Irina Nikolaevna, Ekaterina Semenova. Żizn'i twortestwo tragizeskoj aktrisy. M. 1964.

MeJSNER, DMTrRU IVANOVIC, Mirati i dejstvirel'nost'. Zapiski emigranta. M. 1966.

MEL'GUNov, S.[P.], "'Sud istorii nad intelligenciej.' (K delu Taktiそeskogo Centra'.)." In: Na cuzoj stonone. Istoriko-literatumye sbomiki. 3, Berlin, Praga 1923, S. 137-163.

MeuK-PASAEv, N.Š., "Čelovek budušego." In: A. A[RKA]N [d.i. A.I. ANEKSTtesn], E. Kol'MaN (Hgg.), Zizn' i rechnika budušcego. (Social'nye i naucno-rechnixeskie utopii). M.-L. 1928, S. 337. 431.

- [MeN', Aleksandr Vol'Fovic] Svetlov, EMmanull, Istoki religii, t. 1, Brüssel 1970.

- Men', Aleksandr [Vol'Fovic], "L'eredità di Vladimir Solov'ev." In: Russia Cristiana, 169, 1980, S. 13-28. [Fedorov S. 16]

Mendel, ARthur P., "Fantasy and Revolution. A Russian Tragedy in Three Acts" In: The Psychohistory Review, 12 (1984), 2-3, S. 45-60.

Men'Suttin, A.N., SinjavskU, A.D., Poezija peryych let revoljucii, M. 1964.

MEREŽKovSKu, D[MTRU] S[ERGEEVIC], "O voskresenii." In: Żivaja Žizn', 1, 27.11.1907, S. 3-9.

MEREZKOVSKU, DMTRU SERGEEVIC, Ne mir, no meX. K buduszej kritike christianstva. [1908] $\mathbf{M}$. 1914. ( = Polnoe sobranie sočinenij D.S. Merežkovskogo; 13).

[MereZkovsku, K.S.] Mereschxowsky, C. v., Das indische Paradies. Ein Märchen aus dem 27. Jahthunder. Eine Utopie. Berlin 1903.

METAL[']NIKOV, S[ERGE IVANOVIC], Immontalité et rajeunissement dans la biologie modeme, $\mathrm{Pa-}$ ris 1924.

METAY']NIKov, S[ERgej IVANOVIC], La lutte contre la mont, Paris ${ }^{4} 1937$.

METSCHNIKOFF, ELLAS, siehe MEĆNIKOV, I.I.

METZ, JOHANN BAPTIST, Glaube in Geschichte und Gesellschaft. Studien zu einer praktischen Fundamentaltheologie. Mainz 1978 ('1977).

Michail [ARChIMANDRT, d.i. SEMENOV, PAVEl VASIL'EViC], Kak ja stal nanodnym socialistom, M. 1907. 
Michail [archimandrT, d.i. Semenov, Pa Vel Vasil'evic], Christos v vek masin. (Voprosy religii i obšestvennoj Zizni). SPb. 1907. ( = Svoboda i christianstvo; 1).

- MiChNEvic, IOsIF G., Istoriceskij obzor sonokaletija Risel'euskogo liceja, s 1817 po 1857 gad, Odessa 1857.

- Mihanlov, Mihajlo, Moskauer Sommer 1964, Bern 1965. [Fedorov S. 62]

[Mirnlov, Mihnlo] Michajlov, Michajlo, "Politbjuro i filosofija." In: Russkaja Mysl', 3751, 18.11.1988, S. 12.

- Mikulinsku, S[EMEN] R[OMAnoviC], "Tak li nado otnosit'sja $k$ nasledstvu? (Po povodu vychoda knigi: N.F. Fedorov, Soxinenija [...] M. 1982 [...])." In: Voprosy Filosofii, 1982, 12, S. 151-157.

- Mil'don, V.I., "Besedy o paraliterature." In: Voprosy Filosofii, 1972, 1, S. 147-154.

Miller, Martin A., Kropockin, Chicago, London 1976.

MILLER, MARTIN A., "Freudian Theory Under Bolshevik Rule: The Theoretical Controversy During the 1920s." In: Slavic Review, 44 (1985), S. 625-646.

MILNER, JOHN, Madimir Tatlin and the Russian Avant-Garde, New Haven, London 1983.

- Milner-Gulland, R.R., "Zabolotsky: Philosopher-Poet." In: Soviet Studies, 22 (1971), 4, S. 595608. [Fedorov S. 601]

- Milner-Gulland, R.R., "A. Teskey, Platonov and Fyodorov: The Influence of Christian Philosophy on a Soviet Writer. Amersham 1982." [Rezension] In: Irish Slavonic Studies, 4 (1983), S. 163-166.

MINDLIN, EMILu L'VoviK, Neobyknovennye sobesedniki. Kniga vospominanij. M. 1968.

MINSKU [d.i. VILENKIN], Nikola MICHAJloviC, Religija budušego. Filosofskie razgovory. SPb. 1905.

MIRSKU, DMTTRu S., siehe SVJATOPOLK-MIRSKU, D.P.

- MIRSKy, SAlomon, Der Orient im Werk Velimir Chlebnikovs, München 1975. ( = Slavistische Beitrăge; 85). [Fedorov S. 80]

- Misler, Nicoletta, "Il rovesciamento della prospettiva." In: P. Florensiu, La prospettiva rovesciata e altri scritti, Roma 1984, S. 3-51. [Fedorov S. 10, 38, 41]

MoCalov, I[NAR] I[NAROVIC], "L.N. Tolstoj i V.I. Vernadskij." In: Russkaja Literatura, 1979, 3, S. 193-204.

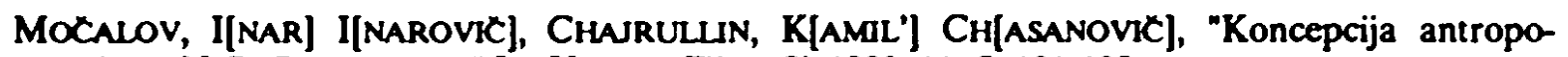
kosmizma N.G. Cholodnogo." In: Voprosy Filosofii, 1982, 11, S. 131-139.

MoCALOV, I[NAR] I[NAROVIC], OVCINNIKOV, N.F., OGURCoV, A.P., "Pis'mo v redakciju." In: Vo prosy Istonii Estestwoznanija i Techniki, 1988, 1, S. 66-71.

- Mocul'sku, K[Onstantin Vasil'eVic], "VI. Solov'ev i N. Fedorov." In: Krug. Al'manach. Kn. 1, Berlin, Paris 1936, S. 148-151.

- Mocul'sku, K[onstantin Vasil'EviC], Vadimir Solov'ev. Zizn'i ucenie. Paris 1936. [Fedorov S. 151-153, 203 u.8.]

- Mocur'ski, K[ONSTANTIN Vasil'eviC), "Ideja social'nogo christianstva v russkoj filosofii." In: Pravoslamoe delo. Sb. 1, Paris 1939, S. 45-61. [Fedorov S. 46, 53, 57-60] - Dass. [engl.] The Idea of Social Christianity in Russian Philosophy." In: St. Vadimir's Seminary Quanerty, 12 (1968), 3-4, S. 157-169.

- Mocul'sku, K[onstantin Vasil'evic], Dostoevskij. Zizn'i tuortestuo. Paris 1947. [Fedorov S. 467f.]

- Mocul'sku, K[onstantin Vasil'evic], Andrej Belyj, Paris 1955. [Fedorov S. 38, 118]

- Motur'sku, K[onstantin Vasil'evič], Valerij Bjiusov, Paris 1962. [Fedorov S. 60]

- Moiseev, N[IKTta NikolaEVIC], "V.I. Vernadskij i estestvennonauŽnaja tradicija." In: Kommunist, 1988, 2, S. 72-81. [Fedorov S. 80]

MoISEEV, N[IKrTA] N[IKOlaEVIČ], "Opravdanie edinstva. (Kommentarii k uðeniju o noosfere)." In: Voprosy Filosofii, 1988, 4, S. 18-30. 
Moluer, Peter Ulf, Posilude to the Kreutzer Sonata. Tolstoj and the Debate on Sexual Morality in Russian Literature in the 1890s. Leiden 1988.

- Molok, JU[RU] A., Kostin, V[LAdimiR] I[VANovič], "Ob odnoj idee 'budušego sinteza živych iskusstv'. (Po materialam pisem V.N. Cekrygina k N.N. Puninu nacala 20-ch godov)." In: Sovetskoe iskusstroznanie 76, 2, M. 1977, S. 287-336.

- MONAs, SidNEY, "St. Lukashevich, N.F. Fedorov 1828-1903: A Study in Russian Eupsychian and Utopian Thought. Newark 1977." [Rezension] In: Russian Review, 37 (1978), 3, S. $367 f$.

- Mondry, Henrietta, "One or Two 'Resurrections' in L. Tolstoy's Writing? (Fedorov and The Kreutzer Sonata)." In: WdSI, 33 (1988), 1, S. 169-182.

MONOD, JACQUES, Zufall und Notwendigkeit. Philosophische Fragen der modemen Biologie. [1970] München 1971.

MOROzOV, MichaIL, Pred licom smerti. Iz souremennych misticeskich $i$ èrotiteskich iskanij: $N$. Berdjaev, Georgij Culkov, A. Mejer, Vjaceslav Ivanov, M. Arcybasev, Leonid Andreev, Fedor Sologub. SPb. 1908.

- Moscansku, A., "Mysli i predskazanija N.F. Fedorova." In: Russkaja Mysl', 35 (1914), 12, S. 140145.

MGLLeR, EberhaRd, "Opportunismus oder Utopie? V.D. Bonð-Bruevið und die russischen Sekten vor und nach der Revolution." In: JfGO, 35 (1987), 4, S. 509-533.

MOLLER, LUDOLF, "Nietzsche und Solov'ev." In: Zeitschrift für philosophische Forschung, 1 $(1947), 4$, S. 499-520.

- Muratov, P., "Russkje mistiki." In: Vozrozdenie, [Paris] 1564, 13.10.1929, S. 5.

- [MURAV'EV] MouraviefF, Boris, Gnósis, étude el commentaires sur la tradition ésotérique de l'onhodarie orientale, t. 1, Paris 1961; t. 2, Paris 1962. [Fedorov t. 1, S. 294; t. 2, S. 189]

Murav'ev, V[alerian Nikolaevic], "Nevedomaja Rossija." In: Russkaja Mysl', 1914, 1, S. 2443.

MURAV'EV, V[ALERIAN] N[IKOLAEVIC], "Rev plemeni." In: Iz glubiny. Sbomik slatej o russkoj renoljucii. [1921] Paris ${ }^{2}$ 1967, S. 227-246.

- Murav'ev, Valerian [Nikolaevic], Ovladenie vremenem kak osnovnaja zadaca organizacii truda, M. 1924. - Dass. [Nachdruck], München 1983. (= Specimina philologiae Slavicae; 51). [Fedorov S. 127]

- Murav'Ev, VL.B., "Neopublikovannye i nezaveršennye povesti i rasskazy." In: Literatumoe nasledstro, t. 85 [Valerij Brjusov], M. 1976, S. 65-113.

- Murvar, Vatro, "Messianism in Russia: Religious and Revolutionary." In: Jounal for the Scientific Study of Religion, 10 (1971), 4, S. 277-338. [Fedorov S. 301]

N.N., O proletarskoj ètike. (Proletarskoe tworkestwo s tocki zrenija realisticeskoj filosofii). S predisloviem i pod redakciej priv.-docenta N.A. Rožkova. M. 1906. ( = Pervaja biblioteka; 46). - Dass., M. 1918. Dass., Char'kov 1923.

N.N., Uber proletarische Ethik. Das proletarische Schaffen vom Standpunkt der realistischen Philosophie. Zürich 1920. - Dass., Hamburg 1921.

- N.N., "Pavel Filonov (1883-1941)." In: A - Ja, 2, 1980, S. 35-40.

- NaIman, ERIC, "Andrej Platonov and the Inadmissibility of Desire." In: Russian Literature, 23, 1988, S. 319-366. [Fedorov S. 322-327, 334, 351, 355f.]

Narodnyj chudoznik RSFSR professor Nikolaj Michajlovic Cemysev 1885-1973. Sbomik matcrialov. M. 1978.

- Nauman Turkevich, Marina, "Death in the Brothers Karamazov." In: St. Vladimir's Theological Quarierly, 25 (1981), 3, S. 159-174. [Fedorov S. 161]

- NeCVOLOdov, ALEKSANDR [DMTTRIEviC], Skazanija o Russkoj Zemle, C. 1-4, izd. 4-oe, SPb. 1913. [Fedorov そ. 1, S. IIIf.]

- NedzVeCKu, Mich[AIL], "Naక̌a liturgija." In: Novoe Slovo, [Berlin] 23 (352), 8.6.1941, S. 4 f. 
- NeElov, Evgeni Michallovic, Volsebno-skazołnye komi naulnoj fantastiki, L. 1986. [Fedorov S. 191]

- Nekrasova, Ekat[erina Stepanovna], "Pamjati N.F. Fedorova." In: Russkie Vedomosii, 353, 24.12.1903, S. 4.

NemLoV, A.V., Żizn' i smert'. Obšedostupnyj očerk. L. 1924.

- Nesdoly, S.J., "Stephen Lukashevich, N.F. Fedorov, 1828-1903: A Study in Russian Eupsychian and Utopian Thought. Newark 1977." [Rezension] In: Canadian Slavonic Papers, 21 (1979), 4, S. $553 f$.

Nesmelov [d.i. Mrtropol'sku], ARSENu IVANoviC, Izbrannaja proza, Orange, Con. 1987.

NiETZSCHE, FrJEDRICH, Wenke in drei Bänden, hg. von Karl Schlechta, Bde. 1-3, München ${ }^{5} 1966$.

- NikIforov, L[EV] P[A VzoviC], "Vospominanija o L.N. Tolstom." In: N.N. GuSEv (Hg.), Lev Nikolaevic Tolstoj. Jubilejnyj sbornik. M.-L. 1928, S. 218-237. [Fedorov S. 225-227]

- NikTtin, V[Alentin ARsen'eviC], "Bogoiskatel'stvo' i bogoborzestvo Tolstogo." In: Prometej, 12, M. 1980, S. 113-138.

- Nikrtin, V[Alentin ARSEN'eviC], "'Bogoslovskie trudy' sborniki 23 i 24." In: ŽMP, 1983, 12, S. $77 f$.

- Nikmin, VAlentin [ARSEN'EViC], "Triptich pamjati N.F. Fedorova (1903)." [Gedichte] In: Vestnik $R C h D, 146,1986$, S. 145-148.

- NIKTIIN, V[ALENTIN] A[RSEN'EVIC], "Russkoe blagocestie i svjatost'." In: Bogoslovskie inudy, 27, 1986, S. 257-265. [Fedorov S. 256]

- NikTtin, V[AlENTIN] A[RSEN'EviC], "Chramovoe dejstvo kak sintez iskusstv. Svjašx. Pavel Florenskij i Nikolaj Fedorov." In: Vestnik RChD, 153, 1988, S. 40-56. - Dass. auch in: Simvol, 20, 1988, S. 219-236. - Dass. [dt.] "Der Kultakt als Synthese der Künste. Theoretische Überlegungen von Priester Pawel Florenski und Nikolai Fjodorow zur orthodoxen Sakralkunst." In: Stimme der Orthodarie, 1988, 11, S. 29-36, 46.

Nikmtin, V[ALENTIN] A[RSEN'EVIC], KUPCENKo, V[LADIMIR] P., "K istorii vzaimootnosenij P.A. Florenskogo i M A. Volosina." In: Minuv'eee. Istoriceskij al'manach. 6, Paris 1988, S. 325-333.

- NikTtin, V[ALENTIN] A[RSEN'EVIC], 'Dostoevskij, pravoslavie i 'russkaja ideja'. (Doklad na XIII Dostoevskich Ctenijach v Leningrade 12 nojabrja 1988 g.)." In: Vestnik $R C h D, 155,1989$, S. 126136. [Fedorow S. 134f.]

Nikmin, V.P., "Perepiska s 'aziatom' V. Ivanovym." In: Evrazijskaja chronika, 6, Paris 1926, S. 612.

Nikrtina, E[vDOKUa] F[edorovna], Russkaja literatura of simvolizma do nasich dnej. Literatumo-sociologiCeskie seminanj. M. 1926.

NILsson, NILs ÁKE, Ibsen in Russland, Stockholm 1958. (= Acta universitatis Stockholmiensis. Etudes de philologie slave; 7 ).

Nilus, SERGej [AlEKSANDRoviC], Velikoe v malom, ili Antichrist, kak blizkaja politizeskaja vozmoznost'. Zapiski pravoslamogo. Carskoe Selo 1905.

- NiqueuX, Michel, "La mémoire de la terre et du ciel: Valentin Raspoutine et la 'littérature paysanne' soviétique." In: Contacts, 115, 1981, S. 174-192. [Fedorov S. 177]

NiqueuX, MicheI, "Blok et l'appel de Kljuev." In: Revue des Érudes slaves, 54 (1982), 4, S. 617. 630.

- Nivat, Georges, Vers la fin du mythe russe. Essais sur la culture russe de Gogol d nos jours. Lausanne 1982. [Fedorov S. 94f.]

Nivière, ANTOINE, "Les moines onomatodoxes et l'intelligentsia russe." In: Cahiers du Monde russe et soviérique, 29 (1988), S. 181-194.

NolDA, S[IGRID], "M.P. Arcybaševs Roman 'Sanin'. Zur Aktualităt eines vergessenen Skandals." In: ZfslPh, 43,2, 1983, S. 387-399.

NOVGORODCEV, P[AVEL IVANOVIC] ], Ob obsCesivennom ideale, vyp. 1 [mehr nicht ersch.], izd. tret'e, Berlin 1921. [M. '1917, Kiev 21918]

Novikov, A VRAAM IzRAILEVIC, Nigilizm i nigilisty. Opyr kriticeskoj chanakeristiki. L. 1972. 
- Novikov, AvraAm IzRaIleviC, Muzy sredi ljudej, L. 1976. [Fedorov S. 145f.]

- Novoe Vino. Durchnedel'nyj [literatumyj] tumal. [M.] 1-3, 1912-1913.

Nudel'man, R[AFAIl IL'IC], "Fantastika roždennaja revoljuciej." In: Fantastika 1966, yyp. 3, M. 1967 , S. 330-369.

OBERLANDER, ERwin, "The All-Russian Fascist Party." In: The Joumal of Contemponary History, 1 (1966), 1, S. 158-173.

OBERLANDER, ERWIN, "Nationalbolschewistische Tendenzen in der russischen Intelligenz. Die 'Smena Vech'-Diskussion 1921-1922." In: JfGO, 16 (1968), S. 194-211.

Oxerki istorii russkoj sovetskoj tumalistiki 1917-1932, M. 1966.

O[chotrikov], F., "A. Gomostaev, Lico ery." [Rezension] In: Zveno, [Paris] 1928, 4, S. 225.

- OaAreva, Ju.M., "Vospominanija." In: Golos Minuusego, 2 (1914), 11, S. 109-127. [Fedorov S. 109-111]

Olcott, Anthony Charles E.C., Andrej Platonov the Citizen-Anist. Ph.D. diss. Stanford Univ. 1976; Ann Arbor, Mich. 1977.

OLESA, JURU KARLOVKC, Izbrannye soxinenija, M. 1956.

Ol'minsku [d.i. Aleksandrov], M[ICHaIl Stepanovic], "Kriticeskie stat'i i zametki." In: Proletarskaja Reudjucija, M.-L. 1931, 1, S. 148-152.

- ONasch, Konrad, Der verschwiegene Christus. Versuch über die Poetisienung des Christentums in der Dichtung F.M. Dostojewskis. Berlin 1976. [Fedorov S. 19, 94f., 237]

ONASCH, KONRAD, "Der verschwiegene Christus im Werk Dostoevskijs." In: Wiener slavistisches Jahruch, 29 (1983), S. 69-90.

ORG, V., siehe PEJ'', V.A.

OrLov, S.V., "Astronomizeskie utopii." In: A. A[RKa]N [d.i. A.I. ANEKSTEJN], E. Kol'man (Hgg.), Żzn' i rechnika budušego. (Social'nye i naứno-lechniceskie utopii). M.-L. 1928, S. 286336

OSTROMROV, A., siche GorsKU, A.K.

- Ovsienko, F.G., "Issledovanie religioznoj utopii N.F. Fedorova. Pazilova V.P. Kritizeskij analiz religiozno-fulosofskogo urenija N.F. Fedorova. M. 1985." [Rezension] In: Vestnik Moskovskngo universitera, ser. 7, filosofija, 1986, 6, S. 76f.

OzEROV, LEV, "Mectat' li o bessmertii? Otkrytoe pis'mo Il'e Sel'vinskomu." In: Literatumaja Rossija, 33, 12.8.1966, S. 16f.

Poox, NA. Berdjaev. (Po litnym vospominanijam)." In: Vesinik RChD, 115, 1975, S. 142-150.

- Pachmuss, Temira (Hg.), Intellect and Ideas in Action. Selected Correspondence of Zinaida Hippius. München 1972. ( = Centrifuga. Russian Reprintings and Printings; 11). [Fedorov S. 449, 452, 459f.]

- Pachmuss, Temira, "Iz archiva K.K. Gersel'mana: 'O bessmertii' i Ton mira'." In: Melboume Slowonic Studies, 17 (1983), S. 79-94. [Fedorov S. 82]

- Pacjuxov, V., "Proekt - mif - koncept." In: A - Ja, 2, 1980, S. 3-5.

- PaLl, P.N., "Konstantin Eduardovic Ciolkovskij." In: Noyj Zumal, 142, 1981, S. 221-252; 143, 1981, S. 216-227. [Fedorov 142, S. 229f.]

Pamjati Nikolaja Aleksandrovica Rotkova. Sbomik statej. M. 1927. ( = Otdel'nyj ottisk iz žurnala 'Katorga i ssylka', 3 [32]).

Pancchava, Il'ja Diommovic, Čelovek, ego tizn'i ibessmertie, M. 1967.

- PANCEnxo, I.G., "Kosmizeskaja' tema v romanach V. Brjusova 'Gora Zvezdy' i A. Tolstogo 'Aclita'." In: Brjusouskie Crenuja 1983 gada, Erevan 1985, S. 248-258. [Fedorov S. 251] 
PANKRATOV, A[LEKSANDR] S[AVVIC], ISCušzie boga. OXerki sowremennych religioznych iskanij i na. stroenij. Kn. 1, M. 1911 [recte 1910]; kn. 2, M. 1911.

- PANKRatov, A[LEKSANDR] S[AvVIC], "Filosof-pravednik." In: Novoe Slovo. EZemesjacnyj Zumal. [SPb.] 5 (1913), 8, S. 17-25.

PANKRATOV, A[LEKSANDR] S[AvVIĆ], Bez chleba. Oterki russkogo bedstrija. (Golod 1898 i 1911 12 88.). M. 1913.

- Papernyj, Vladimar [Zinov'evic], Kul'tura 'Dva', Ann Arbor, Mich. 1983. [Fedorov S. 32]

PAPERNY, Z[INOVu] S[AMojloviC], "Majakovskij v rabote nad poemoj 'Pro éto'." In: Literaturnoe nasledstuo, t. 65 [Novoe o Majakovskom], M. 1958, S. 217-284.

PAPERNYJ, Z[INOVIJ SAMojlovic], "Proletarskaja poezija pervych let sovetskoj épochi." In: Proletarskie poety pernych let sovetskoj epochi, L. 1959, S. 5-74. (= Biblioteka poeta).

Papuludēs, Kōnstantinos K., Hoi Rōsoi Onomatolatrai tu Hagiu Onus, Thessalonikē 1977.

- Paramonov, Boris [Michaulovic], "Bukva 'Život'. (Molodoj Zabolockij)." In: Grani, 111-112, 1979, S. 330-350. [Fedorov S. 331, 347]

- Paramonov, Boris [MichajloviČ], "Čevengur i okrestnosti." In: Kontinent, 54, 1987, S. 333-372.

- PARnov, E[REMEj IUdOVIC], [in dem Artikel] "Fantastika: krizis żanra?" In: Literatumaja Gazeta, 9, 27.2.1980, S. 4.

PAsCAL, PIERRE, Mon Joumal de Russie 1916-1918, Lausanne 1975.

PAsCal, Pierre, En communisme. Mon joumal de Russie 1918-1921. Lausanne 1977.

- Pasternak, Leonid [OsipoviC]], "Iz zapisok Leonida Pasternaka." In: Novyj Zumal, 77, 1964, S. 190-214. [Fedorov S. 207-209]

- Pasternak, Leonid Osipovic, Zapisi raznych let, M. 1975. [Fedorov S. 143-145, 285]

Pavlovski, Alexsej Il'iC, Sovetskaja filosofskaja poezzija. OXerki. L. 1984.

- Paxton, John, Companion to Russian History, London 1984. [Fedorov S. 135]

- PAYNE, Robert, The Three Worlds of Boris Pasternak, London 1962. [Fedorov S. 139f.]

- [Pazilova] Gariban, Valentina Pavlovina, "Religiozno-filosofskaja utopija N.F. Fedorova." In: Aktual'nye problemy nautnogo ateizma, vyp. 4, M. 1979, S. 41-48.

- Pazilova, V[alentina] P[avlovina], "Religiozno-filosofskaja utopija N.F. Fedorova." In: Naucrnye doklady yyš́ej skoly. Filosofskie nauki. 1981, 4, S. 88-94.

- Pazilova, Valentina Pavlovna, Kriticeskij analiz religiozno-filosofskogo uZenija N.F. Fedorova. Avoneferat dissenacii na soiskanie utenoj stepeni kandidata filosofskich nauk. M. 1983.

- Pazilova, V[alentina Pavlovna], "Proekt 'obstego dela' N.F. Fedorova." In: Nauka i Religija, 1983,3 , S. 26-29; 4, S. 37-40.

- Pazilova, Valentina Pavlovna, Kriticeskij analiz religiozno-filosofskogo uxenija N.F. Fedorova, M. 1985.

- [Pesl', Vladimar A.] Org, V., "Kogda my, mertvye, voskresnem?.. K 30-letiju so dnja smerti myslitelja N.F. Fedorova." In: Staryj Narvskij Listok, 145 (1211), 21.12.1933, S. 3.

PERCov, V[LAdIMR] O[sIPOVIC], Majakouskj. Žizn'i twontestwo, t. 1, M. 1950.

Perekovka. Organ KVO Upravlenija Belbaltkombinasa NKVD. 31 (595), 22.5.1936.

Perelesin, V., siehe Salatko-Petriše, V.F

Perel'man, Ja[kov] I[sidorovic], Ciolkovskj. Zizn'i iechnizeskie idei. M.-L. 1937.

PERRETT, ROY W., Death and Immonality. Dordrecht u.a. 1987. (= Studies in Philosophy and Religion; 10).

- Peterson, Nadezhdida L. [Nadezda Leonidovina], Fantayy and Utopia in the Contemporary So viet Novel, 1976-1981. Ph.D. diss. Indiana Univ. 1986; Ann Arbor, Mich. 1986. [Fedorov S. 29, 48 53, 55f., 58, 60f., 64, 73, 77, 98]

- Peterson, N[ikola Pavlovic], "Pis'mo k izdatelju Russkogo Archiva. Po povodu otzyva F.M. Dostoevskogo o N.F. Fedorove." In: Russkaj Archiv, 42 (1904), 6, S. 300 . 
- Peterson, N[ikolas Pavlovic], "Predislovie." In: N.F. Fedorov, Filosofija obšcego dela, t. 1, Vernyj 1906, S. V-XII.

- [Peterson, Nikolas PavloviC] Anon., Pravda o velikom pisatele zemli russkoj, gr. L.N. Tolstom k 55-letnemu jubileju ego literatumoj dejatel'nosti, Novocerkassk 1908. [Fedorov S. 19, 21, 23-27]

- Peterson, N[IKolaj] P[avloviC], "Iz zapisok byvßego uCitelja." In: Mezdunaradnyj tolstovskij al'manach, M. 1909, S. 257-268.

- Peterson, N[IKolas] P[avloviC], N.F. Fedorov i ego kniga 'Filosofija obscego dela' v protivopolotnost' učeniju L.N. Tolstogo 'o neprotivlenii' i drugim idejam nasego vremeni, Vernyj 1912.

- Peterson, N[IKolas Pavlovic], "Zametka po povodu stat'i kn. E. Trubeckogo - 'Ziznennaja zadała Solov'eva i vsemirnyj krizis żizneponimanija', - v 'Voprosach Filosofii i Psichologii', sentjabr'-oktjabr' 1912 goda." In: Voprosy Filosofii i Psichologii, 1913, 3 (118), S. 405-411.

- Peterson, N[ikolas Pavlovic], "Pis'mo N. Petersona k N.A. Caevu o N.F. Fedorove." [16.8.1874] In: Russkj Archiv, 1915, 11-12, S. 280f. Wiederabdr. in: Vselenskoe delo, sb. 2, Riga 1934, S. $160 f$.

- Peterson, N[ikolaj] P[avlovic], O religioznom charaktere uCenija N.F. Fedorova. (Po povodu statej SA. Golovanenki v 'Bogoslovskom Vestnike' 1914 g.). M. 1915.

- Peterson, N[ikolaj PavloviC], "Christianstvo N.F. Fedorova, avtora filosofii Obšego Dela." In: Bogoslovskij Vestnik, 25 (1916), 1, S. 119-130.

- Peterson, Ronald E., Andrei Bely's Shon Prose, Birmingham 1980. (= Birmingham Slavonic Monographs; 11). [Fedorov S. 65]

PethYBridge, Roger, The Social Prelude to Stalinism, New York 1974.

PETR, WINFRIED, "Raumfahrt in der Sowjetunion. Historisch-ideologischer Rahmen und praktische Enwartungen." In: Studies in Soviet Thought, 18 (1978), S. 45-55.

Petrov, Georgu, siehe Filistinsku, BA.

PETROV, VIKTOR [PORFIR'EVIC], Gorod na Sungari, Washington 1984.

Petrovsku, DM[TrRu], "Vospominanija o Velemire Chlebnikovc." In: LEF. Zumal Levogo Fronia Iskusstv. 1923, 1, S. 143-171. Nachdruck München 1970 ( = Slavische Propylăen; 91,I).

Pil'njak [d.i. Vogau], B[oris ANDRfevič], FedorovskiJ, N.M., "Delo smerti." [1927] In: Novyj Mir, 4 (1928), 2, S. 133-140.

- Piskunov, Vladimir Maksimovic, Tema o Rossii. Rossija i revoljucija v literature nacala XX veka. M. 1983. [Fedorov S. 77]

- Pttirim [d.i. NeCAev, Konstantin VladimiroviC], Mitropoi.rt, "Russkaja ideja' i vzaimovlijanie zapadnogo i vostożnogo christianstva." In: A. RAUCH, P. IMHOF (Hgg.), Tausend Jahre zwischen Wolga und Rhein, München, Zürich 1988, S. 54-59. ( = Koinonia; 5). [Fedorov S. 57]

- Pjatidesjatiletie Rumjancevskogo muzeja v Moskue. 1862-1912. Istoriceskij oxerk. M. 1913. [Fedorov S. XXI]

Platonov [d.i. KLIMENTov], ANDREj [PLATONovic], Golubaja glubina. Kniga stichov. Krasnodar 1922.

Platonov [d.i. Klimentov], Andrej [Platonovic], Epifanskie sljuzy, M. 1927.

Piatonov [d.i. Kuimentov], Andrej [Platonovic], Starik i stanucha. Poterjannaja proza. München 1984. (= Arbeiten und Texte zur Slavistik; 33).

Platonov [d.i. Klimentov], ANDRes P[LATONoviC], Kotlovan. Juvenil'noe more. M. 1987.

Platonov [d.i. KLIMENTOV], A[NDRE]] P[LATONoviC], "Normalizovannyj rabotnik." [1920] In: Russian Literature, 23, 1988, S. 428-430.

PLATONOV, Nikolas FEdoRoviC, "Pravoslavnaja cerkov' v bor'be s revoljucionnym dviženiem v Rossii (1900-1917 gg.)." In: Ežegodnik muzeja istorii religii i ateizma, t. 4, M.-L. 1960, S. 103-209.

- [Pletnev, Rostislav Vladimirovic] Pletiniow, Rostislaw, "Grundlinien der philosophischen Lehre N.O. [sic] Fiodorows." In: Festschrift N.O. Losskij zum 60. Geburtstage, Bonn 1934, S. 133140. (= Der russische Gedanke; Ergbd. 3).

- Pletnev, R[ostislav Vladimirovic], N.F. Fedorov i F.M. Dostoevskij. Iz istorii russkogo utopizma." In: Noryj Zumal, 50, 1957, S. 220-245. 
- Pletinev, Rostislav [Vladimarovic], "O mirovozzrenii Dostoevskogo." In: Zapiski nusskoj akademiceskoj gruppy v S.S.A. / Transactions of the Association of Russian-American Scholars in the U.SA., t./vol. 12, New York 1979, S. 79-92. [Fedorov S. 88-91]

- Pobedonoscev, K[onstantin] P[ETROVIC], KP. Pobedonoscevi ego korrespondenty. Pis'ma i zapiski. S predisloviem M.N. Pokrouskogo. T. 1, Novum Regnum, polut. 1-j, M. 1923. (= Trudy Gosudarstvennogo Rumjancevskogo Muzeja; 2).

POKRoVsKu, P.JA., siehe GeorgIevsKu, G.P.

- "PokuSenie Karakozova 4 aprelja 1866 g." In: Krasnyj Anchiv, 17, 1926, S. 91-137.

- Poljakov, M[ARK] Ja[Kovlevic], "Velimir Chlebnikov. Mirovozzrenie i poetika." In: V. ChIlebnikov, Tvorenija, M. 1986, S. 5-35. [Fedorov S. 13f., 19]

- Poltavceva, Natal'ja Grigorievna, Filosofskaja proza Andreja Platonova, Rostov-na-Donu 1981. [Fedorov S. 30, 42, 132]

- PoltorackIJ, N[IKOLA] P[ETROVIC], "Russkaja religioznaja filosofija." In: Mosty, 4, 1960, S. 172 190.

- Pomorska, Kristina [Krystyna], "Majakovskij i vremja. (K chronotopizeskomu mifu russkogo avangarda)." In: Slavica Hierosolymilana, 5-6, 1981, S. 341-353. [Fedorov S. 342, 352f.]

- Pomorska, Krystyna, "The Utopian Future of the Russian Avant-Garde." In: American Contributions to the Ninth Intemational Congress of Slavists, Kiev, September 1983, vol. 2, Columbus, Ohio 1983, S. 371-386.

- POMORSKa, KrystYnA, "Majakouskij's Cosmic Myth." In: A. KodjaK u.a. (Hgg.), Myth in Literature, Columbus, Ohio 1985, S. 170-187. ( = New York University Slavic Papers; S).

- POMORSKA, KRYSTYNA, "Majakovskij and the Myth of Immortality in the Russian Avant-garde." In: N.A. NiLsson (Hg.), The Slavic Literatures and Modemism. A Nobel Symposium. August 5.8 1985. Stockholm 1986, S. 49-69. (= Konferenser; 16). [Fedorov S. 49, 59-61]

- Porret, Eugìne, La philosophie chrétienne en Russie. Nicolas Berdiaeff. Neuchâtel 1944. [Fedorov S. 92-95] - Dass. [dt.] Nikolaj Berdjajew und die christliche Philosophie in Rußland, Heidelberg 1950. [Fedorov S. 118-121]

PospIElovskY, DIMITRY, The Neo-Slavophile Trend and Its Relation to the Contemporary Religious Revival in the USSR." In: P. RAMET (Hg.), Religion and Nationalism in Soviet and East European Politics, Durham, N.C. 1984, S. 41-58, 245-250.

Prat, Naftali [d.i. Partasnikov, Anatolu], "Orthodox Philosophy of Language in Russia." In: Studies in Soviet Thought, 20 (1979), S. 1-21.

Priśvin, Michail [Michajlovic], "Zapisi o tvor restve." In: Kontekst 1974, M. 1975, S. 312-359.

Prisvina, Valerua Dmitrievna, Put'k slovr, M. 1984.

- Pruachin, Vladimir [Fedorovic], Sevast'janov, Vitalu [Ivanovic], "Istoriju tvorit Celovek. Tysjaca i sto dvadcat' pjat' let akademika V.I. Vernadskogo." In: Moskva, 1988, 8, S. 162-168. [Fedorov S. 162f., 165-168]

- Prochanov, Aleksandr, "Metafora sovtemennosti." In: Literatumaja Gazeta, 37, 12.9.1979, S. 4.

"'Prorozeskaja dusa'. V. Chlebnikov v vospominanijach sovremennikov. K 100-letiju so dnja roždenija poetta." In: Literatumoe Obozrenie, 1985, 12, S. 93-104.

- Prugavin, A[Leksandr] S[TEPanovic], "O paradoksach L.N. Tolstogo." In: Sbomik vospominanij o L.N. Tolstom, M. 1911, S. 1-16. [Fedorov S. 2, 7f., 10f.]

PRZYBYLSK, RysZARD, "La questione degli onomatodossi del Monte Athos. Contributo all'ecclesiologia." In: The Common Christian Roots of the European Nations. An International Colloquium in the Vatican. Vol. 2, Florence 1982, S. 763-769.

Putnam, George F., Russian Aliematives to Maxism. Christian Socialism and Idealistic Liberalism in Twentieth-Century Russia. Knoxville 1977. 
Rabinowtrz, Stanley J., Sologub's Literary Children: Keys to a Symbolist's Prose, Columbus, Ohio 1980.

- RachILlo, IVAN [SPIRIdonovic], "Predutrennie zvezdy." In: My naš, my novyj mir postroim. Rasskazy, novelly i acerki... M. 1967, S. 533-544. [Fedorov S. 541f.]

- Radlov, E[RNEST] L[EOPOL'DOViC], Vladimir Solov'ev. Žizn'i učenie. SPb. 1913. [Fedorov S. 80]

- Radlov, E[RNEST] L[EOPOL'DOVZC], "Golosa iz nevidimych stran." In: Dela i dni. Istoriceskij tumal. Kn. 1, Pb. 1920, S. 189-208. [Fedorov S. 190, 200]

- [Radlov, ERnest Leopol'dovic] Radloff, E. von, Russische Philosophie, Breslau 1925. [Fedorov S. 104]

- Raevskana, E[Katerina] I[Vanovina], "Lev Tolstoj stedi golodajuszich." In: Letopisi Gosudarstvennogo Literatumogo muzeja, kn. 2 [L.N. Tolstoj], M. 1938. [Fedorov S. 382, 432]

- Raus, Emmanul, "O poézii Nikolaja Zabolockogo." In: Grani, 102, 1976, S. 121-146. [Fedorov S. 133]

- RAKrtin, V[ASILU IVANOVIC], "Sila obraznogo dramatizma." In: Iskusstvo, 1971, 10, S. 33-39.

- Rakov, V.[P.], "Somatizeskie intuicii v sovetskom literaturovedenii 1920-ch godov." In: Tvortestuo pisatelja i literatumyj process. (Russkaja literatura natala XX veka. Sovetskaja literatura 20.ch godov). Metruzovskij sbomik. Ivanovo 1986, S. 66-78. [Fedorov S. 71f.]

- READ, ChRISTOPHER, Religion, Revolution and the Russian Intelligentsia 1900 1912. The 'Vekhi' Debare and its Intellectual Background. London 1979. [Fedorov S. 32]

READE, WILLIAM WINWOOD, The Martyndom of Man, New York ${ }^{20} 1923$ [ $\left.{ }^{1} 1872\right]$

RECK, VERA T., Boris Pil'niak. A Soviet Writer in Conflict with the State. Montreal, London 1975.

RED'Ko, A.M., Literatumo-chudotestvennye iskanija v konce XIX - natale XX v.v. L. 1924.

RED'Ko, K[LMENT N.], "Vospominanija o V.N. Cekrygine." In: Iskusstro, 1971, 10, S. 39 f.

RENAN, ERNest, "Les sciences de la nature et les sciences historiques." In: Revue des Deux Mondes, 33 (1863), 47, S. 761-774.

Renan, Ernest, "L'Avenir de la Science." In: Ders., Oeuvres complètes, t. 3, Paris 1949, S. 7131151.

REPIN, IL'jA [EFimoviC], "Smert'." In: Smert'. Al'manach. SPb. 1910, S. 265-267.

REUTSKU, I.V., "Razoblazennoe gnezdo sektantskoj kontrrevoljucii." In: Bednota, 3455, 2.11.1929.

Reznikova, N[Atalua SemenovNa], "V russkom Charbine." In: Novyj Zumal, 172-173, 1988, S. 385-394.

- Ruasanovsky, Nicholas V., The Emergence of Eurasianism." In: Calıfomia Slavic Studies, 4, 1967, S. 39-72. [Fedorow S. 60]

RuHA, T., "Russian Emigre Scholars in Prague after World War I." In: Slavic and East European Joumal, 16 (1958), 1, S. 22.26.

- RIPELIINo, ANgelo MARIA, Majakovskij e il teatro nusso d'avanguandia, Torino 1959. [Fedorov S. 60f., 118, 208] - Dass. [dt.] Majakovskij und das russische Theater der Avantgande, Koln 1964.

- Ripellino, Angelo Marla, Chlebnikov. Saggio, antologia, commento. Torino 1968. [Fedorov S. VIII, XXXIII, XXXVII, XL, LXIf., LXX-LXXII, LXXIXf., LXXXII, XCI, 178, 190, 199, 202, $207,210 f ., 217,245,248 f$.]

- Rupeluno, ANgelo Marua, "Play Majakovskij (Divagazioni su 'La cimice')." In: Rossija - Russia, 3, Torino 1977, S. 15-28. [Fedorov S. 17-19]

- Ripeluno, ANgelo Maria, "Rozanov." In: Ders., Saggi in forma di ballate. Divagazioni su temi di letteratura russa, ceca e polacca. Torino 1978, S. 21-76. (= Saggi; 593). [Fedorov S. 43, 50, 55, 62, 74]

- Rupeluno, Angelo Maru, Tentativo di esplorazione del continente Chlebnikov." In: Ders., Saggi in forma di ballate. Divagazioni su temi di letteratura russa, ceca e polacca. Torino 1978, S. 77-150. (= Saggi; 593). [Fedorov S. 78, 99f., 106f., 124, 132, 134, 140-142, 150]

- Ruácikov, Evgenu IVANovic, Zvezdnyj put', M. ${ }^{2}$ 1986. [Fedorov S. 51-54, 58, 66] 
- Roberti, Jean-Claude, "La résurrection de Moscou Troisième Rome ou la face cachée du projet fédorovien." In: Revue des Etudes slaves, 56 (1984), 1, S. 79-85.

- Rodnjanskaja, I[RINa Bencionovina], "Ciolkovskij, Konstantin Eduardovic." [Lexikonartikel] In: Filosofskaja énciklopedija, t. 5, M. 1970, S. 466-468.

Rojzman, Matvej Davidovic, Vse, dto ja pomnju o Esenine, M. 1973.

- Rom[ANicku], [Aleksandr ?] Alex, "K clánku 'Pele-mele' o jezdecké akademii v Cer ̌anech." In: Jezdec a chovatel, [Praha] 3, 1935, ¿. 68, S. 803f.

- RomanickI, A[LEKSANDR ?], "Rab. Rasskaz sportsmena." In: Illjustrinovannaja Rossija, [Paris], 1936, 27, S. 8ff.

- Romanjuk, Sergej Konstantinovie, iz istorii moskovskich pereulkov, M. 1988. [Fedorov S. 132]

Romanoff, Janet ANNe SCHONwald, Vasilij Rozanov - The Jurodivyj of Russian Literature. Ph.D. diss. Stanford Univ. 1974, Ann Arbor, Mich. 1975.

- Romanovsky, I., Kniga i Zizn'. Ozenki o Gosudarstvennoj biblioteke SSSR im. Lenina. M. 1950. [Fedorov S. 60-67]

- Rosenthal, Bernice Glatzer, "Stephen Lukashevich. N.F. Fedorov (1828-1903): A Study in Russian Eupsychian and Utopian Thought. Newark, London 1977." [Rezension] In: Slavic Review, 38 (1979), 1, S. $131 f$.

ROSENTHAL, Bernice Glatzer, "Eschatology and the Appeal of Revolution: Merezhkovsky, Bely, Blok." In: Califomia Slavic Studies, 11, 1980, S. 105-139.

- Rosenthal, Bernice Glatzer, "Introduction." In: Dies. (Hg.), Nietzsche in Russia, Princeton, NJ. 1986, S. 3-48. [Fedorov S. 37, 41-43, 47]

- Rosnlansky, Pierre, "La signification sociale du christianisme dans la philosophie religieuse russe des $19^{\mathrm{e}}$ et $20^{\mathrm{e}}$ siècles." In: Contacts, 121, 1983, S. 33-61. [Fedorov S. 39, 44, 57 ]

ROVNER, ARKADIJ [BORISOVIC], "V.F. Ern." In: N.P. POLTORACKU (Hg.), Russkaja religiozna-filosofskaja mysl' XX veka. Sbomik statej. Pittsburgh 1975, S. 383-391.

- Rovner, ARKadu [BorisoviC], "Sovtemennyj spiritualizm v Rossii." In: Okkul'tizm i ioga, [Asuncion, Paraguay] 64, 1977, S. 10-23. [Fedorov S. 11f.]

ROWLEY, DAVID GRAEME, Millenarian Bolshevism: Empiriomonism, God-Building, Proletarian Culture. Ph.D. diss. Michigan 1982, Ann Arbor, Mich. 1982.

Rozanov, MiCH[AIL], Soloveckij konclager v monastyre 1922-1939 gody. Fakty, domysli, 'parast'. Obzor vospominanij solov'an solov'anami. Kn. 1, o.O. 1979; kn. 2, o.O. 1980.

Rozanov, V[ASILU] V[ASIL'EVIC], Ljudi lunnogo sveta. Metafizika christianstva. SPb. 1911.

- Rozanov, V[asiud VasiL'eVic], "Idejnye spory L.N. Tolstogo i N.N. Strachova." In: Novoe Vremja, 13548, 1913, S. 5.

- Rozanov, V[asilus VASIL'EVIC], 'Turkestanskie proizrastanija." In: Novoe Vremja, 14269, 29.11.(12.12.)1915, S. 5.

Rozanov, V[ASILU VASIL'EVIC], Opavíe list'ja, [1913] Berlin 1929.

RoŽKov, N[IKOLA ALEKSANDROVIC], "ZnaZenie i sud'by novejł̌gego idealizma v Rossii." In: Vo prosy Filosofii i Psichologii, 14 (1903), 2/67, S. 314-332.

RoŽKov, N[IKOLA ALEKSANDROVIC]], Osnovy naǔnoj filosofii, SPb. 1911.

Rožkov, N[IKola Aleksandrovic], Smysl i krasota tizni. (Etjud iz prakticeskoj filosofii). Pg.-M. 1923.

Rožkovskaja, Nina Nikolaevna, Teatral'naja tizn' Kisineva XIX - nacala XX v. (Iz istonii russkogo dramaticeskogo teatra). Kišinev 1979.

Rubakin, Alexsandr Nikolaevic, Rubakin. (Locman kniżnogo morja). M. ${ }^{2} 1979$.

RUDNEV, Aleksej NikolaeviC, "V poiskach Svjatoj Rusi: Iz pisem A.N. Rudneva k V.I. Leonovoj." In: Nadezda. Christianskoe čtenie. Vyp. 6, Frankfurt/M. 1980, S. 271-361. 
- RULlxÖter, BERnd, Die Wissenschafiliche Phantastik der Sowjetunion. Eine vergleichende Untersuchung der spekulativen Literatur in Ost und West. Bern, Frankfurt/M. 1974. (= Europăische Hochschulschriften; XVIII, 5).

RuPPERT, HaNs-JORgen, Die Kosmodizee S.N. Bulgakovs als Problem der christichen Weltanschauung. Theol. Diss. Heidelberg 1977.

- RuPPERT, HANS-JORgeN, "Religioser Utopismus und Eschatologie im russischen Denken." In: Materialdienst. Aus der Evangelischen Zentralstelle für Weltanschauungsfragen der EKD. 44 (1981), 10, S. 276-288.

- Russkie Vedomosti 1863-1913. Sbomik statej. M. 1913. [Fedorow S. 182]

RYNIN, N[IKOLAJ] A[LEKSEEVIC], Kosmičeskie korabli. (Mežplanetnye soobscenija v fantazijach romanistov). L. 1928. (= Priroda i ljudi; 6, 1928).

RYNIN, NiKolas ALEKSEEVIC, Russkaj izobretatel' i uXenyj Konstantin Eduandovic Ciolkovskaj. Ego biografija, rabory i rakety. L. 1931. ( = N.A. RYNIN, Mě̌planetnye soobšenija; t. 3, vyp. 7).

SACHNOVIC, MICHAIL IosifovIC, V.I. Lenin i problemy ateizma. (Kritika religii $v$ trudach V.I. Lenina). M.-L. 1961.

SACHNOVIC, M[ICHAIL] I[OSIFOVIC], Novye voprosy ateizma. Sociologiceskie ocerki. L. 1973.

SAChovskoJ, IOANN [DMTrRu AlexseEviC], Biografija junosti, Paris 1977.

- Śaginjan, Mariétta [Sergeevna], "Čelovek i vremja. Vospominanija." In: Novyj Mir, 1973, 4, S. 112-131 [Fedorov S. 127]; 6, S. 128-153; 1975, 3, S. 132-211. [Fedorov S. 205]

- SAgindan, MARIĖTta [SERgeevna], "Slovo velikoj priznatel'nosti." In: Literatumaja Gazeia, 1975, 6, S. 1.

- Saginjan, Mariétta [Sergeevna], Čelovek i vremja, M. 1980. [Fedorov S. 238, 252, 287, 440, 465]

SAlatko-Petriše, V[aleru] F[rancevic], "Russkie na Dal'nem Vostoke." In: P.E. KovaLEVSKU, Zanubeinaja Rossija, Paris 1971, S. 324-332.

[SAlatko-PetrisCe, Valeru FranceviC] Perelesin, Valeri, "Russkie dal'nevostočnye poety." In: Noyyj Zumal, 107, 1972, S. 255-262.

SAlmon, ANtonella, "Una fonte per lo studio del taylorismo nella Russia sovietica." In: Classe, [Milano] 13 (1982), 22, S. 245-263.

SAltykov, A., "Pervyj illjustrator Majakovskogo." In: Tvortestro, 1965, 12, S. 15.

- Snmbinaco, S.[K.], "Neskolko slov po povodu Fedorovskoj zapisi legendy o Kresinom syne." In: Russkij Archiv, 53 (1915), 11-12, S. 304f.

- SAPoSnKov, B.[V.], "Apostol bol'Sogo iskusstva. Vospominanija o V.N. Čekrygine." In: Makovec, 1922,2, S. 8-10.

- SARkisyanz, Emanuel, Russland und der Messianismus des Orients. Sendungsbewrusstsein und politischer Chiliasmus des Ostens. Tübingen 1955.

- [SATOVSKU-RŽEVSKU, GRIGORU GRIGOR'EVIC] GREJ, D., "Na vtomike Curaevki." In: Russkoe Slovo, [Harbin] 2156, 11.5.1933, S. 6.

- Satta Boschian, Laura, "Le correnti mesianiche russe fra Ottocento e Novecento." In: Studium, [Roma] 80, 1984, S. 177-193. [Fedorov S. 186, 191f.]

- SAVEL'EV, SERGEJ NiKolAEVIC, Idejnoe bankrotstro bogoiskatel'stva v Rossii v nacale XX veka, L. 1987. [Fedoron S. 27f.]

[SA vicku, Petr Nikolaevic] Lubenski, Stepan, "L'Eurasisme." In: Le Monde slave, 8 (1931), 1, S. 69-91.

SAVICKu, P[ETR] N[IKOLAEVIC], "V bor'be za evrazijstvo. Polemika vokrug evrazijstva v 1920 godach." In: Tridcatye gody, Paris 1931, S. 1-52.

- [SA Vicku, PETr NikolaEvic] Vostokov, P., "La philosophie russe durant la période post-révolutionnaire." In: Le Monde slave, 9 (1932), 4, S. 432-457. [Fedorov S. 440] 
[SAvicku, Petr Nikolaevic] Vostokov, P., Stichi, Boulogne sur Seine 1960.

SCANLAN, JAMes P., The New Religious Consciousness: Merezhkousky and Berdyaev. [Beitrag für den Kongreß] La Philosophie Idéaliste en Russie. Aix-en-Provence, 25-29.3.1968.

- Scanlan, J[ames] P., "Ludmila Koehler. N.F. Fedorov: The Philosophy of Action. Pittsburgh 1979." [Rezension] In: Slavic and East European Joumal, 25 (1981), 1, S. 115-117.

- SCERBaKov, M[ICHAIL VASIL'EviC], "Literatura i knigoizdatel'stvo." In: Vrata. Dal'nevosto'nye sbomiki. Kn. 2, Sanchaj 1935, S. 237-242. [Fedorov S. 241]

- SCHEjbert, Peter, "Der Ubermensch in der russischen Revolution." In: E. BeNZ (Hg.), Der Ubermensch, Zürich Stuttgart 1961, S. 179-196.

- SCherbert, Peter, "Die Besiegung des Todes - Ein theologisches Programm aus der Sowjetunion (1926)." In: G. MOLLER, W. ZELLER (Hgg.), Glaube, Geist, Geschichte. Festschrifi für Emst Benz. Leiden 1967, S. 431-447.

- SCheibert, PETER, "Revolution und Utopie. Die Gestalt der Zukunft im Denken der russischen revolutionaren Intelligenz. In: H. BARION u.a. (Hgg.), Epinthosis. Festgabe für Cart Schmitt. Bd. 2, Berlin 1968, S. 633-649.

- SCheibert, Peter, "Lenin, Bogdanov, and the Concept of Proletarian Culture." In: B.W. EisSENSTAT (Hg.), Lenin and Leninism. State, Law, and Sociery. Lexington, Mass. 1971, S. 43-57. [Fedorov S. 46, 55f.]

- SCHERRER, JUTTA, Die Petersburger Religiös-Philosophischen Vereinigungen. Die Entwicklung des religiösen Selbstverstandnisses ihrer Intelligencija-Mitglieder (1901-1917). Berlin, Wiesbaden 1973. (= Forschungen zur Osteuropäischen Geschichte; 19). [Fedorov S. 206, 233, 406]

SCHERRER, JUTTA, "Intelligentsia, religion, revolution: Premières manifestations d'un socialisme chrétien en Russie. 1905-1907." In: Cahiers du Monde russe et soviétique, 17 (1976), 4, S. 427-466; 18 (1977), 1-2, S. 5-32.

SCHERRER, JUTTA, "Pour une thélogie de la revolution. Merejkovski et le symbolisme russe." In: Archives de Sciences sociales des Religions, 45 (1978), 1, S. 27-50.

SCHERRER, JUTTA, "La 'construction de Dieu' marxiste ou la 'recherche de Dieu' chrétienne: les termes 'bogostroitel'stvo' et 'bogoiskatel'stvo'." In: Rossija - Russia, 4, Torino 1980, S. 173-198.

SCHIBLI, SIGFRIED, Alexander Skjabin und seine Musik. Grenzüberschreirungen eines prometheischen Geistes. München, Zürich 1983.

[SCHLOEZER, BORIS] SLECER, B[ORIS FEDOROVIC], "Zapiska B.F. Slecera o Predvaritel'nom Dejstvii." In: Russkie propilei, t. 6, M. 1919, S. 98-119.

- SChLOEZER, Boris DE, Alexandre Scriabine, Paris 1975. [Fedorov S. 193-195]

- Schmemann, Alexander (Hg.), Ultimate Questions. An Anthology of Modem Russian Religious Thought. London, Oxford 1977.

SCHMIDT, ALFRED, Der Begriff der Natur in der Lehre von Marx, Frankfurt/M. ${ }^{2} 1974$.

SCHOPENHAUER, ARTHUR, Parerga und Paralipomena, Bde. 1 u. 2, Leipzig 1938, 1939. (= A. SCHOPENHAUER, Samtliche Werke, hg. v. A. Hübscher; 5 u. 6).

- [SChourtz, OsKar von] SUl'c, OsKar A. Fon, "N.F. Fedorov. Celovek i myslitel'." In: Zvezda, [Paris] 1929, 5, S. 9-18; 6, S. 46-56; 7, S. 34-48; 8, S. 36-45.

- Schultze, Bernhard, Russische Denker, ihre Stellung zu Christus, Kinche und Papsttum, Wien 1950. [Fedorov S. 201-209]

- SChultze, BeRnhaRd, "Die Sozialprinzipien in der russischen Religionsphilosophie." In: Zeitschriff fur katholische Theologie, 73 (1951), 4, S. 385-423. [Fedorov S. 386, 388, 396, 403f., 415, 421423]

SCHULTZE, BERNHARD, "Der Streit um die Gottlichkeit des Namens Jesu in der russischen Theologie." In: Orientalia Christiana Periodica, 17 (1951), S. 321-394.

- SChUltze, Bernhard, "Christozentrik im russischen Gedanken." In: Ostkirchliche Studien, 8 (1959), S. 105-126. [Fedorov S. 112f.]

SECHTEL', L.F., siehe ZEGIN, L.F. 
SEEMANN, KLAUS-DIETER, "Der Versuch einer proletarischen Kulturtevolution in RuBland 19171922." In: JfGO, 9 (1961), S. 179-222.

SEJnMan, Michail MARKovic, Christianskaj socializm. Istorija i ideologija. M. 1969.

- Seleznev, Juru Ivanovic, Dostoevskij, M. 1981. [Fedorov S. 479f.] Sel'viNSKu, IL'Ja [L'vovic], "Otvet L'vu Ozerovu." In: Literatumaja Rossija, 39, 23.9.1966, S. 9. SEL'VINSKU, IL'JA [L'voviC], Davajte pomettaem o bessmeri'e. Stichi. M. 1969. SEMENKIN, N[IKOLA]] S[EMENOVIC], "Krizis teodicei. (O popytkach bogoopravdanija $v$ russkoj religioznoj filosofii)." In: Naučnye doklady uysšej skohy. Filosofskie nauki. 1969, 3, S. 108-116.

- SEMENKIn, Nixolas SEMENovic, Filosofija bogoiskatel'stva. Kritika religiozno-filosofskich idej safiologov. M. 1986. [Fedorov S. 7, 9, 114f., 155]

SEMENov, V.P. (Hg.), Rossija. Polnoe geograficeskoe opisanie našego otecestva. T. 2, SPb. 1902.

- Semenova, S[VetLana] G[Rigor'evna], "Nikolaj Fedoroviz Fedorov. (Žizn' i učnie)." In: Prometej, 11, M. 1977, S. 86-105.

- Semenova, S[Vetlana] G[RIgor'evna], "K publikacii stat'i N.F. Fedorova o Fauste." In: Kontekst 1975, M. 1977, S. 311-314.

- [Semenova, Svetlana Grigor'evna] Sem'onova-GaCeva, S.G., Trorzestvoto na zivota. (Filosofsko-estetiłeskite idei na N.F. Fodorov)." In: Literatuma misăl, 22 (1978), 3, S. 88-107.

- Semenova, S[vetlana] G[RIGor'evNa], "Fedorov, Nikolaj Fedorovic." [Lexikonartikel] In: Kratkaja literatumaja enciklopedija, 1. 9, M. 1978, Sp. 755 f.

- Semenova, SVEtlana [GRIGoR'EVNa], "'V usilii k buduscemu vremeni...' (Filosofija Andreja Platonova)." In: Literatumaja Gruzija, 1979, 11, S. 104-121. - Dass. [bulg.] SEM'ONovA-GACEVA, S.G., "'S usilija kăm bădešctoto...' (Filosofijata na Andrej Platonov)." In: Literatuma misăl, 24 (1980), 6, S. 84-103.

- Semenova, SVetlana [Grigor'eVna], "Ob odnom idejno-filosofskom dialoge. (L.N. Tolstoj i N.F. Fedorov)." In: Sever, 1980, 2, S. 115-128.

- Semenova, S[vetiana Grigor'evna], "Serdečnaja mysl" M. Prišina." In: Volga, 1980, 3, S. 162-170.

- Semenova, Svetlana G[Rigor'eVna], "Celovek, priroda, bessmertie v poezii Nikolaja Zabolockogo." In: Literatumaja Gruzija, 1980, 9, S. 134-152.

- Semenova, S[Vetlana Grigor'evNa], "Tvorלestvo žizni." In: Naš Sovremennik, 1981, 6, S. 175184.

- [Semenova, Svetlana Grigor'evina] Sem'onova-GaCeva, Svetlana, "Prevăzmogvane na esnafa. Otnoß̌enieto kăm smărtta u Maksim Gorki." In: Literaturen Front, 38, 17 9.1981, S. 7.

- Semenova, S[Vetlana Grigor'evna], "Kosmos i chudožestvennoe tvorZestvo." In: Dekorativnoe Iskusstvo SSSR, 1981, 11, S. $11 \mathrm{f}$.

- Semenova, S[Vetrana Grigor'eVNa], "Filosofija optimizma." In: Literatumaja UZeba, 1982, 3, S. 169-172.

- Semenova, S[VEtLana] G[Rigor'evna], "N.F. Fedorov i ego filosofskoe nasledie." In: N.F. FeDOROV, SoCinenija, M. 1982, S. 5-50.

Semenova, S[VETLANa] G[RIGoR'evNa], "Ne vižu predela mošzi razuma'." In: Literatumaja UCeba, 1984, 3, S. 150-156.

- Semenova, S[vetlana] G[Rigor'evina], "Metamorfoza pola: Platon, Frejd i gnosticizm." In: Metodologixeskie problemy issledovanija kul'rury. Kul'tura i kritika psichoanaliza. M. 1987, S. 78107. [Fedorov S. 95, 101f.]

- Semenova, Svetuana [Grigor'evna], "Masterovye ideala. Poezija pervogo posleoktjabr'skogo desjatiletija." In: Oktjabr', 1987, 11, S. 190-198.

- Semenova, Svetlana [Grigor'evna], "Sem'ja idej. K 125-letiju so dnja roždenija V.I. Vernadskogo." In: Znamja, 1988, 3, S. 185-201. [Fedorov S. 187-192, 195, 198, 200]

- Semenova, S[Vetuana] G[RIgor'evna], "Aktivno-evoljucionnaja mysl' Vernadskogo." In: Promerej, 15, M. 1988, S. 221-248. [Fedorov S. 225, 227-231, 233, 236, 242, 244f.] - Dass. [gekürzt] auch in: Celovek i Priroda, 1988, 4, S. 22-77. [Fedorov S. 32, 35-44, 48, 50, 68, 71, 73] 
- Semenova, Svetlana [Grigor'evna], "Opravdanie Rossii." In: Vesinik Prometeja, vyp. 3, M. 1988, S. 128-149.

- Semenova, S[vetlana Grigor'evna], "Ideja żizni" Andreja Platonova." In: A. Platonov, Cevengur, M. 1988, S. 3-20. [Fedorov S. 5]

- Semenova, Svetuana [Grigor'evina], "Mytarstva ideala. K vychodu v svet 'Cevengura' Andreja Platonova." In: Noyyj Mir, 1988, 5, S. 218-231. [Fedorov S. 222-224, 227, 230]

- Semenova, SVEtLANA [GRigor'EVNa], "'Vyšaja ideja sušestvovanija' u Dostoevskogo." In: Voprosy Literatury, 1988, 11, S. 166-195. [Fedorov S. 185-195]

- Semenova, Svetlana [Grigor'evna], "'Da' soznatel'noj evoljucii. P'er Tejjar de Šarden. Fenomen Celoveka... M. 1987." [Rezension] In: Novyj Mir, 1988, 12, S. 253-255.

- Semenova, S[Vetlana] G[RIGoR'eVNa], "Serdečnyj myslitel'." In: Voprosy Filosofii, 1989, 3, S. 26-31.

SENN, Alfred Erich, Nicholas Rubakin. A Life for Books. Newtonville, Mass. 1977. (= Russian Biography Series; 1$)$.

- SEnRok, Vladimir Ivanovic, "Pamjati N.F. Fedorova i A.E. Viktorova." In: IstoriCeskij Vestnik, 25 (1904), 95, 2, S. 663-670.

- Serebrukov, M.A., "Cerkov' i gosudarstvo." In: Russkoe Vozroždenie, 3 (1980), 11, S. 64-76. [Fedorov S. 74f.]

Sestakov, A., "Krestonoscy CČO." In: Novyj Mir, 1929, 12, S. 148-154.

SESTERHENN, RAIMUND, Das Bogostroitel'stvo bei Gor'kij und Lunacarskij bis 1909. Zur ideologischen und literarischen Vorgeschichte der Paneischule von Capri. München 1982. (= Slavistische Beitrăge; 158).

SEstov [d.i. SVARCMAN], LEv, Dobro v učenii gr. Tolstogo i F. Nitše. (Filosofija i propoved'). SPb. 1900.

- [Šestov, d.i. Švarcman], Chiestov, L. [LEV], "N.F. Fedorov, Filosofija obŠzego dela (Philosophie de l'affaire commune), fasc. I a III, Kharbin, 1928, 1929, 1930. - A. Ostromirov, N.F. Fedorov i sovremennost' (N.F. Fedorov et le présent), Kharbin, 1928, 1932, 1933. - A.K. Gornostaev, Pred licom smerti (En face de la mort), (L.N. Tolstoi et N.F. Fedorov), Kharbin, 1929." [Rezension] In: Le Monde slave, 11 (1934), 2, S. 155-158. - Dass. [russ.] "N.F. Fedorov." In: L. SEstov, Umozrenie i okknovenie, Paris 1964, S. 125-130. - Dass. [dt.] in: LEW SCHESTOW [SESTOV], Spekulation und Offenbarung. Essays und kritische Betrachtungen. Hamburg, München 1963, S. 179-184.

SETNICKU, N[IKOLA] A[LEKSANDROVIC], Bol'niznye kassy i zabolevanija mabocich v Odesse 1914 $15 \mathrm{~g}$. Odessa 1919.

SETNICKU, N[IKOLA ALEKSANDROVIC], Statistika, literatura i poezija. $K$ voprosu o plane issledovanija. Odessa 1922.

[SETNICKU, Nikola AlEKSANDROVIC]] siehe auch Smenoboznizestuo, 1926

- SETNICKU, N[IKOLA] A[LEKSANDROVIC], "KapitalistiŽskij stroj v izobraženii N.F. Fedorova." In: Izv Jur.Fak, 3, 1926, S. 9-25. - Auch separat: Harbin 1926. Wiederabdr. in: Versty, [Paris] 3, 1928, S. 259-277.

- SETNICKU, N[IKOLA]] A[LeKSANDRoviC], "Russkie mysliteli o Kitae. (V.S. Solov'ev i N.F. Fedorov)." In: Izv Jur.Fak., 3, 1926, S. 191-222. - Auch separat als Beilage zu: Cemu nauCaaet drevnejšj christianskij pamijatnik v Kitae? Stat'ja N.F. Fedonova. Charbin 1926.

[SETNICKu, Nikola AleksandroviC] ANON., Epafradit. Epopeja. O.O. [Harbin 1927]

- SetNicku, N[IKolas AleksandroviC], "Vladimir Aleksandroviž Koževnikov. 1852-1917-1927." In: Izv.Ju.Fak., 4, 1927, S. 323-328.

- SETNICKu, N[IKOLA AleKSANDRoviC], "N.F. Fedorov o razoruženii." In: Den' Jurista. [Harbin] 7, 1928, S. 4.

- Setnicku, N[IKola Aleksandrovic], "Nauka i trud." In: Novosti Žizni, [Harbin] 28.2.1928, S. 2.

- SETNICKU, N[IKOLA]] A[LEKSANDROVIC], "Eksploatacija. (OCerk 1)." In: IzvJur.Fak., 5, 1928, S. 215-257. - Auch separat: Charbin 1928. 
- [SETnCKu, Nikola Aleksandrovic] "S", "Iz perepiski N.F. Fedorova s V.A. Koževnikovym o Turkestane." In: Versty, 3, 1928, S. 278f.

- SETnICKI, N[IKoln Alexsandrovic], "Central'naja ideja N.F. Fedorova." In: Den' Jurista, 8, 1929, S. 5.

SETNICKU, N[IKOLA] A[LEKSANDROVIC], "O konečnom ideale." In: Izv.Jur.Fak., 7, 1929, S. 191255. - Auch separat: Charbin 1929.

[SETNICKU, NikOLA AlEKSANDROVIC] KORMCU, JAKOV, Valaam. (Poemy). Sanchaj 1931.

- SETNICKU, N[IKOLAJ] A[LEKSANDROVIC], $O$ koneinom ideale, Charbin 1932. [Fedorov S. 66-88] [SETNICKI, Nikolas AleKSANDROVIC] GeŽLINSKI, G.G., Zametki ob iskusstive, 0.O. [Harbin] 1933.

- SETNICKU, N[IKOLA] A[LEKSANDROVIC], "SSSR, Kitaj i Japonija. (Nazal'nye puti reguljacii)." In: IzvJur.Fak., 10, 1933, S. 187-247. - Auch separat: Charbin 1933.

- SeTNICKu, N[ikolas Aleksandrovič], "Sovtemennost' na putjach bor'by so smert'ju." In: Den' Jurista, 13, 1934, S. 3f.

- [SETNICKu, Nikolaj Aleksandrovic] Kozodoev, I.P., "K tridcatiletiju so dnja smerti N.F. Fedorova. (Bibliografǐeskaja zametka)." In: Vrata. Dal'nevostočnye sbomiki. Kn. 1, Sanchaj 1934, S. 183-187.

SETZER, HEINZ, "Die Bedeutung der Energielehre für die Literaturkonzeption Maksim Gor'kijs nach der ersten russischen Revolution." In: WdSl, 25 (1980), 2, S. 394-427.

- Sevast'janov, V[rtalus IVanoviC], "Razmysljaja o budušem." In: Nas Sovremennik, 1981, 6, S. 173-175.

- Sevast'janov, V[ttalu] I[vanovic], Pruachin, V[ladimir] F[edorovic], "Kosmonavtika i novoe politizeskoe mystenie v jademo-kosmireskuju éru." In: Voprosy Filosofii, 1987, 9, S. 34-44. [Fedorov S. 39-41]

- Sevast'janov, V[rtalu] I[vanovic], "Tridcat' let kosmizeskoj ery." In: Voprosy Filosofii, 1987, 10, S. $122 \mathrm{f}$.

SEZEMAN, V[ASILU] E[MIL'EviC], "Valerian Murav'ev. Ovladenie vremenem. Izd. avtora. Moskva 1924." [Rezension] In: Versty, 3, 1928, S. 172-175.

Sgalambro, Manluo, Vom Tod der Sonne, München 1988.

SHADOWA, LARISSA A., siehe ŻadOVA, LARISA A.

SHuw, Nonn D., "Nation and Superstate in Soviet Utopian Literature." In: Actes du IVe Congres de l'Association Intemationale de Litterature Comparte Friboung 1964, Bd. 1, The Hague, Paris 1966, S. 203-208

SHEIN, LouIs J[uLuUs], Readings in Russian Philosophical Thought, Bde. 1-3, The Hague, Waterloo, Ont. 1968-1977.

ShEIN, Lours J[uUus], "Sergius Bulgakov's Critique of Conditional Immortality." In: Abba Salama, [Addis Abeba] 10 (1979), S. 245-256.

SHEIN, Lous J[uLuU], "L.N. Tolstoy's Concept of Immortality." In: Ekklésia kai Theologia, [London] 1 (1980), S. 131-140.

- Shepard, Joe Willwerth, The Origin of a Master. The Early Prose of Andrej Platonov. Ph.D. diss. Indiana Univ. 1973; Ann Arbor Mich. 1974. [Fedorov S. 5, 43-50, 52, 66, 87, 123, 128, 133f., 163 , 165f., 173f., 178, 181, 186, 189f., 192f., 195, 200, 257, 263, 270, 308, 335-337, 350, 353, 452, 483f.]

SIDOROV, ALEKSEJ ALEKSEEVIC, Zapiski sobiratelja. Kniga o risunkach starych i novych. L. 1969.

- Sigrist, A., [Beitrag über N.F. Fedorov] in: Pamjamye kniznye daty 1981, M. 1981, S. 51-53.

SILBERER, MiChAEL, Die Trinitätsidee im Wenk von Pavel A. Florenskij. Versuch einer systematischen Darstellung in Begegnung mit Thomas von Aquin. Würzburg 1984. ( = Das Ostliche Christentum; NF 36).

[SINJA vsku, ANDRej Donatovic] Terc, Abram, Golos iz chora, London ${ }^{2} 1974$ ['1973].

- Sinjavsku, A[NDREj Donatovic], 'Opavsie List'ja' V.V. Rozanova, Paris 1982. (= A. Sinjavsku, Ocerki russkoj kul'tury; 1). [Fedorov S. 8, 13-15, 38, 40] 
- Sinuutin, V., "Pafos poznanija." In: Literatumaja Gazeta, 29 (4471), 17.7.1974, S. 5.

- Sirinsku-Sichmatov, JuRu [AleKSEeVIC], "Dva messianizma." In: Utverídenija, 3, 1932, S. 1943. [Fedorov S. 33f.]

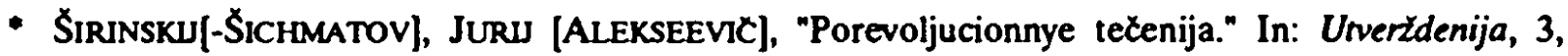
1932, S. 177-183. [Fedorov S. 177]

SIRokov, O.S., "Michail Nikolaevið Peterson (k 20-letiju so dnja smerti)." In: Vestnik Moskouskogo universitera, serija 9, filologija, 1983, 3, S. 57-60.

SiRotinin, A.N., "Ekaterina Semenowna Semenova." In: Istoriðeskij Vestnik, 25 (1886), 7,9, S. 474 508.

SKALON, D., siehe KASKKAROV, JU.D.

SKapskaja, Marua [Michajlovin], Stichi, London 1979.

SKaRENKoV, LeONID KonstantinoviC, Agonija beloj èmigracii, M. 1981.

- Skatov, N[ikola NikolaEvic], "Spor dvuch utopistov." In: Zuezda, 1978, 8, S. 172-180. - Wiederabdr. in: DERs., Dalekoe i blizkoe, M. 1981, S. 196-221.

- Skatov, N[ikolas Nikolaevic], "Lev Tolstoj i Nikolaj Fedorov." In: Ogonek, 1978, 37, S. 14 f.

- Skatov, Nikolaj NikolaEviC, Russkie poety prirody. OXerki. M. 1980. (= Biblioteka 'Ogonek'; 14). [Fedorov S. 8, 12f.]

- Skatov, Nikolas Nikolaevic, Dalekoe i blizkoe. Literatumo-kriticeskie oxerki. M. 1981. [Fedorov S. 111, 196-221]

- ŠKLOVSKU, V[IKTOR] B[ORISOVIC], "Žili-byli." In: Znamja, 1963, 2, S. 169-192. - Wiederabdr. in: DERS., Zili-byli, M. 1964, S. 448-457. M. 21966, S. 519-528.

- SkLovsKu, VIKTOR BORIsOVIC, "O Majakovskom." [1940] In: DERS., Zili-byli. Vospominanija, memuamye zapisi, povesti o vremeni. M. ${ }^{2} 1966$, S. 257-412. [Fedorov S. 278] Auch in: DeRS., Sobranie soxinenij v trech tomach, t. 3, M. 1974, S. 7-142.

- SkLovsku, VikToR [Borisovic], "Kosmonavtika ot A do Ja." In: Literatumaja Gazeta, 15, 7.4.1971, S. 13.

- SKLovSKu, VIKTOR BORIsovic, Lev Tolstoj, M. 1974. (= Sobranie socinenij v trech tomach; 3). [Fedorov S. 477, 541]

SKOLENKO, JURU ANDREEVIC, Filosofija, ekologija, kosmonavika (kriticeskj ocerk burtuaznych doktrin), M. 1983.

Skorino, Luddmla IVanovna, Pisatel' i ego vremja. Żizn'i twortestvo V.P. Kataeva. M. 1965.

- Skurinov, P[AVEl] S[EmenoviC], "V.P. Pazilova, Kritiðeskij analiz religiozno-filosofskogo urenija N.F. Fedorova, M. 1985." [Rezension] In: Voprosy Filosofii, 1986, 11, S. 164-166.

- SxuRlatov, VAlERu IVANoviC, Molodez' i progress. Filosofskie razmystenija o drame suobody, ljubvi $i$ izmeny v istonii. M. 1980. [Fedorov S. 211]

SLECER, BORIS FEDOROVIC, siehe SCHLOEZER, BORIS

SLenczKa, ReinhuRd, "Die Göttlichkeit des Namens und die Rechtfertigung des Sünders. Erwägungen zum dogmatischen Problem des Athosstreits von 1910 bis 1913." In: P. HAUPTMANN (Hg.), Unser ganzes Leben Christus unserem Gott überantworten. Studien zur ostkirchlichen Spiritualität. Fairy v. Lilienfeld zum 65. Geburtstag. Gottingen 1982, S. 417-433. (= Kirche im Osten; Monographienreihe; 17).

ŚuwowSKA, WikToRu, W kregu poprzedników Hercena, Wrockaw u.a. 1971.

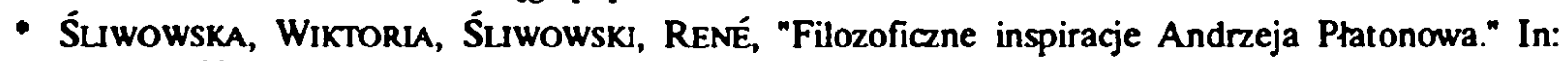
Przegłgd Humanistyczny, 25 (1981), 7-9, S. 1-23.

- Śluwowska, WikToria, ŚLwowsk, ReNÉ, Andrzej Ptatonow, Warszawa 1983.

SLJUSARSKI, ANTON Grigor'EviC, V.N. Kanazin, ego nautnaja i obšCestvennaja dejarel'nost', Char'kov 1955.

- Slonim, MARC [MARK L'vovic], From Cheknov to the Revolution. Russian Literature 1900 1917. New York 1962. Fedorow S. 115. 
Šmal'gauzen, I[van] I[vanovic], Problema smerti $i$ bessmerija, M.-L. 1926. (= Priroda i kul'tura; 19).

ŠMANKEVIC, BoRIs I[VANOVIC], "Meteor." [Gedicht] In: Južnyj Ogonek, [Odessa], 1918, 13, S. 11. "Velikaja pjatnica." [Gedicht] Ebd., 1918, 16, S. 14.

Smer'. Al'manach. SPb. 1910.

Smernobotnicestwo. Koren' eresej, nazdelenij i izwrastenij istinnogo utenija cerkvi. Dogmaticeskie oxerki. C. 1. Bor'ba slovom. O.O. [Harbin] 1926. - Die anonyme Schrift wurde gemeinsam verfaßt von A.K. GORSKU und NA. SETNICKU.

- Smirnov, A., "Dva filosofa: o znakomstve i otnošenii Tolstogo s N.F. Fedorovym." In: Golos Raboxego, [Noginsk] 21.11.1940. [War nicht zugănglich]

- SMIRnov, A., "Nikolaj Fedorovix Fedorov." In: Znamja Kommunizma, [Noginsk], 227 (10036), 19.11.1959, S. 4.

- SMrRnov, IGOR' P., ChudoŽestvennyj smysl i èvoljucija poetiteskich sistem, M. 1977. [Fedorov S. 110]

SMYrniw, Walter, "Tolstoi's Response to Modern Utopian Theories." In: Studies in Honour of Louis Shein, Hamilton, Ont. 1983, S. 135-143.

SOKOLOV, IPPOLTT [VASIL'EVIC], Renessans XX veka, o.O. o.J. [Moskva 1920?].

SoKoLov, N.P., "Kramol'naja' stat'ja L'va Tolstogo." In: Naše Nasledie, 3, 1988, S. 110-112.

- Solvvetti, Carla, "Azbuka uma' Velimira Hljebnikova." In: A. FlakER, D. Ugresić (Hgg.), Pojmounik nuske avangande, 3, Zagreb 1985, S. 223-233. [Fedorov S. 228f., 231f.]

Solne ¿nyj put'. Jutnyj al'manach. Kn. 1, Odessa 1914.

Solodovnikov, A.A., "Sokroviša Vvedenskich gor." In: Nadezda. Christianskoe črenie. Vyp. 9, Frankfurt/M. 1983, S. 217-254.

[SOLOGUB, d.i. TETERNIKOV, FEDOR KUZ'MIC] SSOLOGUB, FJODOR, Totenzauber. Eine Legende im Werden. Roman in fünf Teilen [in zwei Bănden]. München 1913.

- Solov'ev, Vladimir Sergeevic, "Pis'ma k N.F. Fedorovu." In: Ders., Pis'ma, pod red. E.L. Radlova, t. 1, SPb. 1908, S. 12; t. 2, SPb. 1909, S. 345-347.

Solov'ev, Vladimir Sergeevic, Sobranie socinenij, pod red. S.M. Solov'eva i E.L. Radlova, vtoroe izd. SPb. oJ. [1911-1914]

- Solov'ev, Vladimir [Sergeevic], Pis'ma, pod red. E.L. Radlova, t. 4, Pb. 1923. [Fedorov S. 118-120]

Solov'ev, Vyadimir Sergeevic], "Pis'mo VI. Solov'eva $k$ L. Tolstomu. O voskresenii Christa." In: Put', 5, 1926, S. 97-99.

- SOLZENICYN, ALEKSANDR ISAEVIC, Archipelag GULag 1918-1956. Opyt chudožestrennogo issledovanija. T. 3-4, Paris 1974. [Fedorov S. 627]

Spencer, Herbert, System der symthetischen Philosophie, Bde. 1-8, Stuttgart 1875-1889.

SPENGLER, OSKar, Der Mensch und die Technik. Beitrag zu einer Philosophie des Lebens. München 1931.

- SPROEDE, Alfred, Roman et utopie. 'Ćevengur' d'Andrej Platonov dans le contexte littéraire et philosophique. Phil. Diss. Konstanz [Masch.] o.J. [1982].

- StAGLCh, Dieter, Madimir F. Em (1882-1917). Sein philosophisches und publizistisches Werk. Ein Beitrag zur nussischen Geistesgeschichte des beginnenden 20. Jahrhunderns. Phil. Diss. Bonn 1967.

- Stahlberger, Lawrence Leo, The Symbolic System of Majakorskij, The Hague 1964. ( = Slavic Printings and Reprintings; 14). [Fedorov S. 142]

Stal, ISABElle, "De Profundis' ou la critique de la raison révolutionnaire." In: Cahiers du Monde nusse et sovietique, 24 (1983), 1-2, S. 59-81.

Stalin, I.W. [d.i. DZugaśviu, Iosif Vissarionovic], Werke, Bde. 11 und 13, Berlin 1954, 1955.

StAMMa ER, HeINRICH, "Nikolaj KJjuev." In: N. KuJuev, Soxinenija, t. 2, München 1969, S. 5-50. 
Stamaler, Heinrich A., Vasilij Vasil'evic Rozanov als Philosoph, Gießen 1984. (= Vorträge und Abhandlungen zur Slavistik; 5).

- StAROSTiN, BA., "Genezis kosmixeskoj ustanovki v evropejskoj nauke i kul'ture." In: Trudy desjasych i adinnadcarych Clenij, posvjastennych razrabouke naucnogo nasledija i razvitiju idej $K E$. Ciolkouskogo (Kaluga 1975, 1976 88.). Sekcija 'KE. Ciolkouskij i filosofskie problemy oswoenuja kosmosa'. M. 1978, S. 63-77. [Fedorov S. 74f.]

- Starostin, BA., "Osvoenie kosmosa v sisteme istorizeskich form vseobstego truda." In: Trudy desjatych $i$ odinnadcatych C'tenij, posvjastennych razrabolke naußnogo nasledija i razvitiju idej $K E$. Ciolkouskogo (Kaluga 1975, 1976 g8.). Sekcija 'KE. Ciolkovskij i filosofskie problemy osvoenija kosmosa'. M. 1978, S. 110-116. [Fedorov S. 111]

StARR, S. Frederick, "Visionary Town Planning during the Cultural Revolution." In: S. FitzPATRICK (Hg.), Cultural Revolution in Russia, 1928-1931, Bloomington, London 1978, S. 207-240.

- StARr, S. Frederick, Melnikov. Solo Architect in a Mass Sociery. Princeton, NJ. 1981. [Fedorov S. 240, 246, 248-250, 253-256]

- Starr, S. Frederick, "N. Tumarkin, Lenin Lives! The Lenin Cult in Soviet Russia. Cambridge, Mass. 1983." [Rezension] In: Russian Review, 43 (1984), S. 285-287.

STAUdENMAIER, LUDWIG, Die Magie als experimentelle Naturwissenschaft, Leipzig 1912.

STEPANOV, N[IKOLA] L., Velimir Chlebnikov. Żizn' i tvortestvo. M. 1975.

STEPHAN, JoHn J., The Russian Fascists. Tragedy and Farce in Exile 1925-1945. New York 1978.

STEPUN, F[EDOR] A[VGUSTOViC], "Ob obscestvenno-politikeskich putjach 'Puti." In: Sorremennye Zapiski, 29, 1926, S. 442-448.

- STEPUN, FEDOR [AvgUSTOVIC], Mystische Welischau. Fünf Gestalien des russischen Symbolismus. München 1964. [Fedorov S. 63-65, 186]

STITES, RICHARD, Utopia and Experiment in the Russian Revolution: Some Preliminary Thoughts. Washington 1981. ( = Kennan Institute for Advanced Russian Studies. The Wilson Center. Occasional Paper; 152).

StTtes, RichuRd, "Utopias of Time, Space, and Life in the Russian Revolution." In: Revue des Etudes slaves, 56 (1984), 1, S. 141-154.

STTIES, RICIMRD, "Utopias in the Air and on the Ground: Futuristic Dreams in the Russian Revolution." In: Russian History / Histoire Russe, 11 (1984), 2-3, S. 236-257.

StTIES, RICHARD, "Iconoclastic Currents in the Russian Revolution: Destroying and Preserving the Past." In: A. Gle^son u.a. (Hgg.), Bolshevik Culture, Bloomington 1985, S. 1-24.

- StTIEs, Rrchard, "Hopes and Fears of Things to Come: The Foreshadowing of Totalitarianism in Russian Fantasy and Utopia." In: Nondic Joumal of Soviet and East European Studies, 3, 1986, 1, S. 1-20. [Fedorow S. 6, 12]

Strachov, Nikoln Nikolaevic, Mir kak celoe. Cerry iz nauki o prirode. SPb. ${ }^{2} 1892$ [ ${ }^{1} 1872$ ]

- Strachov, Nikola Nikolaevic, [Briefe an L.N. Tolstoj] in: Tolstovskj muzej, t. 2 [Perepiska L.N. Tolstogo s N.N. Strachovym 1870-1894], SPb. 1914.

- STrachov, P.[S.], "Atomy żizni." In: DeRS., Nauka i religija, M. 1915, S. 141-170. [Fedorov S. 167]

- Strada, Vittorio, "Cosi ha sognato l'utopia in Russia." In: Corriere della Sera [Milano], 3.8.1983. - Wiederabdr. in: DERS., URSS - Russia, Milano 1985, S. 137-141. [Fedorov S. 140f.]

- Stratanovsku, Sergej [GeorgieviC], "Fedorov." [Gedicht] In: Russkaja Mysl', 3485, 6.10.1983, S. 12.

- Stremooukhoff, D., Vadimir Soloviev el son oeurre messianique, Paris 1935. (= Publications de la faculté des lettres de l'université de Strasbourg; 65). [Fedorov S. 121f., 138, 173, 217, 221, $280,291]$

- STRIEDTER, JURU, "Journeys Through Utopia. Introductory Remarks to the Post-Revolutionary Russian Utopian Novel." In: Poetics Today, 3 (1982), 1, S. 33-60. [Fedorov S. 52] 
- Struedter, Juru, "Die Doppelfiktion und ihre Selbstaufhebung. Probleme des utopischen Romans, besonders im nachrevolutionăren RuBland." In: D. HENRICH, W. ISER (Hgg.), Funktionen des Fiktiven, München 1983, S. 277-330. (= Poetik und Hermeneutik; 10). [Fedorov S. 319]

- STRUVE, GLEB [PETROVIC], Russkaja literatura v izgnanii. Opyt istoriceskogo obzora zanubetnoj liieratury. Paris ${ }^{2} 1984$ [ ${ }^{1} 1956$ ]

- Struve, Nikrta [A.], "Bessmertnaja nadežda." In: Vestnik RChD, 137 (1982), S. 3f.

- Struve, Nikrta [A.], "Nicolas Fédorov et Léon Tolstoï." In: Cahiers Leon Tolstoi, 2 [Tolstoï philosophe et penseur religieux], Paris 1985, S. 41-46. (= Bibliothèque Russe de l'Institut d'Études Slaves; 73).

STRUVE, Nikrta [A.], "Actualité de La Mort d'Ivan Ilitch." In: Cahiers Léon Tolstö, 3 [Tolstoï et la mort], Paris 1986, S. 77-83. (= Bibliothèque Russe de l'Institut d'Etudes Slaves; 76).

- Struve, Petr [BerngardoviC], "Dnevnik politika." In: Rossija i Slavjanstvo, 164, 16.1.1932, S. 1.

STUPPERICH, ROBERT, "Russische Sektenbewegungen der Nachrevolutionszeit". In: Zeitschrift für systematische Theologie, 13 (1936), 2, S. 241-274.

- Subin, Lev AlexseeviC, Poiski smysla otdel'nogo i obšcego sušcestvovanija. Ob Andree Platonove. M. 1987. [Fedorov S. 151f., 173, 185]

- Suchich, S[tanislav] I[vanovic], "Žizn' Klima Samgina' M. Gor'kogo i 'Fülosofija obšzego dela' N.F. Fedorova." In: M. Gor'kij i voprosy liseratumych zanrov. Mežruzovskij sbomik. Gor'kij 1978, S. 3-38.

- Suchich, S[tanislav] I[vanovic], "M. Gor'kij i N.F. Fedorov." In: Russkaja Literatura, 1980, 1, S. $160-168$.

SUL'C, OSKAR A. FON, siehe SCHOULTZ, OSKAR A. vON

Sumov, V., "Iz prichodskich batjuŠek - v buntari." In: Nauka i Religija, 1980, 11, S. 22.

- Surovcev, Ju., "Ob urokach našej klassovoj pamjati." In: Znamja, 1983, 6, S. 201-225. [Fedorov S. 221]

SUsILUOTO, Ilmari, The Origins and Development of Systems Thinking in the Soviet Union. Political and Philosophical Controversies from Bogdanov and Bukharin to Present-Day Re-Evaluations. Helsinki 1982. (Annales Academiae Scientiarum Fennicae, Dissertationes Humanarum Litterarum; 30).

SUTtER, Alex, Götlliche Maschinen. Die Automaten für Lebendiges bei Descartes, Leibniz, La Metrie und Kant. Frankfurt/M. 1988.

SUVIN, D[ARKo], "The Utopian Tradition of Russian Science Fiction." In: The Modem Language Review, 66, 1971, S. 139-159.

SVANIDZE, BUDU, Im engsten Kreis, Stuttgart 1953.

Svencickaja, N., "Otec Valentin." In: Nadeżda. Christianskoe ctenie. Vyp. 10, Frankfurt/M. 1984, S. $183-220$.

SVENCICKU, VAL[ENTIN PAVLOVIC], 'Christianskoe bratstuo bor'by' i ego programma, M. 1906. (= Religiozno-obšestvennaja biblioteka; $I, 2)$.

SVENCKCK, VaL[entin Pavzovic], "Christianskoe otnoSenie $k$ vlasti i nasiliju." In: Voprosy religii, vyp. 1, M. 1906, S. 5-37.

Svencicku, Vay[entin Paviovic], "Smert' i bessmertie. Po povodu trech dram Meterlinka." In: Suobodnaja sovest'. Literatuma-filosofskij sbomik. Kn. 1, M. 1906, S. 34-67.

SVencicku, Vay [entin Pavlovic], Pis'ma ko usem. (Pamflet). M. 1907.

SVENCICKU, VAL[ENTIN PAVLOVIC], Antichrist. (Zapiski strannogo Celoveka). SPb. ${ }^{2} 1908$.

Svencicku, Val[entin Paviovic], Tertor i bessmertie." In: Voprosy religii, vyp. 2, M. 1908, S. 3-28.

Svencicku, Val[entin Paviovic], "Problema asketizma." In: Russkaja Mysl', 29 (1908), 5, S. 89 103.

SVENCICKU, VAlENTIN [PAvloviC], "Šest' đenij o tainstve pokajanija v ego istorii." In: Nadezda. Christianskoe crenie. Vyp. 2, Frankfurt/M. 1979, S. 105-178. 
[SVEncicku] SVEnTICKU, V[ALENTIN] P[avloviC], "Predsmertnye pis'ma." In: Minuv'see. Istoriceskij al'manach. 1, Paris 1986, S. 294-298.

SVETLOV, EMMANUIL, siehe MEN', ALEKSANDR

SVJATOGOR [d.i. AgIENKo], [AlEKSANDR], Stichety o vertikali, M. 1914.

SVjatogor [d.i. AgIenko], A[LeksandR], Petuch revoljucii, M. 1917.

SVjatogor, [d.i. AgIEnKo], A[LeksandR], IVANICKu, P[AVEL I.] (Hgg.), Biokosmizm. (Materialy - No. 1), M. 1921.

SVJatogor [d.i. AgIENKo], AleksandR, "Naši utverždenija." In: Biokosmist, 1, 1922, S. 3-5.

- Svjatogor [d.i. AgIEnko], Aleksandr, "Doktrina otcov' i anarchizm-biokosmizm." In: Biokosmist, 3-4, 1922, S. 3-21. [Fedorov S. 18-20]

- Sviatogor [d.i. Agienko], Aleksandr (Hg.), Dva. (Biokosmizm, materialy No. 2). M. 1922. Textgleich mit: Biokosmist, 3-4, 1922.

SVjatogor [d.i. Agienko], Aleksandr, "Biokosmireskaja poetika. (Prolog ili gradus pervyj)." In: Ot simudizma do 'Oktjabrja'. Literatumye manifesty. I. Rossija. M. 1924, S. 220-226. - Dass. auch in: Svjatocor, IvaNicku (Hgg.), Biokosmizm. (Materialy - No. 1), M. 1921, S. 3-11.

SVjatopolk-MiRsKU, DMTrRu [PETROVIC], "Vejanie smerti v predrevoljucionnoj literature." In: Versty, 2, 1927, S. 247-253.

[Svjatopolk-MiRsku, DMTrRu PETRovic] MIRSKY, D.S., The Eurasian Movement." In: The Slavanic Review, 1927, 6, S. 311-320.

- Svjatopolk-Mirsku, D[MTrRu Petrovic], "O Tolstom. 1828-1928." In: Evrazija, 1, 24.11.1928, S. $6 f$.

- Svjatopolk-Mirski, D[MTtru Petrovic], "Naš marksizm." In: Evrazija, 11, 2.2.1929, S. 3.

- [SvjatopolK-MIRSKu, DMTTRU PeTROVIC] MIRSKY, D.S., "Some Remarks on Tolstoy." In: The London Mercury, 1929, 20, S. 167-175.

- TAlbott, Nelson Strobridge, Mayakovsky Agonistes. The Myth of Self in the Poetry of Vladimir Mayakovsky. B. Litt. thesis Oxford 1972. [Fedorov S. 116, 234ף]

Tamarcenko, Anna Vladimirovna, O'ga Fors. Zizn', lienost', tuoréestuo. M.-L. 1966.

- TamarCenXo, E., "NauZnaja fantastika i model' revoljucii." In: Canadian-American Slavic Studies, 18 (1985), 1-2, S. 31-41. [Fedorov S. 37]

TAREEV, M[AKSIM MATVEEVIC], "Ortobioz. (Optimistizeskaja nauka i nravstvennost')." In: Bogoslovskij Vestnik, 17 (1908), 3,12, S. 560-582.

TATUR, MELANIE, 'Wissenschaftliche Arbeitsorganisation.' Arbeilswissenschaften und Arbeitsorganisation in der Sowjetunion 1921-1935. Wiesbaden 1979. ( = Philosophische und soziologische Veroffentlichungen; 16).

Teilhurd de chardin, Pierre, Der Mensch im Kosmos. (Le Phénomène Humain). München 1969.

- Teskey, AyleEn EluzABETH, Fedorovian Influences on the Work of Andrey Platonov. M.A. thesis The Queen's Univ. of Belfast 1979.

- Teskey, AyleEN, The Theme of Science in the Early Works of Andrey Platonov." In: Irish Sla. vonic Studies, 1 (1980), S. 3-19.

- TESKEY, AYLEEN, Platonov and Fyodonov. The Influence of Christian Philosophy on a Soviet Writer. Amersham 1982.

- Teskey, AYLEen, "Ludmila Koehler, N.F. Fedorov: The Philosophy of Action. Pittsburgh 1979." [Rezension] In: Irish Slawonic Studies, 3 (1982), S. $131 f$.

- TESkEY, AYLEEN, "Fedorov, Nikolai Fedorovich." [Lexikonartikel] In: MERSL, 7, Gulf Breeze 1984, S. $168-173$.

- Teskey, AyzeEN, "V.N. Murav'ev, Ovladenie vremenem. Moskva 1924. Nachdruck München 1983." [Rezension] In: Irish Slavonic Studies, 5 (1984), S. 256 f. 
- Teskey, AYleEN, "Platonov Criticism since 1958. A Comparison of Soviet and Emigré Attitudes." In: Scortish Slavanic Review, 4 (1985), S. 81-98.

- Tichon, igumen, Nikrtin, V[alentin Arsen'eviC], "Ekkumenireskoe dviženie i Russkaja Pravoslavnaja Cerkov' do ee vstuplenija v VSC." In: ZMP, 1983, 11, S. 59-68. [Fedorov S. 63]

TOLLR, ERNST, Quer durch. Reisebilder und Reden. Berlin 1930.

- Tolstaja, Sof'ja ANDReEvina, "Moja zizn'." In: Noyjj Mir, 1978, 8, S. 34-134.

- TolstanA-SEgAl, E[LENA], "Stichijnye sily': Platonov i Pil'njak (1928-1929)." In: Slavica Hierosolymitana, 3, 1978, S. 89-109.

- Tolstaja-Segal, E[LENA], "Naturfilosofskie temy v tvortestve Platonova 20-ch - 30-ch gg." In: Slavica Hierosolymitana, 4, 1979, S. 223-254.

- Tolstaja-Segal, Elena, "Literaturnyj material v proze Andreja Platonova." In: Voz'mi na radost'. To Honour Jeanne van der Eng-Liedmeier. Amsterdam 1980, S. 193-205.

- Tolstaja-Segal, EleNA, "Ideologiteskie konteksty Platonova." In: Russian Literature, 9, 1981, S. 231-280.

- Tolstoj, IL'Ja L'vovic, Moi vospominanija, M. 1969. [Fedorov S. 189f.]

- Tolstoj, Lev Nikolaevic, Polnoe sobranie soxinenij, M.[-L.], t. 8 (1936), t. 33 (1935), t. 49 (1952), t. 50 (1952), t. 57 (1952), t. 58 (1934), t. 63 (1934), t. 66 (1953), t. 68 (1954), t. 78 (1956), t. 82 (1956), t. 83 (1938).

- TOLSTOJ, S[ERGEJ] L'vovic], Ocenki bylogo, Tula ${ }^{3}$ 1966. [Fedorov S. 137f.]

TOPOROV, VladimiR, "O russkom myslitele Georgii Fedotove i ego knige." In: Naśe Nasledie, 1988,4, S. 45, 50-53.

- Treadgold, Donald W., The West in Russia and China. Religious and Secular Thought in Modem Times. 1 [Russia, 1472-1917], Cambridge 1973. [Fedorow S. 202, 207, 210, 212, 248]

- TREPKA, ANDRZEJ, Wizjoner kosmosu Konstanty Ciołkowski, Katowice 1974. [Fedorov S. 56-71, 130f., 346]

Trifunovic, Z.V., "I.M. Andreevskij." In: Russkoe Vozrozdenie, 1 (1978), 4, S. 211-234.

TrockU [d.i. BRoNSTEJN], L[EV DAVYDOVIC], Lirematura i reudijucija, M. 1923.

TrockU [d.i. Bronstejn], UEv Davydovic], Soxinenija, t. 12, M. 1926; t. 20, M.-L. 1926.

- [TROICKU] TrotTSKY, G[erMAN], "Florensky Alexandrobits Paulos." [Lexikonartikel] In: Thréskeutikē kai Ëshiké Enkyklopaideia, 11, Athēnai 1967, Sp. 1177-1183. [Fedorov Sp. 1179]

- [Troicku] Trortsky, German, "In Memory of the Reverend Pavel Florensky." In: JMP, 1972, 11, S. 74-80. [Fedorov S. 77]

- Trubeckoj, Evgend [NIKolaevic], "Ziznennaja zadala Solov'eva i vsemimyj krizis Zizneponimanija." In: Voprosy Filosofii i Psichologii, 1912, 4 (114), S. 224-287. [Fedorov S. 272279] - Dass. auch in: DeRS., Mirosozercanie V.S. Solov'eva, t. 1, M. o.J. [1913]. [Fedorov S. 78-85]

- Trubeckoj, Evgenu [NikolaeviC], "Neskol'ko slov o Solov'eve i Fedorove. (Otvet N.P. Petersonu)." In: Voprosy Filosofii i Psichologii, 1913, 3 (118), S. 412-426.

- TrubeckoJ, N[IKola]] S[ergeEvic], "Pis'mo v redakciju." In: Eurazija, 7, 5.1.1929, S. 8.

- Trubnikov, P. [NA. Setnicku ?], "Voskrełat' mertvych ili zvat' smert'." In: Segodnja, [Riga] 178, 30.6.1933.

- TRUBNIKov, P. [N.A. SETNICKu ?], "Voskrešat' mertyych ili zvat' smert'?" In: Gun-bao, [Harbin] 2042, 14.7.1933, S. 2.

- TRUBnikov, P. [N.A. SETNicku ?], "Armii narodov - na bor'bu so smert'ju." In: Zarja, [Harbin] $190,16.7 .1933$, S. 6.

- [TsChIZEWSKu] CYZEVs'KYJ, D[MTrRu IVANOVIC], "Schiller und die 'Brüder Karamazov'." In: ZfslPh, 6 (1929), 1-2, S. 1-42. [Fedorov S. 14, 39f., 42]

- [TSCHIZEWSKU] CYZEVs'KYJ, D[MTIRU IVANOVIC], "Fedorov, N.F.: Filosofija obšego dela. T. I, yyp. 1 i 2. Charbin 1928/29. (Philosophie der gemeinsamen Sache. $4^{\circ}, \mathrm{XXX}, 38,75 \mathrm{~S}$.) - Ostromirov, A.: N.F. Fedorov i sovremennost'. Charbin 1928. (N.F. Fedorov und die Gegenwart. $4^{\circ}, 51 \mathrm{~S}$.) - Gornostajev, A.K.: Pred licom smerti. Charbin 1929. (Vor dem Antlitz des Todes. $4^{\circ}, 18$ S.). - 
Gornostajev, A.K.: Raj na zemle. 1929. (Das Paradies auf Erden. Dostojevskij und Fedorov. $4^{\circ}$, 87 S.)" [Rezension] In: Slavische Rundschau, 2 (1930), S. 515f.

- [TschIŽEwSKu] CYŽEvs'KYJ, D[MTtru IVANOVIC], "Die russische Philosophie der Gegenwart." In: Slavische Rundschau, 2 (1930), S. 730-739.

- [TsChIŽEwSKU] ČYŽEvs'KYJ, D[MITRU IVANoviC], "Zum Doppelgăngerproblem bei Dostojevskij." In: DeRs. (Hg.), Dostojevskaj-Studien, Reichenberg 1931, S. 19-50. (= Veröffentlichungen der Slavistischen Arbeitsgemeinschaft an der Deutschen Universităt in Prag; I, 8). [Fedorov S. 48f.]

- [TsChIŽEWSKu] CYZZEvs'KYJ, D[MTrRu IVANOVIC], "Literarische Lesefrüchte, Teil 2." In: ZfslPh, 10 (1933), 3-4, S. 380-401. [Fedorov S. 396-398, 400]

- [Tschižewsku] Cižzvski, DMTTRu [IVANoviと], "Wilhelm Schümer, Tod und Leben bei Dostojevski, Calw o.J." [Rezension] In: Zeitschrift für Kirchengeschichte, 53 (1934), S. 697-699.

[TschnZEwsku, DMTrRu IVANOVIC] ERLENBUSCH, FR., "V.I. Vernadskijs Naturphilosophie." In: Slavische Rundschau, 7 (1935), S. 213-221.

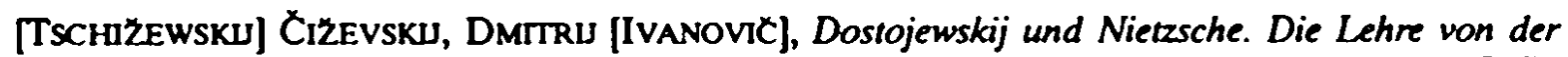
ewigen Wiederkehr. Bonn o.J. [1948]. (= Kleine Schriften aus der Sammlung Deus et Anima; I, 6).

- [TsCHIŽEWSKu] ČIŽEVSKu, DMrTRu [IVANoviC], "Tri knigi o russkoj filosofii." In: Novyj Zumal, 30, 1952, S. 279-287. [Fedorov S. 282]

" [TsChIŽEWSKu] ČIŹEvSKu, DMITRu [IVANOVIČ], "Šiller v Rossii." In: Novyj Žumal, 45, 1956, S. 109-135. [Fedorow S. 132f.]

- TsChIZEWSKu, DMTrRu [IVANOVIC], Hegel bei den Slaven, Darmstadt ${ }^{2} 1961$ [ $^{1} 1934$ ]. [Fedorov S. 354f.]

- Tulaev, Pavel [V.], "Prometej": opyt i problemy razvitija." In: Vestnik Prometeja, vyp. 3, M. 1988, S. 221-228. [Fedorow S. 223, 225]

- Tumarkin, Nina, "Religion, Bolshevism, and the Origins of the Lenin Cult." In: Russian Review, 40 (1981), S. 35-46.

- Tumarkin, Nina, Lenin Lives! The Lenin Cult in Soviet Russia. Cambridge, Mass., London 1983. [Fedorov S. 19, 22, 179, 181]

TUREK, LESZEK, Kultura i rewolucja, Wroctaw u.a. 1973.

- TURsunov, A., "Ideja edinstva mikrokosma $i$ makrokosma $v$ intellektual'noj istorii obšcestva $i$ sovremennoj nauke (opyt filosofskogo analiza)." In: Nauka v social'nych, gnoseologiceskich i cennostnych aspektach, M. 1980, S. 326-344. [Fedorov S. 341, 344]

- Utenie V.I. Vemadskogo o noosfere i global'nye problemy sovremennosti. (Tezisy dokladov Vsesojuznoj konferencii, posvjastennoj 125-letiju so dnja rożdenija V.I. Vemadskogo, Moskva, $1988 \mathrm{~g}$., 30-31 maja). C. 1, M. 1988. [Fedorov S. 5, 55, 94, 104, 210, 221]

URBAN, ADOL'F ADOL'FoviC, Fantastika i nas' mir, L. 1972.

- Urban, Adol'f [Adol'foviC], "Filosofskaja utopija. (Poetiteskij mir V. Chlebnikova)." In: Voprosy Literatury, 1979, 3, S. 153-183. [Fedorov S. 155f.]

- URBAN, AdOL'F [ADOL'FOVIC], Obraz Celoveka - obraz vremeni. Ocerki o sovetskoj poezii. L. 1979. [Fedorov S. 8f., 11, 35, 50, 81, 92-94]

URSU, A[RKADI]] D[MTRIEVIC], "K.E. Ciolkovskij i problema beskoněnnogo progressa relovecestva." In: Trudy pjatych $i$ sestych Ctenij, posvjašstennych razrabotke naučnogo nasledija $i$ razvitiju idej KE. Ciolkouskogo (Kaluga 1970, 1971 g8.). Sekcija 'Issledovanie naučnogo twortestva K.E. Ciolkovskogo'. M. 1972, S. 40-49.

URsul, ARKadu DmTtrievic, Śolenko, JuRu ANDREeviC, Celovek i kosmos, M. 1976.

- Ursul, ARKAdu DMTrRIEViC, Celovecestro, Zemlja, Vselennaja. Filosofskie problemy kosmonavriki. M. 1977.

URSUl, A[RKADIJ] D[MTRIEVIC],"Al'ternativa grjaduš̌ego: gibel' ili bessmertie? (O prognozirovanii dlitel'nosti social'nogo progressa)." In: Trudy desjatych $i$ odinnadcatych Čtenij, po- 
svjašennych mazrabotke naudnogo nasledija i razvitiju idej KE. Ciolkovskogo (Kaluga 1975, 1976 88.) Sekcija 'KE. Ciolkorskij i filosofskie problemy oswoenija kosmosa'. M. 1978, S. 20-31.

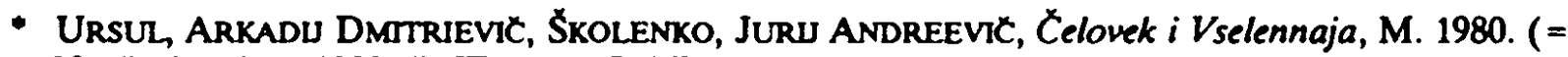
Naučnyj ateizm; 1980, 4). [Fedorov S. 16]

UsPENSKU, B[ORIs] A[NDREEVIC], "Prolegomena k teme: 'Semiotika ikony'." In: Rossija - Russia, 3, Torino 1977, S. 189-212.

Ustrualov, N[IKolaj VAsil'Evic], $V$ bor'be za Rossiju. (Sbomik stasej). Charbin 1920.

Ustrualov, N[IKOLAJ] V[ASIL'EVIC], "Religija revoljucii." In: Korabl'. Literatumo-chudotestvennyj druchnedel'nik. 1923, 7-8, S. 34-39.

- Ustrualov, N[IKolaj VAsil'EviC], Rossija (u okna vagona), Charbin 1926. [Fedorov S. 46] Ustrualov, N[IKolaj] V[ASIL'EviC], Na novom étape, Sanchaj ${ }^{2} 1930$.

- Ustrualov, N[IKolaj] V[Asil'EviC], "Problema progressa." In: Izv.Jur.Fak, 9, 1931, S. 33-70. [Fedorov S. 59-63]

USTRALOV, Nikola [VASIL'EVIC], "Zarubežnaja smena." In: Utverzdenija, 3, 1932, S. 107-118.

- Ustrualov, N[IKolaj] V[asil'evic], "Puti sinteza. (K poznaniju našej epochi)." In: Ders., Nase vremja. Sbomik statej. Sanchaj 1934, S. 61-115. [Fedorov S. 89]

- Ustrualov, N[IKolad] V[asil'EVIC], "Novyj Grad." [1932] In: DeRs., Naše vremja. Sbomik statej. Sanchaj 1934, S. 116-142. [Fedorov S. 134f.]

- Ustrualov, N[IKolaj] V[ASIL'EVIC], "O filosofii N.F. Fedorova v svete sovremennosti." In: DERS., Naše vremja. Sboraik statej. Sanchaj 1934, S. 197-202.

- Utechin, S[ergej] V., "Bolsheviks and Their Allies After 1917: The Ideological Pattern." In: So viet Studies, 10 (1958), 2, S. 113-135.

- UtECHIN, S[ERGE]] V., "Fedorov, Nikolay Fedorovich." [Lexikonartikel] In: DeRs. (Hg.), Everyman's Concise Encyclopaedia of Russia, London 1961, S. $177 \mathrm{f}$.

- UTECHIN, S[ERGEJ] V., "Philosophy and Society: Alexander Bogdanov. In: L. LABEDz (Hg.), Revisionism: Essays on the History of Marxist Ideas, New York 1962, S. 117-125. [Fedorov S. 125]

- Utechin, S[erges] V., Russian Political Thought. A Concise History. London 1964. [Fedorov S. $177-179,211]$

- Utkina, Nina Fedorovna, Pozitivizm, antropologiceskij materializm i nauka v Rossii (vtoraja polovina XIX veka), M. 1975. [Fedorov S. 122f.]

- UtKina, N[INA] F[EdoRovNa], Tema vseedinstva v filosofii VI. Solov'eva." In: Voprosy Filosofii, 1989, 6, S. 59-75. [Fedorov S. 67]

- Uvarova, I., "Kosmos i chudožestvennoe tvorcestvo." In. Dekoratimoe Iskusstvo SSSR, 1981, 11, S. 13.

V.S., "Suscestruet li telesnoe bessmertie?" In: Nov', [M.] 9.3.1914, S. 3f.

- VACHTIN, Boris, "Čelovełeskoe veš̌estvo?" In: Écho. Literatumyj Zumal. [Paris], 1986, 14, S. 5103. [Fedorov S. 21-28, 57]

- Vagin, Evgenu [AleksandroviC], "Interv'ju 'Vestniku RChD'." In: Vestnik RChD, 122, 1977, S. 252-262. [Fedorov S. 256]

- Vagin, E[Vgenu AlexsandroviC], "K sporam o Fedorove." In: Russkaja Žizn', [San Francisco] 20.4.1978.

- Vagin, E[VGenu Aleksandrovile], "N.F. Fedorov i naše vtemja." In: Russkaja Mysl', 3242, 8.2.1979, S. 8.

- Vagin, E[vgenu Aleksandrovic], "O monarchizme N.F. Fedorova." In: Naśa Strana, [Buenos Aires] 26.1.1979. [War nicht zugănglich]

- VAGIN, E[VGENu ALEKSANDROVIC], "Dostoevskij: ot christianskogo socializma k social'nomu christianstur." In: Zapiski nusskoj akademiXeskoj gruppy v S.S.A. / Transactions of the Association of 
Russian-American Scholars in the U.SA., t./vol. 14: Dostoevsky Commemorative vol., New York 1981, S. 261-277.

- Vagin, E[vgenu Aleksandrovic], "Sovetskoe izdanie N.F. Fedorova." In: Vece, [München] 11, 1983, S. 117-135.

- VAll', BORIS [BorISOvic], 'K vychodu v SSSR 'socinenij' N.F. Fedorova. Vozvrašcenie 'moskovskogo Sokrata'." In: Russkaja Mysl', 3484, 29.9.1983, S. 12; 3485, 6.10.1983, S. 12.

Valliere, Paul Richard, M.M. Tareev: A Study in Russian Ethics and Mysticism, Ph.D. diss. Columbia Univ. 1974; Ann Arbor, Mich. 1978.

- VarSavsku, V[ladimir Sergeevic], "Tret'ja Rossija'." In: Noyjj Grad, 13, 1938, S. 175-179.

- VarSavski, V[LAdimiR] S[ERGeEvič], Nezamezennoe pokolenie, New York 1956. [Fedorov S. 161, 255-260, 266f., 281f.]

- VarŚa vski, V[ladimir Sergeevic], "Perecityvaja 'Noyjj Grad'." In: Mosty, 11, 1965, S. 267-285.

- Varsavsku, Vladimir Sergeevic], "Čevengur' i 'Novyj Grad'." In: Novyj Zumal, 122, 1976, S. 193-213. [Fedorov S. 210, 212]

- VarSAVSKI, Vladimir Sergeevic, Rodoslomaja bol'Sevizma, Paris 1982. [Fedorov S. 161-165]

- VASECKU, ANDREJ ANATOL'EVIC, Idei sociokosmizma v proizvedenijach NA. Morozova. Avtoreferat dissertacii na soiskanie uČenoj stepeni kandidata filosofskich nauk. M. 1987. [Fedorov S. 1f.]

- VAsil'EV, M.[V.], "Brjusov - poét kosmonavtiki." In: V mire knig, 1972, 1, S. $12 f$.

- Vasil'Ev, M.V., "Pervyj poet nauð̌noj kosmonavtiki." In: Briusovskie ctenija 1971 goda, Erevan 1973, S. 19-32.

- Vasil'ev, Vladimir [VASIL'EviC], "Literatumaja kritika Andreja Platonova." In: Naš Sovremennik, 1979, 9, S. 174-184. [Fedorov S. 180]

- Vasil'ev, Vladimir Vasil'evic, Andrej Platonov. Oxerk Zizni i montestva. M. 1982. [Fedorov S. $41-43,181,199]$

- Vasil'ev, Vladimir [Vasil'evic], "Andrej Platonov segodnja." In: Literatumaja Gazeta, 39 (5157), 23.9.1987, S. 3.

- Vetnoe solnce. Russkaja social'naja utopija i nautnaja fantastika vtoroj poloviny XIX - nazala XX veka. M. 1979.

- Vel. [N.N. Punin ?, S.P. Bobrov ?, R.V. IVANov-RazumNik ?, L. ARENS ?], "Chlebnikov - osnovatel' budetljan. (28.VII.1885 - 28.VI.1922)." In: Kniga i Revoljucija, 1922, 9-10 (21-22), S. 2025.

- Vel'skU, VIKToR [Pseud.?], "Otkrovenija Viktora Vel'skogo." In: Grani, 75, 1970, S. 3-114.

VerNadSKu, G[EORGU] V[LADIMIROVIC], "P.N. Savickij (1895-1968)." In: Novij Zumal, 92, 1968, S. 273-277.

VerNadSKU, G[EORGU] V[LADIMIRoviC], "Bratstvo 'Prijutino'." In: Novyj Zumal, 97, 1969, S. 218-237.

VeRNadSKu, V[LADIMIR] I[VANovic], Ocerki i reci, t. 1-2, Pg. 1922.

VERNADSKU, V[LADIMIR] I[VANOVIC], NaCalo i večnost' zizni, Pb. 1922.

VERNADSKI, V[LADIMIR] I[VANOVIC], Biosfera, L. 1926.

VERNADSKU, VLADIMIR IVANOVIC, BiogeochimiCeskie ocenki 1922-1932 gg., M.-L. 1940.

VERNADSKU, Vladimir IVANOVIC, Razmystenija naturalista, kn. 1, M. 1975; kn. 2, M. 1977.

- Vernadsku, Vladimir Ivanovic, Živoe vescestro, M. 1978. [Fedorov S. 308]

VERNADSKu, Vladimir IVANOVIC, Filosofskie mysli naturalista, M. 1988.

- Vilenskaja, Emiua Samojlovina, Revoljucionnoe podpol'e v Rossii v seredine 6a-ch godov XIX reka, M. 1965. [Fedorov S. 201f., 212]

VINOGRADOV, IGOR', "Bezumnaja russkaja ideja." In: Moskovskie Novosti, 24, 11.6.1989, S. 11.

VISEV, I.V., "Metodologiteskie obosnovanija idej K.E. Ciolkovskogo o vozmožnosti radikal'nogo prodlenija Žizni Celoveka." In: Trudy Cetymadcatych Ctenij KE. Ciolkovskogo (Kaluga 1979 g.). Sekcija 'KE. Ciolkouskaj i filosofskie problemy oswoenija kosmosa'. M. 1980, S. 101-107. 
Visnjak, Mark [Veniaminovic], Dan' proslomu, New York 1954.

VITKOVSKU, Evg[ENU], "Arsenij Nesmelov. Iz literatumogo nasledija." In: Oktjabr', 1988, 11, S. 144-149.

VOJCECHOVSKU, S[ERGEJ] L'VoviC], Trest. Vospominanija i dołaumenty. London, Ont. 1974.

VouIN [d.i. VolodCENKo], MICHAIL, "Russkie poety v Kitae." In: Kontinent, 34, 1982, S. 337-357.

VolobUEv, O.V., "Voprosy social'noj psichologii v trudach N.A. Rožkova." In: Istorija i psichologija, M. 1971, S. 196-308.

[Volosina-SAbasnikova] Woloschin, Margarta [Vasil'eVNa], Die grüne Schlange. Lebenserinnenungen einer Malerin. Frankfurt/M. 1982 [zuerst: Stuttgart 1954] (= Fischer Taschenbuch; 5514). [Fedorov S. 67f.]

Vol'sku, Stanislav A. [d.i. Sokolov, ANDRej Vladimirovic], Filosofija borby. (Opyt postroenija étiki marksizma). M. 1909.

Volzsku [d.i. Glinka, Aleksandr SERgeEvic], "Problema smerti u prof. Mečnikova." In: DERS., Iz mina literatumych iskanij. Sbomik statej. SPb. 1906, S. 250-266.

- Vorob'Ev, B.N., "Raboty K.E. Ciolkouskogo po mežplanetnym soobšenijam." In: K.E. CiolKovsku, Vne Zemli. Naučno-fantasticeskaja povest'. M. ${ }^{2}$ 1958, S. 5-20. [Fedorov S. 7$]$

Vostokov, P., siehe SAVICKU, P.N.

- VozdVIZENSKI, B., "Ukazavsij dorogu v kosmos." In: Uxirel'skaja Gazeta, 91, 31.7.1982, S. 2.

VROON, Ronald, Velimir Xlebnikov's Shorter Poems: A Key to the Coinages, Ann Arbor 1983.

Vstan', Spjascij!, [Tiflis] 1, 27.4.1906; 2, 7.5.1906.

VUCINICH, ALEXANDER, Social Thought in Tsarist Russia. The Quest for a General Science of Society, 1861-1917. Chicago, London 1976.

- VySeslavcev, B[ORIs Petrovic], "Bessmertie, perevoplostenie i voskresenie." In: Pereselenie dus. Problema bessmertija v okkul'tizme i christianstve. Sbomik statej. Paris o.J., S. 109-134. [Fedorov S. 134]

- VySEslavCev, BORIS PETRovic, Vernoe v nusskoj filosofii, New York 1955. [Fedorov S. 293]

- WALICKI, ANDRZEJ, "L'idée de progrès dans la pensée russe au XIXe siècle." In: Rossija - Russia, 1, Torino 1974, S. 41-91; 2, Torino 1975, S. 129-161. [Fedorov S. 141f.]

WALCKI, ANDRZEJ, The Slawophile Controversy. History of a Conservative Utopia in NineteenthCentury Russian Thought. Oxford 1975.

- WALICKI, ANDRzes, A History of Russian Thought. From the Enlightenment 10 Marxism. Stanford, Calif. 1979 [poln. EA 1973]. [Fedorov S. 386f.]

WALICK, ANDRZEJ, Legal Philosophies of Russian Liberalism, Oxford 1987.

WeBb, JAMEs, The Harmonious Circle. The Lives and Work of G.I. Gurdjieff, P.D. Ouspensky, and Their Followers. London 1980.

WeLlek, NONMA D., "Die sowjetrussischen literarischen Utopien." In: R. VILLGRADTER, F. KREY (Hgg.), Der utopische Roman, Darmstadt 1973, S. 321-329.

- Weluex, Nonna D., "A Mystic's Utopia. St. Lukashevich, N.F. Fedorov 1828-1903: A Study in Russian Eupsychian and Utopian Thought. Newark, London 1977." [Rezension] In: Altemative Futures. The Joumal of Utopian Studies. 2 (1979), 2, S. 93-98.

- WeLls, Rosalind JUDrth, The Theme of Science and Technology in Soviet Literature of the PostStalin Period 1953-64. D.Phil. thesis Univ. of Oxford 1981, Masch. [Fedorov S. 292, 295, 297, 310, 446, 4581., 461, 475, 530] [Siehe auch MARSH, ROSALIND]

Wetrer, Gustav A[NDREAs], "Die russische religiose Philosophie und der Marxismus." In: 600 Jahre theologische Fakultät an der Universität Wien 1384-1984, Wien 1985, S. 73-91. (= Schriftenreihe des Universitătsarchivs; 1).

Wielenga, BastianN, Lenins Weg zur Revolution. Eine Konfrontation mit Sergej Bulgakov und Petr Struve im Interesse einer theologischen Besinnung. München 1971. 
WIENER, Norbert, The Human Use of Human Beings. Cybemetics and Society. Boston 1950.

WIENER, NORBERT, God and Golem, Inc. A Comment on Ceriain Points where Cybernetics Impinges on Religion. Cambridge, Mass. 1966.

- Wiles, Peter, "On Physical Immortality." In: Survey, 56, 1965, S. 125-143; 57, 1965, S. 142-161.

WILLAMS, ROBERT C[HADWEL], Culture in Exile. Russian Emigres in Germany, 1881-1941. Ithaca, London 1972.

- Willuams, Robert C[HADWELL], Antists in Revolution. Pontraits of the Russian Avant-gande, 19051925. Bloomington, London 1977. [Fedorov S. 129-131, 135, 140, 146, 149f., 188]

WILLIAMS, ROBERT C[HADWELL], "Collective Immortality. The Syndicalist Origins of Proletarian Culture, 1905-1910." In: Slavic Review, 39 (1980), 3, S. 389-402.

- Williams, RoBert C[HADWEL], The Other Bolsheviks. Lenin and His Critics, 19041914. Bloomingt on, Indianapolis 1986. [Fedorov S. 98]

WIORA, WALTER, "Die Kultur kann sterben'. Reflexionen zwischen 1880 und 1914." In: $R$. BAUER u.a. (Hgg.), Fin de sizcle. Zur Literatur und Kunst der Jahrhundertwende. Frankfurt/M. 1977 , S. 50-72.

Woloschin, Margarita, siehe Vološina-SabaSnIKoVa, M.V.

- WoroszYrsKu, WikToR, "Vladimir Maïakovski (1893-1930)." In: E. ETKIND u.a. (Hgg.), Histoire de la litterature nusse - Le XXe siecle [2]: La Révolution et les années vingt. O.O. [Paris] 1988, S. 271-308. [Fedorov S. 298f.]

YANOVSKY, V.S., siehe JANOVSKH, V.S.

- Yarmolinsky, AVRahm, Dostoevsky: His Life and Ant, London 1957. [Fedorov S. 348f., 387]

- Young, George MCCracken JR., The Philosopher of the Common Task. A Study of the Life and Thought of Nikolaj Fedorov. Ph.D. diss Yale Univ. 1973; Ann Arbor, Mich. 1974.

- Young, George M. JR., Nikolai F. Fedorov: An Introduction, Belmont, Mass. 1979.

- Young, George M. JR., "L. Koehler, N.F. Fedorov: The Philosophy of Action, Pittsburgh 1979." [Rezension] In: Slavic Review, 41 (1982), 3, S. 573f.

YOUNG, ROBERT, "The Resurrection of the Body." In: Sophia. A Joumal for Discussion in Philosophical Theology. Deakin Univ. Belmont, Vic., Australia, 9 (1970), S. 1-15.

- Zabeun, Igor' [MichajloviC], "Celoverestvo - dlja Zego ono?" In: Moskva, 1968, 5, S. 147-161.

- ZABELIN, IGOR' Michanlovic, Fiziceskaja geografija i nauka budušego, M. ${ }^{2} 1970$. [Fedorov S. $152,154]$

- ZABEun, IGOR' MichnLovic, Celovek i Celovecestuo. Ozenki. M. 1970. [Fedorov S. 194ff.]

- ZABELIN, IGOR' MICHALOVIC, Fiziceskaja geografija v sovremennom estestwoznanii. Voprosy istonii i leorii. M. 1978.

ZABELIN, IGOR' [MicharloviC], "Pompei genial'nogo uma. 'Razmyłlenija naturalista' V.I. Vernadskogo i sovremennaja nauka." In: Novyj Mir, 1979, 4, S. $192-210$.

- ZABEun, I[GOR' Michnlovic], "I.I. Mołalov, Vladimir Ivanoviz Vernadskij (1863-1945). Moskva 1982." [Rezension] In: Novyj Mir, 1983, 8, S. 262-265. [Fedorov S. 264]

- ZABELIN, I[GOR'] M[ICHAJLOVIC], Mudrost' geografii, M. 1986. [Fedorov S. 175-180]

- Zabolocky, Nikola [AlekseEviC], Stichotvorenija, Washington, New York 1965.

ŻADOVA, LARISA [A.], "Poiski chudožestvennogo sinteza na rubeže stoletij." In: Dekoratimoe Is. kusstwo SSSR, 1976, 8, S. 38-43.

[Z̈adova, LARISA A.] Shadowa, LaRISSA A., Kasimir Malewitsch und sein Kreis. Suche und Experiment. Aus der Geschichte der russischen und sowjetischen Kunst zwischen 1910 und 1930. München 1982. 
- Zajcev, ANdRej Dmitrievic, Petr Ivanovic Bantenev, M. 1989. [Fedorov S. 51, 117]

- ZakydalsKY, Taras D., N.F. Fyodorov's Philosophy of Physical Resurrection. Ph.D. diss. Bryn Mawr College 1976.

- ZaKYDAlsKY, TARAs D., "Stephen Lukashevich. N.F. Fedorov (1828-1903): A Study in Russian Eupsychian and Utopian Thought. Newark 1977." [Rezension] In: Slavic and East European Journal, 23 (1979), 2, S. $273 f$.

- ZaKYDalsKY, TARAs D., "Valerian Nikolaevi飞 Murav'ev. Ovladenie vremenem. Reprinted with an introduction by Michael Hagemeister. Munich 1983." [Rezension] In: Canadian Slavonic Papers, 28 (1986), 1, S. 91-94.

- ZaKYdalsKY, TaRAs D., "Fedorov's Critique of Nietzsche, the 'Eternal Tragedian'." In: B.G. Rosentral (Hg.), Nietzsche in Russia, Princeton, NJ. 1986, S. 113-125.

ZALKIND, A[ARON] B[ORISOVIC], "Psichologija reloveka budušcego." In: A. A[RKA]N [d.i. A.I. ANEKSTEJN], E. KOL'MAN (Hgg.), Žizn' $i$ rechnika budustego. (Social'nye i nauðno-rechniZeskie utopii). M.-L. 1928, S. 432-503.

- Zamuatin, Leonid, "'Otec vsegda byl russkim chudožnikom.' Beseda s Žosefinoj Pasternak." In: Literatumaja Gazeta, 39, 28.9.1988, S. 15.

- Zander, YEv] A[LeKsandrovic], Bog i mir. (Mirosozercanie otca Sergija Bulgakova). T. 1-2, Paris 1948. [Fedorov, t. 1, S. 386f.]

- ZaNDER, L[EV] A[LEKSANDROVIC],"Technik und Glaube. Eine Skizze aus russischer Religionsphilosophie." In: Studium Generale, 15 (1962), 5, S. 324-334.

- Zapata, RenÉ, La philosophie russe et soviérique, Paris 1988. [Fedorov S. 6, 64f., 69] Zapiski Instirura Živogo Slova, 1, Pb. 1919.

ZAvadovsKu, V., "Obzor inostrannoj i russkoj literatury po voprosu ob omoloženii." In: Pecar' $i$ Revoljucija, 1921, 2, S. 78-89.

- Zavalishin [Zavalisin], Vyacheslav [Vjaceslav Klavdievic], Early Soviet Writers, New York 1958 ['1962]. [Fedorov S. 25, 83, 85f.]

ZEGIN [d.i. SECHTEL'], LEV] F[EDOROVIC], "Drugu." In: Makovec, 1922, 2, S. 6.

ZEOIN [d.i. SECHTEL'], LEV] F[EDOROVC], "Vospominanija o Majakovskom." In: V. Majakovskij $\checkmark$ wospominanijach sovremennikov, M. 1963, S. 99-102.

- ZEGIN [d.i. SECHTEL'], LeV [FEDOROVIC], "Vospominanija o PA.Florenskom." In: Vestnik RChD, 135, 1981, S. 60-70. [Fedorov S. 63] - Dass. auch in: Nadezda. Christianskoe ctenie. Vyp. 7, Frankfurt/M. 1980, S. 275-297.

- ŽEGIN [d.i. SECHTEL'], LEV] F[eDoroviC], "Vospominanija o V.N. Cekrygine." In: Panorama iskusstv, vyp. 10, M. 1987, S. 195-232.

ZeISS, HeINZ, Elias Metschnikow. Leben und Werk. Jena 1932.

ZEI', siehe SETNICKU, N.A.

- Zeldin, Mary-Barbara, "L. Koehler, N.F. Fedorov: The Philosophy of Action, Pittsburgh 1979." [Rezension] In: Canadian-American Slavic Studies, 15 (1981), 4, S. 594-596.

ZEunsKu, K[ornelu] LJuclanovic], "Bod." In: Okajabr', 1929, 6, S. 182-188.

ZELINSKU, KORNELU LJUCLANOVIC, Na mibete druch époch, M. 1959.

- ZELINSKY, BODO, "Ober die Ästhetik Vladimir Solov'evs." In: Zeitschrift für Ästhetik und allgemeine Kunstwissenschafi, 13 (1968), 1, S. 49-111. [Fedorov S. 109]

ŻELNINA, T.N., "K.E. Ciolkouskij, Grezy o zemle i nebe. Naǔ̌no-fantastiðeskie proizvedenija. Tula 1986." [Rezension] In: Voprosy Istonii Estestwoznanija i Techniki, 1987, 3, S. 151-154.

- ZeN'kovskU, V[ASILU] V[ASIL'EVIC], "Problema bessmertija u L.N. Tolstogo." In: $O$ religii L'va Tolstogo. Sbornik statej. M. 1912, S. 27-58. [Fedorov S. 56]

- Zen'KovSKU, V[ASIU]] V[ASIL'EviC], "Evrazijcy." In: Segodnja, [Riga] 290, 20.10.1933.

- Zen'KovskU, V[ASILU] V[ASIL'EVIC], "Der Geist der Utopie im russischen Denken." In: Orient und Occident, 16, 1934, S. 23-31. [Fedorov S. 24, 291.] 
- ZeN'kovsku, V[AsIn] V[AsIL'EVIC], Russkie mysliteli i Evropa. Kritika evropejskoj kul'tury u nusskich myslitelej. Paris 1934. [Fedorov S. 215-217, 276]

- ZeN'KovskU, V[ASILU] V[ASIL'EVIC], Istorija russkoj filosofii, tt. 1-2, Paris 1948-1950. [Fedorov bes. t. 2, S. 131-147] - Dass. [engl.] A History of Russian Philosophy, vols. 1-2, New York, London 1953. [Fedorov bes. vol. 2, S. 588-604]

- ZEN'KovSKu, V[ASILU] V[ASII'EVIC], "N.F. Fedorov." In: Vestnik RSChD, 1950, 1, S. 2-9; 2, S. 17 22.

- Zen'kovsku, V[asilu VASIL'EVIC], "Certy utopizma v istorii russkoj mysli." In: Novyj Žumal, 42, 1955, S. 221-234. [Fedorov S. 233]

- ZEN'KOVSKU, V[ASILU] V[ASIL'EVIC], O mnimom materializme nusskoj nauki i filosofii, München 1956. [Fedorov S. 62f.]

- Zen'kovsku, V[asilu Vasil'eviC], N.V. Gogol', Paris 1961. [Fedorov S. 173, 192, 212, 227] ZEN'KovSKI, V[ASILU] V[ASIL'EVC], "Iz vospominanij." In: Vestmik RChD, 139, 1983, S. 103-125.

- Zernov, Nicolas [Nixolas Michniovic], Three Russian Prophets. Khomiakov, Dostoevsky, Soloviev. London 1944. [Fedorov S. 110-112, 129f.]

- Zernov, Nicolas [Nikolas Michajlovic], The Russian Religious Renaissance of the Twentieth Century, London 1963. [Fedorov S. 292f.] - Dass., verănd. u. erg. [russ.] Russkoe religioznoe vaznazdenie XX veka, Paris 1974. [Fedorov S. 48, 121, 297, 313f.]

- Zernov, N[ikola MichulloviC], "Introduction." In: N.F. FEdorov, Filosofija obscego dela, t. 1. [Reprint] Westmead, Famborough, Hants 1970, n.p. [2 S.].

Zivaja tizn'. Dvuchnedel'nyj religiozno-filosofskij Zumal. [M.] 1, 27.11.1907; 2, 20.12.1907; 1, 15.1.1908, 2, 30.1.1908.

ZLENKo, G.D., "Neuctennye publikacii proizvedenij A. Bloka." In: Russkaja Literatura, 1983, 1, S. $252 f$.

ZOGRAF, Nixoln GeORGIEviC, Aleksandr Pavlovic Lenskij, M. 1955.

ZOOGRAF], N[IKOLN GeorgIEviC], "Lenskij, Aleksandr Pavlovið." [Lexikonartikel] In: Teainal'naja énciklopedija, t. 3, M. 1964, Sp. 486-490.

- Zuxov, DMtTRU, "Prozrenija." In: Pamjatniki otecestva, 2 (1980), 2, S. $45-47$.

- Zurakovsku, ANATOU, "Tajna ljubvi i tainstvo braka." In: Christianskaja Mysl', [Kiev] 1917, 1, S. 61-75; 3-4, S. 34-54; 5-6, S. 41-51; 7-8, S. 15-29. [Fedorov 1, S. 71; 3-4, S. 51-53; 7-8, S. 24] 


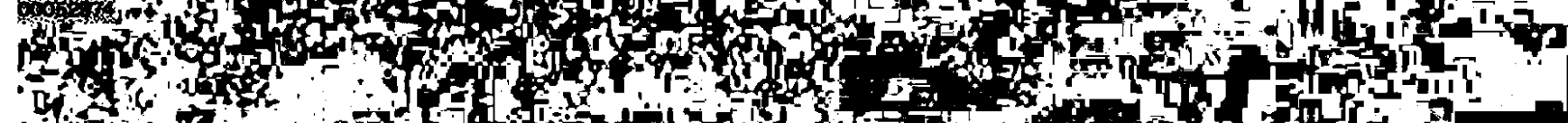

-

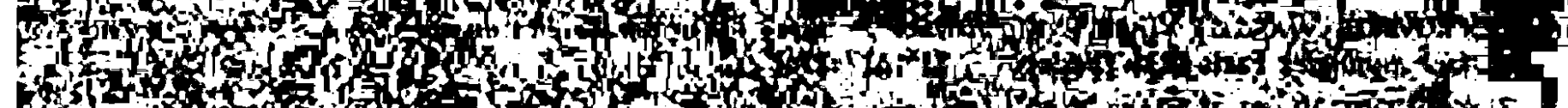

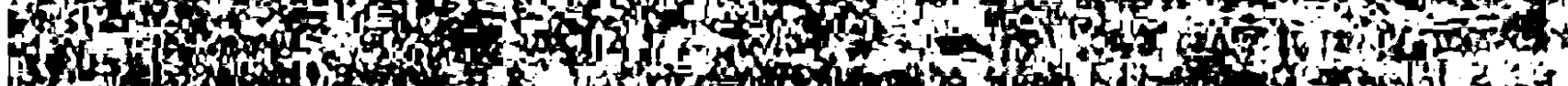

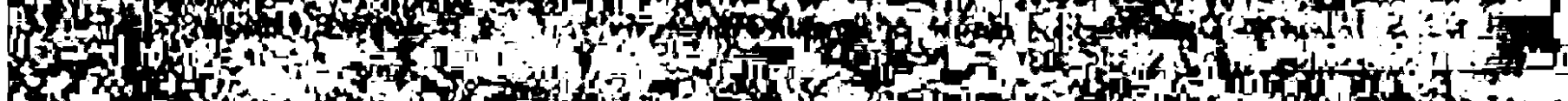
Cif

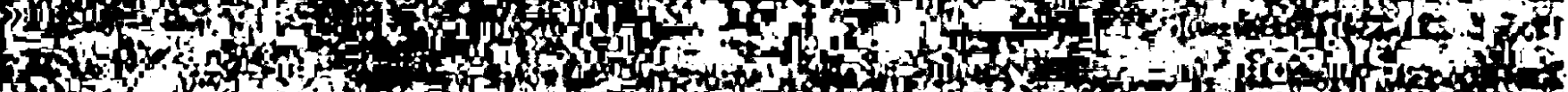
Ff

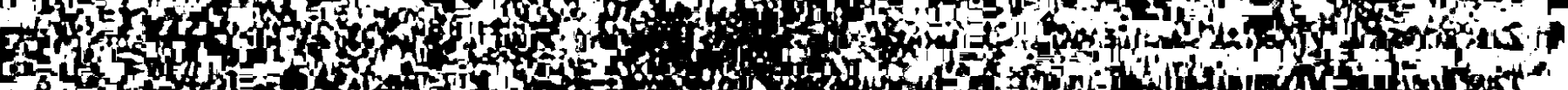

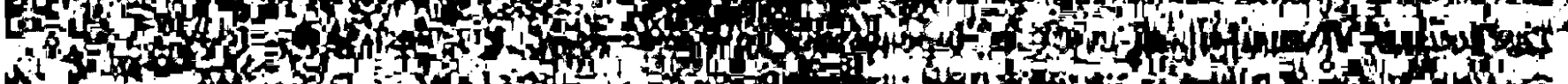

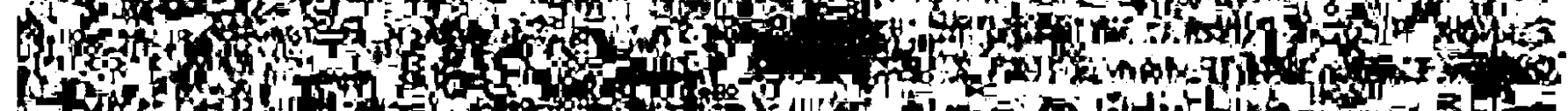

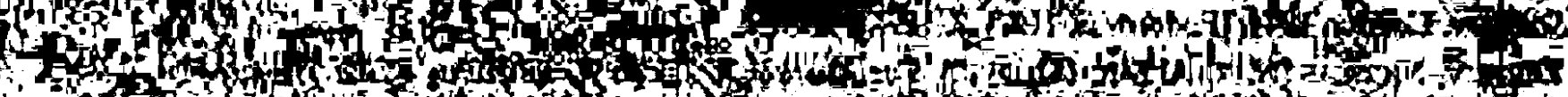

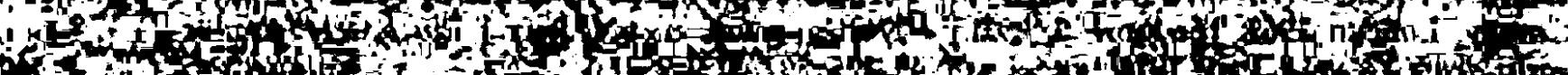
pats Woy

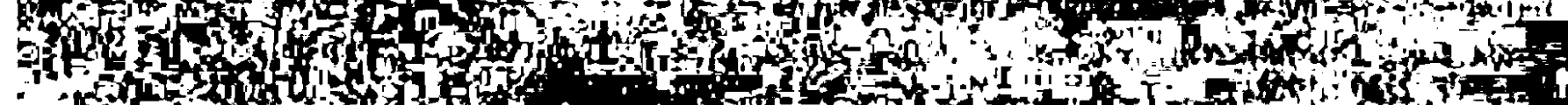

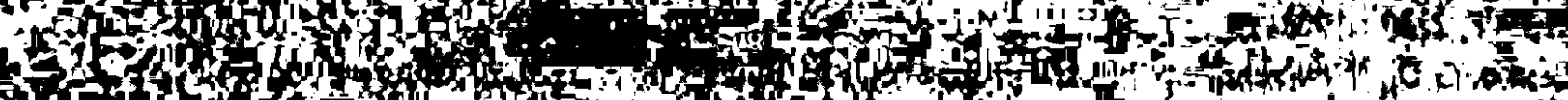

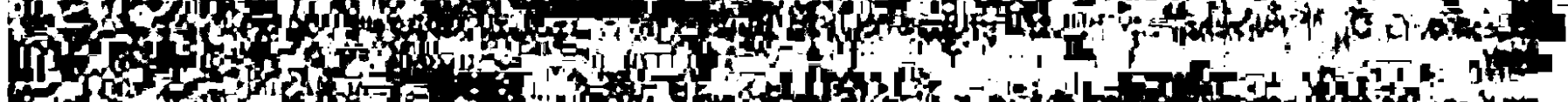
(5) Hofle

-

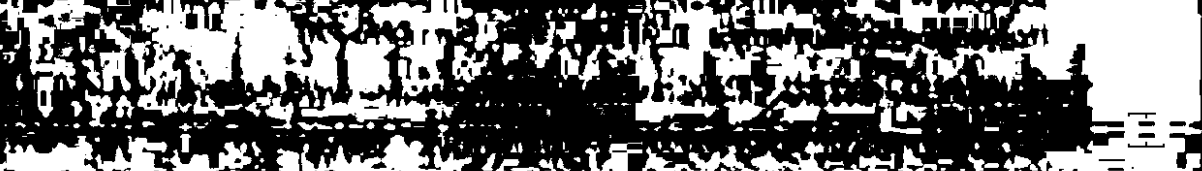

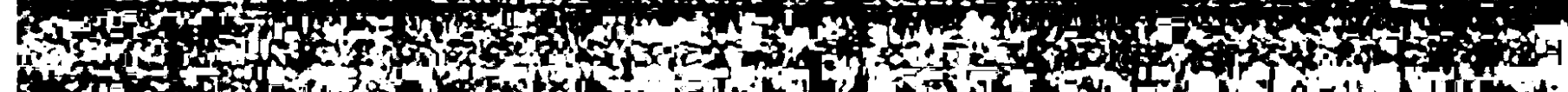

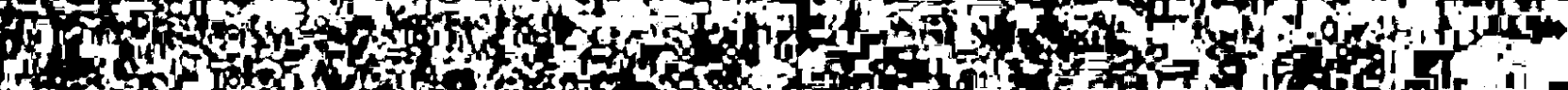

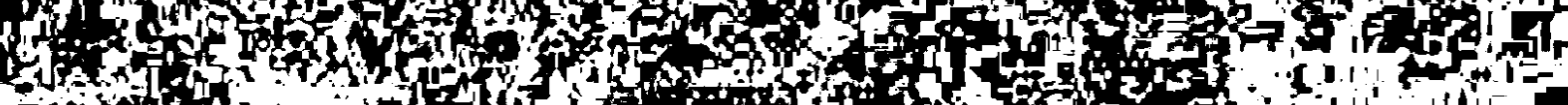

A Wh

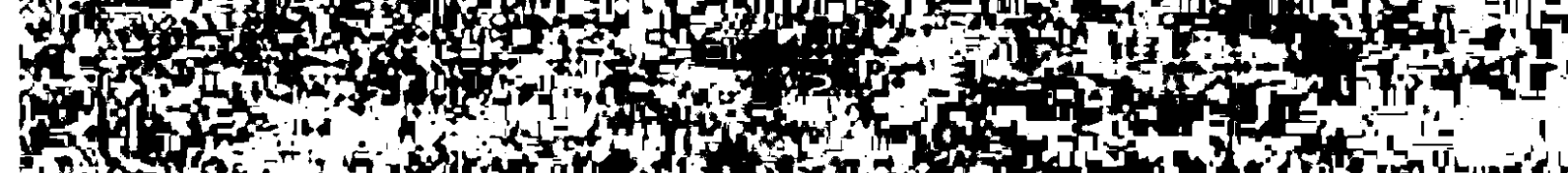

$$
\text { . }
$$

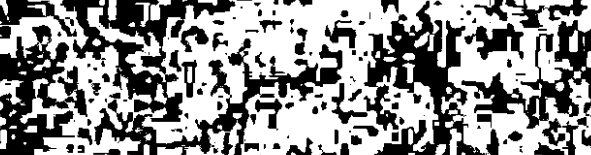

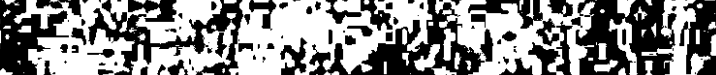

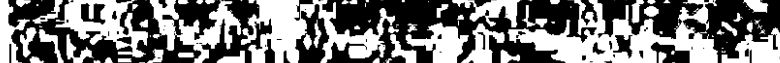

How

I.
- not,

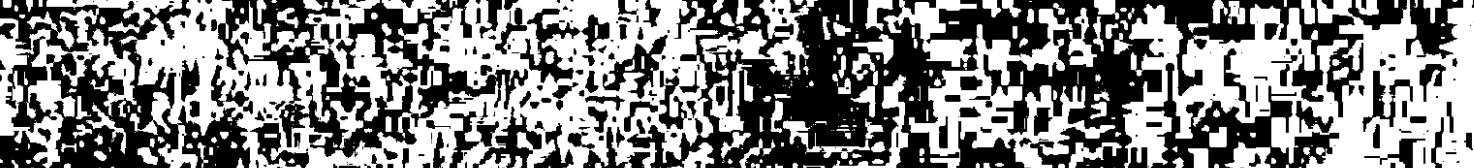

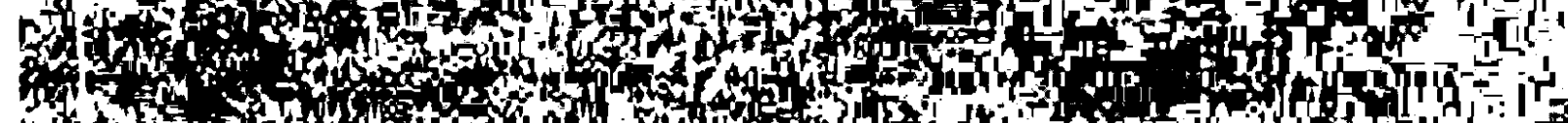

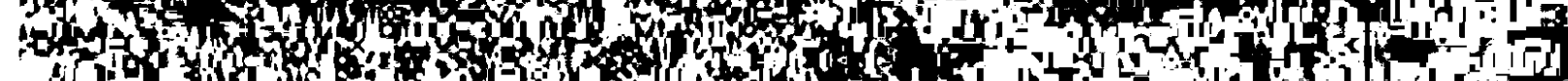
Hof
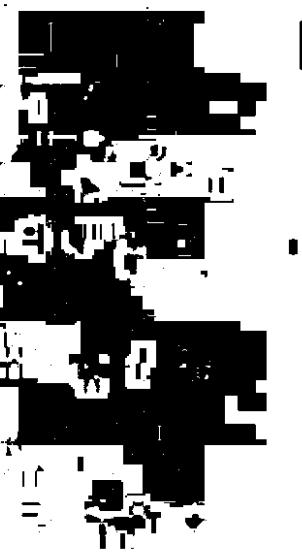


\section{BIBLIOGRAPHISCHER NACHTRAG}

\section{SCHRIFTEN VON N.F. FEDOROV}

"Iz materialov k tret'emu tomu 'Filosofii obscego dela' N.F. Fedorova." In: Kontekst 1988, M. 1989, S. 278-351. [Vstup. stat'ja, publ. i primex. S.G. Semenovoj]

"O pis'menach. Posmertnaja stat'ja." In: Naše Nasledie, 1989, 6, S. 117f. [Wiederabdruck des Artikels in Vesy, $1(1904), 6]$

[Aufsatz über L.N. Tolstoj; 1901] Erstmals veröff. in: N.[N.] SkATOV, "Nikolaj Fedorov o L've Tolstom." In: Literatumaja UČeba, 1989, 3, S. 168-172; hier S. 170f.

[FEDOROV] FJODOROW, N[IKOLA]] F[EDOROVIC], "Philosophie der gemeinsamen Tat." In: W. GOERDT, Russische Philosophie. Texte. Freiburg/Br., München 1989, S. 686-704. [Auszüge aus FOD I, S. 2f., 4, 5f., 11f., 20f., 22f., 27, 27f., 30, 31f.]

\section{V. ÜBRIGE LTTERATUR}

- ANCiferov, N[ikolaj Pavlovič], "Iz vospominanij." In: Zvezda, 1989, 4, S. 117-165. [Kap. "Medvež'ja gora" über A.K. Gorskij, Fedorov S. 147f.]

- Azadovski, K[ONSTANTIN] M[ARKoviC], "Perepiska V.Ja. Brjusova s N.A. Kljuevym (19111914)." In: Russkaja Literatura, 1989, 3, S. 180-199. [Ausführl. über I.P. Brichnizev; Fedorov S. 190]

- Belov, Sergej V[ladimiroviC], "F.M. Dostoevskij v russkoj zarubežnoj kritike." In: Russkaja Mysl', 3794, 22.9.1989, S. 9f. [Fedorov S. 9]

Boneckaja, N[ATal'Ja] K[onstantinovna], "Slovo v teorii jazyka P.A. Florenskogo." In: Studia Slavica Hung., 34 (1988), 1-4, S. 9-25. [Ausführl. zum imijaslavie]

- Calmaev, Viktor AndreeviC, Andrej Platonov. (K sokrovennomu Celoveku). M. 1989. [Fedorov passim]

- Deboser, Lola, "Platonows Romanwelt." In: A. Platonow [Platonov], Die Baugrube. Das Juvenilmeer. Dshan. Berlin 1989, S. 407-459. [Fedorov S. 408, 410-414, 419f., 453]

- Dužına, N.I., "Vse, cto vidimo i ťo skryto...' Kommentarii k proizvedenijam, vkljucennym v sbornik." In: A. Platonov, Kotlovan. Izbrannaja proza. M. 1988, S. 312-317. [Fedorov S. 314f., 317

- Frolov, IVAn Timofeevic, O celoveke i gumanizme, M. 1989. [Fedorov S. 510-518]

- Gasparov, Boris, "Vremennoj kontrapunkt kak formoobrazujuscij princip romana Pasternaka 'Doktor Živago'." In: Boris Pastemak and His Times. Selected Papers from the Second Intemational Symposium on Pastemak. Berkeley 1989, S. 315-358. (= Modern Russian Literature and Culture, Studies and Texts; 25). [Einfluß Fedorovscher Ideen auf 'Doktor Živago' S. 344]

- Gel'perin, Ju.M., "Borodaevskij, Valerian Valerianovix." [Lexikonartikel] In: Russkie pisateli 1800-1917. Biograficeskij slovar'. M. 1989, S. $314 f$.

- Gulyga, A[RSENu Vladimirovic], "Kosmizeskaja otvetstvennost' ducha." In: Nauka i Religija, 1989, 8, S. 32-34. [Fedorov S. 33; "Der russische Kosmismus ist das letzte Wort der Philosophie" S. 34]

GulyGa, ARSENu [VladimiroviC], "Dialektika žizni." In: Rodina, 1989, 10, S. 93-95. [A.F. Losevs Verbindungen zum imjaslavie]

GuMILEv, Lev NikolaeviC, Etnogenez i biosfera Zemli, L. 1989. [Erste Buchausgabe des 1979 in VINITI deponierten Ms.]

- Kedrov, Konstantin AleksandroviC, Poéticeskij kosmos, M. 1989. [Russ. Kosmismus; Fedorov S. 3f., 97, 128f., 445, 452] 
- KosenKo, Pavel Petrovic, Neèvklidovy parallely. Chronika poslednich let Zizni Fedora MichajloviCa Dostoevskogo i nekotorych ego sovremennikov. Alma-Ata 1988. [Dostoevskij und Fedorov S. 85, 200-202]

" Kovtun, EvgENu [F.], "'Pobeda nad solncem' - natalo suprematizma." In: Nase Nasledie, 1989, 2, S. 121-127. [Fedorov, Malevið S. 123]

- Magomedova, D.M., Belodubrovski, E.B., "Brichnitev, Iona Pantelejmonovic." [Lexikonartikel] In: Russkie pisateli 1800 1917. Biograficeskij slovar'. M. 1989, S. 328f.

- Malygina, N.M., Estetika A. Platonova, Irkutsk 1985. [Lag nicht vor]

- MAsing-Deluc, I[RENE], 'Capitalist Bread and Socialist Spectacle: The Janus Face of 'Rome' in Pasternak's 'Doctor Zhivago'." In: Boris Pastemak and His Times. Selected Papers from the Second Intemational Symposium on Pastemak. Berkeley 1989, S. 372-385. ( = Modern Russian Literature and Culture, Studies and Texts; 25). [Fedorovs Einfluß auf Pasternak und 'Doktor Živago' S. 374, 376f., 381, 384f.]

- MUller, LUdDolf, "Russische Eschatologie zwischen Apokalyptik und Utopismus." In: Zeitwende, 59 (1988), 4, S. 207-227. [Fedorov S. 210f., 226]

" Polivanov, K[ONSTANTiN] M[ICHajloviC], "Gorskij, Aleksandr KonstantinoviC." [Lexikonartikel] In: Russkie pisateli 1800-1917. Biografičeskij slovar'. M. 1989, S. 642f.

- Russkij kosmizm i noosfera. (Tezisy dokladov Vsesojuznoj konferencii, Moskva, 1989). C. 1 und 2, M. 1989. [Fedorov pass.]

- Semenova, S[VetLana] G[Rigor'evna], [Vstup. stat'ja, publ. i primeð. zu] "Iz materialov k tret'emu tomu 'Filosofii obšrego dela' N.F. Fedorova." In: Kontekst 1988, M. 1989, S. 278-351.

- Semenova, Svetlana [Grigor'evna], Preodolenie iragedii. 'Veinnye voprosy' v literature. M. 1989. [Zu Fedorov v.a. "Ob odnom idejno-filosofskom dialoge (Tolstoj i Nikolaj Fedorov)." S. 100-132. "'Vyš̌aja ideja suš̌estvovanija' u Dostoevskogo." S. 133-164; Fedorov S. 153-164. Fedorov ferner S. 269, 273, 280f., 286f., 291f., 305, 322f., 361, 379]

- Sikman, Anatolus Pavlovic, Ulica Kirova, 7, M. 1989. [Certkov-Bibliothek, Fedorov, S. 24, 29]

- Skatov, Nikola [NikolaEviC], "Nikolaj Fedorov o L've Tolstom." In: Literatumaja Uxeba, 1989,3, S. $168-172$.

- STTtES, RIChARD, Revolutionary Dreams. Utopian Vision and Experimental Life in the Russian Re. volution. New York, Oxford 1989. [Fedorov S. 154, 169f., 285]

- [Svjatopolk-Mirsky, DMtrRu Petrovic] Mirsky, D.S., "Histoire d'une émancipation." In: La Nouvelle Revue Française, 19 (1931), 216, S. 384-397. ["Begeisterung" der linken Eurasier fur Fedorov S. 393f.] 


\section{Personenregister}

Nicht aufgenommen wurden Personennamen in Zitaten und in bibliographischen Angaben sowie die Namen mythologischer und literarischer Gestalten.

Abraham, K. 235

Achmatova, A. (A.A. Gorenko) 420

Adler, A.S. 423

Agapov, B.N. 302

Aksenov, G.P. 318

Aleksandrov, AA. 382

Aleksandrov, V. 438

Alekseev, I.I. 396-398

Alekseev, N.N. 319, 421, 426-428, 431, 444

Alekseev, V. 18

Alekseev, V.I. $129 f$.

Alekseev-Askol'dov, S.A. 227, 320, 386-388

Aleksej B. 360

Alexander I. (russ. Zar) 20, 248

Alexander II. (russ. Zar) 150

Alymov, S.Ja. 313

Anciferov, N.P. $386,388,396,416$

Andreev, A. 244

Andreev, D.L. 7

Andreev, L.N. 157

Andreevskij, I.M. 386, 388

Anist, V. 306

Antipov, A.P. 433,436

Antonij, archiepiskop (A.S. Mel'nikov) 5, 59

Arakteev, A.A. 118, 248

Arapov, P.S. 421, 424, 429

Arcybašev, M.P. 157,159

Arens, L. 276

Arsen'ev, N.S. 344

Arsen'ev, V.S. 20

Arvatov, B.I. 334

Aseev, N.N. 294, 313, 410

Askarov, G.K. (G.K. Jakobson) 301, 303

August in (Kirchenlehrer) 73, 200

Avenarius, R. 252

Azadovskij, K.M. 221
Babel', I.E. 422

Bachmet'ev, P.I. 187, 228f., 234-236, 264, $272,314,335$

Bacon, F. 181, 283

Bagrickij, E. (E.G. Dzjubin) 231, 238

Bakunin, M.A. 209, 304

Bakuక̌inskij, A.V. 290

Bal'mont, K.D. 248

Baranov, M. 7

Baranov, P. 7

Baratynskij, EA. 352

Bartenev, Ju.P. 18, 39, 188, 203 f.

Bartenev, P.I. 18, 27-29, 39, 42, 189, 204

Bartenev, S.P. 39, 42, 48, 120, 189f., 366

Barthes, R. 265

Bateson, G. 11

Bazanov, V.G. 225

Bazarov, VA. (VA. Rudnev) 170, 176

Bechterev, V.M. 265

Beknev, SA. 245, 250, 354

Beleckij, I.S. 433

Belenson, A.E. 268

Belevskij, F.K. 19

Belinskij, V.G. 157

Beljaev, A. 190

Beljaev, A.R. 245

Bellamy, E. 84, 248, 272

Belozerov, S. 445

Belyj, A. (B.N. Bugaev) 39, 163, 166, 199, 203, 208-211, 215, 218, 234, 293, 301, 304, $320,345,384,447$

Benjamin, W. 161

Berdjaev, N.A. 1, 7, 71-74, 157f., 162, 167, 169f., 196f., 199-201, 210f., 214, 216, 222, $224,260,302-304,319-321,340,344 f ., 354$, $360 f ., 363,371,390,405,407,409,417,429$, $439,443-447,453-456$

Bergson, H. 11, 177, 214, 446, 449, 451

Bertalanffy, L. v. 260 
Berthelot, M. 123

Beta, B. (B.V. Butkeviz) 411 .

Billington, J.H. 409

Blavackaja, E.P. 255, 366

Bloch, E. 72, 165, 260, 264

Blok, A.A. 208, 221f., 225, 232, 238, 304, 352, 380,384

Bobovic, I. 238

Bobrov, S.P. 276

Bogdanov, A. (A.A. Malinovskij) 80, $170-$ $175,178-181,214,247 f ., 252 f$., 255f., 258, 261f., 265, 330f., 338, 348

Bondarču, S.F. 3

Boraneckij, P.S. 241, 341, 443, 448-453

Borisov, I.P. 31

Borisov, V.S. 18f., 41

Borodaevskij, V.V. 203, 211, 234, 237

Borovoj, V. 5

Botkin, V.P. 158

Boullee, E.-L. 333f.

Bourget, P. 53

Bowlt, J.E. 267, 285, 295

Bradbury, R. 37

Brecht, B. 266

Brichnizev, I.P. 24, 42, 47, 63, 166, 168, 207, 217-232, 234-239, 301, 350-352

Brichniteva, V.M. 222, $224 f$.

Brik, L.Ju. 278

Brik, O.M. 269f., 277

Brjusov, V.Ja. 39, 49f,, 203-208, 211, 222 , 225, 234, 236f., 248, 254, 257f., 265, 270, $272,275,277,282,308,319,363,447$

Brusilov, A.A. 366, 382

Büchner, L. 123, 451

Buddha 278

Bulgakov, M.A. 264

Bulgakov, S.N. 30, 60, 74, 157-162, 167, 169, 178, 186, 189f., 196f., 201-203, 210, 216, $222,294,303,320,322,405,407,417,444 f$.

Bunina, V.N. 429

Burljuk, D.D. 287

Burljuk, N.D. 268 f.

Buslaev, F.I. 38

Čaadaev, P.Ja. 19

Cabet, E. 248

Caev, NA. 29,441
Cagareli, G.K. 238

Cajanov, A.V. 228, 277, 312, 334

Calmaev, V.A. 3

Capra, F. 11

Ccheidze, K.A. 270, 340, 407, 410, 413, 422, $424,430,432-439,442 f ., 457$

Cechov, A.P. 427

Cejtlin, Z.A. 312

Čekrygin, V.N. 268, 270f., 277, 285-295, 333f., 353

Cepurkouskij, E.M. 405

Cernogubov, N.N. $24,31,39,42,44,47,49$ f., $63,99,188,204,208$

Čemyšsev, N.M. 292, 294

Cernyševskij, N.G. 26, 333

Certkov, A.D. 29

Chardžiev, N.I. 271, 285 f.

Chlebnikov, V.V. 47, 180, 211, 215, 251, 254, $268,272,276-284,286,289,294,316,327$, 334,353

Chludow, VA. 234,237

Chodaseviz, V.F. 349

Cholodnyj, N.G. 10

Chomjakov, A.S. 419

Christus 94f., 146, 161f., 167, 169, 199, 222$225,350,406,429$

Ciolkouskij, K.E. 2, 4, 10-13, 40, 130, 180, $205,241,244,248 f ., 255-260,263,277,281$, $283,314,316,337,341,376,407$

Ciurlionis, M.K. 255, 293 f.

Civilichin, VA. 3

Ciževskij, A.L. 10f., 257, 259, 280, 314, 376, 420

Cohen, H. 340,361

Comte, A. 11, 92, 122, 173, 176f., 331, 457

Condorcet, M.J.A. 184

Cuev, S.I. 438

Culkov, G.I. 156, 319, 380, 382

Culkov, N.P. 18

Cusanus, N. 72

Cużak, N.F. 253, 267, 334

Cuetaev, I.V. 43

Cvetaeva, M.I. 43, 389, 410, 422, 428, 444

Danilevskij, N.Ja. 363, 419

Danzas, Ju.N. 378

Darwin, Ch. 75 
Daskov, V.A. 43

Davies, R.D. 100

Degtjarev, N.S. 305f., $313 f$.

Descartes, R. 95, 249, 283, 331

Dessauer, F. 72

Dewey, J. 107

Dobbie-Bateman, A.F. $407 f$.

Dobroljubov, A.M. 222

Dokuzaev, V.V. 330, 419

Dorofeeva, N.I. $42,47,63$

Dorogov, A.A. 55, 271, 288

Dostoevskij, A.A. 346

Dostoevskij, F.M. 1, 28, 44, 77, 101, 129, 140 $154,159,190,193,195,231,237 f$., 349, 382, $386,406,408,419,431,434,441,447$

Duganov, R.V. 272

Durylin, S.N. 196

Efron, S.Ja. $364,390,421$., 424, 428, 432

Egorov, D.F. 322, 362, 439

Eimermacher, K. 300

Einstein, A. 251, 272, 275f., 314, 337, 407, 450

Ejchenbaum, B.M. 348, 399

Ekster, A.A. 287

El'zaninov, A.V. 166, $218 f$.

Enčmen, E. 250

Engels, F. 67, 80, 166, 260, 414

Epikur 91

Erberg, K.A. 320

Ermanskij, OA. 249

Em, V.F. 157, 164-166, 186, 218f., 223, 322, 439

Esenin, S.A. 277

Evtusenko, E.A. 3, 316

Pavorskij, V.A. 288, 294, 384

Fechner, G.Th. 232

Fedorov, L.N. 401

Fedorov, N. 19

Fedorov, N.F. passim

Fedoseev, P.N. 4, 57

Fedotov, G.P. 385f., 407, 429, 443f., $446 f$.

Feodor, episkop (Pozdeevskij) 194, 196, 362

Fet, A.A. (A.A. SenSin) 39, 99, 132, 209

Feuerbach, L. 107
Fichte, J.G. 98

Filiptenko, I.G. 244, 265

Filippov, B. (B.A. Filistinskij) 221, 227, 382, 387

Filonow, P.N. 285

Fioletov, A. 238

Fioletov, N.N. 319

Fiske, J. 11

Flammarion, C. 205

Florenskij, P.A. 5-7, 12f., 30, 87, 166, 193f., $196-198,211,218,223,231,236,251 f ., 260$, $275,277,283,288,293-295,304,312,320$, $322 \mathrm{f} ., 326 \mathrm{f}$., 345, 349, 353, 356, 360, 382, $384,388,429,439$

Florovskij, G.V. 122, 151, 406, 417, 419f., $456 f$.

Fondaminskij-Bunakov, I.I. 444

Forక, O.D. 360, 374, 376-378, 384, 389, 409

Forster-Nietzsche, E. 101

Fourier, Ch. 122, 248, 278f., 333, 457

Frank, S.L. 151, 320

Franklin, B. 118

Freud, S. 152, 232, 353, 407

Frite, V.M. 380

Fridlender, G.M. 151

Fudel', I. 196

Fülop-Miller, R. 172, 289, 324, 343f., 386f., 389

Fuss, N. 118

Gagarin, A.I. 19, 21

Gagarin, G.P. 20

Gagarin, I.A. 19f., 23

Gagarin, I.S. 19

Gagarin, K.I. 23-25

Gagarin, P.I. 17-23

Gagarin, P.P. 20

Gagarina, E.P. 20

Gagarina, P.A. 19

Gagarina, Z.P. 21

Gastev, A.K. 177, 248-251, 253, 263, 282, $337 f$.

Gavrjuక̌in, N.K. 5, 60

Georgievskij, G.P. 16f., 31, 39, 132, 134, 138, 150

Gerasimov, K.S. 205

Gerasimov, M.P. 242, 254 
Gercyk, E.K. 222

Gersenzon, M.O. 380

Ginken, A.A. 190

Gins, G.K. 368

Gjurdžiev, G.I. 7, 166

Glazunov, I. 3

Glusko, V.P. 258

Godwin, W. 41, 184, 243

Goethe, J.W. v. 83

Goldt, R. 8, 12, 282

Gollerbach, E.F. 361

Golovanenko, A.S. 193-195

Golovanov, Ja.K. 4

Gor'kij, M. (A.M. Peškov) 170, 177f., 214, $232,243-245,247,263,301,341,348-352$, $360,368,371-374,376-379,384,389-393$, $396-403,406,409,412-415,427,434 f$.

Gor, G.S. 2, $387 f$.

Gorbunov-Posadov, I.I. 222, 234, 236

Gordiny brat'ja (Anarchisten) 244

Gordon, A.L. 303

Gordon, G.O. 361

Goriély, B. 300

Gornostaev, A. siehe Gorskij, A.K.

Gorodeckij, S.M. 225, 227, 238

Gorskij, A.K. (Pseud.: Gornostacv, Ostromirov) 17f., 20-23, 44, 48f., 56, 151, 207f., 217, 225f., 228, 230-239, 275, 309, $324,340,346-350,352-357,360,362,366 \mathrm{f}$, 371f., 376, 380, 382, 384-389, 391-398, 400, $402,406-409,414-416,431,433 f ., 437,441$ $443,447,457$

Gregor v. Nyssa 123

Grigor'ev, S.T. $348,372,376,382$

Grigor'ev, V.P. 282

Grille, D. 172

Groys, B. 267

Grozin, E. 305f., 309

Gruzdev, I.A. 374

Gruzinov, I.V. 255

Grygar, M. 266

Gudzij, N.K. 400

Gul', R.B. 321, 421

Gulyga, A.V. 1, 3, 6-8, 11, 57

Gumilev, L.N. 7, 420

Gumilev, N.S. 320,420

Guscik, V.E. 436
Guyau, J.M. 104, 177, 457

Haeckel, E. 252

Hamann, J.G. 30,98

Hartmann, E.v. 260

Hauptmann, G. 53

Hegel, G.W.F. 98, 157, 208, 213, 265, 380

Heller, L. 179

Helmholtz, H.v. 260

Hemsterhuis, F. 30

Herder, J.G. $30,67,98$

Herriot, E. 401

Herzen, A. (A.I. Gercen) 70, 158, 209

Hessen, S. (S.I. Gessen) 151, 431

Hippius, S. (Z.N. Gippius) 163, 216, 389

Hoerschelmann, K.K. 436

Horkheimer, M. 159

Hume, D. 30,98

Huppert, H. 273

Husserl, E. 380

Huxley, J. 72

Ibsen, H. 53, 163, 220

Ikonnikov, N. 20

Il'in, I A. 320

Il'in, V.N. 340, 360, 417, 420f., 426, 429f., 444

Il'ina, N.I. 368

Ingold, F.Ph. 257

Isutin, NA. 26, 28

Ivakin, I.M. 39, 117, 441

Ivanickij, P.I. 118, 261, 263, 303-306, 309-313, $320,337,346,355$

Ivanov, A.A. 287

Ivanov, P. 7

Ivanov, V.I. 211f., 234, 270, 277, 282, 293f., $303,320,346,373,389$

Ivanov, V.N. 411f., 422

Ivanov, Vjac. Vs. 279, 323

Ivanov, Vs. Vjac. 384

Ivanov-Razumnik, R.V. 276f., 304, 384

Ivanova, E. 17,19

J acobi, F.H. 30,98

Jakobson, R.O. 55, 271, 275f., 431

Jakovenko, B.V. 431 
Jakovleva, A. 19

James, W. 107

Janin, V.L. 4

Janovskij, V.S. 444,446

Jaroslavskij, A.B. 255, 258, 272, 275, 309, 313f., $316 \mathrm{f}$

Jensen, K.M. 172,180

Judas Ischariot 208, 265

Judina, M.V. 384,386

Jußkeviz, P.S. 176

Kalandarił̌vili, N.A. 313

Kalinin, M.I. 393, 396

Kalouskova, Ja. 442

Kamenev, L. (L.B. Rozenfel'd) 218

Kammerer, P. 264

Kandaurov, O. 8

Kandinskij, V.V. 293, 380

Kant, I. 91, 95-98, 106, 162, 194

Karabcievskij, Ju.A. 274

Karakozov, D.V. 26, 28

Karazin, V.N. 66, 107, 115, 118, $311 f$.

Karpov, L.Ja. 265

Karsavin, L.P. 7, 158, 163, 420, 424, 427

Kassil', L.A. 314

Kataev, E.P. 231

Kataev, V.P. 231

Kazem-Bek, A.L. 364,418

Kedrov, V. 234

Kel'berin, L.I. 447

Keržencev, P.M. 337

Kireevskij, I.V. 76

Kirillow, V.T. 254, 257, 308

Kizevetter, A.A. 363

Klevenskij, M.M. 17

Kline, G. 170, 241

Kljuev, N.K. $221-223,225-228,232,238,277$, 387

Kluge, R.-D. 179

Klyckov, S.A. (S.A. Lesenkov) 277

Kobak, A.V. 7

Koehler, L. 59, 148, 152, 154, 209, 216, 409

Kogan, A.E. 401

Kogan, F.I. 228, 234, 238

KolZak, A.V. 363
Kol'cov, N.K. 264, 335

Kol'cov-Mosal'skij, A.G. 412

Kol'man, E. (A. Kolman) 10

Komar, I.E. 221

Komarovix, V.L. 140f., 144, 151, 386-388, 441

Koni, A.F. 320

Konstantin Konstantinovix (GroBfürst), 49, 204

Korovin (Physiologe) 314

Koskarev, N.N. 171

Kotik, N. 245, 353

Kovtun, E.F. 267, 286

Koževnikov, VA. $16,18,30,32,37,39,43 f$. $47-50,52-54,56,59,132,135,145,154$, 188-193, 195-198, 204f., 232, 236, 239, 279, $322,345,348,369 f ., 372-374,378,390,397$, $422,427,441,444$

Koževnikova, A.V. 54

Kožinov, V.V. 2, 4

Kozlov, A.A. 386

Krašeninnikova, E.A. 14, 392, 415

Krasin, L.B. 182, 265f., 274, 310

Kravkov, N.P. 264, 314, 335, 401

Krizanic, Ju. 282

Krjuckoov, P.P. 341, 402

Kropotkin, PA. 19f., 330

Kropotkin, P.N. 19

Kruðenych, A.E. 14

Krutikov, G.T. 286

Kruzenštern-Peterec, Ju.A. 411

Kudrjasev, I. 258

Kuz'min, P.A. 22

Kuzmin, V. 337

Kuznecov, I.N. 301

L'vov, V.E. 2

La Mettrie, J.O. de 249

Lamarck, J. 122, 353

Laplace, P.S. de 331

Lapక̌in, I.I. 434

Larionov, M.F. 271, 288, 290

Lasswitz, K. 179, 316

Lavrenev, B.L. 262

Lavrov, P.L. 208

Lazarev, P.P. 244f., 353

Lazurskij, V.F. 135 
Ledoux, C.-N. 333 .

Leibniz, G.W. 283, 331

Lenin, V.I. (V.I. Ul'janov) 25, 218, 265f., 276, 310f., 350f., 440

Lenskij, A.P. (A.P. Verviciotti) 21-23

Lenskij ["vtoroj"], A.P. (A.P. Verviciotti) 22

Leont'ev, K.N. 7, 168, 211, 304, 363, 419, 440 -

Leopardi, G. 68

Lermontov, M.Ju. 53

Leroux, P.H. 457

Lessing, G.E. 30,98

Licharev, D.S. 386,388

Lidin, P. 306

Lieb, F. 407

Linnér, S. 145

Linnizenko, I.A. 41

Linnik, Ju.V. 7f., 376

Litvinov, L. 314

Ljubistev, A.A. 337

Ljubuskina, $\$ 354$

Ljusin, V. 254

Lobanov, M.P. 3

Locke, J. 30, 98

Loginov, I. 316

Lomonosov, M.V. 118

Lord, R. 15

Losev, A.F. 7, 60, 177, 198, 251f., 304, 320, 322f., 327, 356, 362, 376, 380, 388, 429, 439

Losskij, N.O. 406, 444 f.

Lotze, H. 161

Lovelock, J. 11

Lowith, K. 404

Lucenko, I.M. 234

Lukaš, I.S. 457

Lukashevich, St. 15, 61

Lukrez 91

Lunađarskij, A.V. 170-172, 175-178, 214, 257, 262f., 303, 320

Luppol, I.K. 312

Lur'e, A.S. 424

Lysenko, T.D. 107

Mach, E. 252

Maeterlinck, M. 245, 271
Majakovskij, V.V. 182, 187, 211f., 248, 254, $257,265,268-276,282,287,310,316,340$, $346,410,431,433$

Makarova, E.P. 23

Maksimov, G. (G.P. Lapot') 305

Maleviz, K.S. 254, 268, 279, 284-287, $334-$

Malthus, T.R. 120

Mamcenko, VA. 216

Mandel'stam, N.Ja. 350

Mandel'stam, O.E. 322, 334

Mannovskij, R. 234

Manovskij, R.K. 324, $437-439$

Mansurov, P.B. 30,196

Marinetti, F.T. 248, 267f., 287, 353

Markov, V. 279

Marr, N.Ja. 283

Marx, K. 67, 69, 71, 80, 107, 159, 253, 279, $364,377,424-428,438,442$

Masaryk, T.G. 430

Matjusin, M.V. 281, 285

Matveev, S.I. 190

Manwell, J.C. 260

Maydell, R.v. 416

Merev, A. 345

Meinikov, Il'ja Il'iz 183-187, 243, 262, 264, 403

Męnikov, Ivan Il'ił 186

Mejer, A.A. 385f., 388, 444

Mel'nikov, K.S. 265f., 335, 339

Merezkovskij, D.S. 48f., 156, 161f., 216

Metal'nikov, S.I. 187, 264

Metner, E.K. (E. Medtner) 209

Metz, J.B. 161

Michail, archimandrit, episkop (P.V. Semenov) 167, 222f., 225

Michajlovskij (sowjet. Physiologe) 264

Michnevit, I.G. 25

Micurin, I.V. 107

Mikulinskij, S.R. 5, 52

Miroljubov, A. 442

Mironovic, N.P. 441

Mironoviz-Kuznecova, V.N. 225f., 228, 346, 366f., 380, 437, 441

Mirskij, D. siehe Svjatopolk-Mirskij, D.P.

Mituriž, P.V. 283

Mocul'skij, K.V. 152, 209, 447 
Moiseev, N.N. 8

Moleschott, J. 451

Monod, J. 72

Moreau, G. 285

Mostanskij, A. 192

Mulford, P. 232, 236, 238

Murav'ev, B. 280

Murav'ev, N.V. 319

Murav'ev, V.N. 248, 251, 253, 260f., 266, 308, $318-329,331-341,346,352$, 362f., 365, 380, $385 f$., 400, 402, 422, 429, 431, 440f.

Mussolini, B. 364

Napoleon I. (Bonaparte) 117

Našcokina, N.V. 19

Necrolodov, A.D. $191 f$.

Nedzveckij, M. 412

Nedzveckij, V.K. 234

Nekrasova, E.S. 16

Nemilov, A.V. 187

Nesmelov, A. (A.I. Mitropol'skij) 410, 412, 437

Newton, I. 244

Nietzsche, F. 75, 91, 98-103, 105, 168-170, $175,177 f ., 192,194 f ., 238,241,243,294$. 449

Nikitin, VA. 5-7, 25, 43, 149

Nikitin, V.P. 421, 424

Nikitina, E.F. 300

Nilus, S.A. 168

Ninon de Lenclos 208, 265

Nirenburg, L. 7

Noiré, L. 252

Novgorodcev, P.I. 320, 404, 431

Novoselov, M.A. 30, 52, 196f., 388

Novotný (Leiter d. Handschriftenabt.) 435

Obuchow, V.K. $411 f ., 442$

Ogurcov, I.V. $2 f$.

Okulov, M.A. 19

Olesa, Ju.K. 238

Olsurev, JuA. 196

Oppel', VA. 401

Origenes 73

Ostromirov, A. siehe Gorskij, A.K.

Ostwald, W. 245, 252
Pacelli, E. 371

Palievskij, P.V. 2, 4

Pamirskij, E. (Pseud.?) 396

Pankratov, A.S. 16, 149, 189, 192f., 222, 234, $236 f$.

Paramonov, B.M. 200, 354

Parnov, E.I. 57

Pascal, B. 165

Pascal, P. 319, 321

Pasternak, B.L. 14, 294, 422

Pasternak, E.B. 204

Pasternak, J. 31

Pasternak, L.O. 31, 188, 204, 237, 374, 407

Pasteur, L. 183

Pazilova, V.P. 57, 59

Pejl', VA. 436

Percov, P.P. 49

Perelesin, V. (V.F. Salatko-Petriše) $410 f$.

Perel'man, I.Ja. 256-258

Peskova, E.P. 378, 392

Peterson, G.N. 44

Peterson, M.N. 55, 276, 349, 441

Peterson, N.P. 16-18, 24-30, 40, 43f., 47-50, 52-56, 117, 129, 138-142, 145-151, 153f., 189-193, 195, 197f., 203, 213, 226, 232, 236f., 345, 369, 372, 397, 427, 441, 444

Petnikov, G.N. 280

Petraserskij, M.V. 22

Petrov, V.P. 20

Pil'njak, B. (B.A. Vogau) 187, 272, 364

Pisarev, D.I. 122

Pitirim, mitropolit (K.V. Necaev) 5

Platon 92, 94, 307, 380

Platonov, A.P. (A.P. Klimentov) 14, 200, 245, 249, 261, 266, 311, $354 f$.

Platonov, S.F. 386

Pletnev, R.V. 25, 431

Pobedonoscev, K.P. 137, 145, $150 f$.

Poe, EA. 215f.

Pogrebinskij, Ju A. 7

Pokrouskij, M.N. 399

Poltavcev, K.N. 22 f.

Poltorackij, N.P. 410

Posse, VA. 373f., 378

Postnikov, G.V. 346,360

Povelichina, A.V. 267 
Prigogine, I. (I. Prigožin) 11

Prišin, M.M. 319, 374, 376, 382, 393

Prišvina, V.D. 376

Prokofev, S.S. 422

Protopopov, M.A. 373

Punin, N.N. 276, 285, 287f., 291

Puskin, A.S. 19,53

Rabinovix, E. 10

Rachillo, I.S. 348

Racinskij, GA. 196

Radlov, E.L. 198

Rasputin, V.G. 3

Reade, W.W. 173, 176 f.

Rebikov, V.I. 238

Reich, W. 353

Rejsner, L.M. $414 f$.

Rejsner, M.A. 414i.

Remizov, A.M. 319, 422

Renan, E. 11, 28, 104, 125f., 148, 177

Rerich, N.K. 7f., 255, 389, 411

Rickert, H. 411

Rimbaud, A. 285

Ripellino, A. 214

Rjazanouskij, V.A. 54, 368f.

Robida, A. 104

Rodzaevskij, K.V. 369

Rodzevic, Ju.A. 44, 50

Rojzman, M.D. 302

Rolland, R. 389

Rotcev, A.G. 20

Rovinskij, D.A. 38

Rozanov, V.V. $7,47,168,190,198,212-214$, $234,236 f$., 261, 320, 349, 361, 382, 449, 451, 455

Rožkov, N.A. 181f., 242, 244, 263, 265, 274, $310,328,348$

Rubakin. N.A. 39

Rudin, N.M. 289

Rumanov, A.V. 222

Rusov, N.N. 261, 361

Rybalkin, F. 344

Rynin, NA. 258f.

Bachovskoj, DA. 421

Saginjan, M.S. $196 f$.
Saint-Simon, H. de 457

Samarin, F.D. 30, 196 f.

Samobytnik, A.I. (A.I. MaSirov) 316

Sannikov, GA. 244

Sapoక̌nikov, B.V. 289

Satov (Oberst) 21

Satovskij-Rževskij, G.G. $411 f$.

Savel'ev, V.P. 346

Savickij, P.N. (Pseud.: P. Vostokov) 234, 340, $408,419,421,425,430 f ., 436,442-444$

Savonarola, G. 163

Scerbakov, M.V. 412

Scerbov, I.P. 323

Scheler, M. 260

Schelling, F.WJ.v. 25, 293

Schiaparelli, G. 179

Schiller, F. v. 151

Schlegel, A.W. 293

Schopenhauer, A. 41, 75, 78f., 98f., 102, 156. $159,162,213,215$

Schoultz, O. v. $443 f$.

Schultze, B. 214

Sel'vinskij, I.L. 422

Seleznev, Ju.I. 3

Seliverstov, Ju. 8

Semenov, G.M. 363

Semenova, E.S. 20

Semenova, N.S. 20

Semenova, S.G. 2, 4, 7f., 16, 44, 57, 140, 376

Semenova, V. 8

Senatov, V.G. 261

Senrok, V.I. 16, 39

Sepovalov, A.A. 433

Serafim v. Sarov (Mošin, P.) 49, 386, 408, 439

Sergej v. Radonež 294

Sergij, mitropolit (I.N. Stragorodskij) 388

Seršenevic, V.G. 238

Sesterhenn, R. 177

Sesterkin, M.I. 31, 204

Sestov, L.I. (L.I. Svarcman) 231, 391, 407f., 422

Setnickaja, O.N. 14, 41, 230, 234, 239, 320, $346,351,353,366,369,372,402 f$., 409-411, $414-416,432,438,442$ 
Setnickij, NA. 18, 54, 56, 208, 212, 230-232, $265,309,324,337,341,344-347,349$ f., 355$357,360,362-364,366-374,378-382,384$, $387-394,396-415,421 \mathrm{f} ., 424,426-428,432$, $434-442,455,457$

Sevast'janov, V.I. 2, 4, 8, 57

Severjanin, I. (I.V. Lotarev) 410

Sezeman, V.E. 340,422

Shelley, M. 241, 243

Sidorov, A.A. 380

Simanov, G. 418

Sinjavskij, A.D. 214, 290

Sirinskij-Šichmatov, Ju A. 429, 447

Skapskaja, M.M. 208, 349, 382, 386

Skitalec, S.G. (S.G. Petrov) 402, 412

Sklovskij, V.B. 270

Skrjabin, A.N. 168, 238, 255, 293f., 407

Skurlatov, V.I. 3

Smal'gauzen, I.I. 187

Smankevic, B.I. 212, 238, 269f., 346

Smankevit, V.I. 212,346

Smidt, A.N. 279

Smirnov, I.P. 268

Snegireva, A.I. 52

Sokolov, I.V. 275

Sokolov, V.V. 4

Sokrates 92,94

Sologub, F. (F.K. Teternikov) 156, 212, $215 f$.

Solov'ev, S.M. 319f., 349

Solov'ev, V.S. $1,4,7,11,13,28,31,39,41$, $47,63,74,104,122,141,146,148,152,168$, $190,193,198,200,208 \mathrm{f} ., 213,231 \mathrm{f}, 236-$ $238,267,349,354,371,376,408,411,419$, 440f., 444, 447, 452, 454

Solženicyn, A.I. 264

Sorokin, A.S. 234, 237

Sorokin, P.A. 407

Spencer, H. 11, 85, 104, 252

Spengler, O. 78, 260, 419

Spet, G.G. 320, 361, 380

Stalin, I.V. (I.V. Džugašvili) 107, 217f., 250, $283,364,415$

Starr, S.F. 266, 335

Staudenmeier, L. 353

Steinach, E. 264, 314, 316, 403

Steiner, R. 209

Stepanov, I.V. 442
Stepun, FA. 320, 419, 443f., 447

Stolica, L.N. 225, 228, 234, 238

Storicyn, P. 238

Strachov, N.N. 101, 129, 213

Stravinskij, I.F. 422

Struve, P.B. 60, 157, 169, 319f., 363, 443

Suchich, S.I. 4, 373

Suslov, M.A. 4, 57

Suvtinskij, P.P. 390, 419, 421f., 424, 427, 432

Svencickij, V.P. 156f., 163f., 166-168, 218f., 221-223, 225, 228, 232, 236, 388

Svjatogor, A. (A. Agienko) 301-309, 311, 313f., 344

Svjatopolk-Mirskij, D.P. $157,163,364,390$, 421f., 424, 428f.

Tareev, M.M. 185f.

Tarle, E.V. 386

Tatlin, V.E. $285,334,353$

Taylor, F.W. 250

Teilhard de Chardin, P. 10f., 68, 72, 260

Telberg, G. 369-371

Ternavcev, VA. 231

Tertullian 454

Tesková, A. 428

Thomas v. Aquin 200, 454

ThoB, A.E. 273

Tichomirov, L.A. 196

Tichon, patriarch (V.I. Belavin) 203, 351

Tolstaja, S.A. 134

Tolstaja-Segal, E. 268

Tolstoj, A.K. 364

Tolstoj, A.N. 255, 262, 319

Tolstoj, I.L. 42, 131

Tolstoj, L.N. 1, 18, 25f., 28f., 31, 37, 39, 41, So, 117, 129-139, 141, 149, 157, 185f., 190f., $193,195,213,220 \mathrm{r}$., 236, 302, 348f., 373, $382,388,392 \mathrm{f} ., 400,407,424,441,452$

Tolstoj, S.L. 41,137

Tolstoj, S.N. 26

Tretcikov, N.G. 442

Tret'jakov, S.M. 238, 313, 410

Trockij, L. (L.D. Bronł̌rejn) 175, 183, 242, 244, 247f., 305, 321, 323, 329, 333-335, 339

Troickij, G.F. 197

Trubeckoj, E.N. 7, 30, 196-198, 203, 322, 408, 419,439 
Trubeckoj, N.S. 55, 377, 408, 419f., 425, 427

Trubeckoj, S.N. 419

Trubnikov, P. (Pseud.?) 412

Tschižewskij, D.I. 25, 53, 151f., 209, 340, 408

Tumarkin, N. 266

Tynjanov, Ju.N. 422

Ol'janov, I.N. $25 f$.

Umov, N.A. 260

Usakov, D.N. 55

Uspenskij, P.D. $279 f$.

Ustrjalov, N.V. 319, 336, 340f., 363-366, 368, 403f., 413, 415, 418, 432, 435, 438, 441f., 445, 447

Utechin, S.V. 397

Vagin, E.A. 2, 409

VarSavskij, V.S. 344,444

Vasil'ev, K. 3

Vasil'ev, L.L. 245, 314, 316

Venevitinov, M.A. 43

Verešagin, V.V. 47

Verhaeren, E. 205, 248, 271

Vernadskij, G.V. 421, 427

Vernadskij, V.I. 2, 10-12, 72, 121, 136, 245, $260,330,332,341,376,384,420,429$

Verne, J. 104, 205

Verviciotti, O. 21f.,

Vesely, A. (N.I. Kockurov) 422

VetCinkin, V.P. 258

Vodlinger, A. 234, 238

Vogt, K. 123

Volosin, M.A. 211, 282

Vološina, M.V. 321

Vol'skij, A. (Ja.V. Machajskij) 80, 330

Vol'skij, S. (A.V. Sokolov) 170

Volžskij (A.S. Glinka), 186

Vorob'ev, B.N. 256

Voroncov, M.S. 21

Voronov, S. 264, 335

Vostokov, O. 234, 238

Vostokov, P. siehe Savickij, P.N.

Vrubel', M.A. 287

Vvedenskij, A.I. 303

Vyrubova. L.I. 21

Vyseslavcev, V.P. 319f., 429
Wagner, R. 53, 168, 238, 294

Weismann, A. 187

Wells, H.G. 179, 216, 272, 316, 389

Whitman, W. 271

Wiener, N. 328

Wiles, P. 185

Wilhelm II. (dt. Kaiser) 102, 192

Williams, R.C. 271

Windelband, W. 411

Wolf, J. 435

Wolff, Ch. 30, 98

Wulff, M. (M. Vul'f) 234f., 238, 353

Yassour, A. 172

Young, G.M. 60, 341, 397, 409

Zabelin, I.M. 2, 10

Zabolockij, N.A. 13, 278

Zajcev, B.K. 319

Zakydalsky, T. 60f., 74, 100, 125, 335

Zalkind, A.B. 243

Zamjatin, E.I. 250, 255, 260, 327, 3:3

Zavalishin, V. (V.K. Zavališin) 211257

Zedler, J.H. 249

Žegin, L. (L.F. Sechtel') 197, 270f, 287-289, 294

Zelinskij, F.F. 320

Zelinskij, K.L. 302

Zen'kovskij, V.V. 163, 215, 218, 31c, 423

Zernov, N.M. 56,148

Zikeev, V. 305

Znamenskij (sowjet. Jurist, Diplomat) 396

Zola, E. 53

Zoscenko, M.M. 184

Zukov, D. 3

Zurakovskij, A. 195 